
CALIFO? ARTM IENCES

GRRPY

( 12

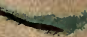

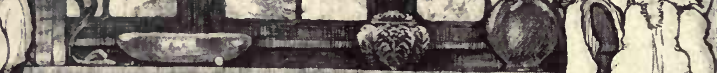

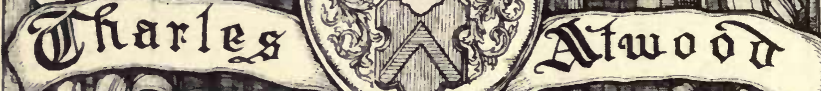
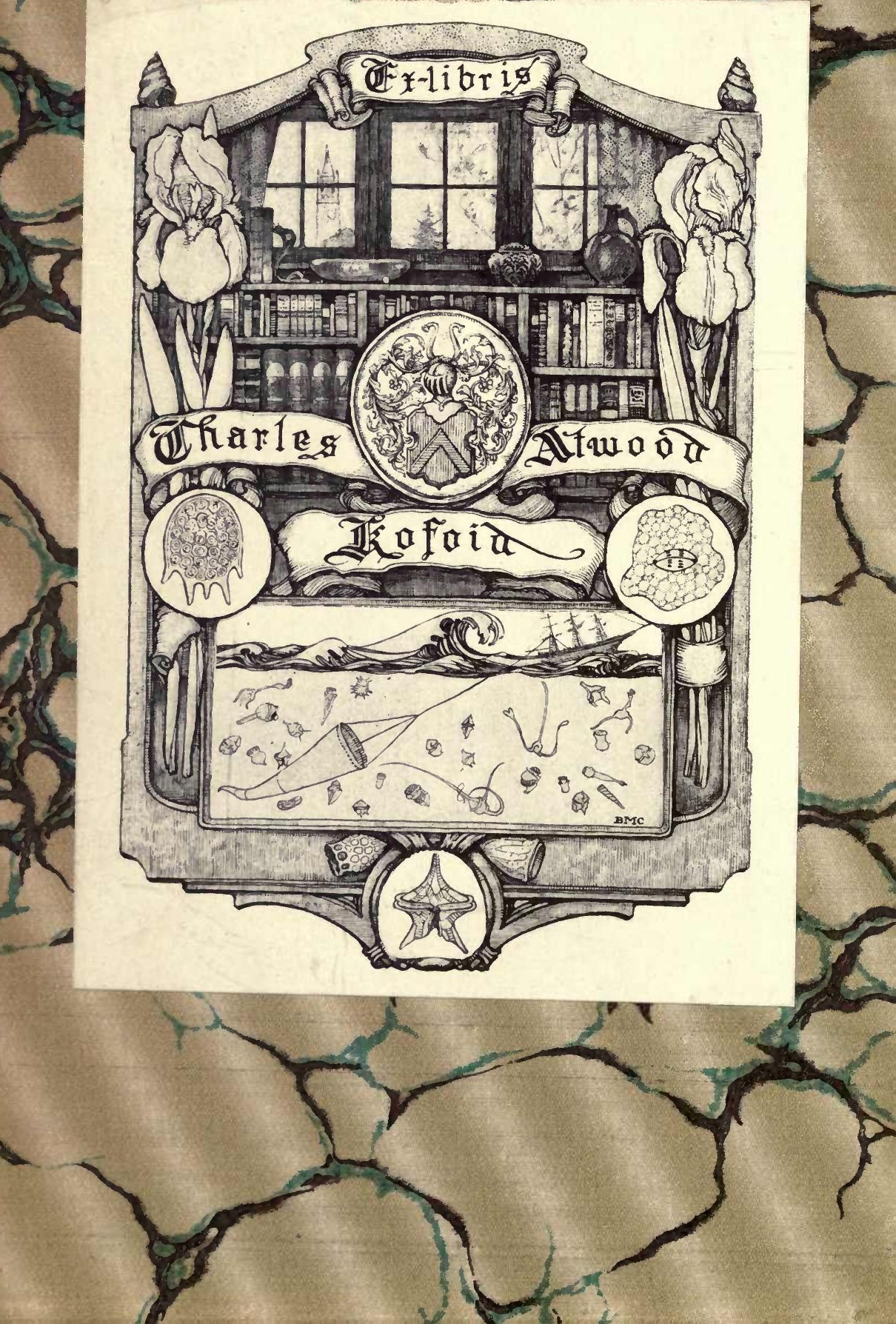


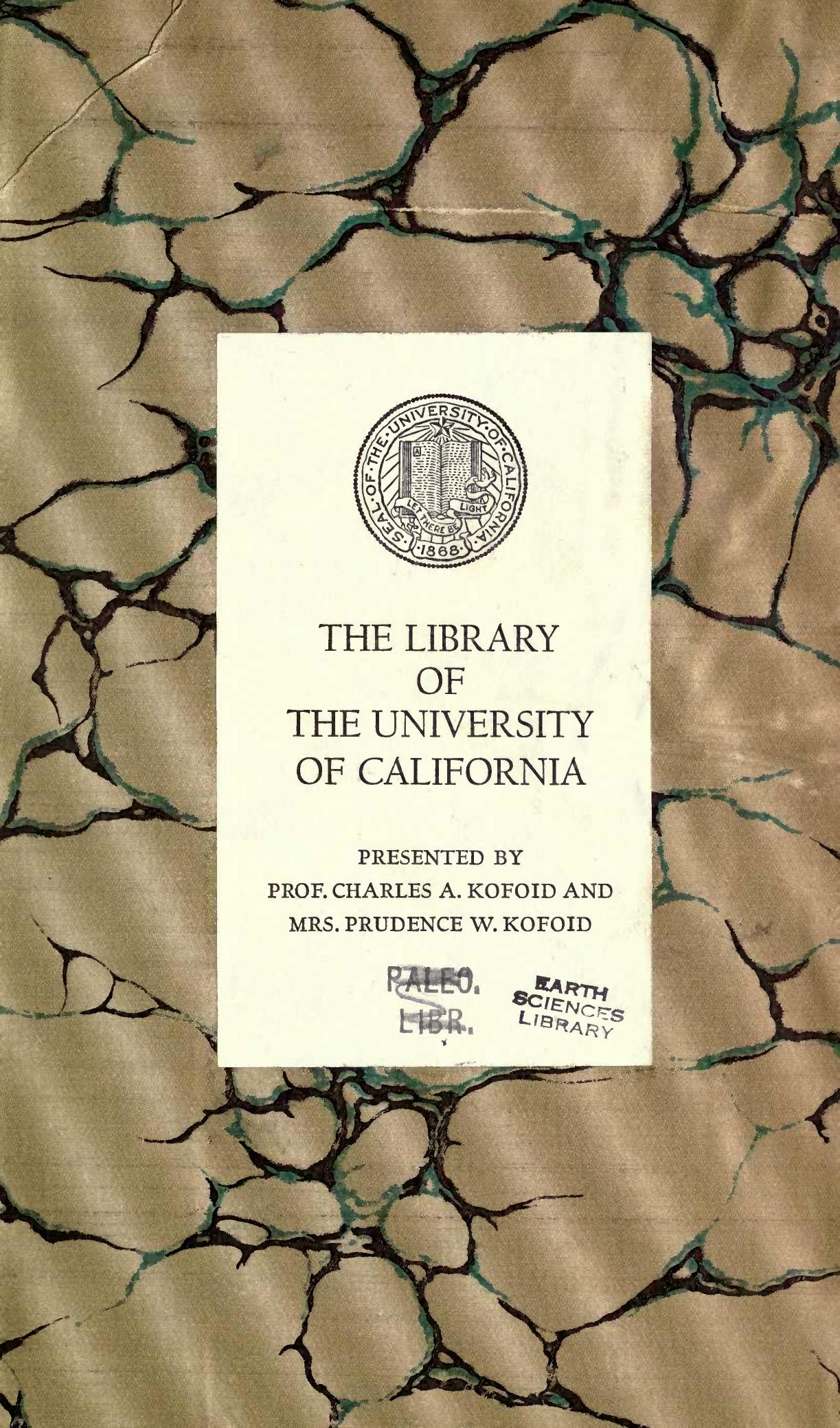







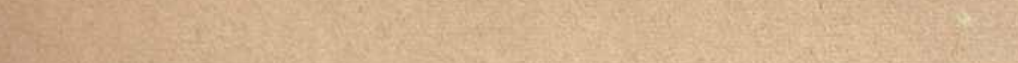

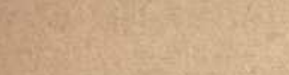

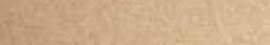

$\cos ^{2}+\sin ^{2}$ 
SMITHSONIAN INSTITUTION

UNITED STATES NATIONAL MUSEUM

Bulletin 100

VOLUME 5

CONTRIBUTIONS TO THE BIOLOGY OF THE PHILIPPINE ARCHIPELAGO AND

\title{
ADJACENT REGIONS
}

\section{OPHIURANS OF THE PHILIPPINE SEAS} AND ADJACENT WATERS

\author{
BY RENE KOEHLER \\ Professor of Zoology in the University of Lyon, France.
}

[Manuscript Translated by Austin H. Clarr ]

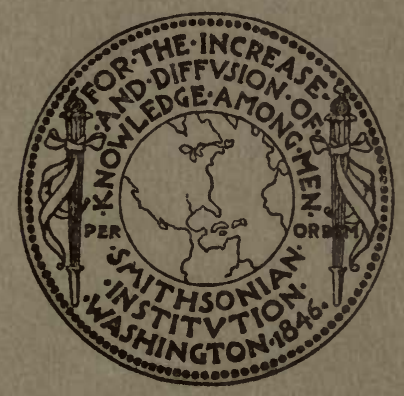




UNITED STATES NATIONAL MUSEUM

\title{
Bulletin 100
}

VOLUME 5

CONTRIBUTIONS TO THE BIOLOGY OF THE PHILIPPINE ARCHIPELAGO AND ADJACENT REGIONS

\section{OPHIURANS OF THE PHILIPPINE SEAS AND ADJACENT WATERS}

\author{
BY RENE KOEHLER \\ Professor of Zoology in the University of Lyon, France. \\ [Manuscript Translated by Austin H. Clark]
}

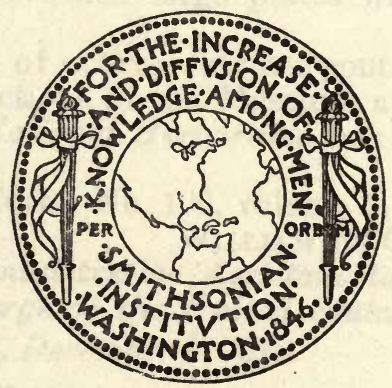




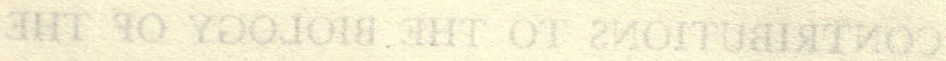

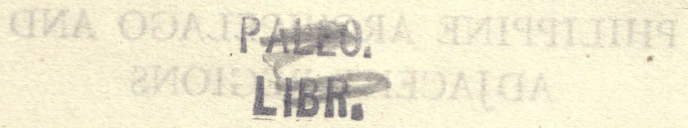

Gift of C. A. Kofoid

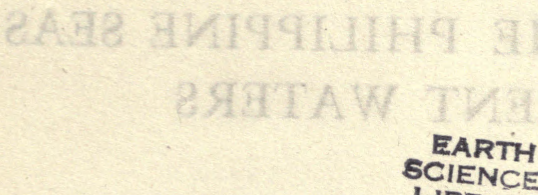 \\ LIBPARY}

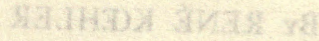

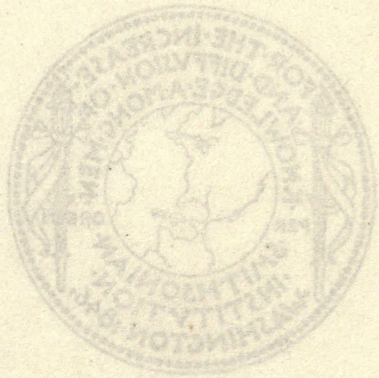


$(x)=12=0$
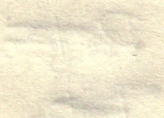

Arits:

है।

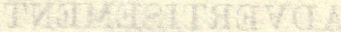

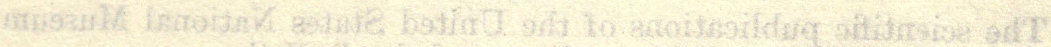

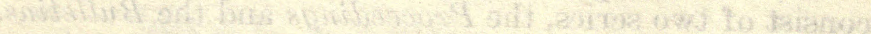

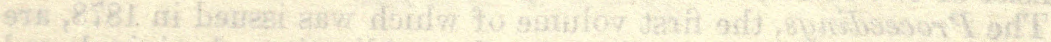

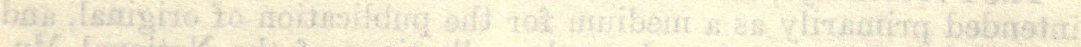

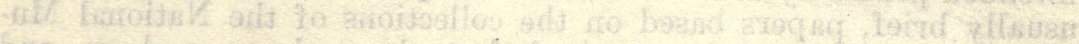

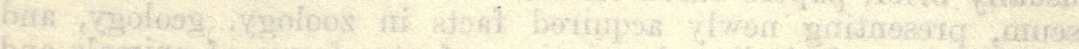

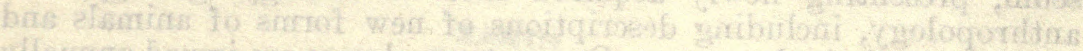

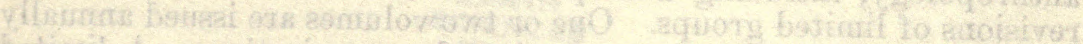

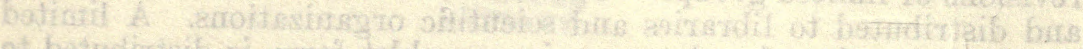

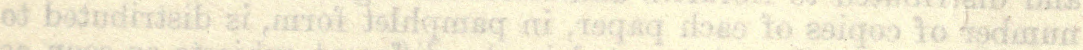

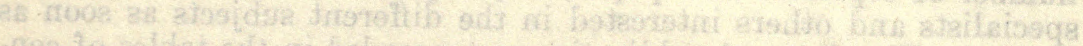

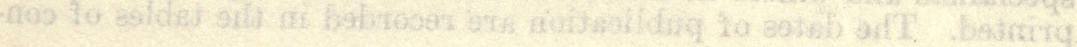

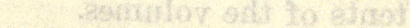

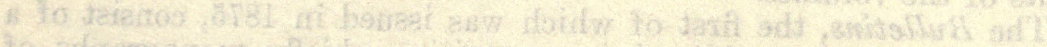

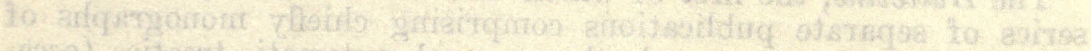

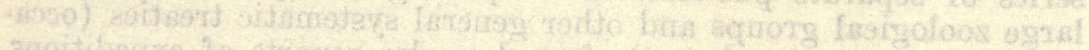

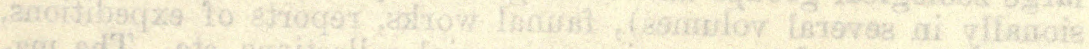

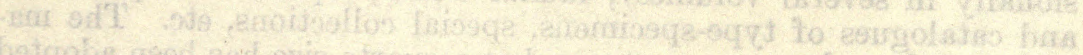

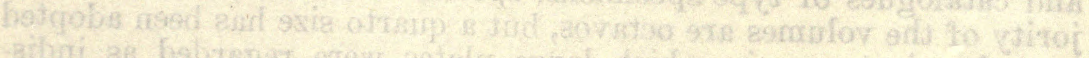

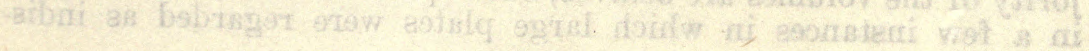

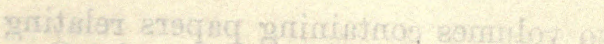

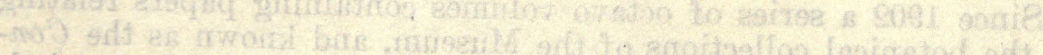

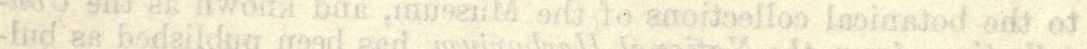

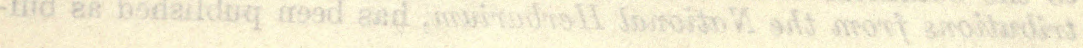

29579e with

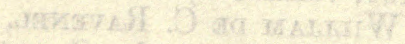

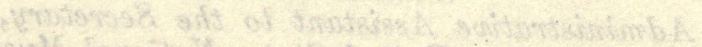

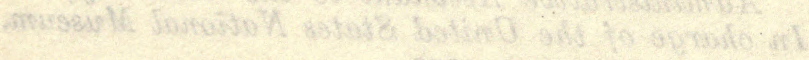

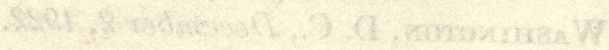




\section{TABLE OF CONTENTS.}

Introduction

Order I. Phrynophiurida__-_-__.

Family Ophiomyxidae

Ophiomyxa bengalensis

Ophiomyxa irregularis _._.

Ophiodera neglecta ___

Neoplax crassipes_______

Ophlocanops

Ophiocanops fugiens

Ophiobyrsella intorta

Ophiophrixus confinis

Family Trichasteridae

Astrocharis virgo

Astroceras pergamena

Asteronyx lovent____._. 34

Family Gorgonocephalidae_____ 35

Astrothamnus deficiens_________ 35

Order II. Loemophiurida____ 38

Family Hemieuryalidae

Ophiomoeris obstricta____ 38

- Ophiomoeris spinosa

Ophiomoeris tenera

Ophiogyptis nodosa

Family Ophiomycetidae

Ophiomyces delata

Family Ophiacanthidae _._.

Ophiodyctis _._. 42

Ophiodyctis uncinatus____ 42

Ophiacantha benigna____ 45

Ophiacantha composita__._. 46

Ophiacantha confusa_______ 47

Ophiacantha dallasii _._. 49

Ophiacantha duplex._. 50

Ophiacantha graphica

Ophiacantha legata _._. 53

Ophiacantha longidens _.. 55

Ophiacantha pacata____ 57

Ophiacantha pentagona

Ophiacantha severa

Ophiacantha vorax 63

Ophiolimna perfida

Ophiogema _. 67

Ophiogema punctata

Ophiotreta eximia 
Order II. Loemophiurida-Continued.

Family Ophiacanthidae-Continued.

Ophiotreta gratiosa

Ophiotreta matura

Ophiotreta spatulifera _._-_- 81

Ophiotreta valenciennesi _._. 84

Ophialcaea congesta _._._. 85

Ophientrema leucostictum _._. 85

Ophiotrema tertium

Ophiotoma assimilis _..._-_._._. 91

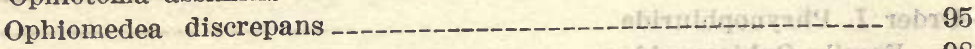

Ophiocopa singularis _._._-__- 98

Ophiothamnus venustus_______________ 100

Ophiurothamnus___ 102

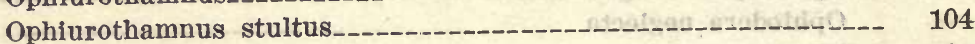

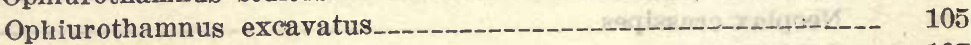

Ophiomitra dives _._. 107

Ophlomitrella exilis________________ 110

Ophiomitrella sagittata___________ 111

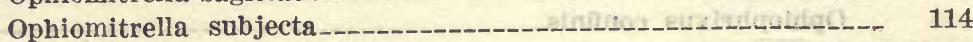

Ophioripa _._. 117

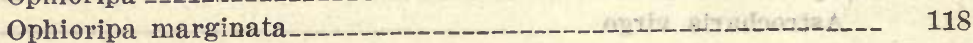

Ophioripa nugator _._. 119

Ophiothalmus ___ 121

Ophiophthalmus relictus_________ 124

Ophiophthalmus suspectus_________ 127

Ophiomelina__a 129

Ophiomelina placida___. 130

Ophioplinthaca chelys_____ 131

Ophioplinthaca globata____ 132

Ophioplinthaca hastata__.________ 137

Ophioplinthaca pulchra 140

Ophioplinthaca rudis____ 142

Ophiocamax rugosa ___

Order III. Gnathophiurida _... 151

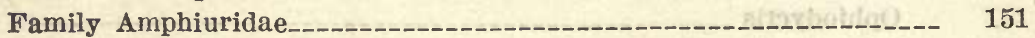

Amphiura agitata___ 151

Amphiura ambigua____ 152

Amphiura commutata

Amphiura dejecta___ 154

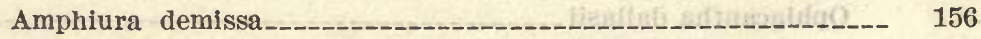

Amphiura diomedeae__._. 158

Amphiura grandisquama _._._._._._._. 159

Amphiura uncinata

Amphiura vadicola____ 161

Amphipholis kochii _... 163

Amphipholis loripes

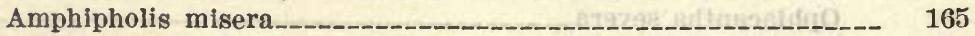

Amphiodia crassa__________ 167

Amphiodia debita__. 168

Amphioplus legatus_______ 169

Amphioplus conductus _._._. 172

Amphioplus impressus _._. 174 
Order III. Gnathophiurida-Continued.

Family Amphiuridae-Continued.

Amphioplus lucidus

Amphioplus luctator

Amphioplus relictus.

Amphioplus rhadinobrachius

Amphilimna multispina

Ophiactis affinis

Ophiactis definita

Ophiactis maculosa

Ophiactis profundi

Ophiactis savignyi

Ophiopholis mirabilis

Ophiocentrus aculeatus

Ophiocentrus asper

Ophiocentrus vexator

Family Amphilepidae

Amphilepis protecta

Amphilepis remittens

Amphiactis duplicata

Ophiothrix aristulata

Ophiothrix armata

Ophiothrix aspidota _._.

Ophiothrix bellax

Ophiothrix capillaris

Ophiothrix coronata

Ophiothrix crassispina________

Ophiothrix cumulata

Ophiothrix deceptor

Ophiothrix elegans _._. 227

Ophiothrix exigua

Ophiothrix expedita _..._.

Ophiothrix expedita, var. rhabdota__._._.

Ophiothrix galatheae

Ophiothrix hirsuta

Ophiothrix longipeda

Ophiothrix foveolata

Ophiothrix hybrida

Ophiothrix infirma

Ophiothrix koreana

Ophiothrix lepida

Ophiothrix marenzelleri _. 248

Ophiothrix martensi__._._. 250

Ophiothrix melanosticta _____ 251

Ophiothrix nereidina _._. 252

Ophiothrix pavida____ 252

Ophlothrix plana

Ophiothrix propinqua__

Ophiothrix prostrata___ 257

Ophiothrix proteus _. 260

Ophiotlirix purpurea 
Order III. Gnathophiurida-Continued.

Family Ophlotrichidae-Continued.

Ophiothrix pusilla _._- 262

Ophiothrix signata _..._. 263

Ophiothrix spinosissima___________ 266

Ophiothrix stelligera __.

Ophiothrix striolata _._._. 277

Ophiothrix trilineata

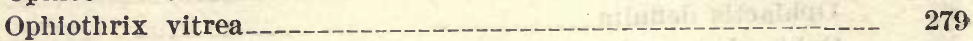

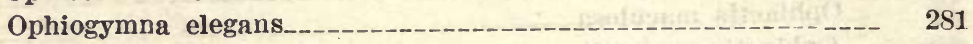

Ophiogymna fulgens_..._._. 288

Ophiogymna funesta_._._._._. 292

Ophiogymna pulchella _._._._._._. 295

Ophlocnemis marmorata _..._. 296

Ophiothela danae

Ophiothela vincula _..._. 298

Ophiomaza cacaotica__._. 299

Ophiomaza fusca

Ophiopteron elegans _..._. 301

Ophiopteron gratum _... 302

Ophiopteron puncto-coeruleum

Order IV. Chllophiurida __. 305

Family Ophiochitonidae _._. 305

Ophiochiton fastigatus _._. 305

Ophionereis dubia _... 310

Ophionereis semoni _._. 310

Ophiodoris contrarius _______ 310

Ophiodoris malignus__._____ 311

Family Ophiocomidae______ 311

Ophiocomina _. 316

Ophiocoma brevipes__. 319

Ophiocoma erinaceus _._._. 322

Ophiocoma lineolata_..._. 324

Ophiocoma scolopendrina _.__________ 325

Ophiocoma wendtii _._. 328

Ophiomastix annulosa _.__ 329

Ophiomastix flaccida_____ 330

Ophiomastix lüitken

Ophiomastix mixta__. 330

Ophiomastix venosa _._. 331

Ophiarthrum elegans _.__ 331

Family Ophiodermatidae__________ 331

Ophiarachna quinquespinosa

Pectinura aequalis_________ 337

Pectinura yoldil

Ophiopezella spinosa__ 338

Ophiarachnella gorgonia____._. 339

Ophiarachnella honorata__._._._._. 340

Ophiarachnella infernalis _... 341

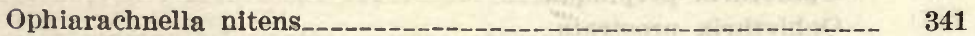

Bathypectinura conspicua 
Order IV. Chilophiurida-Continued.

Family Ophiodermatidae-Continued.

Cryptopelta tecta

Ophiurodon cinctus

Ophiurodon permixtus

Family Ophiolepididae

Ophiopyrgus planulatus

Amphiophiura canaliculata______

Amphiophiura fastigiata_-___-__-__-

Amphiophiura improba_______

Amphiophiura insolita

Amphiophiura paupera

Amphiophiura radiata

363

Amphiophiura sculptilis _-___

364

Amphiophiura sordida _-_._-

364

Amphiophiura spatulifera

365

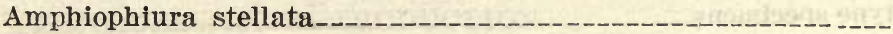

369

Stegophiura sladeni

369

Stegophiura sterilis

370

Ophiura aequális

Ophiura clemens

Ophiura flagellata

Ophiura fluctuans

377

Ophiura irrorata

Ophiura kinbergi

381

Ophiura micrantha

383

Ophiura mitescens _._._-

383

Ophiura sarsi__._-

Homalophiura inflata

386

386

Homalophiura inornata_-_-_-_-

Ophiocten hastatum

388

Ophiomusium altum

389

Ophiomusium armatum ________

Ophiomusium elegans _._.

Ophiomusium facetum

Ophiomusium facundum

Ophiomusium fimbriatum

Ophiomusium impoteus

Ophiomusium ligatum ___

Ophiomusium lunare

Ophiomusium lymani

Ophiomusium morio

Ophiomusium properum

Ophiomusium relictum

Ophiomusium scalare

Ophiomusium simplex

Ophiomusium spinulosum

Ophiolipus granulatus_

Ophioceramis declinans

Ophiozonella bispinosa 
Order IV. Chilophiurida-Continued.

Family Ophiolepldidae-Continued.

Ophlozonella molesta

Ophiozonella subtilis

Ophiozonoida obscura

Ophiomidas reductum

Ophiolepis annulosa

Ophiolepis irregularis

Ophioplocus imbricatus

Family Ophioleucidae

Ophincirce inutilis

Ophiopallas paradoxa

Ophiopallas valens

Ophiernus adspersus

List of stations, with species found at each

Bibliography

List of type specimens 


\section{OPHIURANS OF THE PHILIPPINE SEAS AND ADJACENT WATERS}

\section{By RENÉ Kahler,}

Professor of Zoology in the University of Lyon, France.

[Manuscript translated by Austin H. Clark.]

\section{INTRODUCTION.}

The United States National Museum has been so kind as to entrust to me for study the important collection of ophiurans brought together by the United States Fisheries steamer.Albatross in the course of her investigations among the Philippine Islands during the years 1907-1910. First of all I wish to thank my colleagues of the National Museum for the honor which they have done me in requesting me to undertake this work, and at the same time I wish again to apologize to them for the unavoidable delay in submitting my report. I had hoped that it would be finished in 1915, but the terrible events which have occurred since 1914 have made that impossible.

The collection sent to me included, in addition to the ophiurans collected in the Philippines, several species from Japan and a few specimens from the Samoan Islands; these last I have included with the first.

The total number of species represented is considerable, there being no less than 227, of which 68 are new, including representatives of 5 new genera.

The interest attaching to the collection arises not alone from the rather large proportion of new forms, but quite as much from the presence among those already known of a number of species hitherto insufficiently described and poorly figured. I have taken advantage of this opportunity to redescribe these in detail.

The plates are made up of photographic figures exclusively. The further one advances in the study of systematic zoology the more one becomes convinced of the importance, I may even say the necessity, of reproducing photographically the objects themselves, and not contenting oneself with drawings, which are inevitably more or less schematic and can not give a rigorously exact idea of the general appearance of the species. It has appeared to me advisable in many cases not to limit myself to photographing a single specimen, and I 
have therefore included figures of several, so that perhaps it may be found that $I$ have gone a little too far in some instances. In assembling the illustrations I have paid particular attention to the species of Ophiothrix; I have hoped thus to render a service to my colleagues in indicating the very considerable variations met with in this genus within which specific differentiation is exceptionally difficult.

The representation of complete specimens, or at least of the entire disk together with some of the arms for a greater or lesser part of their length, seems to me indispensable in order to give an exact idea of any ophiuran. In most of the memoirs in which $I$ have figured ophiurans by means of plates drawn by myself and reproduced lithographically I have followed the example of Lyman, who represented the species merely by the portion of the disk included between two arms, together with the basal portion of the latter. Obviously, this method is convenient, and, above all, economical, but these incomplete figures do not give a sufficiently comprehensive idea of the animals, and I therefore definitely abandoned it some years ago.

It has appeared advisable to include a certain number of photomicrographs representing the club spines, granules, etc., which occur upon the disks of various ophiurans, particularly of the families Ophiacanthidae and Ophiotrichidae, and which often assume characteristic shapes. I have also included some photographs of the arm spines of the species of Ophiotrichidae, particularly of the first ventral arm spine, of which the hooklike form shows interesting variations.

The following species are represented in the collection; new species are given in small capitals :

\section{Order I. PHRYNOPHIURIDA}

Family OPHIOMYXIDAF Ijungman, 1866.

Ophiomyxa bengalensis Kœhler.

Ophiomyxa irregularis Kœhler.

Ophiodera neglecta Kœhler.

NEOPLAX CRASSIPES, new species.

OPHIOCANOPS FUGIENs, new genus and species.

OPHIOBYRSELLA INTORTA, new species.

OpHIOPHRIXUs confinis, new species.

Family TRICHASTERIDAE Döderlein, 1911 (emended Matsumoto, 1915).

Astrocharis virgo Kœhler.

Astroceras pergamena Lyman.

Asteronyx loven $i$ Muller and Troschel.

Family GORGONOCEPHAIIDAE Döderlein, 1911.

Astrothamnus Deficiens, new species. 


\section{Order II. LOEMOPHIURIDA.}

Family HEMIEURYALIDAE Verrill, 1899 (emended Matsumoto, 1915).

Ophiomoeris obstricta (Iyman).

Ophiomoeris spinosa Kœhler.

Ophiomoeris tenera Kohler.

Ophiogyptis nodosa Kœhler.

Family OPHIOMYCETIDAE Verrill, 1899.

Ophiomyces delata Kœhler.

Family OPHIACANTHIDAE Verrill, 1899.

Ophionyctis Uncinatus, new genus and species.

Ophiacantha benigna, new species.

Ophiacantha composita Kœhler.

Ophiacantha confusa Kœhler.

Ophiacantha dallasii Duncan.

Ophiacantha duplex Kœhler.

OphIacantha Graphica, new species.

OPHIACANTHA LEgata, new species.

Ophiacantha longidens Lyman.

Ophracantha pacata, new species.

Ophiacantha pentagona Kohler.

OpHIACANTHA seVERA, new species.

Ophiacantha vorax Kœhler.

ophiolimna perfida (Kœhler).

Ophiogema punctata, new genus and species.

ophiotreta eximia (Kœhler).

Ophiotreta gratiosa (Kœhler).

ophiotreta matura (Kohler).

OPHIOTRETA SPATULIFFRA, new species.

Ophiotreta valcnciennesi (Lyman).

Ophialcaea congesta (Kœhler).

Ophientrema leucostictum (H. L. Clark).

OPHIOTREMA TERTIUM, new species.

Ophiotoma assimilis Kœehler.

OPHTOMEDEA DISCREPANS, new species.

OPHIOcopa singularis, new species.

Ophiothamnus venustus Matsumoto.

ophiurothamnus stultus (Kœhler).

OpHIURothamNus excavatus, new species.

Ophiomitra dives, new species.

OPHIOMITRELla ExILIS, new species.

Ophiomitrella sagittata, new species.

OpHIOMITRElla surjecta, new species.

Ophioripa marginata, new genus and species.

OPHIORIPA NUGATOR, new species.

Ophiophthalmus relictus (Kœhler).

OPHIOPHTHALMUS sUSPECTUS, new species.

OpHomelina placida (Kœhler), new genus.

ophioplinthaca chelys (I,yman). 
Ophioplinthaca globata, new species.

OPHIOPLINTHACA Hastata, new species.

Ophioplinthaca pulchra Kohler.

Ophioplinthaca rudis Kœhler.

- Ophiocamax rugosa Kœhler.

\section{Order III. GNATHOPHIURIDA.}

Family AMPHIURIDAE Ljungman, 1867 (emended Matsumoto, 1915).

Amphiura agitata Kœhler.

Amphiura ambigua Kœhler.

Amphiura commutata, new species.

AMPHIURA DEJECTA, new species.

Amphiura dimessa, new species.

Amphiura diomedeae Lütken and Mortensen.

Amphiura grandisquama Lyman.

Amphiura uncinata Kœhler.

Amphiura vadicola Matsumoto.

Amphipholis kochii Lütken.

AMPHIPHOLIS LORIPES, new species.

Amphipholis misera (Kœhler).

Amphiodia crassa (Kœhler).

Amphiodia debrta, new species.

Amphioplus legatus, new species.

Aмphroplus conductus, new species.

Amphioplus impressus (Ljungman).

AмpHIoplus Lucidus, new species.

AMPHTOPLUS LUCtator, new species.

Amphioplus relictus (Kohler).

Amphioplus rhadinobrachius H. L. Clark.

Amphimima multispina, new species.

Ophiactis affinis Duncan.

OPHIACTIS DEFINITA, new species.

Ophiactis maculosa Martens.

Ophiactis profundi Lütken and Mortensen.

Ophiactis savignyi (Müller and Troschel).

Ophiopholis mirabilis (Duncan).

Ophiocentrus aculeatus Ljungman.

Ophiocentrus asper (Kœhler).

OpHIOCENTRUS veXator, new species.

Family AMPHILEPIDAE Matsumoto, 1915.

Amphilepis protecta Kœhler.

Amphilepis Remittens, new species.

Amphiactis duplicata (Lyman).

Family OPHIOTRICHIDAE Ljungman, 1867.

Ophiothrix aristulata Lyman.

Ophiothrix armata Kœhler.

Ophiothrix aspidota Müler and Troschel.

Ophrothrix bellax, new species.

Ophiothrix capillaris Lyman. 
Ophiothrix coronata Kœhler.

Ophiothrix crassispina Kœhler.

Ophiothrix cumurata, new species.

OpHIOTHRTX DECEPTOR, new species.

Ophiothrix elegans Lütken.

Ophiothrix exigua Lyman.

Ophiothrix expedita Kœhler.

Ophiothrix gelatheae Lütken.

Ophiothrix hirsuta Müller and Troschel.

Ophiothrix longipeda (Lamarck).

ophiothrix foveolata Marktanner.

Ophiothrix hybrida H. L. Clark.

Ophiothrix infirma Kœhler.

Ophiothrix koreana Duncan.

Ophiothrix lepida de Loriol.

ophiothrix marenzelleri Kohler.

Ophiothrix martensi Lyman.

Ophiothrix melanosticta Grube.

Ophiothrix nereidina (Lamarck).

OpHIothrix Pavida, new species.

Ophiothrix plana Iyman.

Ophiothrix propinqua Lyman.

OphIOTHRIX PRostrata, new species.

Ophiothrix proteus Kœhler.

Ophiothrix purpurea von Martens:

ophiothrix pusilla Lyman.

OpHIothrix signata, new species.

ophiothrix spinosissima Kœhler.

ophiothrix stelligera Lyman.

Ophiothrix striolata Grube.

Ophiothrix trilineata Lütken.

Ophiogymna elegans Ljungman.

ophiogymna fulgens (Kœehler).

OPHIOGYMNA FUnesta, new species.

Ophiogymna pulchella (Kœhler).

Ophiocnemis marmorata (Lamarck).

Ophiomaza cacaotica Lyman.

Ophiomaza fusca, new species.

Ophiothela danae Verrill.

ophiothela vincula Mortensen.

Ophiopteron elegans Ludwig.

OPHIOPTERON GRATUM, new species.

ophiopteron puncto-coeruleum Kohler.

\section{Order IV. CHILOPHIURDA.}

Family OPHIOCHITONIDAE Matsumoto, 1915.

Ophiochton fastigatus Lyman.

ophionereis dubia (Müller and Troschel).

Ophionereis semoni (Döderleln).

Ophiodoris contrarius Kœhler.

Ophiodoris malignus Kœhler. 
Family OPHIOCOMIDAE Ljungman, 1867.

Ophiocoma brevipes Peters.

Ophiocoma erinaceus Müller and Troschel.

Ophiocoma lineolata Müller and Troschel.

ophiocoma scolopendrina (Lamarck).

ophiocoma vendtii Müller and Troschel.

Ophiomastix annulosa (Lamarck).

Ophiomastix flaccida Lyman.

Ophiomastix lütkeni Pfeffer.

Ophiomastix mixta Lütken.

ophiomastix venosa Peters.

Ophiarthrum elegans Peters.

Family OPHIODERMATIDAE Ljungman, 1867.

OphIARACHNa quinquespinosa. new species.

Pectinura yoldii (Lütken).

Pectinura aequalis (Lyman).

Ophiopezella spinosa (Ljungman).

Ophiarachnella gorgonia (Müller and Troschel).

ophiarachnella honorata (Kœhler).

ophiarachnella infernalis (Müller and Troschel).

ophiarachnella nitens (Kohler).

Bathypectinura conspicua (Kœhler).

Oryptopelta tecta, new specles.

Ophiurodon cinctus (Kœhler).

Ophiurodon permixtus (Kœhler).

Family OPHIOLEPIDIDAE Ljungman, $186 i$.

Ophiopyrgus planulatus, new species.

Amphiophiura canaliculata, new species.

AMphiophiura fastigiata, new species.

Amphiophiura improba (Kœhler).

Amphiophiura insolita (Kohler).

Amphiophiura paupera (Kœhler).

Amphiophiura radiata (Lyman).

Amphiophiura sculptilis (Lyman).

Amphiophiura sordida (Kœhler).

AMphiophiura spatulifera, new specles.

Amphiophiura stellata (Studer).

Stegophiura sladeni (Duncan).

Stegophiura sterilis, new species.

Ophiura aequalis Lyman.

Ophiura clemens Ko hler.

Ophiura flagellata Lyman.

Ophiura rluctuans, new species.

Ophiura irrorata Lyman.

Ophiura kinbergi Lyman.

Ophiura micrantha H. L. Clark.

Ophiura mitescens, new species.

Ophiura sarsii Lütken.

Homalophiura inflata (Kœhler).

Homalophiura inornata (Lyman). 
Ophiocten hastatum Lyman.

Ophiomusium altum (Kœhler).

OpHIOMUSIUM aRmatum, new species.

Ophiomusium elegans Kœhler.

OPHIOMUSIUM FACETUM, new species.

OPHIOMUSIUM FAcUNDUM, new species.

OphIomusium fimbriatum, new species.

OPHIOMUSIUM IMPOTENS, new species.

OpHIomusium ligatum, new species.

Ophiomusium lunare Lyman.

Ophiomusium lymani Wyville Thomson.

Ophiomusium morio, new species.

Ophiomusium properum Kœhler.

Ophiomusium relictum Kœhler.

Ophiomusium scalare Lyman.

Ophiomusium simplex Lyman.

OPHIOMUSIUM SPINULOSUM, new species.

Ophiolipus granulatus Lyman.

ophioceramis declinans Kœhler.

ophiozonella bispinosa (Kœhler).

Ophiozonella casta (Kœhler).

Ophiozonella media (Kœhler.

ophiozonella molesta (Kœhler).

OPHIOZONELLA subTIIIS, new species.

OpHIOzoNoIdA obscura, new specles.

Ophiomidas reductum Kœhler.

Ophiolepis annulosa Müller and Troschel.

Ophiolepis irregularis Brock.

Ophioplocus imbricatus Müller and Troschel.

Family OPHIOLEUCIDAE Matsumoto, 1915.

Ophiocirce inutilis Kœhler.

Ophiopallas paradoxa Kœhler.

Ophropallas valens, new species.

Ophiernus adspersus Lyman.

In the preceding list $\mathrm{I}$ have followed the classification proposed by Matsumoto in 1915 ('15 [1], pp.43-92) in a memoir which, though short, is most noteworthy and abounding in far-reaching observations. The same classification was adopted by Dr. Hubert Lyman Clark in his beautiful memoir entitled "Catalogue of Recent Ophiurans," which also bears the date 1915 . This work being destined to be the reference work-and an exceedingly convenient one-for all those who are engaged in studying the ophiurans I shall follow the classification therein used. However, as my views differ in various matters of detail from those of the learned American zoölogist, a few words of explanation are necessary, and at the same time it appears to me advisable also to make a few remarks in regard to the classification proposed by Matsumoto, in which H. L. Clark has thought it necessary to introduce some slight modifications. 
Regarding these suggestions I may say that in general they are of purely secondary importance and do not affect the broad lines of the classification established by Matsumoto. It is also fair to mention that H. L. Clark stated that if his classification differed from that of Matsumoto it was not at all because he had found the latter at fault. I quote his own words:

It must not be inferred that in those instances where I have not followed Matsumoto I indicate a belief that he is wrong. It merely shows that $I$ have not yet satisfied myself as to the relationships of certain genera and species. In these cases, notably in regard to the genus Ophioconis and its allies, the evidence is perplexing and more light is necessary $(15, \mathrm{pp} .165,166)$.

Matsumoto has elaborated his conclusions in a magnificent work published in 1917, entitled "A Monograph of Japanese Ophiuroidea Arranged According to a New Classification," " which reached me just as I was about to send my report to Washington. I have thus not been able to make use of it in the preparation of this memoir, begun three years previously, though I have been able to insert in the text the bibliographical references, as well as some notes on different points on which I am not entirely in accord with the learned Japanese naturalist.

Matsumoto divided the ophiurans into two primary classes, namely: CEgophiuroida, including only fossil forms with an external ambulacral groove and without ventral arm plates, and

Mrophiuroida, without an external ambulacral groove and with ventral arm plates, including certain paleozoic species and all known living forms.

The latter is divided into four orders:

Phrynophiurida, with three families:

Ophiomyxidae.

Trichasteridae.

Gorgonocephalidae.

Laemophudida, with two families:

Hemieuryalidae.

Ophiacanthidae.

GNATHOPHIURIDA, with three families:

Amphiuridae.

Amphilepididae.

Ophiotrichidae.

Chilophiurida, with five families:

Ophiochitonidae.

Ophiocomidae.

Ophiodermatidae.

Ophiolepididae.

Ophioleucidae.

2 Journ. Coll. Scl., Imp. Univ. Tokyo, vol. 38. art. 2. 
In regard to these four orders and to the several families which are assigned to them $I$ have the following remarks to make:

1. Phrxnophiurida.-Matsumoto has retained in his family Ophiomyxidae the genus Ophiodera which was separated from Ophiomyxa in 1899 by Verrill. H. L. Clark did not admit the distinctness of Ophiodera, but placed in the genus Ophiomyxa both the species in which there exists a border of plates at the periphery of the disk and those in which such a border is absent.

2. Loemopinurida. - The subfamily Ophiochondrinae of Matsumoto includes the three genera Ophiochondrus, Ophiomoeris, and Ophiogyptis. H. L. Clark has recognized the genus Ophiochondrella of Verrill, 1899, which Matsumoto does not mention. Instead of placing in the genus Ophiomoeris, O. obstricta Kohler, as I had done in 1904, Clark retained the genus Ophiurases, which he believed was established in 1911 for this species, forgetting the previous erection of the genus Ophiomoeris. But Matsumoto in his memoir of 1915 had formally indicated that Ophiurases obstrictus is merely a synonym of Ophiomoeris obstricta Kœhler.

Matsumoto placed in the family Ophiacanthidae the genera Ophiothotia and Ophiomyces, which are here associated with numerous other genera, such as Ophiacantha, Ophiomitra, Ophiocamax, etc. I propose to retain for these two genera, which differ so markedly from all the other types placed in the family Ophiacanthidae, as Verrill showed in 1899, the family Ophiomycetidae established by the latter. In the preceding list I have therefore separated Ophiomyces delata from the other ophiacanthids and placed it in a separate family.

The genus Ophiohelus, which Verrill made the type of the family Ophiohelidae, Matsumoto placed in the Ophiomyxinae. This disposition appears to me to be quite correct.

3. Gnathophiurida.-This order was divided by Matsumoto into three families-Amphilepididae, Amphiuridae, and Ophiotrichidae. The first includes, together with the genera Amphilepis and Ophiochytra, a new genus established by Matsumoto, Amphiactis, of which the type is $A$. umbonata. In addition Matsumoto places here the various species previously assigned to the genus Ophiactis, which possess four or five mouth papillæ-O canescens Lyman, $O$. duplicata Lyman, O. patula Lyman, O. partita Kœhler, O. dissidens Kœhler, and $O$. parata Kohler. H. L. Clark has not recognized the family Amphilepididae; he places the six species just mentioned some in the genus Ophiactis and others in the genus Amphivara, and he places the genus Amphitepis in the family Amphiuridae.

Personally I have considered it best to maintain the family Amphilepididae, for I believe that the characters invoked by Matsumoto in its creation, which relate principally to the structure of 
the mouth parts, are in reality of great significance. Moreover, it must be recognized that the species assigned by Matsumoto to his genus Amphiactis have external characters which in no way accord with those of the genera Amphiura (taken in the broad sense) and Ophiactis, between which they were distributed.

In mentioning the several genera which he places in the subfamily Amphiurinae Matsumoto notes "Amphiura, including Ophionephthys," and also "Ophiocentrus, including Amphiocnida." He believes, therefore, that the species of the genus Ophionephthys should be placed in the genus Amphiura, and those of the genus Amphiocnida in the genus Ophiocentrus.

H. L. Clark has not adopted this point of view, maintaining as distinct the genera Amphiocnida ('15, p. 236) and Ophionephthys (p. 239). I shall have occasion to revert to this subject when I discuss Amphiura vadicola and Ophiocentrus aculeatus.

4. Chilophiurida.-The observations which I have to offer concern the families Ophiolepididae and Ophiodermatidae, more particularly the old genera Ophiura and Ophioconis.

Not only am I adopting the divisions established by Matsumoto, but from now on I shall use the name Ophiura in place of Ophioglypha, which I have always used heretofore in order to be in agreement with the nomenclature which echinologists are now using and which H. L. Clark has adopted in his "Catalogue." I should state, however, that in using the name Ophioglypha as I did I had hoped primarily to avoid misconceptions. It is agreed that the rule of priority requires the use of the name Ophiura, but everyone knows that sometimes exceptions must be made to the strict application of the rule if it is not to lead to impossible or even ridiculous results (see the remarks published by Mortensen in 1910 and 1911 regarding the strict application of the rule of priority to the echinoderms).

I have always believed, and still do, that it would be better to set aside the rule of priority than to introduce fundamental changes in the nomenclature. The substitution of the name Ophiura for Ophioglypha would for a time create confusion, as many authors, Lyman for example, have used Ophiura as a synonym of Ophioderma. Such use runs back for a very considerable time, and since 1882 Ophiura, when it has been used, has appeared more commonly as a synonym of Ophioglypha than as a synonym of Ophioderma. The chances of confusion thus have been becoming more and more remote, and that is why I shall henceforth conform to the preferences of my colleagues.

It was in 1915 that Matsumoto first established in the old genus Ophiura (taken in the broad sense) a certain number of divisions representing separate genera, as follows: 
1. Aspidophiura, including in all three species, A. minuta (Lyman), $A$. forbesi (Duncan) (=glyptodisca H. L. Clark), and $\dot{A}$. watasei Matsumoto.

2. Ophiurolepis, including only a single species, O. deshayesi (Lyman), which is a synonym of Ophiolepis carinata Studer. The latter name having priority, the species must henceforth be known as Ophiurolepis carinata.

3. Stegophiura, including about ten species, such as S. elevata (Lyman), S. nodosa (Lütken), S. sladeni (Duncan) (=stiphra H. L. Clark), S. s̀culpta (Duncan), S. sterea (H. L. Clark), etc.

4. Amphiophiura, including about thirty species, such as $A$. butlata (W. Thomson), A. convexa (Lyman), A. improba (Kohler), A. insolita (Kœhler), A. latro (Kœhler), A. paupera (Kœhler), A. sordida (Kœhler), A. undata (Lyman), etc.

5. Matsumoto left in the genus Ophiura, as restricted by him, a large number of species which he divided into two categories, one including those with the arm comb formed of elongated, narrow, and acuminate papillae, such as $O$. albida (Forbes), $O$ ciliata (Retzius) (=texturata Lamarck), O. brevispina Smith, O. aequalis (Lyman), O. carnea (Lütken), O. kinbergi (Lyman), O. lepida (Lyman), O. palliata (Lyman, ${ }^{2}$ and $O$. sarsii (Lütken), the other including those with the arm comb composed of low, short, and blunt papillae, such as $O$. abyssorum (Lyman), $O$. ambigua (Lyman), $O$. clemens (Kœhler), O. confragosa (Lyman), O. inflata (Kœhler), O. inornata (Lyman), O. irrorata (Lyman), O. nana (Lütken and Mortensen), etc.

There is a hiatus in the enumeration of the species given by Matsumoto, for he makes no mention of a number of Antarctic forms, such as $O$. brucei, $O$. flexibilis, $O$. frigida, $O$. gelida, $O$. mimaria, $O$. partita, etc., which I have described within the past few years and which evidently he was unable to place in any of the categories established by him. Furthermore Matsumoto leaves in the genus Ophiura as restricted certain species, such as $O$. abyssorum, $O$. confragosa, and $O$. inornata, which obviously do not conform to the characters of the restricted genus as he understands it. H. L. Clark has created for these several species ('15, p. 235) the genus Homalophiura, which is perfectly homogeneous and which includes about 20 forms. This genus is characterized by the reduction of the arm comb, by having the brachial tentacular pores very slightly developed and not occurring beyond the first arm plates, by having the buccal pores distant from the mouth, etc.

2Matsumoto gives 0 . papillata. This is evidently a typographical error, for he in tended to write palliata. 
Among the genera established by Matsumoto the two genera Aspidophiura and Ophiurolepis are similarly very well characterized, but they only include a very small number of species-four in both combined. The genera Amphiophiura and Stegophiura both include species in which the disk is thick and in which the dorsal and ventral arm plates are well developed and in contact throughout a large portion of the arms; the ventral arm plates especially are large, often as long as broad, and they cover a relatively large portion of the ventral aspect of the arms. Matsumoto differentiates Stegophiura by the short arms which are very broad at the base and diminish very rapidly in breadth, while in Amphiophiura the arms are rather narrow, but in compensation longer and diminishing gradually in width. While the characters cited by Matsumoto are easy of application in a certain number of species, it is not the same for others, and the limits of the two genera are indefinite. This is one of the weak points of Matsumoto's classification, and here there are certain to arise doubtful cases, leading to differences of opinion among zoölogists. I see already an instance in the case of $O$. solida Lyman, which Matsumoto placed in the genus Amphiophiura ('15, p. 77), while H. L. Clark assigned it to the genus Stegophiura ('15, p. 317). The species is retained in Amphiophiura by Matsumoto in 1917. Moreover, Matsumoto himself states that the rather numerous species assigned by him to the genus Amphiophiura form four groups which in their characters approach, respectively, the genera Ophiopyrgus, Aspidophiura, Stegophiura, and Ophiura (in the restricted sense).

Matsumoto has left in the genus Ophiura all the species not assigned to the four genera established by him, and in which the disk and the arms are flattened, the ventral arm plates are very short, the tentacular pores are well developed, the mouth pores are very large, provided with numerous scales, and close to the mouth, etc. I mentioned above that certain species retained by him in this genus as restricted had been removed by H. L. Clark and placed in the genus Homalophiura (O. abyssorum, O. confragosa, etc.). In my opinion certain other species retained by Matsumoto should also be removed from the genus Ophiura (in the restricted sense), some to be placed elsewhere, others to be definitely suppressed. For example, $O$. hexactis does not belong to the genus Ophiura at all, but to the genus Ophionotus, as I showed in 1912 and as I have confirmed in a more recent work ('17, p. 61), where I have given new evidence of the correctness of this disposition based upon the characters of the peristomal plates; $O$. nana Lütken and Mortensen is a synonym of my $O$. inflata described three years earlier, and the name therefore must disappear from zoölogical literature, while the latter species should 
be placed in the genus Homalophiura, as H. L. Clark has done; O. undata is given by Matsumoto both in the genus Amphiophiura (p. 78) and in the genus Ophiura (p. 81). I surmise that this latter is a typographical error and that he intended to write (p. 81) 0 . undulata.

However, everything considered, this first attempt at a reclassification of the species of the old genus Ophiura is of the greatest interest and marks a very considerable progress. In spite of a certain vagueness which persists in regard to the limits of the genera Amphiophiura and Stegophiura, the genera proposed by Matsumoto are worthy of adoption, and I shall follow his nomenclature in the succeeding pages.

In his memoir of 1917 Matsumoto has redefined the characters of the genera established by him in 1915. He accepts H. L. Clark's genus Homalophiura, but he maintains as distinct both $O$. inflata and 0 . nana. He cites 0 . undulata (not undata) among the species of the genus Ophiura, in the restricted sense (p. 268). He no longer retains Ophionotus hexactis in the genus Ophiura, and he now agrees with me that this species should be replaced in the genus Ophionotus (p. 235, note).

$\Lambda$ very detailed study of the species assigned to the old genus Ophioconis had led Matsumoto to propose a complete rearrangement of them in 1915.

The necessity for a revision of this genus, not only to determine the interrelationships of the species commonly assigned to it but also to establish its position in the classification of the ophiurans, had already been suggested by H. I. Clark in 1911 when he was describing his new species from Japan and the Bering Sea ('11, p. 28). When I began in 1914 the preparation of this memoir, I had myself been confronted with this problem, and I was led to establish in the old genus $O$ phioconis three distinct groups in such a way as to separate from $O$. forbesi (the type of the genus), on the one hand, $O$. cincta, O. cupida, O. grandisquama, and $O$. permixta, which form a very homogeneous group, and, on the other hand, 0 . miliaria and $O$. pulverulenta. At the same time I proposed to remove from the genus Ophioconis, O. brevispina Ludwig, of which the teeth do not have at all the form characteristic of those of 0 . forbesi, as well as 0 . indica, which I proposed, provisionally at least, to place near the genus Pectinura, taken in the sense in which it is understood by H. L. Clark.

Matsumoto's memoir, dated 1915, reached me in 1916, long before the work which appears to-day was printed, and it is Matsumoto, therefore, who deserves all the credit of having revised the old genus 
Ophioconis. I only speak of my studies on the subject in order to be able to state that after reading Matsumoto's work I find myself entirely prepared to adopt, in its broad lines, the classification which he proposes. I shall give a short summary of it.

Matsumoto first of all removes from the genus Ophioconis several species which have all the characters of the genus Ophiolimna, and he assigns to the latter $O$. antarctica Lyman, $O$. operculata Kœhler, 0 . diastata H. L. Clark, and O. papillata H. L. Clark. Then, on the basis of the development of the spines and the structure of the teeth, he divides the remaining species into two groups, one including those in which the spines are short and appressed to the arms, forming the genus Ophioconis (restricted), the other including those in which the spines are elongated and not appressed. The latter is again divided into two groups according to whether the teeth are very small, triangular, and pointed, or flattened, slender, and transparent. The species of the first group form the new genus Ophiuroconis and those of the second the new genus Ophiurodon. Matsumoto thus leaves in the genus Ophioconis only $O$. forbesi and 0 . brevispina. As for $O$. indica, this appears to him to be close to the genus Pectinura, though differing from it in a number of characters.

I am in complete accord with Matsumoto's point of view regarding the necessity of erecting the new genera Ophiuroconis and Ophiurodon and the validity of the characters which he attributes to each, as well as in assigning $O$. antarctica, $O$. diastata, and $O$. papillata to the genus Ophiolimna, but I differ from him regarding the limites of the genus Ophioconis (restricted). Matsumoto characterizes it exclusively on the basis of the short, appressed, and hyaline spines, and the covered mouth shields; but I believe that there is a third character quite as important as the two preceding which should be considered, and that is the form of the teeth. In the first species described, $O$. forbesi, which for a long time remained the only species of the genus Ophioconis, the teeth are slender, transparent, and flattened, appearing as a column of broadened lamellae, the free borders of which are more or less denticulate (pl. 81, fig. 1). In the original description of Pectinura forbesi Heller indicated this peculiarity of the teeth which he described as "grosse, rundliche, blattförmige Zähne" ('62, p. 422). This form of the teeth is very remarkable, and it is also found in the species referred by Matsumoto to the genus Ophiurodon. But in O. Urevispina the teeth are not at all of this character. I only know this species, which seems to be very rare and appears never to have been rediscovered, from Ludwig's original description. Ludwig did not describe in detail the form of the teeth and did not compare them with those of $O$. forbesi. He simply says 
that they are conical (kegelförmige), and in his figure they are clearly shown as small, triangular, and pointed, quite the same as the adjacent mouth papillae.

In the form of the teeth, therefore, there is a difference between $O$. forbesi and $O$. brevispina analogous to that separating the genera Ophiurodon and Ophiuroconis. In my opinion these two species can not be placed in the same genus, and I propose to leave in the genus Ophioconis $O$. forbesi only, the genus thus again becoming, as formerly, monotypic. As for $O$. brevispina, it certainly can not be referred to Matsumoto's Ophiuroconis. If the shape of the teeth is really that which Ludwig has figured, it must be very close to the species which H. L. Clark has assembled in his new genus Cryptopelta, and I therefore propose that it be referred to this genus.

There remains to be considered $O$. indica, which $I$ placed in the genus Ophioconis in 1896; but it is evident that it can not remain here, and also that it can not be assigned to either of the new genera proposed by Matsumoto. I agree entirely with the objections which he raises in regard to placing it to the genus Pectinura, on account of the characters of the spines and the presence of a single tentacle scale; but, on the other hand, it is obvious that it is extremely close to the species of Cryptopelta, especially to $C$. aster. It can not, however, be assigned to this genus, of which one of the primary characters is found in the condition of the mouth shields, which are covered with granules, as in $O$. indica these shields are naked. I suggest that it be made the type of a new genus, for which I propose the name Gymnopelta, in contrast to Cryptopelta.

The reclassification of the species assigned to the old genus Ophioconis (taken in the broad sense) is as follows:

Genus Ophioconis Lütken Ophioconis forbesi (Heller).

Genus Ophiurodon Matsumoto Ophiurodon cincta (Kœhler). Ophiurodon cupida (Kœhler). Ophiurodon grandisquama (Kœhler). ophiurodon permixta (Kohler).

Genus Ophiuroconis Matsumoto Ophiuroconis miliaria (Lyman).

Ophiuroconis monolepis Matsumoto. Ophiuroconis pulverulenta (Lyman).

Genus Cryptopelta H. L. Clark Cryptopelta brevispina (Ludwig).

[Cryptopelta aster (Lyman)].

[Cryptopelta granulifera H. I. Clark].

Genus Gymnopelta Kœhler Gymnopelta indica (Kœhler).

Genus Ophiolimna Verrill Ophiolimna antarctica (Lyman).

Ophiolimna diastata (H. L. Clark).

Ophiolimna papillata (H. L. Clark).

The first ten species must be placed in the family Ophiodermatidae, and the three last, assigned to the genus Ophiolimna, in the family Ophiacanthidae. 
This reassignment among two very different families is in conformity with the view of Matsumoto. But an entirely different classification has been followed by H. L. Clark in his catalogue. He maintains the old genus Ophioconis without taking into consideration the divisions proposed by Matsumoto, and he places it bodily, with its thirteen species, in the family Ophiacanthidae.

H. L. Clark has discarded the genus Ophiolimna. Some of the species he places in the genus Ophiacantha $(O$. bairdi, $O$. perfida, $O$. operculata, and $O .7 a m b d a$ ) and the rest in the genus $O$ phioconis ( $O$. antarctica, $O$. diastata, and $O$. papillata).

The redistribution of the species of the old genus Ophioconis which I have just given differs in seyeral details from that which Matsumoto has recently proposed ('17, p. 310). The Japanese author leaves in the genus Ophioconis (restricted) not only $O$. forbesi, but also 0. brevispina, which is very different from it, and, furthermore, he proposes to unite with the genus Ophioconis the genus Ophiocormus described by H. L. Clark. At the same time he is inclined to believe that the genera Ophioconis and Cryptopelta should be reunited, although admitting that they differ in the structure of the arm spines, and he retains in the genus Ophioconis $O$. indica, which formerly he considered as an extreme form of Pectinura.

In concluding I may say that the family Astrophiuridae should be added to the families placed by Matsumoto in the Chilophiurida. In my paper on Astrophiura cavellae I have given the reasons why I believed it necessary to place the genus Astrophiura in a distinct family, and perhaps even in a separate order ('15, p. 15). In his 1917 memoir Matsumoto simply places the genus Astrophiura in the subfamily Ophiomastinae with the genera Ophiophysis Kohler, Ophiomisidium Kœhler, Ophiotypa Kœhler, and Ophiomastus Lyman ('17, p. 234). But I still consider that the remarkable peculiarities of the genus Astrophiura are sufficient to justify the creation of an independent family. ${ }^{3}$

\footnotetext{
${ }^{8}$ When I described Astrophiura cavellae I noted (p. 2) that this species had been mentioned by Chun in his book "Aus den Tlefen des Welt-Meeres." "But apparently Matsumoto has assumed that the form recorded by Chun was a different one. In comparing Astrophiura kavamurai with the species previously known 'he says ('17, p. 245): "This species differs from Chun's Astrophiura from Agulhas Bank, which is not yet named, ..." and, on the following page, "lately, Kohler has described A. cavellae from the vicinity of the Cape of Good Hope." It is not correct to say that Chun's specles has not yet received a specific name, for it is the one to which I gave the name A. cavellae, and $I$ have stated in $m y$ description the exact locality where it was dredged by the Valdivia-latitude $34^{\circ} 33^{\prime}$ S., longitude $18^{\circ} 21^{\prime}$ E., the depth being 318 meters.
} 


\title{
Order I. PHRYNOPHIURIDA.
}

\author{
Family OPHIOMYXIDAE. \\ OPHIOMYXA BENGALENSIS Kœhler. \\ Plate 5 , figs. 5,6 ; plate 92 , fig. 1 .
}

Ophiomyxa bengalensis Ḱ(EHLER, '96, p. 363, pl. 9, figs. 70, 71; '99, p. 69, pl. 12, figs. 91, 92.-H. L. Clark, '15, p. 168.

Locality.-Albatross station 5292; China Sea, in the vicinity of southern Luzon; Escarceo Light bearing N. $36^{\circ}$ W. 6.02 kilometers (3.25 miles) distant (lat. $13^{\circ} 28^{\prime} 45^{\prime \prime}$ N., long. $121^{\circ} 01^{\prime} 12^{\prime \prime}$ E.) ; 296 meters (162 fathoms); July 23, 1908; fne. bk. S.

Eight specimens (Cat. Nos. E.225, E.226, U.S.N.M.).

Notes.-All these specimens agree well with the type series, which was dredged by the Investigator among the Andaman Islands at depths varying between 457 and 1,962 meters (250 and 1,073 fathoms). I give here two photographs of one of the Albatross specimens, which show better than my figures published in 1896 and 1899 the habitus of this species. I also include some photographs of arm spines from different portions of the arms.

\section{OPHIOMYXA IRREGULARIS Kœhler.}

Plate 2, fig. 18 ; plate 5 , figs. 1,2 ; plate 6 , fig. 4 ; plate 92 , fig. 2.

See for bibliography:

Ophiomyxa irregularis KaEHer, '05, p.119, pl. 12, fig. 1.-H. L. ClaRK, '15, p. 170.

Localities.-Albatross station 5135; in the vicinity of Jolo (Sulu); Joló Light bearing S. $46^{\circ}$ W., 22.05 kilometers (11.9 miles) distant (lat. $6^{\circ} 11^{\prime} 50^{\prime \prime}$ N., long. $121^{\circ} 08^{\prime} 20^{\prime \prime}$ E.) ; 294 meters (161 fathoms) ; February 7, 1908; fne. co. S.

Two specimens (Cat. No. E.163, U.S.N.M.).

Albatross station 5140; in the vicinity of Joló; Joló Iight bearing S. $33^{\circ} \mathrm{W}$., 11 kilometers (6.1 miles) distant (lat. $6^{\circ} 08^{\prime} 45^{\prime \prime} \mathrm{N}$., long. $121^{\circ} 03^{\prime}$ E.) ; 139 meters (76 fathoms) ; February 14, 1908; fne. co. S.

One specimen (Cat. No. E.161, U.S.N.M.).

Albatross station 5172; in the vicinity of Jólo; Joló Light bearing E., 46 kilometers ( 24.75 miles) distant (lat. $6^{\circ} 03^{\prime} 15^{\prime \prime}$ N., long. $120^{\circ}$ $35^{\prime} 50^{\prime \prime}$ E.) ; 582 meters (318 fathoms) ; March 5, 1908; fne. S., Sh.

One specimen (Cat. No. E.162, U.S.N.M.).

Albatross station 5174; in the vicinity of Joló; Joló Light bearing E., 4.81 kilometers (2.6 miles) distant (lat. $6^{\circ} 03^{\prime} 45^{\prime \prime} \mathrm{N}$., long. $120^{\circ}$ $57^{\prime} 00^{\prime \prime}$ E.) ; 36 meters (20 fathoms) ; March 5, 1908; crs. S.

Two specimens (Cat. No. E.165, U.S.N.M.). 
Albatross station 5617; Dodinga Bay, Gillolo Island, Moluccas; Ternate Island (SE.) bearing S. $45^{\circ} \mathrm{W} ., 12.97$ kilometers ( 7 miles) distant (lat. $0^{\circ} 49^{\prime} 30^{\prime \prime}$ N., long. $127^{\circ} 25^{\prime} 30^{\prime \prime}$ E.) ; 239 meters (131 fathoms); November 27, 1909.

One specimen (Cat. No. E.166, U.S.N.M.).

Albatross station 5629; Patiente Strait and southward; Doworra Island (S.) bearing S. $62^{\circ}$ W., 11.12 kilometers (6 miles) distant (lat. $0^{\circ} 50^{\prime} 00^{\prime \prime} \mathrm{S}$., long. $128^{\circ} 12^{\prime} 00^{\prime \prime}$ E.) 375 meters (205 fathoms); December 2, 1909 ; co. S.

One specimen (Cat. No. E.164, U.S.N.M.).

Notes.-In the specimens from station 5135 the diameter of the disk is $15 \mathrm{~mm}$. and the arms are from $65 \mathrm{~mm}$. to $70 \mathrm{~mm}$. in length; in that from station 5172, which I figure, the disk is slightly smaller, its diameter varying between $13 \mathrm{~mm}$. and $14 \mathrm{~mm}$, and the arms are almost of the same length as in the preceding, from $60 \mathrm{~mm}$. to $70 \mathrm{~mm}$. long. The arms are moderately rigid; they are $3 \mathrm{~mm}$. broad at the base and taper rapidly. The diameter of the disk of the specimen from station 5629 is $15 \mathrm{~mm}$; the others are smaller.

The disk is pentagonal, with the sides more or less concave. The dorsal surface is covered with an integument which is entirely naked, but beneath which, at the bases of the arms, may be distinguished the radial shields, which are not much elongated, though moderately broad-scarcely twice as long as broad; these shields are covered exteriorly by few imbricated plates which are a continuation of other thicker plates which form a border about the periphery of the disk in the interbrachial spaces. Usually there may be distinguished in the center of each of these spaces a larger oval plate, from either side of which extends a series of smaller narrow and imbricated plates. In general this peripheral border of plates is very evident, but sometimes it is not visible in alcoholic specimens, appearing only after they have been dried (pl. 2, fig. 18).

The ventral face of the disk is covered by a smooth integument. The genital slits, which are broad and elongated, reach almost to the edge of the disk; they are bordered by large plates similarly elongated.

The outlines of the mouth plates can be readily made out in dried individuals. The mouth shields are large and rather broad, triangular, with the sides and angles rounded, and a little broader than long. The adoral plates, which are large and elongated, usually reach the median interradial line where they are in contact, while at the same time they are more or less narrowed inwardly; outwardly, on the other hand, they are broadened and give off a rather narrow process which separates the mouth shield from the first side arm plate. The oral plates are triangular and high. The lateral mouth papillae are 
three in number, increasing in size from the external or distal to the proximal; they are rounded, with a transparent and denticulate border. The terminal unpaired papilla resembles the others, but is a little larger.

The upper arm plates, completely fused with the upper surface of the vertebral pieces, are lozenge-shaped, with the angles rounded off, separated on the sides by soft areas.

The first under arm plate is small, rectangular, broader than long. The following are heart-shaped, as long as broad, with an acute proximal angle, rounded sides, and the distal border deeply notched in the middle. At first they are in contact, later becoming separated by a narrow interval.

The side arm plates carry four moderately developed spines, which are strong and cylindrical, with the tip blunted; their surface is more or less roughened, and often small asperities may be made out. The length of the spines increases very gradually from the first ventral, which is a little shorter than the plate, to the last dorsal, which is almost as long as the plate. These dimensions are taken from a dried specimen; in alcoholic specimens the spines, somewhat sunken in the integument, appear shorter, and their length does not appear much to exceed half that of the joint, as I stated in 1905. Four spines are found throughout the greater part of the arm.

The different photographs given on plate 92 as figure 2 illustrate the character of the spines at different heights on the arms. It is noticeable that toward the extremity of the arms the deticulations tend to become localized along the proximal border of the spines, at the same time becoming very much stronger; this results in transforming the two ventral spines, especially the first, into true hooks with four or five branches (fig. 2c).

Alcoholic specimens have a yellowish color, with the dorsal surface of the disk darker and brownish, or they may be uniformly brownish gray.

I at first (in 1896) considered this Ophiomyxa as a variety of $O$. brevispina, but the study of specimens collected by the Siboga showed me that it is in reality a different species, and the examination of the material collected by the Albatross has confirmed me in that opinion (see Kohler '05, p. 119).

There is evidently a strong resemblance between 0 . irregularis and O. panamensis described by Lütken and Mortensen ('99, p. 182). These authors mention in the latter four mouth papillae instead of three, adding the the edge of these papillae lacks a transparent border; the adoral plates are separated in the median interradial line; the under arm plates in their form recall strongly those of $O$. irregularis, but they are broader than long; the radial shields are also more broadened in $O$. panamensis, and the arm spines may reach 
five in number. These differences are obviously rather slight, and it is undeniable that the two forms are very closely related; without doubt they are corresponding types, one inhabiting the Indian Ocean and the western Pacific, the other the American shores of the latter ocean.

On the basis of the figures given above, in connection with the list of the Albatross stations at which this species was collected, it can be stated that this form is able to live at quite different depths, ranging between 36 and 581 meters (20 and 318 fathoms). The greatest depth at which the Siboga found $O$. irregularis was only 141 meter (81 fathoms).

\section{OPHIODERA NEGLECTA Kœhler.}

Plate 6, figs $3,7,8$.

Ophiodera neglecta KäHLE, '04, p. 153, pl. 18, figs. 6, 7.

Ophiomyxa neglecta H. L. Clark, '15, p. 170.

Localities.-Albatross station 5378; Marinduque Island and vicinity; Mompog Island (E.) bearing N. $38^{\circ}$ W., 31.50 kilometers (17 miles) distant (lat. $13^{\circ} 17^{\prime} 45^{\prime \prime} \mathrm{N}$., long. $122^{\circ} 22^{\prime} 00^{\prime \prime}$ E.) ; 722 meters (395 fathoms); March 4, 1909 ; sft. gn. M.

One specimen (Cat. No. E. 330, U.S.N.M.).

Albatross station 5510; Northern Mindanao and vicinity; Camp Overton Light bearing S. $68^{\circ}$ E., 16.86 kilometers $(9.1$ miles $)$ distant (lat. $8^{\circ} 16^{\prime} 00^{\prime \prime} \mathrm{N}$., long. $124^{\circ} 03^{\prime} 50^{\prime \prime}$ E.) ; 744 meters (423 fathoms) ; August 7, 1909 ; gy. M., fne. S.

One specimen.

Notes.-In the specimen from station 5378 the two diameters of the disk are $15 \mathrm{~mm}$. and $17 \mathrm{~mm}$. The arms are very long and narrow, their length exceeding $90 \mathrm{~mm}$; they remain of the same width almost throughout the proximal half, tapering more rapidly in the distal. The specimen from station 5510 is a little smaller.

I shall here include some notes supplementary to the original description published in 1904. It has seemed advisable also to include three photographs of the specimen from station 5378, which I have dried in order to render the outlines of the plates more readily discernible than they are in alcoholic specimens.

The radial shields are very evident in the dried specimen; they are broadened, rather short, twice, and some of them even three times, as long as broad. There is not the slightest trace of plates on the periphery of the disk, and the species certainly belongs to the genus Ophiodera as that genus was diagnosed by Verrill. The dorsal surface of the disk is covered by a slightly wrinkled integument, and I notice here and there, principally between the radial shields, some small calcareous nodules, which are rounded and few in number. 
The outlines of the mouth plates are fairly well seen in the dried specimens, such as that which I have shown in figure 8. The mouth shields are large and broad, very much broader than long, triangular, with a very obtuse and rounded proximal angle similarly broadly rounded lateral angles, and a convex distal border. The adoral plates are much elongated, narrowed inwardly, but usually reaching the median interradial line; outwardly they are broadened and give off a narrow process which separates the mouth shield from the first side arm plate.

The lateral mouth papillae are four in number in both specimens; they are unequal, and always arranged in a slightly irregular manner, as I stated in 1904. The only papilla of which the form is fairly constant is the proximal, which is rounded, slightly denticulate on its free border, and very much smaller than the terminal papilla; the three others are conical, pointed, and of medium, but variable, dimensions.

The arms are narrow and rather flexible. The shape of the upper arm plates recalls that which I have just described in Ophiomyxa irregularis. The under arm plates are as broad as long, with a rather sharp proximal angle, straight sides, and a deeply notched distal border; this border even projects rather strongly on either side of the notch which is then delimited by two small acute angles, becoming thereby very evident. These plates are separated by a rather narrow interval which, however, is well marked from the second arm segment outward.

As a rule the arm spines are three in number, and sometimes even only two; I have only seen four very rarely, and only on the first arm segments. These spines are moderately thick at their base, which is buried in the integument, thence tapering very rapidly and becoming rather slender and pointed; they bear denticulations only in their distal half, and these are not very strongly developed (pl. 92 , fig. $3 a$ ). The two ventral spines equal or slightly exceed half the length of the segment; the dorsal spine is a little longer, though it does not reach quite the length of the segment. As the arms become narrower the denticulations of the spines, which are rather poorly developed at the base of the arms (pl. 92, fig. $3 a$ ) become stronger (fig. $3 b$ ); they are often more developed along one of the borders of the spine, and thus the first ventral spine sometimes takes. a form approaching that of a hook, though it can not be said that. it becomes converted into a true hook.

I was greatly surprised to find in the integument of $O$. neglectr: both on the disk and on the arms C-shaped spicules analogous to. those known in various echinoids and holothurians; some of these are here figured (fig. $3 c$ ). 
The specimen from station 5378 is of a general bright yellow color; the dorsal surface of the disk is darker and greenish. The other is a rather dark uniform brownish gray.

The type series of this species was found by the Siboga among the Sunda Islands at depths varying between 469 and 595 meters (255 and 322 fathoms).

Although Ophiodera neglecta and Ophiomyxa irregularis belong to two different genera, they show a very great external resemblance, and as the latter is able to descend to a considerable depth it may be met with in the same depth zones as the former. It is important, therefore, to state accurately the characters which distinguish them. The presence of a border of plates about the periphery of the disk obviously establishes a generic differentiation, but as these plates may be greatly obscured in alcoholic specimens it is very important to search for them carefully. Characters peculiar to Ophiomyxa irregularis by which this species may be distinguished from Ophiodera neglecta are the less-broadened mouth shields, the alwaysrounded lateral mouth papillae, which are three in number, the four strongly developed arm spines, the condition of the ventral arm plates, which are in contact along a considerable portion of the arm, and the stiffer appearance and lesser length of the arms.

The distinction between the genera Ophiodera and Ophiomyxa established by Verrill was not recognized by H. L. Clark in his "Catalogue of Recent Ophiurans," published in 1915. Obviously the character invoked by Verrill for the separation of the two has no considerable significance, and the value that he attributes to it can not be accepted; however, that is purely a matter of personal opinion. But it is certain that there can be distinguished in the genus Ophiomyxa, taken in the broad sense in which it was used by Clark, species provided with plates at the periphery of the disk and others which do not have them; each of these groups may be given the status of a genus or of a subgenus. I have thought it best to adopt the nomenclature proposed by Verrill, which is the most convenient; Matsumoto has also accepted it in his memoir of 1917.

\section{NEOPLAX CRASSIPES, new species.}

Plate 2, figs. 1-3.

Locality.-Albatross station 5108; China Sea, off southern Luzon, Corregidor Light bearing N. $39^{\circ}$ E., 41.70 kilometers (22.5 miles) distant (lat. $14^{\circ} 05^{\prime} 05^{\prime \prime} \mathrm{N}$., long. $120^{\circ} 19^{\prime} 45^{\prime \prime}$ E.) ; 24 meters (13 fathoms) ; January 15, 1908; Co.

One specimen (Cat. No. E. 193, U.S.N.M.).

Description.-The diameter of the disk varies between $10 \mathrm{~mm}$. and $11 \mathrm{~mm}$;; none of the arms is complete, the longest being preserved 
for a length of $60 \mathrm{~mm}$.; it could not have been very much longer; the four others are broken off at variable distances from the base. The arms are rather slender, and cylindrical; they appear rather stiffened, and are only very slightly bent.

The disk is pentagonal with the sides straight or gently convex; the dorsal surface is flattened, and the ventral surface is moderately convex.

The dorsal surface of the disk is covered uniformly with a thick and opaque integument, brown in color, from which arise isolated short, conical, sharply pointed spines irregularly arranged, rather widely separated from each other, but becoming closer together near the periphery. There is not the slightest trace of radial shields.

The ventral surface of the disk is covered with an integument thinner than that of the dorsal surface, beneath which may be distinguished, though with some difficulty, imbricated rounded plates rather close together. This surface carries spines similar to those of the dorsal surface but less numerous, and not reaching to the mouth shields.

The genital slits are rather broad and much elongated, extending from the mouth shields nearly to the periphery of the disk.

The mouth shields are rather large, much broadened transversely, twice as broad as long, triangular, with a very blunt and rounded proximal angle and gently convex sides passing over very rounded angles and uniting on the distal border, which is similarly convex; this border bears in the middle a rounded lobe, which is rather broad, but low. The adoral plates are large, rather narrow and elongated, four times as long as broad, with the longer edges parallel; they give off outwardly a narrow process which separates the mouth shield from the first side arm plate. The oral plates are rather large, triangular, twice as high as broad. The mouth papillae number five or six on each side and are elongated and conical, with the point blunted, except for the outermost, which is more broadened. The unpaired terminal papilla is broad and thick with the end blunted.

The upper arm plates are quite indistinguishable, but the integument of the dorsal surface of the arms shows on the seven or eight lowest arm segments little spines similar to those on the dorsal surface of the disk of which they are a continuation; these spines gradually diminish in size, and finally disappear altogether.

The first under arm plate is triangular, with a very obtuse proximal angle and a very strongly convex distal border, broader than long. The following plates, of average dimensions, are a little longer than broad, with the distal border strongly notched in the middle and a very rounded proximal angle; their sides are gently convex 
and divergent. All these plates are separated by a rather narrow interval.

The side arm plates bear six spines, which form a very regular transverse series; with the exception of the first ventral they are equal, rather short, conical, with the point blunted and armed with strong asperities. The lowest spine is very much more developed than the others, and the difference in size is manifest from the second segment onward, increasing to the fourteenth or fifteenth segment where it is much broadened, thick, although slightly flattened, reaching at least a segment and a half in length, while the five other spines do not reach even half the length of a segment. Subsequently the length and the breadth of the ventralmost spine gradually diminish toward the end of the arm, but it always remains broader and a little longer than the others. The surface of this large spine is covered with rather large asperities at the base of the arm, and these asperities decrease in size as the spine enlarges, reassuming their original revelopment as the size of the spine diminishes.

On the first arm segment there may be distinguished a very small conical and pointed tentacle scale, which disappears beneath the first ventral spine when this enlarges, but it reappears again when the size of this spine diminishes, that is to say, beyond the fifteenth segment.

Affinities and distinctive features.-The type of the genus Neoplax is $N$.ophioides described by Prof. F. Jeffrey Bell from the collections made by the Alert at d'Arros Island, in the Amirante group. In that species the ventralmost spine is a little larger than the others, but it is far from attaining the development which it reaches in the new species in which its size becomes quite diagnostic.

\section{OPHIOCANOPS, new genus.}

Description.-The disk is small; the arms are very slender and very long, tapering very gradually. The disk is covered with a naked integument without the least indication of plates either upon its dorsal surface or about the periphery. The outlines of the mouth plates are very clear; the mouth shields are rudimentary, but, on the other hand, the adoral plates are very greatly developed, and are excessively broad. Mouth papillae are present; the teeth are elongated and spiniform, arranged in a regular column of six. With the exception of the first, the under arm plates are entirely lacking. The upper arm plates are completely fused with the dorsal surface of the vertebrae, which are divided into two halves by a longitudinal groove, and the two spaces which on the dorsal side of the arm separate the successive vertebrae are occupied by soft parts for a distance almost equivalent to the length of the vertebra. Each of the side arm plates forms a very large prominent projection on the 
side of the arm. Their external surface is very convex, and their internal concave, and they fit exactly over the corresponding surface of the vertebra; on the ventral surface of the arms they are continued in the form of a process which reaches the median line; each of these processes is separated from the following by a space occupied by soft parts which cover an interval almost as broad as the process itself. The spines, five in number in the type species, are composed of a quite transparent calcareous substance; they are rather small, subequal, each with a row of four or five sharp and gently recurved teeth; they thus assume the form of compound hooks. There is no tentacle scale. The tentacular pores are very small and situated beyond the ventralmost arm spine.

Remarks.-In my opinion the genus Ophiocanops must be placed in the family Ophiomyxidae rather than in the Ophiobyrsinae, if the distinctions established by Matsumoto are accepted; the mouth shields, which are very small, are widely separated from the first side arm plate by the adoral plates, and the articulation of the vertebrae is zygospondylian; it may be seen from the photograph reproduced as figure 5 on plate 2 that this articulation is more complicated than in the Ophiobyrsinae.

This new genus may be compared with the genus Ophiosciasma, but it differs from it markedly in the absence of under arm plates and in having the rather numerous arm spines transformed into compound hooks from the arm bases outward.

Matsumoto has recently described two genera of Ophiomyxidae in which the arm spines are transformed into compound hooks similar to those in the genus Ophiocanops; these two genera are Ophiostiba and Ophiohyalus. In the genus Ophiostiba the upper arm plates are lacking, the side arm plates are subventral, and under arm plates are present; but the disk, which is naked on its dorsal surface, shows a bordering of plates about its periphery. The genus Ophiohyalus, which shows similar features, is distinguished from the preceding by the presence of thin, hyaline, rudimentary upper arm plates. These two genera thus differ from the genus Ophiocanops in the presence of plates on the circumference of the disk and in the presence of under arm plates; furthermore, the arm spines are fewer, only two or three on each segment, and the tentacular pores are very large. I do not find among the Ophiomyxidae any other genera which need be compared with the genus Ophiocanops.

In the Ophiobyrsinae Matsumoto has described a new genus, Ophiosmilax, also from Japan, in which the arm spines are converted into compound hooks; but in this genus there are similarly only two or three arm spines, the upper arm plates are lacking, but under arm plates are present, and there is only a single mouth papilla on each side. 
The genus Ophiobrachion is perhaps nearest to the genus Ophiocanops; its arm spines, seven or eight in number, are also converted into compound hooks, but in the single known species the integument on both surfaces of the disk is armed with spines, there are both upper and under arm plates hidden under the integument, and the tentacular pores are of large size.

Type of the genus.-Ophiocanops fugiens, new species.

OPHIOCANOPS FUGIENS, new specier.

Plate 2, figs. 4-17.

Locality.-Albatross station 5174; vicinity of Joló; Joló Light bearing E., 4.81 kilometers (2.6 miles) distant (lat. $6^{\circ} 03^{\prime} 45^{\prime \prime} \mathrm{N}$., long. $120^{\circ} 57^{\prime} 00^{\prime \prime}$ E.) ; 36 meters (20 fathoms) ; March 5, 1908; crs. S.

One specimen (Cat. No. 41080 , U.S.N.M.).

Description.-The diameter of the disk does not exceed $3 \mathrm{~mm}$. The arms are very long and narrow, reaching a length of from $35 \mathrm{~mm}$. to $40 \mathrm{~mm}$., and are rather strongly rolled up; they are $1 \mathrm{~mm}$. across at the base, remaining of the same width for almost their entire length.

The disk is rounded. The dorsal surface is covered with a smooth and rather thick integument, dark purple in color, which shows numerous small still darker spots, which are continued onto the dorsal surface of the arms. Because of the great development of the adoral plates, which extend quite to the periphery of the disk, the latter has, if it may be so expressed, no ventral surface. I was not able to make out the genital slits.

The outlines of the mouth plates are very easily seen. The mouth shields are extremely small, triangular, confined to the angle formed outwardly by the two adoral plates of each pair, and scarcely visible when the animal is viewed ventrally. The plate which bears the madroporic opening, which is situated on the lateral surface of the disk, is rounded and very large, and shows a large vertical furrow (fig. 15). The adoral plates are extremely developed, very high and broad, a little broader than high, with the borders and the angles rounded (figs. $8,14,15$ ); of themselves they cover a good part of the ventral face of the disk. The oral plates are very much smaller, triangular, a little higher than broad. The mouth papillae, three on either side, are small and conical, with the point blunted; the unpaired terminal papilla is a little more elongated. The teeth form a column of six small conical pieces, which are elongated and spiniform with the points rounded (fig. 14).

The integument which covers the dorsal surface of the arms is at first very thick and opaque, and shows dark spots similar to those seen on the dorsal surface of the disk; it then becomes thinner and lighter in color, and the dorsal surface of the underlying vertebral 
pieces, as well as the muscles between them, can be distinguished through it (figs. 16, 17). The side arm plates are especially developed on the ventral side; each forms a large swelling (figs. 5, 6,17) on which are implanted the arm spines and which are continued onto the ventral surface in the form of a narrow process; this adjoins its fellow in the median line of the arm by a rounded border (fig. 6). The arm spines are five in number and are in the form of compound hooks; the central spines carry usually five or six short, conical, and pointed teeth the size of which decreases toward the tip, while the dorsal and ventral spines as a rule have only four teeth of which the last is often the most developed. As previously stated, the tentacular pores are very small.

The general coloration of the individual is dorsally a dark chocolate brown and ventrally a little lighter.

\section{OPHIOBYRSELLA INTORTA, new species.}

Plate 4, figs. 2-5; plate 92, fig. 4.

Locality.-Albatross station 5491; between Leyte and Mindanao; Diuata Point (W.) bearing S. $9^{\circ}$ W., 35.77 kilometers (19.3 miles) distant (lat. $9^{\circ} 24^{\prime} 00^{\prime \prime}$ N., long. $125^{\circ} 12^{\prime} 00^{\prime \prime}$ E.) ; 1,346 meters (736 fathoms); August 1, 1909 ; gn. M., Co.

One specimen (Cat. No. E. 331, U.S.N.M.).

Description.-The disk is somewhat deformed through being strongly pulled out along one of the rays, on account of which it measures $30 \mathrm{~mm}$. in the longest diameter but only $20 \mathrm{~mm}$. in the shortest; presumably in the living animal it had a diameter of between $22 \mathrm{~mm}$. and $24 \mathrm{~mm}$. The arms are very long and rather narrow, especially in their distal half, where they become extremely slender; their length is difficult to judge, as they are more or less strongly rolled up, but it must be between $250 \mathrm{~mm}$. and $300 \mathrm{~mm}$.; they are $3 \mathrm{~mm}$. broad at the base. They are almost cylindrical, with the ventral face slightly flattened.

In the living animal the disk must have been slightly concave in the interradial spaces, just as between the two radial shields of each pair above the insertion of the arms. The dorsal surface is covered by a thin integument studded with extremely small plates well separated from each other and each bearing a very short and slender spinelet; to the naked eye these spinelets appear as simple little points, which are especially evident through their white coloration, which causes them to stand out in sharp contrast against the dark brown integument of the disk. The integument is raised over the radial shields into elongated ridges which are white in color. The radial shields are narrow, elongated, broadened outwardly, and tapering gradually toward the center of the disk; they are about $7 \mathrm{~mm}$. 
long. These shields are armed with short, rather thick, conical spines, which are especially developed in their distal portions. These are larger than the spines of the rest of the dorsal surface of the disk, into which, however, they grade imperceptibly.

The ventral surface of the disk is covered by an integument which is darker and thicker than that on the dorsal surface, and this is studded with little rounded plates, which are extremely reduced and widely separated from each other. Toward the mouth shields these plates become a little better developed, and in their immediate vicinity they move closer together and even touch each other. The genital slits are broad and very long. The two genital plates, internal and external, which are short, are limited to the distal extremities of these slits, and project outward somewhat.

The outlines of the mouth plates are more or less obscured by the integument. Thanks to the entire absence of pigment they may, however, be made out through it. The mouth shields are small, triangular, and a little broader than long. The rather large adoral plates are thick, triangular, narrower within than without, and in contact in the median interradial line; they are a little longer than broad. The oral plates are triangular and very high, in contact throughout their entire length. Together with the tooth papillae the mouth papillæ form a little bundle of short, slender, and spinulose spines continuous with the teeth which are fairly regular in their arrangement and which have exactly the same form as these papillae; beside this bundle of terminal papillae two distinct and independent lateral mouth papillae can be recognized.

The upper arm plates are divided into two lateral halves each having the form of a triangle of which the base lies along the median line, and separated from its fellow by a narrow interval; the sides of this triangle are slightly projecting; these plates are broadly separated from each other.

The first under arm plate is quadrangular, a little broader than long. The following plates are elongated, a little longer than broad, rectangular, with the proximal border narrower than the distal, which is notched in the middle; they are all in contact with each other. Beyond the disk the plates become smaller, triangular, with a truncated proximal angle, and are separated by soft tissue.

The side arm plates, which are only slightly projecting, bear four and sometimes five spines at the base of the arms; these spines are very delicate and cylindrical, provided with very strong denticulations on the proximal border, and smaller and more crowded ones on the distal border; they are all shorter than the segment and subequal, though sometimes the dorsal spine is a little larger than the others. The first ventral spine bears very strong teeth on its proxi- 
mal border; it very soon loses those on the distal border, simultaneously becoming recurved and transforming very rapidly into a hook with three or four branches. These spines consist of a short opaque white basal portion followed by a very much longer perfectly transparent, though brownish yellow, section. In figure 4 of plate 92 is shown a number of photographs of spines from different heights on the arms.

Each tentacle pore is provided with a very small scale which is easily confused with the base of the first ventral spine.

The disk is dark brown on both surfaces, but the radial shields are white. The arms are lighter; they are brownish on the dorsal surface and on the sides, and almost pure white on the ventral surface; the spines are light brown.

Affinities and distinctive features.-Ophiobyrsella intorta can not be confused with any of the species of the genus Ophiobyrsella known from the Indian Ocean. Ophiobyrsella erinaceus Kohler, found by the Siboga in the Sunda Islands, is a small species in which the integument of the disk is entirely naked and the radial shields alone are armed with spines; the mouth papillae are rather large and the arm spines, which are four in number, are elongated. The two Japanese species which have recently been described by H. L. Clark are very different. Ophiobyrsella acanthinobrachia has six or seven arm spines; 0 . synoptacantha has on the dorsal surface of the disk numerous little plates of which some bear a small spine; the arm spines are four in number, but the mouth shields are longer than broad and the adoral plates are widely separated in the median interradial line.

Ophiobyrsella intorta is equally distinct from all the species known from the Atlantic. It recalls $O$. quadrispinosa Kœhler, by its well developed mouth papillae, but is distinguished from it by the number of arm spines. Ophiobyrsella hystricis Lyman, from the Shetland Islands, has the dorsal surface of the disk armed with more highly developed spines over the radial shields; the arm spines, which are five in number, are rather strong and elongated, as long as the arm segments, and the tooth papillae are arranged differently from those in the Philippine species. O. hystricis is, moreover, the type of Verrill's genus Ophiobyrsa, with the mouth papillae and the tooth papillae rudimentary. In $O$. perrieri Lyman the dorsal surface of the disk is naked, the radial shields are provided with small, short, and conical spines, and the arm spines are six in number.

In his "Catalogue of the Ophiurans" published in $1915 \mathrm{H}$. L. Clark has not maintained the division proposed by Verrill separating Ophiobyrsa and Ophiobyrsella on the basis of the characters of the tooth papillae, though Matsumoto has accepted the distinctness of the two genera. 
OPHIOPHRIXUS CONFINIS, new species.

Plate 3, figs. 1-8.

Localities.-Albatross station 5123; east coast of Mindoro; Malabrigo Light bearing $\mathrm{N} .44^{\circ} \mathrm{W}$., 60.23 kilometer's (32.5 miles) distant (lat. $13^{\circ} 12^{\prime} 45^{\prime \prime} \mathrm{N}$., long. $121^{\circ} 38^{\prime} 45^{\prime \prime} \mathrm{E}$.) ; 518 meters ( 283 fathoms) ; February 2, 1908; gn. M.

One specimen (Cat. No. E. 333, U.S.N.M.).

Albatross station 5592; Sibuko Bay, Borneo, and vicinity; Silungan Island bearing N. $1^{\circ}$ W., 11.86 kilometers ( 6.4 miles) distant (lat. $4^{\circ} 12^{\prime} 44^{\prime \prime}$ N., long. $118^{\circ} 27^{\prime} 44^{\prime \prime}$ E.) ; 558 meters (305 fathoms) ; September 29, 1909 ; gn. M.

One specimen (Cat. No. E. 332, U.S.N.M.).

Description.-The specimen from station 5123 is of large size, the diameter of the disk reaching $23 \mathrm{~mm}$. and the length of the arms $160 \mathrm{~mm}$.; unfortunately, the disk is in poor condition, the dorsal surface has been partially torn away and is more or less out of place. The specimen from station 5592, on the other hand, is in a good state of preservation, but it is much smaller; the diameter of the disk is only $12 \mathrm{~mm}$.; the arms are somewhat unequal; the largest reaches 100 $\mathrm{mm}$. in length the others being much shorter and narrower.

The disk is pentagonal and somewhat excavated in the interradial spaces. The flat dorsal surface is covered with a rather thick integument deeply colored a brownish black without the least indication of plates, except for a few extremely small rounded plates here and there between the outer parts of the radial shields and on the arm bases; these plates are a little more numerous on the individual from station 5123. Each of the radial shields forms a very projecting narrow and elongated rib carrying half a dozen very strong, thick, elongated, and cylindrical spines with their tips rounded and roughened. The two shields of each pair are parallel or very slightly diverging, and they are widely separated from each other.

The ventral surface of the disk in the interradial spaces is covered by a thick and very dark integument identical with that on the dorsal surface, without the least indication of distinct plates. The genital slits are very broad.

The mouthpieces are covered by a very thin fairly transparent integument, light brown in color, under which their outlines appear with a fair degree of sharpness. The mouth shields are small, triangular, a little broader than long, with a very obtuse and rounded proximal angle, lateral angles similarly rounded, and a convex distal side. The adoral plates, which are of average dimensions, are in the form of a crescent with a concave proximal border, a convex distal border, and the angles rounded; they are three times as long 
as broad, and do not separate the mouth shield from the first side arm plate; they are not in contact in the median interradial line, but are separated by a rather broad space which is similarly continued between the oral plates and which is simply covered by integument. The oral plates are very high, elongated and narrow, three times as high as broad, and directed obliquely toward each other; they are separated for half of their length by the space which I have just described and are in contact only in their proximal half. There are two mouth papillae; the outer is small, short, and rounded, with a rugose surface, situated on the internal border of the mouth tentacle pore; the other, which is near the proximal end of the oral plates, is elongated, pointed, spiniform, and conical, and its surface is more rugose than that of the preceding. The teeth, which are spiniform and elongated, form a regular double vertical column, below which are some dental papillae of the same form; these last are usually three in number, a larger unpaired papilla and two smaller lateral papillae.

The upper arm plates are entirely lacking. The first under arm plate is large, rectangular, greatly broadened transversely, almost three times as broad as long. Those following are very large, rectangular, almost as broad as long, and all in contact. On the first arm segments their distal border is more or less strongly notched in the middle, and their sides extend inward somewhat obliquely; they then become regularly quadrangular, and a little broader than long. In the specimen from station 5592 these plates are more broadened, and their distal border remains concave over a large part of the length of the arms; furthermore, they are usually separated by a narrow space filled by soft tissue.

The side arm plates, which are very narrow on the ventral side, carry four much elongated, slender, and transparent arm spines, which are furnished with very strong and closely crowded teeth; these spines much exceed the length of the segment, and the two central spines, which are a little longer than the others, may reach a length of two segments.

In figure 1 on plate 93 I have given figures of some arm spines taken from different heights along the arm. Toward the extremity of the arms the teeth, relatively very strong and well spaced, are often more developed on one of the borders than on the other (fig. 16), but the first ventral spine is never converted into a true hook. and sometimes it even entirely lacks the denticulations (fig. $1 c$ ).

The tentacular pores are extremely large and do not show the least trace of a scale.

In the specimen from station 5592 the disk is dark brown in color, even blackish, on the dorsal surface; the arms are a little lighter; 
their dorsal surface is brownish, and their ventral surface yellowish brown. The other specimen is of a general blackish gray.

As the dorsal surface of the disk of the specimen from station 5123 is entirely torn away, I have taken advantage of this opportunity and have prepared the mouthpieces in such a way as to render visible the outlines of the peristomial plates. Their form may be very clearly made out on the photograph which is here reproduced (pl. 3, fig. 7), and it may here be seen that these plates, two in number, are large, quadrangular, almost as long as broad, and in contact with each other in the median interradial line.

Affinities and distinctive features.-On the basis of the structure of the dental apparatus, and especially of the characters of the teeth and the dental papillae, this species falls well within the genus Ophiophrixus as it was established by H. L. Clark, which hitherto was represented by only a single species. Ophiophrixus confini: has, like this last, four elongated arm spines, and its radial shields, forming projecting ribs, are armed with very strong spines; the under arm plates are also more or less strongly notched on their distal border; but the new species differs from 0 . acanthinus in having the oral plates much elongated instead of being very low, in the existence of two well developed lateral mouth papillae, and in the absence of distinct plates on the dorsal surface of the disk in its central portion. The type of the genus Ophiophrixus, O. acanthinus, was found off Japan (Honshu Island) at a depth of 172 to 274 meters (94 to 150 fathoms), and is represented only by a single specimen.

\section{Family TRICHASTERIDAE.}

ASTROCHARIS VIRGO Kohler.

Astrocharis virgo KoehleR ('04), p. 160, pl. 20, fig. 1; pl. 30, fig. 8.-H. L. Clark ('15), p. 178.

Locality.-Albatross station 5423; Joló Sea; Cagayan Island (S.) bearing $\mathrm{S} .11^{\circ} \mathrm{E} ., 8.89$ kilometers (4.8 miles) distant (lat. $9^{\circ} 38^{\prime} 30^{\prime \prime}$ N., long. $121^{\circ} 11^{\prime} 00^{\prime \prime}$ E.) ; 929 meters (508 fathoms); March 31, 1909 ; gy. M., co. S.

One specimen (Cat. No. E. 67, U.S.N.M.).

Notes.-The diameter of the disk is $7 \mathrm{~mm}$.; the arms are $80 \mathrm{~mm}$. long.

This specimen agrees well with the type series which was collected by the Siboga among the Sunda Islands at depths between 522 and 1,089 meters (286 to 595 fathoms).

I may mention that a second species of this genus, from Sagami Bay, Japan, has been described by Matsumoto under the name of A. ijimai (Matsumoto '15, p. 54, and '17, p. 56). 
ASTROCERAS PERGAMENA Lyman.

Plate 93, fig. 3.

See for bibliography:

Astroceras pergamena KCEHLER ('04), p. 159.-DöDERLEIN ('11), p. 61.-H. I. Crark ('11), p. 284 ; ('15) p. 179.-Matsumoto ('17), p. 35.

Localities.-Albatross station 5502; northern Mindanao and vicinity; Macabalan Point Light (Mindanao) bearing S. $35^{\circ}$ E., 15.19 kilometers (8.2 miles) distant (lat. $8^{\circ} 37^{\prime} 37^{\prime \prime} \mathrm{N}$., long. $124^{\circ} 35^{\prime} 00^{\prime \prime}$ E.) ; 391 meters (214 fathoms); August 4, 1909.

One specimen (Cat. No. E. 328 [part], U.S.N.M.).

Station 5503; northern Mindanao and vicinity; Macabalan Point Light bearing S. $31^{\circ}$ E., 12.23 kilometers ( 6.6 miles) distant (lat. $8^{\circ} 36^{\prime} 26^{\prime \prime}$ N., long. $\left.124^{\circ} 36^{\prime} 08^{\prime \prime}\right) 413$ meters (226 fathoms) ; August 4, 1909; gn. M.

One specimen (Cat. No. E. 328 [part], U.S.N.M.).

Station 5510. One specimen (Cat. No. E. 329, U.S.N.M.).

Notes-In the specimen from station 5502, which is the best preserved, the diameter of the disk measures about $10 \mathrm{~mm}$., and the arms exceed $120 \mathrm{~mm}$. in length. In the other the disk is a little larger, its diameter reaching $11 \mathrm{~mm}$; ; single arm is entire, its length exceeding $130 \mathrm{~mm}$.; the terminal part appears to be undergoing regeneration.

These two specimens, each having five equal arms, agree well with Lyman's description, except in regard to the relative dimensions of the disk and arms. Lyman gives for the latter a length of $100 \mathrm{~mm}$. in a specimen in which the diameter of the disk was $19 \mathrm{~mm}$.; thus the arms are very much longer in the two Albatross specimens, in which the diameter of the disk is only half as great. In both of these the terminal third of the arms is extremely tenuous.

In the proximal region of the arms the two specimens show the movable dorsal spines which are characteristic of the species. In the specimen from station 5503 these spines show almost the same development as far as the fifteenth segment, thence diminishing rapidly in size, and beyond the twentieth segment disappearing completely; in the other the spines disappear after the twelfth segment.

In figure 3 on plate 93 are photographs of some dorsal $(c)$ and ventral $(a$ and $b)$ arm spines as well as the hooks which appear in the terminal part of the arms $(d)$.

Astroceras pergamena was based upon a unique specimen found by the Challenger in latitude $37^{\circ} 07^{\prime} \mathrm{N}$., longitude $138^{\circ} 00^{\prime \prime} \mathrm{E}$., at a depth of 1,033 meters (565 fathoms).

The species was rediscovered by the Siboga in latitude $10^{\circ} \mathrm{S}$., longitude $123^{\circ} \mathrm{E}$., at a depth of 216 meters (118 fathoms). It has 
been collected in many localities off Japan in from 62 to 549 meters ( 34 to 300 fathoms).

H. L. Clark, who has often observed six armed specimens, believes that this figure is the normal one for the young of $A$. pergamena, although the adult only has 5 arms ('11, p. 284); but Matsumoto is not of this opinion ('17, p. 36).

\section{ASTERONYX LOVENI Müller and Troschel.}

See for bibliography:

Asteronyx loveni KGEHLER ('04), p. 167.-H. L. ClaRK ('11), p. 285.-DöDERLein ('11), p. 115.-Mortensen ('12), p. 264.-H. T. Clark ('13), p. 219 ; ('15), p. 180; ('16), p. 78.-Matsumoto ('17), p. 33.

Localities. - Albatross station 5444; East coast of Luzon, San Bernardino Strait to San Miguel Bay; Atalaya Point, Batag Island, bearing S. $65^{\circ} \mathrm{E} ., 9.45$ kilometers ( 5.1 miles) distant (lat. $12^{\circ} 43^{\prime} 51^{\prime \prime}$ N., long. $124^{\circ} 58^{\prime} 50^{\prime \prime}$ E.) ; 563 meters (308 fathoms); June 3, 1909 ; gn. M.

One specimen (Cat. No. E. 168, U.S.N.M.).

Albatross station 5650; Gulf of Boni, Celebes; Lamulu Point bearing N. $5^{\circ}$ W. 23.16 kilometers (12.5 miles) distant (lat. $4^{\circ} 55^{\prime} 45^{\prime \prime}$ S., long. $121^{\circ} 29^{\prime} 00^{\prime \prime}$ E.) ; 988 meters (540 fathoms); December 17 , $1909 ;$ gn. M.

One specimen (Cat. No. E. 167, U.S.N.M.).

Notes.-In the larger individual the dimensions of the disk are $18 \mathrm{~mm}$. by $15 \mathrm{~mm}$. The arms are incomplete, but two of them are preserved for the greater part of their length. In spite of the relatively large dimensions of the disk, the first spine does not show anywhere along the arm the least tendency to become elongated and to take the form so well known in A. loveni. Mortensen has recently shown ('12, p. 264) that this development of the ventral spine usually begins to show itself when the disk reaches a diameter of between $15 \mathrm{~mm}$. and $20 \mathrm{~mm}$., but that it may begin very much later; thus in one of the specimens which he studied, in which the diameter of the disk was $20 \mathrm{~mm}$., the ventral spine had not yet begun to elongate. It is not surprising, therefore, that in my specimen the ventral spine has not yet taken on its normal development.

But by way of compensation I notice in the specimen from station 5444 , which has a disk diameter of only $13.5 \mathrm{~mm}$., an elongation of the first ventral spine $20 \mathrm{~mm}$. beyond the disk, and a little further on this spine reaches almost the length of a segment. 


\section{Family GORGONOCEPHALIDAE.}

ASTROTHAMNUS DEFICIENS, new species.

Plate 1, figs. 1-10.

Locality.-Albatross station 5605, Gulf of Tomini, Celebes; Dodepo Island (W.) bearing N. $14^{\circ}$ W., 10.93 kilometers (5.9 miles) distant (lat. $0^{\circ} 21^{\prime} 33^{\prime \prime}$ N., long. $121^{\circ} 34^{\prime} 10^{\prime \prime}$ E.) ; 1,183 meters (647 fathoms); November 16, 1909.

One specimen (Cat. No. E. 158, U.S.N.M.).

Description.-The specimen unfortunately is not in a very good state of preservation; the arms are broken up into numerous fragments, and two of them are entirely lacking. However, poor as it is, it can be satisfactorily studied and described, and it is evident that it can not be referred to any known species.

The diameter of the disk is $21 \mathrm{~mm}$.; the arms must have had a length of between $120 \mathrm{~mm}$. and $140 \mathrm{~mm}$. They are unbranched for their entire length. The disk is thick and reaches $6.5 \mathrm{~mm}$. in height. The dorsal surface is depressed in the central region, and the ventral surface is strongly convex; the radial and interradial regions are strongly excavated at the periphery. The arms at their bases are very distinct from the disk; they measure $5.5 \mathrm{~mm}$. in width and $6 \mathrm{~mm}$. in height; they taper very gradually, but their height always remains a little greater than their width. Their dorsal surface is strongly convex, and by strongly rounded borders passes over into the sides, which are vertical; their ventral surface is almost flat.

On the dorsal surface of the disk there are 10 much-elevated ribs, which arise in the central region and, progressively increasing in height and width, reach the periphery. The two ribs of each pair are strongly divergent, and at the periphery of the disk they are separated from each other by an interval of about $7 \mathrm{~mm}$., within which lies the base of the arm. The border of the disk is rather strongly excavated between the extremities of the radial ribs, and these on either side pass beyond the base of the corresponding arm. The radial spaces between the two ribs of each pair and the interradial spaces between the pairs are rather strongly depressed. The whole dorsal surface of the disk is covered with small and thin, though not transparent, plates, which are more or less imbricated, irregularly polygonal, with the free border slightly raised, and which become larger over the radial ribs where they are about $1 \mathrm{~mm}$. in diameter; they are smaller in the radial spaces, becoming still smaller in the interradial spaces. Their dimensions still further decrease toward the center of the disk, and they finally become excessively reduced in the central region. Over the radial ribs some of these plates are raised up into a large conical and pointed tubercle, 
of which the base occupies the whole surface of the plate, and the height is a little greater than the breadth. These tubercles are arranged one behind the other in a single, though very irregular, row, extending over two-thirds of the length of the radial ribs; they become more numerous at the ends of the ribs, where they form a little group; they pass onto the lateral faces of the ribs on either side of the base of the arms, but they do not reach the ventral surface. In the interradial spaces the border of the disk shows a row of similar tubercles extending from the extremity of one radial rib to that of the other. In the radial spaces at the bases of the arms there are a few additional tuberosities, but these are smaller and only two or three in number in each space. The other plates of the dorsal surface of the disk are quite unarmed.

The lateral surfaces of the disk included between the much-swollen distal ends of the radial ribs are narrow and very strongly depressed into a sort of oval pit on the borders of which are the genital slits, which are rather short and narrow, and arranged parallel to each other. The ventral border of the interradial depression forms a somewhat projecting edge on which are some conical tubercles, identical with those of the radial ribs, which on the sides pass into the arm spines.

- The ventral surface of the disk is covered with small polygonal plates which are unequal, very close together, not imbricated, but instead very exactly in contact, forming a true pavement. These plates are continued onto the ventral surface of the arms, becoming there a little larger and somewhat thicker. Further, there appear toward the base of the arms and on certain of them small short conical tubercles, with rounded tips, very much smaller than the tubercles of the disk, which are continued in varying numbers onto about twenty of the arm segments; these little tubercles disappear with the progressive tapering of the arms.

The outlines of the mouth plates are quite invisible, for these elements are hidden beneath a covering of small plates identical with those which cover the rest of the ventral surface. The mouth angles carry a bundle of dental spines which are very close together, elongated, flattened, and rounded at the tip; the ventral surface of these spines shows a very evident groove throughout their whole length. The sides of the mouth angles are simply furnished with very small granules passing gradually into the neighboring plates, which are entirely flattened; the ventral surface of the mouth angles, behind the bundle of dental papillae, likewise shows small granules which become obliterated and flattened little by little as the distance from the papillae increases, and which similarly pass over into the plates of the ventral surface of the disk. 
The arm segments are indicated by a succession of rings, alternately slightly projecting and slightly depressed, which appear on the dorsal surface and on the sides of the arms. The projecting portions show for the most part two fairly regular rows of little rounded and projecting nipples which serve for the insertion of the hook. Through almost the entire length of the arms these hooks are for the most part torn away, and it is easy to make out in the middle of the nipples the characteristic small central depression. Between these two ranges of nipples and outside of them the surface of the segment is covered by little plates with a swollen surface, which are somewhat unequal, polygonal or rounded in outline, and which pass over into the very much lower and imbricated plates covering the depressed regions of the arms. These last are narrow, vertically elongated, and form several irregular rows.

The hooks borne by the nipples measure $0.4 \mathrm{~mm}$. in length. Their form is very simple, and they do not show any accessory tooth below their very strongly recurved and pointed tip. In figure 5 I give a photograph of one of them.

The double rows of hooks follow each other with very great regularity, except on the four or five first arm segments, where they are not as yet very regularly arranged, and they continue throughout the whole length of the arm. They may be very easily distinguished on the photographs which I give of arms viewed laterally and at different parts of their length (figs. 3,6).

The arm spines or tentacle scales first appear on the pores of the second pair, which show sometimes a single, sometimes two spines; the pores of the third pair are usually provided with three spines; those of the fourth pair have three and sometimes four, and beyond the fifth pair the number is four; this number is maintained throughout the greater part of the length of the arms. These spines are large, short, thick, and conical, with the point blunted; the three first are subequal, and their length almost equals two-thirds the length of the segment; the fourth (dorsal) spine is a little smaller and a little more slender than the others. Their surface is somewhat rugose and, under the microscope, it shows only very fine, short, and crowded spinules. The four spines are very close together, forming a short transverse row, which lies for the most part on the ventral surface of the arms.

The number of the spines diminishes only near the tip of the arm, and they finally become reduced to two, at the same time becoming relatively more slender, but without ever transforming into hooks.

The color of the specimen in alcohol is uniform gray.

Affinities and distinctive features.-This ophiuran appears to me to fall within the genus Astrothamnus which was erected by Matsu- 
moto in 1915, and which now includes six species; these are $A$. bellator, A. vecors, and A. rigens, which I formerly placed in the genus Astrotoma, and three new species, one from Japan, $A$. echinaceus, described by Matsumoto, another from Bass Strait, $A$. rugosus, recently described by $\mathrm{H}$. L. Clark, and a third, described still more recently by the same author, $A$. megosus.

Astrothamnus deficiens seems to approach most closely $A$. echinaceus on account of the presence on the disk of rather numerous conical protuberances; but it is distinguished from that form by the occurrence of four arm spines instead of three; the pores of the second pair already possess one or two spines, while these first appear on the pores of the third pair in the Japanese species. Furthermore, in $A$. deficiens the dental papillae are flattened, rounded at the tip, and canaliculate throughout their entire length, while in the Japanese species they are conical and pointed (see Matsumoto, '17, p. 86, fig. 25).

Astrothamnus deficiens can not be confused with A. mgosus H. L. Clark, which was discovered by the Endeavour south of Australia in between 146 and 365 meters (80 and 200 fathoms) and which is distinguished by its more slender and longer arms, by the number of the arm spines, etc.

\section{Order II. LOEMOPHIURIDA.}

Family HEMIEURYALIDAE.

OPHIOMOERIS OBSTRICTA (Lyman).

Plate 5, figs. 3 and 4.

Ophioceramis obstricta LXMAN ('82), p. 26, pl. 11, figs. 1-3.

Ophiurases obstrictus H. L. ClaRK ('11), p. 250, fig. 122; ('15), p. 190.

Ophiomoeris obstricta Matsumoto ('15), p. 65; ('17), p. 140.

Locality.-Albatross station 4893; Eastern Sea, between 10 and 20 miles (18.53-37.06 kilometers) southwest of the Goto Islands; Ose Saki : Light bearing N. $2^{\circ}$ W., 10 miles (18.53 kilometers) distant (lat. $32^{\circ} 26^{\prime} 30^{\prime \prime} \mathrm{N}$., long. $128^{\circ} 36^{\prime} 30^{\prime \prime}$ E.) 247 meters (135 fathoms), August 9, 1906.

One specimen (Cat. No. 41007, U.S.N.M.).

Notes.-The diameter of the disk is only $3 \mathrm{~mm}$, and none of the arms is complete. The individual agrees well with the figures and with the notes published in 1911 by H. L. Clark, who completed and corrected Lyman's original description; I notice only that the dorsocentral plate is simply pentagonal and that it does not show the sinuous outline represented by H. I. Clark. The first under arm plate is rectangular, broader proximally than distally, as he shows, 
but it is relatively larger and broader in my specimen; the upper arm plates are also more broadened, and are very much broader than long. The two radial shields of each pair are not always separated; only on two pairs does the line of separation show the conical tubercles which were figured by H. L. Clark; in the three other pairs the radial shields are in contact for half their length, and the tubercles are not yet developed on the line of separation, probably because of the youth of the individual. My specimen must be smaller than that figured by H. L. Clark, in which the diameter of the disk apparently reached $5 \mathrm{~mm}$. The under arm plates decrease very rapidly in size, but the fourth and following are broken up into a number of small rounded fragments.

I give here two photographs of the Albatross specimen, which complete the data which we already have on O. obstricta.

Matsumoto has very recently described ('15, p. 65) a new species of the genus Ophiomoeris, O. projecta, found in Japan at a depth of 300 fathoms. I do not believe that it can be referred to the species of Ophiomoeris dredged by the Albatross, for in $O$. projecta the radial shields are in contact for half their length and the disk bears large and prominent granules, which are found both on the distal border of and along the line of division between the radial shields; sometimes these granules even occur on the outer sides of the shields, a feature not evident in my specimen. These differences may be appreciated by a comparison of my photographs with the figures published by Matsumoto in 1917 ('17, p. 141, fig. 35).

Ophiomoeris obstricta was first dredged by the Challenger in latitude $5^{\circ}$ S., longitude $132^{\circ}$ E., at a depth of 236 meters (129 fathoms). The specimens collected by the Albatross and studied by H. L. Clark were from latitude $30^{\circ}-32^{\circ} \mathrm{N}$., longitude $128^{\circ}-130^{\circ} \mathrm{E}$, and were dredged at depths varying from 174 to 247 meters (95 to 135 fathoms).

H. L. Clark thought it necessary to create for Lyman's Ophioceramis obstricta a new genus, which he called Ophiurases, but he evidently either forgot or misunderstood the genus Ophiomoeris which I created in 1904 for a new species, O. spinosa, discovered by the Siboga, and in which I had placed Lyman's Ophioceramis obstricta and $O$. clausa, as well as my own 0 . tenera (Kohler '04, p. 17), of which he says nothing. The genus $O$ phiurases is absolutely synonymous with the genus Ophiomoeris, which has precedence, and it must therefore disappear from zoölogical nomenclature. Matsumoto did not mention it in the enumeration of the genera which he assigns to the subfamily Ophiochondrinae, and he states that Ophiurases obstrictus H. L. Clark, 1911, is a synonym of Ophiomoeris obstricta Kohler (Matsumoto '15, p. 65). 


\section{OPHIOMOERIS SPINOSA Kœhler.}

Ophiomoeris spinosa KoHLer ('04), p. 17, pl. 4, figs. 1-3.-H. L. CraRK ('15), p. 190.

Locality.-Albatross station, 5577; north of Tawi Tawi; Mount Dromedario bearing S. $9^{\circ}$ W., 20.20 kilometers (10.9 miles) distant (lat. $5^{\circ} 20^{\prime} 36^{\prime \prime} \mathrm{N}$., long. $119^{\circ} 58^{\prime} 51^{\prime \prime}$ E.) ; 439 meters ( 240 fathoms) ; September 23, 1909 ; crs. S.

One specimen (Cat. No. 41006, U.S.N.M.).

Notes.-This specimen is slightly smaller than those dredged by the Siboga; one of the arms is broken off at the base.

The Siboga collected Ophiomoeris spinosa in latitude $5^{\circ}$ N.-5 $5^{\circ}$., and longitude $119^{\circ}-132^{\circ}$ E., at depths varying from 104 to 1901 meters ( 57 to 1,040 fathoms).

OPHIOMOERIS TENERA Kœhler.

Ophioceramis tenera KoEHLER ('96), p. 317, pl. 6, figs. 30, 31; ('99), p. 33, pl. 5 , figs. $42,43$.

Ophiomoeris tenera Koehler ('04), p. 17.-H. L. Chark ('15), p. 190.

Locality.-Albatross station 5423, Joló Sea, Cagayan Island (S.) bearing S. $11^{\circ} \mathrm{E}$, 8.89 kilometers (4.8 miles) distant (lat. $9^{\circ} 38^{\prime} 30^{\prime \prime}$ N., long. $121^{\circ} 11^{\prime} 00^{\prime \prime}$ E.) ; 929 meters (508 fathoms) ; March 31, 1909; gy. M., co. S.

Two small specimens (Cat. No. 41005 , U.S.N.M.).

Notes.-These specimens are smaller than the type of the species, but agree very well with it.

Ophiomoeris tenera was discovered by the Investigator among the Andaman and Laccadive Islands in depths between 484 to 1,160 meters (265 and 636 fathoms).

\section{OPHIOGYPTIS NODOSA Køhler.}

Plate 6, figs. 5, 6.

Ophiogyptis nodosa Koehler ('05), p. 121, pl. 12, figs. 11-14.-H. L. Clark ('15), p. 193.

Locality.-Albatross station 5414; between Cebu and Bohol; Lauis Point Light bearing N. $67^{\circ}$ W., 17.61 kilometers (9.5 miles) distant (lat. $10^{\circ} 10^{\prime} 40^{\prime \prime}$ N., long. $124^{\circ} 02^{\prime} 45^{\prime \prime}$ E.) ; March 24, 1909 .

One specimen (Cat. No. 41004, U.S.N.M.).

Notes.-The specimen is very small, the diameter of the disk being only $2.5 \mathrm{~mm}$.; three of the arms are broken off close to the disk and the two others are preserved for only a portion of their length.

I described $O$. nodosa from several specimens collected by the Siboga among the Sunda Islands at depths between 73 and 113 meters ( 40 and 72 fathoms) in which the diameter of the disk varied between 3 and $5 \mathrm{~mm}$. The Albatross specimen has almost the same dimensions 
as the smallest of these individuals, but the plates of the dorsal surface of the disk, of which the outlines are more distinct, as well as the tubercles which adorn them, have a slightly different arrangement, as may be seen by comparing the photograph which I give here (pl. 6, fig. 5) with the drawing which I published in 1905 ('05, pl. 12, fig. 12). Beyond the dorsocentral plate, which is rounded, there is a circlet of five radials a little larger than the latter and irregularly lozenge shaped, separated from the dorsocentral by a circlet of very small plates; beyond the first circlet there is another circlet of rather large radial plates, each of which separates the two radial shields of each pair. On either side of the group formed by these two large radial plates there are two or three very much smaller plates. The remainder of the interradial space is also occupied by a few plates, which are also very small. All of the large plates bear toward their distal angle a large blunted conical tubercle, and most of the small plates also carry a tubercle of reduced size. These small tubercles are often arranged in such a way as to form a row along the borders of the large primary radial plates. The radial shields are rather small, smaller than in the Siboga specimens, and the two shields of each pair are divergent and widely separated proximally, but approach each other closely distally; these shields are prolonged along the sides of the first upper arm plate. The two first upper arm plates are not in contact, but are separated by a rather large interval occupied by the side arm plates. The fragmentation of the under arm plates begins beyond the third. The genital slits, which are very distinct in spite of the small size of the specimen, are oval in shape.

\section{Family OPHIOMYCETIDAE.}

\section{OPHIOMYCES DELATA Kohler.}

Plate 22, figs. 11, 12 ; plate 96, fig. 13.

Ophiomyces delata KGHLen ('04), p. 100, pl. 17, fig. 9; pl. 18, figs. 1, 2.-

H. L. Clark ('15), p. 221.

Localities.-Albatross station 5647; Buton Strait, North Island (S.) bearing S. $87^{\circ}$ E., 21.50 kilometers (11.6 miles) distant (lat. $5^{\circ} 34^{\prime} 00^{\prime \prime}$ S., long. $122^{\circ} 18^{\prime} 15^{\prime \prime}$ E.) ; 949 meters (519 fathoms); December 16, 1909 ; gn. M.

One specimen (Cat. 41321, U.S.N.M.)

Albatross station 5651; Gulf of Boni, Celebes; Buginkali Point bearing S. $67^{\circ}$ E., 38.92 kilometers (21 miles) distant (lat. $4^{\circ} 43^{\prime} 50^{\prime \prime}$ S., long. $121^{\circ} 23^{\prime} 24^{\prime \prime}$ E.) ; 1,280 meters (700 fathoms); December 17, 1909 ; gn. M.

One specimen (Cat. No. 41320 U.S.N.M.).

Notes.-The individual from station 5647 is larger than the other, and the arms reach a length of $25 \mathrm{~mm}$.; the disk, which is entirely 
torn away, must have had a diameter of about $10 \mathrm{~mm}$. The other specimen is entire; the diameter of the disk is $9 \mathrm{~mm}$., and the arms are $20 \mathrm{~mm}$. long. I give here two photographs of this specimen (pl. 22 , figs. 11, 12), as well as some photographs of isolated arm spines (pl. 96, fig. 13), showing the very small ventral $(a, b)$ and the much larger dorsal $(c)$.

The specimens collected by the Siboga upon which I established the species were dredged between latitude $6^{\circ} \mathrm{N}$. and $4^{\circ} \mathrm{S}$., and between longitude $120^{\circ}-131^{\circ} \mathrm{E}$. at depths varying between 350 and 4,239 meters (191 to 2,311 fathoms).

\section{Family OPHIACANTHIDAE.}

\section{OPHIODICTYS, new genus.}

Description.-The genus Ophiodictys has certain affinities with the genus Ophioplinthaca, but it is remarkable for the presence on the distal border of the side arm plates of a little row of hooks, about six on each plate, which appear at a short distance from the base of the arm; these hooks precede the ordinary arm spines, which are inserted beyond them. In the terminal portion of the arms the ordinary spines disappear and the hooks alone persist. These hooks are absolutely identical with those which exist in the Phrynophiurida of Matsumoto, but the external characters of the skeleton do not permit of assigning this new ophiuran to any of the known forms in that order; on the contrary, it recalls the Loemophiurida. I believe that this new genus should be placed among the genera of the family Ophiacanthidae, from all of which, however, it differs completely through the occurrence of the hooks which I have just described. It thus seems to me to form a very interesting intermediate between the Phrysophiurida and the Loemophiurida.

Type of the genus. - Ophiodictys uncinatus, new species.

OPHIODICTYS UNCINATUS, new species.

Plate 7, figs. 4-11.

Locality.-Albatross station 5668; Macassar Strait; Mamuju Island (E.) bearing S. $31^{\circ}$ E., 19.64 kilometers (10.6 miles) distant (lat. $2^{\circ} 28^{\prime} 15^{\prime \prime}$ S., long. $118^{\circ} 49^{\prime} 00^{\prime \prime}$ E.) ; 1,648 meters (901 fathoms) ; December 29, 1909; gy. M.

One specimen (Cat. No. 41017, U.S.N.M.).

Description.-The specimen is in very good condition; three arms are preserved entire, the two others being broken off some distance from the base. The diameter of the disk is $8 \mathrm{~mm}$.; the arms, which are rather flattened, are between $45 \mathrm{~mm}$. and $50 \mathrm{~mm}$. long.

The disk is rounded and the dorsal surface is flattened. It is strongly concave in the interradial spaces, and each of the incisions 
is continued over the dorsal surface in the form of a deep and narrow depression which reaches almost to the center. The dorsal surface is covered by rather large, somewhat unequal, imbricated plates smallest in the central region and becoming larger in the neighborhood of the radial shields as well as in the interradial spaces. A row of two or three large plates separates the two radial shields of each pair throughout their entire length. These shields, which are of moderate dimensions, are triangular, half again as long as broad, with the external border convex and the proximal angle rounded; their length is equal to almost two and a half times the radius of the disk.

The ventral surface of the disk is covered with small subequal imbricated plates. The genital slits are rather broad.

The radial rather small shields are triangular, as broad as long, with a sharp proximal angle bounded by two straight sides and a strongly convex distal border showing in the middle a small, more or less developed, rounded lobe which may give to some of these shields an almost lozenge-shaped form. The adoral plates are short and rather broad, broader without than within. The oral plates are triangular, but elongated, more than twice as high as broad. The lateral mouth papillae, five in number, are very unequal; the three outermost papillae are broadened and scale-like, especially the two last; the two internal papillae, on the other hand, are small, narrow and pointed; the unpaired terminal papillae is rather large and strong.

The upper arm plates are large and much broadened, triangular, twice as broad as long, with a very obtuse and rounded proximal angle bordered by gently rounded sides, and an almost straight distal border. At some distance from the base the proximal angle becomes truncated, and the plates become quadrangular, with a short proximal border. In the terminal portion of the arms the proximal angle reappears and even becomes very acute, while at the same time the plates elongate so that they end by being a little longer than broad. These plates are in contact, except near the arm tips.

The first under arm plate is small, a little longer than broad, pentagonal, with a very obtuse proximal angle and parallel sides passing over rounded angles into the distal border which is narrow and gently convex. The following plates are very large, extremely broad, twice as broad as long; they are quadrangular with an almost straight proximal border, and a very broad and convex distal border showing in the center a more or less marked notch and passing over by sharp angles into the sides which are divergent and strongly excavated by the corresponding tentacular pores. In the terminal portion of the arms the plates become pentagonal with an 
acute proximal angle, and they are then longer than broad. These plates are almost in contact throughout the length of the arm, but in the terminal portion they end by being separated by an extremely narrow interval occupied by the side arm plates.

The side arm plates project only slightly. They bear on their sides as well as on their ventral border a series of spines numbering five at the base of the arms; this figure falls to four at some distance from the disk. These spines are shorter than the segment, and are appressed against the lateral surface of the arms; they are rather thick, cylindrical, and rugose. The little asperities which they show become more marked toward their tips, which are rounded, and they then form short and extremely small spinules. These spines are all subequal and a little shorter than the segment. In the distal half of the arm their number falls to three, then to two, and finally they disappear entirely. On the first arm segments the insertion of the first dorsal spine is very close to the external angle of the corresponding upper arm plate, then on the following segments it gradually draws away in such a manner as to form on the anterior border of each side arm plate, a rather broad area bare of spines. This area is occupied by a row of little hooks, which at first are two or three in number, but later as many as six. These hooks (figs. 4, 7) formed of an entirely transparent substance, end in a recurved and pointed tip below which are one or two teeth. They are inserted on a little elevation, in the form of a rounded nipple, of the free border of the side arm plate (fig. 8). These nipples are very conspicuous and they indicate the places where the hooks originally stood (fig. 5) after they have been torn off. The hooks measure from $0.5 \mathrm{~mm}$. to $0.6 \mathrm{~mm}$. in length at the base of the arms, gradually decreasing in length distally; those which I have represented in figure 4 in plate 7 , and which are from the terminal third of an arm, are not more than $0.2 \mathrm{~mm}$. in length; the broadened basal part, provided with numerous orifices and composed of a compact substance, is rather short, almost as long as broad, and its length equals almost a third of the total length of the hook. The hook proper, which is formed of an absolutely transparent substance, terminates in a very long tooth, which is recurved, so as to form a right angle with the principal portion of the hook, which it almost equals in length. Behind this terminal tooth there are three or four other teeth, which are very much smaller and diminish rapidly in size toward the base, near which there appears again a last tooth larger than the preceding. In the proximal region the hyaline part of the tooth shows from three to five successive rounded or oval orifices, which are often regularly arranged one after the other.

The tentacular pores each have two unequal scales; the external is very large and broad, rounded, almost as long as broad, while the 
internal is very much narrower although almost as long as the first; this internal scale may be lacking on certain pores, or it may be so small as to be completely hidden by the external scale.

The color of the specimen in alcohol is grayish white.

OPHIACANTHA BENIGNA, new species.

Plate 16, figs. 5, 6.

Locality.-Albatross station 5592; Sibuko Bay, Borneo, and vicinity; Silungan Island (M.) bearing N. $1^{\circ}$ W., 11.86 kilometers (6.4 miles) distant (lat. $4^{\circ} 12^{\prime} 44^{\prime \prime}$ N., long. $118^{\circ} 27^{\prime} 44^{\prime \prime}$ E.) ; 558 meters (305 fathoms); September 29, 1909; gn. M.

One specimen (Cat. No. 41235 , U.S.N.M.).

Description.-The diameter of the disk is $5 \mathrm{~mm}$.; the arms are about $20 \mathrm{~mm}$. in length, and are more or less rolled up.

The disk is subpentagonal. The dorsal surface is covered with small, short, closely crowded club-spines with their bases greatly broadened, each one inserted upon a small rounded plate, which is not very distinct and which can only be made out on certain portions of the disk. These club spines taper rapidly and terminate in a crown of four or five very short and divergent spinules. The radial shields are distinct; they are small, triangular, a little longer than broad, and not in contact though rather close to each other.

That part of the ventral surface which lies beyond the mouth shield in the interradial spaces is insignificant; it is covered with little club-spines similar to those on the dorsal surface, but smaller. The genital slits are rather broad.

The mouth shields, which are of medium size, are a little broader than long, triangular, with a rather open proximal angle bounded by two slightly concave sides, and the distal side strongly convex with rather sharp lateral angles. The adoral plates are extremely broad, and their longer borders are almost parallel; they are half again as broad as long, scarcely narrower outwardly than inwardly. The oral plates are triangular and rather high. The lateral papillae are three in number ( $\mathrm{I}$ find in one instance four of them) rather small, short, and conical, but the distal papilla is a little more broadened than the others; the unpaired terminal papilla is thick and strong. The surface of these papillae is very rugose.

The upper arm plates are small and triangular with a proximal rather open angle and a rounded distal border. The first two or three are a little broader than long, the following becoming almost as long as broad. They are separated from the base of the arm outward by a rather broad interval.

'The first under arm plate is quadrangular, a little longer than broad, with a broad and slightly excavated proximal border, and a 
narrow and rounded distal border. The two or three following plates are triangular, with an extremely obtuse proximal angle, much rounded lateral angles, and a convex distal border; they are three times as broad as long. Those following become less broad, and assume a pentagonal shape with two short lateral borders. These plates are separated beyond the second.

The slightly projecting side arm plates bear six extremely short, thick and cylindrical spines with the point blunted. The first ventral spine is shorter than the segment, and the last scarcely equals a segment and a half, except on the first segment, where its length is slightly greater. On the first segment the two lateral columns of spines come extremely close together in the dorsal median line of the arm and are almost continuous, but beyond this they are widely separated. The surface of the spines is simply rugose.

All of the arm plates, as also the mouth plates, are covered with little rounded granules which are very close together, though not in contact.

The single tentacle scale is small and conical with the point obtuse.

Affinities and distinctive features.-O phiacantha benigna is closely related to 0 . brevispina Kohler, which it recalls in the shortness of the arm spines and in the breadth of the adoral plates, but it differs from it in the form of the latter, which are still more broadened, by the narrower and more elongated mouth papillae, by the rather closely placed radial shields, by the absence of ribs on the dorsal surface of the disk, and in the under arm plates which are at first remarkably broadened; also in $O$. brevispina the armature of the dorsal surface of the disk consists simply of fine and closely placed granules ending in a few extremely short spinules.

OPHIACANTHA COMPOSITA Kohler.

Plate 23, figs. 5, 6, 7 ; plate 93 , fig. 4 .

See for bibliography:

Ophiacantha composita KGHLER ('07), p. 289; ('09), p. 188.

Localities.-Albatross station 5119; Balayan Bay and Verde Island Passage; Sombrero Island bearing S. $80^{\circ}$ E., 35.03 kilometers (18.9 miles) distant (lat. $13^{\circ} 45^{\prime} 05^{\prime \prime} \mathrm{N}$., long. $120^{\circ} 30^{\prime} 30^{\prime \prime}$ E.) ; 721 meters (394 fathoms); January 21, 1908; gn. M., S.

One specimen (Cat. No. 41134, U.S.N.M.).

Albatross station 5601a; Gulf of Tomini, Celebes; Limbe Island (NE. bearing N. 38.36 kilometers (20.7 miles) distant (lat. $1^{\circ} 13^{\prime}$ $10^{\prime \prime}$ N., long. $125^{\circ} 17^{\prime} 05^{\prime \prime}$ E.) ; 1,399 meters (765 fathoms) ; November 13, 1909 ; S., Glob. Ptr.

One specimen in poor condition (Cat. No. 41132, U.S.N.M.). 
Albatross station 5630; south of Patiente Strait; Doworra Island (N.) bearing N. $3^{\circ}$ W., 8.34 kilometers (4.5 miles) distant (lat. $0^{\circ} 56^{\prime}$ $30^{\prime \prime}$ S., long. $128^{\circ} 05^{\prime} 00^{\prime \prime}$ E.; 1,040 meters (569 fathoms); December 2,1909 ; co. S., M.

One specimen (Cat. No. 41133 , U.S.N.M.).

Notes.-These specimens are of rather small size; the diameter of the disk does not exceed $6 \mathrm{~mm}$. in those from stations 5119 and 5630 , and is only $3 \mathrm{~mm}$. in that from station 5601. But they show well the characters of 0 . composita, and the outermost mouth papilla is especially broadened; it is still larger than in the specimens collected by the Siboga, and resembles that characteristic of the genus Ophiolimna; it is almost rectangular and greatly elongated. I show here the two surfaces of the specimen from station 5119, and in figures 5 may be seen the dimensions of this outer mouth papilla, which in one of the mouth angles has a tendency to become divided into two equal halves, and in another is almost completely divided into two very unequal parts. This recalls a more marked anomaly which I had previously noticed in a specimen from the Gulf of Gascony, on which I thought it possible to base a new species, which, however, I no longer recognize (see Kohler '07, p. 290).

I have determined the characters differentiating 0 . composita and O. meridionalis Lyman which, like the first, has the mouth papilla broadened (Kœhler '14, p. 94). H. L. Clark ('15, p. 201) has proposed changing the name meridionatis to mesembria, for he has been able to show that the 0 . meridionalis of Lyman was in reality an $O$. pentacrinus.

The two specimens collected by the Hirondelle in the North Atlantic which I figured in 1898 under the name of $O$. pentagona, var. armata ('98, p. 55) must also be assigned to 0 . mesembria.

\section{OPHIACANTHA CONFUSA Kohler.}

Plate 19, figs. 1, 2.

Ophiacantha confusa Kanler ('05), p. 59, pl. 7, figs. 9-11.

Locality.-Albatross Station 5420; between Cebu and Bohol; Cruz Point (Bohol) bearing S. $20^{\circ}$ E., 11.12 kilometers ( 6 miles) distant (lat. $9^{\circ} 49^{\prime} 35^{\prime \prime}$ N., long. $123^{\circ} 45^{\prime} 00^{\prime \prime}$ E.) ; 232 meters (127 fathoms); March 24, 1909.

One specimen (Cat. No. 41232, U.S.N.M.)

Notes.-In spite of a rather remarkable difference in the form of the adoral plates, I believe that this specimen must be referred to the species which I described in 1905 from a unique and very small specimen collected by the Siboga at the island of Salibabu at a depth of only 36 meters (19.5 fathoms). The diameter of the disk of this 
little individual did not exceed $3 \mathrm{~mm}$. and the arms were $18 \mathrm{~mm}$. in length.

The Albatross specimen is much larger, the diameter of the disk being $6 \mathrm{~mm}$. and the length of the arms more than $40 \mathrm{~mm}$. It seems to me best to describe it here as if the species were not yet known, and I believe that it will be preferable from now on to consider this specimen as the type of the species, the Siboga specimen evidently not having acquired its definitive characters.

The disk is rounded. The dorsal surface is covered with very small thin and transparent imbricated plates which bear extremely small, short and crowded club-spines, of which the length does not greatly exceed the width, and which terminate in three or four very short and slightly diverging spinules. The radial shields are distinct; they are small, triangular, slightly divergent, a little longer than broad, and widely separated.

In the interradial spaces the ventral surface of the disk shows an investment similar to that of the dorsal surface, but the greater part of the plates are naked, doubtless through abrasion. The genital slits are very broad.

The mouth shields are of medium size, triangular, almost as long as broad, or a little broader than long, with the proximal angle almost a right angle, slightly rounded, and bounded by two straight sides; the distal border is slightly convex and shows in the middle a small rounded and narrow lobe; this lobe is already found in the Siboga specimen, which is very much smaller. In the photograph which I reproduce here (pl.19, fig. 1) the form of the mouth shields is not quite exact because of the rather marked convexity of the ventral surface which has led to a slight distortion of the image. The adoral plates are very large, elongated, tapering inwardly, though in contact by a small straight border in the median interradial line; they are much broadened outwardly and separate the mouth shield from the first side arm plate. It is especially in the elongated form of these plates that the Albatross specimen differs from the immature Siboga individual. The oral plates are triangular, two and a half times as broad as long. The lateral mouth papillae, three in number, are rather stout, conical and pointed; their size increases slightly from the outermost to the innermost, which is almost as large as the unpaired terminal papilla. Beyond the external papilla, which is inserted like the preceding on the oral plate, there may be distinguished another papilla inserted at the external angle of the first under arm plate which is elongated, slender, pointed, and slightly incurved.

The upper arm plates are small, triangular, broader than long, with an obtuse proximal angle, two straight sides, and a convex distal border. They are very widely separated from the base of the 
arm outward by an interval greater than their own length which is entirely occupied by the side arm plates.

The first under arm plate is rather large, triangular, with an obtuse and rounded distal angle and similarly slightly rounded sides. The second is large, pentagonal, very much broader than long, with a very obtuse proximal angle bordered by slightly concave sides, the lateral borders excavated by the tentacle scale, and a very broad and convex distal side. This plate is not quite in contact with the first. The following plates become smaller, though remaining pentagonal, but the proximal angle finally becomes so obtuse that its two sides are almost the prolongation of each other, and the lateral borders are almost straight. These plates are always broader than long, and they are widely separated.

The side arm plates, which are strongly projecting, carry seven extremely fine elongated, pointed, vitreous spines, which are provided with rather closely placed small denticulations. The length increases from the first ventral spine, the length of which exceeds that of the segment, to the second from the dorsal end of which the length reaches almost three segments; the last dorsal spine is a little smaller. The two lateral columns of spines come very close together in the median dorsal line on the first arm segments.

The single tentacle scale is rather large, but narrow, spiniform, and pointed, and it reaches almost the length of the corresponding under arm plate.

The color of the dorsal surface of the disk is a rather light brown; the arms are similar in color with indications of spaced white rings; the ventral surface is almost white.

I have mentioned above that the Siboga specimen was found at a littoral station ( 36 meters, or 19.5 fathoms), and therefore at a depth less than the Albatross specimen, which comes from a coastal station in 232 meters ( 127 fathoms). This latter still shows very clear traces of a coloration indicating that it lived at a relatively slight depth to which some luminous radiations must have penetrated.

OPHIACANTHA DALLASII Duncan.

Plate 16, figs. 1-3.

Ophiacantha dallasii DUNCAN ('78), p. 471, pl. 11, figs. 25-27.-DöDERLEIN ('96), p. 291, pl. 14, fig. 3 ; pl. 16, fig. 12.-PFefFer ('O0), p. 83.-Korhler ('05), p. 55.-H. L. Clark ('15), p. 198.-Matsumoto ('17), p. 113.

Localities.-Albatross station 5135 ; vicinity of Joló; Joló Light bearing S. $46^{\circ}$ W., 22.07 kilometers (11.91 miles) distant (lat. $6^{\circ} 11^{\prime}$ $50^{\prime \prime}$ N., long. $121^{\circ} 08^{\prime} 20^{\prime \prime}$ E.) ; 294 meters (161 fathoms) ; February 7,1908 ; fne. co. S.

One specimen (Cat. No. 40925, U.S.N.M.). 
Albatross station 5153; Sulu Archipelago, Tawi Tawi Group; 'l'ocanhi Point bearing S. $27^{\circ}$ E., 3.87 kilometers (2.1 miles) distant (lat. $5^{\circ} 18^{\prime} 10^{\prime \prime} \mathrm{N}$., long. $120^{\circ} 02^{\prime} 55^{\prime \prime}$ E.) ; 89 meters (49 fathoms); liebruary 19, 1908; co. S., Sh.

One specimen (Cat. No. 41131, U.S.N.M.).

Albatross station 5399; north of Cebu; Tanguingui Island Light bearing $\mathrm{N} .70^{\circ} \mathrm{W}$, 42.25 kilometers (22.8 miles) distant (lat. $11^{\circ} 21^{\prime}$ $45^{\prime \prime}$ N., long. $124^{\circ} 05^{\prime} \mathrm{E}$ ) ; 58 meters ( 32 fathoms) ; March 16, 1909; S., Sh.

One specimen (Cat. No. 41130 , U.S.N.M.).

Notes. - This species is well marked and is easy to recognize. The outlines of the plates are not very distinct in the photographs published by Döderlein, and I am giving here some photographs which I have taken from Albatross specimens. In two of these (figs. 2, 3) the tentacle scales, of which the shape was correctly shown by Duncan ('78, pl. 11, fig. 27), may be easily distinguished. Döderlein wrote in 1899 that the tentacle scale is entirely lacking in 0 . dallasi; this is evidently an error.

There is some variation in the development of the spinules which terminate the club spines of the dorsal surface of the disk; I have already had occasion to notice this fact in my work on the Sibogra ophiurans ('05, p. 55).

The type specimen of $O$. dallasii came from the Korean Sea (lat. $38^{\circ}$ N., long. $129^{\circ}$ E., 91 meters [50 fathoms]). The species has been rediscovered at Amboina and at Ternate, and the Siboga met with it in many localities among the Sunda Islands at depths between 15 and 141 meters ( 8 to 77 fathoms). The greatest depth at which $O$. dallasi has been captured is that given above for station 5135, 294 meters (161 fathoms).

\section{OPHIACANTHA DUPLEX Kohler.}

Plate 16, figs. $7-8$.

Ophiacantha duplex Koenler ('96), p. 352, pl. 8, figs. 66, 67; ('99), p. 60, pl. 8, fig. 67 ; pl. 9, figs. 69, 70.-H. L. Clark ('10), p. 206.

(?) Ophiacantha diploa H. L. CLARK ('11), p. 207; ('15), p. 198.

Locality.-Albatross station 5348; Palawan Passage; Point Tabonan bearing S. $89^{\circ}$ E., 62.08 kilometers (33.0 miles) distant (lat. $10^{\circ} 57^{\prime} 45^{\prime \prime}$ N., long. $118^{\circ} 38^{\prime} 15^{\prime \prime}$ E.) ; 686 meters (375 fathoms); December 27, 1908; co., S.

Three specimens (Cat No. 41141, U.S.N.M.).

Notes.-These are smaller than the type specimen, in which the diameter of the disk was $10 \mathrm{~mm}$; in the three Albatross specimens the diameter of the disk does not exceed $5 \mathrm{~mm}$., and the arms, which are entire, are from $30 \mathrm{~mm}$. to $35 \mathrm{~mm}$. in length. I give here two photographs of one of these. 
The type specimen of $O$. duplex was discovered by the Investigator off Colombo, Ceylon, in 1,234 meters (675 fathoms).

Under the name of Ophiacantha diploa H. L. Clark in 1911 ('11, p. 207) described an ophiuran from the southern part of the Sea of Japan (lat. $32^{\circ}$ N., long. $132^{\circ}$ E.), 799 meters (437 fathoms), which differs from 0 . duplex only in unimportant features. In that author's type specimen the diameter of the disk is $7 \mathrm{~mm}$., and the arms are $45 \mathrm{~mm}$. long. I believe that in spite of the differences indicated by $\mathrm{H}$. L. Clark, the two represent the same species. In the Albatross specimens, which unfortunately are of small size, I count eight and even nine spines at the base of the arms, and the dorsal spines approach more closely the median line than in my type; these spines, as can be seen on the two photographs which I give here, are provided with very distinct denticulations, while in H. L. Clark's specimens they are almost smooth. I do not dare to state in a formal manner that the two species are identical, but it seems to me very probable.

The two photographs which I give here will permit of more ready comparisons than the figures which I published of 0 . duplex in 1896 and in 1899.

OPHIACANTHA GRAPHICA, new species.

Plate 18, figs. 4,5 .

Locality.-Unknown.

One specimen (Cat. No. 41233, U.S.N.M.)

Description.-The unique specimen is very well preserved, lacking only a small part of one of the arms; it is unfortunately small; the diameter of the disk scarcely exceeds $3 \mathrm{~mm}$, and the arms are 18 $\mathrm{mm}$. long. In spite of its small dimensions it is well characterized, and I do not see any species to which it may be assigned; I therefore consider it as representing a new form.

The disk is rounded; the arms are slender, delicate, somewhat moniliform, with the segments short and close together.

The dorsal surface of the disk is covered with very closely crowded slender and elongated club-spines, each terminating in three extremely fine and slightly divergent spinules of the same length. These club-spines only leave exposed the distal portion of the radial shields. The ventral surface of the disk in the interradial spaces has a similar covering, but the club-spines, as well as the spinules on their summits, become shorter toward the mouth shields. The genital slits are broad and very evident.

The mouth shields, which are of medium size, are triangular and rather high, broader than long, but the breadth does not exceed once and a half the height; the proximal angle is obtuse, bordered by 
straight sides, and these, passing around very rounded angles, unite to form the distal border, which is almost straight. The adoral plates are large and broad, tapering inwardly, though broadly in contact in the median interradial line; they are broadened outwardly and separate the mouth shield from the first side arm plate. The oral plates are triangular and high, and of medium size. The lateral mouth papillae are sometimes three, sometimes four in number; they are small and conical with the point blunted; the unpaired terminal papilla is a little larger than those adjacent.

The upper arm plates are small and widely separated by the side arm plates; they, are triangular, broader than long, with an obtuse proximal angle bounded by two straight sides which pass around by sharp angles to the distal side, which is gently rounded. In the terminal part of the arms these plates become a little longer than broad.

The first under arm plate is rather small, trapezoidal, with the distal border straight and narrow and the proximal border broader, passing by rounded angles into the sides; these are straight and converge toward the distal border, which is narrow and straight. The two or three following plates are triangular, broader than long, with an obtuse proximal angle and a large and very convex distal border. The second plate is just in contact with the first by its proximal angle, and the following are separated by an interval which at first is very short, but which becomes progressively greater. Toward the fourth or fifth the plates elongate and at the same time their width diminishes; they then become as long as broad, pentagonal, with a proximal angle bounded by two straight sides, two lateral borders slightly divergent and somewhat excavated by the tentacle pores, and a rather narrow convex distal border. Toward the middle of the arm these plates even become a little longer than broad, further on assuming a simply triangular shape with a very sharp proximal angle, and being as broad as long.

The side arm plates are prominent and bear at the arm bases up to ten narrow and slender glassy and strongly echinulate spines. The length of these spines increases progressively from the first ventral, which is a little shorter than the segment, to the eighth of which the length is equal to at least three segments; the two other dorsal spines have almost the same length as the eighth. The number of these spines progressively decreases, falling little by little to six; at the same time the length of the dorsal spines diminishes and scarcely exceeds that of the segment.

The under arm plates show on their surface striations parallel to their distal border which are very conspicuous; similar striations are seen on the side arm plates, but they become very much less evident on the upper arm plates. 
The tentacle scale is small and elongated; it is oval on the first segments, then its extremity becomes pointed and furnished with a few very fine asperities. The pores of these two first pairs possess two scales.

The color of the dorsal surface of the disk and of the arms is a brownish gray; the ventral surface of the disk is of the same color, but the ventral surface of the arms is very much lighter and simply grayish.

Affinities and distinctive features.-Ophiacantha graphica appears to be closely related to $O$. longidens Lyman; the armature of the disk is identical with that which that author has described, and which I also have found in the specimen from station 5153 which $I$ have recorded below and have referred to 0 . longidens. But our species is sharply distinguished from the latter by its more numerous and relatively very long arm spines, which on the first arm segments form rows approaching each other very closely in the dorsal median line and almost joining behind the upper arm plates. It is well to remark that the number of these spines reaches six in a specimen in which the diameter of the disk does not exceed $3 \mathrm{~mm}$., while in Lyman's type specimen, as well as in the specimen from station 5153, in which the disk reaches $4 \mathrm{~mm}$. in diameter, the number of the arm spines is eight only. The mouth papillae, which are sometimes three, sometimes four, in number, are shorter than in $O$. longidens; the mouth shields are triangular, higher, and less broad; the under arm plates especially are less broad and more elongated; they rapidly become as long as broad and even a little longer than broad; the small tentacle scale shows a tendency to become spiniferous, and there are two of them on the pores of the two first pairs.

\section{OPHIACANTHA LEGATA, new species.}

Plate 17, figs. $4,5$.

Locality.-Albatross station 5536; between Negros and Siquijor; Apo Island (C.) bearing S. $26^{\circ}$ W., 21.87 kilometers (11.8 miles) distant (lat. $9^{\circ} 15^{\prime} 45^{\prime \prime}$ N., long. $123^{\circ} 22^{\prime} 00^{\prime \prime}$ E.) ; 510 meters (279 fathoms); August 19, 1909; gn. M.

One specimen (Cat. No. 41373, U.S.N.M.).

Description.-The disk is $4 \mathrm{~mm}$. in diameter, ind the arms are 18 $\mathrm{mm}$. long.

The disk is rounded. The dorsal surface is covered by closely crowded, rather long but thick and stout club-spines, each terminated by three or four short, conical and unequal spinules; the stalk of these club-spines may also show one or two small denticulations: The plates which bear these club-spines are not visible on account of their being so close together. For the same reason only the distal 
ends of the radial shields, which are very widely separated, can be distinguished. The ventral surface of the disk is covered with small imbricated plates, many of which carry club-spines more slender than those of the dorsal surface, which always end in a few short and unequal spinules. The genital slits are rather broad.

The mouth shields, which are of moderate size, are lozenge- shaped, broader than long, with an obtuse proximal angle bordered by two straight sides, rounded lateral angles, and two distal sides which are gently convex and which pass over into each other by a broadly rounded angle. The adoral plates, which are of medium size, have their long borders straight and almost parallel; they are, however, a little broader outwardly than inwardly, and they give off a narrow process separating the mouth shield from the first side arm plate. The oral plates are triangular and very high. The lateral mouth papillae, three in number, are much elongated and cylindrical, with the point obtuse, and subequal; there is sometimes a fourth supplementary papilla near the terminal papilla which is shorter and thicker than the three others. The unpaired terminal papilla is thick and short. The surface of these papillae is very rugose.

The upper arm plates are extremely small and occupy only a very limited portion of the dorsal surface of the arms, the greater part of which is covered by the side arm plates. These plates are triangular, broader than long, and widely separated, with a rather open proximal angle and a very broad and only slightly convex distal border.

The first under arm plate is a little broader than long, quadrangular or trapezoidal, with the distal border narrow, the proximal border broader and convex, and the sides divergent and straight. The following plates are pentagonal, with an obtuse proximal angle, the sides excavated by the tentacular pores, and a strongly convex distal border. They are separated beyond the second; the latter is very much broader than long, those following becoming as long as broad, and finally a little longer than broad.

The side arm plates, which are moderately projecting, carry at the base of the arms ten spines, which, on the first brachial segments, form on the dorsal surface a perfectly continuous series from one side to the other; and on the following segments the two lateral rows of spines still come very close together in the median linet The three or four first ventral spines are subequal, and their length equals that of the segment; the length then increases up to the last dorsal spine, which measures about three segments. These spines are slender and transparent, and are provided with very strong, triangular and pointed teeth, which are rather well spaced. 
The under and side arm plates on the lower surface show fine concentric striations. On the under arm plates these striations at first have their concavity directed toward the arm tip, while in the last third of the plates these striations have the concavity directed toward the mouth. On the upper arm plates these striations are scarcely indicated, or may even be entirely lacking.

The singles tentacle scale is very large, flattened, lanceolate, and pointed, and on the free border in the distal half bears some fine spinules, which cause it almost to justify the appelation spiniferous.

Affinities and distinctive features.-O phiacantha legata approaches most closely $O$. aspera Lyman. It differs from it in the character of the club spines of the dorsal surface of the disk, which are much elongated, in the pointed tentacle scales provided merely with a few rather fine spinules instead of possessing those lobes which are so marked in $O$. aspera, in the shorter mouth shields, in the longer mouth papillae, and in the more elongated under arm plates.

It is also close to $O$. longidens Lyman, which lives at a lesser depth; it is distinguished from that species by its more broadened and shorter mouth shields, and by its more numerous and strongly echinulated arm spines; furthermore, the dorsalmost spine always show very strong and well spaced teeth, and the two lateral series of spines are perfectly continuous on the first arm segments; the upper arm plates are shorter, the tentacle scales bears fine spinules, and the clubspines of the dorsal surface of the disk are stronger and terminated by shorter and more pointed spinules in $O$. legata than in $O$. longidens.

\section{OPHIACANTHA LONGIDENS Lyman.}

Plate 17, figs. $6,7$.

Locality.-Albatross station 5153; Sulu (Joló) Archipelago, Tawi Tawi Group; Tocanhi Point bearing S. $27^{\circ}$ E., 3.89 kilometers, (2.1 miles) distant (lat. $5^{\circ} 18^{\prime} 10^{\prime \prime} \mathrm{N}$., long. $\left.120^{\circ} 02^{\prime} 55^{\prime \prime}\right) ; 90$ meters (49 fathoms); February 19, 1908; co. S., Sh.

One specimen (Cat. No. 41236, U.S.N.M.).

Notes.-It is not without much hesitation that I refer this specimen to O. longidens Lyman. As yet that species is known only from a single individual captured in the Philippines by the Challenger at a depth of between 174 and 183 miles ( 95 and 100 fathoms). As the description given by Lyman is very brief, I requested my colleague, Prof. F. J. Bell, to compare with Lyman's type the photographs which I sent him of my specimen, and his opinion was that they both represented the same species, an opinion which he gave, however, with reservations, for, he wrote me, the very small type is in rather bad condition, two arms only being preserved and these broken off. 
Under these conditions it has seemed to me that it would not be out of place to apply the name $O$. longidens to my specimen, which comes from a region very close to that where the Challenger collected the unique representative of the species, and from a similarly small depth, and to give here a detailed description of it.

The diameter of the disk is $4 \mathrm{~mm}$, and the arms are $18 \mathrm{~mm}$. long. 'The specimen is not quite complete; three almost entire arms remain attached to the disk, the other two being detached and broken off at some distance from the base.

The disk is rounded. The dorsal surface is covered with extremely small and closely crowded plates, each bearing a very slender and very fine club-spine terminating in three remarkably slender spinules of which the length in the central portion of the disk is equal to that of the club-spine itself, but which become shorter toward the periphery. The distal part of the radial shields only is visible, in the form of a small, triangular plate, a little longer than broad, and the two shields of each pair are widely separated; from each of them there extends a much raised rib which remains distinct for almost half the radius of the disk.

The plates which cover the ventral surface of the disk in the interradial spaces each carry a small and very short club-spine terminated by a few spinules, which are also very short. The genital slits are broad.

The mouth shields are small, very much broader than long, with a rather sharp proximal angle and two slightly excavated sides coming together over rounded angles on the distal border, which is convex. This last shows in its center a rounded lobe which projects more or less into the interradial space. The adoral plates, which are of average dimensions, have the long borders parallel and gently recurved in the form of a crescent. The oral plates are very small. The lateral mouth papillae are three in number, elongated and cylindrical, with the point rounded; the two proximal papillae are rather narrow, and the outermost is a little more thickened; the unpaired terminal papilla is a little stouter than the others.

The upper arm plates are small, triangular, a little broader than long, with the distal border convex; they are widely separated from the base of the arms outward.

The first under arm plate is small, triangular, with a rounded distal angle. The second is quadrangular with a narrow proximal border, a very broad and strongly convex distal border, and divergent sides excavated by the tentacle scale. The following plates become pentagonal as a result of the resolution of the proximal border into two small sides united by an obtuse angle; they are broader than long and are separated by a space which becomes rather large beyond the third plate. 
The side arm plates are moderately developed and cover half the length of the segments. They are projecting and carry eight spines, increasing in length from the first ventral, which is a little shorter than the segment, to the antepenultimate dorsal, which is as long as three segments; the last spine is usually a little smaller than that preceding. The two lateral rows of spines are very close together in the dorsal median line of the arms, though without forming a continuous series. The spines are slightly flattened, and the ventral are provided with rather strong and sharp denticulations which become much smaller and less apparent on the dorsal; these last may even be entirely smooth.

The under and side arm plates show on their surface rather wellmarked parallel striations.

The tentacle scale, always single, is of medium size; it is at first oval and rather broadened, beyond the disk becoming pointed; its surface is somewhat rugose, especially toward the point, though without becoming spiniferous.

The color in alcohol is a light brownish pink.

The single specimen was taken at a depth of only 90 meters (49 fathoms); Lyman's type, which came from Cebu, was dredged in 174 to 183 meters (95-100 fathoms).

OPHIACANTHA PACATA, new species.

Plate 18, figs. 1, 2, 3.

Locality.-Albatross station 5589; Sibuko Bay, Borneo, and vicinity; Nabul Island (NW.) bearing N. $3^{\circ}$ W., 5.19 kilometers (2.8 miles) distant (lat. $4^{\circ} 12^{\prime} 10^{\prime \prime} \mathrm{N}$., long. $118^{\circ} 38^{\prime} 08^{\prime \prime}$ E.) ; 475 meters (260 fathoms) ; September 29, 1909 ; fne. gy. S., gy. M.

One specimen (Cat. No. 41234, U.S.N.M.).

Description.-The diameter of the disk is $12 \mathrm{~mm}$., and the arms are $45 \mathrm{~mm}$. long.

The disk is rounded. The dorsal surface is covered with extremely thin and translucent plates not entirely concealing the underlying tissues, which form a very dark mass. These scales become very much smaller and very much more transparent toward the periphery of the disk in the interradial spaces. Each of these carries a strong and elongated similarly translucent spine, of which the base is broadened, but which tapers rapidly into a slender cylindrical stem, this again enlarging toward the extremity and at the same time becoming flattened. This broadened and flattened terminal part bears on its sides one or two short, conical, and pointed teeth of very variable shape and size, and sometimes absent altogether. The smaller interradial plates about the periphery of the disk are without spines. The radial shields are visible; they are small and tri- 
angular, a little longer than broad, with the angles and the borders rounded. Each of these lies at the end of a small projecting rib the length of which is almost equal to half the radius of the disk. The two shields of each pair are very broadly separated by a space which is almost equal to the width of the arms.

The ventral surface of the disk in the interradial spaces is covered with small plates which are rounded or slightly imbricated, extremely thin, and transparent, and which are not always perfectly in contact. The genital slits are much elongated and rather narrow.

The mouth shields are small and triangular, as broad as long, or a little longer than broad, with a very sharp proximal angle bordered by two straight or slightly concave sides, and a convex distal border with a very slightly marked small lobe in the middle. The adoral plates, which are of medium size, rapidly taper inwardly and are broadened in their external portion, which gives off a rather narrow process separating the mouth shield from the first side arm plate; they are about two and a half times as long as broad, and their longer edges are slightly incurved. The oral plates are triangular and rather high. The lateral mouth papillae are three in number; the two outer are cylindrical, rather elongated, with the tip rounded; the internal is a little stouter, conical, with the point blunted; the unpaired terminal papilla is a little thicker than those on either side. The surface of these papillae is very rugose. Beyond the external papilla there is in addition a smaller papilla which is inserted at the angle between the adoral plate and the first under arm plate.

The rather small upper arm plates are triangular, broader than long, with a rather open proximal angle bordered by two straight sides and a slightly convex distal border. They are separated outward from the base of the arms by a narrow interval which does not increase much distally.

The first under arn plate is rather broad, triangular, broader than long, with the distal border convex and the proximal angle obtuse. The second, already separated from the first, is very broad and short, triangular in form, with an obtuse proximal angle, sharp lateral angles, and a convex distal border. The following plates become pentagonal with a very obtuse proximal angle, the sides notched by the corresponding tentacle pore, and a very convex distal border. These plates are at first very much broader than long, becoming a little longer than broad in the outer half of the arms. They are always separated by a rather long space occupied by the side arm plates.

The side arm plates carry eight strong, thick and slightly flattened arm spines. The ventral spines are especially flattened, and they bear rather strong denticulations, which on the three first are par- 
ticularly developed along the proximal border; their tips are rounded. The dorsal spines show only very fine and very closely crowded asperities; they are somewhat narrowed, and their tips form an obtuse point. The length increases from the first ventral spine, which is as long as the segment, to the last dorsal, which may be as long as four segments. The two lateral columns of spines come very close together in the median dorsal line on the first segments, though they are always separated from each other by a small space.

The tentacle pores of the first pair are very large and appear to be without a tentacle scale, or they may have a single almost rudimentary one. The pores of the second pair have a rather large scale, and on one of them the scale is doubled. The following pores have uniformly a single scale of moderate size, which is flattened, rectangular, with a rounded and sometimes even slightly broadened distal border. The surface of these scales is very rugose.

The disk is very dark, blackish brown, because of the extreme thinness of the plates which cover the underlying tissues; the arms are white.

Affinities and distinctive features.-Ophiacantha pacata is easily recognized by the form of the spines on the dorsal surface of the disk, which are borne upon extremely thin and translucent plates, by the presence of three mouth papillae, and by the small mouth shields, which are triangular and almost as long as broad. It seems to me to be most closely related to $O$. prionota, which H. L. Clark described from a unique specimen from southern Japan in 1,008 fathoms, of which the diameter of the disk was $9 \mathrm{~mm}$. It is distinguished from this species by the stouter and longer spines on the dorsal surface of the disk, broadened at the tip, which bear three spinules; by having the mouth shields slightly more elongated toward the proximal angle; by the longer adoral plates; by the more elongated arm spines; by having the upper arm plates broader than long; and by the more elongated and larger under arm plates, which are separated by a narrow interval. These differences are obviously not correlated with the difference in the size of the specimens; as I have just said, in 0. prionota the diameter of the disk is $9 \mathrm{~mm}$., and in 0 . pacata it is $12 \mathrm{~mm}$.; the difference is not very great.

\section{ophiacantha PENTAgona Kohler.}

Plate 21 , figs. $1,5,6$; plate 93 , fig. 5 .

Ophiacantha pentagona KceHLER ('96), p. 343, pl. 8, figs. 56, 57; ('99), p. 53, pl. 4, figs. 27-29; ('04), p. 110.-H. L. CLARK ('11), p. 196; ('15), p. 204.-Matsumoto ('17), p. 116.

Localities.-Albatross station 5116; Balayan Bay and Verde Island Passage; Sombrero Island bearing N. $69^{\circ}$ E., 4.63 kilometers 
(2.5 miles) distant (lat. $13^{\circ} 41^{\prime} 00^{\prime \prime} \mathrm{N}$., long. $120^{\circ} 47^{\prime} 05^{\prime \prime}$ E.), 365 meters (200 fathoms); January 20, 1908.

One specimen (Cat. No. 41201, U.S.N.M.).

Albatross station 5367; Verde Island Passage; Malabrigo Light bearing N. $81^{\circ}$ E., 14.83 kilometers ( 8 miles) distant (lat. $13^{\circ} 34^{\prime} 37^{\prime \prime}$ N., long. $121^{\circ} 07^{\prime} 30^{\prime \prime}$ E.) ; 329 meters (180 fathoms) ; February 22 , $1909 ; \mathrm{S}$.

One specimen (Cat. No. 41202, U.S.N.M.).

Albatross státion 5505; Northern Mindanao and vicinity; Macabalan Point Light (Mindanao) bearing S. $31^{\circ}$ E., 14.27 kilometers (7.7 miles) distant (lat. $8^{\circ} 37^{\prime} 15^{\prime \prime} \mathrm{N}$., long. $124^{\circ} 36^{\prime} 00^{\prime \prime}$ E.) ; 402 meters (220 fathoms); August 5, 1909.

One specimen (Cat. No. 41205, U.S.N.M.).

Albatross station 5522; Northern Mindanao and vicinity; Point Tagolo Light bearing $\mathrm{S} .39^{\circ} \mathrm{W} ., 11.1$ kilometers $(6$ miles) distant (lat. $8^{\circ} 49^{\prime} 00^{\prime \prime}$ N., long. $123^{\circ} 26^{\prime} 30^{\prime \prime}$ E.; 421 meters (230 fathoms) ; August 10, 1909 ; Glob.

One specimen (Cat. No. 41203, U.S.N.M.).

Albatross station 5527; between Siquijor and Bohol Islands; Balicasag Island (C) bearing N. $14^{\circ}$ W., 15.20 kilometers ( 8.2 miles) distant (lat. $9^{\circ} 22^{\prime} 30^{\prime \prime}$ N., long. $123^{\circ} 42^{\prime} 40^{\prime \prime}$ E.) ; 717 meters (392 fathoms); August 11, 1909; glob. Oz.

One specimen (Cat. No. 41204, U.S.N.M.).

Notes.-The diameter of the disk varies between $3 \mathrm{~mm}$. and $5 \mathrm{~mm}$. The specimens resemble perfectly those which the Siboga collected among the Sunda Islands. It has seemed to me worth while to give here some photographs of this species, which will show its characters better than my slightly schematic drawings of 1896 and 1899 (pl. 21, figs. $1,5,6)$.

I also give (fig. 5, pl. 93) some photographs of the club-spines on the dorsal surface of the disk.

H. L. Clark has described a few unimportant variations among the numerous specimens which he has had from the Japanese seas.

The type series of $O$. pentagona came from the Andaman Islands, where the species was discovered by the Investigator in 439 to 686 meters (240 to 375 fathoms); the Siboga collected it in various localities among the Sunda Islands in from 204 to 827 meters (112 to 453 fathoms) between latitude $5^{\circ}$ N. $-5^{\circ}$ S. and longitude $119^{\circ}-132^{\circ}$ E.; H. I. Clark has recorded it from numerous localities in the seas about Japan at depths between 82 and 1,724 meters (45 and 943 fathoms).

Ophiacantha pentagona must be very widely distributed in the Indo-Pacific region, but I do not believe that it occurs in the Atlantic. The two specimens collected by the Hirondelle in the North Atlantic, which I considered as a variety of $O$. pentagona and to which I gave the name of $O$. pentagona var. armata $(' 98$, p. 55$)$, characterized by 
the broadened outer mouth papilla, should be referred to the species originally called $O$. meridionalis by Lyman, to which $\mathrm{H}$. L. Clark has proposed to give the name $O$. mesembria, as I have stated above in discussing $O$. composita.

OPHIACANTHA SEVERA, new species.

Plate 17, figs. 1-3.

Localities. - Albatross station 5629; Patiente Strait and southward; Doworra Island (S.) bearing S. $62^{\circ}$ W., 11.1 kilometers (6 miles) distant (lat. $0^{\circ} 50^{\prime} 00^{\prime \prime}$ S., long. $128^{\circ} 12^{\prime} 00^{\prime \prime}$ E.) ; 375 meters (205 fathoms); December 2, 1909 ; co. S.

One specimen (Cat. No. 41238 , U.S.N.M.).

Albatross station 5645; Buton Strait; North Island (NE.) bearing S. $10^{\circ} \mathrm{W}$., 2.96 kilometers (1.6 miles) distant (lat. $5^{\circ} 29^{\prime} 06^{\prime \prime}$ S., long. $122^{\circ} 36^{\prime} 06^{\prime \prime}$ E.) ; 377 meters (206 fathoms) ; December 16, 1909.

One specimen (Cat. No. 41237 , U.S.N.M.).

Description.-The two specimens are incomplete. In that from station 5629 the diameter of the disk is $5.5 \mathrm{~mm}$.; three arms are preserved for a fairly large part of their length, the fourth, which is detached, is preserved in part, and the fifth is broken off close to the base; the length of the arms must have been between $20 \mathrm{~mm}$. and $25 \mathrm{~mm}$. The specimen from station 5645 is smaller; the diameter of the disk does not exceed $4 \mathrm{~mm}$.; only two arms are preserved, and these are incomplete.

I shall describe the species with special reference to the specimen from station 5629, which is the larger and which is represented in figures $1-3$ on plate 17 .

The disk is rounded. The dorsal surface is covered by thin and transparent very small rounded plates, each of which bears a clubspine which is very broad at the base thence tapering rapidly to a small, cylindrical, rather short column which again broadens at its tip to bear a half dozen short conical, pointed, subequal and divergent spinules. All of the club-spines are of almost the same length, and their spinules also show very great regularity in their arrangement. The result is therefore that when the dorsal surface is seen from above the general appearance of these club-spines forcibly brings to mind the uniform aspect which they present in Ophiothrix stelligera. The club-spines of the central region of the disk are a little smaller and finer than the others. When they are viewed in profile there can be made out on their columns one or two small and more or less developed teeth. In the specimen from station 5645 these club-spines are more elongated, and they resemble small true spines; their terminal spinules are less numerous and less regular than in the first specimen, and they show on their cylindrical columns a 
few conical and pointed teeth which are more developed than in the other. The radial shields are almost completely hidden, and only a very small portion of their distal extremity can be seen.

The ventral surface of the disk in the interradial spaces is covered with club spines identical with those on the dorsal surface, but becoming smaller and smaller toward the mouth shields. The genital slits are large, elongated, and rather broad.

The mouth shields, which are of moderate size, are lozenge-shaped, almost as long as broad, with the proximal angle almost a right angle and bordered by two straight sides; the two distal borders come together over a very rounded angle. The adoral plates are rather elongated, two and a half times as long as broad, tapering slightly inwardly, though in contact in the median interradial line; they broaden a little outwardly and give off a narrow process which separates the mouth shields from the first side arm plate. The oral plates are triangular and high. The side mouth papillae, three in number, are subequal, conical, and pointed; the outermost is a little broader than the two others. The unpaired terminal papilla is a little larger than those on either side. The upper arm plates are small, triangular, broader than long, and widely separated, with an acute proximal angle and a convex distal border.

The first under arm plate is rather large, trapezoidal, with a broad proximal border passing over rounded angles into the two sides, which are convergent and which unite over similarly rounded angles to form the distal border, which is short and straight. The second and third plates are triangular, with an obtuse proximal angle and a very convex distal border. Beyond this the plates, which always remain very large, become pentagonal with an obtuse proximal angle bounded by two straight sides, two straight lateral borders notched by the tentacle scale, and a very convex distal border. They are separated by a narrow interval.

The side arm plates, which are moderately projecting, carry at the base of the arm seven rather large spines which are cylindrical with the tip rounded and provided with rather feebly developed denticulations. Their length increases progressively from the first ventral, which is shorter than the segment, to the antepenultimate dorsal, which is almost as long as three segments; the last spine is shorter than that preceding. The dorsal spines of each series come very close together in the dorsal median line of the arms, though without forming a continuous transverse series. The under and side arm plates show parallel transverse striations which are very marked, and which are less distinct on the upper arm plates.

The single tentacle scale is large, lanceolate, rather broad, and pointed, and its length equals about two-thirds that of the corre- 
sponding under arm plate; its surface is covered with asperities which are especially marked toward the tip, and which make it slightly spiniferous.

The color of the specimen in alcohol is yellowish white.

Affinities and distinctive features.-Ophiacantha severa seems to me to be closely related to $O$. serrata Lyman, but it is difficult to form an exact idea of the latter species from Lyman's description and figures. I requested Prof. F. Jeffrey Bell to compare the photographs of my ophiuran with the Challenger species $O$. serrata, as he had done in the case of $O$. longidens. The opinion of the learned naturalist of the British Museum is that the two species are different. The new species differs from $O$. serrata in its lozenge-shaped mouth shields, which are scarcely broader than long; in the large and strong tentacle scale which is furnished with rather strong asperities and in no way spiniform; in the armature of the dorsal surface of the disk which consists of elongated club-spines terminated by numerous spinules, and which may even become elongated to the point of resembling small true spines, while in $O$. serrata Lyman notes only "minute grains like stumps bearing a crown of blunt thorns"; and finally in the very large under arm plates, the surface of which shows very marked concentric striations, which, moreover, are found also on the other arm plates.

OPHIACANTHA VORAX Kohler.

Plate 15, figs. 4,5 .

Ophiacantha vorax KoeHLER ('96), p. 353, pl. 8, figs. 68, 69; ('99), p. 62, pl. 7, figs. 52-54.-H. I. Clark ('15), p. 208.

Ophiacantha anchilabra H. L. CLARK ('11), p. 205, fig. 95; ('15), p. 196.

Locality.-Albatross station 5606; Gulf of Tomini, Celebes; Dodepo Island (W.) bearing N. $3^{\circ}$ W., 20.01 kilometers (10.8 miles) distant (lat. $0^{\circ} 16^{\prime} 28^{\prime \prime}$ N., long. $121^{\circ} 33^{\prime} 30^{\prime \prime}$ E.) ; 1,525 meters (834 fathoms); November 17, 1909; gn. M.

One specimen (Cat. No. 41142 , U.S.N.M.).

Notes.-The specimen is in fairly good condition, and almost all the arms are preserved for their whole length; the diameter of the disk is $7 \mathrm{~mm}$., and the length of the arms is more than $45 \mathrm{~mm}$.

This individual is a little larger than those which served me as the type series upon which I established the species and which were collected by the Investigator off Cape Comorin in 1,908 meters $(1,043$ fathoms). It agrees well with these except for insignificant variations; for example, the tentacle scale, always very large and broad, is perhaps a little less pointed than in the Investigator specimen, and the arm spines are also somewhat less denticulated, and often smooth, especially the dorsal ones. 
I give here two photographs of the Albatross specimen, which show the characters of the species better than my somewhat schematic drawings.

Under the name of $O$. anchilabra H. L. Clark has described ('11, p. 104), an ophiuran from the Japanese seas at a depth of 1,679 meters (918 fathoms), which is very close to 0 . vorax; it differs from it only in its smooth arm spines and in the entirely hidden radial shields. I do not believe that this specific differentiation, based mainly on the condition of the arm spines, can be maintained. These are less strongly denticulated in the Albatross specimen than in those collected by the Investigator, and many of them are even entirely smooth. As for the extension of the granules over the whole surface of the radial shields, or only over the larger part of their surface, exclusive of the distal extremity, that is a mere case of individual variation of no specific importance.

Matsumoto ('17, p. 117) lists O. anchilabra from Japan without making any comment.

\section{OPHIOLIMNA PERFIDA (Kohler).}

Plate 9, figs. 7-9; plate 92 , fig. 6 .

Ophiacantha perfida Koehler ('04), p. 118, pl. 23, figs. 5, 6.-H. L. ClarK ('15), p. 204.

Ophiacantha lambda H. L. ClARK ('11), p. 231, fig. 108; ('15), p. 199.

Localities.-Albatross station 5119; Balayan Bay and Verde Island Passage; Sombrero Island bearing S. $80^{\circ}$ E., 35.03 kilometers (18.9 miles) distant (lat. $13^{\circ} 45^{\prime} 05^{\prime \prime} \mathrm{N}$., long. $\left.120^{\circ} 30^{\prime} 30^{\prime \prime} \mathrm{E}.\right)$; 721 meters (394 fathoms) ; January 19, 1908; gn. M., S.

Three specimens (Cat. No. 41185 , U.S.N.M.).

Albatross station 5219; between Marinduque and Luzon; Mompog Island (NE.) bearing N. $35^{\circ} 30^{\prime}$ W., 22.70 kilometers (12.25 miles) distant (lat. $13^{\circ} 21^{\prime} 00^{\prime \prime}$ N., long. $122^{\circ} 18^{\prime} 45^{\prime \prime}$ E.) ; 969 meters (530 fathoms); April 23, 1908; gn. M.

One specimen (Cat. No. 41187 , U.S.N.M.).

Albatross station 5444; East coast of Luzon, San Bernardino Strait to San Miguel Bay; Atalaya Point, Batag Island, bearing S. $65^{\circ}$ E., 9.45 kilometers (5.1 miles) distant (lat. $12^{\circ} 43^{\prime} 51^{\prime \prime} \mathrm{N}$., long. $124^{\circ} 58^{\prime} 50^{\prime \prime}$ E.) ; 563 meters (308 fathoms); June 3, 1909 ; gn. M.

Four specimens (Cat. Nos. 41375, E. 41, U.S.N.M.).

Albatross station 5445; east coast of Luzon, San Bernardino Strait to San Miguel Bay; Atalaya Point, Batag Island, bearing S. $56^{\circ}$ E., 9.82 kilometers (5.3 miles) distant (lat. $12^{\circ} 44^{\prime} 42^{\prime \prime} \mathrm{N}$., long. $124^{\circ} 59^{\prime} 50^{\prime \prime}$ E.) ; 700 meters (383 fathoms); June 3, 1909; gn. M., S.

One specimen (Cat. No. E. 42, U.S.N.M.). 
Albatross station 5447; east coast of Luzon, San Bernardino Strait to San Miguel Bay; San Miguel Point bearing S. $7^{\circ}$ W., 6.49 kilometers (3.5 miles) distant (lat. $13^{\circ} 28^{\prime} 00^{\prime \prime} \mathrm{N}$., long. $123^{\circ} 46^{\prime} 18^{\prime \prime} \mathrm{E}$.) ; 567 meters (310 fathoms) ; June 4, 1909; gn. M.

Two specimens (Cat. No. E. 44, U.S.N.M.).

Albatross station 5618; Molucca Passage; Mareh Island bearing S. $69^{\circ}$ E., 14.45 kilometers $\left(7.8\right.$ miles) distant (lat. $0^{\circ} 37^{\prime} 00^{\prime \prime} \mathrm{N}$., long. $127^{\circ} 15^{\prime} 00^{\prime \prime}$ E.) ; 763 meters (417 fathoms) ; November 27, 1909 ; gy. M.

Two specimens (Cat. No. E. 40. U.S.N.M.).

Albatross station 5619; Molucca Passage; Mareh Island (S.) bearing S. $78^{\circ} \mathrm{E}$., 12.97 kilometers (7 miles) distant (lat. $0^{\circ} 35^{\prime} 00^{\prime \prime} \mathrm{N}$., long. $127^{\circ} 14^{\prime} 40^{\prime \prime}$ E.) ; 796 meters (435 fathoms); November 27 , 1909 ; fne. gy. S., M.

Twenty specimens (Cat. Nos. 41374, E. 39, E. 43, U.S.N.M.).

Albatross station 5647; Buton Strait; North Island (S.) bearing S. $87^{\circ}$ E., 21.50 kilometers (11.6 miles) distant (lat. $5^{\circ} 34^{\prime} 00^{\prime \prime} \mathrm{S}$., long. $122^{\circ} 18^{\prime} 15^{\prime \prime}$ E.) ; 949 meters (519 fathoms) ; December 16, 1909 ; gn. M.

One specimen (Cat. No. 41186, U.S.N.M.).

Albatross station 5651; Gulf of Boni, Celebes; Buginkali Point bearing S. $67^{\circ}$ E., 38.92 kilometers (21 miles) distant (lat. $4^{\circ} 43^{\prime} 50^{\prime \prime}$ S., long. $121^{\circ} 23^{\prime} 24^{\prime \prime}$ E.) ; 1,280 meters (700 fathoms); December 17,1909 ; gn. M.

Two specimens (Cat. No. E. 38, U.S.N.M.).

Notes.-These specimens agree perfectly with those collected by the Siboga. The diameter of the disk varies between $10 \mathrm{~mm}$. and $14 \mathrm{~mm}$., and the arms are always very long; in the specimen from station 5618, which has a disk diameter of $12 \mathrm{~mm}$., the arms are 80 $\mathrm{mm}$. in length.

The granules of the dorsal surface of the disk are slightly rugose and are usually somewhat elongated, especially toward the periphery of the disk (pl. 92, fig. 6). The arm spines show certain variations, which do not appear to depend entirely on the size of the individuals. Generally when the diameter of the disk reaches or exceeds $12 \mathrm{~mm}$., the largest arm spines attain a length of two segments, and sometimes even of three; ordinarily the antepenultimate dorsal spine is the longest. But I have at hand specimens in which the disk is more than $12 \mathrm{~mm}$. in diameter, yet the longest arm spine does not exceed a segment and a half. At the base of the arms the spines are seven in number, the figure falling to six beyond the disk, and finally to five toward the middle of the arms. In the smallest specimens the number seven falls rapidly to six, and then to five.

I can not find any character by which 0 . lambda, described in 1911 by H. L. Clark from Japenese specimens, may be distinguished 
from 0 . perfida. In his description he compared his new species only with $O$. bairdi, from which it is obviously very different, and he makes no mention of $O$. perfida, to which it is extremely close. The only difference which can be found is in the number of arm spines. Doctor Clark states that there are five in a specimen with a disk diameter of $10 \mathrm{~mm}$., but as the number of these spines varies and as in specimens with a disk diameter of $10 \mathrm{~mm}$. the number five is acquired very rapidly it is not possible to base a specific separation upon this character alone. I believe, therefore, that $O$. lambda should be united with 0 . perfida.

The Siboga met with 0 . perfida between latitude $0^{\circ}-7^{\circ} \mathrm{S}$. and longitude $116^{\circ}-132^{\circ} \mathrm{E}$., at depths varying from 411 to 959 meters (225 to 525 fathoms). Doctor Clark's 0 . lambda was dredged off southern Japan in $32^{\circ} \mathrm{N}$. latitude, $132^{\circ} \mathrm{E}$. longitude, at a depth of 800 meters ( 437 fathoms).

In his catalogue of the recent ophiurans H. L. Clark did not recognize the genus Ophiolimna established by Verrill in 1899, the type of which is $O$. bairdi (Lyman). In revising the genera Ophioconis, Ophiochoeta, and Ophiolimna Matsumoto redefined the limits of the genus Ophiolimna and assigned to it, in addition to $O$. bairdi, the two species which I described in 1904 and in 1909 under the names of $O$. perfida and $O$. operculata, as well as three species previously placed in the old genus Ophioconis, O. antarctica Lyman, $O$. diastata, and $O$. papillata H. L. Clark. He adds a seventh species, O. lambda H. L. Clark, but, as I have just stated above, this last does not differ from $O$. perfida and falls into its synonymy.

There must also be added to the genus Ophiolimna the Antarctic species discovered by the Belgica which I described under the name of Ophiacantha polaris (Kohler, '01, p. 32, pl. 3, figs. 19-21).

I believe, like Matsumoto, that with the limitations ascribed to it by the Japanese naturalist, the genus Ophiolimna is a perfectly welldefined group; it has certainly the same value as many of Verrill's other genera separated out from the old genus Ophiacantha, such as Ophiopristis, Ophiotreta, Ophialcoea, Ophientrema, etc. There would be more reason to suppress these latter than the former.

In his memoir of 1917 Matsumoto maintains the genus Ophiolimna with the same characters and with the same species as in 1915 ('17, p. 101).

\footnotetext{
- In mentioning 0 . operculata $H$. L. Clark remarked that there is a lack of agreement relative to the date and the depth between the figures which I gave in my preliminary report in 1907 and those in my final memoir published in 1909. He believes that the latter are correct. The figures which I published in 1907 were, as he believes, Jater revised, and it is the information given in my memoir which is correct; the species really comes from the enormous depth of 5,869 meters $(3,209$ : fathoms). I may remark that II. I. Clark himself has made a slip of the pen in citing o. operculata. He has written 0 . opcrcularis $(' 15, \mathrm{pp}, 207,368)$, which is incorrect.
} 


\section{OPHIOGEMA, new genus.}

Description.-This genus is near the genus Ophiacantha. The dorsal surface of the disk is covered with little plates each bearing a rather stout pointed spine; the distal border of the upper arm plates is also armed with spines resembling those of the disk. Following the oral plate, between it and the first under arm plate, there is a supplementary plate which lies on half of the outer border of the adoral plate and carries the outer mouth papilla; this is very much smaller than the following. The under-arm plates are remarkably broadened and short at the commencement of the arms. In the last third of the arms the two first ventral spines show a tendency to become curved towards their tips in such a manner as to direct their points toward the disk, and at the same time they acquire stouter spinules on their concave side without, however, forming a true hook like that seen in Ophientrema leucostictum, Ophiotreta matura, etc.

The peristomial plates are very large and transversely oval; they recall those which Lyman has represented in Ophiolebes scorteus ('82, pl. 41, fig. 8), but their form is truly oval.

Type of the genus.-Ophiogema punctata, new species.

\section{OPHIOGEMA PUNCTATA, new species.}

Plate 29, figs. 7, 8, 9; plate 92, fig. 5 .

Localities.-Albatross station 5166; Sulu Archipelago, Tawi Tawi Group; Observation Island bearing N. $20^{\circ}$ W., 8.52 kilometers (4.6 miles) distant (lat. $4^{\circ} 56^{\prime} 10^{\prime \prime} \mathrm{N}$., long. $119^{\circ} 46^{\prime} 00^{\prime \prime}$ E.) ; 177 meterś (97 fathoms); February 24, 1908; co. S.

Numerous specimens (Cat. Nos. 40989, E. 219, U.S.N.M.).

Albatross station 5167; Sulu Archipelago, Tawi Tawi Group; Observation Island bearing N. $11^{\circ}$ W., 10.4 kilometers ( 5.6 miles) distant $\left(4^{\circ} 55^{\prime} 10^{\prime \prime} \mathrm{N}\right.$., long. $119^{\circ} 45^{\prime} 30^{\prime \prime}$ E. $)$; 201 meters (110 fathoms); February 24, 1908; Co.

Five specimens (Cat. No. 40990, U.S.N.M.).

Albatross station 5168; Sulu Archipelago, Tawi Tawi Group; Observation Island bearing N. $17^{\circ}$ W., 7.78 kilometers (4.2 miles) distant (lat. $4^{\circ} 56^{\prime} 30^{\prime \prime}$ N., long. $119^{\circ} 45^{\prime} 40^{\prime \prime}$ E.) ; 146 meters (80 fathoms) ; February 25, 1908.

Four specimens (Cat. No. 40991, U.S.N.M.).

Description.-The specimens are none of them large, and the diameter of the disk does not exceed $8 \mathrm{~mm}$. The arms are about 50 . $\mathrm{mm}$. long.

The disk is flattened, pentagonal, and more or less excavated in the interradial spaces. The dorsal surface is flat and uniformly 
covered with very small, thin, imbricated, subequal plates; many of these plates bear a small spine which appears to be very easily lost. These spines are elongated, slender and flattened, and they are terminated sometimes by a conical point, and sometimes by two or even three elongated and parallel points; their borders are sometimes smooth, and sometimes furnished with one or two rather strong teeth (pl. 92, fig. 5). They show rounded or oval perforations which are unequal and arranged in a very irregular manner. The radial shields are small, triangular, twice as long as broad, with a very sharp proximal angle; the two shields of each pair are separated from each other by an extremely broad space almost equaling the width of the arm.

In the interradial spaces the ventral surface of the disk is covered with small plates bearing spines which become more and more reduced towards the mouth shields. The genital slits are broad and very evident.

The mouth shields are of moderate dimensions, or even rather small; they are lozenge-shaped, and usually as long as broad with the four sides subequal. The two proximal sides are straight and come together in a rather open angle; the two other sides are gently concave and are united by a distal truncated angle which sometimes forms a small narrow and rounded lobe; the lateral angles are similarly rounded. The two distal edges are thickened and rather prominently raised, while the distal part of the shields which they delimit is more or less strongly depressed, and forms a little hollow. In some specimens the mouth shields, instead of being lozenge-shaped, are, rather, triangular, and their distal border forms a more or less produced lobe, but the surface of this lobe is always very depressed, and the sides are thickened and elevated. The adoral plates are large and broad, and they broaden progressively outward from the median interradial line; they give off outwardly a small process which separates the mouth shield from the first side arm plate. The oral plates are triangular and rather high; they are continued outwardly as far as the first under arm plate by a plate triangular in form and much elongated of which the base touches the first under arm plate and which carries the outermost mouth papilla. The mouth papillae are four on either side; the outermost papilla, which I have just mentioned, is small and short, the following is large and thick, lozenge-shaped, but much broadened at the base; it is inserted both on the oral plate and on the supplementary plate which follows it; the two others, conical in form, are rather narrow and not broadened at the base. The terminal unpaired papilla is conical and short.

The first upper arm plate is extremely short and very broad and bears on its distal edge a row of spines identical with those on the dorsal surface of the disk; the second is larger, trapezoidal, very 
much broader than long, with the proximal border very much shorter than the distal. The following plates are very large, triangular, a little broader than long, with an obtuse proximal angle, convex sides, and a very large distal border similarly convex. This distal border at first bears three or four spines identical with those on the dorsal surface of the disk, but the number of these spines rapidly diminishes, and they usually disappear for good on about the tenth segment. At this level the plates, which, up to now, were in contact, become separated by a narrow space.

The first under arm plate is rather small, broader than long, pentagonal, with a very obtuse proximal angle and a small distal border. The second, which is at least four times as broad as long, is already separated from the first; it shows a very obtuse proximal angle bordered by two gently concave sides, sharp lateral angles, and a very broad distal side slightly notched in the middle. The following plates, always rather broadly separated from each other, at first retain a form similar to that of the preceding, but the proximal angle disappears almost completely; the plates then become quadrangular, with an almost straight proximal border, a slightly concave distal border, and two very rounded sides which, passing over very rounded angles, unite to form the two long borders. Toward the seventh or eighth the plates become smaller, and the proximal side diminishes rapidly, being subsequently replaced by an obtuse angle; from then on the plates assume a pentagonal form with an obtuse proximal angle bounded by two straight sides, two straight lateral borders, and a very broad distal border, while at the same time the interval which separates them becomes somewhat greater. Little by little the width of the plates diminishes and correlatively their length increases, and they then become as long as broad, the interval which separates them increasing still more.

The side arm plates, which project only slightly, carry at the base of the arms seven slender, pointed, and finely echinulated spines; their length increases from the first ventral, which is shorter than the segment, to the antepenultimate dorsal, which equals two segments and a half; the last is a little shorter. These spines are only slightly divergent, remaining in general close to the plates which bear them. without, however, being appressed to them as in the genus Ophiolimna. The single large tentacle scale is broadened on the pores of the first pair, where it is almost as broad as long. It becomes a little narrower on the following segments, and, beyond the disk, it becomes progressively more and more narrow, and finally three times as long as broad with the tip rather pointed.

The specimens in alcohol are slightly pink. The dorsal surface of the disk shows numerous small, rounded brown spots near together. 
The arms bear annulations of a rather light brown separated by lighter and longer bands.

OPHIOTRETA EXIMIA (Kœhler).

Plate 8 , figs. 5,6 ; plate 93 , fig. 7 .

Ophiacantha eximia KaEHLER ('04), p. 116, pl. 21, figs. 3-5.

Ophiotreta eximia H. I. ClaRK ('15), p. 216.

Localities.-Albatross station 5423; Cagayan Island (S.) bearing S. $11^{\circ}$ E., 8.49 kilometers (4.8 miles) distant (lat. $9^{\circ} 38^{\prime} 30^{\prime \prime} \mathrm{N}$., long. $121^{\circ} 11^{\prime} 00^{\prime \prime}$ E.) ; 929 meters (508 fathoms) ; March 31, 1909; gy. M., co. S.

Two specimens (Cat. No. E. 147, U.S.N.M.).

Albatross station 5605; Gulf of Tomini, Celebes; Dodepo Island (W.) bearing N. $14^{\circ}$ W., 10.9 kilometers (5.9 miles) distant (lat. $0^{\circ} 21^{\prime} 33^{\prime \prime} \mathrm{N}$., long. $121^{\circ} 34^{\prime} 10^{\prime \prime}$ E.) ; 1,183 meters (647 fathoms); November 16, 1909.

One specimen (Cat. No. E. 148, U.S.N.M.).

Albatross station 5606; Gulf of Tomini, Celebes; Dodepo Island (W.) bearing N. $3^{\circ}$ W., 20.01 kilometers (10.8 miles) distant (lat. $0^{\circ} 16^{\prime} 28^{\prime \prime}$ N., long. $121^{\circ} 33^{\prime} 30^{\prime \prime}$ E.) ; 1,525 meters (834 fathoms); November 17, 1909 ; gn. M.

Two specimens (Cat. No. E. 149, U.S.N.M.).

Albatross station 5618; Molucca Passage; Mareh Island bearing S. $69^{\circ}$ E., 14.45 kilometers $\left(7.8\right.$ miles) distant (lat. $0^{\circ} 37^{\prime} 00^{\prime \prime} \mathrm{N}$., long. $127^{\circ} 15^{\prime} 00^{\prime \prime}$ E.) ; 763 meters (417 fathoms); November 27, 1909.

One specimen (Cat. No. 41100 , U.S.N.M.).

Albatross station 5619; Molucca Passage; Mareh Island (S.) bearing S. $78^{\circ} \mathrm{E}$., 12.97 kilometers (7 miles) distant (lat. $0^{\circ} 35^{\prime} 00^{\prime \prime} \mathrm{N}$., long. $127^{\circ} 14^{\prime} 40^{\prime \prime}$ E.) ; 796 meters (435 fathoms) ; November 27, 1909 ; fne. gy. S., M.

One specimen (Cat. No. 41099, U.S.N.M.).

Albatross station 5648; Buton Strait; North Island (S.) bearing N. $87^{\circ}$ E., 18.90 kilometers (10.2 miles) distant (lat. $5^{\circ} 35^{\prime} 00^{\prime \prime} \mathrm{S}$., long. $122^{\circ} 20^{\prime} 00^{\prime \prime}$ E.) ; 1,022 meters (559 fathoms) ; December 16 , 1909 ; gn. M.

Six specimens (Cat. Nos. E. 57, E. 150, U.S.N.M.).

Notes.-In the specimens from station 5648 the diameter of the disk reaches from $17 \mathrm{~mm}$. to $18 \mathrm{~mm}$., and the arms are more than 120 $\mathrm{mm}$. long.

I described this species from specimens discovered by the Siboga among the Sunda Islands at depths varying between 724 and 1,788 meters (396 to 978 fathoms). The individuals collected by the 
Albatross agree well with the Siboga specimens, and they also show in the covering of the dorsal surface of the disk variations similar to those which I have already had occasion to notice. There may be club spines terminating in many unequal spinules, or long and slender true spines either with long spinules along their entire length or simply with very much shorter teeth. These spines are shown especially well on the two specimens from station 5423. There occur also forms intermediate between the club spines and the true spines, as may be seen on the photographs which I give in figure 7 on plate 93 . On the two specimens from station 5423 the dorsal surface bears among the granules very fine and short true spines having a length of about $0.5 \mathrm{~mm}$., which may occur as far as the periphery of the disk. The surface of the upper arm plates is always rugose, and the asperities retain more or less strongly the particles of mud which adhere to them. These asperities may be localized chiefly on the distal edge of the plates, there forming a small and very evident border, which, however, always remains formed of simple rugosities.

I give here a photograph of the large specimen from station 5648 (pl. 8, figs. 5, 6).

Ophiotreta eximia, it seems to me, may be assigned to Verrill's genus Ophiotreta, together with $O$. dilecta (Kohler), O. lineolata (Lyman), and $O$. sertata (Lyman), and the species which I will mention below, 0 . gratiosa, 0 . matura, 0 . spatulifera, and 0 . valenciennesi. I recognize the fact that the genus Ophiotreta has no great value and is scarcely more than a subgenus of Ophiacantha. But this division of Ophiacantha proposed by Verrill is nevertheless convenient. H. L. Clark has maintained it in his catalogue ('15, p. 216), but Matsumoto, in 1917, did not distinguish it from the genus Ophiacantha.

I should state that I adopt the genus Ophiotreta with the characters and with the limitations given to it by Verrill and not in. H. L. Clark's sense. The latter assigns to it O. mixta (Lyman) and O. littoralis (Kœhler), which should be placed in Matsumoto's genus Ophiurochocia (see on this subject Matsumoto, '17, pp. $316,317)$.

\section{OPHIOTRETA GRATIOSA (Kohler).}

Plate 11, figs. 1-7; plate 95, fig. 1.

Ophiacantha gratiosa KoehleR ('96), p. 346, pl. 8, figs. 60, 61; ('99), p. 56, pl. 8, fig. 68; pl. 9, figs. 71, 72.-H. L. Clark ('15), p. 199.

Ophiacantha inutilis KGeHLER ('04), p. 111, pl. 21, figs. 6-8.-H. L. CLARK ('11), p. 208; ('15), p. 199.-MAтsumoto ('17), p. 117.

Localities.-Albatross station 5116; Balayan Bay and Verde Island Passage; Sombrero Island bearing N. $69^{\circ}$ E., 4.63 kilometeris 
(2.5 miles) distant (lat. $13^{\circ} 41^{\prime} 00^{\prime \prime}$ N., long. $120^{\circ} 47^{\prime} 05^{\prime \prime}$ E.) ; 365 meters (200 fathoms); January 20, 1908.

Two specimens (Cat. Nos. E. 234, E. 297, U.S.N.M.)

Albatross station 5123; east coast of Mindoro; Malabrigo Light bearing $\mathrm{N} .44^{\circ}$ W., 60.23 kilometers (32.5 miles) distant (lat. $13^{\circ}$ $12^{\prime} 45^{\prime \prime}$ N., long. $121^{\circ} 38^{\prime} 45^{\prime \prime}$ E.) ; 517 meters (283 fathoms) ; February 2,1908 ; gn. $\mathbf{M}$.

Twenty-two specimens (Cat. Nos. E. 232, E. 293, U.S.N.M.).

Albatross station 5124; east coast of Mindoro; Point Origon (N.) bearing S. $56^{\circ}$ E., 38.45 kilometers $\left(20.75\right.$ miles) distant (lat. $12^{\circ}$ $52^{\prime} 00^{\prime \prime}$ N., long. $121^{\circ} 48^{\prime} 30^{\prime \prime}$ E.) ; 514 meters (281 fathoms); February 2, 1908; sft. gn. M.

Two specimens.

Albatross station 5194; off northern Cebu; Chocolate Island bearing N. $66^{\circ} \mathrm{W} ., 14.83$ kilometers (8 miles) distant (lat. $11^{\circ} 15^{\prime} 30^{\prime \prime} \mathrm{N}$., long. $124^{\circ} 11^{\prime} 00^{\prime \prime}$ E.) ; 271 meters (148 fathoms); April 3, 1908; gn. M.

Twenty-two specimens (Cat. No. E. 229, U.S.N.M.).

Albatross station 5197; in the vicinity of western Bohol; Baliscasag Island bearing S. 40.77 kilometers (22 miles) distant (lat. $9^{\circ}$ $52^{\prime} 30^{\prime \prime} \mathrm{N}$., long. $123^{\circ} 40^{\prime} 45^{\prime \prime}$ E.) ; 318 meters (174 fathoms); April 9, 1908; gn. M.

One specimen (Cat. No. 40973, U.S.N.M.).

Albatross station 5201; Sogod Bay, southern Leyte; Limasaua Island (E.) bearing S. $1^{\circ}$ E., 27.43 kilometers (14.8 miles) distant (lat. $10^{\circ} 10^{\prime} 00^{\prime \prime}$ N., long. $125^{\circ} 04^{\prime} 15^{\prime \prime}$ E.) ; 1,013 meters (554 fathoms); April 10, 1908; gy. S., M.

One specimen (Cat. No. E. 294, U.S.N.M.).

Albatross station 5219; between Marinduque and Luzon; Mompog Island (NE.) bearing N. $35^{\circ} 30^{\prime}$ W., 22.70 kilometers (12.25 miles) distant (lat. $13^{\circ} 21^{\prime} 00^{\prime \prime}$ N., long. $122^{\circ} 18^{\prime} 45^{\prime \prime}$ E.) ; 969 meters (530 fathoms); April 23, 1908; gn. M.

Two specimens (Cat. No. E. 241, U.S.N.M.).

Albatross station 5300; China Sea, in the vicinity of southern Luzon; (lat. $20^{\circ} 31^{\prime} 00^{\prime \prime}$ N., long. $115^{\circ} 49^{\prime} 00^{\prime \prime}$ E.) ; 484 meters (265 fathoms); August 8, 1908; gy. M., S.

One specimen (Cat. No. E. 235, U.S.N.M.).

Albatross station 5373; Marinduque Island and vicinity; Tayabas Light (outer) bearing N. $20^{\circ}$ E., 27.80 kilometers (15 miles) distant (lat. $13^{\circ} 40^{\prime} 00^{\prime \prime}$ N., long. $121^{\circ} 31^{\prime} 10^{\prime \prime}$ E.) ; 617 meters (338 fathoms); March 2, 1909; sft. M.

Four specimens (Cat. Nos. 40959, E. 291, U.S.N.M.).

Albatross station 5402; between Leyte and Cebu; Capitancillo Island Light bearing S. $37^{\circ}$ W., 29.84 kilometers (16.1 miles) dis- 
tant (lat. $11^{\circ} 11^{\prime} 45^{\prime \prime}$ N., long. $124^{\circ} 15^{\prime} 45^{\prime \prime}$ E.) ; 344 meters (188 fathoms); March 16, 1909; gn. M.

Numerous specimens (Cat. Nos. 40974, E. 242, E. 289, U.S.N.M.). Albatross station 5404; Dupon Bay (Leyte) and vicinity; Ponson Island $\left(\mathrm{N}\right.$.) bearing S. $79^{\circ}$ E., 12.60 kilometers (6.8 miles) distant (lat. $10^{\circ} 50^{\prime} 00^{\prime \prime} \mathrm{N}$., long. $124^{\circ} 26^{\prime} 18^{\prime \prime}$ E.) ; 347 meters (190 fathoms); March 17, 1909; M.

Fourteen specimens (Cat. No. E. 231, U.S.N.M.).

Albatross station 5406; Dupon Bay (Leyte) and vicinity; Ponson Island (N.) bearing S. $88^{\circ}$ E., 18.90 kilometers (10.2 miles) distant (lat. $10^{\circ} 49^{\prime} 03^{\prime \prime} \mathrm{N}$., long. $124^{\circ} 22^{\prime} 30^{\prime \prime}$ E.) ; 545 meters (298 fathoms); March 17, 1909; M.

One specimen (Cat. No. E. 292, U.S.N.M.).

Albatross station 5409; between Cebu and Leyte; Capitancillo Light bearing N. $19^{\circ}$ W., 40.77 kilometers (22 miles) distant (lat. $10^{\circ} 38^{\prime} 00^{\prime \prime} \mathrm{N}$., long. $124^{\circ} 13^{\prime} 08^{\prime \prime}$ E.) ; 346 meters (189 fäthoms); March 18, 1909; gn. M.

One specimen (Cat. No. 40961, U.S.N.M.).

Albatross station 5410; between Cebu and Leyte; Bagacay Point Light bearing S. $37^{\circ}$ W., 13.34 kilometers (7.2 miles) distant (lat. $10^{\circ} 28^{\prime} 45^{\prime \prime}$ N., long. $124^{\circ} 05^{\prime} 30^{\prime \prime}$ E.) ; 704 meters (385 fathoms); March 18, 1909; gn. M.

Ten specimens (Cat. Nos. E. 237, E. 240, U.S.N.M.).

Albatross station 5420; between Cebu and Bohol; Cruz Point (Bohol) bearing S. $20^{\circ}$ E., 11.1 kilometers (6 miles) distant (lat. $9^{\circ} 49^{\prime} 35^{\prime \prime}$ N., long. $123^{\circ} 45^{\prime} 00^{\prime \prime}$ E.) ; 231 meters (127 fathoms); March 25, 1909.

One specimen (Cat. No. E. 296, U.S.N.M.).

Albatross station 5423; Joló Sea; Cagayan Island (S.) bearing S. $11^{\circ}$ E., 8.89 kilometers ( 4.8 miles) distant (lat. $9^{\circ} 38^{\prime} 30^{\prime \prime} \mathrm{N}$., long. $121^{\circ} 11^{\prime} 00^{\prime \prime}$ E.) ; 929 meters (508 fathoms) ; March 31, 1909; gy. M., co. S.

Two specimens (Cat. No. E. 295, U.S.N.M.).

Albatross station 5445 ; east coast of Luzon; San Bernardino Strait to San Miguel Bay; Atalaya Point, Batag Island, bearing S. $56^{\circ}$ E., 9.82 kilometers (5.3 miles) distant (lat. $12^{\circ} 44^{\prime} 42^{\prime \prime} \mathrm{N}$., long. $124^{\circ}$ $59^{\prime} 50^{\prime \prime}$ E.) ; 700 meters (393 fathoms) ; June 3,1909 ; gn. M., S.

One specimen (Cat. No. E. 284, U.S.N.M.).

Albatross station 5522; northern Mindanao and vicinity; Point Tagolo Light bearing S. $39^{\circ}$ W., 11.1 kilometers (6 miles) distant (lat. $8^{\circ} 49^{\prime} 00^{\prime \prime}$ N., long. $123^{\circ} 26^{\prime} 30^{\prime \prime}$ E.) ; 421 meters (230 fathoms) ; August 10, 1909; Glob.

Six specimens (Cat. No. E. 230, U.S.N.M.).

Albatross station 5527; between Siquijor and Bohol Islands; Balicasag Island (C.) bearing N. $14^{\circ}$ W., 15 kilometers (8.2 miles) 
distant (lat. $9^{\circ} 22^{\prime} 30^{\prime \prime}$ N., long. $123^{\circ} 42^{\prime} 40^{\prime \prime}$ E.) ; 717 meters (392 fathoms); August 11, 1909; glob. Oz.

Three specimens (Cat. No. E. 290, U.S.N.M.).

Albatross station 5529; between Siquijor and Bohol Islands; Balicasag Island (C.) bearing N. $11^{\circ}$ E., 12.59 kilometers (6.9 miles) distant (lat. $9^{\circ} 23^{\prime} 45^{\prime \prime}$ N., long. $123^{\circ} 39^{\prime} 30^{\prime \prime}$ E.) ; 806 meters (441 fathoms); August 11, 1909; gy. M., Glob.

Three specimens (Cat. Nos. E. 233, E. 285, U.S.N.M.).

Albatross station 5536; between Negros and Siquijor; Apo Island (C.) bearing S. $26^{\circ} \mathrm{W}, 21.87$ kilometers (11.8 miles) distant (lat. $9^{\circ}$ $15^{\prime} 45^{\prime \prime} \mathrm{N}$., long. $123^{\circ} 22^{\prime} 00^{\prime \prime}$ E.) ; 510 meters (279 fathoms); August 19, 1909; gn. M.

Seven specimens (Cat. Nos. 40960, E. 286, U.S.N.M.).

Albatross station 5541; Tagolo Light bearing S. $65^{\circ}$ W., 23.54 kilometers (12.7 miles) distant (lat. $8^{\circ} 49^{\prime} 38^{\prime \prime} \mathrm{N}$., long. $123^{\circ} 34^{\prime}$ $30^{\prime \prime}$ E.) ; 400 meters (219 fathoms) ; August 20, 1909; fne. S., brk. Sh.

One specimen (Cat. No. E. 243, U.S.N.M.).

Albatross station 5622; between Gillolo and Makyan Islands; Makyan Island (NE.) bearing N. 66 ${ }^{\circ} \mathrm{W}$.; 503 meters (275 fathoms); November 29, 1909 ; gy. M.

One specimen (Cat. No. E. 238, U.S.N.M.).

Albatross station 5623; between Gillolo and Makyan Islands; Makyan Island (S.) bearing S. $88^{\circ} \mathrm{W} ., 13.90$ kilometers (7.5 miles) distant (lat. $0^{\circ} 16^{\prime} 30^{\prime \prime} \mathrm{N}$., long. $127^{\circ} 30^{\prime} 00^{\prime \prime}$ E.) ; 497 meters (272 fathoms); November 29, 1909; fne. S., M.

Two specimens (Cat. Nos. 40975 , E. 239 , U.S.N.M.).

Albatross station 5624; between Gillolo and Makyan Islands; Makyan Island (S.) bearing N. $67^{\circ}$ W., 16.49 kilometers ( 8.9 miles) distant (lat. $0^{\circ} 12^{\prime} 15^{\prime \prime} \mathrm{N}$., long. $127^{\circ} 29^{\prime} 30^{\prime \prime}$ E.) ; 527 meters (288 fathoms) ; November 29, 1909.

One specimen (Cat. No. E. 287, U.S.N.M.).

Albatross station 5626 ; between Gillolo and Kayoa Islands; Kayoa Island (SE.) bearing S. $5^{\circ}$ W., 12.42 kilometers $(6.7$ miles) distant (lat. $0^{\circ} 07^{\prime} 30^{\prime \prime}$ N., long. $127^{\circ} 29^{\prime} 00^{\prime \prime}$ E.) ; 485 meters (265 fathoms) ; November 29, 1909 ; gy. M., fne. S.

Two specimens (Cat. Nos. E. 236, E. 288, U.S.N.M.).

Notes.-After describing 0 . inutilis on the basis of four specimens collected by the Siboga (Kœhler '05, p. 199), I wrote in the discussion of the affinities of this species that it was very close to 0 . gratiosa, and that I had even hesitated to separate them. The characters upon which I had relied to distinguish these two species were the form of the mouth shields, the development of the small spines which ornament the distal border of the upper arm plates, and the contiguity of the upper and under arm plates at the base of the 
arms in 0 . inutilis. In mentioning this latter species in $1911, \mathrm{H} . \mathrm{L}$. Clark added that the identity which I had suspected with 0 . gratiosa appeared to him probable, but that he did not dare to affirm it ('11, p. 208).

The study of the very fine series collected by the Albatross at a number of different stations has enabled me to determine a number of variations, affecting the form of the mouth shields, the condition of the under arm plates, which are sometimes in contact for a certain distance along the arms, and sometimes separated from the arm bases outward by a more or less well-marked interval, and the development of the tentacle scales and the covering of the disk. The variations which I have observed have convinced me that a specific differentiation can not be based on these characters, and that it is not possible to maintain $O$. inutilis, which thus becomes from now on a synonym of 0 . gratiosa.

Let us review rapidly the variations which may be observed.

The mouth shields may be very large, almost as long as broad, as in the specimen upon which I established 0 . gratiosa, and as I find them in the specimen from station 5300 (pl. 11, fig. 7), which shows a form of mouth shield identical with that which I figured in my drawing of 1896 ('96, pl. 8, fig. 61). These shields may be a little smaller and more elongated, while still remaining of considerable size (specimen from station 5623, pl. 11, fig. 5) ; when their length diminishes while their width remains the same these shields take the form reproduced in figure 3 (station 5622), the proximal angle then becoming very much more obtuse, and may even be replaced by a very convex border. If the length still further diminishes, the mouth shields become very small, twice as broad as long, with the angles usually well marked; this is the condition which $I$ find in a large number of specimens from station 5402 (pl. 11, fig. 4).

The upper arm plates may be in contact on many segments at the base of the arms (pl. 11, fig. 1, station 5410) or they may be separated from the base outward (fig. 6, station 5626); in the first case the plates are usually very much larger than in the second. The spines which occur on the distal border are sometimes five or six in number, sometimes reduced to two or three only, with considerable variation in their thickness and in their length; these spines are rather easily lost.

The tentacle scales may be large and broad (figs. 3,5 ) or they may be thin and narrow (figs. 4,7 ); there are sometimes two scales on the tentacular pores of the three first pairs, sometimes either one or two, alternately or irregularly.

The dorsal surface of the disk is covered with granules, which are sometimes very short (fig. 1), but which may become very much 
elongated and worthy of the name of spines. These spines are sometimes thick and strong, rather well separated from each other (fig. 2), or they may be slender, delicate, and closely placed (fig. 6), interspersed or not with granules. On the photographs which I give (pl. 95 , fig. 1) all the intermediate forms between the granules and the true spines may be traced.

In view of these variations.I have felt justified in uniting 0. grati$o s a$ and $O$. inutilis, between which I find all possible types of intergrades.

On account of the arrangement of the mouth papillae, O. gratiosa, like the following species, should be placed in Verrill's genus Ophiotreta.

Ophiotreta gratiosa was discovered by the Investigator among the Laccadive and Andaman Islands and in the Bay of Bengal at depths between 352 and 263 meters (193 and 144 fathoms). The Siboga dredged it at three stations among the Sunda Islands between 238 and 397 meters ( 130 to 218 fathoms). H. L. Clark has reported it from the Japanese seas in from 80 to 128 meters ( 44 to 70 fathoms).

\section{OPHIOTRETA MATURA (Kohler).}

Plate 12 , figs. $1-6$; plate 13 , figs. $1-5$; plate 14 , figs. $1-5$; plate 15 , figs. $1-3$; plate 95, fig. 2.

Ophiacantha matura KoEHLER ('04), p. 112, pl. 23, figs. 2-4.-H. L. CLARK ('15), p. 207.

Localities.-Albatross station 5349; Palawan Passage; Point Tabonan bearing N. $85^{\circ}$ E., 83.77 kilometers (45.2 miles) distant (lat. $10^{\circ} 54^{\prime} 00^{\prime \prime}$ N., long. $118^{\circ} 26^{\prime} 20^{\prime \prime}$ E.) ; 1,372 meters (750 fathoms) ; December 27, 1908; co. S.

One specimen (Cat. No. E. 179, U.S.N.M.).

Albatross station 5359; Joló Sea (lat. $8^{\circ} 12^{\prime} 45^{\prime \prime}$ N., long. $120^{\circ} 37^{\prime}$ $15^{\prime \prime}$ E.) ; 4,161 meters (2,275 fathoms) ; January 9, 1909.

Four specimens (Cat. Nos. E. 183, E. 196, U.S.N.M.).

Albatross station 5421; between Panay and Guimaras; Lusaran Point Light bearing S. $27^{\circ}$ E., 9.26 kilometers (5 miles) distant (lat. $10^{\circ} 33^{\prime} 30^{\prime \prime}$ N., long. $122^{\circ} 26^{\prime} 00^{\prime \prime}$ E.) ; 251 meters (137 fathoms); March 30, 1909.

One specimen (Cat. No. E. 182, U.S.N.M.).

Albatross station 5424; Joló Sea; Cagayan Island (S.) bearing S. $11^{\circ}$ W., 6.30 kilometers (3.4 miles) distant (lat. $9^{\circ} 37^{\prime} 05^{\prime \prime} \mathrm{N}$., long. $121^{\circ} 12^{\prime} 37^{\prime \prime}$ E.) ; 622 meters (340 fathoms) ; March 31, 1909; co. S.

Three specimens (Cat. No. E. 201, U.S.N.M.).

Albatross station 5425; Joló Sea; Cagayan Island (S.) bearing S. $14^{\circ}$ E., 7.41 kilometers ( 4 miles) distant (lat. $9^{\circ} 37^{\prime} 45^{\prime \prime}$ N., long. 
$121^{\circ} 11^{\prime} 00^{\prime \prime}$ E.) ; 905 meters (495 fathoms) ; March 31, 1909; gy. M., co. S.

Two specimens (Cat. Nos. E. 194, E. 198, U.S.N.M.).

Albatross station 5444; east coast of Luzon, San Bernardino Strait to San Miguel Bay; Atalaya Point, Batag Island, bearing S. $65^{\circ}$ E., 9.45 kilometers (5.1 miles) distant (lat. $12^{\circ} 43^{\prime} 51^{\prime \prime} \mathrm{N}$., long. $124^{\circ} 58^{\prime}$ $50^{\prime \prime}$ E.) ; 563 meters (308 fathoms) ; June 3, 1909 ; gn. M.

One specimen.

Albatross station 5450; east coast of Luzon, San Bernardino Strait to San Miguel Bay; East Point (Batan Island) bearing S. $36^{\circ}$ E., 17.05 kilometers (9.2 miles) distant (lat. $13^{\circ} 23^{\prime} 15^{\prime \prime} \mathrm{N}$., long. $124^{\circ} 00^{\prime} 30^{\prime \prime}$ E.) ; 746 meters (408 fathoms); June 3, 1909 ; gn. M., Co.

Several specimens.

Albatross station 5359; Joló Sea (lat. $8^{\circ} 12^{\prime} 45^{\prime \prime}$ N., long. $120^{\circ}$ $37^{\prime} 15^{\prime \prime}$ E.) ; 4,160 meters (2,275 fathoms); January 9, 1909.

One specimen (Cat. No. 41148, U.S.N.M.).

Albatross station 5467; east coast of Luzon, San Bernardino Strait to San Miguel Bay; Atulayan Island (S) bearing S. $79^{\circ}$ W., 4.63 kilometers (2.5 miles) distant (lat. $13^{\circ} 35^{\prime} 27^{\prime \prime} \mathrm{N}$., long. $123^{\circ} 37^{\prime}$ $18^{\prime \prime}$ E.) ; 878 meters (480 fathoms) ; June 18, 1909; gy. M. (m. b.).

One specimen (Cat. No. E. 200, U.S.N.M.).

Albatross station 5488; between Leyte and Mindanao; San Ricardo Point (Panaon Island) bearing S. 59 $9^{\circ}$ E., 16.68 kilometers (9 miles) distant (lat. $10^{\circ} 00^{\prime} 00^{\prime \prime}$ N., long. $125^{\circ} 06^{\prime} 45^{\prime \prime}$ E.) ; 1,412 meters (772 fathoms); July 31, 1909; gn. M.

Numerous specimens.

Albatross station 5492; between Leyte and Mindanao; Diuata Point (W.) bearing S. $45^{\circ}$ W., 28.17 kilometers (15.2 miles) distant (lat. $9^{\circ} 12^{\prime} 45^{\prime \prime}$ N., long. $125^{\circ} 20^{\prime} 00^{\prime \prime}$ E.) ; 1,344 meters (735 fathoms); August 1, 1909; gy. M.

One specimen (Cat. No. E. 197, U.S.N.M.).

Albatross station 5499; northern Mindanao and vicinity; Macabalan Point Light (Mindanao) bearing S. $20^{\circ}$ E., 21.50 kilometers (11.6 miles) distant (lat. $8^{\circ} 41^{\prime} 30^{\prime \prime} \mathrm{N}$., long. $124^{\circ} 35^{\prime} 40^{\prime \prime}$ E.); 1,013 meters (554 fathoms) ; August 4, 1909 ; gn. M., fne. S.

One specimen (Cat. No. E. 199, U.S.N.M.).

Albatross station 5501; northern Mindanao and vicinity; Macabalan Point Light (Mindanao) bearing S. $35^{\circ}$ E., 15.19 kilometers (8.2 miles) distant (lat. $8^{\circ} 37^{\prime} 37^{\prime \prime}$ N., long. $124^{\circ} 35^{\prime} 00^{\prime \prime}$ E.) ; 391 meters (214 fathoms) ; August 4, 1909; fne. S., gy. M.

Three specimens (Cat. No. E. 178, U.S.N.M.).

Albatross station 5505; northern Mindanao and vicinity; Macabalan Point Light (Mindanao) bearing S. $31^{\circ}$ E., 14.27 kilometers 
(7.7 miles) distant (lat. $8^{\circ} 37^{\prime} 15^{\prime \prime}$ N., long. $124^{\circ} 36^{\prime} 00^{\prime \prime}$ E.) ; 402 meters (220 fathoms); August 5, 1909.

Two specimens (Cat. No. E. 176, U.S.N.M.).

Albatross station 5506; northern Mindanao and vicinity; Macabalan Point Light (Mindanao) bearing S. 41 ${ }^{\circ}$ E., 22.61 kilometers (12.2 miles) distant (lat. $8^{\circ} 40^{\prime} 00^{\prime \prime} \mathrm{N}$., long. $124^{\circ} 31^{\prime} 45^{\prime \prime}$ E.) ; 479 meters (262 fathoms); August 4, 1909; gn. M.

One specimen (Cat. No. E. 180, U.S.N.M.).

Albatross station 5511; northern Mindanao and vicinity; Camp Overton Light bearing S. $80^{\circ}$ E., 28.35 kilometers (15.3 miles) distant (lat. $8^{\circ} 15^{\prime} 20^{\prime \prime} \mathrm{N}$., long. $123^{\circ} 57^{\prime} 00^{\prime \prime}$ E.) ; 750 meters (410 fathoms); August 7, 1909 ; gy. M., S.

Two specimens (Cat. No. 41153 , U.S.N.M.).

Albatross station 5512; northern Mindanao and vicinity; Camp Overton Light bearing S. $76^{\circ}$ E., 25.94 kilometers (14 miles) distant (lat. $8^{\circ} 16^{\prime} 02^{\prime \prime}$ N., long. $123^{\circ} 58^{\prime} 26^{\prime \prime}$ E.) ; 814 meters (445 fathoms) ; August 7, 1909; gy. M., fne. S.

Two specimens (Cat. No. E. 177, U.S.N.M.).

Albatross station 5515; northern Mindanao and vicinity; Camp Overton Light bearing S. $26^{\circ}$ E., 45.59 kilometers (24.6 miles) distant (lat. $8^{\circ} 34^{\prime} 48^{\prime \prime}$ N., long. $124^{\circ} 01^{\prime} 24^{\prime \prime}$ E.) ; August 8, 1909.

Several specimens.

Albatross station 5521; northern Mindanao and vicinity; Point Tagolo Light bearing S. $11^{\circ}$ E., 5.56 kilometers (3 miles) distant (lat. $8^{\circ} 47^{\prime} 00^{\prime \prime}$ N., long. $123^{\circ} 22^{\prime} 30^{\prime \prime}$ E.) ; 404 meters (221. fathoms); August 10, 1909; fne. S.

One specimen.

Albatross station 5526; between Siquijor and Bohol Islands; Balicasag Island (C.) bearing N. $15^{\circ}$ W., 33.43 kilometers (18.4 miles) distant (lat. $9^{\circ} 12^{\prime} 45^{\prime \prime} \mathrm{N}$., long. $123^{\circ} 45^{\prime} 30^{\prime \prime}$ E.) ; 1,472 meters (805 fathoms); August 11, 1909 ; gn. M., Glob.

One specimen (Cat. No. E. 195, U.S.N.M.).

Albatross station 5538; between Negros and Siquijor; Apo Island (C.) bearing S. $64^{\circ} \mathrm{W}$., 13.53 kilometers (7.3 miles) distant (lat. $9^{\circ} 08^{\prime} 15^{\prime \prime}$ N., long. $123^{\circ} 23^{\prime} 20^{\prime \prime}$ E.) ; 468 meters (256 fathoms); August 19, 1909; gn. M., S.

One specimen (Cat. No. E. 202, U.S.N.M.).

Albatross station 5617; Dodinga Bay, Gillolo Island; Ternate Island (SE.) bearing S. $45^{\circ}$ W., 12.97 kilometers (7 miles) distant (lat. $0^{\circ} 49^{\prime} 30^{\prime \prime}$ N., long. $127^{\circ} 25^{\prime} 30^{\prime \prime}$ E.) ; 239 meters (131 fathoms) ; November 27, 1909.

Several specimens.

Albatross station 5618; Molucca Passage; Mareh Island bearing S. $69^{\circ}$ E., 14.45 kilometers $\left(7.8\right.$ miles) distant (lat. $0^{\circ} 37^{\prime} 00^{\prime \prime} \mathrm{N}$., 
long. $127^{\circ} 15^{\prime} 00^{\prime \prime}$ E.) ; 763 meters (417 fathoms); November 27 , 1909; gy. M.

Five specimens.

Albatross station 5648; Buton Strait; North Island (S.) bearing N. $87^{\circ}$ E., 18.90 kilometers (10.2) miles) distant (lat. $5^{\circ} 35^{\prime} 00^{\prime \prime}$ S., long. $122^{\circ} 20^{\prime} 00^{\prime \prime}$ E.) ; 1,022 meters (559 fathoms); December 16, 1909 ; gn. M.

One specimen (Cat. No. E.181, U.S.N.M.).

Notes.- On account of the arrangement of the mouth papillae this species appears to me to find its place rather in the subgenus $O$ phiotreta Verrill than in the group Ophiectodia, to which I had at first assigned it.

The numerous series of specimens collected by the Albatross show that 0 . matura is subject to very considerable variation, and exhibit characters which at first sight seem to separate them widely from the type which I described on the basis of two specimens collected by the Siboga in latitude $5^{\circ} \mathrm{S}$. and longitude $132^{\circ} \mathrm{E}$., in 797 meters (435 fathoms) of water. The variations especially affect the armature of the disk and of the upper arm plates, the form of the tentacle scale, the form of the mouth shields, and the transformation of the first ventral arm spine into a hook.

In the two Siboga specimens the dorsal surface of the disk was covered with small narrow and slender club-spines terminating in two or three unequal and irregular spinules. This condition is rather rare in the Albatross series; I notice it in the specimen from station 5492, and in one of the two from station 5359 (pl. 12, fig. 6), in which these club-spines are rather unequal, not close together, and very short in the central region of the disk, becoming more or less elongated toward the periphery. In the specimen from station 5467 the club-spines are more elongated and almost of equal length, though they are still rather short; but in the majority of the others they have become very long, closely crowded, and always very slender true spines; sometimes these spines are smooth throughout and remain of the same diameter to the extremity which is ordinarily bifurcated, or terminated by three or four small spinules (pl. 12, fig. 1 ; pl. 14, figs. 1,4 ; pl. 15, fig. 2 ); sometimes they are somewhat conical, showing denticulations over a greater or lesser portion of their length (pl. 13, fig. 2 ; pl. 15, fig. 1). On this point there is the greatest possible variation, of which the numerous photographs which I reproduce (pl. 95, figs. $2 a$ and $b$ ) will give an idea.

The upper arm plates as a rule have their distal border armed with small spines which are more or less numerous and more or less developed. Sometimes they are reduced to small short and conical spinelets as I described them in the types; this is the condition seen, for 
instance, in the two specimens from station 5359 (pl. 12, fig. 6) and in those from stations 5505, 5506, and 5526 (pl. 13, fig. 2). Sometimes they are very much more elongated, though remaining very fine, and then, instead of being stiff and straight, they are somewhat incurved or sinuous, as if they had in the living animal a certain amount of flexibility; this is the condition in the specimens from stations 5423, 5424, and 5425 (pl. 15, figs. 4, 5; pl. 14, fig. 1). These spines may even not be confined to the distal border of the upper arm plate, but may also appear on its surface; this occurs, for instance, in the specimens from station 5425 (pl. 12, fig. 5). The number of these spines varies, and often it is impossible to find the least trace of them, but as they are rather deciduous it is assumable that they have been torn off by abrasion.

The mouth shields are typically triangular and broader than long, as I described them in the types, and as some of the photographs which I give here (pl. 12, fig. 3 ; pl. 13, figs. 1, 4, 5; pl. 14, figs. 2, 5) show them. In the specimen from station 5359, figured on plate 13 figure 3, these shields are relatively a little higher and scarcely broader than long. In others they are distinctly longer than broad, for example, in that from station 5424 which is figured in plate 12, figure 2.

The tentacle scales are always two in number on the pores of the first pair, but the following pairs have only one. Usually the scales of the first segment are larger than those following, which become gradually narrower. Sometimes these scales acquire a very great development and maintain almost the same dimensions throughout the greater part of the length of the arms; this is the case in the specimen from station 5538 (pl. 12, fig. 3, and pl. 14, fig. 3). Sometimes these scales, instead of being broadened on the first segments, are as narrow and as thin as on the following segments; this occurs in the specimen from station 5467 (pl. 13, fig. 4). Usually these scales are rugose and provided with asperities, which are especially developed in their distal part, and they are thus more or less strongly spiniferous. These asperities may even become transformed into small more or less developed lobes as may be seen on the specimen from station 5538 (pl. 12, fig. 3, and pl. 14, fig. 3) and on those from stations 5506 (pl. 13, fig. 1), 5424 (pl. 14, fig. 2), 5511 (pl. 14, fig. $5)$, etc.

The tentacle scale, however it may be developed, is always very long, and, as I wrote in 1904, the length is almost equal to that of the segment. It is only in the terminal part of the arms where the segments are considerably elongated that the tentacle scale, which does not become similarly elongated, appears relatively short (pl. 15, fig. 3 ). I show on plate 95 , figure $2 e$, some of these scales isolated. 
I notice that the first ventral arm spine may be transformed into a hook at a greater or lesser distance from the base of the arms, and in the distal part of the arm this transformation always takes place (pl. 15, fig. 3) ; but sometimes, as is seen, for instance, in a specimen from station 5424 , shown on plate 14 , figure 2 , this transformation appears very early and already shows itself on the tenth arm segment. It may happen also that the second spine has the extremity recurved and that its teeth become very large, though rather few, on its proximal or concave border, and that it, too, thus tends to become converted into a hook. On plate 95 , figure 2 , I give some photographs showing the forms which the first $(d)$ and the second (c) ventral arm spines may assume.

I may add that the arm spines, which are more or less elongated, are sometimes very long and extremely slender, and almost silky, as for example in the specimens from station 5424 (pl. 12, fig. 1, and pl. 14, fig. 1); they are still longer but thicker in that from station 5526 (pl. 13, fig. 2), but very much shorter in that from station 5359 (pl. 12, fig. 6).

All of these variations do not prevent the recognition of the species when there are at hand specimens enough to follow the various phases, but with a single specimen one might very easily be led into error. It is for this reason that it has seemed to me advisable to describe these variations in some detail, and especially to include a number of photographs showing the most characteristic forms of 0 . matura.

The transformation of the first ventral arm spine into a hook at some distance from the base of the arms is a very remarkable character, though I do not believe it should be considered of sufficient importance to necessitate a generic separation, and I therefore leave $O$. matura in the genus Ophiotreta near O. gratiosa, to which it is very closely related. I have not been able to observe the least indication of a transformation into a hook of the first ventral arm spine either in 0. gratiosa or in the other species of Ophiacanthidae of which the arms are preserved throughout their entire length.

OPHIOTRETA SPATULIFERA, new species.

Plate 19, figs. 5, 6.

Locality.-Albatross station 5629; Patiente Strait and southward; Doworra Island (S.) bearing S. $62^{\circ} \mathrm{W}$., 11.1 kilometers ( 6 miles) distant (lat. $0^{\circ} 50^{\prime} 00^{\prime \prime}$ S., long. $128^{\circ} 12^{\prime} 00^{\prime \prime}$ E.) ; 375 meters (205 fathoms); December 2, 1909 ; co. S.

One specimen (Cat. No. 41197, U.S.N.M.).

Description.-The diameter of the disk is $8.5 \mathrm{~mm}$.; the arms are broken off near the base, but the greater part of the fragments are 
preserved, and their length may be estimated as from $55 \mathrm{~mm}$. to $60 \mathrm{~mm}$.

The disk is rounded, excavated in the interradial spaces; the dorsal surface is flattened and covered with tine, small, rounded, and imbricated scales of uniform size except in the immediate vicinity of the center where they become much smaller. Each plate bears a slender club-spine, twice as high as broad, terminated by a crown of three or four divergent spinules, which are conical and rather stout. On the surface of the disk are 10 very widely separated radial ribs, only slightly elevated, elongated, and rather narrow, on the surface of which each of the plates bears a club-spine a little stouter than those on the rest of the disk. At the extremity of each rib there may be seen a very small triangular and naked shield.

The ventral surface of the disk in the interradial spaces is covered with small, rounded, imbricated plates identical with those on the dorsal surface, but bearing club-spines only at the extreme periphery of the disk. The genital slits are very broad.

The mouth shields, which are rather large, are triangular and slightly broader than long with a sharp proximal angle bounded by two gently concave sides; the distal border is very strongly convex. The adoral plates are rather broad, two and a half times as long as broad, scarcely broader outwardly than inwardly; they send off a very narrow process which separates the mouth shield from the first side arm plate. The oral plates are triangular, twice as high as broad. The lateral mouth papillae are rather numerous and arranged somewhat irregularly; they are at least six or seven in number. The three or four proximal papillae are elongated and conical with the point obtuse, and they are not aligned exactly in the same plane; then follow ordinarily two papillae, sometimes three, which are flattened and very strongly broadened in their outer half in such a way as to appear spatulate. Following these last there are one or two more spiniform and pointed papillae, and often also a spiniform papilla occurs below the last spatulate papilla. A spiniform papilla, smaller than the preceding, is situated at the outer angle of the first under arm plate. At the tip of the jaw there are ordinarily three tooth papillae, one larger unpaired and two a little smaller placed above it; the unpaired papilla may be replaced by two others smaller, in which case there are four tooth papillae.

The upper arm plates are rather large, a little broader than long, with a rather sharp proximal angle bordered by straight sides and a convex distal edge; these plates are in contact throughout the greater part of the length of the arms.

The first under arm plate is of medium size and trapezoidal with a straight and narrow distal border, well developed sides, and a broad 
and convex proximal border. The second is very large and very broad, very much broader than long, with a straight and narrow proximal border, very strongly divergent sides which are excavated by the tentacle scale, and a convex distal border. The following are pentagonal, with a very obtuse proximal angle and the distal border always strongly convex; their length progressively diminishes beyond the third, and they end by being as long as broad, and finally longer than broad. Beyond the second these plates are separated by a narrow interval which becomes progressively elongated as the plates become smaller.

The side arm plates, which are strongly projecting, bear eight spines, of which the length increases from the first ventral, exceeding the segment, to the last dorsal, which is at least as long as four segments. On the first arm segment the two lateral columns come very close together in the dorsal median line. These spines are rather slender, vitreous, furnished with rather evident and well-spaced denticulations; these denticulations are especially developed on the ventral spines, and they may completely disappear on the large dorsal spines.

The under and side arm plates in the proximal portion of the arms show on their surface rather prominent concentric striations; these striations are scarcely indicated on the upper arm plates.

The single tentacle scale is rather large, somewhat broadened, and pointed; it shows on its borders small asperities which are especially developed toward its tip; its length equals almost that of the corresponding under arm plate. The pores of the first pair are provided with two smaller and rounded scales.

In the specimen in alcohol the dorsal surface of the disk and of the arms is light brown; the spines and the ventral surface of the disk are white.

Affinities and distinctive features.-On account of the arrangement of the mouth papillae it seems to me necessary to place this species in Verrill's genus $O$ phiotreta; its two external mouth papillae are broadened, and these papillae are greatly developed, showing a spatulate form which is doubtless characteristic of the species. The presence of two tentacle scales on the pores of the first pair is likewise rather often observed in the genus Ophiotreta. But $O$. spatulifera is easily distinguished from the other species of this group by having the dorsal surface of the disk armed with very slender elongated and narrow club-spines ending in a crown of fine spinules, as well as by the spatulate form of the two outer mouth papillae. 


\section{OPHIOTRETA VALENCIENNESI (Lyman).}

Plate 16 , fig. 4 ; plate 93 , fig. 6 .

See for bibliography:

Ophiacantha valenciennesi KaEHLER ('04), p. 110; ('07), p. 292; ('09), p.

188.-H. L. Clark ('15), p. 205.

Ophiacantha (Ophiotreta) valenciennesi KaEHLE ('14), p. 102.

Locality.-Albatross station 5306; China Sea, in the vicinity of Hongkong (lat. $20^{\circ} 55^{\prime} 00^{\prime \prime}$ N., long. $116^{\circ} 40^{\prime} 00^{\prime \prime}$ E.) ; 311 meters (170 fathoms); October 26, 1908; co., S.

One specimen (Cat. No. 41151, U.S.N.M.).

Notes.-The single specimen is in rather poor condition; the arms are broken into many fragments, and the dorsal surface of the disk has been almost completely torn away.

Verrill placed $O$. valenciennesi in his subgenus Ophiotreta, with $O$. sertata and $O$. lineolata; H. L. Clark retained in this subgenus $O$. sertata and $O$. Tineolata, to which he added $O$. eximia, $O$. gratiosa, and $O$. sociabilis, but he placed $O$. valenciennesi in the genus $O$ phiacantha ('15, p. 205). I shall follow Verrill's example in placing $O$. valenciennesi in the genus Ophiotreta; it must be recognized, however, that it differs notably from the other species assigned to this genus in having the tentacle scales doubled throughout the length of the arms. But I do not believe that there is any present necessity for placing $O$. valenciennesi in a distinct genus.

The granules on the dorsal surface of the disk are continued onto the two or three first upper arm plates, but I notice that some of the plates which follow, to the number of five or six, or sometimes even less, show in the middle of their distal edge a single rounded granule a little longer than broad, narrower than the granules of the dorsal surface of the disk, and slightly rugose; the following plates lack these granules. These must be very deciduous, and I have not seen them on the various individuals of $O$. valenciennesi which $I$ have examined up to the present time; however, in reexamining the specimens collected by the Travailleur and the Talisman I have been able to find two on one of the specimens.

The granules on the dorsal surface of the disk, as likewise those which are sometimes found on the free edges of the upper arm plates, are not perfectly rounded; isolated and viewed under the microscope they are seen to be very short cylinders inserted by a broadened and flat base, almost as high as broad, and ending in a strongly convex surface furnished with short and conical teeth, which may be continued down the sides of the granule (pl. 93, fig. 6).

I have already had occasion at different times to speak of this species and of its enormous geographical range. 
OPHIALCOEA CONGESTA (Kohler).

Plate 15, figs. 6, 7 .

Ophiacantha congesta Kं ceHLER ('04), p. 103, pl. 24, figs. 1, 2.

Ophialcoea congesta H. L. ClARK ('15), p. 217.

Localities.-Albatross station 5219; between Marinduque and Luzon; Mompog Island (NE.) bearing N. $35^{\circ} 30^{\prime}$ W., 22.70 kilometers (12.25 miles) distant (lat. $13^{\circ} 21^{\prime} 00^{\prime \prime} \mathrm{N}$., long. $122^{\circ} 18^{\prime}$ $45^{\prime \prime}$ E.) ; 969 meters (530 fathoms) ; April 23, 1908; gn. M.

Five specimens (Cat. Nos. $41265,41267,41268$, U.S.N.M.).

Albatross station 5527; between Siquijor and Bohol Islands; Balicasag Island (C.) bearing N. $14^{\circ} \mathrm{W} ., 15.20$ kilometers ( 8.2 miles) distant (lat. $9^{\circ} 22^{\prime} 30^{\prime \prime}$ N., long. $123^{\circ} 42^{\prime} 40^{\prime \prime}$ E.) 717 meters (392 fathoms); August 11, 1909; glob. Oz.

Two specimens (Cat. No. 41266, U.S.N.M.).

Notes. - Three of the specimens from from station 5219 are almost of the same dimensions as the type of the species. The diameter of the disk measures from $7 \mathrm{~mm}$. to $9 \mathrm{~mm}$., and the arms are between $40 \mathrm{~mm}$. and $45 \mathrm{~mm}$. long; in another specimen from station 5527 the diameter of the disk is $5.5 \mathrm{~mm}$. The others are smaller and their disks do not exceed $3 \mathrm{~mm}$. or $4 \mathrm{~mm}$. in diameter.

Judging from the form of the upper arm plates and the form of the arm spines, this species should be placed in Verrill's genus Ophialcoea, where it falls near $O$. nuttingii Verrill, and $O$. tuberculosa (Lyman). It is, however, sharply distinguished from these two species; 0 . nuttingii has the mouth shields large and oval, and the dorsal surface of the disk is covered with small spines, which leave the radial shields naked, while $O$. tuberculosa, in which the mouth shields have a form similar to that which is found in $O$. congesta, has the dorsal surface of the disk covered with large granules, and the radial shields of each pair, which are very close together, are separated by a deep and elongated depression; furthermore, the arm spines are more slender.

The arm spines of $O$. congesta are thick and short; in the Albatross specimens the dorsal spines of the first segments especially show a remarkable thickness, but their width rapidly diminishes.

Ophialcoea congesta was found by the Siboga at two stations between latitude $1^{\circ}-5^{\circ} \mathrm{S}$. and longitude $119^{\circ}-130^{\circ} \mathrm{E}$., at depths of 450 and 798 meters (240 and 439 fathoms).

OPHIENTREMA LEUCOSTICTUM (H. L. Clark).

Plate 8 , figs. $1-4$; plate 10 , tig. 5 ; plate 94 , fig. 1 .

Ophiacantha leucosticta H. L. CLARK ('11), p. 235.

Ophientrema leucostictum H. L. ClaRK ('15), p. 217.

Locality.-Albatross station 5606; Gulf of Tomini, Celebes; Dodepo Island (W.) bearing N. $3^{\circ}$ W., 20.01 kilometers (10.8 miles) 
distant (lat. $0^{\circ} 16^{\prime} 28^{\prime \prime}$ N., long. $121^{\circ} 33^{\prime} 30^{\prime \prime}$ E.) ; 1,525 meters (834 fathoms); November 17, 1909; gn. M.

One specimen (Cat. No. E. 36, U.S.N.M.).

Notes.-The specimen is in good condition; the diameter of the lisk is $14 \mathrm{~mm}$., and the arms are $70 \mathrm{~mm}$. long.

In describing 0 . leucosticta H. L. Clark remarked that this species might belong to a new genus which would be characterized by the incomplete calcification of certain parts of the body and by the peculiar arrangement of the arm spines, as well as of the tentaclc scales. But in his memoir of 1915 he places Ophiacantha leucosticta in Verrill's genus Ophientrema with O. scolopendrica. This assignment to the genus Ophientrema appears to be perfectly justified, and I shall adopt it here. I believe further that H. L. Clark was perfectly right in removing from the genus Ophientrema O. granulosa which Verrill thought should be placed with 0 . scolopendrica; in reality these two species are very different from each other, and if 0 . scolopendrica be taken as the type of the genus Ophientrema, it is not possible to retain in the same genus $O$. granulosa.

The characters to which H. L. Clark drew attention in 1911 and which then seemed to him of such a nature as to justify the creation of a new genus ( $\mathrm{I}$ am speaking of the reduction of the tentacle pores which occur only on the first arm segments and the arrangement of the arm spines) are shown equally well in $O$. scolopendrica, and the mouth plates also agree with those of that species; but H. L. Clark's form is remarkable for the incomplete calcification of different parts of the body, for the form of the upper and under arm plates, and for the characters shown by the ventral spines.

Another species from Japan described by H. L. Clark in 1911 under the name of Ophracantha euphylactea ('11, p. 225, fig. 105) seems to me to approach very closely the genus Ophientrema, though without having the characters as well marked as in $O$. scolopendrica and 0 . leucostictum.

My single specimen is a little smaller than H. L. Clark's type, in which the diameter of the disk was $17 \mathrm{~mm}$. and of which the arms were $70 \mathrm{~mm}$. long. Instead of the dark brown coloration of the dorsal surface of the disk which that author described the present specimen has the central portion of the disk olivaceous green; from this region there diverge five radial bands of the same color, which narrow between the radial shields and do not reach the periphery of the disk, and five interradial bands, which are continued as far as the border of the disk. The intermediate parts, which are chiefly occupied by the radial shields, are a very light yellow, as is also the dorsal surface of the arms. The whole dorsal surface of the disk is studded with little projecting granules, as described by H. L. Clark, of which the 
surface is very rugose, but it is only in the colored portion that I am able to distinguish under the microscope the little black points mentioned by the American author. The ventral surface of the disk is olivaceous, lighter than the dorsal surface, with less numerous granules, which do not reach the mouth shields, and with littlo black scattered dots.

H. L. Clark says that the three or four ventral arm spines are "rough or hooked at the tip." But I notice that the modification is more marked than these words would seem to indicate. These spines are covered with rather strong asperities on the three first arm segments, but beyond the fourth, that is to say almost at the borders of the disk, the asperities which arm the terminal portion of the first spine, and sometimes even of the second, elongate, and one of these develop into a little hyaline hook, which is slightly recurved and turned toward the mouth (pl. 94, fig. 1a). A similar modification appears very rapidly on the other ventral spines (fig. 16 ), and behind the terminal hook the dimensions of which progressively increase, there are two or three other smaller teeth on the adoral or proximal side of the spines. On the distal side the asperities are less marked, though they are developed for some little distance toward the extremity of the spines. The spines so modified recall the central spine of the species of Ophiothrix; but the transformation into a true hook is less marked than in this genus, and the spines always retain the character of spines. The dorsal spines are simply rugose, and their asperities remain very fine and very closely crowded without showing the least tendency to become more developed toward the extremity of the spine (fig. 1c). On plate 10, figure 5, I give a photograph of the lateral surface of an arm on which the relative length of the soft areas which separate the side arm plates may be appreciated.

A true tentacle scale is only found on the arm pores of the second and of the third pairs, and I do not see the least trace of them on those of the fourth pair.

Notwithstanding these few differences, which are quite secondary in character, my specimen incontestably belongs to the same species as that of H. L. Clark.

In his memoir of 1917 Matsumoto ( $p .110$ ) considers $O$. leucostictum (H. L. Clark) identical with O. scolopendrica (Lyman). I do not dare to give an opinion on this synonymy, for, judging by Lyman's description and figures, there are some rather important differences between them, of which I have spoken above; 0 . scolopendrica does not show the same form of upper and under arm plates nor the incomplete calcification of different parts of the body which are found in O. leucostictum; furthermore, Lyman does not indicate 
in his species any modifications of the ventral spines comparable to those which are shown by H. L. Clark's specimen and especially by mine which has exactly the same dimensions as the type of $O$. scotopendrica. However, it is certain that the two forms are very close, and perhaps the study of a more complete series of individuals will show intermediate forms which are now lacking. I may mention also that the type of $O$. scolopendrica was found at a station (lat. $34^{\circ}$ N., long. $138^{\circ}$ E.; 1,033 meters [565 fathoms]) very close to that where $O$. leucostictum was dredged (lat. $34^{\circ} 09^{\prime} \mathrm{N}$., long. $137^{\circ} 55^{\prime} \mathrm{E}$.; 927 meters [507 fathoms]).

\section{OPHIOTREMA TERTIUM, new species.}

Plate 21, figs. 2, 3, 7 .

Locality.-Albatross station 5349; Palawan Passage; Point Tabonan bearing N. $85^{\circ}$ E., 83.77 kilometers (45.2 miles) distant (lat. $10^{\circ} 54^{\prime} 00^{\prime \prime}$ N., long. $118^{\circ} 26^{\prime} 20^{\prime \prime}$ E.) ; 1,335 meters (730 fathoms); December 27, 1908 ; co., S.

One specimen (Cat. No. 41150 , U.S.N.M.).

Description.-The specimen is incomplete. Only one arm, about $65 \mathrm{~mm}$. long, is preserved throughout its entire length. The disk is pentagonal, but it is considerably deformed; it measures $15 \mathrm{~mm}$. in one diameter, but only $11 \mathrm{~mm}$. in the other.

The dorsal surface of the disk is also in a poor state of preservation; it is strongly wrinkled, and certain parts have been completely torn away. It may be seen, however, that this surface is covered by an integument bearing various kinds of structures; there are somewhat elongated and closely packed granules with a very rugose surface; among these granules there are flattened and somewhat lanceolate spines lying on the integument which bears them; these spines are rather obtuse. The radial shields are almost completely hidden, only their distal extremities being visible. The rugose granules of the dorsal surface of the disk are continued onto the two or three first arm segments and cover the upper arm plates as well as the side arm plates. They are somewhat elongated on the arms, there becoming conical though remaining very rugose.

The ventral surface of the disk has a covering similar to that of the dorsal surface, but the spines occur only in the region near the periphery, thence gradually disappearing so that two-thirds of the ventral surface bears only granules which are very closely crowded, and which persist to the mouth shields. The genital slits are large and broad.

The mouth shields are rather large, triangular, broader than long, with the proximal angle sometimes a right angle and sometimes obtuse, the later angles rounded, and the distal border gently con- 
cave. The adoral plates are large, much elongated, and broadened as far as the median interradial line along which they are broadly united with their neighbors; they taper to the level of the mouth tentacle pores, then broaden again in their distal parts and pass around the mouth shield, forming a lobe which separates this shield from the first side arm plate. The oral plates are triangular and high. The lateral mouth papillae are numerous, and there may be as many as eight or nine of them; they are conical, elongated, and pointed; the unpaired terminal papilla is a little longer than those on either side. These papillae are continued along the internal border of the large mouth tentacle pore to the number of at least six on this border; they are unfortunately more or less poorly preserved. They disappear before the distal extremity of the pore, and apparently are not continued on its radial border.

The arms are rather flattened, and their dorsal surface is only slightly convex. The upper arm plates are of medium dimensions, as the side arm plates extend rather broadly over the dorsal surface of the arms. These plates are triangular, almost as long as broad, with a proximal angle which is sharp, though rounded at the tip, and a convex distal border which is often divided into two small sides united by an obtuse angle. They are separated from each other from the base of the arms outward by an interval which is always very narrow.

The first under arm plate is longer than broad, triangular in general form, but with the base ordinarily divided into two short sides passing into each other by an obtuse angle; the lateral borders are excavated by the large mouth tentacle pores, and the distal summit is truncated. The second plate is already separated from the first by the side arm plates, and it is the same for all the following plates. These are very narrow in their proximal portion, that is, in about the first two-thirds of their length, while they are much broadened in their distal third. They have a sharp proximal angle and two lateral borders, strongly excavated by the corresponding tentacle pores, which pass over very rounded angles to form the distal border; this is extremely broadened and shows in the center a small notch.

The side arm plates do not project at all, and they cover a rather large portion of the dorsal and ventral surfaces of the arms. They carry on the first segment six subequal spines of which the length is a little greater than that of the segment. These spines are cylindrical with the point rounded; their surface is rugose, and even sometimes slightly echinulated. They are very close to each other, and are appressed against the lateral surface of the arms; but the two lateral series are very far apart in the median dorsal lines. 
The tentacle pores are very large and rounded and show on their borders the little spines characteristic of the genus Ophiotrema; these spines are very fine, conical, pointed, and rather long, but they are very often broken off, and it is difficult to give their number as well as thcir exact arrangement; it seems to me that typically there are three spines on the internal or radial border of the pore, while another spine, often a little more strongly developed than the preceding, is found on the external border in front of the insertion of the first arm spine.

The specinen in alcohol has the disk rather dark on the dorsal surface: the arms are much lighter, almost white.

Affinities and distinctive features.-The genus Ophiotrema was previously known only from two species, each represented by a small number of specimens all of which are in a more or less poor state of preservation. In the two species already known, O. alberti Kœhler and $O$. gracilis Kœhler, the dorsal surface of the disk shows distinct plates, each of which bears a small spine, while in the new species it is impossible to distinguish any plates on this surface, and the covering of the disk is composed of both granules and more or less recumbent spines. This difference does not seem to justify a generic separation, for the characters shown by the mouth papillae, by the tentacle pores of the mouth and of the arms, by the arm spines, by the upper and under arm plates, etc., agree very well with the characters of the genus Ophiotrema.

I have already had occasion to express my opinion on the subject of the affinities of the genus Ophiotrema (Kœhler '09, p. 196); contrary to Verrill's opinion, I believe that the genus Ophiotrema is near the genus Ophiopora and not at all close to the genus Ophiomitra, as that naturalist has suggested, and near which he has placed it.

This affinity with the genus Ophiopora has been recently admitted by H. L. Clark, but he goes much farther, for he unites the two genera. In his catalogue of the ophiurans ('15, p. 218) he places my $O$. alberti and the genus Ophiotoma. I can not accept this point of view, for I consider that the genus Ophiotrema is perfectly valid and should be retained. I have accepted it as characterized by the presence of small spines on the borders of the arm tentacular pores, as well as by other structural features. This character is absolutely lacking in the genus Ophiopora, where the pores are mostly quite without scales.

Matsumoto's opinion is quite opposed to H. L. Clark's, and he retains the genus Ophiotrema as distinct from the genera Ophiopora and Ophiotoma ('17, p. 93), the presence of the large tentacle pores invoked by H. L. Clark to unite them being, he says, a character 
which appears also in many other genera and which of itself does not suffice to justify this reunion.

opHIOTOMA AsSIMaLIS Kœhler.

Plate 20, figs. 1-7.

Ophiotoma assimilis KenLeR ('04), p. 144, pl. 28, figs. 1, 2.-H. L. Clark ('15), p. 218.

Localities.-Albatross station 5450; east coast of Luzon, San Bernardino Strait to San Miguel Bay; East Point (Batan Island) bearing S. $36^{\circ}$ E., 17.05 kilometers $\left(9.2\right.$ miles) distant (lat. $13^{\circ}$ $23^{\prime} 15^{\prime \prime}$ N., long. $124^{\circ} 00^{\prime} 30^{\prime \prime}$ E.) ; 746 meters (408 fathoms); June 3, 1919; gn. M., Co.

Three specimens (Cat. No. E. 105, U.S.N.M.).

Albatross station 5460; east coast of Luzon, San Bernardino Strait to San Miguel Bay; Sialat Point Light bearing N. $24^{\circ}$ E., 15.20 kilometers (8.2 miles) distant (lat. $13^{\circ} 32^{\prime} 30^{\prime \prime} \mathrm{N}$., long. $123^{\circ} 58^{\prime} 06^{\prime \prime}$. E.) ; 1,033 meters (565 fathoms) ; June 10, 1909; gy. M.

Three specimens (Cat. No. E. 108, U.S.N.M.).

Albatross station 5505; Northern Mindanao and vicinity; Macabalan Point Light (Mindanao) bearing S. $31^{\circ}$ E., 14.27 kilometers (7.7 miles) distant (lat. $8^{\circ} 37^{\prime} 15^{\prime \prime}$ N., long. $124^{\circ} 36^{\prime} 00^{\prime \prime}$ E.) ; 402 meters (220 fathoms); August 5, 1909.

One specimen (Cat. No. E. 107, U.S.N.M.).

Albatross station 5647; Buton Strait; North Island (S.) bearing S. $87^{\circ}$ E., 21.50 kilometers (11.6 miles) distant (lat. $5^{\circ} 34^{\prime} 00^{\prime \prime} \mathrm{S}$., long. $122^{\circ} 18^{\prime} 15^{\prime \prime}$ E.) ; 949 meters (519 fathoms); December 16, 1909 ; gn. M.

Three specimens (Cat. No. E. 106, U.S.N.M.).

Notes.-Only two of the specimens from station 5450 are in good condition; they are of large size, the diameter of the disk being from $20 \mathrm{~mm}$. to $22 \mathrm{~mm}$. and the length of the arms $75 \mathrm{~mm}$. In figures 4 and 5 , plate $20, I$ show the two surfaces of one of these specimens. All the others are in rather bad condition; the dorsal surface of the disk is torn away almost completely and the arms are usually incomplete excepting in the individuals from station 5647, in which the disk is at least $25 \mathrm{~mm}$. in diameter and the arms from $70 \mathrm{~mm}$. to 80 mm. long. Those from station 5460 are smaller, the diameter of their disks varying between $12 \mathrm{~mm}$. and $15 \mathrm{~mm}$, and the arms being from $54 \mathrm{~mm}$. to $60 \mathrm{~mm}$. long. That from station 5505 is still smaller. In spite of a few discrepancies which these specimens show when compared with the description which I gave in 1904 of $O$. assimilis, based upon individuals collected by the Siboga in the Sunda Islands, to which I shall return later, I feel certain that they all belong to the same species. As the specimens collected by the Siboga were more or 
less damaged, I believe that it is advisable to give here a description of those from station 5450, which are in an excellent state of preservation, and then to compare these with the others.

The disk is pentagonal, slightly excavated in the interradial spaces, and also somewhat deformed. The flat dorsal surface is covered by a very thin integument on which may be made out under the microscope small, extremely thin, and imbricated scales; these scales are very difficult to distinguish in the central region of the disk, but they become more apparent toward the periphery and in the vicinity of the radial shields. These latter are very evident, and through their white coloration they stand out in strong contrast against the dark green color of the rest of the disk; they are much elongated, biscuitshaped, four times as long as broad, with the extremities strongly rounded. For more than half their surface these shields are covered by the general integument of the dorsal surface which only leaves exposed a part of their distal region in the form of an elongated triangular area. The two shields of each pair are widely separated by a space at least equal to twice their width.

The ventral surface of the disk in the interradial spaces is covered by an integument which is somewhat thicker than that of the dorsal surface, and the scales which overlie it are thicker, more evident, and somewhat larger. The genital slits are extremely broad; the genital plates are narrow and elongated.

The mouth shields are rather large, triangular, with the angles: rounded; their distal border carries in the middle a small similarly rounded lobe. These shields are broader than long in one of the two specimens from station 5450, and in the other they are almost as broad as long, forming an equilateral triangle, with the angles less: rounded than in the first. The adoral plates are large, very tapering inwardly, but in contact in the interradial median line, much broadened outwardly, and widely separating the mouth shield from the first side arm plate. The oral plates are high and narrow, three times as high as broad. The lateral mouth papillae, which are only slightly developed, are small, conical, and short, numbering five or six on each side, and forming a more or less regular row; there are in addition one or two tooth papillae; toward the other extremity of the jaws there can be made out two and sometimes three small papillae, which are very low and conical, situated on the interradial border of the mouth tentacle pore.

The first upper arm plates, which continue the small plates of the dorsal surface of the disk separating the two radial shields of each pair, are small, irregular, and arranged in several rows on the two first arm segments, but beyond the plates become larger and are arranged very regularly. They are quadrangular, lozenge shaped, 
broader than long, with a rather open proximal angle which is only slightly projecting, and the four sides are almost equal. The proximal angle is truncated for about two-thirds of the length of the arm, becoming sharp in the last third. The plates are then as long as broad, and even, in the terminal portion of the arms, a little longer than broad. They are all in contact.

The first under arm plate is quadrangular, with a narrow distal border, a broader proximal border, and diverging sides; it is a little broader than long. The following plates are quadrangular, with a straight proximal border, and the distal border slightly notched in the middle; the sides are slightly excavated by the tentacle pores. These plates are at first as long as broad, then becoming longer than broad beyond the disk, at the same time becoming separated by a narrow interval occupied by the side arm plates; toward the extremity of the arms they are at.least half again as long as broad.

The side arm plates bear six spines at the base of the arms, and this number is continued for a considerable distance. The first ventral spine exceeds a segment and a half, and the length increases to the last dorsal spine which is as long as three segments. These spines are slender, cylindrical, pointed, and smooth.

I can not discover the least trace of a tentacle scale on the two specimens from station 5450, which are in good condition; but on the third, in which the dorsal surface of the disk is torn away, a certain number of the pores of the eight or nine first segments are provided with a small, short, spiniform and pointed scale.

The color of the disk is a dark green, while the arms are white.

The two specimens from station 5460 are very interesting, because they resemble more than the preceding the type collected by the Siboga. One of them, which $I$ have shown in figures 1 and 3 on plate 20, has the dorsal surface of the disk in a great measure torn away; the two surfaces of the disk show very distinct plates, and furthermore there is a tentacle scale which occurs in an inconstant and irregular manner as far as the pores of the tenth or twelfth pair. These scales are very small, slender, conical, and pointed, and they must be very easily lost. The mouth shields are broader than in the two specimens from station 5450 , and in their shape they strongly recall that of the Siboga specimen, with a small lobe on the middle of their distal edge; the proximal angle is so rounded on some of these shields that it grades into the lateral borders, and the shield finally acquires a semicircular shape. The upper arm plates of the two or three first segments are at first lozenge-shaped, as in the specimens from station 5450 ; they then rapidly elongate, and become triangular as in the Siboga specimen, with this difference, however, that they are a little longer than broad, while in the latter they are a little 
broader than long. The under arm plates have at first the form which I showed in the specimens from station 5450, but they become relatively longer, and toward the extremity of the arms they are twice as long as broad. The arm spines are five in number.

To sum up, the only important difference between these specimens and the two in good condition from station 5450, which, however, is a difference sufficiently important to have caused me at first to hesitate over their determination, is the presence of tentacle scales on some of the segments at the base of the arm; but I have been able to convince myself that the presence of these scales is rather inconstant.

One of the specimens from station 5460 had the dorsal surface of the disk completely torn away, and I have made a preparation of it to show the characters of the peristomial plates; these are represented in figure 6 on plate 20. These plates, two in number, are large and broad, each in the form of a right-angled triangle, a little higher than broad, with the proximal border slightly concave and the distal border convex; the base of the triangle corresponds to the median interradial line, along which may be made out the suture between the two adjacent plates. As a unit, these two plates recall the structure which was represented by Lyman in Ophiochoeta mixta, but in this species the two plates of each pair always remain distinct.

The individual from station 5505 is in very bad condition, and the dorsal face of the disk is completely torn away; the disk must have had a diameter of about $12 \mathrm{~mm}$; the arms are preserved for a considerable length. On the parts of the dorsal surface of the disk which are preserved, and on the ventral surface, there may be made out an investment of very fine imbricated plates. Each of the tentacle pores bears a small scale which is continued almost throughout the length of the arms, but which is sometimes lacking, doubtless on account of having been torn away. The mouth shields are relatively large (fig. 2 ).

The two specimens from station 5647 also have the disk in poor condition, but their arms are mostly complete and well preserved; the external appearance is absolutely identical with that of the two specimens from station 5450, and like these latter they are of rather large size; in one the diameter of the disk may reach $25 \mathrm{~mm}$., and in the other, which is larger, it certainly reaches $27 \mathrm{~mm}$.; the arms are $95 \mathrm{~mm}$. long. Like the preceding individuals, these two specimens have tentacle scales on a certain number of the arm segments, but here these scales are not very constant. They are always lacking on the pores of the first pair, and they may be observed from the pores of the second pair as far as those of about the seventh pair, 
though with some irregularity; they are always lacking beyond the eighth segment.

Thus the tentacle scales may be completely lacking in certain specimens, and in others may be present in a more or less regular way on a certain number of segments, especially at the base of the arms; a specific difference therefore can not be based on this character, and as all the other characters conform to those which I described in 1904 in 0 . assimilis, I believe it necessary to assign the Albatross specimens to the same species.

As for the distinction which I have believed it possible to establish between $O$. assimilis and $O$. coriacea Lyman from the Atlantic, I believe that it should be maintained. The Atlantic species has the mouth shields smaller, without the distal lobe which I find constantly present in $O$. assimilis, the upper and under arm plates have a different shape, and, especially, the under arm plates do not show that median notch on their distal border which seems to me constantly to occur in $O$. assimilis.

Ophiacantha bartletti Lyman and $O$. paucispina Lütken and Mortensen should also be assigned to the genus Ophiotoma. These two species have spines on the two surfaces of the disk, and 0 . paucispina possesses a very small tentacle scale.

Very recently H. L. Clark has united $O$. coriacea Lyman and 0 . bartletti ('15, p. 217). But I notice that the form of the under arm plates and of the mouth shields as described and figured by Lyman is very different in the two species. I am therefore much puzzled by the synonymy given by H. L. Clark, who, I assume, has been able to examine Lyman's types. The figures and the descriptions of that author certainly lead to the conclusion that different forms are concerned; the armature of the disk and the shape of the mouth shields and of the under arm plates do not agree at all. Are there intermediate forms which justify the synonymy indicated by H. L. Clark?

\section{OPHIOMEDEA DISCREPANS, new species.}

Plate 26, figs. 1-4.

Locality.-Albatross station 5359; Joló Sea (lat. $8^{\circ} 12^{\prime} 45^{\prime \prime}$ N., long. $120^{\circ} 37^{\prime} 15^{\prime \prime}$ E.) ; 4,161 meters (2,275 fathoms) ; January 9 , 1909.

One specimen (Cat. No. 41196, U.S.N.M.).

Description.-The specimen is unfortunately not in a good state of preservation, and the dorsal surface of the disk is rather badly damaged; furthermore, the disk has undergone a compression which has deformed it and elongated it in one diameter. The arms are almost complete, except for one which is broken off at the junction 
with the disk. The diameter of the disk is $9 \mathrm{~mm}$. by $6 \mathrm{~mm}$.; the arms are $25 \mathrm{~mm}$. long.

The dorsal surface of the disk is entirely covered with rounded granules, which are slightly flattened and very closely crowded, completely covering the underlying plates, which must be quite invisible in the undamaged animal, though in my specimen they may be distinguished in certain regions which have been abraded; they are extremely thin, quite transparent, imbricated, and very finely striated. The radial shields are quite invisible. The granulation is continued with the same characteristics as far as the periphery of the disk, and it passes over onto the ventral surface without showing the least modification toward the regions which correspond to the radial shields. These granules have a slightly rugose surface. They are continued on the two or three first upper arm plates.

The ventral surface of the disk is covered uniformly with closely crowded granules. The genital slits are very broad.

The mouth shields are large, almost as long as broad, or slightly longer than broad; they are pentagonal, with a rather open proximal angle bounded by two straight sides, and two slightly excavated lateral borders passing over very rounded angles to form the distal side, which is similarly narrow and rounded. On two of the mouth shields I notice that this distal border bears a few granules identical with those on the ventral surface. The adoral plates are elongated and narrow, four or five times as long as broad, and they give off outwardly a rather broad process separating the mouth shield from the first side arm plate. The oral plates are large and elongated. The lateral mouth papillae are about ten in number; they are inserted on the oral plates and are arranged somewhat irregularly in two rows; there is in addition a group of a few tooth papillae. All these papillae are small, conical, a little longer than broad, and their surface is rugose. In addition to these papillae, I find usually two others, which are inserted on the adoral plate, but which are very elongated and spiniform, and beyond these still another short, oval papilla inserted at the angle between the adoral plate and the first under arm plate.

The upper arm plates are rather large, triangular, a little longer than broad, and separated by an interval which increases rapidly. I have stated above that the first plates are covered with granules identical with those of the dorsal surface of the disk.

The first under arm plate, which is of medium size, is broadened transversely; it is pentagonal, with an obtuse and rounded proximal angle bounded by two straight or slightly excavated sides, two somewhat excavated sides, and a short and rounded distal border. The following plates are large, longer than broad, with an obtuse proxi- 
mal angle bounded by two straight sides which appear only toward the third or fourth plate; the two sides are divergent and very strongly excavated by the tentacle pores; the distal border is very, broad and convex. These plates are at first in contact, later becoming separated by a narrow space.

The side arm plates, which project only slightly, bear four spines, which are subequal and a little longer than the segment; their length increases somewhat from the first ventral to the last dorsal (figs. 1 and 4). These spines are flattened, pointed, and appressed against the lateral surfaces of the arms; their surface is slightly rugose. They are hollow, and their wall is very thin.

The first arm segments bear three tentacle scales, two very large, oval and lanceolate, inserted on the side arm plate, and a third, smaller, which arises from the side arm plate and extends perpendicularly to the axis of the arm. This third scale disappears beyond the disk, and the two large scales alone persist.

The color of the specimen in alcohol is white.

Affinities and distinctive features.-I established the genus Ophiomedea for an ophiuran discovered by the expeditions of the Travailleur and the Talisman in the North Atlantic at a depth of 2,000 meters (1,100 fathoms), in which the outer mouth papilla, borne on the adoral plate, is considerably elongated and spiniform; the tentacle pores show, in addition to the principal scale inserted on the side arm plate, a smaller scale inserted on the under arm plate, and the disk is covered with imbricated scales, each armed with a spine. The type of the genus Ophiomedea is $O$. duplicata, which is only represented by a unique specimen in which the diameter of the disk does not exceed 4 millimeters.

Although the species which I have just described differ in some important features from 0 . duplicata, I believe that nevertheless it may be assigned to the same genus. The differences are, the presence of two spiniform mouth papillae inserted on the adoral plate, instead of only one, the existence of three tentacle scales instead of two, and the presence of granules instead of spines covering the dorsal surface of the disk. But none of these characters is sufficient for generic differentiation; the presence of a tentacle scale inserted on the under arm plate and the occurrence of one or of two spiniform external papillae are evidently very characteristic features. It is certainly regrettable that the type species of the genus Ophiomedea should be represented by a single specimen of very small size, rendering comparisons very difficult, but $I$ do not believe $I$ am in error in assigning our species to this genus.

Furthermore, I am in doubt whether the genus Ophiophrura, established by H. L. Clark in 1911 for a Japanese species, also represented 
by a unique specimen, should not be united with the genus Ophiomedea. The disk is uniformly and completely covered with small imbricated plates, which conceal the radial shields, but which bear neither spines nor granules; there are three external spiniform mouth papillae, and the tentacle pores are furnished at first with four scales, the number rapidly falling to three; these scales are short and spiniform; one of them is inserted on the under arm plate, and the two others on the side arm plate; there is thus a very great analogy in structure between Ophiophrura liodisca H. L. Clark and the other species which I assign to the genus Ophiomedea, and I believe that this genus might without inconvenience include all three species. It is interesting to observe the progressive increase in number of the external spiniform mouth papillae; there is only one in Ophiomedea duplicata, two in O. discrepans, and three in Ophiophrura (Ophiomedea) liodisca.

OPHIOCOPA SINGULARIS, new species.

Plate 21, figs. 4, 8, 9.

Localities.-Albatross station 5173; vicinity of Joló; Joló Light bearing N. $82^{\circ}$ E., 12.51 kilometers $\left(6.75\right.$ miles) distant (lat. $6^{\circ}$ $02^{\prime} 55^{\prime \prime}$ N., long. $120^{\circ} 53^{\prime} 00^{\prime \prime}$ E.) ; 340 meters (186 fathoms); March 5, 1908; Sh., Co.

One specimen (Cat. No. 41283, U.S.N.M.).

Albatross station 5348; Point Tabonan bearing S. $89^{\circ}$ E., 33.5 miles distant (lat. $10^{\circ} 57^{\prime} 45^{\prime \prime} \mathrm{N}$., long. $118^{\circ} 38^{\prime} 15^{\prime \prime}$ E.) ; 686 meter's (375 fathoms); co. S.; December 27, 1908.

One specimen (Cat. No. 41280 , U.S.N.M.).

Description.-The specimen from station 5348 is in good condition. The diameter of the disk is $8 \mathrm{~mm}$.; the arms are incomplete, but two of them are preserved for almost their entire length and must have been about $25 \mathrm{~mm}$. long; the fifth is broken off at its origin on the disk. The other is in rather poor condition; the disk is torn into two unequal fragments, one including the greater part with four arms, and the other a fragment with the fifth arm; a rather deep groove divides the dorsal surface into two almost equal halves. The diameter of the disk is $6 \mathrm{~mm}$., and the arms are about $15 \mathrm{~mm}$. long.

The disk is rounded. The dorsal surface is covered with rather large plates, which are subequal and imbricated and which show a thin transparent border. In the specimen from station 5173 a certain number of these plates bear each a rather large spherical globule with a rugose surface, of which the number varies from one to four or five on each plate and which are not all preserved, though the scar indicating their presence on the surface of the plates may be 
easily recognized. All the plates of the dorsal surface of the disk are not provided with globules, these occurring especially on either side of the groove which divides the dorsal surface in the damaged specimen, as well as at the periphery of the disk and between the radial shields; they are also found here and there on certain plates (fig. 4). In the specimen from station 5348 the granules, which are few in number, occur only on the periphery of the disk (fig. 9). The medium-sized radial shields are triangular, almost as broad as long, with the angles much rounded; the two shields of each pair are in contact throughout almost their entire length, and their distal extremities alone are separated. In the specimen from station 5173 the two shields are separated from each other over a somewhat greater distance.

The ventral surface of the disk in the interradial areas is covered with subequal, imbricated plates, very much smaller than those of the dorsal surface, and entirely without granules. The genital slits are narrow.

The medium-sized mouth shields are triangular, a little broader than long, with a rather open proximal angle bounded by two straight sides; the lateral angles are rounded, and the distal border shows in the middle a rather broad lobe which projects into the interradial space. The adoral plates are elongated and narrow, broader without than within, and they give off a rather thick lobe, which separates the mouth shield from the first side arm plate. The oral plates are triangular and low. The mouth papillae number five on each side; the four internal are conical and subequal, although the fifth, or external, papilla is very broad, rectangular, and very much broader than long. The terminal unpaired papilla is broad and short, rounded, and very much thicker than the neighboring papillae.

The upper arm plates, which are of medium size, are triangular, half again as broad as long, with the distal border rounded; they are separated by a narrow interval.

The first under arm plate is quadrangular or pentagonal, with a very obtuse proximal angle bordered by two straight sides; sometimes this angle is so obtuse that it disappears completely; the lateral borders are straight, and the distal edge is broad and somewhat rounded; this plate is broader than long. The following plates are large, pentagonal, broader than long, with an obtuse proximal angle, the sides excavated by the tentacle scale, which is very large, and a convex distal border. These plates are in contact for almost the whole of their length in the specimen from station 5348, but in the other they are separated by a very narrow interval.

The side arm plates, which are rather projecting, bear six spines, the length of which increases from the first ventral, which is almost 
as long as a segment, to the last dorsal, of which the length equals two segments. These spines are flattened, especially the ventral spines; the second and third are broadened in such a way as to become more or less spatulate, though they are markedly less broadened than in O. spatula; their tip is rounded. The dorsal spines are narrower than those preceding, not broadened, and their extremity is pointed. All these spines are provided with very fine and very closely placed asperities.

The tentacle scales are two in number on the pores of the first pair, but single on all the following pores; these scales are large, rounded, and a little longer than broad.

Affinities and distinctive features.-Up to the present time the genus Ophiocopa was only known from a single species, O. spatula, dredged by the Blake in 150 fathoms in the Caribbean Sea. This new species incontestably belongs to the same genus Ophiocopa, and it is distinguished from $O$. spatula by having the arm spines less broadened and less strongly spatulate and by the single tentacle scale beyond the pores of the first pair; the external mouth papilla seems to me also a little more broadened than in the Antillean species. The discovery of a second species of the genus Ophiocopa in the Philippine Islands is very interesting.

\section{OPHIOTHAMNUS VENUSTUS Matsumoto.}

Plate 23, figs. 3, 4.

Locality.-Albatross station 5619; Molucca Passage; Mareh Island (S.) bearing S. $78^{\circ}$ E. 12.97 kilometers (7 miles) distant (lat. $0^{\circ} 35^{\prime}$ $00^{\prime \prime} \mathrm{N}$., long. $127^{\circ} 14^{\prime} 40^{\prime \prime}$ E.) ; 796 meters (435 fathoms) ; November 27, 1909; fne. gy. S., M.

One specimen (Cat. No. 40934, U.S.N.M.).

Notes.-The specimen is not in a perfect state of preservation, and the arms are incomplete; furthermore, the size is very small, the diameter of the disk not exceeding $2.5 \mathrm{~mm}$. The disk is pentagonal, somewhat depressed in the center, and rather strongly notched in the interradial spaces. The dorsal surface is covered with small imbricated plates of which the outlines are only slightly evident; each of these plates carries a small conical club-spine, which is pointed, rather thick at the base, and tapers rapidly to its extremity. The radial shields are rather large, triangular, elongated, twice as long. as broad, in contact throughout almost their whole length and only separated proximally by a small triangular plate. The ventral surface is covered with rather large imbricated plates, which carry club spines only toward the periphery of the disk. The genital slits are narrow, but very evident.

The mouth shields are small, triangular, a little broader than long, with a sharp proximal angle and straight sides which pass over 
rounded angles to unite in a distal border which is similarly rounded. The adoral plates are very large and broad, especially in their external portion, and outwardly they extend much beyond the mouth shield which they separate from the first side arm plate. The oral plates are triangular and rather low. The lateral mouth papillae are three in number; the external is very large, quadrangular, three times as broad as high, and has the form which I have described in the genus Ophioleda; the two others are narrow, conical, and pointed; the unpaired terminal papilla is thick, conical, and rather large.

The arms are moniliform and made up of relatively much elongated segments. The upper arm plates are triangular, elevated, almost. as broad as long, with a proximal angle bounded by two straight sides and a very convex distal border. They are widely separated beyond the first.

The first under arm plate is small, pentagonal, a little longer than broad, with a sharp proximal angle and straight sides; it is widely separated from the second. The following plates are small, pentaonal, with an obtuse proximal angle, straight sides, and a slightly rounded distal border a little depressed in the middle. These plates are a little longer than broad, and are broadly separated from each other.

The side arm plates, which project strongly, bear at the base of the arms six rather long, slender, pointed, and finely denticulated spines; the first ventral spine is shorter than the segment, and the last dorsal exceeds a segment and a half. On the two or three first segments the lateral rows of spines come very close together in the dorsal median line of the arm.

The single tentacle scale is large, elongated, rather narrow. twice as long as broad, with the tip obtuse.

The color of the specimen in alcohol is white.

I had already drawn up the description of this species and assembled the photographs on plate 23 when I received Matsumoto's first memoir-that of 1915. As that naturalist had not, strictly speaking, given any description of $O$. venustus, but had only determined the differences which separate it from Ophiothamnus (Ophiomitra) habrotatus (H. L. Clark), I believed it worth while to give here a description and two photographs of the specimens collected by the Albatross. Matsumoto's final memoir, which appeared in 1917, included a detailed description and figures of $O$. venustus ('17, p. 126, fig. 32). Not being able at this time to alter my plates, $I$ have allowed the explanation accompanying my photographs to stand. It may also be useful to compare the Albatross specimen with Matsumoto's type, in spite of its smaller size.

I will add some notes on the subject of the genus Ophiothamnus. Matsumoto has the great credit of dissipating the doubts which 
have arisen in regard to this genus by showing that various species recently assigned to Ophiothamnus do not possess the characters of that genus at all, while others, assigned to different genera, must be considered as true species of Ophiothamnus.

He places in this genus the following species:
Ophiothamnus vicarius Lyman.
Ophiothammus affinis Ljungman.
Ophiothamnus remotus Lyman.
Ophioleda minima Kœhler.
Ophiomitra habrotata H. L. Clark.
Ophiothamnus venustus Matsumoto.

The other species assigned to the genus Ophiothamnus are placed by Matsumoto in the new genus Ophiurothamnus, which is represented in the Albatross collection by two species, which I shall consider shortly.

From the enumeration of the species given above it is seen that Matsumoto places in the genus Ophiothamnus, Ophioleda minima, which I had at first placed in the genus Ophioplinthaca, and for which I had later believed it necessary to create the genus $O$ phioleda. According to Matsumoto, Ophioleda is a synonym of Ophiothamnus. As the learned Japanese naturalist has given some notes on the internal structure of this last genus, I wished to compare with it the structure of Ophioleda minima. Unfortunately, because of its small dimensions, and especially because of the small number of individuals which I have at my disposal, it has not been possble for me to obtain a sufficient number of preparations to allow me to decide whether the genus Ophioleda should be retained or should be considered as a synonym of the genus Ophiothamnus. I therefore provisionally leave the question open, regarding as very plausible the union proposed by Matsumoto.

\section{Genus OPHIUROTHAMNUS Matsumoto.}

Notes.-Speaking of the genus Ophiothamnus, Matsumoto ('15, p. 63) remarked, as I have stated above, that certain species assigned to this genus did not accord entirely with Lyman's conception of it, or with the type that he had chosen. He notes especially Ophiothamnus exiguus (Lyman), 0 . laevis Lütken and Mortensen, and $O$. stultus Kohler as species which should not have been assigned to Ophiothamnus. I have profited by the opportunity which I have had to study again a specimen of Ophiothamnus stultus with a view to determining the question, and $I$ have arrived at this conclusion, conformable with Matsumoto's view, that it is necessary to create, in addition to the genus Ophiomitrella, a new genus in which Ophiothamnus stultus Kohler and Ophiomitra dicycla H. L. Clark, as 
well as a new species which I shall describe below, may find a place. This genus will have the following characters:

Ophiacanthidae near the genus Ophiomitrella, from which they differ in the small number of plates covering the dorsal surface of the disk; these plates are in compensation rather large, and they are sometimes enough developed to attain a size nearly equal to that of the radial shields; these latter are also rather large, and the two shields of each pair are in contact throughout their entire length; besides these plates there occurs on the periphery of the disk a very well-developed plate occupying the whole interradial space, or at least the greater part of this space, between the pairs of radial shields; this plate passes over to the ventral surface of the disk, which it in a very large part covers, the remainder of this surface being occupied by a very small number of plates. The outermost mouth papilla is more developed than the others, and is ordinarily much broadened; the others, few in number, form a regular series to which is added a terminal unpaired papilla. The adoral plates, which are very broad and rather short, do not separate the mouth shield from the first side arm plate. The arms are more or less moniliform, slender, and elongated; the under arm plates occupy the whole width of their ventral surface, and they are separated very widely by the side arm plates, as are also the upper arm plates. The arm spines are much elongated on the first segments, and the two lateral rows come very close together in the dorsal median line. There is a single tentacle scale.

I can not say anything in regard to the internal structure, having had at my disposal only a single specimen of $O$. stultus, and a single adult of the new species, which I assign to the same genus.

Some years before the publication of Matsumoto's final memoir, which appeared in 1917, I had applied a name to this genus, which I considered as new; since I have studied this memoir I have become aware that the genus Ophiurothamnus, created by Matsumoto, exactly corresponds to my new genus. I hasten, therefore, since I am still able to do it, to replace the name which I had chosen by Ophiurothamnus, which the Japanese naturalist proposes. If the characters which I assign to my genus, and which I have not modified, are compared with those which Matsumoto has given for the genus Ophiurothamnus, it will be seen that they are perfectly in accord, excepting only concerning the transformation of the ventral spine into a hook in the distal portion of the arms, which Matsumoto indicates as being characteristic of the new genus; but this occurs only in one of the four species assigned by Matsumoto to the genus Ophiurothamnus-Ophiothamnus laevis Luitken and Mortensen. I may state in the most explicit way that the first ventral spine retains 
the same form throughout the whole length of the arm in 0 . stultus, which I described in 1904 ('04, p. 141). The description of $O$. dicyclus, published by H. L. Clark ('11, p. 181), makes no mention of this modification, and neither Lyman nor Verrill have made any allusion to it in speaking of $O$. exiguus. I shall describe further on a new ophiuran collected by the Albatross, which I assign to the genus Ophiurothamnus-O. excavatus-and in this, as in O. stultus, I do not observe the least tendency for the first ventral spine to become transformed into a hook in the terminal part of the arm (see pl. 22, figs. 4, 6).

Ophiothamnus laevis thus differs from the other species now included in the genus Ophiurothamnus by this transformation of the first ventral spine into a hook in the distal region of the arms, which was described by Lütken and Mortensen. Is this character sufficient to make it necessary to take this species out of the genus Ophiurothamnus and to place it in another genus? I do not think so, more especially since the transformation into a hook, so far as can be judged by Lütken and Mortensen's figure ('99, pl. 19, fig. 4) is not very marked; there is not a true compound hook here, like that which we have seen appear in Ophiotretx matura and Ophientrema leucostictum, and which recalls that of the species of Ophiothrix; the modification is especially produced by the irregular and unequal denticulations which are developed on one of the borders of the ventral spine, in combination with a curvature of the tip.

But, however that may be, it seems to me indispensable to remove from the diagnosis of the genus Ophiurothamnus established by Matsumoto the phrase relative to the transformation of the first ventral spine into a hook, the more so as it only refers, as I have just said, to a sort of imitation hook. To the four species which Matsumoto has already assigned to the genus Ophiurothamnus-O. dicylus (H. L. Clark) (genotype), O. exiguus (Verrill), O. stultus (Kœhler), and perhaps $O$. laevis (Lütken and Mortensen)-there must be added the new species which I am describing below, and to which I propose to give the name of $O$. excavatus.

\section{OPHIUROTHAMNUS STULTUS (Kohler).}

Plate 22, figs. 1-4.

Ophiothamnus stultus KaHLER ('04), p. 141, pl. 25, figs. 9, 10 ; pl. 26, fig. 1.-

H. L. Clark ('15), p. 209.

Ophiurothamnus stultus Matsumoto ('17), p. 130.

Locality.-Albatross station 5660; Flores Sea; Cape Lassa, bearing S. $88^{\circ} \mathrm{W}$., 37.99 kilometers (20.5 miles) distant (lat. $5^{\circ} 36^{\prime} 30^{\prime \prime}$ S., long. $120^{\circ} 49^{\prime} 00^{\prime \prime}$ E.) ; 1,266 meters (692 fathoms); December 20,1909 ; gy. M., S.

One specimen (Cat. No. 41194, U.S.N.M.). 
Notes.-The diameter of the disk measures $4.5 \mathrm{~mm}$.; the arms are about $25 \mathrm{~mm}$. long.

The individual agrees well with the description which I gave in 1904. For comparison with the following species, I am inserting here four photographs of this specimen (pl. 22, figs. 1-4.)

OPHIUROTHAMNUS EXCAVATUS, new species.

Plate 22, figs. 5-8.

Locality.-Albatross station 5428; eastern Palawan and vicinity; 30th of June Island bearing N. $62^{\circ}$ W., 36.14 kilometers (19.5 miles) distant (lat. $9^{\circ} 13^{\prime} 00^{\prime \prime}$ N., long. $118^{\circ} 51^{\prime} 15^{\prime \prime}$ E.) ; 2,021 meters (1,105 fathoms); April 3, 1909 ; gy. M.

Two specimens (Cat. No. 41195 , U.S.N.M.).

Description.-In the larger specimen, which I have taken as the type, the diameter of the disk is $5.5 \mathrm{~mm}$; the arms are incomplete, broken off at $15 \mathrm{~mm}$. from the base; they must have been about 25 $\mathrm{mm}$. long; in the second specimen, which is much smaller, the diameter of the disk is only $3.5 \mathrm{~mm}$.

The disk is rounded, but in both specimens the dorsal surface is strongly depressed and forms a sort of rather deep cup delimited by a sharp border; the ventral surface is very convex.

The dorsal surface is covered with plates which are rather large, especially in the central region, becoming smaller and also very unequal an the rest of the disk; they are somewhat imbricated. There may be distinguished a large rounded dorsocentral plate, and beyond it four smaller primary radial plates which are transversely broadened and separated from the dorsocentral by a very narrow space. The remaining plates are very much smaller. In the radial areas following the primary radials there are two plates arranged tandem, of which the more distal separates the proximal ends of the two radial shields of each pair. In the interradial areas the plates are irregularly arranged in three rows, and the border of the disk is delimited by three rectangular plates, all having about the same dimensions. Following these three plates there is another very large plate which occupies almost all of the interradial space on the lateral surface of the disk, which is almost vertical (fig. 5); this plate extends over the ventral surface between the genital slits as far as a given distance from the mouth shields. The radial shields are rather small, smaller than the dorsocentral, scarcely longer than broad, and irregularly triangular, with a rounded proximal angle. The two shields of each pair are in contact throughout almost their whole length, and are separated inwardly by the plate which I have noted above. Some of the plates of the central region, about 10 in all, carry a short, thick, blunted spine, of which the surface is covered with fine asperities which elongate somewhat at the tip. Other 
similar spines, more closely crowded and more numerous, are found at the periphery of the disk, where they form a rather regular border. In view of the small height of these spines, they might quite as well be given the name of elongated granules.

The ventral surface of the disk in the interradial spaces runs very obliquely downward because of the strong convexity of that surface. It is covered for the greater part of its area by the large plate which I have noticed above. Following this come two rectangular transversely broadened plates, in contact in the interradial median line, and separated from the mouth shield by two or three very much smaller plates placed on each side of the distal lobe of these shields within the ends of the genital slits. These latter are rather large, very evident, and are continued for more than half the height of the large interradial plate. They are bordered on each side by a narrow plate which throughout its entire length carries extremely fine and very closely crowded teeth which are especially evident under the microscope.

The mouth shields are rather large, triangular or lozenge-shaped, much broader than long, with a very open proximal angle bordered by two concave sides, and a convex distal border showing a more or less marked rounded lobe in the middle. The adoral plates are large and broad, with the long borders parallel, two and a half times as long as broad. The oral plates are triangular, rather low, broader than high. The lateral mouth papillae are three in number; the outermost is very large, rounded, and squamiform; the two others are slender, elongated, and conical. The unpaired terminal papilla is very broad and thick, and its free border is usually excavated in such a way that the papilla ends in two blunted points.

The upper arm plates are very large, triangular, very much broader than long, with an obtuse proximal angle and a very convex distal side; their surface is also very convex. These plates are widely separated from the base of the arm outward by an interval which quickly becomes greater than their own length.

The first under arm plate is large, trapezoidal, a little longer than broad, with the proximal border longer than the distal. The following plates are very large and occupy the whole width of the ventral surface of the arms; they are very much broader than long, pentagonal, with a very obtuse proximal angle bordered by two straight sides, two straight lateral borders, and a slightly convex distal side. They are separated by a space, which, from the third arm segment outward, is greater than their own length.

The very strongly projecting side arm plates carry at the base of the arms five arm spines; the dorsal spines on each side come very close together in the median dorsal line on the first segment without, 
however, forming a continuous row. The length of the first ventral spine equals that of the segment, and this length increases only very slightly to the last dorsal spine, which does not exceed a segment and a half. These spines are thick and strong with a very rugase surface sometimes even showing small irregular and rather well spaced denticulations. As in 0 . stultus the first ventral spine retains the same character throughout the whole length of the arms and does not show the least tendency to become transformed into a hook in their distal portion (fig. 6).

The tentacle scale is small and short, a little longer than broad, with the tip rounded.

The color of the two specimens in alcohol is white.

Affinities and distinctive features.-Ophiurothamnus excavatus falls perfectly well within the genus Ophiurothamnus, with $O$. stultus; it is easily distinguished from the latter by the very large and very short spines of the dorsal surface of the disk, and by the similarly rather short and thick arm spines. The strong depression of the dorsal surface, corresponding to which is the very convex form of the ventral surface, is seen in both the specimens at hand; it may be asked whether this feature occurs in the living animal, or whether it is due simply to the action of the alcohol.

\section{OPHIOMITRA DIVES, new species.}

Plate 10, figs. $1-4$; plate 94 , fig. 2.

Locality.-Albatross station 5543 ; Tagolo Light bearing S. $75^{\circ} \mathrm{W}$., 23.16 kilometers (12.5 miles) distant (lat. $8^{\circ} 47^{\prime} 15^{\prime \prime} \mathrm{N}$., long. $123^{\circ}$ $35^{\prime} 00^{\prime \prime}$ E.) ; 296 meters (162 fathoms); August 20, 1909; S.

Two specimens (Cat. No. E. 22, U.S.N.M.).

Description.-The two individuals are in a very good state of preservation, and the larger is quite complete. The diameter of the disk is $17 \mathrm{~mm}$., and the arms are about $110 \mathrm{~mm}$. long; the arms are rather thick, provided with strong spines, and the habitus of the animal is very robust. The second specimen is a little smaller, and its disk is only $15 \mathrm{~mm}$. in diameter.

The disk is rounded and thick; the dorsal surface is gently depressed in the middle, while the ventral surface is a little convex; the borders are rounded. The dorsal surface between the large radial shields is covered with small, imbricated plates becoming a little larger at the periphery of the disk, in the interradial spaces and in the vicinity of the radial shields. In the interradial spaces, there may be counted four or five series of plates; in the radial spaces between the two shields of each pair there is found only a single series of narrow plates, and sometimes these plates do not reach the periphery of the disk. Each plate carries a large rounded granule, which, 
in the central region of the disk, covers almost the whole surface of the plate. These granules appear smooth to the naked eye, but under the microscope they are seen to be furnished with very fine small teeth (pl. 94, fig. 2); they are continued with the same characters as far as the periphery of the disk and between the radial shields. These last are large, triangular, two and a half times as long as broad, and their length almost equals half the radius of the disk. The two radial shields of each pair are slightly divergent and are separated by a single range of narrow plates; sometimes they are in contact outwardly, and sometimes they are separated by a small interval occupied by a single plate.

The ventral surface of the disk is covered with rather small, irregularly polygonal and slightly imbricated plates, on which I only find in very exceptional cases granules similar to those of the dorsal surface. The genital slits are very broad and extend from the mouth shield to the periphery of the disk.

The mouth shields are small, a little longer than broad, with a rather obtuse proximal angle bounded by two straight sides; the two other sides are slightly excavated, and they pass over two very rounded angles to form the distal border, which is similarly rounded and smaller than the four other almost equal sides. The adoral plates are extremely broad, a little broader without than within, and their length does not very much exceed their width; their four sides are straight, and they are in contact with each other throughout their entire width in the interradial median line. The oral plates are rather large, triangular, higher than broad. The lateral mouth papillae, three in number, are irregularly arranged; they are rather broadened, squamiform and rounded; their dimensions diminish slightly from the outermost to the innermost. In addition there is a group of three or four tooth papillae which are more elongated and conical, with the point blunted.

The arms themselves are not very large, and their width scarcely exceeds $3 \mathrm{~mm}$. even at the base, but the arm spines, which are very long and stout, help to give them a general appearance of extensive development, the more so since the arm segments are rather short. The upper arm plates are small, triangular, twice as broad as long, with an acute proximal angle bounded by two straight sides, a slightly convex distal border, and sharp lateral angles; they are separated from the base of the arm outward by a space almost equal to half their length which is occupied by the side arm plates.

The first under arm plate is rather large, triangular, broader than long, with a broadened proximal border and a rather open and rounded distal angle. The following plates, which are of medium size, are rectangular, broader than long, with a straight and rather 
narrow proximal border, diverging sides very strongly excavated by the tentacle scale, and a very broad and convex distal border; this last passes over into the sides by very prominent rounded angles, almost as broad as the tentacle scales of which they simulate the outline in such a way that in a superficial examination of the arms one might believe that two successive tentacle scales are present. The second plate is in contact with the first, but beyond this these plates are separated by a space which is occupied only on the sides by the side arm plates, the middle being filled with soft tissue. The side arm plates show a much elevated ridge, which, at the base of the arms, carries nine spines, this figure falling to eight and then to seven. These spines are cylindrical, rather stout, with the extremity obtuse and rounded; their length increases from the first ventral, which is almost as long as two segments, to the antepenultimate, which is almost equal to four segments; the last spine is usually a little shorter. Their surface is rugose, and under the microscope very fine and very closely crowded asperities may be made out, which become more marked toward the extremity of the spine. The two lateral rows of spines come very close together in the dorsal median line, but they are not, however, continuous with each other, remaining separated by the proximal angle of the upper arm plates. These spines are solid.

The tentacle scale is single, except on the first segment, on which the pores have two scales, the external a little the smaller; it is not very large, and is oval in form, a little longer than broad.

The general color of the specimen is light red; the plates of the dorsal surface of the disk with their granules are darker. The radial shields are irregularly bordered with dark gray; a straight line, also dark gray, extends along the middle of the dorsal surface of the arms throughout their entire length. The two surfaces of the arms as well as the spines are light red, becoming a little darker in the terminal part. The ventral surface of the disk is roseate, darker in the interradial spaces.

Affinities and distinctive features.-It seems to me that this ophiuran must be placed in the genus Ophiomitra in the restricted sense as adopted by Verrill, because of the presence of tooth papillae and the solid spines, but it differs notably from several species assigned to that genus, and also to related genera in its very robust structure, in the considerable development of the spines, in the form of the under arm plates, and in its coloration, which gives it an appearance recalling that of an Ophiothrix. It shows some resemblance to the species described under the name of Ophiomitra spinosissima by H. L. Clark, which comes from Porto Rico, but this last is not an Ophiomitra in Verrill's sense, and it seems to me rather to represent the type of a special genus. 


\section{OPHIOMITRELLA EXILIS, new Epecies.}

Plate 22, figs. 9, 10.

Locality.-Albatross station 5637 : Bouro Island (S.) and vicinity; Amblau Island (N.) bearing N. $80^{\circ}$ E., 38.92 kilometers (21 miles) distant (lat. $3^{\circ} 53^{\prime} 20^{\prime \prime}$ S., long. $126^{\circ} 48^{\prime} 00^{\prime \prime}$ E.) ; 1,280 meters (700 fathoms); December 10, 1909; gy. M.

One specimen (Cat. No. 40949 , U.S.N.M.).

Description.-The diameter of the disk does not exceed $5 \mathrm{~mm}$., and the arms are about $15 \mathrm{~mm}$. long; three of them are incomplete; they are very narrow, moniliform, and somewhat contorted.

The disk is rounded, but rather strongly excavated in the interradial spaces. The dorsal surface is covered with very numerous plates, which are small, closely crowded, imbricated and subequal, smallest in the central region and becoming a little larger toward the periphery. These plates carry very small, short cylindrical clubspines, which are as long as broad, each terminated by a crown of half a dozen fine and elongated spinules. These club spines are lacking on a rather large portion of the surface of the disk, but they have certainly been rubbed off. The radial shields are small, triangular, with a proximal apex; they are twice as long as broad, and their length does not even reach a quarter of the radius of the disk; the two shields of each pair are widely separated by a space which is almost equal to the width of the arm.

The ventral surface of the disk in the interradial spaces is covered with small, imbricated and equal plates, provided with club-spines identical with those of the dorsal surface, but on which the terminal spinules are shorter; these club-spines are continued to the vicinity of the mouth shields. The genital slits are narrow, but very distinct.

The mouth shields are rather large, triangular, with a sharp and somewhat produced proximal angle, bounded by two slightly concave sides which pass over rounded angles and unite to form the convex distal border; they are a little broader than long. The adoral plates are rather narrow, elongated, at least four times as long as broad, and they give off outwardly a narrow process which separates the mouth shield from the first side arm plate; their internal border is strongly notched by the large external mouth papilla. The oral plates are triangular, and higher than broad. The mouth papillae are four in number on each side. The external papilla, borne by the adoral plate, is very broad at the base, but pointed and conical; the second is also rather large and of a form similar to the preceding, but smaller; the two others are narrow and pointed. The unpaired terminal papilla is stouter than the others; it is similarly conical and pointed.

The upper arm plates are small, triangular, and very convex; they show a rather open proximal angle and a convex distal border. They 
are a little broader than long and are separated from the base of the arm outward by an interval which at first is equal to their length and becomes progressively elongated.

The first under arm plate, which is of medium size, is triangular, with a rounded proximal angle. The following plates are large, pentagonal, very much broader than long, and they occupy the whole width of the ventral surface of the arms. They have a very obtuse proximal angle bounded by two straight sides, two diverging and straight lateral borders, and a slightly rounded distal border; these plates are widely separated from the base of the arms outward.

The strongly projecting side arm plates carry eight spines at the base of the arms, but this figure diminishes very rapidly; the first ventral spine is shorter than the segment, and the length thence increases progressively to the last dorsal spine, which may be as long as three segments, but the relative length of this spine diminishes rapidly. These spines are slender and pointed, and provided with rather well-separated fine denticulations. On the first arm segment the two lateral series of spines come very close together in the median dorsal line and are continuous with each other.

The single tentacle scale is large, oval, and broadened on the pores of the first pair; it becomes progressively narrower and elongated on the following segments, though still remaining oval, and finally becomes spiniform and pointed.

Affinities and distinctive features.-The arrangement of the dorsal plates of the disk and their armature recalls Ophiomitra polyacantha H. L. Clark, but the radial shields of $O$. exilis are very much smaller and more separated, the tentacle scale is smaller, the arm spines are less numerous, and the mouth pieces show a very different arrangement. Ophiomitra exilis also recalls $O$. monitiformis Kœhler, but in this the dorsal plates of the disk bear rounded and smooth granules, the mouth shields are almost as long as broad, the outermost mouth papilla is not especially broadened, and the arm spines are less numerous.

\section{OPUIOMITRELLA SAGITTATA, new species.}

Plate 27 , figs. $1-4,9$; plate 95 , fig. 4 .

Localities.-Albatross station 5621; between Gillolo and Makyan Islands; Makyan Island (S.) bearing N. $54^{\circ}$ W. 5.56 kilometers (3 miles) distant (lat. $0^{\circ} 15^{\prime} 00^{\prime \prime} \mathrm{N}$., long. $127^{\circ} 24^{\prime} 35^{\prime \prime}$ E.) ; 545 meters (298 fathoms); November 28, 1909; gy. and bl. (m. b.).

One specimen (Cat. No. 41009 , U.S.N.M.).

Albatross station 5623; between Gillolo and Makyan Islands; Makyan Island (S.) bearing S. $88^{\circ}$ W., 13.90 kilometers (7.5 miles) distant (lat. $0^{\circ} 16^{\prime} 30^{\prime \prime}$ N., long. $127^{\circ} 30^{\prime} 00^{\prime \prime}$ E.) ; 497 meters (272 fathoms); November 29, 1909 ; fne. S., M.

One specimen (Cat. No. 41010, U.S.N.M.). 
Albatross station 5629; Patiente Strait and southward; Doworra Island (S.) bearing $62^{\circ} \mathrm{W}$., 11.1 kilometers (6 miles) distant (lat. $0^{\circ} 50^{\prime} 00^{\prime \prime}$ S., long. $128^{\circ} 12^{\prime} 00^{\prime \prime}$ E.) ; 374 meters (205 fathoms); December 2,1909 ; co. S.

Two specimens (Cat. 41008, U.S.N.M.).

Description.-In the largest specimen, which is one of those from station 5629, the diameter of the disk is $9 \mathrm{~mm}$.; three entire arms remain attached to the disk; they are rather strongly contorted, and their exact length is difficult to estimate; they must be about $35 \mathrm{~mm}$. long; these arms are rather thick, and in a general way the appearance of the individual is rather robust. In the other specimen from the same station the diameter of the disk is $8 \mathrm{~mm}$.; the arms are a little more slender and a little longer, and also rather strongly rolled up; they must be about $40 \mathrm{~mm}$. long. In the two other individuals the diameter of the disk measures respectively $7 \mathrm{~mm}$. and $4 \mathrm{~mm}$.

I shall describe the species more especially from the two specimens from station 5629, of which the larger is shown in figures 1,2 and 3 on pl. 27; the ventral surface of the other is shown in figure 4. I also reproduce (fig. 9) a photograph of the ventral surface of the specimen from station 5623, in which the shape of the mouth shields is a little different.

The disk is rounded. The dorsal surface is covered with rather large plates, each one of which bears a large, very short, and thick club spine, which broadens abruptly at its extremity into a large, trilobed head; the width of this head may reach twice the length of the cylindrical stem of the club spine (pl. 95, fig. 4). In the vicinity of the periphery of the disk the heads of these club spines are less developed, and often they are simply spherical. The surface of these large heads is very rugose, and under the microscope short and closely crowded asperities may be made out. This structure exactly recalls that which I have previously described in 0 . mutata, to which species $O$. sagittata shows a rather strong resemblance in other ways. As in that species, the radial shields are small, triangular with the angles rounded, and a little longer than broad; the two shields of each pair are divergent and widely separated throughout their whole length. Their surface is always naked, but their distal border sometimes carries two or three small granules.

The ventral surface of the disk is covered with large slightly imbricated plates, almost all of which are without club spines. These occur only at the periphery, in the form of small elongated granules with the end rounded. The genital slits are narrow.

The mouth shields are remarkable for their sagittate form. They are almost as long as broad, or perhaps a little longer than broad; they have a sharp proximal angle, which is prolonged toward the mouth, bounded by two divergent and straight sides which at first 
are directed obliquely outward, and then suddenly form a very obtuse angle and continue outward perpendicularly to the median interradial line; after a certain distance they reunite, each passing over a very acute angle, with the two distal sides which together form an obtuse and very rounded angle. The adoral plates are situated on either side of the mouth shields, and are not in contact in the median interradial line; they are broadened outwardly and taper gradually as far as their proximal end, which is pointed and which lies at the same level as the proximal angle of the mouth shield. The oral plates are triangular, short, and low. The mouth papillae are four in number on each side; their form is rather irregular, especially that of the two proximal papillae, which are flattened with the free border irregularly jagged or lobed; the two distal papillae have the base much broadened and they taper rather abruptly beyond the middle. The unpaired terminal papilla is broadened and flattened, broader than those preceding, and its free border shows three or four small, irregular, and unequal lobes. In the second specimen from station 5629 (pl. 27 , fig. 5 ) the form of the mouth papillae is very much more regular, and it is the same in the two other specimens. In that from station 5623 (fig. 9) the mouth shields have not quite the same outlines as in the others, and the lance-head shape is less marked. This is especially because the proximal angle and the two lateral angles are more or less rounded, and the sides are somewhat incurved.

The upper arm plates are rather large, triangular, broader than long, with a rather acute proximal angle and an almost straight distal border. They are separated from the base of the arm outward by an interval at first very short but gradually elongating. At some distance from the base of the arms these plates become a little longer than broad and slightly bell-shaped.

The first under arm plate is quadrangular or trapezoidal with the distal border a little shorter than the proximal border. The two or three following plates are quadrangular, with a rather narrow proximal border, and an extremely broad and convex distal border passing over sharp angles into the sides which are very divergent and strongly excavated by the tentacle scale; these plates are very much broader than long. Beyond the disk the plates become pentagonal with an obtuse proximal angle, and they soon become a little longer than broad, at the same time becoming separated by a very narrow interval.

The rather strongly projecting side arm plates bear eight or nine large, thick, strong cylindrical spines, with the tips blunted, at least in those which are found on the ventral side; the dorsal spines are more slender and pointed. These latter, on the first segments, come 
very close together in the median dorsal line of the arm, though the two rows remain distinct on each side and are not continuous with each other. The surface of the spines shows a few rugosities which are very irregular and inconstant, but no denticulations properly speaking. The length of the first ventral spine equals that of the segment; the last dorsal spine is as long as two segments.

The tentacle scale of the pores of the first pair is single, rather large, broadened, and almost circular; it becomes narrower on the three or four following pairs, and then conical and rather pointed, though always remaining short.

Affinities and distinctive features.-Ophiomitrella sagittata is very close to O. mutata Kohler, which it recalls in the armature of the dorsal surface of the disk; but the form of the mouth shields is very different, and the elongation of the proximal angle prevents the two adoral plates of each pair from touching each other in the median interradial line; the upper arm plates have the distal border very much less convex, the spines are more numerous and stouter, and, as it seems to me, shorter than in O.mutata. Although these differences are not very important, I have not felt myself justified in uniting the two species; perhaps the examination of more numerous specimens will show intermediate forms, particularly in reference to the outlines of the mouth shields; but at present none are known.

OPHIOMITRLLA SUBJECTA, new species.

Plate 26, figs. 5-9; pl. 94, fig. 4.

Localities.-Albatross station 5280; China Sea in the vicinity of southern Luzon; Malavatuan Island (N.) bearing S. $60^{\circ}$ W., 11.3 kilometers ( 6.1 miles) distant (lat. $13^{\circ} 55^{\prime} 20^{\prime \prime} \mathrm{N}$., long. $120^{\circ} 25^{\prime} 55^{\prime \prime}$ E.) ; 353 meters (193 fathoms) ; July 17, 1908; gy. S.

Three specimens (Cat. No. 41287, U.S.N.M.).

Albatross station 5300; China Sea in the vicinity of southern Luzon (lat. $20^{\circ} 31^{\prime} \mathrm{N}$, long. $115^{\circ} 49^{\prime}$ E.) ; 485 meters 265 fathoms); August 8, 1908; gy. M., S.

One small specimen (Cat. No. 41286 , U.S.N.M.).

Albatross station 5325; off northern Luzon; Hermanos Island (N.) bearing N. $86^{\circ}$ E., 31.04 kilometers (16.75 miles) distant (lat. $18^{\circ} 34^{\prime}$ $15^{\prime \prime}$ N., long. $121^{\circ} 51^{\prime} 15^{\prime \prime}$ E.) ; 410 meters (224 fathoms) ; November 12,1908 ; gn. M.

Two specimens (Cat. No. 41288, U.S.N.M.).

Description.-In the largest specimen, which is one of the two from station 5325 , the diameter of the disk is $9 \mathrm{~mm}$.; the arms are incomplete. The other specimens are a little smaller, and in one of them, in which the disk is $8 \mathrm{~mm}$. in diameter, the arms reach $40 \mathrm{~mm}$. in length. In the smaller from station 5325 the diameter of the disk is only $5 \mathrm{~mm}$. In the specimen from station 5300 the diameter 
of the disk does not exceed $3 \mathrm{~mm}$., and a single arm is preserved for (inly a few segments.

The disk is rounded or pentagonal, with the interradial regions a. little produced. The dorsal surface is covered with plates with very evident outlines, which are rather thick, imbricated, smallest in the central region, becoming larger toward the periphery. Each of these bears a large club spine which abruptly broadens into a welldeveloped head, and this head is divided into three divergent lobes provided with strong conical spinules (pl. 94, fig. 4). The length of the cylindrical portion of the club spine is almost equal to its diameter. These club spines are very closely crowded in the central region of the disk, becoming more separated toward the periphery, their heads at the same time tending to assume a simpler form and to become merely a swelling furnished with pointed spines; then these heads themselves disappear, while simultaneously the clubspine elongates somewhat and from then on resembles a spine. In the large specimen from station 5325, shown in figure 8 , the clubspines are more elongated, and their head is less large and is not trilobed, or at least only has very slightly marked lobes; these clubspines show on their surface very evident spinules, and they thus much resembles true spines, like those which are seen on the border of the disk in the other specimens. The radial shields are small, triangular, and longer than broad; they may bear toward their distal border two or three club-spines terminated by a few short spinules. The two shields of each pair are slightly divergent, and they are widely separated by two or three series of plates.

The ventral surface of the disk is covered with large unequal plates, which do not bear club spines except toward the periphery. The genital slits are rather broad.

The mouth shields are a little broader than long, somewhat lozengeshaped, with a much elongated and pointed proximal angle, which is produced toward the mouth between the two adoral plates and which is bounded by two very concave sides; the lateral angles are sharp and the distal border is convex and shows in the middle, a more or less prominent rounded lobe; it may be said also that this border is composed of two short sides passing into each other by a very rounded obtuse angle. The adoral plates, which are of medium size, are slightly recurved and crescentic; they are three times as long as broad. The oral plates are small, triangular, and little elevated. The lateral mouth papillae, which are four in number, are conical, rather elongated, with the point blunted; the proximal papilla is usually a little broader than the others. The unpaired terminal papilla is thick and stout and a little more developed than those on either side. 
The upper arm plates are rather large, triangular or slightly bellshaped, with a sharp proximal angle and a convex distal border. From the base of the arm outward they are separated from each other by a narrow interval.

The first under arm plate is triangular, with a distal rounded angle and the proximal side excavated; it is a little broader than long. The second is very large, triangular, very much broader than long, with a proximal angle, and with the distal border slightly convex. The following plates become pentagonal, with a very obtuse proximal angle and a convex distal border; they are at first broader than long, but they become progressively elongated, and, beyond the sixth, they are a little longer than broad. Beyond the second they are separated by a narrow interval.

The side arm plates, which project moderately, carry eight or nine stout cylindrical spines with the point rounded and slightly echinulated, especially on the ventral spines. The first ventral spine is as long as the segment and the last dorsal equals two segments and a half.

The rather well-developed tentacle scale is always single. On the pores of the first pair this scale is rounded, rery broad, and rather short; on the following segments it elongates a little and becomes twice as long as broad, with the tip rounded.

Affinities and distinctive features.-Like 0 . sagittata, 0 . subjecta is very close to 0 . mutata Kohler, but it is distinguished from it by the shape of the club spines on the dorsal surface of the disk, in which the head forms three divergent lobes armed with very strong teeth; this head assumes a simply rounded form and gradually disappears at the periphery of the disk in such a way that the club spines end by resembling small true spines; and this last-mentioned character they maintain over the whole extent of the dorsal surface in the largest specimen from station 5325 ; but whatever may be the form of the head, these club spines are sharply differentiated from those which $\mathrm{I}$ have described in $O$. mutata, in which the head remains perfectly smooth. The mouth shields are shorter than in 0 . mutata, and the proximal angle is more elongated and sharper; the upper arm plates are larger, the spines are more or less strongly echinulated, etc.

In 0 . sagittata the club spines of the dorsal surface of the disk are similarly terminated by a trilobed head, the form of which is close to that taken by the club spines in $O$. subjecta toward the periphery of the disk; 0 . sagittata is further distinguished from 0 . mutata and from 0 . subjecta by the form of the mouth shields, which is quite remarkable. Furthermore, the mouth papillae also show peculiar characters, the spines are somewhat echinulated, and the upper arm plates are a little more elongated than in 0. mutata. 
As $O$. mutata was established on the basis of only three specimens, and as $O$. sagittata and $O$. subjecta are both also represented by a very small number of individuals, it is very difficult to appraise the true value of the differences which I have given. Ophiomitrella subjecta from stations 5280 and 5325 seems to me, on account of the armature of its disk, to differ more from $O$. mutata than the individuals which $I$. have described under the name of $O$. sagittata.

However that may be, it has seemed to me preferable to describe under two different names the two forms collected by the Albatross; they can be later considered as simple varieties of $O$. mutato if we obtain new specimens showing intergrading forms.

Under the name of Ophiomitrella stellifera Matsumoto has just described ('17, p. 104) a Japanese species which seems to me also very close to $O$. sagittata, $O$. subjecta, and $O$. mutata. The plates of the disk bear rather broad club spines terminated by a stellate crown of six spinules which seems very regular, the form of the mouth shields is very different from that which I have described in the two species collected by the Albatross, and the upper arm plates are also broader and shorter than in $O$. stelligera.

\section{OPHIORIPA, new genus.}

Description.-I have thought it necessary to create, near the genus Ophiomitrella as defined by Verrill, another genus characterized by having the disk covered with very large subequal plates which are highly developed, especially in the central region, and which may attain dimensions equal to or scarcely less than those of the radial shields. These plates are thin, and, in the two known species of the genus, they show about their periphery a narrow and transparent border; some of them carry granules or spines which are always few in number. The radial shields, which are of medium size, are almost as long as broad. The lateral mouth papillae, three in number, are borne by the oral plates together with an unpaired terminal papilla. The arms, which are slightly or not at all moniliform, are more or less contorted; the upper arm plates are of small size and separated irom the base of the arm outward by the side arm plates. The under arm plates are also very small, widely separated, and only occupying a small portion of the length of the arms. The arm spines are not very long, and the two lateral series are widely separated in the median dorsal line of the arms.

Notes.-The genus Ophioripa differs from the genus Ophiomitrella in the large dorsal plates of the disk, which are provided with a transparent border, in the very small under arm plates, and in the wide separation along the median dorsal line of the arm of the columns of arm spines. It is distinguished from the new genus $O p h i o p h$ thatmus, recently established by Matsumoto and of which I shall 
speak further on, by the characters of the dorsal plates of the disk and by the very small upper arm plates which are separated from the base of the arms outward.

This genus is represented in the Albatross collections by two species, but unfortunately each includes only a single specimen of rather small size; in one of the two the plates of the dorsal surface of the disk bear extremely developed spines, which are as thick as the arm spines; in the other, which I take as the type of the genus, the spines are very much fewer and shorter and are reduced to simple granules.

Type of the genus. - Ophioripa marginata, new species.

OPHIORIPA MARGINATA, new species.

Plate 23, figs. 1, 2.

Locality-Albatross station 4781. One specimen (Cat. No. 41129, U.S.N.M.)

Description.-The diameter of the disk is $4 \mathrm{~mm}$.; the arms are incomplete, but they appear to be very short and could scarcely have exceeded $10 \mathrm{~mm}$. in length.

The disk is rounded. The rather swollen dorsal surface is covered with large subequal plates which are rounded and thin and show a very clearly marked narrow transparent border; their surface is finely granulose, but the granules do not pass onto the peripheral border. The plates of the central region are larger than the others, though a distinct primary rosette can not be recognized. The plates become smaller in the interradial spaces toward the periphery of the disk; in the vicinity of the edge of the disk or on the edge itself some of the plates bear a large elongated and rugose granule. I do not believe that these granules were more numerous on the living animal or that they occurred over the whole extent of the dorsal surface of the disk; in any case I do not see the least indication of scars left by granules which have been rubbed off. The radial shields are a little larger than the large central plates; they are triangular, with the angles and the sides rounded, almost as long as broad, and the two shields of each pair are in contact for almost their entire length, which scarcely reaches a quarter of the radius of the disk.

In the interradial spaces the ventral surface bears a small number of plates similar to those on the dorsal surface and showing, like them, a thin marginal border, but narrower and less evident. These plates occupy almost the distal half of the space included between the edge of the disk and the mouth shields; in the other half the plates suddenly become extremely small, very closely crowded, and imbricated. The very broad genital slits extend from the mouth shield to near the edge of the disk.

The mouth shields are rather small, triangular or lozenge-shaped, much broader than long, with a very obtuse proximal angle bordered 
by two straight sides, and a convex distal border showing in the middle a more or less marked rounded lobe. The adoral plates are elongated, with the long sides parallel, three or four times as long as broad, and they give off outwardly a narrow process which separates the mouth shield from the first side arm plate. The oral plates are large, triangular, higher than broad. The lateral mouth papillae, three in number, are rather large, elongated, rather narrow, pointed, and very rugose; the unpaired terminal papilla is larger than those on either side.

The arms are rather narrow, somewhat moniliform, with the segments elongated, and they are more or less incurved; the upper arm plates are small, triangular, with a rather open proximal angle and a strongly convex distal border; they are almost as long as broad and are separated by a space which is greater than their own length.

The first under arm plate is rather large, rectangular or trapezoidal, a little broader than long. The following, which are rather small, are pentagonal, with an obtuse proximal angle bordered by two straight sides, two straight lateral borders, and a rounded distal side which is more or less notched in the middle; they are a little longer than broad, and are separated from the first outward by a rather large interval. The second and the third plates are still of rather large size, but on the following the size diminishes rapidly.

The side arm plates, which are greatly developed, especially on the dorsal side, project strongly, and they carry at first six rather large, cylindrical, blunt-pointed spines. The first ventral spine is longer than the segment, and the length increases to the last dorsal, which, on the first arm segments, may reach a length of two segments. Their surface is very rugose and may even show very fine and very closely crowded denticulations.

The single tentacle scale is elongated, spiniform, and pointed, and its length equals about three-quarters of the length of the under arm plate.

OPHIORIPA NUGATOR, new species.

Plate 23, figs. $8,9$.

Locality.-Albatross station 4781. One specimen (Cat. No. 41128, U.S.N.M.)

Description.-The diameter of the disk is $5 \mathrm{~mm}$.; the arms, which are rather broad at the base, taper rather rapidly; they are more or less contorted, and their total length may be estimated as $15 \mathrm{~mm}$.

Ths disk is rounded, slightly incised in the interradial spaces. The dorsal surface is covered with large imbricated plates, among which those of the central region, which are very much larger than the others, stand out prominently. These last are unequal in size, and 
in each of the interradial spaces one of them is noticeable on account of its very much greater dimensions. A certain number of plates, and especially the large central plates, carry each a very large cylindrical and thick spine which remains of the same diameter to its rounded extremity; the surface of these spines is very rugose, and their length equals or even exceeds the diameter of the plate which carries them. My specimen has retained nine of these large spines, and I recognize the scars of a few others which must have been torn off. Other smaller spines occur here and there on the plates, and they finally pass into large elongated granules, with the extremity slightly swollen, which are seen on the periphery of the disk; these granules, like the large spines, are covered with very closely crowded asperities. All these dorsal plates show a narrow and very finely denticulated marginal border, less apparent and less broad, however, than in the preceding species. The radial shields are of almost the same dimensions as the large central plates; they are triangular, with the angles and the sides rounded; they are almost as long as broad, and their length is almost equal to one-fourth the radius of the disk; the two shields of each pair are in contact throughout their whole length.

The ventral surface of the disk is covered with rather large plates similar to those on the dorsal surface, but a little smaller, and showing, like them, a narrow and denticulated border; their dimensions diminish toward the mouth shields. The very broad genital slits extend from the mouth shield to the periphery of the disk.

The mouth shields are rather small, triangular, very much broader than long, with a rather prominent proximal angle bordered by two straight or slightly concave sides, and a rounded distal border; on two of the shields this border shows in the middle a small rounded lobe. The adoral plates, which are much elongated, have the long sides almost parallel; they are, however, a little broader distally, and often give off a narrow process which separates the mouth shield from the first side arm plate. The oral plates are triangular, and almost as high as broad. The lateral mouth papillae, three in number, are small, cylindrical, half again as long as broad, with the tip rounded; their surface is covered with very strong asperities. The unpaired terminal papilla is much broadened and obtuse.

The first arm segments are rather short; the following very rapidly elongate, and the arms then become slightly moniliform. The upper arm plates, which are of medium size, are triangular, with an obtuse proximal angle bordered by two straight sides, and a very convex distal border; they are a little broader than long and separated from the base of the arms outward by a progressively increasing interval. 
The first under arm plate is trapezoidal, a little longer than broad, with a proximal border broader than the distal. The following plates are rather small, pentagonal, with a very obtuse proximal angle bounded by two straight sides, lateral borders slightly excavated by the tentacle pores, and a rounded distal border notched in the middle; they are a little longer than broad. These plates are almost in contact as far as the fourth; beyond they are separated by an interval which increases rapidly.

The rather strongly projecting side arm plates carry at the base of the arm five thick cylindrical spines, with the tip rounded, and provided with rather strong and very closely crowded denticulations which are especially marked on the ventral spines. The first ventral spine almost equals the segment in length, and the last dorsal does not quite equal two segments.

The single tentacle scale is rather small, short, and cylindrical, with the tip obtuse, and its surface is covered with rugosities.

The color of the specimen in alcohol is yellowish white.

Afinities and distinctive features.-O phioripa nugator is evidently very close to the preceding species, from which it is immediately distinguished by the large and thick spines on the dorsal surface of the disk. It does not seem to me possible to suppose that $O$. marginata may be an $O$. nugator in which these large spines have been all torn away without leaving the least trace of their insertion or have not yet made their appearance. $O$. nugator also differs from 0 . marginata in having the arms formed of shorter segments, in its similarly shorter arm spines, in having the under arm plates more elongated and almost in contact on the first segments, in the smaller mouth papillae, and in having the tentacle scale also less developed.

\section{Genus OPHIOPHTHALMUS Matsumoto.}

The genus Ophiophthalmus was erected in 1917 by Matsumoto to include a certain number of ophiurans assigned by authors to the genera Ophiomitra or Ophiomitrella, or even to Ophiacantha. This genus, very close to the genus $O$ phiomitrella, differs from it in having the upper arm plates well developed and in contact on the first arm segments, and in having the arm spines numerous and elongated, the two rows on each side never coming close together in the median dorsal line of the arm. In addition this genus shows on the dorsal surface of the disk an investment of more or less imbricated plates, which may be provided with rugose granules; the naked radial shields are rounded or oval.

I agree perfectly with Matsumoto regarding the necessity of separating the genera Ophiomitra and Ophiomitrella from forms such as Ophiacantha normani Lyman, O. relicta Kœhler, Ophiomitra grani- 
fera Lütken and Mortensen, Ophiomitrella placida Koohler, and various others, but I differ completely from him regarding the limits of the genus Ophiophthalmus and the species which should be assigned to it.

The species which are included by Matsumoto in the genus Ophiophthalmus, thirteen in number, are in the following:

ophiomitrella americana Kœhler.

ophiomitrella mutata Kœhler.

Ophiomitrella languida Kœhler.

Ophiacantha cataleimmoida H. I. Clark.

Ophiacantha normani Lyman.

Ophiacantha relicta Kœhler.

Ophiomitra granifera Lütken and Mortensen.

Ophiacantha leucorhabdota H. L. Clark.

Ophiacantha eurypoma H. I. Clark.

Ophiacantha hylacantha H. L. Clark.

Ophiomitra codonomorpha H. L. Clark.

ophiomitrella placida Kœhler.

Ophiomitra microphilax H. L. Clark.

First of all, I believe it necessary to remove from the genus Ophiophthalmus three of these species. First, Ophiomitrella americana; I do not see any plausible reason for not leaving this in the genus Ophiomitrella, of which it shows all the generic characters; it is furthermore very close to O. granulifera Kohler, which Verrill assigned to the genus Ophiomitrella when it was established. I may say as much of $O$. mutata and $O$. languida, which seem to me to find their place much better in the genus Ophiomitrella than in Matsumoto's new genus.

The other species it seems to me possible to separate into three groups. The first of these groups includes first the type chosen by Matsumoto for his genus Ophiophthalmus, which is Ophiacantha cataleimmoida, then the species which are close to it, that is to say, 0 . normani, 0 . granifera, and 0 . relicta. In none of these species, not even in the type of the genus, do the arm spines show the characters indicated by Matsumoto in his diagnosis- "numerous, long, conical, opaque, hardly serrate"-for these spines are not elongated, and they are not numerous; 0 . cataleimmoida has six, $O$. normani four, O. granifera six, and O. relicta five or six, and they are provided with denticulations in the last two species. These four species possess the common character of having the dorsal surface of the disk covered with rounded grains which are found on the distal edge of the upper arm plates for a greater or lesser distance along the arms. The radial shields are large, or at least rather large.

The second group also includes four species; these are Ophiacantha leucorhabdota, O. eurypoma, O. hylacantha, and 0 . condonomorpha. 
All have large radial shields. The arm spines are rather numerous, from seven to nine, rather long in the three first species, without, however, being very long, and decidedly short in O. codonomorpha. The dorsal plates of the disk are small, and sometimes bear rather large granules (O. leucorhabdota), sometimes small club spines $(O$. eurypoma), or even a mixture of granules and true spines $(O$. hylacantha), or they are almost completely bare (O. codonomorpha). The upper arm plates, of various forms, are not truly in contact at the base of the arms except in O. leucorhabdota and 0 . hylacantha.

It is thus seen that these four species show very different characters, and they certainly do not represent a natural assemblage. Ophiacantha eurypoma and $O$. hylacantha approach most closely the type of the genus Ophiophthalmus. Ophiacantha hylacantha, in which the disk carries both spines and granules, these latter passing onto the distal edges of the upper arm plates, may be left in this genus, as well as $O$. eurypoma and $O$. codonomorpha. But $O$. leucorhabdota, with its peculiar upper arm plates, with its numerous mouth papillae, and with, or so it seems to me, a few tooth papillae, differs markedly from all the other species. Would it not better find its place in the genus Ophiomitra in the restricted sense?

There remains two species forming a third group; these are Ophiomitrella placida and Ophiomitra microphilax. I should be disposed to place them in a genus different from that including the preceding, on account of the form of the adoral plates.

In my memoir on the ophiurans of the Siboga expedition, in discussing the genera separated by Verrill from the old Ophiomitra, I expressed myself on the subject of the genus Ophiomitrella (Kohler, '04, p. 123) as follows:

Verrill says in the characterization of this genus that the mouth shields touch the first side arm plate; but the Siboga has found two new species, which I shall describe further on under the names ophiomitrella placida and $O$. moniliformis, in which the adoral plates are broadened outwardly into a lobe which separates the mouth shield from the first side arm plate. It would therefore be necessary either to maintain the genus ophiomitrella strictly within the narrow limits assigned to it by Verrill, or, broadening these limits, to admit the species with the adoral plates extending between the mouth shield and the first side arm plate. But it is indubitable that when Verrill established his genus Ophiomitrella, no species were known which could be assigned to it in which the adoral plates show this arrangement; he therefore did not have to take it into account. I have thought that it would not be unseemly to place in the genus Ophiomitrella the two species discovered by the Siboga, modifying the diagnosis of this genus by stating that the adoral plates may or may not separate the mouth shield from the first side arm plate. The remarks which I have given above on the form of these plates in the genus Ophiacantha show that this form is not perhaps so constant as Verrill thought, and the genus Ophiomitrella is quite sufficlently characterized in spite of the slight modification which I propose to introduce into the original diagnosis. 
After the description of $O$. monitiformis and $O$. placida $\mathrm{I}$ added in the same work ('04, p. 138):

o. placida occupies with $O$. moniliformis a place apart in the genus ophiomitrella: .... they can not be assigned to the genus ophiomitrella except with the reservation which I made on page 123 on the subject of the adoral plates.

The scruples which I had in 1914 regarding the generic separation of these two species from the other species of Ophiomitrella have no longer any force, for the species are becoming more and more numerous, and the necessity has arisen for circumscribing more closely the characters of the species in order to reassign them to genera with more exact limits. I believe, therefore, that it is necessary to establish a new genus for Ophiomitrella placida and 0 . moniliformis, and I believe that Ophiomitra microphylax H. L. Clark must also be included in it. This genus, to which I propose to give the name of Ophiomelina, would be characterized by having the adoral plates elongated into a distal lobe separating the mouth shield from the first side arm plate, by having the upper arm plates large, in contact at the base of the arms, and by having the elongated, fine, more or less numerous arm spines restricted to the sides of the arms. I will come back to it again shortly.

I thus propose to leave in the genus Ophiophthalmus only the seven following species:

o. cataleimmoida (H. I. Clark).

o. normani (Lyman).

O. graniferus (Lütken and Mortensen).

o. relictus (Kœhler).

o. eurypomus (H. L. Clark).

o. hylacanthus (H. L. Clark).

o. codonomorphus (H. L. Clark).

Of the different species which Matsumoto has placed in his genus Ophiophthalmus, two occur in the Albatross collection; the one which should be retained in this genus is $O$. relictus (Kohler); the other is made the type of the genus Ophiomelina; this is 0 . placida (Koehler). I shall discuss these below. I shall also place in the genus Ophiophthalmus, though with some doubts, a new species collected by the Albatross and represented by a single specimen.

\section{OPHIOPHTHALMUS RELICTUS (Kohler).}

Plate 9, figs. $1-4$; plate 95 , fig. 3.

Ophiacantha reliota Kohler ('04), p. 106, pl. 17, figs. 4-6.-H. L. Clark ('15), p. 204.

Ophiacantha oedidisca H. I. ClaRK ('11), p. 219, fig. 101; ('15), p. 203.

Ophiophthalmus relictus Matsumoto ('17), p. 106.

Ophiosemnotes oedidisca Matsumoto ('17), p. 137.

Localities.-Albatross station 5618; Molucca Passage; Mareh Island bearing S. $69^{\circ}$ E., 14.45 kilometers $(7.8$ miles) distant (lat. 
$0^{\circ} 37^{\prime} 00^{\prime \prime} \mathrm{N}$., long. $127^{\circ} 15^{\prime} 00^{\prime \prime}$ E.) ; 763 meters (417 fathoms); November 27,$1909 ;$ gy. M.

Two specimens (Cat. No. 41239 , U.S.N.M.).

Albatross station 5630; south of Patiente Strait; Doworra Island (N.) bearing N. $3^{\circ} \mathrm{W}$., 8.34 kilometers $\left(4.5\right.$ miles) distant (lat. $0^{\circ}$ $56^{\prime} 30^{\prime \prime}$ S., long. $128^{\circ} 05^{\prime} 00^{\prime \prime}$ E.) ; 1,041 meters (569 fathoms) ; December 2,1909 ; co. S., M.

One specimen (Cat. No. 41244, U.S.N.M.).

Albatross station 5647; Buton Strait; North Island (S.) bearing S. $87^{\circ}$ E., 21.50 kilometers (11.6 miles) distant (lat. $5^{\circ} 34^{\prime} 00^{\prime \prime} \mathrm{S}$., long. $122^{\circ} 18^{\prime} 15^{\prime \prime}$ E.) ; 949 meters (519 fathoms); December 16, 1909 ; gn. M.

One specimen (Cat. No. 41246, U.S.N.M.).

Albatross station 5648; Buton Strait; North Island (S.) bearing N. $87^{\circ}$ E., 18.90 kilometers (10.2 miles) distant (lat. $5^{\circ} 35^{\prime} 00^{\prime \prime} \mathrm{S}$., long. $122^{\circ} 20^{\prime} 00^{\prime \prime}$ E.) ; 1,022 meters (559 fathoms) ; December 16 , 109 ; gn. M.

Two specimens (Cat. Nos. 41242,41243 , U.S.N.M.).

Albatross station 5652; Gulf of Boni, Celebes; Lamulu bearing S. $36^{\circ}$ E., 13.90 kilometers ( 7.5 miles) distant (lat. $4^{\circ} 35^{\prime} 00^{\prime \prime}$ S., long. $121^{\circ} 23^{\prime} 06^{\prime \prime}$ E.) ; 960 meters (525 fathoms); December 17, 1909 ; gn. M.

One specimen (Cat. No. 41240, U.S.N.M.).

Albatross station 5657; Gulf of Boni, Celebes; Olang Point bearing N. $61^{\circ}$ W., 28.72 kilometers (15.5 miles) distant (lat. $3^{\circ} 19^{\prime} 40^{\prime \prime}$ S., long. $120^{\circ} 36^{\prime} 30^{\prime \prime}$ E.) ; 900 meters (492 fathoms) ; December 19, 1909 ; gy. M.

Nine specimens (Cat. Nos. 41245,41241 , U.S.N.M.).

Notes. - The specimens are absolutely identical with those from the Siboga expedition on which I established the species.

In the synonymy above I have united Ophiacantha oedidisca H. L. Clark with $O$. relictus. I can not see any character permitting the differentiation of $O$. relictus, which I described in 1904 from specimens collected by the Siboga among the Sunda Islands, from $O$. oedidisca, which H. L. Clark based on Japanese specimens. In comparing this last species with $O$. normani and $O$. relictus the American naturalist says that his species differs from both in its general appearance, due to the thickness of the disk and the narrow arms provided with spines. But in describing $O$. relictus and in comparing it with $O$. norman $i \mathrm{I}$ had already mentioned that the disk of $O$. relictus was convex and that the arms, more or less rolled up, appeared more flexible and less rigid than in 0 . normani, and that, furthermore, the under arm plates were widely separated from the base of the arms outward. I stated also that the arm spines, six in number, 
were irregularly echinulated and relatively short. But all these characters are those which $\mathrm{H}$. L. Clark attributes to $O$. oedidisca. This naturalist notes that between the successive under arm plates there exists a more or less marked depression, and that it is difficult to decide whether the side arm plates do or do not penetrate into this depression. I have determined on certain specimens that the part of the ventral surface of the arms which separates the successive arm plates in the median line is slightly depressed, but on individuals dried and then treated with glycerinated alcohol, I can easily show that the side arm plates penetrate as far as the median line of the arm, along which they are in contact, and that they separate completely the successive under arm plates. This may be readily seen on the specimen of which I give a photograph here (fig. 4).

Furthermore, there can not be the least confusion between $O$. normani and $O$. relictus. I have included (pl. 9, figs. 5, 6) photographs of a specimen of $O$. normani collected by the Albatross, of which I spoke in 1904 (Kœhler '04, p. 107), and it may be seen that the two species differ absolutely from each other in the characters of the arm spines and in the form of the mouth shields, as well as in that of the under arm plates; the disk of $O$. normani is flattened, while it is thick, with a very convex dorsal surface, in 0 . relictus, as the photograph reproduced in figure 2 on plate 9 shows.

Ophiophthalmus relictus was found by the Siboga at different stations between $0^{\circ}-10^{\circ} \mathrm{S}$. latitude and $116^{\circ}-131^{\circ} \mathrm{E}$. longitude, at depths varying between 538 and 1,624 meters (310 to 887 fathoms).

H. L. Clark's Ophiacantha oedidisca was dredged in the Japanese seas between 405 and 578 fathoms.

The preceding lines were written in 1914, and consequently a long time before the appearance of Matsumoto's memoir; I believe there is no necessity for the least modification of them, and I still consider Ophiacantha oedidisca a synonym of $O$. relictus. In his memoir of 1917 Matsumoto not only maintains the first as a distinct species, but he even places it, in a different and new genus to which he gives the name of Ophiosemnotes and of which the type is H. L. Clark's Ophiolebes tylota. Besides these two species, Matsumoto assigns to the genus Ophiosemnotes four others placed by H. L. Clark in the genus Ophiolebes-O. pachybactra, O. diaphora, $O$. paucispina, and $O$. brevispina-and in addition Ophiactis clavigera Ljungman, placed by Lyman in the genus Ophiolebes.

In mentioning $O$. oedidisca, Matsumoto ('17, $p .137$ ) adds that although this species resembles certain forms of the genus Ophiophthalmus, it differs from them in its disk, which is very convex. But we have seen that one of the principal characters of $O$. relictus, and one which I have emphasized, is this same height of the disk. H. L. Clark has already relied on this same character as well as 
on the slenderness of the arms, which are provided with short spines, to separate $O$. oedidisca from $O$. normani and $O$. relictus. Evidently the two authors have completely misunderstood the characters of $O$. relictus. I therefore continue to consider $O$. oedidisca as a synonym of $O$. relictus.

\section{OPHIOPHTHALMUS SUSPECTUS, neW species.}

\section{Locality.-Not given.}

Plate 6, figs. 1, 2.

One specimen (Cat. No. 41164 , U.S.N.M.).

Description.-The disk is $8 \mathrm{~mm}$. in diameter, and the arms are $45 \mathrm{~mm}$. long.

The disk is rounded, and notched in the interradial spaces. It is rather thick and the dorsal surface is depressed in the central region. This surface is covered with small, rather crowded, thin and transparent imbricated plates, the contours of which are only slightly evident; each of them carries a broad and very short club spine, scarcely longer than broad, which rapidly expands into a large convex head; it would be quite as exact to say that these plates bear slightly pediculate globules. The rounded surface of these club spines or globules is very rugose, and under the microscope it is seen to be provided with short and closely crowded spinules. The globules themselves are very close to each other, and in contact in the central region of the disk; they are less closely crowded, and also a little larger, toward the periphery of the disk and between the radial shields; in these regions the plates which carry the globules are themselves larger and their outlines are more distinct. The radial shields are large, irregularly triangular in shape, with the angles and the borders rounded, scarcely longer than broad; they are in contact throughout almost their entire length, which almost equals a third of the radius of the disk. In the interradial spaces the investment of plates does not extend quite to the periphery of the disk, leaving naked a marginal region which is covered only by a membraneous integument showing here and there a small calcified nodule.

The ventral surface of the disk bears only extremely thin and transparent plates which do not even form a continuous covering. The genital slits are rather broad, but the genital plates are only slightly developed.

The radial shields are rather small and short, though very broad, at least three times as broad as long; they show an obtuse though rather projecting angle, two slightly concave sides, and a convex distal border, of which the middle is swollen into a slightly projecting lobe. The adoral plates are short, rather broad, especially outwardly, and about twice as long as broad; they do not give off any 
process separating the mouth shield from the first side arm plate. The oral plates are triangular, a little higher than broad. The lateral mouth papillae, three in number, are subequal and conical, with the point blunted; their surface is very rugose and provided with small and very closely crowded asperities. The unpaired terminal papilla is a little stouter than those on either side.

The upper arm plates are rather small, triangular, broader than long, with a sharp proximal angle, two straight sides, and an almost straight distal border passing into the preceding by rather sharp angles. All these plates are separated from the base of the arms outward by an interval which is occupied by the side arm plates.

The first under arm plate is elongated, with a very convex distal border, which is broader than the straight proximal border. The following plates are very broad, pentagonal, with an obtuse proximal angle bounded by two straight sides, two sides slightly excavated by the tentacle scale, and a very broad strongly convex distal border. Beyond the disk these plates become a little less broad, and they end by being as broad as long; they are separated beyond the second by a rather long interval occupied by the side arm plates. On the surface of these plates and in their distal half there may be made out a few parallel striae, which are, however, but little marked.

The very strongly projecting side arm plates carry at the base of the arms $10 \mathrm{arm}$ spines; the two lateral columns come very close together in the median line, though without being continuous. The length of the spines increases from the first ventral, which is equal to a segment and a half, to the last dorsal, of which the length equals two and a half or three segments. These spines are large and strong, with their tips rounded and their surface very rugose; the ventral spines even show very fine and closely placed asperities, which, however, are not worthy of the name of teeth.

The single tentacle scale is rather large, elongated, and oval, with the extremity obtuse or rounded; its surface is very rugose and its border even shows more or less marked fine asperities.

In the alcoholic specimen the disk has a brownish-yellow color, very light on the dorsal surface, and the arms show light-brown annulations separated by longer uncolored portions. To judge from the coloration, $O$. suspectus must have come from shallow water.

Affinities and distinctive features.-I have been much puzzled in placing generically this unique specimen, which I have called Ophiophthalmus suspectus, for it shares in its characters both the characters of the genus Ophiomitrella and those of the genus Ophiophthalmus, the first considered in the restricted sense given it by Matsumoto. It recalls this genus in the two lateral series of arm spines, which come very close together in the dorsal median 
line, but it differs from it in the slightly moniliform arms, in the large upper arm plates, which are only slightly separated from each other at the base of the arms, and in the very large and contiguous radial shields. $O$. suspectus conversely approaches the genus Ophiophthalmus in its numerous and elongated arm spines, in the large radial shields of which the size is much greater than that of the other plates of the dorsal surface of the disk, which are very small, the two shields of each pair being in contact throughout almost their whole length, and in the large upper arm plates. But our ophiuran differs from the other species of this genus by the character of these same upper arm plates, which are not in contact on the first arm segments, and in the very closely crowded spines on either side of the median dorsal line of the arm.

I have thought it necessary, however, to assign it to the genus Ophiophthalmus, with which it certainly has more affinities than with the genus Ophiomitrella. It recalls especially one of the species assigned by Matsumoto to the first genus-O. graniferus (Ophiomitra granifera Lütken and Mortensen); however, it differs from it in its much longer, thicker, and almost smooth spines, the two lateral series coming closer together in the median dorsal line, in the thick adoral plates, in the broadly triangular upper arm plates with sharp angles, by the somewhat longer under arm plates, in the absence of granules on the free border of the radial shields, as well as on the distal border of the two first upper arm plates, and in having the radial shields in contact throughout almost their whole length.

There is a certain resemblance, purely superficial, however, between $O$. suspectus and the new Ophiomitra which $I$ have described below under the name of Ophiomitra dives, but there should be no confusion here, for in this latter species the arm spines are hollow, the ventral surface of the arms is incompletely calcified, the mouth shields are large and especially extremely broad, the mouth papillae are less numerous, and the tentacle scale is larger, and there is only a single papilla at the extremity of the jaws.

\section{OPHIOMELINA, new genus.}

Description.-Ophiacanthidae near the genera Ophiomitrella Verrill and Ophiophthalmus Matsumoto, from which it differs in the greatly developed and elongated adoral plates, sending off a distal lobe which separates the mouth shield from the first under arm plate. As in the genus Ophiophthalmus, the disk is covered with irregular, more or less imbricated plates, provided with club spines or with rugose granules. The radial shields are small and widely separated. The mouth papillae are three or four in number. The upper arm plates, which are very large, cover a large part of the dorsal surface of the arms, and are very close together or contiguous on the 
first arm segments. The rather numerous arm spines are elongated, fine, often echinulated, and the two lateral rows never come close together in the median dorsal line at the base of the arms. There is a single tentacle scale.

Notes.-The type of the genus Ophiomelina is $O$. placida, which at the time I described it I placed in the genus Ophiomitrella, and which the Albatross has rediscovered in the Philippines; the genus also includes Ophiomitrella moniliformis Kohler and $O$. microphylax H. L. Clark.

In $1915 \mathrm{H}$. L. Clark placed $O$. placida in the genus Ophiacantha, but this disposition can not be maintained, for in all its characters, and notably in the upper and under arm plates, in the arm spines, and in the covering of the disk, this species differs markedly from all the known species of Ophiacantha.

Type of the genus.-Ophiomelina placida (Kohler).

\section{OPHIOMELINA PLACIDA (Køhler).}

Plate 30 , figs. 8,9 ; plate 94 , fig. 3.

Ophiomitrella placida Kanler ('04), p. 137, pl. 31, figs. 3, 4.

Ophiacantha placida H. L. ClarK ('15), p. 207.

Ophiophthalmus placidus Matsumoto ('17), p. 106.

Localities.-Albatross station 5618; Molucca Passage; Mareh Island bearing S. $69^{\circ}$ E., 14.45 kilometers ( 7.8 miles), distant (lat. $0^{\circ}$ $37^{\prime} 00^{\prime \prime}$ N., long. $127^{\circ} 15^{\prime} 00^{\prime \prime}$ E.) ; 763 meters (417 fathoms) : November 27,1909 ; gy. M.

One specimen (Cat. No. E. 55, U.S.N.M.).

Albatross station 5629; Patiente Strait and southward; Doworra Island (S.) bearing S. $62^{\circ}$ W. 11.1 kilometers $(6$ miles) distant (lat. $0^{\circ} 50^{\prime} 00^{\prime \prime}$ S., long. $128^{\circ} 12^{\prime} 00^{\prime \prime}$ E.) ; 375 meters (205 fathoms); December 2, 1909; co. S.

Two specimens (Cat. No. E. 53, U.S.N.M.).

Albatross station 5661; Flores Sea; Cape Lassa bearing N. $21^{\circ}$ E. 23.16 kilometers (12.5 miles) distant (lat. $5^{\circ} 49^{\prime} 40^{\prime \prime}$ S., long. $120^{\circ}$ $24^{\prime} 30^{\prime \prime}$ E.) ; 329 meters (180 fathoms) ; December 20, 1909 ; hrd.

One specimen (Cat. No. E. 54, U.S.N.M.).

Notes.-The specimens from stations 5618 and 5629 bear granules only on the dorsal surface of the disk (pl. 94, fig. 3); on that from station 5661 the central region shows very fine and very short club spines terminated by a few asperities, and these club spines gradually transform into granules toward the periphery of the disk.

In the specimen from station 5618 the disk is strongly excavated in the interradial spaces, and it is still more so in the two specimens from station 5629, but without enabling it to be said that it is really notched. In the specimen from station 5661, shown in figure 8 on plate 30 , it is seen that in three interradii the notches are continued 
more or less deeply over the disk, and form grooves similar to those which we typically find in the genus Ophioplinthaca. However, these interradial incisions or notches are not bounded by plates noticeably larger than the others, and the radial shields are likewise very small. It is for this reason that in 1904 I placed this species in the genus Ophiomitrella.

The Siboga discovered $O$. placida among the Sunda islands at depths between 204 and 304 meters (112 to 166 fathoms); in the type of the species the diameter of the disk measured $10 \mathrm{~mm}$.

\section{OPHIOPLINTHACA CHELYS (Wyville Thomson).}

Plate 19, figs. 3, 4.

Ophiacantha chelys Wyville Thomson ('77), p. 64, figs. 16, 17.

Ophiomitra chelys LyMaN ('77), p. 152, pl. 9, figs. 239-241; ('82), p. 205.

Ophioplinthaca chelys KoEHLER ('04), p. 131; ('07), p. 294; ('07a), p. 324; ('09), pl. 193.-H. L. Cr.ARK ('15), p. 211.

Locality.--Albatross station 5637; Bouro Island (south) and vicinity; Amblau Island (N.) bearing N. $80^{\circ}$ E., 38.92 kilometers (21 miles) distant (lat. $3^{\circ} 53^{\prime} 20^{\prime \prime}$ S., long., $126^{\circ} 48^{\prime} 00^{\prime \prime}$ E.) ; 1,280 meters (700 fathoms); December 10, 1909; gy. M.

One specimen (Cat. No. 41060, U.S.N.M.).

Notes.-The diameter of the disk is $5.5 \mathrm{~mm}$.; only three arms remain attached to the disk, a single one being complete; it reaches about $25 \mathrm{~mm}$. in length.

The plates of the dorsal surface of the disk bear a few large club spines which are rather thick and which broaden toward their extremity into a disk bearing fine spinules. In his description Lyman says that the plates of the disk bear "short, blunt, usually smooth, stumps or spines"; but the figure which he published in 1877 (pl. 9, fig. 240), in which these club spines are represented in face view, show that they have a broadened extremity furnished with spinules quite comparable to those which I observe in my specimen; these club spines are not numerous.

I have already described the variations which may be observed in the form and in the number of the club spines of the dorsal surface of the disk in the specimens of $O$. chelys collected by the Siboga in the Sunda Archipelago (Kohler '04, p. 131); certain of these specimens only showed small, short, cylindrical and smooth club spines, while others bore large granules with the extremity broadened, identical with those which I find on the Albatross specimen. ${ }^{5}$

The drawings of Wyville Thomson and of Lyman are somewhat schematic; I have thought it advisable to reproduce here two photographs of the specimens collected by the Albatross (pl. 19, figs. 3, 4).

5 I must correct a typographical error which I notice in the last line of page 131 of my memoir of 1904. In place of "Station 135 " read " Station 227." 
The Challenger specimens came from the Atlantic, and were captured between $25^{\circ}-30^{\circ} \mathrm{N}$. latitude and $18^{\circ}-20^{\circ} \mathrm{W}$. longitude, at a depth of 2,055 to 2,789 meters ( 1,124 to 1,525 fathoms). The Travailleur and Talisman expeditions found $O$. chelys in $39^{\circ} \mathrm{N}$. latitude and $12^{\circ} \mathrm{W}$. longitude, in 3,307 meters (1,814 fathoms). The Siboga met with $O$. chelys in the Sunda Archipelago between $2^{\circ} \mathrm{N}$. latitude and $4^{\circ} \mathrm{S}$. latitude and $125^{\circ}-127^{\circ} \mathrm{E}$. longitude, at depths varying from 1,165 to 2,081 meters (637 to 1,141 fathoms). The species therefore appears to have a rather extensive geographical range and always to occur in deep water.

\section{OPHIOPLINTHACA GLOBATA, new species.}

Plate 24, figs. 7,8 ; plate 25 , figs. $1-8$; plate 94 , fig. 6 .

Localities.-Albatross station 5119; Balayan Bay and Verde Island Passage; Sombrero Island bearing S. $80^{\circ}$ E., 35.02 kilometers (18.9 miles) distant (lat. $13^{\circ} 45^{\prime} 05^{\prime \prime} \mathrm{N}$., long. $120^{\circ} 30^{\prime} 30^{\prime \prime}$ E.) ; 721 meters (394 fathoms); January 21, 1908; gn. M., S.

Eight specimens (Cat. No. E. 71, U.S.N.M.).

Albatross station 5123; east coast of Mindoro; Malabrigo Light bearing $\mathrm{N} .44^{\circ} \mathrm{W}$., 60.23 kilometers (32.5 miles) distant (lat. $13^{\circ} 12^{\prime}$ $45^{\prime \prime}$ N., long. $121^{\circ} 38^{\prime} 45^{\prime \prime}$ E.) ; 518 meters (283 fathoms) ; February 2,1908 ; gn. M.

Some specimens.

Albatross station 5187; Tanon Strait, east coast of Negros; Apo Island bearing S. $21^{\circ} \mathrm{W}$., 23.16 kilometers (12.5 miles) distant (lat. $9^{\circ} 16^{\prime} 45^{\prime \prime} \mathrm{N}$., long. $123^{\circ} 21^{\prime} 15^{\prime \prime}$ E.) ; 411 meters (225 fathoms) ; March 31, 1908; sft. gn. M.

One small specimen (Cat. No. E. 78, U.S.N.M.).

Albatross station 5201; Sogod Bay, southern Leyte Island; Limasaua Island (E.) bearing S. $1^{\circ}$ E., 27.43 kilometers (14.8 miles) distant (lat. $10^{\circ} 10^{\prime} 00^{\prime \prime}$ N., long. $125^{\circ} 04^{\prime} 15^{\prime \prime}$ E.) ; 1,013 meters (551 fathoms); April 10, 1908; gy. S., M.

One specimen (Cat. No. E. 79, U.S.N.M.).

Albatross station 5219 ; between Marinduque and Luzon; Mompog Island (NE.) bearing $\mathrm{N} .35^{\circ} 30^{\prime}$ W., 22.70 kilometers (12.25 miles) distant (lat. $13^{\circ} 21^{\prime} 00^{\prime \prime} \mathrm{N}$., long. $122^{\circ} 45^{\prime} 00^{\prime \prime}$ E.) ; 969 meters (530 fathoms); April 23, 1908; gn. M.

One specimen.

Albatross station 5348; Palawan Passage; Point Tabonan bearing S. $89^{\circ}$ E., 62.08 kilometers (33.5 miles) distant (lat. $10^{\circ} 57^{\prime} 45^{\prime \prime} \mathrm{N}$., long. $118^{\circ} 38^{\prime} 15^{\prime \prime}$ E.) ; 686 meters ( 375 fathoms) ; December 27 , 1908 ; co. S.

One specimen (Cat. No. E. 69, U.S.N.M.).

Albatross station 5374.

One specimen (Cat. No. E. 70, U.S.N.M.). 
Albatross station 5377; Marinduque Island and vicinity; Mompog Island (E.) bearing N. $55^{\circ}$ W., 16.68 kilometers ( 9 miles) distant (lat. $13^{\circ} 26^{\prime} 00^{\prime \prime}$ N., long. $122^{\circ} 19^{\prime} 00^{\prime \prime}$ E.) ; 732 meters (400 fathoms); March 4, 1909; sft. gn. M.

One specimen (Cat. No. E. 73, U.S.N.M.).

Albatross station 5423; Joló Sea; Cagayan Island (S.) bearing S. $11^{\circ}$ E., 8.89 kilometers (4.8 miles) distant (lat. $9^{\circ} 38^{\prime} 30^{\prime \prime} \mathrm{N}$., long. $121^{\circ} 11^{\prime} 00^{\prime \prime}$ E.) ; 929 meters (508 fathoms) ; March 31, 1909; gy. M., co. S.

One specimen (Cat. No. E. 76, U.S.N.M.).

Albatross station 5424; Joló Sea; Cagayan Island (S.) bearing S. $11^{\circ} \mathrm{W}$., 6.30 kilometers (3.4 miles) distant (lat. $9^{\circ} 37^{\prime} 05^{\prime \prime} \mathrm{N}$., long. $121^{\circ} 12^{\prime} 37^{\prime \prime}$ E.) ; 622 meters (340 fathoms); March 31, 1909; co. S.

One specimen.

Albatross station 5444; east coast of Luzon; San Bernardino Strait to San Miguel Bay; Atalaya Point, Batag Island, bearing S. $65^{\circ}$ E., 9.45 kilometers ( 5.1 miles) distant (lat. $12^{\circ} 43^{\prime} 51^{\prime \prime} \mathrm{N}$., long. $124^{\circ}$ $58^{\prime} 50^{\prime \prime}$ E.) ; 563 meters (308 fathoms); June 3, 1909 ; gn. M.

Six specimens (Cat. Nos. E. 72, E. 77, U.S.N.M.).

Albatross station 5510; northern Mindanao and vicinity; Camp Overton Light bearing S. $68^{\circ}$ E., 16.86 kilometers (9.1 miles) distant (lat. $8^{\circ} 16^{\prime} 00^{\prime \prime} \mathrm{N}$., long. $124^{\circ} 03^{\prime} 50^{\prime \prime} \mathrm{E}$.) ; 774 meters ( 423 fathoms) ; August 7, 1909; gy. M., fne. S.

One specimen (Cat. No. E. 74, U.S.N.M.).

Albatross station 5511; northern Mindanao and vicinity; Camp Overton Light bearing S. $80^{\circ}$ E., 28.35 kilometers (15.3 miles) distant (lat. $8^{\circ} 15^{\prime} 20^{\prime \prime}$ N., long. $123^{\circ} 57^{\prime} 00^{\prime \prime}$ E.) ; 750 meters (410 fathoms) ; August 7, 1909; gy. M., S.

One specimen (Cat. No. E. 68, U.S.N.M.).

Albatross station 5656; Gulf of Boni, Celebes; Olang Point bearing N. $67^{\circ} \mathrm{W}$., 26.87 kilometers (14.5 miles) distant (lat. $3^{\circ} 17^{\prime} 40^{\prime \prime} \mathrm{S}$., long. $120^{\circ} 36^{\prime} 45^{\prime \prime}$ E.) ; 885 meters (484 fathoms); December 19, $1909 ;$ gy. M.

One specimen (Cat. No. E. 75, U.S.N.M.).

Description.-I shall describe this species on the basis of one of the specimens from station 5123, which is represented in figure 8 on plate 25 , as well as from the specimen from station 5219 , which is represented in figures 6,7 . I also give photographs of the individuals from station 5656 (pl. 25 , figs. 1,2 ), as well as of the ventral surface of one of those from station 5444 (fig. 3) and another from station 4523 (figs. 4,5 ); one of the young specimens from station 5187 , in which the diameter of the disk is only $4 \mathrm{~mm}$., is figured on plate 24 (figs. 7,8 ). 
The diameter of the disk in adult specimens varies between $10 \mathrm{~mm}$. and $15 \mathrm{~mm}$, and the arms may reach a length of from $120 \mathrm{~mm}$. to $140 \mathrm{~mm}$.

The disk is thick, more or less strongly excavated in the interradial spaces; the radial regions, on the other hand, are projecting. Interradial incisions more or less deep are seen on the border of the disk and continue over the dorsal surface in the form of more or less marked depressions. These depressions, however, are not absolutely constant, and they only occur, so to speak, in the specimen from station 5123 figured in figure 8 on plate 25 . The dorsal surface is covered between the radial shields with numerous irregularly polygonal plates which are small and crowded in the central region becoming larger toward the periphery of the disk. These plates attain their largest dimensions toward the interradial incisions, but without being noticeable for any great size, as is ordinarily the case in the genus Ophioplinthaca. They are provided with formations which vary between simple granulations and rather strong and elongated spines. In the specimen from station 5129 (fig. 7) the central part of the disk shows small, short, conical and closely crowded club spines, terminated by two or three very short spinules, these club spines becoming thicker and less crowded, and passing progressively into slightly elongated granules the size of which increases toward the periphery of the disk, and the edges of the radial shields. In the specimen from station 5123, shown in figure 8, the small club spines of the central region preserve their character of club spines in approaching the periphery, simply becoming here a little larger and conical. In the other specimens from station 5123 granules may be observed to pass gradually into small spines. Thus in the specimen represented in figure 4 there occurs a mixture of rather elongated spines and of granules of variable dimensions, the latter smooth, the former terminated by small spinules. In the specimen from station 5656 , shown in figure 2, there is scarcely anything to be seen except a few spines which are thick and rather long, furnished on their borders with rather strong denticulations.

In figure 6 on plate 94 I show the different formations which $I$ have met with on the dorsal surface of the disk-rounded and simply rugose granules, small and short club spines furnished at their extremity with a few short spinules, larger club spines provided with numerous spinules, elongated club spines terminated solely by two or three much developed points, and lastly true spines.

The radial shields are rather small, elongated, twice as long as broad, oval, or triangular with the angles rounded. 'They are slightly divergent in their proximal portion, and remain separated for their whole length by an interval which is equal to almost half their width. 
Their length is less than half the radius of the disk. In the specimen from station 5656, represented in figure 2 on plate 25 , these shields, instead of being elongated, are broadly oval and scarcely half again as long as broad. But in the specimen from station 5123, shown in figure 8, certain shields are much elongated and very narrow, three times as long as broad, while others are shorter and more broadened. Intermediate forms occur in the specimens shown in figures 4 and 7 .

The ventral surface of the disk in the interradial spaces is covered with polygonal plates which are rounded and unequal, and only bear a few rare spherical granules toward the periphery of the disk. The genital slits are broad.

The mouth shields are small, lozenge-shaped, broader than long, with the four sides almost equal. The proximal angle is obtuse; the distal angle is also obtuse, but much rounded, and sometimes it is prolonged into a small rounded lobe; the two rather acute lateral angles are also slightly rounded. Sometimes the distal angle of these shields is so obtuse and rounded that it disappears altogether, and the mouth shields then become triangular with the distal border more or less convex; this occurs in the specimen from station 5656 represented in figure 1 and somewhat less marked in that from station 5444 (fig. 3). The adoral plates, which are of medium size, are slightly recurved and crescentic, about two and a half times as long as broad, and not broadened outwardly. The oral plates are rather high and triangular. The lateral mouth papillae are usually three in number, and sometimes four; they are conical, strong, and pointed; there is in addition a very reduced papilla inserted at the angle between the adoral plate and the first under arm plate. Between this last and the third papilla there is a little group of from four to six rounded and closely crowded granules, of which the number and the development varies with the individuals; these granules are also more or less apparent, depending doubtless on the contraction or extension of the neighboring parts. The papilla which is inserted on the first under arm plate is very often confused with these rounded granules. 'I'his structure is quite identical with that which H. L. Clark has described and figured in Ophiomitra bythiaspis, and which $I$ also found in Ophioplinthaca pulchra. The unpaired terminal papilla is conical and a little stouter than those on either side.

The upper arm plates are large and strongly convex, triangular, with a very obtuse and rounded proximal angle, a rounded distal border, and rather sharp lateral angles; these plates are a little broader than long, and they are usually separated from the base of the arms ontward by a narrow interval.

The first under arm plate is small, triangular or pentagonal, with the distal angle bounded by two short sides which are almost as long 
as broad. The following plates are large, and especially very broad, almost twice as long as broad, pentagonal, with the proximal angle very obtuse and formed by two short, slightly excavated sides; the lateral borders are divergent and very strongly excavated by the tentacle pores; the distal side is somewhat convex. These plates are very widely separated by a space occupied by the side arm plates.

These last are very strongly projecting in their distal part, which forms a very marked rim on which are inserted the arm spines. These number six or seven at the base of the arm. The length of the four ventral spines increases very gradually from the first, which is almost as long as the segment; the three others on the dorsal side are very much longer, and, at the base of the arms, the length of the sixth and the seventh may reach five segments; sometimes the last spine is a little shorter than that preceding. The four ventral spines are provided with rather strong and closely set denticulations; the other spines are less strongly denticulated.

The tentacle scale is single and of large size. It is especially large on the first segment, where it is oval or rounded, and sometimes it is doubled on the pores of the first pair; the size gradually diminishes on the three or four following segments, and it then becomes lanceolate, while at the same time its borders become furnished with denticulations, usually very marked, which cause it to be more or less strongly spiniferous. In certain individuals it tapers more rapidly than in others, but it is always much elongated. Sometimes, instead of tapering in its distal half, it remains very broad, and even a little broader than at the base; this occurs, for example, in the specimen from station 5219 , shown in figure 6.

Affinities and distinctive features.-Because of the occurrence of a group of granules, replacing the last lateral mouth papilla and inserted on the adoral plate, as well as on account of the form of the upper and under arm plates, Ophioplinthaca globata approaches $O$. bythiaspis described by H. L. Clark ('11, p. 185), which was found in Japan at a depth of 1,724 meters (943 fathoms). It differs from it, however, in the form of the radial shields, which are broader and closer together in each pair, and especially are not sunken; I have, however, had occasion to note above that the radial shields of $O$. globata are sometimes longer and narrower than usual (the individual from station 5123, shown in figure 8 ). The arm spines are more numerous, and the dorsal spines especially are much longer than in O. bythiaspis; the mouth shields are broader than long, and the under arm plates are more elongated; lastly, the tentacle scale is also more developed, or at least so it seems to me. It is possible, however, that the radial shields, much sunken in 0 . bythiaspis do not constitute a specific character, as that feature, noted by H. L. Clark, was seen only on a single specimen. But at present I do not 
believe myself justified in uniting my species with 0 . bythiaspis, from which, moreover, it differs in the other ways $I$ have just indicated.

In 0 . plicata, Lyman has also shown a group of granules between the last and the penultimate mouth papillae ('79, fig. 233), but these granules possibly do not occur in the adult; at least, Lyman does not mention them and has not shown them in his figure in the Challenger report (' 82, pl. 10, fig. 7 ); in any case, 0. globata can not be confused with 0. plicata.

I shall have occasion further on to describe in 0 . pulchra the presence of a small group of granules identical with those of which I have just spoken, and which replace the penultimate mouth papilla. But $O$. globata differs from $O$. pulchra in the armature of the dorsal plates of the disk, which is entirely different, in the very much smaller and always separated radial shields, in the also smaller mouth shields, which are broader than long and without the distal lobe always developed in $O$. puchra, and which projects strongly into the interradial space; furthermore, the under arm plates are widely separated, the arm spines are longer, etc.

I shall give further on the characters separating 0 . globata from $O$. hastata, which I am describing below.

\section{OPHIOPLINTHACA HASTATA, new species.}

Plate 18 , figs. 6,7 , and 8 ; plate 94 , fig. 7 .

Localities.-Albatross station 5281; China Sea, in the vicinity of southern Luzon; Malavatuan Island (N.) bearing S. $84^{\circ}$ W., 7.97 kilometers ( 4.3 miles) distant (lat. $13^{\circ} 52^{\prime} 45^{\prime \prime} \mathrm{N}$., long. $120^{\circ} 25^{\prime} 00^{\prime \prime}$ E.; 368 meters (201 fathoms); July 18, 1908; dk. gy. S.

One specimen (Cat. No. 41003, U.S.N.M.).

Albatross station 5586; Sibuko Bay, Borneo, and vicinity; Sipadan Island (M.) bearing W., 17.42 kilometers (9.4 miles) distant (lat. $4^{\circ} 06^{\prime} 50^{\prime \prime}$ N., long. $118^{\circ} 47^{\prime} 20^{\prime \prime}$ E.; 635 meters (347 fathoms); September 28, 1909; gy. M.

One specimen (Cat. No. 41002 U.S.N.M.).

Description. - I shall describe this species from the specimen from station 5586, in which the diameter of the disk is $7 \mathrm{~mm}$. and the arms are about $30 \mathrm{~mm}$. long, only two being preserved entire.

The disk is rounded. In the interradial spaces it shows very marked incisions, which, however, are a little less deep than in the majority of the other species of the genus Ophioplinthaca.

The dorsal surface is covered with rather large imbricated plates, each surrounded by a fairly regular border of very much smaller plates. Along the radial incisions there is a raw of distinct plates, but these are not larger than the others. Each of the large plates 
carries a large and thick club spine, which broadens toward its extremity into a head bristling with rather closely crowded spinules, the cylindrical stem being simply rugose (pl. 94, fig. 7). The length of these club spines is equal to four times their thickness. In my specimen very many of the plates have lost the club spines, but it is easy to recognize the mark representing their insertion. These club spines also occur on the plates which separate the two radial shields of each pair, and some even pass onto the first upper arm plate; they become a little smaller and more slender toward the periphery of the disk. The radial shields are relatively rather small, triangular, almost as broad as long, and divergent; they are close together, though not in contact in their distal portion; these shields are less developed than in the majority of the species of the genus Ophioplinthaca.

The ventral surface of the disk is covered in the interradial spaces by imbricated plates, the majority of which bear a spine which is a little narrower than those on the dorsal surface, and which are also found on the plates bordering the mouth shields. The genital slits are rather narrow.

The mouth shields have a lance-head form, with a very sharp and produced proximal angle bordered by two very concave sides; the lateral angles are very sharp and produced, the two distal sides are shorter than the two others and they pass into each other over a rounded angle. The adoral plates are not very large; they are much broadened outwardly and gradually narrow toward the median interradial line along which they are in contact by their internal angles. The oral plates are small; the lateral mouth papillae, four in number, are rather stout and thick; the two external papillae are approximately cylindrical, and slightly swollen at their strongly rounded tip; the two others are more conical in shape, with the point blunted. The unpaired terminal papilla is a little more elongated than those on either side. All these papillae have their surface very rugose, or even provided with extremely fine and closely set spinules. An additional very small papilla is inserted at the external angle of the first under arm plate. Between this and the external mouth papilla there is a small group of granules identical with that which H. L. Clark has described in $O$. bythiaspis, and which I have found myself in 0 . globata, as I have just said, as well as in 0. pulchra. This little group of granules is only slightly evident in this individual; it is better indicated in the specimen from station 5280 .

The upper arm plates, which are of medium size, are triangular, a little longer than broad, with an acute proximal angle, slightly convex sides, and a gently rounded distal border. Beyond the second they are separated by a very narrow interval. 
The first under arm plate is small, triangular, a little longer than broad, with a convex distal border. The second is quadrangular, broader than long, with a narrow proximal border, very diverging sides strongly excavated by the tentacle pores, and a very broad and convex distal border with the lateral angles very sharp. 'The following become pentagonal on account of the resolution of the proximal border into two short sides united by a very obtuse angle. Beyond the second these plates are separated by a narrow interval.

The side arm plates, which project only slightly, bear seven strong cylindrical spines, rounded at their tip, with a very rugose surface; but the asperities, which are very small and very closely crowded, are only visible under the microscope. Their length increases from the first ventral spine, which is a little longer than the segment, to the last dorsal, which is as long as three segments.

The tentacle scale is very large and very broad, oval, and almost as long as the segment, with a rounded distal border; its surface is very rugose. The tentacle pores of the first pair bear two scales, but on those following the scale is always single.

The color of the specimen in alcohol is entirely white.

In the specimen from station 5280 the disk reaches only $6 \mathrm{~mm}$. in diameter; the arms are broken off near the base. It differs from the type specimen which I have just described in having the radial shields relatively smaller, and in the armature of the dorsal surface of the disk, which is composed of more slender and more elongated spines; furthermore, the interradial incisions are very much deeper. The tentacle scale is very well developed; it is as long as in the type specimen, but a little narrower; the proximal angle of the mouth shields is a little less elongated.

Affinities and distinctive features.-Ophioplinthaca hastata may be assigned to the genus Ophioplinthaca, although it differs from the other species of this genus by the less deep interradial incisions and in its radial shields, which are smaller and shorter than usual. In this respect it recalls $O$. globata, which $I$ have described above, and it stands, like that form, on the dividing line between the genera Ophioplinthaca and Ophiomitrella; however, it is sharply distinguished from 0 . globata by the very much larger plates of the disk, by the very small radial shields, by the form of the mouth shields, by the development of the tentacle scale, etc.

Ophioplinthaca hastata is rather close to O. citata Kohler, discovered by the Siboga, but it is distinguished from it by its very much shorter and somewhat broader radial shields, by the form of the mouth shields, and by the very much larger tentacle scale, which is doubled on the pores of the first pair. It is equally well distinguished from $O$. vicina Kohler by the shorter and smaller radial shields, 
which are divergent and not in contact, by the form of the mouth shields, by the larger and longer under arm plates, etc.

\section{OPHIOPLINTHACA PULCHRA Kohler.}

Plate 30 , figs. $1-7$; plate 94 , fig. 5 .

Ophioplinthaca pulchra Karrer ('04), p. 125, pl. 27, figs. 5-8.-H. L. Clark ('15), p. 211.

Ophioplinthaca mitis Kouler ('04), p. 127, pl. 25, figs. 1-3.-H. L. Clark ('15), p. 211.

Localities.-Albatross station 5280; China Sea, in the vicinity of southern Luzon; Malavatuan Island (N.) bearing S. $60^{\circ}$ W., 11.3 kilometers (6.1 miles) distant (lat. $13^{\circ} 55^{\prime} 20^{\prime \prime} \mathrm{N}$., long. $120^{\circ} 25^{\prime} 55^{\prime \prime}$ E.) ; 353 meters (193 fathoms); July 17, 1908; gy. S.

'Two specimens (Cat. No. E. 102, U.S.N.M.).

Albatross station 5527; between Siquijor and Bohol Islands; Balicasag Island (C.) bearing N. $14^{\circ}$ W., 15.20 kilometers ( 8.2 miles) distant (lat. $9^{\circ} 22^{\prime} 30^{\prime \prime}$ N., long. $123^{\circ} 42^{\prime} 40^{\prime \prime}$ E.) ; 717 meters (392 fathoms) ; August 11, 1909; glob. Oz.

One specimen (Cat. No. E. 103, U.S.N.M.).

Albatross station 5577; north of Tawi Tawi; Mount Dromedario bearing S. $9^{\circ} \mathrm{W}$., 20.20 kilometers (10.9 miles) distant (lat. $5^{\circ} 20^{\prime}$ $36^{\prime \prime}$ N., long. $119^{\circ} 58^{\prime} 51^{\prime \prime}$ E.) ; 439 meters (240 fathoms) ; September 23,1909 ; crs. S.

One small specimen (Cat. No. 41061, U.S.N.M.).

Albatross station 5629; Patiente Strait and southward; Doworra Island (S.) bearing S. $62^{\circ}$ W., 11.1 kilometers (6 miles) distant (lat. $0^{\circ} 50^{\prime} 00^{\prime \prime}$ S., long. $128^{\circ} 12^{\prime} 00^{\prime \prime}$ E.) ; 375 meters (205 fathoms); December 2, 1909 ; co. S.

Two specimens, of which one is small (Cat. No. E. 101, U.S.N.M.). Albatross station 5661; Flores Sea ; Cape Lassa bearing N. $21^{\circ}$ E., 23.16 kilometers (12.5 miles) distant (lat. $5^{\circ} 49^{\prime} 40^{\prime \prime}$ S., long. $120^{\circ}$ $24^{\prime} 30^{\prime \prime}$ E.) ; 329 meters (180 fathoms) ; December 20, 1909; hrd.

One large specimen (Cat. No. E. 100, U.S.N.M.).

Albatross station 5664; Macassar Strait; Kapoposang Light bearing N. $66^{\circ}$ E., 7.04 kilometers (3.8 miles) distant (lat. $4^{\circ} 43^{\prime} 22^{\prime \prime}$ S., long. $118^{\circ} 53^{\prime} 18^{\prime \prime}$ E.) ; 732 meters (400 fathoms); December 28, 1909 ; hrd.

One small specimen (Cat. No. 41059 , U.S.N.M.).

Notes. - The examination of the series of specimens collected by the Albatross has convinced me that there is no reason for maintaining the distinction between Ophioplinthaca mitis and O. pulchra, both of which I described in 1904 from the Siboga collection, in which certain intermediates which I find in the Albatross collection were lacking. 
I described 0. pulchra from specimens in which the diameter of the disk did not exceed $11 \mathrm{~mm}$., and 0 . mitis from specimens of large size in which the diameter of the disk reached $18 \mathrm{~mm}$. I distinguished 0 . mitis especially by the characters of the dorsal surface of the disk, which is covered by numerous plates provided with rounded, smooth, small, and crowded granules, by the relatively smaller radial shields, by the more numerous arm spines, by the also more numerous mouth papillae, and by the tentacle pores of the first pair, which are furnished with two scales. But if the differences in the armature of the disk were well marked in the Siboga specimens, it is by no means the same in those of the Albatross, and it is impossible for me to separate the smaller specimens having more or less the characters of 0 . pulchra from the larger in which the characters are those of $O$. mitis.

I do not find in the Albatross collection any specimens with granules quite so large as in those from Siboga station 297, of which I figured one in 1904 ('04, pl. 27, fig. 6). It is on one of the two individuals from station 5280, in which the diameter of the disk is $9 \mathrm{~mm}$., that I find the largest granules; I give here a photograph of the dorsal surface of this specimen (pl. 30, fig. 3). These granules are shown separately and more enlarged in figure $5 a$, plate 94 . It may be seen that their surface is simply rugose. I also show for comparison in figure $5 b$ a granule from one of the Siboga specimens which is a little larger than the preceding and on which the asperities are very much stronger. In the other specimen from the same station, in which the diameter of the disk is a little greater $(9.5 \mathrm{~mm}$.), the granules are very much smaller and more numerous (pl. 30, fig. 5 ); the dorsal surface recalls my figure published in 1904 (pl. 27, fig. 5), but with the granules a little more numerous. It is the same with the specimen from station 5527 in which the diameter of the disk is $9 \mathrm{~mm}$. In the smaller specimens from stations 5664, 5577, and 5629 , in which the diameter of the disk varies between $6 \mathrm{~mm}$. and 7 $\mathrm{mm}$., the granules are a little less large than in the first specimen from station 5280 .

It is not to be supposed that the size of the granules decreases with age; this $I$ have already emphasized in my description of $O$. pulchra ('04, p. 126).

As for the two larger specimens from stations 5629 and 5661, in which the diameter of the disk reaches, respectively, $14 \mathrm{~mm}$. and $15 \mathrm{~mm}$., they are identical with those from the Siboga collection which I made the types of 0 . mitis; this last was merely a little larger, the diameter reaching $18 \mathrm{~mm}$. These two specimens also do not differ much from the larger specimen from station 5280 represented in figure 5 on plate 30 , except that the granules of the dorsal 
surface have become more numerous. The examination of a series of specimens such as those of which I give photographs here (pl. 30 , figs. $1,3,5)$, which represent two individuals from station 5280 and a larger one from station 5661, clearly show that we have to do with only a single species.

The other characters which I invoked to separate $O$. mitis from o. pulchra, taken from the radial shields, the mouth papillae, the arm spines, and the double tentacle scale on the pores of the first pair, are very well explained by the differences in the size and age of the subjects. As for the number of the tentacle scales, it is not always constant. Thus in the largest specimen from station 5280 (fig. 6) I find on the pores of the first pair sometimes a single scale and sometimes two smaller scales. In the large specimen from station 5661 (pl. 30, fig. 2) there is only a single tentacle scale on the pores of the first pair, but this scale is very large; on the other hand, the number two is constant in the Siboga specimens with a disk diameter of $18 \mathrm{~mm}$. (fig. 7). This character therefore can not be utilized for specific differentiation.

It may be noticed that on the individual from station 5661, shown in figure 2, the arrangement of the mouth papillae is a little irregular; there are sometimes four and sometimes five on either side; in this connection I must recall a characteristic of 0 . pulchra which struck me in 1904. As may be seen on the photographs of the specimen from station 5661 (fig. 2) and of the two specimens from station 5280 (figs. 4, 6), there is found, between the outer mouth papilla, which is more broadened than those preceding, and the first under arm plate a small group of rounded and crowded granules, from four to six in each group, which are somewhat unequal and of which the outlines are not very well brought out. These granules are usually very much more apparent in the large specimens, and they are more difficult to detect in the small, where they remain very slightly developed; it is even necessary to be aware of their presence to recognize them, and it is only in the small individual from station 5280 , a photograph of which is given here (fig. 4), that they appear at all clearly.

These granules are analogous to those which $I$ have noted in $O$. globata and in O. hastata and which H. L. Clark has found in $O$. bythiaspis.

\section{OPHIOPLINTHACA RUDIS (Kohler).}

Plate 24, figs. $1-6$; plate 96 , fig. 1 .

See for bibliography:

Ophioplinthaca rudis KaHLer ('04), p. 132,-H. L. Clark ('15), p. 211.

Localities.-Albatross station 5124; east coast of Mindoro; Point Origon (N.) bearing S. $56^{\circ}$ E., 38.45 kilometers (20.75 miles) distant 
(lat. $12^{\circ} 52^{\prime} 00^{\prime \prime}$ N., long. $121^{\circ} 48^{\prime} 30^{\prime \prime}$ E.) ; 514 meters (281 fathoms) ; February 2, 1908; sft. gn. M.

Four specimens (Cat. No. E. 272, U.S.N.M.).

Albatross station 5201; Sogod Bay, southern Leyte Island; Limasaua Island (E.) bearing S. $1^{\circ}$ E., 27.43 kilometers (14.8 miles) distant (lat. $10^{\circ} 10^{\prime} 00^{\prime \prime}$ N., long. $125^{\circ} 04^{\prime} 15^{\prime \prime}$ E.) ; 1,013 meters (554 fathoms); April 10, 1908; gy. S., M.

Five specimens (Cat. No. E. 247, U.S.N.M.).

Albatross station 5203; Sogod Bay, southern Leyte Island; Limasaua Island (S.) bearing S. $38^{\circ}$ W., 10.2 kilometers (5.5 miles) distant (lat. $9^{\circ} 58^{\prime} 00^{\prime \prime}$ N., long. $125^{\circ} 07^{\prime} 40^{\prime \prime}$ E.) ; 1,417 meters (775 fathoms); April 10, 1908; gn. M.

Two specimens (Cat. No. E. 254, U.S.N.M.).

Albatross station 5236; Pacific Ocean, off the east coast of Mindanao; Magabao Island (S.) bearing N. $85^{\circ}$ W., 16.86 kilometers (9.1 miles) distant (lat. $8^{\circ} 50^{\prime} 45^{\prime \prime}$ N., long. $126^{\circ} 26^{\prime} 52^{\prime \prime}$ E.) ; 903 meters (494 fathoms); May 11, 1908; fne. gy. S.

One specimen (Cat. No. E. 268 , U.S.N.M.).

Albatross station 5376; Marinduque Island and vicinity; Tayabas Light (outer) bearing N. $53^{\circ}$ W., 34.65 meters (18.7 miles) distant (lat. $13^{\circ} 42^{\prime} 50^{\prime \prime} \mathrm{N}$., long. $121^{\circ} 51^{\prime} 30^{\prime \prime} \mathrm{E}$.) ; 165 meters (90 fathoms); March 2, 1909 ; gy. M., S. (m. b.).

One specimen.

Albatross station 5423; Joló Sea; Cagayan Island (S.) bearing S. $11^{\circ}$ E., 8.89 kilometers (4.8 miles) distant (lat. $9^{\circ} 38^{\prime} 30^{\prime \prime} \mathrm{N}$., long. $121^{\circ} 11^{\prime} 00^{\prime \prime}$ E.) ; 929 meters (508 fathoms) ; March 31, 1909; gy. M., co. S.

Two specimens (Cat. Nos. E. 261, E. 275, U.S.N.M.).

Albatross station 5424; Joló Sea; Cagayan Island (S.) bearing S. $11^{\circ}$ W., 6.30 kilometers (3.4 miles) distant (lat. $9^{\circ} 37^{\prime} 05^{\prime \prime} \mathrm{N}$., long. $121^{\circ} 12^{\prime} 37^{\prime \prime}$ E.) ; 622 meters (340 fathoms) ; March 31, 1909; co. S.

One specimen (Cat. No. E. 273, U.S.N.M.).

Albatross station 5444 .

One specimen (Cat. No. E. 257, U.S.N.M.).

Albatross station 5445; east coast of Luzon; San Bernardino Strait to San Miguel Bay; Atalaya Point, Batag Island, bearing S. $56^{\circ}$ E.: 9.82 kilometers (5.3 miles) distant (lat. $12^{\circ} 44^{\prime} 42^{\prime \prime}$ N., long. $124^{\circ}$ $59^{\prime} 50^{\prime \prime}$ E.) ; 700 meters (383 fathoms); June 3, 1909; gn. M., S.

Eleven specimens (Cat. Nos. E. 250, E. 263, U.S.N.M.).

Albatross station 5450.

Twelve specimens (Cat. Nos. E. 258 , E. 270 , U.S.N.M.).

Albatross station 5467; east coast of Luzon; San Bernardino Strait to San Miguel Bay; Atulayan Island (S.) bearing S. $79^{\circ} \mathrm{W} ., 4.63$ 
kilometers (2.5 miles) distant (lat. $13^{\circ} 35^{\prime} 27^{\prime \prime} \mathrm{N}$., long. $123^{\circ} 37^{\prime}$ $18^{\prime \prime}$ E.) ; 878 meters (480 fathoms); June 18, 1909; gy. M. (m. b.).

Three specimens (Cat. Nos. 41333 , E. 32, U.S.N.M.).

Albatross station 5468; east coast of Luzon; San Bernardinu Strait to San Miguel Bay; Atulayan Island (S.) bearing S. $83^{\circ} \mathrm{W}$., 10.6 kilometers (5.7 miles) distant (lat. $13^{\circ} 35^{\prime} 39^{\prime \prime}$ N., long. $123^{\circ}$ $40^{\prime} 28^{\prime \prime}$ E. ; 1,041 meters (569 fathoms); June 18, 1909; gn. M. (m. b.).

Five specimens.

Albatross station 5470; east coast of Luzon; San Bernardino Strait to San Miguel Bay; Atulayan Island (E.) bearing S. $68^{\circ}$ W., 12.42 kilometers (6.7 miles) distant (lat. $13^{\circ} 37^{\prime} 30^{\prime \prime} \mathrm{N}$, long. $123^{\circ} 41^{\prime}$ $09^{\prime \prime}$ E.) ; 1,024 meters (560 fathoms); June 18, 1909; M.

Two specimens (Cat. No. E. 252, U.S.N.M.).

Albatross station 5471; east coast of Luzon; San Bernardino Strait to San Miguel Bay; Sialat Point Light bearing N. $71^{\circ}$ E., 27.80 kilometers (15 miles) distant (lat. $13^{\circ} 34^{\prime} 57^{\prime \prime}$ N., long. $123^{\circ} 47^{\prime}$ $06^{\prime \prime}$ E.) ; 1,039 meters (568 fathoms) ; June 19, 1909.

Nine specimens (Cat. No. E. 267, U.S.N.M.).

Albatross station 5487; between Leyte and Mindanao; San Ricardo Point (Panaon Island) bearing S. $50^{\circ}$ E., 20.76 kilometers (11.2 miles) distant (lat. $10^{\circ} 02^{\prime} 45^{\prime \prime}$ N., long. $125^{\circ} 05^{\prime} 33^{\prime \prime}$ E.) ; 1,339 meters (732 fathoms); July 31, 1909; gn. M.

Six specimens (Cat. Nos. E. 249, E. 264, U.S.N.M.).

Albatross station 5488; between Leyte and Mindanao; San Ricardo Point (Panaon Island) bearing S. 59 $9^{\circ}$ E., 16.68 kilometers (9 miles) distant (lat. $10^{\circ} 00^{\prime} 00^{\prime \prime}$, long. $125^{\circ} 06^{\prime} 45^{\prime \prime}$ E.) ; 1,412 meters (772 fathoms); July 31, 1909; gn. M.

One hundred and six specimens (Cat. No. E. 278, U.S.N.M.). Albatross station 5492; between Leyte and Mindanao; Diuata Point (W.) bearing S. $45^{\circ}$ W., 28.17 kilometers (15.2 miles) distant (lat. $9^{\circ} 12^{\prime} 45^{\prime \prime}$ N., long. $125^{\circ} 20^{\prime} 00^{\prime \prime}$ E.) ; 1,344 meters (735 fathoms) ; August 1, 1909; gy. M.

One specimen (Cat. No. 41058, U.S.N.M.).

Albatross station 5515; northern Mindanao and vicinity; Camp Overton Light bearing S. $26^{\circ}$ E., 45.59 kilometers (24.6 miles) distant (lat. $8^{\circ} 34^{\prime} 48^{\prime \prime}$ N., long. $124^{\circ} 01^{\prime} 24^{\prime \prime}$ E.) ; August 8, 1909.

Ten specimens (Cat. Nos. E. 260, E. 277, U. S. N. M.). Albatross station 5576 .

One specimen (Cat. No. E. 31, U.S.N.M.)

Albatross station 5605 .

Three specimens (Cat. Nos. E. 35, E. 265, U.S.N.M.).

Albatross station 5606.

Two specimens (Cat. Nos. E. 256, E. 274, U.S.N.M.). 
Albatross station 5610; Gulf of Tomini, Celebes; Batu Daka Island (S.) bearing N. $87^{\circ}$ W., 38.73 kilometers (20.9 miles) distant (lat. $0^{\circ} 36^{\prime} 00^{\prime \prime}$ S., long. $121^{\circ} 01^{\prime} 00^{\prime \prime}$ E.) ; 1,240 meters ( 678 fathoms); November 19, 1909; gy. M.

One specimen (Cat. No. E. 33, U.S.N.M.).

Albatross station 5617; Dodinga Bay, Gillolo Island; Ternate Island (SE.) bearing $\mathrm{S}^{\circ} 45^{\circ}$ W., 12.97 kilometers ( 7 miles) distant (lat. $0^{\circ} 49^{\prime} 30^{\prime \prime}$ N., long. $127^{\circ} 25^{\prime} 30^{\prime \prime}$ E.) ; 239 meters (131 fathoms); November 27, 1909.

Ten specimens (Cat. No. E. 276, U.S.N.M.).

Albatross station 5618; Molucca Passage; Mareh Island bearing S. $69^{\circ}$ E., 14.45 kilometers (7.8 miles) distant (lat. $0^{\circ} 37^{\prime} 00^{\prime \prime}$ N., long. $127^{\circ} 15^{\prime} 00^{\prime \prime}$ E.) ; 762 meters (417 fathoms); November 27 , 1909 ; gy. M.

Seven specimens (Cat. Nos. E. 255, E. 259, E. 271, U.S.N.M.).

Albatross station 5621; between Gillolo and Makyan Islands; Makyan Island (S.) bearing N. $54^{\circ}$ W., 5.56 kilometers (3 miles) distant (lat. $0^{\circ} 15^{\prime} 00^{\prime \prime}$ N., long. $127^{\circ} 24^{\prime} 35^{\prime \prime}$ E.) ; Niovember 28 , 1909 ; gy. and bk. S. (m. b.)

One specimen (Cat. No. E. 34, U. S.N.M.).

Albatross station 5631; south of Patiente Strait; Doworra Island (N.) bearing N. $58^{\circ}$ E., 19.46 kilometers (10.5 miles) distant (lat. $0^{\circ} 57^{\prime} 00^{\prime \prime}$ S., long. $127^{\circ} 56^{\prime} 00^{\prime \prime}$ E.) ; 1,480 meters (809 fathoms); December 2, 1909; gn. M. (in net).

One specimen (Cat. No. E. 30, U.S.N.M.).

Albatross station 5648; Buton Strait; North Island (S.) bearing N. $87^{\circ}$ E., 18.90 kilometers (10.2 miles) distant (lat. $5^{\circ} 35^{\prime} 00^{\prime \prime} \mathrm{S}$., long. $122^{\circ} 20^{\prime} 00^{\prime \prime}$ E.) ; 1,022 meters (559 fathoms); December 16 , 1909 ; gn. M.

Seven specimens (Cat. Nos. E. 248, E. 262, U.S.N.M.).

A7batross station 5654; Gulf of Boni, Celebes; C. Tabako bearing N. $17^{\circ}$ E., 39.84 kilometers (21.5 miles) distant (lat. $3^{\circ} 42^{\prime} 00^{\prime \prime} \mathrm{S}$., long. $120^{\circ} 45^{\prime} 50^{\prime \prime}$ E.) ; 1,472 meters (805 fathoms); December 18 , 1909.

Three specimens (Cat. No. E. 253, U.S.N.M.).

Albatross station 5656; Gulf of Boni, Celebes; Olang Point bearing N. $67^{\circ}$ W., 26.87 kilometers (14.5 miles) distant (lat. $3^{\circ} 17^{\prime} 40^{\prime \prime}$ S., long. $120^{\circ} 36^{\prime} 45^{\prime \prime}$ E.) ; 885 meters (484 fathoms); December 19 , $1909 ;$ gy. M.

One specimen (Cat. No. E. 266, U.S.N.M.).

Albatross station 5657; Gulf of Boni, Celebes; Olang Point bearing N. $67^{\circ} \mathrm{W}$., 28.73 kilometers (15.5 miles) distant (lat. $3^{\circ} 19^{\prime} 40^{\prime \prime} \mathrm{S}$, long. $120^{\circ} 36^{\prime} 30^{\prime \prime}$ E.) ; 900 meters (492 fathoms); December 19, 1909 ; gy. М.

Eight specimens (Cat. No. E. 251, U.S.N.M.). 
Albatross station 5660 ; Flores Sea; Cape Lassa bearing S. $88^{\circ} \mathrm{W}$., 38.00 kilometers (20.5 miles) distant (lat. $5^{\circ} 36^{\prime} 30^{\prime \prime}$ S., long. $120^{\circ}$ $49^{\prime} 00^{\prime \prime}$ E.) ; 1,266 meters (692 fathoms) ; December 20, 1909; gy. M., S.

Two specimens (Cat. Nos. E. 28, E. 29, U.S.N.M.).

Albatross station 5668. Five specimens (Cat. No. E.269, U.S.N.M.). Notes.-As I wrote in 1904, there are wide variations in the development of the spines on the dorsal surface of the disk. I give here photographs of two specimens of which one, from station 5450 , shows very few spines (pl. 24, fig. 1), while the other, from station 5618 , has the spines very numerous and elongated (fig. 3 ). I also include photographs of these different spines (pl. 96, fig. 1).

In comparing the Albatross specimens with those collected by the Siboga I may remark that in my description in 1896 , which was drawn up from a single specimen, I did not lay sufficient emphasis on the characters of the under arm plates. It is more correct to say that these plates are pentagonal, with a proximal angle so obtuse that it may almost completely disappear; this angle is bounded by two straight sides; the lateral borders are notched by the tentacle scale, and the gently convex distal side is extremely broad (pl. 24, figs. 2, 4,6). These plates are separated from the second or third outward, and the space between them may be longer or shorter according as the plates are themselves longer or shorter; but, generally speaking, they are very short in proportion to their width; sometimes they may be three times as broad as long, and separated by an interval which itself is rather long. In certain specimens the plate is even not very much longer than this interval.

The distal border of the upper arm plates is sometimes convex and very regular and joins very exactly the adjacent side arm plates; but sometimes it seems to be slightly elevated and it then appears more or less jagged, showing very small and very short denticulations, which are often rounded, and are arranged very regularly along the border; this feature is more marked in some specimens than in others. I give here a photograph of the dorsal surface of one arm of the specimen from Station 5444 which shows this character very pronouncedly (fig. 5); it may also be seen, though less accentuated, in the specimen represented in figure 1.

As I stated in 1904, the tentacle scale is rather thick at the base and pointed at the tip; it is sometimes somewhat lanceolate and spiniferous (fig. 6). It often happens that the scale, at first broadened at the base, tapers sharply and becomes from then on very narrow in the outer two-thirds or even three-fourths of its total length (fig. 4).

The type of $O$. rudis was found by the Investigator in the Andaman Islands at a depth of 780 fathoms. The Siboga met with it at 
numerous stations in the Sunda Archipelago, between $2^{\circ} \mathrm{N}$. latitude and $10^{\circ} \mathrm{S}$. latitude and $117^{\circ}-131^{\circ} \mathrm{E}$. longitude, at depths varying between 462 and 1,886 meters (251 to 1,047 fathoms).

\section{OPHIOCAMAX RUGOSA Kohler.}

Plate 27 , figs. $5-8$; plate 28 , figs. $1-6$; plate 29 , figs. $1-6$; plate 94 , fig. 8 .

Ophiocamax rugosa Konler ('04), p. 139, pl. 26, figs. 4-7.-H. L. ClaRK ('15), p. 214.

Ophiocamax polyploca H. L. ClakK ('11), p. 193, fig. 90; ('15), p. 214.

Localities.-Albatross station 5116; Balayan Bay and Verde Island Passage; Sombrero Island bearing N. $69^{\circ}$ E., 4.63 kilometers (2.5 miles) distant (lat. $13^{\circ} 41^{\prime} 00^{\prime \prime} \mathrm{N}$., long. $120^{\circ} 47^{\prime} 05^{\prime \prime}$ E.) ; 366 meters (200 fathoms); January 20, 1908.

Three specimens (Cat. No. E. 360, U.S.N.M.).

Albatross station 5135 ; vicinity of Joló; Joló Light bearing S. $46^{\circ} \mathrm{W}$., 22.05 kilometers (11.9 miles) distant (lat. $6^{\circ} 11^{\prime} 50^{\prime \prime} \mathrm{N}$., long. $121^{\circ} 08^{\prime} 20^{\prime \prime}$ E.) ; 294 meters (161 fathoms) ; February 7, 1908; fne. co. S.

One specimen (Cat. No. 41327, U.S.N.M.).

Albatross station 5166; Sulu (Joló) Archipelago, Tawi Tawi Group; Observation Island bearing N. $20^{\circ}$ W., 8.52 kilometers (4.6 miles) distant (lat. $4^{\circ} 56^{\prime} 10^{\prime \prime} \mathrm{N}$., long. $119^{\circ} 46^{\prime} 00^{\prime \prime}$ E.) ; 177 meters (97 fathoms); February 24, 1908; co. S.

Two specimens (Cat. Nos. 40917, E. 356, U.S.N.M.).

Albatross station 5167; Sulu Archipelago, Tawi Tawi Group; Observation Island bearing N. $11^{\circ}$ W., 10.4 kilometers ( 5.6 miles) distant (lat. $4^{\circ} 55^{\prime} 10^{\prime \prime}$ N.) ; 201 meters (110 fathoms); Co.

Five specimens (Cat. Nos. 41328, 41329, U.S.N.M.).

Albatross station 5168; Sulu Archipelago, Tawi Tawi Group; Observation Island bearing $\mathrm{N} .17^{\circ} \mathrm{W} ., 7.78$ kilometers (4.2 miles) distant (lat. $4^{\circ} 56^{\prime} 30^{\prime \prime} \mathrm{N}$., long. $119^{\circ} 45^{\prime} 40^{\prime \prime}$ E.) ; 146 meters (80 fathoms); February 25, 1908; co. S.

Two specimens (Cat. No. 41326, U.S.N.M).

Albatross station 5187; Tanon Strait, east coast of Negros; Apo Island bearing $\mathrm{S} .21^{\circ}$ W., 23.16 kilometers (12.5 miles) distant (lat. $9^{\circ} 16^{\prime} 45^{\prime \prime}$ N., $123^{\circ}$ ); 411 meters (225 fathoms); March 31, 1908; sft. gn. M.

Seven specimens (Cat. Nos. E. 327 , E. 359, U.S.N.M.).

Albatross station 5275; China Sea, in the vicinity of southern Luzon; Malavatuan Island (N.) bearing S. $71^{\circ}$ E., 19.92 kilometers (10.75 miles) distant (lat. $13^{\circ} 55^{\prime} 55^{\prime \prime}$ N., long. $120^{\circ} 10^{\prime} 15^{\prime \prime}$ E.) ; 214 meters (117 fathoms); July 16, 1908; fne S.

One specimen (Cat. No. 41207, U.S.N.M.).

Albatross station 5353; Balabac Strait; Cape Melville Light bearing S. $85^{\circ}$ E., 31.13 kilometers (16.8 miles) distant (lat. $7^{\circ} 50^{\prime} 45^{\prime \prime}$ 
N., long. $116^{\circ} 43^{\prime} 15^{\prime \prime}$ E.) ; 271 meters (148 fathoms); January 1 , 1909.

One specimen (Cat. No. 41206, U.S.N.M.).

Albatross station 5415; between Cebu and Bohol; Lauis Point Light bearing N. $24^{\circ}$ W., 13.34 kilometers (7.2 miles) distant (lat. $10^{\circ} 07^{\prime} 50^{\prime \prime} \mathrm{N}$., long. $123^{\circ} 57^{\prime} 00^{\prime \prime}$ E.) ; 161 meters (88 fathoms); March 24, 1909; fne. S.

Twelve specimens (Cat. Nos. E.358, E.362, U.S.N.M.).

Albatross station 5420; between Cebu and Bohol; Cruz Point (Bohol) bearing S. $20^{\circ}$ E., 11.1 kilometers (6 miles) distant (lat. $9^{\circ}$ $49^{\prime} 35^{\prime \prime}$ N., long. $123^{\circ} 45^{\prime} 00^{\prime \prime}$ E.) ; 231 meters (127 fathoms) ; March 25,1909 .

One specimen (Cat. No. E.357, U.S.N.M.).

Albatross station 5440; west coast of Luzon, Manila Bay to Lingayen Gulf; San Fernando Point Light bearing N. $82^{\circ}$ E., 42.81 kilometers (23.1 miles) distant (lat. $16^{\circ} 33^{\prime} 52^{\prime \prime} \mathrm{N}$., long. $119^{\circ} 52^{\prime}$ 54 " E.) ; 314 meters (172 fathoms); May 10, 1909; fne. gy. S., Glob.

Four specimens (Cat. No. E.361, U.S.N.M.).

Albatross station 5442; west coast of Luzon, Manila Bay to Lingayen Gulf; San Fernando Point Light bearing N. $39^{\circ}$ E., 15.57 kilometers (8.4 miles) distant (lat. $16^{\circ} 30^{\prime} 36^{\prime \prime} \mathrm{N}$, long. $120^{\circ} 11^{\prime}$ $06^{\prime \prime}$ E.) ; 82 meters (45 fathoms); May 10, 1909; co. S.

One specimen (Cat. No. 41209 , U.S.N.M.).

Albatross station 5459; east coast of Luzon; San Bernardino Strait to San Miguel Bay; Legaspi Light bearing S. $88^{\circ}$ W., 26.50 kilometers (14.3 miles) distant (lat. $13^{\circ} 10^{\prime} 21^{\prime \prime}$ N., long. $123^{\circ} 59^{\prime} 54^{\prime \prime}$ E.) ; 368 meters (201 fathoms); June 8, 1909.

One specimen (Cat. No. 41208 U.S.N.M.).

Albatross station 5519; northern Mindanao and vicinity; Point Tagolo Light bearing S. 71 ${ }^{\circ} \mathrm{W} ., 16.12$ kilometers ( 8.7 miles) distant (lat. $8^{\circ} 47^{\prime} 00^{\prime \prime}$ N., long. $123^{\circ} 31^{\prime} 15^{\prime \prime}$ E.) ; 333 meters (182 fathoms) ; August 9, 1909; Glob., S.

One specimen (Cat. No. E.326, U.S.N.M.).

Albatross station 5520; northern Mindanao and vicinity; Point Tagolo Light bearing S. $48^{\circ}$ W., 8.34 kilometers (4.5 miles) distant (lat. $8^{\circ} 41^{\prime} 15^{\prime \prime} \mathrm{N}$., long. $123^{\circ} 18^{\prime} 30^{\prime \prime}$ E.) ; 186 meters (102 fathoms) ; August 10, 1909.

One specimen (Cat. No. E.324, U.S.N.M.).

Albatross station 5523; northern Mindanao and vicinity; Point Tagolo Light bearing S. $48^{\circ} \mathrm{W}$., 12.42 kilometers ( 6.7 miles) distant (lat. $8^{\circ} 48^{\prime} 44^{\prime \prime}$ N., long. $123^{\circ} 27^{\prime} 35^{\prime \prime}$ E.) ; August 10, 1909.

Two specimens (Cat. No. E.323, U.S.N.M.).

Albatross station 5536; Apo Island (C.) bearing S. $26^{\circ}$ W., 21.87 kilometers (11.8 miles) distant (lat. $9^{\circ} 15^{\prime} 45^{\prime \prime} \mathrm{N}$., long. $123^{\circ} 22^{\prime} 00^{\prime \prime}$ E.) ; 510 meters (279 fathoms) ; August 19,1909 ; gn. M. 
One specimen (Cat. No. E.325, U.S.N.M.).

Albatross station 5541; Tagolo Light bearing S. $65^{\circ}$ W., 23.54 kilometers (12.7 miles) distant (lat. $8^{\circ} 49^{\prime} 38^{\prime \prime} \mathrm{N}$., long. $123^{\circ} 35^{\prime} 30^{\prime \prime}$ E. ; 400 meters (219 fathoms); August 20, 1909; fne S., brk. Sh.

Two specimens (Cat. No. E.322 U.S.N.M.).

Albatross station 5543; Tagolo Light bearing . S. $75^{\circ}$ W., 23.16 kilometers (12.5 miles) distant (lat. $8^{\circ} 47^{\prime} 15^{\prime \prime} \mathrm{N}$., long. $123^{\circ} 35^{\prime}$ $00^{\prime \prime}$ E.) ; 296 meters (162 fathoms) ; August 20, 1909; S.

Four specimens (Cat. No. E.321, U.S.N.M.).

Notes. - The study of the very fine series of specimens collected by the Albatross has convinced me that $O$. polyploca, described by H.L. Clark in 1911 and met with in various localities in the Japanese seas between 85 and 152 fathoms, can not be separated from $O$. migosa, which I described in 1904 from specimens collected by the Siboga in the Sunda Archipelago, and I am convinced that the two in reality represent only a single species which shows very considerable variation.

H. L. Clark characterized his 0 . polyploca by the radial shields of very large size covering the major portion of the dorsal surface of the disk, by the dorsal arm spines, which are very long and smooth, and by the small mouth shields, which are provided with a narrow and elongated distal lobe projecting into the interradial space. In his description he states that the upper arm plates have the distal border furnished with fine spinules, that the under arm plates show a rounded and projecting distal lobe which beyond the first segments is furnished with rugosities or spines, of which the number little by little increases.

Almost all the Albatross Philippine specimens show the same form of mouth shield, and this form is identical with that which H. L. Clark has described and figured; it may be recognized on the photographs which I give here (pl. 28, figs. 2, 5). The elongation of the distal lobe is more or less marked, and the principal part of the shield itself is sometimes very small, but sometimes, on the other hand, relatively rather large; in the specimen from station 5167, shown in figure 2, this part is of medium size, and it is often smaller, while in the specimen from station 5187 , represented in figure 5 , it is larger. In the specimen from station 5275 (pl. 27, fig. 6) the mouth shields are appreciably larger than usual, and their distal lobe is less accentuated. This form recalls that which I had noticed among the Siboga specimens; I stated in my description that these mouth shields are small, triangular, with a distal lobe which may become rather prominent and give them a lozenge-shaped form, though this lobe remains ordinarily rather broad and short; I notice, however, that on one of the specimens from station 254 this lobe 
elongates into a little narrow stalk quite comparable to that which H. L. Clark has described in O. polyploca.

In their dimensions relative to the diameter of the disk the radial shields show certain variations. In a specimen from station 5187 (pl. 28, fig. 4) these shields are much elongated and rather narrow; in another from the same station (fig. 6) they are a little shorter and relatively broader; in the specimens from stations 5167 (figs. 1, 3), 5540 (pl. 29, fig. 1), and 5541 (pl. 29, fig. 5) they are still shorter; in a specimen from station 5167 (pl. 28, fig. 3) they are, on the other hand, relatively large. As for the armature of the dorsal surface of the disk, it consists sometimes of small, short club spines terminated by a crown of spinules, as may be seen in the specimen from station 5167 (pl. 28, fig. 3); these club spines may become very much thicker and larger with a crown of very strong spinules, a condition seen in the individual from station 5275 shown in figure 7 on plate 27 , in which the plates of the dorsal surface of the disk are themselves very much larger. The club spines may elongate, at the same time remaining slender, and thus constitute a fairly uniform covering (station 5187; pl. 28, fig. 4) ; moreover, certain of them transform into spines which are sometimes slender and elongated (pl. 28, fig. 6 , and pl. 29, fig. 5), but sometimes rather thick and short (pl. 28 , fig. 1). In the numerous specimens from station 5520 the greater part of the plates of the dorsal surface of the disk bear very long spines which are rather thick at the base and stongly denticulate throughout their whole length (pl. 29, fig. 1). In figure 8 on plate 94 I show the whole series of forms which may be observed between the very short club spines and the very strongly developed true spines like those which are met with in the individuals from station 5520 .

I have already noted in my original description, published in 1904, the variations which may occur in the armature of the upper and under arm plates. The small conical and short spines which these plates bear may remain slender and little developed, and become localized on their distal border (specimen from station 5275, pl. 27 , figs. 6,7 ) ; or they may extend over almost the whole extent of the surface of these plates, being sometimes well spaced, and sometimes closely crowded. In figures 2,3 , and 6 on plate 29 I show portions of the arms of individuals from stations 5167, 5187, and 5541, in which these little spines are seen at different stages of development.

As for the arm spines, these may remain rather short on the dorsal side (specimen from station 5167, pl. 28, fig. 3 ) ; or they may become more elongate, as is seen in the other specimen from station 5167 (fig. 1) and in that from station 5275 (pl. 27, figs. 6, 7); or they may become very long, as is the case in the specimens from station 5187 
(pl. 28, figs. 4,6 ), and especially in that from station 5541 (pl. 29, fig. 4), in which the dorsal spines at the base of the arms have a length of more than six segments. I notice that these dorsal spines, especially when they are very long, have denticulations less strong than those on the ventral spines, but these denticulations never disappear entirely, and I have not been able to find spines which were absolutely smooth.

It seems to me that in view of these variations it is not possible to maintain the specific distinction established by $\mathrm{H}$. L. Clark between $O$. rugosa and $O$. polyploca, and that this latter must be united with the former.

The greater part of the alcoholic specimens are entirely white, or slightly yellowish; but those from station 5520 are rather dark gray.

The Siboga met with O. rugosa at different localities in the Sunda archipelago between $5^{\circ}$ and $10^{\circ} \mathrm{S}$. latitude and $119^{\circ}-132^{\circ} \mathrm{E}$. longitude, at depths varying from 204 to 520 meters (112 to 289 fathoms). The Albatross collected the form described by $\mathrm{H}$. L. Clark in the Japanese seas between $30^{\circ}$ and $32^{\circ} \mathrm{N}$. latitude and $128^{\circ}-130^{\circ} \mathrm{E}$. longitude at depths of from 155 to 278 meters ( 85 to 152 fathoms).

\section{Order III. GNATHOPHIURIDA.}

Family AMPHIURIDAE.

\section{AMPHIURA AgITATA Kœhler.}

Amphiur agitata Kahler ('04), p. 79, pl. 13, figs. 5, 6, 7.-H. L. ClakK ('15), p. 233.

Locality.-Albatross station 5592; Sibuko Bay, Borneo, and vicinity; Silungan Island (M.) bearing N. $1^{\circ}$ W., 11.86 kilometers (6.4 miles) distant (lat. $4^{\circ} 12^{\prime} 44^{\prime \prime} \mathrm{N}$., long. $118^{\circ} 27^{\prime} 44^{\prime \prime}$ E.) ; 558 meters (305 fathoms); September 29, 1909; gn. M.

One specimen (Cat. No. 41166 , U.S.N.M.).

Notes.-This specimen is a little larger than those collected by the Siboga upon which I based the species; the diameter of the disk is $8.5 \mathrm{~mm}$.; the arms are incomplete, but they taper rather rapidly and their length could not have been very great.

I notice certain differences between this specimen and the type of the species; they are correlated without doubt with the larger size of the specimen. The dorsal plates of the disk are smaller and closely crowded, and they do not become larger in the central region; the outer mouth papilla is relatively a little less broad than in the smaller specimens; the distal lobe of the mouth shields is also a little broader, and passes more gradually into the principal part of the shield; and 
the arm plates have the distal border slightly notched. These differences are entirely secondary, and the two indubitably belong to the same species.

The type of $A$. agitata was dredged in $6^{\circ} 08^{\prime} \mathrm{N}$. latitude and $121^{\circ}$ $19^{\prime} \mathrm{E}$. longitude, at a depth of 275 meters (153 fathoms).

\section{AMPHIURA AMBIGUA Kohler.}

Plate 69 , figs. 5 , 6 ; plate 96 , fig. 3.

Amphiura ambigua KoeHLer ('05), p. 39, pl. 4, figs. 9-11.-H. L. ClakK ('15), p. 233.

Locality.-Albatross station 5158; Sulu (Joló) Archipelago, Tawi Tawi Group; Tonakta Island (N.) bearing N. $89^{\circ} \mathrm{W}$., 3.52 kilometers (1.9 miles) distant (lat. $5^{\circ} 12^{\prime} 00^{\prime \prime} \mathrm{N}$., long. $119^{\circ} 54^{\prime} 30^{\prime \prime}$ E.) ; 22 meters (12 fathoms) ; February 21, 1908; crs. S., Sh.

One specimen (Cat. No. 41162, U.S.N.M.).

Notes.-I described this species from two specimens found by the Siboga in the Jolo Archipelago at a depth of 13 meters (7 fathoms), and these two were of very small size, the diameter of the disk measuring respectively $2 \mathrm{~mm}$. and $3 \mathrm{~mm}$. In the Albatross specimen the diameter of the disk is also $3 \mathrm{~mm}$. The third and fourth arm spines, sometimes even the second, always show the little hook directed posteriorly which occurs at their extremity, and which I pointed out in my original description. I give here a photograph of the ventral surface of the specimen, and of one of the arms, more enlarged ( $\mathrm{pl}$. 69 , figs. 5,6 ), as well as figures of some of the arm spines seen under the microscope (pl. 96, fig. 3).

\section{AMPHIURA COMMUTATA, new species.}

Plate 66, figs. $1,2,3$; plate 96 , fig. 6 .

Locality.-Hakodate, Japan.

One hundred and sixty-two specimens (Cat. No. 41174; type, Cat. 41175, U.S.N.M.).

Description.-In the two larger specimens the diameter of the disk is $6 \mathrm{~mm}$.; the arms are from $35 \mathrm{~mm}$. to $38 \mathrm{~mm}$. in length.

The disk is rounded. The dorsal surface is covered with numerous small, subequal, rounded, and imbricated plates, a little larger in the vicinity of the radial shields, and becoming a little smaller on the periphery of the disk. Six primary plates may be made out which are very rounded, and all of the same size; but they are scarcely larger than the plates adjoining the radial shields; the five radials are separated from the dorso-central by three or four rows of plates. The radial shields are triangular, two and a half times as long as broad, very close together or in contact outwardly, and rather strongly divergent inwardly, where they are separated by three or four rows 
of plates; their proximal angle is rather sharp; the length of these shields is less than half the radius of the disk.

The ventral surface of the disk bears only a narrow border of peripheral plates, remaining entirely naked over the rest of its extent. The genital slits are rather broad.

The mouth shields are lozenge-shaped, as long as broad, with the angles rounded; the two proximal sides are very gently convex, and the two distal sides are almost straight. The adoral plates are small, triangular, much narrowed inwardly, and scarcely in contact in the median interradial line; sometimes they even do not touch each other; they are much broadened outwardly, and, as they are very close to the median radial line, they include between them the first under arm plate. The oral plates are rather high, half again as high as broad. The internal mouth papilla is large and strong; the following is triangular with a very sharp apex; the external, which is inserted upon the adoral plate, is spiniform and more or less erect; but it is always short, thick and obtuse.

The upper arm plates are small, elongated, longer than broad, and almost oval on the two first segments, then broadening somewhat and becoming almost as long as broad with a rather narrow proximal border and a broad and strongly convex distal border continuing the rounded lateral borders. At some distance from the disk the upper arm plates are less confined by the side arm plates, and they then become broader than long, and almost transversely oval. All these plates are in contact.

The first under arm plate, enclosed by the neighboring adoral plates, is much narrowed in its distal part, but broadens in its proximal part; it is pentagonal in shape. The following are rectangular, a little broader than long, with the sides straight and the angles rounded; they are all in contact.

The side arm plates are much developed, and they encroach considerably on the dorsal surface of the arm, especially at the arm bases, where they bear eight spines; the number of these falls later to seven, then to six. These spines are subequal, and their length equals that of the segment, except that of the last dorsal, which is a little shorter. All these spines are slightly flattened, rather thick, especially the ventral spines, and their thickness diminishes from the dorsal side. The first ventral spine is almost cylindrical, with the tip rounded. The two or three following have the extremity obtuse, and often even truncated; they bear in their distal region very fine asperities which become stronger at their tip; on the posterior angle one of these asperities tends to form a very small tooth, but this feature is only slightly indicated; the four dorsal spines have their tips rounded (pl. 96 , fig. $6 a$ ). 
The single tentacle scale is very large, squamiform, slightly oval, furnished on its distal border with a row of very fine denticulations (fig. 6b).

The color of the specimens in alcohol is yellowish gray.

Affinities and distinctive features.-Amphiura commutata is very easily distinguished from the species of Amphiura-indeed, very few in number-in which the ventral surface of the disk is naked and which possess only a single tentacle scale. The forms which approach it most closely are $A$. concinna Kohler, found by the Siboga in the Sunda Archipelago, and A. glabra Lyman, which the Challenger collected in $4^{\circ} \mathrm{N}$. latitude and $127^{\circ} \mathrm{E}$. longitude at a depth of 500 fathoms; both are deep-sea forms with which the Albatross species can not be confused.

\section{AMPHIURA DEJECTA, new species.}

Plate 66, figs. 4, 5.

Locality.-Albatross station 5592 ; Sibuko Bay, Borneo, and vicinity; Silungan Island (M.) bearing N. $1^{\circ}$ W., 11.86 kilometers (6.4 miles) distant (lat. $4^{\circ} 12^{\prime} 44^{\prime \prime} \mathrm{N}$., long. $118^{\circ} 27^{\prime} 44^{\prime \prime}$ E.) ; 558 meters (305 fathoms); September 29, 1909; gn. M.

One specimen.

Description.-The diameter of the disk is $9 \mathrm{~mm}$; the arms are broken off $20 \mathrm{~mm}$. or $22 \mathrm{~mm}$. from their base, but they can not be very long, for the longest stump is already markedly narrowed at the place where it is broken off; these arms are somewhat flattened, and of medium size.

The disk is rounded. The dorsal surface is covered with numerous subequal imbricated plates, becoming smaller at the periphery of the disk, and a little larger in the vicinity of the radial shields; each interradial space includes from ten to twelve rows of plates. There is not the least indication of primary plates. The radial shields are rather small, two and a half times as long as broad, with the proximal angle pointed and the external border very convex. The two shields of each pair are close together but not in contact outwardly, and slightly divergent inwardly. Their length is much less than half the radius of the disk.

The ventral surface is covered with extremely small, imbricated, very closely crowded plates, but in the immediate vicinity of the mouth shields these plates become rounded, and are simply in contact, sometimes even showing small bare spaces between them. The genital slits are narrow.

The mouth shields are longer than broad, lozenge-shaped, with the proximal sides elongated and the distal sides shorter; the four angles are rounded. The triangular adoral plates are rather small, and are 
limited to the two proximal sides of the mouth shields; they are very narrow inwardly and do not reach the interradial median line; outwardly they bocome much broadened and send off a narrow process which separates the mouth shield from the first side arm plate. The oral plates are twice as high as broad, but they are in contact only in their proximal half; they thus delimit a naked triangular space, of which the base is formed by the proximal extremities of the mouth shield and the adoral plates. The terminal mouth papilla is rather thick, almost cubical, with the proximal face channeled. The second papilla, inserted on the oral plate, is elongated, conical, with the point blunted; the external papilla, inserted on the adoral plate, is broadened, sometimes rounded and sometimes triangular, with the tip much blunted.

The upper arm plates are very large, covering the greater part of the dorsal surface of the arm. They are semicircular or almost biconvex, with a somewhat rounded distal side, and are very much broader than long; all of them are in contact.

The first under arm plate is small, trapezoidal, with a narrow distal border, a longer proximal border, and divergent sides. The following plates are pentagonal, a little longer than broad, with a truncated and rounded proximal angle, the lateral borders slightly notched by the tentacle scale, and the distal side slightly excavated in the middle. They are all in contact.

The side arm plates, which are only slightly projecting, bear five subequal spines, the length of which almost equals that of the segment; this number falls to four at some distance from the base. These spines are rather thick and cylindrical, with the tip rounded; on the second ventral spine especially the tip is rather thick. Their surface is simply rugose without showing distinct asperities.

The single tentacle scale is very large, flattened, markedly longer than broad, with the tip rounded.

The specimen in alcohol is grayish white.

Affinities and distinctive features.-Amphiura dejecta belongs to the section of the genus Amphiura in which the disk is covered with plates on both surfaces, and which only possesses a single tentacle scale. It may be compared with $A$. abbreviata Kohler, A. agitatı Kœhler, $A$. angularis Lyman, $A$. duncani Lyman (=A. lütkeni Duncan), and $A$. macraspis H. L. Clark, but it can not be confused with any of these. Amphiura abbreviata has the radial shields very narrow and elongated, the primary plates distinct, and the arm spines six in number, half of them bihamulate; $A$. agitata possess seven arm spines, and the dorsal plates of the disk are larger; $A$. angulariz, which has only four arm spines, has the external mouth papilla smaller and the tentacle scale also smaller; $A$. duncani has six arm 
spines, and the mouth shields are triangular. A. macraspis, which has recently been described by $\mathrm{H}$. L. Clark, has extremely small radial shields, and triangular upper arm plates.

\section{AMPHIURA DEMISSA, new species.}

Plate 69, figs. 1 and 2.

Locality.-Albatross station 5492; between Leyte and Mindanao; Diuata Point (W.) bearing S. $45^{\circ}$ W., 28.17 kilometers (15.2 miles) distant (lat. $9^{\circ} 12^{\prime} 45^{\prime \prime}$ N., long. $125^{\circ} 20^{\prime} 00^{\prime \prime}$ E.) ; 1,344 meters (735) fathoms); August 1, 1909; gy. M.

One specimen (Cat. No. 41177, U.S.N.M.)

Description.-The diameter of the disk is $8 \mathrm{~mm}$.; the slender and flattened arms are very long; the longest is preserved over a length of $70 \mathrm{~mm}$., and is incomplete; this arm tapers very gradually from the base. The specimen is not in a good state of preservation; there are rents on the dorsal surface of the disk, and the mouth plates are somewhat deformed; nevertheless the characters are easily made out, and $I$ do not know any species to which it may be assigned.

The disk is rounded, rather strongly excavated in the interradial spaces, and very gently notched above the bases of the arms. The dorsal surface is covered with extremely small but very distinct plates; these plates are subequal and imbricated; they become still smaller at the periphery of the disk, but a little larger in the vicinity of the radial shields. There is no indication of primary plates. The rather small radial shields are moderately broad, a little more than twice as long as broad, with the external border very convex, the internal border straight, and the proximal angle rounded; the two shields of each pair are in contact outwardly, and diverge from that point inward. Their length is a little greater than one-third the radius of the disk.

The ventral surface is covered with plates which are a little smaller than those of the dorsal surface, but nevertheless very distinct; they become a little larger in the vicinity of the mouth shields and the genital slits. These last are broad and very evident.

The mouth shields are a little broader than long, lozenge-shaped, with the angles very rounded and the sides equal. The adoral plates, which are of medium size, are triangular, tapering inwardly, and their rounded tip does not quite reach the median interradial line; they are much broadened outwardly and give off a process which separates the mouth shield from the first side arm plate. The oral plates are rather high. The proximal mouth papilla is of medium size, somewhat elongated, with the tip rounded; the second papilla, inserted on the oral plate, is much broadened and low, rectangular, 
three times as long as broad; the external, inserted on the adoral plate, is conical with the point blunted, and is not very well developed.

The upper arm plates are extremely broad, two and a half times as broad as long, triangular, with a very obtuse and rounded proximal angle bordered by straight sides which pass over very rounded angles to the convex distal border. The side arm plates penetrate between these last as far as the neighborhood of the median line, but the upper arm plates remain in contact by the apex of their proximal angle.

The first under arm plate is very small, trapezoidal, very much longer than broad, narrowing in its distal region which is inclosed between the corresponding adoral plates. The following plates are pentagonal, a little broader than long, with a truncated and very rounded proximal angle, and the sides and distal border gently concave. These plates are in contact.

The side arm plates, which are only slightly projecting, carry five spines on the segments immediately following the disk, but this number very soon falls to four; these spines are subequal, cylindrical, with the tip rounded, and their surface is rugose; their length almost equals that of the segment.

The single tentacle scale is small, and only slightly longer than broad, with the tip rounded. A few pores of the first pair sometimes show two scales in contact inserted side by side on the side arm plate.

The color of the specimen in alcohol is grayish white.

Affinities and distinctive features.-Amphiura damissa is easily distinguished from all the other species of the genus Amphiura (in the restricted sense) with both surfaces of the disk provided with scales and with only a single tentacle scale. Its central mouth papilla, which is low and broadened, recalls the form seen in $A$. capensis Lyman, but except for this character there is not the slightest resemblance between the two species.

If the description which I have just given be compared with that of $A$. fusco-alba published by Brock, numerous points of resemblance will be noticed, but it does not seem to me possible to confuse these two species, which, moreover, come from very different depths. Brock says that the radial shields of $A$. fusco-alba are very large and that their length equals half the radius of the disk, that the plates of the dorsal surface of the disk are grouped regularly around a central plate, while the plates of the ventral surface are extremely small, and, as they are rather elevated, they take on the form of granules; the internal mouth papilla is very large; the mouth shields are triangular, with an external lobe which causes them to appear cordiform; the upper arm plates are twice as broad as long and are separated, and 
the arm spines are six in number. All these characters seem to me to separate the abyssal form found by the Albatross sharply from $A$. fusco-alba, which is essentially littoral.

\section{AMPHIURA DIOMEDEAE Lïtken and Mortensen.}

\section{Plate 67 , figs. $7-10$.}

Amphiura diomedeae LüTken and Montensex ('99), p. 151, pl. 12, figs. 1-7.-H. L. ClaRK ('11), p. 140; ('13), p. 214 ; ('15), p. 225.

Localities.-Albatross station 5111; China Sea, off southern Luzon; Sombrero Island bearing S. $41^{\circ}$ E., 8.34 kilometers (4.5 miles) distant (lat. $13^{\circ} 45^{\prime} 15^{\prime \prime} \mathrm{N}$., long. $120^{\circ} 46^{\prime} 30^{\prime \prime}$ E.) ; 432 meters (236 fathoms); January 16, 1908.

Five specimens (Cat. Nos. 41213, 41214, U.S.N.M.).

Albatross station 5281; China Sea, in the vicinity of southern Luzon; Malavatuan Island (N.) bearing S. $84^{\circ}$ W., 7.97 kilometers (4.3 miles) distant (lat. $13^{\circ} 52^{\prime} 45^{\prime \prime}$ N., long. $120^{\circ} 25^{\prime} 00^{\prime \prime}$ E.) ; 368 meters (201 fathoms); July 18, 1908; dk. gy. S.

Two specimens (Cat. No. 41210, U.S.N.M.).

Albatross station 5325; off northern Luzon; Hermanos Island (N.) bearing N. $86^{\circ}$ E., 31.04 kilometers (16.75 miles) distant (lat. $18^{\circ} 34^{\prime} 15^{\prime \prime}$ N., long. $121^{\circ} 51^{\prime} 15^{\prime \prime}$ E.) ; 410 meters (224 fathoms); November 12,$1908 ; \mathrm{gn}$. M.

One specimen (Cat. No. 41211, U.S.N.M.).

Albatross station 5535; between Cebu and Siquijor; Apo Island (C.) bearing S. $24^{\circ} \mathrm{W}$., 31.50 kilometers $\left(17\right.$ miles) distant (lat. $9^{\circ}$ $20^{\prime} 30^{\prime \prime}$ N., long. $123^{\circ} 23^{\prime} 45^{\prime \prime}$ E.) ; 567 meters (310 fathoms) ; August 19,1909 ; gy. glob. Oz.

One specimen (Cat. No. 41212 , U.S.N.M.).

Notes.-In the largest specimen, which comes from station 5111 , the diameter of the disk reaches $8 \mathrm{~mm}$., and the arms are from 28 $\mathrm{mm}$. to $30 \mathrm{~mm}$. long.

I have been able to compare these specimens with a very typical example of $A$. diomedeae sent to me by the United States National Museum, which was dredged by the Albatross. I show here (pl. 67 , figs. 7,8$)$ the two surfaces of this specimen, which $I$ have used for comparison. The specimen from station 5281, in which the diameter of the disk is $6.5 \mathrm{~mm}$., agrees well with it; most of the others agree also, with it but they are very small.

The largest specimen from station 5111 (figs. 9, 10) differs from this typical specimen in the arrangement of the dorsal plates of the disk which are not imbricated in the central region, but remain rounded, and the primary plates are still fairly distinct. The plates imbricate only toward the periphery of the disk, where they 
become abruptly smaller; there is a very sharp line of demarcation between these smaller marginal plates and those which cover the rest of the dorsal surface of the disk. The upper arm plates also have a form slightly different from those in the specimen from the National Museum. But I notice that their form is exactly the same as that which Lütken and Mortensen have shown in one of their figures ('99, pl. 12, fig. 6), while the specimen from the National Museum has the dorsal plates identical with those which these authors have represented in plate 12 as figure 2. All the other characters agree well with those of $A$. diomedeae. I believe, therefore, that I am able to assign all my specimens to this species.

Amphiura diomedeae appears to have a vast geographical range. Lütken and Mortensen described it from specimens found between $7^{\circ}-22^{\circ} \mathrm{N}$. latitude and $79^{\circ}-107^{\circ} \mathrm{W}$. longitude, at depths varying between 935 and 2,877 meters ( 511 and 1,573 fathoms). The specimens of Amphiura diomedeae which H. L. Clark has studied came from numerous localities in the Japanese seas (Honshu Island, Kagoshima, Suruga Gulf, Sagami Bay, Omai Saki, etc.) and from depths between 71 and 1,369 meters (39 and 749 fathoms). The Albatross specimens which I have mentioned above were captured between $9^{\circ}-18^{\circ} \mathrm{N}$. latitude and $120^{\circ}-123^{\circ} \mathrm{E}$. longitude, at depths varying from 368 to 567 meters (201 to 310 fathoms).

Matsumoto considers $A$. diomedeae a synonym of $A$. koreae Duncan ('17, p. 198) and believes that the former name should be suppressed. He is apparently right, but as it is very difficult to recognize the species described by Duncan from his description, and especially from his figures, which are quite inadequate, it would be necessary, in order to be certain, to examine Duncan's type. So, in the absence of more definite information, I prefer to use the name diomedeae given to a species well described and well figured.

\section{AMPHIURA GRANDISQUAMA Lyman.}

Plate 66, figs. 6-8.

See for bibliography:

Amphiura grandisquama KoHLer ('09), p. 177; ('14), p. 63.-H. L. ClABK ('15), p. 266.

Localities.-Albatross station 5348; Palawan Passage; Point Tabonan bearing S. $89^{\circ}$ E., 62.08 kilometers (33.5 miles) distant (lat. $10^{\circ} 57^{\prime} 45^{\prime \prime}$ N., long. $118^{\circ} 38^{\prime} 15^{\prime \prime}$ E.) ; 686 meters (375 fathoms); December 27, 1908; Co., S.

Thirteen specimens (Cat. Nos. 41277, 41278, U.S.N.M.).

Albatross station 5413; between Cebu and Bohol; Lauis Point Light bearing N. $68^{\circ}$ W., 18.53 kilometers (10 miles) distant (lat. 
$10^{\circ} 10^{\prime} 35^{\prime \prime} \mathrm{N}$., long. $124^{\circ} 03^{\prime} 15^{\prime \prime}$ E.) ; 77 meters (42 fathoms); March 24, 1909.

Four specimens (Cat. No. 41279, U.S.N.M.).

Albatross station 5475; San Bernardino Light bearing S. $27^{\circ} \mathrm{W}$, 20.38 kilometers (11 miles) distant (lat. $12^{\circ} 56^{\prime} 26^{\prime \prime}$ N., long. $124^{\circ}$ $24^{\prime} 12^{\prime \prime}$ E.) ; 357 meters (195 fathoms).

One specimen (Cat. No. 41276 , U.S.N.M.).

Notes.-Amphiura grandisquama has not been found heretofore except in the Atlantic Ocean, and its presence in the Pacific Ocean is rather unexpected. There can not be the least doubt, however, regarding the determination of the specimens, which I have compared with others from the Atlantic, both from the east and from the west coasts, I give here photographs of two specimens from station 5348 .

The geographical range of $A$. grandisquama is therefore very great, and the depth at which it is found likewise varies between very broad limits. The Albatross met with it between 247 and 440 fathoms, and the West Indian collection of the United States National Museum, which I have recently studied, contains specimens collected in the Carribean Sea at depths between 10 and 240 fathoms; The Princesse-Alice dredged A. grandisquama in the North Atlantic between 552 and 1,850 meters (301 to 1,017 fathoms).

\section{AMPHIURA UNCINATA Kohler.}

Plate 65 , figs. $6-8$; plate 96 , fig. 4 .

Amphiura uncinata KoeHler ('04), p. 76, pl. 14, figs. 3, 4.-H. I. CrarK ('15), p. 235.

Locality.-Albatross station 5123; east coast of Mindoro; Malabrigo Light bearing $\mathrm{N} .44^{\circ} \mathrm{W}$., 60.23 kilometers (32.5 miles) distant (lat. $13^{\circ} 12^{\prime} 45^{\prime \prime} \mathrm{N}$., long. $121^{\circ} 38^{\prime} 45^{\prime \prime}$ E.) ; 518 meters (283 fathoms) ; February 2, 1908; gn. M.

One specimen (Cat. No. 41144, U.S.N.M.).

Notes.-I originally described this species from several specimens collected by the Siboga in the Sunda Archipelago at depths between 250 and 330 meters (135 to 180 fathoms). These specimens were not in a good state of preservation.

The single specimen collected by the Albatross is in excellent condition, and the arms are preserved for a large portion of their length, which exceeds $100 \mathrm{~mm}$.; the diameter of the disk is $11 \mathrm{~mm}$. I include two photographs of the dorsal and ventral surfaces, as well as of a portion of an arm at the base, in order to show the characteristic hook which terminates the central spines on the first arm segments; it is represented more enlarged in figure 4 , plate 96 . 


\section{AMPHIURA VADICOLA Matsumoto.}

Plate 65 , figs. $1-5$; plate 96 , fig. 5 .

Amphiura vadicola Matsumoto ('15), p. 71.-H. L. Clark ('15), p. 235. Ophionephthys phalerata MARKTANNER-TuRNERETSCHER ('87), p. 301 (not of Lyman, 1874).

Locality.-Otaru, Hokkaido, Japan.

Six specimens (Cat. Nos. 41135, 41136, U.S.N.M.).

Notes.-The specimens are in a very poor state of preservation; the arms are broken into numerous fragments; they must be very long and very much coiled, but also very fragile; the disks themselves are more or less distorted. Nevertheless the characters of the species are perfectly recognizable; they belong without doubt to the old genus Ophionephthys, and agree absolutely with the form which Matsumoto has recently described under the name of Amphiura vadicola.

The diameter of the disk is about $5 \mathrm{~mm}$; the length of the arms must exceed $100 \mathrm{~mm}$. or $120 \mathrm{~mm}$. The color of the specimens in alcohol is a brownish yellow.

Amphiura vadicola was created by Matsumoto for a species which is extremely common at Kagoshima; it is the same ophiuran which Marktanner had referred with some doubt to Ophionephthys phaterata ('87, p. 301), but which is certainly different from Lyman's species. Acording to Matsumoto, $A$. vadicola differs from $O$. phalerata in the larger radial shields, in the pentagonal and not oval mouth shields, in having the adoral plates not in contact in the median interradial line, in the higher oral plates, in the contiguous upper arm plates, and in having the arm spines not cylindrical, but flattened; furthermore, the second ventral spine shows a very peculiar form; Matsumoto says that it is "spur-shaped," without more definitely defining the outline.

$\mathrm{My}$ specimens agree well with the description of $A$. vadicola given by Matsumoto; but the form of the mouth shields is not exactly pentagonal as described by the Japanese naturalist; these shields also are not oval and transversely broadened; they have rather the form of a triangle of which the base is proximal and the angles are very rounded, with the sides almost equal. As for the adoral plates, they conform to Matsumoto's description, and are not in contact by their radial or external angle; they are merely very close together and they inclose between them the first under arm plate which is narrow, without forming a continuous circle, as Lyman has described in his Ophionephthys phalerata. The radial shields are much elongated, almost four times as long as broad, simply triangular, and not "pearseed shaped." The separation of the under arm plates varies a little 
in the proximal portion of the arms, and at certain places these plates are in contact; it is only at a considerable distance from the disk that they become separated by a narrow interval.

The upper arm plates are not very broad, and the first plates, especially, are narrower than those following, a character which separates $A$. vadicola from another very closely related Japanese species, $A$. aestuarii Matsumoto. The arms are in fragments, and it is difficult to estimate their length, but they may easily be thirty times the diameter of the disk, corresponding to the figure given by Matsumoto.

The spines are covered with asperities throughout almost their entire length, and especially at their tips; they are more or less flattened and subequal, but the second acquires, at some distance from the disk, a quite characteristic form (pl. 96, fig. 5a). It is at first rather broad and flattened, then, after tapering very gradually, it broadens abruptly into a sort of disk of which the width equals almost that of the basal portion of the spine, and which is covered with short and closely crowded spinules. This tip thus resembles the rowel of a spur, and this form justifies Matsumoto's comparison when he says that the second spine is "spur-shaped."

A species closely related to $A$. vadicola has been recently described by H. L. Clark under the name of A. ecnomiotata ('11, p. 148), from a single specimen found at a littoral station in Japan, but it is very distinct from A. vadicola. Another Japanese species, also described by H. L. Clark, is $A$. acrystata, which is especially interesting because it shows that the principal character upon which the old genus Ophionephthys was based is essentially variable. In certain specimens (H. L. Clark '11, p. 146, fig. a) the plates of the dorsal surface of the disk are localized about the periphery of the radial shields, leaving the rest of the surface of the disk naked, while in others this border of plates broadens (fig. $d$ ), and sometimes it even covers the entire dorsal surface of the disk (fig. $g$ ).

Matsumoto has suggested the advisability of suppressing the genus Ophionephthys and including it in the genus Amphiura, and I hold absolutely the same opinion. I have already had occasion to remark recently, in describing Amphiura latispina ('14, p. 50), that the dorsal plates of the disk in that species show the arrangement which authors consider characteristic of the genus Ophionephthys, but I have thought it necessary nevertheless to retain it in the genus Amphiura.

Matsumoto's memoir of 1917 includes figures of Amphiura aestruarii (p. 209, fig. 57) and of $A$. vadicola (p. 211, fig. 58), and I have been able by comparing the Albatross specimens with these to confirm my determination; thev are without doubt $A$. vadicola. 


\section{AMPHIPHOLIS KOCHII Lïtken.}

Plate 70, figs. 1-3.

Amphipholis kochii Lütken ('72), p. 10, pls. 1 and 2, fig. 6.-LxaraN ('82), p. 146.-Matsunoto ('17), p. 192, fig. 52.

Locality.-Hakodate, Japan.

One specimen.

Notes.-The specimen is unfortunately incomplete, and the whole dorsal surface of the disk is torn away; the arms also are not preserved for their full length; they must be rather long, and two of them are preserved, respectively, for a length of $4 \mathrm{~mm}$. and $6 \mathrm{~mm}$.

I had at first some hesitation in referring my specimen to $A$. kochii, for it differs from Lütken's description and figures by a slight variation in the form of the mouth shields; but all the other characters are well enough in agreement to permit this determination. The specimen shows the following features:

The mouth shields are large, longer than broad, pyriform, with the proximal angle somewhat rounded and the two sides slightly convex, passing over rounded angles to the distal border; this last is convex, and shows in the middle a small lobe which projects into the interradial space. The adoral plates, which are of medium size, are narrowed inwardly, but they are in contact in the median interradial line; they broaden outwardly and send off a process which separates the mouth shield from the first side arm plate. The oral plates are rather high and narrow. The proximal mouth papilla is elongated, rather thick, cylindrical, and twice as long as broad; the second is small, short, almost as long as broad, with the free border rounded; the third or external papilla is very broad, squamiform, twice as long as broad, with the free border rounded.

The upper arm plates are very large, and especially extremely broad; they cover almost the entire dorsal surface of the arms, only leaving a very small and very narrow triangular space for the side arm plates. The proximal border is broad and convex, or better, it is formed by two sides which are united by a very obtuse and rounded angle; the distal border is straight or slightly concave; the sides are very short, strongly rounded, passing over by also very rounded angles to the two long sides. All these plates are in contact. Very many of the dorsal plates in the proximal region of the arms are divided into two by a longitudinal or somewhat oblique groove which is usually found near the middle.

The first under arm plate, which is narrowed by the neighboring external mouth papillae, is very small and triangular, with the apex proximal. The others are large, pentagonal, broader than long, with a very obtuse proximal angle bounded by two straight sides; their dis. 
tal border, which is also straight, is sometimes very slight sinuous; the lateral angles are slightly rounded. They are all in contact.

The side arm plates are poorly developed, especially on the dorsal side; they carry three strong subequal spines, the length of which equals at least a segment and a half. The two ventral spines are cylindrical, with the tip rounded, while the dorsal spine is sharply flattened; its extremity is also rounded.

The two tentacle scales are extremely large, especially the distal, which is inserted along the whole lateral border of the under arm plate; it is squamiform and very broad. The proximal scale, inserted on the side arm plate, is smaller, triangular in form, with the tip rounded. These two scales are very exactly in contact.

The color of the specimen in alcohol is a light brownish yellow. The dorsal plates at the tip of the two longer arms as preserved are seen to show irregular brownish spots.

I was very glad on receiving Matsumoto's work of 1917 to find therein a description and figures of $A$. kochii, which confirmed absolutely my determination. Matsumoto, who has examined numerous specimens of $A$. kochii from Misaki, states that the species is very variable. The form of the mouth shields which he shows agrees well with that which I have observed in the specimen collected by the Albatross, and I notice that on one of the two figures which he has given of the dorsal surface, the mouth shield is appreciably longer than in the other. The form of the mouth shields may therefore vary to a certain degree, and this explains the difference which I find between my specimen and Lütken's type.

AMPHIPHOLIS LORIPES, new species.

Plate 68, figs. 4, 5.

Locality.-Albatross station 5375; Marinduque Island and vicinity; Tayabas Light (outer) bearing N. $49^{\circ}$ W., 33.73 kilometers (18.2 miles) distant (lat. $13^{\circ} 42^{\prime} 15^{\prime \prime} \mathrm{N}$., long. $121^{\circ} 50^{\prime} 15^{\prime \prime}$ E.) ; 196 meters (107 fathoms); March 2, 1909; gn. M.

One specimen (Cat. No. 41190, U.S.N.M.).

Description.-The specimen is incomplete, and the dorsal surface of the disk is torn; the diameter of the part which remains scarcely reaches $3 \mathrm{~mm}$. The arms are narrow, extremely long, and must certainly reach $100 \mathrm{~mm}$. in length. In spite of the incomplete state of the only specimen, its principal characters may be perfectly well recognized, and it can be shown that it does not belong to any known species.

The mouth shields are very large, longer than broad, lozengeshaped, with the angles very rounded and the sides slightly convex. The adoral plates are small, triangular, with the borders slightly 
concave; they are narrowed inwardly and do not reach the median interradial line; but outwardly they are much broadened and separate the mouth shield from the first side arm plate. The oral plates are high, twice as high as broad. The proximal mouth papilla is not very large; it is rectangular, with the oral border a little broadened; the second, a little smaller, is conical, rather thick, with the tip truncated; the external papilla, which is inserted both on the oral and on the adoral plate, is broadened, and twice as broad as long; its proximal border is markedly larger than the distal border; this gives it a form resembling a triangle of which the apex is slightly produced.

The upper arm plates are large, and they cover a large proportion of the dorsal surface of the arms. They are almost semicircular, with the proximal border very regularly rounded, and the distal border almost straight; the lateral angles are also rounded. They are half again as long as broad, and are separated by a narrow interval occupied by the side arm plates.

The first under arm plate is triangular, with the distal border straight and the lateral angles much rounded. The following plates are pentagonal, almost as long as broad, with an obtuse proximal angle bordered by two straight sides, the lateral borders straight or slightly notched by the tentacle scale, and the distal side excavated in the middle. All these plates are in contact.

The rather strongly projecting side arm plates bear three subequal conical spines with the point blunted, of which the length almost reaches that of the segment.

The single tentacle scale, which is of medium size, is slightly elongated, with the tip rounded.

The color of the specimen in alcohol is white.

Affinities and distinctive features.-The species of Amphiphotis having only a single tentacle scale are not numerous. $A$. vitax Kohler, which the Siboga collected in the Sunda Archipelago, belongs to this category, but it possesses many arm spines and a very different arrangement of the mouth plates; our species can not be confused with it.

\section{AMPHIPHOLIS MISERA (Køhler).}

Plate 70, figs. 4-8.

Amphiura misera Karhler ('99), pl. 8, figs. 61-65.

Amphipholis misera H. L. ClaRK ('15), p. 243.

Localities.-Albatross station 5100; China Sea, off southern Luzon; Corregidor Light bearing N. $16^{\circ}$ E., 10.56 kilometers (5.7 iniles) distant (lat. $14^{\circ} 17^{\prime} 15^{\prime \prime}$ N., long. $120^{\circ} 32^{\prime} 40^{\prime \prime}$ E.) ; 64 meters (35 fathoms) ; January 2, 1908; gy. S.

One specimen (Cat. No. 41302, U.S.N.M.). 
Albatross station 5371; Marinduque Island and vicinity; Tayabas Light (outer) bearing N. $43^{\circ}$ W., 11.1 kilometers ( 6 miles) distant (lat. $13^{\circ} 49^{\prime} 40^{\prime \prime} \mathrm{N}$., long. $121^{\circ} 40^{\prime} 15^{\prime \prime} \mathrm{E}$.) ; 152 meters (83 fathoms) ; February 24, 1909; gn. M. (m. b.).

Four specimens (Cat. Nos. 41159, 41301, U.S.N.M.).

Albatross station 5537; between Negros and Siquijor; Apo Island (C.) bearing S. $46^{\circ} \mathrm{W}$., 16.12 kilometers ( 8.7 miles) distant (lat. $9^{\circ}$ $11^{\prime} 00^{\prime \prime}$ N., long. $123^{\circ} 23^{\prime} 00^{\prime \prime}$ E.) ; 464 meters (254 fathoms) ; August 19, 1909; gn. M.

One specimen (Cat. No. 41303, U.S.N.M.).

Hakodate, Japan.

One specimen (Cat. No. 41305, U.S.N.M.).

Nan Wan, Formosa (Taiwan).

One specimen (Cat. No. 41304, U.S.N.M.).

Notes.-The specimens from station 5371 are of large size; the diameter of the disk reaches $7 \mathrm{~mm}$., and the arms exceed $50 \mathrm{~mm}$. in length; the others are much smaller.

I notice some variations in the form of the mouth shields; these are triangular and rather narrow and a little longer than broad in the specimen from Hakodate (pl. 70, fig. 8) and in those from station 5100 ; they are triangular and very much broadened, as long as broad, or even a little broader than long, in the specimen from station 5537 (fig. 5); in the two from station 5371 they are lozenge-shaped (fig. 6). The plates of the dorsal surface of the disk are largest in the specimen from station 5537, and in this a large dorsocentral with five primary radials, though only slightly evident, may be made out (fig. 4), while in that from Hakodate all the plates are small and equal; in those from station 5371, which are larger, the primary rosette is fairly distinct, and the five radials are smaller than the dorsocentral (fig. 7 ) ; this primary rosette is also recognizable in the individual from station 5100.

It is to be noticed that the different specimens mentioned above come from somewhat different depths; that from station 5371 was captured at 152 meters ( 83 fathoms), that from station 5537 at 464 meters (254 fathoms), and that from station 5100 at 64 meters (35 fathoms) ; the depth of the habitat of the individuals from Hakodate and from Formosa is not mentioned.

The variations which I have just noted are of secondary significance, and we are undoubtedly dealing with the same species, of which the essential characters as a whole conform with those which I have described in the type of $A$. misera, which was captured by the Investigator among the Andaman Islands at a depth of 485 meter (265 fathoms) and which was only represented by a single specimen, in which the diameter of the disk did not exceed $4 \mathrm{~mm}$. 
AMPHIODIA CRASSA (Kœhler).

Plate 69, fig. 11.

Amphiura crassa KoEHLER ('04), p. 83, pl. 15, figs. 1, 2.

Amphiodia crassa H. L. ClaRK ('15), p. 249.

Localities.-Albatross station 5145; vicinity of Joló; Joló Light bearing S. $16^{\circ}$ E., 1.57 kilometers $\left(0.85\right.$ mile) distant (lat. $6^{\circ} 04^{\prime}$ $30^{\prime \prime}$ N., long. $120^{\circ} 59^{\prime} 30^{\prime \prime}$ E.) ; 42 meters (23 fathoms); February 15, 1908 ; co. S., Sh.

One specimen (Cat. No. 40951 , U.S.N.M.).

Albatross station 5261; off southeastern Mindoro; Balanja Point bearing N. $80^{\circ}$ W., 11.1 kilometers ( 6 miles) distant (lat. $12^{\circ} 30^{\prime} 55^{\prime \prime}$ N., long. $121^{\circ} 34^{\prime} 24^{\prime \prime}$ E.) ; 265 meters (145 fathoms); June 4, 1908; S., M.

Three specimens (Cat. No. 40952 , U.S.N.M.).

Albatross station 5282; China Sea, in the vicinity of southern Iuzon; Malavatuan Island (N.) bearing S. $84^{\circ}$ W., 11.5 kilometers (6.2 miles) distant (lat. $13^{\circ} 53^{\prime} 00^{\prime \prime}$ N., long. $120^{\circ} 26^{\prime} 45^{\prime \prime}$ E.) ; 453 meters (248 fathoms); July 18, 1908; dk. gy. S.

One specimen (Cat. No. 40953, U.S.N.M.).

Notes.-The specimens' are all of small size, and the diameter of the disk scarcely reaches $3 \mathrm{~mm}$. They are therefore very much smaller than the type in which the diameter of the disk was $12 \mathrm{~mm}$ I show here the ventral surface of the specimen from station 5282, and it may be noticed that in this young individual the external mouth papilla is broader than the two others; from this it may be asked whether the species should not be placed in the genus Amphiphotis, but as in the adult the three papillae have almost the same dimensions and collectively form a very regular row, the assignment of the species to the genus Amphiodia is more correct; this is also the classification adopted by H. L. Clark in 1905 . I may remark also that in these young specimens the oral plates are low, broadened, and triangular, while in the Siboga specimens they are short and rounded.

Apart from these differences in the form of the external mouth papilla and of the oral plate, these young specimens agree entirely with the type; the dorsal plates of the disk have exactly the same characters, and the arm spines are always five in number, the first ventral being very strongly thickened.

The type of $A$. crassa was found by the Siboga in the Sunda Archipelago at depths between 450 and 2,291 meters (245 to 1,250 fathoms). The Albatross specimens were dredged at depths of 42, 265 , and 453 meters $(23,145$, and 248 fathoms). If there has not been an error in the labeling, the very great range in depth between 
the two extreme Siboga stations is still further increased by the Albatross stations, and the species rises to within the littoral zone.

AMPHIODIA DEBITA, new species.

Plate 69, figs. 3, 4.

Locality.-Otaru, Japan.

Three specimens (Cat. No. 41199, U.S.N.M.).

Description.-All the specimens are incomplete; the dorsal surface of the disk is torn off, and none of the arms is preserved for the full length; the largest is $40 \mathrm{~mm}$. long. The arms must have been very long.

The mouth shields, which are of medium size, are pentagonal, with a rather sharp proximal angle, limited by two straight sides; these unite over very rounded angles.with two other sides, which are shorter than the preceding, and which converge toward the distal border with which they form a rounded angle; this distal border itself is narrow and almost straight. The adoral plates are small, triangular, tapering inwardly, but in contact in the median interradial line; they broaden outwardly and by a narrow process separate the mouth shield from the first side arm plate. The oral plates are small and rather high. The three mouth papillae are subequal, thick, short, and rounded; the two external are inserted on the oral plate. The proximal is not larger than the others.

The upper arm plates are extremely large and by themselves cover almost the entire dorsal surface of the arms; they are almost semicircular, with the proximal border very strongly convex, and the distal border straight or slightly rounded; the lateral angles are also rounded. They are all in contact.

The first under arm plate is small, triangular, broader than long, with the proximal base strongly notched and the distal angle rounded. The following plates are rather small, pentagonal, broader than long, with a very obtuse and rounded proximal angle, straight lateral borders, and a distal side more or less strongly notched in the middle. These plates are in contact, but, because of the notching of their distal border, there remains between the successive plates a more or less marked interval filled with soft tissue.

The side arm plates, which are only slightly projecting, carry three subequal conical spines with the point blunted; their length almost equals that of the segment. The surface of these spines is smooth; the ventral spine is a little thicker than the two others.

The tentacle scales are two in number; the external, rounded and inserted on the side arm plate, is of medium size; but the internal, inserted on the whole length of the external border of the under arm plate, is very large, elongated, and broad, with the free border convex. 
Affinities and distinctive features.-Amphiodia debita is distinguished from all the other species of Amphiodia with two tentacle scales and three arm spines by the unusual dimensions of the inner tentacle scale. It possibly approaches $A$. brocki (Döderlein) which has, like itself, three equal mouth papillae, but the adoral plates are not in contact in the interradial median line, the under arm plates are as long as broad with the distal border convex, and, although the two tentacle scales are rather large, the dimensions of the internal scale are inferior to those which we see in $A$. debita.

In its three almost equal arm spines, in the form of the mouth shields, and in the size of the tentacle scales, the new species recalls A. grata (Kohler) of the Siboga expedition, which is an abyssal species; but this latter possesses numerous arm spines and the upper and under arm plates are of an entirely different form.

$A$. debita approaches $A$. lütkeni (Ljungman) ; that species is especially characterized by the presence at the border of the disk of little spines, a character which we can not determine here, as the disk is torn off, but the internal tentacle scale is shorter. the arm spines are very much thicker, and the mouth papillae are more elongated. It is evidently a very different species. Amphiodia debita also can not be confused with $A$. occidentalis (Lyman) from California, in which the mouth shields have a different form, or A. ochroleuca (Brock), in which the tentacle scales are moderately developed, but in which the mouth shields and the upper and under arm plates have a different form, and in which the mouth papillae are unequal. Amphiodia urtica (Lyman) recalls our species in its mouth plates, but its tentacle scales are very small.

AMPHIOPLUS LEGATUS, new species.

Plate 67 , figs. $1-3$; plate 96 , fig. 9.

Locality.-Albatross station 5119; Balayan Bay and Verde Island Passage; Sombrero Island bearing S. $80^{\circ}$ E., 35.03 kilometers (18.9 miles) distant (lat. $13^{\circ} 45^{\prime} 05^{\prime \prime}$ N., long. $120^{\circ} 30^{\prime} 30^{\prime \prime}$ E.) ; 721 meters (394 fathoms); January 21, 1908; gn. M., S.

One specimen (Cat. No. 41179 , U.S.N.M.).

Description.-The diameter of the disk is $10 \mathrm{~mm}$. ; four arms are broken off at a short distance from the base, and the fifth is preserved for a length of $150 \mathrm{~mm}$. The jar contains in addition two fragments of arms, of which one exceeds $40 \mathrm{~mm}$.; the arms therefore must be fairly long.

The disk is rounded, a little depressed in the middle of the interradial spaces, and slightly excavated above the insertions of the arms; it is rather thick. The two surfaces are plane, and the borders are very rounded. 
The dorsal surface is uniformly covered with small, imbricated, subequal, rounded plates, becoming a little larger in the vicinity of the radial shields and a little smaller towards the periphery of the disk; there is not the slightest indication of primary plates. The medium-sized radial shields are triangular, with a straight internal border and a convex external border; they are two and a half times as long as broad. The two shields of each pair are only in contact by their external angle, diverging rather strongly inwardly; the length of these shields is less than half the radius of the disk.

Passing to the ventral surface of the disk the plates become very much smaller and especially extremely narrow; they are imbricated, very closely crowded, and retain the same form over the whole extent of the ventral surface. The genital slits are very broad.

The medium-sized mouth shields are large, longer than broad, pentagonal, with the proximal angle very broadly rounded, bounded by two somewhat sinuous and slightly divergent sides which pass over strongly obtuse and very rounded angles to the two lateral borders; these are a little shorter and gently convex; the distal border is narrow, almost straight or slightly rounded. The adoral plates, which are of medium size and short, are triangular, broader outwardly than inwardly, where, however, they are still rather broad, and terminate in a rounded angle; they are not quite in contact in the median interradial line. The oral plates are small and rather low. The lateral mouth papillae, four in number, are not greatly developed; the proximal papilla is rather stout, conical, with the tip rounded; the following is small and conical; the third is larger and broader, and rounded; the fourth is very much smaller and still more rounded. These two last are inserted on the adoral plate.

Compared with the diameter of the disk, the arms are narrow and slender. The upper arm plates are not very broad, but the under arm plates are extremely narrow. The upper arm plates are half again as broad as long, triangular in shape, with the proximal angle broadly rounded, and a very convex distal border; their form may even become biconvex; they are all in contact.

The first under arm plate is small, quadrangular, broader than long. The following plates are, as I have just said, especially narrow; they are pentagonal, longer than broad, with a very obtuse and broadly truncated proximal angle, straight sides, and a slightly rounded distal border; they are all in contact.

The well-developed side arm plates carry at the base of the arms six spines which are almost equal in size; the two first, however, are the largest, then the size decreases to the last dorsal which is shorter than the arm segment. These spines are slightly flattened, and much broadened in their proximal half; they taper rather rapidly in their 
distal half which terminates in a rounded point; on the second and third ventral spine the tip is slightly incurved, but strictly speaking it does not form a hook. The surface of the first ventral spine and of the last dorsal is simply rugose, but the others show narrow and elongated teeth which are very closely crowded, especially in the basal half of the spine, and principally along the proximal border, and which disappear in the terminal part (pl. 96, fig. 9).

The two tentacle scales are very small, equal, oval in form, and stand at right angles to each other.

The color of the specimen in alcohol is greenish, and rather light. Affinities and distinctive features.-The species of the genus Amphioplus possessing two tentacle scales are very numerous, and in general are very closely related to each other, though easy to distinguish. The new species can not be confused with any deep sea form known from the Indian or Pacific Oceans. Amphioplus confinis Kœhler has the dorsal plates of the disk very large and the mouth shields triangular; $A$. debilis (Kœehler) and $A$. firmus (Kohler) also have the dorsal plates of the disk rather large and the mouth shields triangular; in $A$. depressus (Ljungman) the two radial shields of each pair are in contact and the under arm plates are very broad. Among the littoral species, A. causatus (Kœhler), A. cesareus (Kœhler), A. conditus (Kœhler), A. hastatus (Ljungman), A. integer (Ljungman), A. intermedius (Kœhler), A. laevis (Lyman), and $A$. praestans (Kœhler) all have the radial shields elongated and in contact except $A$. conditus in which the shields are divergent, but that species possesses distinct primary plates and the mouth shields have a very much elongated and pointed proximal angle. The other species of Amphioplus differ greatly from the new species, and it can not be confused with any of them.

The majority of the species which I have just named possess only three arm spines. Amphioplus rhadinobrachius H. L. Clark and A. acanthinus H. L. Clark are also in this category, and, furthermore, they differ from our species in numerous other characters. Amphioplus lobatus Ljungman, from Sydney, New South Wales, is only known from Ljungman's very short diagnosis; it possesses six arm spines, but the terms "boucliers radiaux allongés," as well as "plaques brachiales dorsales deux fois et demie plus larges que longues, plaques brachiales ventrales à bord distal émarginé," are characters which do not apply to our species. A Japanese form which was described by H. L. Clark under the name of $A$. lobatodes is perhaps identical with A. lobatus (H. L. Clark, '15, p. 254, pl. 7, figs. 12, 13) ; but $A$. legatus is very distinct from it, as may be seen by comparing my photographs with those of H. L. Clark; the mouth shields especially have a very different form, and the under arm plates, which are as broad as long in A. lobatodes, are not narrow as in A. legatus. 
AMPHIOPLUS CONDUCTUS, new species.

Plate 67, figs. 4-6.

Locality.-Albatross station 5410; between Cebu and Leyte; Bagacay Point Light bearing $\mathrm{S} .37^{\circ}$ W., 13.34 kilometers (7.2 miles) distant (lat. $10^{\circ} 28^{\prime} 45^{\prime \prime}$ N., long. $124^{\circ} 05^{\prime} 30^{\prime \prime}$ E.) ; 704 meters (385 fathoms); March 18, 1909; gn. M.

One specimen (Cat. No. 41161, U.S.N.M.).

Description.-The specimen is in fairly good condition, although none of the arms are complete; one of them is preserved for a length of almost $60 \mathrm{~mm}$. The arms must be very long; they are slender and narrow, and maintain the same width throughout the entire remaining portions.

The diameter of the disk is $6 \mathrm{~mm}$.; the disk is rounded. The dorsal and ventral surfaces are slightly convex, and the borders are thin. The dorsal surface is uniformly covered with almost equal plates, a little larger in the central region and in the vicinity of the radial shields, a little smaller in the middle of the interradial spaces and at the periphery of the disk. The radial shields are rather narrow, elongated, at least three times as long as broad, with a straight internal border and a slightly convex external border; the two shields of each pair are in contact only by their external right angle; inwardly they diverge rather slowly. Their length is less than half the radius of the disk.

The ventral surface is uniformly covered with thin, rounded, equal plates, almost as long as broad, imbricated, and becoming more closely crowded in the vicinity of the mouth shields and of the genital slits. These last are broad and very evident.

The mouth shields are cordiform, almost as broad as long, with a major portion triangular, bounded by two convex sides passing over a rather open proximal angle, and a distal lobe which is broader than long and rounded. The adoral plates are triangular, broader outwardly than inwardly, always in contact in the interradial median line by a small straight side, and giving off outwardly a process which separates the mouth shield from the first side arm plate. The oral plates, which are of medium size, are half again as high as broad. 'The mouth papillae are four in number. The internal papilla is broadened, rectangular, a little longer than broad, with the proximal border rounded or in the form of a very blunted point; the three others are conical; the second papilla is the smallest, while the two external are larger and subequal; they are inserted on the adoral plate. Below the second papilla may be seen the elongated and spiniform tentacle scale of the first mouth pore.

The upper arm plates are large and cover the greater part of the dorsal surface of the arms; they are almost semicircular, with the 
proximal border broadly convex; the distal border is slightly rounded. These plates are separated from the base of the arms outward by an extremely narrow space occupied by the side arm plates.

The first under arm plate is rectangular, a little longer than broad, with the sides slightly excavated. The following plates are large, almost as long as broad, pentagonal, with the proximal angle truncated, the sides straight, and the distal border straight or slightly concave. They are all in contact.

The side arm plates carry at first five spines, the number then falling very quickly to four, and a little further on to three. These spines are slender, elongated, conical, and subequal, and their length equals that of the segment. Their surface is rugose, especially that of the second ventral spine, which shows very fine asperities and of which the tip shows two little hooks forming a right angle with the axis of the spine, thus causing it to appear bihamulate; this character is very marked in my specimen.

The tentacle scales, two in number, are small, elongated and oval, and stand at right angles to each other.

The color of the specimen in alcohol is slightly pinkish white on the dorsal surface; the ventral surface of the disk is gray.

Affinities and distinctive features.-It may be seen from the preceding description that $A$. conductus is very close to the species which I described above under the name of $A$. legatus. I have placed them side by side on the same plate so that the resemblances and also the differences might be easily appreciated. The differences do not permit of the least confusion between them. The disk, rather flattened with the borders rounded in A. legatus, is thicker in $A$. conductus, and the plates of the dorsal surface of the disk, which are so closely crowded and so short in $A$. legatus, are rounded and as long as broad here; the radial shields are narrower, more elongated, and less divergent. The mouth shields are shorter, cordiform, and more broadened in $A$. conductus, while they are relatively elongated in A. legatus, and the adoral plates are always in contact in the interradial median line in $A$. conductus. The under arm plates are remarkably narrow in A. legatus, and in this respect the difference between the two species is striking. The arm spines, which are six in the first species, have the tip recurved, but, on the other hand, they show fine, elongated, and closely crowded denticulations which are completely lacking in A. conductus where the spines, at first five in number, and then four, are simply rugose, and the second ventral is bihamulate. These differences are sufficient to prevent any confusion between the two species. 


\section{AMPHIOPLUS IMPRESSUS (Ljungman).}

Plate 64, figs. 3,4 .

Amphipholis impressa LJUNGMaN ('66), p. 314.

Amphiura impressa LYMAN ('82), p. 148.

Amphioplus impressa H. L. ClaRK ('15), p. 258.

Localities.-Albatross station 5369; Marinduque Island and vicinity; Tayabas Light (outer) bearing N. $50^{\circ}$ W., 16.30 kilometers (8.8 miles) distant (lat. $13^{\circ} 48^{\prime} 00^{\prime \prime}$ N., long. $121^{\circ} 43^{\prime} 00^{\prime \prime}$ E.) ; 194 meters (106 fathoms); February 24, 1909; bk. S.

One specimen (Cat. No. 41170, U.S.N.M.).

Albatross station 5371; Marinduque Island and vicinity; Tayabas Light (outer) bearing N. $43^{\circ}$ W., 11.1 kilometers $(6$ miles) distant (lat. $13^{\circ} 49^{\prime} 40^{\prime \prime}$ N., long. $121^{\circ} 40^{\prime} 15^{\prime \prime}$ E.) ; 152 meters (83 fathoms) ; February 24, 1909; gn. M. (m. b.).

One specimen (Cat. No. 41171, U.S.N.M.).

Notes.-The diameter of the disk in the two specimens is $8 \mathrm{~mm}$. and $6.5 \mathrm{~mm}$. respectively; the arms are incomplete in both; one of the arms of the smaller may have had a length of about $37 \mathrm{~mm}$. or $38 \mathrm{~mm}$.

The disk is rounded, slightly convex on the two surfaces, with the borders thin. The dorsal surface is covered with rather large and stout plates, especially in the central region, which become smaller toward the periphery; these plates are polygonal, rounded, and slightly imbricated. A central rosette of rounded primary plates, all of the same size and scarcely larger than the neighboring plates, may be with difficulty distinguished; the radials are in contact with the dorsal central plate, but are separated from each other by a narrow plate. At the periphery of the disk there may be distingushed a very marked bordering made up of rectangular plates which are broader than long. All these plates bear on their surface extremely fine striae which are irregularly sinuous, recalling the striae of the madreporic plate of a starfish, but very much finer and less evident. The radial shields are elongated, three times as long as broad, with the external border convex, the internal border straight, and the proximal angle sharp; the two shields of each pair are in contact through three-quarters or four-fifths of their length, and they are separated inwardly by a small triangular plate. The surface of these shields shows striae similar to those of the other plates of the disk, but these striae are much broader and deeper, and consequently more evident.

The ventral surface of the disk is covered with small, subequal, polygonal or rounded, and slightly imbricated, plates. The genital slits are very narrow.

The mouth shields are lozenge-shaped, a little longer than broad in the larger specimen, and almost as long as broad in the other; the 
two proximal sides are slightly longer than the two others, and they are united by an acute angle, while the distal sides are united by a very broadly rounded angle. The medium-sized adoral plates are narrowed inwardly, but they are in contact in the interradial median line by a narrow border. They have a straight proximal side and a slightly excavated distal side; they are broadened outwardly, and separate the mouth shield from the first side arm plate. The oral plates are triangular, rather low, a little broader than high. The terminal mouth papilla, which is of medium size, is conical, almost as long as broad; the second is very small, conical, and pointed; the third is a little larger and rounded; the fourth, or external, is large, squamiform, broader than long with the free border rounded.

The upper arm plates are large and cover a large part of the dorsal surface of the arm; they are almost semicircular, with a very convex proximal border, and a slightly rounded distal border showing in the middle a small and very slightly accentuated lobe. These plates are half again as broad as long. They are barely in contact at the base of the arms in the large specimen, and beyond are separated by a narrow interval; in the smaller they are separated from the bases of the arms outward.

The first under arm plate is pentagonal, as long as broad, or a little longer than broad, with an obtuse proximal angle. The following plates are pentagonal, markedly broader than long, with an obtuse proximal angle, straight sides, and an almost straight or rery slightly convex distal border; they are separated beyond the second. In the small specimen the second and third plates are still triangular in form, and become pentagonal from the fourth outward.

The slightly projecting side arm plates carry three poorly developed arm spines; the central spine is a little longer and a little stouter than the two others, its length equalling almost that of a segment. These spines are conical, with the point blunted, and their surface is smooth.

The two tentacle scales are small, placed side by side, parallel to the distal border of the side arm plate; the proximal scale is a little longer than the other, which is inserted on the under arm plate, and which is rounded.

Although Ljungman's description is very short and somewhat lacking in precision, $I$ do not think $I$ am wrong in assigning the two Albatross specimens to his Amphipholis impressa. All the characters which I observe are in perfect accord with those given by that author. I translate the word "impressis," which he applies to the dorsal plates of the disk, by "gravées," and I suppose that Ljungman intended by this word to call attention to the sinuous lines which give the more or less deep "impressions" on the surface of the plates. 
Ljungman's type was captured in deep water between Batavia and Singapore.

\section{AMPHIOPLUS LUCIDUS, new species.}

Plate 68 , figs. $6-10$; plate 96 , fig. 10.

Localities.-Albatross station 5161; Sulu (Joló) Archipelago, Tawi Tawi Group; Tinakta Island (E.) bearing N. $12^{\circ}$ W., 3.33 kilometers (1.8 miles) distant (lat. $5^{\circ} 10^{\prime} 15^{\prime \prime} \mathrm{N}$., long. $119^{\circ} 53^{\prime} 00^{\prime \prime}$ E., 29) meters (16 fathoms); February 22, 1908; fne. S., blk. Sp.

Two specimens (Cat. No. 41127, U.S.N.M.).

Albatross station 5371; Marinduque Island and vicinity; Tayabas Light (outer) bearing N. $43^{\circ}$ W., 11.1 kilometers ( 6 miles) distant (lat. $13^{\circ} 49^{\prime} 40^{\prime \prime}$ N., long. $121^{\circ} 40^{\prime} 15^{\prime \prime}$ E.) ; 152 meters (83 fathoms) ; February 24, 1909; gn. M. (m. b.).

One specimen (Cat. No. 41126, U.S.N.M.).

Description.-All the specimens are incomplete; the dorsal surface of the disk is torn off, and the arms are not preserved for their whole length. In the specimen from station 5371, which is the largest, the portion of the disk which remains has a diameter of $3.5 \mathrm{~mm}$., and the arms are preserved for a fairly long distance; one of them measures $90 \mathrm{~mm}$, and the width remains the same for all this length; it is certain that these arms were extremely long. I shall describe this species more especially from this specimen, but as the radial shields have not quite the same form as in those from station 5161, I shall also give the characters of these as found in the latter.

In the specimen from station 5371 (pl. 68, fig. 9) the mouth shields are much elongated and relatively narrow; they are twice as long as broad, quadrangular, with a narrow and very strongly rounded proximal border, a broader and also rounded distal border, and straight or very slightly concave and slightly divergent sides. In the two specimens from station 5161, of which I give photographs in figures 6 and 7 , it may be seen that the mouth shields may become markedly broader, and their form even somewhat different in these two specimens; they are, however, always longer than broad. But in the specimen shown in figure 7 two of these shields become cordiform; they show a major triangular portion of which the angles are rounded, and a distal lobe which is as long as broad; while in the other shields this lobe is merged with the principal portion of the plate, which, as a whole, is lozenge-shaped with the sides rounded and the distal angle truncated (two of the shields appear shorter in my photograph because they are seen foreshortened). The adoral plates, which are of medium size, are triangular, tapering inwardly, but contiguous in the median interradial line by a very narrow border; they are broadened outwardly and separate the mouth shield from the first side arm plate. The oral plates are rather large, twice as high as broad. The mouth 
papillae are four in number. The terminal papilla is strong, elongated, thick, and conical, twice as long as broad; the three others are rather small and rounded; the second, inserted on the oral plate, is the smallest, and the third, which arises in the angle between the oral and adoral plates, is larger, somewhat squamiform and broadened; the fourth, which is sometimes separated from the preceding by a narrow interval, is smaller; it is inserted on the adoral plate. Between the first and the second papilla, and on a higher level, may be seen the papilla of the mouth tentacle pore, which is conical and rather short.

The upper arm plates are very large, and they cover almost the entire dorsal surface of the arms. They are almost biconvex, but the distal border sometimes divides into two short sides which are united by a very obtuse and rounded angle. They are all in contact.

The first under arm plate is very small, triangular, with a rather marked proximal angle in the specimen from station 5161 (fig. 7), while in that from station 5371 (fig. 9) it is a little larger and rectangular. The following plates are pentagonal, with a very obtuse proximal angle, the sides slightly notched by the tentacle pore, and the distal border more or less excavated in the middle; they are a little broader than long in the specimen from station 5371, and in the others they are as long as broad, or even a little longer than broad. They are at first in contact, then becoming separated by a short interval at a greater or lesser distance from the disk.

The rather strongly projecting side arm plates bear at the base of the arms seven or eight spines. This figure falls to six, and then to five. These spines are small, conical, subequal, and a little shorter than the segment. The second and third ventral spines are terminated by a small hyaline point recurved toward the arm tip, thus forming a small hook which is more or less accentuated. In the basal half and on its proximal border the second spine ordinarily shows some small fine teeth, which are moderately elongated and closely crowded, but which disappear in the distal half, the latter being merely somewhat rugose, as is also the distal border throughout its whole length (pl. 96, fig. 10b). The other spines are simply rugose $(a$ and $c)$.

The two tentacle scales are small, oval, and placed at right angles to each other.

Affinities and distinctive features.-The incomplete condition of the specimens, which have all lost the dorsal surface of the disk, makes comparisons difficult. The dimensions of the mouth shields separate $A$. lucidus from all the known species of Amphioplus possessing numerous arm spines and two tentacle scales. There is some analogy with $A$. laevis Lyman from the Philippines, but this has the 
mouth shields smaller, the under arm plates broader, and the upper arm plates of different shape. It can not be confused with $A$. luctator, which I have described below, as the latter has only three arm spines.

\section{AMPHIOPLUS LUCTATOR, new species.}

Plate 68, figs. $1-3$.

Localities.-Albatross station 5339; Palawan Passage ; Cauayan Island (N.) bearing S. $59^{\circ}$ E. 18.53 kilometers (10 miles), distant (lat. $11^{\circ} 22^{\prime} 00^{\prime \prime}$ N., long. $119^{\circ}$ ); 95 meters (52 fathoms); December 20,1908 ; $M$.

One specimen (Cat. No. 41157 , U.S.N.M.)

Albatross station 5358; Jolo Sea; Sandakan Light bearing S. $34^{\circ}$ W. 36.51 kilometers (19.7 miles) distant (lat. $6^{\circ} 06^{\prime} 40^{\prime \prime}$ N., long. $118^{\circ} 18^{\prime} 15^{\prime \prime}$ E.) ; 71 meters (39 fathoms); January 7, 1908; M.

One specimen (Cat. No. 41158 , U.S.N.M.).

Description.-Both of the specimens are of almost the same size, and both have the disk torn away; the part of the disk which remains has a diameter slightly more than $4 \mathrm{~mm}$. The arms are all incomplete; one of them is preserved for a length of more than 80 $\mathrm{mm}$.; they must have been very long.

The radial shields are very large, and a little longer than broad. In the specimens from station 5358 (fig. 1) they are pentagonal, with an acute proximal angle bounded by two elongated sides, which pass over two rounded angles into the two lateral sides which are almost straight, a little shorter than the preceding, and which converge slightly toward the narrow and straight distal side; it is at the level of the rounded lateral angles that the shield reaches its maximum width. In the specimen from station 5339 (fig. 3 ) these shields are relatively a little more elongated and narrower, and the distal border is rounded; that is the only difference which I find between these two specimens. The adoral plates are large and rather broad, tapering inwardly, though in contact by a narrow border in the median interradial line; they are much broadened outwardly, and they may even touch those adjacent in the radial line, in such a way as to form an almost continuous ring. In the specimen from station 5358 , this ring is completely closed, all the adoral plates touching their neighbors, while in that from station 5339 this ring is not quite complete, and the adoral plates are separated by an extremely narrow space, within which is included the first under arm plate. The oral plates are not very high, being almost as high as broad. The lateral mouth papillae are four in number; the innermost is thick, conical, and short; the second, inserted on the oral plate, is rectangular, almost as long as broad, with the free border convex; the third, which is the most developed, arises from the angle between the oral and 
adoral plates; it is rectangular, and broader than long; the last, which is the smallest, is simply rounded; it is inserted on the adoral plate.

The upper arm plates are extremely large and broad, and they cover almost the whole width of the dorsal surface of the arms; they are almost two and a half times as broad as long, with a slightly concave proximal border, the distal border very broad and convex passing over by very rounded angles into the sides, which are strongly divergent. All these plates are in contact.

The first under arm plate is considerably reduced, sometimes squeezed in between the adoral plates, which are very close together, sometimes shoved back inwardly from these last; it is triangular, with a distal angle, and a little longer than broad. The following plates are very large and very broad and they cover the greater part of the ventral surface of the arms; they are quadrangular, almost as broad as long, with an almost straight proximal border, a rounded distal border, and similarly rounded sides which are scarcely depressed at the level of the tentacular pores.

The side arm plates are slightly developed, and only slightly projecting. Each of them carries three small spines, which are rather slender, conical, with the extremity rounded, and of which the length is almost equal to that of the segment.

The tentacle scales, two in number, are small, rounded, placed side by side, and of similar dimensions.

Affinities and distinctive features.-Amphioplus luctator differs from all the known species of Amphioplus possessing two tentacle scales and three arm spines in the considerable development of the mouth shields, as well as in the large dimensions of the dorsal and ventral arm plates, while at the same time the tentacle scales remain of relatively small size. In the absence of the dorsal surface of the disk the affinities of this species can not be determined, but I do not see any form with which it may be compared. It obviously differs from the species from stations 5161 and 5371, which I described above under the name of $A$. lucidus and which possesses several arm spines.

\section{AMPHIOPLUS RELICTUS (Kœhler).}

Plate 70 , fig. 9 ; plate 71 , figs. $4-8$.

Amphiura relicta KaHLER ('98), p. 68, pl. 4, figs. 37, 38; ('05), p. 41.

Amplioplus relictus H. L. Clark ('15), p. 256.

Localities._Albatross station 5206; off western Sámar; Badian Island (N.) bearing N. $27^{\circ}$ E., 10.66 kilometers (5.75 miles) distant (lat. $11^{\circ} 31^{\prime} 40^{\prime \prime} \mathrm{N}$., long. $124^{\circ} 42^{\prime} 40^{\prime \prime}$ E.) ; 58 meters (32 fathoms) ; April 14, 1908; gn. M.

One large specimen (Cat. No. 41257, U.S.N.M.). 
Albatross station 5207; off western Sámar; Badian Island (N.) bearing S. $74^{\circ}$ E., 8.73 kilometers $\left(4.7\right.$ miles) distant (lat. $11^{\circ} 38^{\prime}$ $05^{\prime \prime}$ N., long. $124^{\circ} 40^{\prime} 45^{\prime \prime}$ E.) ; 64 meters (35 fathoms); April 14, 1908; gn. M., S.

Two specimens (Cat. Nos. 41252,41256 , U.S.N.M.).

Albatross station 5244; Pujada Bay and vicinity; Uanivan Island (N.) bearing S. $52^{\circ} 30^{\prime}$ E., 7.41 kilometers (4 miles) distant (lat. $6^{\circ} 52^{\prime} 05^{\prime \prime}$ N., long. $126^{\circ} 14^{\prime} 15^{\prime \prime}$ E.) ; 313 meters (171 fathoms); May 15, 1908; gy. M.

One specimen (Cat. No. 41255, U.S.N.M.).

Albatross station 5247.

One specimen (Cat. No. 41250, U.S.N.M.).

Albatross station 5342; Malampayo Sound, Pelawan Island, Endeavor Point (S.) bearing S. $58^{\circ}$ E., 0.92 kilometer ( 0.5 mile) distant (lat. $10^{\circ} 56^{\prime} 55^{\prime \prime} \mathrm{N}$., long $119^{\circ} 17^{\prime} 24^{\prime \prime}$ E.) ; 26-46 meters (14-25 fathoms) ; December 23, 1908; gy. M.

Two specimens (Cat. Nos. 41249, 41254, U.S.N.M.).

Albatross station 5358; Joló Sea; Sandakan Light bearing S. $34^{\circ}$ W., 36.51 kilometers (19.7 miles) distant (lat. $6^{\circ} 06^{\prime} 40^{\prime \prime} \mathrm{N}$., long. $118^{\circ} 18^{\prime} 15^{\prime \prime}$ E.) ; 71 meters (39 fathoms); January 7, 1908; M.

One specimen (Cat. No. 41247, U.S.N.M.).

Little Harbor at Luneta, Manila Harbor; December 18, 1907.

One small specimen (Cat. No. 41253, U.S.N.M.).

Kagoshima, Japan.

Sixty-four specimens (Cat. Nos. 41248,41251 , U.S.N.M.).

Notes. - The specimens agree very well with the type which I described from specimens collected by the Investigator on the Ganjam coast of India and among the Andaman Islands between 7 and 25 fathoms. The Siboga rediscovered this species in different localities in the Sunda archipelago at depths between 0 and 112 meters ( 0 to 62 fathoms). ${ }^{6}$

In the majority of the Albatross specimens I have found the elongated form of the mouth shields, but I notice some variation. Thus the shields are sometimes very narrow (station 5207, pl. 71, fig. 5), sometimes somewhat broadened, as in different specimens from Kagoshima (fig. 7); they may even broaden still more, and in the specimen from Manila Harbor they are broader than long (fig. 6); in this case they are composed of a triangular main portion which is almost as long as broad with the angles rounded, and a small narrow and also rounded distal lobe. In all other characters this specimen agrees absolutely with $A$. relictus, though in the absence of intermediates, one might be tempted to consider it a different species.

- I notice a typographical error in my memoir of 1905 ; on page 41 , first line, after the list of localities, there is written: "les boucliers radiaux sont toujours tres allonges et étroits. ..." It should be "boucliers buccaux." 
I have previously described and figured ('05, p. 68, pl. 4, fig. 37) the arrangement of the peripheral plates of the dorsal surface of the disk; these stop rather abruptly at the periphery, and often form a distinct marginal row. This character is seen on the photograph which I give here (pl. 71, fig. 8). Sometimes even the plates of this marginal row are turned upward so as to stand more or less erect, and then they recall the character on which the genus Ophiophragmus was based. This arrangement is even more pronounced in the majority of the Albatross specimens than in those which I have had occasion to study heretofore, and because of this external resemblance to the genus Ophiophragmus I was anxious to determine whether the internal structure of this last genus, which is, as is known, very characteristic, was found in $A$. relictus.

On plate 70 , on figure 8, I give a photograph of a specimen of which the dorsal surface of the disk has been removed and which has been prepared to show the peristomial plates with the adjacent parts, as well as the internal and external genital plates. If this photograph be compared with the figure published by Lyman of Ophiophragmus wurdemani ('82, pl. 40, fig. 4), important differences are immediately noticed, and, on the other hand, it is found that there is much analogy with the figures published by authors of species of the genera Amphiura or Amphioplus (compare for example the figure of Amphiura bellis given by Lyman in fig. 16). Regarding the genital plates, the internal plate, or adradial, of $A$. relictus is very stout, thick, and stubby; it is rather short, and does not exceed, or scarcely reaches, the third vertebra; the external genital plate, or interradial, is very small, narrow, and still shorter than the other, and it does not exceed the fourth vertebra.? We may also compare this arrangement with that which Duncan has described and figured in Ophiophragmus affinis. In the figure which he published in 1886 ('86, pl. 8, fig. 6) we find that these two plates are much elongated; they reach the first vertebra, and they remain very narrow. Duncan's figure, though schematic, should be exact, for the author says ( $p .89$ ) in regard to the characters of the genus Ophiophragmus: "The genital plate is long and slender, and simply ' knob headed,' and the generative scale is long and slender and longer than the plate."

\footnotetext{
"Authors habitually use the terms " scale" and "plate" to designate the plates which I call, respectively, "outer genital plate" (or "interradial") and "internal genital plate" (or "adradial"). I believe that the terms "scale" and "plate" may lead to confusion, as they are sometimes used indifferently one for the other; some authors call "scales," others "plates," the structures which cover the disk; that is why I prefer to use the word "plate" only when followed by an adjective indicating the position of the plate when that is necessary, but as for the most part in systematic descriptions the characters furnished by the interradial plate alone (genital scale) are used it is to that that I apply always and exclusively the term "genital plate" without further designation.
} 
Amphioplus relictus can not, therefore, be placed in the genus Ophiophragmus, and the arrangement of its mouth papillae necessitates placing it in the genus Amphioplus.

This question was interesting not only because of the necessity of making a correct generic determination, but also because there depends upon the answer a case of synonymy, for the ophiuran from the Mergui Archipelago which Duncan described under the name of Ophiophragmus affinis shows sigular external resemblances to our species, as may be seen in glancing over the figures published by Duncan ('86, pl. 8, figs. 4 and 5); these resemblances are even sufficiently marked so that one is justified in asking whether it does not deal with the same species. We notice, however, that the mouth shields of $O$ : affinis have a form different from that which we know in A. relictus, and I have never observed in this latter a form identical with that which Duncan has figured. But the characters furnished by the study of the internal skeleton prevent all possibility of bringing them together.

Duncan had noticed the mixed characters of his species, and he confessed the difficulty that he had in placing it either in the genus Ophiophragmus or in the genus Amphiura (that is, in the present terminology, in the genus Amphioplus). I believe that it would be more correct to place the species from the Mergui Archipelago in the genus Amphioptus, but this question has no place here. What is of consequence to decide is whether Ophiophragmus affinis Duncan is or is not a synonym of Amphioplus relictus (Kœhler). If Duncan's figures and description are correct in regard to the characters of the genital plates, there can be no question of considering these two forms as synonyms. Until proof to the contrary is shown, I have therefore believed it necessary to maintain Amphioplus relictus as a species distinct from Ophiophragmus affinis.

Even if it were proved that Duncan's Ophiophragmus affinis was not an Ophiophragmus, but an Amphioplus, and that my Amphioplus retictus was identical with it, our species would not bear any other name than that of Amphioplus relictus. In that case Duncan's species would according to rule assume the name of Amphioplus affinis. But the name affinis has been applied to an ophiuran from south Georgia described by Studer in 1885, while Duncan's species dates from 1886. It is for the Antarctic species that the name $A m$ phioplus affinis must be reserved. If Duncan's species must be placed in the genus Amphioplus, it will be necessary to give it another specific name; the simplest solution would be to give it the name of $O$. relictus. This is, moreover, the nomenclature which H. L. Clark adopted in 1915. He considers Amphioplus relictus (Kohler) as a synonym of Ophiophragmus affinis Duncan, and in his catalogue ('15, p. 697) he cites $A$. relictus under No. 697 , while in the table 
of contents (p. 353) he gives $O$. affinis Duncan as a synonym of $A$. relictus (Kœhler). I may say that it is because of this synonymy proposed by H. L. Clark that I have thought it necessary to give the preceding explanation, for, as I have said above, I consider Ophiophragmus affinis Duncan different from my A. relictus, with the reservation, of course, that Duncan's description and figure, from which alone the characters of his $O$. affinis may be appreciated, are correct.

\section{AMPHIOPLUS RHADINOBRACHIUS H. L. Clark.}

Amphioplus rhadinobrachius H. L. Clark ('11), p. 167, fig. 74; ('15), p. 256.

Locality.-Albatross station 5113; China Sea, off southern Luzon; Sombrero Island bearing S. $7^{\circ}$ W., 17.60 kilometers $(9.5$ miles) distant (lat. $13^{\circ} 51^{\prime} 30^{\prime \prime}$ N., long. $120^{\circ} 50^{\prime} 30^{\prime \prime}$ E.) ; 291 meters (159 iathoms); January 17, 1908; dk. gn. M.

One specimen (Cat. No. 41193, U.S.N.M.).

Notes.-The diameter of the disk is $6 \mathrm{~mm}$.; the arms are excessively long.

The specimen agrees well with H. L. Clark's description, except for a very slight difference in the form of the mouth shields, which are rather more triangular than oval.

The type series of specimens came from Suruga Gulf and Sagami Bay, Japan, 516 to 920 meters (282 to 503 fathoms).

\section{AMPHLIMNA MULTISPINA, new speciez.}

Plate 61 , figs, $4-9$; plate 96 , fig. 7 .

Localities.-Albatross station 5220; between Marinduque and Luzon; San Andreas Island (W.) bearing S. $57^{\circ}$ W., 15.75 kilometers (8.5 miles) distant (lat. $13^{\circ} 38^{\prime} 00^{\prime \prime} \mathrm{N}$., long. $121^{\circ} 58^{\prime} 00^{\prime \prime}$ E.) ; 91 meters (50 fathoms); April 24, 1908; sft. gn. M.

One specimen (Cat. No. E. 23, U.S.N.M.).

Albatross station 5221; between Marinduque and Luzon; San Andreas Island (W.) bearing S. $27^{\circ}$ E., 10.19 kilometers ( 5.5 miles) distant (lat. $13^{\circ} 38^{\prime} 15^{\prime \prime} \mathrm{N}$., long. $121^{\circ} 48^{\prime} 15^{\prime \prime}$ E.) ; 353 meters (193 fathoms); April 24, 1908; gn. M.

Thirteen specimens (Cat. Nos, E. 26, E. 27, U.S.N.M.).

Albatross station 5222; between Marinduque and Luzon; San Andreas Island (W.) bearing S. $57^{\circ}$ E., 17.05 kilometers (9.2 miles) distant (lat. $13^{\circ} 38^{\prime} 30^{\prime \prime}$ N., long. $121^{\circ} 42^{\prime} 45^{\prime \prime}$ E.) ; 357 meters (195 fathoms); April 24, 1908; gn. M.

Four specimens (Cat. No. E. 25, U.S.N.M.).

Albatross station 5223; between Marinduque and Luzon; Malabrigo Light bearing W., 18.16 kilometers (9.8 miles) distant (lat. $13^{\circ}$ $36^{\prime} 00^{\prime \prime}$ N., long. $121^{\circ} 25^{\prime} 30^{\prime \prime}$ E.) ; April 24, 1908.

One specimen (Cat. No. E. 24, U.S.N.M.). 
Albatross station 5375; Marinduque Island and vicinity; Tayabas Jight (outer) bearing N. $49^{\circ}$ W., 33.73 kilometers ( 18.2 miles) distant (lat. $13^{\circ} 42^{\prime} 15^{\prime \prime} \mathrm{N}$., long. $121^{\circ} 50^{\prime} 15^{\prime \prime}$ E.) ; 196 meters (107 fathoms); March 2, 1909; gn. M.

Four specimens (Cat. No. E. 4, U.S.N.M.).

Description.-I shall describe this species from one of the specimens, from station 5375 (pl. 61, figs. 5, 6, 7), which is the largest. The diameter of the disk, which is slightly deformed, is $12.5 \mathrm{~mm}$. by $11 \mathrm{~mm}$. In the other specimens the diameter of the disk is between $6 \mathrm{~mm}$. and $8 \mathrm{~mm}$. The arms are extremely long, rolled up, rather slender, and flattened; in the specimen which I am describing their length is more than $150 \mathrm{~mm}$.

The dorsal surface of the disk is covered with slender, conical, and pointed spines, which are rather elongated and very closely crowded, and which conceal the contours of the underlying plates; these spines become less crowded and may even be completely lacking on the central region of the disk in young specimens. In the adults the contours of the plates are always more or less obscured by the integument; sometimes, however, they may be distinguished, and it is then seen that they are very small in the central region of the disk, becoming a little larger toward the periphery, where they imbricate. In the small specimens, like the second from station 5375 which is shown in figure 9 , the plates are very much more evident and larger, and there is in particular a row of large plates in the middle of each interradial space; on either side of this row, the plates become smaller and imbricated, while the central region of the disk is occupied by small rounded plates. The radial shields are very narrow, elongated, in contact throughout their whole length, and in the large specimens four times as long as broad, while in the small ones they are relatively shorter and somewhat broadened.

The ventral surface of the disk is uniformly covered with small, imbricated, equal plates, becoming a little larger in the vicinity of the genital slits; these plates carry spines identical with those on the dorsal surface and rather closely crowded. The genital slits are very narrow and elongated.

The mouth shields are longer than broad, lanceolate, consisting of a triangular major portion which is almost as long as broad with a rather sharp proximal angle, of which the apex is ordinarily slightly rounded, plus a lobe which projects in a variable manner into the interradial space. In the large specimens (fig. 7) this lobe is less developed than in the small ones in which it is narrower but more elongated, as may be seen in figure 8 . The adoral plates are narrow; they are especially developed on the side of the mouth shield, and, behind it, they send off a process separating the mouth shield from the first side arm plate; they taper in their proximal portion, and 
do not always reach even to the median interradial line. The oral plates are small, twice as high as broad. The lateral mouth papillac are five in number, unequal, and a little separated from each other. The two outermost, slightly broadened and elongated, are inserted on the adoral plate, and they cover the opening of the mouth tentacle pore; the three others are conical, narrow, and pointed, inserted on the oral plate. Besides these there are two or three small tooth papillae which are smaller than the mouth papillae.

The upper arm plates are very large, and they cover a large part of the dorsal surface of the arms. They are a little broader than long and broadly rounded; in the large specimens their form is almost circular; in the smaller they become almost semicircular, with a slightly excavated proximal border (figs. 4, 5); in the smallest these plates are triangular, with a more or less distinct proximal angle, and a little longer than broad; their distal border is convex, and sometimes it is resolved into two short sides which pass into each other over an obtuse angle.

The first under arm plate is rather small, and triangular. The following plates are quadrangular, a little longer than broad, with the proximal border straight, the sides excavated by the tentacle scale, and the distal border a little broader than the proximal border and almost straight; they are all broadly in contact.

The side arm plates, which are rather projecting, carry eight or even nine arm spines in the large specimens; this number falls to six in the small. These spines are very close to each other, slightly flattened, subequal, and their length equals almost that of the segment; their surface is smooth (pl. 96, fig. 7b).

The single tentacle scale is large, rounded, and oval in form. On the first arm segments there is added to this principal scale a small internal scale inserted on the under arm plate which disappears more or less rapidly according to the size of the animal; this scale in the large specimens is found on at least seven or eight segments, while on the smaller it is only found on the first four or five, and sometimes disappears even more rapidly. The supplementary scale is smaller than the other, cylindrical and slightly spiniform.

The color of the specimens in alcohol is grayish white or gray. In the two largest the borders of the upper arm plates are margined with a light brownish line, a little more marked in some places than in others, which gives the impression of an irregular and weak annulation.

Affinities and distinctive features.-On account of the number of mouth papillae this ophiuran must be placed in the genus Amphiiimna. Among the five species known belonging to this genus, three possess two tentacle scales-A. caribbaea (Ljungman), A. olivacea (Lyman) and $A$. pentacantha (H. L. Clark); but the two others- 
A. libera (Kohler) and A. sexradia (Duncan)-have only a single one. The new species has some affinity with $A$. libera, from the Cape Verde Islands, in which the mouth shields are elongated and which possesses two tentacle scales on the pores of the first pair; but it is distinguished from it by its radial shields, which are quite in contact, by the existence of a small supplementary scale on the first arm segments, and also by the number of arm spines. As for $A$. sexradia, from the Mergui Archipelago, it possesses six arms.

Amphilimna sexradia and $A$. libera, as well as $A$. pentacantha, have just been removed from the genus Amphilimna by Matsumoto, who places them in his new genus Amphiacantha ('17, p. 178). The question arises whether the new species discovered by the Albatross should not also be placed in the genus Amphiacantha. I do not think so, in spite of the presence of two tentacle scales. Matsumoto has characterized the genus Amphiacantha by the very closely crowded ("close-set") mouth papillae of which the outermost is neither elongated nor spiniform, but short and flattened, by the diverging radial shields, by the restricted number of the arm spines (three or four), and by the short, flattened and "leaf-like" tentacle scales. These different characters, apart from the last, do not apply to the Albatross ophiuran.

In the genus Amphitimna, on the other hand, the mouth papillae are well spaced and more or less conical, the two radial shields of each pair are in contact, and the arm spines are numerous. However, Matsumoto only leaves in the genus Amphilimna species with two tentacle scales, and these scales are spiniform, especially the inner, or adradial. By the presence of a single tentacle scale which, moreover, is oval, our species differs from all the others assigned by Matsumoto to the genus Amphilimna. But I believe that the significance of the characters peculiar to this last genus which we find in it is much greater than that of the characters diagnostic of the new genus Amphiacantha. It must be noticed also that the Albatross species possesses a small supplementary tentacle scale on the first arm segments which is somewhat spiniform. I therefore believe it necesary to leave $A$. multispina in the genus in which I had placed it before having seen Matsumoto's memoir.

\section{OPHIACTIS AFFINIS Dunean.}

Plate 62 , fig. 6 ; plate 63 , fig. 5 .

Ophiactis affinis DUNCAN ('79), p. 469, pl. 10, fig. 23 ; pl. 11, fig. 24.-LYMAN ('82), p. 121.-Kohler ('98), p. 71; ('05), p. 26.-H. L. Clark ('15), p. 266.-Matsumoto ('17), p. 155.

Locality.-San Juanico Strait, Samar Leyte Reefs; April 13, 1908. One specimen (Cat. No. 41052, U.S.N.M.).

Notes.-The specimen is of small size; the diameter of the disk does not exceed $4 \mathrm{~mm}$., and only two of the arms are preserved. It 
agrees well with Duncan's description and figures, but as these last are very schematic, I have thought it well to give here two photographs of an 0 . affinis collected in the Kei Islands, which is better preserved than the Albatross specimen.

The type of $O$. affinis was captured in the Korean (Chosen) Straits at a depth of 37 fathoms. The Siboga found this species in the Kei Islands at a depth of 90 meters (49 fathoms).

OPHIACTIS DEFINITA, new species.

Plate 64, figs. $1,2,7$.

Localities.-Albatross station 5119; Balayan Bay and Verde Island Passage; Sombrero Island bearing S. $80^{\circ}$ E. 35.03 kilometers (18.9 miles) distant (lat. $13^{\circ} 45^{\prime} 05^{\prime \prime}$ N., long. $120^{\circ} 30^{\prime} 30^{\prime \prime}$ E.) ; 721 meters (394 fathoms) ; January 21, 1908; gn. M., S.

Two specimens (Cat. No. E. 49, U.S.N.M.).

Albatross station 5598; Sibuko Bay, Borneo, and vicinity; Sipadan Island (W.) bearing S. $12^{\circ}$ E., 7.04 kilometers (3.8 miles) distant (lat. $4^{\circ} 10^{\prime} 35^{\prime \prime} \mathrm{N}$., long. $118^{\circ} 37^{\prime} 12^{\prime \prime}$ E.) ; 759 meters ( 415 fathoms); September 28, 1909.

Two specimens.

Albatross station 5587.

A few specimens (Cat. Nos. E. 51 [part], E. 52, U.S.N.M.).

Albatross station 5589; Sibuko Bay, Borneo, and vicinity; Mabul Island; (NW.) bearing N. $3^{\circ}$ W., 5.19 kilometers (2.8 miles) distant (lat. $4^{\circ} 12^{\prime} 10^{\prime \prime} \mathrm{N}$., long. $118^{\circ} 38^{\prime} 08^{\prime \prime}$ E.) ; 475 meters (260 fathoms); September 29, 1909 ; fne. gy. S., gy. M.

Two specimens (Cat. Nos. E. 48, E. 51 [part], U.S.N.M.).

Albatross station 5619; Molucca Passage; Mareh Island (S.) bearing S. $78^{\circ}$ E., 12.87 kilometers 12.97 miles) distant (lat. $0^{\circ} 35^{\prime} 00^{\prime \prime}$ N., long. $127^{\circ} 14^{\prime} 40^{\prime \prime}$ E.) ; 796 meters (435 fathoms) ; November 27 , 1909 ; fne. gy. S., M.

One specimen (Cat. No. E. 46, U.S.N.M.).

Albatross station 5637; Bouro Island (south) and vicinity; Amblau Island (N.) bearing N. $80^{\circ}$ E., 38.92 kilometers (21 miles) distant (lat. $3^{\circ} 53^{\prime} 20^{\prime \prime}$ S., long. $126^{\circ} 48^{\prime} 00^{\prime \prime}$ E.) ; 1,280 meters (700 fathoms); December 10, 1909; gy. M.

One specimen (Cat. No. E. 47, U.S.N.M.).

Philippines.

Three specimens (Cat. Nos. E. 45, E. 50, U.S.N.M.).

Description.-I shall describe the species more especially on the basis of the two specimens from station 5119, of which I give photographs (pl. 64, figs. 1, 2, 7).

The diameter of the disk is $9 \mathrm{~mm}$.; the length of the arms is from $30 \mathrm{~mm}$. to $32 \mathrm{~mm}$. The arms, always five in number, are broad and 
slightly flattened; the general appearance of the animal is rather robust.

The disk is rounded or subpentagonal. The dorsal surface is covered with subequal imbricated plates, of medium size, which are a little larger toward the middle of the interradial spaces, and become a little smaller at the periphery of the disk; they are quite without spines. The radial shields are rather large and broad, with an almost straight internal border, a strongly convex external border, and a very pointed proximal angle; the two shields of each pair are close together, but not in contact distally, where they are separated by a narrow plate, and they are slightly divergent proximally. They are twice as long as broad, and their length is slightly less than half the radius of the disk.

The ventral surface is uniformly covered with smaller plates than those of the dorsal surface which are equal and imbricated and entirely without spines. The genital slits are rather broad.

The mouth shields are of medium size, or rather small, almost as long as broad, and are composed of a triangular major portion which is broader than long with an obtuse and rounded proximal angle, plus a distal rounded lobe which projects more or less strongly into the interradial space. The adoral plates are rather small, narrow, twice as long as broad, and recurved in the form of a crescent; they are in contact in the median interradial line, and outwardly they approach very closely to their neighbors. The oral plates are twice as high as broad. The single external mouth papilla is very large, broadened, with the form of a right-angled triangle of which the hypotenuse is slightly serrate and the proximal angle is more or less sharp; the internal or proximal papilla is thick, with a somewhat irregular free edge.

The upper arm plates are large and greatly broadened; they are relatively short in proportion to their width, and are at least two and a half times as broad as long. They are quadrangular, with a very small and straight proximal border, straight and very strongly divergent sides, and a broad straight or slightly convex distal border; the lateral angles are sharp, but slightly rounded at the apex. At some distance from the disk the proximal side, which has become progressively reduced, disappears and is replaced by an obtuse angle. All the plates are in contact.

The first under arm plate is small and triangular, with the apex distal; it is very narrow and is enclosed between the two neighboring adoral plates; sometimes these two adoral plates come into contact, and when this is the case, the first under arm plate is enclosed within them (fig. 2); sometimes also it is divided into 
two parts by a transverse groove (fig. 1). The following plates are large, quadrangular, with a straight proximal border, a convex distal border, and straight sides; they are at first broader than long, in the terminal portion of the arms becoming a little longer than broad. They are all in contact.

The side arm plates, which are rather strongly projecting, bear three strong, thick and cylindrical arm spines, with the tips blunted; their length slightly exceeds that of the segment, and the central one is a little longer than the other two; the dorsal spine is slightly attenuated. In the distal half of the arms the spines elongate and become relatively a little narrower, while their length reaches a segment and a half.

The single tentacle scale is very large, oval, and squamiform.

The color of the specimens in alcohol is gray or sometimes pinkish on the dorsal surface.

Affinities and distinctive features.-Ophiactis definita is most closely related to $O$. perplexa Kohler found by the Investigator off Cape Comorin in 1,315 meters (719 fathoms), but it is sharply distinguished from it by having the radial shields always separated, by having the mouth shields longer and much less broad than in 0 . perplexa, by having the under arm plates markedly broader than long, by having the outermost mouth papilla very much more developed and more pointed, by having the central arm spine more developed, and by having the upper arm plates broad and short. It differs markedly from 0 . maculosa Martens from the Philippines in having the dorsal plates of the disk less numerous, in having the upper arm plates with rather sharp lateral angles, in having the outermost mouth papilla very much smaller, in having the tentacle scale also smaller, etc.

Ophiactis definita shows also some affinities with $O$. brachgenys, which H. L. Clark described from specimens found in Japan between 120 and 720 fathoms; but the differences are rather important. The dorsal plates of the disk are more uniform in size, and the radial shields are very much broader in the new species, and the latter are always separated throughout their whole length; the mouth shields are as broad as long, or even a little longer than broad, and the adoral plates are crescentic in form; furthermore, the under arm plates are very regularly in contact in $O$. definita, and they are never separated by an interval of soft tissue. 


\section{OPHIACTIS MACULOSA Martens.}

Plate 63, figs. 6, 7 .

Ophiactis maculosa Mariens ('70), p. 248.-Lyman ('82), p. 122.-H. L. Clark ('15), p. 263, pl. 11, figs. 3, 4.

Locality.-Albatross station 5136; vicinity of Joló; Joló Light bearing S. $37^{\circ}$ E., 1.30 kilometers (0.7 mile) distant (lat. $6^{\circ} 04^{\prime}$ $20^{\prime \prime}$ N., long. $120^{\circ} 59^{\prime} 20^{\prime \prime}$ E.) ; 40 meters (22 fathoms); February 14,$1908 ;$ S., Sh.

One specimen (Cat. No. 41051 , U.S.N.M.).

Notes.-This individual is not in good condition; some of the plates of the dorsal surface of the disk are torn away, and the arms are incomplete, broken off at a certain distance from the base. It can be seen nevertheless that it agrees well with the two photographs which H. L. Clark has published of this species ('15, pl. 11, figs. 3, 4). Martens' description, which is altogether vague and insufficient, can not be relied upon, so I have thought it advisable to give here some notes relative to the Albatross specimen, which is unfortunately not in a satisfactory state of preservation, at the same time regretting that H. L. Clark has not described the one from the Philippines which he has photographed and which appears to be very well preserved.

The disk must be $5 \mathrm{~mm}$. in diameter, and the arms might reach 30 $\mathrm{mm}$. in length. The disk appears slightly excavated in the interradial spaces. Its dorsal surface is covered with rather large, unequal plates, larger in the central region and becoming smaller toward the periphery. I can not recognize any primary plates in my specimen; in H. L. Clark's photograph there seems to be a circlet of five large interradial plates. The plates are not imbricated in the central region of the disk, and they are here without spines. Only the peripheral plates, which are very much smaller than the others, bear a few spines and these are small, short, and conical with the point blunted. These spines are found on the plates of the ventral surface of the disk, but these plates do not cover the whole of this surface, and are found only in a triangular area of which the apex is at some distance from the mouth shields, and which does not reach the genital slits. The radial shields, which are of medium size, are triangular, with the external side convex and the apex proximal; they are two and a half times as long as broad, and their length exceeds half the radius of the disk. The two shields of each pair are only slightly separated; they are in contact distally by their external angle or even for a small part of their length, and are separated inwardly by a series of plates.

The outlines of the mouth plates, which are not very evident in H. L. Clark's photograph, show very clearly in my specimen. The 
mouth shields are rather large, broader than long, almost biconvex or lozenge-shaped, with the angles and the sides rounded. Their distal angle is produced into a narrow, but rather elongated, lobe, which projects more or less strongly into the interradial space. Martens says that these shields are "kreisförmig," but I do not see why he adds " nicht untereinander zusammenhängend." The adoral plates are confined to the sides of the mouth shields; they are extremely attenuated inwardly and do not reach the median interradial line; while outwardly they are developed into a much elongated lobe which goes to meet that of its fellow, and may even touch it in the median radial line, thus completely separating the first under arm plate from the second. This form of the adoral plates may be recognized, though with difficulty, on H. L. Clark's photograph. The oral plates are small, twice as high as broad. They carry a terminal unpaired mouth papilla which is transversely broadened. The second papilla, which is situated toward the proximal extremity of the adoral plate, is much broadened, squamiform, twice as long as broad, with the free border rounded.

The upper arm plates are extremely broad; they seem to me to be relatively a little broader in my specimen than in H. L. Clark's; this evidently is correlated with the difference in size, the disk having in the last a diameter of only $4 \mathrm{~mm}$. These plates are almost four times as long as broad, with the two longer sides parallel; the proximal border is a little shorter than the distal, into which it passes by slightly divergent sides and over rounded angles. All of these plates are broadly in contcat.

The first under arm plate is rather small, triangular, with the apex distal; it is a little broader than long and separated from the second, as I have said above. This last is quadrangular, a little longer than broad, with the proximal border a little smaller than the distal. Beyond, the plates rapidly become broader than long, with the proximal side slightly shorter than the distal, and the latter passing over by rounded angles into the lateral sides, which are also rounded. All these plates are broadly in contact.

The side arm plates, which project only slightly, are not greatly developed, especially on the dorsal side, where they only cover a very reduced portion of the arms. They bear four short thick arm spines with the tip rounded, the size of which increases slightly from the first ventral to the last dorsal. and of which the length almost equals that of the segment.

The tentacle scale is rather large and elongated, with the two sides parallel, and the tip rounded; it is half again as long as broad.

The general color is a light greenish yellow, with a few slightly marked spots on the dorsal surface of the disk, and indications of rings on the dorsal surface of the arms. 


\section{OPHIACTIS PROFUNDI Lütken and Mortensen.}

Plate 63, fig. 8.

Ophiactis profundi LÜTKeN and Mortensen ('99), p. 140, pl. 6, figs. 4-6.-Kahler ('09), p. 173.

ophiactis pteropoma H. L. CLARK ('11), p. 134, fig. 50; ('15), p. 264.-MATsuмото ('17), p. 154.

Localities.-Albatross station 5325; off northern Luzon; Hermanos Island (N.) bearing N. 86 E., 31.04 kilometers (16.75 miles) distant (lat. $18^{\circ} 34^{\prime} 15^{\prime \prime} \mathrm{N}$., long. $121^{\circ} 51^{\prime} 15^{\prime \prime}$ E.) ; 410 meters (224 fathoms) ; November 12, 1908; gn. M.

One specimen (Cat. No. 41314, U.S.N.M.).

Albatross station 5522; northern Mindanao and vicinity; Point Tagolo Light bearing S. $39^{\circ} \mathrm{W} ., 11.1$ kilometers ( 6 miles) distant (lat. $8^{\circ} 49^{\prime} 00^{\prime \prime}$ N., $123^{\circ} 26^{\prime} 30^{\prime \prime}$ E.) ; 421 meters (230 fathoms); August 10, 1909; Glob.

Two specimens (Cat. No. 41312, U.S.N.M..).

Albatross station 5605; Gulf of Tomini, Celebes; Dodepo Island (W.) bearing $\mathrm{N} .14^{\circ} \mathrm{W} ., 10.93$ kilometers (5.9 miles) distant (lat. $0^{\circ}$ $21^{\prime} 33^{\prime \prime}$ N., long. $121^{\circ} 34^{\prime} 10^{\prime \prime}$ E.) ; 1,183 meters (647 fathoms); November 16, 1909.

One specimen (Cat. No. 41313, U.S.N.M.).

Notes.-All the specimens are of small size; in the two from station 5522 the diameter of the disk varies between $3 \mathrm{~mm}$. and $4 \mathrm{~mm}$., and the others are slightly smaller. All have six arms; the individuals from stations 5522 and 5605 possess three large arms and three others very small which are in process of regeneration, and their disks are also regenerating. In the specimen from station 5325 all the arms are broken off near the base and the disk is circular and does not seem to be undergoing regeneration.

Although all my specimens are of small size, I do not believe that there can be any doubt regarding their identification.

Furthermore, I do not hesitate to unite with $O$. profundi, $O$. pteropoma which H. L. Clark has recently established from specimens from Japan and which also possesses six arms. Apart from a slight difference in length of the arm spines, there is a remarkable concordance in the descriptions and figures published by H. L. Clark, and those previously published by Lütken and Mortensen. In particular H. L. Clark has again found the peculiar character of the upper arm plates, which are separated from each other by a small interval not occupied by the side arm plates. The only difference which I can find between $O$. profundi Lütken and Mortensen and 0 . pteropoma H. L. Clark, from a comparison of the descriptions and figures of the authors, is that in the latter the dorsal arm spine is 
about twice as long as the ventral, which is equal in length to the segment; this is as H. L. Clark describes it in specimens in which the disk has a diameter of $5 \mathrm{~mm}$. However, in one of his specimens in which the diameter of the disk reaches $6 \mathrm{~mm}$., and which is the largest of all, H. L. Clark noticed that the dorsal arm spine is shorter, but he does not specify what its exact length is and whether or not it is equal to the other two. From this observation the inference is that in the specimens studied by H. L. Clark there are certain variations in the relative dimensions of this dorsal arm spine, and as the only difference which I can find between the descriptions and the figures of 0 . pteropoma and 0 . profundi consists in the relative length of the dorsal arm spine, I do not believe that it is possible to maintain a distinction between the two species. The first name, having priority, should therefore alone be conserved.

H. L. Clark has not discussed the comparative characters of $O$. pteropoma and he does not refer in any way to its affinities with O. profundi.

As may be seen from the photograph which I reproduce on plate 63 as figure 8, the dorsal arm spine is a little longer than the two others, but it is less thick than the central spine; Lütken and Mortensen say that in $O$. profundi the median spine is the stoutest.

The color of the two specimens from station 5522 is pink; the two others are a grayish white.

Ophiactis profundi was captured at depths of 1,008 and 1,644 meters (551 and 899 fathoms), between $0^{\circ}$ and $4^{\circ} \mathrm{N}$. latitude and $81^{\circ}$ and $90^{\circ} \mathrm{W}$. longitude. Ophiactis pteropoma H. L. Clark was based upon eight specimens, all with six arms, dredged in the Japanese seas between 349 and 463 meters (191 and 253 fathoms). I have myself recorded the occurrence of $O$. profundi, or of a form extremely close to it, in the Atlantic, which was found by the Princesse-Alice at a depth of from 214 to 650 meters (122 to 355 fathoms) in $36^{\circ} \mathrm{N}$. latitude and $31^{\circ} \mathrm{W}$. longitude (Kœehler '09, p. 173).

Matsumoto ('17, p. 154) believes that 0 . pteropoma is extremely close to $O$. profundi, from which it only differs in having the arm spines unequal instead of being subequal.

\section{OPHIACTIS SAVIGNYI Müller and Troschel.}

Plate 64, figs. 5, 6 ; plate 96 , fig. 2.

See for bibliography:

Ophiactis savignyi KäLER ('05), p. 26; ('05a), p. 184; ('13), p. 351; ('14), p. 41; ('14a), p. 184.-H. L. ClarK ('15), p. 265; ('15a), p. 90.-Matsumoto ('17), p. 158.

Localities.-Albatross station 5123; east coast of Mindoro; Malabrigo Light bearing N. $44^{\circ}$ W., 60.23 kilometers (32.5 miles) dis$55269-22-$ Bul. $100-13$ 
tant (lat. $13^{\circ} 12^{\prime} 45^{\prime \prime} \mathrm{N}$., long. $121^{\circ} 38^{\prime} 45^{\prime \prime}$ E.) ; 518 meters (283 fathoms); February 2, 1908; gn. M.

One specimen (Cat. No. 41048, U.S.N.M.).

Albatross station 5139; in the vicinity of Joló; Joló light bearing S. $51^{\circ}$ W., 6.67 kilometers $\left(3.6\right.$ miles) distant (lat. $6^{\circ} 05^{\prime} 00^{\prime \prime} \mathrm{N}$.g long. $121^{\circ} 02^{\prime} 30^{\prime \prime}$ E.) ; 36 meters (20 fathoms) ; February 14, 1908 ; co. S.

Four specimens (Cat. No. 41106, U.S.N.M.).

Albatross station 5145; vicinity of Joló; Joló light bearing S. $16^{\circ}$ E., 1.57 kilometers ( 0.85 mile) distant (lat. $6^{\circ} 04^{\prime} 30^{\prime \prime}$ N., long. $120^{\circ}$ $59^{\prime} 30^{\prime \prime}$ E.) ; 42 meters (23 fathoms) ; February 15, 1908; co. S., Sh.

Two specimens (Cat. Nos. 41047, 41105, U.S.N.M.).

Albatross station 5147; Sulu (Joló) Archipelago, in the vicinity of Siasi; Sulade Island (E.) bearing N. $3^{\circ}$ E., 15.57 kilometers (8.4 miles) distant (lat. $5^{\circ} 41^{\prime} 40^{\prime \prime}$ N., long. $120^{\circ} 47^{\prime} 10^{\prime \prime}$ E.) ; 38 meters (21 fathoms) ; February 16, 1908; co. S., Sh.

Two specimens (Cat. No. 41021 , U.S.N.M.).

Albatross station 5205 ; off the east coast of Leyte Island; Caguayan Point bearing N. $2^{\circ}$ E., 1.30 kilometers $\left(0.7\right.$ mile) distant (lat. $11^{\circ}$ $19^{\prime} 30^{\prime \prime}$ N., long. $124^{\circ} 58^{\prime} 05^{\prime \prime}$ E.) ; 15 meters (8 fathoms); April 13, 1908.

One specimen (Cat. No. 41049, U.S.N.M.).

Albatross station 5249; Gulf of Dávao; Lanang Point bearing $\mathrm{N}$. 1.85 kilometers ( 1 mile) distant (lat. $7^{\circ} 06^{\prime} 06^{\prime \prime} \mathrm{N}$., long. $125^{\circ} 40^{\prime}$ $08^{\prime \prime}$ E.) ; 42 meters (23 fathoms) ; May 18, 1908; Co., S.

Four specimens (Cat. No. 41107, U.S.N.M.).

Albatross station 5257; southern Mindanao; eastern Illana Bay; Utara Point, Bongo Island, bearing N. $88^{\circ} \mathrm{W} ., 14.27$ kilometers (7.7 miles) distant (lat. $7^{\circ} 22^{\prime} 12^{\prime \prime}$ N., long. $124^{\circ} 12^{\prime} 15^{\prime \prime}$ E.) ; 51 meters (28 fathoms); May 22, 1908; M.

Two specimens (Cat. No. 41111, U.S.N.M.).

Albatross station 5321; China Sea, in the vicinity of Formosa (Taiwan) ; Ibugos Island (S. end) bearing S. $89^{\circ}$ W., 3.72 kilometers (1.25 miles) distant (lat. $20^{\circ} 19^{\prime} 30^{\prime \prime}$ N., long. $121^{\circ} 51^{\prime} 15^{\prime \prime}$ E. : 47 meters (26 fathoms); November 9, 1908; wh. S., Co., brk. Sh.

Three specimens (Cat. No. 41109, U.S.N.M.).

Albatross station 5355; north Balabac Strait; Balabac Light bearing S. $61^{\circ}$ W., 30.76 kilometers (16.6 miles) distant (lat. $8^{\circ} 08^{\prime} 10^{\prime \prime}$ N., long. $117^{\circ} 19^{\prime} 15^{\prime \prime}$ E.) ; 80 meters (44 fathoms); January 5, 1908; Co., S.

One specimen (Cat. No. 41103, U.S.N.M.).

Albatross station 5400; north of Cebu; Tanguingui Island Light bearing $\mathrm{N} .77^{\circ} \mathrm{W} ., 41.70$ kilometers (22.5 miles) distant (lat. $11^{\circ} 24^{\prime}$ 
$24^{\prime \prime}$ N., long. $124^{\circ} 05^{\prime} 30^{\prime \prime}$ E.) ; 46 meters (25 fathoms); March 16 , 1909 ; S., Sh.

Two specimens (Cat. No. 41104, U.S.N.M.).

Albatross station 5401; north of Cebu; Tanguingui Island Light bearing $\mathrm{N} .79^{\circ}$ W., 42.62 kilometers (23 miles) distant (lat. $11^{\circ} 24^{\prime}$ $45^{\prime \prime}$ N., long. $124^{\circ} 06^{\prime} 00^{\prime \prime}$ E.) ; 55 meters (30 fathoms); March 16, 1909; fne. S.

One specimen (Cat. No. 41108 , U.S.N.M.).

Albatross station 5554; Joló Island and vicinity; Cabalian Point (Joló) bearing $\mathrm{N} .76^{\circ} \mathrm{E}$., 7.04 kilometers $\left(3.8\right.$ miles) distant (lat. $5^{\circ}$ $52^{\prime} 27^{\prime \prime}$ N., long. $120^{\circ} 52^{\prime} 18^{\prime \prime}$ E.) ; 46 meters (25 fathoms); September 18, 1909; Co., S.

Eighteen specimens (Cat. No. 41110, U.S.N.M.).

Joló Island; February 11, 1908.

Two specimens (Cat. No. 41101, U.S.N.M.).

Marongas Island; Shore Canal; February 10, 1908.

Six specimens (Cat. No. 41102, U.S.N.M.).

Joló (interior of pearl oyster).

One specimen (Cat. No. 41050 , U. S. N. M.).

Notes.-The specimens from stations 5249, 5257, and 5321 have five arms; one of the individuals from station 5147 has five arms, and the other has six. All the remainder have six arms.

The two mouth papillae are not very evident in the photographs which I published in 1914 ('14a, pl. 7, fig. 15, and pl. 9, fig. 8). I give here two photographs (pl. 63, figs. 5, 6) of the ventral surface of two specimens collected by the Albatross, one with five, the other with six arms, on which these two papillae may be better seen. I also give on plate 96 as figure 2 some photographs of the arm spines as seen under the microscope.

\section{OPHIOPHOLIS MIRABILIS (Duncan).}

Plate 61, fig. 3 ; plate 96 , fig. 14.

Ophiolepis mirabilis Duncan ('79), p. 460, pl. 9, fig. 12 ; pl. 10, figs. 13, 14. Ophiopholis mirabilis LyMaN ('79), p. 43; ('82), p. 112.-H. L. ClarK ('11), p. 117, fig. 43; ('15), p. 268.-Матsumoto ('17), p. 160, fig. 40.

\section{Locality.-Hakodate, Japan.}

Seventy-one specimens (Cat. No. E. 37, U.S.N.M.).

Notes.-The diameter of the disk varies between $15 \mathrm{~mm}$. and $4 \mathrm{~mm}$.

Ophiophotis mirabilis is a very easy species to recognize, and the specimens collected by the Albatross are quite characteristic. I notice that the upper arm plates are a little larger than in the figure published by H. L. Clark ('11, p. 117, fig. 43); sometimes these plates are divided into two parts by a groove which is more or less 
oblique in reference to the longitudinal axis of the arm, and this groove may even bifurcate. The supplementary dorsal plates are themselves also sometimes divided into two. I give here a photograph of the dorsal surface of one of the Albatross specimens (pl. 61, fig. 3).

On plate 96 as figure 14 I give some photographs of the elongated granules borne on the dorsal surface of the disk $(d)$; the dimensions of these granules vary considerably. I include also photographs of the first ventral arm spine at the commencement of the arms $(a)$, in the distal half $(b)$, and at the tip after it has become definitely transformed into a hook $(c)$.

The type of Ophiophotis mirabilis, described by Duncan, came from the Korean Sea (Dondai Bay). H. L. Clark reports the species from numerous localities in Japan (Hakodate, Doumiki Saki, Ando Saki, Uraga Strait, Kinkwasan Light, etc.), at depths included between 11.5 and 79 fathoms. Matsumoto gives various other localities, and at the same time he describes the variations which he has observed in the coloration of the living animals.

It seems to me that Ophiophotis mirabilis is a decidedly different form from 0 . aculeata (Linnaeus) which must be specifically distinguished from it.

\section{OPHIOCENTRUS ACULEATUS Ljungman.}

Plate 71, figs. $1-3$; plate 96 , fig. 8 .

Ophiocentrus aculcatus LJUNGMaN ('66), p. 321.-LYMaN ('82), p. 167.-H. L. Clark ('15), p. 268.

Locality.-Albatross station 5302; China Sea, in the vicinity of Hongkong (lat. $21^{\circ} 42^{\prime} 00^{\prime \prime}$ N., long. $114^{\circ} 50^{\prime} 00^{\prime \prime}$ E.) ; 69 meters (38 fathoms); August 9, 1908; sft. gy. M.

One specimen (Cat. No. 41011, U.S.N.M.).

Notes.-Ophiocentrus aculeatus is known only from Lijungman's very short diagnosis, and it does not appear to have come to light since 1864. My specimen differs in some respects from Ljungman's description, but I believe nevertheless that it represents the same species. First of all I shall give a description of it in order to be able most advantageously to make a comparison with that of the Swedish author.

The diameter of the disk, measured between the distal extremity of a radial shield and the deepest part of the opposite interradial space is $8 \mathrm{~mm}$; the specimen is thus larger than that of Ljungman, who gives $6 \mathrm{~mm}$. as the diameter of the disk; the arms reach from 75 $\mathrm{mm}$. to $80 \mathrm{~mm}$. in length.

The disk is rather strongly excavated in the interradial spaces. The dorsal surface is in a large part occupied by the radial shields, 
which are very large, elongated, and about four times as long as broad, with the long borders almost parallel, an almost straight distal border, and a more or less marked proximal angle. The two shields of each pair are very slightly divergent, in contact distally, and proximally separated by an extremely narrow triangular space covered with small plates. Outside of each shield there is a band formed of small, closely crowded, and imbricated plates; these bands, which at first are very narrow, toward the distal extremity of the shield gradually broaden toward the proximal angle, which they widely exceed, without, however, reaching the central region of the disk, which remains naked.

A rather large number of these plates carry a small, elongated, stout, conical, and pointed spine which is inserted on the plate by a broadened base. The interradial spaces are naked, but sometimes there may be observed here and there a few small isolated plates, each of which carries a spine identical with the preceding. The central region of the disk is entirely without plates. Altogether, the arrangement of the dorsal plates of the disk and of the radial shields, as well as the disposition of the regions which remain uncovered, recalls exactly the features which have heretofore served to characterize the old genus Ophionephthys.

The ventral surface of the disk is absolutely naked. The genital slits are rather broad; they are provided on their internal border with a row of rather broad plates which assist in narrowing the naked portion of the ventral surface.

The mouth shields are rather large, lozenge-shaped, almost as long as broad, with an obtuse proximal angle bounded by very slightly convex sides; the two lateral borders, on the other hand, are slightly concave, and the distal angle is thick and rounded, and forms a lobe which projects into the interradial space. The rather small adoral plates have the form of a crescent, and they are not in contact in the median interradial line; they are rather elongated and maintain almost the same width over their whole length. The oral plates are elongated, two and a half times as high as broad; they are each terminated by a stout, thick, short, and conical papilla, which is almost as long as broad. A second papilla is found beyond the first, but on a higher level, and it develops along the oral plate and terminates in a slender and pointed tip. The outermost papilla, which is inserted both on the oral and on the adoral plate, arises on the radial border of the second mouth tentacle pore; it is rather thick, cylindrical, and short, and its tip is rounded.

The upper arm plates of the first arm segments are almost oval, a little longer than broad, and a rather small; these plates then broaden little by little, becoming as long as broad, or even a little 
broader than long, and assuming an almost circular form; they are all in contact.

The first under arm plate has its distal portion much narrowed between the neighboring adoral plates, which are very close together in the radial line, while the proximal portion broadens and takes the form of a triangle which is broader than long. The following plates are hexagonal, with three short proximal sides; the lateral borders are much elongated, slightly convex and almost straight; the distal border is narrow and slightly excavated in the middle. All these plates are narrow and very much longer than broad; they are all in contact.

The rather strongly projecting side arm plates bear each seven rather strong, subequal spines equaling the segment in length; sometimes the central spines are a little more developed than the others. These spines are cylindrical, and they bear at their tip some transparent asperities, of which one is especially developed on the second, third, and fourth spines, forming a little hook which is directed toward the extremity of the arm (pl. 96, fig. 8).

The tentacle pores are extremely large, but tentacle scales are completely lacking.

The color of the specimen in alcohol is a very light brownish gray.

If we compare the preceding description with Ljungman's short diagnosis, we find the following differences:

First, Ljungman in speaking of the radial shields says: "Ionga, cuneiforma, ... parte minuta supra insertionem brachiorum nuda excepta, cute tecta." But the radial shields in my specimen are not cuneiform; they are naked throughout their whole length, and adjoining them there is found, instead of a naked integument, a band of small plates broadening progressively toward the proximal extremity of these shields where they form several rows, an arrangement not mentioned by Ljungman. Furthermore, Ljungman says that the mouth shields are much longer than broad; I find that they are almost as long as broad. He also says that the under arm plates are "parum longiora quam latiora"; in reality I notice that these plates are very much longer than broad.

The two last differences are not of much importance; as for the first, it perhaps is due to the fact that my specimen is larger than Ljungman's. In addition, the Swedish author says, in the diagnosis of the genus Ophiocentrus, that the dorsal surface of the disk is provided with small erect spines, but he does not specify whether he has distinguished the plates which bear these spines, which, however, may well have been the case.

The other characters mentioned by Ljungman conform so well with those which I observe in my specimen that I have not had any hesita- 
tion in referring it to the same species, the more so since it comes from a locality near that where the type was collected. Ljungman says "hab. in profundo mari inter Bataviam et Singapore." The term "profundo" is rather vague and may apply to very different depths.

In his memoir of 1915 , in speaking of the genus Ophiocentrus, Matsumoto says: "Ophiocentrus incl. Amphiocnida" ('15, p. 69, note V). I believe also that there is really no important difference between the genus Ophiocentrus and the genus Amphiocnida which Verrill established in 1899 ; it is advisable therefore, to assign to the genus Ophiocentrus the species which up to the present have been placed in the genus Amphiocnida, and the former thus find itself suddenly enriched with the many following species:
ophiocentrus aculeatus Ljungman.
Ophiocentrus alboviridis (Brock).
ophiocentrus asper (Kœhler).
Ophiocentrus brachiatus (Montagu).
Ophiocentrus dilatatus (Kœhler).
ophiocentrus inaequalis (H. L. Clark).
Ophiocentrus pilosus (Lyman).
ophiocentrus putnami (Lyman).
ophiocentrus semisquamatus (Kohler).
Ophiocentrus verticillatus (Döderlein).

to which there must be added a new species which I shall describe below under the name of Ophiocentrus vesator, making eleven species in all.

\section{OPHIOCENTRUS ASPER (Køhler).}

Plate 62, figs. 7-9; plate 96, fig. 12.

Ophiocnida aspera KGeHLER ('05), p. 29, pl. 2, figs. 11-13; ('07b), p. 244.

A mphiocnida aspera H. L. ClARK ('15), p. 237.

Locality.-Albatross station 5249; Gulf of Dávao; Lanang Point bearing N., 1.85 kilometers (1 mile) distant (lat. $7^{\circ} 06^{\prime} 06^{\prime \prime} \mathrm{N}$., long. $125^{\circ} 40^{\prime} 08^{\prime \prime}$ E.) ; 42 meters (23 fathoms); May 18, 1908; Co., S.

One specimen (Cat. No. 40950 , U.S.N.M.).

Notes.-The diameter of the disk is $6 \mathrm{~mm}$., and the arms are about $45 \mathrm{~mm}$. in length.

I described this species from two specimens collected by the Siboga in the Sunda archipelago, at depths between 54 and 36 meters (30 and 20 fathoms).

The Albatross specimen differs from those of the Siboga collection only in the outermost mouth papilla, which, instead of being elongated with an obtuse point, remains rather low and a little broader than long. The side arm plates carry five or six arm spines; the 
central spines have the tip obtuse and slightly broadened; the extremity is armed with little asperities as in the type, and one of them is a little more developed than the others, but without forming a true hook (pl. 96, fig. 12).

In spite of the slightly different form of the outermost mouth papilla, I do not believe that there is any necessity for separating. this specimen from Ophiocentrus asper.

\section{OPHIOCENTRUS VEXATOR, new species.}

Plate 62, figs. 1-5; plate 96 , fig. 11.

Locality.-Albatross station 5181; off eastern Panay; Antonir Island (S.) bearing S. $63^{\circ}$ W., 12.25 kilometers (6.6 miles) distant (lat. $11^{\circ} 36^{\prime} 40^{\prime \prime}$ N., long. $123^{\circ} 26^{\prime} 35^{\prime \prime}$ E.) ; 47 meters (26 fathoms); March 27, 1908; M., fne. S.

Two specimens (Cat. Nos. E. 10, E. 11, U.S.N.M.).

Description.-The larger specimen, which I have taken as the type, is almost complete. The disk is slightly deformed and measures 12 $\mathrm{mm}$. by $9 \mathrm{~mm}$. in diameter; the arms, almost all complete, are about $60 \mathrm{~mm}$. to $70 \mathrm{~mm}$. long. In the other specimen the incomplete disk is $10 \mathrm{~mm}$. in diameter, and a single arm is preserved.

The dorsal surface of the disk is covered with extremely small imbricated plates, with indistinct outlines, some of which bear a rather thick, but not very long, conical spine with the point blunted. These spines become more closely crowded toward the periphery of the disk. The radial shields are three times as long as broad, with a rounded proximal angle; their form is that of a slightly curved triangle. The two shields of each pair are sometimes very close together outwardly without, however, being in contact, and they diverge in such a way as to leave between them a rather broad space: the separation of the shields varies in the different pairs.

The ventral surface of the disk is covered with small rounded. imbricated, equal plates, which are very finely granulose and provided with more pointed spines than those on the plates of the dorsal surface; these spines are very closely crowded toward the periphery of the disk, but they disappear rapidly before reaching the mouth shields, leaving a more or less extensive portion of the ventral surface naked. The genital slits are very narrow and elongated.

The mouth shields are longer than broad; they have a form recalling that of a very short rocket, or, in other words, they show a transversely broadened and oval principal portion with a broad and slightly convex proximal border and the angles and sides very strongly rounded, plus a lobe which projects into the interradial space and which is almost as long as broad with the distal border rounded. 
The adoral plates are rather short and very narrow in their proximal portion where they are almost in contact in the median interradial line; outwardly they broaden very greatly and separate the mouth shield from the first side arm plate. The oral plates are small, half again as high as broad. The mouth papillae, three in number, are arranged as in the genus Amphiura; the proximal papilla is very thick and cubical in form, the second, situated on a higher level, is conical and pointed; the outermost papilla, borne by the adoral plate, is broad, thick, and conical.

The upper arm plates are small, rounded, as long as broad, or a little longer than broad, with an almost straight proximal border; the sides are rounded and convex, and they are united over a similarly rounded distal border. They are all in contact.

The first under arm plate is very narrow and crowded in between the neighboring adoral plates, but it is rather elongated. The following plates are rectangular, almost as long as broad, and rather small, with a straight or slightly convex proximal border, a distal border very distinctly concave and excavated in the middle, and straight sides; they are all in contact.

The very strongly projecting side arm plates are also much developed, and they cover a large part of the dorsal and ventral surfaces of the arms. They bear ten arm spines, which are conical and subequal with the point blunted, and almost equal the arm segments in length. The lateral spines - that is, those between the second and fifth, inclusive-often have their tip slightly broadened and provided with two or three small conical teeth, which may be equal or unequal; it is rarely that one of these last is developed more than the others, forming a small slightly incurved hook directed toward the distal extremity of the arm (pl. 96, fig. 11).

The tentacle pores are without scales.

The color of the specimen in alcohol is grayish.

Affinities and distinctive features.-Ophiocentrus vexator is very close to 0 . verticillatus (Döderlein) and one might suppose that it is only a simple variety of it, but the conical arm spines, which are not at all flattened, and are terminated by two or three teeth, of which one may form a little hook at the tip, are so different from the flattened spines broadened in the middle with the tip rounded which Döderlein has described that it seems to me impossible to unite the two forms.

My description was written some time before I became acquainted with Matsumoto's memoir of 1917. I am uncertain whether my $O$. vexator may not be identical with the Japanese species which he refers to 0 . verticillatus. 


\section{Family AMPHILEPIDAE.}

\section{AMPHILEPIS PROTECTA Kœhler.}

Plate 69, figs. 9, 10.

Amphilepis protecta KGeHLeR ('04), p. 94, pl. 23, figs. 8, 9.-H. L. ClarK ('15), p. 244

Locality.-Albatross station 535̃9; Joló Sea (lat. $8^{\circ} 12^{\prime} 45^{\prime \prime} \mathrm{N}$., long. $120^{\circ} 37^{\prime} 15^{\prime \prime}$ E.) ; 4,161 meters (2,275 fathoms) ; January 9, 1909.

Two specimens (Cat. No. 41013, U.S.N.M.).

Notes. - The diameter of the disk varies between $6 \mathrm{~mm}$. and $6.5 \mathrm{~mm}$. The arms are preserved for a considerable length; one of them. which is entire, exceeds $45 \mathrm{~mm}$.; these arms diminish rather rapidly in width, becoming extremely slender in their distal half.

The two Albatross specimens are a little larger than the type, which was discovered by the Siboga, in which the diameter of the disk did not exceed $4.5 \mathrm{~mm}$. But they agree very well with my original description. The upper arm plates show in the middle a small elongated depression; the under arm plates are separated by a rather broad space. I give here two photographs of the larger of the two individuals.

The type of Amphilepis protecta was found in the Sunda Archipelago at a depth of 1,158 meters (632 fathoms).

\section{AMPHILEPIS REMITTENS, new species.}

\section{Plate 69 , figs. 7,8 .}

Locality.-Albatross station 5637; Bouro Island (south) and vicinity; Amblau Island (N.) bearing $80^{\circ}$ E., 38.91 kilometers (21 miles) distant (lat. $3^{\circ} 53^{\prime} 20^{\prime \prime}$ S., long. $126^{\circ} 48^{\prime} 00^{\prime \prime}$ E.) ; 1,280 meters (700 fathoms); December 10, 1909; gy. M.

One specimen (Cat. No. 41112, U.S.N.M.).

Description.-The specimen is of small size and the diameter of the disk does not exceed $3 \mathrm{~mm}$. The arms, of which four are complete, are not $10 \mathrm{~mm}$. in length; they are relatively rather thick and taper progressively without however becoming very narrow in their distal part. Unfortunately the central portion of the dorsal surface of the disk is torn away.

The disk is rather strongly excavated in the interradial spaces. The plates which remain on the dorsal surface are large, rounded, and scarcely imbricated; they become suddenly very much smaller toward the periphery. The radial shields are large, with the internal border almost straight, the external border very convex, and an acute proximal angle; the two shields of each pair are in contact for about a third of their length, and they are separated inwardly by an elongated triangular plate. The length of these shields is more than twice their width, and is almost equal to half the radius of the disk. 
The plates of the ventral surface continue those of the periphery of the disk on the dorsal surface, but they are smaller, rounded, thin and imbricated. The genital slits are broad.

The mouth shields, which are of medium size, are triangular, a little broader than long, with a rather sharp proximal angle bounded by two almost straight sides; the lateral angles are all rounded, and the distal border is almost straight, or slightly convex. The adoral plates are rather large, two and a half times as long as broad, with the longer borders almost parallel; but they taper somewhat inwardly, and they are broadly in contact in the median interradial line; they are somewhat enlarged outwardly, but do not separate the mouth shield from the first side arm plate. The oral plates are rather large, triangular, as high as broad. The inner mouth papilla is small and conical; the outer papilla is large, elongated, inserted on the whole free border of the oral plate; it is broader than long, with the proximal angle slightly produced and sharp. The mouth tentacle pore is furnished with a single small rounded scale.

The upper arm plates are large, very much broader than long, almost semi-circular, with a very obtuse and very rounded proximal angle bordered by two convex sides which pass over by rounded angles to the convex distal border. The two or three first plates are almost in contact, and the following are separated by a narrow interval.

The first under arm plate shows a principal portion which is quadrangular, a little broader than long, from which is given off a small narrow lobe delimiting the radial border of the mouth tentacle pore. The following are rather large, pentagonal, a little. longer than broad, with a sharp proximal angle and straight sides. They are separated beyond the fifth by a narrow interval.

The slightly projecting side arm plates carry three narrow, conical, subequal arm spines of which the length equals almost that of the segment.

The arm tentacle pores bear two very small, subequal, oval scales set at right angles to each other.

The color of the specimen in alcohol is white.

Affinities and distinctive features.-In spite of its small size this species shows very pronounced characters which do not permit of referring it to any of the known species of the genus Amphilepis, from which it differs by the presence of a single tentacle scale on the mouth pore, while the arm pores possess two. Amphilepis remittens differs markedly from A. protecta Koehler in the size of the plates of the dorsal surface of the disk, in having the mouth shields a little broader than long, in having the under arm plates a little longer than broad, and in the very short and relatively thick arms. 


\section{AMPHIACTS DUPLICATA (Lyman).}

Plate 63, figs. $1-4$.

Amphiura duplicata LyMAN ('74), p. 19, pl. 5, fig. 78; ('79), p. 226; ('82),

p. 136. -KGHLER ('95), p. 74; ('98), p. 49.

Amphiura partita KळHLER ('96), p. 336, pl. 7, figs. 50, 51; ('99), p. 48;

pl. 10 , figs. $79, \mathrm{S0}$; ('04), p. 96.

Ophiactis duplicata LÜTKen and MoRtensen ('99), p. 142.-KähleR ('07a),

p. 311 ; ('14), p 40.-H. L. ClaRK ('15), p. 261.

Amphiactis duplicata Matsumoto ('15), p. 67; ('17), p. 147.

A mphiodia partita H. L. ClARK ('15), p. 248.

Amphiactis partita Matsumoto ('17), p. 147.

Localities.-Albatross station 5348; Palawan Passage; Point Tabonan bearing $\mathrm{S} .89^{\circ} \mathrm{E}$., 62.08 kilometers (33.5 miles) distant (lat. $10^{\circ}$ $57^{\prime} 45^{\prime \prime}$ N., long. $118^{\circ} 38^{\prime} 15^{\prime \prime}$ E.) ; 685 meters (375 fathoms); December 27, 1908; Co., S.

Five specimens (Cat. Nos. 41053,41057 , U.S.N.M.).

Albatross station 5475; east coast of Luzon; San Bernardino Strait to San Miguel Bay; San Bernardino Light bearing S. $27^{\circ}$ W., 20.38 kilometers (11 miles) distant (lat. $12^{\circ} 55^{\prime} 26^{\prime \prime} \mathrm{N}$., long. $124^{\circ} 22^{\prime} 12^{\prime \prime}$ E.) ; 357 meters (195 fathoms); June 24, 1909; Sh.

One specimen (Cat. No. 41055 , U.S.N.M.).

Albatross station 5658; Gulf of Boni, Celebes; Cape Loko Loko bearing S. $31^{\circ}$ W., 19.84 kilometers (12 miles) distant (lat. $3^{\circ} 32^{\prime}$ $40^{\prime \prime}$ S., long. $120^{\circ} 31^{\prime} 30^{\prime \prime}$ E.) ; 933 meters (510 fathoms) ; December 19,1909 ; gy. M.

One specimen (Cat. No. 41056 , U.S.N.M.).

Notes.-Following the example of Matsumoto I am placing this species in the genus Amphiactis established by him, the creation of which is abundantly justified by the arrangement of the mouth papillae and by the internal structure.

The specimens are all of small size, and the diameter of the disk does not exceed $5 \mathrm{~mm}$. They agree well with the description which I published of Amphiura partita (pl. 63, figs. 3, 4). The dorsal plates of the disk are rather thick with the borders raised, and sometimes they are even somewhat thickened. The mouth shields in general show the form which I have described and figured in $A$. partita ('96, p. 336, pl. 7, fig. 51), but I notice some variations; sometimes these shields are as long as broad, and they may even be a little longer than broad, while on other specimens they are shorter and broader, and they thus assume the form which is represented by Lyman and by Lütken and Mortensen in Ophiactis dupticata. Under these conditions it does not seem to me to be worth while to maintain the distinction which I had thought it necessary to make between $A$. partita and $A$. duplicata, and I believe that the first should be considered as a synonym of the second. 
Lütken and Mortensen stated that they were not absolutely certain of their determination, but it seems to me beyond doubt that the specimens which they described and figured belong to $A$. duplicata. Amphiactis duplicata must therefore have an enormous geographical range.

The specimen from station 5658 has an appearance somewhat different from that of the others (figs. 1,2). It is a little larger and the diameter of the disk reaches $7 \mathrm{~mm}$.; the dorsal surface is remarkable for the thickness of the plates which cover it. These are very stout, and the borders are much swollen, while the central region is a little depressed; the arm spines are short and thick. But otherwise the characters conform absolutely to those of $A$. duplicata, and in this specimen we have to do merely with an exaggeration of the thickness of the plates of the dorsal surface of the disk.

\section{Family OPHIOTRICHIDAE. \\ OPHIOTHRIX ARISTULATA Lymah.}

See for bibliography:

Ophiothrix aristulata KoEHLER ('04), p. 151.-DöberLein ('10), p. 254, pl. 5, figs. 4, 5.-H. L. Clark ('15), p. 269; ('16), p. 89.

Localities.-Albatross station 5517; northern Mindanao and vicinity; Point Tagolo Light bearing S. $83^{\circ}$ W., 19.46 kilometers (10.5 miles) distant (lat. $8^{\circ} 45^{\prime} 30^{\prime \prime}$ N., long. $123^{\circ} 33^{\prime} 45^{\prime \prime}$ E.) ; 309 meters (169 fathoms); August 9, 1909; Glob.

One specimen (Cat. No. E. 96, U.S.N.M.).

Albatross station 5519; northern Mindanao and vicinity; Point Tagolo Light bearing S. $71^{\circ} \mathrm{W} ., 16.12$ kilometers ( 8.7 miles) distant (lat. $8^{\circ} 47^{\prime} 00^{\prime \prime}$ N., long. $123^{\circ} 31^{\prime} 15^{\prime \prime}$ E.) ; 333 meters (182 fathoms); August 9, 1909; Glob., S.

One specimen (Cat. No. E. 97, U.S.N.M.).

Albatross station 5523; northern Mindanao and vicinity; Point Tagolo Light bearing S. $48^{\circ}$ W., 12.42 kilometers ( 6.7 miles) distant (lat. $8^{\circ} 48^{\prime} 44^{\prime \prime}$ N., long. $123^{\circ} 27^{\prime} 35^{\prime \prime}$ E.) ; August 10, 1909.

Two specimens (Cat. Nos. E. 98, E. 99, U.S.N.M.).

Notes.-The specimens which I previously described and figured, which were dredged by the Investigator in the Indian Ocean (Andaman Islands and coast of Coromandel), have, as I wrote in 1896 ('96, p. 363), a more robust habitus and the radial shields are more developed than in Lyman's type; the spines of the dorsal surface of the disk are stronger and longer, and the arm spines are larger. I felt myself justified in establishing on the basis of these differences a variety which I called investigatoris, which, however, evidently is of no great value, and the study of more numerous specimens from different localities will no doubt show intermediates between this variety and the type. 
The spines of the dorsal surface of the disk, ordinarily very long and stout (as those which I show on plate 97 in figure $1 a$ ), become sometimes very short, and then deserve the name of club spines $(b)$. In certain of these latter the teeth assume a very great development toward the free extremity of the spine, while they tend to disappear along the rest of its length $(c)$. In certain specimens, as for example that from station 5519, the stem of these club spines shortens while the terminal teeth become very greatly developed, and multifid club spines thus pass into trifid and even bifid club spines, such as those which I show here (fig. $1 d$ ) ; certain of these last are remarkable for the extraordinary development of the terminal spinules.

I figure here the dorsal surface of two specimens coming, respectively, from stations 5517 and 5523 (pl. 35, figs. 2, 3), as well as the dorsal surface of a specimen collected by the Challenger. I include these photographs not so much to show the very slight differences: which may be found between the two first individuals and the third as to illustrate the resemblances and the differences which exist between $O$. aristulata and certain forms of $O$. fragitis.

Döderlein ('10, p. 254) has given the name of $O$. aristulata to some specimens of an Ophiothrix from the Bay of Lüderitz, remarking that the specimens show a very great resemblance to the variety pentaphyllum of $O$. fragilis. He recalls, moreover, that I have myself recorded that last species on the western coast of South Africa. Döderlein concludes that the only character separating $O$. aristulatce from $O$. fragilis, var. pentaphyllum consists in the slightly different armature of the dorsal surface of the disk.

Since the publication of Döderlein's memoir I have had occasion to study other specimens Ophiothrix from South Africa, from Swakomunde and the Bay of Lüderitz. I have mentioned these in a work published in 1914 ('14c, p. 209), in which I wrote as follows:

Ces exemplaires sont identiques à ceux que la S'cotia a recueillis dans la Baie de Saldanha (Cap) et que j'ai mentionnés en 1908 sous le nom d'O. fragilis var. pentaphyllum; ils me paraissent d'autre part être parfaitement conformes a ceux que Döderlein a décrits en 1910 sous le nom d'O. aristulata et qui proviennent de la baie de Lüderitz, autant que j'en puis juger d'après les photographies publiées par ce savant. Ils s'écartent au contraire des 0 . aristulata que je possède dans ma collection et qui proviennent de l'Océan Indien, et jecrois devoir maintenir la détermination à laquelle je me suis arrêté en 1908.

In referring to the photographs which Döderlein has published of the Ophiothrix from the Bay of Lüderitz I believe I am able to state that that author had at hand not $O$. artistulata but the variety pentaphyllum of $O$. fragilis. I can not find any difference between the specimen photographed by Döderlein ('10, pl. 5, figs. 4, 5) and the numerous individuals which I have in my collection of $O$. fragilis, var. pentaphyllum from different localities on the coasts of France: 
and England. I give here photographs of the dorsal surface of two of them, one from the coasts of England (pl. 35, fig. 4) and the other from Belle-Ile (fig. 5), and the close resemblance to the specimen photographed by Döderlein will be seen. I also include photographs of two specimens from South Africa, one from the Bay of Lüderitz (fig. 7) and the other from Saldanha (fig. 6), which I assign without the least hesitation to $O$. fragilis, var. pentaphyllum.

The two specimens of 0 . artistulata from station 5523 and that from station 5519 show the usual coloration; in that from station 5517 the dorsal surface of the disk and of the arms is of a uniformly violet pink color, and the longitudinal median dorsal line of the arms is scarcely indicated.

The characters which distinguish 0 . artistulata from 0 . pentaphyllum, without being of great importance, do not allow of the confusion nor of the union of the two forms. They concern principally the armature of the dorsal surface of the disk, the number and the arrangement of the arm spines, the relative dimensions of the disk and of the arms, and the coloration. It may be added that $O$. aristulata has generally been found at some depth, while $O$. pentaphyllum is a littoral form.

The armature of the dorsal surface of the disk of 0 . aristulata consists of elongated spines, of somewhat variable length and thickness, but always well developed, strongly denticulated and very closey crowded (pl. 97, fig. 1a); the covering which they form on the disk, between the large radial shields, is uniform, and between these large spines there are no club spines. These last appear only at the periphery of the disk, in the interradial regions which bulge outward between the arms; these club spines are always slender and more or less elongated, and they are furnished with strong, elongated, and pointed teeth, which sometimes occur only on their free tip, and sometimes in greater or lesser number on different parts of their length (pl. 97, fig. $1 b$ and $c$ ). In $O$. pentaphyllum the spines on the dorsal surface of the disk are always few in number, usually short and thick, and the covering consists especially of club spines, which also are short, thick, and conical and are not elongated except towards the periphery of the disk in the interradial spaces.

The arms are always very much longer in respect to the diameter of the disk in 0 . aristulata than in 0 . pentaphyllum. The arm spines, which are in general greatly developed, rapidly attain their maximum length beyond the first ventral spine; this is very short and very slender; the second, which is much longer, reaches and even exceeds the length of the segment; the third, which is already almost as thick as those following, reaches at least the length of two segments, and sometimes even three. The following spines are still larger. This increase from the first ventral spine to the second, and from 
the second to the third, and then to those following, takes place in an extremely rapid manner. In 0 . pentaphyllum, on the contrary, the augmentation in the length of the spines takes place progressively, as I showed in 1915, and as Russo described it in 1893.

The armature of the disk and the rapid increase in the length of the arm spines in $O$. aristulata, strongly recalls the conditions which occurs in 0 . quinquemaculata Delle Chiajes of the Mediterranean.

I will add further that the general appearance of 0 . aristulata is very much more robust than that of $O$. pentaphyllum, the arms are thicker, stouter, and longer, and the arm spines are more developed. These are the comparative differences. The coloration of $O$. aristulata appears very uniform, the specimens being always of a light color, grayish pink or pink, and they never show variations so extended over the whole gamut of colors as those known in $O$. pentaphyllum.

The type of $O$. aristulata was found by the Challenger in $34^{\circ} \mathrm{S}$. latitude and $18^{\circ} \mathrm{E}$. longitude, at a depth of 274 meters ( 150 fathoms), as well as at the entrance of Port Phillip in 69 meters (38 fathoms) and in the Bay of Twofold in 219 meters (120 fathoms). The Investigator found it among the Andaman Islands and on the coast of Coromandel between 238 and 530 meters (130 and 290 fathoms). H. L. Clark has recorded it from the coasts of Tasmania and of South Australia at different depths between 119 and 366 meters (65 and 200 fathoms).

\section{OPHIOTHRIX ARMATA Kœhler.}

Plate 57, figs. $3-6$; plate 97 , fig. 2.

Ophiothrix armata KaHLER ('05), p 103, pl. 10, figs. 1, 2.-H. L. CLARK ('15), p. 2 so.

Locality.-Celebes.

One specimen (Cat. No. 41046, U.S.N.M.).

Notes.-I refer to Ophiothrix armata a very small specimen from Celebes, of which the state of preservation leaves something to be desired and in which the diameter of the disk scarcely exceeds $2.5 \mathrm{~mm}$. On plate 57, figure 5 I give a photograph of its dorsal surface. This specimen differs only in its coloration from the type which I described in 1905 . The general coloration is gray with a few small dark blue spots. Toward the distal angle of the radial shields there appears a very light band, bordered on each side by a dark blue line which continues onto the median dorsal line of the arms; this band

\footnotetext{
${ }^{8}$ Ophiothrix quinquemaculata is the species which Russo in 1893 recorded under the name of 0 . echinata, a synonymy which I erroneously adopted from him in my work of 1895 and which I have followed in all my later publications. It is sufficient to mention the fact here in passing. I intend to return to it in the near future, in taking up again, in more detail than I did in 1895 , the study of the species of Ophiathrix of the European seas, in order to describe in some detall the numerous variations which the armature of their disks show.
} 
broadens slightly toward the distal border of each upper arm plate and narrows a little toward their middle; the upper arm plates and likewise the side arm plates, are also studded with very small blue spots; the ventral surface is yellowish gray. The spines are transparent and slightly bluish. I give here for comparison two photographs of one of the Siboga specimens upon which I based the species and which will better serve to show the characters than my schematic drawings of 1905 (figs. 3,4). I also show on plate 97, as figure 2, two of the first ventral arm spines transformed into hooks with three branches of the type most usual in Ophiothrix (a), as well as two tentacle scales $(b)$; these last are small and delicate, and terminate in a rather long point.

The type of 0 . armata came from Banda; it is a strictly littoral form.

\section{OPHIOTHRIX ASPIDOTA Müller and Troschel.}

Plate 32 , figs. $1-5$; plate 33 , fig. 7 ; plate 97 , fig. 3.

See for bibliography:

Ophiothrix aspidota Kamler ('04a), p. 87, figs. 50-54.-H. L. Clark ('15), p. 269 .

Locality.-Albatross station 5321; Ibugos Island (south end) bearing S. $89^{\circ}$ W., 2.32 kilometers (1.25 miles) distant (lat. $20^{\circ} 19^{\prime}$ $30^{\prime \prime}$ N., long. $121^{\circ} 51^{\prime} 15^{\prime \prime}$ E.) ; 47 meters (26 fathoms); November 9,1908 ; wh. S., Co., brk. Sh.

One specimen (Cat. No. E. 9, U.S.N.M.).

Notes.-The diameter of the disk is $9 \mathrm{~mm}$. The arms are not preserved for a greater length than $40 \mathrm{~mm}$., but judging from the fragments which accompany the specimen, and which appear to me to represent a total length of more than 80 or $90 \mathrm{~mm}$., they must be very long; the arms are flattened and remain of the same width over a very large part of their length (figs. $3,4,5$ ).

The club spines of the dorsal surface of the disk are short, rather broad, and ordinarily terminate in three subequal spinules; sometimes these spinules are four in number, or two only; it may happen that one of them is greatly elongated at the expense of the others (pl. 97, fig. $3 a$ ). Toward the borders of the disk the club spines become a little longer and more slender. The first ventral arm spine becomes transformed rather rapidly into a hook which never becomes very large, and which may show as many as eight or nine subequal points on its concave side; the convex side also often shows some asperities toward the terminal part (pl. 97, fig. 3b). The following spines bear very closely crowded and much elongated teeth on their proximal border, while the teeth are short, conical and few on the distal border (fig. $3 c$ and $d$ ). The tentacle scale is elongated and ends in a sharp point $(e)$. 
The general coloration is light pink; the dorsal surface of the disk is light; the arms are a little darker and show slightly darker annulations. On the ventral surface the disk is light gray and the arms are pinkish gray, with traces of annulations and a darker spot toward the middle of each of the under arm plates; the spines are colorless. Some dark purple dots are found on the radial shields and on the upper arm plates at the base of the arms; there is not the least trace of a dorsal median line.

In $1904 \mathrm{I}$ had the opportunity of redescribing the original specimen of $O$. aspidota, in which the diameter of the disk is $10.5 \mathrm{~mm}$.; at the same time I described the characters of a specimen from Trincomalee in my own collection, which I referred to $O$. aspidota. It seems to me worth while to reproduce here (pl. 32, figs. 1, 2) two photographs of this last for comparison with the individual collected by the Albatross represented in figures 3, 4, 5 .

Müller and Troschel's type is completely decolorized, and it is impossible to learn the color which it had in life; that from Trincomalee is violet gray; the radial shields are lighter than the rest of the dorsal surface of the disk, and they show toward their borders a rather irregular and noncontinuous line of dark blue; the upper arm plates show toward their distal outer angle a lighter line, and here and there is an indication, very vague, however, of a lighter median dorsal line; the spines are gray. The Albatross specimen differs very sharply in its coloration from that from Trincomalee, but in all its morphological characters I find it so conformable with the type of $O$. aspidota that it does not seem to me possible to separate it from that species; the question of the color can not enter into consideration here because the type of 0 . aspidota is entirely faded out.

The radial shields of the specimen collected by the Albatross are large, absolutely naked, and their surface is very finely granulose. The granulation of the upper arm plates is scarcely marked. The form of these plates is absolutely identical with that in the type; they are trapezoidal with the distal border almost straight, and the lateral angles are very sharp (pl. 33, fig. 7). I remarked in 1904 the peculiar form of the adoral plates in O. aspidota; these plates are widely removed from the median interradial line and they show an irregularly rounded principal portion continuing by a slender process which separates the mouth shield from the first side arm plate; I find this form again in the Albatross specimen, as I had also observed it in that from Trincomalee.

The only character by whch the Albatross specimen differs from the two others is the form of the under arm plates, which are square, as long as broad, with the distal border very gently rounded. In Müller and Troschel's type and in the specimen from Trincomalee these plates are distinctly broader than long. I believe that this 
difference has to do with the size of the subjects. In the type of the species, which is a little larger than the Albatross specimen, the relative width of the under arm plates is far from being as pronounced as in the specimen from Trincomalee, in which the disk reaches 17 $\mathrm{mm}$. in diameter; in the last, the ventral plates are very much broader than long, and their distal border is no longer convex; it becomes sometimes even slightly concave. I do not believe that this slight difference in the form of the under arm plates necessitates a specific separation, and I believe that the name $O$. aspidota may be perfectly well applied to the Albatross specimen.

However, it must be noticed that this individual differs in its coloration from my specimen from Trincomalee. Must it be assumed from this that the latter is not an $O$. aspidota? I do not think so, and we know other species of Ophiothrix in which the blue coloration replaces the red coloration, or the reverse; I have been able to observe, for example, that in 0 . proquinqua the general coloration is sometimes blue and sometimes red.

I may add that the club spines of the dorsal surface of the disk and the arm spines show the same microscopical characters in the specimen from the Philippines and in mine from Trincomalee.

Müller and Troschel's original specimen is given as coming from the East Indies; Lyman mentions 0 . aspidota from Celebes; the species is also known from Madagascar, from Ceylon, and from Kurrachee.

\section{OPHIOTHRIX BELLAX, new species.}

Plate 47 , figs. $1-3$; plate 97 , fig. 4.

\section{Locality.-Unknown.}

One specimen (Cat. No. 41026, U.S.N.M.).

Description.-The diameter of the disk is $9 \mathrm{~mm}$. The arms must be rather long, though none is complete; one of them is preserved for a length of $70 \mathrm{~mm}$. and it only seems to lack a small part of its distal portion.

The disk is rounded. The dorsal surface is uniformly covered between the radial shields with rather stout, elongated, somewhat unequal, and irregular spines, showing at different heights some rather strong conical and pointed teeth, their tips ending in two or three short and pointed spinules (pl. 97, fig. 4a). In the midst of these spines are some cylindrical club spines terminated by two or three unequal spinules, and all intermediate forms between the longest spines and the shortest club spines may be found; but the spines are in the majority; this whole investment is rather close. At the periphery of the disk the spines become progressively shorter, and only the club spines pass over onto the ventral surface. The radial shields are covered, but they only bear small club 
spines which are shorter than those on the rest of the dorsal surface; as these club spines are not very closely crowded, the outlines of the radial shields are very evident. They are triangular and bounded by straight sides, half again as long as broad, and their length equals almost half the radius of the disk.

The club spines of the ventral surface, which are at first elongated and terminated by several spinules, become progressively shorter and simply conical toward the mouth shields; but they almost entirely cover the whole surface. The genital slits are narrow.

The mouth shields are slightly pyriform, almost as long as broad, with the proximal angle rather sharp, though with the apex rounded, bordered by two slightly concave sides passing over by very broadly rounded angles into the dorsal side, which is more or less convex. The medium sized adoral plates are triangular, narrowing inwardly, and not in contact in the median interradial line, much broadened outwardly, but not separating the mouth shield from the first side arm plate. The oral plates are extremely broad and not very high. The tooth papillae form two lateral rows between which are found two other median rows which are a little more irregular.

The upper arm plates are trapezoidal, a little broader than long, with a straight and narrow proximal border, a broad and convex distal border, and divergent sides; the lateral angles are rounded. They are all in contact.

The first under arm plate is large, quadrangular, almost as broad as long, with the sides convex; this plate is as broad as, and even a little broader than, the following plate. This is longer than broad, with the proximal border straight and narrower than the distal border, which is convex; the sides are divergent and concave. The third plate is also a little longer than broad, with the distal border convex, and broader than the proximal border. The fourth is almost as long as broad, and, beyond the fifth, the plates become a little broader than long with the proximal border always a little narrower than the distal border, and the latter, instead of being rounded, becomes slightly excavated in the middle. All these plates are broadly in contact. The three first under arm plates are rather deeply excavated, the excavation taking the form of a groove down the middle, while the lateral borders are elevated; sometimes this groove is slightly marked on the fourth plate, but beyond that the surface of the underarm plates remains quite flat.

The side arm plates, which are slightly projecting, carry at the base of the arms ten arm spines, but this number rapidly falls to eight and then to seven. The three first ventral spines remain very short, shorter than the segment; the fourth is very much longer than the third, and its length much exceeds that of the segment; 
then the length increases rapidly, and the three following almost equal three segments and a half; the last dorsal spine is generally shorter than the preceding. The lateral spines broaden toward the tip, at the same time becoming samewhat flattened, but the dorsal spines does not broaden and ends in a point. All are perfectly transparent and furnished with strong pointed and closely placed denticulations. The first ventral spine beyond the tenth segment is converted into a somewhat elongated hook with generally four branches the length and thickness of which increase from the first to the last (pl. 97 , fig. $4 b$ ).

The tentacle scale is small, oval, with the tip rounded, scarcely longer than broad (fig. 4c).

The general coloration is red. The dorsal surface of the disk is rather dark, of a quite uniform slightly brownish red. A white line runs along the median dorsal line of the arms, narrowing slightly toward the middle of each upper arm plate and broadening toward the distal border. On either side runs a very narrow red line which follows the outlines of the white band; small red longitudinal striae are seen on the pink background of the upper arm plates outside of this median line. The ventral surface of the disk is dark brown, but the spines which it bears are roseate. The ventral surface of the arms is pink; a white band runs throughout the whole length of the ventral median line and it is bounded on each side by an extremely narrow scarcely darker line which shows at the plane of the border of each segment a small darker dot. The spines are transparent, though slightly roseate.

Affinitities and distinctive features.-Ophiothrix bellax belongs to the section of Ophiothrix in which the radial shields are covered and the arms are very long, and it approaches $O$. puncto-limbata Martens, O. longipeda (Lamarck), O. hirsuta Müller and Troschel, $O$. belli Döderlein, O. obtusa Kœhler, and O. expedita Kœhler. It is distinguished from $O$. belli by the much longer arm spines which are denticulated throughout their whole length, broadening gradually and not abruptly in their distal half; the covering of the disk consists of small short spines mixed with club spines, and the radial shields are more covered than in 0 . belli. It differs from $O$. obtusa, in which the surface of the disk is simply covered with little rugose granules and in which the arms are shorter. In the form of the upper arm plates $O$. bellax is sharply distinguished from $O$. hirsuta, 0 . Tongipeda, and 0 . puncto-timbata. Furthermore the coloration is entirely different in the species which I have just mentioned. Only 0 . expedita has a coloration comparable to that of 0 . bellax; it is, however, a little darker and verging toward brown; but the form of the radial shields is very different and the arms of $O$. expedita show on their dorsal surface three very characteristic white lines. 
OPHIOTHRIX CAPILLARIS Lyman.

Plate 37 , figs. $2-4$; plate 97 , fig. 5.

Ophiothrix capillaris LYMAN ('79), p. 51, pl. 14, figs. 401-404; ('82), p. 222, pl. 21, figs. 5-8.-F. J. BeLL ('94), p. 397.-KaEhler ('04), p. 151.

Localities.-Albatross station 5113; China Sea, off southern Luzon; Sombrero Island bearing S. $7^{\circ} \mathrm{W}$., 17.60 kilometers $(9.5$ miles) distant (lat. $13^{\circ} 51^{\prime} 30^{\prime \prime}$ N., long. $120^{\circ} 50^{\prime} 30^{\prime \prime}$ E.) ; 291 meters (159 fathoms); January 17, 1908; dk. gn. M.

Three specimens (Cat. No. 41124, U.S.N.M.).

Albatross station 5118; Balayan Bay and Verde Island Passage; Sombrero Island bearing S. $47^{\circ}$ E., 18.53 kilometers $(10$ miles) distant (lat. $13^{\circ} 48^{\prime} 45^{\prime \prime}$ N., long. $120^{\circ} 41^{\prime} 51^{\prime \prime}$ E.; 291 meters) 159 fathoms); January 21, 1908; dk. gn. M.

Eight specimens (Cat. No. 41125, U.S.N.M.).

Albatross station 5166; Observation Island bearing N. $20^{\circ} \mathrm{W}$., 8.52 kilometers (4.6 miles) distant (lat. $4^{\circ} 56^{\prime} 10^{\prime \prime} \mathrm{N}$., long. $119^{\circ} 46^{\prime}$ $00^{\prime \prime}$ E.) ; 177 meters (97 fathoms) ; February 24, 1908; co. S.

One small specimen (Cat. No. 40930, U.S.N.M.).

Albatross station 5168.

Nine specimens (Cat. No. E, 146, U.S.N.M.).

Albatross station 5198; in the vicinty of western Bohol; Baliscasag Island bearing S. $6^{\circ}$ E., 18.99 kilometers (10.25 miles) distant (lat. $9^{\circ} 40^{\prime} 50^{\prime \prime}$ N., long. $123^{\circ} 39^{\prime} 45^{\prime \prime}$ E.) ; 402 meters ( 220 fathoms); April 9, 1908; gn. M.

Five specimens (Cat. No. E. 143, U.S.N.M.).

Albatross station 5260; off southeastern Mindoro; Balanja Point bearing N. $28^{\circ}$ W., 13.34 kilometers (7.2 miles) distant (lat. $12^{\circ}$ $25^{\prime} 35^{\prime \prime}$ N., long. $121^{\circ} 31^{\prime} 35^{\prime \prime}$ E.) ; 428 meters (234 fathoms) ; June 3, 1908; gn. M., S.

One specimen (Cat. No. 41070 , U.S.N.M.).

Albatross station 5367; Verde Island Passage; Malabrigo Light bearing $\mathrm{N} .81^{\circ} \mathrm{E} ., 14.83$ kilometers ( 8 miles) distant (lat. $13^{\circ} 34^{\prime}$ $37^{\prime \prime}$ N., long. $121^{\circ} 07^{\prime} 30^{\prime \prime}$ E.) ; 329 meters (180 fathoms) ; February 22,$1909 ; \mathrm{S}$.

Four specimens (Cat. No. 40940, E. 113 [part], U.S.N.M.).

Albatross station 5406; Dupon Bay (Leyte) and vicinity; Ponson Island (N.) bearing S. $88^{\circ}$ E., 18.90 kilometers (10.2 miles) distant (lat. $10^{\circ} 49^{\prime} 03^{\prime \prime}$ N., long. $124^{\circ} 22^{\prime} 30^{\prime \prime}$ E.) ; 545 meters (298 fathoms) ; March 17, 1909; M.

Three specimens (Cat. No. E. 104 [part], U.S.N.M.).

Albatross station 5407; Dupon Bay (Leyte) and vicinity; Ponson Island (N.) bearing S. $76^{\circ}$ E., 22.61 kilometers (12.2 miles) distant 
(lat. $10^{\circ} 51^{\prime} 38^{\prime \prime}$ N., long. $124^{\circ} 20^{\prime} 54^{\prime \prime} \quad$ E.) ; 640 meters (350 fathoms); March 17, 1909; gn. M.

Two specimens (Cat. No. E. 142, U.S.N.M.).

Albatross station 5411.

Three specimens (Cat. No. E. 114, U.S.N.M.).

Albatross station 5440; west coast of Luzon, Manila Bay to Lingayen Gulf; San Fernando Point Light bearing N. $82^{\circ}$ E., 42.81 kilometers (23.1 miles) distant (lat. $16^{\circ} 33^{\prime} 52^{\prime \prime}$ N., long. $119^{\circ} 52^{\prime}$ $54^{\prime \prime}$ E.) ; 314 meters (172 fathoms) ; May 10, 1909; fne. gy. S., Glob.

Twenty-four specimens (Cat. No. E. 131, U.S.N.M.).

Albatross station 5504; northern Mindanao and vicinity; Macabalan Point Light (Mindanao) bearing S. $39^{\circ}$ E., 11.1 kilometers (6 miles) distant (lat. $8^{\circ} 35^{\prime} 30^{\prime \prime} \mathrm{N}$., long. $124^{\circ} 36^{\prime} 00^{\prime \prime} \mathrm{E}$.) ; 366 meters (200 fathoms); August 5, 1909; gn. M.

Five specimens.

Albatross station 5505; northern Mindanao and vicinity; Macabalan Point Light (Mindanao) bearing S. $31^{\circ}$ E., 14.27 kilometers (7.7 miles) distant (lat. $8^{\circ} 37^{\prime} 15^{\prime \prime}$ N., long. $124^{\circ} 36^{\prime} 00^{\prime \prime}$ E.) ; 402 meters (220 fathoms); August 5, 1909.

One specimen (Cat. No. E. 104 [part], U.S.N.M.).

Albatross station 5511; northern Mindanao and vicinity; Camp Overton Light bearing S. $80^{\circ}$ E., 28.35 kilometers (15.3 miles) distant (lat. $8^{\circ} 15^{\prime} 20^{\prime \prime} \mathrm{N}$., long. $123^{\circ} 57^{\prime} 00^{\prime \prime}$ E.) ; 750 meters (410 fathoms) ; August 7, 1909; gy. M., S.

Two specimens.

Albatross station 5518; northern Mindanao and vicinity; Point Tagolo Light bearing S. $64^{\circ} \mathrm{W} ., 16.12$ kilometers ( 8.7 miles) distant (lat. $8^{\circ} 48^{\prime} 00^{\prime \prime}$ N., long. $123^{\circ} 31^{\prime} 00^{\prime \prime}$ E.) ; 366 meters (200 fathoms) ; August 9, 1909; gy. M., Glob.

One specimen (Cat. No. 41380, U.S.N.M.).

Albatross station 5519; northern Mindanao and vicinity; Point Tagolo Light bearing S. $71^{\circ}$ W., 16.12 kilometers ( 8.7 miles) distant (lat. $8^{\circ} 47^{\prime} 00^{\prime \prime}$ N., long. $123^{\circ} 31^{\prime} 15^{\prime \prime}$ E.) ; 333 meters (182 fathoms) ; August 9, 1909; Glob., S.

Two specimens (Cat. No. 41380 , U.S.N.M.).

Albatross station 5523; northern Mindanao and vicinity; Point Tagolo Light bearing S. $48^{\circ} \mathrm{W}$., 12.42 kilometers (6.7 miles) distant (lat. $8^{\circ} 48^{\prime} 44^{\prime \prime}$ N., long. $123^{\circ} 27^{\prime} 35^{\prime \prime}$ E.) ; August 10, 1909.

One specimen.

Albatross station 5536; between Negros and Siquijor; Apo Island (C.) bearing S. $26^{\circ} \mathrm{W} ., 21.87$ kilometers (11.8 miles) distant (lat. $9^{\circ} 15^{\prime} 45^{\prime \prime}$ N., long. $123^{\circ} 22^{\prime} 00^{\prime \prime}$ E.) ; 510 meters (279 fathoms); August 19, 1909; gn. M.

Some specimens. 
Albatross station 5538; between Negros and Siquijor; Apo Island (C.) bearing S. $64^{\circ} \mathrm{W} ., 13.53$ kilometers (7.3 miles) distant (lat. $9^{\circ} 08^{\prime} 15^{\prime \prime}$ N., long. $123^{\circ} 23^{\prime} 20^{\prime \prime}$ E.) ; 468 meters (256 fathoms) ; August 19, 1909; gn. M., S.

Some specimens.

Albatross station 5543; Tagolo Light bearing S. $75^{\circ}$ W., 23.16 kilometers (12.5 miles) distant (lat. $8^{\circ} 47^{\prime} 15^{\prime \prime} \mathrm{N}$, , long. $123^{\circ} 35^{\prime}$ $00^{\prime \prime}$ E.) ; 296 meters (162 fathoms) ; August 20, 1909.

Three specimens (Cat. No. E. 113 [part], U.S.N.M.).

Albatross station 5560; Joló Island and vicinity; Cabalian Point bearing $\mathrm{N}$. $76^{\circ} \mathrm{W}$., 9.26 kilometers ( 5 miles) distant (lat. $5^{\circ} 52^{\prime} 00^{\prime \prime}$ N., long. $121^{\circ} 01^{\prime} 06^{\prime \prime}$ E.) ; 26 meters (14 fathoms) ; September 18 , 1909.

One specimen.

Albatross station 5573; north of Tawi Tawi; Simaluc Island (N.) bearing S. $86^{\circ}$ E., 0.74 kilometer $\left(0.4\right.$ mile) distant (lat. $5^{\circ} 28^{\prime} 30^{\prime \prime}$ N., long. $120^{\circ} 13^{\prime} 00^{\prime \prime}$ E.) ; 22 meters (12 fathoms); September 22, 1909.

One specimen (Cat. No. E. 104 [part], U.S.N.M.)

Albatross station 5576; north of Tawi Tawi; Mount Dromedario bearing S. $22^{\circ}$ W., 31.87 kilometers (17.2 miles) distant (lat. $5^{\circ} 25^{\prime}$ $56^{\prime \prime}$ N., long. $120^{\circ} 03^{\prime} 39^{\prime \prime}$ E.) ; 507 meters (277 fathoms) ; September 22,1909 ; $\mathrm{S}$.

One specimen (Cat. No. E. 113 [part], U.S.N.M.)

Notes.-The specimens are in general very fine and in an excellent state of preservation. The diameter of the disk varies between 13 $\mathrm{mm}$. and $24 \mathrm{~mm}$. The coloration is always very light and varies from a pinkish gray to a clear pink on the dorsal face of the disk and of the arms; the ventral surface is very pale and almost white. The line which runs along the middle of the dorsal surface of the arms is broad, brownish red, sometimes perfectly uniform and sometimes lighter in the middle. Some specimens show a general rather dark brown coloration. I give here (pl. 37, fig. 3) a figure of a specimen from station 5440 in which the radial shields show a covering of rather closely crowded club spines, and another from station 5536 (fig. 2) in which, conversely, the club spines are rare and very small on the radial shields the surface of which is almost naked and which are relatively larger. Isolated and examined under the microscope these club spines show variations of importance only in their dimensions (pl. 97 , fig. $5 a$ ), some remaining very short, others becoming rather long and relatively rather slender; they usually have three or four terminal spinules. At some distance from the disk the first ventral arm spine is transformed into a hook with three branches of the form most usual in the genus Ophiothrix (fig. 5b). The tentacle scale is large and rounded $(c)$. 
The Challenger discovered 0 . capillaris in $12^{\circ} \mathrm{N}$. latitude and $122^{\circ}$ E. longitude at a depth of 182 to 210 meters (100 to 115 fathoms); she found it again at Cebu in 182 meters (100 fathoms). The Siboga found the species in the Sunda Archipelago in about $5^{\circ} \mathrm{S}$. latitude and $132^{\circ} \mathrm{E}$. longitude at a depth of 304 to 310 meters (166 to 169 fathoms).

\section{OPHIOTHRIX CORONATA Køhler.}

Plate 40 , fig. 5 ; plate 41 , figs. $1-4$; plate 98 , fig. 1 .

Ophiothrix coronata Kamler ('05), p. 91, pl. 9, figs. 8, 9.-H. L. ClakK ('15), p. 280.

Locality.-Albatross station 5108; China Sea, off southern Luzon; Corregidor Light bearing N. $39^{\circ}$ E., 41.70 kilometers (22.5 miles) distant (lat. $14^{\circ} 05^{\prime} 05^{\prime \prime} \mathrm{N}$., long. $120^{\circ} 19^{\prime} 45^{\prime \prime}$ E.) ; 24 meters (13 fathoms) ; January 15, 1908; Co.

One specimen.

No locality.

One specimen (Cat. No. E. 8, U.S.N.M.).

Notes.-The diameter of the disk in the specimen from station 5108 is $7 \mathrm{~mm}$.; the arms are broken off at a greater or lesser distance from the base, and the largest is preserved for almost $50 \mathrm{~mm}$. of its length. The specimen shows a bluish-gray coloration, with narrow reddish annulations at intervals on the dorsal surface of the arms, which is covered with small very closely crowded spinulate club spines.

The specimen without locality was associated with the Ophiothrix which I have described above under the name of 0 . bellax; it is larger than that from station 5108, the diameter of its disk reaching $14 \mathrm{~mm}$., and the arms exceeding $110 \mathrm{~mm}$. in length. The general coloration is a rather dark pink on the dorsal surface of the disk and arms; the ventral surface is lighter.

The characters of these two specimens agree well with those of the Siboga specimen which served me as the type of $O$. coronata, and I believe it necessary to refer them to this species rather than to $O$. demessa. The arm spines are very long, their length exceeding three segments; the under arm plates are markedly longer than broad. I have not thought it necessary to separate these two specimens in spite of the difference in coloration, for their morphological characters are absolutely identical. They are very different in size, and the smaller, while showing a general blue color, has reddish tints which recall the general coloration of the larger.

The type specimen of $O$. coronata was found by the Siboga in the Sunda Archipelago (lat. $0^{\circ} \mathrm{N}$., long. $130^{\circ} \mathrm{E}$.) at a depth of 83 meters (47 fathoms).

The microscopical characters of the club spines which cover the disk, of the arm spines, etc., are identical in the two specimens; they 
usually terminate in three much elongated, pointed, and rather stout spinules (pl. 98, fig. 1b). The small club spines of the dorsal surface of the upper arm plates are short, rather broad, and carry two or three rather well developed and subequal spinules (fig. 1a).

In both specimens the first ventral spine rapidly becomes converted into a hook resembling that which $I$ have described in $O$. aspidota; that is to say, it shows on its concave border seven or eight parallel points, while its convex border bears toward the tip two or three asperities (pl. 98, fig. 1c). The tentacle scale is large and elongated, terminated sometimes by a single elongated point, sometimes by two or three unequal points $(e)$.

\section{OPHIOTHRIX CRASSISPINA Kœhler.}

Plate 49, figs. $1-6$; plate 50 , fig. 1 ; plate 52 , figs. $3-5$; plate 98 , fig. 2.

Ophiothrix crassispina KGHLER ('04), p. 147, pl. 28, figs. 3-5; pl. 29, fig. 1; pl.. 30, fig. 4.-H. L. Clark ('15), p. 280.

Localities.-Albatross station 5168; Sulu (Joló) Archipelago, Tawi Tawi Group; Observation Island bearing N. $17^{\circ}$ W., 7.78 kilometers (4.2 miles) distant (lat. $4^{\circ} 56^{\prime} 30^{\prime \prime} \mathrm{N}$., long. $119^{\circ} 45^{\prime} 40^{\prime \prime} \mathrm{E}$.) ; 146 meters (80 fathoms); February 25,1908 ; co. S.

Four specimens (Cat. No. E. 144, U.S.N.M.).

Albatross station 5170; Sulu Archipelago, Tawi Tawi Group; Sibutu Island (south end) bearing N. $38^{\circ}$ E., 25.02 kilometers (13.5 miles) distant (lat. $4^{\circ} 28^{\prime} 00^{\prime \prime} \mathrm{N}$., long. $119^{\circ} 19^{\prime} 30^{\prime \prime}$ E.) ; 234 meters (128 fathoms); February 27, 1908; crs. S.

One specimen (Cat. No. E. 145, U.S.N.M.).

Notes.-The specimens are of different sizes; in the largest the diameter of the disk is $7.5 \mathrm{~mm}$, and the arms are between $30 \mathrm{~mm}$. and $35 \mathrm{~mm}$. in length; in the others the diameter of the disk varies between $6 \mathrm{~mm}$. and $4 \mathrm{~mm}$.

They agree well with the type which I described from two specimens collected by the Siboga in the Sunda Archipelago, in which the diameter of the disk varies between $7 \mathrm{~mm}$. and $9 \mathrm{~mm}$.

The photographs which I reproduce here (pl. 49, figs. 1-6; pl. 50, fig. 1 ; pl. 52, figs. $3-5$ ) render it unnecessary for me to describe the modifications of the arm spines; it is sufficient to complete in certain respects my description of 1904 .

I described the arm spines as eight in number, adding that the length increased from the first to the sixth; this progressive elongation may be especially well appreciated on the photograph representing a fragment of an arm seen from the ventral surface (pl. 52, fig. 5 ), and it will be remarked that the three first spines remain very short. I emphasize this character, as well as the number of the arm spines, which will permit us to separate $O$. crassispina from the new 
species which I am describing below under the name of $O$. cumulata, in which the dorsal spines are sometimes thickened.

In my description of $1904 \mathrm{I}$ did not mention that the upper arm plates may show on their distal border a row of extremely fine spines, which, however, are not constant, but which I usually find on the specimens collected by the Albatross; perhaps these spines did not occur on the Siboga specimens. They appear to be, however, more developed in the younger individuals, and they occur only for a certain distance beyond the arm bases. Thus on the smallest of the Albatross specimens these spines are very evident (pl. 52, fig. 4) and on one of the arms they even occur beginning with the third segment, where they are two or three in number, becoming more numerous and more obvious in the distal half of the arms; their number and their size varies, however, with the individual, and as a rule they only appear on the segments the arm spines of which are not thickened.

The thickening of the arm spines appears certainly to depend on the age of the individuals, as I wrote in 1904; however, this thickening does not appear to be exactly proportionate to the size of the specimens. In all those collected by the Albatross the dorsal spines are strongly thickened and shortened in the proximal portion of the arms; the thickening occurs on the last dorsal spine and sometimes also on that preceding the last, where it is, however, a little less accentuated. The degree of thickening varies somewhat and it is not entirely proportional to the size of the specimen. This thickening is very marked in the largest individuals in which the disk reaches $7.5 \mathrm{~mm}$. in diameter ( $\mathrm{pl} .49$, figs. 4,5 ), but it is equally marked in a smaller specimen in which the disk is only $5.5 \mathrm{~mm}$. in diameter (fig. 6). It is slightly accentuated in a specimen in which the diameter of the disk is $5 \mathrm{~mm}$., while in another in which this diameter reaches only $4.5 \mathrm{~mm}$. it is more marked (pl. 49, fig. 3 ; pl. 52, fig. 5.). A single specimen, in which the disk is $4 \mathrm{~mm}$. only in diameter (fig. 2), has the dorsal spines scarcely modified; however the indication of a tendency toward thickening may be noticed.

On plate 98 as figure $2 c$ I give some photographs of the club spines of the dorsal surface of the disk, which are always very short; they are cylindrical, almost as high as broad, and carry on their outer surface short and conical subequal spinules. The hook which represents the first ventral arm spine, while agreeing with the type most frequent in the genus Ophiothrix, is remarkable for the great development of the terminal branch, while the two others remain very short and very narrow (fig. 2b). The tentacle scale is stout and rounded, provided on its free border with a few short, conical, and unequal points $(a)$. 
The type series was collected by the Siboga in latitude $8^{\circ} 19^{\prime} \mathrm{S}$. and longitude $117^{\circ} 41^{\prime}$ E., at a depth of 274 meters (150 fathoms).

OPHIOTHRIX CUMULATA, new species.

Plate 50 , figs. $2-8$; plate 51 , figs. $1-5$; plate 52 , figs. 1,2 ; plate 98 , fig. 3.

Localities.-Albatross station 5112.

Three specimens (Cat. No. E. 15, U.S.N.M.).

Albatross station 5212; east of Masbate Island; Panalangan Point bearing $\mathrm{S} .54^{\circ} 30^{\prime}$ E., 26.87 kilometers (14.5 miles) distant (lat. $12^{\circ}$ $04^{\prime} 15^{\prime \prime}$ N., long. $124^{\circ} 04^{\prime} 36^{\prime \prime}$ E.) ; 197 meters (108 fathoms) ; April 20, 1908; gy. S., M.

Twenty-six specimens (Cat. Nos. 41068, E.14, E. 21, U.S.N.M.). Albatross station 5265 .

Twenty-seven specimens (Cat. No. E.16, U.S.N.M.).

Description.-The diameter of the disk varies between $10 \mathrm{~mm}$. and $13 \mathrm{~mm}$. in the majority of the specimens; the arms reach $70 \mathrm{~mm}$. in length in an individual in which the disk has a diameter of $13 \mathrm{~mm}$. In the smallest the diameter reaches only $8 \mathrm{~mm}$. and the length of the arms varies between $40 \mathrm{~mm}$. and $45 \mathrm{~mm}$.

The disk usually has a pentagonal outline, though sometimes it is rounded. The dorsal surface between the large radial shields is covered with small and very short club spines, which are almost as long as broad and to which might well be given the name of elongated granules; their outer surface carries a number of closely crowded spinules, usually short and single, but capable of elongating somewhat (pl. 50, figs. 6,$7 ; \mathrm{pl} .98$, fig. 3 a). In the smallest specimens the club spines are a little more elongated, and the spinules are a little stouter than in the larger ones, but these club spines scarcely become elongate at the periphery of the disk, and do not pass over onto the ventral surface, which is naked. The radial shields are very large, triangular, almost twice as long as broad, and their length equals three-quarters of the radius of the disk. The two shields of each pair are in contact outwardly, and are separated throughout their whole length by a narrow interval. In the small specimens these shields are relatively less developed. As a rule the surface of the radial shields is naked, though sometimes a few club spines may be found, especially toward their proximal angle.

The ventral surface of the disk in the interradial spaces is almost entirely naked except for a very small triangular space toward the periphery (pl. 51, figs. 3,4). The genital slits are broad.

The rather small mouth shields are lozenge-shaped, a little broader than long, with two slightly excavated proximal borders; the two distal sides have a somewhat variable form, and the distal angle is produced into the interradial space as a more or less apparent small 
rounded lobe (pl. 51, figs. 3, 4). In the specimen shown in figure 3 it is noticeable that two of the mouth shields are malformed; one of them bears the madreporic pore, and it is not surprising that it should be deformed; but its shape differs from that which I notice on the specimen represented in figure 4 , and it is especially developed obliquely toward the right anterior radius. Furthermore the two adjacent adoral plates are smaller than the others, and are widely separated from the median interradial line. The mouth shield of the neighboring interradius also shows an abnormal outline; it is larger than the others, and its outline is asymmetrical. The adoral plates, which are rather small, are triangular, broadened outwardly, and terminate in a rounded angle; they are not in contact with each other in the median interradial line. The oral plates are high. The tooth papillae are very numerous, and within the two lateral rows, which are very regular in arrangement, there may be counted four and sometimes even five more or less irregular rows.

The dorsal surface of the arms is flattened. The upper arm plates are large, lozenge-shaped, very much broader than long, with the proximal angle truncated and the distal angle rounded; the lateral angles are rather sharp; they are all in contact. The distal border of these plates bears a variable number of small spinules which are short, conical, and pointed. Toward the base of the arms these spinules generally remain localized on the rounded distal angle of the dorsal plates, from which they progressively extend over the sides of these plates.

The first under arm plate is small, square, with the angles and the sides somewhat rounded; the proximal border is sometimes slightly notched. The second plate is elongated, a little broader at its distal extremity than proximally, with a narrow and straight proximal border and a more or less convex distal border, which sometimes resolves itself into two sides passing into each other over an obtuse angle; the two lateral borders are divergent. The third plate is almost as broad as long, with a rounded distal border and slightly divergent sides. Beyond this the plates become markedly broader than long, with the proximal border slightly concave and shorter than the distal border, which is broadened and convex; the lateral angles are much rounded. All these plates are in contact.

The rather strongly projecting side arm plates bear very much developed spines, of which the number may reach the figure eight on the first segments; but this figure falls very rapidly to six. The length of these spines increases very rapidly from the first ventral spine to the fourth; the two following are the longest, and the last dorsal spine is a little shorter than the preceding. The very rapid increase in length which the arm spines show from the first ventral upward, the second spine already sometimes attaining the length of 
the corresponding under arm plate, may be appreciated from the different photographs which I include (pl. 51, figs. 1-4; pl. 52, figs. 1, 2). The longest lateral spines may reach and even exceed a length of five segments. These spines are cylindrical, rather slender, with the tip rounded, and they are provided throughout their whole length with rather fine and closely placed denticulations.

These are the characters of the spines seen on individuals which may be considered as typical, as those of which I include photographs on plate 51, as figures 1, 2, and on plate 52, as figure 1. But in a certain number the dorsal spines undergo a remarkable transformation; they shorten and thicken considerably, as in the case in the individual represented on plate 50 as figures 2,3 . This modification takes place especially on the last dorsal spine, which may become almost globular; the one before the last is also shortened and thickened, though in a much less marked manner. This transformation of the dorsal spines appears only on the twelve or fifteen first arm segments; beyond that the dorsal spines preserve their usual character. The transformation is progressive, beginning on the second or third segment, the spines being at first slightly thickened, the thickening becoming rapidly accentuated and the spines retaining the same characters for about twelve segments, then little by little reassuming their normal size and length. The specimens which show this modification thus greatly resemble 0 . crassispina, which I have just discussed, but they can not be assigned to that species for the reasons which I shall give further on.

This remarkable thickening of the dorsal spines does not show itself by any means on all the specimens collected by the Albatross. In the 20 which the collection contains, 14 have normal spines, and only four have the dorsal spines modified in the way which $I$ have just described, and which my photographs show. On two others a shortening and thickening of the spines may be also observed, but the modification is very much less marked. It is rather well shown in the specimen figured on plate 50 , figure 5 , but it only appears on three arms, while the fourth is normal, and the fifth is lacking; in the other specimen, which is shown on plate 51 , figure 1 , it may be seen that the dorsal spines are not as long as usual at the base of the arm, and some of them already show traces of a slight thickening.

I notice that in the regions where the dorsal spines are thickened the corresponding upper arm plates are also slightly modified; they are a little less broad and more projecting than usual, and their distal border is entirely without spinules.

The first ventral spine does not transform into a hook until some distance from the disk; this hook is rather slender, but elongated, and shows four branches, the last large and stout, the following smaller, and two others very short and very narrow (pl. 98, fig. $3 b$ ). 
The tentacle scale in all the specimens is large and very evident; it is rounded or slightly oval (p. 98, fig. $3 d$ ).

The color of the specimens in alcohol is gray or yellowish gray.

Affinities and distinctive features.-Ophiothrix cumulata naturally approaches $O$. crassispina because of the thickening of the dorsal spines observable in certain specimens. The individuals in which the dorsal spines are thickened indeed strongly recall $O$. crassispina, the more so since also in this latter the upper arm plates at the base of the arms are without spinules on their distal border, these spinules not appearing for some distance beyond the disk; the armature of the dorsal surface of the disk also shows a very strong similarity in the two species. But the other characters are very different. Only a small number of individuals of $O$. cumulata show the dorsal spines thickened, while all the known specimens of $O$. crassispina have this character, and it is already manifest in individuals of very small size. That which constitutes an anomaly in the first species becomes the rule in the second. In O. cumulata the arms are relatively longer, and the dorsal spines are longer, more slender, and more finely denticulate; the specimens have a more robust appearance and may reach a larger size. In $O$. crassispina the individuals do not seem to exceed a rather small size, and in the largest which was dredged by the Siboga the diameter of the disk is only $9 \mathrm{~mm}$. To appreciate fully the differences between the two species, it is well to compare individuals of the same size, and there fortunately exists in the Albatross collection a specimen of $O$. cumulata in which the diameter of the disk is $7 \mathrm{~mm}$. I give a photograph of this specimen on plate 51 as figure 2. By comparing it with the specimen of 0 . crassispina shown on plate 49 as figure 4 , in which the diameter of the disk is also $7 \mathrm{~mm}$., it is made clear that the two can not be referred to the same species, even without invoking the thickening of the spines which occurs only in the specimen of $O$. crassispina. The form of the upper arm plates is entirely different in the two species; in 0 . crassispina they are less broad and more elongated, their surface is more convex, their lateral angles are less sharp and their distal border is convex. The number of arm spines is larger in the first species, but especially the increase in their length takes place in a very much more gradual manner. The comparison of the two photographs which I give here (pl. 52, figs. 2, 5) is very interesting from this point of view; it may be seen that in $O$. crassispina the three first spines are very short, and that the third does not reach even the length of the corresponding under arm plate, while in 0 . cumulata the second spine is very much longer than the first, and attains the length of that plate. The hook formed by the first ventral spine is more elongated in $O$. cumulata, where it shows typically four branches, the two outer well developed, while in 0 . crassispina this hook has only three branches, 
the outermost only being well developed. I also notice that the ventral surface of the disk is in part covered with club spines identical with those of the dorsal surface in 0 . crassispina, while in $O$. cumulata it is almost entirely naked; but this character has no great value.

I may add that the coloration of these two species may be quite different in the living animal, at least judging from the specimens in alcohol; these are quite white in $O$. crassispina, while they all retain a grayish-yellow coloration in 0 . cumulata.

For these reasons I believe it necessary to separate 0 . cumulata from 0 . crassispina and to consider that the remarkable transformation that the dorsal spines in certain specimens of the former undergo is fortuitous and does not constitute a specific character.

We must therefore inquire to what cause may be due the thickening of these spines. The first idea which naturally comes to mind is that this thickening is induced by a parasite, especially when one recalls the modification described by Mortensen and by myself which the spines of certain Antarctic species of Clenocidaris and Rhynchocidaris undergo under the influence of a parasite called by Mortensen Echinophyces mirabilis (see Mortensen '10, p. 12; Mortensen and Kolderup Rosenvinge '10, p. 339; Kœhler '12, p. 154). But this is not the case. I have examined under the microscope a number of sections made of the thickened spines of 0 . cumulata and I have not been able to observe the least trace of a parasite. These spines are solid; they are formed of a perfectly regular calcareous substance composed of rods radiataing from the center to the periphery, and they do not show the least trace of foreign bodies, as may be seen in the photograph which I give here (pl. 50, fig. 4).

The thickening of the dorsal spines in certain specimens of $O$. cumulata seems to be rather to be compared with that known in certain species of Ophiocoma, and in particular in $O$. scolopendrina. In this species some specimens have the last dorsal spine very short, thickened, and strongly swollen, while in others this spine is scarcely modified in its form, or even remains quite cylindrical and elongated. This modification of the dorsal spine in 0 . scolopendrina and in other related species ${ }^{\theta}$ is quite individual and has no specific significance The only difference to be remarked is that the thickening of the dorsal spine shows itself somewhat irregularly in the specimens of Ophiocoma in which it occurs, while in O. cumulata when the modification is produced it involves all the successive dorsal spines of the bases of the arms, which all show, over a considerable distance and in the most regular manner, the same transformation.

- I shall notice further on the simflar variations in the two dorsal spines of ophiocoma lineolata. 
Can there be a relation between age, or perhaps even between the sex, of the individuals and the transformation of the dorsal spine? Are all the individuals destined to undergo this transformation or does it only take place accidentally and then under the influence of certain conditions? These are questions which I can not answer.

\section{OPHIOTHRIX DECEPTOR, neW species.}

Plate 58 , figs. 1,2 ; plate 97 , fig. 6.

Locality.-Albatross station 5414; between Cebu and Bohol; Lauis Point Light bearing N. $67^{\circ}$ W., 17.60 kilometers (9.5 miles) distant (lat. $10^{\circ} 10^{\prime} 40^{\prime \prime}$ N., long. $124^{\circ} 02^{\prime} 45^{\prime \prime}$ E.) ; no depth given; March $24,1909$.

One specimen (Cat. No. E.13, U.S.N.M.).

Description.-The diameter of the disk is $5 \mathrm{~mm}$; the arms are thin and slender, from $30 \mathrm{~mm}$. to $32 \mathrm{~mm}$. long.

The disk is subpentagonal, with the sides slightly excavated. The dorsal surface between the very large radial shields is covered with very small unequal plates rounded in the central region and becoming elongated and extremely narrow in the interradial spaces; the outlines of these plates are not very evident, for they are covered by a thin integument. A certain number bear a rather large, projecting granule, which is somewhat conical, with the extremity rounded. At the periphery of the disk, outside the radial shields and in the interradial spaces, the plates become very thin and transparent, short and transversely broadened, and they form a continuous covering on which may be perceived here and there a very small conical and pointed granule which is very much smaller than those of the rest of the dorsal surface. The radial shields are very large and they cover a large part of the dorsal surface of the disk; the radial and interradial spaces are very narrow. The two shields of each pair are in contact by their external angle, thence separating slightly, especially because of the slightly concave form of their internal border; the outer angle of each shield is separated from the corresponding angle of the shield of the neighboring pair by a very narrow interval; from that point onward the interradial spaces progressively increase somewhat. The shields themselves are triangular, with a pointed proximal angle and a concave distal border; they are longer than broad, and their length reaches or exceeds two-thirds of the radius of the disk. Their surface is entirely naked.

The ventral surface of the disk is covered with extremely small, thin, transparent, slightly imbricated, and very narrow plates. The genital slits are broad and very evident.

The mouth shields are short and much broadened, almost three times as broad as long, with a rather sharp proximal angle projecting 
somewhat between the adoral plates; this angle is bounded by slightly excavated sides; the lateral angles are rounded, and the distal border is slightly convex. The adoral plates are elongated and rather narrow, a little tapering inwardly, and they terminate in rounded angles which are not in contact in the median interradial line; these plates are broadened outwardly, and they send off a very narrow process which separates the mouth shield from the first side arm plate. The oral plates are high and rather broad. The tooth papillae at first form two regular lateral rows, within which the other papillae form sometimes one, and sometimes two, very irregular rows.

The upper arm plates are lozenge-shaped, longer than broad, with the proximal angle truncated; the two proximal borders are markedly longer than the two distal borders, and the maximum width of the plate is nearer the distal angle, which is obtuse. All these plates are in contact.

The first under arm plate is pentagonal, a little longer than broad, with a very obtuse proximal angle bounded by two straight sides; the lateral borders are convergent and straight, and the distal side is also: almost straight. The following plates are very large and elongated, longer than broad, with a straight proximal border, a very broad and convex distal border, and divergent sides excavated by the tentacle pores. These plates are separated by a narrow interval occupied by soft tissue.

The rather strongly projecting side arm plates carry at the base of the arms five slender transparent and pointed spines. The first ventral spine is very short and is almost immediately transformed into a hook; beyond the disk the length of the following spines increases rapidly from the second, which is shorter than the segment, to the last, the length of which reaches four segments. These spines are smooth in their proximal portion, and in their distal half are furnished with very strong and sharp well spaced teeth.

There is a small, rather thin, pointed and spiniform tentacle scale (pl. 97, fig. 6c), but it appears to be absent on the three first arm segments; this scale can never be mistaken for the first ventral spine, which is very rapidly converted into a three branched hook (fig. $6 a$ ).

The general color is pinkish gray. A large brownish-purple spot appears toward the distal angle of the upper arm plates, but there is no continuous median line. The ventral surface is pink; a somewhat darker median line interrupted toward the distal border of each ventral plate runs all along the arms. The spines are pink and sometimes show slight purple annulations.

Affinities and distinctive features.-Ophiothrix deceptor is especially close to O. lepida Loriol, O. fallax Loriol, and O. purpurea Martens. It is immediately distinguished from 0 . lepida by the 
size and width of the radial shields, as well as by the form of the upper arm plates in which the broadest part is close to the distal border, and by the dorsal surface of the disk which is entirely without spines and only shows small granules. The coloration is also different. In the development of the radial shields 0 . deceptor recalls more especially $O$. fallax, but it is distinguished from that species by having the under arm plates longer and the radial and interradial spaces of the dorsal surface of the disk more reduced, by the absence of spines on the dorsal surface of the disk, by having the ventral surface of the disk furnished with very small, though evident, plates, and by the form of the upper arm plates of which the maximum width is close to the distal border, while according to de Loriol's figures this maximum occurs towards the middle of the plate in 0 . fallax. It is distinguished from 0 . purpurea, which has, like itself, large radial shields, by the very different coloration, by the absence of spines on the disk, and by having the upper and under arm plates longer than broad.

\section{OPHIOTHRIX ELEGANS Lütken.}

Plate 56, figs. 1-3.

\section{See for bibliography:}

Ophiothrix elegans KaHLER ('04a), p. 110, fig.-H. L. CLARK ('15), p. 271.

Locality.-Albatross station 5179; Romblon Light bearing S. $56^{\circ}$ E., 8.34 kilometers ( 4.5 miles) distant (lat. $12^{\circ} 38^{\prime} 15^{\prime \prime} \mathrm{N}$., long. $122^{\circ}$ $12^{\prime} 30^{\prime \prime}$ E.) ; 67 meters (37 fathoms) ; March 25,1908 , hrd. S.

One specimen (Cat. No. 41014, U.S.N.M.).

Notes.-I have thought it best to refer to Ophiothrix elegans a specimen of small size of which the color pattern forcibly recalls Lütken's description. The diameter of the disk is $5 \mathrm{~mm}$., and the arms are scarcely $20 \mathrm{~mm}$. long. The dorsal surface of the disk is uniformly covered with small club spines ending in three or four fine, divergent, subequal, and rather elongated spinules. These club spines occur also on the radial shields, but they are there less closely crowded. They elongate somewhat toward the borders of the disk, and become longer on the ventral surface, which they cover in large part; they are always terminated by three or four elongated spinules. The outlines of the upper and under arm plates, as well as those of the mouth plates, the arm spines, etc., show well all the characters which I described in $O$. elegans in 1904 from the type specimen in the Copenhagen Museum ('04a, p. 110). I may notice only that the distal border of the under arm plates is a little more rounded.

The general color is pinkish gray on the dorsal surface. A darkbrownish purple band runs all along the median line of the arms and extends to the neighborhood of the center of the disk. This 
band is much broadened, and its borders are indefinite; they are not quite so clearly defined as in the type specimen.

This specimen differs from the type of $O$. elegans by a slight dissimilarity in the armature of the disk, which consist exclusively of club spines; these become stouter on the ventral surface, and in the broadening of the dark band which runs along the middle of the dorsal surface of the arms.

Lütken's type came from the China Sea.

\section{OPHIOTHRIX EXIGUA Lyman.}

Plate 40 , figs. $1-4$; plate 98 , fig. 4.

See for bibliography:

Ophiothrix exigua KäHLER ('05), p. 86, pl. 9, figs. 15, 16; ('05b), p. 458; ('07), p. 332.-MCINTosh ('11), p. 164.-H. L. ClaRK ('15) p. 272 ; ('15a), p. 90 .

Localities.-Albatross station, 5160; Sulu (Joló) Archipelago, Tawi Tawi Group; Tinakta Island (N.) bearing S. $72^{\circ}$ W., 5.10 kilometers (2.75 miles) distant (lat. $5^{\circ} 12^{\prime} 40^{\prime \prime} \mathrm{N}$., long. $119^{\circ} 55^{\prime} 10^{\prime \prime} \mathrm{E}$.) ; 22 meters (12 fathoms); February 22, 1908; S.

One specimen (Cat. No. 41300, U.S.N.M.).

Albatross station 5181; off eastern Panay; Antonio Island (S.) bearing S. $63^{\circ}$ W., 12.23 kilometers ( 6.6 miles) distant (lat. $11^{\circ} 36^{\prime}$ $40^{\prime \prime}$ N., long. $123^{\circ} 26^{\prime} 35^{\prime \prime}$ E.) ; 47 meters (26 fathoms) ; March 27, 1908; M., fne. S.

Two specimens (Cat. No. 41298 , U.S.N.M.).

Albatross station 5401; north of Cebu; Tanguingui Island Light bearing $\mathrm{N} .79^{\circ} \mathrm{W}$., 42.62 kilometers (23 miles) distant (lat. $11^{\circ} 24^{\prime}$ $45^{\prime \prime} \mathrm{N}$., long. $124^{\circ} 06^{\prime} 00^{\prime \prime}$ E.) ; 55 meters (30 fathoms); March 16, 1909 ; fne. S.

Two specimens (Cat. No. 41299, U.S.N.M.).

Philippines, without further locality.

One specimen (Cat. No. 41297, U.S.N.M.).

Notes.-The specimens are well characterized. The dorsal surface of the disk shows only slender club spines terminated by elongated spinules.

In previous memoirs I have already discussed the characters of 0 . exigua. As this species has often been confused with other species of Ophiothrix, notably by Marktanner and by de Loriol, who have not distinguished it from 0 . comata, it has seemed to me worth while to include here some photographs of the Albatross specimen. The under arm plates always have their distal border more or less strongly notched, and it is noticeable that this notching is particularly deep in the specimen from station 5160, shown in figure 4. 
On plate 97 , as figure 4 , I give some photographs of the trifid club spines of the dorsal surface of the disk $(a)$, of the hook which the first under arm spine very rapidly forms and which has three or four branches $(b)$, of the second and third arm spines $(c)$, and of the small tentacle scale which has a very long point ( $d)$.

Ophiothrix exigua appears to be very widespread throughout the whole Indo-Pacific region; it is known to occur in the Red Sea, in the Philippines, in the Mergui Archipelago, and at numerous stations in the Sunda Islands, where the Siboga found it between 0 and 36 meters ( 0 to 20 fathoms). It is always littoral.

OPHIOTHRIX EXPEDITA Kohler.

Plate 31 , fig. 6 ; plate 33 , fig. 5 ; plate 98 , fig. 5 .

Ophiothrix expedita Konler ('05), p. 96, pl. 9, figs. 10-14; pl. 15, fig. 5; ('10), p. 294.-H. L. Clark ('15), p. 272.

Localities.-Albatross station 5147; Sulu (Joló) Archipelago, in the vicinity of Siasi ; Sulade Island (E.) bearing N. $3^{\circ}$ E., 15.57 kilometers (8.4 miles) distant (lat. $5^{\circ} 41^{\prime} 40^{\prime \prime}$ N., long. $120^{\circ} 47^{\prime} 10^{\prime \prime}$ E.) ; 38 meters (21 fathoms) ; February 16, 1908; co. S., Sh.

One specimen (Cat. No. 41390 , U.S.N.M.).

Albatross station 5149; Sulu Archipelago, in the vicinity of Siasi; Sirun Island (W.) bearing N. $39^{\circ}$ E., 4.45 kilometers (2.4 miles) distant (lat. $5^{\circ} 33^{\prime} 00^{\prime \prime}$ N., long. $120^{\circ} 42^{\prime} 10^{\prime \prime}$ E.) ; 18 meters (10 fathoms); February 18, 1908; Co., Sh.

One specimen (Cat. No. 41388, U.S.N.M.).

Albatross station 5165; Sulu Archipelago; Tawi Tawi Group; Observation Island bearing N. $70^{\circ} \mathrm{W} ., 11.86$ kilometers (6.4 miles) distant (lat. $4^{\circ} 58^{\prime} 20^{\prime \prime} \mathrm{N}$, long. $119^{\circ} 50^{\prime} 30^{\prime \prime}$ E.) ; 16 meters (9 fathoms); February 24, 1908; Co.

One specimen (Cat. No. 41389, U.S.N.M.).

Notes.-The three specimens agree perfectly in morphological characters, as well as in coloration, with the type which I described from the specimens collected by the Siboga at different stations in the Sunda Archipelago. In the specimen from station 5149, which is the largest, the diameter of the disk reaches $19 \mathrm{~mm}$.; the two others are smaller.

The photographs which I give here will complete the notes which I have already given on $O$. expedita. It will be noticed that the hook formed by the first ventral arm spine (pl. 98, fig. $5 d$ ) by the rather numerous points along its concave border strongly recalls the form which $I$ have described in $O$. aspidota and in $O$. coronata, and which we find again in 0 . longipeda and in 0 . puncto-limbata.

The dorsal surface of the disk bears club spines mixed with true spines, which are sometimes very long and which are more or less 
numerous, according to the individual. The club spines properly so called maintain a rather regular length of from $0.25 \mathrm{~mm}$. to $0.30 \mathrm{~mm}$. in the large specimens; they are conical and usually bear three subequal points. The longest club spines may attain and even surpass $1 \mathrm{~mm}$. in length.' Others are shorter. All transitional forms may be observed (pl. 98, figs. $5 a$ and $b$ ). The oval tentacle scale shows on its free border a few short, conical, and pointed spines (fig. $5 e$ ).

OPHIOTHRIX EXPEDITA, var. RHABDOTA (H. L. Clark).

Plate 31, fig. 5.

Ophiothrix rhabdota H. L. ClakK ('15), p. 278, pl. 13, fig. 4.

Locality.-Marrougas; shore; from a coral head.

Two specimens (Cat. No. E 340, U.S.N.M.).

Philippines.

One specimen (Cat. No. E. 363, U.S.N.M.).

Notes.-One of the specimens is in a very fine state of preservation, and the arms are almost all complete; the diameter of the disk is 13 $\mathrm{mm}$., and the arms are from $250 \mathrm{~mm}$. to $300 \mathrm{~mm}$. long. The other specimen, which is a little smaller, is in rather poor condition; the. disk is deformed, and its dorsal surface is strongly wrinkled; the arms are broken off at a rather short distance from their base.

The dorsal surface of the disk is covered with small, short, slender, and pointed spines, showing a certain number of conical and rather strong teeth. In the midst of these spines are found small club spines terminated by a few unequal and rather strong spinules; all intermediate forms between the true spines and the club spines occur, exactly as in the type. The club spines persist on the radial shields, and, as they are not very closely crowded, the outlines of these shields are easily visible. On the largest specimen they are rather large and triangular; the internal border is slightly concave, the external border is rather strongly concave, while the third, or interradial, edge is almost straight; this last is markedly longer than the distal border; because of this the interradial angle is very close to the periphery of the disk and lies almost at a level of one-third of the length of the shields. In the other specimen the radial shields appear a little more elongated, but the disk is deformed in such a way that the exact shape of these shields can be ascertained only with difficulty. The photograph of the dorsal surface of $O$. rhabdota published by H. L. Clark ('15, pl. 13, fig. 4) shows clearly enough the outlines of the radial shields, and it seems to me that the form of these shields is close to that which I describe, but the distal and interradial angle is a little nearer the middle of the shield, without, however, being exactly at the middle.

I have described carefully the form of the radial shields in $O$. rhabdota because I hoped that they would furnish characters which 
would permit of distinguishing it from 0 . expedita. Generally speaking, the radial shields of this last named species are relatively somewhat more elongated; they occur in the form of a very flattened isosceles triangle of which the base is turned from the radial side and of which the very rounded apex is situated almost in the middle of its length. This apex is thus a little further from the periphery of the disk than in 0 . rhabdota, but I do not believe that this character, which is not very reliable, can be utilized to separate these two species of Ophiothrix.

In the largest of the specimens collected by the Albatross the general coloration is bluish gray. The dorsal surface of the disk is a rather dark gray, and the radial shields are lighter with a bluish tinge. The arms show, on the dorsal surface, three longitudinal light lines, which, in the alcoholic specimen, are white and stand out clearly from the blue background. 'The white bands are not absolutely continuous, and they are interrupted at the line of separation of the successive upper arm plates; the median band is a little broader than the others. On the other specimen the three lines are narrower, while the two blue bands which border the median white band on either side are more marked and broader, and their outlines are a little clearer. Beside these very constant lines, there are on both specimens indications of rings alternately a little lighter and a little darker. $A$ white band runs all along the ventral median line of the arms and is bordered on either side by a blue line beyond which is found on each segment an elongated white spot. On the ventral surface of the arms also traces of rings are to be seen, and in the large specimen these annulations are alternately blue and reddish, the blue portions being slightly washed with white; furthermore, in this same individual, the arm spines are slightly washed with red at the base, and this red coloration shows itself especially in the distal half of the arms. On the smaller individual the white and blue lines of the ventral surface of the arms are better marked than in the other, the blue color being somewhat more intense, but it is not mixed with red and the annulations are alternately blue and white.

H. L. Clark does not seem to have proposed O. rhabdota without a certain amount of hesitation, and according to him this species is only distinguished from various forms of the $O$. longipeda group by its coloration and especially by the three light lines which run along the whole length of the dorsal surface of the arms. These lines, which are white in alcoholic specimens, are yellowish in the living animal. The general coloration of the specimens is not indicated by Clark in his description, but he informs me by letter that that color was blue. The color scheme which I find in my specimen is thus very similar to that of the specimen studied by H. L. Clark. 
Among the species of Ophiothrix of the 0 . longipeda group a single one shows three light lines extending longitudinally over the dorsal surface of the arms. This is 0 . expedita which I described from specimens discovered by the Siboga in the Sunda Archipelago, and which has since been rediscovered at the Aru Islands; this species occurs also in the Albatross collection, as I have noted above.

Apart from the general coloration, which differs in $O$. expedita and 0 . rhabdota, the ornamentation of the arms is the same in the two species; I am convinced that if the specimens studied by H. L. Clark had been red instead of blue he would not have hesitated to apply to them the name of $O$. expedita. Can a difference be found to separate these two forms other than that shown by the coloration? I must state first of all that $O$. expedita shows in all its morphological characters, as well as in its coloration, a remarkable constancy. The individuals collected by the Siboga at 10 different stations in the Sunda Archipelago at depths varying between 13 and 73 meters, those which I have recorded from the Aru Islands, and those collected by the Albatross are quite identical and do not show the least trace of variation; it may be noted, furthermore, that the general red coloration is sometimes rather bright, and sometimes darker and verging toward brown; this may depend on the preservation, and also on the age of the individuals. I note also that the two dark lines which extend on either side of the median longitudinal white line of the arms are sometimes perfectly continuous, and sometimes interrupted, and that their borders are sometimes straight and sometimes slightly sinuous; these details are of no importance. I have compared with the greatest care the different specimens of $O$. expedita which I possess with two specimens of $O$. rhabdota collected by the Albatross, and I must say that, apart from the coloration, it has been impossible for me to recognize between them the slightest difference in structure. The blue coloration of $O$. rhabdota does not appear to be absolutely constant; of the two specimens at hand, one shows a rather dark-blue general coloration, mixed only with white, while in the other this blue coloration, which is a little paler, is grayish and mixed with red, the color of typical $O$. expedita. Under these conditions I would be rather inclined to consider H. L. Clark's $O$. rhabdota as a blue variety of $O$. expeditn.

The conspicuously red coloration of $O$. expedita sharply separates typical examples from related forms of the $O$. longipeda group, especially from 0 . longipeda (Lamarck) and from O. puncto-limbata Martens, but as there occurs in $O$. expedita a blue or gray blue variety which corresponds to the form rhabdota it is worth while to reconsider the distinctive characters of these two species and of $O$. expedita. This last is evidently very close to 0 . longipeda, which it recalls in the arrangement and the characters of the arm spines, as 
well as by the upper arm plates showing very sharp lateral angles, but the covering of the dorsal surface of the disk between the radial shields consists of a mixture of rather well-developed and strongly echinulated true spines and club spines; furthermore, the radial shields are more elongated, and the upper arm plates are of different shape, for they are relatively longer and less broad, and their distal border is more rounded in 0 . expedita. These differences may be appreciated on the photographs which I give here of $O$. expedita (pl. 31, fig. 6, and pl. 33, fig. 5) and of 0 . longipeda (pl. 31, figs. 3, 4, and pl. 33, figs. 9, 10), and they are entirely independent of the characters taken from the coloration.

As for 0 . puncto-limbata, in which the form of the radial shields recalls that which is found in 0 . expedita, the dimensions of the specimens are always rather small, and they never attain the size which we know in 0 . expedita or in its variety 0 . rhabdota. The dorsal surface of the disk bears club spines only, which are sometimes a little elongated, but there are no true spines as in 0 . expedita; the arm spines are much weaker, shorter, and less strongly echinulated, and the lateral angles of the upper arm plates are less sharp. The general color of 0 . puncto-limbata is a somewhat light violet, or rather light blue, and the surface of the arms never shows light and dark longitudinal lines. Furthermore, in 0 . puncto-limbata I have never observed spines properly so called among the club spines of the dorsal surface of the disk such as are seen in 0 . expedita.

OPHIOTHRIX GALATHEAE Lütken.

Plate 33 , fig. 11 ; plate 34 , figs. $1-4$; plate 99 , fig. 1.

See for bibliography:

Ophiothrix galatheae KaHLER ('05), p. 84; ('05b), p. 458; ('07), p. 333; ('10), p. 294; ('15), p. 272.

Localities.-Dumurug Point, Masbate; April 19, 1908.

One specimen (Cat. No. E. 306, U.S.N.M.).

Maricaban Island, Balayan Bay, Luzon.

One specimen (Cat. No. E. 307, U.S.N.M.).

Makasser Island; tide pools.

One specimen (Cat. No. E. 364, U.S.N.M.).

Nasugbu Reef.

One specimen (Cat. No. E. 339, U.S.N.M.).

Port Palapag; June 3, 1909.

One specimen (Cat. No. E. 305, U.S.N.M.).

Philippines.

Three specimens (Cat. No. E. 337, U.S.N.M.).

Notes.-On plate 34, figures 1, 2, I show two specimens from Dumurug Point in which the radial shields bear a few scattered. 
granules, which are especially evident on the specimen represented in figure 1.

I also give photographs of the dorsal surface of two specimens of Ophiothrix galatheae which are in my collection, both of which come from Billiton; in one of these (pl. 34, fig. 3) the radial shields have the usual dimensions, and are absolutely naked, showing only small blue dots; in the other (fig. 4) these shields are remarkable for their large size; their surface is also entirely naked, and the two shields of each pair are very close together with the internal borders straight. The granules which cover the dorsal surface of the disk in the interradial spaces instead of being short and conical with three or four short and blunt points as usual (pl. 99, fig. 1a), are here peculiarly elongated forming true spines with rather elongated points (fig. 1b).

On the same plate I also show a number of arm spines as well as the tentacle scale. On the first arm segments the first ventral spine $(h)$, which is thick and strong, shows a few asperities which may end in sharp points; it is only at some distance from the disk that these points develop further, while the dimensions of the spine become somewhat reduced $(g)$; when the transformation into a hook is complete $(f)$ this first spine is also greatly reduced in size, and usually shows four elongated and rather well-spaced points; the terminal point, which forms the extremity of the hook, is a little stouter than the three others, which remain subequal. This form of hook is different from that seen in 0 . Tongipeda, 0 . hirsuta, and 0 . puncto-limbata. The tentacle scale is large and rounded, and it bears on its free border a few conical and subequal points (i).

Ophiothrix galatheae has been found in numerous localities in the Indo-Pacific region.

\section{OPHIOTHRIX HIRSUTA Müller and Troschel.}

Plate 31, figs. 1, 2 ; plate 33 , fig. 13 ; plate 99 , fig. 2.

See for bibliography:

Ophiothrix hirsuta KঞHLER ('05), p. 93 ; ('07), p. 333 ; ('07b), p. 252.-MACIntosh ('11), p. 93.-H. L. Clark ('15), p. 272.-Matsumoto ('17), p. 225.

Locality.-Albatross station 5174; in the vicinity of Joló; Joló Light bearing E., 4.82 kilometers (2.6 miles) distant (lat. $6^{\circ} 03^{\prime} 45^{\prime \prime}$ N., long. $120^{\circ} 57^{\prime} 00^{\prime \prime}$ E.) ; 36 meters (20 fathoms) ; March 5, 1908.

One specimen (Cat. E. 338, U.S.N.M.).

Notes.-The general color of the specimen in alcohol is gray; the radial shields are lighter, with small blue spots; a series of small blue spots runs along the distal border of each upper arm plate. The radial shields show only small and closely crowded granules 
which leave naked a considerable part of their surface. The upper arm plates have the typical form (pl. 31, fig. 2, and pl. 33, fig. 13).

I show here another specimen of Ophiothrix hirsuta from my own collection which comes from the Red Sea in which the radial shields are very much more extensively covered than in the Albatross individual (pl. 31, fig. 1).

The club spines of the dorsal surface of the disk are usually thick and stout (pl. 99, fig. 2a) and conical in form, and they terminate in thick points the number of which varies from four to six. At some distance from the disk the first ventral arm spine transforms into a hook with three or four branches of the form which is most commonly seen in the genus Ophiothrix (fig. 2b), that is to say, with the terminal point very stout, the second much weaker, and the third or the two following still weaker. This form is different from that which I have shown in O. galatheae and from that which we find in 0 . longipeda and 0 . puncto-limbata. I show (c) the forms taken by the first ventral arm spine before its complete transformation into a hook. The rounded or oval tentacle scale ends in a point, sometimes single, sometimes accompanied by one or two others very much smaller $(d)$.

Ophiothrix hirsuta is very widely spread throughout the whole Indo-Pacific region.

OPHIOTHRIX LONGIPEDA (Lamarck).

Plate 31, figs. 3,4 ; plate 33 , figs. 9,10 ; plate 100 , fig. 2.

See for bibliography:

Ophiothrix longipeda KGHLER ('05), p. 92; ('07), p. 334; ('07b), p. 252.-H. L. Clark ('08), p. 298.-KGHLER ('10), p. 294.-H. L. ClarK ('15), p. 274; ('15a), p. 90.-МАтsUмото ('17), р. 227.

Localities.-Albatross station 5179; vicinity of Romblon; Romblon light bearing S. $56^{\circ}$ E., 8.36 kilometers (4.50 miles) distant (lat. $12^{\circ} 38^{\prime} 15^{\prime \prime}$ N., long. $122^{\circ} 12^{\prime} 30^{\prime \prime}$ E.) ; 68 meters ( 37 fathoms); March 25, 1908; hrd. S.

One specimen (Cat. No. E. 334, U.S.N.M.).

Albatross station 5249; Gulf of Dávao; Lanang Point bearing N. 1.85 kilometers ( 1 mile) distant (lat. $7^{\circ} 06^{\prime} .06^{\prime \prime}$ N., long. $125^{\circ} 40^{\prime}$ $08^{\prime \prime}$ E.) ; 42 meters (23 fathoms) ; May 18, 1908; Co., S.

Two specimens (Cat. Nos. E. 336, E. 365, U.S.N.M.).

Albatross station 5401; north of Cebu; Tanguingui Island Light bearing $\mathrm{N}$. $79^{\circ} \mathrm{W}$., 42.62 kilometers (23 miles) distant (lat. $11^{\circ}$ $24^{\prime} 45^{\prime \prime}$ N., long. $124^{\circ} 06^{\prime} 00^{\prime \prime}$ E.) ; 54 meters (30 fathoms); March 16,1909 ; fne. S.

One arm (Cat. No. 41072 , U.S.N.M.).

Albatross station 5524; northern Mindanao and vicinity; Point Tagolo Light bearing S. $34^{\circ}$ W., 31.50 kilometers (17 miles) distant 
(lat. $8^{\circ} 58^{\prime} 07^{\prime \prime}$ N., long. $123^{\circ} 32^{\prime} 45^{\prime \prime}$ E.) ; 658 meters (360 fathoms); August 10, 1909; S.

One specimen.

Albatross station 5558; Joló Island and vicinity; Cabalian Point bearing S., 2.04 kilometers (1.1 miles) distant (lat. $5^{\circ} 51^{\prime} 33^{\prime \prime} \mathrm{N}$., long. $121^{\circ} 00^{\prime} 58^{\prime \prime}$ E.) ; 27 meters (15 fathoms); September 18, 1909; Co.

One specimen (Cat. No. 41073, U.S.N.M.).

Tobea Island; December 15, 1909.

One detached arm (Cat. No. 41071, U.S.N.M.).

Dávao Bay; from pearl oysters.

One specimen (Cat. No. E. 335, U.S.N.M.).

Samoa (Sir Charles N. E. Elliot).

One specimen (Cat. No. E. 336, U.S.N.M.).

Notes.-In the specimen from station 5558 (pl. 31, fig. 4) tho dorsal surface of the disk is gray, with small blue spots on the radial shields. The dorsal surface of the arms is blue, somewhat spotted with lighter and darker. A white band runs along the dorsal median line of the arms. The spines are light gray; the central surface of the arms is white, with, on the sides, blue spots which are more or less close together and very unequal in size.

The specimen from station 5179 has the dorsal surface very dark gray blue, and a white line runs along the whole length of the dorsal surface of the arms.

In the specimen from station 5249 the general color is dark gray; the dorsal surface of the arms is of a more or less marked blue, but perfectly uniform; the arm spines are gray blue. The dorsal surface of the disk is uniformly covered with small granules.

In the specimen from Dávao Bay the diameter of the disk is 15 $\mathrm{mm}$.; the general coloration is gray blue; a longitudinal line extends along the middle of the dorsal surface of the arms, but is only. faintly marked; the arms are ringed with lighter and darker.

In the specimen from station 5524, in which the diameter of the disk is only $7 \mathrm{~mm}$., the general color is uniform grayish blue.

To the specimens collected by the Albatross in the Philippines was added a large specimen from Samoa collected by Sir Charles N. E. Elliot. I show here a portion of the dorsal surface of one of its arms (pl. 33, fig. 10).

The club spines of the dorsal surface of the disk are ordinarily rather narrow, three or even four times as long as broad, and cylindrical rather than conical; they terminate in a few, usually three, points, which are equal and regularly arranged, but it is not rare to meet with four or even five more or less unequal points (pl.100, fig. 2a). The first ventral spine is transformed into a hook at some distance from the disk, and the hooks once definitely formed are rather 
small; they show on their concave border behind the terminal point a series of from six to eight very elongated points, which are narrow and arranged parallel to each other. The terminal point is not appreciably larger than the others, and is even sometimes smaller than the second (fig. $2 d$ ). On the convex border and toward the tip are a few unequal and irregular asperities. This form of hook recalls that which I have described in 0 . expedita, and which we find again in 0 . propinqua and 0 . puncto-limbata; it is very different from that which we know in the majority of the species of Ophiothrix, and which occurs in $O$. hirsuta. It is to be noticed also that the difference between this hook and the second ventral spines is not very great In figure $2 c \mathrm{I}$ show the first ventral spine at a short distance from the disk, where it has not yet acquired the definitive form of a hook provided with regular points. The tentacle scale $(b)$ is oval and terminated by a long point.

Ophiothrix longipeda has been met with in a large number of localities in the Indo-Pacific region.

I have continued to consider as different species 0 . galatheae, 0 . hirsuta, and $O$. longipeda, and in fact the specimens included in the Albatross collection can be perfectly well and easily assigned to one or the other, their characters being well marked. It is not worth while to review their characters here, nor those of 0 . puncto-limbata which I enumerated and discussed in 1905 ('05, pp. 94, 95). But I have thought that it might be useful to include some photographs which will facilitate the determination of these forms. To the species brought back by the Albatross I have added (pl. 32, fig. 6) a photograph of the dorsal surface of an $O$. puncto-limbata; the specimen came from Amboina and was given me by Professor de Loriol; it is one of those which he described in his memoir of 1893 (p. 416). I have added to the photographs showing the dorsal surfaces of the arms of various species of Ophiothrix (pl. 33) one of an O. obtusa, the upper arm plates of this species recalling those of certain forms of $O$. hirsuta, which it. likewise approaches in the armature of the dorsal surface of the disk; but 0 . obtusa is easily distinguished from the $O$. galatheae-hirsuta-longipeda group by its very short arms.

In his recent catalogue of the living ophiurans $\mathrm{H}$. L. Clark wrote in regard to $O$. rhabdota $(15$, p. 278) that he strongly doubted the validity of 0 . galatheae, $O$. hirsuta, and 0 . puncto-limbata, and he believed that further studies would lead without doubt to uniting them with $O$. longipeda, while $O$. expedita, on the other hand, appeared to him better characterized. For the moment, I can not share the opinion of the learned American naturalist, and, after having had occasion to study a rather large number of Ophiothrix belonging to the species named above, I do not see my way clear to unite certain of them with 0 . longipeda. To be sure the characters on 
which they are separated are not of very great value, but I have never been at a loss in recognizing them, even when there has been some encroachment upon their distinctive features. Thus I have had occasion above to record two specimens of $O$. galatheae from Dumurug Point in which the radial shields, instead of being entirely naked, as is ordinarily the case, show on their surface a certain number of granules similar to those of the rest of the dorsal surface of the disk; but these granules, which are few in number, do not form a covering comparable to that which is found in 0 . Tongipeda, from which $O$. galatheae is sharply distinguished by its arm spines.

Moreover, the form of the first ventral arm spine when transformed into a hook may furnish a good criterion for determination. In 0 . hirsuta it shows the characters which are usually met with in the species of the genus Ophiothrix; it is large, with three or four points only, the terminal point is very strong and strongly recurved, and the following are smaller and diminish rapidly in size (pl. 99, fig. 26 ). In $O$. galatheae, $O$. longipeda, and $O$. puncto-limbata the first ventral spine does not form a hook, properly speaking; it resembles rather a spine furnished on its concave border with many successive, elongated, closely crowded points which are arranged parallel to each other. However, it is especially in O. longipeda (pl. 100, fig. 2d) and $O$. puncto-limbata (pl. 101, fig. $7 b$ ) that these characters are shown with the greatest clearness; in $O$. galatheae the transformation into a hook is more pronounced and the lateral points are less numerous (pl. 99, fig. 1f). In these three species once the definitive characters are acquired the first ventral spine always remains of relatively small dimensions.

Generally speaking, the examination of this spine permits the differentiation of $O$. galatheae, $O$. hirsuta, and $O$. longipeda; as for $O$. puncto-limbata, it is evidently very close to $O$. longipeda; in my opinion it is the only form of the group about which it is possible to have doubts regarding its specific validity.

I have given above my views on the subject of $O$. rhabdota, which I consider as a variety of $O$. expedita.

\section{OPHIOTHRIX FOVEOLATA Marktanner.}

Plate 47 , figs. $4-7$; plate 98 , fig. 6 .

See for bibliography:

Ophiothrix foveolata KGEHLER ('05), p. 76; ('10), p. 294.-MACINTOSH: ('11), p. 161.-H. L. ClaAk ('15), p. 280.

Locality.-Albatross station 5131; Sulu (Joló) Sea, off western Mindanao; island off Panabutan Point bearing N. $20^{\circ}$ E., 0.74 kilometer ( 0.4 mile) distant; 49 meters ( 27 fathoms) ; February 6, 1908; gn. M., co. S.

Two specimens (Cat. No. 41025, U.S.N.M.). 
Notes.-The two specimens are of small size; the diameter of the disk in one is $5 \mathrm{~mm}$. and in the other $3.5 \mathrm{~mm}$. The coloration recalls that which $I$ have recorded in certain specimens from the Siboga collection, from stations 64 and 153. In the larger, the general color is roseate; the dorsal surface of the disk shows somewhat wavy purple lines, the upper arm plates show a red spot in the center and also a dark line along their distal border, and the spines are dark red. The second is lighter; the dorsal surface of the disk shows large red spots, one in the central region and the others covering a part of the radial shields; the upper arm plates are uniformly red; the spines are light gray or slightly roseate.

Ophiothrix foveolata is not always easily recognized, and I have thought it worth while to give here for comparative purposes in addition to the photographs of the specimens collected by the Albatross (figs. $4,5,6$ ) a phatograph of the dorsal surface of one of the Siboga specimens in which the general appearance is somewhat different from that of the two specimens which I have just mentioned (fig. 7); in this individual the general coloration is grayish, and the dorsal surface of the disk shows only a few dark blue lines on the borders of the radial shields, or a few small spots of the same color on the shields themselves, as well as in the interradial spaces.

On plate 98 , as figure $6 c$, I show the first ventral arm spine, which transforms rapidly into a hook of the typical form with three, or sometimes with only two, branches, two tentacle scales $(a)$, and some arm spines $(b$ and $d)$.

The type of $O$. forveolata came from the Aru Islands. The Siboga met with it in many localities in the Sunda Archipelago at depths between 9 and 141 meters ( 5 to 77 fathoms). The species also has been recorded from the Mergui archipelaga.

\section{OPHIOTHRIX HYBRIDA H. L. Clark.}

Plate 46 , figs. $4-6$; plate 99 , fig. 3 .

Ophiothrix hybrida H. L. CLARK ('15), p. 272, pl. 12, fig. 5.

Locality.-Albatross station 5321; China Sea, in the vicinity of Formosa; Ibugos Island (south end) bearing S. $89^{\circ}$ W., 2.32 kilometers (1.25 miles) distant (lat. $20^{\circ} 19^{\prime} 30^{\prime \prime} \mathrm{N}$., long. $121^{\circ} 51^{\prime} 15^{\prime \prime}$ E.) ; 47 meters (26 fathoms) ; November 9 , 1908; wh. S., Co., brk. Sh.

One specimen (Cat. No. E. 56, U.S.N.M.).

Notes.-The diameter of the disk is $10 \mathrm{~mm}$.; the arms are all incomplete, and one of them is preserved for a length of only $50 \mathrm{~mm}$; they must have been very long.

Ophiothrix hybrida was recently described by H. L. Clark from a unique specimen, and he considered it a hybrid between $O$. tritineata and $O$. longipeda, believing that it shared the characters of 
these two species. In his type the diameter of the disk measured $8 \mathrm{~mm}$., and the arms were $65 \mathrm{~mm}$. long.

My specimen agrees exactly with H. L. Clark's description and photographs. The dorsal surface of the disk is light red, while the arms have a bluish red coloration. The white marblings of the radial shields are little marked, though quite recognizable. The white longitudinal line which runs all along the dorsal surface of the arms is very well marked, and it is bordered on either side by a red line; some white spots appear beyond it, and at some distance from the median line. These successive spots on the side arm plates form an irregular and interrupted line which is situated toward the dividing line between the dorsal and side arm plates; these last each show another white spot. The ventral surface of the disk and of the arms show the coloration described by H. L. Clark; the arm spines are glassy and slightly bluish.

The only difference that I notice between my specimen and H. L. Clark's type is that the spines of the dorsal surface of the disk appear to me a little thicker and less pointed than in the latter (pl. 99 , fig. $3 a$ ) ; this slight difference may, hawever, be correlated with the somewhat smaller size.

Ophiothrix hybrida may be compared with $O$. tenuis Brock and 0 . virgata Lyman, but it differs from both of these species by its coloration; furthermore, it differs from $O$. tenuis in the form of the upper and under arm plates, in the fourth dorsal spine, which is not broadened, and in the radial shields which are not in contact in each pair; it also differs from $O$. virgata in the smaller radial shields, in the upper arm plates, etc.

The tentacle scale is large with one or two short points on its free border (fig. $3 c$ ). The hook-like form which the first ventral spine assumes at some distance from the disk is interesting (fig. $3 d$ ); it is, in fact, intermediate between that usually seen in the genus $O$ phiothrix and that which $I$ have recorded in $O$. longipeda, 0 . punctolimbata, 0. propinqua, etc. The hook is elongated and it ends in a strong recurved point behind which there is another, weaker; following this are four smaller subequal points, which are straight and parallel to each other. These mixed characters offer an argument in favor of H. L. Clark's hypothesis that O. hybrida is a hybrid between 0 . longipelda and $O$. trilineata.

The exact habitat of H. L. Clark's unique specimen is not certain; it was purchased from the Museum Godeffroy and was labeled "Fiji or Samoa." 
OPHIOTHRIX INFIRMA Kohler.

Plate 48 , figs. $5,6,7$; plate 100 , fig. 1 .

Ophiothrix infirma Kähler ('05), p. 89, pl. 8, figs. 10-13.-H. L. ClaRK ('15), p. 281.

Locality.-Albatross station 5153; Sulu (Joló) Archipelago, Tawi Tawi Group, Tocanhi Point bearing S. $27^{\circ}$ E., 3.89 kilometers (2.1 miles) distant (lat. $5^{\circ} 18^{\prime} 10^{\prime \prime} \mathrm{N}$., long. $120^{\circ} 02^{\prime} 55^{\prime \prime}$ E.) ; 90 meters (49 fathoms) ; February 19, 1908; co. S., Sh.

Two specimens (Cat. No. E. 12, U.S.N.M.).

Notes.-The two specimens are in fairly good condition, especially one of them, which is almost complete and which I have shown on plate 48 as figures 5-7; the disk measures $11 \mathrm{~mm}$. in diameter. The other specimen is a little larger.

The radial shields are very large, almost completely naked, and separated by a narrow interval. The interradial spaces are relatively narrow. The dorsal plates of the disk have fairly distinct outlines, and bear small and very numerous club spines terminated by a few short spinules which are rather obtuse, unequal, and erect (pl. 100, fig. 1a), without the least indication of true spines. As I said in describing the species in 1905 , the tentacle scale is very large (fig. $1 d$ ); it is rounded, with a few slightly developed asperities on its free border. The first ventral spine beyond the proximal third of the arms assumes the form of a three branched hook which is very large and strongly developed (fig. 1c). The two distal branches of the hook are especially well developed, but the third is very much less so; often a more strongly curved fourth point is added toward the base of the hook.

The coloration of the two specimens is pink. A white line extends throughout the whole length of the dorsal surface of the arms broadening and narrowing on each group of three or four segments; it is bordered on either side by a dark purple line which toward the distal border of each upper arm plate forms a very pronounced spot; another dark spot, somewhat smaller, lies at the base of the last dorsal spine. The ventral surface of the arms shows a broad white line outside of which the general coloration is pink, and there is also on each side of the white line a dark purple spot toward the distal border of the under arm plate.

In discussing the characters of $O$. infirma in $1905 \mathrm{I}$ compared it with $O$. stelligera Lyman, from which $I$ said it is distinguished by having its radial shields in part naked, by having the arm plates larger, and especially remarkably broad, and by having the tentacle scale very large and rounded. The affinity of these two species is still $55269-22-$ Bul. $100-16$ 
closer than I had supposed, as is shown by the study of certain specimens of $O$. stelligera such as those which I have shown on plate 4 as figure 4 , in which the very large radial shields are only slightly covered. But the two species may always be distinguished by the club spines of the dorsal surface of the disk, which are terminated by a few short and unequal spinules in $O$. infirma, by the somewhat smaller arm spines, and especially by the tentacle scale, which is remarkably large. I shall return again to the characters of $O$. stelligera when I discuss that species.

\section{OPHIOTHRIX KOREANA Duncan.}

Plate 45 , figs. $1-6$; plate 99 , fig. 4.

Ophiothrix koreana DUNCAN ('79), p. 473, pl. 11, figs. 28-32.-LYMAN ('82), p. 226.-MARKTANNER ('87), p. 308.-H. L. ClARK ('11), p. 257, figs. 127, 128; ('15), p. 273.-MAтsumoto ('17), p. 220.

Localities.-Albatross station 5116; Balayan Bay and Verde Island Passage; Sombrero Island bearing N. $69^{\circ}$ E., 4.63 kilometers (2.5 miles) distant (lat. $13^{\circ} 41^{\prime} 00^{\prime \prime}$ N., long. $120^{\circ} 47^{\prime} 05^{\prime \prime}$ E.) ; 366 meters (200 fathoms); January 20, 1908.

Four specimens (Cat. Nos. 41085, E. 86, U.S.N.M.).

Albatross station 5135 ; vicinity of Joló; Joló Light bearing S. $46^{\circ}$ W., 22.05 kilometers (11.9 miles) distant (lat. $6^{\circ} 11^{\prime} 50^{\prime \prime} \mathrm{N}$., long. $121^{\circ} 08^{\prime} 20^{\prime \prime}$ E.) ; 294 meters (161 fathoms) ; February 7, 1908; fne. co. S.

Four specimens (Cat. No. 41082, U.S.N.M.).

Albatross station 5179 ; vicinity of Romblon; Romblon Light bearing S. $56^{\circ}$ E., 8.34 kilometers (4.5 miles) distant (lat. $12^{\circ} 38^{\prime} 15^{\prime \prime} \mathrm{N}$., long. $122^{\circ} 12^{\prime} 30^{\prime \prime}$ E.) ; 68 meters (37 fathoms) ; March 25, 1908 ; hrd. S.

Three specimens (Cat. Nos. 41083, E. 92, U.S.N.M.).

Albatross station 5187; Tanon Strait, east coast of Negros; Apo Island bearing S. $21^{\circ}$ W., 23.16 kilometers (12.5 miles) distant (lat. $9^{\circ} 16^{\prime} 45^{\prime \prime}$ N., long. $123^{\circ} 00^{\prime} 00^{\prime \prime}$ E.) ; 411 meters (225 fathoms); March 31, 1908; sft. gn. M.

Two specimens (Cat. Nos. E. 90, E. 91, U.S.N.M.).

Albatross station 5212; east of Masbate Island; Panalangan Point bearing S. $54^{\circ} 30^{\prime}$ E., 26.87 kilometers (14.5 miles) distant (lat. $12^{\circ} 04^{\prime} 15^{\prime \prime} \mathrm{N}$., long. $124^{\circ} 04^{\prime} 36^{\prime \prime}$ E.) ; 197 meters (108 fathoms) ; April 20, 1908; gy. S., M.

One specimen (Cat. No. E. 89, U.S.N.M.).

Albatross station 5213 ; Destacado Island (S.) bearing N. $87^{\circ}$ E., 15.75 kilometers (8.5 miles) distant (lat. $12^{\circ} 15^{\prime} 00^{\prime \prime} \mathrm{N}$., long. $123^{\circ} 57^{\prime}$ $30^{\prime \prime}$ E.) ; 146 meters (80 fathoms); April 20,1908; S, M., Sh.

One specimen (Cat. No. E 93, U.S.N.M.). 
Albatross station 5221; between Marinduque and Luzon; San Andreas Island (W.) bearing S. $27^{\circ}$ E., 10.19 kilometers (5.5 miles) distant (lat. $13^{\circ} 38^{\prime} 15^{\prime \prime}$ N., long. $121^{\circ} 48^{\prime} 15^{\prime \prime}$ E.) ; 353 meters (193 fathoms); April 24, 1908; gn. M.

One specimen (Cat. No. 41087, U.S.N.M.).

Albatross station 5257; southern Mindanao, eastern Illana Bay; Utara Point, Bongo Island, bearing N. $88^{\circ}$ W., 14.27 kilometers (7.7 miles) distant (lat. $7^{\circ} 22^{\prime} 12^{\prime \prime}$ N., long. $124^{\circ} 12^{\prime} 15^{\prime \prime}$ E.) ; 51 meters (28 fathoms); May 22, 1908; M.

One specimen (Cat. No. E. 83, U.S.N.M.).

Albatross station 5265; Verde Island Passage and Batangas Bay; Matocot Point, Luzon, bearing S. $17^{\circ}$ E., 6.12 kilometers (3.3 miles) distant (lat. $13^{\circ} 41^{\prime} 15^{\prime \prime} \mathrm{N}$., long. $120^{\circ} 00^{\prime} 50^{\prime \prime}$ E.) ; 247 meters (135 fathoms); June 6, 1908; S., M.

Several specimens.

Albatross station 5373; Marinduque Island and vicinity; Tayabas Light (outer) bearing N. $20^{\circ}$ E., 27.80 kilometers (15 miles) distant (lat. $13^{\circ} 40^{\prime} 00^{\prime \prime}$ N., long. $121^{\circ} 31^{\prime} 10^{\prime \prime}$ E.) ; 618 meters (338 fathoms); March 2, 1909; sft. M.

Two specimens (Cat. No. E. 84, U.S.N.M.).

Albatross station 5391; between Sámar and Masbate; Tubig Point (Destacado Island) bearing N. $31^{\circ}$ E., 5.56 kilometers (3 miles) distant (lat. $12^{\circ} 13^{\prime} 15^{\prime \prime} \mathrm{N}$., long. $124^{\circ} 05^{\prime} 03^{\prime \prime}$ E.) ; 216 meters (118 fathoms); March 13, 1909.

Three specimens (Cat. Nos. E. 85, E. 87, U.S.N.M.).

Albatross station 5392; between Sámar and Masbate; Tubig Point bearing $\mathrm{N} .49^{\circ}$ E., 9.26 kilometers ( 5 miles) distant (lat. $12^{\circ} 12^{\prime} 35^{\prime \prime}$ N., long. $124^{\circ} 02^{\prime} 48^{\prime \prime}$ E.) ; 247 meters (135 fathoms); March 13, 1909 ; gn. M., S.

Two specimens (Cat. Nos. 41084, 41086, U.S.N.M.).

Albatross station 5420; between Cebu and Bohol; Cruz Point (Bohol) bearing S. $20^{\circ}$ E., 11.1 kilometers (6 miles) distant (lat. $9^{\circ} 49^{\prime} 35^{\prime \prime}$ N., long. $123^{\circ} 45^{\prime} 00^{\prime \prime}$ E.) ; 231 meters (127 fathoms); March 25, 1909.

One specimen (Cat. No. E. 88, U.S.N.M.).

Notes.-Duncan's description was based upon specimens from the Korean Straits in 25 fathoms; it is fairly complete, but the figures which accompany it are quite unsatisfactory and scarcely permit the recognition of the species. Since the publication of Duncan's memoir, Ophiothrix lcoreana does not appear to have been seen again until 1911. Brock in 1888, without giving evidence in support of his assertion, suggested that 0 . koreana is a synonym of 0 . comata ('88, p. $511,512,515)$; but it is certain that the Ophiothrix considered by Brock as an $O$. comata did not at all conform to Müller 
and Troschel's type, and that the real characters of this latter species completely eluded him, as has been the case also with other authors (see Kohler, '04a, p. 105).

To.H. L. Clark belongs the credit of having clearly established the characters of $O$. koreana, and especially of having shown the very great variations which this species may show, principally in regard to the armature of the dorsal surface of the disk. He was able to examine a very considerable series of specimens, 411 in all, which were collected in the Japanese seas at depths between 11.5 and 302 fathoms. I refer the reader to the memoir of this American naturalist for the description of the principal variations which he has ascertained ('11, p. 257 and following pages).

The specimens which have been sent to me also show variations, but these are less extensive than those of the specimens studied by $\mathbf{H}$. I. Clark; it is true that my collection is less extensive than his. The majority of the specimens agree with that from station 5116, of which I give two photographs (pl. 45, figs. 2,3 ). The dorsal surface of the disk is uniformly covered with club spines terminated by three long divergent spinules, identical with those which H. L. Clark has represented ('11, fig. 128a), and of which I give a few photographs; sometimes these club spines bear four points, or more rarely two only; but in general they show a great regularity (pl. 94, fig. 4a). The very large radial shields are always more or less covered with club spines. Such are the characters which the individuals from stations $5135,5179,5212,5265,5391,5392$, and 5421 present; in those from station 5257 the radial shields are almost naked; in the other specimens, these shields, which are almost entirely naked, become relatively still larger, as may be seen in the specimens from stations 5187 and 5373, of which I give photographs (pl. 45, figs. 4,5), and on that from station 5541; in the specimen from station 5221 the radial shields which are similar to those of the preceding in dimensions, bear a certain number of club spines. In the specimens which $I$ have just mentioned, with the exception of that from station 5187, the dorsal surface of the disk carries only trifid or sometimes quadrified clul spines, but these club spines may elongate and transform into small true spines. This transformation may be easily followed in the specimen from station 5179, in which the central region of the disk shows typical club spines which elongate little by little toward the periphery and become transformed into very elongated, thin, and rather slender true spines, furnished with denticulations throughout their length (pl. 45, fig. 1). The indivdual from station 5213, on the other hand, bears club spines in the peripheral part of the disk, and these elongate little by little in the central region to form eventually true spines, which are, however, very much less developed than in the 
preceding individual. The two specimens from station 5187 possess only spines, but these remain rather short, slender, and well spaced (fig. 5). In a specimen which was sent to me by the United States National Museum and which was determined by H. L. Clark (station 4833, Shima Hondo, 79 fathoms) the spines are remarkably developed; they are stout, thick, and elongated especially in the central region of the disk, becoming shorter toward the periphery. Another specimen, which was also sent to me by the National Museum, and which came from station 4893 , is remarkable for the feeble development of the armature of the dorsal surface of the disk; as is shown by the photograph which I give of it (fig. 6), the outlines of the dorsal plates of the disk, which are relatively large, and each of which only bears a very small club spine, are easily distinguishable. In the specimen from station 5187, which I have already mentioned, the armature of the disk also is rather slightly developed; the plates are separated from each other by soft parts, especially in the central region where they are never in contact.

I include (pl. 99, figs. $4 a, b$, and $c$ ) some photographs of club spines and of isolated true spines which will show the principal forms found in $O$. koreana. The trifid or sometimes quadrifid club spines shown at $a$ represent the normal form, which is most frequently observed when the disk bears nothing but club spines. When true spines occur among the club spines, and before these become transformed into small true spines, abnormal forms are sometimes found, such as those which are shown in fig. $4 b$; the three spinules instead of becoming long and subequal are very much shortened; they become very unequal, and their number falls to two, or they may even disappear altogether, so that the club spine is reduced to a very elongated cone. I show at $c$ different forms of spines, some very short, others much developed, as I observe them, for example, in the specimen from station 5179 , the whole dorsal surface of which is shown on plate 45 as figure 1 .

In all the specimens in the collection which has been sent me the radial shields are very large, whether they are completely naked or covered with a greater or lesser number of club spines, and I consider that this relatively large size of the radial shields constitutes one of the specific characters of $O$. koreana; it may already be noticed in the smallest specimens. The shape of the upper arm plates is also very characteristic, and I find it the same on all the adult specimens. The photographs which I include (pl. 45, figs. 1, 2, 4, 5, 6) give a good idea of the outlines of these plates; the distal angle makes a sort of rounded and slightly projecting beak, and the two sides which bound it are very slightly turned inwardly instead of being straight, or even somewhat convex, as is the case in the species of Ophiothrix related to O. koreana. 
The hook which is formed by the first ventral arm spine at a little distance from the disk always remains very stout and large; it shows three branches of which the last is thick and much developed; the two others are very much less developed (pl. 99, fig. $4 e$ ). Duncan says that the tentacle scale is small; this is not quite correct; this scale is rather large, oval in shape, and shows on its distal border sometimes a short conical point broadened at the base, and sometimes several smaller points (fig. $4 f$ ).

The general coloration is always roseate; sometimes it passes into a reddish yellow. It is not rare to see a white band extending all along the median dorsal line of the arms, bounded on either side by a red or pink band showing a more or less dark purple spot toward the distal border of each upper arm plate. In some specimens from station 5265 the upper arm plates show at intervals a large dark purple spot which occupies the greater part of their surface.

\section{OPHIOTHRIX LEPIDA LORIOI.}

Plate 36 , fig. 5 ; plate 100 , fig. 3.

Ophiothrix lepidus LORIOL ('93), p. 45, pl, 25, fig. 1.-KGHLER ('98), p. 102. Ophiothrix lepida H. L. ClaRK ('15), p. 281.

Localities.-Albatross station 5152; Sulu (Joló) Archipelago, Tawi Tawi Group; Pajumajan Islands (W.) bearing S. $2^{\circ}$ W., 3.71 kilometers (2 miles) distant (lat. $5^{\circ} 22^{\prime} 55^{\prime \prime} \mathrm{N}$., long. $120^{\circ} 15^{\prime} 45^{\prime \prime}$ E.) ; 62 meters ( 34 fathoms) ; February 18, 1908; wh. S.

Two specimens (Cat. No. E. 6, U.S.N.M.).

Albatross station 5153; Sulu Archipelago, Tawi Tawi Group; Tocanhi Point bearing S. $27^{\circ}$ E., 3.89 kilometers (2.1 miles) distant (lat. $5^{\circ} 18^{\prime} 10^{\prime \prime} \mathrm{N}$., long. $120^{\circ} 02^{\prime} 55^{\prime \prime}$ E.) ; 90 meters (49 fathoms); February 19, 1908; co. S., Sh.

One specimen (Cat. No. E. 7, U.S.N.M.).

Albatross station 5640; Molucea Sea; Labuan Blanda Island bearing N. $88^{\circ}$ E., 1.61 kilometers (1 mile) distant (lat. $4^{\circ} 27^{\prime} 00^{\prime \prime} \mathrm{S}$., long. $122^{\circ} 55^{\prime} 40^{\prime \prime}$ E.) ; 44 meters (24 fathoms) ; December 13, 1909.

One specimen (Cat. No. E. 5, U.S.N.M.) ; S., brk. Sh.

Notes.-The two specimens from station 5152 have a rather pale general coloration; the dorsal surface of the disk is a very light greenish white, with a slight indication of an extremely fine purple line along the inner border of the radial shields in the larger; the arms are roseate, and the spines banded white and pink. A purple line extends all along the median line of the dorsal surface of the arms, but this line is somewhat irregular and is sometimes discontinuous. The ventral surface is lighter, and the arms show in the median line a band interrupted at each segment. 
In the specimen from station 5640 the general coloration is a rather dark greenish; the dorsal surface of the disk shows light purple spots on the radial shields, and the small spines borne by the plates in the interradial regions are purple; these plates themselves show a purple bordering; the arm spines are grayish white banded with red. A median longitudinal purple line extends the whole length of the dorsal surface of the arms, but it is formed by a succession of little spots very close together.

The hook formed by the first ventral arm spine at some distance from the disk is peculiarly elongated and slender, and exceeds 0.5 $\mathrm{mm}$. in length in specimens of medium size (pl. 100, fig. $3 a$ ). On its concave border it bears four or five rather short and thick spines, and the terminal spine is not stouter than the following; it is even sometimes shorter; in the distal half or third of the arms the number of arm spines falls to three. The tentacle scale is rather small, oval and delicate, and ends in a very long point, sometimes accompanied by a second almost equally developed (fig. $4 b$ ).

I have already discussed (Kohler '98, p. 102, the affinities of $O$. lepida with 0 . purpurea. Aside from the characters based upon the number of arm spines and the form of the mouth shields-for the two species resemble each other very greatly in these respects-they may be distinguished from each other especially by the form of the radial shields, which are much elongated and very narrow in 0 . lepida, where their proximal apex comes very near the center of the disk (pl. 36, fig. 5), while in 0 . purpurea these shields are very much broader and triangular in form, and their proximal apex is some distance from the center of the disk. The outlines of these shields may be made out on the photograph published by Döderlein ('99, pl.17, fig. 23), as well as on that which I give here (pl. 58, fig. $3)$. The upper arm plates are also a little more elongated in $O$. lepida, in which they have a lozenge shape form with the two external angles tuncated, their greatest breadth being found almost at their middle, while in $O$. purpurea the greatest breadth is close to the distal border. Döderlein says that these plates are a little broader than long with the internal and external borders almost straight and equal; but this is inexact, and on the photograph which he has published, although the outlines of these plates are not very distinct, it may be shown that their form does not correspond with the description given in the text. I have thought it well to include two photographs (pl. 58, figs. 3,4) of an 0 . purpurea from the Sunda Archipelago which is in my collection, in which better than in Döderlein's photograph the outlines of the different plates may be made out and which permits a more exact comparison with 0 . lepida. I may add that the very robust tentacle scale of $O$. purpurea is very 
different from the more delicate and finer scale which $\mathrm{I}$ find in 0 . lepida.

Loriol has stated that 0 . lepida was without a tentacle scale ('93, p. 47), and he says the same thing for 0 . fallax (p. 48); this statement is not correct. This scale certainly is present; I have described its characters above and I include photographs of it (pl. 100, fig. $3 b)$. To be sure, this scale may be lacking on certain segments, but I believe that this absence is accidental. The tentacle scale can not be confused with the first ventral arm spine, for the latter, which is very much more elongated, is always easily recognized and furthermore it transforms into a hook a short distance from the base of the arms. After having stated that the tentacle scale is lacking in O. lepida and $O$. fallax, Loriol has allowed an error to remain in the figures which he has published of these two species (pl. 25, figs. $1 d$ and $2 c$ ) showing the ventral surface of the arms. These figures show a very large, broad, and oval tentacle scale of a size that would be quite unusual in an Ophiothrix; evidently the artist should have represented a pore in place of this scale.

I may mention that in 1898 ('98, p. 102) I wrote that $O$. fallax was perhaps only a variety of $O$. lepida; my opinion on that subject has not been changed.

The type of 0 . lepida came from Mauritius. The species was rediscovered by the Investigator in the Andaman Islands and in the Laccadive and Mergui Archipelagoes at depths varying between 15 and 50 fathoms.

\section{OPHIOTHRIX MARENZELLERI Kœhler.}

Plate 39 , figs. $3-5$; plate 100 , fig. 4.

Ophiothrix marenzelleri KGHLER ('04a), p. 103, figs. 76-78.-H. I. CLARK ('15), p. 281.-Матsuмото ('17), p. 220.

Locality.-Yenoshima, Japan.

One specimen (Cat. No. 41024, U.S.N.M.).

Notes.-I refer to Ophiothrix marenzelleri a single specimen of smaller size than those upon which I originally based the species; the diameter of the disk is $6 \mathrm{~mm}$., and the length of the arms varies between $25 \mathrm{~mm}$. and $30 \mathrm{~mm}$. The dorsal surface is uniformly covered with elongated and rather thick club spines, to which might almost be given the name of spines; these club spines are cylindrical or slightly conical, smooth, and ending in short, unequal, and thick spinules varying from two to four in number (pl. 100, fig. $4 a$ ); they are very closely crowded and almost entirely cover the radial shields. These club spines become a little longer, but less closely crowded, on the ventral surface of the disk which they cover in large part, without, however, extending as far as the mouth shields or the genital slits. 
The upper and under arm plates have the forms which $I$ have gave for them in my original description, the former with the proximal angle truncated and slightly produced and the latter with the distal border concave. The under arm plates, while broader than long, are perhaps a little less broadened than in my type; this comes-about doubtless from the difference in size of the individuals; in the specimen which I figured in 1904 ('04a, fig. 76), the diameter of the disk is $10 \mathrm{~mm}$., while in the Albatross specimen this diameter does not exceed $6 \mathrm{~mm}$. The arm spines are flattened, rather thick and strong, slightly broadened at the tip; they are finely denticulate throughout their whole length.

The hook formed by the first ventral arm spine is fairly well developed (pl. 100, fig. 4c); it usually shows three branches, sometimes only two, the terminal branch very much stouter than the two others.

The tentacle scale, which is of medium size, is oval, ending in a stout point often accompanied by a few others very much smaller (fig. $4 b$ ).

The general color is an olivaceous gray on the dorsal surface of the disk; the arms are lighter, with traces of reddish bands. The ventral surface of the disk is light gray and the arms show darker annulations; there is not the least indication of a lighter or darker longitudinal line on the arms.

In $1904 \mathrm{I}$ mentioned that the specimens upon which $\mathrm{I}$ based this species, and which had been labeled by Marenzeller $O$. stelligera, were in reality very different from the latter; I had not then had the opportunity of studying $O$. koreana, and I was not able consequently to compare it with 0 . marenzelleri. I now maintain that these two species are rather closely related, and $\perp$ notice especially a great resemblance between $O$. marenzelleri and $O$. hylodes from Japan, which H. L. Clark described under a different specific name, though saying that he was tempted to consider it merely as a variation of $O$. koreana. The only difference which I can find is shown by the spines which cover the dorsal surface of the disk in $O$. hylodes and which pass over onto the radial shields, where they become less closely crowded. These spines differ from those which I find in $O$. marenzelleri, which, moreover, had perhaps better be called club spines. They have a smooth surface, and they bear only two or three unequal spinules at their tip; they appear to me to be shorter and less stout than in 0 . hylodes, while on the other hand the arm spines are more slender in the latter.

Ophiothrix marenzelleri also shows affinities with 0 . caespitosa from Australia; to facilitate comparison I include three photographs of a specimen which I have of this latter species from Port Jackson, Iyman's type locality (pl. 38, figs. 6, 7, 8). 
The club spines which cover the dorsal surface of the disk of 0 . caespitosa are finer and more elongated, and they are furnished with finer spinules than in 0 . marenzelleri. In the single specimen which I have a few spines are mingled with the club spines, a feature which Lyman did not mention but which H. L. Clark found in some $O$. caespitosa from Australia collected both by the Thetis (H. L. Clark, '09, p. 549) and by the Endeavour ('16, p. 90). The upper and under arm plates have almost the same form in the two species, but the arm spines are more slender and more finely denticulate, and not broadened at the extremity in 0 . caespitosa, and they are nine instead of only seven in number; but the mouth shields especially are very much broader than long, while in 0 . marenzelleri they are scarcely broader than long and their form is almost lozenge-shaped.

The specimens from the Vienna Museum upon which I based 0 . marenzelleri came from Japan.

Matsumoto ('17, p. 220) has recorded 0 . marenzelleri from various localities in Japan, at depths between 0 and 70 fathoms. He distinguished a littoral form, in which the disk is uniformly covered with echinulated and closely crowded spines, and a sublittoral form in which the disk bears club spines ending in numerous spinules. $\mathrm{He}$ also considers 0 . marenzelleri as closely related to $O$ koreana which the sublittoral form especially approaches, and he gives 0 . hylodes H. L. Clark as a synonym of $O$ marenzelleri.

\section{OPHIOTHRIX MARTENSI Lyman.}

See for bibliography:

Ophiothrix martensi KaELER ('05), p. 80; ('07), p. 334; ('07b), p. 252; ('10), p. 294.-MACINTosh ('11), p. 162.-H. L. CLARK ('15), p. 275.

Localities.-Albatross station 5141; vicinity of Joló; Joló Light bearing S. $17^{\circ} \mathrm{E} ., 10.19$ kilometers ( 5.5 miles) distant (lat. $6^{\circ} 09^{\prime} 00^{\prime \prime}$ N., long. $120^{\circ} 58^{\prime} 00^{\prime \prime}$ E.) ; 53 meters (29 fathoms) ; February 15 , 1908 ; co. S.

One specimen (Cat. No. 41264, U.S.N.M.).

Albatross station 5145 ; vicinity of Joló; Joló Light bearing S. $16^{\circ}$ E., 1.57 kilometers (0.85 mile) distant (lat. $6^{\circ} 04^{\prime} 30^{\prime \prime}$ N., long. $120^{\circ}$ $59^{\prime} 30^{\prime \prime}$ E.) ; 42 meters (23 fathoms) ; February 15, 1908; co. S., Sh.

Three specimens (Cat. No. 41263, U.S.N.M.).

Albatross station 5147; Sulu (Joló) Archipelago, in the vicinity of Siasi ; Sulade Island (E.) bearing N. $3^{\circ}$ E., 15.57 kilometers (8.4 miles) distant (lat. $5^{\circ} 41^{\prime} 40^{\prime \prime}$ N., long. $120^{\circ} 47^{\prime} 10^{\prime \prime}$ E.) ; 38 meters (21 fathoms) ; February 16, 1908; co. S., Sh.

Six specimens (Cat. Nos. E. 17, E. 18, U.S.N.M.).

Albatross station 5554; Joló Island and vicinity; Cabalian Point (Joló) bearing N. $76^{\circ}$ E., 7.04 kilometers (3.8 miles) distant (lat. $5^{\circ}$ 
$52^{\prime} 27^{\prime \prime}$ N., long. $120^{\circ} 52^{\prime} 18^{\prime \prime}$ E.) ; 45 meters (25 fathoms) ; September 18,1909 ; Co., $\mathrm{S}$.

Two specimens (Cat. No. 41262, U.S.N.M.).

Marougas; shore; coral head.

Four specimens (Cat. No. E. 19, U.S.N.M.).

No locality.

Two specimens (Cat. No. 41261, U.S.N.M.).

Notes.-Ophiothrix martensi has been met with in a large number of localities in the Indo-Pacific region, principally at littoral stations, though the Siboga collected it in the Sunda Archipelago at various depths down to 73 meters ( 40 fathoms).

\section{OPHIOTHRIX MELANOSTICTA Grube.}

Plate 59, figs. 5,6 ; plate 100 , fig. 5 .

See for bibliography:

Ophiothrix melanosticta KashleR ('05), p. 77, pl. 8, figs. 4-6; pl. 14, fig. 3; ('07b), p. 253.-H. L. CLARK ('15), p. 275.

Locatities.-Albatross station 5146; Sulu (Joló) Archipelago, in the vicinity of Siasi; Sulade Island (E.) bearing N. $18^{\circ}$ W., 6.30 kilometers ( 3.4 miles) distant (lat. $5^{\circ} 46^{\prime} 50^{\prime \prime} \mathrm{N}$., long. $120^{\circ} 48^{\prime} 50^{\prime \prime}$ E.) ; 44 meters (24 fathoms) ; February 16, 1908; co. S., Sh.

Three specimens (Cat. Nos. 41381, E. 3, U.S.N.M.).

Albatross station 5147; Sulu Archipelago, in the vicinity of Siasi; Sulade Island (E.) bearing N. $3^{\circ}$ E., 15.57 kilometers ( 8.4 miles) distant (lat. $5^{\circ} 41^{\prime} 40^{\prime \prime}$ N., long. $120^{\circ} 47^{\prime} 10^{\prime \prime}$ E.) ; 38 meters (21 fathoms); February 16, 1908; co. S., Sh.

Three specimens (Cat. Nos. 41382, E. 2, U.S.N.M).

Albatross station 5174; in the vicinity of Joló; Joló Light bearing E. 4.82 kilometers (2.6 miles) distant (lat. $6^{\circ} 03^{\prime} 45^{\prime \prime} \mathrm{N}$., long. $120^{\circ}$ $57^{\prime} 00^{\prime \prime}$ E.) ; 36 meters (20 fathoms) ; March 5, 1908; crs. S.

Two specimens (Cat. No. E. 1, U.S.N.M.).

Philippines (without further data).

One specimen (Cat. No. 41383, U.S.N.M.).

Notes.-In 1905 I gave a description of this species based upon the specimens collected by the Siboga in the Sunda Archipelago; it has been found in various localities in the Indian Ocean, but it seems up to the present to be always rather rare.

The large spines of the dorsal surface of the disk are almost always smooth (pl. 100, fig. $5 b$ ). Among these there may be found some others, very much shorter, which deserve the name of club spines (fig. $5 c$ and $d$ ).

The first ventral arm spine at some distance from the disk transforms into a hook with three or four branches of the usual type 
(fig. $5 f$ ) ; but I generally notice that the terminal branch is shorter and more feeble than the following, which is the most developed.

The tentacle scale is of medium size $(e)$; it usually ends in a short, thick, and conical point; sometimes there are two parallel points.

Ophiothrix melanosticta is a preeminently littoral species, though the Siboga found it in the Sunda Archipelago at depths as great as 73 meters (40 fathoms). The Challenger dredged it southwest of New Guinea (lat. $8^{\circ}$ S., long. $136^{\circ}$ E.) in 90 meters ( 49 fathoms).

\section{OPHIOTHRIX NEREIDINA (Lamark).}

Plate 101, fig. 1.

See for bibliography:

Ophiothrix nereidina KCHLER ('05), p. 81; ('07), p. 334; ('10), p. 294.-H.

L. Clark ('15), p. 275; ('15a), p. 90 ; ('16), p. 91 ; ('17), p. 224.

Localities.-Albatross station 5108; China Sea, off southern Luzon; Corregidor Light bearing N. $39^{\circ}$ E., 41.70 kilometers $(22.5$ miles) distant (lat. $14^{\circ} 05^{\prime} 05^{\prime \prime} \mathrm{N}$., long. $120^{\circ} 19^{\prime} 45^{\prime \prime}$ E.) ; 24 meters (13 fathoms) ; January 15, 1908; Co.

One specimen (Cat. No. E. 110, U.S.N.M.).

Albatross station 5179; vicinity of Romblon; Romblon Light bearing S. $56^{\circ}$ E., 8.34 kilometers (4.5 miles) distant (lat. $12^{\circ} 38^{\prime} 15^{\prime \prime} \mathrm{N}$., long. $122^{\circ} 12^{\prime} 30^{\prime \prime}$ E.) ; 68 meters (37 fathoms) ; March 25, 1908; hrd. S.

One specimen (Cat. No. E. 111, U.S.N.M.).

Albatross station 5249; Gulf of Dávao; Lanang Point bearing N. 1.85 kilometers (1 mile) distant (lat. $7^{\circ} 06^{\prime} 06^{\prime \prime}$ N., long. $125^{\circ}$ $40^{\prime} 08^{\prime \prime}$ E.) ; 42 meters (23 fathoms) ; May 18, 1908; Co., S.

Two specimens (Cat. No. E. 109, U.S.N.M.).

Albatross station 5254; Gulf of Dávao; Linao Point bearing N. $44^{\circ}$ E., 1.29 kilometers (0.7 mile) distant (lat. $7^{\circ} 05^{\prime} 42^{\prime \prime} \mathrm{N}$., long. $125^{\circ} 39^{\prime} 42^{\prime \prime}$ E.) ; 38 meters (21 fathoms) ; May 18, 1908; S., Co.

Two specimens (Cat, No. E. 112, U.S.N.M.).

Notes.-The hook formed by the first ventral arm spine has three branches and is of the usual type (pl. 101, fig. 1a). The tentacle scale, which is of medium size, ends in a long conical point sometimes replaced by two parallel and slightly shorter points (fig. 1b).

Ophiothrix nereidina is very widely distributed in the Indo-Pacific region and has mostly been collected in littoral stations. The Siboga, however, found it at various depths down to 45 meters (27 fathoms).

\section{OPHIOTHRIX PAVIDA, new species.}

Plate 39, figs. 6,7 .

Locality.-Albatross station 5179; in the vicinity of Romblon; Romblon Light bearing S. $56^{\circ}$ E., 8.34 kilometers (4.5 miles) distant 
(lat. $12^{\circ} 38^{\prime} 15^{\prime \prime}$ N., long. $122^{\circ} 12^{\prime} 30^{\prime \prime}$ E.) ; 68 meters (37 fathoms); March 25, 1908; hrd S.

One specimen (Cat. No. 41018, U.S.N.M.).

Description.-The diameter of the disk is $5 \mathrm{~mm}$.; the arms are unfortunately all broken off near the base, and they are not preserved for a greater length than $7 \mathrm{~mm}$.

The disk is rounded, with the two surfaces slightly convex. The dorsal surface is covered between the radial shields, which are of medium size, with numerous plates, of which the outlines are fairly evident, and which bear both small club spines ending in divergent spinules which are rather thick at the base, unequal, and often three in number, and slender, sharp, and rather long true spines, provided with fine denticulations, which are mixed with the club spines, and are rather numerous. All intermediate stages between these spines and the club spines are found, especially toward the periphery of the disk. The radial shields are not very large, as I have just said, though their length is a little greater than the radius of the disk; they are triangular, in contact outwardly, and separated inwardly by a row of plates bearing club spines or true spines. These shields themselves carry on their surface a certain number of spines mixed with club spines.

The ventral surface of the disk in its median portion is covered with rounded plates, each one bearing a club spine ending in unequal spinules which are shorter than those on the dorsal surface. These plates reach almost to the bottom of the interradial areas, but they leave naked a broad band along the genital slits.

The mouth shields, which are of medium size, are triangular, with the sides slightly excavated, and joining over a rather prominent angle the apex of which is rounded; the distal border is very strongly convex. The adoral plates are rather small, broadened outwardly and in contact inwardly through a narrow and rounded border. The oral plates are high and strong. The tooth papillae are arranged in several rows.

The upper arm plates are large, quadrangular, a little longer than broad, with a very narrow and straight proximal border and divergent and slightly excavated sides; the distal border is very broad and very strongly convex, and it is sometimes resolved into three sides which are united by very obtuse angles. All these plates are in contact.

The first under arm plate is rather large, broader than long, with the distal border convex. The following are very large, almost as long as broad, with a straight proximal border, the sides very slightly excavated by the tentacle pores, and passing over very rounded angles to the distal border, which is slightly convex. They are all in contact. 
The very strongly projecting side arm plates carry seven spines and often even eight at the base of the arms; these spines are slender, tapering and pointed, and quite transparent. The two dorsal spines are very narrow and their length exceeds two and a half segments; they are provided with small, well-spaced, sharp teeth. The other lateral spines are thicker and shorter, provided with stronger and more closely placed denticulations. The length of these spines increases from the second, which is shorter than the segment, to the sixth, which usually almost or quite equals two segments. The first ventral spine is extremely small, very short and slender, and becomes converted into a hook a few segments beyond the disk.

The tentacle scale is small and oval.

The dorsal surface of the disk is of a rather light pinkish-gray color; the arms are more red. I find no special ornamentation except upon the radial shields, which have a purple line along their borders. Along the median dorsal line of the arms runs a white band bordered on either side by a purple line; there is another wavy and irregular purple line near the lateral borders of the upper arm plates. The ventral surface of the arms shows a broad median white band bounded by two somewhat irregular and wavy purple lines; the rest of the surface of these plates is pink with a few purple spots. The arm spines and the spines of the dorsal surface of the disk are faintly pink and always very transparent. The ventral surface of the disk is dark brown.

Affnities and distinctive features.-Ophiothrix pavida may be compared with the species of the 0 . suensoni group, although the arms spines do not have the great length usually found in that group. It recalls especially 0 . proteus Koehler, 0 . picteti Loriol, and 0 . comata Müller and Troschel. It differs from 0 . proteus in having the radial shields smaller, and sometimes carrying large spines, while the interradial spaces are very much broader, the upper arm plates broader, the mouth shields longer and less flattened, and the arm spines less developed. It differs from 0 . comula in having the upper arm plates longer than broad, the under arm plates with a slightly rounded distal border, the spines on the dorsal surface of the disk numerous and less elongated, and also passing onto the radial shields, and the mouth shields longer and less broadened. It differs from 0 . pictet $i$ in the presence of club spines among the spines of the dorsal surface of the disk, in having the radial shields furnished with spines, the arm spines shorter (Loriol says that in $O$. picteti the length of these spines reaches that of five or six segments), and the upper arm plates a little broader than long.

Its affinities with $O$. picteti seem to me to be rather pronounced, and as that species is little known, I have thought it well to give here 
(pl. 41, figs. 7, 8), two photographs of a specimen from Amboina, the one which I described in 1904 (Koehler '04a, p. 110).

Ophiothrix pavida may be also compared with $O$. armata Kœhler, but it is immediately distinguished by its smaller radial shields which are covered with spines, by the entirely different form of the upper and under arm plates, by the more slender arm spines, and by the coloration. It differs still more from 0 . virgata Lyman in having its radial shields in contact outwardly, in its longer arm spines, in the form of the upper and under arm plates, and in the coloration, which is entirely different.

\section{OPHIOTHRIX PLANA Lyman.}

Plate 38, figs. $3-5$; plate 101 , fig. 2.

\section{See for bibliography:}

Ophiothrix plana KGEHLER ('05), p. 75.-H. L. ClARK ('15), p. 276.

Locality.-Albatross station 5179 ; vicinity of Romblon; Romblon Light bearing S. $56^{\circ}$ E., 8.34 kilometers (4.5 miles) distant (lat. $12^{\circ}$ $38^{\prime} 15^{\prime \prime}$ N., long. $122^{\circ} 12^{\prime} 30^{\prime \prime}$ E.) ; 68 meters (37 fathoms); March 25,1908 ; hrd. S.

One specimen (Cat. No. 41015, U.S.N.M.).

Notes.-The single specimen collected by the Albatross agrees very well with Lyman's type, and the dorsal surface of the disk is quite naked, as may be seen on the photograph which I give of it (pl. 38 , fig. 3). In $1905 \mathrm{I}$ described the variations which this species shows in the armature of the disk, and I include (fig. 4) a figure of the dorsal surface of a specimen from the Sunda Islands in which the dorsal plates of the disk bear small conical granules.

In the Albatross specimen the adoral plates are very widely separated from each other; they broaden very much outwardly, and are continued by a very broad distal lobe separating the mouth shields from the first side arm plate. The distal border of the first under arm plates is at first slightly convex and rounded, becoming beyond the disk rather strongly excavated.

The hook formed by the first ventral arm spine shows the usual form with two or three branches which are always well developed (pl. 101, fig. $2 a$ ). The tentacle scale ends in a conical point which is rather broad at the base (fig. $2 b$ ).

The coloration of the specimen is pinkish gray on the dorsal surface of the disk and of the arms, as well as on the ventral surface of the latter; the ventral surface of the disk is a very dark brown in those portions which are not covered with spines.

Ophiothrix plana is a littoral species which has been found in a number of localities in the Indian Ocean; the Siboga met with it at various depths, from the surface down to 54 meters ( 30 fathoms). 
OPHIOTHRIX PROPINQUA Lyman.

Plate 38 , figs. 1,2 ; plate 101 , fig. 4 .

See for bibliography:

Ophiothrix propinqua KäHLER ('05), p. 81; ('05a), p. 184; ('07), p. 336; ('07b), p. 253.-H. L. ClarK ('15), p. 277.

Localities.-Albatross station 5108; China Sea, off southern Luzon; Corregidor Light bearing N. $39^{\circ}$ E., 41.70 kilometers (22.5 miles) distant (lat. $14^{\circ} 05^{\prime} 05^{\prime \prime}$ N., long. $120^{\circ} 19^{\prime} 45^{\prime \prime}$ E.) ; 24 meters (13 fathoms); January 15, 1908; Co.

One specimen (Cat. No. 41269, U.S.N.M.).

Albatross station 5321; China Sea, in the vicinity of Formosa; Ibugos Island (south end) bearing S. $89^{\circ}$ W., 23.16 kilometers (1.25 miles) distant (lat. $20^{\circ} 19^{\prime} 30^{\prime \prime}$ N., long. $121^{\circ} 51^{\prime} 15^{\prime \prime}$ E.) ; 47 meters (26 fathoms); November 9, 1908; wh. S., Co., brk. S.

Two specimens (Cat. No. 41270 , U.S.N.M.).

Notes.-The specimen from station 5108 is in a good state of preservation, but the diameter of the disk is only $4 \mathrm{~mm}$.; the two others are incomplete, and in a rather poor state of preservation.

I include a photograph of the dorsal surface of the specimen from station 5108 (pl. 38, fig. 1). The upper arm plates have not quite the same form as those in the specimen which I figured in 1898, which came from the Andaman Islands ('98, pl. 3, fig. 20); the proximal border is shorter than the distal, giving to these plates a pronouncedly trapezoidal shape. This is the form which I find in the small specimens, while in the larger the proximal border is broader at the base of the arms becoming narrow at some distance from the disk.

The hook formed by the first ventral arm spine in 0 . propinqua assumes a rather unexpected shape which recalls that which I described in $O$. aspidota and in 0 . expedita. Behind the terminal point, which is not very much developed, there are several similar, conical, pointed and straight prongs, which are close together and parallel to each other. The number of these prongs varies from six to nine (pl. 101, fig. $4 c$ ). The convex border of the hook often shows toward its extremity two or three small asperities.

The rather large tentacle scale ends in a strong point (fig. $4 a$ ).

$O$ phiothrix plana and $O$. propinqua show a very similar arrange ment of the plates on the dorsal surface of the disk, and the resem. blance is further accentuated by the fact that some specimens of $O$. plana may bear small granules, while in 0 . propinqua the plates may be completely unarmed. But the upper arm plates do not have the same form in the two species; their distal border is very convex in 0 . plana, while it is almost straight in $O$. propinqua, in which species it is broader and often slightly trilobed; furthermore, the spines of 
the periphery of the disk and of the ventral surface are more elongated in 0 . plana, while in 0 . propinqua they are shorter and resemble those usually borne on the rest of the dorsal surface, though becoming more closely crowded; the arm spines are more swollen in 0 . plana in their terminal portion, where the denticulations are very close together, while in 0 . propinqua they are more uniform in thickness, with the denticulations more regularly distributed. But the most important difference which separates these two species is found in the length of the arms in relation to the diameter of the disk. The arms are very short in 0 . plana, while they are very long in 0 . propinqua. I include for comparison photographs of two almost complete specimens of 0 . propinqua and 0 . plana, both from the Sunda Islands, which show most clearly the differences in the length of the arms (pl. 38, figs. 2,5).

The very different form of the hook formed by the first ventral arm spine also furnishes an important character permitting of the easy separation of the two species. The strong and thick hook provided with three small branches found in $O$. plana can not be confused with the smaller hook furnished with from six to ten small slender and crowded points following each other all along its concave border in O. propinqua.

Ophiothrix propinqua is rather widely spread throughout the whole Indo-Pacific region; the Investigator found it at depths down to 31 meters (17 fathoms) and the Siboga dredged it among the Sunda Islands in from 12 to 54 meters ( 7 to 30 fathoms).

\section{OPHIOTHRIX PROSTRATA, new species.}

Plate 39, figs. 1, 2.

Locality.-Albatross station 5342; Malampaya Sound, Palawan Island; Endeavor Point (S.) bearing S. $58^{\circ}$ E., 0.93 kilometer (0.5 mile) distant (lat. $10^{\circ} 56^{\prime} 55^{\prime \prime} \mathrm{N}$., long. $119^{\circ} 17^{\prime} 24^{\prime \prime}$ E.) ; $26-46$ meters (14-25 fathoms); December 23, 1908; gy. M.

One specimen (Cat. No. 41023 , U.S.N.M.).

Description.-The diameter of the disk is $5 \mathrm{~mm}$.; all the arms are broken off at a short distance from the base; they are rather narrow and apparently they do not reach any great length.

The disk is rounded; the slightly convex dorsal surface between the very large radial shields shows small imbricated plates with very distinct outlines, rounded in the central region of the disk, but becoming very much longer in the radial and interradial spaces. In the interradial spaces these plates form five or six rows, but in the radial spaces there is only a single row of narrow rectangular plates which separate the two shields of each pair throughout their whole length. In general each of these plates carries a small cylindrical $55269-22-$ Bul. $100-17$ 
club spine of which the tip is rounded and slightly broadened, and which is provided with a few very short and very fine spinules. These club spines become a little shorter toward the periphery of the disk, while on the other hand their spinules become a little more developed. In the radial spaces, which are always very narrow, the club spines are very much rarer and when they occur they are extremely short. The radial shields are very large, triangular, half again as long as broad, and their length is almost equal to threequarters of the radius of the disk. The two shields of each pair are very close together, though not in contact, and they scarcely diverge at all, the two straight inner sides being almost parallel; the external border is somewhat sinuous, and the proximal angle is rather sharp. The surface of these shields is entirely naked.

The ventral surface of the disk is occupied in part by very small rounded plates each of which bears a club spine identical with those on the dorsal surface, the base of which occupies almost the entire surface of the plate which carries it. These plates cover a triangular space which reaches neither the mouth shields nor the genital slits. These latter are rather broad.

The mouth shields are large, triangular, broader than long, with a rather prominent but rounded proximal angle bounded by two slightly concave sides; these pass over by rounded angles to the distal border, which is convex and shows in the middle a very small rounded lobe. The adoral plates, which are of medium size, are triangular and their proximal apex is very close to the median interradial line, but it does not quite reach its fellow; the very broadened base of these plates sends off a narrow process which separates the mouth shields from the first side arm plate. The oral plates are rather broad, but only slightly elevated. The tooth papillae form two very regular lateral rows, bounding three other rows which are very much more irregular.

The rather small upper arm plates are as broad as long, or even slightly longer than broad. They are almost lozenge-shaped, with a truncated proximal angle bounded by two straight sides; the two other sides are slightly convex and they are united over a rather obtuse and rounded distal angle. All these plates are in contact.

The first under arm plate is rather small, rectangular, with the sides convex; the proximal border, which is slightly rounded, is narrower than the distal border, which is straight. The following plates are large, rectangular, longer than broad, with the proximal border straight and a little shorter than the distal border, which is slightly concave; the sides are somewhat divergent and slightly excavated; the lateral angles are rounded. All these plates are in contact. 
The slightly projecting side arm plates carry at the base of the arms eight arm spines. The three first ventral spines are very short, and the length increases from the fourth, which almost equals a segment, to the last, which is as long as two segments. The three first ventral spines have a rugose surface, and the first is transformed into a hook a few segments beyond the disk. From the fourth to the penultimate the spines show in their distal half conical, pointed, and stout denticulations, which become more closely crowded toward tho tip; this tip has almost the same thickness as the. rest of the spine. But the last dorsal spine tapers gradually to the tip and only shows slightly developed and well-spaced denticulations. All these spines are glassy and very transparent.

The tentacle scale is small, oval, and a little longer than broad.

The general color is a light greenish gray; the radial shields have a few gray-blue spots, and the dorsal plates of the disk also show a few small and barely evident spots. The upper arm plates are studded with elongated dark-blue spots, which tend to arrange themselves in three irregular and interrupted longitudinal lines, one median and two lateral. The ventral surface of the disk in the parts covered with plates is light gray, but the naked regions are dark brown; the ventral surface of the arms is light gray; the under arm plates show a median band which is lighter than the lateral portions, but the difference in the coloration is scarcely noticeable.

Affinities and distinctive features.-Ophiothrix prostrata seems to me to be near 0 . plana, and the plates of the dorsal surface of the disk have an arrangement very much like that seen in that species, but they are provided with cylindrical club spines and the radial shields are relatively larger than in 0 . plana; the arm spines are provided with denticulations only in their distal half, though this portion of the spines is not broadened. There is also a rather close similarity to 0 . liodisca recently described by H. L. Clark ('15, p. 273 , pl. 12, fig. 3 ) from Torres Straits. This species is placed by the author near the genus Ophiotrichoides, but it seems to me clearly to belong to the group of O. plana; judging from H. L. Clark's photograph the arrangement of the dorsal plates of the disk is identical with that shown in this species; the arm spines are slightly broadened in their terminal portion, which bears denticulations; on the other hand, 0 . liodisca differs sharply from 0 . plana in its very long arms. Ophiothrix prostrata is distinguished from $O$. liodisca by the same characters which differentiate it from 0 . plana. The form of the arm spines and the arrangement of the dorsal plates of the disk bring 0 . prostrata near $O$. foveolata, but it differs from it at once in the presence of small club-spines instead of true spines on the dorsal surface of the disk, in the elongated upper and under arm plates, in its larger mouth shields, and in its coloration. There 
is also some resemblance between our species and 0 . pbecilodisca recently described by H. L. Clark from specimens from Zanzibar ('15, p. 276, pl. 13, fig. 5). The arrangement of the plates of the dorsal surface of the disk recalls that of 0 . prostrata, with moro slender spines and smaller radial shields. H. L. Clark says that the arm spines are slender, smooth and pointed, and sometimes stouter, with the extremity thickened and spinulose; the upper and under arm plates are broader than long. The general red color, with a beautiful color pattern, is entirely different from that of $O$. prostrata.

\section{OPHIOTHRIX PROTEUS Kohler.}

Plate 36 , figs. 3,4 ; plate 101 , fig. 3.

See for bibliography:

Ophiothrix proteus KGHLER ('05), p. 100; ('07), p. 336.-H. L. CLARK ('15), p. 277.

Localities.-Albatross station 5152; Sulu (Joló) Archipelago, Tawi Tawi Group; Pajumajan Island (W.) bearing S. $2^{\circ}$ W., 3.71 kilometers (2 miles) distant (lat. $5^{\circ} 22^{\prime} 55^{\prime \prime} \mathrm{N}$., long. $120^{\circ} 15^{\prime} 45^{\prime \prime}$ E.) ; 62 meters (34 fathoms); February 18, 1908; wh. S.

One specimen (Cat. No. E. 152, U.S.N.M.).

Albatross station 5432; eastern Palawan and vicinity; Corandagos Island (NW.) bearing N. $30^{\circ}$ E., 10.56 kilometers (5.7 miles) distant (lat. $10^{\circ} 37^{\prime} 50^{\prime \prime} \mathrm{N}$., long. $120^{\circ} 12^{\prime} 00^{\prime \prime}$ E.) ; 93 meters ( 51 fathoms) ; April 8, 1909; S.

One specimen (Cat. No. E. 151, U.S.N.M.).

Notes.-In the specimen from station 5432 the diameter of the disk is $5 \mathrm{~mm}$., and the arms are about $50 \mathrm{~mm}$. in length; in the other the diameter of the disk reaches almost $7 \mathrm{~mm}$, but the arms are very incomplete.

The hook formed by the first ventral arm spine is rather narrow and somewhat elongated; it shows three or four branches, the first stouter than the others (pl. 101, fig. $3 d$ ). The tentacle scale (fig. $3 c$ ) is elongated and shows on its free border a few spines one of which is usually more developed than the others.

In the specimen from station 5152 the coloration agrees with that which I have described, and all along the median dorsal line of the arms there extends a white band bordered on either side by a narrower purple line. The ventral surface of the arms shows a broad white line, which also extends the whole length of the arms and which is bordered by a somewhat irregular broad pink band.

In the specimen from station 5152 the white band which extends along the median line of the arms is extremely narrow, and it is often interrupted toward the proximal and distal borders of each upper arm 
plate; it is bordered on either side by a very much broader dark green line. It might be said just as well that the median dorsal line of the arms throughout its whole length is occupied by a dark green band with a light line in the middle. The ventral surface of the disk and of the arms shows the same coloration as that of the specimen from station 5432 .

I include two photographs of this latter which will supplement the schematic figures which I published in 1898 (pl. 36, figs. 3, 4).

Ophiothrix proteus was discovered by the Investigator at Pointe de Galle, Ceylon, in 34 fathoms; the Siboga found the species again in numerous localities among the Sunda Islands from the surface down to 83 meters ( 46 fathoms) ; the Paris Museum possesses a specimen from New Caledonia.

\section{OPHIOTHRIX PURPUREA Martens.}

Plate 58, figs. 3,4 ; plate 101 , fig. 6 .

See for bibliography:

Ophiothrix purpurea KaHLER ('05), p. 102; ('07a), p. 336; ('07b), p. 253.-H. L. Clark ('15), p. 277.

Localities-Albatross station 5108; China Sea, off southern Luzon; Corregidor Light bearing N. $39^{\circ}$ E., 41.70 kilometers (22.5 miles) distant (lat. $14^{\circ} 05^{\prime} 05^{\prime \prime} \mathrm{N}$., long. $120^{\circ} 19^{\prime} 45^{\prime \prime}$ E.) ; 24 meters (13 fathoms); January 15, 1908; Co.

One specimen (Cat. No. 41258 , U.S.N.M.).

Albatross station 5179 ; vicinity of Romblon; Romblon Light bearing S. $56^{\circ}$ E., 8.34 kilometers (4.5 miles) distant (lat. $12^{\circ} 38^{\prime} 15^{\prime \prime} \mathrm{N}$., long. $122^{\circ} 12^{\prime} 30^{\prime \prime}$ E.) ; 68 meters (37 fathoms); March 25, 1908; hrd. S.

Four specimens (Cat. No. 41260 , U.S.N.M.).

Albatross station 5257; southern Mindanao, eastern Illana Bay; Utara Point, Bongo Island, bearing N. $88^{\circ}$ W., 14.27 kilometers (7.7 miles) distant (lat. $7^{\circ} 22^{\prime} 12^{\prime \prime} \mathrm{N}$., long. $124^{\circ} 12^{\prime} 15^{\prime \prime}$ E.) ; 51 meters (28 fathoms); May 22, 1908; M.

One specimen (Cat. No. 41259 , U.S.N.M.).

Notes.-All the Albatross specimens are of small size; in the largest, which is that from station 5179, the diameter of the disk is only $5 \mathrm{~mm}$.

I include photographs of a specimen from the Sunda Islands from my own collection, which will show the form of the radial shields and of the upper arm plates, the outlines of which do not appear clearly in the photographs which Döderlein published in 1899 ('99, pl. 17, fig. 23); these photographs will permit the easy appreciation of the differences which separate $O$. purpurea from 0 . lepida. 
The hook which represents the first ventral arm spine is rather stout, provided with two or three thick and stout points, and conforms to the type most frequent among the species of Ophiothrix (pl. 101, fig. $6 c$ ). The tentacle scale is large and stout, somewhat elongated, and terminates in a stout point which is broad at the base and very sharp (fig. $6 d$ ).

Ophiothrix purpurea has been met with in a number of localities in the Indo-Pacific region, among the Sunda Islands, at New Caledonia, on the southwest coasts of Australia, at Madagascar, etc. It is a littoral species, though the Siboga dredged it at very varying depths down to 113 meters (62 fathoms), and one specimen from station $65 a$ (lat. $7^{\circ}$ S., long. $120^{\circ} 34^{\prime}$ E.) bears a label reading 400 to 120 meters ( 220 to 68 fathoms).

\section{OPHIOTHRIX PUSILLA Lyman.}

Plate 40 , figs. 6,7 ; plate 101 , fig. 8 .

See for bibliography:

Ophiothrix pusilla KGEHLER ('05), p. 85, pl. 9, fig. 7; ('07), p. 337.-H. L. Clark ('15), p. 278.

Localities.-Albatross station 5158; Sulu (Joló) Archipelago; Tawi Tawi Group; Tinakta Island (N.) bearing N. $89^{\circ}$ W., 3.52 kilometers (1.9 miles) distant (lat. $5^{\circ} 12^{\prime} 00^{\prime \prime} \mathrm{N}$., long. $119^{\circ} 54^{\prime} 30^{\prime \prime}$ E.) ; 22 meters (12 fathoms) ; February 21,1908 ; crs. S., Sh.

Two specimens (Cat. No. 40957, U.S.N.M.).

Albatross station 5215; east of Masbate Island; Palanog Light bearing S. $5^{\circ} 30^{\prime} \mathrm{E}$., 15.75 kilometers (8.5 miles) distant (lat. $12^{\circ} 31^{\prime}$ $30^{\prime \prime}$ N., long. $123^{\circ} 35^{\prime} 24^{\prime \prime}$ E.) ; 1,105 meters (604 fathoms) ; April 21, 1908; gn. M.

One specimen.

Albatross station 5218; between Burias and Luzon; Anima Sola Island (E.) bearing N. $10^{\circ}$ W., 3.71 kilometers (2 miles) distant (lat. $13^{\circ} 11^{\prime} 15^{\prime \prime} \mathrm{N}$., long. $123^{\circ} 02^{\prime} 45^{\prime \prime}$ E.) ; 36 meters (20 fathoms) ; April 22, 1908; crs. S.

Two specimens (Cat. Nos. 40954, 40956, U.S.N.M.).

Albatross station 5249; Gulf of Dávao; Laneng Paint bearing N. 1.85 kilometers ( 1 mile) distant (lat. $7^{\circ} 06^{\prime} 06^{\prime \prime} . \mathrm{N}$., long. $125^{\circ} 40^{\prime}$ $08^{\prime \prime}$ E.) ; 42 meters (23 fathoms) ; May 18, 1908; Co., S.

One specimen (Cat. No. 40955, U.S.N.M.).

Albatross station 5400; north of Cebu; Tanguingui Island Light bearing $\mathrm{N} .77^{\circ} \mathrm{W} ., 41.70$ kilometers (22.5 miles) distant (lat. $11^{\circ} 24^{\prime}$ $24^{\prime \prime}$ N., long. $124^{\circ} 05^{\prime} 30^{\prime \prime}$ E.) ; 46 meters (25 fathoms); May 16, 1909 ; S. Sh.

One specimen (Cat. No. 40958, U.S.N.M.). 
Notes.-Although Ophiothrix pusilla is easily recognizable, I have thought it well to include two photographs of the specimen from station 5249, which will supplement the figures published by Lyman and by myself.

The hook representing the first ventral arm spine has two or three branches and does not show any distinctive character (pl. 101, fig. $86)$. The tentacle scale is very small, and terminates in a very long point (fig. $8 a$ ).

Ophiothrix pusilla is an essentially littoral species which has been found in many localities in the Indo-Pacific region. The Siboga dredged in the Sunda Archipelago at depths between 22 and 54 meters (12 to 30 fathoms).

\section{OPHIOTHRIX SIGNATA, new species:}

Plate 36, figs. 1, 2.

Locality.-Albatross station 5140; vicinity of Joló; Joló Light bearing S. $33^{\circ}$ W., 11.30 kilometers (6.1 miles) distant (lat. $6^{\circ} 08^{\prime}$ $45^{\prime \prime}$ N., long. $121^{\circ} 03^{\prime} 00^{\prime \prime}$ E.) ; 139 meters (76 fathoms) ; February 14, 1908 ; fne. co. S.

One specimen (Cat. No. 41069 , U. S.N.M.).

Description.-The diameter of the disk is $11 \mathrm{~mm}$.; the arms are unfortunately all broken off at the base and the longest is preserved for a length of $17 \mathrm{~mm}$. only.

The disk is pentagonal. Between the radial shields, which are very large, the dorsal surface shows numerous small, thickened, rounded plates with a swollen surface; each of these plates bears either a rather elongated and cylindrical club spine ending in a few short, unequal, and divergent spinules, or a true spine of greater or lesser length. Intermediates of all types between the club spines and the true spines may be found; the true spines are slender, provided with fine and pointed denticulations, irregularly arranged, and their points usually bear two or three small and very short spinules. The true spines are especially found in the central region of the disk and in the interradial spaces; they disappear toward the periphery, where only club spines occur; they are also absent from the radial spaces. These spaces, which are very narrow, are occupied by two rows of plates each of which bears its little club spine. At the periphery of the disk the plates tend to separate from each other; they are scarcely in contact, and they begin to assume the characters which they show on the ventral surface. The radial shields are very large, triangular, very much longer than broad, and their length equals two-thirds the radius of the disk. Their surface is naked except for a row of small club spines near and parallel to their radial border. The two shields of each pair are very close to each other, but they are never in con- 
tact, even at their distal angle; their internal borders are always parallel with each other for their whole length.

The ventral surface of the disk is partly naked. Passing over the sides of the disk the dorsal plates become less closely crowded, and when they reach the ventral surface they are entirely separated from each other; these plates, which are unequal, then assume a rounded form and they reach neither the mouth shields nor the genital slits; their dimensions diminish toward the mouth shields, but this diminution does not occur in a regular manner. Each plate carries a cylindrical club spine similar to those on the dorsal surface, but the spinules at the tip become shorter and shorter, and finally the club spine ends in a simply rugose point. The genital slits are very broad.

The mouth shields are triangular, very much broader than long, with a very rounded proximal angle bounded by two straight or slightly concave sides; the lateral angles are rounded and the distal border is slightly convex with a tendency to form a very small lobe in the midde. The adoral plates, which are rather thick, are triangular; they taper inwardly and are not in contact in the median interradial line; they are much broadened outwardly and send off a process separating the mouth shield from the first side arm plate. The oral plates are very high. The tooth papillae are arranged in five rather regular rows.

The upper arm plates are large, lozenge-shaped, with the four sides subequal; they are a little broader than long, with the proximal angle obtuse and the distal angle rounded; the lateral angles are rather sharp. These plates are strongly carinate, and the keel forms a narrow and very prominent line. They are all in contact.

The first under arm plate is pentagonal, with the proximal angle very rounded and bounded by two slightly excavated sides; the lateral borders are convex and they pass over by very rounded angles to the distal border, which is almost straight. The following plates are large, quadrangular, almost as long as broad, with the proximal border slightly concave, and the distal border convex and rather broadened; the sides are slightly excavated. All these plates are in contact.

The projecting side arm plates carry ten arm spines at the base of the arms, the number falling to eight and then to seven. The two first ventral spines remain rather short, and especially very slender; their dimensions then increase rapidly from the third, the length of which equals or exceeds two segments, but which remains rather slender, to the penultimate dorsal, which may reach a length of eight segments; the last spine is shorter. These spines are fine, transparent, and provided with rather small pointed teeth which are very close together and regularly arranged. The two lateral rows of 
arm spines always remain separated by a rather broad interval from the base of the arms outward.

The tentacle scale is large, elongated, half again as long as broad, with the tip somewhat broadened and provided with two or three small spinules.

The dorsal surface of the disk is pinkish gray; the radial shields are studded with small rounded spots of a rather light brownish purple; some similar, though very much smaller, spots occur on the plates in the radial spaces of the dorsal surface of the disk; in the interradial spaces these spots are very much broader and may cover the whole surface of the plates. The dorsal surface of the arms is extremely dark in color, a very dark green, almost black; this coloration extends to the whole space included between the two lateral rows of spines, that is to say, to the upper arm plates and to the adjacent portions of the side arm plates, in such a way as to form a very broad band, but the width of this band diminishes somewhat at some distance from the disk. The most projecting part of the dorsal keel is marked by a somewhat lighter and extremely narrow line which is bounded by two darker and also extremely narrow lines; sometimes this triple line can scarcely be distinguished from the very dark general coloration of the dorsal surface of the arms. The ventral surface of the disk shows a very dark brown coloration in the parts not covered with plates, but the plates themselves are of a pinkish gray. The mouth pieces and the ventral surface of the arms are of this same pinkish gray coloration; a somewhat darker band brownish in color runs all along this ventral surface on rither side and at some distance from the median line, almost follow "ng the sides of the under arm plates, and it forms a rounded spot rear the proximal border of each of these plates.

Afinities and distinctive features.-Ophiothrix signata belongs to the $O$. suensoni group and appears to be especially close to $O$. viridialb a Martens; unfortunately the description which Martens gave of this species is very short, and is not accompanied by figures; it is very difficult, therefore, to form an exact idea of it. However, certain characters attributed by Martens to 0 . viridi-alba do not agree with those which I find in my species. The radial shields are completely unarmed, the upper arm plates, which are longer than broad, are slightly carinate, and the arm spines number four or five; while in $O$. signata the radial shields bear a row of club spines along their radial border, the upper arm plates, which are slightly broader than long, are very strongly carinate, and the arm spines are very much more numerous. Regarding the coloration, Martens says that the upper arm plates are "lebhaft grün," while the coloration is so dark in O. signata that it appears almost black. 
In the key to the species of Ophiothrix which he published in the Challenger reports Lyman (p. 218) attributes to 0 . viridi-alba nine to ten arm spines, without giving any reference except to Martens' description; also I do not at all understand what this same author means by "tentacle scale running along outer edge of arm plate." Does this mean that the tentacle scale is attached along the border of the under arm plate, which is nothing remarkable and is scarcely worth the trouble of recording in a synoptic table, or has Lyman wished to indicate that the tentacle scale, running along the external border of the arm plate, reaches the length of the latter? That is what I can not understand. However that may be, 0 . signata seems to me very distinct from $O$. viridi-alba for the reasons which I have just given.

\section{OPHIOTHRIX SPINOSISSIMA KKohler.}

Plate 57, figs. 1, 2, 7 ; plate 101, fig. 5.

Ophiothrix spinosissima KøHLER ('05), p. 104, pl. 11, figs. 3-5.-H. L. Clark ('15), p. $2 S 2$.

Localities.-Albatross station 5108; China Sea, off southern Luzon; Corregidor Light bearing N. $39^{\circ}$ E., 41.70 kilometers (22.5 miles) distant (lat. $14^{\circ} 05^{\prime} 05^{\prime \prime} \mathrm{N}$., long. $120^{\circ} 19^{\prime} 45^{\prime \prime}$ E.) ; 24 meters (13 fathoms); January 15, 1908; Co.

One specimen (Cat. No. 41282, U.S.N.M.).

Albatross station 5165; Sulu (Joló) Archipelago, Tawi Tawi Group; Observation Island bearing N. $70^{\circ} \mathrm{W}$., 11.86 kilometers (6.4 miles) distant (lat. $4^{\circ} 58^{\prime} 20^{\prime \prime}$ N., long. $119^{\circ} 50^{\prime} 30^{\prime \prime}$ E.) ; 16 meters (9 fathoms); February 24, 1908; Co.

One specimen (Cat. No. 41281, U.S.N.M.).

Notes.-The two specimens are of small size, as was also the type upon which I established this species; in the specimen from station 5108, which is almost complete, the diameter of the disk is $4 \mathrm{~mm}$, and the arms are about $20 \mathrm{~mm}$. long; the other specimen is a little smaller, and the arms are preserved for a lesser length.

In the first individual the radial shields are very large, a little larger than the second, and the covering of the dorsal surface of the disk consists chiefly of club spines ending in long and fine spinules, while the true spines are not at all numerous; perhaps a certain number of the latter have been torn away. In the specimen from station 5165 , on the other hand, the true spines are very numerous; they are very long and very fine, pointed at the tip and denticulate throughout their whole length.

The upper arm plates are elongated, lozenge shape, relatively a litttle broader in the specimen from station 5108 than in the other, and they are perceptibly elevated, or better thickened, in their distal region. The under arm plates are much elongated and strongly notched on their distal border. 
The hook which represents the first ventral arm spine is strongly developed and robust almost to the base of the arms; it carries three large thick spines; the two first are almost of the same size, and the

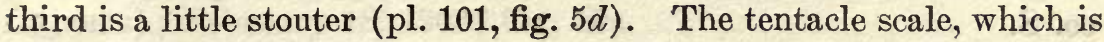
very small, ends in a long point and recalls that of $O$. pusilla $(e)$.

The coloration of the two specimens from the Philippines is slightly different from that of the Siboga specimen which served me for the type of the species; as a whole the general coloration is gray with blue spots. In the specimen from station 5108 the dorsal surface of the disk is gray, with a rounded blue spot on each radial shield; this spot is very close to the internal border and the distal angle of the shield. Each upper arm plate regularly shows at its base and on either side of the median line a small blue spot, and there is further an indication of a white median line bordered by darker areas extending throughout the whole length of the arms. The ventral surface of the disk is dark brown, and the arms are yellowish gray without blue spots.

In the specimen from station 5165 the blue markings are more accentuated. Each radial shield bears a large blue spot toward its distal angle, and within this there is another smaller. The dorsal surface of the arms shows broad blue transverse striae which cover the proximal part of the upper arm plates and of the side arm plates. The ventral surface shows the same coloration as in the other; in both the spines of the disk and of the arms are gray.

Ophiothrix spinosissima was discovered by the Siboga at Lombock and Banda at depths between 9 and 36 meters ( 5 to 20 fathoms).

\section{OPHIOTHRIX STELLIGERA LYMan.}

Plate 53, figs. $1-5$; plate 54, figs. $1-6$; plate 55 , figs. $1-4$; plate 56 , figs. $4-7$; plate 102 , figs. $2-3$.

See for bibliography and synonymy:

Ophiothrix stelligera KoEHLER ('05), p. 87; ('07b), p. 253 ; ('10), p. 294.Macintosh ('11), p. 163.-H. L. ClakK ('14), p. 153; ('15), p. 279.

Ophiothrix ciliaris KaEhLE ('04a), p. 100.

Localities.-Albatross station 5131; Sulu (Joló) Sea, off western Mindanao; island off Panabutan Point bearing N. $20^{\circ}$ E., 0.74 kilometer (0.4 mile) distant; 49 meters (27 fathoms) ; February 6, 1908; gn. M., co. S.

One specimen (Cat No. 41033, U.S.N.M.).

Albatross station 5138; in the vicinity of Joló; Joló Light bearing S. $19^{\circ} \mathrm{E} ., 4.63$ kilometers $\left(2.5\right.$ miles) distant (lat. $6^{\circ} 06^{\prime} 00^{\prime \prime} \mathrm{N}$., long. $120^{\circ} 58^{\prime} 50^{\prime \prime}$ E.) ; 35 meters (19 fathoms) ; February 14, 1908; S., Co.

One specimen (Cat. No. 41030, U.S.N.M.). 
Albatross station 5139 ; in the vicinity of Joló; Joló Light bearing S. $51^{\circ}$ W., 6.67 kilometers (3.6 miles) distant (lat. $6^{\circ} 06^{\prime} 00^{\prime \prime} \mathrm{N}$., long. $121^{\circ} 02^{\prime} 30^{\prime \prime}$ E.) ; 36 meters (20 fathoms) ; February 14, 1908; co. S.

Thirty-four specimens (Cat. Nos. 41019, 41031, E. 130, U.S.N.M.) Albatross station 5141; in the vicinity of Joló; Joló Light bearing S. $17^{\circ} \mathrm{E}$., 10.19 kilometers ( 5.5 miles) distant (lat. $6^{\circ} 09^{\prime} 00^{\prime \prime} \mathrm{N}$., long. $120^{\circ} 58^{\prime} 00^{\prime \prime}$ E.) ; 53 meters (29 fathoms) ; February 15, 1908; co. S.

Fifty-seven specimens (Cat. Nos. 41040,41045 , E. 132, U.S.N.M.). Albatross station 5142; in the vicinity of Joló; Jolo Light bearing S. $50^{\circ} \mathrm{W} ., 7.23$ kilometers (3.9 miles) distant (lat. $6^{\circ} 06^{\prime} 10^{\prime \prime} \mathrm{N}$., long. $121^{\circ} 02^{\prime} 40^{\prime \prime}$ E.) ; 38 meters (21 fathoms) ; February 15, 1908; co. S., Sh.

Two specimens (Cat. Nos. 41034, 41036, U.S.N.M.).

Albatross station 5143; in the vicinity of Joló; Joló Light bearing S. $50^{\circ}$ W., 6.30 kilometers (3.4 miles) distant (lat. $6^{\circ} 05^{\prime} 50^{\prime \prime} \mathrm{N}$., long. $121^{\circ} 02^{\prime} 15^{\prime \prime}$ E.) ; 35 meters (19 fathoms) ; February 15, 1908; co. S.

Two specimens.

Albatross station 5144 ; in the vicinity of Joló; Joló Light bearing S. $50^{\circ}$ W., 6.30 kilometers (3.4 miles) distant (lat. $6^{\circ} 05^{\prime} 50^{\prime \prime} \mathrm{N}$., long. $121^{\circ} 02^{\prime} 15^{\prime \prime}$ E.) ; 35 meters (19 fathoms); February 15, 1908; co. S.

Fourteen specimens (Cat. Nos. 41028, 41041, E. 135, U.S.N.M.).

Albatross station 5145 ; in the vicinity of Joló; Joló Light bearing S. $16^{\circ}$ E., 1.57 kilometers $\left(0.85\right.$ mile) distant (lat. $6^{\circ} 04^{\prime} 30^{\prime \prime} \mathrm{N}$., long. $120^{\circ} 59^{\prime} 30^{\prime \prime}$ E.) ; 42 meters ( 23 fathoms) ; February 15, 1908 ; co. S., Sh.

Seven specimens (Cat. Nos. 41027, 41042, U.S.N.M.).

Albatross station 5146; Sulu (Joló) Archipelago, in the vicinity of Siasi ; Sulade Island (E.) bearing N. $18^{\circ}$ W., 6.30 kilometers (3.4 miles) distant (lat. $5^{\circ} 46^{\prime} 40^{\prime \prime}$ N., long. $120^{\circ} 48^{\prime} 50^{\prime \prime}$ E.) ; 44 meters (24 fathoms) ; February 16, 1908; co. S., Sh.

Fourteen specimens (Cat. Nos. E. 129, E. 134, E. 138, U.S.N.M.). Albatross station 5147; Sulu Archipelago, in the vicinity of Siasi; Sulade Island (E.) bearing N. $3^{\circ}$ E., 15.57 kilometers ( 8.4 miles) distant (lat. $5^{\circ} 41^{\prime} 40^{\prime \prime} \mathrm{N}$., long. $120^{\circ} 47^{\prime} 10^{\prime \prime}$ E.) ; 38 meters (21 fathoms) ; February 16, 1908; co. S., Sh.

Twenty-six specimens (Cat. Nos. 41039, 41044, E. 133, E. 139, E. 141, U.S.N.M.).

Albatross station 5148; Sulu Archipelago, in the vicinity of Siasi; Sirun Island (N.) bearing S. $80^{\circ}$ W., 7.04 kilometers (3.8 miles) distant (lat. $5^{\circ} 35^{\prime} 40^{\prime \prime}$ N., long. $120^{\circ} 47^{\prime} 30^{\prime \prime}$ E.) ; 31 meters (17 fathoms); February 16, 1908; co. S.

One specimen. 
Albatross station 5149; Sulu Archipelago, in the vicinity of Siasi ; Sirun Island (W.) bearing N. $39^{\circ}$ E., 4.45 kilometers (2.4 miles) distant (lat. $5^{\circ} 33^{\prime} 00^{\prime \prime} \mathrm{N}$., long. $120^{\circ} 42^{\prime} 10^{\prime \prime}$ E.) ; 16 meters (10 fathoms) ; February 18, 1908; Co., Sh.

\section{A few specimens.}

Albatross station 5153; Sulu Archipelago, Tawi Tawi Group; Tocanhi Point bearing S. $27^{\circ}$ E., 3.89 kilometers (2.1 miles) distant (lat. $5^{\circ} 18^{\prime} 10^{\prime \prime} \mathrm{N}$., long. $120^{\circ} 02^{\prime} 55^{\prime \prime}$ E.) ; 90 meters (49 fathoms); February 19, 1908; co. S., Sh.

Five specimens (Cat. Nos. 41020,41029 , U.S.N.M.).

Albatross station 5158; Sulu Archipelago, Tawi Tawi Group; Tinakta Island (N.) bearing N. $89^{\circ}$ W., 3.52 kilometers (1.9 miles) distant (lat. $5^{\circ} 12^{\prime} 00^{\prime \prime} \mathrm{N}$., long. $119^{\circ} 54^{\prime} 30^{\prime \prime}$ E.) ; 22 meters (12 fathoms) ; February 21, 1908; crs. S., Sh.

One specimen (Cat. No. 41035 U.S.NM.).

Albatross station 5163; Sulu Archipelago, Tawi Tawi Group; Observation Island bearing N. $79^{\circ} \mathrm{W} ., 12.41$ kilometers (6.7 miles) distant (lat. $4^{\circ} 59^{\prime} 10^{\prime \prime} \mathrm{N}$., long. $119^{\circ} 51^{\prime} 00^{\prime \prime}$ E.) ; 51 meters (28 fathoms); February 24, 1908; co. S.

One specimen (Cat. No. 41022, U.S.N.M.).

Albatross station 5164; Sulu Archipelago, Tawi Tawi Group; Observation Island bearing S. $82^{\circ} \mathrm{W}, 14.82$ kilometers ( 8 miles) distant (lat. $5^{\circ} 01^{\prime} 40^{\prime \prime} \mathrm{N}$., long. $119^{\circ} 52^{\prime} 20^{\prime \prime}$ E.) ; 33 meters (18 fathoms) ; February 24, 1908; gn. M.

One specimen (Cat. No. 41038 U.S.N.M.).

Albatross station 5174; vicinity of Joló; Joló Light bearing E., 4.81 kilometers (2.6 miles) distant (lat. $6^{\circ} 03^{\prime} 45^{\prime \prime} \mathrm{N}$., long. $120^{\circ}$ $57^{\prime} 00^{\prime \prime}$ E.) ; 36 meters (20 fathoms) ; March 5, 1908; crs. S.

Eleven specimens (Cat. No. E. 137, U.S.N.M.).

Albatross station 5248; Gulf of Dávao; Lanang Point bearing S. $33^{\circ}$ W., 0.74 kilometer ( 0.4 mile) distant (lat. $7^{\circ} 07^{\prime} 25^{\prime \prime}-\mathrm{N}$., long. $125^{\circ} 40^{\prime} 24^{\prime \prime}$ E.) ; 33 meters (18 fathoms); May 18, 1908; Co.

Two specimens (Cat. No. 41037, U.S.N.M.).

Albatross station 5554; Joló Island and vicinity; Cabalian Point (Joló) bearing N. $76^{\circ}$ E., 7.04 kilometers (3.8 miles) distant (lat. $5^{\circ}$ $52^{\prime} 27^{\prime \prime}$ N., long. $120^{\circ} 52^{\prime} 18^{\prime \prime}$ E.) ; 46 meters (25 fathoms); September 18, 1909; Co., S.

Five specimens (Cat. No. E. 136, U.S.N.M.).

Marongas; canal head; shore; October 2, 1908.

Five specimens (Cat. No. E. 140, U.S.N.M.).

Philippines.

Two specimens (Cat. Nos. 41032, 41043, U.S.N.M.).

No locality.

One specimen. 
Notes.-I refer numerous specimens to Ophiothrix stelligera, of which the Albatross has collected a very fine and very interesting series showing the very considerable variations to which this species is subject, especially in regard to the armature of the dorsal surface of the disk, as may be seen by comparing my photographs on plate 53 , figures 2,3 , with those on plate 55 , figures 1,4 , showing the extremes of which the intermediate types are represented in various figures on plates 53-56. I have thought it well to include photographs of a rather large number of specimens in order to facilitate the determination of this species which is not always easy to recognize because of its variations. The coloration also shows rather considerable differences.

As was determined by Lyman, Ophiothrix stelligera is especially characterized by having the dorsal surface of the disk covered with club spines ending in a crown of five or six slightly divergent and very regular spinules, an arrangement to which the species owes its name; these club spines may pass over onto the radial shields, where they are usually less closely crowded than on the rest of the disk, and true spines may occur among them. The arrangement of the arm spines and the shape of the upper and under arm plates have been described by Lyman, by Döderlein, and by myself (see Kohler '05, p. 87). I am figuring a certain number of individuals in which the dorsal surface is covered exclusively with club spines, coming from the following stations: Station 5142 (pl. 54, fig. 3) ; station 5145 (pl. 54, figs. 1, 2) ; station 5146 (pl. 56, fig. 7) ; station 5147 (pl. 53, fig. 2); and "Philippines" (pl. 53, fig. 4). These examples are quite typical. The same is true of numerous others in which true spines, which are usually rather rare, are intermixed with the club spines; of this type are the specimens from stations 5146 (pl. 55, fig. 3) and 5147 (pl. 53, fig. 5, and pl. 56, fig. 4). In all these specimens the-few true spines are relatively little developed, remaining slender and rather short. But in others these spines may be more developed, either in numbers or in dimensions; this occurs for example in the specimen from station 5141 (pl. 54, figs. 4, 5), and especially in those from station 5144 (pl. 55, figs. 1, 2), in which these spines are very numerous and very stout, and are provided with very evident denticulations. The covering formed by these spines gives: the disk an appearance very different from that which is usually seen in $O$. stelligera. It does not seem to me possible, however, to separate these specimens specifically from those in which the spines are smaller and less numerous, or even completely lacking, for I find all possible intermediates. The radial shields may also show rather important variations, both in their size and in their covering; sometimes they are covered with club spines almost as closely placed as 
over the rest of the disk, and their outlines are scarcely evident (pl. 53 , fig. 5 ; pl. 54 , fig. 3 ) ; sometimes the club spines are less numerous (pl. 54, figs. 1, 2; pl. 55, figs. 3, 4), and in this case the radial shields usually become very large, as may be seen in the last example; in this also the variations may be very considerable.

The microsopic examination of isolated club spines from the dorsal surface of the disk shows that the spinules which surround them have not such equal dimensions nor so regular an arrangement as would be supposed from the examination of the dorsal surface of the entire animal. I give (pl. 102, figs. $2 a$ and $b$ ) photographs of a rather large number of club spines from different individuals, and it may be seen on some of them that the spinules of the same club spine are not always of the same length and of the same diameter. These differences do not appear when the dorsal surface of the disk, covered with club spines which are always very closely crowded and of which the spinules are more or less interlocked, is examined, even under the microscope; the general appearance in direct view gives to the club spines a regularly stellate appearance to which the species owes its name, and which is similar to that figured by Döderlein ('96, pl. 14, fig. 9a).

'The study of the true spines which are sometimes mixed with the club spines in 0 . stelligera has brought out in a certain number of them a very curious and quite unexpected character. These spines are sometimes bifurcated, and I find on the same specimen spines which remain simple and others which are bifurcated. These latter are always less numerous than the others, and moreover they are not found on all individuals. I give photographs of some of these bifurcated spines (pl. 102, fig. $2 f$ ). It is seen that the bifurcation occurs always very near the base, and the two branches, which are parallel to each other, remain very close together. Both of them reach almost the same length, and the variations which are found in this respect are insignificant. The length of the bifurcated spines is the same as that of the simple spines, and the structure is quite identical in the two cases, the same general appearance, the same denticulations, etc. The simple spines (pl. 102, fig. 2e) are ordinarily elongated in a perfectly straight line, but some of them show a rather sharp curvature near their base; this curvature occurs almost at the point where the bifurcation takes place in the bifurcated spines. It might be supposed that the spine belonged to a group of two and that it was separated from its fellow, but that certainly is not the case, for there is never seen any trace of that separation and the width remains the same proximal and distal to the inflection. This form is especially well seen on the second and third spines to the left which I show in fig. $2 e$. 
I am not aware that anyone has ever noticed an analogous bifurcation of the spines of the dorsal surface of the disk among the ophiurans. I know, however, of another case which I met with very recently in an Antarctic Ophiacantha collected by the Australian Antarctic expedition, which is part of an important collection the study of which has been intrusted to me; I shall have occasion to come back to it presently.

The hook formed by the first ventral arm spine at a little distance, from the disk in 0 . stelligera is strong and thick; it usually shows three branches, rarely four; the two first branches, which are subequal, are always much thickened and much elongated (pl. 102, figs. $2 c$ and $d)$.

The tentacle scale is small and terminated by a strong point; sometimes it is doubled $(g)$.

The coloration of the individuals, which is so often very constant in the different species of Ophiothrix, is extremely variable in $O$. stelligera; sometimes the general coloration is very light, generally of a pinkish gray; sometimes it is darker, gray or yellowish gray, or it may pass into red or even to a dark brick red. In the median dorsal line of the arms there may be seen a light longitudinal band bordered by two dark lines; sometimes these lines are thin and regular, and sometimes they are broken up into successive darker spots which appear toward the distal angle of the upper arm plates; sometimes the two lines are quite discontinuous and are broken up into successive elongated spots which may be very irregularly arranged and lacking on certain segments. The red or reddish specimens usually show in the median dorsal line of the arms a succession of white spots which are unequal and irregular, not forming a continuous line.

Two specimens show a very peculiar color type, which recalls that of 0 . elegans; they come from stations 5139 and 5142 ; both are of very small size and the diameter of their disks is only $4 \mathrm{~mm}$. The first (pl. 56, fig. 6), which is of a general light grayish color, has the dorsal surface of the disk covered with club spines which run over a little onto the radial shields, and among which are a very few true spines; a very dark narrow blue line with very clear borders extends along the median line of the arms to their tips. The other specimen (pl. 56, fig. 5) has a darker general coloration; the club spines of the dorsal surface of the disk cover in large part the radial shields of which the outlines are scarcely evident, and there are in addition some long and strong spines, which are rather numerous; a dark line, of a blackish violet, occurs also on the median dorsal line of the arms, but that line does not pass beyond the first ten segments. In neither of the two specimens is the dark line of the arms continued on the disk, while in 0 . elegans it reaches almost the center of it. In all the 
other characters these two specimens agree well with 0 . stelligera, and there can be no question of referring them to $O$. elegans. It may be noticed, furthermore, that this latter species is very close to $O$. stelligera, from which it is distinguished especially by the broad band which runs all along the dorsal median line of the arms and which continues over the dorsal surface of the disk to the neighborhood of the center, and by the club spines of the dorsal surface of the disk, which end in two or three unequal spinules; it is for this reason that $I$ have assigned to $O$. elegans the specinen from station 5179 which I have recorded above.

The specimens of $O$. stelligera which possess club spines only on the dorsal surface of the disk might be confused with certain species such as $O$. miles Kœhler and $O$. infirma Kohler. I have already described the principal characters which distinguish the former from 0 . stelligera ('05, p. 91) ; I may recall that the most important consists in the presence of very fine small spines on the distal border of the upper arm plates; furthermore the arm spines of $O$. miles are shorter and less strongly denticulate, and the radial shields are large and largely naked. In order to facilitate comparison I have thought it well to include three photographs of a specimen of $O$. miles collected by the Siboga (pl. 52, figs. 8,9,10). As for O. infirma, the dimensions of its tentacle scale will not permit of ever confusing it with $O$. stelligera.

There remains to be compared with 0 . stelligera, 0 . ciliaris (Lamarck). I described its characters in detail in 1904 (Kohler, 04a, p. 102) from a reexamination of the original specimens studied by Müller and Troschel which are in the Paris Museum. But it seems to me worth while, after having studied more closely the microscopical characters of the club spines of the dorsal surface of the disk in $O$. stelligera, to compare them again with those of $O$. ciliaris.

First of all I may state that the only authentic specimens of $O$. ciliaris which we have are the types preserved in the Paris $\mathrm{Mu}$ seum; they are three in number and in a deplorable state of preservation; furthermore, they are of small size and the largest reaches scarcely $6 \mathrm{~mm}$. in diameter. I include (pl. 52, fig. 6) a photograph of the dorsal surface of one of these; it bears, in addition to the club spines, a few short and thick true spines with the surface rugose and provided with short and irregular denticulations; all intermediates may be found between the typical club spines and the longest true spines. Both surfaces of a second specimen are shown, with a greater magnification (pl. 53, figs. 6,7 ); the dorsal surface of the disk bears only club spines. I show also (pl. 52, fig. 7) the third specimen from the Paris Museum, which is of very small $55269-22-$ Bul. $100-18$ 
size; its arms are incomplete and in a very bad state of preservation; the diameter of the disk is only $4 \mathrm{~mm}$. The arm spines are almost all torn away, and the dorsal surface of the disk does not have its covering of club spines intact. This specimen is remarkable for the large elongated spot of purplish black which occurs in the middle of each upper arm plate; these successive spots form a very broad longitudinal line which is interrupted at the level of each segment.

As I stated in 1904 (Kœhler '04a, p. 101, 102), the upper arm plates of the Paris Museum specimens do not have the distal border slightly trilobed as stated by Müller and Troschel and as Lyman figured it in 1874 (Lyman, '74, pl. 4, fig. 29). I imagine that this trilobed appearance of the distal border is due less to a real inflection of this border than to two dark red spots which were still to be seen toward the distal border of the upper arm plates when Müller and Troschel and later Lyman studied the types, but of which there is now no longer any trace, the specimens being completely decolorized. The form of the upper arm plates in the specimens in the Paris Museum, as I find it, does not differ from that shown in $O$. stelligera; this can not be invoked, therefore, to separate this species from $O$. ciliaris.

Regarding the club spines of the dorsal surface of the disk, Müller and Troschel say simply that this surface is covered with granules; Lyman speaks of "minute stumps," and he shows on plate 4 as figure 30 a small narrow club spine ending in a few subequal spinules.

In 1904 I emphasized the form of the under arm plates, of which the distal border is always rounded and passes over to the sides by equally rounded angles; this form, described by Müller and Troschel, was accurately figured by Lyman ('74, pl. 4, fig. 31), and it is easily recognized on the photograph which I give (pl. 53, fig. 6). I added on this subject ('04a, p. 102) : Je crois pouvior poser en principe que toute Ophiothrix dont les plaques brachiales ventrales n'auraient pas le bord distal arrondi et convexe n'est point une 0 . ciliaris." It is evidently from not having sufficiently studied the form of the under arm plates that certain authors have confused $O$. ciliaris with other species.

The under arm plates of $O$. stelligera alsu have the distal border rounded and convex, as Lyman has described and figured it ('74, p. 237, pl. 3, fig. 15), and no more than in the case of the upper arm plates can their shape furnish a character allowing the differentiation of 0 . stelligera from $O$. ciliaris.

It was for these reasons that in $1904 \mathrm{I}$ was only able definitely to invoke a single character for the separation of these two species; this was the form of the club spines of the dorsal surface of the 
disk which are terminated in 0 . ciliaris by a few short and unequal spinules instead of as in $O$. stelligera by a very regular crown of spinules with the so characteristic stellate appearance (Kœhler '04, p. 102). Only it is necessary here to show an important difference. It is especially in examining the dorsal surface of the disk of $O$. stelligera as a whole, and without isolating the club spines, under a lens or under a microscope that this stellate form so characteristic of their heads, such as Döderlein has represented and as is seen again in my photograph, is noticed; but as I have explained above, when these club spines are isolated, and when instead of being viewed directly from above, they are seen in profile, the length and the thickness of each spinule may be judged exactly, and it may then be seen that these are far from being perfectly identical.

On isolating the club spines of the disk of the $O$. ciliaris preserved in the Paris Museum and examining them under the microscope, I was struck with their perfect resemblance to the club spines of the same size in my 0 . stelligera. If we compare the club spines of $O$. stelligera shown in plate 102 as figures $2 a$ and $b$ with those of $O$. ciliaris (fig. 3), we can not determine any important difference; sometimes the spinules are fairly regularly arranged and almost equal, sometimes they are unequal, as may also be the case in 0 . stelligera. These spinules are sometimes shorter, sometimes longer, but these variations have no importance and do not have to be considered. Furthermore, I find these same variations in the different specimens of $O$. ciliaris which I have examined, both in those of the Paris Museum and in those of the Challenger expedition. Also we notice that the club spines of $O$. ciliaris have the spinules shorter than is usual in $O$. stelligera, but I find in different specimens of the latter some club spines absolutely identical with those seen in $O$. ciliaris.

It is impossible to find in the characters of the club spines of the dorsal surface of the disk any important differences permitting the separation of 0 . stelligera from the type specimens of $O$. ciliaris preserved in the Paris Museum. I believe, therefore, that they must belong to the same species.

I am convinced that when Lyman established 0 . stelligera he forgot to compare it with 0 . ciliaris, for if he had then referred to the characters of this latter species he would certainly have been struck with the resemblances which they present. He would have been able at least to indicate these resemblances and to explain why he thought it necessary to create by the side of 0 . ciliaris the new species which he called stelligera, while he was content to compare the latter with $O$. carinata and $O$. pusilla. And Lyman knew $O$. ciliaris well, because he speaks of the original specimens which he had studied at the 
Paris Museum. Curiously enough, his description of 0 . stelligera ('74, p. 237) is found in the same work and a few pages further on than the few observations added (p. 233) by the learned naturalist to the description of $O$. ciliaris given by Müller and Troschel, as a result of the study which he had made at Paris of the original specimens.

Obviously, if the rule of priority were strictly adhered to the name stelligera would have to disappear and the species would have to be called $O$. ciliaris. But I think we should retain the name stelligera. It refers to well-known forms studied by numerous zoologists, of which there exist in collections numerous specimens to which it is easy to refer. Ophiothrix ciliaris, on the other hand, is only represented by three specimens in a very poor state of preservation and incomplete, and in however slight a degree they may be the object of further examination, they will of necessity be broken up and will be definitely lost. Furthermore, the name $O$. ciliaris has been wrongly applied by different authors and in many different ways. Thus Lyman ('82, p. 220) has recorded among the ophiurans of the $C$ hallenger expedition $O$. ciliaris, which was found near Cebu (lat. $10^{\circ} 10^{\prime}$ N., long. $123^{\circ} 55^{\prime}$ E.) ; 74-183 meters (95-100 fathoms). I have had occasion to study some of these Challenger specimens, which were once given me by Prof. F. Jeffrey Bell, and I can state that they agree neither with the types of $O$. ciliaris nor with $O$. stelliger $a$, whatever may be the opinion adopted on the relative value of these two species. In these specimens the distal border of the under arm plates is concave, and this character of itself suffices to exclude all approximation. The club spines of the dorsal surface of the disk are rather stout, somewhat elongated, and unequal, and they are armed with very unequal spinules. These specimens secm to me identical with those which I recorded in 1904 ('04a, p. 103) and which are in the Berlin Museum under the label " $O$. ciliaris Rothes Meer, No. 3358." These specimens approach forms such as $0 . m a-$ renzelleri rather than $O$. stelligera; I propose to come back to them some day.

In 1884 Professor Bell recorded O. ciliaris from Port Jackson. New South Wales. Was he referring to $O$. stelligera, or was his species not rather $O$. coespitosa? In recording $O$. ciliaris from Japan, H. L. Clark ('11, p. 257) suggests that this species is perhaps only a form of $O$. koreana. It is superfluous to state that $I$ can not agree at all with this point of view, for the original specimens of $O$. ciliaris, as well as the numerous known specimens of $O$. stelligera, never show the club spines terminated by three long spinules, and the form of their upper arm plates is different from that which we know in $O$. lioreana. On this subject I recall also that Brock considered $O$. 
merguiensis Duncan às identical with $O$. ciliaris; $I$ have already criticized this approximation ('04a, p. 102), and I shall not return to it.

\section{OPHIOTHRIX STRIOLATA Grube.}

Plate 33 , figs. 1,2 ; plate 34 , fig. 5 ; plate 102 , fig. 1.

\section{See for bibliography:}

Ophiothrix striolata KळеHLEB ('05), p. 76, pl. 15, fig. 9; ('07), p. 338; ('07b), p. 253.-H. I. Clark ('15), p. 279.

Localities.-Albatross station 5139 ; in the vicinity of Joló; Joló Light bearing S. $51^{\circ}$ W., 6.67 kilometers (3.6 miles) distant (lat. $6^{\circ}$ $06^{\prime} 00^{\prime \prime} \mathrm{N}$., long. $121^{\circ} 02^{\prime} 30^{\prime \prime}$ E.) ; 36 meters (20 fathoms); February 14,1908 ; co. S.

One specimen (Cat. No. 41121 , U.S.N.M.).

Albatross station 5146; Sulu (Joló) Archipelago, in the vicinity of Siasi; Sulade Island (E.) bearing N. $18^{\circ}$ W., 6.30 kilometers (3.4 miles) distant (lat. $5^{\circ} 46^{\prime} 40^{\prime \prime}$ N., long. $120^{\circ} 48^{\prime} 50^{\prime \prime}$ E.) ; 44 meters (24 fathoms); February 16, 1908; co. S., Sh.

Two specimens (Cat. No. E. 185, U.S.N.M.).

Albatross station 5147; Sulu Archipelago, in the vicinity of Siasi; Sulade Island (E.) bearing N. $3^{\circ}$ E., 15.57 kilometers (8.4 miles) distant (lat. $5^{\circ} 41^{\prime} 40^{\prime \prime} \mathrm{N}$., long. $120^{\circ} 47^{\prime} 10^{\prime \prime}$ E.) ; 38 meters (21 fathoms); February 16, 1908 ; co. S., Sh.

One specimen (Cat. No. 41119 , U.S.N.M.).

Albatross station 5159; Sulu Archipelago, Tawi Tawi Group; Tinakta Island (N.) bearing N. $82^{\circ}$ W., 2.59 kilometers (1.4 miles) distant (lat. $5^{\circ} 11^{\prime} 50^{\prime \prime} \mathrm{N}$., long. $119^{\circ} 54^{\prime} 00^{\prime \prime}$ E.) ; 18 meters (10 fathoms); February 21, 1908; co. S.

One specimen (Cat. No. E. 184, U.S.N.M.).

Albatross station 5355; north Balabac Strait; Balabac Light bearing S. $61^{\circ}$ W., 30.76 kilometers (16.6 miles) distant (lat. $8^{\circ} 08^{\prime} 10^{\prime \prime}$ N., long. $117^{\circ} 19^{\prime} 15^{\prime \prime}$ E.) ; 80 meters (44 fathoms) ; January 5, 1909 ; Co., S.

One specimen (Cat. No. 41123 , U.S.N.M.).

Albatross station 5401; north of Cebu; Tanguingui Island Light bearing $\mathrm{N}$. $79^{\circ} \mathrm{W} ., 42.62$ kilometers (23 miles) distant (lat. $11^{\circ} 24^{\prime}$ $45^{\prime \prime}$ N., long. $124^{\circ} 06^{\prime} 00^{\prime \prime}$ E.) ; 55 meters (30 fathoms); March 16, 1909 ; fne. S.

One specimen (Cat. No. E. 186, U.S.N.M.).

No locality.

Two specimens (Cat. Nos. 41120, 41122, U.S.N.M.).

Notes.-The specimen from station 5146 is very typical. The disk has a diameter of $13 \mathrm{~mm}$., and the arms are almost $60 \mathrm{~mm}$. long. The radial shields are not very large, and the interradial regions of 
the dorsal surface of the disk are furnished with elongated and numerous spines. The distal portion of the radial shields shows a light blue spot and their surface is also studded with dark blue points. The arms show blue striae which are alternately longer and shorter; the shorter consist of an elongated and narrow blue line, the longer of dark blue dots immersed in a light blue spot.

The other specimens are also very typical, excepting that from station 5401. I figure this last (pl. 33, figs. 1, 2). The diameter of its disk varies between 13 and $14 \mathrm{~mm}$, and the arms are very much more elongated than usual, their length reaching at least $80 \mathrm{~mm}$.; they are extremely slender in their distal third. The radial shields are very large and the rest of the disk is covered with extremely short spines. The radial shields show dark blue dots with a more or less developed light blue spot toward the distal extremity. The colored dots on the arms do not form the type of striae to which the species owes its name; instead of these there occurs toward the distal border of each upper arm plate two dark blue dots surrounded by a clearer ring; sometimes another dot occurs somewhere on the surface of the plate.

I have thought it best to record the peculiarities which this specimen shows, though they evidently are not sufficient for separating it from the others. The most important difference is found in the arms, which are very much longer than usual; as for the dimensions of the radial shields, they are susceptible of very great variation in $O$. striolata. In my collection I have an 0 . striolata from the Sunda Archipelago in which these radial shields are as large as in the specimen from station 5401; the spines of the dorsal surface are very much more developed than in the latter, though they are very much less numerous than in the specimen from station 5146, and the arms are not longer than usual. I include a photograph of the dorsal surface of this specimen (pl. 34, fig. 5). I also give a photograph of some spines from the dorsal surface of the disk of the specimen from station 5146 (pl. 102, fig. 1a). The hook formed by the first ventral arm spine has the usual form and show three or four branches (fig. 1d). The tentacle scale usually ends in a rather strong point to which there may be added one or two others smaller $(b)$.

Ophiothrix striolata has been found in different localities in the Indian Ocean, and it scarcely ever leaves the littoral region; the Siboga met with it in the Sunda Archipelago at depths varying from 12 to 59 meters (7 to 33 fathoms). 
Plate 46 , figs. $1-3$; plate 102 , fig. 4.

See for bibliography:

Ophiothrix trilineata LoRIOL ('93), p. 43.-KGEHLER ('05), p. 73; ('07), p. 339.-H. L. Clark ('15), p. 279.

Locality.-Albatross station 5109; China Sea, off southern Luzon; Corregidor Light bearing N. $42^{\circ}$ E., 47.81 kilometers (25.8 miles) distant (lat. $14^{\circ} 03^{\prime} 45^{\prime \prime} \mathrm{N}$., long. $120^{\circ} 16^{\prime} 30^{\prime \prime}$ E.) ; 22 meters (12 fathoms); January 15, 1908; Co.

Five specimens (Cat. No. 41336, U.S.N.M.).

Notes.-The specimens are not in very good condition, but the determination is not open to question. I have not been able to obtain good photographs of them, but I include photographs of a specimen in good state of preservation which I have in my own collection and which comes from Mauritius. I have chosen this specimen for illustration in order to show that the three light lines which run all along the dorsal surface of the arms are not always well marked; at least the two lateral lines do not always have very clear outer borders, for the darker bordering which often occurs beyond them may be only barely indicated.

On plate 102 as figure 4 I give photographs of some arm spines ( $a$ and $b$ ), of some spines from the dorsal surface of the disk $(d)$, of the tentacle scale, which ends in a rather stout point $(c)$, and of the hook representing the first ventral arm spine $(e)$; this last has the usual form, with three branches.

Ophiothrix trilineata is very widely distributed in the Indo-Pacific region; the Siboga dredged it at different stations among the Sunda Islands at depths up to 54 meters (30 fathoms), and a specimen from the anchorage of Pasir-Pandjan was even labeled 278 meters (154 fathoms).

\section{OPHIOTHRIX VITREA Döderlein.}

Plate 48 , figs. $1-4$; plate 102 , fig. 5 .

Ophiothrix vitrea DöDerLein ('96), p. 295 , pl. 14, fig. 10 ; pl. 16, fig. 21.Koemler ('98), p. 101.-H. L. Claruk ('15), p. 282.

Localities.-Albatross station 5139 ; in the vicinity of Joló; Joló Light bearing S. $51^{\circ}$ W., 6.67 kilometers ( 3.6 miles) distant (lat. $6^{\circ} 06^{\prime} 00^{\prime \prime}$ N., long. $121^{\circ} 02^{\prime} 30^{\prime \prime}$ E.) ; 36 meters (20 fathoms) ; February 14,1908 ; co. S.

One specimen (Cat. No. 41324, U.S.N.M.).

Albatross station 5179; in the vicinity of Romblon; Romblon Light bearing S. $56^{\circ}$ E., 8.34 kilometers (4.5 miles) distant (lat. 
$12^{\circ} 38^{\prime} 15^{\prime \prime}$ N., long. $122^{\circ} 12^{\prime} 30^{\prime \prime}$ E.) ; 68 meters (37 fathoms) ; March 25, 1908; hrd. S.

One specimen (Cat No. 41323, U.S.N.M.).

Albatross station 5593; Sibuko Bay, Borneo and vicinity; Mount Putri (sea tangent), Borneo, bearing N. $52^{\circ} \mathrm{W}$., 31.87 kilometers (17.2 miles) distant (lat. $4^{\circ} 02^{\prime} 40^{\prime \prime} \mathrm{N}$., long. $118^{\circ} 11^{\prime} 20^{\prime \prime} \mathrm{E}$. ) ; 70 meters (38 fathoms); September 29, 1909; fne. S.

One specimen (Cat. No. 41322, U.S.N.M.).

Notes.-The specimen from station 5593 is in a very good state of preservation, and the arms are almost complete; the diameter of the disk is $5.5 \mathrm{~mm}$., and the arms exceed $45 \mathrm{~mm}$. (pl. 48, figs. 1, 3) in length. The two others have the arms broken off at a greater or lesser distance from the base. The specimen from station 5139 is the smallest, and its disk is only $3.5 \mathrm{~mm}$. in diameter, while that from station 5179 is larger, its disk diameter being $7 \mathrm{~mm}$.

The specimens from stations 5139 and 5593 (figs. 1, 2) have the dorsal surface of the disk uniformly covered with fine and closely crowded club spines ending in three large, divergent, and extremely slender spinules, while on that from station 5179 the club spines are mixed with elongate and very fine true spines (fig. 4). I give a few photographs of these club spines (pl. 102, fig. 5c). They are always trifid, with subequal spinules; the only variations which they show concern the relative size of the stem and of the terminal spinules; sometimes the stem is short and rather broad, with strong and very long spinules, and sometimes the stem is slender and elongated with the spinules weaker and shorter. The tentacle scale is rather large and terminates in a chief point accompanied by a few other smaller points (fig. $5 b$ ). The hook which the first ventral spine very soon forms is of the usual type $(a)$; it is rather elongated, but usually the terminal branch only is well developed and very strong, the others remaining very slender and narrow. The second arm spine is rather thick and its denticulations, which are more closely crowded toward the extremity, are very stout $(d)$, while the other spines are very narrow with very fine denticulations $(e)$.

In 1898 I recorded three specimens of $O$. vitrea collected by the Investigator among the Andaman Islands and on the Malabar coast; their scheme of coloration was a little different from that of the single specimen which served Döderlein as his type, but, as I stated, this latter naturalist, to whom I sent one of my specimens, considered that it was $O$. vitrea. The three individuals collected by the Albatross recall those of the Investigator in their coloration; that is to say the dorsal surface of the arms shows a purple median line, on each side of which is a white band and outside of that another purple line. The median purple line is not always entirely continuous, and it is 
more or less obliterated toward the distal border of each upper arm plate.

The specimen from station 5593 has a general very light pinkish gray color; the two others have the arms more red; the arm spines are always uncolored and perfectly transparent.

In the three specimens the radial shields are provided over almost their whole area with more or less numerous club spines which leave the distal region only naked.

The type of $O$. vitrea was found at Amboina; the specimens collected by the Investigator in the Indian Ocean came from the Andaman Islands and the Malabar coast from a depth of 36 fathoms.

\section{OPHIOGYMNA ELEGANS Ljungman.}

Plate 43 , figs. $3-8$; plate 103 , fig. 4 .

Ophiogymna elegans Ljungman ('66), p. 163.-H. L. Clark ('15), p. 286; pl. 12 , figs. 7,8 .

Ophiocampsis inermis KaEHLER ('05), p. 115, pl. 13, fig. 3.

Localities.-Albatross station 5151; Sulu (Joló) Archipelago, Tawi Tawi Group; Sirun Island (C.) bearing N. $58^{\circ}$ E., 35.77 kilometers (19.3 miles) distant (lat. $5^{\circ} 24^{\prime} 40^{\prime \prime}$ N., long. $120^{\circ} 27^{\prime} 15^{\prime \prime}$ E.) ; 44 meters (24 fathoms); February 18, 1908; co. S., Sh.

Five specimens (Cat. Nos. 41284, 41285, E. 62, U.S.N.M.).

Albatross station 5152; Sulu Archipelago, Tawi Tawi Group; Pajumajan Island (W.) bearing S. $2^{\circ}$ W., 3.71 kilometers (2 miles) distant (lat. $5^{\circ} 22^{\prime} 55^{\prime \prime}$ N., long. $120^{\circ} 15^{\prime} 45^{\prime \prime}$ E.) ; 62 meters (34 fathoms); February 18, 1908; wh. S.

Two specimens (Cat. No. E. 59, U.S.N.M.).

Albatross station 5154; Sulu Archipelago, Tawi Tawi Group; Bakun Point bearing S. $11^{\circ}$ W., 1.30 kilometers ( 0.7 mile) distant (lat. $5^{\circ} 14^{\prime} 50^{\prime \prime} \mathrm{N}$., long. $119^{\circ} 58^{\prime} 45^{\prime \prime}$ E.) ; 22 meters (12 fathoms); February 19, 1908; co. S.

Seven specimens (Cat. Nos. E. 63, E. 65, U.S.N.M.).

Albatross station 5165; Sulu Archipelago, Tawi Tawi Group; Observation Island bearing $\mathrm{N} .70^{\circ} \mathrm{W} ., 11.86$ kilometers (6.4 miles) distant (lat. $4^{\circ} 58^{\prime} 20^{\prime \prime} \mathrm{N}$., long. $119^{\circ} 50^{\prime} 30^{\prime \prime}$ E.) ; 16 meters (9 fathoms); February 24, 1908; Co.

One specimen (Cat. No. E. 64, U.S.N.M.).

Albatross station 5253; Gulf of Dávao; Linao Point bearing N. $22^{\circ}$ E. 2.78 kilometers (1.5 miles) distant (lat. $7^{\circ} 04^{\prime} 48^{\prime \prime} \mathrm{N}$., long. $125^{\circ}$ $39^{\prime} 38^{\prime \prime}$ E.) ; 51 meters (28 fathoms) ; May 18, 1908; Co.

Fifteen specimens (Cat. Nos. E. 60, E. 61, E. 66, U.S.N.M.).

Notes. - The genus Ophiocampsis established by Duncan in 1886 for an ophiuran from the Mergui Archipelago, to which he gave the name of $O$. pellicula, is evidently identical with the genus Ophio- 
gymna which Ljungman created in 1866 and of which the type is $O$. elegans from Singapore and Hongkong. This genus must, therefore, disappear from zoölogical nomenclature. The species which I described in 1905 under the name of Ophiocampsis inermis is synonymous with Ophiogymna elegans, and Duncan's Ophiocampsis pellicula must be called Ophiogymna pellicula. We shall see later on that the genus Ophiogymna, the characters of which I shall define, must include, in addition to these two species assigned heretofore to the genus Ophiocampsis, a few others previously placed by myself in the genus Ophiothrix. Before beginning the discussion of the characters and the limits of the genus Ophiogymna, I shall give some notes on the specimens collected by the Albatross.

These specimens agree very well with those collected by the Siboga in the Sunda Archipelago which I described under the name of ophiocampsis inermis. All these individuals are distinguished from 0 . pellicula by the entire absence of spines or of granules from the disk. The diameter of the disk varies between $5 \mathrm{~mm}$. and $9 \mathrm{~mm}$.; two specimens from station 5151 are extremely small; I shall speak of them further on.

The general coloration of the specimens in alcohol is pinkish, tending more or less toward yellow, with more or less numerous red dots on the dorsal surface of the disk; there is usually a spot outside of each radial shield and another within the two shields of each pair. The arms ordinarily show annulations formed by an assemblage of small red dots.

The dorsal surface of the disk is provided with a rather thick and folded integument including some calcareous nodules, but it is quite without granules or spines. The radial shields are in part covered by the integument and the region which remained naked, oval in shape, is more or less extensive, as may be seen by comparing the two photographs which I give (pl. 43, figs. 4,5). The ventral surface of the disk in the interradial spaces is covered with an integument identical with that of the dorsal surface, but thicker and with more developed calcareous nodules, though without the least trace of spines or of granules.

Contrary to general opinion, the upper arm plates, instead of being absent, are assuredly present; to be sure they are hidden under a more or less thick integument, and in alcoholic specimens they are invisible; but in order to find them it is only necessary to examine dried examples (figs. 5, 6). These plates are broken up into numerous unequal and irregular fragments, especially in the proximal region of the arms where it is not ordinarily possible to distinguish among these fragments the borders of the successive segments. But these borders usually appear at some distance from the disk. In 0. pelli- 
cula the upper arm plates show the same characters as in $O$. elegans (pl. 43, fig. 1).

Furthermore, if the dorsal surface of the arms be followed almost to their extremity, it will be seen in both these species that the breaking up of the dorsal plates ends a short distance from the tip; the plates from then on are entire, as may be seen on the photograph which I give on plate 43 as figure 7 . These plates are longer than broad, with the proximal border narrower than the convex distal border; I notice also that on the photograph of $O$. elegans published by H. J. Clark in 1915 ('15, pl. 12, fig. 7) the breaking up of the upper arm plates may be very well made out, and the limits of the successive plates may be sometimes distinguished.

I may add that in the young individuals the breaking up of the plates is not yet evident; this condition I find in the two small specimens from station 5151, in which the disk is only $3 \mathrm{~mm}$. in diameter. I include a photograph of the dorsal surface of one of them (pl. 43, fig. 3), and it may be seen that the upper arm plates show very clearly with the contours very distinct from the base of the arms outward, and that they are quite entire throughout the whole length of the arm.

The arms are always very long, and their length may reach from 10 to 15 times the diameter of the disk; they taper very gradually and are very slender in their terminal quarter. They are always more or less twisted, and seem to be able to bend as easily in the vertical plane as in the horizontal. The arm spines number six, and their length increases from the first to the fifth, which is almost equal to two segments; the sixth is a little shorter. The first ventral spine transforms into a hook with three or four branches at a short distance from the disk ( $\mathrm{pl} .103$, fig. $7 a$ ) ; its insertion is rather far from the border of the tentacular pore, which is without a scale. These spines are opaque and, except for the dorsalmost, which is a little more pointed, they maintain almost the same width throughout their whole length; their tip is rounded (fig. $7 d$ ). Their denticulations are slightly developed on the proximal three-quarters of their length, but they become very stout in the terminal region. They are somewhat unequal, thick, conical, not very sharp, and often slightly recurved in the form of a hook. Generally speaking, the denticulations are more developed on the proximal border of the spine.

Ophiogymna elegans has been recorded by Ljungman from Singapore and from Hongkong. The Siboga met with it at Banda and at the Kei Islands in from 9 to 36 meters ( 5 to 20 fathoms) of water. 


\section{Genus OPHIOGYMNA.}

I may recall that Ljungman in creating the genus Ophiogymna characterized it by the presence of a thick integument covering the whole dorsal surface of the disk and leaving exposed only the distal extremities of the radial shields; this integument includes within it calcareous nodules with poorly defined outlines. The mouthpieces are formed as in the genus Ophiothrix. The arms are very long, and the arm spines, numbering from five to ten, are often three times as long as the segment; they are more or less glassy and denticulated. Ljungman does not make any mention of the characters of the upper arm plates, either in his short diagnosis of the genus or in the very short description which he gives of $O$. elegans.

Lütken in 1869 ('69, p. 60) added a few notes to Ljungman's description, and he says especially on the subject of the upper arm plates "egentlige Armrygplader synes at mangle i dets. ..."

In 1886 Duncan created the genus Ophiocampsis, which is a true synonym of the genus Ophiogymna. He characterized his new genus by the presence of an integument covering the disk as well as the radial shields and bearing a few spinulous club spines; he formally stated that the upper arm plates are lacking, but that an integument including small calcareous plates covers the dorsal surface of the arms, which is broad and convex, etc.

The two genera Ophiogymna and Ophiocampsis have always been listed separately in the family Ophiotrichidae by all authors since 1886, and Matsumoto also mentioned both of them in 1915. H. L. Clark was the first to recognize the identity of the two, and in his recent catalogue of the living ophiurans he gives Ophiocampsis inermis as a synonym of Ophiogymna elegans; he places in the same geus, Ophiogymna, O. pellicula Duncan. The genus Ophiocampsis thus falls into synonymy and must disappear.

Judging from the supplementary remarks given by Liitken on the subject of Ophiogymna elegans ('69, p. 60), and also from the diagnosis of the genus Ophiocampsis given by Duncan, the upper arm plates should be completely lacking. But we have seen that this statement is quite inexact and that upper arm plates occur; it is true, however, that they are concealed by the integument and more or less broken up in the adult animal. It is therefore necessary to rectify the diagnosis of the genus Ophiogymna, taking into consideration the presence of these plates; and I emphasize this point, for the same error is found repeated in different works; for example, Delage, ${ }^{10}$ McIntosh ('11, p. 161), and Meissner ${ }^{11}$ all say that the upper

${ }^{10}$ Traité de zoologie concrète, vol. 3, p. 156.

11 Bronn's Thierreich, vol. 2, Abtb. 3 ; Echinodermen III, Schlangenseesterne, p. 942. 
arm plates are lacking in the genus Ophiocampsis (a synonym of Ophiogymna).

The diagnosis given by Ljungman of the genus Ophiogymna is therefore correct, seeing that this author does not speak of the presence or of the absence of upper arm plates. But it is necessary to complete this diagnosis by mentioning that the upper arm plates exist in the genus though they are always broken up into numerous fragments in the adult, and are only entire in very young specimens, or near the distal extremity of the arms in the adults. His diagnosis is insufficient, and I believe that it is necessary to make it more precise and to complete it by the inclusion of a few other characters.

The most striking feature of the genus Ophiogymna is the great length of the arms and especially the faculty which they possess of rolling up in all planes; often forming circles with a very short radius; they are aways contorted, and in conseguence twisted around each other. Duncan in establishing the genus Ophiocampsis appreciated the value of this character and made investigations to find out whether a special structure of the articular facets of the vertebrae did not explain this peculiarity, which is not known in the related genus Ophiothrix. Comparing the articular facets of the vertebrae in Ophiocampsis pellicula and in Ophiothrix variabilis he recognized the fact that these facets had a more simple structure in the former than in the latter species. "The absence of a peg or its analogue," says Duncan, "the length of the hollow for the umbo and the presence of a pair of nodules characterize this species in reference to the aboral surface of the arm bone. On the other hand, the long umbo and the defective knobs of the adoral surface are just as peculiar" (Duncan '86a, p. 118). However, the figures which Duncan published ('86a, pl. 10, figs. 16-20, and pl. 11, figs. 23, 24) are too schematic and somewhat inaccurate. It has seemed to me worth while to take up the question again, especially in view of the notes published in 1913 by Mortensen on the characters of the vertebral articulations in different genera of ophiurans. I have taken as a basis for comparison Ophiothrix pentaphyllum of our coasts of the English Channel, which is very close to Ophiothrix fragitis studied by Mortensen of which that author figured the articular facets ('13a, pl. 2, figs. 8-12). I give photographs of the articular facets of 0 . pentaphyllum (pl. 103, figs. $6 a$ and $b$ ) for comparison with those of Ophiogymna elegans (figs. $7 e$ and $f$ ). It may be safely asserted that my photographs of 0 . pentaphyllum are quite in agreement with Mortensen's figures, and, considering only the interesting structures, we recognize perfectly on the distal or aboral facet the median tubercle, and on either side the well-known depression or fossa; on the proximal or adoral facet, the median fossa, and on either side the articular tubercle; these different parts mutually correspond. A 
glance at the articular facets of Ophiogymna elegans (figs. $7 a$ and $b$ ) suffices to make it clear that the tubercles and the articular fossae are almost completely obliterated, and that it is difficult to find any traces of them. Under these conditions we can understand that the articulations are very much looser in the latter species, and that the very flexible arms are able to curve about in all planes.

The vertebral facets thus show a peculiar structure, and it is necessary to mention this character in the diagnosis of the genus Ophiogymna. I might even say that this character exceeds in importance that which Ljungman invoked for creating the genus Ophiogymna - that is, the presence of an integument covering the disk.

Having found in the Albatross collections two ophiurans discovered by the Siboga which I had assigned heretofore to the genus Ophiothrix-0. fulgens and 0. pulchella-and also a new species near these two, which I shall describe under the name of $O$. funesta, my attention was attracted again to the forms with flexible arms. Instead of comparing them with other species of Ophiothrix, as I had done in 1905 , it seemed to me that their affinities were rather toward the genus Ophiogymna; moreover, they had quite the appearance of the species of that genus. The comparative study of the vertebral articular facets showed me that these three species show characters absolutely identical with those of Ophiogymna elegans (see pl. 103, figs. $8 g$ and $h$ and $9 f$ and $g$ ). Considering the external characters, these species have, like the last, very long and contorted arms, and the tentacle scale, similarly absent in the new species, is very slightly developed and disappears at a short distance from the disk in $O$. fulgens and $O$. pulchella. The tegumentary investment of the disk and of the arms in these three species shows rather wide variations. Generally speaking, in 0 . pulchella this integument is most developed, and the outlines of the plates are least apparent; in $O$. fulgens it varies very much individually on the dorsal surface of the disk, but the upper arm plates are always distinct; it is the same in the new species in which the integument of the dorsal surface of the disk is still less apparent. We find also in these three species a characteristic feature of Ophiogymna elegans and $O$. pellicula, and that is the breaking up of the upper arm plates which always occurs, more or less marked according to the species or the individuals.

I may add that the arm spines of $O$. fulgens and of $O$. pulchella, like those of the new species, show the same characters as those of Ophiogymna elegans; the denticulations, which are very fine over the greater part of their length, develop only in the vicinity of the tip of the spine. A glance at the photographs which I give of the 
arm spines in Ophiogymna elegans (pl. 103, fig. $7 d$ ) and in $O$. fulgens (fig. 8e), $O$. pulchella (fig. 5a), and $O$. funesta (figs. $9 a$ and $e$ ) will show these resemblances.

I may state that in all these species the tentacle scale is completely lacking, or if it exists it remains only slightly developed and disappears at a short distance from the disk, which is the case, as I have just said, in $O$. fulgens and in 0 . pulchella. In the new species the tentacle scale is also almost completely lacking.

For all these reasons I believe that the two species which I had at first assigned to the genus Ophiothrix-O. fulgens and 0 . pulchellaas well as the new species discovered by the Albatross, which is very closely related to them, are better placed in the genus Ophiogymna than in the genus Ophiothrix. I may add that still another species which I have recently described and assigned to the genus Ophiothrix-O. convoluta from the Caribbean Sea-has, like the preceding forms, which it quite resembles in its general appearance, flexible and very contorted arms, and is without the tentacle scale; although I have not had occasion to study the articular facets of the arms, I believe it necessary to assign it to the genus Ophiogymna.

To sum up, I believe that it is necessary at present to refer to the genus Ophiogymna the six following species:

ophiogymna elegans (Ljungman) (genotype).

ophiogymna pellicula (Duncan).

ophiogymna fulgens (Kœhler).

ophiogymna pulchella (Kœhler).

ophiogymna convoluta (Kœhler).

ophiogymna funesta, new species.

In accordance with the preceding remarks, I propose to modify and to complete the diagnosis of the genus Ophiogymna as follows:

Ophiotrichidae with the arms very long and narrow, very flexible and twining, capable of rolling up in every plane thanks to a structure of the articular facets of the vertebrae simpler than that found in the genus Ophiothrix. The disk and even the arms may be covered by an integument which more or less completely conceals the outlines of the subjacent plates; these plates themselves are only slightly developed on the disk; they are lacking on the ventral surface, and on the dorsal surface they are separated from each other by soft areas. The upper arm plates are present, but concealed under the integument and more or less broken up; the cylindrical and opaque arm spines show well developed denticulations only in their terminal regions. The tentacle scale is absent, or if it occurs it is reduced and disappears at a short distance from the disk. 


\section{OPHIOGYMNA FULGENS (Kohler).}

Plate 42 , figs. $1-8$; plate 43 , figs. 9,10 ; plate 44 , fig. 8 ; plate 60 , fig. 6 ; plate 103, fig. 8 .

Ophiothrix fulgens KaEhler ('05), p. 107, pl. 10, figs. 3-6.-H. L. ClaRK ('15), p. 280.

Localities.-Albatross station 4935; Eastern Sea, off Kagoshima Gulf; Sata Misaki Light bearing N. $58^{\circ}$ E., 8.34 kilometers (4.5 miles) distant (lat. $30^{\circ} 57^{\prime} 20^{\prime \prime}$ N., long. $130^{\circ} 35^{\prime} 10^{\prime \prime}$ E.) ; 188 meters (103 fathoms); August 16, 1906.

Six specimens (Cat. Nos. 41088, 41096, U.S.N.M.).

Albatross station 4948; off southern Japan; O Shima Light bearing N. $11^{\circ}$ E., 22.24 kilometers (12 miles) distant (lat. $31^{\circ} 19^{\prime} 00^{\prime \prime}$ N., long. $131^{\circ} 23^{\prime} 00^{\prime \prime}$ E.) ; 119 meters (65 fathoms); August 21, 1906.

One specimen (Cat. No. 41090, U.S.N.M.).

Albatross station 5070; Suruga Gulf, Japan; Ose Saki bearing S $8^{\circ} \mathrm{W}$., 3.34 kilometers (1.8 miles) distant (lat. $35^{\circ} 03^{\prime} 25^{\prime \prime}$ N., long. $138^{\circ} 47^{\prime} 40^{\prime \prime}$ E.) ; 197 meters (108 fathoms) ; October 15, 1906.

One specimen (Cat. No. 41092 , U.S.N.M.).

Albatross station 5080; off Omai Saki Light, southern Japan; Omai Saki Light bearing N. $23 \frac{1}{2}^{\circ}$ E., 51.89 kilometers (28 miles) distant (lat. $34^{\circ} 10^{\prime} 30^{\prime \prime}$ N., long. $138^{\circ} 40^{\prime} 00^{\prime \prime}$ E.) ; 923 meters (505 fathoms) ; October 19, 1906.

One specimen (Cat. No. 41054, U.S.N.M.).

Albatross station 5117; Balayan Bay and Verde Island Passage; Sombrero Island bearing S. $17^{\circ}$ E., 20.01 kilometers (10.8 miles) distant (lat. $13^{\circ} 52^{\prime} 22^{\prime \prime} \mathrm{N}$., long. $120^{\circ} 46^{\prime} 22^{\prime \prime}$ E.) ; 216 meters (118 fathoms) ; January 21, 1908.

One specimen (Cat. No. 41093, U.S.N.M.).

Albatross station 5138; vicinity of Joló; Joló Light bearing S. $19^{\circ}$ E., 4.63 kilometers (2.5 miles) distant (lat. $6^{\circ} 06^{\prime} 00^{\prime \prime} \mathrm{N}$., long. $120^{\circ}$ $58^{\prime} 50^{\prime \prime}$ E.) ; 35 meters (19 fathoms); February 14, 1908; S., Co.

One specimen (Cat. No. 41001, U.S.N.M.).

Albatross station 5141; vicinity of Joló; Joló Light bearing S. $17^{\circ}$ E., 10.19 kilometers ( 5.5 miles) distant (lat. $6^{\circ} 09^{\prime} 00^{\prime \prime}$ N., long. $120^{\circ}$ $58^{\prime} 00^{\prime \prime}$ E.) ; 53 meters (29 fathoms) ; February 15, 1908; co. S.

One specimen (Cat. No. 41089, U.S.N.M.).

Albatross station 5255; Gulf of Dávao; Dumalag Island (S.) bearing S. $65^{\circ}$ W., 8.34 kilometers (4.5 miles) distant (lat. $7^{\circ} 03^{\prime} 00^{\prime \prime}$ N., long. $125^{\circ} 39^{\prime} 00^{\prime \prime}$ E.) ; 183 meters (100 fathoms); May 18, 1908; sft. M.

One specimen (Cat. No. 41094 , U.S.N.M.).

Albatross station 5393; between Sámar and Masbate; Panganalan Point, Talajit Island, bearing S. $59^{\circ}$ E., 27.43 kilometers (14.8 miles) 
distant (lat. $12^{\circ} 03^{\prime} 30^{\prime \prime}$ N., long. $124^{\circ} 03^{\prime} 36^{\prime \prime}$ E.) ; 249 meters (136 fathoms); March 13, 1909; hrd. S.

Five specimens (Cat. Nos. 41079, 41098, U.S.N.M.).

Albatross station 5413; between Cebu and Bohol; Lauis Point Light bearing N. $68^{\circ}$ W., 18.5 kilometers (10 miles) distant (lat. $10^{\circ}$ $10^{\prime} 35^{\prime \prime}$ N., long. $124^{\circ} 03^{\prime} 15^{\prime \prime}$ E.) ; 77 meters (42 fathoms); March 24, 1909.

One specimen (Cat. No. 41091, U.S.N.M.).

Albatross station 5414; between Cebu and Bohol; Lauis Point Light bearing N. $67^{\circ}$ W., 17.60 kilometers (9.5 miles) distant (lat. $10^{\circ} 10^{\prime} 40^{\prime \prime}$ N., long. $124^{\circ} 02^{\prime} 45^{\prime \prime}$ E.) ; March 24, 1909.

Two specimens (Cat. No. 41095 , U.S.N.M.).

Albatross station 5519; northern Mindanao and vicinity; Point Tagolo Light bearing S. $71^{\circ}$ W., 16 kilometers ( 8.7 miles) distant (lat. $8^{\circ} 47^{\prime} 00^{\prime \prime} \mathrm{N}$., long. $123^{\circ} 31^{\prime} 15^{\prime \prime}$ E.) ; 333 meters (182 fathoms) ; August 9, 1909; Glob., S.

One specimen (Cat. No. 41097, U.S.N.M.).

Albatross station 5545; Jolo Island and vicinity; Noble Point, Tulayan Island (E.), bearing S. $19^{\circ} \mathrm{W} ., 5.56$ kilometers (3 miles) distant (lat. $6^{\circ} 04^{\prime} 45^{\prime \prime}$ N., long. $121^{\circ} 20^{\prime} 20^{\prime \prime}$ E.) ; 208 meters (114 fathoms); September 15, 1909 ; fne. co. S.

Six specimens (Cat. Nos. 41078, E. 20, U.S.N.M.).

Notes.-The specimens exhibit well the essential characters of $O$. fulgens which I described from specimens collected by the Siboga in the Sunda Archipelago, but they show a few variations which it is interesting to observe.

In the Siboga specimens the dorsal surface of the disk, which is covered with a thick integument, carries both club spines and true spines; in certain individuals the club spines remain in the condition of conical granules which scarcely elongate toward the periphery of the disk; the radial shields, which are of medium size, are triangular and their length is equal to a third the radius of the disk. The large upper arm plates are trapezoidal, a little broader than long, sometimes more or less strongly keeled, sometime furnished in the middle and toward the distal border with a small tubercle. These plates are sometimes broken up, and they may show on their surface a few irregularly disposed and also inconstant granules. The fragmentation of the upper arm plates is less marked than in $O$. elegans and in 0 . pellicula, and the borders of the plates are always distinct. It is not rare to find the plates quite whole over a more or less extended portion of the length of the arms. On plate 43 as figure 9 I show a portion of an arm on which the breaking up of the dorsal plates is carried to an extreme. The arms are always very long and more or less strongly convoluted. The coloration of the specimens is: 
light pink, and the arms are banded with pink and white; one coming from a depth of 90 meters was quite decolorized.

I may recall that I separated $O$. fulgens from $O$. pulchella, which also occurs in the Albatross collection, on the basis of the armature of the dorsal surface of the disk, the smaller size of the radial shields, the shorter arm spines, and the entirely different coloration.

The principal variations which I find in the Albatross specimens concern the armature of the dorsal surface of the disk, the dimensions of the radial shields, the presence or absence of small granules on the upper arm plates, and the more or less carinate form of the last. In certain specimens, as those from station 5117 (pl. 42, fig. 7), the dorsal surface of the disk shows only rather large rounded granules arranged very uniformly on the plates, and the radial shields are remarkably large. In others, as those from station 5070 (fig. 5) the granules are much less numerous and there are in addition a few large, thick, and short spines, with their tips rounded; the number of these spines is a little greater in the specimens from stations 4935 , $4948,5138,5255,5395$, and especially 5217. In the small specimen from station 5413 and in those from stations 5141 and 5393 (pl. 42, figs. 1,2 ) these spines are especially numerous and very long; they have the tip pointed and are provided with fine and closely crowded denticulations; their presence gives to these specimens a general appearance very different from those which are without spines. Certain individuals from station 5545 are identical with those from station 5393, of which I give a photograph on plate 42 as figure 2, having very large radial shields, and on one of them these radial shields carry two or three spines identical with those on the rest of the dorsal surface of the disk. While the small example from station 5414 shows the spines greatly developed, the other is almost entirely without them. The photographs which I give on plate 103 as figure $8 b$ and $c$ show the intermediates between club spines and true spines.

On some individuals the plates which carry the club spines and the true spines are very distinct, such as those of which photographs are given on plate 42 as figures $1,2,4,5$, and 7 , and in this case the radial shields remain very large. In others the plates are concealed under an integument which is pierced by the spines and the club spines, and the radial shields may be in part covered by this integument, which more or less restricts their visible surface; this occurs, for example, in the specimen from station 5545 which I figure (fig. 8). The specimens from station 5545 are interesting to compare with each other because of the variations which they show in the appearance of the dorsal surface of the disk; all carry true spines, but in some these spines are rather slender, elongated, and similar to those which are represented on plate 42 as figure 4 ; the plates of the dorsal surface of the disk, which do not appear to be covered with integument, 
and the radial shields, which are exposed over their entire area, may be clearly distinguished. In others, as that which is represented in figure 8 , and which I have just mentioned, the spines are shorter and thicker, and the dorsal surface of the disk is covered with a fairly developed integument which more or less completely conceals the underlying plates and encroaches more or less upon the radial shields.

The specimen from station 5080 (fig. 6) is remarkable for the rudimentary condition of the armature of the dorsal surface of the disk; the club spines are not very numerous, and are of small size, conical, and well spaced; they become a little stouter and a little more numerous toward the periphery of the disk. In its general appearance this specimen quite brings to mind an Ophiogymna pellicula, but the characters of the upper arm plates do not permit of referring it to that form.

The upper arm plates only show variations in form of slight importance; they are always trapezoidal, with a fairly straight and slightly concave proximal border, and a very broad and strongly convex distal border, usually made up of two short sides united by an obtuse angle; the lateral borders are straight and divergent, and they pass to the distal side over rounded angles; these plates are relatively more elongated in the young where they are still, however, broader than long. The upper arm plates have the form of a dihedral angle with a more or less well marked dorsal keel, and usually they show toward the middle, but a little nearer the distal border, a rather broad rounded and flattened tubercle, which sometimes is detached from the general surface of the plate on which the keel is only slightly visible, and sometimes is continuous with the keel itself, which is more strongly marked. The presence of small granules on the surface of the upper arm plates is rather rare in the Albatross specimens and occurs very irregularly. One of the specimens on which they are found rather abundantly is that from station 5141 which I show on plate 42 as figure 1. The form of these granules, which are somewhat conical, pointed, and rather fine, may be seen on the arm shown in profile; they occur only in the proximal half of the arms. On other specimens a few granules may be met with which are sometimes conical, sometimes rounded, always few in number, and occurring in a very irregular manner exclusively in the proximal region of the arms; I include a figure (pl. 43, fig. 10) of the dorsal surface of the arm of a specimen from station 5545 which shows a few of these rounded granules.

The arm spines are rather large, comparatively short in the small specimens, but their length increases proportionately with the size of the individual. In specimens of small and of medium size the lateral spines have the tip somewhat broadened and very rounded; in the large this tip is always rounded, but it is only slightly or not 
at all broadened. These spines retain almost the same width throughout their whole length. The denticulations, which are especially developed toward the tip, appear also less strong on the longest spines (pl. 103, fig. 8e). The last dorsal spine is always more or less pointed. The first ventral spine at some distance from the disk forms an elongated hook showing at first five or six points, then, further on, three only; the two outer points are very much more developed than the third.

As I said in 1905, the tentacle scale is small and pointed. I give a photograph of it on plate 103 as figure 8f. But following out along the arm I notice that this scale does not persist very long, and disappears at a short, though variable, distance from the disk. This character impressed me in 1905 . The dominant coloration of the specimens collected by the Albatross is light pink; the ventral surface of the disk is a more or less dark brown; but the specimen from station 5138 is very dark red; on the other hand, certain specimens are almost completely colorless, as for example those from stations 5080 and 5145. The annulations of the arms are only slightly evident, and sometimes not evident at all.

On its ventral surface and affixed near the mouth, the specimen from station 4948 bears two parasitic prosobranchs belonging to the genus Mucronalia and representing without doubt a new species. The length of the shells is respectively $3 \mathrm{~mm}$. and $2 \mathrm{~mm}$. On plate 60 , figure 6 , I show the ventral surface of the parasitized ophiuran with the two gasteropods in place.

\section{OPHIOGYMNA FUNESTA, new species.}

Plate 44 , figs. $1-7$; plate 103 , fig. 9.

Locality.-Albatross station 5213; east of Masbate Island: Destacado Island (S.) bearing N. $87^{\circ}$ E., 15.75 kilometers ( 8.5 miles) distant (lat. $12^{\circ} 15^{\prime} 00^{\prime \prime}$ N., long. $123^{\circ} 57^{\prime} 30^{\prime \prime}$ E.) ; 146 meters (80 fathoms); April 20, 1908; S., M., Sh.

Sixty-six specimens (Cat. Nos. E. 187, E. 374, U.S.N.M.).

Description.-The diameter of the disk varies between $8 \mathrm{~mm}$. and $10 \mathrm{~mm}$.; the arms are extremely long, more or less contorted, and rather slender; their length usually exceeds $100 \mathrm{~mm}$.

The disk is rounded. The dorsal surface is covered with rather numerous small plates, the outlines of which are not very evident, and which are covered by a thin integument, often concealing a more or less extensive portion of the radial shields. These are extremely large and triangular, and their length appears to reach three-quarters the radius of the disk, judging from the slight projection which they cause under the integument; this last leaves exposed a certain portion of the distal region of the shields, but the extent of this naked 
part is rather variable; it is rather large and triangular in shape in the specimen represented on plate 44 as figure 3 , less extensive on that represented in figure 7, and still smaller on that in figure 6 , where this naked portion is small and oval. The two shields of each pair are rather strongly divergent. The plates of the dorsal surface of the disk may carry small, short, and rounded granules which often show a tendency to rise up into small pointed cones (pl. 44, fig. 6, and pl. 103, fig. $9 b$ ). In other specimens a certain number of granules transform rather abruptly into spines which are rather large, elongated, stout, and pointed, and are furnished with asperities or even with small irregular teeth. These spines may be very few in number and relatively small (fig. 3), or they may become very abundant and very strong, rather thick, long, and pointed, with the surface rugose or denticulated (fig. 7). The spines or the granules continue over a small portion of the ventral surface of the disk but they never advance very far, and the major portion of this surface remains naked. The genital slits are large and broad; the genital plates are extremely large.

The mouth pieces are only slightly developed. The mouth shields are small, broader than long, triangular or lozenge-shaped, with an obtuse proximal angle sometimes prolonged a little toward the mouth and bordered by two slightly excavated sides; the distal border is very convex and is often broken up into two short sides united by a very obtuse and rounded angle. The adoral plates are elongated, broader outwardly than inwardly, and they usually send off a process which separates the mouth shield from the first side arm plate; they taper inwardly, but are in contact in the median interradial line. The oral plates are of medium size. The tooth papillae are much developed; there can usually be recognized two lateral rows, and in addition a median cluster composed of three very irregular rows.

As I said above, the arms are very long, but very slender; their dorsal surface is quite plane. The upper arm plates are very large and extremely broad, and they cover almost the whole dorsal surface of the arms. They are very much broader than long, with the two long sides almost parallel; the proximal border, which is almost straight, is a little shorter than the distal border, which is sometimes straight, and sometimes a little convex, and in the large specimens is very often slightly excavated in the middle; the sides are a little divergent, and they pass over to the distal border by sharp angles. The form of these plates is somewhat inconstant, as may be seen from the photographs which I give (pl. 44, figs. 3-7), and these plates may be broken up into fragments, of which the form, the dimensions, and the number are extremely variable; in this respect the greatest differences are found in different specimens, and in different arms of the same specimen, or even in different parts of a 
single arm. Sometimes all the successive plates are broken up over a rather considerable length of an arm, while sometimes broken plates appear suddenly in the midst of others which are quite entire, and no rule appears to govern these occurrences. Even in the vicinity of the arm tip the upper arm plates may be divided into two or three fragments; in this region they become relatively less broad and their length may then be equal to their width. In general the breaking up of the upper arm plates is not carried very far, and the number of the fragments is not as great as in 0 . elegans and $O$. pellicula; most commonly the plates are simply divided into several fragments by one or two longitudinal or oblique grooves, as occurs in $O$. fulgens and $O$. pulchella. All the upper arm plates are broadly in contact throughout the whole length of the arm.

The first under arm plate is rather small, rectangular, and a little broader than long. The following are not very large, and they do not occupy any great part of the ventral surface of the arms. They are at first a little broader than long, with a proximal border a little narrower than the distal, and slightly excavated sides; at some distance from the disk they become as broad as long. The proximal border is sometimes slightly notched on the first segments, on the following becoming slightly convex; it is the same with the distal border, which is sometimes slightly notched at the base of the arms but which from then on is almost straight. These slightly different forms of the adjacent sides of the under arm plates depend doubtless on the fact that they are sometimes very close together, to the point of being almost in contact, and sometimes separated by a space occupied by soft tissue.

The side arm plates are much developed and projecting, and they carry at least eight arm spines at the base of the arms. The length of these increases from the first ventral to the third, which is slightly shorter than the segment; the fourth is longer than the segment; the fifth equals two segments, and the two following are slightly longer still, while the last dorsal spine is shorter than the preceding. These spines are slender and transparent, furnished with asperities which are more or less developed, though not forming true denticulations except in the terminal portion (pl. 103, figs. $9 a$ and $e$ ). The fourth to the seventh arm spines have the tip rounded, and the last dorsal spine is pointed. The first ventral spine is transformed into a hook almost at the base of the arms, and the second spine quickly undergoes the same transformation (fig. $9 c$ ).

The tentacle scale is rudimentary or lacking. In certain specimens I have been able to recognize traces of it on the first arm segments, but upon those following it is impossible to distinguish it.

All the specimens are of an absolutely uniform slightly rosy gray; the ventral surface of the disk in the interradial spaces is brown 
because of the absence of plates, and the thinness of the integument which covers the underlying tissues.

Affinities and distinctive features.-Ophiogymna funesta shows a very great resemblance to $O$. fulgens (Kohler), and the dorsal surface of the disk shows in the two species some almost identical characters, both because of the existence of an integument covering the underlying plates more or less encroaching upon the radial shields, as well as on account of the armature, which may include small club spines only, or may be a mixture of club spines and true spines, these latter sometimes assuming a very great development. In both species the upper arm plates may similarly break up, but their shape is entirely different; in $O$. fulgens they are as long as broad, or scarcely broader than long, and they have the form of a dihedral angle with an always very apparent median keel; their lateral angles are rounded, and the distal border is very convex. In $O$. funesta they are very broad, flattened, and never carinate, and their distal border is straight or even slightly excavated; the lateral angles are very sharp. I have never found the least indication of intermediates between these two forms. The arm spines are also a little longer and stronger in 0 . funesta, and their tip is not swollen.

But the two species are evidently very closely allied, and they may be easily confused. I do not for a moment believe, however, that they can be united, for it does not seem to me possible to deny the importance of the differences which we have shown in the form of the upper arm plates.

\section{OPHIOGYMNA PULCHELLA (Kohler).}

Plate 37, figs. $1,5,6$; plate 43 , fig. 11 ; plate 103 , fig. 5 .

Ophiothrix pulchella KaHLER ('05), p. 106, pl. 11, figs. 11, 12; pl. 15, fig. 3.- H. L. Clark ('15), p. 281.

Localities.-Albatross station 5131; Sulu (Joló) Sea, off western Mindanao; island off Panabutan Point bearing N. $20^{\circ}$ E., 0.74 kilo. meters ( 0.4 miles) distant; 49 meters (27 fathoms); February 6 , 1908 ; gn. M., co. S.

One specimen (Cat. No. 41294, U.S.N.M.).

Albatross station 5132; Sulu Sea, off western Mindanao; island off Panabutan Point bearing N. $15^{\circ}$ W., 0.55 kilometer ( 0.3 mile) distant; 47 meters (26 fathoms) ; February 6, 1908; gn. M., S.

Two specimens (Cat. Nos. 41293,41295 , U.S.N.M.).

Albatross station 5133; Sulu Sea, off western Mindanao; island off Panabutan Point bearing N. 52 ${ }^{\circ}$ E., 2.78 kilometers (1.5 miles) distant; 69 meters (38 fathoms) ; February 6, 1908; gn. M., S.

One specimen (Cat. No. 41.296, U.S.N.M.). 
Notes.-These specimens agree well with those from the Siboga expedition; they are all of small size, and the diameter of the disk does not exceed $5 \mathrm{~mm}$. I do not find in them variations comparable to those which $I$ have recorded in the specimens of $O$. fulgens from the Siboga and Albatross collections, excepting in regard to the number of the small spines which may be met with on the upper arm plates, spines the presence of which is more constant here than in 0 . fulgens. These spines are more or less numerous; they are always very small, very short, and terminated by a few extremely fine diverging points. The outlines of the upper arm plates, even on the dried specimens, are sometimes less apparent than in $O$. fulgens, as may be seen in the individual of which I include a photograph (pl. 37, fig. 6) and which is from the Siboga collection, while these outlines are very clearly shown in the specimen from station 5132, of which a photograph is given in figure 5. The breaking up of these plates is, generally speaking, very much less marked in $O$. pulchella than in the other species of the genus; the broken plates occur only on the first arm segments, and the fragments, delimited by one or two grooves only, are always few in number.

The tentacle scale, a little more developed than in 0 . fulgens, is, however, of rather small size; I give a photograph of it (pl. 103, fig. $5 f$ ). As in 0 . fulgens, this scale disappears at a short distance from the disk.

Ophiogymna pulchella was found by the Siboga in a few localities in the Sunda Archipelago at depths between 73 and 247 meters (40 to 135 fathoms); one specimen from Amboina, without a record of the depth, was undoubtedly collected at low tide.

\section{OPHIOCNEMIS MARMORATA (Lamarck).}

See for bibliography:

Ophiocnemis marmorata KaHLER ('05), p. 112; ('07), p. 339.-MACINTOSH ('11), p. 166.-H. L. Clark ('15), p. 283; ('15a), p. 90.

Locality.-Albatross station. 5421; between Panay and Guimaras; Lusaran Point Light bearing S. $27^{\circ}$ E., 9.27 kilometers (5 miles) distant (lat. $10^{\circ} 33^{\prime} 30^{\prime \prime}$ N., long. $122^{\circ} 26^{\prime} 00^{\prime \prime}$ E.) ; 250 meters (137 fathoms); March 30, 1909; gn. M.

One specimen (Cat. No. 41178, U.S.N.M.).

Notes.-The single specimen is of small size, the diameter of the disk being only $7 \mathrm{~mm}$.

Ophiocnemis marmorata is very widely distributed over the whole Indo-Pacific region; it is known from Zanzibar, Ceylon, the Mergui Archipelago, Singapore, the Sunda Archipelago, the coast of northwestern Australia, etc. 
OPHIURANS OF THE PHILIPPINE AND ADJACENT WATERS. 297

\section{OPHIOTHELA DANAE Verrill.}

Plate 59, figs. 1, 2, 3 ; plate 103, fig. 1.

See for bibliography:

Ophiothela danae KoeHLER ('05), p. 117; ('05b), p. 458; ('07), p. 340; ('O7b), p. 253.-H. L. Clark ('15), p. 284.-Matsumoto ('17), p. 231.

Localities.-Albatross station 5139 ; in the vicinity of Joló; Joló Light bearing S. $51^{\circ}$ W., 6.67 kilometers (3.6 miles) distant (lat. $6^{\circ} 06^{\prime} 00^{\prime \prime}$ N., long. $121^{\circ} 02^{\prime} 30^{\prime \prime}$ E.) ; 36 meters (20 fathoms) ; February 1 1908; co. S.

$\rightarrow$ Ty suecimens (Cat. No. 41274, U.S.N.M.).

Albatross station 5147; Sulu (Joló) Archipelago, in the vicinity of Siasi; Sulade Island (E.) bearing N. $3^{\circ}$ E., 15.57 kilometers (8.4 miles) distant (lat. $5^{\circ} 41^{\prime} 40^{\prime \prime}$ N., long. $120^{\circ} 47^{\prime} 10^{\prime \prime}$ E.) ; 38 meters (21 fathoms) ; February 16, 1908; co. S., Sh.

One specimen (Cat. No. 41275, U.S.N.M.).

Albatross station 5151; Sulu Archipelago, Tawi Tawi Group; Sirun Island (C.) bearing N. $58^{\circ}$ E., 35.77 kilometers (19.4 miles) distant (lat. $5^{\circ} 24^{\prime} 40^{\prime \prime}$ N., long. $120^{\circ} 27^{\prime} 15^{\prime \prime}$ E.) ; 44 meters (24 fathoms); February 18, 1908; co. S., Sh.

One specimen (Cat. No. 41273, U.S.N.M.).

Albatross station 5169; Sulu Archipelago, in the vicinity of Sibutu Island; Sibutu Island (SE.) bearing N. $38^{\circ}$ E., 14.83 kilometers (8 miles) distant (lat. $4^{\circ} 32^{\prime} 15^{\prime \prime}$ N., long. $119^{\circ} 22^{\prime} 45^{\prime \prime}$ E.) ; 18 meters (10 fathoms); February 27, 1908; co. S.

One specimen (Cat. No. 41271, U.S.N.M.).

Albatross station 5218; between Burias and Luzon; Anima Sola Island (E.) bearing N. $10^{\circ}$ W., 3.71 kilometers ( 2 miles) distant (lat. $13^{\circ} 11^{\prime} 15^{\prime \prime}$ N., long. $123^{\circ} 02^{\prime} 45^{\prime \prime}$ E.) ; 36 meters (20 fathoms) ; April 22, 1908; crs. S.

One specimen (Cat. No. 41272 , U.S.N.M.).

Notes.-The specimens from station 5139 are very small, and the diameter of their disks seldom exceeds $1.5 \mathrm{~mm}$; that from station 5147 , which is a little larger, is in process of schizogonic multiplication, and the completely developed arms are only four. The other two have six almost equal arms.

On plate 103, as figure 1, I show the hook formed by the first ventral arm spine, at the base of the arms $(b)$ and in their terminal part $(a)$, as well as the other arm spines $(c)$.

On the dorsal surface of the disk the specimen from station 5151 shows rather large and abundant tubercles such as are usually seen in the species; it agrees well with the descriptions which have been published by Lütken in 1872 and by Loriol in 1893 under the name of $O$. isidicola. On the dorsal surface of the arms there may be 
distinguished the transverse tubercles, larger than the others, which were especially noticed by Loriol (pl. 69, fig. 3).

The general coloration is pinkish gray, with dark blue striae on the dorsal surface of the disk and on the arms. The specimen from station 5169, which is almost of the same size as the preceding, shows a darker coloration; the general tint on the dorsal surface of the disk is a rather dark blue, and the ventral surface is gray; the dorsal surface of the disk shows wavy striae with some dark blue spots which are more numerous than on the specimen from station 5151; this individual is remarkable for the slight developme the tubercles of the dorsal surface of the disk. These tubercle rcely appear except toward the periphery of the disk, and it is seldom that a small one is seen here and there on the radial shields; the central region of the disk is quite without them. On the arms these tubercles are relatively less numerous than in the specimen from station 5151; but in compensation the transverse tubercle of each segment is more marked while the others are smaller and less numerous, and do not form the two more or less apparent transverse series which are distinguishable in that from station 5151. These smaller tubercles occur only on the first arm segments, and they disappear rapidly so that the large transverse tubercle alone persists.

I have thought it necessary to give my specimens the name of Ophiothela danae for the same reasons that $I$ gave in 1905 , and I still believe that there is no necessity for separating $O$. danae and $O$. isidicola; the species so understood is rather widely distributed in the Indo-Pacific region.

Matsumoto, who has recently recorded $O$. danae from various localities in Japan, also concedes its identity with $O$. isidicola, and with $O$. verrilli Duncan as well. He describes the different variations of Japanese individuals ('17, p. 230).

\section{OPHIOTHELA VINCULA Mortensen.}

Plate 59, fig. 4.

Ophiothela vincula Mortensen ('13), p. 14, pl. 1, figs. 11-13.-H. L. CLARK ('15), p. 285.

Locality.-Albatross station 5218; between Burias and Luzon; Anima Sola Island (E.) bearing N. $10^{\circ}$ W., 3.71 kilometers (2 miles) distant (lat. $13^{\circ} 11^{\prime} 15^{\prime \prime}$ N., long. $123^{\circ} 02^{\prime} 45^{\prime \prime}$ E.) ; 36 meters (20 fathoms); April 22, 1908; crs. S.

One specimen.

Notes.-The specimen agrees well with Mortensen's description. The diameter of its disk is $4 \mathrm{~mm}$. I include a photograph of it.

The type series of $O$. vincula came from the Philippines (San Bernardino Strait), where it was met with at a depth of from 50 to 100 fathoms (92 to 184 meters). 
See for bibliography:

Ophiomaza cacaotica KäLER ('05), p. 111; ('07), p. 339.-H. L. ClARK ('15), p. 283.

Localities.-Albatross station 5147; Sulu (Joló) Archipelago, in the vicinity of Siasi; Sulade Island (E.) bearing N. $3^{\circ}$ E., 15.57 kilometers (8.4 miles) distant (lat. $5^{\circ} 41^{\prime} 40^{\prime \prime} \mathrm{N}$., long. $120^{\circ} 47^{\prime} 10^{\prime \prime}$ E.) ; 38 meters (21 fathoms) ; February 16,1908 ; co. S., Sh.

Two specimens (Cat. No. E. 160, U.S.N.M.).

Albatross station 5205; off the east coast of Leyte Island; Caguayan Point bearing N. $2^{\circ}$ E., 1.30 kilometers $(0.7$ mile) distant (lat. $11^{\circ} 19^{\prime} 30^{\prime \prime}$ N., long. $124^{\circ} 58^{\prime} 05^{\prime \prime}$ E.) ; 15 meters (8 fathoms); April 13, 1908.

One specimen (Cat. No. E. 159, U.S.N.M.).

Limbones Coves.

One small specimen (Cat. No. 41156 , U.S.N.M.).

Notes.-Ophiomaza cacaotica has been recorded from various localities in the Indo-Pacific region-Sea of Japan, Sunda Islands, New Caledonia, east coast of Australia, Mergui Archipelago, Trincomalee, Zanzibar, etc.; the Siboga found it in the Sunda Archipelago at depths between 16 and 69 meters ( 9 to 38 fathoms).

OPHIOMAZA FUSCA, new species.

Plate 41, figures 5, 6.

Locality.-Albatross station 5145 ; in the vicinity of Joló; Joló Light bearing S. $16^{\circ}$ E., 1.57 kilometers $(0.85$ mile) distant (lat. $6^{\circ} 04^{\prime} 30^{\prime \prime}$ N., long. $120^{\circ} 59^{\prime} 30^{\prime \prime}$ E.) ; 42 meters (23 fathoms) ; February 15,1908 ; co. S., Sh.

One specimen (Cat. No. 41167, U.S.N.M.).

Description.-The diameter of the disk is $9.5 \mathrm{~mm}$.; the arms are rather thick and short, but it is difficult to appreciate their exact length, as they are more or less strongly incurved, and, besides, three of them are incomplete; but I do not believe that their length could have exceeded $25 \mathrm{~mm}$.

The individual is not quite normal; one of the arms, which is very small, is in process of regeneration; furthermore, the arrangement of the upper arm plates of the disk show certain irregularities.

The disk is almost rectangular, with three sides straight and the fourth convex. The dorsal surface is covered with irregularly polygonal plates, which are very unequal and disposed without any order; the primary plates are quite indistinct. The radial shields are rather large, very much larger than the other plates of the dorsal surface; they are oval, half again as long as broad, and their length is in gen- 
eral equal to a third of the radius of the disk; but they are very unequal. On two adjacent pairs the shields are widely separated from each other by a row of plates; in the pair at the base of the small arm the two shields are separated by two rows of plates, while in the pair opposite the two shields are in contact. The two shields of the fifth pair appear fused into a single plate which must have united with a certain number of the neighboring plates, for it is very much larger than the sum of two normal radial shields.

The part of the ventral surface of the disk beyond the large mouth shields and between the two genital plates is naked. The genital slits are very broad. The genital plates are large, much broadened, three times as long as broad.

The mouth shields are extremely large, triangular, at least twice as broad as long, with a very obtuse proximal angle; the lateral angles are broadly rounded, and the distal side is concave. The adoral plates are large and short, half again as long as broad, and oval; the oral plates are large and high. The tooth papillae are arranged in three rows: the external papillae are larger and stouter than those in the median region. The mouth shields and the adoral plates are covered with small shining granules, surrounded by a dark circle, and widely separated from each other; the same granules occur on the under arm plates.

The first upper arm plates which follow the dorsal plates separating the radial shields of each pair, are at first small and more or less irregular, or even broken up into unequal fragments, and they do not cover the whole space outwardly bounded by the side arm plates; but these plates soon become regular and then appear very large, twice as broad as long, with the long sides parallel, the distal a little convex, and the proximal a little concave; the sides are each bounded by two small straight borders forming between them an obtuse angle. At some distance from the base of the arms, these two sides are replaced by an uninterrupted border directed obliquely outward and united by a sharp angle to the distal side, this last from that point onward becoming appreciably larger than the proximal side. All these plates are in contact.

The first under arm plate is quadrangular, a little longer than broad. The second is also quadrangular, with a very short and rounded proximal border, the sides strongly divergent and excavated in the middle by the corresponding tentacle pore, and a very broad and very strongly convex distal border; this plate is a little longer than broad. On the following plates the proximal border broadens and becomes equal to the distal side, while the sides become very much shorter; the plates then assume a strictly quadrangular form. The third plate is almost as long as broad, but the following become 
much broader than long, and they are finally three times as broad as long. These plates are not in contact, but remain separated from each other by a narrow interval occupied by soft tissue.

The side arm plates, which are rather projecting, bear at the base of the arms four rather thick arm spines which are broadened at the base with the tip rounded; the two ventral spines are rather short; the two others are longer and their length may equal two segments on the ten or fifteen first arm segments. The third spine is usually a little longer than the fourth. Beyond the fifteenth segment the spines become shorter, and they scarcely exceed the segment in length. Seen under the microscope, the surface of these spines appears covered with fine asperities.

The tentacle scale is small, short, and rounded, and its surface is also provided with fine asperities.

The color of the specimen in alcohol is black, with no ornamentation.

Affinities and distinctive features.-The genus Ophiomaza up to now has included only three species-O. cacaotica Lyman, O. moerens Kohler, and $O$. obscura (Ljungman). The new species, which most certainly belongs to the same genus, differs from the three others, and especially from $O$. cacaotica, by its very much smaller radial shields; it is further distinguished from them by its large mouth shields which with the genital plates cover a large part of the ventral surface of the disk.

Very recently Matsumoto has described a species from Japan-O. kanekoi ('17, p. 227) -from which $O$. fusca also differs in the reduced size of its radial shields and in the greater dimensions of its mouth shields. H. L. Clark has referred to the genus Ophiomaza Brock's Lütkenia cataphracta ('15, p. 283), which raises to six the total number of the species in the genus Ophiomaza.

\section{OPHIOPTERON ELEGANS Ludwig.}

Plate 60 , figs. 1, 2, 5 ; plate 103, fig. 4.

See for bibliography:

Ophiopteron elegans KGHLER ('04), p. 112.-H. L. ClaRK ('15), p. 282.

Localities.-Albatross station 5136; in the vicinity of Joló; Jolo Light bearing S. $37^{\circ}$ E., 1.30 kilometers $\left(0.7\right.$ mile) distant (lat. $6^{\circ}$ $04^{\prime} 20^{\prime \prime}$ N., long. $120^{\circ} 59^{\prime} 20^{\prime \prime}$ E.) ; 40 meters (22 fathoms); February 14,$1908 ;$ S., Sh.

One specimen (Cat. No. 41308 , U.S.N.M.).

Albatross station 5150; Sulu (Jolo) Archipelago, in the vicinity of Siasi; Sirun Island (W.) bearing N. $34^{\circ}$ E., 21.68 (11.7 miles) distant (lat. $5^{\circ} 23^{\prime} 20^{\prime \prime} \mathrm{N}$., long. $120^{\circ} 35^{\prime} 45^{\prime \prime}$ E.) ; 38 meters (21 fathoms) ; February 18, 1908; co. S., Sh.

Two specimens (Cat. Nos. 41310, 41311, U.S.N.M.). 
Albatross station 5179; in the vicinity of Romblon; Romblon Light bearing S. $56^{\circ}$ E., 8.34 kilometers (4.5 miles) distant (lat. $12^{\circ} 38^{\prime} 15^{\prime \prime}$ N., long. $122^{\circ} 12^{\prime} 30^{\prime \prime}$ E.) ; 68 meters (37 fathoms); March 25, 1908; hrd. S.

One specimen (Cat No. 41309 U.S.N.M.).

Notes.-The two specimens from station 5150, in which the diameter of the disk does not reach $5 \mathrm{~mm}$., are quite in agreement with Ludwig's description, especially in reference to the form of the club spines with their funnel-like ends which cover the dorsal surface of the disk. I show the two surfaces of one of these, as well as a more enlarged portion of the dorsal surface of the disk (pl. 60, figs. $1,2,5)$.

The specimen from station 5136, in which the diameter of the disk is only $4 \mathrm{~mm}$., is interesting in that its club spines are less developed and resemble rather club spines terminated by a crown of simple spinules like those met with in numerous species of Ophiothrix. These club spines are smaller than is usual in $O$. elegans, and they bear a crown formed by a half dozen short spinules which are united by a slightly developed membrane (pl. 103, fig. $4 d$ ). In the specimen from station 5179, in which the disk has almost the same diameter, these club spines are more differentiated, and their funnel-like form, which is more marked, recalls those which I find in the specimens from station 5150. On the border of the disk the transformation of the complicated club spines of the dorsal surface into the ordinary club spines terminated by simple spinules which are seen on the central surface may be followed.

The hook formed by the first ventral arm spine is thick and well developed; it agrees with the ordinary three-branched form; the size of the branches diminishes from the last to the first, which may be rather stout (pl. 103, fig. $4 b$ ). The tentacle scale, which is fairly well developed, ends in a very long point $(e)$.

Ophiopteron elegans has been found in a number of localities in the Indian Ocean, in the Sunda Archipelago, in the Andaman, Laccadive, and Maldive Islands, and on the Macclesfield Bank, but it is always rare and has never been taken except in very small numbers.

OPHIOPTERON GRATUM, new species.

Plate 60 , figs. 3,4 ; plate 103 , fig. 2.

Locality.-Albatross station 5152; Sulu (Joló) Archipelago, Tawi Tawi Group; Pajumajan Island (W.), bearing S. $2^{\circ}$ W., 3.70 kilometers (2 miles) distant (lat. $5^{\circ} 22^{\prime} 55^{\prime \prime} \mathrm{N}$., long. $120^{\circ} 15^{\prime} 45^{\prime \prime}$. E.) ; 62 meters ( 34 fathoms) ; February 18, 1908; wh. S.

One specimen (Cat. No. 41307, U.S.N.M.). 
Description.-The diameter of the disk is $3 \mathrm{~mm}$; the arms are from $15 \mathrm{~mm}$. to $18 \mathrm{~mm}$. long.

The disk is rounded. The dorsal surface is covered with few plates, among which a circular dorso-central which is very much larger than the others may be distinguished. These plates form five broad interradial bands in which they are arranged in two or three rows; they are rounded or oval, somewhat unequal, and those which are close to the dorso-central plate are larger than the others. Toward the periphery of the disk the plates become rapidly very much smaller and more numerous, and they cover a semicircular space which projects outward between the arms, encroaching upon about half the length of the distal border of each radial shield. The dorsal plates of the disk are without club spines, and these only occur at the periphery of the disk on the plates of the latter, or on those of the two last rows, whence they continue onto the ventral surface. The elub spines are short, rather thick, ending in three or four triangular and very short spinules. The radial shields are triangular and rather small; their length equals about half the radius of the disk, and they are almost twice as long as broad; the two shields of each pair are slightly divergent and close together, though not in contact, outwardly and separated by a single row of plates.

The ventral surface of the disk does not show distinct plates, but it is covered over its whole extent with club spines which are more developed than those seen at the periphery of the disk on viewing the ophiuran from the dorsal surface, and these club spines all terminate in three or four short and triangular spinules.

The mouth shields, which are broader than long, are lozengeshaped, with the angles rounded. The adoral plates are triangular with the apex rounded; they are in contact in the median interradial line, and they broaden progressively outwardly. The oral plates are high. The tooth papillae are arranged in three rows only, two lateral and a median.

The upper arm plates, which are large and broad, are trapezoidal with a straight and slightly concave proximal border, and a broad and convex distal border passing over by rounded angles into the sides, which are very slightly concave. All these plates are broadly in contact.

The first under arm plate is small, rectangular, and broader than long. The following plates are rectangular, at first as broad as long, then becoming a little longer than broad, with the sides slightly convex and the angles rounded. They are very broadly in contact.

The side arm plates carry eight spines at the base of the arms. The four ventral sines are free. From the commencement of the arms the first assumis the form of a hook which usually shows only 
two branches; these are stout and subequal (pl. 103, fig. 2a). The following spines develop progressively from the second to the fifth; the elongation is insignificant from the second $(c)$ to the third $(d)$ and to the fourth $(e)$; this last exceeds the segment in length, and the fifth, which is markedly stouter $(f)$, reaches a length of two segments. These spines are smooth over almost two-thirds of their length, and they show in their terminal third numerous very stout and much elongated pointed teeth which are very close to each other. The general appearance of these teeth with the integument which covers them is that of a well-developed head terminating the spine. The three following spines are smaller and their length as well as their thickness decreases rapidy to the last dorsal, which is short and very slender. These four last spines are united by a thin and transparent wing-like expansion such as occurs in the genus Ophiopteron, which is continued as far as the tip of the arms, though not including more than three spines. This expansion remains strictly limited to the sides of the arms, and does not pass onto their ventral surface.

The tentacle scale is much elongated and is chiefly formed by a spine rather thick at the base which tapers gradually in such a way as to reach a considerable length (fig. 2b.)

The general color of the specimen is gray. In the middle of the disk there is a dark blue central spot, which gives off radially five broad bands passing between the radial shields of each pair and encroaching upon their internal borders, which continue along the median line of the arms, where their width diminishes. On either side of this dark blue line there is a less well defined line of lighter blue which is slightly marked at the level of the distal border of the dorsal plates. The ventral surface is light gray; the middle of the arms has the same light coloration, and on either side there runs a rather broad light blue band bounded by the lateral borders of the under arm plates.

Affinities and distinctive features.-Ophiopteron gratum is very close to O.gymnatum, which MacIntosh described in 1911 from specimens from the Mergui Archipelago. The dorsal plates of the disk have a somewhat different arrangement, but the radial shields are larger in $O$. gymnatum and the interradial plates are arranged in several rows. The club spines of the ventral surface of the disk do not reach the dorsal surface at all in O. gymnatum, while in the new species they encroach slightly from that surface. The adoral plates are extremely slender in the species from the Mergui Archipelago, instead of being triangular and rather thick outwardly as in $O$. gratum; the color of the dark lines which extend sver the dorsal surface of the disk and over the arms is quite dif rent; it is purple in 0 . gymnatum instead of being blue. These ]'nes, though they have 
the same arrangement, are narrower in 0. gymnatum. I have a specimen of 0 . gymnatum kindly sent me by Mr. MacIntosh, and I have been able to convince myself that the two species are entirely different.

The discovery of a new Ophiopteron raises the number of known species in this interesting genus to six.

\section{OPHIOPTERON PUNCTO-COERULEUM Kœhler.}

Plate 58 , figs $5,6,7$; plate 103 , fig. 3 .

Ophiopteron puncto-coeruleum KoHLER ('05), p. 114, pl. 12, figs. 5-7; pl. 15, fig. 6.-H. I. ClaRK ('15), p. 282.

Locality.-Albatross station 5150; Sulu (Joló) Archipelago, in the vicinity of Siasi; Sirun Island (W.) bearing N. $34^{\circ}$ E., 21.68 kilometers (11.7 miles) distant (lat. $5^{\circ} 23^{\prime} 20^{\prime \prime} \mathrm{N}$., long. $120^{\circ} 35^{\prime} 45^{\prime \prime}$ E.) ; 38 meters (21 fathoms) ; February 18, 1908; co. S., Sh.

One specimen (Cat. No. 41306, U.S.N.M.).

Notes.-The diameter of the disk is $3 \mathrm{~mm}$.; the arms are from 20 $\mathrm{mm}$. to $22 \mathrm{~mm}$. long.

On plate 58, figures 5, 6, 7, I give three photographs of this pretty little species, which show better than the figures which I have previously published its elegant scheme of coloration and the arrangement of the blue spots on the two surfaces of the body. In addition the photographs on plate 103, figure 3 , show the hook corresponding to the first ventral arm spine, which is always well developed and has sometimes two and sometimes three branches $(a)$, the third ventral spine $(b)$ and one of the lateral spines $(c)$, and two tentacle scales $(d)$. These last are moderately developed and end in a long point which is usually single, though frequently there are two equal or unequal points.

Ophiopteron puncto-coeruleum was found by the Siboga at Flores, Rotti, and the Aru Islands, at depths varying from 13 to 40 meters (7 to 22 fathoms).

\section{Order IV. CHILOPHIURIDA.}

Family OPHIOCHITONIDAE.

\section{OPHIOCHITON FASTIGATUS Lyman.}

Plate 76, figs. $1-8,10,11$.

Ophiochiton fastigatus LYMAN ('78), p. 132, pl. 7, figs. 182, 183; ('82), p.

176, pl. 24, figs. 13-15.-H. L. CLARK ('11), p. 133; ('15), p. 287.

Localities.-Albatross station 5348; Palawan Passage; Point Tabonan bearing $\mathrm{S} .89^{\circ}$ E., 62.08 kilometers ( 33.5 miles) distant (lat. $10^{\circ} 57^{\prime} 45$ N., long. $118^{\circ} 38^{\prime} 15^{\prime \prime}$ E.) ; 685 meters ( 375 fathoms); December 27,1908 ; Co., S. 
One specimen (Cat. No. E. 171, U.S.N.M.).

Albatross station 5582; in the vicinity of Darvel Bay, Borneo; Si Amil Island (N.) bearing S. $82^{\circ}$ W., 11.5 kilometers $(6.2$ miles $)$ distant (lat. $4^{\circ} 19^{\prime} 54^{\prime \prime}$ N., long. $110^{\circ} 58^{\prime} 38^{\prime \prime}$ E.) ; 1,628 meters (890 fathoms); September 26, 1909 ; gy. M., fne. S.

One specimen (Cat. No. E. 170, U.S.N.M.).

Albatross station 5585; Sibuko Bay, Borneo, and vicinity; Sipadan Island (N.) bearing S. $89^{\circ} \mathrm{W} ., 19.84$ kilometers (12 miles) distant (lat. $4^{\circ} 07^{\prime} 00^{\prime \prime}$ N., long. $118^{\circ} 49^{\prime} 54^{\prime \prime}$ E.) ; 870 meters (476 fathoms) ; September 28, 1909 ; gy. M.

One specimen (Cat. No. E. 169, U.S.N.M.).

Albatross station 5619; Molucca Passage, Mareh Island (S.) bearing S. $78^{\circ}$ E., 12.97 kilometers ( 7 miles) distant (lat. $0^{\circ} 35^{\prime} 00^{\prime \prime} \mathrm{N}$., long. $127^{\circ} 14^{\prime} 40^{\prime \prime}$ E.) ; 796 meters (435 fathoms); November 27, 1909 ; fine. gy. S., M.

One specimen (Cat. No. E. 172, U.S.N.M.).

Albatross station 5650; Gulf of Boni, Celebes; Lamulu Point bearing N. $5^{\circ}$ W., 23.16 kilometers (12.5 miles) distant (lat. $4^{\circ} 53^{\prime} 45^{\prime \prime}$ S., long. $121^{\circ} 29^{\prime} 00^{\prime \prime}$ E.) ; 988 meters ( 540 fathoms) ; December 17 , 1909 ; gn. M.

One specimen (Cat. No. E. 173, U.S.N.M.).

Notes.-The diameter of the disk varies between $16 \mathrm{~mm}$. (in the specimen from station 5619) and $26 \mathrm{~mm}$. (in that from station 5348).

H. L. Clark ('11, p. 133) has already recorded certain variations observed by him in specimens of $O$. fastigatus from Japan, which have to do principally with the form of the mouth shields and of the adoral plates, as well as the number of arm spines. He finds that the mouth shields, which typically are broader than long, may acquire an oval outline and become as long as broad; the arm spines are sometimes only two in number, but reach four in the large specimens. The adoral plates are sometimes very greatly reduced and may even be completely lacking when the oral plates are elongated. The development of the ventral keel of the arms varies considerably.

In five specimens from the Albatross collection I find still more extensive variations, and these variations involve not only the form of the mouth shields and of the ventral keel of the arms, as well as the number of arm spines, but. also the relative dimensions of the dorsal plates of the disk and of the radial shields, and the arrangement of the tentacle scales.

Regarding the dorsal plates of the disk, I may first of all state that the two figures published by Lyman in 1878 and 1882 are not perfectly in accord. In the first figure ('78, fig. 183) the dorsal plates of the disk are all very small and almost equal, the primary plates are distinct but also very small, and the radial shields are ex- 
tremely reduced, their length equaling almost one-fifth of the radius of the disk. In the figure published in 1882 (pl. 24, fig. 14), on the other hand, the plates become larger at the periphery of the disk and in the vicinity of the radial shields; the primary plates are larger, and the radial shields are also larger, their length exceeding a third of the radius of the disk; in both cases the same specimen from Challenger station 232 is the subject. I may add that I find among my specimens the two alternatives figured by Lyman.

The plates of the dorsal surface of the disk are always very numerous and very small, but with some variations; an arrangement which may be considered as the mean is that shown by the specimens from stations 5582 and 5585 (pl. 76, figs. 1, 2); these plates are a little larger in the specimen from station 5619 (fig. 10). On the other hand, in that from station 5348 they are of an extreme minuteness (fig. 4), and they become only a little larger toward the borders of the disk and in the vicinity of the radial shields; the six primary plates are also extremely small, though they are more evident. The dimensions of the radial shields also vary; in the specimen from station 5619 (fig. 10) they are elongated and rather slender, three times as long as broad, pointed inwardly, and their length is equal to a third the radius of the disk. In the specimen from station 5582 (fig. 2), and especially in that from station 5650 , these shields are shorter and relatively a little broader, their length scarcely reaching a quarter the radius of the disk; they are still more reduced in the specimen from station 5585 (fig. 1), and especially in that from station 5348 (fig. 4), in which their length scarcely reaches a fifth the radius of the disk; in the last they are small, triangular, scarcely longer than broad, with the proximal angle rounded and the internal border convex.

The keel on the ventral surface of the arms is generally only slightly marked; the specimen from station 5583 alone (fig. 3) shows a fairly developed keel. This is scarcely indicated in those from stations 5348, 5585, and 5650; it is not all evident in that from station 5619 which, it is true, is smaller than the others, the diameter of the disk not exceeding $16 \mathrm{~mm}$.

It is only in the specimen from station 5582 (fig. 3) that the mouth shields show the broadened and low form described by Lyman; these shields are a little higher and less broad in the two from stations 5585 (fig. 7 ) and 5619 (fig. 5), while in that from station 5348 (fig. 8) they are still broader than long, but their proximal angle no longer exists, being replaced by a convex border in such a way that the shields become semicircular with a small lobe on the middle of the distal border. In the specimen from station 5650 (fig. 6) they are simply triangular and pronouncedly 
longer than broad, with the proximal angle strongly marked and sharp.

I shall record also the variations shown by the tentacle scales. These are typically two in number, the outer rapidly becoming very much larger than the inner. These two scales may remain subequal on the first arm segments and the internal scale may not become really reduced until beyond about the tenth; this is what occurs in the specimens from stations 5582 (fig. 3), 5585 (fig. 7), and 5650 (fig. 6), but in that from station 5348 (fig. 8) this internal scale becomes very much smaller than the other beyond the second segment, and it is considerably reduced on the following segments. On the other hand, this same scale may be doubled; this occurs over a large part of the length of the arms in the specimen from station 5582, which possesses three tentacle scales (fig. $11)$, one very large and the two others very small.

The adoral plates are much elongated and more or less narrow, but I do not find any variations so great as those which have been described by H. L. Clark, and which may go as far as the complete disappearance of these plates through a sort of reciprocity with the oral plates.

The determination of the rather important variations which I have just noted in 0 . fastigatus has led me to take up again the study of the comparative characters of this species and of 0 : ambulator, which I established in 1896 from specimens dredged by the Investigator in different localities in the Indian Ocean, at depths varying betweeen 200 and 890 fathoms. Before inquiring into whether 0 . ambutator does not represent simply one or other of the variations which I have just described in $O$. fastigatus, I may say that I consider $O$. carinatus, described by Lütken and Mortensen three years after my description of $O$. ambulator, as being absolutely identical with it. I had already foreseen this in 1904 ('04, p. 70).

One of the principal characters which distinguishes $O$. ambutator from $O$. fastigatus is the large size of the radial shields, for these shields are only a little shorter than half the radius of the disk; this is the same proportion which is shown by Lütken and Mortensen in their $O$. carinatus. Whatever may be the variations shown by the radial shields in $O$. fastigatus, they always remain very reduced in size and never reach the dimensions which they show in $O$. ambulator (fig. 12). Other characters also show that 0 . ambulator is a species very distinct from $O$. fastigatus. The keel which extends throughout the whole length of the ventral median line of the arms in $O$. ambulator occurs with very great constancy; it shows a very remarkable development and is very much more accentuated than in $O$. fastigatus, in which it may sometimes entirely disappear. The character furnished 
by the keel is so prominent that Luitken and Mortensen have referred to it in the name chosen by them to designate the species which they believed new. The dorsal surface of the arms is elevated in both species, but the upper arm plates of $O$. ambulator are less broad than those of 0 . fastigatus, and the under arm plates have a more sinuous outline, the middle of their distal border projecting into a small and very prominent lobe coresponding to the ventral keel which does not occur in $O$. fastigatus. The tentacle scales are very unequal in the two species; in $1896 \mathrm{I}$ wrote that in 0 . ambulator they are inserted on the same side of the tentacle pore and are not opposite each other; this is correct only for the pores of the first pairs, for beyond the disk the small inner scale becomes inserted on the under arm plate, and it then occurs opposite the other very much larger scale as is the condition in $O$. fastigatus.

In studying $O$. ambulator anew, I find on one specimen a feature which I had not noticed in 1896, and which, moreover, only occurs on this one individual. This is the presence on the first arm segments of much developed and very evident ventral pores; I can easily count 10 pairs of them. These pores, quite comparable to thase which are known in the genera Ophiarachna, Ophiopeza, etc., are placed on either side of the ventral median keel between the anterior border of the under arm plate and the posterior border of the side arm plates. These pores may be easily seen on the photograph which I give (fig. 13). I do not find the least trace of them in the other specimens which I have reexamined, all of which agree with that of which I give a photograph in figure 9. Lütken and Mortensen did not mention these pores in their $O$. carinatus. I shall have occasion to describe in Bathypectinura conspicua similar variations, regarding ventral pores, certain specimens possessing up to seven or eight pairs, and others completely lacking them; comparable differences also occur in Ophiarachna affinis. The presence or absence of these proes therefore cannot be invoked to establish specific distinctions.

$I$ believe that $O$. ambulator (including $O$. carinatus) can not be united with $O$. fastigatus particularly on account of the dimensions of the radial shields and of the development of the ventral keel, which is never lacking in the first species.

Matsumoto has just published some figures and notes on the subject of $O$. fastigatus ('17, p. 328, fig. 91). He records especially variations in the form of the adoral plates and the accidental presence of the small accessory mouth shields. He considers Lütken and Mortensen's $O$. carinatus as a synonym of $O$. fastigatus, an opinion which I can not share; as I have just explained, $O$. carinatus is identical with $O$. ambulator, which is very different from $O$. fastigatus. 
OPHIONEREIS DUBIA (Müller and Troschel).

See for bibliography:

Ophionereis dubia LoRIol ('94), p. 19.-H. L. CLARK ('01), p. 248.-KäLLR ('05b), p. 458; ('07), p. 315; ('07b), p. 246.-H. L. CLARK ('15), p. 289.

Locality.-Albatross station 5159; Sulu (Joló) Archipelago; Tawi Tawi Group; Tinakta Island (N.) bearing N. $82^{\circ}$ W., 2.59 kilometers (1.4 miles) distant (lat. $5^{\circ} 11^{\prime} 50^{\prime \prime}$ N., long. $119^{\circ} 54^{\prime} 00^{\prime \prime}$ E.) ; 18 meters (10 fathoms); February 21, 1908; co. S.

One specimen (Cat. No. 41016, U.S.N.M.).

Notes.-The diameter of the disk is $5.5 \mathrm{~mm}$. The specimen agrees well with the descriptions of authors and with Savigny's figures. The genital slits are entirely smooth, and this feature does not permit of referring the specimen to 0 . porrecta, which is frequently met within the Indo-Pacific region.

OPHIONEREIS SEMONI (Döderlein).

Plate 61, figs. 1, 2.

Ophiotriton semoni Döderlein ('97), p. 28s, pl. 15, figs. \$, $8 a$.

Ophionereis semoni КовнLе ('05), p. 54, pl. 6, figs. 7,8 ; pl. 14, fig. 4.-H.

L. Clark ('15), p. 290.

Locality.-Albatross station 5249; Gulf of Dávao; Lanang Point bearing $\mathrm{N}$., 1.85 kilometers ( 1 mile) distant (lat. $7^{\circ} 06^{\prime} 06^{\prime \prime} \mathrm{N}$., long. $125^{\circ} 40^{\prime} 08^{\prime \prime}$ E.) ; 42 meters (23 fathoms) ; May 10, 1908; Co., S.

One specimen (Cat. No. 41012, U.S.N.M.).

Notes.-The specimen is of small size, but it is very well characterized; the diameter of the disk is $4 \mathrm{~mm}$., and the arms are $25 \mathrm{~mm}$. long. The color of the disk is a light greenish yellow; the arms show evenly spaced narrow brown cross bands.

I have thought it well to include two photographs of this specimen with a greater enlargement than that which Döderlein used (pl. 61, figs. 1,2 ).

In 1905 I gave the reasons for which it seemed to me necessary to retain $U$. semoni in the genus Ophionereis.

Ophionereis semoni has been found in different localities in the Sunda Islands at very variable depths down to 94 meters (52 fathoms).

\section{OPHIODORIS CONTRARIUS Kohler.}

Ophiodoris contrarius KGHLER ('04), p. 75, pl. 12, figs. 3, 4.-H. L. ChaRK ('15), p. 290.

Locality.-Albatross station 5601a; Gulf of Tomini, Celebes; Limbe Island (NE.) bearing N. 38.36 kilometers (20.7 miles) distant (lat. $1^{\circ} 13^{\prime} 10^{\prime \prime} \mathrm{N}$., long. $125^{\circ} 17^{\prime} 05^{\prime \prime}$ E.) ; 1,399 meters (765 fathoms) ; November 13, 1909; S., Glob., Ptr.

One specimen (Cat. No. 41334, U.S.N.M.). 
Notes.-The diameter of the disk is $7.5 \mathrm{~mm}$.; the arms are broken off near the base.

The specimen agrees in every way with the type series which I described in 1904 from individuals collected by the Siboga between $2^{\circ}$ $\mathrm{N}$. latitude and $8^{\circ} \mathrm{S}$. latitude and $119^{\circ}-127^{\circ} \mathrm{E}$. longitude, at depths varying from 1,158 to 1,301 meters ( 635 to 711 fathoms).

\section{OPHIODORIS MALIGNUS Kohler.}

Ophiodoris malignus Kaehuer ('04), p. 73, pl, 12, figs. 5, 6.-H. L. Clark ('15), p. 290.

Locality.-Albatross station 5135; in the vicinity of Joló; Joló Light bearing S. $46^{\circ}$ W., 22.05 kilometers (11.9 miles) distant (lat. $6^{\circ} 11^{\prime} 50^{\prime \prime} \mathrm{N}$., long. $121^{\circ} 08^{\prime} 20^{\prime \prime}$ E.) ; 294 meters (161 fathoms); February 7, 1908; fne. co. S.

One specimen (Cat. 41335 , U.S.N.M.).

Notes. - The diameter of the disk is $6 \mathrm{~mm}$.; the arms, which are long and slender exceed $60 \mathrm{~mm}$. in length; they are all intact.

The six primary plates of the dorsal surface of the disk are very distinct. The adoral plates are not strictly limited to the sides of the mouth shield as in the type, but they may come into contact in the median interradial line by means of an extremely narrow prolongation.

The color of the dorsal surface of the disk is a slightly olivaceous gray, but some plates are lighter than others, becoming almost white. The upper arm plates show a median spot darker than the adjacent parts, which sometimes extends in such a way as to form a ring, though this is only very slightly marked.

\section{Family OPHIOCOMIDAE.}

The species belonging to the genus Ophiocoma known up to the present time are 21 in number; these are, alphabetically arranged, as follows:

Ophiocoma aethiops Lütken.

Ophiocoma alexandri Lyman.

ophiocoma bollonsi Farquhar.

Ophiocoma brevipes Peters.

ophiocoma brevispina Smith.

ophiocoma canaliculata Lütken.

ophiocoma döderleini Loriol.

ophiocoma echinata (Lamarck).

ophiocoma erinaceus Müller and Troschel.

Ophiocoma insularia Lyman.

Ophiocoma lineolata Müller and Troschel.

Ophiocoma lubrica Kohler.

ophiocoma marmorata Marktanner.

ophiocoma parva H. L. Clark. 
Ophiacoma pumila; Lütken.

Ophiocoma riisei Lütken.

ophiocoma schönleini Müller and Troschel.

ophiocoma scolopendrina Lamarck.

Ophiocoma valenciae Müller and Troschel.

Ophiocoma variegata Smith.

Ophiocoma wendtii Müller and Troschel.

I have not included in this list Ophiocoma papillosa Lyman from California, which really belongs to the genus Ophiopteris, nor $O$. variabitis Grube, which is not recognizable and which Lyman supposes to be $O$. schönleini.

Ophiocoma echinata, 0 . pumila, $O$. riisei, and 0 . marmorata belong to the Atlantic Ocean; O. marmorata is recorded by Marktanner as coming from a locality situated in the middle of the Atlantic; this is evidently an error. Among the other species 0 . brevipes, 0 . erinaceus, 0 . lineolata, 0. scolopendrina, O. döderleini, O. schönleini, $O$. valenciae, and $O$. wendtii belong to the Indo-Pacific region, and the four first species are very common there. The others have been found less frequently and appear to have more restricted habitats. Ophiocoma aethiops and $O$. alexandri come from the Pacific coast of Central America and California; 0 . canaliculata has only been met with in Australia, and $O$. bollonsi in New Zealand. Ophiocoma brevispina and $O$. variegata, collected at the island of Rodriguez, are perhaps only forms of 0 . brevipes. Ophiocoma hubrica comes from the Laccadive Islands, and $O$. insularia from the Hawaiian Islands.

In regard to these different species I have the following notes:

Ophiocoma döderleini.-In 1915 H. L. Clark gave $O$. döderleini as a synonym of $O$. brevipes; I do not share that opinion. I shall discuss further on in speaking of $O$. brevipes the characters which distinguish this latter from 0 . döderleini.

Ophiocoma aethiops. - This species is known from the descriptions of Lütken ('59, p. 145) and of Lyman ('65, p. 78); very recently H. L. Clark has published two photographs of it ('15, pl. 13, figs. $6,7)$. Lyman has already described the variations shown by $O$. aethiops regarding the number of the tentacle scales and the development of the granules on the ventral surface of the disk. The tentacle scale is usually single, and it is only double on the two first arm segments; but often two tentacle scales occur over a large number of successive segments, and I have in my collection specimens from Panama in which the tentacle scales are two in number on most of the arm segments as far as the twentieth. In these specimens the granules only extend over a very restricted portion of the ventral surface of the disk. The mouth shields, which are hexagonal in form, are very much longer than broad, and they may even be almost twice as long 
as broad with the sides almost straight and the angles slightly rounded. The first dorsal arm spine is a little shorter than the following, but it is thicker, though without ever becoming swollen.

Ophiocoma alexandri--This species, from the west coast of Central America and Lower California, is well known through Lyman's excellent description which unfortunately was not accompanied by a figure; but H. L. Clark has just given two photographs ('15, pl. 16, figs. 5,6 ) of it. Ophiocoma alexandri does not appear to show much variation; in a specimen which I have in my collection the tentacle scales are two in number as far as the sixth segment (inclusive) on one of the arms; the mouth shields are almost circular, though they may be considered as triangular with the angles very rounded.

Ophiocoma valenciae.-This species occurs throughout the whole Indo-Pacific region, from the Red Sea, the east coast of Africa, Madagascar, Mauritius, and the neighboring regions to the Maldive, Laccadive, and Mergui Archipelagoes, the Fiji Islands, and Samoa. The descriptions of Müller and Troschel and of Lütken have been supplemented by the remarks of Loriol ('93, p. 30), Marktanner, ('87, p. 303), and MacIntosh ('11, p. 160); very recently H. L. Clark has given very good photographs of it ('15, pl. 16, figs. 7, 8). Ophiocoma valenciae does not show much variation; in a specimen which $I$ have from the Red Sea the granules of the disk are rather large on the dorsal surface, and at the periphery they elongate into very short spines of which the point is rounded and which pass over onto the ventral surface where they become slightly more elongated. The mouth shields, which are very much rounded, are as long as broad, as is also shown in H. L. Clark's photograph. In another specimen from the Mergui Archipelago the mouth shields, here also very rounded, are distinctly a little broader than long, and the arm spines are six in number at the base of the arms, the number then falling to five; it is not the second dorsal spine but the third which is the longest. I find two tentacle scales on the two first pairs of pores only, and a single one throughout the remainder of the arms.

Ophiocoma schöleini.-I am not familiar with this species, as I have never handled it. Lyman considered it doubtful as he also did O. wendtii, but very recently H. L. Clark ('08, p. 296) found in a collection from Amboina three quite characteristic specimens of $O$. schöleini which he described and of which he published later two photographs ('15, pl. 15, figs. 1, 2). H. L. Clark considers $O$. schönleini as very close to $O$. erinaceus; it is distinguished from the latter by the presence of a single tentacle scale on all the arm segments and of two on the pores of the first pair, sometimes on those of the second, and even of the third; the arm spines are shorter and the mouth shields are slightly broader than in $O$. erinaceus. According to the same author $O$. schönleini is distinguished from $O$. wendtii by having 
the mouth shields broader, shorter, and almost equally broad toward both extremities, distal and proximal, by having the first under arm plates broader than long, and by never having the dorsal arm spine thickened or claviform.

Ophiocoma canaliculata is only known from a single specimen which I redescribed in some detail and figured in 1904 ('04a, p. 75). It is the only species of Ophiocoma in which the adoral plates are developed in front of the mouth shields, and are broadly united to each other in the median interradial line. Lyman ('82, p. 168) says that $O$. canaliculata possesses small imbricated scales at the base of the first dorsal arm spine, a feature which Lütken did not mention; neither did I mention it in my description in 1904, and I do not find in my notes any mention of it; moreover, $I$ do not find in the photographs which I took of the unique type preserved in the Copenhagen Museum the least trace of it. However that may be, $O$ canaliculata stands quite by itself in the genus Ophiocoma and perhaps the study of other specimens will one day show that it must be placed in a new genus.

Ophiocoma bollonsi from New Zealand appears to be very close to 0 . scolopendrina, but it possesses six arm spines at the base of the arms.

As for Ophiocoma lubrica, this species has two tentacle scales throughout the whole length of the arms, and the adoral plates are confined to the sides of the mouth shields; it is a true Ophiocoma, which is especially characterized by the peculiar form of the under arm plates.

Ophiocoma insularia from the Hawaiian Islands was described by Lyman as a distinct species in 1861, but it was later united by him with 0 . brevipes. H. L. Clark again considered it as a distinct species, and he gave two photographs of it in 1915 ('15, pl. 15, figs. $3,4)$.

It may be noticed that I have not recorded above among the Atlantic species of the genus Ophiocoma 0 . nigra from the North Atlantic. This species, which runs down from the coast of Norway along the coast of the British Isles and of France as far as the Azores and enters the Mediterranean sea, it seems to me must be removed from the genus Ophiocoma to form an independent genus. Ophiocoma nigra is distinguished from all the known species of the genus Ophiocoma by its hollow arm spines and it was for this reason that Lyman assigned it to the genus Ophioconis, comparing it with Ophioconis miliaria and $O$. antarctica. Furthermore, Ophiocoma nigra shows broad and thick peristomial plates very different from those which are known in the other species of Ophiocoma; I include a photograph of an internal view of the mouth pieces of $O$. nigra (pl. 
63, fig. 6) for comparison with a similar view of the same structures in 0 . scolopendrina (fig. 5 ), and it may be seen that the differences are very striking. The peristomial plates of $O$. scolopendrina are very thin, elongated, and four times as along as broad, while in $O$. nigra these plates are very much more developed and broadened; they are twice as long as broad only, with the borders slightly recurved. Viewed externally the mouth pieces of 0 . nigra show another peculiarity. The mouth shields are very much broader than long, contrary to what is found in the genus Ophiocoma, in which they are ordinarily elongated and longer than broad, rarely as long as broad, and they are only broader than long quite exceptionally in the single form from the island of Rodriguez which Smith has described under the name of $O$. brevispina. The adoral plates are very elongated, and they extend for the whole length of the proximal border of the mouth shield as far as the median interradial line where they are in contact; they thus come to be three or four times as long as broad; these plates are very tapering in their internal portion which runs along the proximal border of the mouth shield, while they broaden outwardly to form a much developed lobe separating the mouth shield from the first side arm plate. This form of the adoral plate contrasts with that which occurs in the genus Ophiocoma in which they remain always localized on the sides of the mouth shield, showing a triangular shape and rather reduced dimensions; I have recorded above the single exception known in $O$. canaliculata. The oral plates of $O$. nigra are high and elongated, two or three times as high as broad, while in the genus Ophiocoma they usually are very low.

These characters may be appreciated on the photographs which I give here of different specimens of $O$. nigra, some from the northern seas or from Roscoff, the others from the Azores and from Sicily (pl. 75, figs. 1-6).

In the catalogue of recent ophiurans which $\mathrm{H}$. L. Clark has just published $O$. nigra is given in the genus Ophiacantha under the name of 0 . sphaerulata (Pennant). This generic treatment, which is certainly based on the similarity in the characters of the spines, does not seem to me acceptable for, among other things, the peristomial plates of $O$. nigra differ entirely from those which we know in the genus Ophiacantha, in which there occurs in each interradius a single large and rounded peristomial plate, a condition which is entirely different from that which my photograph shows (compare it with the figures of Lyman '92, pl. 41, fig. 12, and also with that of Matsumoto '17 pl. 3, fig. 1).

It therefore appears to me necessary to create for 0 . nigra a new genus, to which I propose to give the name Ophiocomina and which is characterized as follows: 


\section{Genus OPHIOCOMINA Kœhler. ${ }^{22}$}

Ophiocomidae, with the spines hollow; like those of Ophiacantha; the disk is covered with granules on both surfaces; the mouth shields are transversely broadened; the much-elongated adoral plates are in contact in the median interradial line; they broaden outwardly and more or less widely separate the mouth shield from the first side arm plate; the oral plates are high; the mouth and tooth papillae are arranged as in the genus Ophiocoma.

Except for the characters shown by the spines there are none which recall the genus Ophiacantha, and all the affinities of the genus Ophiocomina are with the genus Ophiocoma.

The genus Ophiocomina as yet seems to be represented only by a single species, O. nigra, which lives in the North Atlantic between the coasts of Norway and the Azores and enters the Mediterranean. ophiocomina nigra, with its long divergent arm spines, has a general appearance recalling very strongly that of Ophiacantha bidentata, and it is certain that these two species have been very often confused. This is evidently the reason why certain authors have mentioned $O$. nigra from the Arctic seas, from Spitzbergen and from the Barents Sea, for example; they refer in reality to Ophiacantha bidentata, for O. nigra, an essentially boreal species, does not ascend to these very high latitudes and does not appear to pass the latitude of Trondhjem or of Storeggen.

Since I have had occasion here to speak of 0 . nigra, I shall request permission to add a few more words regarding the variations which this species shows.

First of all I may mention that besides $O$. nigra two related forms figure in zoological literature-O. raschi, described by G. O. Sars in 1872 from specimens from the coasts of Norway (Storeggen, 146-183 meters [80-100 fathoms]) and O. tumida Müller and Troschel, from Genoa.

Ophiocomina raschi is listed by Lyman in the Challenger report ('82, p. 172), but the reference which this author gives is incorrect, for this species is not described in the Danish publication "Vid. selsk. forh." (1872, p. 39), but in the Norwegian "Vid. selsk. forh." published at Christiania in 1872, and the description is found on page 109. I do not believe that $O$. raschi should be maintained as a distinet species; as Sars himself stated at the beginning of his description it does not differ from 0. nigra except in its larger size and a different coloration; "color disci et brachiorum laete ruber, spinarum albidus," says the learned Norwegian naturalist, and he gives for the dimensions, diameter of the disk $20 \mathrm{~mm}$., length of the

12 See Kœhler, in Mortensen, Vidensk, Medd, fra Dansk naturh. Foren., København, vol. 12, 1921, p. 53 ; Kœhler, Faune de France, Echinodermes, 1921, p. 93. 
arms about $90 \mathrm{~mm}$. As for the morphological characters themselves, all those which the author gives may just as well apply to 0 . nigra which, as we shall see, shows much variation. I shall mention further on a specimen from the coasts of Sicily in which the diameter of the disk reaches $23 \mathrm{~mm}$.; the size given by Sars for $Q$. rasch $i$ is thus much exceeded.

Concerning the coloration, I may recall that it is true the disk of O. nigra is generally more or less dark, usually blackish brown, but Forbes has recorded an orange colored variety which is rather frequent in the northern seas, and he has also found in the Shetland Islands individuals of a very beautiful pink. On the coasts of England Ophiocomina nigra appears capable of descending to depths as great as those recorded by Sars on the coasts of Norway, and it has been captured at all depths between sea level and 146 meters (80 fathoms) (see F. Jeffrey Bell, '84, p. 129).

I have had the opportunity of studying some specimens from the Faroe Islands collected by Doctor Charcot in which the disk is very light gray, with the spines almost white; I am speaking of alcoholic specimens, for the coloration in life was not noted; but it is very probable that the color was lighter than usual, for in the specimens of O. nigra in alcohol which I possess from the coasts of England and France the disk always shows a more or less dark brownish or brownish yellow coloration.

As for Ophiocomina tumida, this species was created by Müller and Troschel, who only published a very short description of four lines, in which they mention four arm spines only, and as the habitat Genoa, Lyman ('65, p. 70) says on this subject: "The original in the Leyden Museum is marked 'Gulf of Genoa'' but this looks like a mistake. I do not remember to have seen any Ophiocoma at all from the Mediterranean," etc.

But many years ago I received from my excellent colleague, Prof. A. Russo, an ophiuran from the coast of Sicily which he asked me to determine for him and which I assigned without hesitation to 0 . nigra. This specimen, of which I figure here the ventral surface (pl. 75, fig. 4), is of very large size; the diameter of the disk reaches $23 \mathrm{~mm}$.; the arms, which measure $4 \mathrm{~mm}$. in width at the base, are in fragments, but their total length may be estimated as $100 \mathrm{~mm}$.; the dorsal surface of the disk is of a rather dark brown; that of the arms is lighter, and the spines are yellowish.

The occurrence of $O$. nigra in the Mediterranean should not be surprising, for this species occurs also at the Azores, where it was found by the Princesse Alice. I include some photographs showing two specimens from this latter locality (figs. 1, 2,3).

To complete these comparisons, I give a photograph of the ventral surface of a specimen from Roscoff (pl. 75, fig. 5). I believe that 
all these specimens from different localities belong to one and the same species. Without speaking of the differences of the kind which MacIntosh has so carefully noted ('03, p. 463), the principal variations, always of secondary importance, which I have been able to find in my specimens concern more particularly the form of the mouth shields, and in each of the five individuals of which I include photographs these plates show slightly different outlines; but in all these shields are always broader than long. In the specimen from Roscoff (fig. 5) the mouth shields are quadrangular; the extremely obtuse proximal angle is bounded by two almost straight or slightly convex sides; the two other sides, which are very convex, are united over an angle so broad and so rounded that together they form a single semicircular border; the shield carrying the water pore alone has two distinct distal sides which are very slightly excavated and united by an angle which develops into a small median lobe. In the specimen from the Faroe Islands collected by Doctor Charcot (fig. 6) the proximal angle is extremely obtuse and is bounded by very rounded sides; the two other sides are distinct; they are slightly excavated, and the distal angle forms a small rounded lobe projecting into the interradial space. On the other hand, in the Sicilian specimen (fig. 4) the distal border of the mouth shields is semi-circular as in that from Roscoff, while the two proximal sides are united over an angle which projects in the form of a blunted point between the two adoral plates. In a specimen from the Azores (fig. 2) the mouth shields are lozenge-shaped, but less broad and a little longer, relatively, than in the others; the proximal and the distal angle are both very obtuse, though distinct, and almost of the same form. In another from the Azores (fig. 3) the mouth shields are broader and the relation between their length and their breadth is almost the same as in those from the Faroe Islands, from Roscoff, and from the Azores; the form recalls that which I have noted in the Sicilian individual, with the proximal angle a little less accentuated. The variations which may be observed in the form of the oral and adoral plates are quite insignificant. The arm spines are usually seven in number at the base of the arms; there are eight on the first arm segments in the Sicilian specimen, which is larger than the others.

It thus seems to me impossible to establish a specific separation between the examples from the northern region and those of the temperate or warm regions of the Atlantic, and it is evident that 0 . nigra extends from the coasts of Norway as far as the Azores, entering the Mediterranean where it will certainly be found in other localities than the coasts of Sicily.

It remains to be seen what should be done with 0 . tumida. I believe that this name must disappear from zoölogical nomenclature. 
Whether it refers to an Ophiocoma resembling $O$. echinata, of which the habitat is given is entirely erroneous, as Lyman suggested, or whether it refers to an Ophiocomina nigra the occurrence of which on the coasts of Sicily is now known, is the question. It appears to me more difficult to admit this latter hypothesis, at least if Müller and Troschel's diagnosis be considered correct, since they attribute to the specimen from Genoa only four arm spines. The re-examination of the type specimen in the Leyden Museum will alone remove this uncertainty.

Genus OPHIOCOMA L. Agassiz.

OPIIOCOMA BREVIPES Peters.

Plate 72, figs. 6-9.

See for bibliography:

Ophiocoma brevipes Kachler ('05), p. 61 ; ('07), p. 325; ('07b), p. 246.-H.

1. Clark ('08), p. 296; ('11), p. 256.-Macintosh ('11), p. 160.-BenhaM

('11), p. 153.-H. L. ClakK ('15), p. 291.-Matsumoto ('17), p. 343.

Localities.-Albatross station 5165; Sulu (Joló) Archipelago, Tawi Tawi Group; Observation Island bearing N. $70^{\circ}$ W. 11.86 kilometers (6.4 miles) distant (lat. $4^{\circ} 58^{\prime} 20^{\prime \prime} \mathrm{N}$., long. $119^{\circ} 50^{\prime} 30^{\prime \prime} \mathrm{E}$.) ; 16 meters (9 fathoms); February 24, 1908; Co.

One specimen (Cat. No. 41067, U.S.N.M.).

Albatross station 5321.

Albatross station 5321; China Sea, near Hongkong; Ibugos Island (south end) bearing S. $89^{\circ}$ W., 2.32 kilometers (1.25 miles) distant (lat. $20^{\circ} 19^{\prime} 30^{\prime \prime}$ N., long. $121^{\circ} 51^{\prime} 15^{\prime \prime}$ E.) ; 38 meters (21 fathoms); November 9, 1908; wh. S., Co., brk. Sh.

Two specimens (Cat. No. 40927, U.S.N.M.).

Reef; Nasugbu, Luzon; January 14, 1908.

Three specimens (Cat. No. 41064, U.S.N.M.):

Dumurug Point, Masbate; shore; April 19, 1908.

Three specimens (Cat. No. 41065, U.S.N.M.).

San Pascial, Burias Island; tide pools; March 8, 1909.

Two specimens (Cat. No. 41066, U.S.N.M.).

Mahinog, Camiguin Island; August 3, 1909.

One specimen (Cat. No. 40936, U.S.N.M.).

Naso Point, southwest corner of Panay; February 4, 1908.

T'wo specimens (Cat. No. 41062, U.S.N.M.).

Port Palapag; June 3, 1909.

One specimen (Cat. No. 41063, U.S.N.M.).

Notes. - A good description of this species was given by Loriol ('93, p. 26) ; Walther has also published some interesting notes upon it ('85, p. 371), and more recently Benham has described a specimen from the Kermadec Islands ('11. p. 153). 
Ophiocoma brevipes varies especially in regard to its coloration, which is sometimes very light and whitish gray, sometimes very dark and almost black; certain individuals sometimes show very elegant markings. Its characters appear more constant than those of $O$. scolopendrina and $O$. erinaceus, with which this species is frequently associated; but there are some variations in the number of the arm spines on which certain authors have thought it possible to base distinct species, as, for example, O. ternispina Martens, which have not been maintained.

I shall speak here only of the variations in the form of the mouth shields about which Loriol has already said a few words. Independently of the outlines, which are sometimes angular, sometimes rounded, these shields may be very much longer than broad, or on the other hand as broad as long, and in the latter case they become almost circular. The two photographs which I include, one of the Philippine specimens (fig. 6) and the other of one from Mauritius in my own collection (fig. 7), show these two different forms; in the individual represented in figure 9 the form of the shield is intermediate.

The knowledge of these variations in the form of the mouth shields appears to be of some importance, and possibly will permit of determining the degree of affinity that 0 . brevispina and 0 . variegata, species which Smith described from specimens from the island of Rodriguez and which have not since been seen, have with 0 . brevipes. These two forms are evidently very close to 0 . brevipes and perhaps some day we shall be led to unite them with it, as Lyman has already suggested ('82, p. 172) and as Jeffrey Bell appears to believe ('84, p. 139). The mouth shields of $O$. variegata have exactly the form which is seen in $O$. brevipes, in which they are usually elongated. In $O$. brevispina these shields are distinctly broader than long, a form which I have never met with in 0 . brevipes, but to which individuals such as those shown in figure 6 show an approach. The question evidently can not be solved except by having at hand specimens from Rodriguez. But the location of that island, which is very close to Mauritius, and which is situated near $20^{\circ} \mathrm{S}$. and $64^{\circ} \mathrm{E}$., renders very probable the presence of $O$. brevipes, the more so since Smith recorded at the same time $O$. erinaceus and Ophiomastix venosa, species often associated with 0 . brevipes.

Ophiocoma brevipes is widely distributed throughout the whole Indo-Pacific region, and according to the record published by Benham it reaches as far as the Kermarlec Islands.

I have already mentioned that H. L. Clark ('14, pp. 291 and 359) considered $O$. döderleini as a synonym of $O$. brevipes. Thanks to the kindness of my excellent friend M. Bedot, director of the museum at 
Geneva, I have been able to examine the type of $O$. döderleini, and I include three photographs of it (pl. 72, figs. 1, 2, 3), which will supplement the data given by Loriol ('99, p. 110, pl.·3, fig. 2) and which will permit forming an opinion of its affinities with 0 .brevipes.

I may mention that the type of $O$. döderleini is represented by a single specimen of very large size; the diameter of the disk given by Loriol is $31 \mathrm{~mm}$. I have never had any specimen of $O$. brevipes which reached these dimensions, and Loriol himself states that the diameter of the disk of 0 . brevipes is between 7 and $27 \mathrm{~mm}$. It is rather curious that Loriol, after describing $O$. döderleini in 1899 , compared it only with $O$. scolopendrina, and did not dream of discussing its affinities with 0 . brevipes. But these affinities are in reality very close. However, at least three characters seem to me to separate the two forms; first the ornamentation of the disk, then the relative size of the arms, and lastly the number of arm spines. The ornamentation of the disk was described by Loriol, and his type shows well the small black spots which involve not only the granules but also the underlying plates. Loriol compares these spots to a sort of oscula, which is evidently an exaggeration, for we have to do here with a simple color change, as is evident from the somewhat enlarged photograph which I give (pl. 72, fig. 3) of a fragment of the dorsal surface of the disk of $O$. döderleini. These little spots are arranged very irregularly on both surfaces of the disk, but they all have almost the same dimensions; I find that each of them is surrounded by a lighter circle, a feature which Loriol did not notice. Whatever may be the ornamention and the coloration of the disk of $O$. brevipes I have never seen, and no one has ever described this character.

A feature which immediately strikes one on examining $O$. döderleini is the remarkable width of the arms, a width which results both from the development of the arms themselves without the arm spines, and from the length of the latter. Although Loriol's type is very large, the diameter of the disk reaching $31 \mathrm{~mm}$., the width of the arms is certainly greater than it would be in an 0 . brevipes in which the disk had the same diameter. I have unfortunately not had at hand specimens of this species of which the disk reached that size, and perhaps such do not exist; Loriol gives as the maximum diameter of the disk in 0 . brevipes $27 \mathrm{~mm}$. I have in my own collection several specimens of $O$. brevipes from Mauritius which may be considered as rather large, and the diameter of their disks varies between $26 \mathrm{~mm}$. and $27 \mathrm{~mm}$. One of these is shown on plate 72 as figure 7 ; the width of the arms with the spines quite erect is about $12 \mathrm{~mm}$. at the place where the width is greatest, that is to say a few segments beyond the disk. In 0 . döderleini this width reaches $17 \mathrm{~mm}$. If 
the increase in the width of the arms were proportional to that of the disk, the arms of an 0 . brevipes with the disk $31 \mathrm{~mm}$. in diameter would thus be only $14 \mathrm{~mm}$. broad. I believe, therefore, that this very marked width of the arms constitutes a specific character of considerable value.

Loriol recorded in $O$. döderleini five arm spines, this figure falling to four at some distance from the base of the arms. In 0 . brevipes the number five is quite abnormal, and I have never noticed it in my large specimens from Mauritius; four is the normal number at the base of the arms. These spines are not altogether as described by Loriol; the antepenultimate dorsal spine is the largest, and its length exceeds two segments and a half; the other spines, which are slightly smaller, are subequal. Generally speaking, these spines are longer than those of 0 . brevipes, in which the longest reaches only two segments. I shall not consider the annulation of the spines which may be noticed, although very rarely, in 0 . brevipes.

I believe, therefore, that $O$. döderleini should be considered as a species distinct from 0 . brevipes and that it is necessary to maintain it. It is very unfortunate that my comparison has only been with the single specimen in the Geneva Museum and that I have not been able to compare it with the second known specimen of this speciesthat collected by the Siboga on the east coast of Borneo-which I recorded in 1905 ('05, p. 60) ; in that specimen the diameter of the disk was only $19 \mathrm{~mm}$. I have very much wished to be able to study this specimen again and to compare it also with $O$. brevipes, but it was impossible under the circumstances to dream of asking the Leyden Museum for it; I find in my notes only that this specimen agrees absolutely with Loriol's description and figures.

\section{OPHIOCOMA ERINACEUS Müller and Troschel.}

Plate 73, fig. 7 .

See for bibliography:

Ophiocoma scolopendrina, var. erinaceus KarLer ('05), p. 60; ('07), p. 326.-Matsumoto ('17), p. 345.

Ophiocoma erinaceus H. L. CLARK ('08), p. 296 ; ('11), p. 257 ; ('15), p. 291.

Localities.-Albatross station 5109; China Sea, off southern Luzon; Corregidor Light bearing N. $42^{\circ}$ E., 47.81 kilometers (25.8 miles) distant (lat. $14^{\circ} 03^{\prime} 45^{\prime \prime} \mathrm{N}$., long. $120^{\circ} 16^{\prime} 30^{\prime \prime}$ E.) ; 22 meters (12 fathoms) ; January 15, 1909; Co.

Two specimens (Cat. No. 40939, U.S.N.M.).

Port Binang, Subig Bay; January 9, 1908.

Two specimens (Cat. No. 40938, U.S.N.M.).

Notes.-Ophiocoma erinaceus is a well known form which is very widely spread throughout the whole Indo-Pacific region. It is very 
close to 0 . scolopendrina, and authors have already many times raised the question whether it should be considered as a distinct species or reduced to the status of a simple variety of the latter. In recording it among the littoral ophiurans collected by the Siboga, I did not separate it specifically from 0 . scolopendrina, and in that I followed the example of many of my predecessors, Ludwig, Marktanner, and Döderlein. This point of view has not been accepted by H. L. Clark ('08, p. 296), who considers $O$. erinaceus as a very distinct species, though he writes a little further on in the same memoir (p. 297): "I shall not be surprised if more extended observation carried on at the shore proves that erinaceus, schönleini, scolopendrina, and wendtii are merely intergrading forms of a single variable species."

I looked into the question again in studying the rather numerous specimens of Ophiocoma scolopendrina collected by the Albatross, and I finally arrived at the conclusion that in spite of the rather extensive variations of $O$. scolopendrina, $O$. erinaceus may always be distinguished from it; I may even add that I have always been able to distinguish the two easily and that $I$ have never hesitated an instant in referring a given specimen either to 0 . scolopendrina or to 0 . erinaceus. It is true that the distinctive characters have an entirely secondary significance. The most obvious, or so it seems to me, is afforded by the granulation of the disk, which stops in an extremely abrupt manner at the periphery without passing over to the ventral surface in $O$. erincceus, while in 0 . scolopendrina a more or less extensive portion of the ventral surface is always found to be covered with granules. In the first species the under arm plates never have the distal border notched, the spines are stout and robust, the dorsal spine is elongated and often thickened, and it is always more robust and more developed than in 0 . scolopendrina; the tentacle scales number two throughout the greater part of the length of the arms; the arms always maintain a certain rigidity. The coloration is black on both surfaces of the disk, and the spines are not ringed as is often the case in $O$. scolopendrina.

It is indubitable that none of these characters have any great significance, but it must be recognized that some other species of the genus Ophiocoma are not better characterized; for instance, $O$. aethiops lütken has no characters very much more distınctive, and it is better differentiated by its place of origin than by its morphological features. As H. L. Clark has stated in the sentence which I have quoted above, the names erinaceus, schönteini, and wendtii perhaps only apply to forms of a single very variable species, but as $O$. schönleini and $O$. wendtii are not distinguished from $O$. scolopendrina by characters more marked than those which separate these from $O$. erinaceus it is evident that if a specific name is to be applied 
to the two first it is logically necessary to distinguish the last also in a similar way.

Matsumoto ('17, p. 346) believes that 0 . scolopendrina, O. erinaceus, and $O$. schönleini belong to one and the same species, and he designates them, respectively, under the names $O$. scolopendrina typical, $O$. scolopendrina, var. crinaccus, and $O$. scolopendrina, var. schönleini.

In 1915 H. L. Clark published very good photographs of a quite typical 0 . erinaceus ('15, pl. 15, figs. 5, 6). I shall content myself with figuring here (pl. 73, fig. 7) the dorsal surface of a specimen in which the first dorsal spine is especially developed and elongated (station 5109).

OPHIOCOMA LINEOLATA Müller and Troschel.

Plate 73, figs. 1-4.

Synonyms :

Ophiocoma pica Mürtuer and Trosches.

ophiocoma sannio LrMan.

See for bibliography:

Ophiocoma lineolata Lorior ('93), p. 28.

Ophiocoma pica KoEHLER ('05), p. 62; ('O7), p. 326.-H. L. CLABK ('15), p. 293.

Localities.-Albatross station 5108; China Sea, off southern Luzon; Corregidor Light bearing N. $39^{\circ}$ E. 41.70 kilometers (22.5 miles) distant (lat. $14^{\circ} 05^{\prime} 05^{\prime \prime} \mathrm{N}$., long. $120^{\circ} 19^{\prime} 45^{\prime \prime}$ E.), 24 meters (13 fathoms) ; January 15, 1908; co.

Two specimens (Cat. No. E. 302, U.S.N.M.).

Albatross station 5109; China Sea, off southern Luzon; Corregidor Light bearing N. $42^{\circ}$ E., 47.81 kilometers (25.8 miles) distant (lat. $14^{\circ} 03^{\prime} 45^{\prime \prime}$ N., long. $120^{\circ} 16^{\prime} 30^{\prime \prime}$ E.) ; 22 meters (12 fathoms) ; January 15,1908 ; co.

Twelve specimens (Cat. Nos. 40914, E. 303, E. 304, U.S.N.M.).

Notes.-Authors who since Müller and Troschel have published descriptions of this species (Lyman '65, p. 90; Walther '85, p. 370; Lorion '93, p. 28) have discussed especially the variations which it shows in its coloration, but they have not spoken of the differences which may be observed in its structure, and particularly the differences in the form and in the length of the arm spires. Lyman expresses himself thus on the subject of the arm spines: "Arm spines six, remarkably slender, tapering and regular;" these are the characters which are most usually observed, and they are those which I find in several specimens from station 5109. As these are mostly not in a good state of preservation, and especially as they are more or less incomplete, I have selected for photographing a specimen which I have in my own collection from Ceylon, of which the characters agree well with Müller and Troschel's description and with 
the description published by Lyman (pl. 73, figs. 1, 4). I also give (fig. 3) a photograph of another specimen from station 5109 in which the two dorsal spines, instead of being the longest, are shorter than the lateral spines, but they are rather strongly swollen, recalling the form which is often observed in $O$. erinaceus, for example; the lateral spines have the usual length. In another individual shown in figure 2 the thickening of the two dorsal spines is still more marked; these spines are very short, their length scarcely equaling two segments, and they are much swollen in their central region. The lateral spines are not thickened, but they are shorter than usual, and their length scarcely exceeds that of the two dorsal spines. This specimen came from Mauritius. It is part of a small but very interesting series which $I$ have in which $I$ find all possible intermediates between very slender and much elongated dorsal spines, such as those most often met with, and spines which are short, thickset, and very strongly swollen.

Similar variations have often been noticed in $O$. scolopendrina and in $O$. erinacens, but $I$ do not know that they have ever before been described in $O$. lineolata.

The remarks given by Müller and Troschel on the subject of the arm spines of $O$. lineolata are not very clear. These authors say, speaking of $O$. pica, that the spines are slender, twice as long as the upper arm plates, and a little longer than the width of the arms; and of those of $O$. lineolata that they are all almost of the same length, this length equalling the width of the arms, and a little thicker at the base of the arms. According to Lyman, who has seen Müller and Troschel's original specimens, these spines are more elongated than these authors describe; in a specimen of $O$. pica in which the diameter of the disk is $15 \mathrm{~mm}$. the first dorsal spine is $3.2 \mathrm{~mm}$. long; in $O$. lineolata the dorsal spine and the lateral spines are longer than the others.

Ophiocoma lineolata, from which it is not necessary to separate $O$. pica Müller and Troschel and O. sannio Lyman, is widely distributed throughout the whole Indo-Pacific region. It is frequently associated with $O$. scolopendrina and with $O$. erinaceus, but it is usually less abundant than the two last.

OPHIOCOMA SCOLOPENDRINA (Lamarck).

Plate 73 , fig. 5 ; plate 74 , figs. $1-7$.

See for bibliography:

Ophiocoma scolopendrina KøHLER ('05), p. 60; ('05a), p. 184; ('07), p. 326 ; ('07b), p. 246.-H. L. Clark ('08), p. 297.-Macintosh ('11), p. 160.-H. L. Clatr ('15), p. 293.

ophiocoma scolopendrina typical Matsumoto ('17), p. 346.

Localities.-Port Binang, Subig Bay; January 9, 1908.

One specimen (Cat. No. E. 218, U.S.N.M.). 
Tataan, Simulac Island; February 19, 1908.

Two specimens.

Makasser Island; December 16, 1909.

Two specimens.

Sabtan Island; November 8, 1908.

Four specimens (Cat. No. E. 205, U.S.N.M.).

Port Palapag; June 3, 1909.

One specimen (Cat. No. E. 216, U.S.N.M.).

Negros Island, Philippines; Bashford Dean.

Two specimens (Cat. No. E. 215, U.S.N.M.).

Dumurug Point, Masbate; April 19, 1908.

Thirteen specimens (Cat. No. E. 206, U.S.N.M.).

Reef off Cebu; April 7, 1908.

One specimen (Cat. No. E. 212, U.S.N.M.).

Sitanki Island; February 26, 1908.

Three specimens (Cat. No. E. 211, U.S.N.M.).

Batan Island; July 22, 1909.

Five specimens (Cat. No. E. 244, U.S.N.M.).

Batan Island; June 5, 1909.

One specimen (Cat. No. E. 210, U.S.N.M.).

Ligpo Point, Balayan Bay, Luzon; January 18, $19(18$.

One specimen (Cat. No. E. 214, U.S.N.M.).

Marongas; shore; coral head; October 2, 1908.

Two specimens (Cat. No. E. 209, U.S.N.M.).

Mariveles, Luzon; June 30, 1913.

Seven specimens (Cat. No. E. 204, U.S.N.M.).

Bonin Islands.

One specimen.

Nasugbu, Luzon; reef; January 2, 1908.

One specimen (Cat. No. E. 245, U.S.N.M.).

Nasugbu, Luzon; reef; January 16, 1908.

Two specimens (Cat. No. E. 208, U.S.N.M.).

Pandanon Island; March 23, 1909.

One specimen (Cat. No. E. 213, U.S.N.M.).

Maricaban, Balayan Bay, Luzon; January 20, 1908.

Two specimens (Cat. No. E. 207, U.S.N.M.).

Nan Wan, Formosa (Taiwan) ; January 27, 1913.

Fourteen specimens (Cat. No. E. 246, U.S.N.M.).

Siasi Island, Joló; shore; February 17, 1908.

One specimen (Cat. No. E. 217, U.S.N.M.).

Small island a half mile off west coast of Java ; December 15, 1908.

Two specimens.

No locality given.

One specimen. 
Philippines; E. A. Mearns.

Two specimens (Cat. No. 41325, U.S.N.M.).

Philippines; J. B. Steere.

One specimen (Cat. No. 40947, U.S.N.M.).

Notes.-Several authors have given detailed descriptions of $O$. scolopendrina or have published notes on the variations which it shows; I shall refer especially to Loriol's memoirs ('93, p. 23, and '93a, p. 407). The variations have to do especially with the form and number of the arm spines, the shape of the upper arm plates and of the mouth shields, and the number of the tentacle scales. I have given (pl. 74) a few photographs of individuals in which these variations are very marked. The two photographs (figs. 1 and 6) represent the dorsal surface of specimens in which the upper arm plates show rather different outlines; in that shown in figure 1, which was collected by the Albatross, these plates are not very broad in relation to their length, and their angles are very rounded; while in the other, which is from Mauritius, these plates are very broad and short with sharp lateral angles; in the latter the spines show a medium development, while in the first the dorsal spine is remarkably thickened, recalling in that respect the common form in 0 . erinaceus. In these two specimens the ventral surface of the disk is more or less covered with granules.

Figures 3 and 4 represent an individual from the Philippines, not collected by the Albatross, which was sent to me with another, also dried, both bearing the number 47,782 . These two specimens are unfortunately in rather bad condition, but $I$ have been able nevertheless to secure satisfactory photographs of them. The upper arm plates are seen to be much broadened, somewhat irregular and unequal in form, with the lateral angles sharp; the dorsal spine shows average development; the general coloration is brownish, and the spines are ringed with white. The ventral surface of these two specimens is especially interesting because of the variations in the number of the tentacle scales. Most commonly the tentacle scale is single; this single scale may appear even on the second segment of one of the arms, and it remains single on almost all the following segments, save for a few exceptions. The other arms frequently bear a single scale, sometimes and most commonly, two on the earlier segments; but beyond the disk the scale is usually single, and this character is maintained throughout the whole length of the arms; however, occasionally and abruptly, sometimes very far from the base of the arms, the scale is doubled.

A similar disposition is found in another individual from Batavia, which is in my own collection and of which I give a photograph in figure 5. There is, as a rule, only a single tentacle scale beyond 
the second segment, and this scale remains single throughout the whole length of the arms, save for very rare and quite isolated exceptions. The upper arm plates resemble those of the two preceding individuals; the dorsal spine is a little shorter but more swollen.

The two photographs reproduced in figures 2 and 7 show the variations of the mouth shields. Figure 2 shows the ventral surface of the specimen given in figure 1 ; the shields are here appreciably more elongated than in the individual shown in figure 7 , which comes from Mauritius, in which they are shorter; they are also a little shortened in the specimen from Batavia (fig. 5).

The under arm plates have the distal border slightly broadened and usually notched in the middle. This character is also rather variable; the notching is well marked in the individual shown in figure 7, but it is less marked in that shown in figure 3, and especially in those shown in figures 2 and 5.

In all the specimens the ventral surface is covered with granules over a more or less extended area; the triangular granulose area thus formed extends toward the mouth shields and always leaves free a more or less broad band along the genital slits. This character is absolutely constant. I find the least development of the granulose areas in the specimen shown in figure 3.

OPHIOCOMA WENDTII Müller and Troschel.

Plate 75, figs. 7, 8 .

See for bibliography:

Ophiocoma wendtii Koreter ('05), p. 63, pl. 14, figs. 5-7; ('07), p. 327, pl. 13, fig. 38; ('07b), p. 246.-H. L. CLARK ('08), p. 297 ; ('11), p. 294.

Localities.-Little Santa Cruz Island, Zamboango, Mindanao; May 26, 1908.

One small specimen (Cat. No. 40948, U.S.N.M.).

Samoa.

Five specimens.

Notes.-I shall add some supplementary observations to the account which I have already given of this interesting species, which I described and figured in 1905 and 1907. The specimens from Samoa show characters so distinct that I do not hesitate to give here two photographs of one of them in which the diameter of the disk is $12 \mathrm{~mm}$. (figs. 7, 8).

The large dorsal spines are much developed and follow each other on every second or third segment. The tentacle scales are two in number on the two first segments, except on one of the pores of the second segment, where there is only a single one; the two pores of the third segment of one of the arms both show two tentacle scales. Every- 
where else there is only a single scale, which is rather large and rounded in form.

In another specimen, which is a little larger, and in which the disk has a diameter of $14 \mathrm{~mm}$., the majority of the pores of the four first segments have two scales each, and a single pore of the fifth pair also has two of them; all the others have only a single scale, which remains single throughout the length of the arms.

Specimens as typical as those from Samoa and as those which I described in 1905 and 1907 are easily determinable, and there is no difficulty in referring them to $O$. wendtii; but because of the variations which I have described above under $O$. scolopendrina, it may happen that the determination of certain individuals offers some difficulty. Knowing that in $O$. scolopendrina the tentacle scales may sometimes be single after the first two or three arm segments and that the dorsal spines become thickened in certain specimens, one may be led to ask whether individuals showing these peculiarities should be assigned to $O$. scolopendrina or to $O$. wendtii. I may say that in this case I am stating a purely gratuitous hypothesis, and that I have nevel had the slightest hesitation in referring such a specimen either to one or to the other of the two species. The dorsal spines of $O$. wendtii, even when they are not thickened, are always more elongated than in $O$. scolopendrina; furthermore, the mouth shields of the former species are always very much longer and narrower than in the latter, while the tentacle scale is larger. Thus no doubt can arise; nevertheless, it is worth while to draw attention to this point.

\section{OPHIOMASTIX ANNULOSA (Lamarck).}

Plate 72, figs. 4,5 .

See for bibliography:

Ophiomastix annulosa KceHLer ('05), p. 65; ('07), p. 329.-H. L. Clark ('08), p. 297; ('15), p. 294.-Matsumoto-('17), p. 350.

Localities.-Nasugbu, Luzon; reef; January 16, 1908.

Two specimens (Cat. No. E. 228, U.S.N.M.).

Joló, Joló Island; March 6, 1908.

One specimen (Cat. No. E. 227 , U.S.N.M.).

Notes.-Although the species is frequent in collections, there are no good figures of it. The colored figure published by Herklots ('68, pl. 4, fig. 1) gives a good idea of the color in the living state, but it does not show the elegant ornamentation of the disk and of the arms. I have thought it well to reproduce here two photographs of the specimen from Nasugbu, in which the characteristic designs shown by the different parts of the body appear clearly.

Matsumoto also has just published a few figures of 0 . annulosa ('17, p. 350, fig. 99). 


\section{OPHIOMASTIX FLACCIDA Lyman.}

See for bibliography:

Ophiomastix flaccida KaEHLER ('05), p. 67; ('07), p. 329.-H. L. ClARK ('15), p. 296.

Locality.-Mactan Island; tide pools; August 3, 1909.

One specimen (Cat. No. 40915, U.S.N.M.).

\section{OPHIOMASTIX LÜtTKENI Pfeffer.}

Ophiomastix lütkeni Pfeffer ('00).-H. L. Clark ('15), p. 296, pl. 16, figs. 3, 4.-MAтsumoto ('17), p. 349, fig. 98.

Locality.-Albatross station 5109; China Sea, off southern Luzon; Corregidor Light bearing N. $42^{\circ}$ E., 47.81 kilometers (25.8 miles) distant (lat. $14^{\circ} 03^{\prime} 45^{\prime \prime}$ N., long. $120^{\circ} 16^{\prime} 30^{\prime \prime}$ E.) ; 22 meters (12 fathoms) ; January 15, 1908; Co.

One specimen (Cat. No. 40926, U.S.N.M.).

Notes.-The specimen is in poor condition; two arms are broken off, and the three others are strongly bent upward above the disk, of which a part of the dorsal surface is torn off; it is nevertheless very well characterized.

Without assuming the club-like form which is sometimes met with, the dorsal spine is considerably developed on each third or fourth segment, becoming greatly elongated and thickened. The general coloration is very dark and almost black, with yellowish bands on the dorsal surface of the disk, the spines of which are of a light yellow washed with dark. The arms show on each segment a yellow transverse band on the dorsal surface as well as on the ventral; toward their long borders, the mouth shields show two broad yellow longitudinal striae, and some yellow dots are also to be seen on the oral plates as well as on the mouth papillæ.

H. L. Clark has published two excellent photographs and Matsumoto some figures of this species which was only known from Pfeffer's description. This author's type series came from Ternate and from Cebu, and H. L. Clark's specimen from the Riu-Kiu Islands (Japan).

The species has not yet been found outside of these localities.

\section{OPHIOMASTIX MIXTA Lütken.}

See for bibliography:

Ophiomastix mixta Kachler ('05), p. 68, pl. 6, fig. 15; pl. 15, fig. 1.-H. I. Clark ('11), p. 256, fig. 126; ('15), p. 296.-Matsumoto ('17), p. 348, fig. 97.

Locality.-Albatross station 5109; China Sea, off southern Luzon; Corregidor Light bearing N. $42^{\circ}$ E., 47.81 kilometers $(25.8$ miles) distant (lat. $14^{\circ} 03^{\prime} 45^{\prime \prime} \mathrm{N}$., long. $120^{\circ} 16^{\prime} 30^{\prime \prime} \mathrm{E}$.) ; 22 meters (12 fathoms); January 15, 1908; Co. 
(One small specimen (Cat. No. 40916, U.S.N.M.).

Notes.-The specimen is of small size and the diameter of the disk does not exceed $5 \mathrm{~mm}$.; the arms are broken off near the base and measure only $10 \mathrm{~mm}$. in length. Although it is not in very good condition, it is perfectly recognizable and very well characterized. The large dorsal spines are not claviform, as I found them in the individuals which I described in 1905 .

Ophiomastix mixta is known from different localities in the Sunda Archipelago, where it was found by the Siboga, in the Fiji Islands, etc.

\section{ouhiomastix Venosa Peters.}

See for bibliography:

Ophiomastix venosa KoeHLER ('04a), p 73, figs. 28, 29; ('07), p. 329.-MACINTOSH ('11), p. 161.-H. I. CLARK ('15), p. 296.

Locality.-Malochin Harbor, Linapalan Island; December 18, 1908. One specimen (Cat. No. 40937, U.S.N.M.).

\section{OPHIARTHRUM ELEGANS Peters.}

See for bibliography:

Ophiarthrum elegans Kahler ('05), p. 73; ('07), p. 329.-H. L. Crark ('08), p. 297; ('15), p. 297.-Матsumoto ('17), p. 351, fig. 100.

Localities.-Albatross station 5165; Sulu (Joló) Archipelago, Tawi Tawi Group; Observation Island bearing N. $70^{\circ} \mathrm{W}$., 11.86 kilometers (6.4 miles) distant (lat. $4^{\circ} 58^{\prime} 20^{\prime \prime}$ N., long. $119^{\circ} 50^{\prime} 30^{\prime \prime}$ E.) ; 16 meters (9 fathoms); February 24, 1908; Co.

One specimen (Cat. No. E. 369, U.S.N.M.).

Marongas; shore; coral head; October 2, 1908.

Three specimens (Cat. No. E. 368, US.N.M.).

Mactan Island; April 30, 1909.

One specimen (Cat. No. E. 371, U.S.N.M.).

Port Palapag; June 3, 1909.

One specimen (Cat. No. E. 372, U.S.N.M.).

Batan; July 22, 1909.

One specimen (Cat. No. E. 370, US.N.M.).

Samoa; Sir Charles N. E. Elliot.

Ten specimens (Cat. Nos. 35615, E. 373, U.S.N.M.).

\section{Family OPHIODERMATIDAE.}

OPHIARACHNA QUINQUESPINOSA, new species.

Plate 7, figs. 1-3.

Locality.-Albatross station 5172; vicinity of Joló; Joló Light bearing E., 45.87 kilometers (24.75 miles) distant (lat. $6^{\circ} 03^{\prime} 15^{\prime \prime} \mathrm{N}$.: 
long. $120^{\circ} 35^{\prime} 30^{\prime \prime}$ E.) ; 582 meters (318 fathoms) ; March 5, 1908 ; fne. S., Sh.

One specimen (Cat. No. E. 128, U.S.N.M.).

Description.-The single specimen is of large size and in a very good state of preservation, with the arms complete. The disk, which is slightly deformed, measures $21 \mathrm{~mm}$. by $25 \mathrm{~mm}$. in diameter; the arms are from $170 \mathrm{~mm}$. to $180 \mathrm{~mm}$. in length.

The disk is pentagonal with the borders more or less rounded. It is covered on both surfaces with very fine and closely crowded granules which on the dorsal surface leave exposed only the radial shields. These are very small and only measure from $1.4 \mathrm{~mm}$. to $1.5 \mathrm{~mm}$. in length; they are irregularly oval, and half again as long as broad. The two shields of each pair are separated by a space which is almost equal to the width of the arm. The granules of the dorsal surface of the disk do not pass out onto the dorsal surface of the arms, and the radial notches includes only the first upper arm plate.

The ventral surface of the disk is covered with granules identical with those of the dorsal surface, and some may be found which, broadening somewhat, continue onto the distal border of the mouth shields. These same granules are found slightly elongated all along the interradial border of the genital slits, and at the base of these on the free portion of the adoral plates. The genital slits are narrow.

The mouth shields are large, triangular, with the angles and the borders very rounded, almost as long as broad; the distal border is convex and it even forms a rather marked lobe which projects into the interradial space, but there is not the least indication of an accessory shield. The adoral plates are rather small, limited to the sides of the mouth shield, tapering to a point inwardly and broadly separated in the median interradial line; they are outwardly very much broadened, separating the mouth shield from the first side arm plate. The oral plates are triangular, very low, covered with granules which are a little larger than those of the rest of the ventral surface. The lateral mouth papillae are seven or eight in number; the two outermost are broad, rounded, almost as broad as long; the others are slender, cylindrical, and pointed. Below the group of tooth papillae there are in addition two or three papillae identical with these and placed on the same plane.

The first upper arm plate is small, triangular, placed in the radial notch of the disk. The following plates are very large, rectangular, very much broader than long, with the sides slightly divergent. Toward the tip of the arms these plates become as long as broad and even a little longer than broad. They are all broadly in contact.

The first under arm plate is small, triangular, with a rounded distal apex, and broader than long; the angles are rounded. The following plates are rectangular, almost as broad as long, with a rounded distal 
border and slightly divergent sides. Beyond the middle of the arms these plates become a little longer than broad. They are all broadly in contact. Between the first and the second under arm plate there is a pair of rather well-developed pores which are obliquely elongated and identical with those which occur in O. affinis. A second pair of pores which are smaller, close together, and rounded occurs between the second and the third under arm plates.

The side arm plates, which do not project outward, bear five flattened spines, which are sometimes appressed against the arms and sometimes more or less divergent, especially the dorsal spines. All these spines are longer than the segment; the first ventral spine, which is longer than the others, even equals a segment and a half. These spines are inserted on the distal border of the side arm plates.

The two tentacle scales are oval, elongated, and rather narrow. The external, which is a little smaller than the internal, does not overlap the base of the first ventral spine.

The color of the specimen in alcohol is very light yellowish gray. The dorsal surface of the disk shows numerous small dark brown spots; the arms show spaced annulations of a rather light brown which involve a variable number of segments, on the average from six to ten, and the length of these darker regions is always greater than that of the light areas which separate them. The ventral surface is light gray.

Affinities and distinctive features.-The species of the genus Ophiarachna at present known are four in number; they are $O$. affinis Lütken, with which it is necessary to unite $O$. clavigera Brock, O. incrassata Lamarck, O. mauritiensis Loriol, and O. robillardi Loriol.

The new species can not be confused with any of these. In the first place all four normally show a supplementary mouth shield which is lacking in $O$. quinquespinosa. Regarding the other characters, our species comes closest to $O$. affinis, but it differs from it in the more numerous lateral mouth papillae, in the naked radial shields, in the thicker arm spines, and in the completely different color. Ophiarachna robillardi, which has the radial shields naked as in 0 . quinquespinosa, has the mouth shields much elongated and the arm spines, which at first are five in number but which rapidly fall to four and then to three, fine and slender. Ophiarachna mauritiensis has six or seven very fine and slender arm spines.

It remains to be seen whether our species is justifiably referred to the genus Ophiarachna. It is particularly on account of the length of the arm spines that I have thought it necessary to refer it to this genus. I believe that there can be little if any hesitation as between the two genera Ophiarachna and Pectinura, the latter being understood in the restricted sense given it by H. L. Clark, 
that is to say, corresponding to the old genus Ophiopeza. To justify placing it in the genus Pectinura, only the unique case of $P$. dambyi (Farquhar) could be invoked, this species having the arm spines very much longer than usual. But that raises the question whether $P$. dambyi, which is only known from a single specimen from the Kermadec Islands and which recalls the genus Ophiarachna by its arm spines, should be retained in the genus Pectinura. I would be rather disposed to place it in the genus Ophiarachna because of the development of its arm spines, and these spines, some of which are appressed against the side arm plates while the others are more or less divergent, strongly recall those of Ophiarachna.

The new species differs from the species of the genus Ophiarachna in two characters; there are no supplementary mouth shields and the outer tentacle scale does not overlap the base of the first ventral arm spine. In regard to the first difference, I may remark that the occurrence of a supplementary mouth shield is never constant in the species where it is usually found; thus in a specimen of $O$. affinis from Amboina, which $I$ have in my collection and of which I figure the ventral surface (pl. 4, fig. 1), this supplementary shield is lacking in one of the interradial spaces. ${ }^{13}$ Similar variations are also known in O. incrassata, as well as in the genus Pectinura. As for the position of the outer tentacle scale, it occupies, as H. L. Clark has remarked, the same place in the genus Ophiarachna as in the genus Pectinura and in the related genera; the difference which $I$ have indicated, therefore, can not be invoked for placing our species in the genus Pectinura rather than in the genus Ophiarachna. Moreover, it must be noticed that the overlapping of the outer tentacle scale over the first ventral arm spine occurs in different degrees in the genus Ophiarachna. It is only slightly marked in $O$. incrassata, in which the two tentacle scales are very small, and very much more marked in $O$. affinis, in which these scales are larger.

The two differences which $I$ have just indicated are not sufficient to necessitate a generic separation, and in consequence the creation of a new genus. I believe, therefore, that our species may be retained in the genus Ophiarachna.

In Ophiarachna incrassata, which is the type of the genus, there is a pair of pores between the successive under arm plates, and this feature occurs over a rather large portion of the length of the arms with some variations in the development of these pores (pl. 4, fig. 6). In the new species there are two pairs of pores only, and those of the first pair, instead of being small, circular, and placed on the

${ }^{2}$ H. L. Clark has also published two photographs of 0 . affinis ('15, pl. 18, figs. 1, 2). I notice that one of the mouth shields of the specimen photographed is without the supplementary plate, and a second seems to me to be in the same condition. The ventral pores are in two pairs, and they appear to have exactly the same characters as in the specimen of which I give a photograph here; but the outlines are not very clear. 
distal border of the first under arm plate, are on the sides of the latter; they are much elongated and form a small and very evident groove. This arrangement is therefore very different from that which exists in $O$. incrassata, but it recalls very strongly that in $O$. affinis. In this species the ventral, pores are very much less numerous than in $O$. incrassata, and usually number two pairs only; those of the first pair are situated on the sides of the first under arm plate and not on its distal border, and they are more or less elongated as in the new species. In a specimen of $O$. affinis which is in my collection and which comes from Amboina (pl. 4, fig. 1), there are, as a rule, two pairs of ventral pores; the pores of the second pair, instead of being elongated like those of the first pair, are circular and situated on the distal border of the under arm plate; they are also only slightly developed, and on one of the arms they are almost invisible; on the other hand, on another arm I find traces of a third pair. The Geneva Museum has two specimens of $O$. affinis belonging to Loriol's collection, and also from Amboina. I have examined the arrangement of their ventral pores, and I find that they show interesting variations. In the larger specimen, in which the disk has a diameter of $15.5 \mathrm{~mm}$., there exists first between the first and the second under arm plates a pair of pores identical with those which I have noticed above; these pores, always situated on the sides of the first under arm plate, are elongated and narrow, but they are extremely well marked. Furthermore, there occurs between the following under arm plates a series of small rounded pores arranged as in $O$. incrassata - that is, placed on the distal border of the plates; I am able to distinguish four successive pairs of these rounded pores. In the second specimen, which is smaller (the diameter of the disk is $12 \mathrm{~mm}$.), the pores of the first pair are extremely narrow, and I can not distinguish beyond them but a single pair of rounded pores of very small size; but on two arms I recognize the traces of a third pair.

This shows that the ventral pores of $O$. affinis may vary in their development as well as in their number; there are always, however, at least two pairs of them. This is also the number which I find in two other species of the genus $O$. mauritiensis and $O$. robillardi, described by Loriol. But in describing these species the learned Swiss naturalist did not mention the ventral pores, and his figures also do not show the least trace of them. Having had an opportunity of studying Loriol's types at the Geneva Museum I am able to make good this slight deficiency. Ophiarachna mauritiensis is represented by two specimens in which the ventral pores are arranged exactly as in my specimen of $O$. affinis, and they quite agree with the photograph which I give here of this latter species (pl. 4, fig. 1). In O. robillardi, which is only represented by one rather 
small specimen (the diameter of the disk is $11 \mathrm{~mm}$.), these pores also have the same arrangement, but they are very much smaller than in 0 . mauritiensis and very much less evident.

The presence of ventral pores, a feature concerning which most authors have said nothing, must be considered as one of the essential characters of the genus Ophiarachna. Usually there are two pairs only at the base of the arms; this figure is sometimes exceeded in 0 . affinis, while in $O$. incrassata the number of successive pairs is very much higher.

An opportunity presenting itself of including a photograph of the ventral surface of $O$. incrassata for comparison with the new species, I have seen fit to profit by it in reproducing also a photograph of the dorsal surface of the same specimen (pl. 4, fig. 7). H. L. Clark ('08, p. 298), in mentioning the coloration of a specimen from Amboina which he had been able to study, says that the markings of this species conform to the description of Mïller and Troschel "disk greenish, center and areas over radial shields light brownish (not in marked contrast) spotted with yellow; arms reddish buff; arms spines light yellow," etc.

This type of coloration is different from that which Herklots has shown. I have been able to determine that the Siboga individuals had markings quite comparable to those which Herklots has reproduced in his colored plate ('68, pl. 6), and I mentioned this fact in 1905. The photograph which I include of a Siboga specimen can not, of course, show the coloration, but it indicates the arrangement of the spots on the two surfaces of the disk. The general color of the individual is a slightly yellowish green, a little lighter on the ventral surface; the spots, surrounded by a dark-brown circle, which occur on the dorsal surface are slightly lighter than the rest of that surface and of a more yellowish color; the light-yellow spines show one or two darker rings only at their base.

In its external appearance and in the very fine granulation of the disk, which is studded with dark spots, 0 . quinquespinosa shows a resemblance, though a rather vague and quite superficial one, with Ophiocoma döderleini, which I have already discussed. The length of the spines and the arrangement of the two tentacle scales accentuates the resemblance with an Ophiocoma. But aside from the two pairs of pores which occur at the base of the arms, there could be no question of assigning to the genus Ophiocoma an ophiuran which does not possess that vertical clump of tooth papillae so characteristic of the latter genus. If I speak of this purely external resemblance, it is especially for the purpose of calling to mind an error made by Lyman which was noticed by Loriol and more recently by H. L. Clark $(' 09$, p. 113). In the diagnosis which he gives of the genus Ophia- 
rachna Lyman attributes to this latter, as well as to the genus: Ophiocoma, very numerous tooth papillae arranged in a vertical clump, which is quite contrary to the original diagnosis of Müller and Troschel. It is interesting to compare the diagnoses of the genus Ophiocoma and of the genus Ophiarachna which were given by Lyman in the Challenger reports ('82, p. 167 and 173); the question arises by what character does Lyman distinguish externally these two genera (I am not speaking of the differences in the form of the peristomial plates). As Lyman's error has been repeated by certain authors, and especially in Bronn's Thierreich (Echinodermen, III, Schlangesternen, p. 939), it can not be noticed too often in order that naturalists may be put on their guard against it.

\section{PECTINURA AEQUALIS (Lyman).}

Plate 77, figs. 16, 17.

Ophiopeza aequalis LYMAN ('82), p. 12, pl. 27, figs. 7-9. - KäHLER ('04), p. 10. Pectinura acqualis H. L. ClarK ('09), p. 118; ('15), p. 303.

Localities. - Albatross station 5415; between Cebu and Bohol; Lauis Point Light bearing N. $24^{\circ}$ W., 13.34 kilometers (7.2 miles distant (lat. $10^{\circ} 07^{\prime} 50^{\prime \prime} \mathrm{N}$., long. $123^{\circ} 57^{\prime} 00^{\prime \prime}$ E.) ; 161 meters (88 fathoms); March 24, 1909; fne. S.

Two specimens (Cat. No. E. 279, U.S.N.M.).

Albatross station 5523; northern Mindanao and vicinity; Point Tagolo Light bearing S. $48^{\circ}$ W., 12.42 kilometers (6.7 miles) distant (lat. $8^{\circ} 48^{\prime} 44^{\prime \prime} \mathrm{N}$., long. $123^{\circ} 27^{\prime} 35^{\prime \prime}$ E.) ; August $10,1909$.

One specimen (Cat. No. E. 280 , U.S.N.M.).

Albatross station 5541; Tagolo Light bearing S. $65^{\circ}$ W., 23.54 kilometers (12.7 miles) distant (lat. $8^{\circ} 49^{\prime} 38^{\prime \prime} \mathrm{N}$., long. $123^{\circ} 34^{\prime} 30^{\prime \prime}$ E.) ; 401 meters (219 fathoms) ; August 20, 1909, fne. S., brk. Sh.

Three specimens (Cat. Nos. E. 281, E.282, U.S.N.M.).

Notes.-The diameter of the disk varies between $25 \mathrm{~mm}$. and 30 $\mathrm{mm}$. The specimens from stations 5415 and 5541 are almost completely decolorized; that from station 5523, which is the largest of all, still has the dorsal surface of the disk pink, and the arms show annulations which are alternately very light pink and a darker red, these latter broader than the former. It is only in this specimen that I find ten arm spines as indicated by Lyman; usually the arm spines are eight in number.

The mouth shields are almost as long as broad. The two specimens from station 5415 show a slight variation in their form; in one of them the mouth shields are slightly longer than broad and in the other they are a little broader than long. I give photographs of ventral surface of these two specimens (pl. 77, figs. 16, 17). 
The Challenger specimens which served as Lyman's types came from northeast of New Guinea in 274 meters ( 150 fathoms) and from the Kei Islands in 209 meters (114 fathoms). The Siboga collected the species in $5^{\circ} \mathrm{S}$. latitude and $120^{\circ} \mathrm{E}$. longitude, in 204 meters (111.5 fathoms).

\section{PECTINURA YOLDII (Luitken).}

Ophiopeza yoldii LÜTKEN ('56), p. 9.-LYMAN ('82), p. 12.

Ophiopsammus yoldii LÜTKEN ('69), p. 37 (p. 98).

Ophiopeza conjungens BeLL ('84), p. 137.-DöDERLEIN ('96), p. 281, pl. 6,

fig. 1.-KaELER ('05), p. 12; ('07a), p. 283.

Pectinura yoldii H. T. Clark ('09), p. 119; ('15), p. 303.

Locality.-Albatross station 5152; Sulu (Joló) Archipelago, Tawi Tawi Group; Pajumajan Island (W.), bearing S. $2^{\circ}$ W., 3.70 kilometers (2 miles) distant (lat. $5^{\circ} 22^{\prime} 55^{\prime \prime} \mathrm{N}$., long. $120^{\circ} 15^{\prime} 45^{\prime \prime} \mathrm{E}$.) ; 62 meters (34 fathoms) ; February 18, 1908; wh. S.

One specimen (Cat. No. 41184 , U.S.N.M.).

Notes.-The diameter of the disk is $15 \mathrm{~mm}$.

Pectinura yoldii has a rather extensive geographical range. It is known from Amboina and from Thursday Island, in Torres and Sapeh Straits, from the north of New Guinea, from Sumatra, from the Philippines, and from Australia (New South Wales and Queensland), etc. It is usually met with at littoral stations, but it may descend as far as 215 meters. This species had been usually described under the name of Ophiopeza conjungens until H. L. Clark ('09, p. 119) showed that this name was a synonym of Pectinura yoldii (Lütken).

I have not mentioned in the bibliographic list above a note by Verrill, who records $P$. yoldii from the Antilles, ${ }^{14}$ for this record is certainly erroneous.

\section{OPHIOPEZELLA SPINOSA (LüUngan).}

See for bibliography:

Ophiopezella spinosa H. I. CLARK ('09), p. 120; ('15). 1. 304

Localities.-Albatross station 5139 ; in the vicinity of Jolo; Joló Light bearing S. $51^{\circ}$ W., 6.67 kilometers (3.6 miles) distant (lat. $6^{\circ}$ $06^{\prime} 00^{\prime \prime}$ N., long. $121^{\circ} 02^{\prime} 30^{\prime \prime}$ E.) ; 37 meters (20 fathoms) ; February 14,1908 ; co. S.

One specimen (Cat. No. 41290 , U.S.N.M.).

Albatross station 5141 ; vicinity of Joló; Joló Light bearing S. $17^{\circ}$ E. 8.85 kilometers (10.19 miles) distant (lat. $6^{\circ} 09^{\prime} 00^{\prime \prime} \mathrm{N}$., long. $120^{\circ}$ $58^{\prime} 00^{\prime \prime}$ E.) ; 53 meters (29 fathoms) ; February 15, 1908; co. S.

One specimen (Cat. No. 41289, U.S.N.M.).

${ }^{4}$ Trans, Connecticut Acad., vol. 10, 1899, p. 373. 
Albatross station 5218; between Burias and Luzon; Anima Sola Island (E.) bearing $\mathrm{N} .10^{\circ}$ W., 3.70 kilometers (2 miles) distant (lat. $13^{\circ} 11^{\prime} 15^{\prime \prime} \mathrm{N}$., long. $123^{\circ} 02^{\prime} 45^{\prime \prime} \mathrm{E}$.) ; 37 meters (20 fathoms) ; April 22, 1908 ; crs. S.

One specimen (Cat. No. 41291 , U.S.N.M.).

Albatross station 5555; Joló Island and vicinity; Cabalian Point (Joló) bearing N. $50^{\circ}$ W., 6.11 kilometers ( 3.3 miles) distant (lat. $5^{\circ} 51^{\prime} 15^{\prime \prime}$ N., long. $120^{\circ} 58^{\prime} 35^{\prime \prime}$ E.) ; 62 meters ( 34 fathoms) ; September 18, 1909 ; crs. S.

One specimen (Cat. No. 41292, U.S.N.M.).

Notes.-The synonymy of this species was cleared up in 1909 by H. L. Clark, who showed that $O$. lütkeni Loriol is not different from 0 . spinosa, and must laspe into synonymy, and that, on the other hand, contrary to Lütken's opinion, Ophiopeza fallax Peters is different from this latter, and must be placed in the genus Pectinura, as H. L. Clark redefined it. There remain in the genus $O$ phiopezella, therefore, only two species- $O$. spinosa, characterized by the very numerous (12 to 14 ) arm spines as well as by its brown coloration, and 0 . dubiosa Loriol, with only nine spines and gray in color. This latter is as yet known only from Mauritius, while $O$. spinosa has been met with in various localities - the Tonga Islands, the Fiji Islands, Amboina, the Society Islands, the island of Nusa Laut (Siboga collection), etc., regions to which must be added the three localities listed above. It scarcely seems to reach beyond littoral station; the Siboga found it in 46 meters (25 fathoms) and the Albatross (station 5555) in 61 meters ( 33.5 fathoms).

The three Albatross specimens are well characterized, and their color is brownish gray, with darker annulations on the arms; the diameter of the disk varies between $7 \mathrm{~mm}$. and $8 \mathrm{~mm}$.

OPHIARACHNELLA GORgONIA (Müller and Trogchel).

See for bibliography:

Pectinura gorgonia KaeHLer ('05), p. 8.-H. L. Clark ('08), p. 289.KGemLER ('O7). p. 284; ('O7b), p. 243.-Macintosh ('11), p. 157.

ophiarachnella gorgonia H. L. CLARK ('09), p. 123; ('15), p. 305.-MATsuмото ('17), p. 323.

Localities.-Albatross station 5165; Sulu (Joló) Archipelago, Tawi Tawi Group; Observation Island bearing N. $70^{\circ} \mathrm{W}, 11.86$ kilometers (6.4 miles) distant (lat. $4^{\circ} 58^{\prime} 20^{\prime \prime}$ N., long. $119^{\circ} 50^{\prime} 30^{\prime \prime}$ E.); 16 meters (9 fathoms); February 24, 1908; Co.

One specimen (Cat. No. E. 223, U.S.N.M.).

Albatross station 5558; Joló Island and vicinity; Cabalian Point bearing S., 2.04 kilometers (1.1 miles) distant (lat. $5^{\circ} 51^{\prime} 33^{\prime \prime} \mathrm{N}$, 
long. $121^{\circ} 00^{\prime} 58^{\prime \prime}$ E.) ; 27 meters (15 fathoms); September 18, 1909 ; Co.

One specimen (Cat. No. E. 222, U.S.N.M.).

Nasugbu, Luzon; reef; January 14, 1908.

Four specimens (Cat. No. E. 221, U.S.N.M.).

San Pascual.

Two specimens.

Batan Island.

Three specimens (Cat. No. E. 220, U.S.N.M.).

Samoa; Sir Charles N. E. Eliot.

One specimen (Cat. No. E. 224, U.S.N.M.).

Notes.-The specimen from station 5165 is gray; the annulations of the arms are narrow and of a light brown color. The three others are green with darker annulations on the arms.

In 1909 H. L. Clark discussed and cleared up the synonymy of this species and showed that Pectinura marmorata Lyman, P. ramsayi Bell, $P$. intermedia Bell, $P$. stearnsii Ives, and $P$. venusta Loriol must be united with it.

Ophiarachnella gorgonia is one of the most widely distributed species in the Indo-Pacific region; it is preëminently littoral and scarcely ever descends to more than 50 meters (28 fathoms); but the Siboga found it at the roadstead of Pasir Pandjong, on the west coast of Binongka, in 278 meters (152 fathoms).

\section{OPHIARACHNELLA hONORATA (Kohler).}

Peotinura honorata KoEHLer ('04), p. 8, pl. 2, figs. 1-3.

Ophiarachnella honorata H. L. CLARK ('09), p. 125; ('15), p. 306.

Locality.-Albatross station 5661; Flores Sea; Cape Lassa bearing N. $21^{\circ}$ E., 23.16 kilometers (12.5 miles) distant (lat. $5^{\circ} 49^{\prime} 40^{\prime \prime}$ S., long. $120^{\circ} 24^{\prime} 30^{\prime \prime}$ E.) ; 339 meters (180 fathoms); December 20,1909 .

Four specimens (Cat. No. E. 203, U.S.N.M.).

Notes.-The diameter of the disk varies between $24 \mathrm{~mm}$. and $27 \mathrm{~mm}$.; the arms reach a length of $180 \mathrm{~mm}$. and may even exceed this.

The specimens all agree perfectly with the type of the species, and do not show the least variation.

The dorsal surface of the disk and of the arms is a more or less dark brownish gray, or a lighter yellowish brown.

The arms show dark annulations which involve usually two or three segments, and which are separated by lighter portions including usually three or four segments. The ventral surface is almost white. This coloration appears to becorrelated with the relatively slight depth at which $O$. honorata has been collected. The Siboga captured it at a depth of 304 meters (167 fathoms) in $5^{\circ} \mathrm{S}$. lattitude and $132^{\circ} \mathrm{E}$. longitude. 
OPHIURANS OF THE PHILIPPINE AND ADJACENT WATERS. 341

OPHIARACHNELLA INFERNALIS (Müller and Troschel).

See for bibliography:

Pectinura infernalis KGeHLER ('05), p. 7 ; ('07); p. 285.-H. L. CLARK ('08), p. 289.-KGHLER ('10), p. 289.-MACINTOSH ('11), p. 157.

ophiarachnella infernalis H. L. ClaRK ('09), p. 124 ; ('15), p. 305.-MATSUмото ('17), p. 324.

Locality.-Tataan, Simulac; February 19, 1908.

One specimen (Cat. No. 41173 , U.S.N.M.).

Notes.-The specimen is of small size, the diameter of the disk being only $10 \mathrm{~mm}$.

In $1910 \mathrm{I}$ gave the reasons why I continue to distinguish 0 . infernalis from $O$. similis, which I described in 1905, in spite of the contrary opinion of H. L. Clark. I maintain absolutely that separation. Furthermore, H. L. Clark has now recanted on his previous opinion, and in his magnificent work of 1915 he includes as distinct species both $O$. infernalis and $O$. similis $(15$, p. 305 and 306 , Nos. 1082 and 1096).

\section{OPHIARACHNELLA NITENS (Kœhler).}

Pectinura nitens KäHLER ('05), p. 10, pl. 1, figs. 10-12.

Ophiarachnella nitens H. L. CLARK ('09), p. 125; ('15), p. 306.

Localities.-Albatross station 5139; in the vicinity of Joló; Joló Light bearing S. $51^{\circ}$ W., 5.79 kilometers (3.6 miles) distant (lat. $6^{\circ} 06^{\prime} 00^{\prime \prime}$ N., long. $121^{\circ} 02^{\prime} 30^{\prime \prime}$ E.) ; 37 meters (20 fathoms) ; February $14,1908$.

One specimen (Cat. No. E. 320, U.S.N.M.).

Albatross station 5152; Sulu (Jóló) Archipelago; Tawi Tawi Group; Pajumajan Island (W.) bearing S. $2^{\circ}$ W., 3.22 kilometers (2 miles) distant (lat. $5^{\circ} 22^{\prime} 55^{\prime \prime}$ N., long. $120^{\circ} 15^{\prime} 45^{\prime \prime}$ E.) ; 62 meters (34 fathoms); February 18, 1908.

One specimen (Cat. No. F. 319, U.S.N.M.).

Albatross station 5161; Sulu Archipelago, Tawi Tawi Group; Tinakta Island (E.) bearing N. $12^{\circ}$ W., 2.90 kilometers (1.8 miles) distant (lat. $5^{\circ} 10^{\prime} 15^{\prime \prime} \mathrm{N}$., long. $119^{\circ} 53^{\prime} 00^{\prime \prime}$ E.) ; 29 meters (16 fathoms) ; February 22, 1908.

One specimen (Cat. No. 318, U.S.N.M.).

Notes.-The specimen from station 5139 is the largest, and the disk measures $18 \mathrm{~mm}$. in diameter; it is therefor larger than my type specimen in which this diameter reaches only $16 \mathrm{~mm}$. The two others are smaller, the diameter of the disk measuring respectively $10 \mathrm{~mm}$. and $7 \mathrm{~mm}$.

These three specimens agree very well with the type, which was' collected by the Siboga in Sapeh Strait, in 69 meters (38 fathoms). I find, however, this slight difference, that in the largest specimen the mouth shields are a little elongated and their proximal angle 
is more rounded. The general color is rather light pinkish gray, and the annulations of the arms are only slightly marked.

The two smaller specimens are darker, of a general brownish gray color, with the annulations of the arms better marked.

The specimen from station 5161 has two regenerating arms. BATHYPECTINURA CONSPICUA (Kohler).

Plate 77, figs. 1-15.

Pectinura conspicua KaHLER ('96), p. 322, pl. 6, figs. 36, 37; ('99), p. 32 , pl. 2 , figs. 14,15 ; ('04), p. 9 , pl. 1 , fig. 1.

Pectinura modesta KoemLer ('04), p. 7, pl. 2, figs 4-6.

Pectinura elata Korler ('06), p. 7, pl. 1, figs. 1-3; ('07), p. 249, pl. 18, figs. 1-3; ('07a), p. 284.

Bathypectinura conspicua H. L. CLARK ('09), p. 130; ('15), p. 306.

Bathypectinura modesta H. L. CrARK ('09), p. 130; ('15), p. 307.

Bathypectinura elata H. L. ClaRK ('09), p. 130 ; ('15), p. 306.

And the following are without doubt also synonyms:

Pectinura heros Lyman ('79), p. 48, pl. 14, figs. 389-391; ('82), p. 16, pl. 23 ,

figs. 7-9.-Kahler ('96), p. 325; ('99), p. 38; ('04), p. 9.

Bathypectinura heros H. L. CLARK ('09), p. 130; ('15), p. 307.

Pectinura tessellata Lyman ('83), p. 230, pl. 3, figs. 1-3.

Bathypectinura tessellata H. I. ClaRK ('09), p. 130; ('15), p. 306.

Bathypectinura gotoi Matsumoto ('15), p. 87.-H. L. Clark ('15), p. 306.

Localities.-Albatross station 5114; Balayan Bay and Verde Island Passage; Sombrero Island bearing N. $36^{\circ}$ E., 11.58 kilometers (7.2 miles) distant (lat. $13^{\circ} 36^{\prime} 11^{\prime \prime} \mathrm{N}$., long. $120^{\circ} 45^{\prime} 26^{\prime \prime}$ E.) ; 622 meters (340 fathoms); January 20, 1908.

One specimen (Cat. No. E. 127, U.S.N.M.).

Albatross station 5216; between Burias and Luzon; Anima Sola Island bearing $\mathrm{N} .44^{\circ} \mathrm{W}$, 47.47 kilometers (29.5 miles) distant (lat. $12^{\circ} 52^{\prime} 00^{\prime \prime} \mathrm{N}$., long. $123^{\circ} 23^{\prime} 30^{\prime \prime}$ E.) ; 393 meters (215 fathoms); April 22, 1908.

One specimen (Cat. No. E. 157, U.S.N.M.).

Albatross station 5274; China Sea, in the vicinity of southern Luzon; Malavatuan Island (N.) bearing S. $73^{\circ} 30^{\prime}$ E., 28.16 kilometers (17.5 miles) distant (lat. $13^{\circ} 57^{\prime} 30^{\prime \prime} \mathrm{N}$., long. $120^{\circ} 03^{\prime} 25^{\prime \prime}$ E.) ; 960 meters (525 fathoms) ; July 16, 1908.

One specimen (Cat. No. E. 115, U.S.N.M.).

Albatross station 5286; China Sea, in the vicinity of southerr Luzon; Malavatuan Island (S.) bearing N. $45^{\circ} \mathrm{W}$., 31.38 kilometers (19.5 miles) distant (lat. $13^{\circ} 38^{\prime} 15^{\prime \prime}$ N., long. $120^{\circ} 34^{\prime} 20^{\prime \prime}$ E.) ; 823 meters (450 fathoms); July 20, 1908.

One specimen (Cat. No. E. 153, U.S.N.M.).

Alzatross station 5445; east coast of Luzon, San Bernardino Strait to San Miguel Bay; Atalaya Point, Batag Island, bearing S. $56^{\circ} \mathrm{E}$., 8.53 kilometers (5.3 miles) distant (lat. $12^{\circ} 44^{\prime} 42^{\prime \prime}$ N., long. $124^{\circ}$ $59^{\prime} 50^{\prime \prime}$ E.) ; 701 meters (383 fathoms); June 3, 1909.

One specimen (Cat. No. E. 119, U.S.N.M.). 
Albatross station 5460; east coast of Luzon, San Bernardino Strait to San Miguel Bay; Sialat Point Light bearing N. $24^{\circ}$ E., 13.19 kilometers (8.2 miles) distant (lat. $13^{\circ} 32^{\prime} 30^{\prime \prime} \mathrm{N}$., long. $123^{\circ} 58^{\prime}$ $06^{\prime \prime}$ E.) ; 1,033 meters (565 fathoms); June 10, 1909.

One specimen (Cat. No. E. 154, U.S.N.M.)

Albatross station 5468; east coast of Luzon, San Bernardino Strait to San Miguel Bay; Atulayan Island (S.) bearing S. $83^{\circ}$ W., 9.17 kilometers (5.7 miles) distant (lat, $13^{\circ} 35^{\prime} 39^{\prime \prime}$ N., long. $123^{\circ} 40^{\prime} 28^{\prime \prime}$ E.) ; 1,041 meters (569 fathoms); June 10, 1909.

Three specimens (Cat. No. E. 126, U.S.N.M.).

Albatross station 5492; between Leyte and Mindanao; Diuata Point (W.) bearing S. $45^{\circ}$ W., 24.46 kilometers (15.2 miles) distant (lat. $9^{\circ} 12^{\prime} 45^{\prime \prime}$ N., long. $\left.125^{\circ} 21\right)^{\prime} 00^{\prime \prime}$ E.) ; 1,344 meters (735 fathoms); August 1, 1909.

One specimen (Cat. No. E. 116, U.S.N.M.).

Albatross station 5494; between Leyte and Mindanao; Diuata Point (N.) bearing N. $74^{\circ}$ W., 7.78 kilometers (4.2 miles) distant (lat. $9^{\circ} 06^{\prime} 30^{\prime \prime}$ N., long. $125^{\circ} 18^{\prime} 40^{\prime \prime}$ E.) ; 1,240 meters (678 fathoms); August 2, 1909 ; gn. M., S.

One specimen (Cat. No. E. 123, U.S.N.M.).

Albatross station 5495; between Leyte and Mindanao; Diuata Point (N.) bearing S. $76^{\circ}$ E., 17.42 kilometers (9.4 miles) distant (lat. $9^{\circ} 06^{\prime} 30^{\prime \prime}$ N., long. $125^{\circ} 00^{\prime} 20^{\prime \prime}$ E.) ; 1,785 meters (976 fathoms) ; August 2, 1909; gy. M.

Three specimens (Cat. No. E. 155, U.S.N.M.).

Albatross station 5505; northern Mindanao and vicinity; Macabalan Point Light (Mindanao) bearing S. $31^{\circ}$ E., 14.27 kilometers (7.7 miles) distant (lat. $8^{\circ} 37^{\prime} 15^{\prime \prime}$ N., long. $124^{\circ} 36^{\prime} 00^{\prime \prime}$ E.) ; 402 meters (220 fathoms); August 5, 1909.

One specimen (Cat. No. E. 124, U.S.N.M.).

Albatross station 5587; Sibuko Bay, Borneo, and vicinity ; Sipadan Island (W.) bearing S. $12^{\circ}$ E., 7.04 kilometers (3.8 miles) distant (lat. $4^{\circ} 10^{\prime} 35^{\prime \prime} \mathrm{N}$., long. $118^{\circ} 37^{\prime} 12^{\prime \prime}$ E.) ; 759 meters ( 415 fathoms September 28, 1909 ; gn. M., S.,

One specimen (Cat. No. E. 125, U.S.N.M.).

Albatross station 5608; Guif of T'omini, Celebes; Binang Unang Island Peak bearing S. $87^{\circ}$ E., 35.21 kilometers (19 miles) distant (lat. $0^{\circ} 08^{\prime}\left(00^{\prime \prime} \mathrm{S}\right.$., long. $121^{\circ} 19^{\prime}(1)^{\prime \prime}$. E.) ; 1,992 meters $(1,089$ fathoms); November 18, 1909 ; gy. M.

One specimen (Cat. No. E. 117, U.S.N.M.).

Albatross station 5613; Gulf of Tomini, Celehes; Buka Buka Island (E.) bearing S. $28^{\circ}, 7.41$ kilometers (4 miles) distant (lat. 
$0^{\circ} 42^{\prime} 00^{\prime \prime}$ S., long. $121^{\circ} 44^{\prime} 00^{\prime \prime}$ E.) ; 1,375 meters (752 fathoms) ; November 20,1909 ; gy. M.

One specimen (Cat. No. E. 156, U.S.N.M.).

Albatross station 5617; Dodinga Bay, Gillolo Island; Ternate Island (SE.) bearing S. $45^{\circ}$ W., 12.97 kilometers ( 7 miles) distant (lat. $0^{\circ} 49^{\prime} 30^{\prime \prime} \mathrm{N}$., long. $127^{\circ} 25^{\prime} 30^{\prime \prime}$ E.) ; 239 meters (131 fathoms) ; November 27, 1909.

One specimen (Cat. No. E. 118, U.S.N.M.).

Albatross station 5648; Buton Strait; North Island (S.) bearing N. $87^{\circ}$ E., 18.90 kilometers (10.2 miles) distant (lat: $5^{\circ} 35^{\prime} 00^{\prime \prime} \mathrm{S}$, long. $122^{\circ} 20^{\prime} 00^{\prime \prime}$ E.) ; 1,022 meters ( 559 fathoms) ; December 16, 1909 ; gn. M.

One specimen (Cat. No. E. 122, U.S.N.M.).

Albatross station 5657; Gulf of Boni, Celebes; Olang Point bearing N. $61^{\circ}$ W., 28.72 kilometers (15.5 miles) distant (lat. $3^{\circ} 19^{\prime} 40^{\prime \prime}$ S., long. $120^{\circ} 36^{\prime} 30^{\prime \prime}$ E.) ; 900 meters (492 fathoms) ; December 19, 1909 ; gy M.

Four specimens (Cat. Nos. E. 120, E. 121, U.S.N.M.).

Notes.-The study of the large series of specimens collected by the Albatross has lead to quite unexpected conclusions which for a long time I hesitated more or less to admit. The examination of these specimens and their comparison with other Bathypectinuras from different localities which I had referred to different species, has lead me to the conclusion that $B$. conspicua is a very variable form, and that it is not possible to separate from it $B$. elata and $B$. modesta from which I had previously distinguished it. I should not even be surprised if it should be found that Lyman's $B$. heros and B. Zactertosa should also be united with B. conspicua.

I described $B$. conspicua in 1896 from specimens collected by the Investigator in the delta of the Godavery at a depth of 110 fathoms, and the principal characters of this species were the very large size, the diameter of the disk reaching $40 \mathrm{~mm}$., the shape of the mouth shields, which are a little broader than long, the number of the arm spines, which are at first four, falling to three at a little distance from the arm base, the occurrence of numerous pores between the under arm plates at the base of the arms, and the presence of a large tentacle scale. I rediscovered $B$. conspicua in the Siboga collection, that ship having collected this species at different stations between $0^{\circ}-9^{\circ} \mathrm{S}$. latitude and $116^{\circ}-119^{\circ} \mathrm{E}$. longitude, at depths varying from 538 to 2,029 meters (295 to 1,110 fathoms); the diameter of the disk of these specimens was between $25 \mathrm{~mm}$. and $50 \mathrm{~mm}$.

I thought it necessary to distinguish in the Siboga collection a species smaller than the majority of the specimens of $B$. conspicua, 
in which the diameter of the disk was $25 \mathrm{~mm}$; this species, to which I gave the name of Pectinura modesta, possessed five arm spines, the ventral spine being appreciably larger than the others, in this last character recalling Lyman's $P$. tessellata. The specimen, unfortunately unique, came from a locality very near that where $B$. conspicua had been found $\left(7^{\circ} \mathrm{S}\right.$. latitude and $114^{\circ} \mathrm{E}$. longitude, at a depth of 330 meters, or 180 fathoms).

Under the name of Pectinura elata I also described in 1907 a species collected by the expeditions of the Travailleur and the Talisman in localities widely different from the preceding (lat. $25^{\circ} \mathrm{N}$., long. $19^{\circ} \mathrm{W}$. ) at a depth of from 2,325 to 2,518 meters $(1,273$ to 1,380 fathoms); this ophiuran, which was of rather large size, the diameter of the disk exceeding $30 \mathrm{~mm}$, was, like $P$. modesta, without ventral pores. I characterized $P$. elata by the presence of three arm spines which are less than half the arm segment in length, by having the mouth shields as long as broad, and by the presence of a single tentacle scale to each pore, this tentacle scale reaching a very large size on the first arm segments. The affinities of this species seemed to me especially toward $P$. heros Lyman, but it is distinguished from that species by having the mouth shields as long as broad, by the large size of the tentacle scales on the first arm segments, and by having the arm spines larger on the first segments.

But I find in the Albatross collection a large series of specimens showing characters so variable, or rather showing in such a complete manner all the intermediates between the different characters upon which I had thought it possible t'o base a distinction between the three species which I have just mentioned-B. conspicua, B. modesta, and $B$. elata-that it does not seem to me possible to maintain the two latter. I shall go even further and add that Lyman's $P$. heros and $P$. tesselata, Atlantic species like $B$. elata, should probably not be separated from $B$. conspicua, which thus ceases to be peculiar to the Indo-Pacific region. I do not dare, however, to make a definite statement concerning these two species, which I have not personally examined.

To summarize the observations which I made on the specimens collected by the Albatross, I shall record briefly the notes which made, considering successively the size of the specimens, the shape of the mouth shields, and the occurrence of a supplementary plate beyond the latter, the tentacle scales, the ventral pores, and the number and dimensions of the arm spines.

Regarding the dimension of the specimens, it may be said that all sizes are represented, since the diameter of the disk measures in the smallest $11 \mathrm{~mm}$. (station 5114), while in the largest it reaches $45 \mathrm{~mm}$.. 
with numerous intermediate sizes which I give in the following table:

\begin{tabular}{|c|c|c|c|}
\hline Stations. & $\begin{array}{l}\text { Diameter of } \\
\text { the disk. }\end{array}$ & Stations. & $\begin{array}{l}\text { Diameter of } \\
\text { the disk. }\end{array}$ \\
\hline 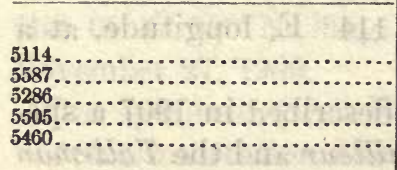 & \begin{tabular}{r|} 
Millimeters. \\
11 \\
19 \\
19 \\
21 \\
122 \\
23
\end{tabular} & 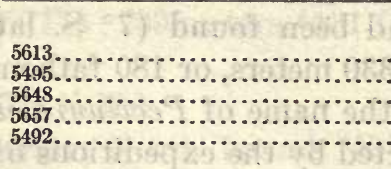 & \begin{tabular}{|r|} 
Millimeters. \\
27 \\
$27,28,33$ \\
$38,44,44,45$ \\
45
\end{tabular} \\
\hline
\end{tabular}

Whatever the size may be, the general form of the individuals remains the same; in the dorsal median line the arms are raised up into a very pronounced dihedral angle, and their cross section is triangular; the spines are almost confined to the ventral surface. In the smallest specimens the triangular form of the arm is naturally less marked, though in them the dorsal median line is already strongly elevated.

In none of the Abatross specimens have I found the ventral pores as developed as in the Investigator specimens which served me as the type series. For comparison I show on plate 77, as figure 1 , one of the latter in which at least five pairs of pores can be recognized, and even the traces of a sixth pair. In describing the species I remarked that the number of these pores was not constant, and that in certain specimens there were three or four pairs only (Koehler '96, p. 324). The Albatross specimens in which these pores are most developed are that from station 5492, in which the disk measures $45 \mathrm{~mm}$. in diameter, and that from station 5494, in which the diameter of the disk is $41 \mathrm{~mm}$.; I have shown the latter in figure 2; two pairs of pores are visible on each arm, and the third is usually indicated. The specimens from station 5274, which have the disk 43 $\mathrm{mm}$. in diameter, also show two pairs of pores at the base of each arm, but the second pair is only slightly evident. On the other large specimens these pores are not generally visible; but I find one pair well marked, though on only three arms, in the specimen from station 5697 (fig. 2). On other smaller specimens the pores of the first pair are often present; I find them for instance in the three individuals from station 5495, in which the diameter of the disk measures, respectively, 27,28 , and $33 \mathrm{~mm}$; these pores are especially well shown on two specimens of which I show the ventral surface in figures 9 and 11. I also find them on a specimen from station 5216 with a disk diameter of from $27 \mathrm{~mm}$. to $28 \mathrm{~mm}$, and on another (fig. 6) from station 5587 with a disk diameter of $19 \mathrm{~mm}$., in which the pores are visible on two arms only. On the small specimen from station 5114 (fig. 3), in which the disk is only $11 \mathrm{~mm}$. in diameter, this first 
pair of pores appeal on all the arms. Everywhere else the pores are lacking.

In Pectinura elata from the Atlantic, as I stated in my original description in 1907, the ventral pores are always lacking; I give a photograph of the ventral surface of one of the specimens collected by the expeditions of the Travailleur and of the Talisman (fig. 8).

The tentacle scales are always very large on the first arm segments, and their size decreases rather rapidly from the first pair onward, but their dimensions are rather variable; perhaps there is some relation between their size and the presence or absence of the ventral pores. It is not rare to see the scale of the pores of the first pair doubled, and this may even happen on the pores of the second pair. The scales of the first pair may be broadened so as almost to be in contact in the median line of the arms, as I find in two specimens from station 5657 (fig. 7) and on that from station 5608 (fig. 5). I have already recorded this considerable development of the first tentacle scale in $P$. elata collected by the Talisman, and it may be seen in the photograph which I give of it (fig. 8). When these tentacle scales are not in contact, though much broadened, the second under arm plate tapers rapidly in its proximal region; this is what occurs in the specimen from station 5657, shown in figure 7 , and in that from station 5608 (fig. 5). I also find the same feature in the specimen from station 5648 , which has a disk diameter of 35 mm., as well as in those from stations 5460 and 5613, which are smaller, with the diameter of the disk from $23 \mathrm{~mm}$. to $25 \mathrm{~mm}$. In other larger specimens the tentacle scale is less developed. The more or less large dimensions which this scale may assume are not therefor exclusively correlated with size.

The form of the mouth shields also shows very great variation. As a general rule these shields are triangular and a little broader than long, their outlines being somewhat modified by the more or less considerable development of the granules which to a varying degree extend over their borders as well as also over the adoral and oral plates. In the Investigator specimen shown in figure, 1 these shields are markedly broader than long; it is the same in the specimen from station 5494 (fig. 2) and in one of those from station 549:; (fig. 11). These shields are almost as long as broad, with some variation possible in the same specimen; I show here specimens from stations 5114 (fig. 3), 5587 (fig. 6), 5657 (fig. 7), and 5495 (fig. 9) in which the mouth shields are almost as long as broad. These shields may become much elongated and appreciably longer than broad; this occurs, for instance, in the large specimen from station 5608 (fig. 5), in the two from station 5468, and in one of the three from station 5495 (fig. 10). A comparison of the three specimens from this last station is very interesting, for one of them has the 
mouth shields almost as long as broad (fig. 9), the other has then a little longer than broad (fig. 10), and in the third they are broader than long (fig. 11). I have shown these three specimens side by side (figs. 9-11). In $P$. elata from the Talisman collection the mouth shields are as long as broad (fig. 8).

As for the supplementary plate which may be found beyond the mouth shield, it appears in certain individuals and is lacking in others; it may even occur in two or three interradii and be lacking in the others in the same individual; there does not seem to be the least relation between the presence of this plate and the size of the specimen.

If we examine the arm spines, we find that it is only in the small specimen from station 5114 that they do not exceed three at the base of the arms (fig. 15), and this number falls to two at a little distance from the disk; but on the two or three first arm segments sometimes I find a very small fourth supplementary spine, which appears at the superior angle of the side arm plate. In the other specimens in which the diameter of the disk varies between $19 \mathrm{~mm}$. and $25 \mathrm{~mm}$. there are always some arm segments at the base of the arms which have four spines, and in the larger specimens this number reaches five, falling afterwards to four and in the distal half of the arms to three. In the small specimen from station 5114 the three spines are equal; in that from station 5587 (fig. 4) the four spines are short and equal. In the other specimens the spines are generally a little longer, and the ventral spine slightly exceeds the others. Sometimes the arm spines are rather long at the base of the arm, and they may even reach the length of the segment; I find this condition in the specimen from station 5505 (fig. 13), but usually these spines do not exceed half the segment, and they become smaller as the distance from the disk increases. In the large specimens the number five is frequent at the base of the arms and is maintained for a variable length, it falling to four and finally to three, as I have just said, but with rather frequent irregularities. Here again the variations are very great. I may recall that the presence of five arm spines, with the ventral the largest, was one of the principal characters upon which I based my Pectinura modesta. In Pectinura elata the spines are four in number at the base of the arms, and then three for a rather large portion of their length; but $I$ sometimes find five at the base of the arms, though that is very rare; these spines are subequal, but the ventral spine is sometimes a little larger than the others.

Considering all these variations, I believe that $B$. conspicua should be considered as a rather polymorphic species, and I no longer believe myself justified in maintaining the two species which I established on characters which to-day appear inadequate- $P$. modesta, 
which was only represented by a single specimen with five arm spines, the first ventral the largest, and without distinct pores between the under arm plates, as well as $P$. elata, an Atlantic form, also without ventral pores and possessing very large tentacle scales on the first pair of pores, with four subequal spines at the base of the arms.

Bathypectinura conspicua, taken in a very broad sense, has a vast geographical range, for it exists in the three great oceans-the Atlantic, the Indian, and the Pacific. Its bathymetrical range is also rather great, since the extreme limits of the depths at which it has been captured are 393 meters (215 fathoms)-Albatross station 5216 -and 335 meters (183 fathoms) $-B$. modesta of the Sibogaon the one hand and 2,503 meters (1,375 fathoms)-P. elata of the Talisman-on the other.

In speaking of the variations of $B$. conspicua, I have only considered the forms which $I$ have been able personally to study $-B$. modest $a$ and $B$. elata; but, as I have said above, I am led to believe that two other species also referred to the genus Bathypectinura should be united with $B$. conspicua; these are Pectinura heros Lyman, which the $C$ hallenger found in $5^{\circ} \mathrm{S}$. latitude and $134^{\circ} \mathrm{E}$. longitude in 1,460 meters ( 800 fathoms) in the vicinity of the station where the Siboga dredged $B$. conspicua, and $P$. tesselleta Lyman, which the Blake collected in the Danish West Indies in 451 fathoms (824 meters).

In Lyman's Pectinura heros the diameter of the disk is $22 \mathrm{~mm}$.. and the length of the spines, which are three in number, almost equals half that of the segment; but Lyman does not say. whether these spines are equal or unequal; on the figures which he published, both in 1879 ('79, pl. 14, fig. 391) and in 1882 ('82, pl. 23, fig. 10), he shows the ventral spine longer than the others. In $P$. tessellata the diameter of the disk is $17.5 \mathrm{~mm}$., the spines are four or five in number, and according to Lymans figure ('83, pl. 3, fig. 3) the ventral spine is a little longer than the others. These two species seem to me quite identical with certain specimens of $B$. conspicua of the same size.

Very recently Matsumoto ('15, p. 87) described under the name of Bathypectinura gotoi an ophiuran from Sagami Bay, 311 meters (170 fathoms), represented by two specimens in which the diameter of the disk reached $50 \mathrm{~mm}$. and the length of the arms $190 \mathrm{~mm}$.; these are therefore large-sized individuals. The arm spines are four in number over a large part of the length of the arms, the number then falling to three. I find nothing in Matsumoto's description permitting the separation of this form from $B$. conspicua, and I am inclined to believe that the two represent the same species. Matsumoto compares $B$. gotoi with $B$. lacertosa Lyman, which was found 
off Grenada in 159 fathoms, but the latter has very short arms, and this character seems to me sufficient to separate it from $B$. conspicua. $I$ can not understand why Matsumoto in describing $B$. goto $i$ compares it only with $B$. lacertosa, which has the arms very short, and does not mention the other species of the genus which have the arms elongated like itself.

If the identity of $B$. heros and $B$. tessellata with $B$. conspicua which I suspect should be confirmed, it is obvious that the name heros must be used, as that name has priority; but I do not dare to make this change before I have more complete comparative data, and $I$ have thought it best to call the species collected by the $A l b a$ tross, $B$. conspicua.

\section{CRYPTOPELTA TECTA, new species.}

Plate 78, figs. 1, 2.

Locality-Albatross station 5174; in the vicinity of Joló; Joló Light bearing E., 4.82 kilometers (2.6 miles) distant (lat. $6^{\circ} 03^{\prime} 45^{\prime \prime}$ N., long. $120^{\circ} 57^{\prime} 00^{\prime \prime}$ E.) ; 37 meters (20 fathoms) ; March 5, 1908; crs. S.

One specinen (Cat. No. 41391, U.S.N.M.).

Description.-The diameter of the disk is $7 \mathrm{~mm}$; the arms are $30 \mathrm{~mm}$. long; they are relatively broad, and much flattened.

The disk is pentagonal; the dorsal surface is uniformly covered with very small granules, which continue over the ventral surface, where they cover not only the mouth pieces, but also the four or five first under arm plates. These granules are not perfectly spherical, but are somewhat elongated, and seen in profile they resemble small and extremely short spines. In the vicinity of the genital slits, which are broadly open and much elongated, these granules become somewhat coarser. The mouth papillae number nine or ten on either side; the four or five outer are broader than the others, almost as long as broad, with the free border rounded; the other papillae are narrower and conical.

The first upper arm plate, which is quadrangular, is short, very much broader than long, with the distal border rounded. The second is similarly quadrangular, and also a little broader than long. The third and the fourth are almost as long as broad, and the following plates become a little longer than broad, while at the same time their proximal border become shorter; the distal border always remains convex. Toward the extremity of the arms the proximal border disappears; the plates are then triangular and elongated, with a very sharp proximal angle. The dorsal plates remain in contact throughout almost the whole length of the arms, being separated only on the last segments. 
The first under arm plates are entirely covered by granules, as I have stated above, and their outlines are quite hidden; these granules may extend as far as the fifth plate. The following plates are hexagonal, a little longer than broad, with three short proximal borders, two sides notched by the tentacle pores, and a rounded distal border; they are at first in contact. At some distance from the disk the three short proximal sides become converted into an acute angle, and the plates become pentagonal, always remaining a little longer than broad, and at the same time they become separated by a narrow interval.

The side arm plates usually bear six short subequal spines which are a little shorter than half the segment; the three or four first segments have usually seven of them.

The single tentacle scale is of medium size and oval.

The color of the specimen in alcohol is light gray with broad light brown annulations on the arms.

Affinities and distinctive features.-The genus Cryptopelta was established by H. L. Clark for Ophiopeza aster Lyman, and he later described a second species, $C$. granulifera, from a specimen from Mauritius, which was distinguished from $C$. aster by its flattened arms and different coloration. Cryptopelta tecta seems to me very close to $C$. granulifera, but it differs from it, as from $C$. aster, by having its upper and under arm plates longer than broad, by having the granules covering the first under arm plates, and by having the arm spines only six in number except on the first segments.

\section{OPIIURODON CINCTUS (Breck).}

$$
\text { Plate } 81 \text {; fig. } 5 \text {. }
$$

Ophioconis cincta Brock ('88), p. 480.-KaEHLER ('05), p. 14, pl. 2, figs. 2 , 3.-H. L. Clark ('15), p. 218.

Ophiurodon cinctus Matsumoto ('15), p. 84; ('17), p. 315.

Locality.-Albatross station 5147; Sulu (Joló) Archipelago, in the vicinity of Siasi; Sulade Island (E.) bearing N. $3^{\circ}$ E., 15.57 kilometers (8.4 miles) distant (lat. $5^{\circ} 41^{\prime} 40^{\prime \prime}$ N., long. $120^{\circ} 47^{\prime} 10^{\prime \prime}$ E.) ; 38 meters (21 fathoms) ; February 16, 1908; co. S., Sh.

One specimen.

Notes.-This species was described by Brock in 1888, and two specimens were collected by the Siboga in the Sunda Archipelago, near Timor, at depths between 27 and 54 meters ( 15 to 30 fathoms).

In 1905 I recorded a slight difference in the arrangement of the tentacle scales on the first pores in the Siboga specimens and in Brack's type. In the Philippine individual the pores of the first pair show four and even five scales of medium size, as Brock has described; the pores of the second pair have generally three of them, 
and on those of the third pair the large single scale is usually seen which is continued on the following pores. This scale, however, is sometimes accompanied by a second smaller scale. I do not find on the Albatross specimen the infradental papilla described by Brock, but instead a small group of two or three papillæ quite identical with those in the Siboga specimens.

In order to permit comparisons between the genera Ophioconis, in the restricted sense, and Ophiurodon, I include a photograph of the ventral surface of an Ophioconis forbesi which I collected at La Ciotat (pl. 81, fig. 1).

\section{OPHIURODON PERMIXTUS (Kohler).}

Ophioconis permixta KoHLER ('05), p. 14, pl. 2, figs. 4, 7.

Ophiurodon permixtus Matsumoto ('15), p. 84.-H. I. Clark ('15), p. 219.-Matsumoto ('17), p. 315.

Locality.-Albatross station 5400; north of Cebu; Tanguingui Island Light bearing N. $77^{\circ}$ W., 41.70 kilometers (22.5 miles) distant (lat. $11^{\circ} 24^{\prime} 24^{\prime \prime}$ N., long. $124^{\circ} 05^{\prime} 30^{\prime \prime}$ E.) ; 45 meters ( 25 fathoms) ; March 16, 1909; S., Sh.

A single specimen.

Notes.-The diameter of the disk is $6 \mathrm{~mm}$. The specimen is unfortunately in rather bad condition. The arms are broken off near the base, and the disk is somewhat damaged, especially on the dorsal surface. The identification is, nevertheless, certain, and it may be stated that the specimen agrees well with the type which the Siboga dredged in the Sunda Archipelago between 75 and 94 meters (41 and 52 fathoms).

\section{Family OPHIOLEPIDIDAE.}

Kemarks.-Before describing the species which belong to the family Ophiolepididae it seems to me well to consider the character on which Matsumoto has divided it; that is, the position of the mouth tentacle pores of the second pair, and to add a few remarks on the manner of occurrence of these pores in the genus Ophiura, as well as in those genera which have been split off from it by Matsumoto and by H. L. Clark, as I mentioned at the beginning of this memoir.

The family Ophiolepididae was divided by Matsumoto into two subfamilies according to whether the mouth tentacle pores of the second pair opened entirely into the mouth slits (Ophiolepidinae) or whether they opened more or less completely outside of these slits (Ophiomastinae). This latter subfamily includes, among others, the genera Ophiomastus, Ophiotypa, Ophiomisidium, Ophiophycis, etc., as well as the genera Ophiura, Amphiophiura, Stegophiura, etc. 
It is indisputible that only the genera included in Matsumoto's subfamily Ophiolepidinae-that is, the genera Ophiomisidium, Ophiolepis, Ophiozona, etc.-possess mouth pores opening into the mouth slits in the strict sense of the word, and these pores, situated more or less deeply, are not visible externally when the ophiuran is viewed on the ventral surface. But this is not the case in the subfamily Ophiomastinae in the different representatives of which these pores, whatever may be their external appearance and however near they may approach the mouth slits, never, strictly speaking, open into the mouth. Let us consider the ventral surface of forms such as Stegophiura sterea (pl. 83, fig. 2), S. sladeni (pl. 83, fig. 4), S. sterilis (pl. 83, fig. 9), Ophiura sarsii (pl. 84, figs. 10, 11), 0 . flagellata (pl. 86, figs. 1, 2), in order to take as illustrations only species of which photographs are included here, and we shall see that these pores are always very much developed, that they are more or less elongated, and that they very often have their proximal extremity broadened; certain of them appear to open entirely into the mouth slits, and others, which are somewhat more distant from it, appear not to open into it. Actually these pores do not really open into the mouth, and if we believe that we see them opening thus this is due to a superficial appearance. The opening of these pores is on the same plane as the ventral surface of the corresponding oral plates-that is, on a plane slightly lower than that of the mouth slit-and it is always separated from the latter by an interval, very slight, it is true, though actually existing. Furthermore, a careful examination often permits the determination of the presence of one or two mouth papillae which affirm, in a way, this separation; in default of mouth papillae, the border of the oral plate itself forms a sort of ceiling to the tentacle pore and separates it from the mouth.

In the species which I have just mentioned and in many others, the mouth pores in reality open like the following pores on the ventral surface of the arms, and it is not correct to say that these pores open into the mouth slits; it is preferable to say that these pores, which are elongated and much developed, often broadened and even gaping from the side of the mouth slits, have their proximal extremity rather close to these slits and thus appear to open into them.

If the arrangement of these pores be compared with that which is noticed in species such as Ophiura imbecillis, Homalophiura, inornata, H. nana, Amphiophiura undata, A. abcissa, etc., a considerable difference will be found. In these latter species the pores are small, narrow, always distant from the mouth slits, and their proximal end is closed like their distal. In speaking of these pores we say-H. L. Clark and myself-that they do not open into the mouth; that is not sufficient to distinguish them from the pores of species 
such S. sterea, S. sladeni, etc.; it is better to say that their proximal extremity is closed, and that they are some distance from the mouth slit.

Whatever may be the conditions and the development of the mouth pores, they never open into the mouth in the different species of the genus Ophiura, taken in the broader sense. But it is evident that between the mouth pores of species like those of the first group which I have cited above (S. sterea, S. stadeni, etc.) and those of the second group which I have just mentioned ( $A$. abcissa, 0 . imbecillis, etc.) there are considerable differences, and these may furnish us with good characters for the differentiation of the species; but these differences must be stated in precise and correct terms. Thus not only will serious errors be avoided, but also differences of opinion and uncertainties in interpretation such as have sometimes occurred.

For example, H. L. Clark, in drawing up the key of the species of Ophiura belonging to the variabilis group ('09, p. 295), observed that I placed $O$. insolita among the species in which the mouth pores open into the mouth, but that that is in contradiction with my figure of $O$. insolita. In reality my figure is slightly schematic, and as for the text to be correct I would have to say, as I have advocated above, that the mouth pores are elongated, gaping at their proximal extremity, and very close to the mouth slit. I include a photograph of the ventral surface of $O$. (Amphiophiura) insolita in which the exact relations of the tentacle pores to the mouth slits may be seen (pl. 84, fig. 9).

In his descriptions H. L. Clark has also used the incorrect expression "the mouth pores open (or do not open) into the mouth slits." In different species described by him in 1911, for instance in 0 . leptoctenia ('11, pp. 51-52), O. quadrispina (p. 56), O. monostoecha (p. 66), O. megapoma (pp. 79 and 80), O. penichra (pp. 84, 85), 0 . actacta (p. 86), etc., he says that the mouth pores open into the mouth; this statement is evidently inaccurate, and in these species the mouth pores do not open into the mouth slits any more than they do in S. sterea and S. sladeni or in A. insolita.

In speaking of the first two species H. L. Clark declares that the mouth pores do not open into the mouth, and yet they have as great a development as in the species described by him which I have just named. I may even add that in studying different specimens of S. sterea and of S. sladeni the impression is often given that these pores really open into the mouth slits, as may be seen in some of my photographs (pl. 83, figs. 2,$4 ; \mathrm{pl} .84$, fig. 1). The appearance of the ophiuran which makes us say sometimes that the pores open and sometimes that they do not open into the mouth often has to do with the state of contraction or of relaxation of these pores when the 
animal is plunged into alcohol, and also without doubt to the action of the preserving liquid itself.

I believe that in saying of the mouth pores that they are very close to or distant from the mouth slits and that they are developed and. elongated from the side of these slits or, on the other hand, that they are small, narrow, short, and distant from the slits we express conditions corresponding to valid characters which are very useful to employ in classification, and not to modifications caused by the action of reagents or the reactions which result from them in the ophiuran, or which are perhaps dependent on the age and on the size of the subject.

\section{OPHIOPYRGUS PLANULATUS, new species.}

Plate 81 , figs. 3,4 .

Locality.-Albatross station 5613; Gulf of Tomini, Celebes; Buka Buka Island (E.) bearing S. $28^{\circ} ; 7.41$ kilometers (4 miles) distant (lat. $0^{\circ} 42^{\prime} 00^{\prime \prime}$ S., long. $121^{\circ} 44^{\prime} 00^{\prime \prime}$ E.) ; 1,375 meters (752 fathoms); November 20, 1909; gy. M.

One specimen (Cat. No. 40928, U.S.N.M.).

Description.-The diameter of the disk is $4.4 \mathrm{~mm}$; the arms are $22 \mathrm{~mm}$. long.

The disk is rather thick; the two surfaces, the dorsal and the ventral, are slightly convex, but the dorsal is not at all elevated; it is entirely covered by six large plates, a dorso-central and five primary radials, without the least trace either of intercalated plates or of radial shields. The dorso-central, which is of very large size, is pentagonal, with straight sides; it covers almost half of the expanse of the disk. The radial plates, which are also very large, are trapezoidal, broadened transversely, about twice as broad as long, with a straight proximal side, straight and divergent lateral borders, and a rounded distal border forming the boundary of the periphery of the disk; this distal border is swollen in its central region into a rounded lobe the width of which equals that of the corresponding arm, and which forms a slight prominence above the surface of the disk. The radial papillae are scarcely evident, and, in fact, $I$ only distinguish them at the base of two arms, and only when the animal is viewed from the side or from the ventral surface; they are extremely small, conical, and only three or four in number.

The ventral surface of the disk in the interradial spaces is in very large part covered exclusively by the mouth shields, these being very greatly developed, and there is not the least trace of plates other than the mouth pieces. The mouth shields are triangular, a little broader than long, with a rather open proximal angle and a very convex distal border forming the periphery of the disk, the 
middle of which is continued into a small prolongation ending in an obtuse angle which reaches the dorsal surface of the disk between the radial plates. The lateral borders of these shields are divided into two sides-one, which is proximal and straight, is very short; the other, which is elongated, is slightly concave. The genital slits are scarcely distinguishable, and they extend along about a third of the length of the corresponding shield. The adoral plates are much developed, thick, with the parallel borders slightly incurved; they are rather short, but very broad; their surface is slightly convex. The oral plates are small and triangular. The mouth papillae are not very distinct; I can make out, however, on either side three low rectangular papillae which are very much broader than high, and one unpaired terminal papilla, which is rather short and broadened.

The first upper arm plate is extremely small and very short, in the form of a very depressed arc of a circle. The following are larger, though always remaining of small size and widely separated; they are triangular, broader than long, with a very obtuse proximal angle, straight sides, and a very slightly convex distal border. They extend as far as the tip of the arms, though becoming extremely small terminally.

The under arm plates are more developed than the upper; their size diminishes progressively from the first outward. This is rather large, pentagonal, a little longer than broad, with an obtuse and slightly rounded proximal angle, sides strongly excavated by the corresponding tentacle pores, and a slightly convex distal border. The four following plates have a similar form, but their dimensions progressively decrease and their sides are less strongly notched by the tentacle pores; they are widely separated. Beyond the fifth segment the tentacle pores disappear and the plates are quite rudimentary; from this point they disappear rapidly.

The side arm plates, which are very large and elongated, are broadened and projecting in their distal portion, which carries two extremely small and rather separated arm spines situated toward the middle of their height.

There are four pairs of tentacle pores which are rather large, especially those of the two or three first pairs. On the pores of the first pair there may be distinguished one or two scales on each border; the pores of the second pair usually still have one scale on either side, but the following are without them.

The color of the specimen in alcohol is a rather dark brownish yellow.

Affinities and distinctive features.-I believe it necessary to refer this species to the genus Ophiopyrgus rather than to the genus 
Ophiomastus because of the development of the tentacle pores and the large size of the mouth shields which cover the whole ventral surface of the disk; but the rudimentary state of the radial comb and the low form of the disk separate it from the majority of the species of the former genus. But the radial papillae, slightly developed though they are, nevertheless occur, and the same low form of the disk is found in O. depressus which the Siboga dredged in $4^{\circ} \mathrm{S}$. latitude and $118^{\circ} \mathrm{E}$. longitude in 2,029 meters (1,110 fathoms). The new species is distinguished from the latter by having the plates of the dorsal surface of the disk reduced to the primary rosette, and by having only two arm spines.

\section{AMPHIOPHIURA CANALICULATA, new epecies.}

Plate 82, figs. 10-12.

Locality.-Albatross station 5356; North Balabac Strait; Balabac Light bearing S. $64^{\circ}$ W., 28.72 kilometers (15.5 miles) distant (lat. $8^{\circ} 06^{\prime} 40^{\prime \prime}$ N., long. $117^{\circ} 18^{\prime} 45^{\prime \prime}$ E.) ; 106 meters (58 fathoms); January 5, 1909 ; S., Sh.

One specimen (Cat. No. 41341 , U.S.N.M.).

Description.-The specimen is almost entire, one of the arms only being broken off near the base. The diameter of the disk is $8 \mathrm{~mm}$.; the arms are $16 \mathrm{~mm}$. long.

The disk is rather thick, with the two surfaces slightly convex; the arms are rather slender, almost as high as broad, and they taper rather slowly to the tip, which is pointed.

The dorsal surface of the disk is covered with rather large plates which are few in number. The central rosette covers almost half the width of that surface; the dorso-central plate is large and pentagonal; the five primary radials have almost the same dimensions, but they are somewhat unequal; they are broadened transversely and their distal border is strongly convex. Following each one of them there is in the radial space a single very much smaller and especially shorter plate which is trapezoidal with the distal border broadened and strongly convex, and which separates the two radial shields of each pair in their proximal region. The interradial spaces are each occupied by a series of three plates, the first very large and the second smaller; the third, which is very much broader, occupies the periphery of the disk and even passes over onto the ventral surface. On either side of the last three are to be seen two very much smaller plates situated outside the radial shield and also on the periphery of the disk. The radial shields are markedly smaller than the six primary plates; they are irregularly quadrangular, twice as long as broad, strongly divergent, and in contact for about a third of their length. The radial papillæ are large, elongated, cylindrical. and tapering to the slightly rounded extremity. 
The ventral surface of the disk between the radial shields and the peripheral plate which I have noticed above is only occupied by a transverse row of three very small plates, the median smaller than the two others. The genital plate covers only a very restricted portion of the ventral surface of the disk; it carries a few small and low papillae which become elongated at the periphery of the disk. The genital slits are very narrow, but very elongated, and they extend to the vicinity of the proximal angle of the mouth shields.

The mouth shields are very large, elongated, at least half again as long as broad, and pyriform, with a sharp proximal angle and a very convex distal border. The adoral plates are very small and narrow. The oral plates are more developed than those preceding and broader, with the borders straight and parallel. The lateral mouth papillae are generally only three in number; they are small, low, and rectangular, the outermost very much broader than the others. The unpaired terminal papilla is stouter than those on either side, though it is not very much developed.

The upper arm plates are lozenge-shaped and of medium size. The first is a little broader than long with a very obtuse and rounded proximal angle. The following are almost as broad as long or a little broader than long, with the proximal angle sharper than the distal angle, and the two proximal sides longer than the two others which are united over a very obtuse angle. These plates are separated from the second outward by a small interval which, in the distal half of the arms, becomes almost as long as the plates themselves.

The first underarm plate is triangular, almost as broad as long, with the angles and the sides equal. The following are much developed, trapezoidal, with a very narrow proximal side and an extremely broad distal side; the lateral borders are very divergent. At some distance from the base of the arms these plates become pentagonal, the proximal border being replaced by two small sides, making with each other a very obtuse angle; the plates then become a little longer than broad with a rather narrow and slightly convex distal border. They are separated beyond the disk by an interval which progressively elongates. These plates show throughout their whole length a median depression in the form of a rather broad groove with parallel borders, and the succession of these depressions, supplemented by corresponding depressions on the side arm plates when the ventral plates become separated, form a very clearly marked furrow which is of considerable depth on the four or five first plates; beyond this the depth gradually diminishes, but the groove persists to the tip of the arms. This groove is only slightly marked and not very deep on the first under arm plate, but it is abruptly excavated on the second, on which it reaches its maximum depth. 
The side arm plates are fairly well developed, but only slightly projecting; they carry on their distal border three small spines which are equally spaced and closer to the ventral than to the dorsal side.

The tentacle pores are very large and much developed through almost the whole length of the arms. The pores of the first pair are somewhat separated from the mouth slits, and they have, like the two following, four or five scales on each border; the pores of the fourth, fifth, and sixth pairs have three scales on each border; the number of the scales then diminishes little by little, first on the distal border then on the proximal border; they finally are reduced to a single scale in the last third of the arms.

The color of the specimen in alcohol is white.

Affinities and distinctive features.-Amphiophiura canaliculata belongs to the group of species of Amphiophiura in which the under arm plates become longer than broad, and it recalls $A$. solida (Lyman), A. convexa (Lyman), etc., in the arrangement of the dorsal plates of the disk. It differs from them in the form of the mouth shields. and especially in the longitudinal groove which exists throughout the whole length of the median ventral line of the arms and which I do not know in any other species. It is exactly the opposite arrangement from that shown by Stegophiura elevata (Lyman), S. macrarthra (H. L. Clark), and S. sterea (H. L. Clark), in which an elongated prominence extends along the middle of the under arm plates. In the form of the arms, which are rather slender at the base and which de not taper rapidly, this species falls well within Matsumoto's genus Amphiophiura, and not in the genus Stegophiura.

\section{AMPHIOPHIURA FASTIGIATA, new species.}

Plate 82, figs. $1-4$.

Locality.-Albatross station 5259; off northwestern Panay; Caluya Island (S.) bearing S. $73^{\circ} \mathrm{W} ., 19.84$ kilometers (12 miles) distant (lat. $11^{\circ} 57^{\prime} 30^{\prime \prime} \mathrm{N}$., long. $121^{\circ} 42^{\prime} 15^{\prime \prime}$ E.) ; 571 meters (312 fathoms) ; June 3, 1908; gy. M., Glob.

One specimen (Cat. No. 41344, U.S.N.M.).

Description.-The specimen is in very good condition, but the arms are all broken off at some distance from the base; one of them is preserved for a length of $44 \mathrm{~mm}$. The diameter of the disk is $16 \mathrm{~mm}$.

The disk is pentagonal and very thick The dorsal surface is plane, the ventral a little convex. The arms are rounded: their sides are vertical, but directed obliquely inward. The habitus of the animal is very robust.

The dorsal surface of the disk in its central region shows only a very small number of plates of small diameter, while the peripheral part, is occupied by the radial shields, which are very large, between which 
there is only a single row of very much narrower interradial plates. The central rosette is irregular, for the dorso-central plate is replaced by four other very small plates, and one of the primary radial plates is itself divided into two. These radial plates are rounded, a little broadened transversely, and they measure about $2 \mathrm{~mm}$. in width. Outside of the circle which they form there is another circle of larger interradial plates, which are oval and radially elongated, and separate the proximal angle of each radial shield from the corresponding angle of the shield of the neighboring pair. Each of these plates is followed by another a little larger, usually triangular in shape, with the base very close to the periphery of the disk. Following this last there is a large plate which delimits the vertical borders of the disk between the genital plates in each interradial space; a very small part of this plate is seen when the animal is viewed from above. Between this last and the triangular plate which precedes it there is on either side a very small intercalated plate; between the first and the second interradial plates also there is a group of two very small plates. In the radial spaces, between the primary radial plates and the radial shields, there is only a rather constant group of three very small plates of which the median, triangular in shape, separates the two radial shields of each pair at their proximal extremity. All these plates are projecting and strongly convex, and they are separated from each other by rather deep grooves; their surface is perfectly smooth and very shiny. The radial shields are very large and form a broad peripheral ring which covers a large part of the dorsal surface of the disk. These shields are elongated, triangular, with the borders and angles very rounded; they are half again as long as broad and are in contact throughout almost their entire length, which, reaching on the average $4.5 \mathrm{~mm}$., exceeds half the radius of the disk. Their surface is very convex and perfectly smooth like that of the other plates of the dorsal surface. The radial papillae are cylindrical, rather short, with the point obtuse, and very close to each other.

The ventral surface of the disk in the interradial spaces includes only a small number of plates. Usually two paired plates, which are rather small and rounded, suffice to cover the space between the mouth shield, the genital plates, and the large interradial plate which limits the sides of the disk and encroaches somewhat on the ventral surface. Sometimes one or two extremely reduced plates are found at each external angle of the mouth shield. The genital plates are of medium size. The narrow and elongated genital slits are provided along their whole interradial border with a range of low and obtuse papillae.

The mouth shields are large, elongated, and their distal half occupies the whole width of the ventral surface of the disk between the genital plates. They are longer than broad and pentagonal in shape, with a rather sharp proximal angle bordered by two small straight 
sides; the lateral borders are convex and they pass over by very rounded angles to the distal side which is also convex; a rather marked notch corresponding to the bottom of the genital slits separates the anterior region of the shield, which is very short, from the very much more important posterior region. The adoral plates are rather small with the two sides parallel and twice as long as broad. The oral plates are broader and a little shorter than the adoral plates. The lateral mouth papillae are four in number; they are small and low; the three outermost are rectangular and the last is a little more elongated and conical. The unpaired terminal papilla is conical and a little stronger than those on either side.

The first upper arm plate is small, trapezoidal, a little broader than long. The following are at first broader than long, quadrangular, with the proximal border narrow and the sides diverging and straight; the distal border is convex or, better, is formed of two short sides which unite over an obtuse and rounded angle. On the following plates the proximal border becomes progressively shorter and it disappears at about the twelfth plate; the plates then become triangular, but always remain a little broader than long; they are at first in contact, later becoming separated by a narrow interval.

The first under arm plate is rather large, triangular, a little broader than long, with an obtuse and somewhat truncated proximal angle and a very convex distal border. The second is rectangular with the proximal border a little narrower than the rounded distal border. The following plates are pentagonal with a slightly obtuse proximal angle which is truncated on the third and fourth plates, and which is bounded by two concave borders; the sides are straight and they unite over rounded angles to form the distal border, which is also rounded. Little by little the lateral borders disappear, and the plates become simply triangular. They are always broader than long, and beyond the disk they are separated by an increasingly elongated interval.

The side arm plates carry three small equal papilliform spines; the dorsal spine is separated from the median spine by a space which is a little larger than that separating the latter from the ventral spine.

The mouth tentacle pores are much elongated and very close to the mouth slits; they have five scales on each of their borders. The following pores have also four or five scales on each border. The number of these scales progressively diminishes and the pores of the sixth pair have two or three proximal scales and a single distal scale. This last finally disappears and there remains only a single proximal scale.

Affinities and distinctive features.-Amphiophiura fastigiata is related to $A$. remota and A. latro (Kœhler) collected by the Siboga, and to $A$. undata (Lyman). The arrangement of the dorsal plates 
of the disk recalls that which I have described in the two first species, but the characters of the ventral surface, the upper and under arm plates, and the number of the spines are entirely different. The differences which separate this species from 0 . undata are very much more marked; in this species the radial shields are not larger than the plates of the primary rosette, the upper arm plates and the mouth shields have a different shape, the arm spines are four in number, etc.

\section{AMPHIOPHIURA IMPROBA (Kœhler).}

Plate 84, figs. 4, 5 .

Ophioglypha improba KoHLER ('04), p. 48, pl. 8, flgs. 4-6.

amphiophiura improba Matsumoto ('15), p. 77.-H. L. ClarK ('15), p. 314.-Matsumoto ('17), p. 261.

Localities.-Albatross station 5630; south of Patiente Strait; Doworra Island (N.) bearing N. $3^{\circ}$ W., 8.34 kilometers ( 4.5 miles) distant (lat. $0^{\circ} 56^{\prime} 30^{\prime \prime}$ S., long. $128^{\circ} 05^{\prime} 00^{\prime \prime}$ E.) ; 1,041 meters (569 fathoms); December 2, 1909 ; co. S., M.

Three specimens (Cat. Nos. 41138,41139 , U.S.N.M.).

Albatross station 5631; south of Patiente Strait; Doworra Island (N.) bearing N. $58^{\circ}$ E., 19.46 kilometers (10.5 miles) distant (lat. $0^{\circ} 57^{\prime} 00^{\prime \prime}$ S., long. $127^{\circ} 56^{\prime} 00^{\prime \prime}$ E.) ; 1,479 meters (809 fathoms); December 2, 1909; gn. M. (in net).

Four specimens (Cat. No. 41137, U.S.N.M.).

Notes.-These specimens are quite in agreement with the type which was discovered by the Siboga among the Sunda Islands (lat. $5^{\circ}$ S., long. $127^{\circ}$ E.) at a depth of 1,595 meters ( 873 fathoms).

\section{AMPHIOPHIURA INSOLITA (Kohler).}

Plate 84, figs. 8, 9.

Ophioglypha insolita KoEHLER ('04), p. 47, pl. 7, figs. 4-6.-H. L. Cr.ARK ('08), p. 295.

Amphiophiura insolita Matsumoto ('15), p. 77.-H. L. Clark ('15), p. 315.-MATSUmoto ('17), p. 261.

Localities.-Albatross station 5268; Verde Island Passage and Batangas Bay; Matocot Point bearing S. $50^{\circ}$ E., 10.75 kilometers (5.8 miles) distant (lat. $13^{\circ} 42^{\prime} 00^{\prime \prime} \mathrm{N}$., long. $120^{\circ} 57^{\prime} 15^{\prime \prime}$ E.) ; 311 meters (170 fathoms); June 8, 1908; S., P.

Two specimens (Cat. No. 41116, U.S.N.M.).

Albatross station 5289; China Sea, in the vicinity of southern Luzon; Matocot Point bearing S. $42^{\circ}$ E., 9.26 kilometers ( 5 miles) distant (lat. $13^{\circ} 41^{\prime} 50^{\prime \prime}$ N., long. $120^{\circ} 58^{\prime} 30^{\prime \prime}$ E.) ; 256 meters (140 fathoms); July 22, 1908; brk. Sh., S.

Nine specimens (Cat. No. 41113 , U.S.N.M.).

Albatross station 5297; Matocot Point bearing S. $50^{\circ}$ E., 9.45 kilometers (5.1 miles) distant (lat. $13^{\circ} 41^{\prime} 20^{\prime \prime}$ N., long. $120^{\circ} 58^{\prime} 00^{\prime \prime} \mathrm{E}$.) ; 362 meters (198 fathoms); July 24, 1908; M., S. 
Eighteen specimens (Cat. Nos. 41117, 41118, U.S.N.M.).

Albatross station 5366; Batangas Bay, Luzon; Escarceo Light bearing S. $5^{\circ}$ E., 14.27 kilometers ( 7.7 miles) distant (lat. $13^{\circ} 39^{\prime}$ $00^{\prime \prime}$ N., long. $120^{\circ} 58^{\prime} 30^{\prime \prime}$ E.) ; 439 meters (240 fathoms); February 22,1909 .

Twelve specimens (Cat. No. 41115, U.S.N.M.).

Albatross station 5420; between Cebu and Bohol; Cruz Point (Bohol) bearing S. $20^{\circ}$ E., 11.1 kilometers (6 miles) distant (lat. $9^{\circ} 49^{\prime} 35^{\prime \prime}$ N., long. $123^{\circ} 45^{\prime} 00^{\prime \prime}$ E.); 231 meters (127 fathoms); March 25, 1909.

Twelve specimens (Cat. No. 41172, U.S.N.M.).

Albatross station 5476; east coast of Luzon; San Bernardino Strait to San Miguel Bay; San Bernardino Light bearing S. $37^{\circ}$ W., 25.01 kilometers (13.5 miles) distant (lat. $12^{\circ} 56^{\prime} 24^{\prime \prime}$ N., long. $124^{\circ}$ $25^{\prime} 24^{\prime \prime}$ E.) ; 494 meters (270 fathoms) ; June 24, 1909.

Two specimens (Cat. No. 41114, U.S.N.M.).

Notes.-The diameter of the disk varies between $4 \mathrm{~mm}$. and $14 \mathrm{~mm}$.

In the grouping which he gave in 1908 of the species of Ophiura belonging to the variabilis group, H. L. Clark remarked that $O$. insolita also belongs to this group, but that it is incorrect to say, as I have just done, that the second mouth tentacle pores open into the mouth slits. I have considered this point in the remarks which I have made above regarding the arrangement of these pores in the species of the genera Ophiura, Amphiophiura, etc..

\section{AMPHIOPHIURA PAUPERA (Kohler).}

Plate 84, figs. 6, 7.

Ophioglypha paupera Karhler ('96), p. 200, pl. 5, figs. 11-13; ('99), p. 11.

Amphiophiura paupera Matsumoto ('15), p. 77.-H. L. Clark ('15), p. 313.-матsumoto ('17), p. 261.

Locality. Albatross, station 5274; China Sea, in the vicinity of southern Luzon; Malavatuan Island (N.) bearing S. $73^{\circ} 30^{\prime}$ E., 32.43 kilometers (17.5 miles) distant (lat. $13^{\circ} 57^{\prime} 30^{\prime \prime} \mathrm{N}$., long. $120^{\circ} 03^{\prime}$ $25^{\prime \prime}$ E.) ; 960 meters (525 fathoms); July 16, 1908; gy. M., S.

A single specimen (Cat. No. 41143 , U.S.N.M.).

Notes.-This species was discovered by the Investigator among the Laccadive Islands and on the Malabar coast at depths of 743 and 1,289 meters (406 and 705 fathoms).

\section{AMPHIOPHIURA RADIATA (Lyman).}

Ophioglypha radiata LyMAN ('77), p. 89 , pl. 3 , figs. 65,66 ; ('82), p. 64, pl. 7 , figs. 1-3.-KGHLER ('96), p. 300 ; ('99), p. 19 ; ('04), p. 55.

amphiophiura radiata Matsumoto ('15), p. 78.-H. L. Clark ('15), p. 313.-Matsumoto ('17), p. 262. 
Locality.-Albatross station 5601 ${ }^{a}$; Gulf of Tomini, Celebes; Limbe Island (NE.) bearing N., 38.36 kilometers (20.7 miles) distant (lat. $1^{\circ} 13^{\prime} 10^{\prime \prime}$ N., long. $125^{\circ} 17^{\prime} 05^{\prime \prime}$ E.) ; 1,399 meters (765 fathoms) ; November 13, 1909; S., Glob., Ptr.

A small specimen (Cat. No. 41176, U.S.N.M.).

Notes.-The diameter of the disk does not exceed $5 \mathrm{~mm}$.

The Challenger discovered this species among the Philippine Islands at a depth of 1,920 meters (1,050 fathoms), and the Siboga met with it at neighboring stations between 1,158 and 2,053 meters (635 to 1,122 fathoms). The Investigator also dredged it at Minicoy in 2,195 meters ( 1,200 fathoms).

Synonym:

\section{AMPHIOPIIURA SCULPTILIS (Lyman).}

Ophioglypha variabilis LYMAN.

See for bibliography:

Ophioglypha sculptilis KaELER ('14), p. 24.

Amphiophiura sculptilis Matsumoto ('15), p. 77 ; ('17), p. 261.-H. L. CLaRK ('15), p. 313.

Locality.-Albatross station 5639; Molucca Sea; Cape Pamali (Wowoni Island) (N.) bearing S. $77^{\circ}$ W., 43.44 kilometers (27 miles) distant (lat. $3^{\circ} 54^{\prime} 50^{\prime \prime}$ S., long. $123^{\circ} 27^{\prime} 20^{\prime \prime} \mathrm{E}$.) ; 2,853 meters (1,560 fathoms) ; December 13,$1909 ;$ gy. M.

Two specimens (Cat. No. 41152 , U.S.N.M.).

Notes. - The diameter of the disk is between $11 \mathrm{~mm}$. and $12 \mathrm{~mm}$. In one of the two specimens the large marginal plate which delimits the vertical sides of the disk in the interradial spaces is replaced by two contiguous plates; in the other, this modification occurs in four of these spaces, so that only a single interradius shows the usual arrangement.

I discussed the identity of this species with $\mathrm{O}$. variabilis as well as its geographical distribution in my memoir of 1914, cited above.

AMPHIOPHIURA SORDIDA (Kœhler).

Plate 84, figs. 12, 13.

Ophioglypha sordida KaHleR ('96), p. 292, pl. 5, figs. 14, 15; ('99), p. 13, pl. 5, figs. $39-41$; ('04), p. 47.

Amphiophiura sordida Matsumoto ('15), p. 77.-H. L. Clark ('15), p. 314.-Matsumoto ('17), p. 261.

Localities.-Albatross station 5299; China Sea, in the vicinity of southern Luzon (lat. $20^{\circ} 05^{\prime} 00^{\prime \prime}$ N., long. $116^{\circ} 05^{\prime} 00^{\prime \prime}$ E.) ; 958 meters (524 fathoms); August 8, 1908.

Five specimens (Cat. No. 40980, U.S.N.M.).

Albatross station 5300; China Sea, in the vicinity of southern Luzon (lat. $20^{\circ} 31^{\prime} 00^{\prime \prime}$ N., long. $115^{\circ} 49^{\prime} 00^{\prime \prime}$ E.) ; 485 meters (265 fathoms) ; August 8, 1908; gy. M., S. 
One hundred and fifteen specimens (Cat. Nos. 40977, 40979, 41081, U.S.N.M.).

Albatross station 5551; Joló Island and vicinity: Joló Light (E.) bearing N. $60^{\circ}$ E., 33.36 kilometers (18 miles) distant (lat. $5^{\circ} 54^{\prime}$ $48^{\prime \prime}$ N., long. $120^{\circ} 44^{\prime} 24^{\prime \prime}$ E.) ; 353 meters (193 fathoms) ; September 17,1909 ; fne. $S$.

Two specimens (Cat. No. 40982, U.S.N.M.).

Albatross station 5585; Sibuko Bay, Borneo, and vicinity; Sipedan Island (M.) bearing S. $89^{\circ} \mathrm{W}$., 19.84 kilometers (12 miles) distant (lat. $4^{\circ} 07^{\prime} 00^{\prime \prime}$ N., long. $118^{\circ} 49^{\prime} 54^{\prime \prime}$ E.) ; 870 meters ( 476 fathoms) ; September 28, 1909 ; gy. M.

Two specimens (Cat. No. 40984, U.S.N.M.).

Albatross station 5619; Molucca Passage; March Island (S.) bearing S. $78^{\circ}$ E., 12.97 kilometers ( $T$ miles) distant (lat. $0^{\circ} 35^{\prime} 00^{\prime \prime} \mathrm{N}$., long. $127^{\circ} 14^{\prime} 40^{\prime \prime}$ E.) ; 796 meters (435 fathoms); November 27 , 1909 ; fne. gy. S., M.

One specimen (Cat. No. 40981, U.S.N.M.).

Albatross station 5648; Buton Strait; North Island (S.) bearing N. $87^{\circ}$ E., 18.90 kilometers (10.2 miles) distant (lat. $5^{\circ} 35^{\prime} 00^{\prime \prime}$ S., long. $122^{\circ} 20^{\prime} 00^{\prime \prime}$ E.) ; 1,022 meters (559 fathoms) ; December 16, 1909 ; gn. M.

One specimen (Cat. No. 40976, U.S.N.M.).

Albatross station 5651; Gulf of Boni, Celebes; Buginkali Point bearing S. $67^{\circ}$ T., 38.92 kilometers (21 miles) distant (lat. $4^{\circ} 43^{\prime}$ $50^{\prime \prime}$ S., long. $121^{\circ} 23^{\prime} 24^{\prime \prime}$ E.) ; 1,280 meters (700 fathoms); December 17,1909 ; gn. M.

One specimen (Cat. No. 40983, U.S.N.M.).

Albatross station 5652; Gulf of Boni ; Lamulu bearing S. $36^{\circ}$ E., 13.90 kilometers (7.5 miles) distant (lat. $4^{\circ} 35^{\prime} 00^{\prime \prime}$ S., long. $121^{\circ}$ $23^{\prime} 06^{\prime \prime}$ E.) ; 959 meters (525 fathoms); December 17, 1909 ; gn. M.

One specimen (Cat. No. 40978 U.S.N.M.).

Notes.-Amphiophiura sordida was discovered by the Investigator among the Andaman Islauds in 1,026 meters (561 fathoms); the Siboga found it again in different localities among the Sunda Islands at depths varying from 411 to 959 meters (226 to 525 fathoms).

\section{AMPHIOPHIURA SPATULIFERA, new species.}

Plate 82 , figs. $5-8,13$.

Localities.-Albatross station 5274; China Sea, in the vicinity of southern Luzon; Malavatuan Island (N.) bearing S. $73^{\circ} 30^{\prime}$ E., 32.43 kilometers (17.5 miles) distant (lat. $13^{\circ} 57^{\prime} 30^{\prime \prime} \mathrm{N}$., long. $120^{\circ}$ $03^{\prime} 25^{\prime \prime}$ E.) ; 959 meters (525 fathoms) ; July 16, 1908; gy. M., S.

One specimen (Cat. No. 41074, U.S.N.M.).

Albatross station 5425; Joló Sea; Cagayan Island (S.) bearing S. $14^{\circ}$ E., 7.41 kilometers ( 4 miles) distant (lat. $9^{\circ} 37^{\prime} 45^{\prime \prime} \mathrm{N}$., 
long. $121^{\circ} 11^{\prime} 00^{\prime \prime}$ E.) ; 905 meters (495 fathoms) ; March 31, 1909 ; gy. M., co. S.

One specimen (Cat. No. 41075 , U.S.N.M.).

Description.-The specimen from station 5274 is the larger, and the diameter of its disk reaches $9 \mathrm{~mm}$.; in the other this diameter does not exceed $6 \mathrm{~mm}$. The arms are incomplete; the longest are preserved over a length of from $12 \mathrm{~mm}$. to $14 \mathrm{~mm}$., and they scarcely could have much exceeded this length.

These two specimens show a slightly different arrangement of the plates of the dorsal surface of the disk, which appears solely due to a difference in age. I shall consider them individually, designating the one from station 5245 by the letter $A$ and that from station 5274 by the letter $B$.

The disk is pentagonal, thick, with both the dorsal and the ventral surfaces a little convex. In $\mathrm{A}$, in which the plates of the dorsal surface of the disk are less numerous than in the other, they are very large, and in the very narrow intervals which they leave between them there are intercalated a few small plates. The plates of the primary rosette are very large, and they cover almost half of the surface of the disk. The dorso-central is pentagonal and in contact for the whole extent of its margin with the primary radials, which are quadrangular, with a strongly convex distal border, and a little broader than long. These five radial plates are also in contact with each other. In the interradial spaces there are three large successive plates, the first rounded, and the second quadrangular and almost as long as broad; the third, which is also quadrangular, is found at the periphery of the disk of which it delimits the vertical face, and only its very narrow border is visible when the animal is viewed from above. In the radial spaces there is found only a small plate which is broader than long and triangular in shape with the angles rounded. This plate separates the two radial shields of each pair for a small part of their length at their proximal extremities. A few other very small rounded plates also appear here and there, especially toward the distal border of the five primary radials. The radial shields are not larger than these latter; they are triangular with the proximal angle very obtuse and rounded, or sometimes irregularly quadrangular, and almost as long as broad; their length exceeds a third of the radius of the disk. The two shields of each pair are in contact throughout the greater part of their length. The radial papillae are rather long, somewhat flattened and broadened, and broadening especially in their distal half, in such a way as to assume a more or less spatulate form; these papillae are very close together.

In specimen B the plates of the dorsal surface of the disk are more numerous and the large plates are relatively smaller than in $\mathrm{A}$. The six primary plates are of the same size and their shape is rounded; 
the five radials touch the dorso central only by a rounded proximal angle; furthermore, they are separated from each other for their entire length by three or four small plates which do not occur in $\mathbf{A}$. The two large interradial plates are smaller, but the third plate, which lies at the periphery of the disk, extends much farther over the dorsal surface than in $\mathbf{A}$. The radial shields are triangular and in contact only for a little more than half of their length. The radial papillae are more developed than in the first specimen, and their spatulate form is still more pronounced.

The ventral surface of the disk is almost entirely occupied by the mouth shields, which are extremely large. In A, beyond each shield, there is the lower part of the vertical interradial plate which I have noticed above, and which covers only an extremely narrow portion of this surface. The remainder is occupied on either side by a rather large triangular genital plate which disappears toward the middle of the length of the mouth shield and which carries on its free border broad and obtuse papillae which are relatively large and few in number. In $B$ the mouth shields are still larger and the vertical interradial plate is not visible on the ventral surface; these shields cover the whole ventral surface of the disk in the interradial spaces, and the genital plates are themselves very much smaller than in A.

As I have just said, the mouth shields are very large, and they occupy the whole ventral surface of the disk except for the more or less reduced portion occupied by the genital plate. They are pentagonal in form with a very rounded proximal angle bordered by two small excavated sides; this excavation corresponds to the proximal end of the genital slit; the sides are rounded and they pass over by a very rounded edge to the straight distal border. In $A$ these shields are almost as long as broad; in B they are a little broader than long and the proximal angle is replaced by a rounded border. The adoral plates are narrow and elongated, with a rather sinuous outline; they are a little broader inwardly than outwardly. The oral plates are large, twice as long as broad, with the borders parallel. The mouth papillae are six or seven in number on either side in $\mathrm{A}$, but their outlines are not very distinct; the external papilla is low and broadened; the following are rounded. In $B$ the papillae are a little larger, and I can only count four of them; the outermost is rounded. The unpaired terminal papilla is conical, and a little larger than those on either side.

The arms are of medium width, but the segments of which they are composed become very much elongated beyond the disk.

The first upper arm plate is rather large, trapezoidal, very much broader than long, with the distal border convex. The second is triangular, as broad as long, with the angles sharp and the distal border convex. Farther out, the plates are separated by an interval which 
becomes promptly very long; and they remain a little broader than long and triangular in shape.

The first under arm plate is large, triangular, and as broad as long. The two or three following plates are quadrangular with the proximal border narrow, the distal border very broadened and convex, and the sides strongly excavated by the tentacle pores. Beyond the plates become progressively elongated and pentagonal with an obtuse proximal angle bounded by two short straight sides, two lateral borders strongly excavated by the tentacle pores, and a very broad and very convex distal side which is often resolved into two short sides united by an obtuse angle. Beyond the disk these plates are separated and the interval between them soon becomes very long.

The side arm plates are much elongated. They carry only three small papilliform spines which are very short and rather widely separated from each other; one of the spines is situated toward the middle of the distal border, and the two others occur respectively in the vicinity of each angle, the dorsal and the ventral, of the plates.

The tentacle pores of the three or four first pairs are very large. Those of the first pair are widely open at their proximal end, which is very close to the corresponding mouth slit; they usually show on either side four large scales, and sometimes five. The pores of the second pair bear four scales outwardly, and three or four inwardly; the pores of the third pair have usually three scales on each border, and those of the fourth pair two only; then the number of the scales progressively diminishes, and there remains only a single proximal scale.

The color of the specimen in alcohol is white.

Affinities and distinctive features.-Amphiophiura spatulifera is close to $A$. oediplax, which H. L. Clark described from specimens from Japan, collected in between 322 and 448 meters (176 and 245 fathoms) of water. The type of this species was of small size, and the diameter of the disk did not exceed $5 \mathrm{~mm}$., the arms being $12 \mathrm{~mm}$. in length. The species from the Philippines differs from it in the presence of small plates intercalated between the large plates of the dorsal surface of the disk, which are especially numerous in specimen $B$, in the occurrence of two large interradial plates instead of only one, in the form of the radial papillae, which are more elongated and broadened in their outer portion so as to assume a spatulate form, and in having the mouth shields broader, the tentacle scales larger, the upper arm plates broadly triangular, and three small arm spines instead of only one.

Amphiophiura oediplax is itself near A. bullata (Wyville Thomson) and $A$. convexa (Lyman), but A. spatulifera differs considerably from these species and can not in any way be confused with them. 
AMPHIOPHIURA STELLATA (Studer).

Ophioglypha stellata Studer ('82), p. 11, pl. 1, fig. 5.-Kahler ('98), p. 59, pl. 2, figs. 3-5.

Amphiophiura stellata Matsumoto ('15), p. 77.-H. L. Clark ('15), p. 314.-Matsumoto ('17), p. 261.

Locality.-Albatross station 5400 ; north of Cebu; Tanguingui Island Light bearing $\mathrm{N} .77^{\circ} \mathrm{W} ., 41.70$ kilometers (22.5 miles) distant (lat. $11^{\circ} 24^{\prime} 24^{\prime \prime}$ N., long. $124^{\circ} 05^{\prime} 30^{\prime \prime}$ E.) ; 46 meters (25 fathoms); March 16, 1909 ; S., Sh.

One specimen (Cat. No. 41188 , U.S.N.M.).

Notes. - The specimen agrees well with those I described in 1898 which were collected by the Investigator among the Andaman Islands in from 37 to 64 meters ( 20 to 35 fathoms). The type was found by the Gazelle at Amboina and on the western coast of Australia at a depth of from 5 to 7 meters (3 to 4 fathoms).

STEGOPHIURA SLADENI (DunCan).

Plate 83 , figs. $4-7$; plate 84 , fig. 1.

Ophioglypha sladeni Duncan ('79), p. 458, pl. 9, figs. 9-11.

Ophiura stiphra H. L. ClARK ('11), p. 83, fig. 25.

Stegophiura sladeni Matsumoto ('15), p. 79.-H. L. Clark ('15), p. 317.Matsumoto ('17), p. 259, fig. 12.

Locality.-Hakodate.

Fifteen specimens (Cat. Nos. 41376,41377 , U.S.N.M.).

Notes.-The average diameter of the disk is $15 \mathrm{~mm}$.

The specimens agree well with H. L. Clark's description and figure.

In 1915 Matsumoto showed that Ophiura stiphra, described as a new species by H. L. Clark in 1911 , is a synonym of $O$. sladeni, which Duncan described from specimens from Korea (Chosen), and this has been accepted by H. L. Clark. Sladen's description is fairly good, but his figures are very schematic, and they are even somewhat inexact, especially figure 11 , which shows a side view of the arm and which is entirely erroneous. These figures certainly would not permit the recognition of the species.

The specimens upon which H. L. Clark described his Ophiura stiphra all came from different stations off southern Japan at which the depth varied between 44 and 152 fathoms (Honshu Island, Ose Zaki, Kagoshima Gulf, and the Korean Straits).

As H. L. Clark has remarked ('11, p. 84), S. sladeni is very close to S. sterea (H. L. Clark), which is also a Japanese form, and the two species are distinguished especially by the characters of the arm spines. I have not found $S$. sterea in the collection which was sent to me, but I have been able to study this species from a specimen which the United States National Museum had the kindness to give me and which had been determined by H. L. Clark. It came from Honshu Island (station 3771, 61 fathoms, or 111 meters). I have 55269-22-Bull. $100-24$ 
thought it well to include here some photographs of $S$. sterea and of S. sladeni, not only to facilitate comparison between the two species but also to permit of distinguishing both of them from a new species which I am describing below under the name of $S$. steritis.

The arm spines are all very distinct in S. sterea, while in S. sladeni the secondary spines are united into a sort of fringe (pl. 83, figs. 3 , 6, 7; see also Matsumoto '17, figs. 71, 72). The very marked median prominence which the first under arm plates show in $S$. sladeni is also very characteristic of this species. In the specimen of $S$. sterea which I have at hand the two first under arm plates have the median region very swollen, thus giving a first indication of that keel which becomes so developed in S. sladeni.

In both species the radial shields have the same shape, and the two shields of each pair are very strongly divergent and very broadly separated inwardly, and their respective median lines form with each other a very obtuse angle.

\section{STEGOPHIURA STERILIS, new species.}

Plate 83, figs. 8-11.

Locality.-Albatross station 5301; China Sea, in the vicinity of Hongkong (lat. $20^{\circ} 37^{\prime} 00^{\prime \prime}$ N., long. $115^{\circ} 43^{\prime} 00^{\prime \prime}$ E.) ; 380 meters (208 fathoms); August 8, 1908; gy. M., S.

Thirty-two specimens (Cat. Nos. 41379, U.S.N.M.).

Description.- The diameter of the disk varies between $12 \mathrm{~mm}$. and $15 \mathrm{~mm}$. In the specimen of which I give photographs ( $\mathrm{pl}$. 83 , figs. $8-11$ ) the diameter of the disk is $15 \mathrm{~mm}$., and the arms are from $45 \mathrm{~mm}$. to $50 \mathrm{~mm}$. in length. The two surfaces of the disk are flattened, and they are united by rounded borders; the height is $4 \mathrm{~mm}$. The arms are almost as high as broad, and their section is a triangle with a rounded apex; their width at the base is $4 \mathrm{~mm}$., and this width diminishes rather slowly to the tip.

The dorsal surface of the disk is covered with rather numerous, unequal, irregular, polygonal or rounded plates, among which can be distinguished a large pentagonal dorso-central with the angles and the sides rounded and five primary radials each separated from it by a small plate. These primary radials stand out less by their size, which is not greater than that of the other plates of the disk, than by their slightly darker coloration and rather peculiar form; they are pentagonal, narrow, and almost three times as long as broad, with an obtuse proximal angle and a straight distal border. The other plates are irregularly arranged. In the median radial line there is a rather large triangular plate separating the proximal extremities of the two radial shields of each pair. In the interradii there are usually four rows of plates between the radial shields, and 
none of these plates are conspicuous by their size. The radial shields are large, triangular, half again as long as broad, and their length is slightly more than a third of the radius of the disk. The two shields of each pair are separated outwardly for a quarter or a fifth of their length by the first upper arm plate which is triangular and transversely broadened, and inwardly over a somewhat greater distance by the triangular radial plate mentioned above; these shields are therefore in contact in their middle portion for about a third of their length. The papillae of the radial combs are much elongated, fine, and close together, and below them may be distinguished a small supplementary comb.

The ventral surface of the disk is covered with plates which are few in number, rounded, subequal, and slightly imbricated. The genital slits are narrow. The genital plates are also narrow and they are provided with papillae which are all very obtuse and short, but which rapidly become elongated at the periphery of the disk.

The mouth shields are large, longer than broad, pentagonal, with an obtuse proximal angle and a very strongly convex distal border; the lateral borders are slightly notched by the bottom of the genital slits. The adoral plates are narrow, strongly tapering in their outer quarter, and more broadened inwardly. The oral plates are high and broad. The lateral mouth papillae are five in number; the four outer are small and somewhat irregular; the last is elongated, conical, and almost of the same size as the neighboring unpaired terminal papilla.

The first upper arm plate is rather large, triangular, broader than long, with a very obtuse and very rounded proximal angle; it separates the distal portions of the two radial shields of each pair. The second plate, smaller and narrower than the preceding, is rectangular or trapezoidal; it lies between the radial combs. The third is very much larger, trapezoidal in shape, twice as broad as long. The fourth is still broader, though scarcely longer than the preceding. The width of the following plates diminishes beyond the fifth, while their length increases; these plates then become hexagonal, with the proximal border straight and a little longer than the distal border, which is also straight, and lateral borders each formed by two short straight sides united by an obtuse angle. The length is at first less than the width; they then become little by little as long as broad, remaining broadly in contact, and finally longer than broad. The two ends, the proximal and the distal, become shorter and shorter so that the plates assume a lozenge-shaped form and toward the extremity of the arms they are twice as long as broad and barely in contact by their adjacent angles.

The first under arm plate is large, hexagonal, with the proximal border slightly excavated and the distal border somewhat rounded; 
it is somewhat broader than long. The following plates become larger and broader, quadrangular, with the proximal border narrower than the distal border, which is always rounded; the lateral borders, which are slightly divergent, are excavated by the tentacle pores. At some distance from the disk these plates become as long as broad, and then longer than broad, while at the same time their proximal border becomes more and more reduced, being finally replaced by an acute angle. The plates then become lozenge-shaped, a little longer than broad; their length then diminishes and they become separated by a space which elongates little by little; at last they become very small and a little broader than long. The four first plates have their ventral surface much swollen in the median region, though without forming a true keel as in S. stadeni.

The side arm plates are very high. They bear spines the arrangement of which recalls strongly that in S. sterea - that is to say, the greater part of their free border is occupied by a series of narrow and pointed spines closely crowded against each other and appressed against the lateral surfaces of the arm, of which the outlines are very distinct; these are the secondary spines of $\mathrm{H}$. L. Clark. Independently of these there occurs toward the ventral border of the plate a group of three larger and longer conical and pointed spines which are at first subequal, though the second spine soon becomes broader than the two others. At the dorsal angle of the side arm plates there is another spine, smaller than the preceding, and finally, at some distance from this dorsal spine, toward the upper third of the plate, there is a fifth spine. The secondary spines number about 15 at the base of the arms, the number progressively diminishing, while at the same time the primary spines also become reduced, and the number of the ventral spines falls to two, so that in the last third of the arm there remain only four small spines separated by two or three secondary spines.

The tentacle pores are very large; those of the first pair bear seven or eight scales on either side, and they open immediately below the mouth slits. The following pores are very large over a considerable number of arm segments; their scales, which number seven or eight on the proximal border and six or seven on the distal, decrease progressively to four; the distal scales then disappear little by little, except for the last, which persists for a considerable time; the number of the proximal scales remains at six or five over a rather considerable portion of the arms; the number then falls rapidly to four, to three, and to two.

Affinities and distinctive features.-Stegophiura sterilis is close to S. sterea (H. L. Clark) and S. sladeni (Duncan), and it is because of these affinities that I have retained it in the genus Stegophiura; but it is indubitable that it occurs on the limits of that genus and 
that it might quite as well be placed in the genus Amphiophiura. While $S$. sladeni and $S$. sterea have the arms short, very stout, and broadened at the base, thence decreasing rapidly in breadth, the new species does not have the arms much broadened at the base, and their width decreases rather slowly; furthermore, the arms are markedly longer than those of the two species which $I$ have just mentioned. As I have already had occasion to remark, the dividing line between the genera Stegophiura and Amphiophiura is not a sharp one.

This difference in the form of the arms thus immediately separates $S$. sterilis from $S$. sterea and S. sladeni. Another difference is found in the radial shields; these, which are a little longer and broader in the new species, are not divergent; they are in contact only in their central portion, and the inner borders of the two shields of each pair are parallel instead of separating and diverging considerably as in S. sterea and $S$. stadeni. The mouth shields are also a little more elongated. The absence of a true keel on the first under arm plates recalls $S$. sterea. The arrangement of the arm spines also recalls that species, though the secondary spines are closer together and tend to form a fringe comparable to that seen in S. sladeni; in $S$. sterea these secondary spines are more independent of each other and thus more resemble the primary true spines, from which it is sometimes difficult to distinguish them, and which are more numerous than in S. sladeni.

\section{OPHIURA AEQUALIS Lyman.}

Plate 81, figs. 2, 6, 10.

Ophioglypha aequalis LrMAN ('78), p. 72, pl. 3, figs. 74, 75; ('82), p. 45, pl. 4, figs. 14, 15.-K KEHLER ('96), p. 297, pl. 6, fig. 19; ('99), p. 16, pl. 5, fig. 38; ('04), p. 55.

Ophiura aequalis Matsumoto ('15), p. 81.-H. L. Clark ('15), p. 318.MATSUMOTO ('17), p. 267.

Localities.-Albatross station 5332; Mindoro Strait; Apo Light bearing S. $66^{\circ}$ W., 33.73 kilometers (18.2 miles) distant (lat. $12^{\circ}$ $47^{\prime} 15^{\prime \prime}$ N., long. $120^{\circ} 41^{\prime} 00^{\prime \prime}$ E.) ; 1,363 meters (745 fathoms); December 12,1908 ; gn. M.

One specimen (Cat. No. 41337, U.S.N.M.).

Albatross station 5471; east coast of Luzon, San Bernardino Strait to San Miguel Bay; Sialat Point Light bearing N. $71^{\circ}$ E., 27.80 kilometers (15 miles) distant (lat. $13^{\circ} 34^{\prime} 57^{\prime \prime} \mathrm{N}$., long. $123^{\circ} 47^{\prime} 06^{\prime \prime}$ E.) ; 1,039 meters (568 fathoms); June 19, 1909.

One specimen (Cat. No. 41319, U.S.N.M.).

A7batross station 5601a; Gulf of Tomini, Celebes; Limbe Island (NE.) bearing N., 38.36 kilometers (20.7 miles) distant (lat. $1^{\circ} 13^{\prime}$ $10^{\prime \prime}$ N., long. $125^{\circ} 17^{\prime} 05^{\prime \prime}$ E.) ; 1,399 meters (765 fathoms); November 13 , 1909 ; gy. M. 
One specimen (Cat. No. 41315, U.S.N.M.).

Albatross station 5605; Gulf of Tomini, Celebes; Dodepo Island (W.) bearing $\mathrm{N} .14^{\circ} \mathrm{W} ., 10.93$ kilometers (5.9 miles) distant (lat. $0^{\circ} 21^{\prime} 33^{\prime \prime}$ N., long. $121^{\circ} 34^{\prime} 10^{\prime \prime}$ E.) ; 1,183 meters (647 fathoms); November 16, 1909.

One specimen (Cat. No. 41317 , U.S.N.M.).

Albatross station 5612; Gulf of Tomini, Celebes; Buka Buka Island (E.) bearing S. $3^{\circ}$ E., 12.97 kilometers $(7$ miles) distant (lat. $0^{\circ} 38^{\prime} 00^{\prime \prime}$ S., long. $121^{\circ} 45^{\prime} 40^{\prime \prime}$ E.) ; 1,371 meters ( 750 fathoms) ; November 20, 1909.

Two specimens (Cat. No. 41316, U.S.N.M.).

Albatross station 5647; Buton Strait; North Island (S.) bearing S. $87^{\circ}$ E., 21.50 kilometers (11.6 miles) distant (lat. $5^{\circ} 34^{\prime} 00^{\prime \prime}$ S., long. $122^{\circ} 18^{\prime} 15^{\prime \prime}$ E.) ; 949 meters (519 fathoms); December 16 , 1909 ; gn. M.

One specimen (Cat. No. 41318 , U.S.N.M.).

Albatross station 5648; Buton Strait; North Island (S.) bearing N. $87^{\circ}$ E., 18.90 kilometers (10.2 miles) distant (lat. $5^{\circ} 35^{\prime} 00^{\prime \prime}$ S., long. $122^{\circ} 20^{\prime} 00^{\prime \prime}$ E.) ; 1,022 meters (559 fathoms); December 16 , 1909 ; gn. M.

One specimen (Cat. No. 41338 , U.S.N.M.).

Notes.-In my memoir of 1896 I supplemented and corrected Lyman's description, and I find the characters typical for the species in the Albatross specimens. The spines, which are four or five in number on the first arm segments, may subsequently reach six. I include here three photographs of the specimen from station 5647 (pl. 81, figs. 2, 6, 10).

Lyman's type came from the vicinity of New Guinea (depth 1,957 meters $[1,070$ fathoms $]$ ). The Investigator found $O$. aequalis in the Laccadive and Andaman Islands, in 896 and 2,194 meters (490 and 1,200 fathoms), and the Siboga in the Sunda Archipelago (828 to 1,788 meters, or 455 to 980 fathoms).

\section{OPHIURA CLEMENS (Kœhler).}

Ophioglypha clemens KoEHLER ('04), p. 51, pl. 8, figs. 7-9; ('07), p. 260; ('07a), p. 291.

Ophiura clemens Matsumoto ('15), p. 81.-H. L. Clark ('15), p. 319.Matsumoto ('17), p. 268.

Localities. - Albatross station 5348; Palawan Passage; Point Tabonan bearing S. $89^{\circ}$ E., 62.08 kilometers (33.5 miles) distant (lat. $10^{\circ} 57^{\prime} 45^{\prime \prime}$ N., long. $118^{\circ} 38^{\prime} 15^{\prime \prime} \quad$ E.) ; 686 meters (375 fathoms) ; December 27, 1908; Co., S.

Three specimens (Cat. No. 41192, U.S.N.M.).

Albatross station 5467; east coast of Luzon; San Bernardino Strait to San Miguel Bay; Atulayan Island (S.) bearing S. $79^{\circ}$ W., 4.63 
kilometers (2.5 miles) distant (lat. $13^{\circ} 35^{\prime} 27^{\prime \prime}$ N., long. $123^{\circ} 37^{\prime}$ $18^{\prime \prime}$ E.) ; 787 meters (480 fathoms) ; June 18, 1909; gy. M. (m. b.).

One specimen (Cat. No. 41191, U.S.N.M.).

Notes.-Ophiura clemens has a rather wide geographical range. I based the species on specimens from the Siboga collection dredged in numerous localities among the Sunda Islands between 694 and 1,633 meters (382 to 892 fathoms). The Travailleur and of the Talisman expeditions had previously found it in the Gulf of Gascony in 1,916 meters ( 1,013 fathoms).

\section{OPHIURA FLAGELlata Lyman.}

Plate 85 , figs. $1,6,7$; plate 86 , figs. $1-4,10$.

See for bibliography:

Ophioglypha flagellata KGHLER ('04), p. 56; ('07a), p. 261.

Ophiura flagellata H. L. Clark ('11), p. 60 ; ('13), p. 208.-Matsumoto ('15), p. 81.-H. L. Crark ('15), p. 320.

Gymnophiura coerulescens LüTKEN and MORTENSEN ('99), p. 114.

Localities.-Albatross station 5582; in the vicinity of Darvel Bay, Borneo; Si Amil Island (N.) bearing S. $22^{\circ}$ W., 11.49 kilometers (6.2 miles) distant (lat. $4^{\circ} 19^{\prime} 54^{\prime \prime}$ N., long. $118^{\circ} 58^{\prime} 38^{\prime \prime}$ E.) ; 1,628 meters (890 fathoms); September 26, 1909; gy. M., fne. S.

One specimen (Cat. No. 41147, U.S.N.M.).

Albatross station 5647; Buton Strait; North Island (S.) bearing S. $87^{\circ}$ E., 21.50 kilometers (11.6 miles) distant (lat. $5^{\circ} 34^{\prime} 00^{\prime \prime} \mathrm{S}$., long. $122^{\circ} 18^{\prime} 15^{\prime \prime}$ E.) ; 949 meters (519 fathoms); December 16, 1909 ; gn. M.

Three specimens (Cat. No. 41146, E. 191, U.S.N.M.)

Albatross station 5651; Gulf of Boni, Celebes; Buginkali Point bearing $\mathrm{S} .67^{\circ} \mathrm{E} ., 38.92$ kilometers (21 miles) distant (lat. $4^{\circ} 43^{\prime} 50^{\prime \prime}$ S., long. $121^{\circ} 23^{\prime} 24^{\prime \prime}$ E.) 1,280 meters (700 fathoms) ; December 17 , 1909.

Three specimens (Cat. No. 41145 , E. 192, U.S.N.M.)

Notes.-Ophiura flagellata is a well-known and easily recognizable species which has been collected in the course of various explorations. To the descriptions of Lyman and of Lütken and Mortensen (these latter recording it under the name of Gymnophiura coerulescens) H. L. Clark has added a number of very interesting observations, especially concerning the variations which this species shows regarding the form of the radial shields, the length of the arm spines, the number of the tentacle scales, and the degree of calcification of the disk. It must also be added that variations may occur in the length of the papillae of the radia comb. H. L. Clark shows these as very long ('11, fig. 15A), as do Lütken and Mortensen ('99, p. 7, fig. 6), 
and the former states that they are longer and more delicate than Lyman's figure shows ('82, pl. 4, fig. 17). I believe that Lyman's figure may perfectly well be correct, for I find a similar form of the radial papillae in one of the Albatross specimens - that from station 5647 - of which I show the dorsal surface on plate 85 as figure 7 . These papillae are here extremely small and short and a little less conical than in Lyman's figure. But the other specimens-for example that from station 5651, of which a photograph is reproduced in figure 6-have very long, fine, and pointed radial papillae. These therefore show rather extensive variation.

I give here some photographs of $O$. flagellata which will serve as a basis for comparison with the following species, which is rather closely related to it, though I have thought it best, however, to keep the two separate. On these photographs the differences in form shown by the upper and under arm plates on the normal arms and on the parts of the arms in process of regeneration (p. 86, figs. 1, 2, $4,10)$ may also be seen. The under arm plates are relatively narrower and longer in the regenerated portions and they thus recall the form observed in the young; the differences, however, are not as marked as those shown in H. L. Clark's figure ('11, fig. 15b).

In all my specimens the mouth shields are very large, rather pentagonal in form, with the lateral borders more or less strongly excavated by the bottom of the genital slits; they are as long as broad, or even a little longer than broad; Lütken and Mortensen, as well as H. L. Clark, have also shown the mouth shields as longer than broad. On the figures published by Lyman, first in 1878 and later in 1882 , there is a lack of agreement in the form of these shields; in the figure in his bulletin ('78, p. 2, fig. 49) the shield is longer than broad, while in that in the Challenger report ('82, pl. 4, fig. 16) the shield is very much shorter, and it may be even a little broader than long. The pentagonal form with strongly excavated sides and a rather narrow distal border shown by the specimen represented on plate 86 as figure 2 is not peculiar to the A7batross specimens, for I also find it in those which were collected by the Siboga, by the Travailleur and the Talisman, and by the Investigator. I show the ventral surface of one of these last on plate 86 as figure 1.

I stated in 1907 ('07, p. 262) that O. flagellata has a rather wide geographical distribution; in 1899, in mentioning that the Chatlenger had found the species between the Philippines and the Caro. lines, I made a slight error, to which H. L. Clark called attention in 1911 ('11, p. 62); this error arose from the fact that in giving the latitude of Challenger station $232 \mathrm{I}$ wrote $15^{\circ}$ instead of $35^{\circ}$, which made me say that $O$. flagellata had been found "between the Philippines and the Carolines" instead of "in Japan." Since then, how- 
ever, $O$. flagellata has been collected in the Philippines and at different stations in the Sunda Archipelago.

Ophiura flagellata has a much wider distribution than was supposed in 1907, for the Albatross has found it as far as the Bering Sea and the Aleutian Islands to the north and in the Pacific off the coast of Mexico.

The principal localities at which 0 . flagellata has been taken, with the depths, are the following:

Challenger Iyman ('82, p. 52) $35^{\circ}$ N. latitude, $139^{\circ}$ E. longitude (Japan) ; 622 meters (340 fathoms).

Investigator Kœhler ('99, p. 19) Andaman Islands; 990 to 1,000 meters (490 to 495 fathoms).

Albatross Lüitken and Mortensen ('99, p. 114) $22^{\circ}-24^{\circ}$ N. latitude, $107-108^{\circ}$ W. longitude (off the coast of Mexico) ; 1,681 to 1,820 meters (919 to 995 fathoms).

Siboga Kœhler ('04, p. 56) $2^{\circ}$ N. $-7^{\circ}$ S. latitude, $117^{\circ}-131^{\circ}$ E. longitude (Sunda Islands); 96 to 1,264 meters (63 to 831 fathoms).

Travailleur and Talisman Kœhler ('07, p. 261) $19^{\circ}-29^{\circ} \mathrm{N}$. latitude, $14^{\circ}-20^{\circ}$ W. longitude (off the coast of the Sahara); 932 to 2,330 meters (613 to 1,533 fathoms).

Albatross H. L. Clark ('11, p. 61) $35^{\circ}-54^{\circ}$ N. latitude, $129^{\circ}-170^{\circ}$ E. longitude (Bering Sea, Aleutian Islands, Japan, etc.); 128 to 1,602 meters (70 to 876 fathoms).

Albatross Kœhler ('17) $4^{\circ}$ N. $-5^{\circ}$ S. latitude, $118^{\circ}-122^{\circ}$ E. longitude (Philippines and Sunda Islands); 949 to 1.280 meters (519 to 700 fathoms).

We thus see that $O$. Alagellata has been found at a rather large number of stations in our three great oceans-Pacific, Indian, and Atlantic-at depths varying from 96 to 2.330 meters (52.5 to 1,275 fathoms).

\section{OPHIURA FLUCTUANS, new species.}

Plate 85, figs. 2-5.

Locality.-Albatross station 5652; Gulf of Boni, Celebes; Lamulu bearing S. $36^{\circ}$ E., 13.90 kilometers (7.5 miles) distant (lat. $4^{\circ} 35^{\prime} 00^{\prime \prime}$ S., long. $121^{\circ} 23^{\prime} 06^{\prime \prime}$ E.) ; 960 meters (525 fathoms); December 17 , 1909 ; gn. M.

Two specimens (Cat. No. 41356 , U.S.N.M.).

Description.-In one of the specimens the diameter of the disk is $19 \mathrm{~mm}$; the arm which is best preserved reaches a length of $80 \mathrm{~mm}$.. and it must have had a total length of about $100 \mathrm{~mm}$. In the other specimen the diameter of the disk, which is slightly oval, measures from $14 \mathrm{~mm}$. to $15 \mathrm{~mm}$; the arms are broken off at a little distance from the base. The width of the arms at their base is $4.5 \mathrm{~mm}$. in the first specimen, $3.5 \mathrm{~mm}$. in the second. The relation between the diameter of the disk and the width of the arms is therefore $1: 4.2$ in the first and $1: 4.28$ in the second. 
The disk is rounded. The dorsal surface is depressed in the central region, which is entirely without plates and covered only by a very thin membrane of a light yellowish brown color in the larger specimen, greenish in the smaller. The uncalcified region is relatively larger in the second specimen, and from it extend ten prolongations; five radial and five interradial, which run toward the periphery of the disk, though without reaching it, and give to this membranous part a stellate form. This feature is nothing out of the ordinary, and it is observable also in specimens of 0 . flagellata of medium size ( $\mathrm{pl} .85$, fig. 6). The remainder of the dorsal surface is covered with very small, thin, transparent, imbricated plates, somewhat unequal in size, which become stouter toward the periphery of the disk and in the vicinity of the radial shields. These last are very small, triangular, longer than broad in the small specimen, almost as long as broad in the larger, in which they are relatively less developed. The papillæ of the radial comb are very large, elongated, rather thick, conical, and pointed.

The ventral surface of the disk in the interradial spaces is covered with plates larger than those of the dorsal surface. These plates are smaller toward the periphery of the disk, where they are imbricated, and they become very much larger in the vicinity of the radial shields, where the imbrication ceases. The genital slits are narrow. The genital plates are narrow and elongated; they show on their free border some papillæ which are at first small, short, and pointed, but which rapidly become elongated toward the periphery of the disk.

The mouth shields are large, triangular, with a rather open proximal angle bordered by straight sides passing over by very rounded angles into the broad and straight distal border. The form is almost the same in the two specimens; though in the larger the shields are a little broader than long, and in the smaller they are as long as broad. There is not the least trace of notching at the level of the bottom of the genital slits. The adoral plates are narrow and extremely elongated, narrowed slightly a little before their ends by the mouth tentacle pore, and they are in contact in the median interradial line. The oral plates are a little broader and very much shorter than the last. The mouth papillae number six or seven on each side; the outermost papillae is very short, low, and scarcely evident, the length then progressively increasing to the last, which is elongated, conical, and a little smaller than the terminal papilla with which it is in contact.

The three first upper arm plates, included within the notching of the disk, are small and narrow; their length increases from the first to the third; their form also varies. The third plate is already two or three times as broad as long, the width still further increasing on the two following plates, and the fifth being almost twice as broad 
as long. On the succeeding plates the length increases rather rapidly and the plates become as long as broad, then longer than broad in the distal half of the arms. These plates are always widely in contact, with the proximal border narrower than the distal, which is slightly convex, and with the lateral angles very pronounced.

The first under arm plate is large, triangular, broader than long, or simply oval and transversely broadened. The two following are quadrangular, with the proximal border very much narrower than the distal, which is much broadened; they are very much broader than long, and broadly in contact. The proximal border narrows very much on the fourth plate, and beyond the fifth it is replaced by an obtuse angle. The following plates become very much shorter and very broad, and they are separated by a space which becomes greater and greater; their distal border is sinuous, and shows a small median lobe.

The side arm plates bear three spines which are rather broad at - the base, flattened, and very pointed, of which the length increases progressively from the first to the third; the first is shorter than the segment, the second almost equals the segment, and the third is slightly longer (fig. 5).

The tentacle pores are very large and provided with numerous scales. Those of the first pair carry about six on either side; those of the second, third, and fourth pairs also have six on their proximal side, and four, and then three, on their distal side; those of the fifth pair have five proximal scales and three distal; then the number of the scales decreases little by little, the distal scales disappearing rather rapidly while the proximal scales fall to three in number and then to two.

Affinities and distinctive features.-Ophiura fluctuans is very close to $O$. flagellata, and it may be asked whether these are not really young specimens of this latter species, but such a supposition would be quite erroneous, as a comparison of specimens of the same size belonging to both species shows. I have given on plate 85 , figure 6 , the dorsal surface of $O$. flagellata, in which the diameter of the disk is $18 \mathrm{~mm}$.; it is consequently very nearly of the same size as the larger specimen of $O$. fluctuans which $I$ have just described and of which the dorsal surface is represented in figure 2 of the same plate. By comparing these two photographs the differences in the relative dimensions of the arms and of the disk are at once seen; the arms are very broad in $O$. Alagellata, while they are very narrow in $O$. fluctuans; the relation between the width of the arms and the diameter of the disk is $1: 3.3$ in the first species and $1: 4.2$ to $1: 4.3 \mathrm{in}$ the second. The upper arm plates, which are four times as broad as long on the 10 or 15 proximal arm segments in 0 . flagellata, are scarcely half again as broad as long on the six proximal segments 
in 0 . fuctuans, and they become as long as broad toward the fitteenth. The form of the mouth shields is also very different; they are larger, usually longer than broad, with a strong notch on the sides corresponding to the bottom of the genital slits in 0 . flagellata, and simply triangular, as long as broad, or even a little broader than long, with the outlines very much more simple in $O$. fluctuans. 'The arm spines are relatively stouter and thicker in $O$. flagellata, and the dorsal spine especially is more developed than in O. fluctuans. The ventral interradial areas are narrower than in $O$. flagellata, resulting from the broadening of the arms, but the plates here are more numerous and smaller than in the new species in specimens of the same size.

It has therefore not seemed to me possible to unite the two forms in the same species, and the differences which I have given, especially regarding the width of the arms and the form of the mouth shields, can not be attributed to a difference in the age of the individuals.

\section{OPHIURA IRRORATA (Lyman).}

See for the bibliography:

Ophiura irrorata H. L. ClaRK ('13), p. 209.-Matsumoto ('15), p. 81.H. L. Clark ('15), p. 320.-Matsumoto ('17), p. 277.

Ophioglypha irrorata KaHLER ('14), p. 18.

Localities.-Albatross station 5602; Gulf of Tomini, Celebes; Gorontalo Pier bearing N. 13.16 kilometers (7.1 miles) distant (lat. $0^{\circ} 22^{\prime} 00^{\prime \prime} \mathrm{N}$., long. $132^{\circ} 03^{\prime} 30^{\prime \prime}$ E.) ; 1,759 meters (962 fathoms); November 14, 1909; gy. M.

One specimen (Cat. No. 41343, U.S.N.M.).

Albatross station 5614; Molucca Passage ; Tifori Island (C.) bearing N. $19^{\circ}$ E., 56.52 kilometers (30.5 miles) distant (lat. $0^{\circ} 31^{\prime} 00^{\prime \prime}$ N., long. $125^{\circ} 58^{\prime} 45^{\prime \prime}$ E.) ; 2,012 meters (1,100 fathoms) ; November 22, 1909 ; gy. M., S., Glob.

One specimen (Cat. No. 41342, U.S.N.M.).

Notes.-The diameter of the disk is $15 \mathrm{~mm}$. in the specimen from station 5602 and $19 \mathrm{~mm}$. in the other; in both the arms are broken off near the base.

In the specimen from station 5602 the arrangement of the plates on the dorsal surface of the disk recalls one of the figures published by Lüitken and Mortensen ('99), pl. 1, fig. 10) under the name of 0 . tumulosa, with small, distinct primary plates. The mouth shields are a little broader than long; the upper arm spine is rather elongated, and its length exceeds a third of the segment. In the other specimen the primary plates are no longer distinct and the dorsal spine is very much smaller. Regarding the synonymy of this species, as well as its geographical distribution, which is very extensive, I refer to my memoir of 1914, to which I have nothing to add. 
OPHIURANS OF THE PHILIPPINE AND ADJACENT WATERS. 381

OPHIURA KINBERGI Ljungman.

Synonym:

Ophioglypha sinensis LrMaN.

See for bibliography:

Ophioglypha kinbergi KaHLER ('05), p. 22; ('07), p. 294.

Ophioglypha sinensis MacINTOSH ('11), p. 158.

Ophiura kinbergi H. L. Clark ('11), p. 37.-Matsumoto ('15), p. 81.-

H. L. Clark ('15), p. 321.-Matsumoto ('17), p. 271, fig. 73.

Localities. - Albatross station 5097; Corregidor Light bearing N. $6^{\circ}$ E., 6.67 kilometers (3.6 miles) distant (lat. $14^{\circ} 19^{\prime} 15^{\prime \prime} \mathrm{N}$., long. $120^{\circ} 33^{\prime} 05^{\prime \prime}$ E.) ; gy. M., S., Sh.

One specimen (Cat. No. 40970, U.S.N.M.).

Albatross station 5104; China Sea, off southern Luzon; Sueste Point Light bearing S. $58^{\circ}$ W., 2.39 kilometers $(1.3$ miles) distant (lat. $14^{\circ} 45^{\prime} 48^{\prime \prime}$ N., long. $120^{\circ} 12^{\prime} 20^{\prime \prime}$ E.) ; 60 meters (33 fathoms); January 8, 1908.

One specimen (Cat. No. 41218 , U.S.N.M.).

Albatross station 5105; China Sea, off southern Luzon; Sueste Point Light bearing N. 57 W., 3.52 kilometers (1.9 miles) distant (lat. $14^{\circ} 43^{\prime} 55^{\prime \prime} \mathrm{N}$., long. $120^{\circ} 12^{\prime} 50^{\prime \prime}$ E.) ; 46 meters (25 fathoms) ; January 8, 1908.

Two specimens (Cat. No. 41220 , U.S.N.M.).

Albatross station 5107; Corregidor Light bearing S. $17^{\circ}$ E., 32.43 kilometers (1.75 miles) distant (lat. $14^{\circ} 24^{\prime} 30^{\prime \prime} \mathrm{N}$., long. $120^{\circ} 33^{\prime}$ $40^{\prime \prime} \mathrm{E} ; 51$ meters (28 fathoms) January 9, 1908).

One specimen (Cat. No. 41227 , U.S.N.M.).

Albatross station 5158; Sulu (Joló) Archipelago, Tawi Tawi Group; Tinakta Island (N.) bearing N. $89^{\circ}$ W., 3.52 kilometers (1.9 miles) distant (lat. $5^{\circ} 12^{\prime} 00^{\prime \prime}$ N., long. $119^{\circ} 54^{\prime} 30^{\prime \prime}$ E.) ; 22 meters (12 fathoms); February 21, 1908; crs. S., Sh.

Five specimens (Cat. Nos. 41215, 41228, 41230, U.S.N.M.).

Albatross station 5160; Sulu Archipelago, Tawi Tawi Group; Tinakta Island (N.) bearing S. $72^{\circ}$ W., 5.09 kilometers $(2.75$ miles) distant (lat. $5^{\circ} 12^{\prime} 40^{\prime \prime} \mathrm{N}$., long. $119^{\circ} 55^{\prime} 10^{\prime \prime}$ E.) 22 meters (12 fathoms); February 22, 1908; S.

Two specimens (Cat. Nos 40966,41229 , U.S.N.M.).

Albatross station 5169; Sulu Archipelago, in the vicinity of Sibutu Island; Sibutu Island (SE.) bearing N. $38^{\circ}$ E., 14.82 kilometers (8 miles) distant (lat. $4^{\circ} 32^{\prime} 15^{\prime \prime}$ N., long. $119^{\circ} 22^{\prime} 45^{\prime \prime}$ E.) ; 18 meters (10 fathoms) ; February 27, 1908; co. S.

One specimen (Cat. No. 40963 , U.S.N.M.).

Albatross station 5207; off western Sámar; Badian Island (N.) bearing $\mathrm{S} .74^{\circ} \mathrm{E}$., 8.71 kilometers (4.7 miles) distant (lat. $11^{\circ} 38^{\prime} 05^{\prime \prime}$ N., long. $124^{\circ} 40^{\prime} 45^{\prime \prime}$ E.) ; 64 meters (35 fathoms) ; April 14, 1908; gn. M., S. 
Four specimens (Cat. No. 40962, U.S.N.M.).

Albatross station 5342; Malampaya Sound, Palawan Island; Endeavor Point (S.) bearing S. $58^{\circ}$ E., 0.93 kilometer $(0.5$ mile) distant (lat. $10^{\circ} 56^{\prime} 55^{\prime \prime}$ N., long. $119^{\circ} 17^{\prime} 24^{\prime \prime}$ E.; 26 to 46 meters (14 to 25 fathoms); December 23, 1908; gy. M.

Six specimens (Cat. Nos. 40969, 41226, U.S.N.M.).

Albatross station 5358; Joló Sea; Sandakan Light bearing S. $34^{\circ}$ W., 36.5 kilometers (19.7 miles) distant (lat. $6^{\circ} 06^{\prime} 40^{\prime \prime} \mathrm{N}$., long. $118^{\circ} 18^{\prime} 15^{\prime \prime}$ E.) ; 71 meters (39 fathoms); January 7, 1909 ; M.

Two specimens (Cat. No. 40964, U.S.N.M.).

Albatross station 5363; Balayan Bay, Luzon; Cape Santiago Light bearing S. $79^{\circ} \mathrm{W}$., 8.34 kilometers $\left(4.5\right.$ miles) distant (lat. $13^{\circ} 47^{\prime}$ $20^{\prime \prime}$ N., long. $120^{\circ} 43^{\prime} 30^{\prime \prime}$ E.) ; 329 meters (180 fathoms); February $20,1909$.

One specimen (Cat. No. 51225, U.S.N.M.).

Albatross station 5398; between Masbate and Leyte; Gigantangan Island (S.) bearing S. $45^{\circ}$ E., 5.00 kilometers (2.7 miles) distant (lat. $11^{\circ} 35^{\prime} 12^{\prime \prime}$ N., long. $124^{\circ} 13^{\prime} 48^{\prime \prime}$ E.) ; 208 meters (114 fathoms) ; March 15, 1909; gn. M.

Two specimens (Cat. Nos. 41223, 41231, U.S.N.M.).

Albatross station 5415; between Cebu and Bohol; Lauis Point Light bearing N. $24^{\circ} \mathrm{W}$., 13.34 kilometers (7.2 miles) distant (lat. $10^{\circ} 07^{\prime} 50^{\prime \prime}$ N., long. $123^{\circ} 57^{\prime} 00^{\prime \prime}$ E.) ; 161 meters (88 fathoms) : March 24, 1909 ; fne. S.

One specimen (Cat. No. 41221, U.S.N.M.).

Albatross station 5420; between Cebu and Bohol; Cruz Point (Bohol) bearing S. $20^{\circ}$ E., 11.1 kilometers ( 6 miles) distant (lat. $9^{\circ} 49^{\prime} 35^{\prime \prime}$ N., long. $123^{\circ} 45^{\prime} 00^{\prime \prime}$ E.) ; 231 meters (127 fathoms); March 24, 1909.

Three specimens (Cat. No, 40967, U.S.N.M.).

Albatross station 5442; west coast of Luzon, Manila Bay to Lingayen Gulf; San Fernando Point Light bearing N. $39^{\circ}$ E., 15.57 kilometers (8.4 miles) distant (lat. $16^{\circ} 30^{\prime} 36^{\prime \prime}$ N., long. $120^{\circ} 11^{\prime} 06^{\prime \prime}$ E.) ; 82 meters ( 45 fathoms) ; May 10,1909 ; co. S.

Eight specimens (Cat. Nos. 40965,41224 , U.S.N.M.).

Albatross station 5448; east coast of Luzon, San Bernardino Strait to San Miguel Bay; San Miguel Point bearing N. $23^{\circ}$ E., 2.78 kilometers (1.5 miles) distant (lat. $13^{\circ} 23^{\prime} 10^{\prime \prime} \mathrm{N}$., long. $123^{\circ} 45^{\prime} 19^{\prime \prime}$ E.) ; 86 meters (47 fathoms); June 4, 1909.

Two specimens (Cat. No. 40968, U.S.N.M.).

Wakanoura, Kiushu.

Six specimens (Cat. No. 41217, U.S.N.M.).

Yenoshima.

Seven specimens (Cat. No. 41219, U.S.N.M.).

Otaru. 
Two specimens (Cat. No. 41216, U.S.N.M.).

Subig Bay.

One specimen (Cat. No. 41222, U.S.N.M.).

Notes.-The union of Ophiura sinensis with $O$. kinbergi which I proposed in 1905 has been accepted and confirmed by H. L. Clark, who has been able to examine Lyman's type of $O$. sinensis, which came from Australia.

Ophiura kinbergi appears to be very widely distributed in the Indian Ocean, as well as in the western Pacific. It is known from various localities in the Bay of Bengal, Ceylon, the Malabar coast, the Andaman Islands, the Mergui Archipelago, the Philippines, the Sunda Archipelago, and Australia. It is usually littoral, but it is rather frequently met with as far as 100 meters ( 55 fathoms), and the Siboga found it at 216 meters (118 fathoms) in $10^{\circ} \mathrm{S}$. latitude and $123^{\circ} \mathrm{E}$. longitude. The Albatross dredged it at very similar depths-208 meters (station 5398) and 232 meters (station 5420), or 114 and 128 fathoms.

OPHIURA MICRANTHA (H. L. Clark).

Plate 86 , fig. 6 .

Ophiura micrantha H. I. ClaRK ('11), p. 47, fig. 10.-MATSUMoto ('15), p.

81.-H. L. Clark ('15), p. 322.-Matsumoto ('17), p. 268.

Localities.-Albatross station 5256; southern Mindanao, eastern Illana Bay; Utara Point, Bongo Island, bearing N. $76^{\circ}$ W., 5.19 kilometers (2.8 miles) distant (lat. $7^{\circ} 21^{\prime} 45^{\prime \prime} \mathrm{N}$., long. $124^{\circ} 07^{\prime}$ $15^{\prime \prime}$ E.) ; 289 meters (158 fathoms) ; May 22, 1908; M.

Two specimens (Cat. Nos. 41384,41385 , U.S.N.M.).

Albatross station 5661; Flores Sea ; Cape Lassa bearing N. $21^{\circ}$ E., 23.16 kilometers (12.5 miles) distant (lat. $5^{\circ} 49^{\prime} 40^{\prime \prime}$ S., long. $120^{\prime \prime}$ $24^{\prime} 30^{\prime \prime}$ E.) ; 329 meters (180 fathoms) ; December 20, 1909; hrd.

One specimen (Cat. No. 41386, U.S.N.M.).

Philippines.

Two specimens (Cat. No. 41387, U.S.N.M.).

Notes.-The form of the mouth shields is slightly different from that which H. L. Clark has described and figured, and the sides of these shields show a rather deep notch corresponding to the bottom of the genital slits. I include a photograph of the ventral surface of a specimen from station 5256 .

OPHIURA MITESCENS, new species.

Plate 81, figs. 7-9.

Locality.-Hakodate.

One specimen (Cat. No. 41200 , U.S.N.M.).

Description.-The diameter of the disk is $14 \mathrm{~mm}$; the arms are broken off rather near the base, and they are only preserved for a very short distance. 
The disk is pentagonal, with the sides rounded, and its form is slightly oval. The dorsal surface is plane and the ventral slightly. convex; the dorsal surface is strongly notched at the base of the arms. It is covered with extremely numerous small plates, which are slightly imbricated and of which the outlines are more or less obscured by a thin integument. There may be distinguished a dorso-central plate which is rounded and slightly larger than those adjacent, and, far removed from it and almost equidistant from the center and from the periphery of the disk, five primary radials scarcely larger than the other plates, which, however, may be recognized by their slightly darker color and their rounded form. All the other plates, which are very small, are subequal; but they become slightly larger in the vicinity of the radial shields. These are small, irregularly triangular, almost as long as broad, divergent, and separated outwardly by a single row of plates; their length is about equivalent to a sixth or a seventh of the radius of the disk. The radial papillae are large, elongated, slightly flattened, and rounded at the tip; they maintain the same width over their whole length.

The ventral surface of the disk is covered with numerous imbricated and equal plates which are smaller than those on the dorsal surface. The genital plates are narrow and scarcely evident; the genital slits are elongated and narrow. The radial papillae which I described above occur only on the dorsal side, and they disappear on the ventral surface of the disk in such a way that the borders of the genital slits are without papillae except at the proximal end, where a few may be found which, however, are inconstant.

The mouth shields, almost as long as broad, are pentagonal with a rather open proximal angle; the two sides are straight and notched toward their proximal third by the bottom of the genital slits; they pass over by very rounded angles into the distal border, which is convex. The adoral plates are rather narrow and much elongated. The oral plates are narrower than the adoral, and especially are shorter. The lateral mouth papillae are four in number; the three outermost are obtuse and rectangular; and the last is more elongated and pointed; the unpaired terminal papilla is larger and conical.

The arms are flattened. The three first upper arm plates, included within the incisions of the disk, are small and short. The following plates are very large, quadrangular, very much broader than long, with the angles rounded and the sides convex; their width becomes progressively reduced and they soon become as broad as long; they are very broadly in contact.

The first under arm plate is large, almost hexagonal, with a broad proximal side and a narrower distal side which is notched in the middle; the sides are formed by the union of two small, straight bor- 
ders, forming with each other a very obtuse angle. The second plate is quadrangular, broader than long, with the proximal border narnow; the distal border, which is very broad and convex, is itself composed of two narrow sides united by a very obtuse angle. The following plates become triangular, very much broader than long, with a very obtuse proximal angle, very strongly divergent sides, and a convex distal border. They are at first in contact beyond the disk, becoming separated by a narrow interval. The side arm plates carry four spines on the first segments and only three on those following. These spines are rather long, and their length increases from the first ventral, which is half as long as the segment, to the dorsal, the length of which equals almost that of the segment. These spines are much flattened and rather strongly broadened in their mid-region, with the tip rounded.

The tentacle pores of the first pair are very large, and their proximal end is very close to the mouth; they show on either border four or five very large scales. The two pairs of pores following are still fairly well developed; the pores of the second pair have three scales on the outer border and two on the inner; the pores of the third pair have two scales on each side. The pores of the fourth pair have only a single scale on each border, and beyond this the pores, which become, very much smaller, show only a single proximal scale, very much more reduced than the neighboring spine.

The color of the specimen in alcohol is brownish white.

Affinities and distinctive features.-Ophiura mitescens is especially close to $O$. flagellata (Lyman) and to O. palliata (Lyman) in regard to the length of the arm spines and the characters of the dorsal plates of the disk, which are very numerous, with poorly marked outlines. The radial papillae are longer and less numerous than in 0 . palliata, in which they are very fine and very pointed, and the tentacle pores are continued less far than in that species; the arm spines are broader and more flattened. In $O$. flagellata the radial papillae are usually elongated and pointed, the arm spines are conical and also very pointed, the dorsal surface of the arms is carinate, and the under arm plates are shorter; furthermore, the arms of $O$. flagellata are very much more broadened than those of 0 . mitescens. The new species differs still more from 0 . bathybia (H. L. Clark), from the Bering Sea, in which the three arm spines are pointed and the dorsal is larger than the two others; the radial shields are extremely elongated and narrow, the radial papillae are pointed, and spines occur on both surfaces of the disk, structures which are entirely lacking in $O$. mitescens.

Ophiura mitescens also shows affinities with 0 . fluctuans, which I described above. It is easily distinguished from it by its very broadened arm spines, maintaining almost the same width throughout 
their whole length and rounded at the tip, while these are conical and very pointed in $O$. fluctuans; the radial papillae are also rounded at the tip and not pointed, and the upper arm plates have the lateral angles rounded instead of being sharp as in 0 . fluctuans.

\section{OPHIURA SARSII Lütken.}

Plate 84, figs. 10, 11 .

See for bibliography:

Ophiura sarsii Grieg ('07), p. 15.-SUssbach and Breckner ('11), p. 248.-H. L. Clark ('11), p. 37.-MortenseN ('13), p. 348.-Matsumoto ('15).-H. L. Clark ('15), p. 323.-MATSumoto ('17), p. 272, fig. 74.

Ophioglypha sarsii KaEHLEB ('09), p. 155; ('14), p. 23.

Locality.-Hakodate.

Fifteen specimens (Cat. Nos. 40992, 41163, U.S.N.M.).

Notes.-These specimens are not of large size, and the diameter of the disk scarcely reaches $15 \mathrm{~mm}$. in the largest.

\section{HOMALOPHIURA INFLATA (Kohler).}

Plate 84, figs. $2,3$.

Ophioglypha inflata KळEHLER ('96), p. 2S8, pl. 5, figs. 10, 11; ('99), p. 10, pl. 11, figs. 83-85.

Ophioglypha nana LÜTKEN and MoRTensen ('99), p. 126, pl. 2, figs. 10-12. Ophiura inflata Matsumoto ('15), p. 81.

Ophiura nana Matsumoto ('15), p. 81.

Homalophiura inflata H. L. ClaRK ('15), p. 326.-Matsumoto ('17), p. 267. Homalophiura nana H. L. ClaRK ('15), p. 327.-MATSUMoto ('17), p. 267.

Locality.-Albatross station 5660; Flores Sea ; Cape Lassa bearing S. $88^{\circ} \mathrm{W}$., 37.99 kilometers (20.5 miles) distant (lat. $5^{\circ} 36^{\prime} 30^{\prime \prime} \mathrm{S}$., long. $120^{\circ} 49^{\prime} 00^{\prime \prime}$ E.) ; 1,266 meters (692 fathoms); December 20 , 1909 ; gy. M., S.

One specimen (Cat. No. 41165, U.S.N.M.).

Notes.-The single individual measures $4.5 \mathrm{~mm}$. in the diameter of the disk.

The study which I have been able to make of this species has convinced me that the species of Ophiura, described by Lütken and Mortensen under the name of Ophioglypha nana, is quite identical with my 0 . inflata, described three years previously; this specific name, therefore, must be used.

The Albatross specimen is, like all the others known, of very small size, and the diameter of the disk is only $4.5 \mathrm{~mm}$.; the arms, which are very slender, may reach $15 \mathrm{~mm}$. in length. The plates of the dorsal surface of the disk are more numerous and smaller than in my type, and than in the $O$. nana described by Lütken and Mortensen. The upper arm plates are much elongated, very much longer than broad, with the distal border almost straight; the first under 
arm plate is triangular, elongated, with the distal border slightly convex; its outline agrees better with the figure which I published in 1896 ('96, pl. 5, fig. 11) than with that of Lütken and Mortensen ('99, pl. 2, fig. 10). The second under arm plate is triangular and almost equilateral. The following become very much broader than long; all have the distal border almost straight, or only slightly convex.

The Albatross specimen is slightly deformed and it seems to have suffered a flattening on the dorsal surface, which has affected unequally the different portions of this surface.

The type, from the Investigator collection, was captured off Colombo, Ceylon, at a depth of 1,092 meters (597 fathoms). Lütken and Mortensen's $O$. nana came from the Pacific and was dredged off Panama in 1,650 meters (902 fathoms).

\section{HOMALOPHIURA INORNATA (Lyman).}

Plate 82 , fig. 9.

Ophioglypha inormata LrMAN ('78), p. 97, pl. 2, figs. 26. 27; ('82), p. 73, pl. 3, figs. 10-12.-KäLER ('07), p. 294 ; ('07a), p. 262 ; ('14), p. 18.

Ophioglypha divisa LütkeN and MoRtensen ('99), p. 127, pl. 4, figs. 10-12: pl. 5, figs. 1, 2.-KöHLER ('04), p. 40.

Ophiura inornata Matsumoto ('15), p. 81.

Homalophiura inornata H. L. Clark ('15), p. 326.-Matsumoto ('17), p. 266.

Homalophiura divisa Matsumoto ('17), p. 267.

Localities. - Albatross station 5444; east coast of Luzon, San Bernardino Strait to San Miguel Bay; Atalaya Point, Batag Island, bearing $\mathrm{S} .65^{\circ} \mathrm{E} ., 9.45$ kilometers (5.1 miles) distant (lat. $12^{\circ} 43^{\prime} 51^{\prime \prime}$ N., long. $124^{\circ} 58^{\prime} 50^{\prime \prime}$ E.) ; 563 meters (308 fathoms); June 3, 1909 ; gn. M.

One specimen (Cat. No. 41077, U.S.N.M.).

Albatross station 5445; east coast of Luzon, San Bernardino Strait to San Miguel Bay; Atalaya Point, Batag Island, bearing S. $56^{\circ} \mathrm{E}$., 9.82 kilometers (5.3 miles) distant (lat. $12^{\circ} 44^{\prime} 42^{\prime \prime} \mathrm{N}$,, long. $124^{\circ}$ $59^{\prime} 50^{\prime \prime}$ E.) ; 701 meters (383 fathoms) ; June 3, 1909 ; gn. M., S.

One specimen (Cat. No. 41340, U.S.N.M.).

Albatross station 5618; Molucca Passage; Mareh Island bearing S. $69^{\circ}$ E., 14.45 kilometers ( 7.8 miles) distant (lat. $0^{\circ} 37^{\prime} 00^{\prime \prime} \mathrm{N}$., long. $127^{\circ} 15^{\prime} 00^{\prime \prime}$ E.) ; 762 meters (417 fathoms); November 27, 1909; gn. M.

One specimen (Cat. No. 41339 , U.S.N.M.).

Albatross station 5619; Molucca Passage; Mareh Island (S.) bearing S. $78^{\circ} \mathrm{E}$., 12.97 kilometers (7 miles) distant (lat. $0^{\circ} 35^{\prime} 00^{\prime \prime} \mathrm{N}$., long. $127^{\circ} 14^{\prime} 40^{\prime \prime}$ E.) ; 796 meters (435 fathoms); November 27, 1909 ; fne. gy. S., M.

One specimen (Cat. No. 41076, U.S.N.M.). 
Notes.-The diameter of the disk varies between $9 \mathrm{~mm}$. and $16 \mathrm{~mm}$. All the upper-arm plates are very regularly divided into two equal halves by a longitudinal groove which sometimes bifurcates toward the middle of the plate. In the specimens from station 5444 the mouth shields are entire, except in one, in which the proximal region is separated from the rest by an oblique groove, and the large interradial plate which follows the mouth shield is divided into two parts in three interradii. In the two specimens from station 5618 all the mouth shields are broken up into at least three fragments; but in the largest specimen, which is from station 5445 , neither the mouth shields nor the plates which follow them are fragmented.

I have already emphasized at different times ('04, p. 40; '07a, p. 262 ; '14, p. 18) the extent of the variations shown by 0 . inornata, the geographical range of which is very great. It has been met with in the three great oceans-the Atlantic, the Indian, and the Pacific. In the Atlantic the Challenger found it in $1^{\circ} \mathrm{N}$. latitude, $24^{\circ} \mathrm{W}$. longitude, in 3,384 meters (1,850 fathoms), and the Albatross in $11^{\circ} \mathrm{N}$. latitude, $58^{\circ} \mathrm{W}$. longitude, in 1,069 meters ( 880 fathoms). In the Indian Ocean the Siboga found it at different stations in the Sunda Archipelago between 470 and 1,264 meters (260 to 693 fathoms). In the Pacific the Albatross dredged it between $0^{\circ}-2^{\circ} \mathrm{N}$. latitude and $90^{\circ}-92^{\circ} \mathrm{W}$. longitude, 2,175 to 2,487 meters (1,189 to 1,360 fathoms).

\section{OPHIOCTEN HASTATUM Lyman.}

Ophiocten hastatum LYMAN ('78), p. 103, pl. 5, figs. 133, 134; ('82), p. 82, pl. 9, figs. 10, 11.-Kainler ('98), p. 42 , pl. 7, figs. 32,33 ; ('09), p. 165 ; ('14), p. 37.-H. L. Crark ('15), p. 328.

Ophiocten pacificum LÜTKEN and MORTENSEN ('99), p. 131, pl. 3, flgs. 5-7.H. L. Clark ('11), p. 96 ; ('15), p. 328.

Locality.-Albatross station 5080; off southern Japan; Omai Saki Light bearing N. $23 \frac{1}{2}^{\circ}$ E., 51.89 kilometers (28 miles) distant (lat. $34^{\circ} 10^{\prime} 30^{\prime \prime} \mathrm{N}$., long. $138^{\circ} 40^{\prime} 00^{\prime \prime}$ E.) ; 923 meters (505 fathoms); October 19, 1906 ; fne. gy. S., Glob.

One very small specimen (Cat. No. 40932, U.S.N.M.).

Notes. - I certainly see no reason for separating from Ophiocten hastatum 0 . pacificum, which Lütken and Mortensen described in 1899 from specimens collected at numerous stations between $0^{\circ}-7^{\circ}$ $\mathrm{N}$. latitude and $78^{\circ}-86^{\circ} \mathrm{W}$. longitude, at depths varying from 1,408 to 1,877 meters ( 770 to 1,573 fathoms).

Ophiocten hastatum was met with in different localities in the North Atlantic by the Hirondelle and the Princesse-Alice between $33^{\circ}-40^{\circ} \mathrm{N}$. latitude and $9^{\circ}-30^{\circ} \mathrm{W}$. longitude, at depths between 1,674 and 1,900 meters (917 to 1,040 fathoms). The Albatross captured it between $30^{\circ}-42^{\circ} \mathrm{N}$. latitude and $50^{\circ}-79^{\circ} \mathrm{W}$. longitude, in 219 to 805 meters (120 to 440 fathoms). H. L. Clark records the species (under 
the name of $O$. pacificum) from many localities between $45^{\circ}-51^{\circ} \mathrm{N}$. latitude and $124^{\circ}-130^{\circ} \mathrm{W}$. longitude, as well as between $34^{\circ}-45^{\circ}$ $\mathrm{N}$. latitude and $137^{\circ}-139^{\circ} \mathrm{E}$. longitude, at depths of 916 to 1,602 meters (501 to 876 fathoms).

The specimens of $O$. hastatum from the Challenger collection which served Lyman as the type of the species came from the North Atlantic in $37^{\circ} \mathrm{N}$. latitude and $25^{\circ} \mathrm{W}$. longitude, and therefore from localities very close to those where the Princesse-Alice rediscovered it, from the southern part of the Indian Ocean $\left(46^{\circ} \mathrm{S}\right.$. latitude and $45^{\circ} \mathrm{E}$. longitude), and from the Pacific Ocean $\left(40^{\circ} \mathrm{S}\right.$. latitude and $177^{\circ} \mathrm{E}$. longitude). Ophiocten hastatum therefore has a very extensive geographical and bathymetric distribution.

\section{OPHOMUSIUM ALTUM Kœhler.}

Plate 80, figs. 6, 7, 12.

Ophiomusium altum KøHLER ('04), p. 57, pl. 10, figs. 2-4.-H. L. Clark ('15), p. 333.

Locality.-Albatross station 5668; Macassar Strait; Mamuju Island (E.) bearing S. $31^{\circ}$ E., 19.64 kilometers (10.6 miles) distant (lat. $2^{\circ} 28^{\prime} 15^{\prime \prime}$ S., long. $118^{\circ} 49^{\prime} 00^{\prime \prime}$ E.) ; 1,648 meters (901 fathoms); December 29, 1909; gy. M.

One specimen (Cat. No. 40921, U.S.N.M.).

Notes. - The specimen is almost of the same size as that upon which I established the species, and the diameter of the disk barely reaches $5 \mathrm{~mm}$.; the arms are preserved for a greater or lesser part of their length, and one of them, which is complete, measures $15 \mathrm{~mm}$; they are very slender.

I find in this specimen all the essential characters of 0 . altum, and I notice only slight differences in the outlines of some of the dorsal plates of the disk. The primary rosette is a little irregular, one of the five radials being replaced by two plates. The two small interradial plates which separate these primary radials are triangular, sometimes in contact by their apices, sometimes slightly separated from each other; the two radial shields of each pair are in contact for at least three-quarters of their length and the plate which separates them inwardly, instead of being elongated, is triangular and scarcely longer than broad. I can distinguish a few small papillae along the very short genital slits.

The type of Ophiomusium altum was discovered by the Siboga in $4^{\circ} \mathrm{S}$. latitude and $118^{\circ} \mathrm{E}$. longitude (Straits of Macassar) at a depth of 2,029 meters (1,110 fathoms).

\section{OPHIOMUSIUM ARMATUM, new species.}

Plate 89, figs. 8-10.

Locality.-Albatross station 5428; eastern Palawan and vicinity; 30th of June Island bearing N. $62^{\circ}$ W., 36.14 kilometers (19.5 miles) 
distant (lat. $9^{\circ} 13^{\prime} 00^{\prime \prime} \mathrm{N}$., long. $118^{\circ} 51^{\prime} 15^{\prime \prime}$ E.) ; 2,021 meters (1,105 fathoms); April 3, 1909; gy. M.

Two specimens (Cat. Nos. 40923, 40924, U.S.N.M.).

Description.-The diameter of the disk is $14 \mathrm{~mm}$.; the arms are all incomplete.

The disk is pentagonal with the borders concave and the angles pass imperceptibly into the arms. The dorsal surface is covered with numerous plates of medium size which are fairly uniform and slightly imbricated. The dorso-central plate is a little larger than those adjacent, but it is scarcely distinguishable from them, and the primary radials can not be recognized. On the border of the disk in each interradial space there is a larger plate which is rounded and transversely broadened. The radial shields are rather large, much elongated, twice or two and a half times as long as broad, triangular, with the angles very rounded and separated throughout their whole length by a broad space occupied by a row of plates; the length of these shields is slightly less than half the radius of the disk.

The ventral surface of the disk in the interbrachial spaces is covered by rather numerous small plates fairly uniform in size and imbricated. The genital plates are very narrow and elongated. The genital slits, which are also very narrow, extend as far as the border of the disk, and they are furnished, on both borders, with small, low, and rounded papillae. The papillae of the interradial row may be continued somewhat toward the outer border of the radial shields and even onto the border of the disk, and some of them may elongate into small and very short spines which may even occur at some distance from the arms.

The mouth shields are rather large, as long as broad, or a little longer than broad. They show a triangular principal portion which is longer than broad with a proximal angle and very convex sides; the lateral angles are much rounded. This part is followed by a quadrangular and somewhat narrower distal lobe terminated by a convex border; the dividing line between these two parts is marked by the bottom of the genital slit, which forms a slight notch. The adoral plates are much elongated, extremely narrow in the part adjacent to the mouth shields, which represents three-fifths of their length, and strongly broadened outwardly in such a way as to separate the mouth shield from the first side arm plate over a very considerable space along which they border the genital slit; this portion which delimits the bottom of the genital slit bears a row of papillae identical with those along the rest of the slit. The oral plates are large and high. The lateral mouth papillae are six and sometimes seven in number; the first is rather small and quadrangular, the second is also quadrangular, but very much larger, and the following 
are elongated and become smaller and smaller, except for the last which is a little larger than the preceding; the unpaired terminal papilla is larger than those on either side, and conical.

The two first upper arm plates are short and transversely broadened. The first is quadrangular, and the second, which is in contact with the first, is triangular with a distal angle. The following plates are small, lozenge-shaped, longe: than broad, and widely separated; they become smaller and smaller, although they persist throughout the whole preserved portion of the arms.

The first' under arm plate is very small, pentagonal, a little broader than long; the three following are large, triangular, with a sharp proximal angle, the sides excavated by the tentacle pore, and the distal border slightly convex. The second plate is almost in contact with the third, and the fourth is separated from the preceding. Beyond the disk the plates become very much smaller, and they are widely separated; they are triangular, a little broader than long, but they persist throughout the whole preserved portion of the arms.

The side arm plates carry at first six small and short spines, the number then falling to five, and later to four.

The tentacle pores number three pairs; those of the first pair are very large and resemble those of an Ophiura; they carry three large scales on each of their borders. The two following pores are still very large; those of the second pair have two or three internal scales, and one or two external scales; those of the third pair have two internal and one external scales.

The color of the specimen in alcohol is yellowish.

Affinities and distinctive features.-Ophiomusium armatum is especially close to $O$. armigerum Lyman; it is distinguished from it by having the dorsal plates of the disk more uniform, without the least indication of primary plates, by having the radial shields smaller, by having the upper arm plates also smaller, by the slightly different form of the mouth shields, by the development of the tentacle pores, especially those of the first pair, as well as by the number of scales which they bear on each border, and by having the arm spines slightly more numerous.

\section{OPHIOMUSIUM ELEGANS Kœhler.}

Plate 88, figs. 1-9.

Ophiomusium elegans KđEHLER ('96), p. 305, pl. 6, figs. 22,23 ; ('99), p. 23, pl. 3, figs. 22-24; ('04), p. 66.-H. L. ClARK ('15), p. 334.

Localities.-Albatross station 5127; Sulu (Joló) Sea, in the vicinity of southern Panay; Nogas Island (W.) bearing N. $11^{\circ} 30^{\prime} \mathrm{E}, 40.77$ kilometers (22 miles) distant (lat. $10^{\circ} 02^{\prime} 45^{\prime \prime} \mathrm{N}$., long. $121^{\circ} 48^{\prime} 15^{\prime \prime}$ E.) ; 1,752 meters (958 fathoms) ; February 4, 1908; gy. M., Glob.

Two specimens (Cat. Nos. 40995, 40997, U.S.N.M.). 
Albatross station 5428; Eastern Palawan and vicinity; 30th of June Island bearing N. $62^{\circ}$ W., 36.14 kilometers (19.5 miles) distant (lat. $9^{\circ} 13^{\prime} 00^{\prime \prime}$ N., long. $118^{\circ} 51^{\prime} 15^{\prime \prime}$ E.) ; 2,021 meters $(1,105$ fathoms); April 3, 1909; gy. M.

One specimen (Cat. No. 40998, U.S.N.M.).

Albatross station 5605; Gulf of Tomini, Celebes; Dodepo Island (W.) bearing $\mathrm{N} .14^{\circ} \mathrm{W}, 10.93$ kilometers (5.9 miles) distant (lat. $0^{\circ} 21^{\prime} 23^{\prime \prime}$ N., long. $121^{\circ} 34^{\prime} 10^{\prime \prime}$ E.) ; 1,183 meters (647 fathoms); November 16, 1909.

One specimen (Cat. No. 41000, U.S.N.M.).

Albatross station 5623; between Gillolo and Makyan Islands; Makyan Island (S.) bearing S. $88^{\circ} \mathrm{W} ., 13.90$ kilometers ( 7.5 miles) distant (lat. $0^{\circ} 16^{\prime} 30^{\prime \prime} \mathrm{N}$., long. $127^{\circ} 30^{\prime} 00^{\prime \prime}$ E.) ; 497 meters (272 fathoms) ; November 29, 1909; fne. S., M.

Eight specimens (Cat. No. 40999, U.S.N.M.).

Albatross station 5624 ; between Gillolo and Makyan Islands; Makyan Island (S.) bearing N. 67 $7^{\circ}$ W., 16.49 kilometers ( 8.9 miles) distant (lat. $0^{\circ} 12^{\prime} 15^{\prime \prime} \mathrm{N}$., long. $127^{\circ} 29^{\prime} 30^{\prime \prime}$ E.) ; 527 meters (288 fathoms) ; November 29, 1909 ; fne. S., M.

One specimen (Cat. No. 40996, U.S.N.M.).

Notes. - The specimens from the three first stations are the smallest, and the diameter of the disk scarcely exceeds $10 \mathrm{~mm}$; in those from station 5623 the diameter of the disk varies between 10 and $18 \mathrm{~mm}$.; this last dimension is also found in the single example from station 5624 .

In these different specimens I find some interesting variations. I may recall that the principal characters on which I established the species in 1896 are the form of the mouth shields, the existence of small radial papillae outside of the radial shields, papillae which are continued over the two borders of the genital slits, the presence of three pairs of tentacle pores, and the arrangement of the dorsal plates of the disk. My original specimens, three in number, came from the Laccadive and Andaman Islands, and the diameter of their disks varied between 11 and $13 \mathrm{~mm}$. The series collected by the $A l$ batross is more numerous, and includes larger specimens, the diameter of the disk reaching $18 \mathrm{~mm}$. I show on plate 83 , as figures 5,6 , the two surfaces of a large sized specimen from station 5623; and in figure 9 the ventral surface of the specimen from station 5624 . which has the same dimensions. Two smaller individuals, from stations 5428 and 5127, in which the diameter of the disk is only between 10 and $11 \mathrm{~mm}$, are shown in figures 1,2 .

In the dorsal plates of the disk I do not find any important differences; on the small individuals I always notice in the interradial spaces the three large tandem plates, which I showed in 1896 (fig. 2), but in the large ones there are only two plates (fig. 5). In these 
large specimens the radial papillae usually appear as small rounded granules, forming a little more or less important clump on each side of the base of the arms (figs. 7, 8). Sometimes these granules elongate somewhat, especially on reaching the ventral surface, but in the small specimens the papillae are very much longer, and they even elongate in such a way as to form true spines (figs. $2,3,4$ ).

More important variations are found in the mouth shields. In my type these shields are lanceolate, twice as long as broad, with a sharp proximal angle. This is the form which they have in all the specimens from station 5623; but in that from station 5624, which is of large size, these shields are shorter and very much broader; they are not even half again as long as broad, and their proximal angle is obtuse or even rounded (fig. 9). A similar form is seen in the small specimens from stations 5127, 5428, and 5605 (fig. 1); but in these specimens they are more elongated than in the large individual from station 5624; the proximal angle is rather sharp, and they are at least half again as long as broad.

I find also some differences in the arm spines, which may be four in number at the base of the arms.

The tentacle scales are usually larger and more important than I described them in 1896 ; I then indicated only one large tentacle scale, but I have found on the Albatross specimens that in addition to a large tentacle scale which occupies the proximal border of the pore there may be present two or even three small scales on the distal border. When the pores are contracted these distal scales may not be apparent, and it is doubtless this which occurred on the Investigator specimens; but I always find them on those from the Albatross collection, even in small specimens like that in figure 1. In the large specimens of which photographs are given in figures 6 and 9 it may happen also that the proximal scale is divided into two or three small scales. The tentacle pores are rather large, especially those of the first pair, and their size decreases progressively to that of the third pair.

Because of the variations to which $O$. elegans is subject $I$ have reexamined the specimens on which in $1896 \mathrm{I}$ established $O$. familiare, a species which is rather close to $O$. elegans; but the comparison between these specimens and the $O$. elegans collected by the Albatross has confirmed the validity of the first species, which is abundantly distinct from the second. The arm spines of 0 . familiare are five in number, and sometimes I find six of them at the base of the arms in the large individuals; the two first ventral spines are somewhat closer together, and they form a small distinct group while four others follow at regular intervals along the distal border of the side arm plate. The largest number of arm spines which $I$ find in the large specimens of $O$. elegans is four, and the normal number is three. 
The radial shields in 0 . familiare are always more rounded and less elongated than in $O$. elegans. The small radial granules are less numerous and less evident, and I have never seen them elongate into small spines as sometimes occurs in $O$. elegans. The mouth shields are shorter and smaller in $O$ familiare, and they always have the form which I described and figured in 1896. A last difference, which I did not mention in 1896, is afforded by the tentacle pores which, in O. famitiare, are smaller and always covered by a single oval scale, while in $O$. elegans, as I have said above, there may be one or two scales on each border, and sometimes there may even be three; these pores also are appreciably larger in this last species and their size decreases from the first to the third.

I consider $O$. jolliensis, which MacClendon described and figured in 1909 ('09, p. 36) and of which H. L. Clark has given a more detailed description and figures ('11, p. 111) also as a species near $O$. elegans. It may be asked why MacClendon has written "jolliensis" and not "jolliense;" H. L. Clark has also written "jolliensis," but Matsumoto ('17, p. 291) corrected it and piaced the word in the neuter gender. H. L. Clark approximates $O$. jolliense with $O$. cancellatum, $O$. armigerum, and $O$. eburneum, without mentioning $O$. elegans and 0 . familiare, but I find that its affinities with these two last species, and particularly with $O$. elegans, are especially close. To judge from H. L. Clark's description and figures, it seems, however, to be distinct; the radial papillae are more numerous and more developed, the tentacle pores are more reduced and usually provided with a single scale, the arm spines do not exceed three in number, and on a specimen in which the disk is only $10 \mathrm{~mm}$. in diameter there are only two. The form of the mouth shields in 0 . jotliense is quite similar to that which is found in typical $O$. elegans, as well as in $O$. familiare, and H. L. Clark does not mention any variations in their form.

\section{OPHIOMUSIUM FACETUM, new species.}

Plate 91, figs. 1-5.

Localities.-Albatross station 5114; Balayan Bay and Verde Island Passage; Sombrero Island bearing N. $36^{\circ}$ E., 13.34 kilometers (7.2 miles) distant (lat. $13^{\circ} 36^{\prime} 11^{\prime \prime} \mathrm{N}$., long. $120^{\circ} 45^{\prime} 26^{\prime \prime}$ E.) ; 622 meters (340 fathoms); January 20, 1908; fne. S.

One specimen (Cat. No. 41371, U.S.N.M.).

Albatross station 5124; east coast of Mindoro; Point Origon (N.) bearing $\mathrm{S} .56^{\circ}$ E., 39.45 kilometers (20.75 miles) distant (lat. $12^{\circ} 52^{\prime}$ $00^{\prime \prime}$ N., long. $121^{\circ} 48^{\prime} 30^{\prime \prime}$ E.) ; 513 meters (281 fathoms) ; February 2, 1908; sft. gn. M.

One specimen (Cat. No. 41355, U.S.N.M.).

Albatross station 5127; Sulu (Joló) Sea, in the vicinity of southern Panay; Nogas Island (W.) bearing N. $11^{\circ} 30^{\prime}$ E., 40.77 kilo- 
meters (22 miles) distant (lat. $10^{\circ} 02^{\prime} 45^{\prime \prime}$ N., long. $121^{\circ} 48^{\prime} 15^{\prime \prime}$ E.) ; 1,752 meters (958 fathoms); February 4, 1908; gy. M. Glob.

One specimen (Cat. No. 41370 , U.S.N.M.).

Albatross station 5263; off eastern Mindoro; Point Origon bearing N. $85^{\circ}$ E., 52.45 kilometers (28.3 miles) distant (lat. $12^{\circ} 38^{\prime} 30^{\prime \prime} \mathrm{N}$., long. $121^{\circ} 37^{\prime} 30^{\prime \prime}$ E.) ; June 4, 1908.

One specimen.

Albatross station 5423; Joló Sea; Cagayan Island (S.) bearing S. $11^{\circ}$ E., 8.89 kilometers (4.8 miles) distant (lat. $9^{\circ} 38^{\prime} 30^{\prime \prime}$ N., long. $121^{\circ} 11^{\prime} 00^{\prime \prime}$ E.) ; 929 meters (508 fathoms) ; March 31, 1909; gy. M., co. S.

Two specimens (Cat. No. 41372, U.S.N.M.).

Albatross station 5429; eastern Palawan and vicinity; Fondeado Island (SE.) bearing N. $18^{\circ}$ E., 27.80 kilometers (15 miles) distant (lat. $9^{\circ} 41^{\prime} 30^{\prime \prime} \mathrm{N}$, long. $118^{\circ} 50^{\prime} 22^{\prime \prime}$ E.) ; 1,401 meters (766 fathoms); April 5, 1909; gn. M.

One specimen.

Description.-I shall describe the species especially from the specimen from station 5127 , of which I show the ventral surface on plate 91 as figure 2, and from the largest specimen from station 5423, the dorsal surface of which is shown in figure 3. In the latter the diameter of the disk is $20 \mathrm{~mm}$., and one of the arms, which is preserved for almost its entire length, reaches almost $80 \mathrm{~mm}$.; in the other specimen from the same station, which is identical with it, the diameter of the disk is $13 \mathrm{~mm}$. only. In the specimen from station 5127 the diameter of the disk is $17 \mathrm{~mm}$., and the arms are broken off rather close to the base. The largest specimen is that from station 5263 , in which the diameter of the disk reaches $23 \mathrm{~mm}$.

The disk is pentagonal, with the sides straight; the dorsal surface is plane and the ventral surface is slightly convex; the borders are rounded.

The arms are rather narrow, almost cylindrical, with the ventral surface slightly flattened; they measure $3.5 \mathrm{~mm}$. in width at the base in the specimen from station 5127.

The dorsal surface of the disk shows a circular central region bounded by the rounded apices of the radial shields, which are very large and covered with numerous subequal, small, and nonimbricated plates, among which it is impossible to distinguish the least indication of primary plates. In the interradial spaces and between the two shields of each pair the plates become larger. In the radial spaces there is only to be distinguished a single row of three or four tandem plates, of which the proximal is more elongated than the others. In the interradial spaces there is a large triangular plate almost as broad as long or a little broader than long, with a proximal 
apex; this plate occupies the whole interradial space between the radial shields at the periphery of the disk. Beyond it there is only to be seen the upper border of the large interradial plate, which occupies the whole ventral surface of the disk beyond the mouth shields, with, on either side, one or two very small plates. The radial shields are extremely large, triangular, with a rounded proximal apex, a straight internal border, and a convex external border; they are twice as long as broad and their length, which exceeds $5 \mathrm{~mm}$., is greater than half the radius of the disk. These shields are slightly divergent and broadly separated for their whole length by the plates which I have mentioned above. Outside of the radial shields are two small tandem plates which on the ventral surface of the disk adjoin the genital plate.

The ventral surface outside of the mouth shield shows only a single large plate which curves upward at the periphery of the disk to form its lateral surfaces and of which the end is visible when the animal is viewed from above. This plate shows a straight and narrow proximal border and divergent sides uniting by a very rounded border into the distal side, which is itself rounded; it is a little broader than long. On either side of its distal border is found a small intercalated plate which with its fellow contributes to reduce the length of this border. It sometimes happens also that still another smaller plate appears on each side of the distal border of the mouth shield. One of these plates is seen in the specimen from station 5127, of which a photograph is given in figure 2, but in two interradii only, while in the two specimens from station 5423 these small plates appear almost regularly in all the interradii; in the other specimens they are almost always :absent. The genital plate is large, elongated, and rather broad. The genital slits are narrow and sinuous and end at the distal border of the second side arm plate.

The mouth shields are rather large, longer than broad, pentagonal, with the proximal angle almost a right angle, the sides at first straight and parallel, then outwardly incurved in such a way that the shield broadens gradually to beyond the middle; thence the sides become straight and slightly convergent, and they join the straight distal border by slightly obtuse angles. The adoral plates are large, rather long, broadened outwardly, and widely in contact in the median interradial line. The oral plates are triangular and high. The lateral mouth papillae are six in number; the outermost is extremely large and very much longer than broad, but the others are small, rectangular, or square; the unpaired terminal papilla, which is a little stouter than those on either side, is conical and pointed.

The first upper arm plate is small and very short, trapezoidal, with the distal border rounded. The following remain very small 
and widely separated; they disappear after the twelfth segment. Their form is triangular. The first plate is a little more developed than those following and is longer than broad; the others are very small, as long as broad, or even a little broader than long.

The first under arm plate is small, trapezoidal, with an obtuse proximal angle, slightly convergent sides, and a narrow distal border. The two following are large, pentagonal, a little longer than broad, with the distal border almost straight; they are widely separated. Beyond this the ventral plates are entirely lacking.

The side arm plates carry seven spines at the base of the arms, and beyond only six. In the largest specimen from station 5423 the spines number eight at the base. These equal spines form a regular series toward the distal border of the plate; they are slightly conical and rather elongated, with the point rounded.

The tentacle pores number two pairs only; they are rather large and covered each with a single oval scale larger on the pores of the first pair than on those of the second.

The color of the specimens in alcohol is yellowish.

In figure $1 \mathrm{I}$ show the specimen from station 5263, which is larger than the others and more robust; the diameter of the disk is $24 \mathrm{~mm}$., and the arms are almost $5 \mathrm{~mm}$. in width at the base. The radial shields, always very large, have the proximal angle strongly rounded, which slightly diminishes their length; among the dorsal plates of the disk some may be distinguished which are a little larger than the others, and six of these without doubt represent a primary rosette in which the five radials are widely separated from the dorso-central. There may be as many as nine spines at the base of the arms, but this number falls quickly to eight and then to seven.

The specimen from station 5114 is smaller than that from station 5127 ; the diameter of its disk is $14.5 \mathrm{~mm}$. I give a photograph of its dorsal surface in figure 4. This specimen shows a facies somewhat different from that of the others, resulting from having the plates of the dorsal surface of the disk all slightly swollen; the side arm plates are also a little more swollen than usual. The plates of the central region of the disk are not as numerous as in the other larger specimens; this is also the case in the small specimen from station 5423 , but while in this last the primary radial plates are rounded, here they are broadly oval and almost twice as long as broad. Furthermore, all the characters of the species are well marked, and there can be no question of applying another name to this individual.

Affinities and distinctive features.-Ophiomusium facetum must be placed among the species of Ophiomusium in which the under arm plates are not continued beyond the disk and which possess only two pairs of tentacle pores. It may be compared with 0 . validum Lyman. 
which it recalls in the characters of the ventral surface of the disk, but it is immediately distinguished from it by the more numerous arm spines and by the also more numerous dorsal plates of the disk. When the arm spines reach the number of eight or nine the new species might be confused with $O$. lymani, but the large ventral plate which follows the mouth shields, and which almost entirely fills the interradial space between the genital plates, can always be recognized as well as the perfectly smooth dorsal plates of the disk and of the arms.

\section{OPHIOMUSIUM FACUNDUM, new species.}

Plate 89 , figs. $1,2,5,6$.

Localities.-Albatross station 5114; Balayan Bay and Verde Island Passage; Sombrero Island bearing N. $36^{\circ}$ E., 13.34 kilometers (7.2 miles) distant (lat. $13^{\circ} 36^{\prime} 11^{\prime \prime}$ N., long. $120^{\circ} 45^{\prime} 26^{\prime \prime}$ E.) ; 622 meters 340 fathoms); January 20, 1908; fne. S.

Two specimens (Cat. No. 41361, U.S.N.M.).

Albatross station 5123; east coast of Mindoro; Malabrigo Light bearing $\mathrm{N} .44^{\circ} \mathrm{W}$., 60.23 kilometers (32.5 miles) distant (lat. $13^{\circ} 12^{\prime}$ $45^{\prime \prime}$ N., long. $121^{\circ} 38^{\prime} 45^{\prime \prime}$ E.) ; 518 meters (283 fathoms); February 2,1908 ; gn. M.

Three specimens.

Albatross station 5124; east coast of Mindoro; Point Origon (N.) bearing S. $56^{\circ}$ E., 38.45 kilometers (20.75 miles) distant (lat. $12^{\circ}$ $52^{\prime} 00^{\prime \prime}$ N., long. $121^{\circ} 48^{\prime} 30^{\prime \prime}$ E.) ; 514 meters (281 fathoms) ; February 2,1908 ; sft. gn. $\mathbf{M}$.

One specimen.

Albatross station 5202; Sogod Bay, southern Leyte Island; Limasaua Island (E.) bearing S. $2^{\circ}$ E., 30.95 kilometers ( 16.7 miles) distant (lat. $10^{\circ} 12^{\prime} 00^{\prime \prime}$ N., long. $125^{\circ} 04^{\prime} 10^{\prime \prime}$ E.) ; 918 meters (502 fathoms); April 10, 1908; gy. M.

One specimen (Cat. No. 41366, U.S.N.M.).

Albatross station 5259; off northwestern Panay; Caluya Island (S.) bearing $\mathrm{S} .73^{\circ} \mathrm{W}$., 19.84 kilometers (12 miles) distant (lat. $11^{\circ} 57^{\prime}$ $30^{\prime \prime}$ N., long. $121^{\circ} 42^{\prime} 15^{\prime \prime}$ E.) ; 571 meters (312 fathoms); June 3, 1908; gy. M., Glob.

Two specimens (Cat. Nos. 41359, 41363, U.S.N.M.).

Albatross station 5263; off eastern Mindoro; Point Origon bearing $\mathrm{N} .85^{\circ}$ E., 54.45 kilometers (28.3 miles) distant (lat. $12^{\circ} 38^{\prime} 30^{\prime \prime} \mathrm{N}$., long. $121^{\circ} 37^{\prime} 20^{\prime \prime}$ E.) ; June 4, 1908.

Two specimens (Cat. Nos. 41369 , E. 58, U.S.N.M.).

Albatross station 5282; China Sea, in the vicinity of southern Luzon; Malavatuan Island (N.) bearing S. $84^{\circ}$ W., 11.49 kilometers (6.2 miles) distant (lat. $13^{\circ} 53^{\prime} 00^{\prime \prime}$ N., long. $120^{\circ} 26^{\prime} 45^{\prime \prime}$ E.) ; 454 meters (248 fathoms); July 18, 1908; dk. gy. S. 
One specimen (Cat. No. 41362, U.S.N.M.).

Albatross station 5373; Marinduque Island and vicinity; Tayabas Light (outer) bearing N. $20^{\circ}$ E., 27.80 kilometers (15 miles) distant (lat. $13^{\circ} 40^{\prime} 00^{\prime \prime} \mathrm{N}$., long. $121^{\circ} 31^{\prime} 10^{\prime \prime} \mathrm{E}$.) ; 618 meters (338 fathoms); March 2, 1909; sft. M.

One specimen (Cat. No. 41357, U.S.N.M.).

Albatross station 5429; off eastern Palawan; Fondeado Island (SE.) bearing N. $18^{\circ}$ E. 27.79 kilometers $\left(15\right.$ miles) distant (lat. $9^{\circ}$ $41^{\prime} 30^{\prime \prime}$ N., long. $118^{\circ} 50^{\prime} 22^{\prime \prime}$ E.) ; 1,400 meters (766 fathoms); April 5, 1909; gn. M.

One specimen (Cat. No. 41368, U.S.N.M.).

Albatross station 5527; between Siquijor and Bohol Islands, Balicasag Island (C.) bearing N. $14^{\circ}$ W., 15.20 kilometers ( 8.2 miles) distant (lat. $9^{\circ} 22^{\prime} 30^{\prime \prime}$ N., long. $123^{\circ} 42^{\prime} 40^{\prime \prime}$ E.) ; 717 meters (392 fathoms); August 11, 1909; glob. Oz.

Four specimens (Cat. No. 41365 , U.S.N.M.).

Albatross station 5538; between Negros and Siquijor; Apo Island (C.) bearing S. $64^{\circ}$ W., 13.53 kilometers $\left(7.3\right.$ miles) distant (lat. $9^{\circ}$ $08^{\prime} 15^{\prime \prime}$ N., long. $123^{\circ} 23^{\prime} 20^{\prime \prime}$ E.) ; 468 meters (256 fathoms); August 19, 1909; gn. M., S.

One specimen (Cat. No. 41364, U.S.N.M.)

Albatross station 5623; between Gillolo and Makyan Islands; Makyan Island (S.) bearing S. $88^{\circ}$ W., 13.90 kilometers (7.5 miles) distant (lat. $0^{\circ} 16^{\prime} 30^{\prime \prime} \mathrm{N}$., long. $127^{\circ} 30^{\prime} 00^{\prime \prime}$ E.) ; 497 meters (272 fathoms) ; November 29,1909 ; fne. S., M.

One specimen.

No locality.

Two specimens (Cat. No. 41367, U.S.N.M.).

Description.-In the majority of these specimens the diameter of the disk usually varies between $15 \mathrm{~mm}$. and $18 \mathrm{~mm}$.; the specimen from station 5623 is very much larger than the others, and the diameter of its disk reaches $27 \mathrm{~mm}$. Some are smaller; in one of the two from station 5123 the diameter of the disk is only $10 \mathrm{~mm}$., and in those from station 5527 this diameter varies between $11 \mathrm{~mm}$. and $14 \mathrm{~mm}$.

I shall describe the species especially from the specimen from station 5378, in which the diameter of the disk is $18 \mathrm{~mm}$.; its arms are not complete; I include two photographs of it (pl. 89, figs. 1, 2). I shall mention also the larger individual from station 5259; the diameter of its disk is $17 \mathrm{~mm}$.; three of its arms, which are preserved for almost their entire length, measure from $60 \mathrm{~mm}$. to $65 \mathrm{~mm}$.

The disk is rounded and the dorsal surface is almost plane; the ventral surface is slightly convex, and the borders are rounded.

The dorsal surface is covered in the central region by subequal polygonal plates, with the angles rounded, which are not very nu- 
merous; in the specimen from station 5378 the primary plates are not recognizable, but in others there occurs a more or less distinct rosette of six contiguous and equal plates. Among the other plates there may be distinguished in the radial spaces a series of three plates separating the two shields of each pair; the first is elongated and the third short and trapezoidal. In the interradial spaces there are two tandem elongated plates, the first a little the shorter and pentagonal, the second trapezoidal with the distal border broadened and in contact with the dorsal border of the large interradial plate which by itself covers the ventral surface of the disk outside of the radial shields; a small part of this plate is visible when the animal is viewed from the dorsal surface. The radial shields are triangular, with the apex rounded, slightly divergent, and separated for their entire length; they are half again as long as broad, and their length is equal to half the radius of the disk. All these plates of the dorsal surface are covered with rounded granules, which are slightly flattened, in contact, and always very evident; these granules also occur on the distal portion of the ventral interradial plate, but they disappear on the ventral surface, properly speaking, of this plate.

This large ventral plate is trapezoidal, at least twice as broad as long, with a rather narrow straight proximal border, sinuous and strongly divergent lateral borders, and a slightly rounded distal side which reaches the dorsal surface of the disk; this plate, which is extremely large, covers the whole ventral surface of the disk beyond the mouth shield, and there are no plates intercalated between this and the genital plate. This large plate is smooth over the greater part of its surface, and the granules appear abruptly near the periphery, forming on the ventral surface only three or four successive rows; this narrow border represents the only portion of the ventral surface of the disk which is granulated, and over all the rest of the ventral surface of the disk and of the arms the plates are perfectly smooth. In figure 5 I give a photograph of this plate and of the neighboring regions, taken obliquely from the ventral side in order to show not only the disposition of these granules, but also the entire extent of this plate in the interradial area. The genital plates are elongated and broadened at the level of the point of union between the mouth shields and the large interradial plate, where their outlines follow a very obtuse angle.

Some variation may be found in the development of the granules which cover the plates of the dorsal surface of the disk. Sometimes these granules are much flattened and consequently only slightly evident. This occurs, for instance, in the largest specimen from station 5259, and the granules along the border of the large ventral interradial plate are particularly very slightly evident. 
In this same example from station $5259 \mathrm{I}$ find a peculiarity which is also found in the small specimen from the same station and which I have not found in any other. At each of the angles of the distal border of the mouth shield there occurs a very small intercalated plate which causes this angle to be somewhat truncated. This plate is very constant and is lacking only in one of the angles of the mouth shield of the large specimen. The appearance of this plate is not correlated with the age of the subject, as I find it both in the small and in the large specimen, and it is lacking in the other large specimens. But $I$ find an indication of it in the form of two very small plates in the specimen from station 5527.

The mouth shields are large, a little longer than broad, pentagonal, with a sharp proximal angle bordered by straight sides, two convex and slightly convergent sides, and a straight distal border. The adoral plates are large, rather short, twice as long as broad, much broadened in their outer half, and tapering inwardly. The oral plates are triangular and high. The lateral mouth papillae are six in number; they are large and rather broad, especially the outermost, which is very highly developed, rectangular in form, and broader than long; the four following are almost square, and the last is conical and pointed; the unpaired terminal papilla is slightly stouter than the preceding.

The first upper arm plate is rectangular, broader than long, with the distal border convex. The following are small, triangular, a little broader than long, and their size decreases very rapidly; they are all widely separated.

The first under arm plate is small, pentagonal, almost as broad as long, with a rather sharp proximal angle. The two following are rather large, elongated, pentagonal, with a sharp proximal angle; they are widely separated; the third is a little broader than the second. Beyond this the plates become extremely small, but they are continued over the greater part of the length of the arms.

The side arm plates are projecting and strongly swollen in their distal dorsal region; they are covered with granules similar to those of the dorsal surface of the disk, but somewhat less evident; these granules soon disappear; and they are, moreover, very unequally developed in different specimens. The arm spines are four in number; the two first form a small group close to the ventral border of the plate, and the second is twice as broad as the first; the two others, somewhat separated from each other and from the small group formed by the two preceding, are smaller and thinner; they are at first some distance from the distal border of the plate on the first arm segments, then little by little they approach that border. I sometimes find at the base of the arms three ventral spines instead of only two. 
The single tentacle scale is oval and larger on the pores of the first pair than on those of the second.

The large specimen from station 5623, in which the diameter of the disk reaches $27 \mathrm{~mm}$., differs in certain respects from the other specimens. The granules of the dorsal surface of the disk are less marked, and the large interradial plate which covers the greater portion of the ventral surface of the disk has the border entirely smooth. The arm spines may reach seven at the base of the arms; there is always a small ventral group of spines which are subequal and relatively small, and separated from these by a short interval a series of five very short spines, papilliform and smaller than the two ventral; this figure falls rather rapidly to four and then to three, and this last number continues over a large part of the length of the arm; I find it still at $50 \mathrm{~mm}$. from the base. But in the interval $I$ find a few segments which have only two dorsal spines, and consequently the total number of spines is here reduced to four; and even on two or three segments these two dorsal spines are entirely lacking. When viewed from the dorsal surface this large specimen very strongly recalls an $O$. lymani; it has the dorsal plates of the disk granulose like this last species, and arranged in similar manner. The smaller specimens also show a certain external resemblance to the young of $O$. lymani, and this resemblance is still further accentuated by the number of the tentacle pores, which are reduced to two pairs; but the arm spines are more numerous in 0 . lymani, and the ventral surface of the disk in the interradial spaces shows a larger number of plates than in the new species; in this, as I have stated, the entire ventral surface is occupied by the large interradial plate, which even reaches the dorsal surface of the disk. In 0 . Jymani the plate which follows the mouth shield is very much smaller, and beyond it the ventral surface of the disk shows several other plates. In reference to this point, the photographs which I give of the ventral surface of the disk of three specimens of $O$. Tymani (pl. 86, figs. $7,8,9$ ) may be compared with those of this species.

Affinities and distinctive features.-Ophiomusium facundum is close to $O$. validum Lyman, but it can not be confused with that species, from which it differs in having the dorsal plates of the disk rather coarsely granulose, in the somewhat different arrangement of the plates of the ventral surface, in the larger size of the mouth shield, in the arrangement of the arm spines, which are generally four in number, the two lowest close to the ventral border of the side arm plate and almost in contact, forming a small group separated from the two others, while the dorsal spines, which are well separated from each other, are arranged somewhat irregularly and are less constant in their number, and the under arm plates are continued over a rather large part of the length of the arms. 
Ophiomusium facundum can not be confused either with the species which $I$ have described above under the name of $O$. facetum, in which the arm spines are more numerous, seven or eight in number at the base of the arms, and very regularly disposed along the distal border. Furthermore, in $O$. facetum the dorsal plates of the disk are entirely smooth, the under arm plates are entirely lacking beyond the third, and the large ventral interradial plate which follows the mouth shield is less developed.

The large specimen from station 5623, of which I have spoken above, in which the granules are very much less developed on the plates of the dorsal surface of the disk and in which the arm spines are more numerous, may seem rather close to 0 . facetum, but there are nevertheless very considerable differences. I find in this specimen that the large ventral interradial plate reaches a very considerable width at the periphery of the disk, the under arm plates are continued throughout the whole preserved portion of the arms, the small group of two ventral spines is always very recognizable and very distinct whatever may be the number of other spines, and the granulation of the dorsal surface of the disk, though less developed, is no less evident.

\section{OPHIOMUSIUM FIMBRIATUM, new species.}

Plate 90, figs. 6-8.

Locality.-Albatross station 5614; Molucca Passage; Tifori Island (C.) bearing $\mathrm{N} .19^{\circ} \mathrm{E}$., 56.52 kilometers (30.5 miles) distant (lat. $0^{\circ} 31^{\prime} 00^{\prime \prime}$ N., long. $125^{\circ} 58^{\prime} 45^{\prime \prime}$ E.) ; 2,011 meters (1.100 fathoms); November 22, 1909 ; gy. M., S., Glob.

One specimen (Cat. No. E. 188, U.S.N.M.).

Description.-The diameter of the disk is $20 \mathrm{~mm}$; the arms are incomplete; one of them is preserved over a length of $40 \mathrm{~mm}$. They are rounded, rather narrow, and measure $4 \mathrm{~mm}$. in width at the base.

The disk is pentagonal with the sides straight; the dorsal surface is plane, the ventral surface is somewhat swollen, and the borders are rounded and somewhat sharpened. The dorsal surface is covered in the central region with numerous small rounded nonimbricated subequal plates, among which it is impossible to find the least indication of primary plates. These plates become larger, and especially they elongate, in the radial and interradial spaces. In the radial spaces they are arranged in three or four rows which separate the two radial shields of each pair for their entire length. In the interradial spaces they form four to five rows, the median ones being a little larger than the others. Toward the periphery of the disk there is a large, transversely broadened, triangular plate which is much arched and three times as broad as long, beyond which are two smaller 
plates; this plate does not occupy quite the entire width of the interradial space. The radial shields are large, much elongated, triangular in form, with the proximal angle very rounded; they are two and a half times as long as broad, and they are not very much broader in their distal portion than in their proximal. The internal borders of the two shields of each pair are parallel and widely separated. Their length is greater than half the radius of the disk.

The ventral surface is covered with rounded plates which are slightly imbricated, subequal, and larger than those which occupy the central region of the dorsal surface. The genital plates are narrow and elongated. The genital slits are very narrow and rather short, occupying scarcely half the length of the interradial area of the ventral surface; they are provided along both borders with small very low rectangular papillae with indistinct outlines. Beyond the genital plate there is a small triangular space extending between the region which separates the side arm plates of the second and third arm segments and the border of the disk; this space is covered with small rounded granules, but these do not continue the genital papillae from which they differ in shape. These small granules extend as far as the outer border of the radial shields, but they are not visible on the dorsal surface; they are well seen only by viewing the arm from the side (fig. 8).

The mouth shields, which are of medium size, are triangular, almost as long as broad, with a rather sharp proximal angle and straight sides which pass over by rounded angles into the more or less excavated distal side. The adoral plates are rather broad in the outer two-thirds of their length, with the two longer sides parallel; they then taper rapidly inward, not touching the median interradial line except by a very short border. The oral plates are triangular and rather high. The lateral papillae are six in number; they are all rectangular and low, with the free border straight; the second papilla is the largest, and the height decreases from the first to the last, which still remains rectangular. The separation of these papillae is not very marked. The unpaired terminal papilla is short, triangular, and obtuse.

The three first upper arm plates are extremely short, and rectangular in form. The following is still very broad, but triangular, with a very obtuse and rounded distal angle. Beyond this the plates assume a lozenge-shaped form with the two proximal sides longer than the two others. The first of these lozenge-shaped plates has the proximal angle truncated and is in contact with the preceding, but beyond this the dorsal plates are separated by a space which increases progressively.

The first under arm plate is rather small, trapezoidal, with the proximal border a little broader than the distal, which is slightly 
convex. The three following plites are large, triangular, as long as broad, with a sharp proximal angle, the sides notched by the tentacle pores, which are rather large, and an almost straight distal border; they are separated by a narrow interval. The following plates become almost triangular; they are very much smaller, broader than long, and widely separated. It can not be said that these plates have a strictly triangular shape, for the two lateral borders are usually broken up into two short sides united by a very obtuse angle, and the two proximal sides are slightly concave.

The side arm plates carry a series of small spines which extend for almost the entire length of their distal border; these spines are very short, conical, and very closely crowded, and altogether they form a sort of fringe in which there may usually be counted nine spines; but there may be only eight of them, or their number may rise to ten.

The tentacle pores number three pairs; those of the first pair are rather large, and they bear on each border three rather small and rounded scales; sometimes the proximal and external border shows only two scales which are a little larger than usual. The pores of the second and of the third pairs in general have only a single proximal scale; sometimes they add two small scales on the distal and internal border.

The color of the specimen in alcohol is yellowish.

Affinities and distinctive features.-Ophiomusium fimbriatum is very close to 0 . multispinosum $\mathrm{H}$. L. Clark. The dorsal surface of the disk shows a very similar arrangement of plates, and the mouth papillae and the adoral and oral plates have also the same characters, but the mouth shields have the distal border slightly concave instead of showing a short and broadened lobe. The greatest difference consists in the number of tentacle pores, which in the new species are three pairs only instead of four; furthermore, these pores appear more developed, and those of the first pair, which are rather elongated, have a few scales on each border; the spines are less numerous than in 0 . multispinosum, in which their number varies between twelve and sixteen. Ophiomusium glabrum Lütken and Mortensen, which, according to H. L. Clark, is perhaps identical with $O$. multispinosum, has four pairs of pores furnished with a single scale on each border, and, according to the authors' figure, the pores of the first pair are not larger than those following; the distal border of the mouth shields is slightly convex, and the number of spines varies between seven and eleven.

In the arrangement of the dorsal plates of the disk and the relative shortness of the genital slits $O$. fimbrintum also recalls $O$. planum Lyman, but it differs from it in the more numerous arm spines, as well as in the form of the mouth shields. 


\section{OPHIOMUSIUM IMPOTENS, new species.}

Plate 90, figs. 9-11.

Locality.-Albatross station 5605; Gulf of Tomini, Celebes; Dodepo Island (W.) bearing N. $14^{\circ}$ W., 10.93 kilometers $(5.9$ miles) distant (lat. $0^{\circ} 21^{\prime} 33^{\prime \prime}$ N., long. $121^{\circ} 34^{\prime} 10^{\prime \prime}$ E.) ; 1,183 meters (647 fathoms); November 16, 1909.

One specimen (Cat. No. 40920, U.S.N.M.).

Description.-The specimen, unfortunately unique, has suffererl an accidental deformation, which was certainly antecedent to its capture, the result of which has been a modification in the form, the arrangement, and the characters of the plates, principally on the dorsal surface of the disk; it seems as if the individual had been stretched in such a way as to elongate the disk in one direction and and narrow it in another. But the characters on which a specific distinction may be based do not appear to have been very much altered, and the individual may be satisfactorily studied. I do not know any species to which it may be referred, and I consider it therefore as representing a new form. I believe that it should be described in spite of the abnormal state of the single specimen.

The disk is flattened; it measures $9 \mathrm{~mm}$. in diameter in the broader part and $7 \mathrm{~mm}$. in the narrower. The arms, which reach $20 \mathrm{~mm}$. in length, are slender, and they become extremely attenuated in their terminal third.

The dorsal surface of the disk is covered with plates of medium size which are more or less imbricated and subequal. There may be recognized a rounded dorso-central, a little larger than the neighboring plates; there must have been five primary radials transversely broadened, and all a little larger than the other plates, separated from the dorso-central by a row of smaller plates. The other plates are arranged without any order. At the periphery of the disk and in the middle of each interradial space a slightly larger plate may be made out; in each radial space, at the level of the proximal angle of the radial shields, there is also found a plate which is a little larger than those around it. The radial shields are rather large, triangular, half again as long as broad, and slightly divergent; the two shields of each pair are widely separated for their whole length by a single row of plates in the distal portion, and by two or three plates in the proximal portion. The radial shields do not appear to have preserved their normal form except on a single ray; in two other radii a single shield of each pair has the normal form, while its more or less reduced fellow is shoved off to one side. In the two other radii the plates which appear to represent the radial shields are very small. 
The ventral surface of the disk is covered with subequal, irregularly polygonal or rounded plates, which are slightly imbricated and of medium size. A rather broad and elongated genital plate can be recognized. The genital slits are very narrow, and they appear to extend from the border of the disk as far as the distal angle of the adoral plates. I find on their interradial border some small and obtuse papillae which do not always form a continuous row; but the gaps are evidently accidental.

The rather large mouth shields are pyriform, a little longer than broad, with a sharp proximal angle and a rounded distal border. They are well developed only in three interadii, and in the two others I find instead of these shields and in their place only a small plate resembling those about it. The adoral plates are large and elongated, a little broader outwardly, with the borders slightly sinuous. The oral plates are rather elongated, three times as long as broad. The mouth papillae are six or seven in number on each side; the first proximal papilla is small, but conical and pointed; the two following are rather low and short, and the distal papillae are thicker and broader, especially the penultimate. The unpaired terminal papilla is elongated and conical, scarcely larger than those on either side.

The two first upper arm plates are short and transversely broadened. The following is quadrangular, as long as broad, with the proximal border narrow, the distal border a little longer, and the sides straight and slightly divergent. The fourth plate is a little longer and narrower, and trapezoidal in form, though it still remains a little broader than long. All these plates are in contact, but those following are separated by a wide interval; they are triangular with a sharp proximal angle and a convex distal border which may be resolved into two short sides united by a very obtuse angle; they remain a little broader than long. Their dimensions become progressively reduced, though they may be recognized as far as the vicinity of the arm tip.

The first under arm plate is small, pentagonal, with an obtuse proximal angle, converging and slightly excavated sides, and a straight and narrow distal border. The two following are pentagonal, longer than broad, with a straight and narrow proximal border, elongated sides which are more or less excavated by the corresponding tentacle pores, and two short distal sides united by a rounded angle. The dimensions diminish rapidly from the second to the fourth, which is no longer in contact with the preceding. The following plates become very much smaller and are broadly separated; they are triangular, a little broader than long, with a convex distal border; their size diminishes progressively toward the tip of the arms. 
The side arms, which are elongated and slightly projecting, bear at first seven and then six small, short, papilliform spines, which are situated along their distal borders; the number of the spines falls rather rapidly to five and then to four, and finally to only three.

The tentacle pores number three pairs; they are sometimes covered by a large oval scale, and sometimes by two smaller scales; the pores of the first pair are rather large, and their size diminishes progressively as far as the third pair.

The color of the specimen in alcohol is whitish.

Affinities and distinctive features.-Ophiomusium impotens belongs to that section of the genus Ophiomusium in which the dorsal and ventral plates persist throughout almost the entire length of the arms. It shows some affinities with $O$. cancellatum Lyman, 0 . corticosum Lyman, $O$. diomedeae Lütken and Mortensen, $O$. properum. Kohler, and $O$. serratum Lyman, but it differs markedly from all these species and can not be confused with any of them. Ophiomusium cancellatum has only two or three arm spines, and the dorsal surface of the disk is covered with numerous imbricated plates; 0 . corticosum, which has, like $O$. impotens, numerous arm spines, has four pairs of tentacle pores; $O$. diomedeae has the mouth shields very small; $O$. properum has only three pairs of tentacle pores, and its arm spines are very different; 0 . serratum, which has four or five arm spines, has the dorsal plates of the disk larger and less numerous, the mouth shields larger, the radial shields smaller, etc.

\section{OPHIOMUSIUM LIGATUM, new species.}

Plate 90 , figs. $3-5$.

Localities.-Albatross station 5445; east coast of Luzon, San Bernardino Strait to San Miguel Bay; Atalaya Point, Batag Island, bearing S. $56^{\circ}$ E., 9.82 kilometers $\left(5.3\right.$ miles) distant (lat. $12^{\circ} 44^{\prime}$ $42^{\prime \prime}$ N., long. $124^{\circ} 59^{\prime} 50^{\prime \prime}$ E.) ; 700 meters (383 fathoms) ; June 3, 1909 ; gn. M., S.

One specimen (Cat. No. E. 80, U.S.N.M.).

Albatross station 5650; Gulf of Boni, Celebes; Lamulu Point bearing $\mathrm{N}$. $5^{\circ} \mathrm{W}$., 23.16 kilometers (12.5 miles) distant (lat. $4^{\circ} 53^{\prime} 45^{\prime \prime}$ S., long. $121^{\circ} 29^{\prime} 00^{\prime \prime}$ E.) ; 987 meters (540 fathoms) ; December 17, 1909 ; gn. M.

Two specimens (Cat. No. E. 81, U.S.N.M.).

Description.-The three specimens are of very large size and the diameter of the disk varies between $20 \mathrm{~mm}$. and $22.5 \mathrm{~mm}$.; one of the arms of the specimen from station 5445 , which is entire, exceeds $110 \mathrm{~mm}$. in length. The habitus is very robust, and the individuals recall very strongly 0 . trychnum, described by H. L. Clark from specimens from Japan from depths varying between 128 and 1,057 
meters ( 70 and 578 fathoms). I have even asked myself whether there were not really of the same species or rather of a variety of the form described by H. L. Clark; but the differences seem to me sufficiently marked to justify a specific separation.

The disk is rather thick, and its height reaches $4 \mathrm{~mm}$. But this is far from the figure given by H. L. Clark for O. trychnum, in which the height reaches $6 \mathrm{~mm}$. in a specimen of the disk of which is 18 $\mathrm{mm}$. in diameter; the figure $4 \mathrm{~mm}$., representing the height, is meas: ured on a specimen from station 5445 in which the disk has a diameter of $22.5 \mathrm{~mm}$.

The disk is pentagonal, with the sides straight; the two surfaces are plane and parallel. The arrangement of the dorsal plates recalls 0 . trychnum, but the plates which occupy the central region are more numerous; furthermore, the three successive plates which occupy alone each interradial space in 0 . trychnum are more reduced, and they are each surrounded by a circlet of very small plates; these interradial plates; like the radial shields, do not show the least indication of that coarse tuberosity which occurs in 0 . trychnum, and which appears to be quite characteristic of that species; in the new species all these plates are simply furnished with rounded granules which are rather closely crowded and only slightly prominent, and do not in any way deserve the name of tuberosities. Beyond the radial shields in place of the three or four plates which occur in $O$. trychnum there are to be seen a large number of very small rounded plates forming three more or less regular principal rows, to which are added some other still smaller plates. The two interradial plates which lie at the periphery of the disk are in no way swollen as in $O$. trychnum.

The mouth shields have a form slightly different from that shown by H. L. Clark's figures, the sides being parallel and not divergent, and the distal border rounded.

The form of the upper, under, and side arm plates is the same as in 0 . trychnum, but there is an important difference in the number of the arm spines which reaches in the new species eight or nine at the base of the arms, then remaining seven for the greater part of their length, while there are only five or six in O.trychnum. These spines, which are very small, are inserted slightly behind the distal border of the side arm plate, thus forming an oblique row which toward the ventral side progressively retreats from the distal border: the first ventral spines, numbering four on the first segments and three on those following, are very close together and form a small group somewhat distinct from the following spines which are regnlarly disposed at equal intervals.

To sum up, the principal differences are found in the dorsal plates of the disk, which are simply granulose, and the arm spines, 
which are more numerous in 0 . ligatum than in 0 . trychnum; these differences have seemed to me important enough to separate from this last the species from the Philippines.

\section{OPHIOMUSIUM LUNARE LYman.}

Plate 87 , fig. 8.

Ophiomusium lunare LYMAN ('78), p. 116, pl. 1, figs. 4-6; ('82), p. 84, pl. 1, figs. 13-16.-KGeHLer ('04), p. 58.-H. L. ClaAk ('11), p. 107; ('15), p. 330.-Matsumoto ('17), p. 289.

Localities-Albatross station 5444; east coast of Luzon, San Bernardino Strait to San Miguel Bay; Atalaya Point, Batag Island, bearing S. $65^{\circ}$ E., 9.45 kilometers $\left(5.1\right.$ miles) distant (lat. $12^{\circ} 43^{\prime}$ $51^{\prime \prime} \mathrm{N}$., long. $124^{\circ} 58^{\prime} 50^{\prime \prime}$ E.) ; 563 meters (308 fathoms); June 3, 1909 ; gn. M.

Two specimens (Cat. Nos. 41168, 41169, U.S.N.M.).

Albatross station 5445; east coast of Luzon; San Bernardino Strait to San Miguel Bay; Atalaya Point, Batag Island, bearing S. $56^{\circ}$ E., 9.82 kilometers (5.3 miles) distant (lat. $12^{\circ} 44^{\prime} 42^{\prime \prime} \mathrm{N}$., long. $124^{\circ} 59^{\prime}$ $50^{\prime \prime}$ E.; 701 meters (383 fathoms); June 3, 1909; gn. M., S.

Two specimens (Cat. No. 40918, U.S.N.M.).

Notes.-The diameter of the disk varies between $10 \mathrm{~mm}$. and $13 \mathrm{~mm}$.

In the arrangement of the dorsal plates of the disk these specimens differ somewhat from the type described by Lyman, but I believe that these differences are due simply to a difference in the size of the specimens. Lyman's type had the disk only $7 \mathrm{~mm}$. in diameter, and the plates were less numerous than in the specimens collected by the Albatross, in which the large plates of the disk, which alone occur in Lyman's type, are separated by a certain number of smaller plates. But I find that the latter are less numerous in the small specimens than in the large, which would confirm my supposition. I have already called attention ('04, p. 59) to similar differences due to age in describing the specimens collected by the Siboga. The two radial shields of each pair are separated for their entire length in the largest specimens, but in the smallest they are in contact by their outer angle, while in Lyman's type they are in contact for half of their length. They are a little larger in my specimens than in the latter. The mouth shields are also a little more elongated. But the other characters are so in agreement with Lyman's description that I do not hesitate to refer my specimens to 0 . lunare.

In the specimens which he examined, in which the diameter of the disk varied between $6 \mathrm{~mm}$. and $13 \mathrm{~mm}$., H. L. Clark ('11, p. 107), also found differences correlated with the size of the individuals similar to those which I have noted in the arrangement of the dorsal plates of the disk. I may add also that in the two specimens from 
station 5445 the two or three first side arm plates usually bear, at some distance from the group formed by the two small normal spines, a third spine still smaller than these two latter, which is close to the dorsal border of the plate; this arrangement is more marked in the small specimen in which the diameter of the disk is $10.5 \mathrm{~mm}$. than in the other in which this diameter reaches $13 \mathrm{~mm}$.

\section{OPHIOMUSIUM LYMANI Wyville Thomson.}

Plate 86 , figs. 5, 7-9.

\section{See for bibliography:}

Ophiomusium lymani KaehleR ('04), p. 58; ('09), p. 61.-MACClendon ('09), p. 36 , pl. 1, figs. 3, 4.-H. L. Crakk ('11), p. 107 ; ('13), p. 213.-MortenSen ('13), p. 254.-Farran ('13), p. 34.-KGhler ('14), p. 26.-H. L. Clark ('15), p. 331.-Matsumoto ('17), p. 289.

Localities.-Aibatross station 5283; China Sea, in the vicinity of southern Luzon; Malavatuan Island (N.) bearing N. $64^{\circ}$ W., 16.21 kilometers (8.75 miles) distant (lat. $13^{\circ} 48^{\prime} 30^{\prime \prime} \mathrm{N}$., long. $120^{\circ} 28^{\prime}$ 40 " E.) ; 512 meters (280 fathoms); July 18, 1908; dk. gy. S.

Four specimens (Cat. No. E. 310, U.S.N.M.).

Albatross station 5349; Palawan Passage; Point Tabonan bearing N. $85^{\circ}$ E., 83.77 kilometers (45.2 miles) distant (lat. $10^{\circ} 54^{\prime} 00^{\prime \prime}$ N., long. $118^{\circ} 26^{\prime} 20^{\prime \prime}$ E.) ; 1,335 meters (730 fathoms); December 27, 1908; Co., S.

Fifteen specimens, of which some are very large (diameter of the disk from 30 to $35 \mathrm{~mm}$.) (Cat. No. E. 367, U.S.N.M.).

Albatross station 5423; Joló Sea; Cagayan Island (S.) bearing S. $11^{\circ}$ E., 8.89 kilometers (4.8 miles) distant (lat. $9^{\circ} 38^{\prime} 30^{\prime \prime} \mathrm{N}$, long. $121^{\circ} 11^{\prime} 00^{\prime \prime}$ E.) ; 929 meters (508 fathoms) ; March 31, 1909; gy. M., co. S.

Six specimens (Cat. No. E. 311, U.S.N.M.).

A7batross station 5601; Gulf of Tomini, Celebes; Limbe Island (NE.) bearing N., 38.36 kilometers (20.7 miles) distant (lat. $1^{\circ} 1^{\prime}$ $10^{\prime \prime}$ N., long. $125^{\circ} 17^{\prime} 05^{\prime \prime}$ E.) ; 1,398 meters (765 fathoms); November 13, 1909; S., Glob., Ptr.

Thirteen specimens (Cat. No. E. 283, U.S.N.M.).

Albatross station 5602; Gulf of Tomini, Celebes; Gorontalo Pier bearing $\mathrm{N}$., 13.16 kilometers $(7.1 \mathrm{miles})$ distant (lat. $0^{\circ} 22^{\prime} 00^{\prime \prime} \mathrm{N}$., long. $132^{\circ} 03^{\prime} 30^{\prime \prime}$ E.) ; 1,759 meters (962 fathoms); November 14, 1909 ; gy. M.

Three specimens (Cat. Nos. E. 174 [part], E. 175 [part], U.S.N.M.) Albatross station 5603; Gulf of Tomini, Celebes; Gorontalo Pier bearing N. $6^{\circ} \mathrm{W} ., 10.56$ kilometers (5.7 miles) distant (lat. $0^{\circ} 24^{\prime} 00^{\prime \prime}$ N., long. $123^{\circ} 03^{\prime} 45^{\prime \prime}$ E.) ; 1,469 meters (803 fathoms) ; November 15,$1909 ; \mathrm{S}$. 
A disk in bad condition (Cat. No. 41180, U.S.N.M.).

Albatross station 5605; Gulf of Tomini, Celebes; Dodepo Istanc (W.) bearing N. $14^{\circ}$ W., 10.93 kilometers (5.9 miles) distant (lat. $0^{\circ} 21^{\prime} 33^{\prime \prime} \mathrm{N}$., long. $121^{\circ} 34^{\prime} 10^{\prime \prime}$ E.) ; 1,183 meters (647 fathoms); November 16, 1909.

Two small specimens (Cat. No. 41182 , U.S.N.M.).

Albatross station 5606; Gulf of Tomini, Celebes; Dodepo Islanà (W.) bearing N. $3^{\circ}$ W., 20.01 kilometers (10.8 miles) distant (lat. $0^{\circ} 16^{\prime} 28^{\prime \prime}$ N., long. $121^{\circ} 33^{\prime} 30^{\prime \prime}$ E.) ; 1,525 meters (834 fathoms); November 17, 1909 ; gn. M.

Nine specimens (Cat. No. E. 308, U.S.N.M.).

Albatross station 5608; Gulf of Tomini, Celebes; Binang Unang Island peak bearing S. $87^{\circ}$ E., 35.21 kilometers (19 miles) distant (lat. $0^{\circ} 08^{\prime} 00^{\prime \prime}$ S., long. $121^{\circ} 19^{\prime} 00^{\prime \prime}$ E.) ; 1,992 meters $(1,089$ fathoms); November 18, 1909; gy. M.

One small specimen (Cat. No. 41181 , U.S.N.M.).

Albatross station 5614; Molucca Passage; Tifori Island (C.) bearing N. $19^{\circ} \mathrm{E} ., 56.52$ kilometers (30.5 miles) distant (lat. $0^{\circ} 31^{\prime} 00^{\prime \prime} \mathrm{N}$., long. $125^{\circ} 58^{\prime} 45^{\prime \prime}$ E.) ; 2,012 meters (1,100 fathoms) ; November 22 , 1909 ; gy. M., S. Glob.

Two specimens (Cat. No. E. 174 [part], U.S.N.M.).

Albatross station 5623; between Gillolo and Makyan Islands; Makyan Island (S.) bearing S. $88^{\circ}$ W., 13.90 kilometers (7.5 miles) distant (lat. $0^{\circ} 16^{\prime} 30^{\prime \prime} \mathrm{N}$., long. $127^{\circ} 30^{\prime} 00^{\prime \prime}$ E.) ; 497 meters (272 fathoms); November 29, 1909; fne. S., M.

Two specimens (Cat. No. E. 309, U.S.N.M.).

Albatross station 5648; Buton Strait; North Island (S.) bearing N. $87^{\circ}$ E., 18.90 kilometers $\left(10.2\right.$ miles) distant (lat. $5^{\circ} 35^{\prime} 00^{\prime \prime} \mathrm{S}$., long. $122^{\circ} 20^{\prime} 00^{\prime \prime}$ E.) ; 1,022 meters (559 fathoms) ; December 16, 1909 ; gn. M.

Two specimens (Cat. No. E. 82, U.S.N.M.).

Albatross station 5651; Gulf of Boni, Celebes; Buginkali Point bearing S. $67^{\circ} \mathrm{E}$., 38.91 kilometers (21 miles) distant (lat. $4^{\circ} 43^{\prime} 50^{\prime \prime}$ S., long. $121^{\circ} 23^{\prime} 24^{\prime \prime}$ E.) ; 1,280 meters (700 fathoms) ; December 17, 1909.

Two specimens (Cat. No. 41140 , U.S.N.M.).

Albatross station 5652 ; Gulf of Boni, Celebes; Lamulu bearing S. $36^{\circ}$ E., 13.90 kilometers (7.5 miles) distant (lat. $4^{\circ} 35^{\prime} 00^{\prime \prime} \mathrm{S}$., long. $121^{\circ} 23^{\prime} 06^{\prime \prime}$ E.) ; 960 meters (525 fathoms) ; December 17,1909 ; gn.M.

Two specimens (Cat. No. E. 174 [part], U.S.N.M.).

Albatross station 5656; Gulf of Boni, Celebes; Olang Point bearing N. $67^{\circ}$ W., 26.87 kilometers (14.5 miles) distant (lat. $3^{\circ} 17^{\prime} 40^{\prime \prime}$ S., $120^{\circ} 36^{\prime} 45^{\prime \prime}$ E. ; 885 meters (484 fathoms) ; December 19, 1909 ; gy. M.

Fragment (Cat. No. 41183, U.S.N.M.). 
Albatross station 5670; Macassar Strait; Chenoki Point bearing S. $60^{\circ}$ E., 74.13 kilometers (40 miles) distant (lat. $1^{\circ} 19^{\prime} 00^{\prime \prime}$ S., long. $118^{\circ} 43^{\prime} 00^{\prime \prime}$ E.) ; 2,160 meters (1,181 fathoms) ; December 30, 1909 ; gy. M.

Some specimens (Cat. No. E. 175 [part], U.S.N.M.).

Notes.-A number of variations of this species, which is very widely distributed at great depths, have been described by authors. The mouth shields and the plate which follows them on the ventral surface of the disk in particular show rather variable outlines. I include figures of the ventral surface of three specimens in order to show the differences in the form of the mouth shields including the majority of the ordinary cases; these three specimens came from station 5349. In the specimen shown in figure 7 the shields are almost as long as broad and trifoliate in form; the plate which follows them is short, and very much broader than long. In the specimen shown in figure 8 the shields are triangular and elongated, very much longer than broad, with the sides straight; the interradial plate which follows is still broader than long, but a little shorter than in the preceding specimen. In the specimen shown in figure 9 the mouth shields, which are trifoliate, are deeply notched by the bottom of the genital slits, and they are longer than broad; the following plate is almost as broad as long, and sometimes even slightly longer than broad.

In these different specimens, and in others such as those which Liitken and Mortensen have figured ('99, pl. 3, fig. 10), the same proportionate size of the mouth shields and of the plate which follows them in reference to the dimensions of the other ventral plates of the disk is maintained. In a specimen from station 5652 the size of the mouth shields, as well as that of the following plate, is extremely reduced, and it scarcely exceeds that of the other plates of the ventral surface.

The number of arm spines may exceed the figures usually given. Lütken and Mortensen, who have recorded different variations in 0 . Tymani, give the number six to eight as being usual. More recently MacClendon ('09, p. 36), in recording a specimen in which the diameter of the disk is $30 \mathrm{~mm}$., also gives six to eight spines. I find in the majority of the large specimens that these spines are very much more numerous, and 10 to 12 are not rare; on the arm which 1 show on plate 86 as figure 5 , which is from a specimen from station 5349 , some segments may even bear as many as 13 arm spines.

OPHIOMUSIUM MORIO, new species.

Plate 89 , figs. 3,4 .

Locality.-Albatross station 5392; between Sámar and Masbate; Tubig Point bearing N. $49^{\circ}$ E., 9.27 kilonıeters ( 5 miles) distant (lat. 
$12^{\circ} 12^{\prime} 35^{\prime \prime}$ N., long. $124^{\circ} 02^{\prime} 48^{\prime \prime}$ E.; 247 meters (135 fathoms); March 13, 1909.

One specimen (Cat. No. 40993, U.S.N.M.).

Description.-The diameter of the disk is $14 \mathrm{~mm}$.; the arms are all broken off at some distance from their base.

The disk is rounded; the dorsal surface is slightly convex, and the ventral surface is quite plane. The arms are rather broad, and they taper gradually and regularly; the ventral surface is plane; the dorsal surface is slightly depressed along the median line.

The dorsal surface of the disk is covered with plates which are not very numerous and rather large, and the radial shields are very large; the general appearance strongly recalls the arrangement described and figured by Lyman in 0 . simplex. There can be distinguished a primary rosette of contiguous plates, the polygonal dorsocentral and the radials, which are almost as large, and slightly broadened transversely. Then comes a pair of smaller plates, and then a series of three plates separating the two radial shields of each pair; the first of these plates is large and triangular, the second is small, elongated and very narrow, and the third is short and trapezoidal. In the interradial spaces there are found two successive large plates which are longer than broad, the outermost of which lies very near the periphery of the disk and is bounded below by two small rounded and projecting plates; some very small plates are seen here and there between the preceding, but they are not numerous. The radial shields are very large and very broad, triangular, with the angles rounded; they are half again as long as broad, and their length equals or slightly exceeds half the radius of the disk; the two shields of each pair are slightly divergent inwardly, and are separated for their whole length.

The ventral surface of the disk beyond the large mouth shields is occupied by a single large plate which is quadrangular, with the sides divergent and rounded, and a convex distal border which passes over into the sides by very rounded angles. On either side of this large plate is found the small projecting plate described above, which is visible both from the dorsal and from the ventral surface. The genital plate is much broadened and is notched toward its proximal third by the genital slit. This, of a very peculiar form and very short, appears as a small triangle the apex of which notches the genital plate, and the base of which rests upon the first side arm plate toward its distal angle.

The mouth shields are large, elongated, and triangular, with tht proximal apex sharp and produced, extending between the adoral plates; the sides are slightly convex, and the distal border is straight or slightly excavated; they are very much longer than broad. On four of them the proximal region is separated from the rest by a 
transverse groove. The adoral plates are large, triangular, broadened outwardly, and tapering and pointed inwardly. The oral plates are triangular and much elongated, a shape correlated with the great length of the mouth slits. The mouth papillae number eight or nine on either side, forming a very narrow fringe in which the borders of the individual papillae are only slightly marked, except those of the two outermost, which are larger and a little broader than the others and rectangular in form. The unpaired terminal papilla is also only slightly developed.

The first upper arm plate is trapezoidal, broader than long, with the distal border slightly convex; the second, which is in contact with the preceding, is long, trapezoidal, with the proximal border narrower. The following are triangular, and they become rapidly small, though they persist throughout the whole preserved portion of the arms; they are widely separated from each other and remain a little broader than long.

The first under arm plate is small, rectangular, almost square, or a little longer than broad. The two following are rather large, polygonal, and widely separated; the second is a little longer than broad, and the third is almost as long as broad or a little broader than long. Beyond this the ventral plates are entirely lacking.

The side arm plates, which are slightly projecting, bear two very small spines situated close to the ventral border.

The tentacle pores, which number two pairs, are very small, and are each covered by an extremely reduced scale.

The color of the specimen in alcohol is a very light yellowish white.

Affinities and distinctive features.-Ophiomusium morio very much resembles $O$. simplex Lyman, and the arrangement of the plates of the disk is almost the same in the two species with in 0 . morio a few additional plates separating the radial shields, which in this species are not in contact. It might be supposed that the differences observed depended on the age of the specimens, for 0 . simplex was described by Lyman from a specimen in which the diameter of the disk was only $6 \mathrm{~mm}$. But H. L. Clark has shown that the dorsal plates of the disk become very numerous in the adult $O$. simplex, which then assumes an aspect so different that I described this adult as a different species, to which I gave the name of 0 . sanctum. If 0 . simplex when adult takes on the characters of $O$. sanctum, it naturally can not retain the arrangement of the dorsal plates that it had when young, and which is exactly what I find in my specimen, the disk of which is $14 \mathrm{~mm}$. in diameter. It may be seen by comparing the photograph which I give here of 0 . morio with that which I give of an 0 . simplex (pl. 88, figs. 10, 11) of almost the same size (which therefore shows the characters of my 
O. sanctum) that the two ophiurans can not belong to the same species and that they differ not only in the arrangement of the plates of the dorsal surface, but also in the characters of the ventral surface. The new species differs from $O$. simplex as that species was described by Lyman in the radial shields, of which the proximal portion is produced into a very sharp angle, and in the great development of the ventral interradial plate which follows the mouth shield, of which the distal border is very convex. But it is especially remarkable for the very peculiar form of the genital slits, a form which is not met with in any other species of the genus Ophiomusium, and which appears to me to be quite characteristic.

\section{OPHIOMUSIUM PROPERUM Kohler.}

Ophiomusium properum K(EHLER ('04), p. 62, pl. 10, figs. 11-13.-H. L. Clark ('15), p. 334.

Locality.-Albatross station 5646; Buton Strait; North Island (S.) bearing S. $68^{\circ}$ E., 13.90 kilometers $\left(7.5\right.$ miles) distant (lat. $5^{\circ}$ $31^{\prime} 30^{\prime \prime}$ S., long. $122^{\circ} 22^{\prime} 40^{\prime \prime}$ E.) ; 834 meters ( 456 fathoms); December 16,1909 ; gn. M.

One specimen (Cat. No. 40994, U.S.N.M.).

Notes.-The diameter of the disk is $10 \mathrm{~mm}$.

This specimen agrees well with the types collected by the Siboga in the Sunda Archipelago between $0^{\circ}-7^{\circ}$ S. latitude and $117^{\circ}-119^{\circ}$ E. longitude, in 695 to 724 meters ( 383 to 497 fathoms), in which the diameter of the disk varied between $11 \mathrm{~mm}$. and $12 \mathrm{~mm}$.

\section{OPHIOMUSIUM RELICTUM Kœhler.}

Plate 91, figs. 6-8.

Ophiomusium relictum KíceHLER ('04), p. 61, pl. 10. figs. 5-7.-H. L. ClaRK ('15), p. 334.

Locality.-Albatross station 5651; Gulf of Boni, Celebes; Buginkali Point bearing S. $67^{\circ}$ E., 38.91 kilometers (21 miles) distant (lat. $4^{\circ} 43^{\prime} 50^{\prime \prime}$ S., long. $121^{\circ} 23^{\prime} 24^{\prime \prime}$ E.) ; 1,280 meters (700 fathoms); December 17, 1909.

One specimen (Cat. No. 40919, U.S.N.M.).

Notes. - The diameter of the disk is $9 \mathrm{~mm}$. One of the arms, which is preserved for its entire length, measures $35 \mathrm{~mm}$.

The specimen agrees well in its principal characters with the types which were collected by the Siboga in $0^{\circ}-7^{\circ} \mathrm{S}$. latitude, $117^{\circ}-$ $119^{\circ} \mathrm{E}$. longitude, at depths between 695 and 724 meters (383 to 396 fathoms), and in which the diameter of the disk varied between 11 $\mathrm{mm}$. and $12 \mathrm{~mm}$. The Albatross specimen differs from them only in having the tuberosities of the dorsal plates of the disk more marked and in having the arm spines a little more developed. I include on plate 91 as figures 6-8 photographs of the two surfaces of the disk, and a side view of the arms. 


\section{OPHIOMUSIUM SCALARE Lyman.}

Plate 89 , fig. 7 ; plate 90 , figs. $1,2$.

Ophiomusium scalare LyMAN ('78), p. 117, pl. 1, figs. 1-3; ('82), p. 95, pl. 1, figs. 4-6.-KGeHLER ('96), p. 308, pl. 6, figs. 24, 25; ('99), p. 26, pl. 2, figs. 12, 13 ; pl. 3, fig. 21.-H. I. Clark ('15), p. 334.-Matsumoto ('17), p. 285, fig. 77.

Locality.-Albatross station 5135; vicinity of Joló; Joló Light bearing S. $46^{\circ}$ W., 22.05 kilometers (11.9 miles) distant (lat. $6^{\circ} 11^{\prime}$ $50^{\prime \prime}$ N., long. $121^{\circ} 08^{\prime} 20^{\prime \prime}$ E.) ; 294 meters (161 fathoms) ; February 7,1908 ; fne. co. S.

One specimen (Cat. No. 40941, U.S.N.M.).

Notes. - The diameter of the disk is $9 \mathrm{~mm}$.

I have had occasion at different times ('96, p. 308; '99, p. 26; and '04, p. 65) to describe the variations shown by 0 . scalare. The Albatross specimen recalls the one which the Siboga collected at station 280. The radial shields are triangular, and the two plates of each pair are in contact outwardly, or very close to each other; the arm spines are three in number. I give photographs of the dorsal and ventral surfaces of the disk, as well as a side view of the arm, of this specimen.

Ophiomusium scalare was discovered by the Challenger in $28^{\circ} \mathrm{S}$. latitude and $177^{\circ} \mathrm{W}$. longitude, 1,097 meters (600 fathoms); it was rediscovered by the Investigator in the Andaman Islands, in 204 meters (112 fathoms), and by the Siboga in two localities in the Sunda Islands $\left(8^{\circ}\right.$ and $10^{\circ} \mathrm{S}$. latitude, $123^{\circ}$ and $127^{\circ} \mathrm{E}$. longitude [520 and 1,224 meters; 285 and 672 fathoms]). Matsumoto has just recorded it from Japan (Ukishima, 549 meters [300 fathoms]).

\section{OPHIOMUSIUM SIMPLEX Lyman.}

Plate 88, figs. 10, 11.

Ophiomusium simplex Lyman ('78), p. 115, pl. 1, figs. 10, 11; ('82), p. 93, pl. 1, figs. 7-9.-H. I. Clark ('11), p. 109; ('15), p. 333.

Ophiomusium sanctum KGHLER ('04) p. 59, pl. 11, figs. 7-9.

Localities.-Albatross station 5356; north Balabac Strait; Balabac Light bearing S. $64^{\circ}$ W., 28.72 kilometers (15.5 miles) distant (lat. $8^{\circ} 06^{\prime} 40^{\prime \prime}$ N., long. $117^{\circ} 18^{\prime} 45^{\prime \prime}$ E.) ; 106 meters (58 fathoms); January 5, 1909 ; S., Sh.

Five specimens (Cat. No. 40985, U.S.N.M.).

Albatross station 5357; north Balabac Strait; Balabac Light bearing S. $65^{\circ} \mathrm{W}$., 26 kilometers (14.3 miles) distant (lat. $8^{\circ} 06^{\prime} 00^{\prime \prime} \mathrm{N}$., long. $117^{\circ} 17^{\prime} 10^{\prime \prime}$ E.) ; 124 meters (68 fathoms) ; January 5, 1909; Co., S.

Seven specimens (Cat. Nos. 40987, 40988, U.S.N.M.).

Albatross station 5433; eastern Palawan and vicinity; Corandagos Island (NW.) bearing N. $30^{\circ}$ E., 12.05 kilometers ( 6.5 miles) dis- 
tant (lat. $10^{\circ} 37^{\prime} 30^{\prime \prime} \mathrm{N}$., long. $120^{\circ} 11^{\prime} 05^{\prime \prime}$ E.) ; 99 meters (54 fathoms); April 8, 1909; gn. M., co. S.

One specimen (Cat. No. 40986, U.S.N.M.).

Notes. - The diameter of the disk varies between $8 \mathrm{~mm}$. and $10 \mathrm{~mm}$.

In $1904 \mathrm{I}$ described under the name of Ophiomusium sanctum an Ophiomusium which I believed to be new and which did not agree with the description given by Lyman of 0 . simplex; my specimens were larger than the single individual on which Lyman established this latter species, which had a disk only $6 \mathrm{~mm}$. in diameter. H. L. Clark, who has had at hand a series of 16 specimens in which the diameter of the disk varied between $4 \mathrm{~mm}$. and $14 \mathrm{~mm}$., has been able to convince himself that all intermediate forms between 0 . simplex Lyman and my $O$. sanctum exit; it is therefore necessary to unite the two forms (see for further details H. L. Clark's memoir, '11, p. 109). The specimens collected by the Albatross are quite identical with those collected by the Siboga upon which I based $O$. sanctum in 1904.

\section{OPHIOMUSIUM SPINULOSUM, new species.}

Plate 87, figs. 1-7.

Localities.-Albatross station 5650; Gulf of Boni, Celebes; Lamulu Point bearing N. $5^{\circ}$ W., 23.16 kilometers (12.5 miles) distant (lat. $4^{\circ} 53^{\prime} 45^{\prime \prime}$ S., long. $121^{\circ} 29^{\prime} 00^{\prime \prime}$ E.) ; 987 meters (540 fathoms); December 17, 1909 ; gn. M.

Two specimens (Cat. No. E. 189, U.S.N.M.).

Albatross station 5651; Gulf of Boni; Buginkali Point bearing S. $67^{\circ}$ E., 38.92 kilometers (21 miles) distant (lat. $4^{\circ} 43^{\prime} 50^{\prime \prime}$ S., long. $121^{\circ} 23^{\prime} 24^{\prime \prime}$ E.) ; 1,280 meters (700 fathoms) ; December 17, 1909.

One specimen (Cat. No. E. 190, U.S.N.M.).

Description.-The two specimens from station 5650 are complete, and one of them is in an excellent state of preservation; in the other the disk is somewhat damaged. The diameter of their disks is $18 \mathrm{~mm}$, and the arms reach $55 \mathrm{~mm}$. in length. In the specimen from station 5651 the diameter of the disk is $20 \mathrm{~mm}$; three arms are broken off at the line of contact with the disk and the two others a little further out.

I shall describe the species more especially from the specimen from station 5651, which is a little larger than the others.

The disk is pentagonal, with the borders straight; it is flattened on the two surfaces, which are slightly depressed toward the center. The dorsal surface is covered with very numerous small, subequal, imbricated plates among which it is impossible to recognize the primary plates (fig. 3.); but on the two specimens from station 5650 (fig. 5) six very small, rounded, and slightly swollen plates may be 
distinguished, the radials being far removed from the dorsocentral. The plates become a little larger toward the periphery of the disk, and in the middle of each interradial space between the radial shields there is a rather large rounded plate which is somewhat broadened transversely, on either side of which are three or four rows of small plates. Between the two radial shields of each pair there are six to eight more or less regular rows of plates, the median a little the larger. Except in the central region of the disk, where they are entirely unarmed, these plates bear very small spines which are extremely reduced, conical, with the point blunted; each plate may carry from one to three of these spines which are sometimes inserted toward the borders and sometimes over the surface of the plate. These spines are more or less developed in the specimen from station 5651 ; in the two others they are not very common and are not seen except toward the periphery of the disk or in the vicinity of the radial shields. These last are rather large, triangular, with the angles very rounded, somewhat divergent, and widely separated by sereral rows of plates; they are longer than broad, and their length is equal to a third of the radius of the disk. On their surface in the proximal half and toward the outer border they bear spines identical with those of the other plates of the disk; these spines are a little shorter and relatively thicker in the example from station 5651.

The ventral surface of the disk is covered with numerous imbricated plates, which are larger than those on the dorsal surface and somewhat unequal. Toward the periphery spines identical with those on the dorsal surface are found, but there are only a few of them here. The genital plates are rather large, elongated, and broadened in their distal part. The genital slits are narrow and extend over a length of about two-thirds of the radius of the ventral surface of the disk; they are furnished on their two borders with small and closely crowded papilae.

The mouth shields are elongated, longer than broad, sagittate in form and pentagonal, with a sharp proximal angle, two straight sides slightly notched toward their distal third by the bottom of the genital slits, and a slightly rounded distal border. In the specimen from station 5661 these shields are more elongated and narrower; the notching corresponding to the bottom of the genital slit is better indicated, and the distal region beyond is slightly tapering. In the two specimens from station 5650 these shields are thicker and shorter and the lateral notching is very slightly marked. The adoral plates are elongated, triangular, and extremely narrow inwardly, and they do not come in contact in the median interradial line where the proximal angle of the mouth shield projects; on the other hand, they are markedly broadened outwardly. The oral 
plates are very large and very high, triangular, and twice as long as broad. The lateral mouth papillae are eight or nine in number on each side; the four or five outermost are rectangular, with the free border straight, and the second is larger than those on either side; the three or four proximal papillae elongate somewhat and become conical with the sides rounded, especially the last, which is stout, rather elongated, and almost of the same size as the unpaired terminal papilla.

The two or three first upper arm plates are transversely broadened, short, and quadrangular; the following become triangular, longer than broad, with a very sharp proximal angle and convex distal border; they are at first in contact, then becoming separated by an interval which progressively elongates; they then become as long as broad. These plates bear on their surface a few granules or spines identical with those of the dorsal surface of the disk, the number of which is variable.

The first under arm plate is small, transversely broadened, lozenge-shaped or simply biconvex in form. The following plates are at first rather large, with the distal border rounded and the sides somewhat convex; the second is a little longer than broad with the proximal angle rounded; the third is also a little longer than broad with a sharp proximal angle; the fourth is as broad as long. These plates are separated by a narrow interval. The following plates are smaller, triangular, transversely broadened with the proximal angle obtuse, and they are very widely separated from each other. All these plates are unarmed.

The side arm plates, which are not very projecting, bear on their surface, especially in their dorsal region, small elongated granules identical with those on the dorsal surface of the disk and of the upper arm plates, and these little spines may be confused more or fess with the true arm spines from which it is difficult to distinguish them. Two principal spines, which are somewhat elongated and situated close to the ventral border of the plate, may be recognized; there may also be observed near the dorsal border a few granules larger than the others which might be considered as spines. In the individual from station 5651 these spines are best observed (figs. $6,7)$, but they always are inconstant in their appearance, and it is impossible to say whether they are true spines or not.

The tentacle pores number three pairs; they are rather large, especially those of the first pair, which carry on each border from one to three scales; the pores of the second pair usually have one external or proximal scale and two internal or distal scales; those of the third pair have a single proximal and one distal scale.

The color of the specimen in alcohol is yellowish. 
OPHIURANS OF THE PHILIPPINE AND ADJACENT WATERS. 421

Affinities and distinctive features.-Ophiomusium spinulosum belongs to that section of the genus Ophiomusium in which the upper and under arm plates continue throughout the whole length of the arms. It is easily distinguished from all the other species of this group having three pairs of tentacle pores by the large size of these pores, the borders of which may carry each two or three scales, and by the numerous spinules which occur on the dorsal surface of the disk, as well as on the upper and side arm plates.

OPHIOLIPUS GRANULATUS Køhler.

Ophiolipus granulatus ḰEHLER ('96), p. 315, pl. 6, figs. 28, 29; ('99), p. 31, pl. 7 , figs. $55-57$.

Locality.-Albatross station 5135; in the vicinity of Joló: Joló Light bearing S. $46^{\circ}$ W., 22.05 kilometers (11.9 miles) distant (lat. $6^{\circ} 11^{\prime} 50^{\prime \prime}$ N., long. $121^{\circ} 08^{\prime} 20^{\prime \prime}$ E.) ; 294 meters (161 fathoms); February 7, 1908; fne. co. S.

A single specimen (Cat. No. 41149, U.S.N.M.).

Notes.-The diameter of the disk is $5 \mathrm{~mm}$.

This specimen agrees well with the type which $\mathrm{I}$ described in 1896, based upon two somewhat larger specimens dredged by the Investigator among the Andaman Islands in 205 meters (112 fathoms).

Ophiolipus granulatus has not otherwise been found.

OPHIOCERAMIS DECLINANS Kohler.

Ophioceramis declinans KoEHLER ('04), p. 15, pl. 4, figs. 1-3.-H. L. ClaRK ('15), p. 337.

Localities.-Albatross station 5213; east of Masbate Island; Destacado Island (S.) bearing N. $87^{\circ}$ E., 15.75 kilometers ( 8.5 miles) distant (lat. $12^{\circ} 15^{\prime} 00^{\prime \prime}$ N., long. $123^{\circ} 57^{\prime} 30^{\prime \prime}$ E.) ; 146 meters (80 fathoms) ; April 20, 1908; S., M., Sh.

One specimen (Cat. No. E. 301, U.S.N.M.).

Albatross station 5214; east of Masbate Island; Palanog Light, Masbate, bearing S. $17^{\circ}$ W., 4.82 kilometers (2.6 miles) distant (lat. $12^{\circ} 25^{\prime} 18^{\prime \prime} \mathrm{N}$., long. $123^{\circ} 37^{\prime} 15^{\prime \prime}$ E.) ; 399 meters (218 fathoms); April 21, 1908; gn. M.

One specimen in poor condition (Cat. No. E. 298, U.S.N.M.).

Albatross station 5519; northern Mindanao and vicinity; Point Tagolo Light bearing S. $71^{\circ} \mathrm{W} ., 16.12$ kilometers (8.7 miles) distant (lat. $8^{\circ} 47^{\prime} 00^{\prime \prime}$ N., long. $123^{\circ} 31^{\prime} 15^{\prime \prime}$ E.) ; 333 meters, (182 fathoms) ; August 9, 1909 ; Glob., S.

One specimen (Cat. No. E. 300, U.S.N.M.).

Albatross station 5541; Tagolo Light bearing S. $65^{\circ}$ W., 23.54 kilometers (12.7 miles) distant (lat. $8^{\circ} 49^{\prime} 38^{\prime \prime} \mathrm{N}$., long. $123^{\circ} 34^{\prime} 30^{\prime \prime} \mathrm{E}$.) ; 401 meters (219 fathoms); August 20, 1909; fne. S., brk. Sh.

One specimen (Cat. No. E. 299, U.S.N.M.). 
Notes. - In the largest specimen, which is from station 5187, the diameter of the disk is $15 \mathrm{~mm}$; the others are a little smaller; all are therefore of a size slightly greater than that of the two type specimens which the Siboga collected in the Sunda Archipelago, in which the diameter of the disk was $11 \mathrm{~mm}$. and $8 \mathrm{~mm}$., respectively. They are, however, quite identical with these last.

The dorsal surface of the body is darker than the ventral surface; it is brownish or reddish with traces of annulations on the arms; the ventral surface is grayish.

\section{OPHIOZONELLA BISPINOSA (Kohler).}

Ophiozona bispinosa KaHLER ('96), p. 319, pl. 6, figs. 32, 33; ('99), p. 34, pl. 2, figs. 10, 11.

Ophiozonella bispinosa Matsumoto ('15), p. 82-H. L. Clark ('15), p. 340.-Matsumoto ('17), p. 294.

Localities.-Albatross station 5420; between Cebu and Bohol; Cruz Point (Bohol) bearing S. $20^{\circ}$ E., 11.1 kilometers $(6$ miles) distant (lat. $9^{\circ} 49^{\prime} 35^{\prime \prime}$ N., long. $123^{\circ} 45^{\prime} 00^{\prime \prime}$ E.) ; 232 meters (127 fathoms) ; March 25, 1909.

Seventeen specimens (Cat. Nos. 40911, 40912, U.S.N.M.).

Albatross station 5421; between Panay and Guimaras; Luaran Point Light bearing S. $27^{\circ}$ E., 9.26 kilometers ( 5 miles) distant (lat. $10^{\circ} 33^{\prime} 30^{\prime \prime} \mathrm{N}$., long. $122^{\circ} 26^{\prime} 00^{\prime \prime}$ E.) ; 251 meters (137 fathoms); March 30, 1909 ; gn. M.

One specimen (Cat. No. 40913, U.S.N.M.).

Notes.-These specimens agree very well with the type which I described from specimens collected by the Investigator among the Andaman Islands at a depth of 205 meters (112 fathoms). The diameter of the disk does not exceed $10 \mathrm{~mm}$. in the largest, and it is usually between $7 \mathrm{~mm}$. and $9 \mathrm{~mm}$.

Matsumoto has separated from the genus Ophiozona a new genus, to which he has given the name of Ophiozonella, which includes the deep-sea forms having sometimes one and sometimes two tentacle scales. Ophiozona bispinosa must be placed in this new genus with $O$. casta, $O$. depressa, and $O$. media, as well as with the new species which I describe below.

H. L. Clark has described ('11, p. 31, fig. 6) a species very close to 0 . bispinosa from Japan, to which he has given the name of $O$. elevata. According to this author the new species is distinguished from $O$. bispinosa by its thick and elevated disk, by having the arm spines shorter, and by the form of the upper arm plates. I believe that there may be added, as a differential character, the form of the mouth shields; in my description in $\mathbf{1 8 9 6}$ and in my figure ('96, p. 319 , pl. 6, fig. 33) I showed that the mouth shields of 0. bispinosa are longer than broad, while in $O$. elevata they are as broad as long. I 
find this elongated form of the mouth shields in all the Albatross specimens.

\section{OPHIOZONELLA CASTA (Kohler).}

Plate 78, figs. 5-8.

Ophiozona easta KermLer ('04), p. 22, pl. 5, fig. 9; pl. 6, figs. 1, 2.-MAtsuмото ('15), p. 82.

Ophiozonella casta H. L. Clark ('15), p. 340.-Matsumoto ('17), p. 294.

Locality.-Albatross station 5428; eastern Palawan and vicinity; 30th of June Island bearing N. $62^{\circ}$ W., 36.14 kilometers (19.5 miles) distant (lat. $9^{\circ} 13^{\prime} 00^{\prime \prime}$ N., long. $118^{\circ} 51^{\prime} 15^{\prime \prime}$ E.) ; 2,021 meters $(1,105$ fathoms) ; A pril 3, 1909; gy. M.

Two specimens (Cat. No. 41154 , U.S.N.M.).

Notes.-These two specimens are somewhat different from each other in their external appearance; in the larger, in which the diameter of the disk is $7.5 \mathrm{~mm}$., the dorsal surface is strongly convex so that the disk is very thick and high, but in the second, which is smaller and in which the diameter of the disk does not exceed $5 \mathrm{~mm}$., the dorsal surface of the disk is almost plane. But the arrangement of the plates themselves shows such agreement that there can be no question of separating the two specimens, and except for the height of the disk they both agree well with the specimens collected by the Siboga on which I based $O$. casta. In the latter the disk, of which the diameter is $5 \mathrm{~mm}$., although rather elevated does not reach quite the height of that in the larger Albatross specimen, but it is higher than that of the smaller. The only difference which I can detect consists of the form of the mouth shields which are here a little broader than long and simply triangular with the distal border very strongly convex. The mouth papillae decrease in height from the outermost to the innermost, and the two innermost are very low, although much elongated. In the larger specimen the plates of the dorsal surface of the disk are more numerous than in the Siboga type, while in the smaller the arrangement is almost the same, and the dorso-central, which is pentagonal in form, is very much larger than the five primary radials which are broadly in contact with it (fig. 5). In the large example (fig. 7) the dorsocentral is circular, larger than the five radials, which are themselves very large; these plates show a proximal angle, and their distal border is very strongly convex; they are separated from the dorsocentral by a row of small plates, and only two of them just touch the dorso-central by their proximal angle. In the interradial spaces there are two large tandem plates, and the second, which is triangular in shape and a little longer than broad, reaches the periphery of the disk. In the radial spaces there is a large plate, the convex distal border of which is close to the radial shields. The rest 
of the disk is occupied by some smaller, but unequal, imbricated plates, with the distal border rounded. The radial shields are of the same size as the primary radials; they are triangular, with rounded angles, as long as broad, and their length equals one-fourth the radius of the disk. The two shields of each pair are rather divergent, and they are separated for their whole length by a row of plates, though outwardly they come close together; in one of the radii they are even in contact for a short part of their length. (The shape of the plates found at the periphery of the disk, such as the radial shields or the large interradial plate can not be judged from the photograph which I give in figure 7 , for, because of the strong convexity of the disk, the peripheral plates, seen foreshortened, are rather strongly distorted and their length is considerably diminished.)

\section{OPHIOZONELLA MEDIA (Kœhler).}

Plate 78 , figs. $9-10$.

Ophiozona depressa, var. media KGHLER ('04), p. 24, pl. 4, figs. 11, 12.

Ophiozonella depressa, var. media MAtsumoto ('17), p. 294.

Locality.-Albatross station 5601; Gulf of Tomini, Celebes; Limbe Island (NE.) bearing N. 38.36 kilometers (20.7 miles) distant (lat. $1^{\circ} 13^{\prime} 10^{\prime \prime}$ N., long. $125^{\circ} 17^{\prime} 05^{\prime \prime}$ E.) ; 1,399 meters (765 fathoms); November 13, 1909 ; S., Glob., Ptr.

One'specimen (Cat. No. 41355, U.S.N.M.).

Notes.-The diameter of the disk is $11 \mathrm{~mm}$.

This specimen agrees well with some individuals collected by the Siboga in the Sunda Archipelago, which I considered as representing a simple variety of $O$. depressa Lyman; I described this in 1904 under the name of $O$. depressa, var. media. But in comparing the Albatross specimen with the description and the figures which Lyman gives of 0 . depressa it seemed to me that the form from the Sunda Islands and from Celebes differed decidedly too much from Lyman's. type to make it possible to consider it as a simple variety, and I propose to raise it to specific rank, giving it the name of Ophiozonella media. The Albatross specimen is of exactly the same size as Lyman's $O$. depressa, and as this is the case the differences may be apreciated more readily.

If we compare the photographs which I give here (pl. 78, figs. $9,10)$ with the figures which Lyman has given of 0 . depressa ('82, pl. 2, figs. 16-18) we see that the dorsal plates of the disk are more numerous in 0 . media, and especially that the plates of the central rosette do not have that tuberosity described by Lyman (and which also does not occure in the Siboga specimens). The mouth shields: are less elongated and broader, and in the Albatross specimen they 
are a little broader than long; in those from the Siboga collection they are as long as broad, while in Lyman's type they are longer than broad. The adoral plates are broader and longer, and there are often two tentacle scales on the pores of the first pair. In 1904 I noted the presence of five lateral mouth papillae, the outermost very small. In the Albatross individual this outermost mouth papilla is extremely reduced, and sometimes it is quite invisible, either because it is hidden under the following papilla, or because it is fused with it; the second papilla is extremely broad; the three others are also broad and thick, and on some sides of the mouth slits they are only two in number.

Under these conditions I believe it preferable to consider $O$. media as an independent species.

The Siboga specimens were collected in $1^{\circ} \mathrm{N}:-10^{\circ} \mathrm{S}$. latitude and $123^{\circ}-127^{\circ} \mathrm{E}$. longitude, between 918 and 1,264 meters (505 and 693 fathoms).

\section{OPHIOZONELLA MOLESTA (Køhler).}

Plate 78, figs. 3, 4 ; plate 79 , figs. 5, 8, 10.

Ophiozona molesta Kahler ('04), p. 23, pl. 6, figs. 3-5.-MAtsumoto ('15), p. 82 ; ('17), p. 294.-H. L. Cr.ARK ('15), p. 340.

Localities.-Albatross station 5114; Balayan Bay and Verde Island Passage; Sombrero Island bearing N. $36^{\circ}$ E., 13.34 kilometers (7.2 miles) distant (lat. $13^{\circ} 36^{\prime}, 11^{\prime \prime} \mathrm{N}$., long. $120^{\circ} 45^{\prime} 26^{\prime \prime}$ E.) ; 622 meters (340 fathoms); January 20, 1908; fne. S.

Four specimens (Cat. Nos. 40943, 40944, U.S.N.M.).

Albatross station 5115; Balayan Bay and Verde Island Passage; Sombrero Island bearing N. $49^{\circ}$ E., 13.53 kilometers (7.3 miles) distant (lat. $13^{\circ} 77^{\prime} 11^{\prime \prime}$ N., long. $120^{\circ} 43^{\prime} 40^{\prime \prime}$ E.) ; 622 meters ( 340 fathoms) ; January 20, 1908.

One specimen (Cat. No. 40946, U.S.N.M.).

Albatross station 5305; China Sea, in the vicinity of Hongkong (lat. $21^{\circ} 54^{\prime} 00^{\prime \prime}$ N., long. $114^{\circ} 46^{\prime} 00^{\prime \prime}$ E.) ; 68 meters ( 37 fathoms); October 24, 1908; sft. gy. M.

Four specimens (Cat. No. 40942, U.S.N.M.).

Albatross station 5429; Eastern Palawan and vicinity; Fondeado Island (SE.) bearing N. $18^{\circ}$ E., 27.79 kilometers (15 miles) distant (lat. $9^{\circ} 41^{\prime} 30^{\prime \prime}$ N., long. $118^{\circ} 50^{\prime} 22^{\prime \prime}$ E.) ; 1,401 meters (766 fathoms); April 5, 1909; gn. M.

One specimen (Cat. No. 40945 , U.S.N.M.).

Notes.-I am persuaded that all these specimens belong to 0 . molesta, which I described in 1904 from an unique specimen collected by the Siboga, although this last had only two arm spines, while three is the normal number in the Albatross specimens. But my type was of very small size, as the diameter of the disk did not exceed $6 \mathrm{~mm}$. 
I find in the Albatross collection one specimen (station 5429) with the same dimensions, in which the majority of the arm segments have only two spines; a few of them already have three, but this figure is rare and it only appears, fortuitously, at some distance from the disk. It is therefore quite probable that the number of two arm spines is correlated with the youth of the subject and that the third spine appears later. All the other characters agree so well that it seems to me impossible to separate the Albatross specimens from my 0 . molesta. I give a figure of the ventral surface of the young example of which I have just spoken (pl. 79, fig. 5), and this may be compared with the figure which I have previously given of $O$. molesta ('04, p. 6, fig. 4); a comparison of the photographs which I give here, some of a specimen in which the disk is $10.5 \mathrm{~mm}$. in diameter (pl. 78, figs. 3, 4), and the other (pl. 79, fig. 10) of a specimen in which the disk is $8 \mathrm{~mm}$. in diameter, with the corresponding figure of the type specimen ('04, pl. 6, fig. 3), shows well the identity of these different forms.

It seems to me worth while to describe this species again from adult examples.

Description.-The diameter of the disk varies between $9 \mathrm{~mm}$. and $12 \mathrm{~mm}$. In a specimen from station 5114 which I have taken as the type (pl. 78, figs. 3,4) the diameter of the disk is $10.5 \mathrm{~mm}$. and the arms are $25 \mathrm{~mm}$. long; the habitus of the animal is very robust. The disk is rounded and rather thick; the arms are short, very broad at the base, and taper rapidly to the tip.

The two surfaces of the disk are plane and parallel, and they pass into each other over a rounded border; the outline of the disk is also rounded. The dorsal surface is covered with unequal and slightly imbricated plates, among which a primary rosette of large plates separated from each other by a single row of very much smaller plates may be distinguished. The rounded dorso-central is larger than the radial plates, which are slightly broadened transversely. Among the other plates there may be distinguished an interradial row, including usually three rather large tandem plates, and, in the interradii, two plates of which the outer penetrates between the two radial shields of each pair. These plates are more or less polygonal. The other plates are small, unequal, more or less polygonal in outline, and, in the interradii, there are generally two or three rows on each side of the median line. The radial shields, which are rather small, are triangular, longer than broad, with a sharp proximal angle and a slightly convex distal border; their length is equal to a third of the radius of the disk. The two shields of each pair are divergent inwardly, and they are separated throughout their whole length, proximally by two or three plates, and distally by a single plate. 
Their surface is smooth, without the least indication of tuberosities or of any prominences whatever. -

The ventral surface of the disk is covered with rounded plates which are slightly imbricated and unequal; the larger are a little more developed than the smallest plates of the dorsal surface. The genital slits are narrow.

The mouth shields are small, elongated, almost twice as long as broad, pentagonal, with a sharp proximal angle bordered by two straight or slightly concave sides passing over into the lateral borders by very rounded angles; the mouth shields have their maximum width at the level of these angles; their sides are notched toward the proximal third by the ends of the genital slits, and they pass over by zounded angles to the distal border, which is narrow and slightly convex. The adoral plates are rather narrow inwardly, but they broaden outwardly and form a process which separates the mouth shield from the first side arm plate. The oral plates are very small and triangular. The mouth papillae are usually five in number on each side; the three outer are rather broad; the first is triangular with a pointed apex, the second and the third are quadrangular; the two following papillae are smaller and pointed. The unpaired terminal papilla is not very much larger than those on either side.

The two or three first upper arm plates are extremely short; the following are quadrangular, with a concave proximal border which is slightly narrower than the convex distal border; their sides are very divergent and straight and they pass over by sharp angles to the distal border; these plates are very much broader than long. As the distance from the base of the arms increases, the proximal border little by little diminishes in length, but it is only near the extremity of the arms that it disappears; the plates then become triangular, and they are almost as long as broad.

The first under arm plate is small, transversely broadened, pentagonal, with a very obtuse proximal angle bordered by two concave sides; the two lateral borders are short, and they converge toward the rather narrow distal side, into which they pass over by rounded angles. The following plates are quadrangular, with the proximal border straight and narrower than the convex distal border; the sides are divergent and broadly excavated by the tentacle scales. These plates are at first as long as broad; they then become a little longer than broad, and at the same time their proximal border becomes more and more narrow, and is finally replaced by a very open angle. All these plates are in contact.

The side arm plates, which are only slightly projecting, each bear three subequal spines of which the length is almost equal to half that of the segment; these spines are thick and cylindrical, and their point is rounded; they are not appressed against the lateral surfaces 
of the arms, but they are more or less erect and consequently very evident.

The tentacle pores, which are very large, are each covered by two large rounded scales, the external scale a little larger than the internal; these two scales persist throughout the whole length of the arms.

The coloration of the specimens in alcohol is yellowish.

Affinities and distinctive features.-Among the species of $O$ phiozonella which possess two tentacle scales throughout the whole length of the arms this species, in the form of the mouth shields and the other mouth pieces, as well as by the presence of three arm spines, recalls especially Lyman's $O$. tessellata, but the arrangement of the dorsal plates of the disk is different, the radial shields are smaller, and they do not possess the large broadened and short spine on their distal border in 0 . tessellata.

The specific characters which I have described are always well marked in all the specimens which I have been able to examine, and they are already manifest in the smallest specimens.

These youngest examples already show the same robust habitus as the adults, and they also have thick and short arms; the upper arm plates are quadrangular for a large part of the length of the arms, the arm spines are thick and short, etc. This may be determined from a specimen from station 5114 in which the diameter of the disk is only $8 \mathrm{~mm}$. and of which the arms are $20 \mathrm{~mm}$. long (pl. 79, fig. 10). In a specimen from station 5305 the diameter of the disk is $9 \mathrm{~mm}$., and the arms are $25 \mathrm{~mm}$. long. Another individual of considerable interest is that from station 5429 (pl. 79, fig. 5). Its disk is only $6 \mathrm{~mm}$. in diameter; the arms, which are very broad at the base, are robust and taper rapidly, their length not exceeding $17 \mathrm{~mm}$; t the first upper arm plates are quadrangular, and their proximal angle, which narrows little by little, disappears only toward the seventh or eighth segment. The arm spines are thick and stout; they are sometimes three in number, but usually two, even on the first arm segments. In this young specimen the mouth shields are appreciably broader than in the larger; they have exactly the form which I described in 1904 in $O$. molesta from the single very young individual which $I$ had at hand, which again confirms the specific identity which I have seen fit to establish.

OPHIOZONELLA SUBTILIS, new species.

Plate 79, figs. 3, 4, 9, 11, 12.

Localities.-Albatross station 5371; Marinduque Island and vicinity; Tayabas Light (outer) bearing N. $43^{\circ}$ W., 11.1 kilometers (6 miles) distant (lat. $13^{\circ} 49^{\prime} 40^{\prime \prime}$ N., long. $121^{\circ} 40^{\prime} 15^{\prime \prime}$ E.) ; 
152 meters (83 fathoms); February 24, 1909; gn. M. (m. b.).

Two specimens (Cat. No. 41346, U.S.N.M.)

Albatross station 5420; between Cebu and Bohol; Cruz Point (Bohol) bearing S. $20^{\circ}$ E., 11.1 kilometers $\left(6\right.$ miles) distant (lat. $9^{\circ}$ $49^{\prime} 35^{\prime \prime}$ N., long. $123^{\circ} 45^{\prime} 00^{\prime \prime}$ E.) ; 231 meters (127 fathoms) ; March 24, 1909.

Thirteen specimens (Cat No. 40931, U.S.N.M.).

Albatross station 5423; Joló Sea; Cagayan Island (S.) bearing S. $11^{\circ}$ E., 8.89 kilometers (4.8 miles) distant (lat. $9^{\circ} 38^{\prime} 30^{\prime \prime} \mathrm{N}$., long. $121^{\circ} 11^{\prime} 00^{\prime \prime}$ E.) ; 929 meters (508 fathoms); March 31, 1909; gy. M., co. S.

One specimen (Cat No. 41345, U.S.N.M.)

Description.-I shall describe this species from the two specimens from station 5371 ; in the larger the diameter of the disk reaches $10 \mathrm{~mm}$., but the arms are all incomplete; in the smaller the diameter of the disk is $8 \mathrm{~mm}$. and the arms are $30 \mathrm{~mm}$. long; the arms are slender, thin and elongated, only slightly broadened at the base, and they taper very slowly. The specimens from stations 5420 and 5423 are identical with the smaller specimen from station 5371, and the diameter of their disk varies between $7 \mathrm{~mm}$. and $8 \mathrm{~mm}$. The arms are thin, slender, and relatively long. In different specimens from station 5420 the diameter of the disk varies between $7 \mathrm{~mm}$. and $8 \mathrm{~mm}$, and the arms, which are very long and always rather narrow, may reach a length of $40 \mathrm{~mm}$.

The disk is subpentagonal; the two surfaces are almost plane, passing into each other over a rounded border. The dorsal surface is covered with numerous unequal plates, among which there is distinguishable a certain number which are larger than the others and rather uniform in size; they are all rounded; between them are found a large number of very much smaller plates. The six primary plates are scarcely larger than the others, and the dorsocentral plate is a little smaller than the five radials; between these latter and the central plate there is a circlet of five smaller interradial plates, and several other extremely reduced plates.

The other large plates include a row of four or five consecutive plates which occupy the middle line of each interradius; these are circular except that on the periphery of the disk, which is transversely broadened. In the radial regions there is a large plate the external border of which lies almost at the level of the proximal angle of the radial shields; following this there is a smaller plate, then a series of three or four rectangular plates which are continuous with the upper arm plates, and, with the preceding plate, separate the two radial shields of each pair. Other smaller rounded plates occur intercalated between the preceding, especially in the 
interradii. The spaces between all these plates are filled with numerous extremely small unequal plates which are more or less rounded and not imbricated. The radial shields are rather large, triangular, with the angles rounded, and very much longer than broad; their length exceeds one-third the radius of the disk; the two shields of each pair are somewhat divergent and they are separated for their entire length by several rows of plates.

The ventral surface is covered with rather large plates which are irregularly polygonal and somewhat unequal. The genital plates are narrow and elongated. The genital slits are narrow.

The mouth shields are small, narrow, and elongated, pentagonal in shape, at least twice as long as broad, with a sharp proximal angle, and a strongly convex distal border which is continued over very rounded angles into the sides, which on the specimen which I am describing are almost straight; on other specimens these sides are more or less excavated by the bottom of the genital slits. The adoral plates are rather broad and short, narrower inwardly than outwardly, and they send off a usually very slender process, separating the mouth shield from the first side arm plate. The oral plates are triangular and rather large. The lateral mouth papillae are five in number; the most external is elongated and terminates in a point which is recurved to follow the outline of the adjacent border of the following papilla; this is rectangular, very broad, broader than long; the third, which is smaller, is narrower and almost square; the two last papillae are conical and pointed.

The first upper arm plate is short, transversely broadened, from two and a half to three times as broad as long. The second is rectangular, with a straight proximal border, very divergent sides, and a very broad distal border usually broken up into two sides passing into each other by a very obtuse and rounded angle; it is very much broader than long; the following plates are triangular, a little broader than long, with a proximal angle at first very slightly truncated but rapidly becoming sharp; the distal border ordinarily is broken up into two slightly excavated sides which pass into each other by a very obtuse and rounded angle; the lateral angles are very sharp. These plates are in contact on the ten or twelve first arm segments, then becoming separated by a narrow space, and at the same time becoming a little longer than broad.

The first under arm plate is transversely broadened, very short, pentagonal, with a very obtuse proximal angle bordered by two straight sides; the lateral borders are short, and they pass over into the narrow distal side by rounded angles. The second plate is rectangular with a narrow and straight proximal border, and divergent sides broadly excavated by the tentacle pores; the distal border is very broad and slightly rounded. On the following plates the proximaI 
border becomes rapidly smaller, and gives place to an acute angle; the plates then become pentagonal. At some distance from the disk they assume a simply triangular form and are separated by a narrow interval.

The side arm plates, which project only slightly, bear three very slender cylindrical and pointed arm spines, which are usually appressed against the lateral surface of the arms; their length does not reach usually half the length of the segment. The two or three first arm segments often bear four spines; the two dorsal spines are usually close to each other, while the ventral spine is somewhat separated from the little group thus formed; but this arrangement is only noticeable on the first arm segments.

The rather large tentacle pores are provided with two scales throughout the length of the arms; these scales are subequal and of medium size.

The color of the specimens in alcohol is white or slightly yellowish. Affinities and distinctive features.-Ophiozonella subtilis is evidently very close to $O$. molesta, which it recalls by the form of the mouth shields; it is distinguished from it by its very much less robust habitus, by having the arms narrower, relatively longer, and tapering less rapidly. The plates of the dorsal surface of the disk are very numerous, rounded, and separated by other extremely small plates; the radial shields are more elongated. The adoral plates are thicker and shorter; the oral plates are larger. The upper arm plates are triangular from the third or the fourth outward, and the two tentacle scales are appreciably smaller in $O$. subtilis than in $O$. motesta; the arm spines also are slender, ordinarily shorter and smaller, appressed against the side arm plate, and not very evident; they are sometimes four in number on the first arm segments and the first ventral spine is separated from the others, a feature not found in $O$. molesta.

These differences certainly are not due to the age of the individuals, or to their lesser size. The comparison with small specimens of $O$. molesta, such as those from station 5429 and the small one from station 5114, of which I give photographs here and of which I described the characters above, is quite conclusive and shows well that the two species are very distinct.

\section{OPHIOZONOIDA OBSCURA, new species.}

Plate 80, figs. 8, 9, 13.

Locality.-Albatross station 5255; Gulf of Dávao; Dumalag Island (S.) bearing S. $65^{\circ}$ W., 8.34 kilometers $\left(4.5\right.$ miles) distant (lat. $7^{\circ}$ $03^{\prime} 00^{\prime \prime}$ N., long. $125^{\circ} 39^{\prime} 00^{\prime \prime}$ E.) ; 183 meters (100 fathoms) ; May. 18, 1908 ; sft. M.

A single specimen (Cat. No. 41155 , U.S.N.M.). 
Description.-The diameter of the disk does not exceed $2 \mathrm{~mm}$. The arms are $8 \mathrm{~mm}$. in length; they are rather narrow at the base, and their width diminishes very slowly; the arm segments are a little broader than long.

The disk is rounded; the dorsal surface is a little swollen, and the ventral surface is plane. The dorsal surface is covered with large imbricated plates, which are not very numerous, among which may be distinguished a central group of six plates somewhat irregularly arranged and doubtless representing the primary rosette; the dorsocentral plate is ellipsoidal in form; the five other plates, which are slightly smaller, are rounded, but unequal. Outside of these plates there may be recognized in the radial spaces a rather large triangular single plate which extends between the two radial shields of each pair, separating them in their proximal half. In the interradial spaces there is a group of three consecutive plates; the first is large and rounded, the second is rectangular and very short, and the third, which is almost square, reaches the periphery of the disk. Here and there a very small plate occupying the intervals between the large plates may be met with, but these are very rare. The radial shields are smaller than the plates of the central rosette; they are triangular, almost as long as broad, divergent inwardly and in contact outwardly for a half or a third of their length. This length is a little greater than one-third the radius of the disk. The surface of all these plates is rather coarsely granulose.

The ventral surface of the disk in the interradial spaces is occupied by a small number of rounded, somewhat imbricated, and unequal plates. The genital slits are scarcely evident, and very narrow.

The mouth shields, which are of medium size, are pentagonal, a little longer than broad, with an almost straight proximal angle bounded by two straight sides, and two straight lateral borders converging toward a very narrow and rounded distal side; this distal side is sometimes replaced by a rounded angle and the mouth shields then assume a lozenge-shaped form. The adoral plates are rather broad, almost twice as long as broad, with the long sides straight and parallel. The oral plates are very small and triangular. The mouth papillae number five on each side. The three outermost papillae are rounded and squamiform; the proximal papilla is slightly elongated, conical, with the point blunted; it is crowded against its neighbor.

The first upper arm plate is small, quadrangular or trapezoidal, as long as broad. The second is rectangular, twice as broad as long, with the sides divergent and the angles rounded. The following plates are large, triangular, with a sharp proximal angle bounded by two straight sides which pass over by rounded angles to the distal border, which is itself slightly rounded. These plates are as long 
as broad; they are at first in contact, then become separated by a narrow interval.

The first under arm plate is rather large, triangular, broader than long. The following are very large, pentagonal, with a sharp proximal angle bounded by two short straight sides, and two lateral borders excavated by the tentacle scale which pass over by very rounded angles into the distal side, which is broad and rounded. The proximal angle is truncated on the second plate. These plates are almost as long as broad, and they are in contact as far as the fourth, thence becoming separated by a space which progressively elongates, and becomes simply triangular.

The side arm plates, which are rather strongly projecting, bear three spines which are short, thick, and subequal, with the surface rugose.

All the arm plates have their surface covered with rather coarse granules like the plates of the disk.

The tentacle scale is single, oval, and of medium size.

'The general color of the dorsal surface of the body is rather dark; it is a brownish green, and each of the dorsal plates of the disk shows a large very dark spot, which on the central plates covers almost their entire surface. The upper arm plates also show a similar large spot. The ventral surface is very much lighter, and the plates show similar but very much smaller and less well marked spots.

Affinities and distinctive features.-This species evidently falls into the genus Ophiozonoida, which $\mathrm{H}$. L. Clark has very recently erected for an ophiuran from New Zealand, Ophiozona picta ('15, p. 340), and the Philippine species is so close to it that I have hesitated to separate them. But the differences which I find are not negligible. The dorsal plates of the disk are less numerous and larger than in the New Zealand species, the mouth shields have a slightly different outline and they are a little narrower and more elongated, and the under arm plates are appreciably larger. The coloration is very different. The dark spots on the large dorsal plates of the disk cover almost the whole surface, as I have described above; the arms are not at all annulated, but show a large dark spot on each upper arm plate. The coloration is quite otherwise in $O$. picta, and the spots which the different plates show are of a very much more brilliant color - "dull brownish with a purple tinge," according to H. L. Clark. These spots occur on the small plates of the dorsal surface of the disk and are not confined to the large plates, and they also occur on alternate arm segments, while the upper arm plates of the segments which remain light show a small dark spot. This elegant livery is very different from that of the Philippine specimen, which is very dark on the dorsal surface. 


\section{OPHIOMIDAS REDUCTUM Kœhler.}

Ophiomidas reductum KaEHLER ('04), p. 27, pl. 5, figs. 6-8.

Ophiomidas reductus H. L. CLARK ('15), p. 342.

Locality.-Albatross station 5668; Macassar Strait; Mamuju Island (E.) bearing S. $31^{\circ}$ E., 19.64 kilometers $\left(10.6\right.$ miles) distant (lat. $2^{\circ}$ $28^{\prime} 15^{\prime \prime}$ S., long. $118^{\circ} 49^{\prime} 00^{\prime \prime}$ E.) ; 1,648 meters (901 fathoms) ; December 29,1909 ; gy. M.

One specimen.

Notes.-The diameter of the disk is $5 \mathrm{~mm}$. It is a little smaller than the two specimens collected by the Siboga, upon which I established the species and in which the diameter was from $6 \mathrm{~mm}$. to $7 \mathrm{~mm}$. These were captured in $8^{\circ} 04^{\prime} 07^{\prime \prime} \mathrm{S}$. latitude, $118^{\circ} 44^{\prime} 03^{\prime \prime}$ E. longitude, at a depth of 2,060 meters (1,125 fathoms).

Ophiomidas reductum has not been otherwise found.

\section{OPHIOLEPIS ANNULOSA (Blainville).}

See for bibliography:

Ophiolepis annulosa KäHLER ('05), p. 17 ; ('05a), p. 184; ('07), p. 287.-H.

L. Clark ('08), p. 289.-Matsumoto ('17), p. 300, fig. 82.

Ophiolepis superba H. L. ClakK ('15), p. 343 ; ('15a), p. 89.

Localities.-Batan Island; tide pools; June 5, 1909.

One specimen (Cat. No. E. 313, U.S.N.M.).

Ficas Island; San Miguel Harbor; April 21, 1908.

One specimen (Cat. No. E. 312, U.S.N.M.).

Notes.-I see no benefit whatever in the change of the specific name which H. L. Clark has proposed in order to avoid confusion between the Ophiura annulosa of Blainville and the Ophiura annulosa of Lamarck, these two species having been for a very long while placed in two different genera and being universally known. Matsumoto also has rejected the change of name suggested by H. L. Clark.

\section{OPHIOLEPIS IRREGULARIS Brock.}

Plate 80, figures 1, 5, 10, 11.

Ophiolepis irregularis BROCK ('88), p. 475.-BELL ('$(4)$, p. 395.-KaEHLEB ('05), p. 17.-H. L. Clark ('15), p. 343.

Locality.-Albatross station 5253; Gulf of Dávao; Linao Point bearing N. $22^{\circ}$ E., 2.78 kilometers (1.5 miles) distant (lat. $7^{\circ} 04^{\prime} 48^{\prime \prime}$ N., long $125^{\circ} 39^{\prime} 38^{\prime \prime}$ E.) ; 51 meters (28 fathoms) ; May 18, 1908 ; Co.

One specimen (Cat. No. 40929, U.S.N.M.).

Notes. - The diameter of the disk is $9 \mathrm{~mm}$. Two of the arms are almost complete; the three others are broken off at some distance from the base.

The specimen does not quite agree with Brock's description, and it also differs slightly from the examples collected by the Siboga, of 
which I have already described the characters. The plates of the dorsal surface of the disk are arranged more irregularly and the difference in size between the largest and the smallest is less marked. These differences have no great importance.

The surface of the upper arm plates in $O$. irregularis is not plane, but is raised up very markedly toward the distal border, as may be appreciated from the lateral view of the arm which I give in plate 80 as figure 1 . There is no large rounded tubercle like that observable in 0. nodosa Duncan or $O$. mugosa Kœhler; there is a thickening of the whole distal portion of the plate which can not be compared with the projecting rounded and clearly defined tubercle which occurs in the last two species; in these the upper arm plates are very much narrower than in $O$. irregularis.

I notice that the majority of the tentacle pores have, in addition to the two well-known scales, a very small supplementary scale situated toward the proximal border of the pore. There may also be some irregularities in the arrangement of the scales; thus sometimes this supplementary scale reaches a rather large size, while the two normal scales become smaller, so that there are three subequal scales. This peculiarity has already been described by Duncan in 0 . nodosa; I do not believe that this constitutes an important specific character. The same feature has also been described by Lyman in $O$. elegans, and I find it also in other species, for example, in $O$. affinis Studer; it may be recognized in the photographs which I published of these two species in 1914 (see Kœhler '14a, pl. 9, figs. $16,18)$, but the outlines of the tentacle scales are not very distinct, for the plates have suffered somewhat in reproduction. I notice traces of this third scale in 0 . cincta Müller and Troschel, but it is here less developed than in the species which I have just cited.

The dorsal surface of the body shows an orange coloration, which is very pronounced, especially in the central region of the disk, surrounded by a broad black circle with an irregular contour; the arms are ringed with black. The ventral surface is grayish white studded with numerous small light orange spots.

OPHIOPLOCUS IMBRICATUS (Müller and Troschel).

See for bibliography:

Ophioplocus imbricatus KänLER ('05), p. 18; ('07), p. 288; ('07b), p. 243.-H. L. Clark ('08), p. 289 ; ('11), p. 30; ('15), p. 344 ; ('15a), p. 89.-Mатsumoto ('17), p. 301, fig. 83.

Localities.-Albatross station 5212; east of Masbate; Panalangan Point bearing S. $54^{\circ} 30^{\prime}$ E., 26.87 kilometers (14.5 miles) distant 
(lat. $12^{\circ} 04^{\prime} 15^{\prime \prime}$ N., long. $124^{\circ} 04^{\prime} 36^{\prime \prime}$ E.) 197 meters (108 fathoms); April 20, 1908; gy. S., M.

One specimen (Cat. No. 41189 , U.S.N.M.).

Port Binanga, Subig Bay; January 9, 1908.

Two specimens (Cat. No. E. 316, U.S.N.M.).

Batan Island; tide pool; June 5, 1909.

Three specimens (Cat. No. E. 314, U.S.N.M.).

Dumurug Point, Masbate; shore; April 19, 1908.

One specimen (Cat. No. E. 315, U.S.N.M.).

Reef at Nasugbu, Luzon.

One specimen (Cat. No. E. 317, U.S.N.M.).

No locality.

Two specimens.

Family OPHIOLEUCIDAE.

\section{OPHIOCIRCE INUTILIS Kœhler.}

Ophiocirce inutilis KoEHLER ('04), p. 13, pl. 3, figs. 4, 5.-H. I. Crarí ('15), p. 346.

Locality.-Albatross station 5398; between Masbate and Leyte; Gigantangan Island (S.) bearing S. $45^{\circ}$ E., 5.00 kilometers (2.7 miles) distant (lat. $11^{\circ} 35^{\prime} 12^{\prime \prime} \mathrm{N}$., long. $124^{\circ} 13^{\prime} 48^{\prime \prime}$ E.) ; 209 meters (114 fathoms); March 15, 1909; gn. M.

Two specimens (Cat. No. 41198, U.S.N.M.).

Notes.-These two specimens agree well with those discovered by the Siboga in latitude $9^{\circ} 00^{\prime} 03^{\prime \prime} \mathrm{S}$., longitude $126^{\circ} 24^{\prime} 05^{\prime \prime} \mathrm{E}$. at a depth of 112 meters ( 62 fathoms).

The species has not otherwise been found.

OPHIOPALLAS PARADOXA Kohler.

Plate 79, figs. $1,2$.

Ophiopallas paradoxa KaHLeR ('04), p. 12, pl. 3, figs. 1-3.-H. L. CLARK ('15), p. 348.

Localities.-Albatross station 5280; China Sea, in the vicinity of southern Luzon; Malavatuan Island (N.) bearing S. $60^{\circ}$ W., 11.3 kilometers (6.1 miles) distant (lat. $13^{\circ} 55^{\prime} 20^{\prime \prime} \mathrm{N}$., long. $120^{\circ} 25^{\prime}$ $55^{\prime \prime}$ E.) ; 353 meters (193 fathoms) ; July 17, 1908; gy. S.

One specimen (Cat. No. 41349, U.S.N.M.).

Albatross station 5353; Balabac Strait; Cape Melville Light bearing S. $85^{\circ}$ E., 31.13 kilometers (16.8 miles) distant (lat. $7^{\circ} 50^{\prime} 45^{\prime \prime}$ N., long. $116^{\circ} 43^{\prime} 15^{\prime \prime}$ E.) ; 271 meters (148 fathoms) ; January $1,1909$.

One specimen (Cat. No. 41350 , U.S.N.M.).

Albatross station 5516; Northern Mindanao and vicinity; Point Tagolo Light (Mindanao) bearing S. $80^{\circ}$ W., 17.98 kilometers (9.7 
miles) distant (lat. $8^{\circ} 46^{\prime} 00^{\prime \prime}$ N., long. $123^{\circ} 32^{\prime} 30^{\prime \prime}$ E.) ; 320 meters (175 fathoms); August 9, 1909; Glob.

Nine specimens (Cat. No. 41353 , U.S.N.M.).

Albatross station 5541; Tagolo Light bearing S. $65^{\circ}$ W., 23.54 kilometers (12.7 miles) distant (lat. $8^{\circ} 49^{\prime} 38^{\prime \prime} \mathrm{N}$., long. $123^{\circ} 34^{\prime}$ $30^{\prime \prime}$ E.) ; 401 meters (219 fathoms) ; August 20, 1909; fne. S., brk. Sh.

Three specimens (Cat. Nos. 41347, 41348, 41352, U.S.N.M.).

Philippines; without further data.

One specimen (Cat. No. 41351, U.S.N.M.).

Notes.-The diameter of the disk averages $5 \mathrm{~mm}$. and rarely exceeds $6 \mathrm{~mm}$.

The arms are very long and very slender, and they reach $60 \mathrm{~mm}$. in length in the specimens in which the diameter of the disk is 5 $\mathrm{mm}$. This is the only remark which I have to add to the description which I gave of this species in 1904 based upon the specimens collected by the Siboga; as the Albatross specimens are a little larger and better preserved than those from the Siboga collection, they permit the appreciation of this arm length, which seems to constitute one of the characters of the species; since the Siboga individuals had all the arms incomplete, I was not able to measure their length. This length may be judged on one of the two photographs which I give here (pl. 79, fig. 2) of a specimen from station 5116 .

I find also that there always occurs toward the point of contact of the two oral plates of each pair, a group of small granules, inconstant in number, which appear to be rather decidous. I did not observe these granules in the Siboga individuals and it is probable that they had been rubbed off.

Ophiopallas paradoxa was discovered by the Siboga between $0^{\circ}-5^{\circ} \mathrm{S}$. latitude and $119^{\circ}-132^{\circ} \mathrm{E}$. longitude, at depths varying from 204 to 450 meters (112 to 270 fathoms). It has not been seen since.

\section{OPHIOPALLAS VALENS, new species.}

Plate 80 , figs. $2-4$.

Locality.-Albatross station 5178; vicinity of Romblon; Point Origon (N.) bearing S. $5^{\circ}$ E., 4.26 kilometers (2.3 miles) distant (lat. $12^{\circ} 43^{\prime} 00^{\prime \prime} \mathrm{N}$., long. $122^{\circ} 06^{\prime} 15^{\prime \prime}$ E.) ; 143 meters (78 fathoms); March 25, 1908; fne. S.

A single specimen (Cat. No. 41354, U.S.N.M.).

Description.-The specimen is in very good condition; two of the arms are entire, and the three others are preserved for a rather large portion of their length. The diameter of the disk is $13 \mathrm{~mm}$, and the arms are $45 \mathrm{~mm}$. long.

The disk is rather thick, but its two surfaces are plane and parallel; the outline is subpentagonal. The dorsal surface is rather 
strongly notched at the base of the arms, and it includes at least the two first upper arm plates. This surface is covered with fine and closely crowded granules, which occur over its whole extent and entirely cover the radial shields; thanks to a slight difference in color, the outlines of these shields may however sometimes be distinguished, and they are seen to be elongated and oval, those of each pair widely separated from each other, and also separated from the first upper arm plate, by several rows of granules. The distal extremities of the genital slits which pass on to the dorsal surface in accordance with the characteristics of the genus, extend almost to the level of the proximal border of these shields, and they are separated from the first upper arm plates by several rows of granules. This dorsal part of the genital slits is bordered by granules somewhat more elongated than those adjoining; it is very narrow and sometimes only slightly evident, though it can always be recognized, and there is not doubt regarding the generic position of the ophiuran.

The ventral surface of the disk is naked over the greater portion of its surface and it shows at the periphery a narrow border of granules which continues along the genital slits; this peripheral border, which includes at first three or four rows of granules, becomes reduced to a single row on the proximal third of these slits. It is probable that this denudation of the ventral surface of the disk is accidental, but I can not state this in a definite manner. The portions of the ventral surface which are without granules are covered with small unequal plates, which are irregularly polygonal and not imbricated. The genital slits are of medium size and slightly broadened at their proximal extremity in such a way as slightly to notch the sides of the corresponding mouth shields.

These shields are rather large, a little longer than broad, and pentagonal, with a rather open proximal angle bordered by two straight sides passing over by very rounded angles to the two lateral sides which are slightly convex and notched toward their proximal third by the bottom of the genital slits. These sides also pass over by rounded angles to the distal border, which is itself slightly rounded. The adoral plates are much elongated and very narrow, in contact in the median interradial line; they broaden a little outwardly and form a small lobe separating the mouth shield from the first side arm plate. The oral plates are triangular, twice as high as broad, and covered in the neighborhood of the median interradial line by a group of rounded granules a little larger than those of the disk. The two or three granules which cover the tip of the oral plates are slightly elongated in the direction of the mouth. The mouth papillae usually number six on either side. The outermost papilla is large, squamiform, very much broadened, at least three times as long as broad, a little broader inwardly than outwardly, with 
the free border rounded; it is inserted both on the oral plate and on the adoral. The following papilla is very much smaller, almost quadrangular, and a little broader than long; the three following are small, conical, and pointed, but the proximal papilla is stronger, and almost of the same size as the unpaired papilla which terminates the jaw, and which is also conical and pointed. Beyond the outermost mouth papilla there is a papilla inserted on the first under arm plate which is much elongated, narrow, pointed, and slightly recurved.

The arms are rather broad at the base, and when they are viewed from the ventral surface, it may be seen that their width increases progressively and rather rapidly as far as the border of the disk, then decreases very much more gradually.

The first upper arm plate is very small, triangular, with the angles rounded. The second, which is larger, is trapezoidal with a narrow proximal border and very divergent sides. These two plates are always included in the radial incisions of the disk. The third plate is very much larger than the preceding; it is trapezoidal, also with divergent sides, and two and a half times as broad as long. The granules of the dorsal surface of the disk stop at a variable level on this plate, and sometimes they reach its distal border. The following plates are quadrangular, very much broader than long, with straight borders; the proximal border is a little narrower than the distal, and the sides are slightly divergent.

The first under arm plate is short and very much broadened, at least three times as broad as long; its proximal border, which is very broad, curves outwardly and passes over by sharp angles to the short and oblique sides; the distal border is straight and as broad as the proximal side of the second plate. The following plates are quadrangular, broader than long, with the proximal border straight; the distal border, which is a little broader, is very slightly notched in the middle and rounded on either side of the notch; the sides are broadly excavated by the tentacle pores and they pass over into the distal border by sharp angles.

The side arm plates, which are not very projecting, carry at the base of the arms eight spines; this number soon falls to seven and then to six. These spines are slender, flattened, broadened, and pointed, more or less lanceolate in form, and appressed against the side arm plate. The three or four first ventral spines have almost the length of the segment, the following little by little become shorter, and the last only reaches a length of half a segment.

The tentacle scales are two in number throughout the whole length of the arms; they are very large and oval; the internal scale is a little larger than the external, which it slightly overlaps. 
The dorsal surface of the disk is of a rather light brown; the arms are a little darker. In the middle of each upper arm plate there is a more or else elongated white spot, which on the eight or ten first segments comes in contact with the following spot in such a way as to form an almost continuous band. At intervals a feebly marked white annulation occurs. The ventral surface of the disk and of the arms is a slightly yellowish white except for the denuded portion of the ventral surface of the disk, which is quite white.

Affinities and distinctive features.-The type of the genus Ophiopallas is $O$. paradoxa, which was discovered by the Siboga in the Sunda Archipelago and rediscovered by the Albatross at the different stations given above. The new species is distinguished from $O$. paradoxa by a more robust habitus, by having the arms broader and shorter, by having the arm spines flattened and lanceolate in form, their length diminishing toward the dorsal side, while in $O$. paradoxa the dorsal spines are the longest, by having the disk more strongly notched at the base of the arms on the dorsal surface, by the pointed proximal angle of the mouth shields, by the considerable broadening of the outermost mouth papilla, by the form of the under arm plates, the distal border of which is slightly notched, and especially by the presence of two tentacle scales instead of a single one.

OPHIERNUS ADSPERSUS Lyman.

See for bibliography:

ophiernus adspersus KGeHLER ('04), p. 20; ('07), p. 251.-H. L. ClaRK ('11), p. 95 ; ('13), p. 212.-Kähler ('14), p. 95.-H. L. Crark ('15), p. 347.мatsumoto ('17), p. 307.

Ophiernus annectens LÜTKEN and MoRTENSEN ('99), p. 107.

Localities.-Albatross station 5123; east coast of Mindoro; Malabrigo Light bearing $\mathrm{N} .44^{\circ}$ W., 60.23 kilometers (32.5 miles) distant (lat. $13^{\circ} 12^{\prime} 45^{\prime \prime}$ N., long. $121^{\circ} 38^{\prime} 45^{\prime \prime}$ E.) ; 517 meters (283 fathoms) ; February 2, 1908; gn. M.

Twenty specimens (Cat. No. E. 353, U.S.N.M.).

Albatross station 5124; east coast of Mindoro; Point Origon (N.) bearing S. $56^{\circ}$ E., 38.45 kilometers $\left(20.75\right.$ miles) distant (lat. $12^{\circ}$ $52^{\prime} 00^{\prime \prime}$ N., long. $121^{\circ} 48^{\prime} 30^{\prime \prime}$ E.) ; 514 meters (281 fathoms); February 2,$1908 ;$ sft. gn. $M$.

Five specimens (Cat. No. E. 355, U.S.N.M.).

Albatross station 5373; Marinduque Island and vicinity; Tayabas Light (outer) bearing N. $20^{\circ}$ E., 27.79 kilometers (15 miles) distant (lat. $13^{\circ} 40^{\prime} 00^{\prime \prime}$ N., long. $121^{\circ} 31^{\prime} 10^{\prime \prime}$ E.) ; 618 meters (338 fathoms); March 2, 1909; sft. M.

One small specimen (Cat. No. 41331, U.S.N.M.).

Albatross station 5423; Joló Sea; Cagayan Island (S.) bearing S. $11^{\circ}$ E., 8.89 kilometers (4.8 miles) distant (lat. $9^{\circ} 38^{\prime} 30^{\prime \prime} \mathrm{N}$., long. 
$121^{\circ} 11^{\prime} 00^{\prime \prime}$ E.) ; 929 meters (508 fathoms) ; March 31, 1909; gy. M., co. S.

Three specimens (Cat. No. E. 350, U.S.N.M.).

Albatross station 5424; Joló Sea; Cagayan Island (S.) bearing S. $11^{\circ} \mathrm{W}$., 6.30 kilometers (3.4 miles) distant (lat. $9^{\circ} 37^{\prime} 05^{\prime \prime} \mathrm{N}$., long. $121^{\circ} 12^{\prime} 37^{\prime \prime}$ E.) ; 622 meters (340 fathoms); March 31,1909 ; co. S.

Four specimens (Cat. No. E. 349, U.S.N.M.).

Albatross station 5425; Joló Sea; Cagayan Island (S.) bearing S. $14^{\circ}$ E., 7.41 kilometers (4 miles) distant (lat. $9^{\circ} 37^{\prime} 45^{\prime \prime} \mathrm{N}$., long. $121^{\circ} 11^{\prime} 00^{\prime \prime}$ E.) ; 905 meters (495 fathoms) ; March 31, 1909; gy. M., co. S.

Three specimens (Cat. No. E. 342, U.S.N.M.).

Albatross station 5428; eastern Palawan and vicinity; 30th of June Island bearing N. $62^{\circ}$ W., 36.14 kilometers (19.5 miles) distant (lat. $9^{\circ} 13^{\prime} 00^{\prime \prime} \mathrm{N}$., long. $118^{\circ} 51^{\prime} 12^{\prime \prime}$ E.) ; 2,021 meters (1,105 fathoms); April 3, 1909 ; gy. M.

Three specimens (Cats. Nos. 41330, E. 345, U.S.N.M.).

Albatross station 5429; eastern Palawan and vicinity; Fondeado Island (S.) bearing N. $18^{\circ}$ E., 27.80 kilometers (15 miles) distant (lat. $9^{\circ} 41^{\prime} 30^{\prime \prime} \mathrm{N}$., long. $118^{\circ} 50^{\prime} 22^{\prime \prime}$ E.) ; 1,401 meters (766 fathoms); April 5, 1909; gn. M.

One specimen (Cat. No. E. 348, U.S.N.M.).

Albatross station 5465 ; east coast of Luzon, San Bernardino Strait to San Miguel Bay; Atulayan Island (E.) bearing S. $50^{\circ}$ W., 13.53 kilometers ( 7.3 miles) distant (lat. $13^{\circ} 39^{\prime} 42^{\prime \prime} \mathrm{N}$., long. $123^{\circ} 40^{\prime} 39^{\prime \prime}$ E.) ; 915 meters (500 fathoms); June 17, 1909; gy. M. (m. b.).

Two specimens (Cat. No. 352, U.S.N.M.).

Albatross station 5586; Sibuko Bay, Borneo, and vicinity; Sipadan Island (M.) bearing W., 17.42 kilometers (9.4 miles) distant (lat. $4^{\circ} 06^{\prime} 50^{\prime \prime} \mathrm{N}$., long. $118^{\circ} 47^{\prime} 20^{\prime \prime}$ E.) ; 635 meters (347 fathoms); September 28, 1909; gy. M.

Four specimens (Cat. No. E. 354, U.S.N.M.).

Albatross station 5602; Gulf of Tomini, Celebes; Gorontalo Pier bearing $\mathrm{N}$., 13.16 kilometers (7.1 miles) distant (lat. $0^{\circ} 22^{\prime} 00^{\prime \prime} \mathrm{N}$., long. $132^{\circ} 03^{\prime} 30^{\prime \prime}$ E.) ; 1,759 meters (962 fathoms); November 14, 1909 ; gy. M.

One specimen (Cat. No. E. 346, U.S.N.M.).

4lbatross station 5637 ; Bouro Island (south) and vicinity; Amblau Island (N.) bearing N. $80^{\circ}$ E., 38.92 kilometers (21 miles) distant (lat. $3^{\circ} 53^{\prime} 20^{\prime \prime}$ S., long. $126^{\circ} 48^{\prime} 00^{\prime \prime}$ E.) ; 1,280 meters (700 fathoms); December 10, 1909; gy. M.

A small specimen (Cat. No. 41332, U.S.N.M.).

Albatross station 5648; Buton Strait; North Island (S.) bearing N. $87^{\circ}$ E., 18.90 kilometers (10.2 miles) distant (lat. $5^{\circ} 35^{\prime} 00^{\prime \prime} \mathrm{S}$., 
long. $122^{\circ} 20^{\prime} 00^{\prime \prime}$ E.) ; 1,022 meters ( 559 fathoms); December 16 , 1909 ; gn. M.

One specimen (Cat. No. E. 341, U.S.N.M.).

Albatross station 5654; Gulf of Boni, Celebes; Cape Tabako bearing N. $17^{\circ} \mathrm{E}$., 39.84 kilometers (21.5 miles) distant (lat. $3^{\circ} 42^{\prime} 00^{\prime \prime}$ S., long. $120^{\circ} 45^{\prime} 50^{\prime \prime}$ E.) ; 1,472 meters (805 fathoms); December 18,1909 .

Two specimens (Cat. No. E. 347, U.S.N.M.).

Albatross station 5657; Gulf of Boni; Olang Point bearing N. $61^{\circ}$ W., 28.72 kilometers (15.5 miles) distant (lat. $3^{\circ} 19^{\prime} 40^{\prime \prime} \mathrm{S}$., long. $120^{\circ} 36^{\prime} 30^{\prime \prime}$ E.) ; 900 meters (492 fathoms); December 19, 1909; gy. M.

Three specimens (Cat. No. F. 351, U.S.N.M.).

Albatross station 5660; Flores Sea; Cape Lassa bearing S. $88^{\circ} \mathrm{W}$., 37.99 kilometers (20.5 miles) distant (lat. $5^{\circ} 36^{\prime} 30^{\prime \prime}$ S., long. $120^{\circ}$ $49^{\prime} 00^{\prime \prime}$ E.) ; 1,266 meters (692 fathoms); December 20, 1909; gy M., S.

Three specimens (Cat. No. E. 343, U.S.N.M.).

Albatross station 5668; Macassar Strait; Mamuju Island (E.) bearing S. $31^{\circ}$ E., 19.64 kilometers (10.6 miles) distant (lat. $2^{\circ} 28^{\prime} 15^{\prime \prime}$ S., long. $118^{\circ} 49^{\prime} 00^{\prime \prime}$ E.) ; 1,648 meters (901 fathoms); December 29, 1909 ; gy. M.

One specimen (Cat. No. E. 344, U.S.N.M.).

Notes.-The majority of these specimens are in rather bad condition and the dorsal surface of the disk is almost always torn away. All are white in color, except those from station 5654, which are a very dark gray.

Ophiernus adspersus has a very great geographical and bathymetrical range. It lives at very different depths from 291 to 3,653 meters (159 to 1,997 fathoms). In 1911 H. L. Clark listed the principal regions in which this species has been found. It was he who established the synonymy of $O$. adspersus and of $O$. annectens; I refer to his memoir for further details (H. L. Clark '11, p. 96.).

LIST OF STATIONS, WITH THE SPECIES FOUND AT EACH.

\begin{tabular}{|c|c|c|c|c|}
\hline $\begin{array}{l}\text { Sta- } \\
\text { tions. }\end{array}$ & $\begin{array}{c}\text { Latitude N. } \\
\text { (unless } \\
\text { otherwise } \\
\text { specified). }\end{array}$ & $\begin{array}{l}\text { Longi- } \\
\text { tude E. }\end{array}$ & Depth. & 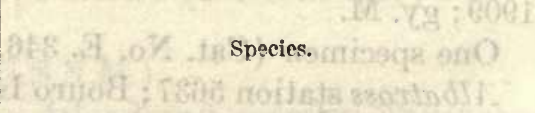 \\
\hline & - , "I & - , II & Meters. Fathoms. & 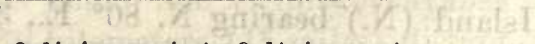 \\
\hline $\begin{array}{l}4781 \\
4893\end{array}$ & $\begin{array}{l}521430 \\
323200\end{array}$ & $\begin{array}{lll}174 & 1300 \\
128 & 32 & 50\end{array}$ & $882 \quad 482$ & $\begin{array}{l}\text { Ophioripa marginata, Ophioripa nugator. } \\
\text { ophiomoeris obstricta. }\end{array}$ \\
\hline 4935 & 305720 & 1303510 & $238 \quad 103$ & ophingymna fulgens. \\
\hline 4948 & 311900 & 1312300 & & Ophiogymna fulgens. \\
\hline 5070 & 35 C.3 25 & 1384740 & 198 & $\begin{array}{l}\text { Ophiogymna fulgens. } \\
\text { ophiogymna fulgens, ophiocten hastatum. }\end{array}$ \\
\hline $\begin{array}{l}5080 \\
5097\end{array}$ & $\begin{array}{l}341030 \\
141915\end{array}$ & $\begin{array}{l}138 \quad 1000 \\
120 \\
33352\end{array}$ & $\begin{array}{rr}924 & 505 \\
55 & 30\end{array}$ & $\begin{array}{l}\text { Ophiogymna fulgens, O phiocten hastatum. } \\
\text { Ophiura kinbergi. }\end{array}$ \\
\hline 5100 & $1417 \quad 15$ & 1203240 & $64 \quad 35$ & Amphipholis misera. \\
\hline 5104 & 144548 & 1201220 & $60 ; 33$ & Ophiura kinbergi. \\
\hline $\begin{array}{l}5105 \\
5107\end{array}$ & $\begin{array}{lll}14 & 43 & 5.5 \\
14 & 24 & 30\end{array}$ & $\begin{array}{lll}120 & 12 & 50 \\
120 & 33 & 40\end{array}$ & $\begin{array}{rr}46 & 25 \\
51 & 28\end{array}$ & $\begin{array}{l}\text { Ophiura kinbcrgi. } \\
\text { Ophiura kinbergi. }\end{array}$ \\
\hline
\end{tabular}


List of stations, with the species found at each-Continued.

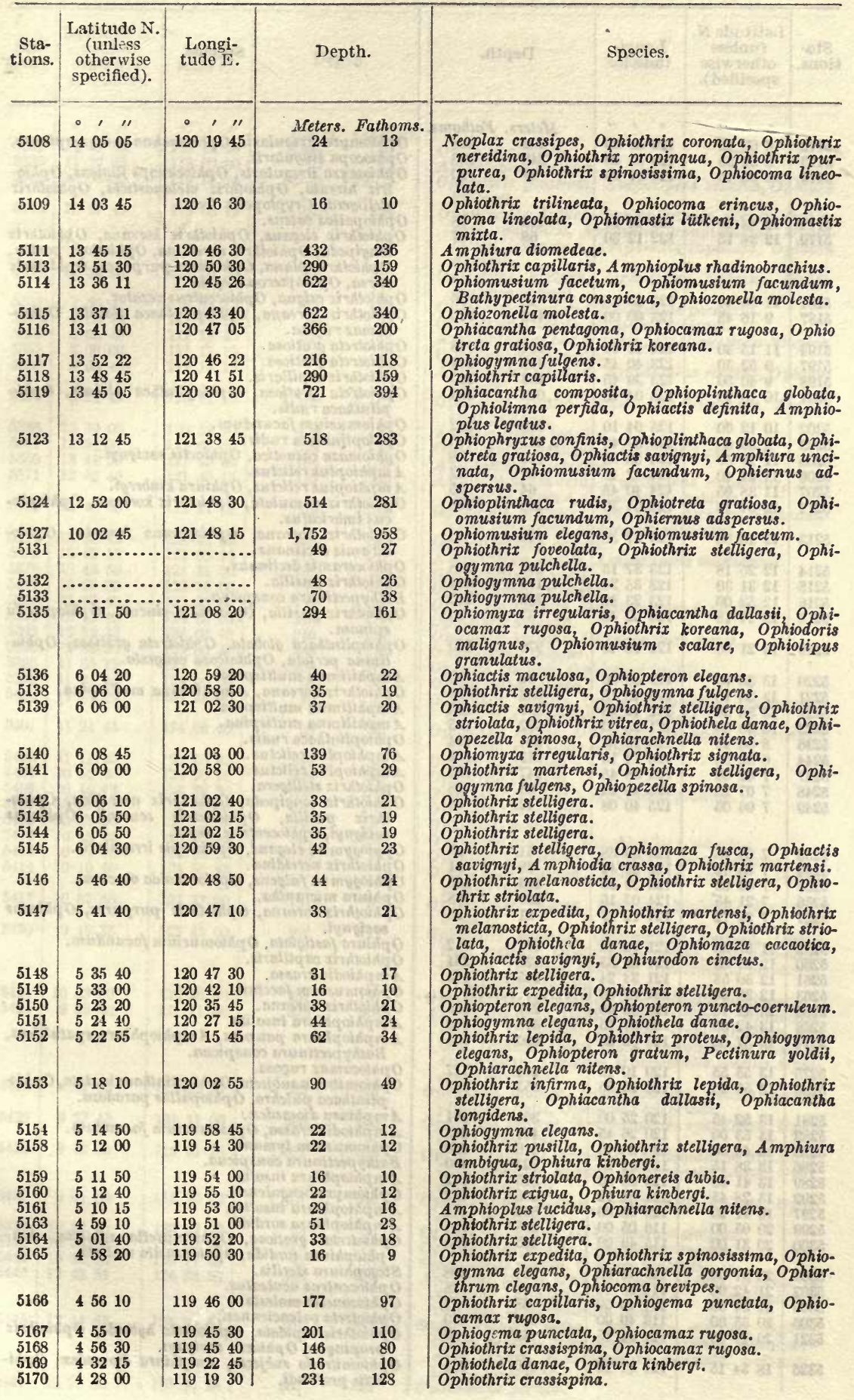


List of stations, with the species found at each-Continued.

\begin{tabular}{|c|c|c|c|c|}
\hline $\begin{array}{l}\text { Sta- } \\
\text { tions. }\end{array}$ & $\begin{array}{c}\text { Latitude N. } \\
\text { (unless } \\
\text { otherwise } \\
\text { spocified). }\end{array}$ & $\begin{array}{l}\text { Longi- } \\
\text { tude E. }\end{array}$ & Depth. & Species. \\
\hline & - ' & - , " & Meters. Fathoms. & \\
\hline 5172 & & 1203530 & $582 \quad 318$ & Ophiomyxa irregularis, Ophiarachna quinqu \\
\hline 5173 & 60255 & & 186 & \\
\hline & 608 & 1205700 & 37 & $\begin{array}{l}\text { Ophiomyxa irregularis, Ophiocanops fugiens, Ophio- } \\
\text { trix hirsuta, Ophiothrix melanosticta, Ophiothrix }\end{array}$ \\
\hline 5178 & 124300 & & 78 & stelligera, Cryptopelta tecta. \\
\hline 5179 & 123815 & 1221230 & 37 & Ophiothrix elegans, ophiothrix koreana, ophiothrix \\
\hline & 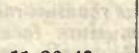 & & 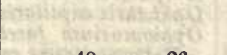 & $\begin{array}{l}\text { Ophiothrix plana, Ophiothrix purpurea, Ophiothrix } \\
\text { vitrea, Ophiopteron elegans. }\end{array}$ \\
\hline $\begin{array}{l}5181 \\
5187\end{array}$ & $\begin{array}{rrr}11 & 36 & 40 \\
9 & 16 & 45\end{array}$ & $\begin{array}{l}1232635 \\
1230000\end{array}$ & $\begin{array}{rr}48 & 26 \\
412 & 225\end{array}$ & $\begin{array}{l}\text { Ophiothrix exigua, Ophiocentrus vexator. } \\
\text { Ophothrix koreana, Ophioplinthaca globata, ophio- } \\
\text { camax rugosa. }\end{array}$ \\
\hline 5194 & 111530 & 1241100 & 271 & ophiotreta gratiosa. \\
\hline $\begin{array}{l}5197 \\
5198\end{array}$ & 952 & 1234 & 318 & Ophiotreta gratiosa. \\
\hline $\begin{array}{l}5198 \\
5201\end{array}$ & $\begin{array}{r}94050 \\
101000\end{array}$ & & $\begin{array}{r}403 \\
1,013\end{array}$ & Ophiothrix capillaris. \\
\hline 5202 & 101200 & 1250410 & 918 & $\begin{array}{l}\text { plinthaca rudis. } \\
\text { ophiomusium facundum. }\end{array}$ \\
\hline 203 & & 1250740 & 1,417 & Ophioplinthaca rudis. \\
\hline 205 & 11 & 1245 & 15 & Ophiomaza cacaotica, Ophiactis savignyi. \\
\hline 206 & 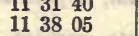 & $\begin{array}{l}1244240 \\
1244045\end{array}$ & $\begin{array}{l}59 \\
64\end{array}$ & $\begin{array}{l}\text { A mphioplus relictus. } \\
\text { A mphioplus relictus, ophi }\end{array}$ \\
\hline 212 & 120 & 1240436 & 198 & $\begin{array}{l}\text { Ophiothrix cumulata, Ophiothrix koreana, ophioplo- } \\
\text { cus imbricatus. }\end{array}$ \\
\hline 5213 & 121500 & 1235730 & 146 & $\begin{array}{l}\text { Ophiothrix koreana, Ophiogymna funesta, ophio- } \\
\text { ceramis declinans. }\end{array}$ \\
\hline 5214 & $\begin{array}{lll}12 & 2518 \\
12 & 31 & 30\end{array}$ & $\begin{array}{ll}1233715 \\
123 & 3524\end{array}$ & $\begin{array}{r}399 \\
1,105\end{array}$ & Ophioceramis declinans. \\
\hline 15 & 12 & $\begin{array}{lll}123 & 35 & 24 \\
123 & 23 & 30\end{array}$ & $\begin{array}{r}1,105 \\
393\end{array}$ & $\begin{array}{l}\text { Ophiothrix pusilla. } \\
\text { Bathypectinura conspicua. }\end{array}$ \\
\hline 18 & 13 & 1230245 & 37 & Ophiothrix pusilla, Ophiothela vincula, Ophiopezella \\
\hline 5219 & 132100 & 1221845 & 970 & $\begin{array}{l}\text { Ophioplinthaca globata, Ophiotreta gratiosa, Ophio- } \\
\text { limna perfida, Ophialcoea congesta. }\end{array}$ \\
\hline 5220 & 133 & 1215800 & 91 & A mphilimna multispina. \\
\hline 21 & & 121 & 353 & Ophiothrix koreana, A mphilimna multispina. \\
\hline & & $\begin{array}{ll}121 & 4 \\
121 & 2\end{array}$ & & Amphilimna $n$ \\
\hline & 8 & 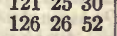 & $\begin{array}{l}357 \\
904\end{array}$ & Ophi \\
\hline & & & 313 & A mphioplus relictus. \\
\hline & & & & A mphioplus relictus. \\
\hline & 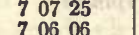 & 1254024 & 33 & Ophiothrix stelligera. \\
\hline & 70606 & 1254008 & & $\begin{array}{l}\text { Ophiothrix longipeda, Ophiothrix nereidina, ophio- } \\
\text { thrix pusilla, Ophionereis semoni, Ophiactis } \\
\text { savignyi, Ophiocentrus asper. }\end{array}$ \\
\hline $\begin{array}{l}5253 \\
5254\end{array}$ & $\begin{array}{lll}7 & 04 & 48 \\
7 & 05 & 42\end{array}$ & $\begin{array}{l}1253938 \\
125 \quad 3942\end{array}$ & $\begin{array}{l}51 \\
38\end{array}$ & $\begin{array}{l}\text { Opyiogymna elegans, Ophiolepis irregularis. } \\
\text { Ophiothrix nereidina. }\end{array}$ \\
\hline & & 1253 & 183 & Ophiogym na fulgens, ophiozonoida obscura. \\
\hline & 72 & 1240 & 158 & Ophiura micrantha. \\
\hline & & 124 & 51 & $\begin{array}{l}\text { Ophiothrix koreana, Ophiothrix purpurea, Ophiactis } \\
\text { savignyi. }\end{array}$ \\
\hline $\begin{array}{l}5259 \\
5260\end{array}$ & & $\begin{array}{lll}121 & 42 & 15 \\
121 & 31 & 35\end{array}$ & $\begin{array}{l}571 \\
428\end{array}$ & $\begin{array}{l}\text { Ophiura fastigiata, Ophio } \\
\text { Ophiothrix capillaris. }\end{array}$ \\
\hline & & & 265 & A mphiodia crassa. \\
\hline & 12 & & & Ophiom usium facetum. \\
\hline & & & & Ophiothrix koreana. \\
\hline & & 12 & & Amphiophiura insolita. \\
\hline & & & & $\begin{array}{l}\text { A mphiophiura paupera, A mphiophiura spatulifera, } \\
\text { Bathypectinura conspicua. }\end{array}$ \\
\hline 75 & 135 & n & 214 & Ophi \\
\hline & & & & $\begin{array}{l}\text { Ophiomitrella subjecta, O phioplinthaca hastata, ophio- } \\
\text { plinthaca pulchra, Ophiopallas paradoxa. }\end{array}$ \\
\hline & $\begin{array}{lll}135245 \\
135300\end{array}$ & 202500 & $\begin{array}{l}368 \\
454\end{array}$ & Amphiura diomedex. \\
\hline & & & $\begin{array}{l}454 \\
510\end{array}$ & m. \\
\hline & & & 82 & $\begin{array}{l}\text { Ophiomusium lymani. } \\
\text { Bathypectinura conspicu }\end{array}$ \\
\hline & & & 31 & Amphiophiura insolita. \\
\hline & & & & yxa bengalensis. \\
\hline & & & & Amphiophiura insolita. \\
\hline & & & & Amphiophiura sordida. \\
\hline & & & & $\begin{array}{l}\text { Ophiotreta gratiosa, Ophiomitrella subjecta, Am- } \\
\text { phiophiura sordida, Ophiozonella molesta. }\end{array}$ \\
\hline $\begin{array}{l}5301 \\
5302\end{array}$ & $\begin{array}{l}203700 \\
214200\end{array}$ & $\begin{array}{l}1154300 \\
1145000\end{array}$ & $\begin{array}{r}380 \\
70\end{array}$ & hiura sterilis. \\
\hline & & & 68 & ozonella molesta. \\
\hline & & & 170 & Ophiotreta valcnciennesí. \\
\hline & & & & $\begin{array}{l}\text { Ophiothrix aspidota, Ophiothrix hybrida, Ophiothrix } \\
\text { propingua, Ophiactis savionyt. }\end{array}$ \\
\hline 5325 & 183415 & 1215115 & 410 & $\begin{array}{l}\text { Ophiomitrella subjecta, Amphiura diomedex, Opht- } \\
\text { actis profundi. }\end{array}$ \\
\hline
\end{tabular}


List of stations, with the species found at each-Continued.

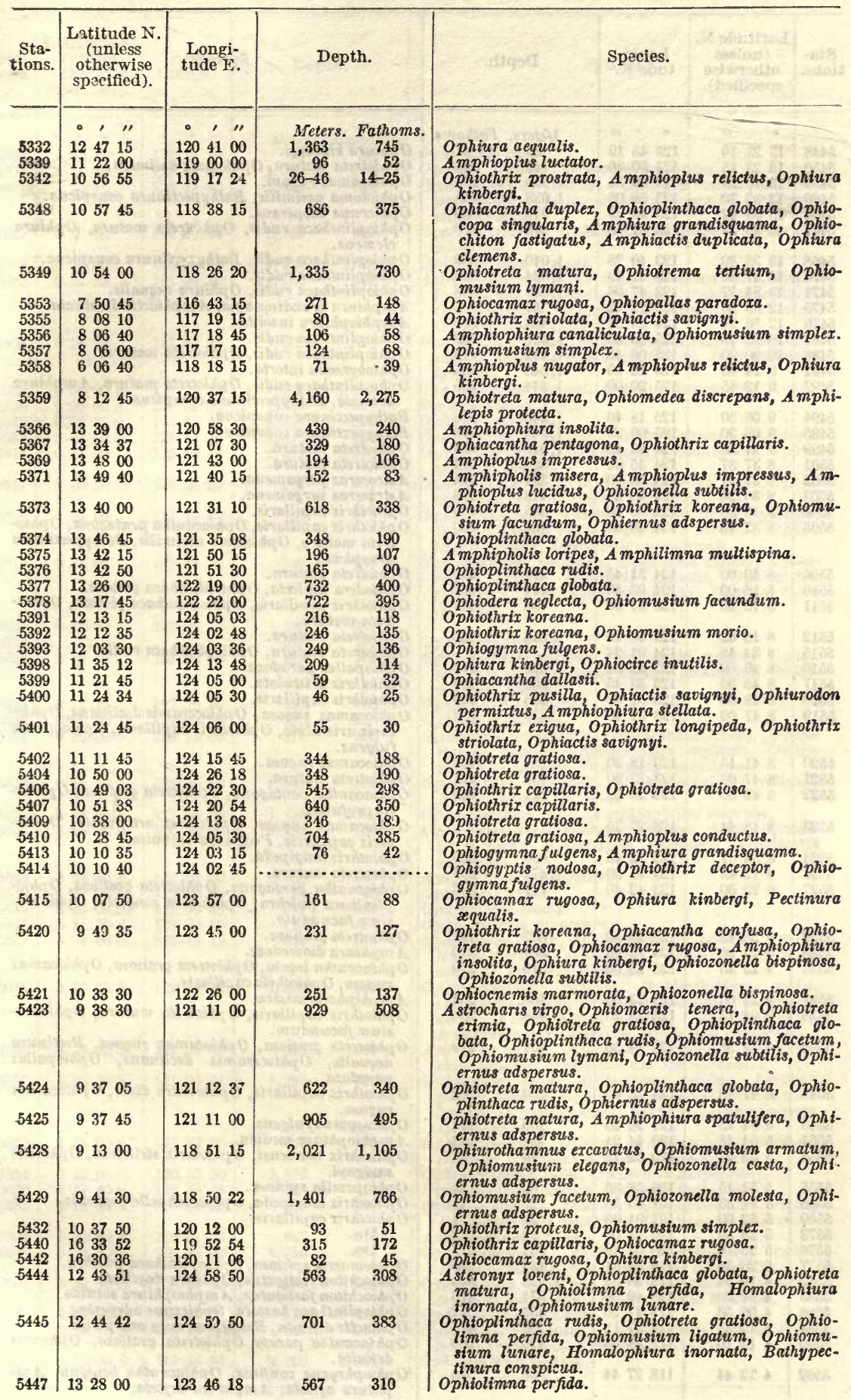


List of stations, with the species found at each-Continued.

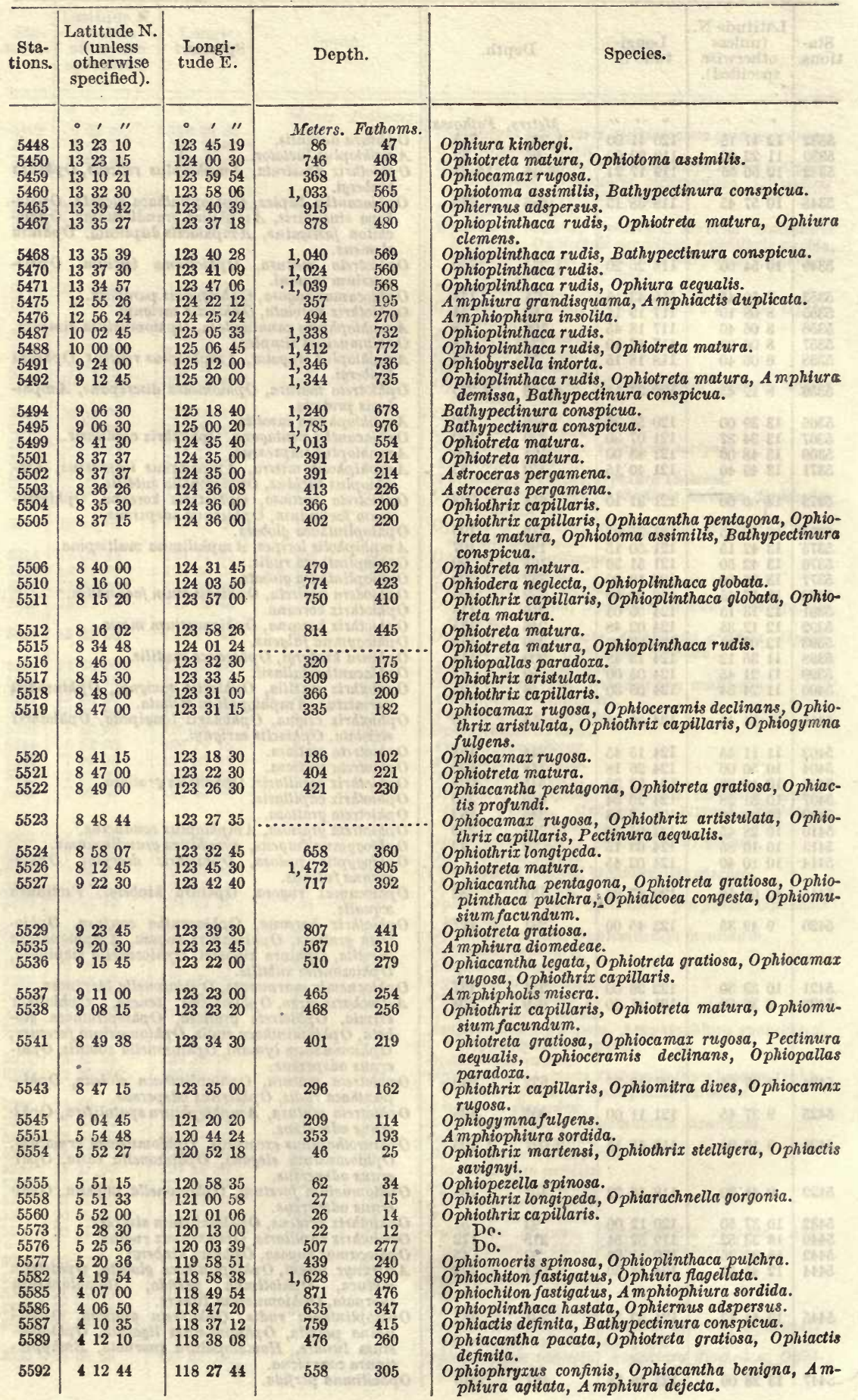


List of stations, with the species found at each-Continued.

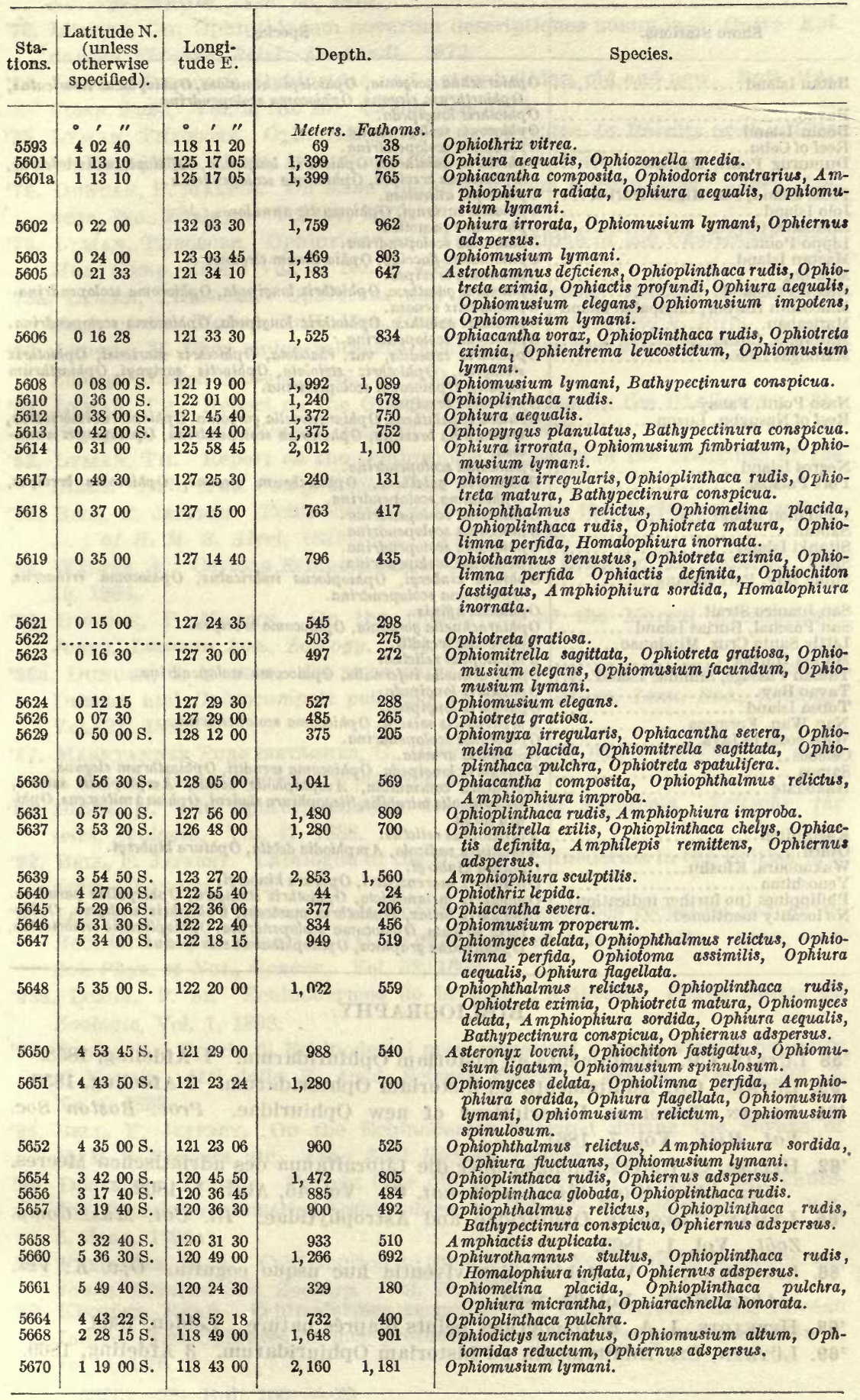


List of stations, with the species found at each-Continued.

Shore Stations.

Batan Island.

Bavao

Bonin Island.

Reef of Cebu.

(1)

Dumurug Point, Masbate.

Ficas Island, San Miguel Harbor... Jolo Island....................... Limbones Cove

Lippo Point..

Mactan Island

Makinog.

Makasser Island

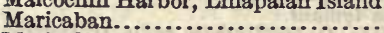

Mariveles, Luzon

Marongas Island.

Naso Point, Panay

Reel of Nasugbu, Luzon ...........

Negros Island.

Port Palapag.

Pandanon Island

Sabtan.

Sitanki Island

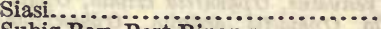

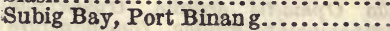

San Juanico Strait.

San Pascual, Burias Island ............ Little Santa Cruz, Mindanao.........

Manila Harbor.

Tataan Passage, Simulac Island.....

Tavao Bay...

Tobea

Nan Wan Formos.....

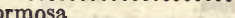

West coast of Java......................

Celebes.

Samoa..................................

Hakodate.................. .6

Kagoshims

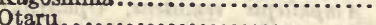

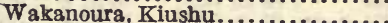
Yenoshima........................... Philippines (no further indication)... No locality mentioned.

Species.

Ophiarachna gorgonia, Ophiolepis annulosa, Ophioplocus imbricatus, Ophiarthrum elegans, Ophiocoma scolopendrina.

Ophiothrix longipeda.

ophiocoma scolopendrina.

Ophiocoma scolopendrina.

Ophiothrix galatheae, Ophiothrix longipeda, Ophioplocus imbricatus, Ophiocoma brevipes, Ophiocoma scolopendrina.

Ophiolepis annulosa.

Ophiactis savignyi, Ophiomastix annulosa.

Ophiomaza cacaotica.

ophiocoma scolopendrina.

Ophiomastix flaccida, O phiarthrum elegans.

Ophiocoma brevipes.

Ophiothrix galathex, Ophiothrix longipeda, Ophiocoma scolopendrina. Ophiomastix vcnosa.

Ophiothrix galathex, ophiothrix longipeda, ophiocoma scolopendrina. Ophiocoma scolopendrina.

Ophiothrix expedita, var. rhabdota, Ophiothrix martensi, Ophiothrix stelligera, Ophiothrix striolata, Ophiactis savignyi, Ophiarthrum elegans, Ophocoma scolopendrina.

Ophiocoma brevipes.

Ophiothrix galatheae, Ophiarachnella gorgonia, Ophioplocusimbricatus, Ophiocoma brevipes, Ophiocoma scolopendrina, Ophiomastix annulosa.

Ophiocoma scolopendrina.

Ophiothrix galatheae, Ophiarthrum elegans, Ophiocoma brevipes, Ophiocoma scolopendrina.

Ophiocoma scolopendrina.

Ophiocoma scolopendrina.

ophiocoma scolopendrina.

Ophiocoma scolopendrina.

ophiura kinbergi, Ophioplocus imbricatus, Ophiocoma crinaceus, ophiocoma scolopendrina.

Ophiactis affinis.

Ophiarachnella gorgonia, O phiocoma brevipes.

ophiocoma wendtii.

A mphioplus relictus.

Ophiarachnella infernalis, Ophiocoma scolopendrina.

Ophiothrix longipeda.

Ophiothrix longipeda.

Amphipholis misera, Ophiocoma scolopendrina.

ophiocoma scolopendrina.

Ophiothrix armata.

Ophiothrix longipeda, Ophiocoma wendtii, Ophiarthrum elegans.

Amphiura commutata, Amphipholis kochi, Amphipholis misera, Ophiopholis mirabilis, Stegophiura sladeni, Ophiura mitescens, Ophi. ura sarsii.

A mphioplus relictus.

A mphiura vadicola, A mphiodia debita, Ophiura kinbergi.

Ophiura kinbergi.

Ophiothrix marenzelleri, ophiura kinbergi.

Ophiothrix melanosticta, Ophiothrix stelligera, Ophiopallas paradoxa.

Ophiothrix bellax Ophiothrix martensi, Ophiothrix stelligera, Ophio-

thrix strioata, Ophiocoma scolopendrina, Ophioplocusio iombricatus, Ophiacantha graphica, Ophiophthalmus suspectus.

\section{BIBLIOGRAPHY.}

'58 LÜткIN, CH. Additamenta ad historiam Ophiuridarum. 1 Afdeling, 1858.

'59. LǗrkeN, CH. Additamenta ad historiam Ophiuridarum. 2 Afdeling, 1859.

'61. Lyman, Theodore. Descriptions of new Ophiuridae. Proc. Boston Soc. Nat. Hist. Vol. 7, 1861.

'62. HeLler, C. Untersuchungen über die Litoralfauna des adriatischen Meeres. Sitz. Akad. Wiss. Wien, math.-nat. Cl. Vol. 46, Abth. 1, 1862.

'65. Lyman, Theodore. Ophiuridae and Astrophytidae. Ill. Cat. Mus. Comp. Zoöl. Vol. 1, 1865.

'66. Ljungman, A. V. Ophiuroidea viventia huc usque cognita. Öfv. $K$. Vet. Akad. Förh. Vol. 23, 1866.

'68. Herklots, J. A. Echinodermes peints d'aprés nature. Leiden, 1868.

'69. Lütren, CH. Additamenta ad historiam Ophiuridarum. 3 Afdeling, 1869. 
'70. Martens, E. von. Die Ophiuriden des indischen Archipels. Archiv für Naturgeschichte. Vol. 36, 1870.

'72. LÜtKeN, CH. Ophiuridarum novarum descriptiones nonnullae. Overs. Kgl. danske Vidensk. Selsk. Forhandl., 1872.

'74. LYMAN, Theodore. Ophiuridae and Astrophytidae, old and new. Bull. Mus. Comp. Zoöl. Vol. 3, No. 10. Cambridge, 1874.

'75. LyMAN, Theodore. Ophiuridae and Astrophytidae, in Results of the Hassler Expedition. Mem. Mus. Comp. Zoöl. Vol. 4, 1875.

'78. Duncan, P. MartiN. On some Ophiuridea from Korean Seas. Journ. Linnean Soc., Zoology. Vol. 14, 1879.

'78. LyMAN, Theodore. Ophiurldae and Astrophytidae of the Challenger. Bull. Mus. Comp. Zoöl. Vol. 5, No. 7, 1878.

'78a. LYMAN, THEODORE. Ophiurans and Astrophytons. Results of the dredgings of the Blake. Bull. Mus. Comp. Zoöl. Vol. 5, No. 9, 1878.

'80. Ludwig, H. Über einige seltenere Echinodermen des Mittelmeeres. Mitth. Zoolog. Station Neapel. Vol. 2, 1880.

'82. Lyman, TH. Report on the Ophiuroldea dredged by the Challenger. The Voyage of the Challenger, Zoology. Vol. 5, 1882.

'83. Lyman, Th. Report on the Ophiuroidea. Results of the dredgings of the Blake. Bull. Mus. Comp. Zoöl. Vol. 10, 1883.

'84. BELL, F. JEFFREY. Echinodermata, in Report on the Zoological collections . . . of H. M. S. Alert, 1881-1882. London, 1884.

'84. Walter, A. Ceylons Echinodermen. Jenaische Zeitschr. für Naturvo. Vol. $18,1884$.

'86. Duncan, P. Martin. On the Ophluridae of the Mergui Archipelago. Journ. Linnean Soc., Zoology. Vol. 21, 1886.

'86a. Duncan, P. Martin. On some parts of anatomy of Ophiothrix variabilis Duncan and Ophiocampsis pellicula Duncan. Journ. Linn. Soo., Zoology. Vol. 21, 1886.

'87. MarktanNer-Turneretscher, G. Beschreibungen neuer Ophiuriden. Ann. k. k. nat. Hof-museums. Wien, vol. 2, 1887.

'88. Ввоск, J. Die Ophiuridenfauna des indischen Archipels. Zeitschr. für wiss, Zoologie. Vol. 47, 1888.

'92. BeLL, F. Jerraey. Catalogue of the British Echinoderms in the British Museum. London, 1892.

'93. Loriol, P. DE. Catalogue raisonné des t́chinodermes recueillis par M. de Robillard a l'île Maurice, III. Ophiuridés et Astrophytidés. Mém. Soc. Sci. Phys. et Nat., Genève. Vol. 32, 1893.

'93a. Lorior, P. DE. Cchinodermes de la baie d'Amboine. Revue Suisse de Zoologie, Vol. 1, 1893.

'93. Russo, A. Specie di Echinodermi poco conosciuti e nuovi viventi nel golfo di Napoli. Atti della $R$. Acad. Scienze Fisiche e Matem. Vol. 6, ser. 2, No. 1, 1893.

'94. BeLt, F. JEFfrey. On the Echinoderms collected during the voyage of H. M. S. Penguin, etc. Proc. Zool. Society, London, 1894.

'96. Döderlein, Ludwig. Bericht über die von Semon bei Amboina und Thursday Islands gesammelten Ophiuroidea, in Semon's Forschungsreisen. Vol. 5, Jena, 1896.

'97. FArquhar, H. A. Contribution to the history of New Zealand Echinoderms. Journ. Linnean Soc. Zoology. Vol. 26, 1897.

'97. KGHLER, RENE. Echinodermes recueillis par l'Investigator dans l'Océan Indien. Les Ophiures de mer profonde. Ann. Sci. Nat., Zoologie. Sér. 8, vol. $4,1897$.

$55269-22-$ Bull. $100-29$ 
'98. KđHLER, RENE. Echinodermes recueillis par l'Investigator dans l'Océan Indien. II, Les Ophiures littorales. Bulletin scientifique. Vol. 31, 1898.

'98a. KaHLer, RENE. Échinides et Ophiures provenant des campagnes du yacht Hirondelle. Rés. Sci. campagnes du Prince de Monaco. Fasc. 12, 1898.

'99. Kahler, Rent. An account of the deep sea Ophiuridea collected by the Roy. Indian Marine Survey Ship Investigator. Calcutta, 1899.

'99. LoRIoL, P. DE. Notes pour servir a l'histoire des chinodermes, VII. Mém. Soc. Sci. Phys. et Nat. Genève, 1899.

'99. LütKen, СH., and Mortensen, TH. The Ophiuridae, in Report on an exploration . . by the Steamer Albatross. Mem. Mus. Comp. Zoöl. Vol. 23, No. 2, 1899.

99. VerRill, A. E. Report on the Ophiuroidea collected by the Bahama Expedition, 1893. Bull. Lab. Nat. Hist. Univ. Iova, 1899.

99a. Verrill, A. E. North American Ophiuroidea. Trans. Connecticut Acad. Arts and Sci. Vol. 10, 1899.

'00. Pfeffer, Georg. Echinodermen von Ternate. Abh. Senckenb. Naturf. Gesellsch. Vol. 25, 1900.

'01. Clakk, Hubert Lyman. The Echinoderms of Porto Rico. Bulletin U.S. Fish Commission for 1900. Vol. 2, Washington, 1901.

'03. MacIntosh, D. C. Variation in Ophiocoma nigra. Biometrika. Vol. 2, 1903.

'03. Mortensen, TH. Echinoderms from East Greenland. Meddelelser om Grönland. Vol. 29, 1903.

'04. Kanler, Rent. Ophiures de l'Expédition du Siboga, pt. 1, Ophiures de mer profonde. Leiden, 1904.

'04a. Kohler, ReNe. Ophiures nouvelles ou peu connues. Mém. Soc. Zoologique de France. Vol. 17, 1904.

'05. Koehler, Renc. Ophiures de l'Expédition du Siboga, pt. 2, Ophiures littorales. Leiden, 1905.

'05a. Koehler, ReNE. Echinides, Ophiures et Stellérides recueillis par M. Gravier dans la mer Rouge (Folfe de Trajurah). Bulletin du Muséum. Paris, 1905.

'05b. Koehler, Rent. Echinides, Stellérides et Ophiures recueillis par MM. Bonnier et Perez dans la mer Rouge (côtes d'Arabie). Bulletin $d u \mathbf{M u}$ séum. Paris, 1905.

'06. Kaehler, Rene. Résultats scientifiques de la campagne du Caudan dans le golfe de Gascogne. Echinodermes. Lyon, 1906.

'07. Grieg, JAMes. A. Echinodermata, in Reports of the second Norwegian Arctic Expedition in the Fram, 1898-1902. Christiania, 1907.

'07. KøHLkr, RENe. Révision des Ophiures du Muséum d'Histoire Naturelle. Bull. S'cientif. Vol. 44, 1907.

'07a. KøHLER, ReNé. Ophiures. Résultats scientifiques des campagnes du Travailleur et du Talisman. Vol. 8, 1907.

'07b. Kohler, René. Ophiuroidea, in Fauna Südwest Australiens. Vol. 1, Lief. 4, Jena, 1907.

'08. Clark, Hubert Lyman. Some Japanese and East Indian Echinoderms. Bull. Mus. Comp. Zoöl. Vol. 51, No. 11, 1908.

'09. Clark, Hubert Lyman. Notes on some Australian and Indo-Pacific Echinoderms. Bull. Mus. Comp. Zoöl. Vol. 52, No. 7.

'09a. Clark, Hubert Lyman. Echinoderma, in Scientific Results of the trawling Expedition of H. M. S. Thetis. Mem. Australian Museum. Vol. 4, Sydney, 1909. 
09. Kanler, Rent. Echinodermes provenant des campagnes du yacht Princesse-Alice. Rés. Sci. campagnes du Prince de Monaco. Fasc. 34, 1909.

09. MacClendon, J. F. The Ophiurans of the San Diego Region. University of California Publications in Zoology. Vol. 6, No. 3, 1909.

'10. DöDERLerN, Ludwig. Echinodermata, in L. Schultze, Zoologische und anthrop. Ergebnisse in Südafrika. Vol. 4, Lief, 1, Jena, 1910.

'10. KoHler, Rent. Astéries et Ophiures des iles Aru et Kei. Abh. Senckenb. Naturf. Gesells. Vol. 33, 1910.

'10. Mortensen, Th. Die Echinoiden der deutschen Südpolar Expedition. Deutsch. Südpolar Expedition. Vol. 2, Heft 1, 1910.

'10. Mortensen, Th., and Koldebup Rosenvinge, L. Sur quelques plantes: parasites dans les Echinodermes. Bull. Acad. Roy. des Sciences et Lettres de Danemark. No. 4, 1910.

'11. Benham, W. B. Stellerids and Echinids from the Kermadec Islands. Transact. Newo Zealand Institute. Vol. 43, 1911.

'11. Clark, Hubert Lyman. North Pacific Ophiurans in the collection of the U. S. Nat. Mus. Bull. U. S. Nat. Mus. No. 75, 1911.

'11. Döderlein, Ludwia. Über japanische und andere Euryalae. München Abh. Akad. Wiss. Math.-phys. Klasse. Suppl., Vol, 2, 1911.

'11. Macintosh, Donald C. The Marine fauna of the Mergui Archipelago. The Ophiuroidea. Edinburgh Proc. Roy. Phys. Soc. Vol. 18, 1911.

'11. Sussbach, S., and Breckner, A. Die Seeigel, Seesterne und Schlangensterne der Nord- und Ostsee. Wiss. Meeresunters. Kiel. 1911.

'12. Kahler, ReNe. Echinotermes. Deuxième Expédition Antarctique francaise commandée par le Dr. J. Charcot. Paris, 1912.

'12. Mortensen, TH. Über Asteronyx Loveni. Zeit. f. wiss. Zool. Vol. 101, 1912.

'13. Clark, Hubert Lyman. Echinoderms from Lower California, in Scientific Results of the Expedition to the Gulf of California ... by the steamer Albatross in 1911.

'13. FArran, G. P. The Deep-Water Asteroidea, Ophiuroidea and Echinoidea of the west of Ireland. Department of Agriculture Scientific Investigations. 1912, No. 4.

'13. Kaehler, Rene. Ophiures. Zool. Jahrb. Suppl. Vol. 11, 1913.

'13. Mortensen, Th. Conspectus faunæ Groenlandiæ. Echinodermer, in Meddelelser om Grönland, vol. 23. Köbenhavn. 1913.

'13a. Montensen, Th. On the alleged primitive Ophiuroid, Ophioteresis elegans Bell, with description of a new species of Ophiothela. Köbenhavn Mindeskrift for $J$. Steenstrup, 1914.

'14. Clark, Hubert LyMan. The Echinoderms of the Western Australian Museum. Records W. A. Museum. Vol. 1, 1914.

'14. Koehler, Rent. A Contribution to the Study of Ophiurans of the United States National Museum. Bulletin U. S. Nat. Mus. 84. Washington, 1914.

'14a. Karhler, ReNE. Echinoderma I. Beiträge zur Kenntniss der Meeresfauna Westafrikas. Hamburg, 1914.

'15. Clark, Hubert Lyman. Catalogue of recent Ophiurans. Mem. Mus. Comp. Zoöl. Vol. 25, No. 4. Cambridge, 1915.

'15a. Clark, Hubert Lyman. The Echinoderms of Ceylon other than Holothurians. Spolia Zeylanica. Vol. 10, part 37, 1915.

'15. Kanler, RenE. Description d'une nouvelle espèce d'Astrophiura, l'Astrophiura Cavella. Bull. Musée Oćsanographique. No. 311. Monaco, 1915.

'15. Matsumoto, H. A new classification of the Ophiuroidea. Proc. Acad. Nat. sciences of Philadelphia, 1915. 
'16. Clark, Hubert Lrman. Report on the Sea-lilies, Starfishes, Brittle-Stars and Sea-Urchins obtained by the F. I. S. Endeavour on the Coast of Queensland. Biological Results of the . . Endeavour 1909-14. Sydney, 1916.

'17. Matsumoto, H. A Monograph of Japanese Ophiuridea, arranged according to a new classification. Journal of the College of Science. Vol. 38, art. 2, Tokyo, 1917.

\section{LIST OF TYPE SPECIMENS.}

The following specimens have been designated by the Museum as types of the new species described by $M$. Kohler:

\begin{tabular}{|c|c|c|c|}
\hline Name. & Page. & $\begin{array}{l}\text { Catalogue } \\
\text { No. }\end{array}$ & Locality. \\
\hline & & & \\
\hline Amphilimna multispina... & $\begin{array}{l}202 \\
183\end{array}$ & $\begin{array}{r}41112 \\
\text { E.1049 }\end{array}$ & $\begin{array}{l}\text { Station } 5637 . \\
\text { Station } 5375 \text {. }\end{array}$ \\
\hline Amphiodia debita....... & 168 & E.1048 & Otaru, Japan. \\
\hline Amphiophiura canaliculata. & 357 & 41341 & Station 5356. \\
\hline Amphiophiura fastigiata... & 359 & 41344 & Station 5259. \\
\hline Amphiophiura spatulifera. & 365 & 41074 & Station 5274. \\
\hline Amphioplus conductus... & 172 & 41161 & Station 5410 . \\
\hline Amphioplus legatus... & 169 & 41179 & Station 3119. \\
\hline Amphioplus lucidus.. & 176 & 41126 & Station 5371. \\
\hline Amphioplus luctator... & 178 & 41157 & Station 5339 \\
\hline Amphipholis loripes.... & 164 & 41190 & Station 5375. \\
\hline Amphiura commutata.. & 152 & E.1046 & Hakodate, Japan. \\
\hline Amphiura dejecta...... & 154 & E.1047 & Station 5592. \\
\hline ura demissa...... & 156 & 41177 & Station 5492 . \\
\hline Astrothamnus deficiens .. & 35 & E.158 & Station 5605. \\
\hline cta.......... & 350 & 41391 & Station 5174. \\
\hline Neopl & 22 & E.193 & Station 5108. \\
\hline Ophiacantha benigna... & 45 & 41235 & Station 5592. \\
\hline aphica...... & 51 & 41233 & No locality. \\
\hline Ophiacantha legata... & 53 & 41373 & Station 5536. \\
\hline Ophiacantha pacata.. & 57 & 41234 & Station 5589. \\
\hline Ophi & 61 & 41238 & Station 5645 . \\
\hline Ophiactis definita... & 187 & E.1050 & Station 5119. \\
\hline quinquespinosa.... & 331 & E.128 & Station 5172. \\
\hline Ophiobyrsella intorta..... & 27 & E.331 & Station 5491. \\
\hline nops fugiens... & 26 & 41080 & Station 5174. \\
\hline Ophi & 200 & E.1051 & Station \\
\hline Ophi & 98 & 41280 & Station 5348. \\
\hline Ophiodyctis uncinatus ... & 42 & 41017 & Station 5668. \\
\hline Ophiogema punctata..... & 67 & E.1040 & Station 5166. \\
\hline yymna funesta..... & 292 & E.1053 & Station 5213. \\
\hline Ophi & 299 & 41167 & Station 5145. \\
\hline dea discrepans ... & 95 & 41196 & Station 5359. \\
\hline mitra dives......... & 107 & E.1042 & Station 5543. \\
\hline itrella exilis....... & 110 & 40949 & Station 5637. \\
\hline mitrella sigittata.... & 111 & E.1043 & Station 5629. \\
\hline itrella subjecta.... & 114 & E.1044 & \\
\hline nusium armatum... & 389 & 40923 & Station 5428. \\
\hline Ophiomusium facetum..... & 394 & 41370 & Station 5127. \\
\hline Ophiomusium facundum... & 398 & 41369 & Station 5623. \\
\hline Ophiomusium fimbriatum. & 403 & E.188 & Station 5614 . \\
\hline Ophiomusium impotens......... & 406 & 40920 & Station 5605. \\
\hline Ophiomusium ligatum.......... & 408 & E. 80 & Station 5445 \\
\hline omusium morio...... & 413 & 40993 & Station 5392. \\
\hline Ophiomusium spinulosum. & 418 & E.190 & Station 5651. \\
\hline Ophiopallas valens........... & 437 & 41354 & Station 5178. \\
\hline & 30 & E.333 & Station 5123. \\
\hline & 127 & 41164 & No locality. \\
\hline
\end{tabular}




\begin{tabular}{|c|c|c|c|}
\hline 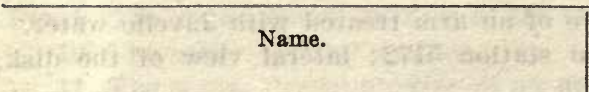 & Page. & $\begin{array}{l}\text { Catalogue } \\
\text { No. }\end{array}$ & Locality. \\
\hline 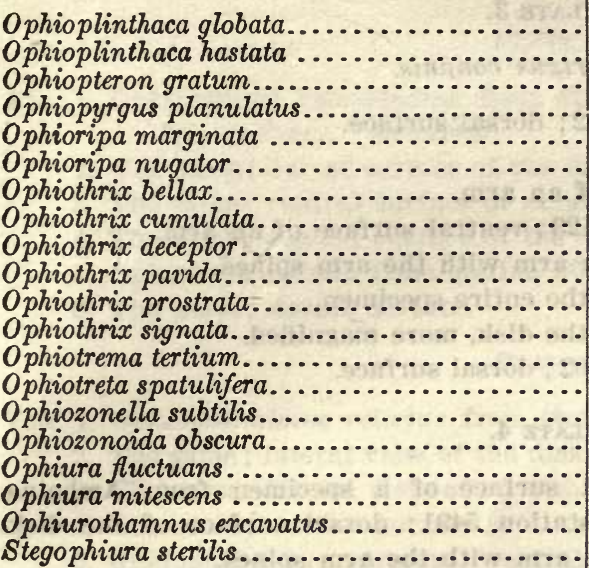 & $\begin{array}{r}132 \\
137 \\
302 \\
355 \\
118 \\
119 \\
211 \\
220 \\
225 \\
252 \\
257 \\
263 \\
88 \\
81 \\
428 \\
431 \\
377 \\
383 \\
105 \\
370\end{array}$ & $\begin{array}{r}\text { E.1045 } \\
41002 \\
41307 \\
40928 \\
41129 \\
41128 \\
41026 \\
\text { E.1052 } \\
\text { E. } 13 \\
41018 \\
41023 \\
41069 \\
41150 \\
41197 \\
\text { E.1056 } \\
41155 \\
\text { E.1055 } \\
41200 \\
\text { E.1041 } \\
\text { E.1054 }\end{array}$ & $\begin{array}{l}\text { Station } 5123 . \\
\text { Station } 5586 . \\
\text { Station } 5152 . \\
\text { Station } 5613 . \\
\text { Station } 4781 . \\
\text { Station } 4781 . \\
\text { No locality. } \\
\text { Station } 5212 . \\
\text { Station } 5414 . \\
\text { Station } 5179 . \\
\text { Station } 5342 . \\
\text { Station } 5140 . \\
\text { Station } 5349 . \\
\text { Station } 5629 . \\
\text { Station 5371. } \\
\text { Station 5255. } \\
\text { Station 5652. } \\
\text { Hakodate, Japan. } \\
\text { Station 5428. } \\
\text { Station 5301. }\end{array}$ \\
\hline
\end{tabular}

\section{EXPLANATION OF PLATES.}

The outlines of many of the figures have suffered somewhat owing to the limitations of the process of reproduction.

All figures enlarged unless otherwise stated.

\section{Plate 1.}

\section{Astrothamnus deficiens from station 5605 .}

Fig. 1. An entire specimen, dorsal surface.

2. Lateral view of an arm.

3. The same.

4. Ventral surface of an arm.

5. A hook-shaped spine.

6. Lateral view of an arm.

7. The same.

8. Lateral view of the disk.

9. Slightly oblique view of an arm near the tip.

10. Ventral surface of the disk.

Priate 2.

FiG. 1. Neoplax crassipes from station 5108; ventral surface.

2. The same; dorsal surface.

3. Ventral surface of an arm.

4. Ophiocanops fugiens from station 5174; dorsal surface of an entire specimen.

5. The same; a vertebra, with the side arm plates.

6. The same; ventral surface of an arm treated with Javelle water.

7. The same; lateral view of an arm with the arm spines.

8. The same; oblique view of an interradial area of the disk, to show the adoral plates.

9-12. The same; arm spines.

13. The same; dorsal surface of the disk.

14. The same; ventral surface of the disk.

15. The same; lateral surface of the disk, showing the madreporic orifice. 
Fic. 16. 17. The same; dorsal surface of an arm treated with Javelle water. 18. Ophiomyxa irregularis from station 5172; lateral view of the disk.

Plate 3.

Ophiophrixus confinis.

FIG. 1. A specimen from station 5592; dorsal surface.

2. The same; ventral surface.

3. The same; ventral surface of an arm.

4. The specimen from station 5123 ; ventral surface of an arm.

5. The same; lateral view of an arm with the arm spines.

6. The same; dorsal surface of the entire specimen.

7. The same; dorsal surface of the disk, more magnified.

8. The specimen from station 5592 ; dorsal surface.

\section{Plate 4.}

FIG. 1. Ophiarachna affinis; ventral surface of a specimen from Amboina.

2. Ophiobyrsella intorta from station 5491; dorsal surface of the disk.

3. The same; lateral view of an arm with the arm spines.

4. The same; dorsal surface of the entire specimen. Reduced.

5. The same; ventral surface of the disk.

6. Ophiarachna incrassata from the Sunda Islands; ventral surface.

7. The same; dorsal surface.

Piate 5.

FIG. 1. Ophiomyxa irregularis from station 5172; ventral view of the entire specimen.

2. The same; dorsal surface of the disk.

3. Ophiomoeris obstricta from station 4893 ; ventral surface.

4. The same; dorsal surface.

5. Ophiomyxa bengalensis from station 5292; dorsal surface.

6. The same; ventral surface.

\section{Plate 6.}

Fra. 1. Ophiophthalmus suspectus; ventral surface.

2. The same; dorsal surface.

3. Ophiodera neglecta from station 5378; lateral view of an arm.

4. Ophiomyxa irregularis from station 5172; lateral view of an arm.

5. Ophiogyptis nodosa from station 5414; dorsal surface.

6. The same; ventral surface.

7. Ophiodera neglecta from station 5378; dorsal surface.

8. The same; ventral surface.

Plate 7.

Fig. 1. Ophiarachna quinquespinosa from station 5172; dorsal surface.

2. The same; ventral surface.

3. The same; lateral view of an arm.

4. Ophiodictys uncinatus from station 5668; a hook-shaped spine.

5. The same; dorsal surface of an arm toward the proximal third.

6. The same; two arm spines from about the middle of an arm.

7. The same; a hook-shaped spine.

8. The same; a side arm plate seen in profile. 
Frg. 9. The same; dorsal surface of the entire specimen. Reduced.

10. The same; ventral surface.

11. The same; dorsal surface of an arm near the tip.

\section{Plate 8.}

Fic. 1. Ophientrema leucostictum from station 5606; dorsal surface of the entire specimen. Reduced.

2. The same; dorsal surface of the disk more magnifled.

3. The same; ventral surface of an arm.

4. The same; ventral surface of the disk.

5. Ophiotreta eximia from station 5648 ; ventral surface.

6. The same; dorsal surface.

Plate 9.

FIG. 1. Ophiophthalmus relictus from station 5648; dorsal surface.

2. The same; lateral view of the disk.

3. The same; lateral view of an arm.

4. The same; ventral surface.

5. Ophiophthalmus normani; ventral surface

6. The same; dorsal surface.

7. Ophiolimna perfida from station 5619 ; dorsal surface.

8. The same; ventral surface.

9. The same; lateral view on an arm.

Plate 10.

Fic. 1. Ophiomitra dives from station 5543; dorsal surface of the entire specimen. Reduced.

2. The same; dorsal surface, more magnified.

3. The same; ventral surface of an arm.

4. The same; ventral surface of the disk.

5. Ophientrema leucostictum; lateral view of an arm with the arm spines removed.

Plate 11.

\section{Ophiotreta gratiosa.}

FIG. 1. A specimen from station 5410 ; dorsal surface.

2. A specimen from station 5529 ; dorsal surface.

3. A specimen from station 5622 ; ventral surface.

4. A specimen from station 5402 ; ventral surface.

5. A specimen from station 5623 ; ventral surface

6. A specimen from station 5626 ; dorsal surface.

7. A specimen from station 5300 ; ventral surface.

Plate 12.

Ophiotreta matura.

FIG. 1. A specimen from station 5424; dorsal surface.

2. The same; ventral surface.

3. A specimen from station 5538; ventral surface.

4. A specimen from station 5424; dorsal surface of an arm.

5. A specimen from station 5425 ; dorsal surface of an arm.

6. A specimen from station 5359 ; dorsal surfảce. 
Plate 13.

\section{Ophiotreta matura.}

Fig. 1. A specimen from station 5506; ventral surface.

2. A specimen from station 5526; dorsal surface.

3. A specimen from station 5339 ; ventral surface.

4. A specimen from station 5467; ventral surface.

5: A specimen from station 5499; ventral surface.

Prate 14.

\section{Ophiotreta matura.}

Fro. 1. A specimen from station 5424; dorsal surface.

2. The same; ventral surface.

3. A specimen from station 5538; ventral surface of an arm.

4. A specimen from station 5511; dorsal surface.

5. The same; ventral surface.

\section{Plate 15.}

FIG. 1. Ophiotreta matura from station 5648; a portion of the dorsal surface of the disk.

2. Ophiotreta matura from station 5124 ; a portion of the dorsal surface of the disk.

3. Ophiotreta matura; a portion of the ventral surface of an arm.

4. Ophiacantha vorax from station 5606; dorsai surface.

5. The same; ventral surface.

6. Ophialcaea congesta from station 5219 ; ventral surface.

7. The same; dorsal surface.

Plate 16.

Fia. 1. Ophiacantha dollasii from station 5399; dorsal surface.

2. The same; ventral surface.

3. Ophiacantha dollasii from station 5135; ventral surface.

4. Ophiotreta valenciennesi from station 5306; dorsal surface of an arm.

5. Ophiacantha henigna from station 5592 ; ventral surface

6. The same; dorsal surface.

7. Ophiacantha duplex from station 5348; dorsal surface

8. The same; ventral surface.

\section{Plate 17.}

FIG. 1. Ophiacantha severa from station 5629; dorsal surface.

2. The same; ventral surface.

3. Ophiacantha severa from station 5645; dorsal surface.

4. Ophiacantha legata from station 5536; dorsal surface.

5. The same; ventral surface.

6. Ophiacantha longidens from station 5153 ; ventral surface.

7. The same; dorsal surface.

Prate 18.

Fig. 1. Ophiacantha pacata from station 5589; dorsal surface.

2. The same; a portion of the dorsal surface more magnified.

3. The same; ventral surface. 
Fre. 4. Ophiacantha graphica; dorsal surface.

5. The same; ventral surface.

6. Ophioplinthaca hastata from station 5280; dorsal surface

7. Ophioplinthaca hastata from station 5586; dorsal surface.

8. The same; ventral surface.

\section{Plate 19.}

Fro. 1. Ophiacantha confusa from station 5240; ventral surface.

2. The same; dorsal surface.

3. Ophioplinthaca chelys from station 5637 ; dorsal surface.

4. The same; ventral surface.

5. Ophiotreta spatulifera from station 5629 ; ventral surface.

6. The same; dorsal surface.

Plate 20.

\section{Ophiotoma assimilis.}

Fic. 1. A specimen from station 5460 ; dorsal surface.

2. A specimen from station 5505 ; ventral surface.

3. A specimen from station 5460 ; ventral surface.

4. A specimen from station 5450 ; ventral surface.

5. The same; dorsal surface.

6. A specimen from station 5460 ; dorsal surface.

7. A specimen from station 5647 ; ventral surface.

\section{Puate 21.}

Fia. 1. Ophiacantha pentagona from station 5116 ; a portion of the dorsal surface magnified.

2. Ophiotrema tertium from station 5349; dorsal surface.

3. The same; a portion of the dorsal surface, more magnified.

4. Ophiocopa singularis from station 5173; dorsal surface.

5. Ophiocantha pentagona from station 5116; dorsal surface.

6. The same; ventral surface.

7. Ophiotrema tertium from station 5349 ; ventral surface.

8. Ophiocopa singularis from station 5348; ventral surface

9. The same; dorsal surface.

\section{Plate 22.}

FIG. 1. Ophiurothamus stultus from station 5660 ; dorsal surface.

2. The same; ventral surface.

3. The same; lateral view of the disk.

4. The same; ventral surface of an arm toward its distal extremity.

5. Ophiurothamnus excavatus from station 5428; lateral view of disk.

6. The same; ventral surface of an arm in the distal third.

7. The same; ventral surface.

8. The same; dorsal surface.

9. Ophiomitrella exilis from station 5637 ; ventral surface.

10. The same; dorsal surface.

11. Ophiomyces delata from station 5651 ; ventral surface.

12. The same; lateral view.

\section{Plate 23.}

FIG. 1. Ophioripa marginata from station 4781 ; ventral surface.

2. The same; dorsal surface.

3. Ophiothamnus venustus from station 5619 ; ventral surface. 
Fig. 4. The same; dorsal surface.

5. Ophiacantha composita from station 5119 ; ventral surface.

6. The same; dorsal surface.

7. The same; a portion of the dorsal surface, more magnified

8. Ophioripa nugator from station 4781 ; dorsal surface

9. The same; ventral surface.

\section{Plate 24.}

FIG. 1. Ophioplinthaca rudis, a specimen from station 5450; dorsal surface.

2. The same; ventral surface.

3. A specimen from station 5618 ; dorsal surface.

4. A specimen from station 5606 ; ventral surface of an arm.

5. A specimen from station 5444; dorsal surface of an arm.

6. A specimen from station 5450 ; ventral surface of an arm.

7. Ophioplinthaca globata from station 5187 ; ventral surface.

8. The same; dorsal surface.

Plate 25.

\section{Ophioplinthaca globata.}

Fra. 1. A specimen from station 5656 ; ventral surface.

2. The same; dorsal surface.

3. A specimen from station 5444 ; ventral surface.

4. A specimen from station 5423 ; dorsal surface.

5. The same; ventral surface.

6. A specimen from station 5219 ; ventral surface.

7. The same; dorsal surface.

8. A specimen from station 5123 ; dorsal surface.

Plate 26.

Fig. 1. Ophiomedea discrepans from station 5359 ; lateral view of an arm with the arm spines.

2. The same; ventral surface.

3. The same; dorsal surface.

4. The same; lateral view of an arm without the arm spines.

5. Ophiomitrella subjecta from station 5280; dorsal surface.

6. The same; ventral surface.

7. The same; dorsal surface more magnified.

8. A specimen from station 5325 ; dorsal surface.

9. The other specimen; dorsal surface.

Plate. 27.

FIG. 1. Ophiomitrella sagittata from station 5629; dorsal surface.

2. The same; ventral surface.

3. The same; dorsal surface; more magnified.

4. The second specimen from station 5629 ; ventral surface.

5. Ophiocamax rugosa from station 5275 ; dorsal surface.

6. The same; ventral surface.

7. The same; dorsal surface of an arm at its base, more magnified.

8. The same; ventral surface of an arm near its tip.

9. Ophiomitrella sagittata from station 5623; ventral surface. 
Ophiocamax rugosa.

Fra. 1. A specimen from station 5167; dorsal surface.

2. The same; ventral surface.

3. Another specimen from station 5167; dorsal surface.

4. A specimen from station 5187; dorsal surface.

5. The same; ventral surface.

6. Another specimen from station 5187; dorsal surface.

\section{Prate 29.}

Fic. 1. Ophiocamus rugosa from station 5510; dorsal surface.

2. A specimen from station 5167; a portion of the ventral surface of an arm.

3. The same; ventral surface of an arm.

4. A specimen from station 5541; lateral view of an arm

5. The same; dorsal surface.

6. A specimen from station 5167; portion of the dorsal surface of an arm.

7. Ophiogema punctata from station 5166 ; internal view.

8. The same; ventral surface.

9. The same; dorsal surface.

Platz 30.

Fig. 1. Ophioplinthaca pulchra from station 5661; dorsal surface.

2. The same; ventral surface.

3. A specimen from station 5280 ; dorsal surface.

4. The same; ventral surface.

5. The second specimen from the same station; dorsal surface.

6. The same; ventral surface.

7. A specimen collected by the Siboga; ventral surface.

8. Ophiomelina placida from station 5661 ; ventral surface.

9. The same; dorsal surface.

\section{Piate 31.}

Fig. 1. Ophiothrix hirsuta from the Red Sea; dorsal surface.

2. A specimen from station 5174 ; dorsal surface.

3. Ophiothrix longipeda from Samoa; dorsal surface.

4. A specimen from station 5558; dorsal surface.

5. Ophiothrix expedita, var. thabdota from Marongas; dorsal surface.

6. Ophiothrix expedita from the Sunda Islands; dorsal surface.

\section{Plate 32.}

FIG. 1. Ophiothrix aspidota from Trincomalee; dorsal surface.

2. The same; ventral surface.

3. A specimen from station 5321 ; dorsal surface.

4. The same; dorsal surface, more magnified.

5. The same; ventral surface.

6. Ophiothrix puncto-limbata from Amboina; dorsal surface. 
Plate 33.

Fi. 1. Ophiothrix striolata from station 5401; dorsal surface. Reduced.

2. The same; dorsal surface, more magnified.

3. Ophiothrix quinquemaculata from La Ciotat; ventral surface of an arm.

4. Ophiothrix aristulata from station 5523; ventral surface of an arm.

5. Ophiothrix expedita from the Sunda Islands; dorsal surface of an arm.

6. Ophiothrix expedita, var. rhabdota from Marongas; dorsal surface of an arm.

7. Ophiothrix aspidota from station 5321; dorsal surface of an arm.

8. A specimen from Trincomalee; dorsal surface of an arm.

9. Ophiothrix longipeda from station 5558; dorsal surface of an arm.

10. A specimen from Samoa; dorsal surface of an arm.

11. Ophiothrix galatheae from Dumurug; dorsal surface of an arm.

12. Ophiothrix obtusa from the Sunda Islands; dorsal surface.

13. Ophiothrix hirsuta from station 5174; dorsal surface of an arm.

\section{Plate 34.}

Fra. 1. Ophiothrix galatheae from Dumurug; dorsal surface.

2. Another specimen from Dumurug; dorsal surface.

3. A specimen from Billiton; dorsal surface.

4. Another specimen from Billiton; dorsal surface.

5. Ophiothrix striolata from the Sunda Islands; dorsal surface.

Plate 35.

F19. 1. Ophiothrix aristulata collected by the Challenger; dorsal surface.

2. A specimen from station 5523; dorsal surface.

3. A specimen from station 5517 ; dorsal surface.

4. Ophiothrix fragilis var. pentaphyllum from the coasts of England; dorsal surface.

5. A specimen from Belle Isle; dorsal surface.

6. A specimen from Saldanha; dorsal surface.

7. A specimen from Lüderitz Bay; dorsal surface.

8. Ophiothrix quinquemaculata from La Ciotat; dorsal surface.

\section{Plate 36.}

Fxa. 1. Ophiothrix signata from station 5140; dorsal surface.

2. The same; ventral surface.

3. Ophiothrix proteus from station 5432 ; ventral surface.

4. The same; dorsal surface.

5. Ophiothrix lepida from station 5153; dorsal surface.

Plate 37.

Fr. 1. Ophiogymna pulchella; dorsal surface of an arm.

2. Ophiothrix capillaris from station 5536; dorsal surface.

3. A specimen from station 5440 ; dorsal surface.

4. Ophiothrix capillaris from station 5536; ventral surface.

5. Ophiogymna pulchella from station 5132; dorsal surface.

6. A specimen from the Sunda Islands; dorsal surface. 
Plate 38.

FIG. 1. Ophiothrix propinqua from station 5108; dorsal surface.

2. A specimen from the Andaman Islands; dorsal surface.

3. Ophiothrix plana from station 5179; dorsal surface.

4. A specimen from the Sunda Islands; dorsal surface.

5. Another specimen from the same source; dorsal surface.

6. Ophiothrix coespitosa from Port Jackson; ventral surface.

7. The same; dorsal surface.

8. The same; dorsal surface, more magnified.

\section{Pu.ATe 39.}

FIG. 1. Ophiothrix prostata from station 5342; dorsal surface.

2. The same; ventral surface.

3. Ophiothrix marenzelleri from Yenoshima; dorsal surface.

4. The same; dorsal surface, more magnified.

5. The same; ventral surface.

6. Ophiothrix pavida from station 5179; ventral surface.

7. The same; dorsal surface.

\section{Plate 40.}

FIG. 1. Ophiothrix exigua from the Sunda Islands; dorsal surface.

2. The same; dorsal surface of the entire specimen.

3. A specimen from station 5181 ; ventral surface.

4. A specimen from station 5160 ; ventral surface.

5. Ophiothrix coronata; magnifled view of a portion of the dorsal surface of the disk and of the beginning of an arm of the large specimen.

6. Ophiothrix pusilla from station 5218; ventral surface.

7. The same; dorsal surface.

\section{Plate 41.}

FIa. 1. Ophiothrix coronata; dorsal surface of the large specimen.

2. A specimen from station 5108; ventral surface of an arm.

3. The same; ventral surface of an arm of the second specimen.

4. The same; ventral surface of the specimen represented in Figure 1.

5. Ophiomaza fusca from station 5145; ventral surface.

6. The same; dorsal surface.

7. Ophiothrix picteti from Amboina; dorsal surface.

8. The same; dorsal surface; more magnified.

\section{Prate 42.}

\section{Ophiogymna fulgens.}

Fig. 1. A specimen from station 5141; dorsal surface.

2. A specimen from station 5393 ; dorsal surface.

3. The same; ventral surface.

4. A specimen from station 5545 ; dorsal surface.

5. A specimen from station 5070 ; dorsal surface.

6. A specimen from station 5080 ; dorsal surface.

7. A specimen from station 5117 ; dorsal surface.

8. A specimen from station 5545; dorsal surface. 


\section{Plate 43.}

FIG. 1. Ophiogymna pellicula from the Aru Islands; dorsal surface.

2. The same; ventral surface.

3. Ophiogymna elegans from station 5151 ; dorsal surface of a very young specimen.

4. A specimen from station 5253 ; dorsal surface.

5. A specimen from station 5151; dorsal surface.

6. A specimen from station 5154; portion of the dorsal surface of an arm near its origin.

7. A specimen from station 5165 ; portion of the dorsal surface of an arm near its tip.

8. A specimen from station 5151 ; ventral surface.

9. Ophiogymna fulgens from station 5151 ; portion of the dorsal surface of an arm of which the dorsal plates are much fragmented.

10. A specimen from station 5545 ; dorsal surface of an arm.

11. Ophiogymna pulchella from station 5133 ; dorsal surface.

Plate 44.

FIG. 1. Ophiogymna funesta from station 5213; ventral surface.

2. The same; dorsal surface of an entire specimen.

3. The same; dorsal surface, more magnified.

4 and 5. The same; dorsal surfaces of two arms from two different specimens.

6. The same; dorsal surface of the disk of a specimen without arm spines.

7. The same; dorsal surface of the disk of a specimen furnished with large arm spines.

8. Ophiogymna fulgens from station 5545; dorsal surface of an entire specimen. Reduced.

\section{Plate 45.}

\section{Ophiothrix koreana.}

Fic. 1. A specimen from station 5179; dorsal surface.

2. A specimen from station 5116 ; dorsal surface.

3. The same; ventral surface.

4. A specimen from station 5373 ; dorsal surface.

5. A specimen from station 5187 ; dorsal surface.

6. A specimen from station 4893 ; dorsal surface.

\section{Plate 46.}

FIG. 1. Ophiothrix trilineata from Mauritius; ventral surface.

2. The same; dorsal surface.

3. The same; dorsal surface, more magnified.

4. Ophiothrix hybrida from station 5321; dorsal surface of the entire specimen. Reduced.

5. The same; dorsal surface, more magnified.

6. The same; ventral surface.

\section{Plate 47.}

Fig. 1. Ophiothrix bellax; dorsal surface of the entire individual.

2. The same; dorsal surface, more magnified.

3. The same; ventral surface. 
Fig. 4. Ophiothrix foveolata from station 5151; dorsal surface.

5. The same; ventral surface.

6. Another specimen; dorsal surface.

7. A specimen from the Sunda Islands; dorsal surface.

Plate 48.

Fig. 1. Ophiothrix vitrea from station 5593; dorsal surface.

2. A specimen from station 5139 ; dorsal surface.

3. The entire specimen from station 5593 ; dorsal surface.

4. The specimen from station 5179; dorsal surface, more magnified.

5. Ophiothrix infirma from station 5153; dorsal surface.

6. The same; dorsal surface, more magnified.

7. The same; ventral surface.

Plate 49.

\section{Ophiothrix crassispina.}

Frg. 1. A specimen from station 5168; ventral surface.

2. Another specimen; dorsal surface; diameter of the disk $4 \mathrm{~mm}$.

3. Another specimen; dorsal surface; diameter of the disk $4.5 \mathrm{~mm}$.

4, 5. Another specimen; dorsal surface; diameter of the disk $7.5 \mathrm{~mm}$.

6. Another specimen; diameter of the disk $5.5 \mathrm{~mm}$.

\section{Plate 50.}

FIg. 1. Ophiothrix crassispina; magnified portion of the dorsal surface.

2. Ophiothrix cumulata; dorsal surface with very thick dorsal spines.

3. The same; dorsal surface less magnified

4. The same; transverse section of a thick spine.

5. The same; dorsal surface with dorsal spines not very thick.

6. The same; dorsal surface of the disk.

7. Another specimen; portion of the dorsal surface of the disk.

8. The same; portion of the dorsal surface of an arm on which the dorsal spines are strongly thickened.

Plate 51.

Ophiothrix cumulata.

Fra. 1. A specimen with dorsal arm spines not thickened; dorsal surface.

2. Another specimen on which the granules of the dorsal surface of the disk are more developed; dorsal surface.

3. The specimen represented in Fig. 1; ventral surface.

4. Another specimen; ventral surface.

5. A specimen with dorsal arm spines not thickened; portion of the surface of an arm.

\section{Plate 52.}

FIG. 1. Ophiothrix cumulata; dorsal surface of a young specimen (diameter of the disk $7 \mathrm{~mm}$.).

2. The same; portion of the ventral surface of an arm.

3. Ophiothrix crassispina; portion of the dorsal surface of an arm of a young specimen (diameter of the disk $5 \mathrm{~mm}$.).

4. A still younger specimen; portion of the dorsal surface of an arm diameter of the disk $4.5 \mathrm{~mm}$.). 
Fra. 5. The same; portion of the ventral surface of an arm.

6. Ophiothrix ciliaris from the Paris Museum; dorsal surface.

7. Another smaller specimen; dorsal surface.

8. Ophiothrix miles from the Sunda Islands; dorsal surface.

9. The same; portion of the dorsal surface of an arm.

10. The same; portion of the dorsal surface of the disk.

\section{Plate 53.}

FIG. 1. Ophiothrix stelligera from station 5147 ; dorsal surface.

2. The same; magnified portion of the dorsal surface of the disk.

3. The same; ventral surface.

4. A specimen from the Philippines; dorsal surface.

5. Another specimen from station 5147; dorsal surface of the disk.

6. Ophiothrix ciliaris; the specimen in the Paris Museum; ventral surface.

7. The same; dorsal surface.

\section{Plate 54.}

\section{Ophiothrix stelligera.}

FIG. 1. A specimen from station 5145; dorsal surface.

2. The same; portion of the dorsal surface.

3. Another specimen from station 5142 ; portion of the dorsal surface.

4. A specimen from station 5141 ; dorsal surface.

5. The same; dorsal surface of the disk.

6. The same; ventral surface.

Piate 55.

\section{Ophiothrix stelligera.}

Fia. 1. A specimen from station 5144 ; dorsal surface.

2. The same; dorsal surface, more magnified.

3. A specimen from station 5146 ; dorsal surface.

4. The same; dorsal surface, more magnified.

Plate 56.

FIG. 1. Ophiothrix elegans from station 5179; dorsal surface.

2. The same; dorsal surface, more magnified.

3. The same; ventral surface.

4. Ophiothrix stelligera from station 5147; dorsal surface.

5. A specimen from station 5142 ; dorsal surface.

6. A specimen from station 5139 ; dorsal surface.

7. A specimen from station 5146 ; $^{\circ}$ dorsal surface.

Plate 57.

FIa. 1. Ophiothrix spinosissima from station 5108; dorsal surface.

2. The same; ventral surface.

3. Ophiothrix armata from Banda; dorsal surface.

4. The same; ventral surface.

5. A specimen from Celebes; dorsal surface.

6. The same; ventral surface.

7. Ophiothrix spinosissima from station 5165 ; dorsal surface. 
Plate 58.

FIG. 1. Ophiothrix deceptor from station 5414; dorsal surface.

2. The same; ventral surface.

3. Ophiothrix purpurea from the Sunda Islands; dorsal surface.

4. The same; ventral surface.

5. Ophiopteron puncto-coeruleum from station 5150; dorsal surface of the entire individual.

6. The same; dorsal surface, more magnified.

7. The same; ventral surface.

\section{Prate 59.}

Fra. 1. Ophiothela danae from station 5169; dorsal surface.

2. The same; ventral surface.

3. Another specimen from station 5151; dorsal surface.

4. Ophiothela vincula from station 5218; dorsal surface.

5. Ophiothrix melanosticta; dorsal surface.

6. The same; ventral surface.

Plate 60.

Fra. 1. Ophiopteron elegans from station 5150 ; ventral surface.

2. The same; dorsal surface of the disk.

3. Ophiopteron gratum from station 5152 ; dorsal surface.

4. The same; ventral surface.

5. Ophiopteron elegans from station 5150; dorsal surface.

6. Ophiogymna fulgens from station 4948 bearing two prosobranch parasites; ventral surface.

Plate 61.

Fia. 1. Ophionereis semoni from station 5249 ; dorsal surface.

2. The same; ventral surface.

3. Ophiopholis mirabilis from Hakodate; dorsal surface.

4. Amphilimna multispina from station 5375; dorsal surface.

5. The same; dorsal surface of the disk of the largest specimen.

6. The same; lateral view of an arm.

7. The same; ventral surface.

8. Another specimen from station 5375 ; ventral surface.

9. The same; dorsal surface.

Plate 62.

Fro. 1. Ophiocentrus vexator from station 5181; dorsal surface.

2. The same; portion of the dorsal surface of an arm.

3. The same; portion of the ventral surface of an arm.

4. The same; ventral surface of the disk of the second specimen.

5. The same; dorsal surface of the disk.

6. Ophiactis afinis from the Kei Islands; dorsal surface.

7. Ophiocentrus asper from station 5249; portion of the dorsal surface of an arm.

8. The same; ventral surface.

9. The same; dorsal surface.

Plate 63.

Fra. 1. Amphiaetis duplicata from station 5658; dorsal surface.

2. The same; ventral surface.

55269-22-Bull. $100-30$ 
Fre. 3. A specimen from station 5348; dorsal surface.

4. The same; ventral surface.

5. Ophiactis affinis; ventral surface of the specimen represented in plate 62 , fig. 6.

6. Ophiactis maculosa from station 5136; ventral surface.

7. The same; dorsal surface.

8. Ophiactis profundi from station 5522 .

\section{Puate 64.}

FIG. 1. Ophiactis definita from station 5119; ventral surface.

2. Another specimen from the same station; ventral surface.

3. Amphioplus impressus from station 5371; ventral surface.

4. The specimen from station 5369 ; dorsal surface.

5. Ophiactis savignyi from station 5147; ventral surface of a specimen with five arms.

6. Ophiactis savignyi from the same station; ventral surface of a specimen with six arms.

7. Ophiactis definita; dorsal surface of the specimen represented in fig. 1.

\section{Prate 65.}

Fic. 1. Amphiura vadicola from Otaru; ventral surface.

2. Anotber specimen; ventral surface.

3. The same; dorsal surface.

4. The same; portion of the dorsal surface of an arm.

5. The same; portion of the ventral surface of an arm.

6. Amphiura uncinata from station 5123 ; ventral surface.

7. The same; dorsal surface.

8. The same; portion of the ventral surface of an arm at the base.

\section{Plate 66.}

Fig. 1. Amphiura commutata from Hakodate; dorsal surface.

2. The same; ventral surface.

3. The same; dorsal surface of an entire specimen.

4. Amphiura dejecta from station 5592; dorsal surface.

5. The same; ventral surface.

6. Amphiura grandisquama from station 5348; dorsal surface.

7. The same; ventral surface.

8. Another specimen from the same station; ventral surface.

\section{Plate 67.}

Fig. 1. Amphioplus legatus from station 5119; dorsal surface.

2. The same; ventral surface.

3. The same; portion of the ventral surface of an arm, more magnifiel.

4. Amphioplus conductus from station 5410 ; portion of the ventral surface of an arm.

5. The same; dorsal surface.

6. The same; ventral surface.

7. Amphiura diomedeae from the United States National Museum; dorsal surface.

8. The same; ventral surface.

9. A specimen from station 5111 ; ventral surface.

10. The same; dorsal surface. 
Plate 68.

Fig. 1. Amphioplus luctator from station 5358; ventral surface.

2. The same; portion of the dorsal surface of an arm.

3. A specimen from station 5339 ; ventral surface.

4. Amphipholis toripes from station 5375; ventral surface

5. The same; dorsal surface.

6. Amphioplus lucidus from station 5161; ventral surface.

7. Another specimen from the same station; ventral surface.

8. The same; portion of the dorsal surface of an arm.

9. A specimen from station 5371 ; ventral surface.

10. The same; dorsal surface.

\section{Plate 69.}

Fig. 1. Amphiura demissa from station 5492; ventral surface.

2. The same; dorsal surface.

3. Amphiodia debita from Otaru; ventral surface.

4. The same; portion of the dorsal surface of an arm.

5. Amphiura ambigua from station 5158; portion of the ventral surface of an arm.

6. The same; ventral surface.

7. Amphilepis remittens from station 5637; dorsal surface.

8. The same; ventral surface.

9. Amphilepis protecta from station 5359 ; dorsal surface.

10. The same; ventral surface.

11. Amphiodia crassa from station 5282 ; ventral surface.

\section{Plate 70.}

Fr. 1. Amphipholis kochii from Hakodate; ventral surface of the entire specimen.

2. The same; ventral surface, more magnified.

3. The same; dorsal surface.

4. Amphipholis misera from station 5537; dorsal surface.

5. The same; ventral surface.

6. A specimen from station 5371 ; ventral surface.

7. The same; dorsal surface.

8. A specimen from Hakodate; ventral surface.

9. Amphioplus relictus; a specimen on which the dorsal surface of the disk has been raised to show the mouthpieces on the interior surface.

\section{Prate 71.}

Fig. 1. Ophiocentrus aculeatus from station 5302; dorsal surface

2. The same; dorsal surface of the disk, more magnified.

3. The same; ventral surface.

4. Amphioplus relictus from station 5206; dorsal surface.

5. A specimen from station 5207 ; ventral surface.

6. A specimen from Manila Harbor; ventral surface.

7. A specimen from Kagoshima; ventral surface.

8. Another specimen from Kagoshima; dorsal surface.

\section{Plate 72.}

Fra. 1. Ophiocoma döderleini; Loriol's type; dorsal surface. Reduced.

2. The same; ventral surface. Reduced.

3. The same; magnified portion of the dorsal surface. 
Fra. 4. Ophiomastis annulosa from Nasugbu reef; ventral surface.

5. The same; dorsal surface.

6. Ophiocoma brevipes; ventral surface.

7. A specimen from Mauritius; ventral surface.

8. The same; dorsal surface.

9. The same; ventral surface.

Prate 73.

Fra. 1. Ophiocoma lineolata from Ceylon; dorsal surface.

2. A specimen from Mauritius; dorsal surface.

3. A specimen from station 5109; dorsal surface.

4. The specimen from Ceylon; ventral surface.

5. Ophiocoma scolopendrina; the dorsal part of the disk is raised to show the mouthpleces on thelr interior surface.

6. Ophiocomina nigra; same preparation.

7. Ophiocoma crinaceus from station 5109; dorsal surface.

\section{Puate 74.}

\section{Ophiocoma scolopendrina.}

FIG. 1. A specimen with the upper arm plates rather small; dorsal surface.

2. The same; ventral surface.

3. A specimen from the Philippines; ventral surface.

4. The same; dorsal surface.

5. A specimen from Batavia; ventral surface.

6. A specimen from Mauritius with the upper arm plates very large; dorsal surface.

7. The same; ventral surface.

\section{Plate 75.}

Fra. 1. Ophiocomina nigra from the Azores; dorsal surface.

2. The same; ventral surface.

3. Another specimen from the same region; ventral surface.

4. A specimen from Sicily; ventral surface.

5. A specimen from Roscoff; ventral surface.

6. A specimen from the Faroe Islands; ventral surface.

7. Ophiocoma wendtii from Samoa; dorsal surface.

8. The same; ventral surface.

\section{Prate 76.}

Fre. 1. Ophiochiton fastigatus from station 5585; dorsal surface.

2. A specimen from station 5582 ; dorsal surface.

3. The same; ventral surface.

4. A specimen from station 5348 ; dorsal surface.

5. A specimen from station 5619 ; ventral surface.

6. A specimen from station 5650 ; ventral surface.

7. A specimen from station 5585 ; ventral surface.

8. A specimen from station 5348; ventral surface.

9. Ophiochiton ambulator from the Sunda Islands; ventral surface.

10. Ophiochiton fastigatus from station 5619 ; dorsal surface.

11. A specimen from station 5582; portion of the ventral surface.

12. Ophiochiton ambulator from the Sunda Islands; dorsal surface.

13. The same; ventral surface. 
Plate 77.

Fig. 1. Bathypectinura conspicua from the Sunda Islands; ventral surface.

2. A specimen from station 5494 ; ventral surface.

3. A specimen from station 5114 ; ventral surface.

4. A specimen from station 5587; lateral view of an arm.

5. A specimen from station 5608 ; ventral surface.

6. A specimen from station 5587 ; ventral surface.

7. A specimen from station 5657 ; ventral surface.

8. A specimen collected by the Travailleur and the Talisman; ventral surface.

9 to 11 . The three specimens from station 5495 ; ventral surface.

12. A specimen collected by the Travailleur and the Talisman; lateral view of an arm.

13. A specimen from station 5505 ; lateral view of an arm.

14. A specimen from station 5657 ; lateral view of an arm.

15. A specimen from station 5114 ; lateral view of an arm.

16. Pectinura acqualis from station 5415 ; ventral surface.

17. Another specimen from the same station; ventral surface.

Plate 78.

Fra. 1. Crytopelta tecta from station 5174; dorsal surface.

2. The same; ventral surface.

3. Ophiozonella molesta from station 5154 ; ventral surface.

4. The same; dorsal surface.

5. Ophiozonella casta from station 5428; dorsal surface.

6. Another specimen; ventral surface.

7. The same; dorsal surface.

8. The same; lateral view.

9. Ophiozonella media from station 5601; dorsal surface.

10. The same; ventral surface.

Puate 79.

Fig. 1. Ophiopallas paradoxa from station 5516 ; ventral surface.

2. The same; dorsal surface.

3. Ophiozonella subtilis from station 5371; dorsal surface.

4. The same; ventral surface.

5. Ophiozonnella molesta from station 5429 ; ventral surface.

6. Ophiopallas paradoxa from station 5516; lateral view of an arm.

7. Ophiopallas valens from station 5178 ; lateral view of an arm.

8. Ophiozonella molesta from station 5114; lateral view of an arm.

9. Ophiozonella subtilis from station 5371; lateral view of an arm.

10. Ophiozonella molesta from station 5114; dorsal surface.

11. Ophiozonella subtilis from station 5420 ; ventral surface.

12. The same; dorsal surface.

\section{Plate 80.}

FIG. 1. Ophiolepis irregularis from station 5253; lateral view of an arm.

2. Ophiopallas valens from station 5178; dorsal surface.

3. The same; dorsal surface, more magnified.

4. The same; ventral surface.

5. Ophiolepis irregularis from station 5253; portion of the ventral surface of an arm.

6. Ophiomusium altum from station 5668; dorsal surface. 
FIG. 7. The same; dorsal surface, more magnified.

8. Ophiozonoida obscura from station 5255; dorsal surface.

9. The same; ventral surface.

10. Ophiolepis irregularis from station 5253; dorsal surface.

11. The same; ventral surface.

12. Ophiomusium altum; lateral view of the disk.

13. Ophiozonoida obscura from station 5255 ; lateral view of an arm.

\section{Plate 81.}

Fra. 1. Ophioconis forbesi from La Ciotat; ventral surface.

2. Ophiura aequalis from station 5647; lateral view of an arm.

3. Ophiopyrgus planulatus from station 5613 ; dorsal surface.

4. The same; ventral surface.

5. Ophiurodon cinctus from station 5147; ventral surface.

6. Ophiura aequalis from station 5647; dorsal surface.

7. Ophiura mitescens from Hakodate; ventral surface.

8. The same; lateral view of an arm.

9. The same; dorsal surface.

10. Ophiura aequalis from station 5647 ; ventral surface.

\section{Plate 82.}

Fig. 1. Amphiophiura fastigiata from station 5259 ; lateral view.

2. The same; ventral surface.

3. The same; dorsal surface.

4. The same; dorsal surface, more magnified.

5. Amphiophiura spatulifera from station 5274; dorsal surface of the specimen $\mathbf{B}$.

6. The same; ventral surface.

7. The specimen A from station 5425 ; dorsal surface.

8. The same; ventral surface.

9. Homalophiura inornata from station 5444; dorsal surface.

10. Amphiophiura canaliculata from station 5356; ventral surface.

11. The same; dorsal surface.

12. The same; lateral view of an arm.

13. Amphiophiura spatulifera from station 5274 ; lateral view of an arm.

Plate 83.

Frg. 1. Stegophiura sterea from station 3771 ; dorsal surface.

2. The same; ventral surface.

3. The same; lateral view of an arm.

4. Stegophiura sladeni from Hakodate; ventral surface.

5. The same; dorsal surface.

6. The same; lateral view of the disk.

7. The same; lateral view of an arm.

8. Stegophiura sterilis from station 5301; dorsal surface.

9. The same; ventral surface.

10. The same; lateral view of an arm.

11. The same; lateral view of the disk.

Plate 84.

FIG. 1. Stegophiura sladeni from Hakodate; ventral surface of a specimen with four arms.

2. Homalophiura inflata from station 5660 ; dorsal surface. 
Fra. 3. The same; ventral surface.

4. Amphiophiura improba from station 5631 ; ventral surface.

5. The same; dorsal surface.

6. Amphiophiura paupera from the Sunda Islands; dorsal surface.

7. The same; ventral surface.

8. Amphiophiura insolita from station 5297; dorsal surface.

9. The same; ventral surface.

10. Ophiura sarsii from the coasts of Norway; ventral surface.

11. Another specimen; ventral surface.

12. Amphiophiura sordida from station 5300; ventral surface.

13. The same; dorsal surface.

\section{Plate 85.}

FIG. 1. Ophiura flagellata from station 5647; dorsal surface of an arm.

2. Ophiura fuctuans from station 5652; dorsal surface.

3. Another specimen; dorsal surface.

4. The same; ventral surface.

5. The same; lateral view of an arm.

6. Ophiura flagellata from station 5651 ; dorsal surface.

7. The specimen from station 5647 ; dorsal surface.

\section{Plate 86.}

Frg. 1. Ophiura flagellata from the Andaman Islands; ventral surface.

2. A specimen from station 5647 ; ventral surface.

3. The same; lateral view of an arm.

4. The same; ventral surface of an arm.

5. Ophiomusium lymani from station 5349; lateral view of an arm.

6. Ophiura micrantha from station 5256 ; ventral surface.

7, 8, 9. Ophiomusium lymani from station 5349; ventral surface of three specimens.

10. Ophiura fagellata from station 5647 ; ventral surface of an arm.

\section{Plate 87.}

Fig. 1. Ophiomusium spinulosum from station 5650; ventral surface.

2. A specimen from station 5651 ; dorsal surface of an arm.

3. The same; dorsal surface.

4. The same; ventral surface.

5. The specimen from station 5650 ; dorsal surface.

6. The specimen from station 5651 ; lateral view of an arm at its base.

7. The same; lateral view of an arm from about its middle.

8. Ophiomusium lunare from station 5444 ; dorsal surface.

\section{Plate 88.}

Fig. 1. Ophiomusium elegans from station 5428; ventral surface.

2. A specimen from station 5127 ; dorsal surface.

3. The specimen from station 5428; portion of the rentral surface of an arm.

4. The same; portion of the dorsal surface of an arm.

5. A specimen from station 5623 ; dorsal surface.

6. The same; ventral surface.

7. The same; oblique view of the base of an arm to show the radial granules. 
Fig. 8. A specimen from station 5624 ; lateral view of an arm.

9. The same; ventral surface.

10. Ophiomusium simplex from station 5357 ; dorsal surface.

11. The same; ventral surface.

\section{Prate 89.}

Fra. 1. Ophiomusium facundum from station 5378; ventral surface.

2. The same; dorsal surface.

3. Ophiomusium morio from station 5392; ventral surface.

4. The same; dorsal surface.

5. Ophiomusium facundum from station 5378; oblique view of the ventral surface of the disk.

6. The same; lateral view of an arm.

7. Ophiomusium scalare from station 5135 ; ventral surface.

8. Ophiomusium armatum from station 5428; ventral surface.

9. The same; lateral view of an arm.

10. The same; dorsal surface.

\section{Platis 90.}

Fra. 1. Ophiomusium scalare from station 5135; dorsal surface.

2. The same; lateral view of an arm.

3. Ophiomusium ligatum from station 5445 ; ventral surface.

4. The same; dorsal surface.

5. The same; lateral view of an arm.

6. Ophiomusium fimbriatum from station 5614; dorsal surface.

7. The same; ventral surface.

8. The same; lateral view of an arm.

9. Ophiomusium impotens from station 5605 ; dorsal surface.

10. The same; ventral surface.

11. The same; lateral view of an arm.

PLate 91.

Fig. 1. Ophiomusium facetum from station 5263; dorsal surface.

2. A specimen from station 5127 ; ventral surface.

3. A specimen from station 5423 ; dorsal surface.

4. A specimen from station 5114 ; dorsal surface.

5. A specimen from station 5127; lateral view of an arm.

6. Ophiomusium relictum from station 5641 ; ventral surface.

7. The same; dorsal surface.

8. The same; lateral view of an arm.

Plate 92.

In the figures on this plate, as well as on those following, the arm spines and tentacle scales, unless otherwise indicated, are from the proximal third of the arms.

FIG. 1. Ophiomyxa bengalensis; arm spines from different heights on the arms.

2. Ophiomyxa irregularis; arm spines:

$a$, from the base of the arms.

$b$, from the terminal third.

lalfis $c$, in the immediate vicinity of the extremity where the arm spines are transformed into hooks at several points. 
Fro. 3. Ophiodera neglecta; $a$ and $b$, arm spines:

$a$, from the base of the arms.

$b$, from the terminal third.

$c$, spinules of the integuments in $\mathrm{C}$.

4. Ophiobyrsella intorta; arm spines:

$a$, ordinary spines at the beginning of the arms.

$b$, first ventral arm spine transformed into a hook on the same level.

c, spines of the terminal third.

$d$, first ventral spine on the same level.

$e$, spines in the vicinity of the extremity of the arms.

$f$, first ventral spine on the same level.

5. Ophiogema punctata; spines of the dorsal surface of the disk.

6. Ophiolimna perfida; granules of the dorsal surface of the disk.

\section{Plate 93.}

Fra. 1. Ophiophryxus confinis; arm spines:

$a$, toward the base of the arms.

$b$, in the terminal third.

$c$, first ventral arm spine at the extremity of the arms.

2. Astrocharis virgo; arm spines.

3. Astroceras pergamena; arm spines:

$a$ and $b$, ordinary arm spines on the ventral surface of the arms.

$c$, spines on the dorsal surface of the arms.

$d$, spines transformed into hooks in the terminal part of the arms.

4. Ophiacantha composita; club spines on the dorsal surface of the disk.

5. Ophiacantha pentagona; club spines on the dorsal surface of the disk. (except the first club spine on the left shown magnified).

6. Ophiotreta valenciennesi; granules on the dorsal surface of the disk.

7. Ophiotreta eximia; club spines and arm spines on the dorsal surface of the disk.

Plate 94.

Fig. 1. Ophientrema leucostictum; arm spines:

$a$, first ventral arm spine transformed into a hook.

$b$, second ventral spine transformed into a hook.

$c$, ordinary lateral and dorsal arm spines.

2. Ophiomitra dives; granules on the dorsal surface of the disk.

3. Ophiomelina placida; granules on the dorsal surface of the disk.

4. Ophiomitrella subjecta; club spines on the dorsal surface of the disk.

5. Ophioplinthaca pulchra; granules on the dorsal surface of the disk.

$a$, of a specimen from station 5280 collected by the Albatross.

$\boldsymbol{b}$, of a specimen collected by the Siboya on which the asperities are larger.

6. Ophioplinthaca globata; granules, club spines, and spines of the dorsal surface of the disk in different specimens.

7. Ophioplinthaca hastata; club spines of the dorsal surface of the disk.

8. Ophiocamax rugosa; club spines and spines of the dorsal surface of the disk. 
Plate 95.

Fig. 1. Ophiotreta gratiosa; club spines and spines of the dorsal surface of the disk.

2. Ophiotreta matura:

$a$, club spines and spines of the dorsal surface of the disk in different specimens.

$b$, very short club spines of the specimen from station 5359 .

$c$ and $d$, the first $(d)$ and second $(c)$ ventral arm spines transformed into a hook.

$e$, tentacle scale.

3. Ophiophthalmus relictus; granules on the dorsal surface of the disk.

4. Ophiomitrella sagittata; club spines on the dorsal surface of the disk.

\section{Plate 96.}

FIG. 1. Ophioplinthaca rudis; club spines on the dorsal surface of the disk.

2. Ophiactis savignyi; arm spines.

3. Amphiura ambigua; arm spines.

$a$, second and third spine.

$b$, fourth spine.

$c$, first ventral spine.

4. Amphiura uncinata; first ventral arm spine at the base of the arm.

5. Amphiura vadicola; arm spines.

$a$, second spine.

$b$, other spines.

6. Amphiura commutata:

$a$, arm spines.

$b$, tentacle scale.

7. Amphilimna multispina:

$a$, spines on the dorsal surface of the disk.

$b$, arm spine.

8. Ophiocentrus aculeatus; arm spines.

9. Amphioplus legatus; arm spines.

10. Amphioplus lucidus; arm spines.

$a$, first ventral spine.

$b$, second spine.

$c$, third spine.

11. Ophiocentrus vexator; arm spines.

12. Ophiocentrus asper; arm spines.

13. Ophiomyces delata; arm spines:

$a$, small ventral spines.

$b$, the same.

$c$, lateral and dorsal spines.

14. Ophiopholis mirabilis; first ventral arm spine and granules of the dorsal surface of the disk.

$a$, first ventral spine in the first third of the arm.

$b$, first ventral spine in the second third of the arm.

$c$, first ventral spine toward the tip.

$d$, three granules of different sizes on the dorsal surface of the disk. 
Plate 97.

FIG. 1. Ophiothrix aristulata:

$a$, arm spines of the dorsal surface of the disk.

$b$, club spines of different sizes.

$c$, club spines with lateral and terminal spinules.

$d$, hook formed by the first ventral arm spine in the terminal part of the arms (specimen collected by the Albatross).

$e$, hook formed by the first ventral arm spine in a small sized specimen collected by the Challenger.

$f$, two tentacle scales on the same level with $c$.

2. Ophiothrix armata:

$a$, first ventral arm spine transformed into a hook.

$b$, tentacle scale.

3. Ophiothrix aspidota:

$a$, club spines on the dorsal surface of the disk.

$b$, first ventral arm spine transformed into a hook at several places.

$c$, second and third arm spine.

$d$, fourth arm spine.

$e$, tentacle scale.

4. Ophiothrix bellax:

$a$, club spines and arm spines of the dorsal surface of the dist.

$b$, first ventral arm spine transformed into a hook.

$c$, tentacle scale.

5. Ophiothrix capillaris:

$a$, club spines of the dorsal surface of the disk.

$b$, first ventral spine transformed into a hook.

$c$, second arm spine transformed into a hook.

$\boldsymbol{d}$, tentacle scale.

6. Ophiothrix deceptor:

$a$, first ventral arm spine transformed into a hook.

$b$, second arm spine.

$c$, tentacle scale.

FIG. 1. Ophiothrix coronata:

Plate 98.

$a$, club spines of the dorsal arm plates.

$b$, club spines of the dorsal surface of the disk.

$c$, first ventral arm spine transformed into a hook at several places.

$d$, second and third arm spine.

c, tentacle scale.

2. Ophiothrix crassispina:

$a$, tentacle scale.

$b$, first ventral arm spine transformed into a hook.

$c$, club spines of the dorsal surface of the disk.

$d$, second and third arm spine.

3. Ophiothrix cumulata:

$a$, club spines of the dorsal surface of the disk.

$b$, first ventral arm spine transformed into a hook.

$c$, tentacle scale.

$d$, second and third arm spine.

4. Ophiothrix exigua:

$a$, club spines of the dorsal surface of the disk.

$b$, second and third arm spines.

$r$, tentacle scale. 
Fia. 5. Ophiothrix expedita:

$a$, club spines of the dorsal surface of the disk.

$b$, spines of the dorsal surface of the disk.

$c$, second arm spine.

$d$, first ventral arm spine transformed into a hook.

$e$, tentacle scale.

6. Ophiothrix foveolata:

$a$, tentacle scale.

$b$, second arm spine.

$c$, first ventral arm spine transformed into a hook.

$d$, lateral arm spines.

Plate 99.

Fra. 1. Ophiothrix galatheae:

$a$, club spines of the dorsal surface of the disk.

$b$, club spines of the dorsal surface of the disk in the interradii, in an individual from Billiton.

c, various lateral arm spines.

$d$, second lateral arm spine.

$e$, third lateral arm spine.

$f$, first ventral arm spine transformed into a hook at some distance from the disk.

$g$, first ventral arm spine nearer the disk.

$h$, first ventral arm spine at the beginning of the arm.

$i$, tentacle scale.

2. Ophiothrix hirsuta:

$a$, club spines of the dorsal surface of the disk.

$b$, first ventral arm spine transformed into a hook.

c, first ventral arm spine commencing to be transformed into a hook.

$d$, tentacle scale.

$e$, lateral arm spines.

$f$, second arm spine.

$g$, lateral arm spines toward the extremity of the arm.

3. Ophiothrix hybrida:

$a$, spines of the dorsal surface of the disk.

$b$, lateral arm spines.

$c$, tentacle scale.

$d$, first ventral arm spine transformed into a hook.

4. Ophiothrix koreana:

$a$, club spines of the dorsal surface of the disk; normal forms.

$b$, ciub spines of the dorsal surface of the disk; simplified forms.

c, more or less developed spines of the dorsal surface of the disk.

$d$, second arm spine.

$e$, first ventral arm spine transformed into a hook.

$f$, tentacle scale.

\section{Plate 100.}

Fia. 1. Ophiothrix infirma:

$a$, club spines of the dorsal surface of the disk.

$b$, second arm spine.

$c$, first arm spine transformed into a hook.

$\boldsymbol{d}$, tentacle scale. 
Fra. 2. Ophiothrix longipeda:

$a$, club spines of the dorsal surface of the disk.

$b$, tentacle scale.

c, first ventral arm spine commencing to be transformed into a hook toward the base of the arm.

$d$, first arm spine transformed into a hook at several places.

$e$, second arm spine on the same level.

$f$, third arm spine in the terminal part of the arm.

$g$, lateral arm spines.

$h$, a lateral arm spine toward the base of the arms.

3. Ophiothrix lepida:

$a$, first ventral arm spine transformed into a hook.

$b$, tentacle scale.

$c$, spines of the dorsal surface of the disk.

$d$, second arm spine.

4. Ophiothrix marenzelleri:

$a$, club spines of the dorsal surface of the disk.

$b$, tentacle scale.

$c$, first ventral arm spine transformed into a hook.

$d$, second arm spine.

$e$, third and fourth arm spine.

5. Ophiothrix melanosticta:

$a$, lateral arm spine.

$b$, spines of the dorsal surface of the disk.

$c$, club spine of the dorsal surface of the disk.

$d$, club spine of the dorsal surface of the disk.

$e$, tentacle scale.

$f$, first ventral arm spine transformed into a hook.

$g$, third arm spine.

$h$, second arm spine magnified.

6. Ophiothrix martensi:

$a$, tentacle scale.

$b$, arm spines.

c, first arm spine transformed into a hook.

Plate 101.

Fia. 1. Ophiothrix nereidina:

$a$, first ventral arm spine transformed into a hook.

$b$, tentacle scale.

$c$, three successive arm spines.

2. Ophiothrix plana:

$a$, first ventral arm spine transformed into a hook.

$b$, tentacle scale.

$c$, dorsal arm spine.

$d$, second and third arm spine.

3. Ophiothrix proteus:

$a$, lateral arm spines.

$b$, second arm spine.

$c$, tentacle scale.

$d$, first arm spine transformed into a hook.

$e$, spines of the dorsal surface of the disk. 
Fic. 4. Ophiothrix propinqua:

$a$, tentacle scale.

$b$, first ventral arm spine near the disk.

llood a citil $c$, first ventral arm spine transformed into a hook.

$\boldsymbol{d}$, second arm spine.

$e$, third arm spine.

$f$, fourth arm spine.

- $g$, dorsal spine.

5. Ophiothrix spinosissima:

$a$, lateral arm spine.

$b$, second arm spine.

$c$, dorsal spine.

$d$, first arm spine transformed into a hook.

$e$, tentacle scale.

6. Ophiothrix purpurea:

$a$, spines of the dorsal surface of the disk.

$b$, second arm spine.

$c$, first arm spine transformed into a hook.

$\boldsymbol{d}$, tentacle scale.

7. Ophiothrix punato limbata:

$a$, second and third arm spines.

$b$, first arm spine transformed into a hook at several places.

$c$, club spines of the dorsal surface of the disk.

$d$, tentacle scale.

8. Ophiothrix pusilla:

$a$, tentacle scale.

$b$, first ventral arm spine transformed into a hook.

$c$, dorsal arm spine.

$d$, second, third and fourth arm spines.

\section{Plate 102.}

Fre. 1. Ophiothrix striolata:

$a$, spines of the dorsal surface of the disk.

$b$, tentacle scale.

$c$, second arm spine.

$d$, first arm spine transformed into a hook.

2. Ophiothrix stelligera:

$a$, club spines of the dorsal surface of the disk.

$b$, club spines of the dorsal surface of the disk.

$c$ and $d$, first veutral arm spine transformed into a hook with three or four branches.

$e$, ordinary spines of the dorsal surface of the disk.

$t$, bifurcated spines.

3. Ophiothrix ciliaris:

$a$, club spines of the dorsal surface of the disk.

4. Ophiothrix trilineata:

$a$, lateral arm spines.

$\boldsymbol{b}$, second arm spine.

$c$, tentacle scale.

$d$, spines of the dorsal surface of the disk.

$e$, first arm spine transformed into a hook. 
FrG. 5. Ophiothrix vitrea:

$a$, first ventral arm spine transformed into a hook.

$b$, tentacle scale.

$c$, club spines of the dorsal surface of the disk.

$d$, second arm spine.

$e$, dorsal arm spine.

Plate 103.

Fig. 1. Ophiothela danae:

$a$, first ventral arm spine transformed into a hook at the end of the arm.

$b$, first ventral arm spine transformed into a hook at the beginning of the arm.

c, arm spines.

2. Ophiopteron gratum:

$a$, first ventral arm spine transformed into a hook.

$b$, tentacle scale.

$c$, second arm spine.

$d$, third arm spine.

$e$, fourth arm spine.

$f$, fifth arm spine.

3. Ophiopteron puncto coeruleum:

$a$, first ventral arm spine transformed into a hook.

$b$, second arm spine.

$c$, lateral spine.

$d$, tentacle scale.

4. Ophiopteron elegans:

$a$, lateral arm spines.

$b$, first arm spine transformed into a hook.

$c$, second arm spine.

$d$, club spines of the dorsal surface of the disk.

$e$, tentacle scale.

5. Ophiogymna pulchella:

$a$, various arm spines.

$b$, first arm spine transformed into a hook.

$c$, second arm spine.

$d$, spines of the dorsal surface of the disk.

$e$, club spines of the dorsal surface of the disk.

$f$, tentacle scale.

6. Ophiothrix pentaphyllum; vertebra of an arm:

$a$, proximal surface.

$b$, distal surface.

7. Ophiogymna elegans:

$a$, first ventral arm spine transformed into a hook.

$b$, second arm spine.

$c$, second arm spine more magnified.

$d$, various arm spines.

$e$, proximal surface of a vertebra.

$f$, distal surface of the same. 
Fra. 8. Ophiogymna fulgens:

$a$, second arm spine, more magnified.

$b$, club spines of dorsal surface of the disk.

$c$, spines of the dorsal surface of the disk.

$d$, first ventral arm spine transformed into a hook.

$e$, lateral arm spines.

$f$, tentacle scale.

$g$, proximal surface of a vertebra.

$h$, the same, distal surface.

\section{Ophiogymna funesta:}

$a$, lateral arm spines.

$b$, club spines of the dorsal surface of the disk.

$c$, first ventral arm spine transformed into a hook at different levels.

$d$, second arm spine.

$e$, dorsal arm spine.

$f$, proximal surface of a vertebra.

0 , the same, distal surface.

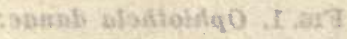

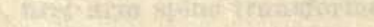

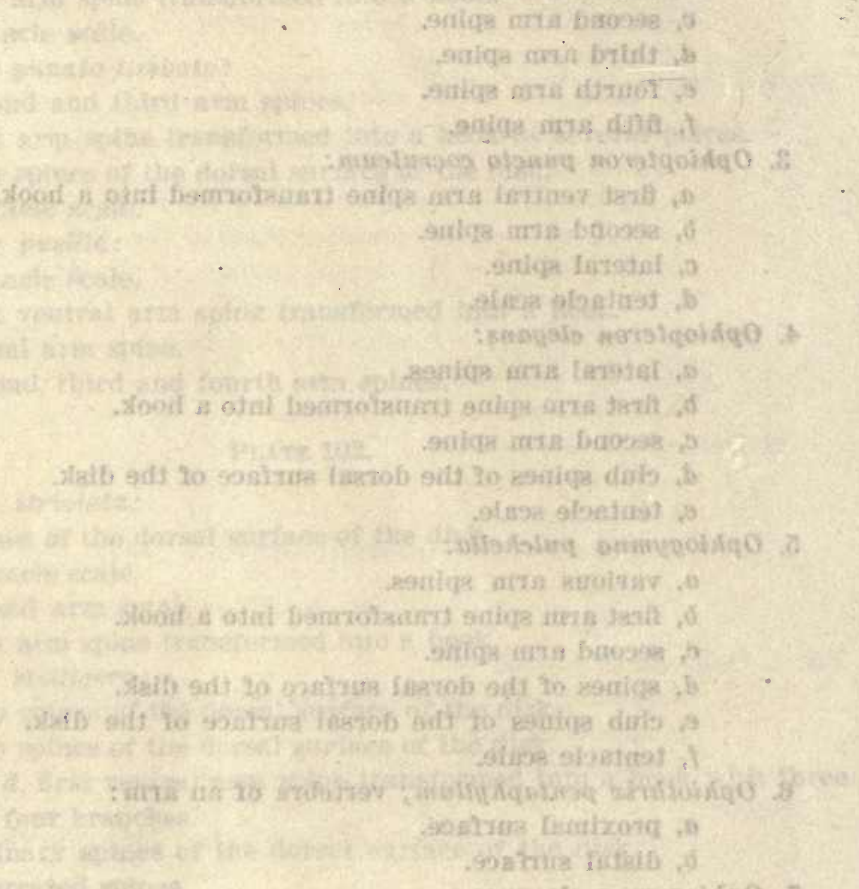




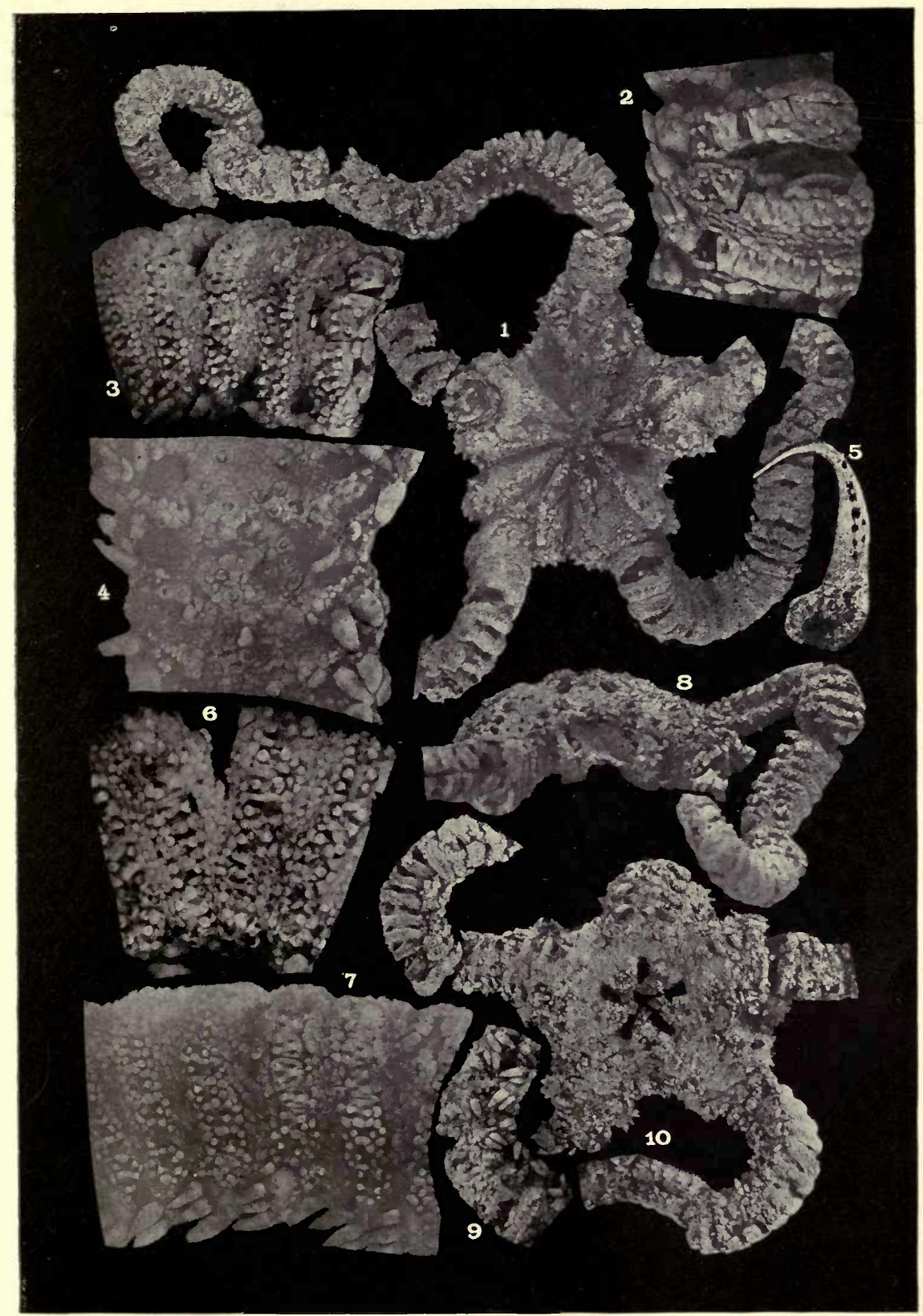

Ophiurans of the Philippine Seas and adjacent Waters:

For EXPLANATION OF PLATE SEe PAgE 453. 


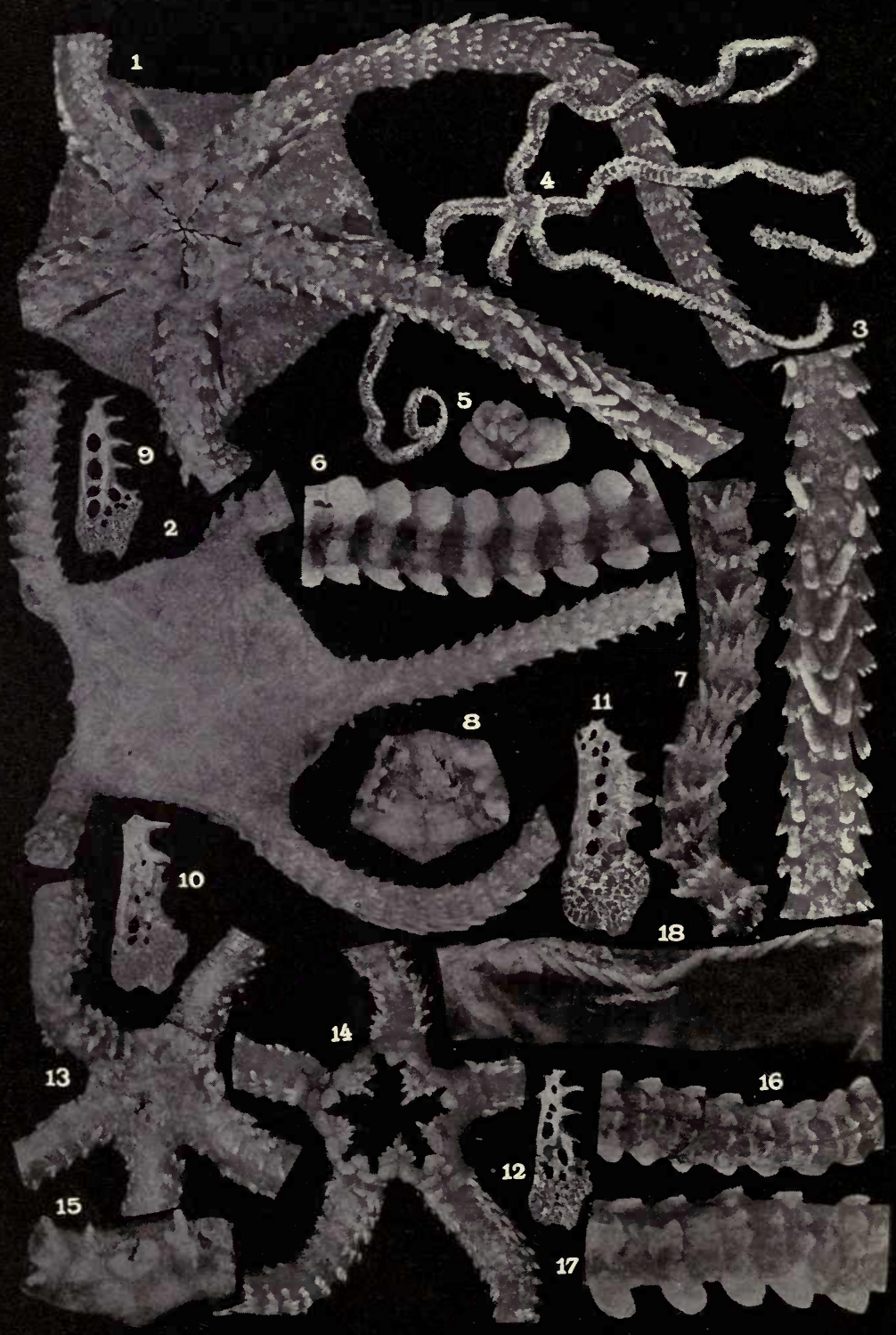

Ophiurans of the Philippine Seas and Adjacent Waters.

FOR EXPLANATION OF PLATE SEE PAGES 453 AND 454. 


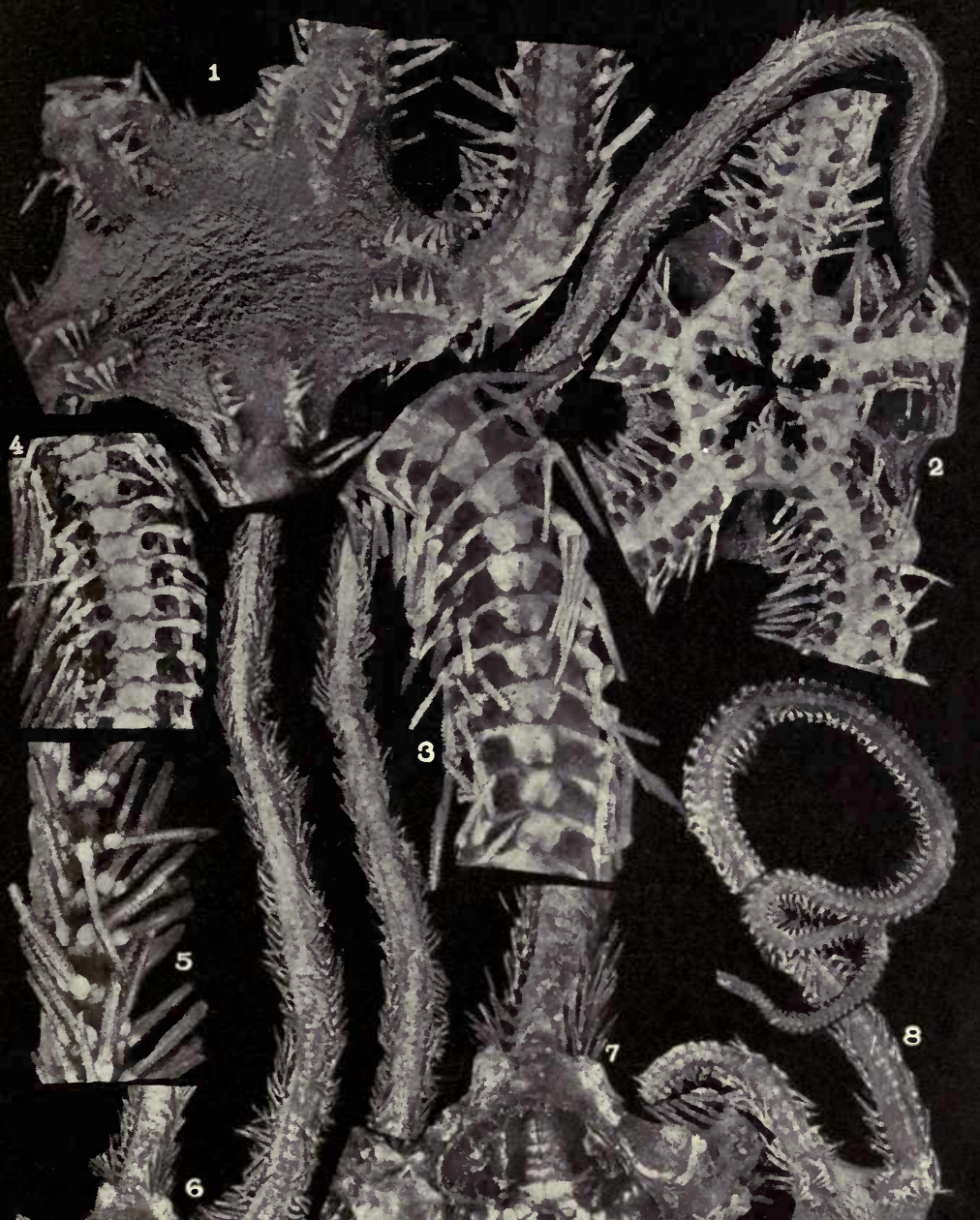

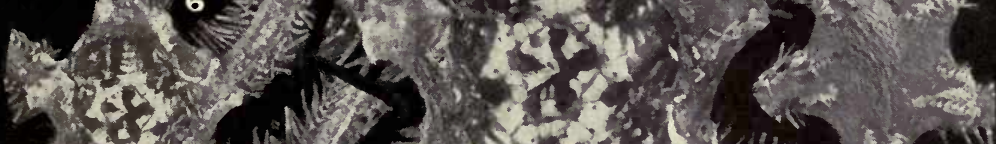

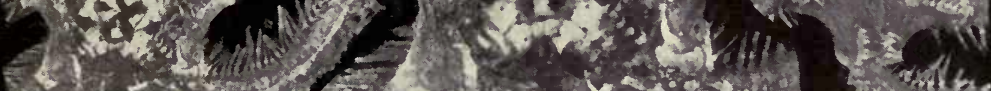

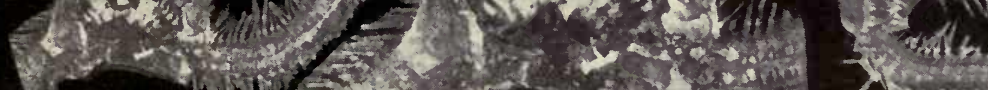
Wur

Ophiurans of the Philippine Seas and Adjacent Waters.

For explanation of plate see page 454. 


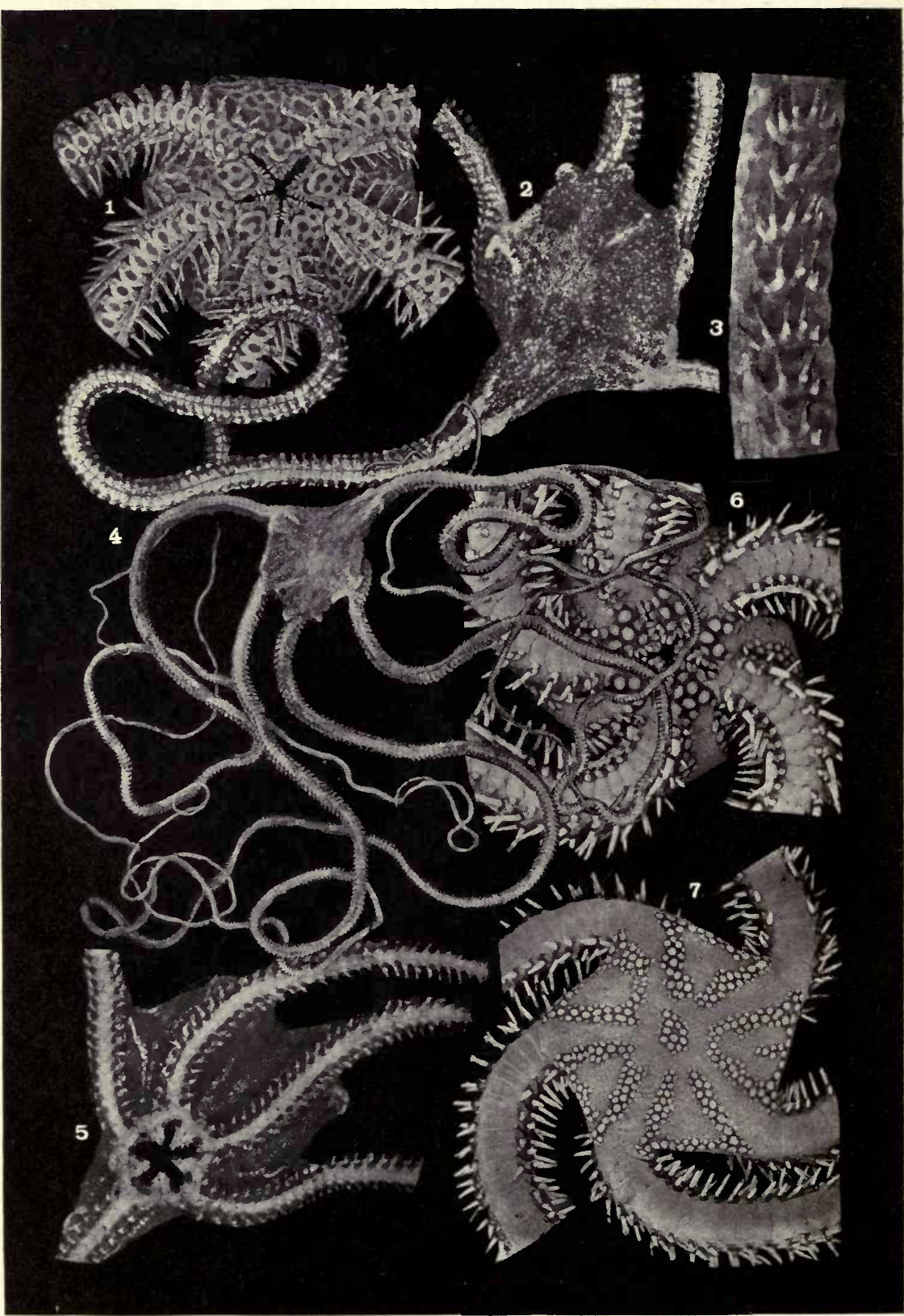

Ophiurans of the Philippine Seas and Adjacent Waters.

For explanation of plate see page 454. 


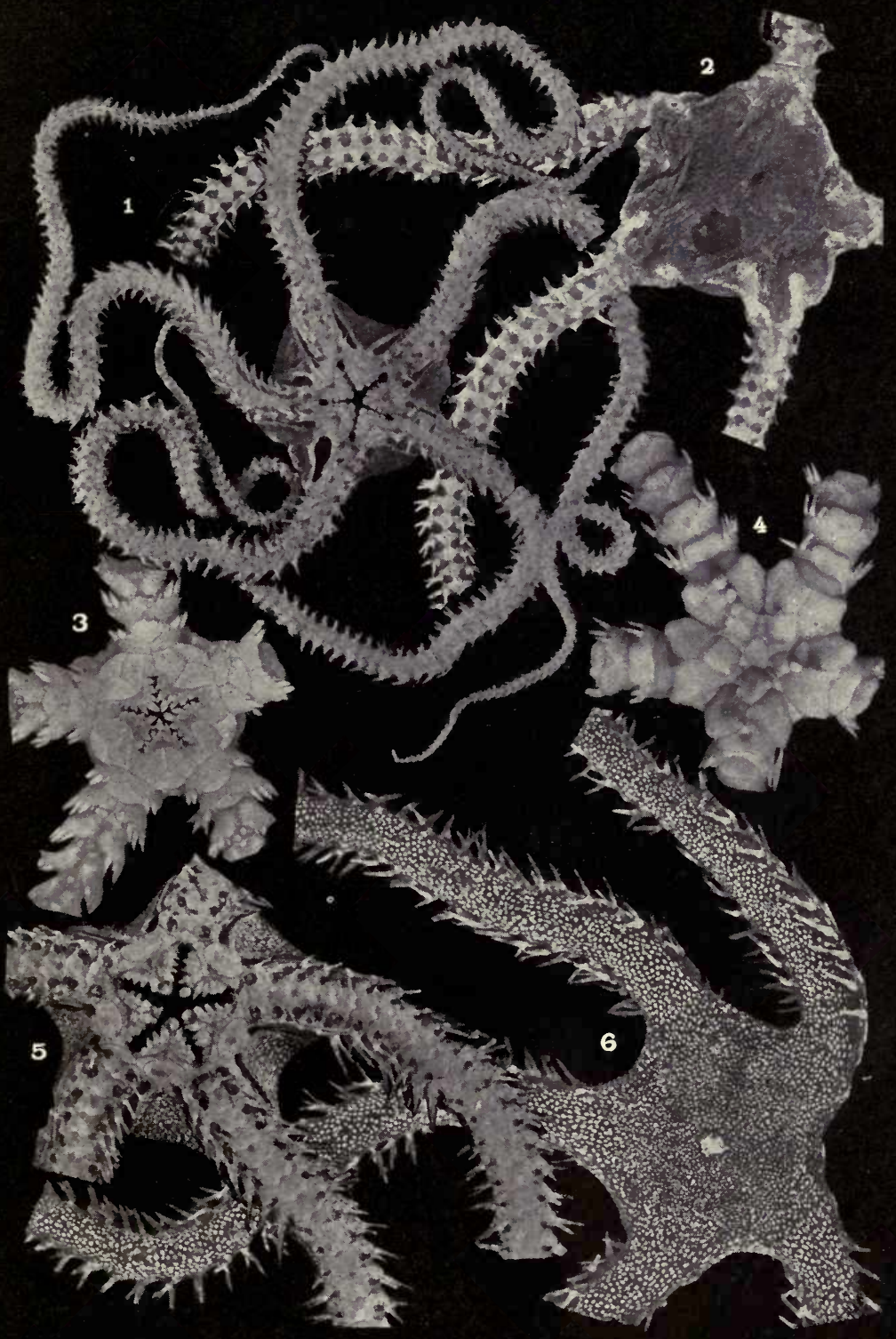

Ophiurans of the Philippine Seas and adjacent Waters.

For EXPLANATION OF PLATE see PAge 454 


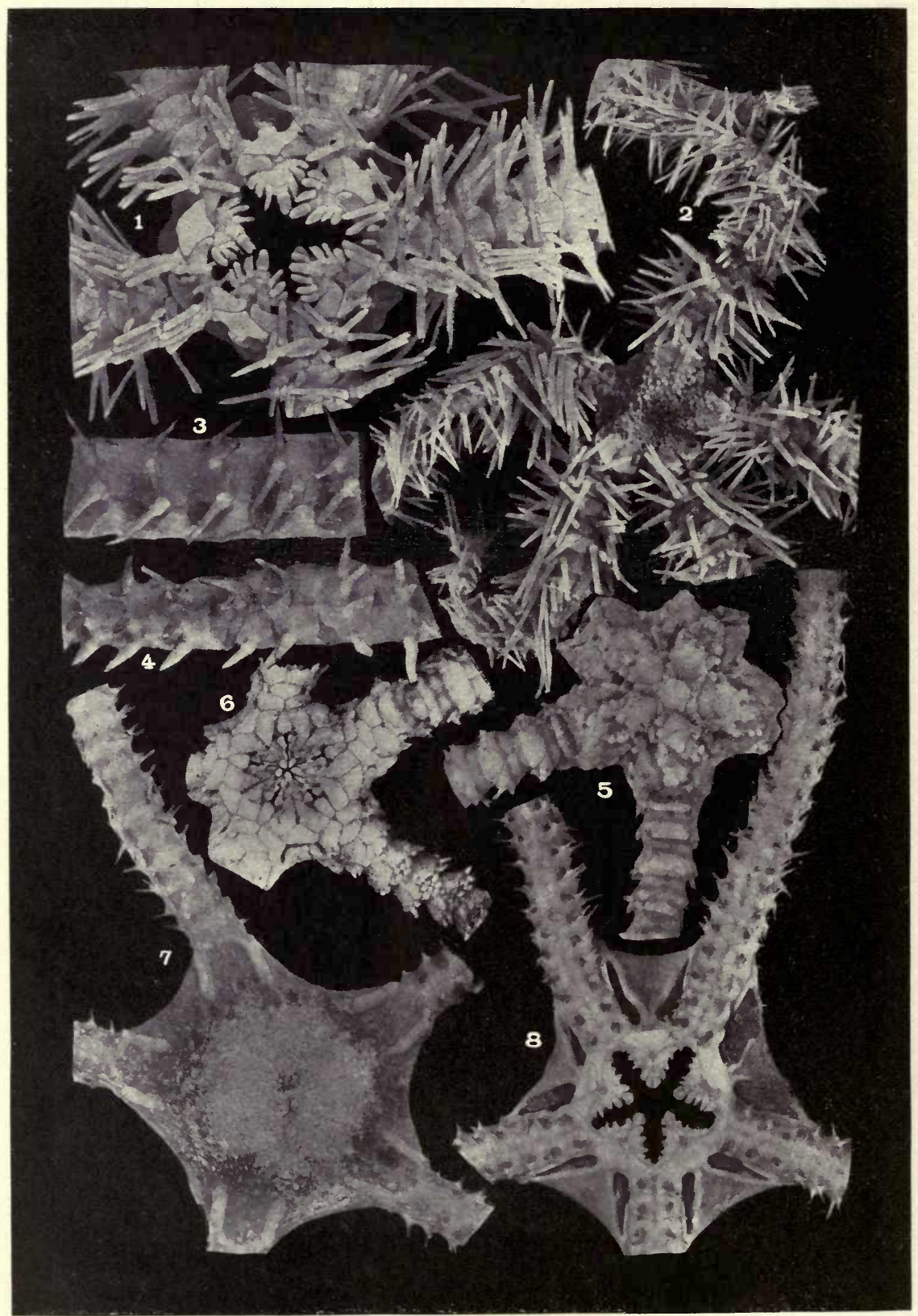

Ophiurans of the Philippine Seas and adjacent Waters.

For EXPLANATION OF PLATE SEe PAgE 454. 


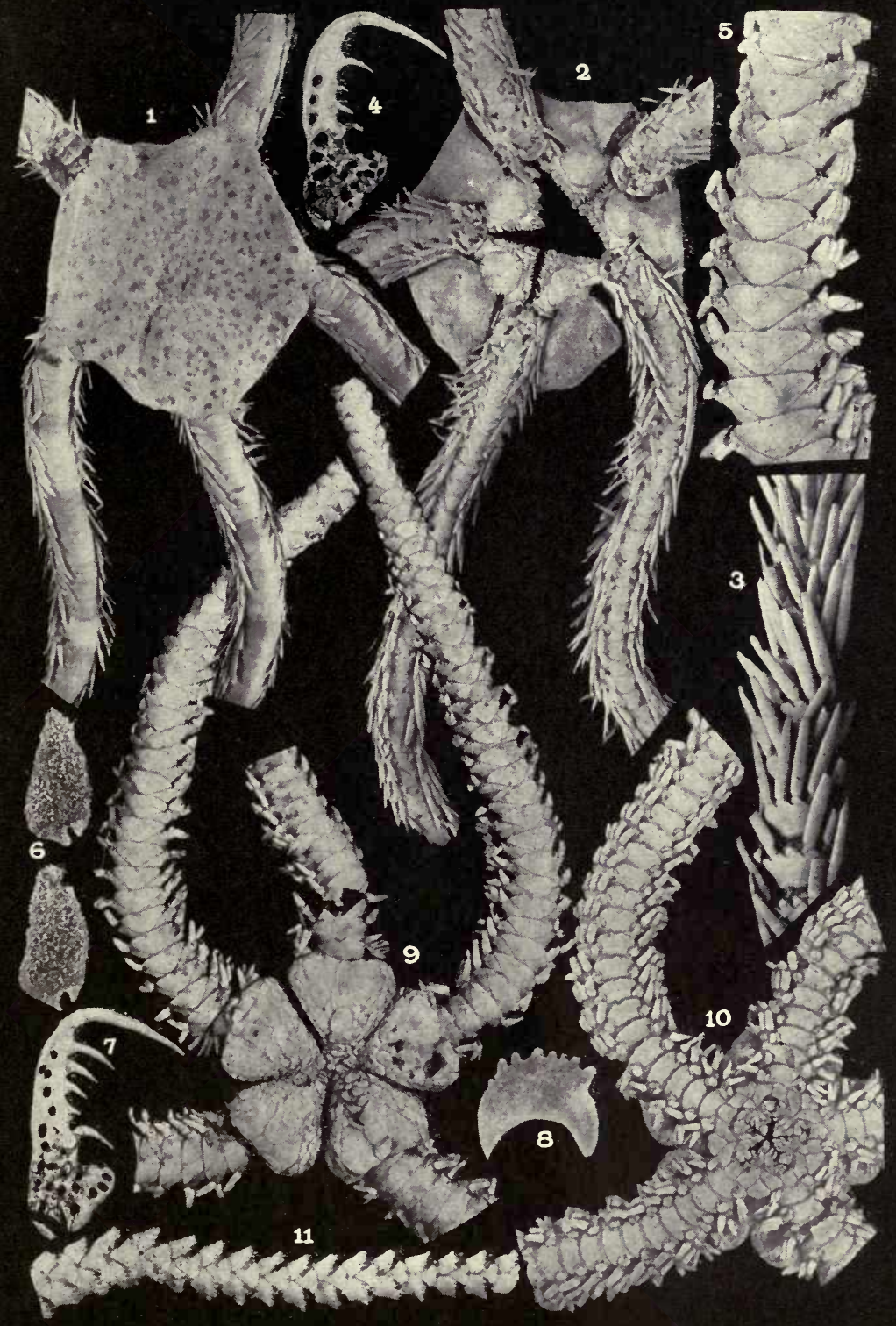

Ophiurans of the Philippine Seas and Adjacent Waters.

For Explanation of PLATE SEe PAges 454 AND 455. 


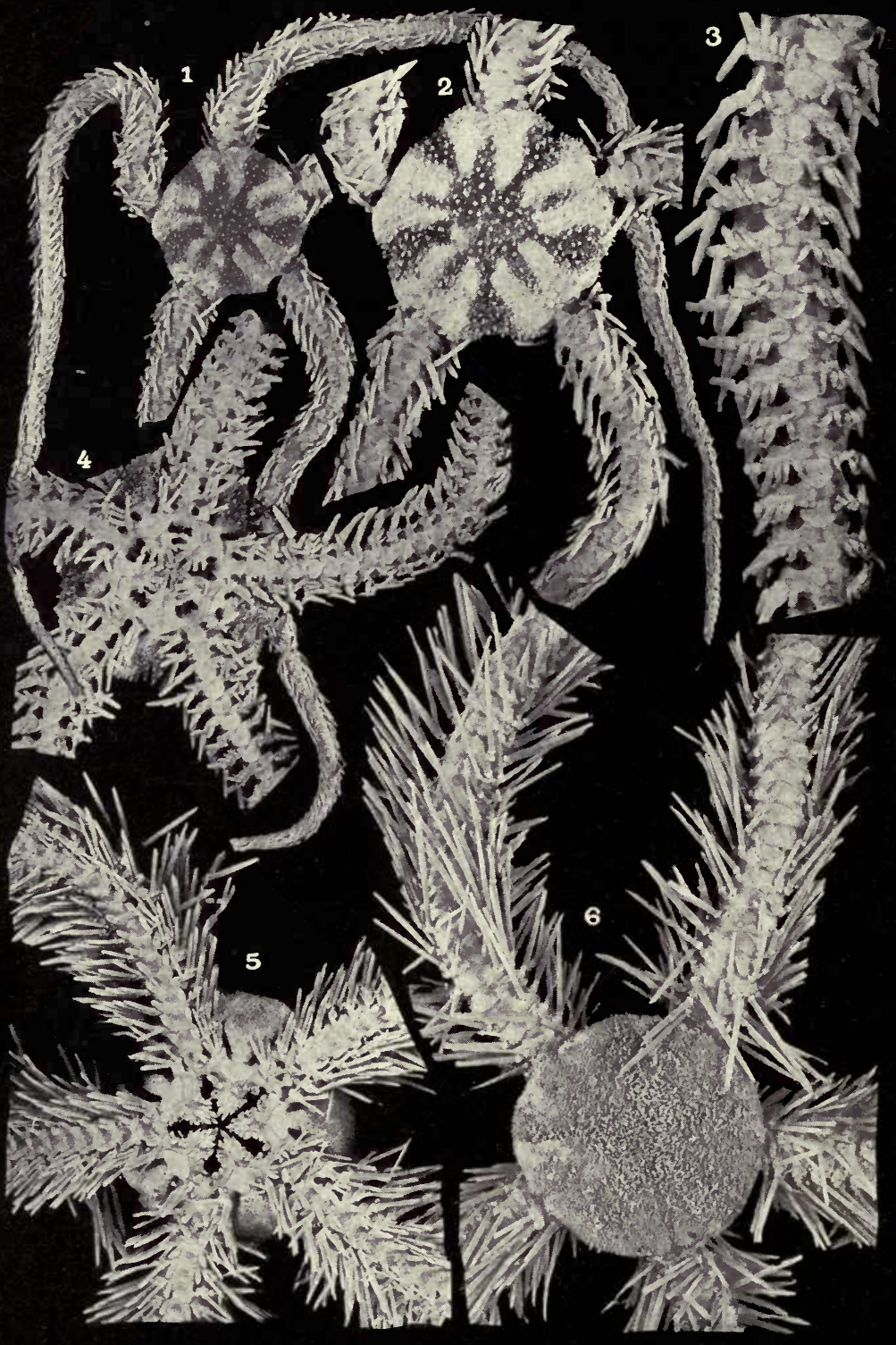

Ophiurans of the Philippine Seas and Adjacent Waters.

For EXPLANATION OF PLATE SEe PAge 455. 


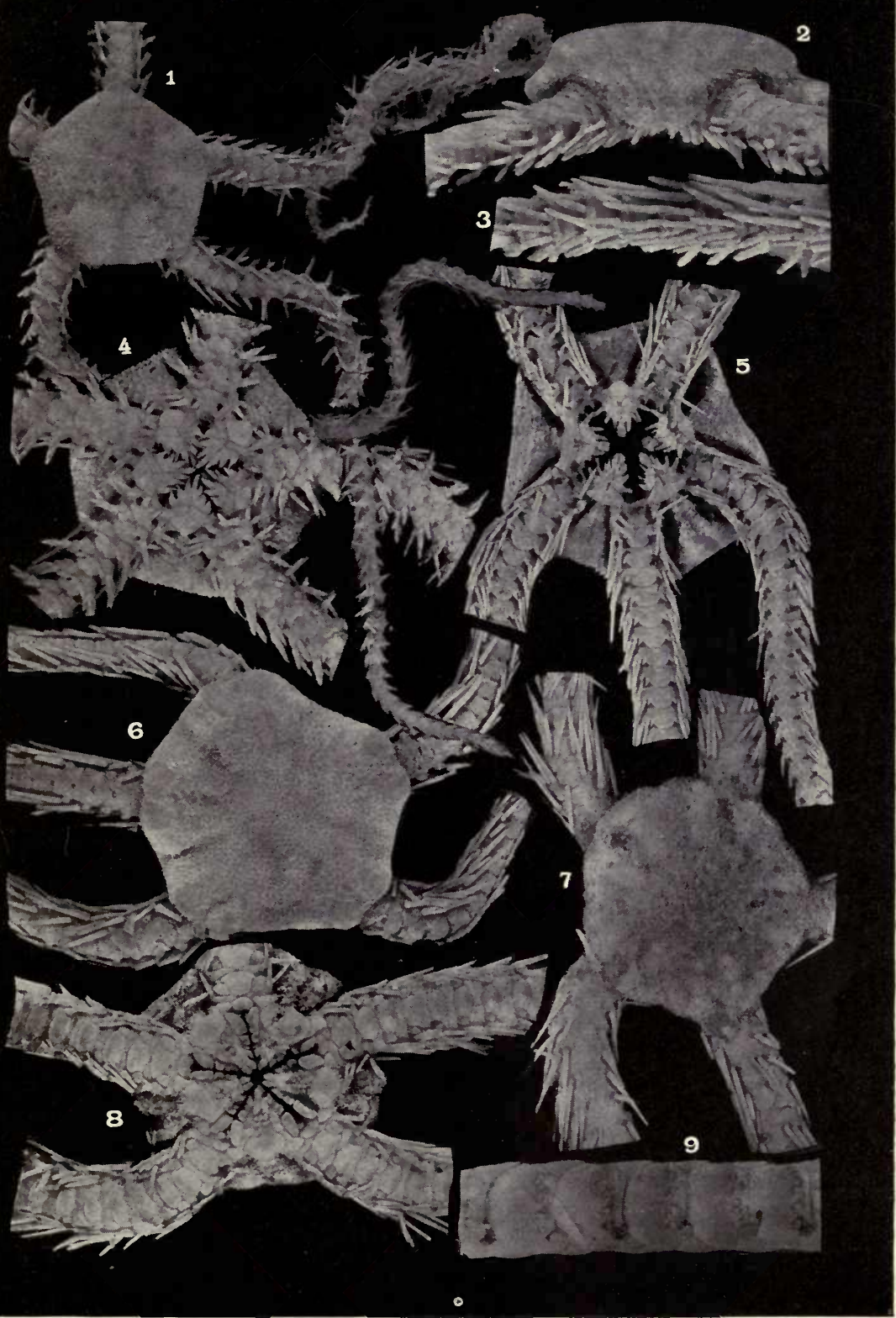

Ophiurans of the Philippine Seas and adjacent Waters.

Ifor explanation of plate see page 465. 
wiyly,

and

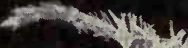

Pat $17=$

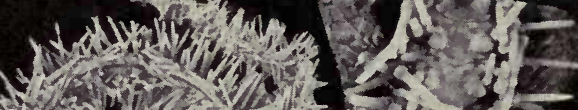

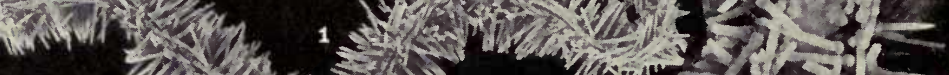

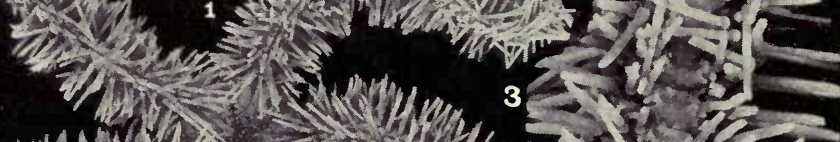

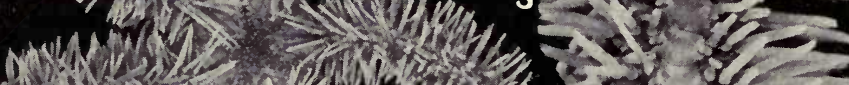

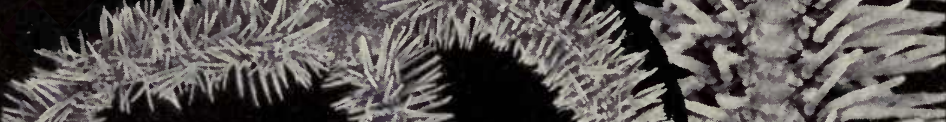
sile $3 x^{3}$

E.

(1)

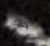

(9)

3ritis

10

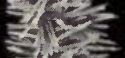

$=-10$

$x=13+5=$

$x=3 x+3$

$-1-3 x_{1}$

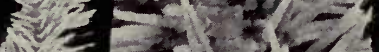

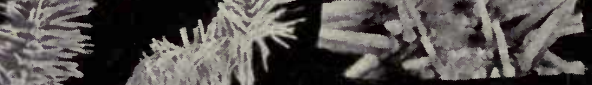

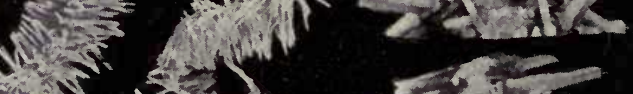

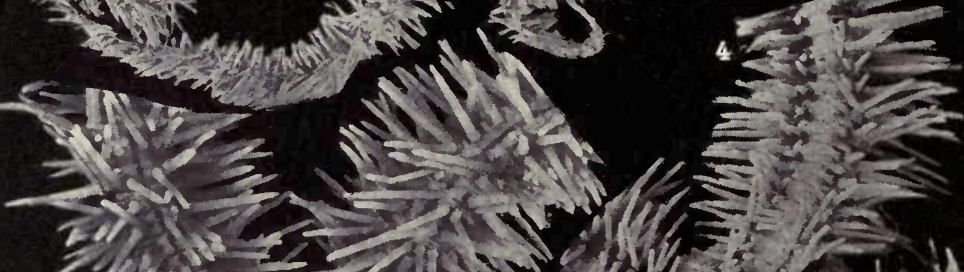

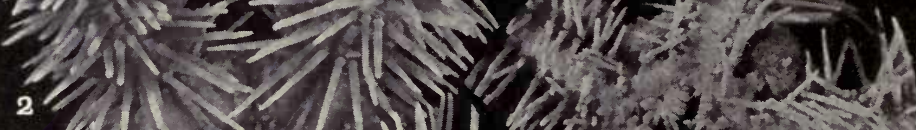

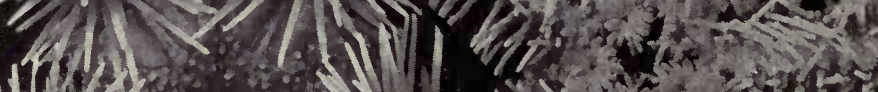

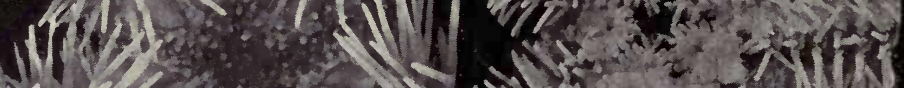

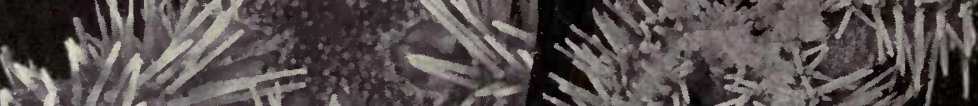

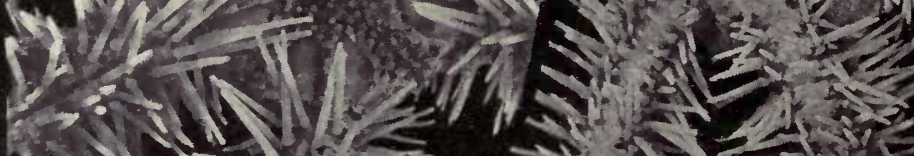

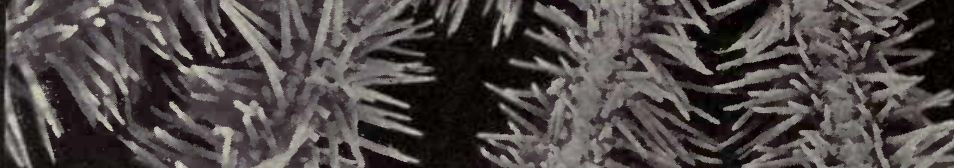

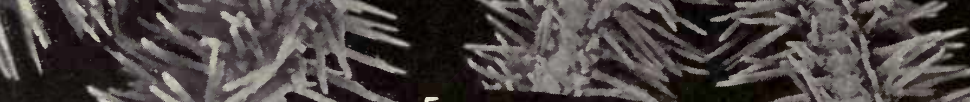

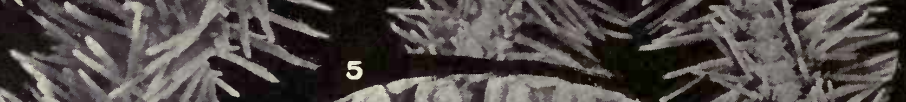

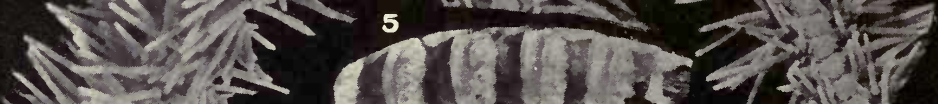
$21-2+15$

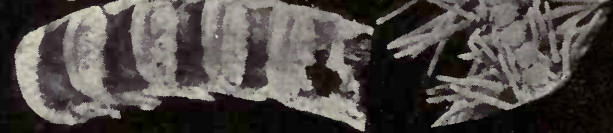

Ophiurans of the Philippine Seas and adjacent Waters.

For EXPLANATION of PLATE SEe PAge 455. 


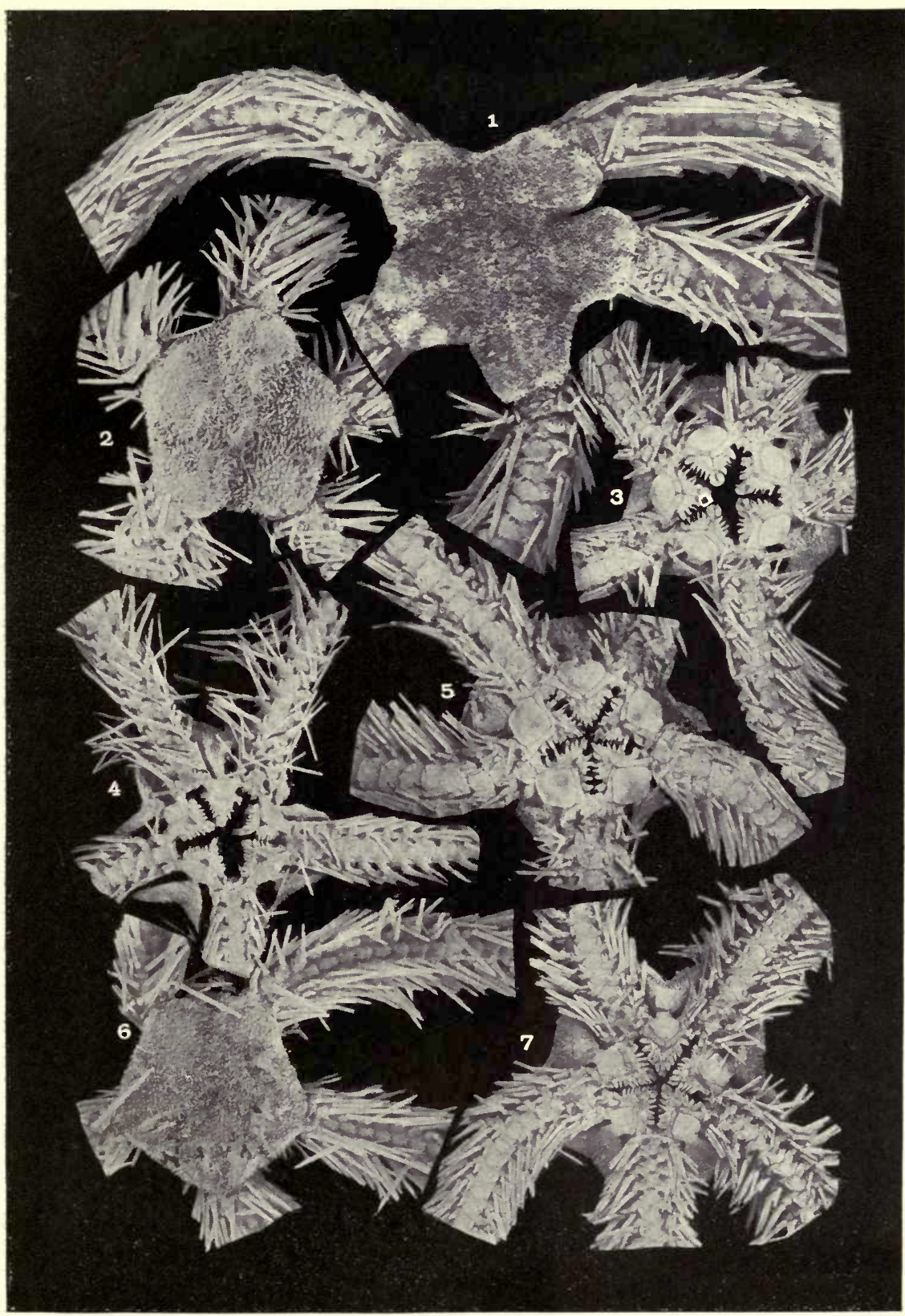

Ophiurans of the Philippine Seas and Adjacent Waters.

For explanation of PLATE SEe PAge 455. 


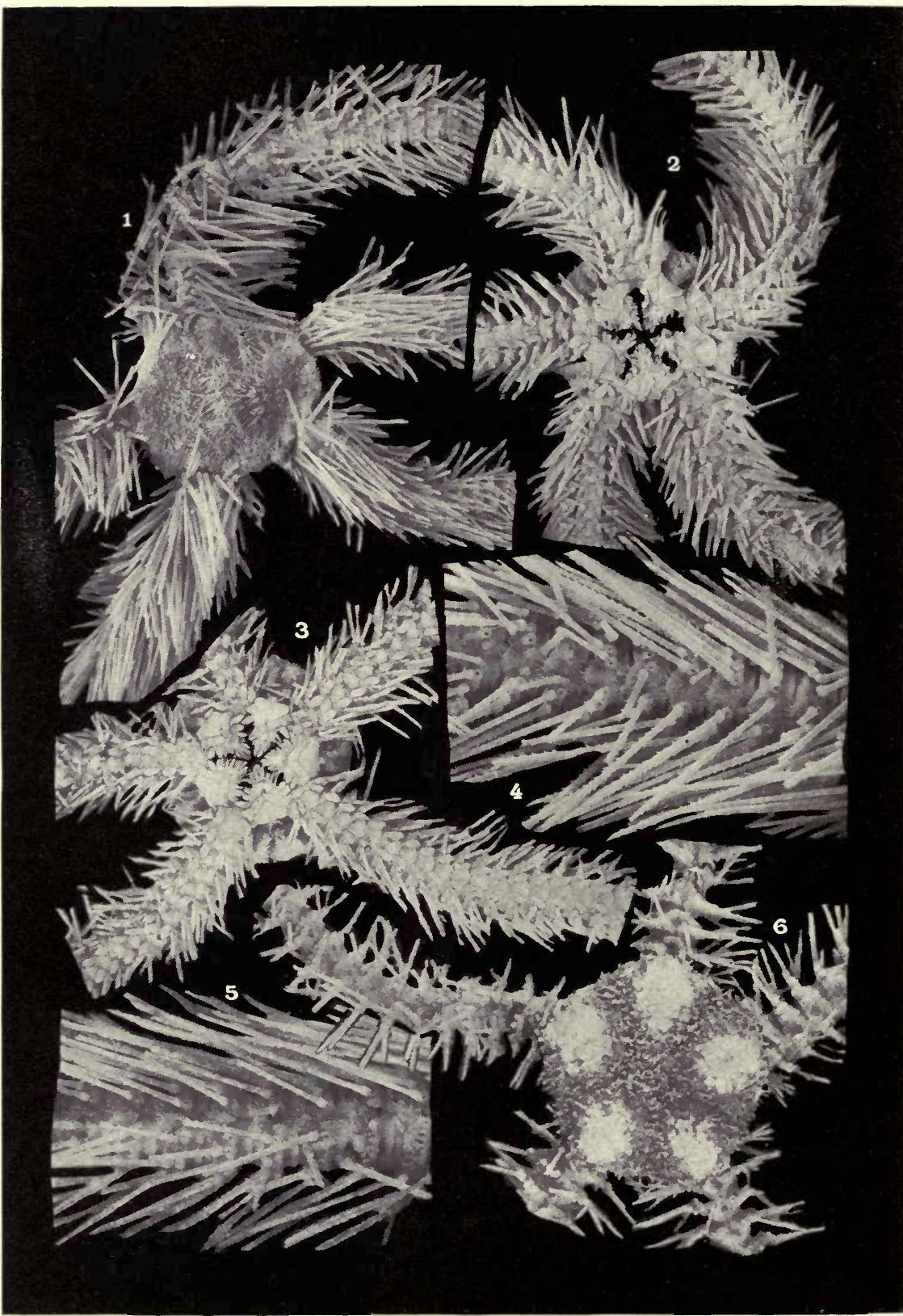

Ophiurans of the Philippine Seas and adjacent Waters.

For EXPLANATION OF PLATE SEe PAge 455 


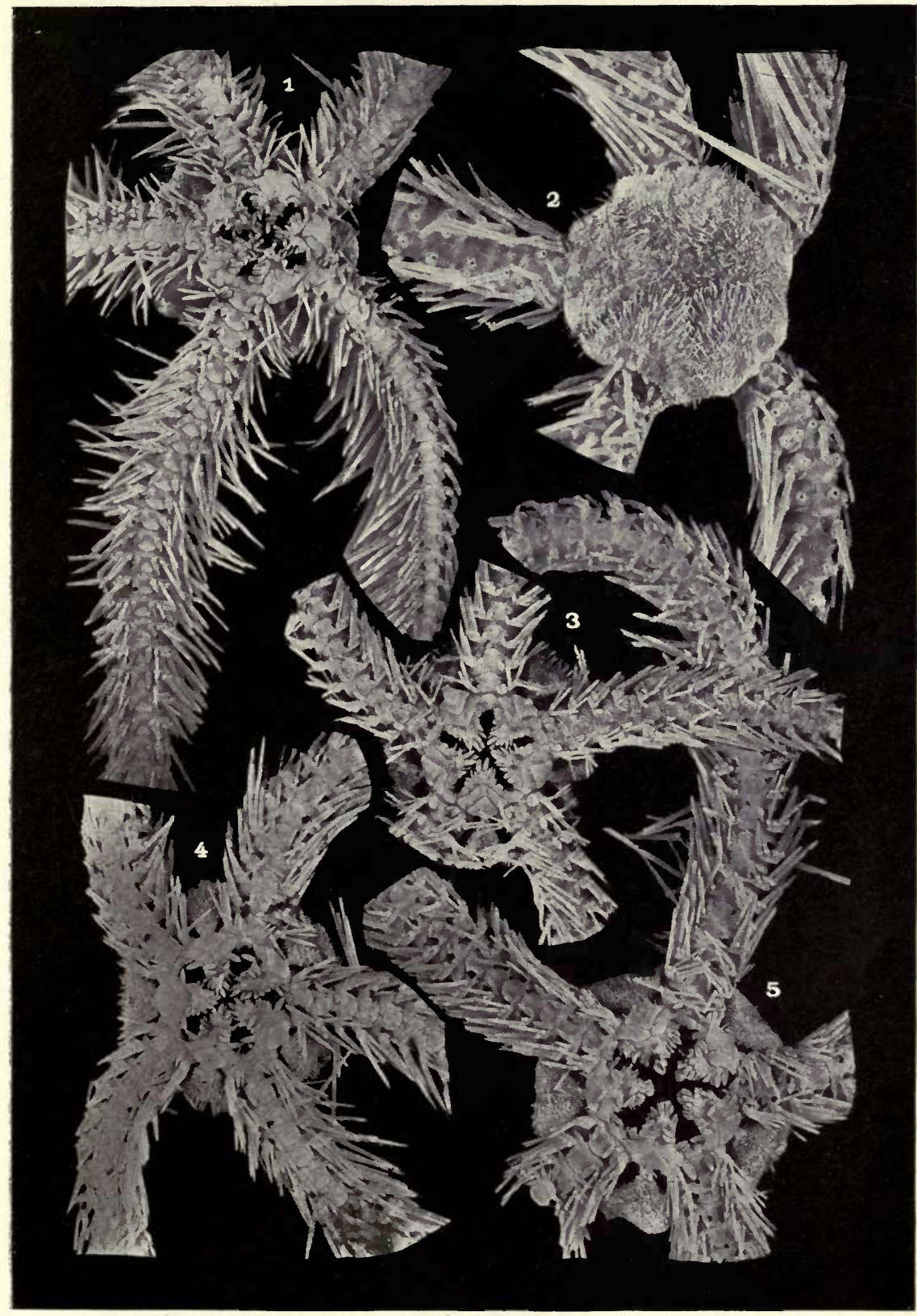

Ophiurans of the Philippine Seas and Adjacent Waters.

For EXPLANATION OF PLATE SEe PAge 456. 

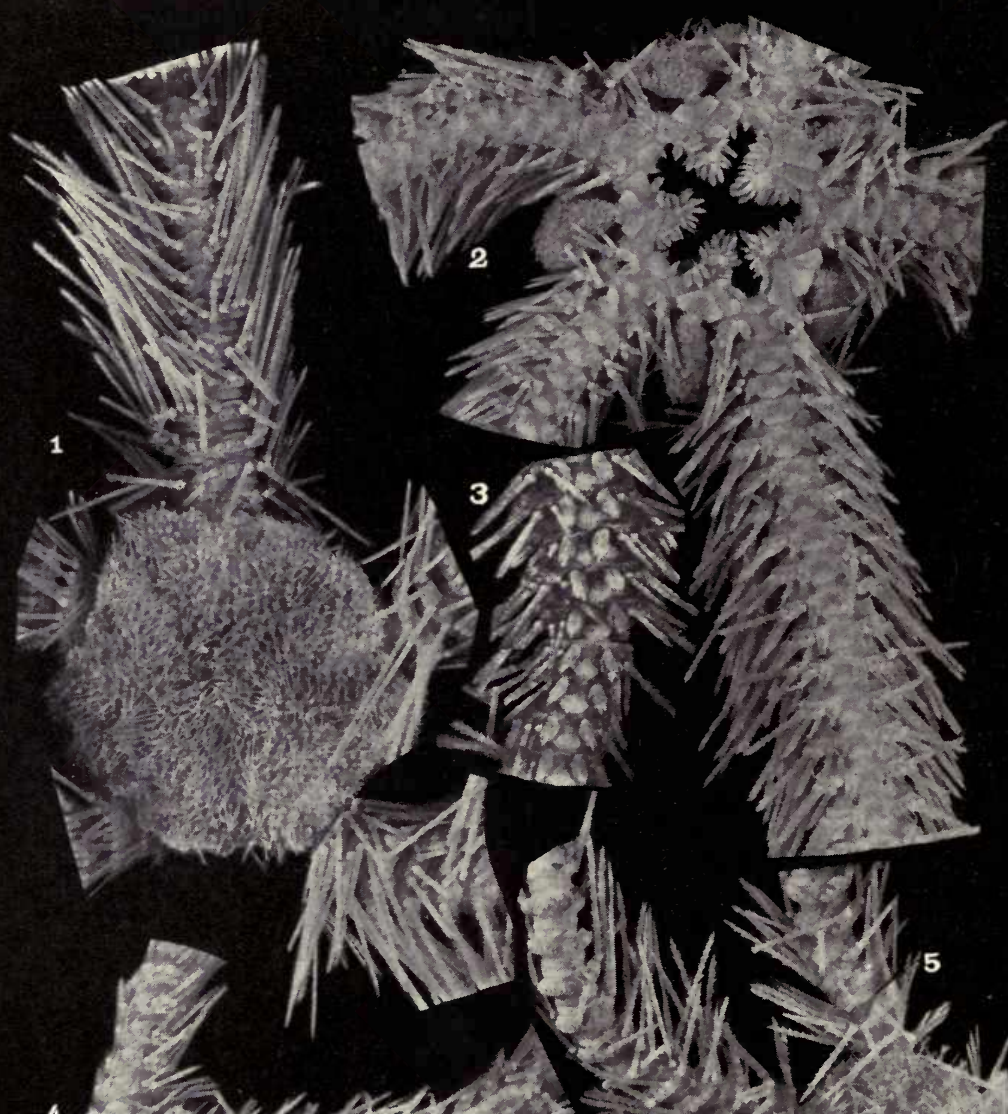

4

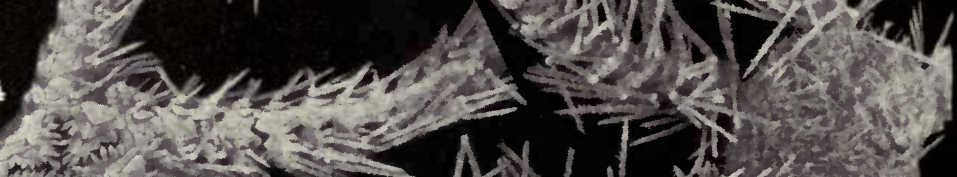

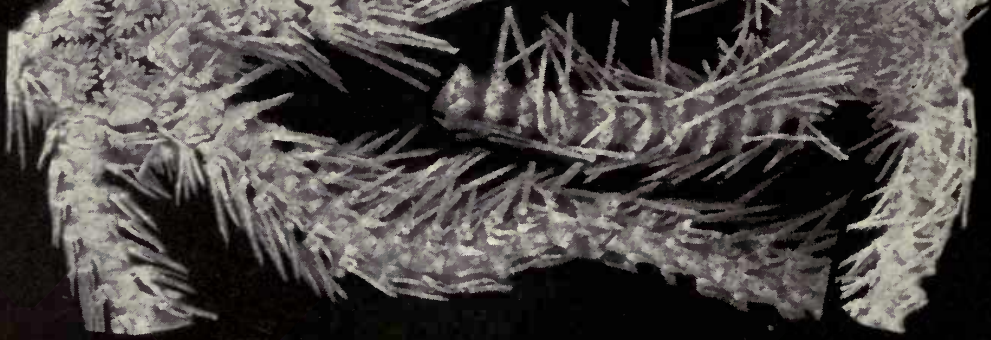

Ophiurans of the Philippine Seas and adjacent Waters.

For explanation of PLATE SEe PAge 458. 


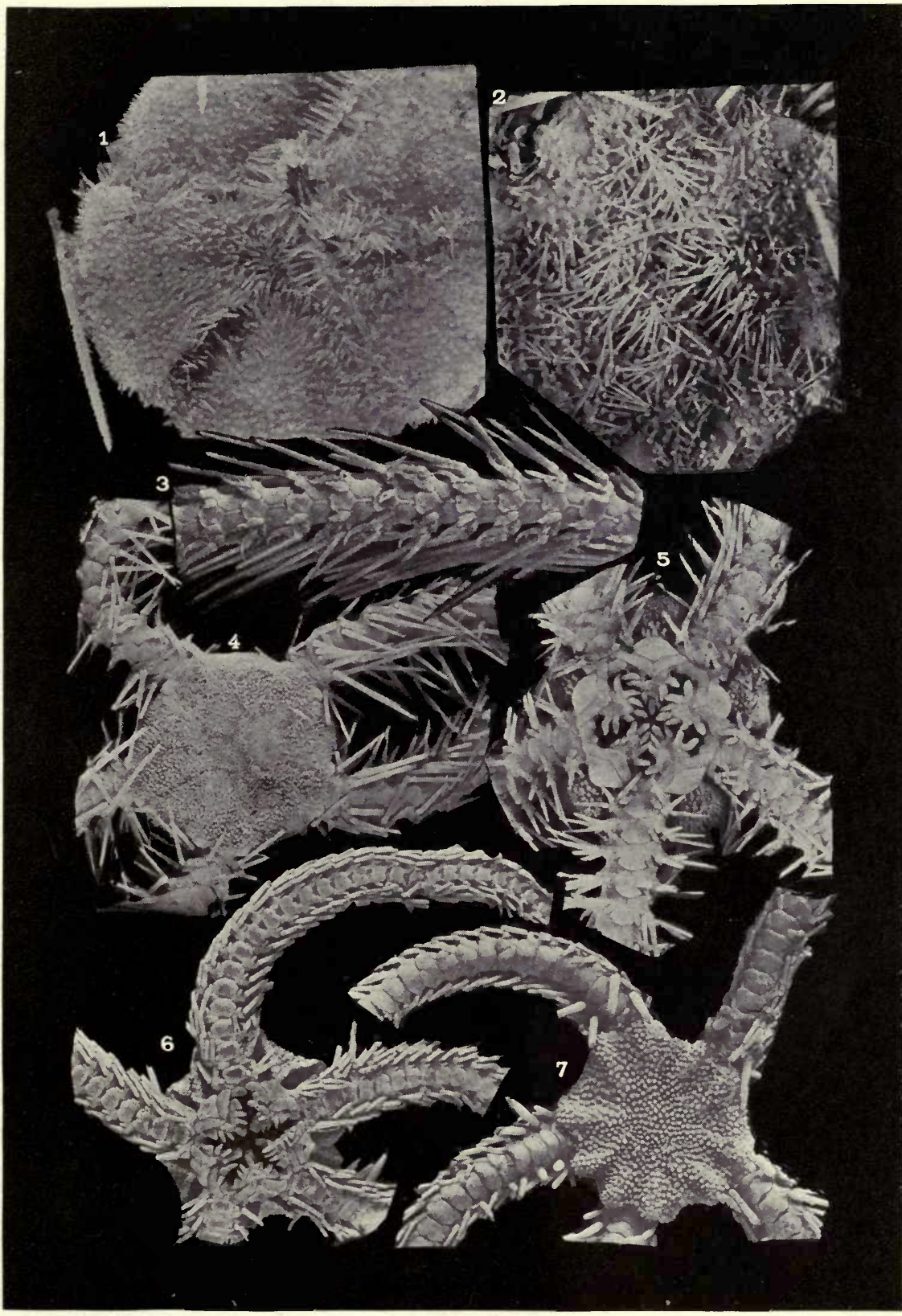

Ophiurans of the Philippine Seas and adjacent Waters.

For explanation of plate see page 456. 


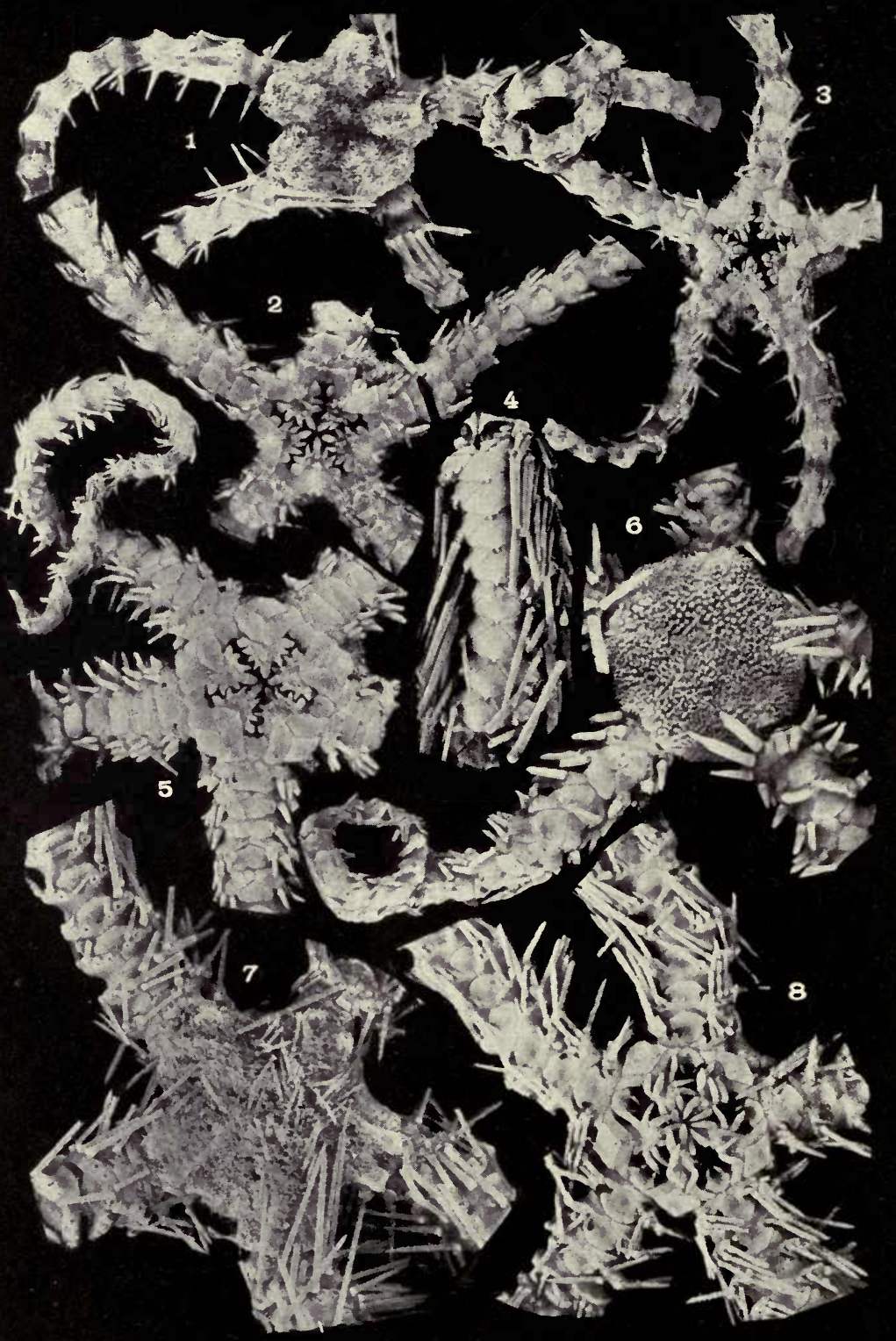

Ophiurans of the Philippine Seas and adjacent Waters.

For explanation of plate see page 456. 


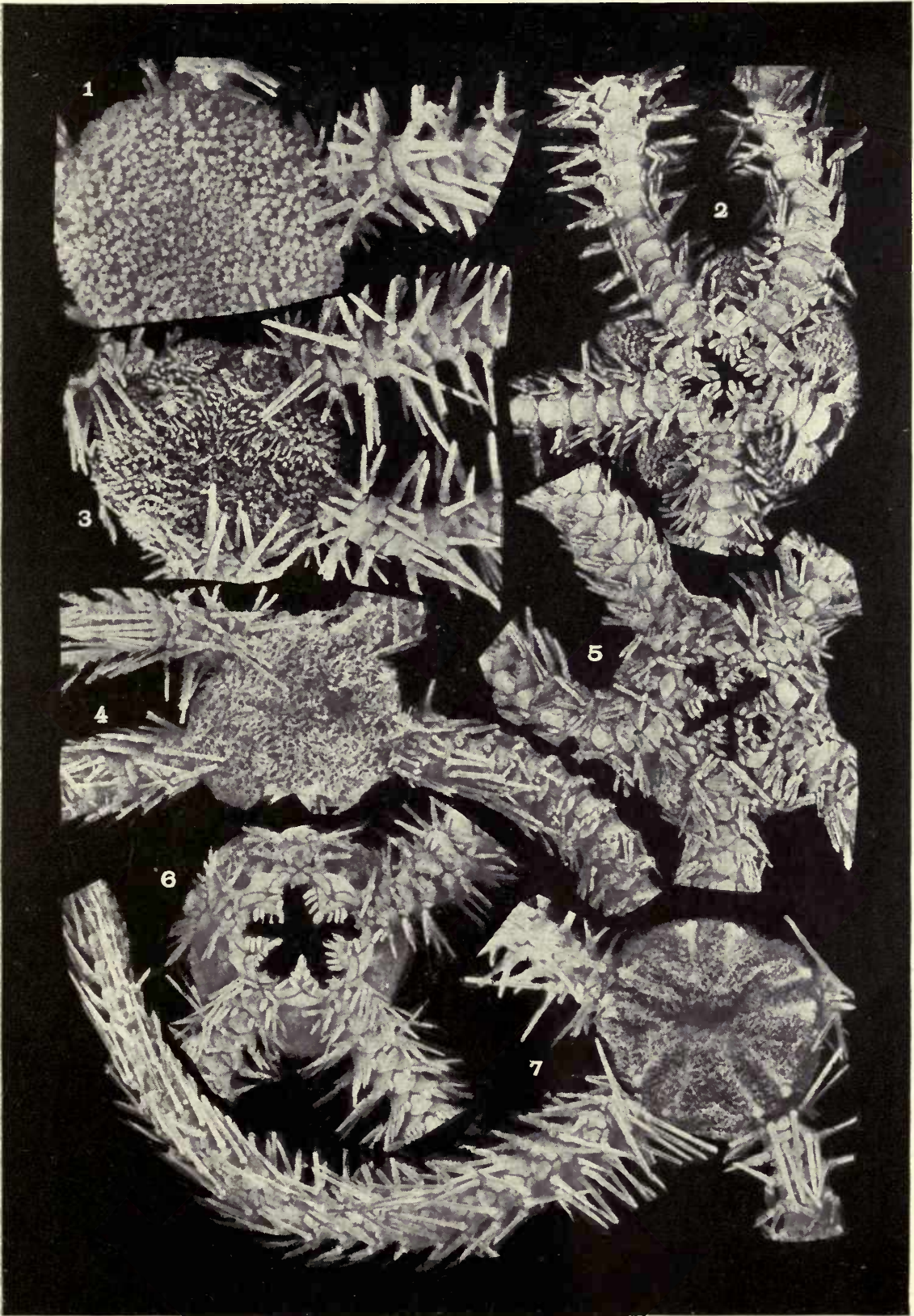

Ophiurans of the Philippine Seas and Adjacent Waters.

For explanation of plate see page 456 


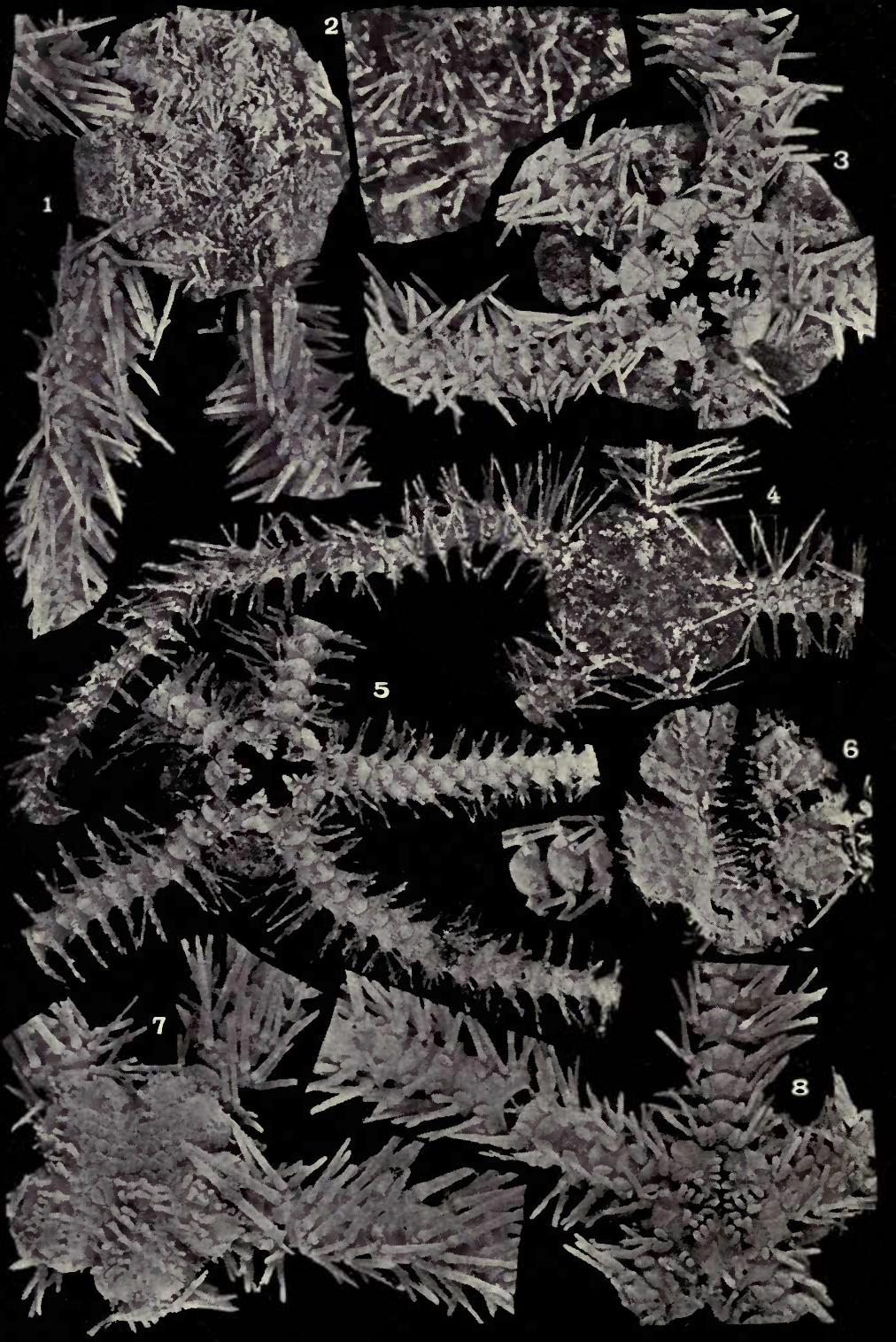

Ophiurans of the Philippine Seas and adjacent Waters.

Fon EXPLANATION OF PLATE SEE PAgES 456 AND 457. 


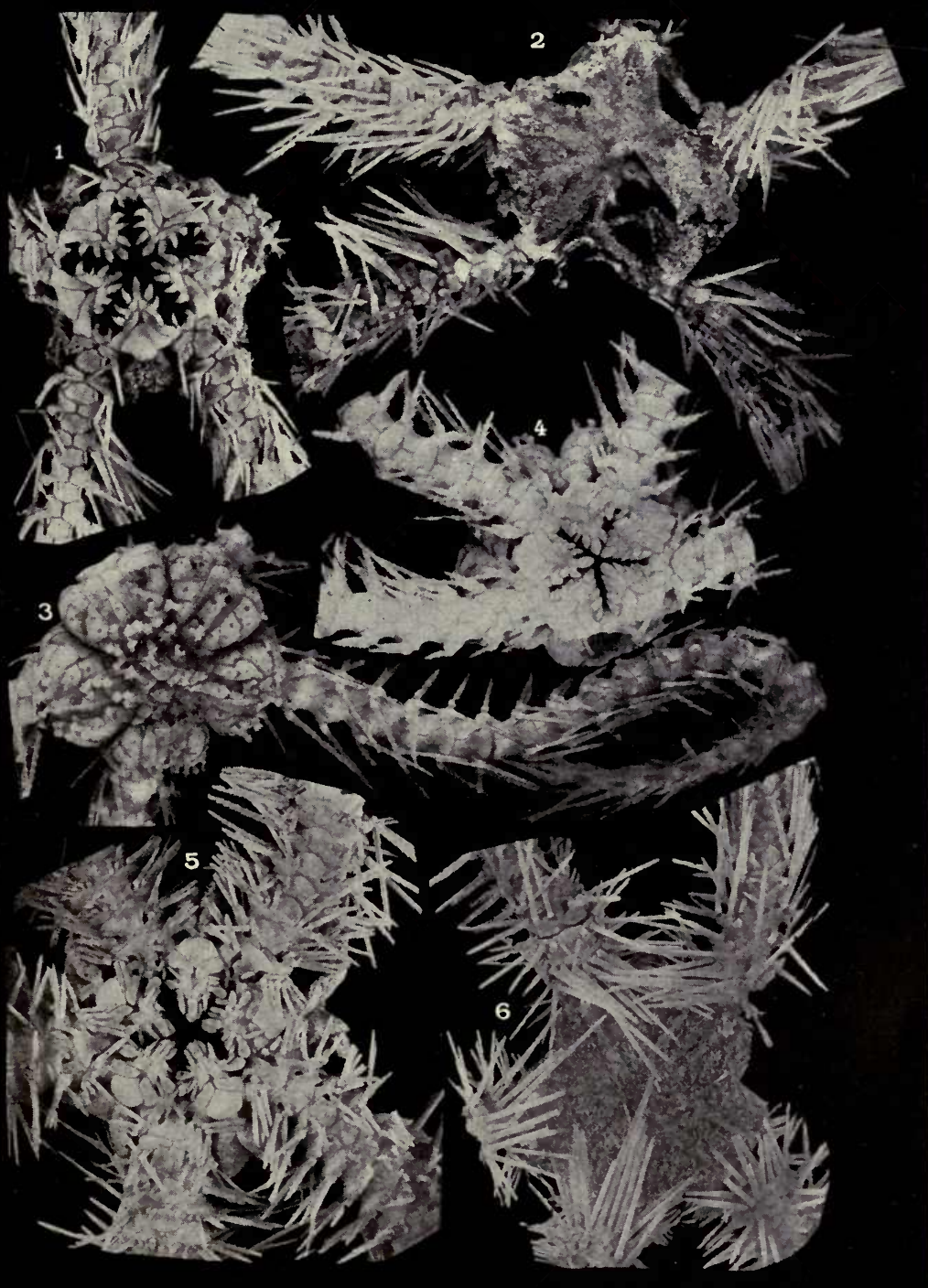

Ophiurans of the Philippine Seas and Adjacent Waters.

For explanation of plate see page 457. 


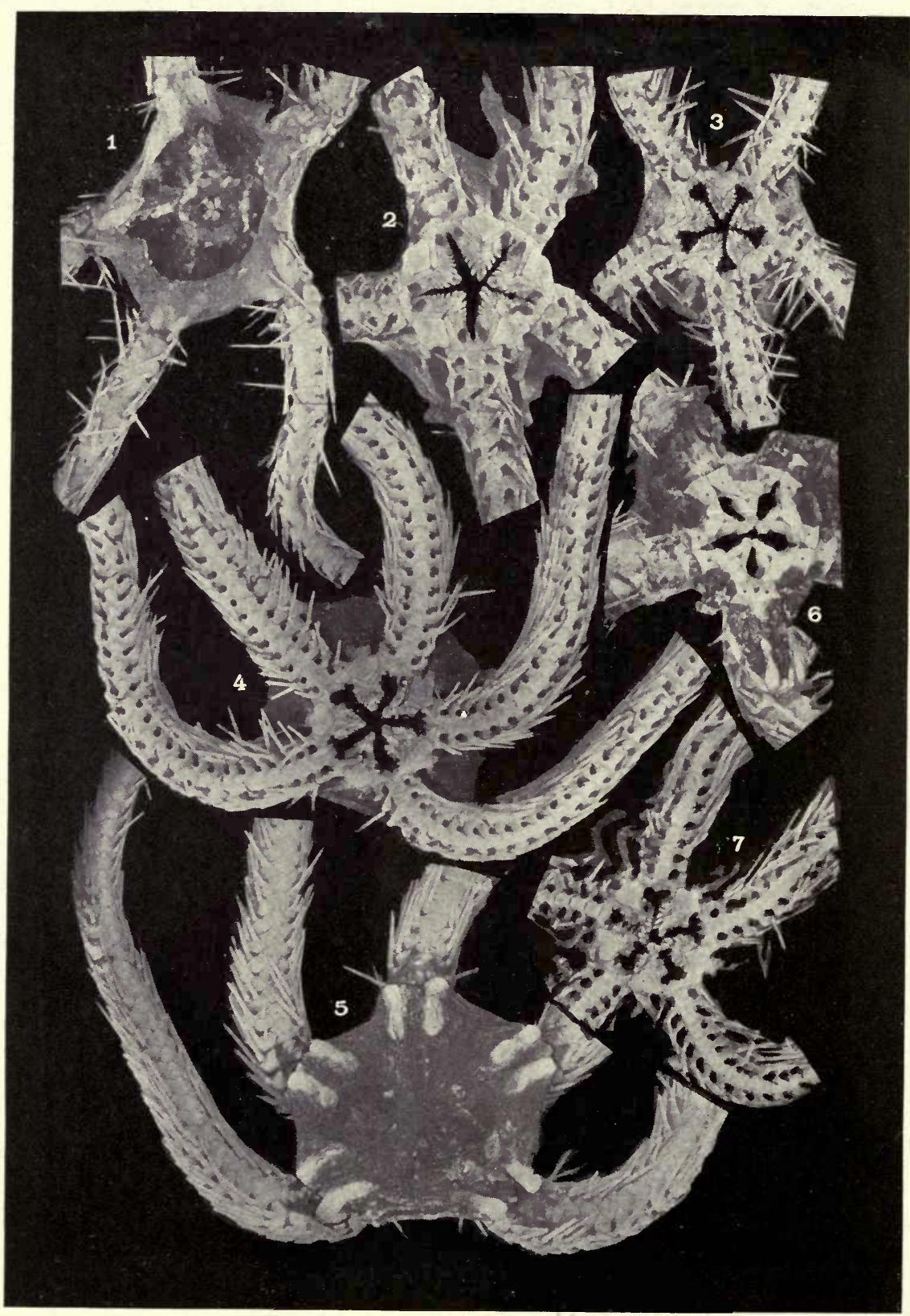

Ophiurans of the Philippine Seas and Adjacent Waters.

For EXPLANATION OF PLATE SEE PAGE 457 


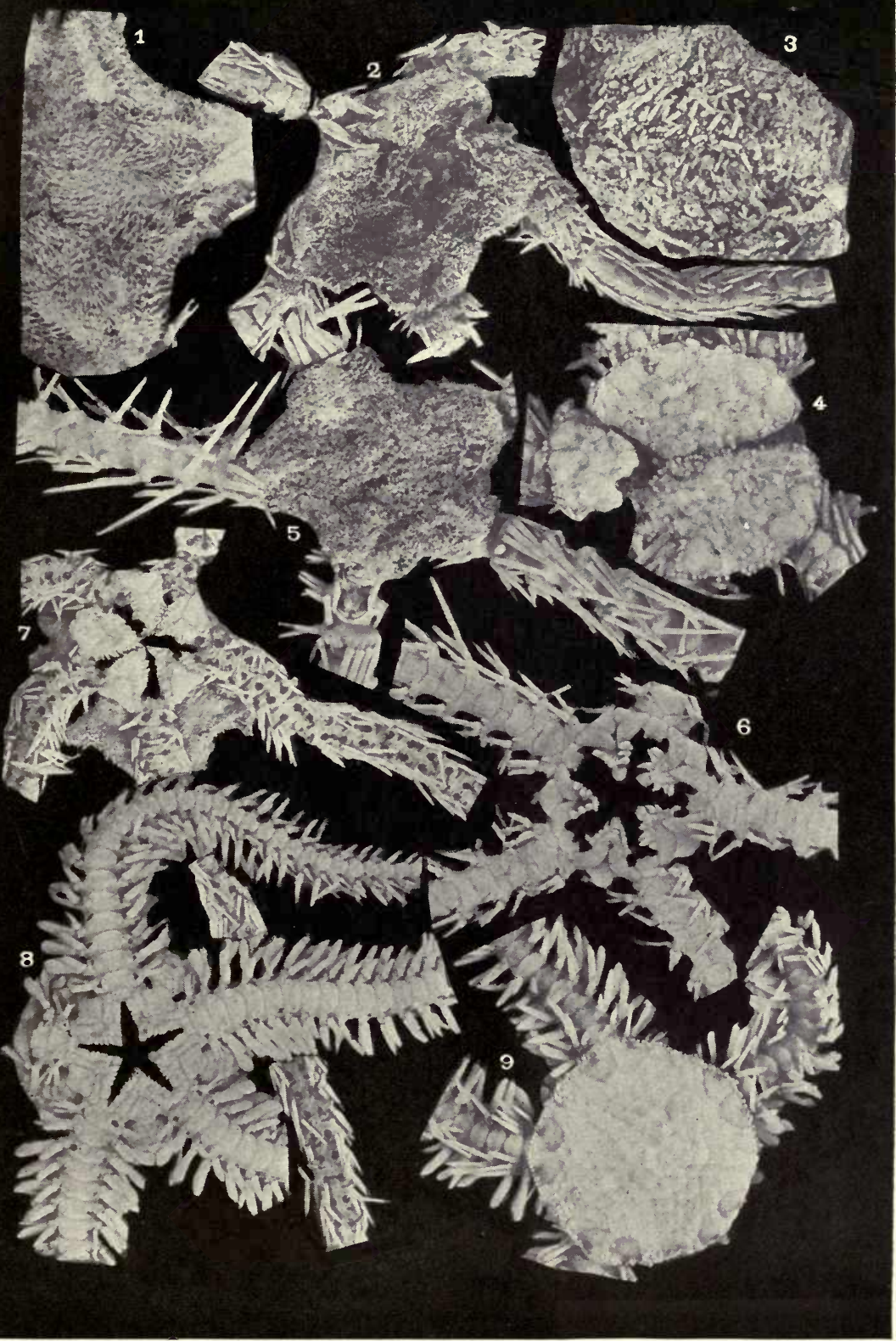

Ophiurans of the Philippine Seas and adjacent Waters. 


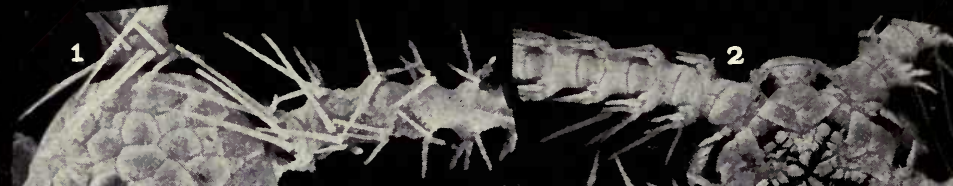

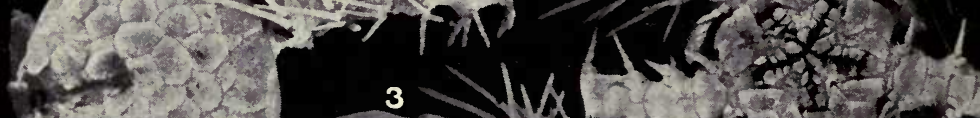

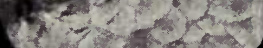

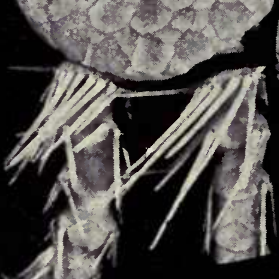

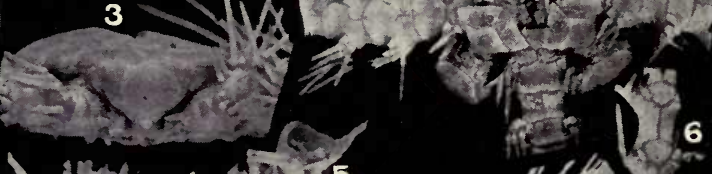
(M) $1 / 2)^{2}$

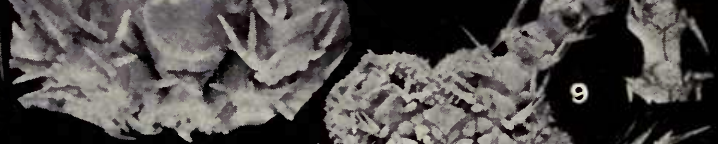

inters 302

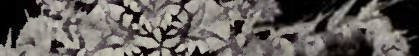
$x^{2}+x^{2}+y^{7}$ s. 3 . 190.4092 if

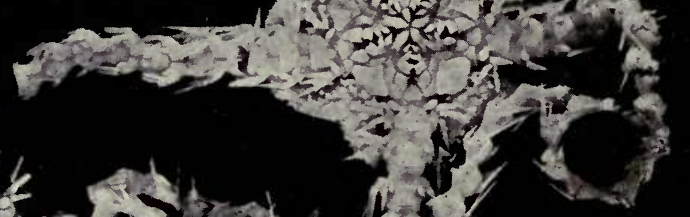

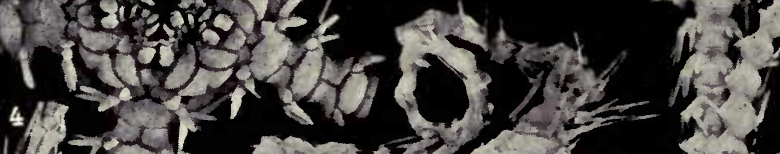

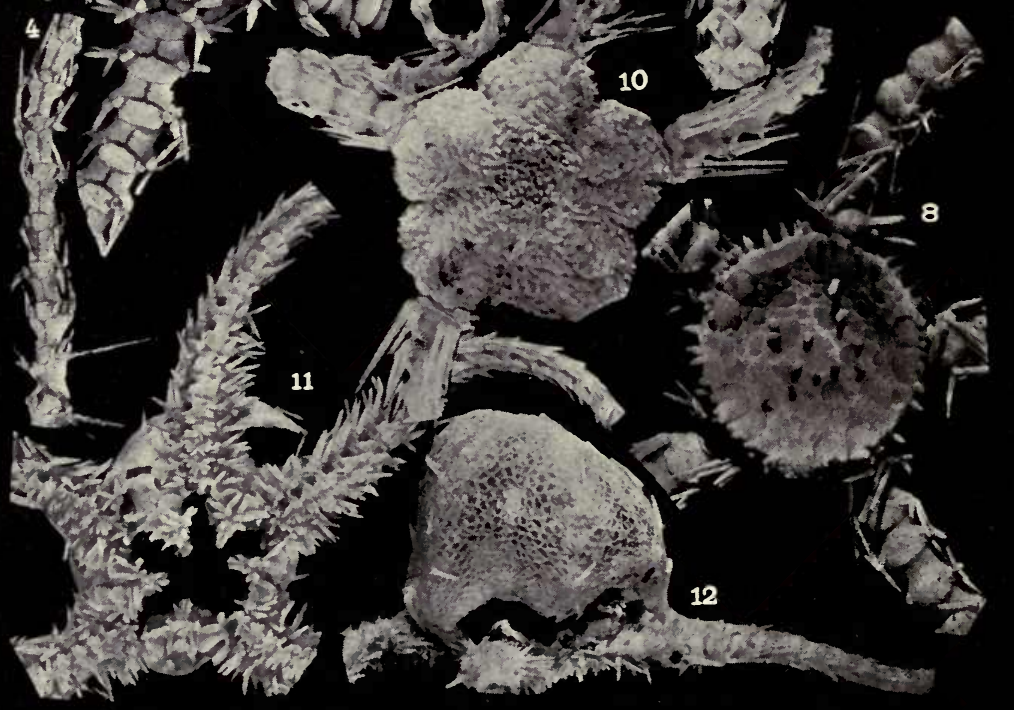

Ophiurans of the Philippine Seas and Adjacent Waters.

For explanation of plate see page 467. 


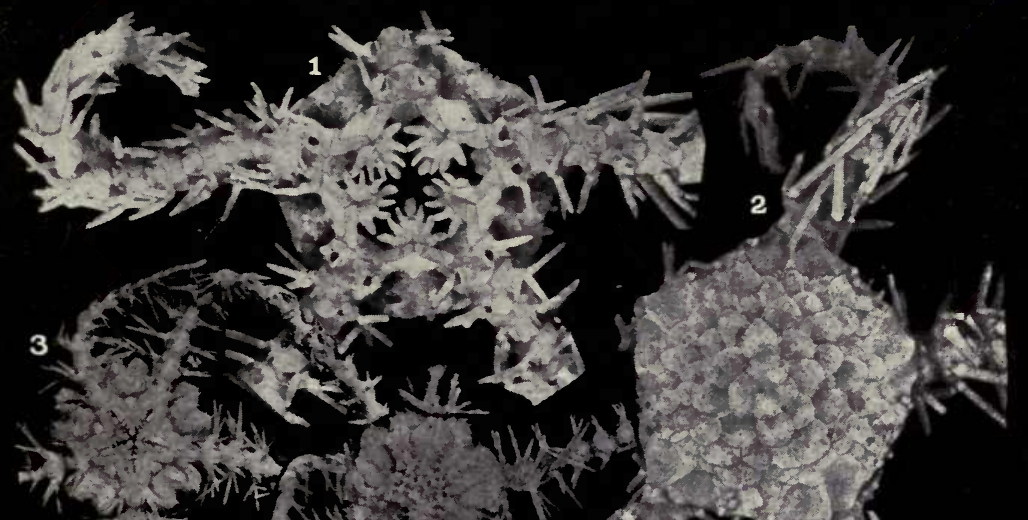

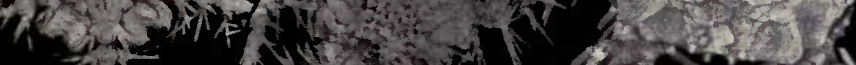

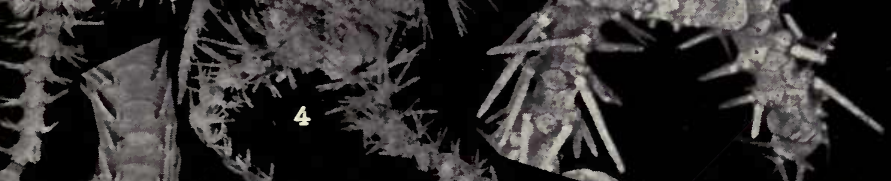

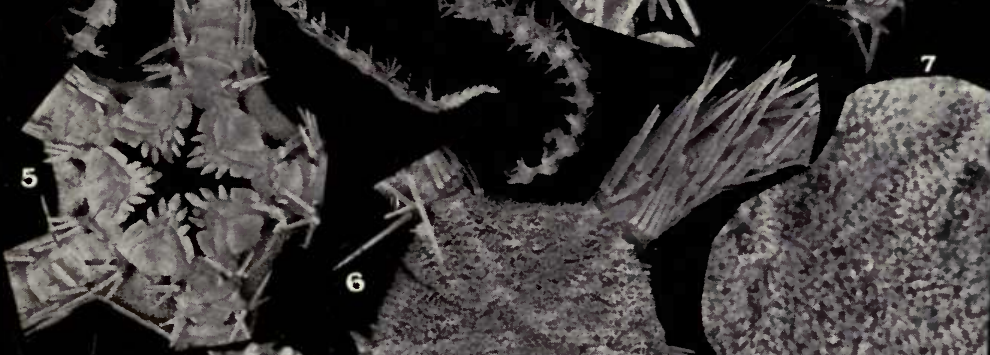

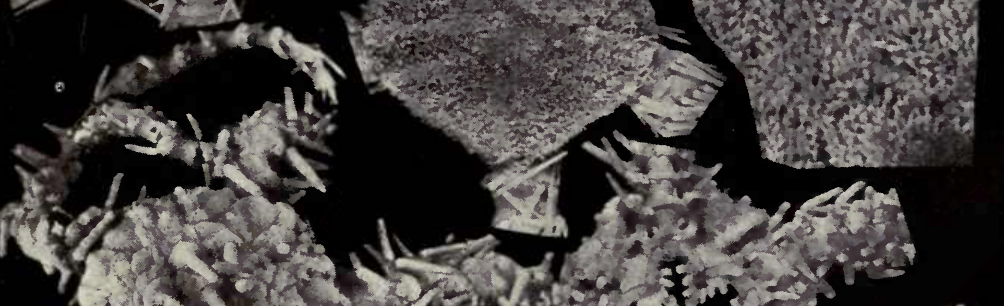

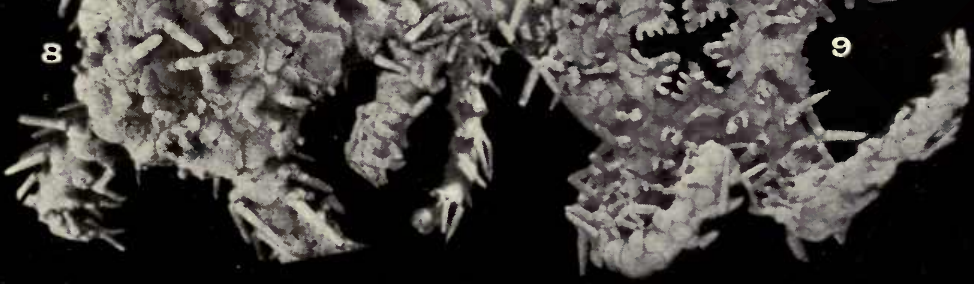

Ophiurans of the Philippine Seas and Adjacent Waters.

For EXPLANATION OF PLATE SEe PAges 457 and 458. 


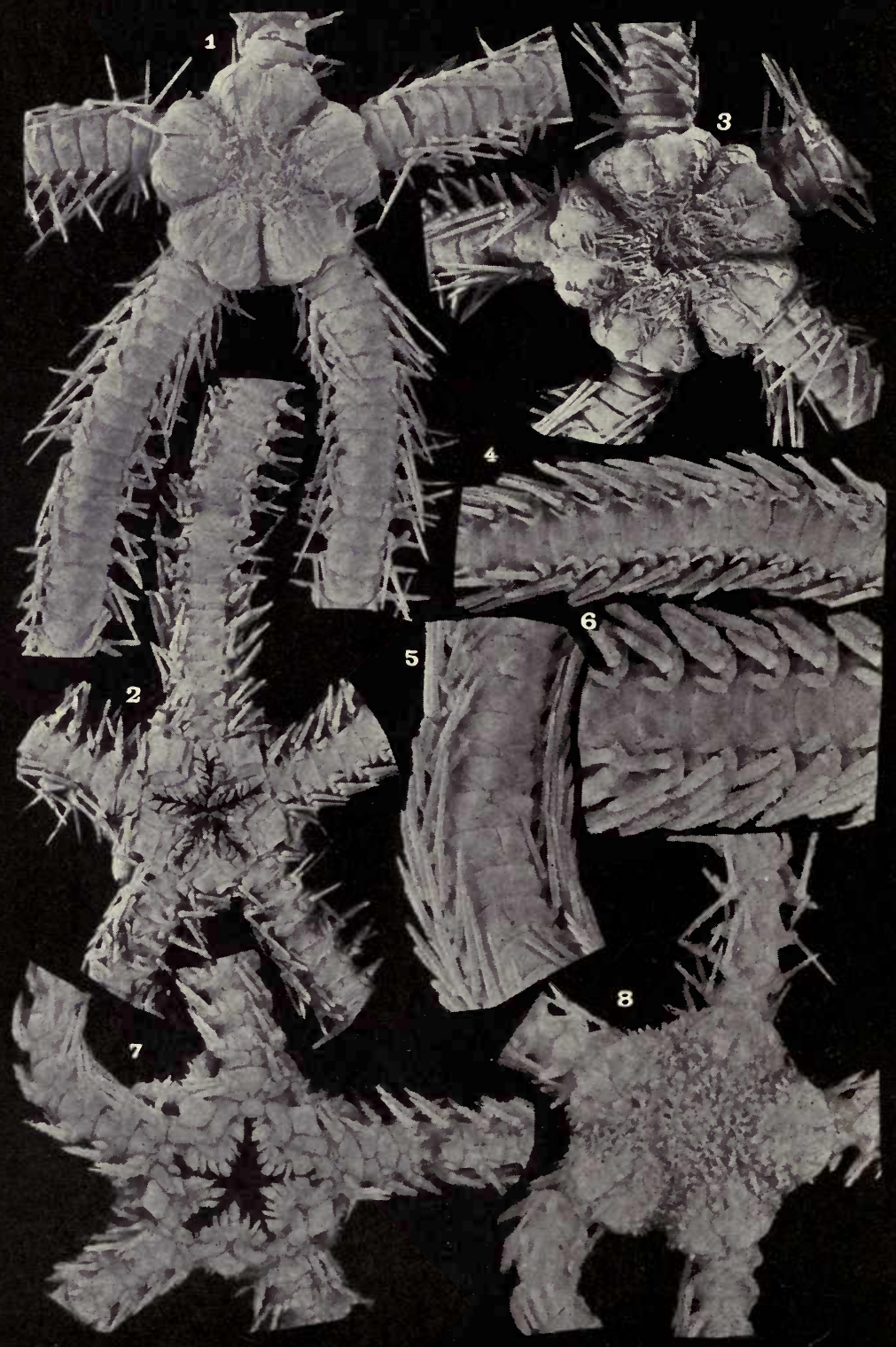

Ophiurans of the Philippine Seas and adjacent Waters.

For explanation of PLATE SEe PAge 458. 


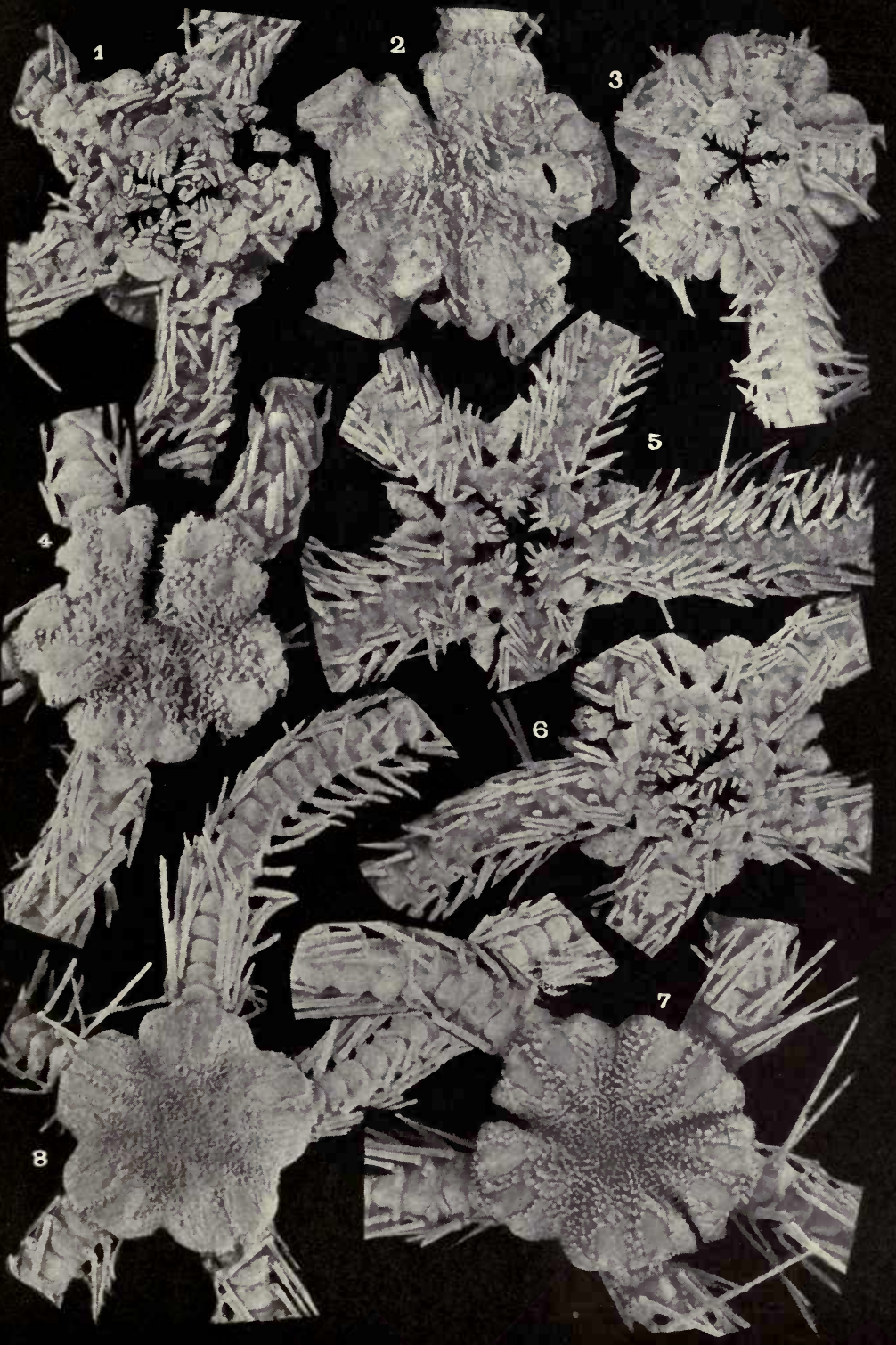

Ophiurans of the Philippine Seas and Adjacent Waters.

For explanation of plate see page 458. 


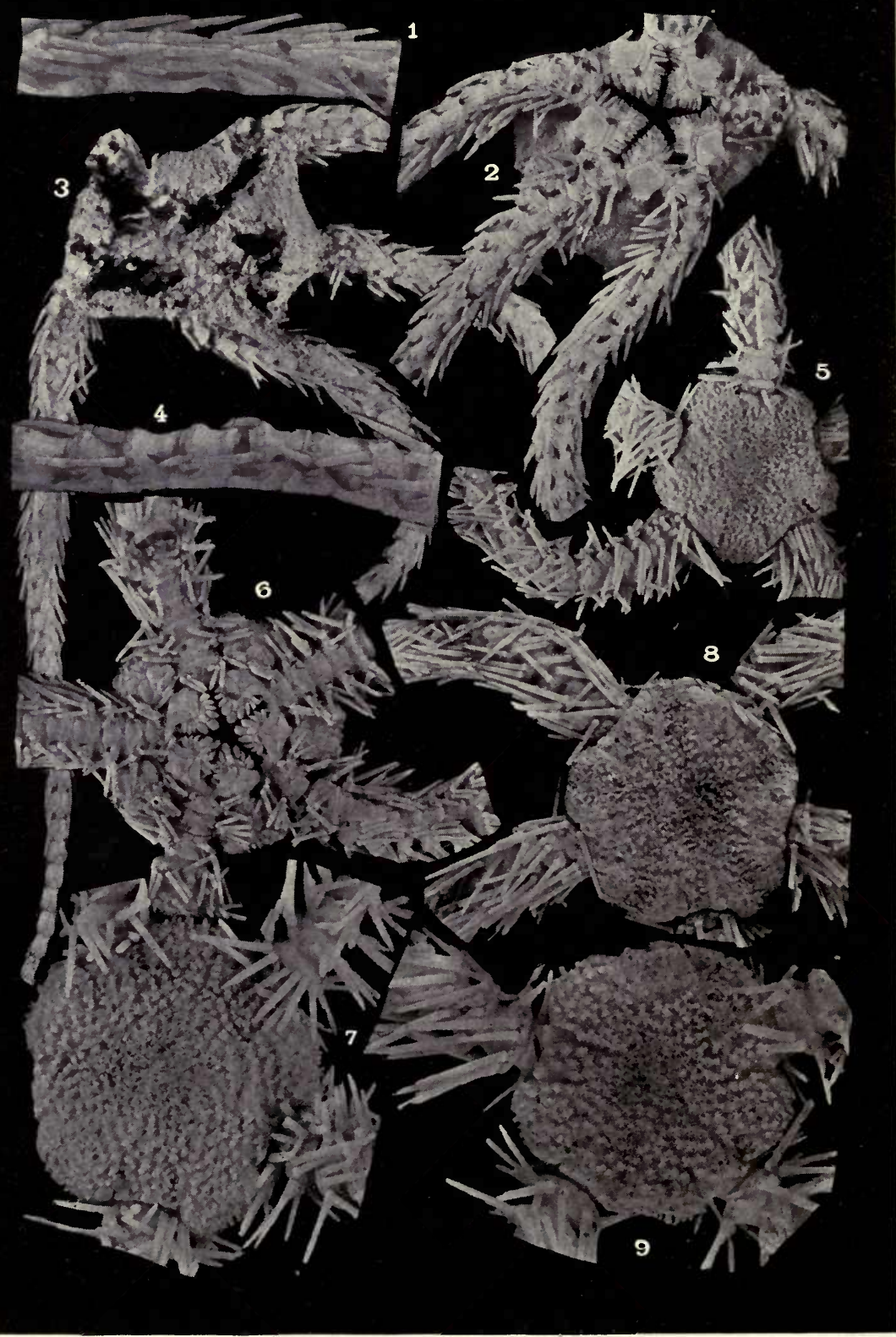

Ophiurans of the Philippine Seas and adjacent Waters.

For explanation of PLATE SEe PAge 468. 


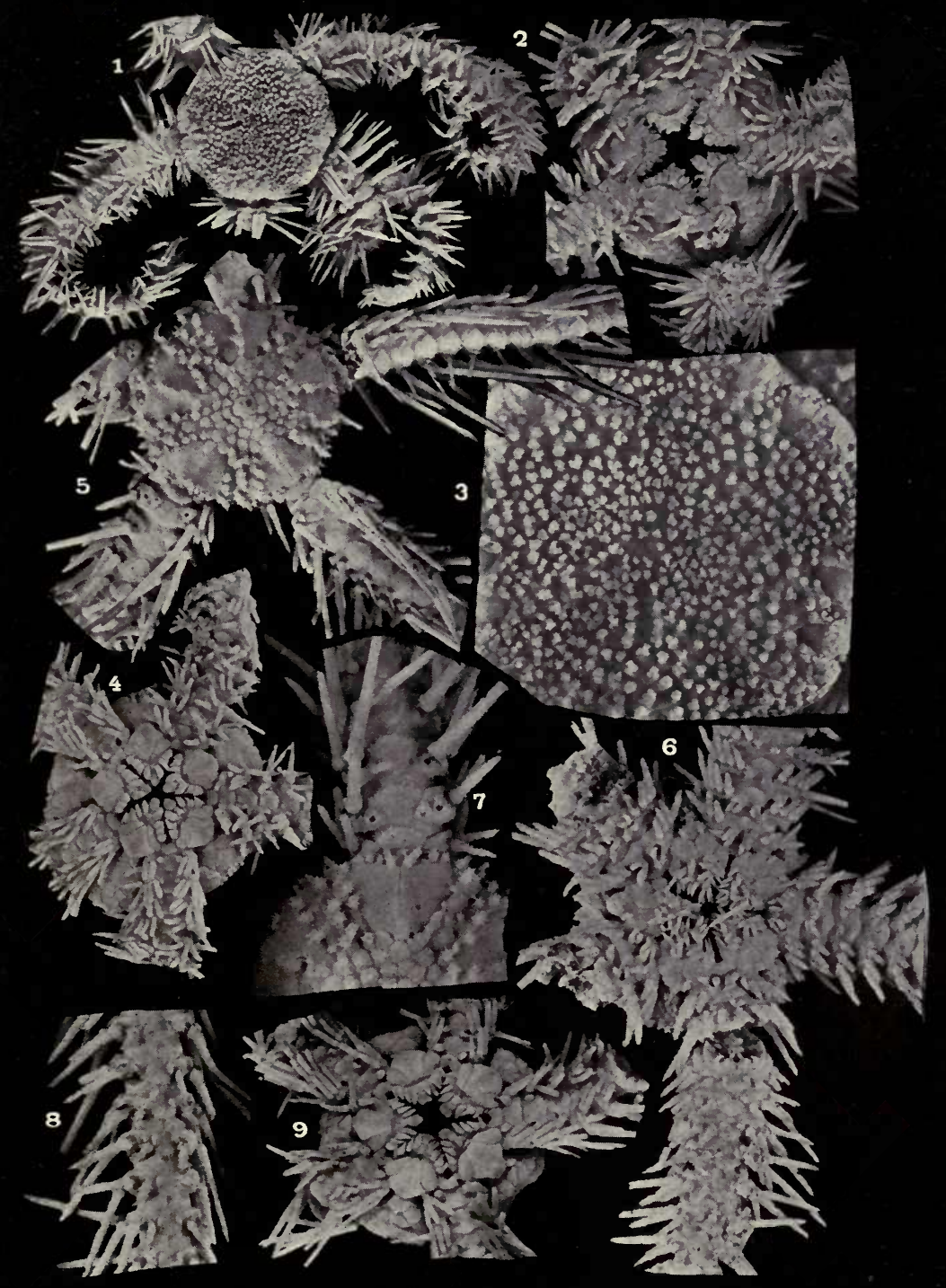

Ophiurans of the Philippine Seas and adjacent Waters.

For EXPLANATION OF PLATE SEe PAge 458. 


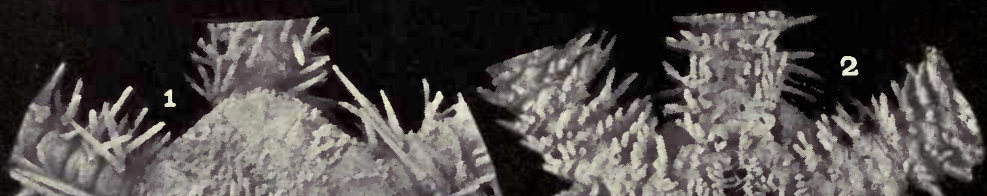

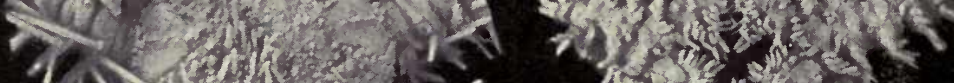
tha N vendy

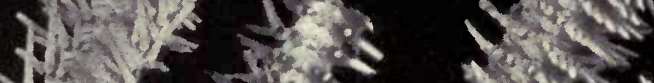
+ 5 we no

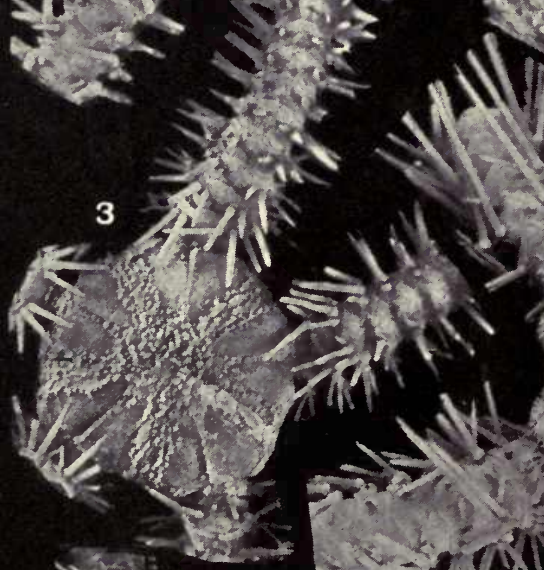
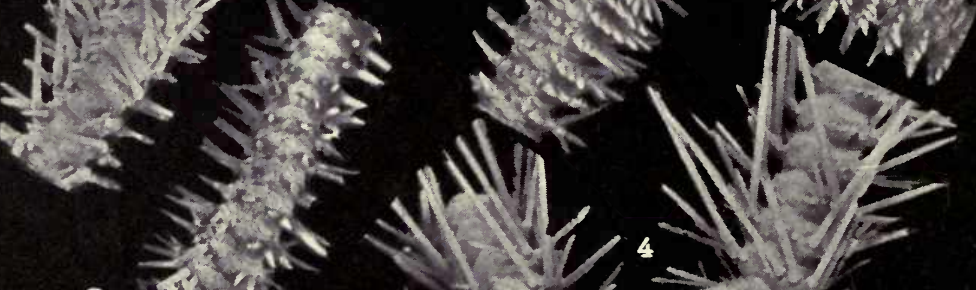

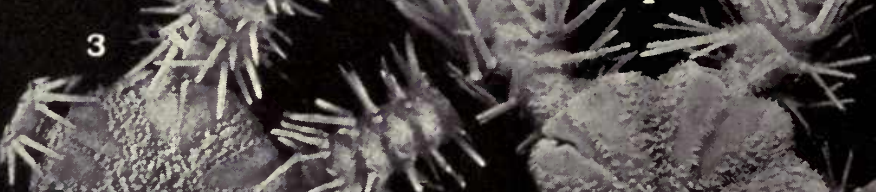

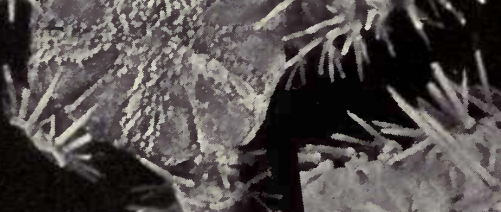

$-x+1$

Ningt

rents

7 ante

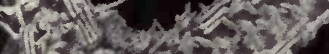

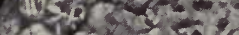

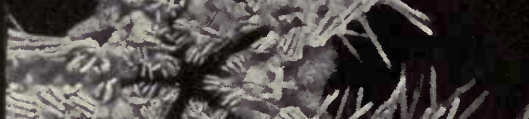

$=-1040$

, a

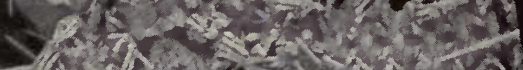

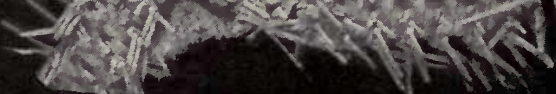

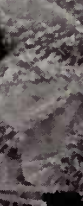

$\int^{3}+2$

$$
\text { (1) }
$$

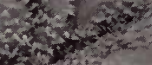

$4 x+2$

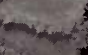

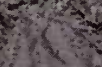

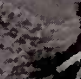

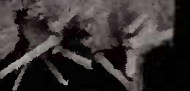

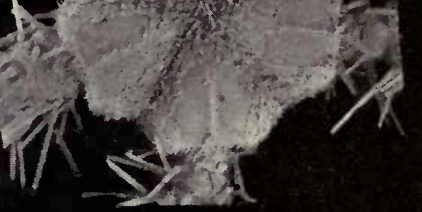

Ophiurans of the Philippine Seas and Adjacent Waters. 


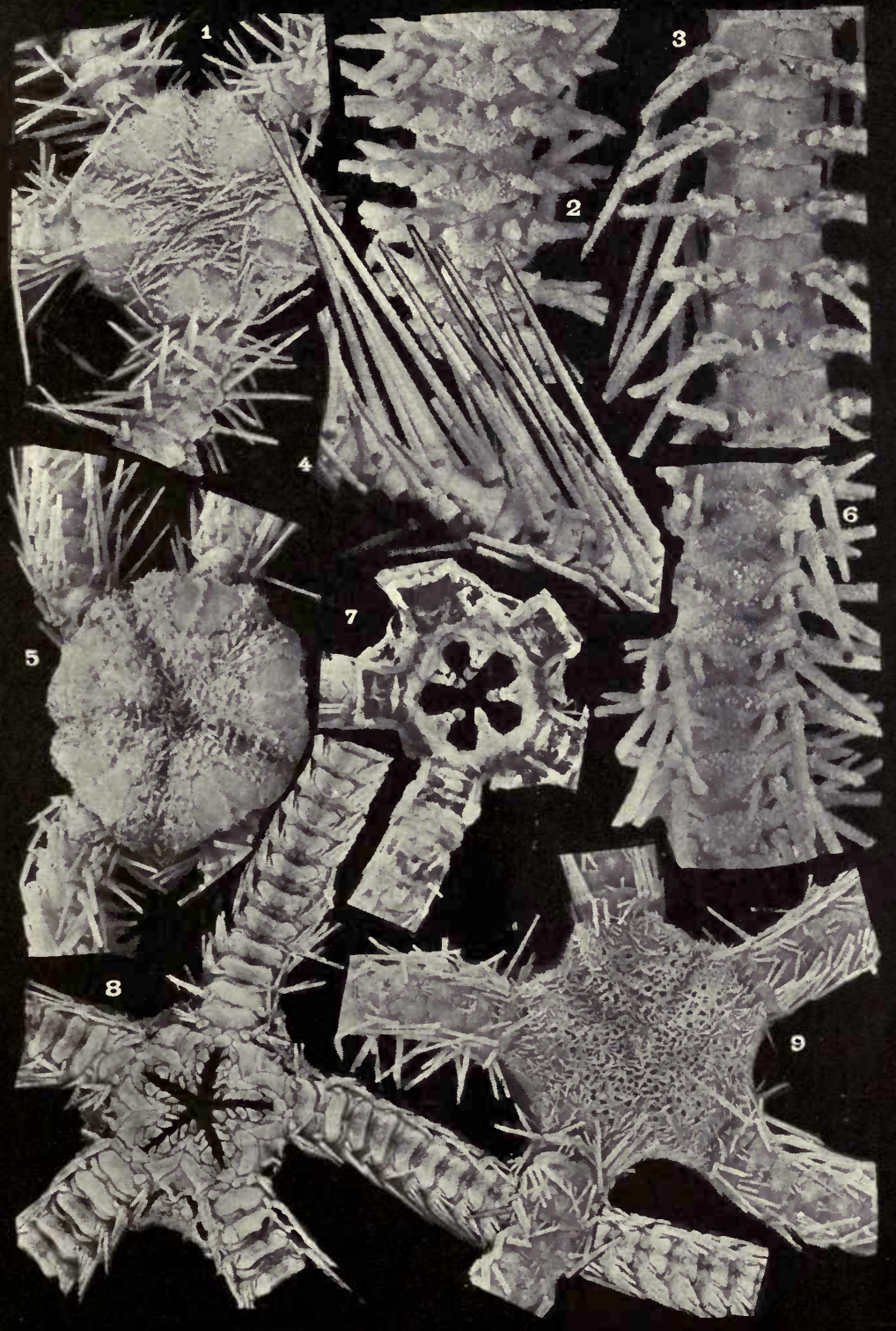

Ophiurans of the Philippine Seas and Adjacent Waters.

For EXPLANATION OF PLATE SEE PAGE 459. 


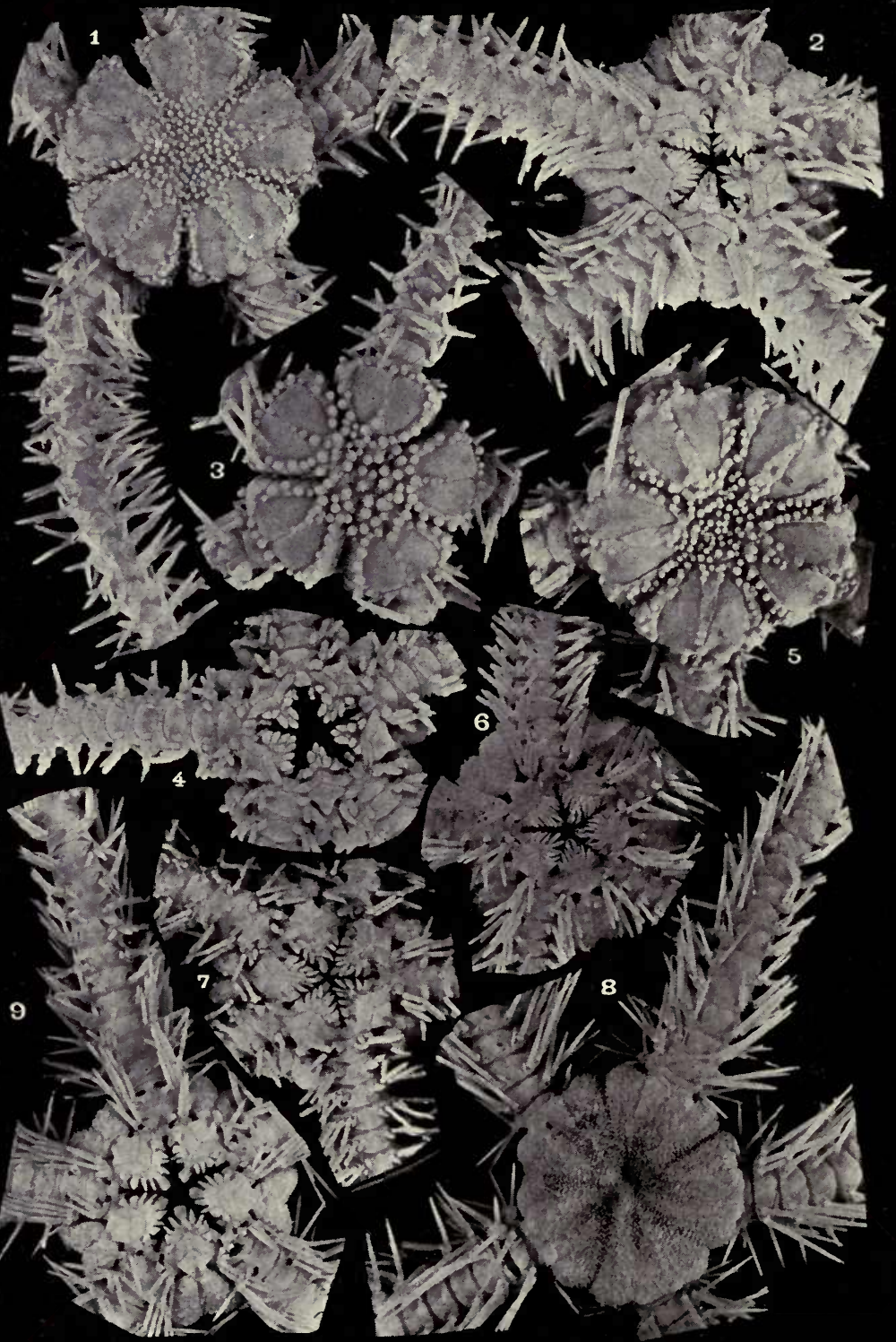

Ophiurans of the Philippine seas and adjacent Waters.

FOR EXPLANATION OF PLATE SEE PAGE 469 
$\leq$

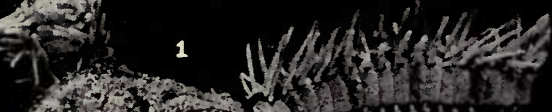

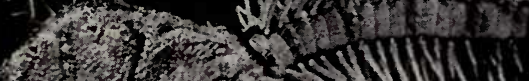

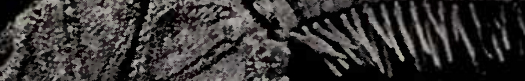

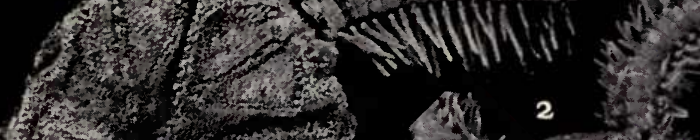

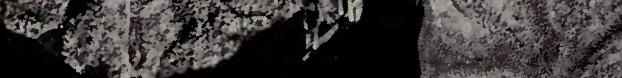

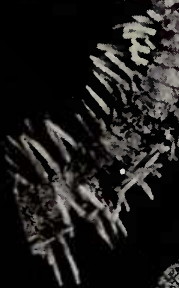

the 3 as of of A.t.

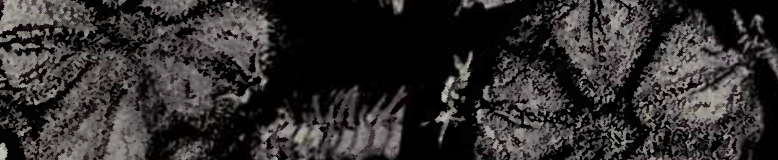

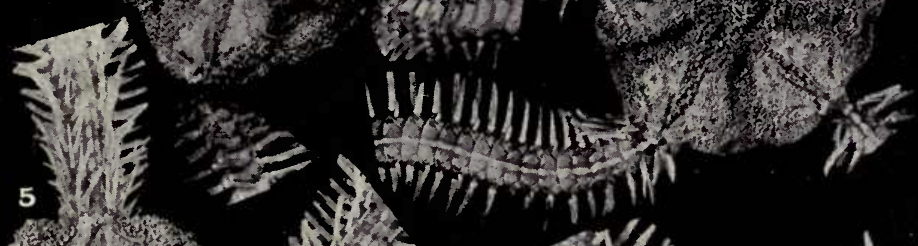
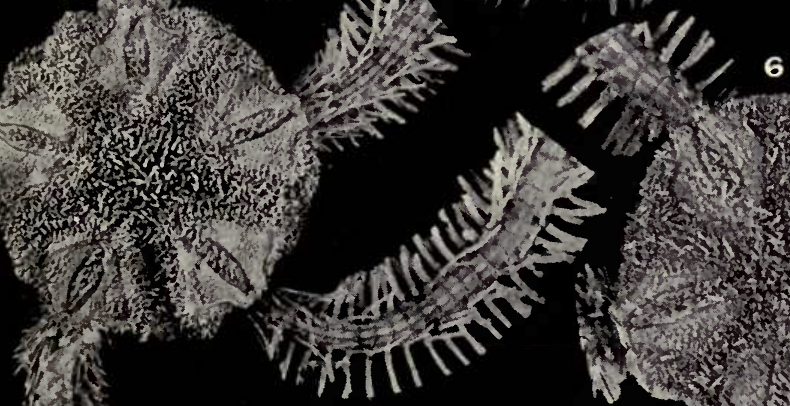

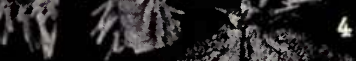




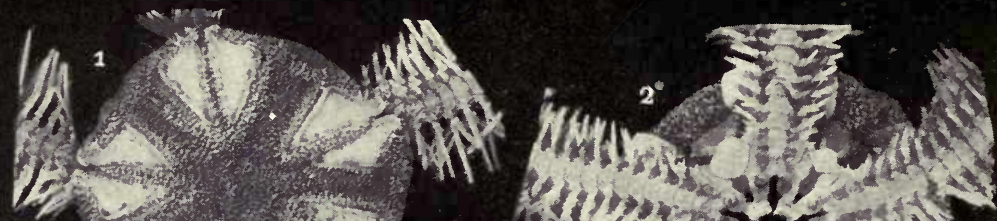

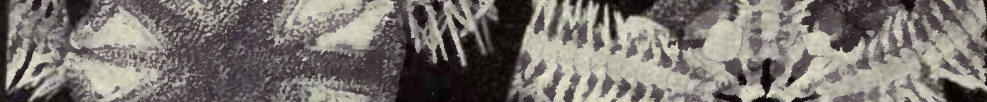

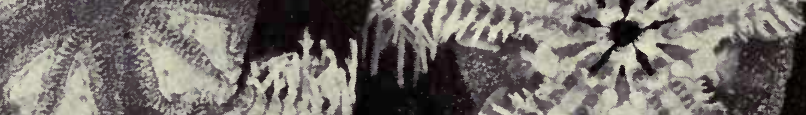

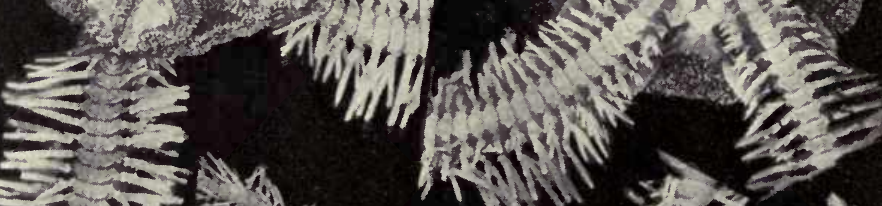

$2-1-2=$

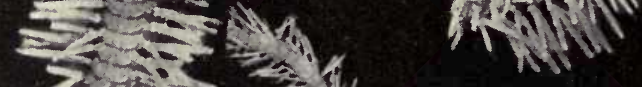

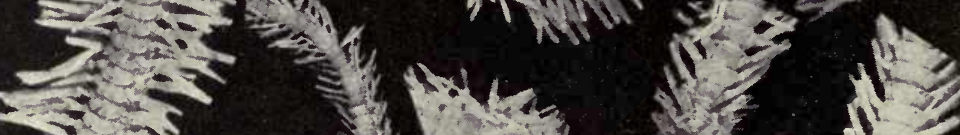

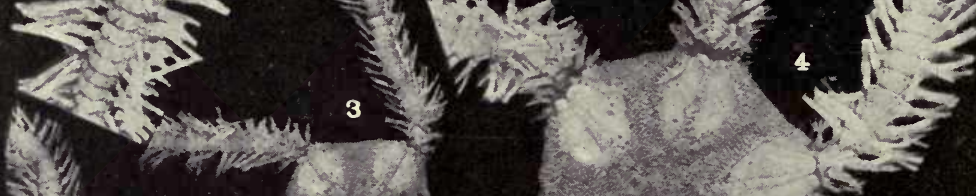

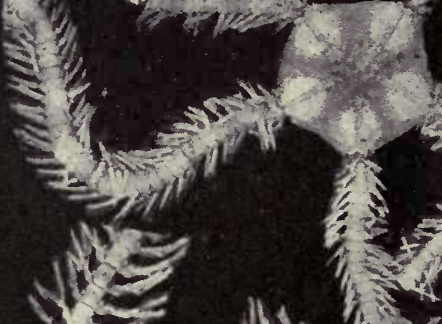

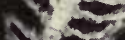

$N=$

$N=N$

wi 23

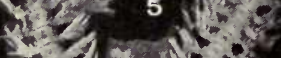

$\rightarrow-2\left(x, x^{2}+3\right.$

$5-10,3+2$

ant

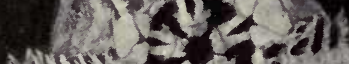
Mini- 1 (x)

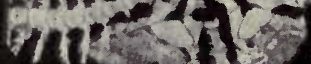

$$
\begin{array}{r}
1 \\
+
\end{array}
$$

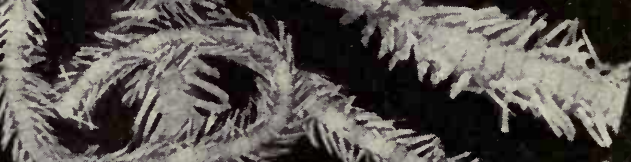

$$
\text { a. }-\frac{3}{2}
$$
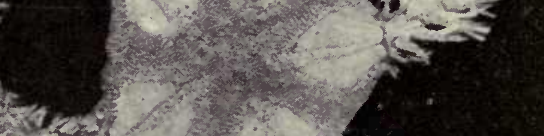

2.1.
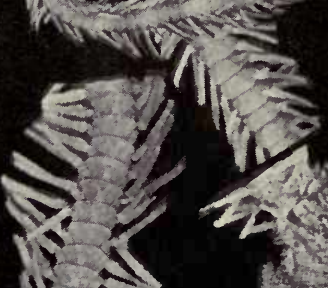

250 .

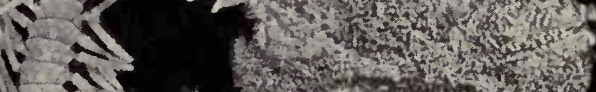

1.15

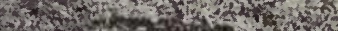

$x-5110-3$ t

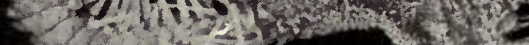

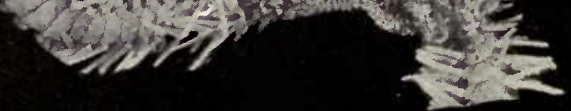

Ophiurans of the Philippine SEAS and Adjacent Waters. 


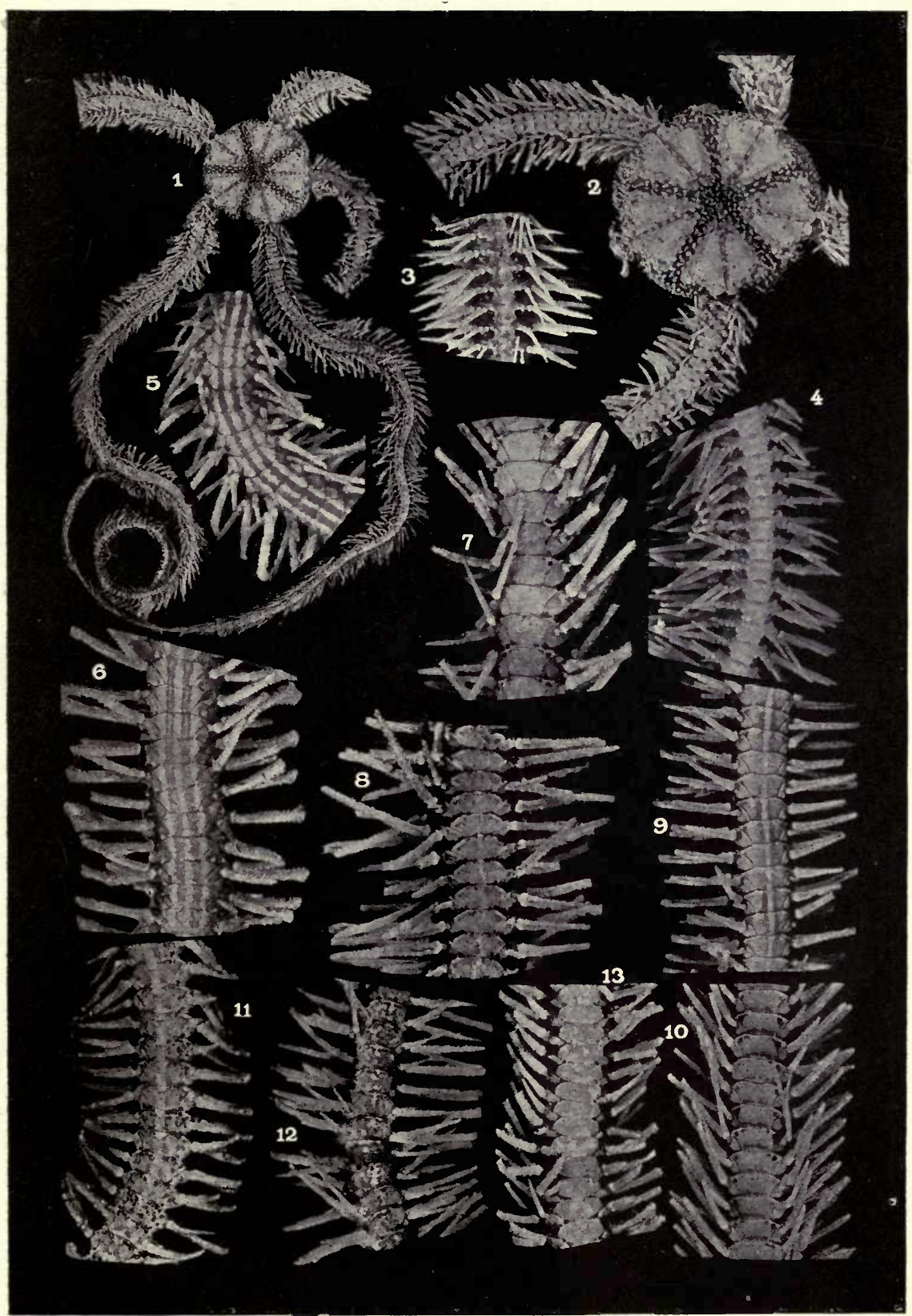

Ophiurans of the Philippine Seas and adjacent Waters.

For explanation of PLATE see page 460. 


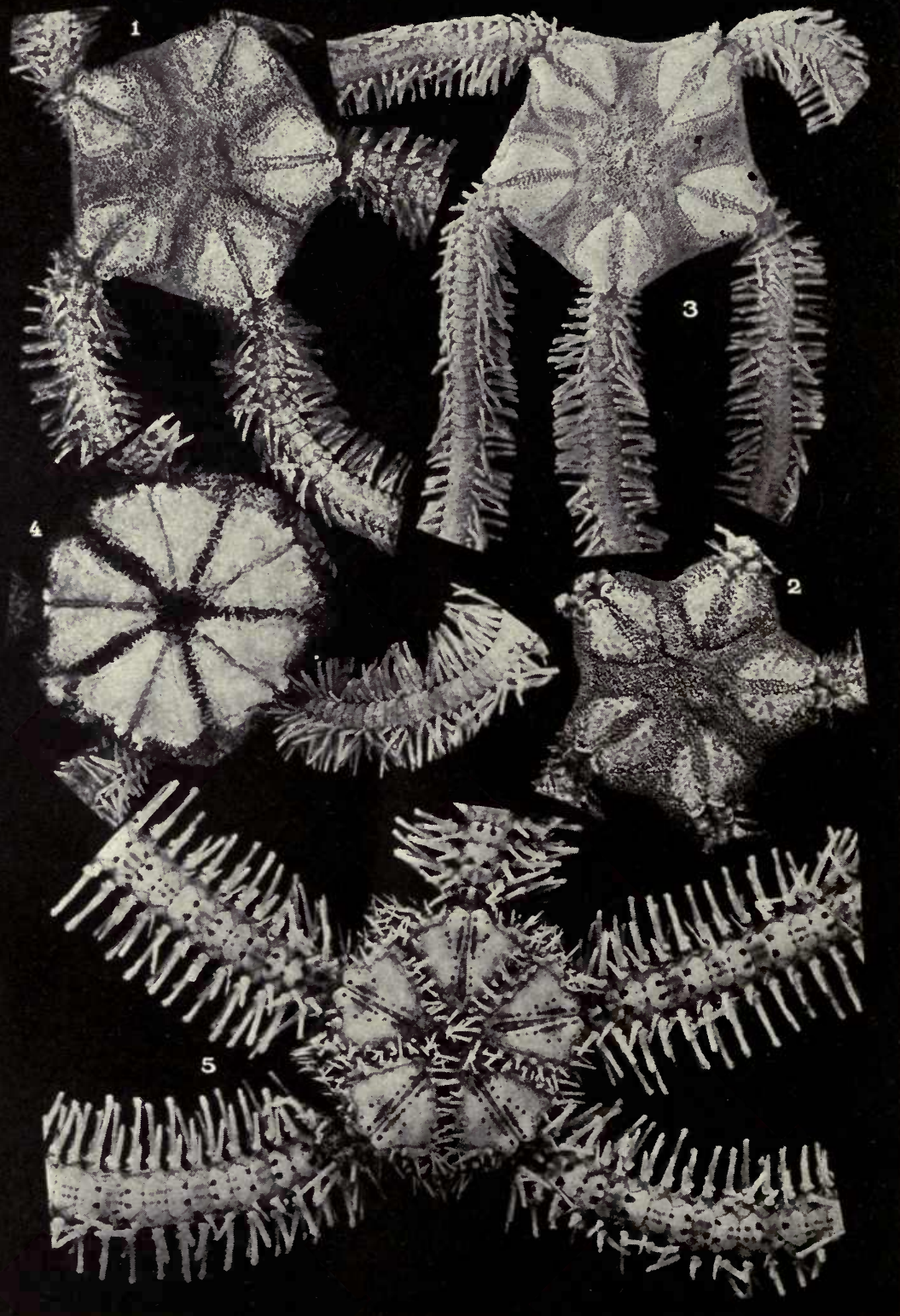

Ophiurans of the Philippine Seas and Adjacent Waters.

For explanation of plate see page 460. 


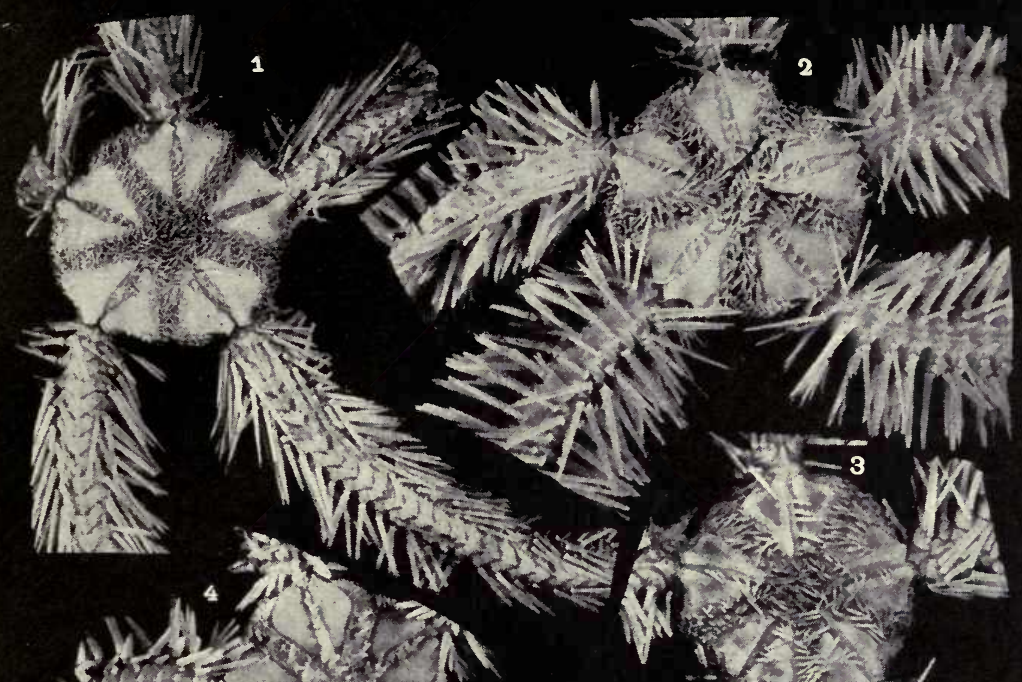
敉

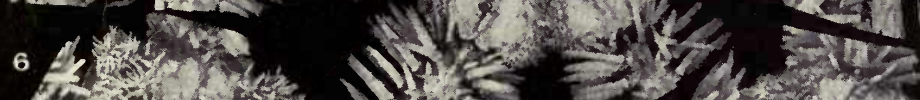

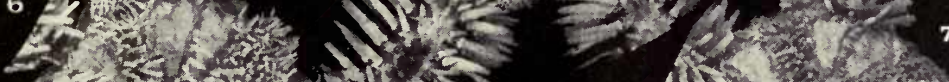
3.1.

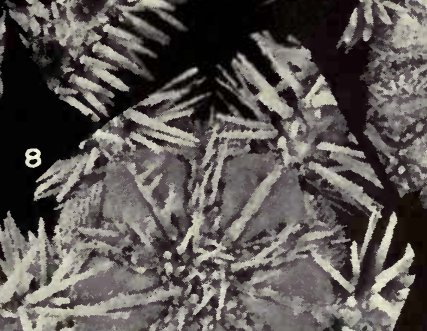
m.

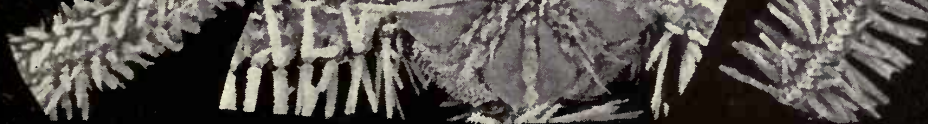

Ophiurans of the Philippine Seas and adjacent Waters.

For explanation of pLATE SEe PAge 460. 


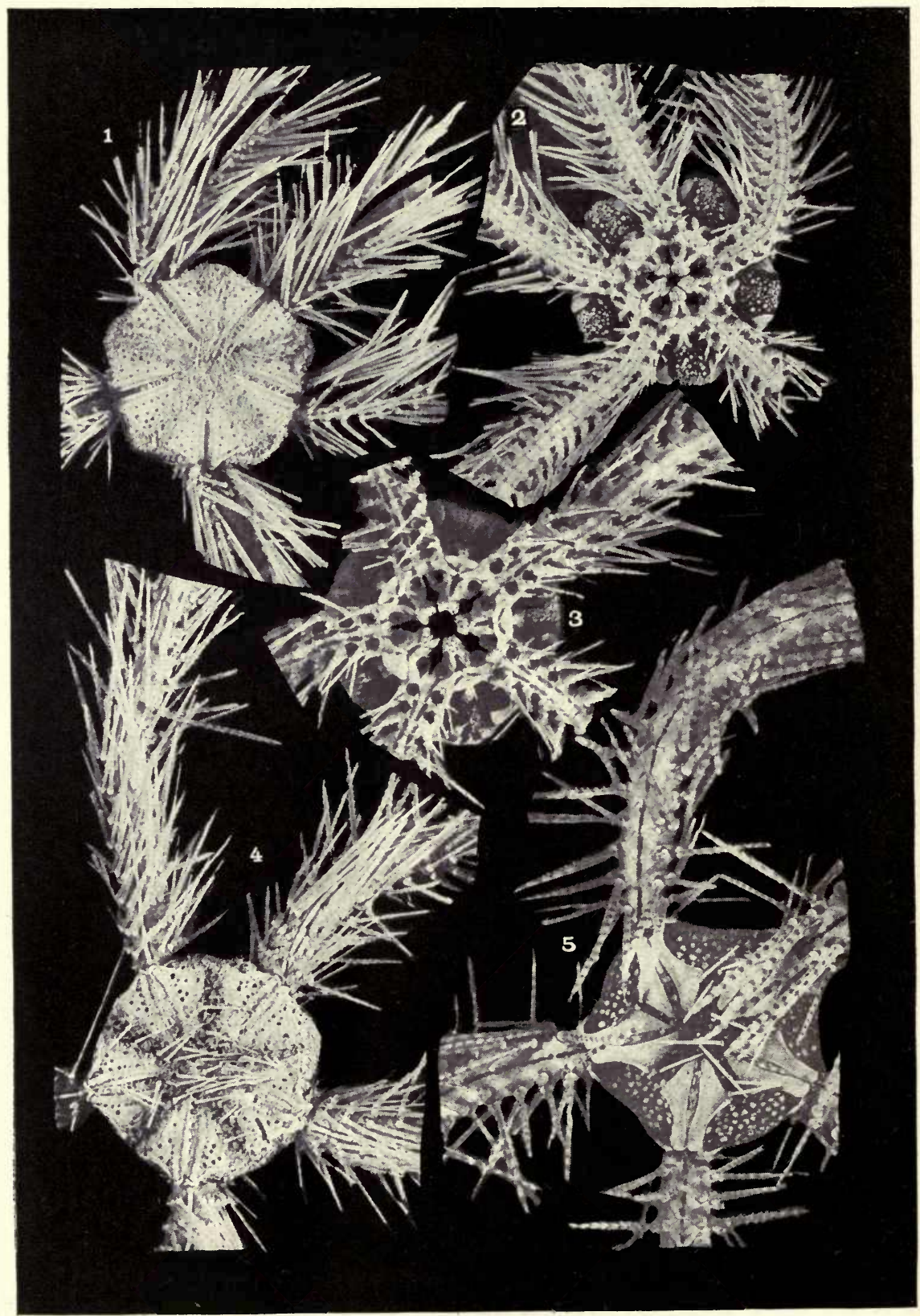

Ophiurans of the Philippine Seas and Adjacent Waters.

for explanation of plate see page 460. 


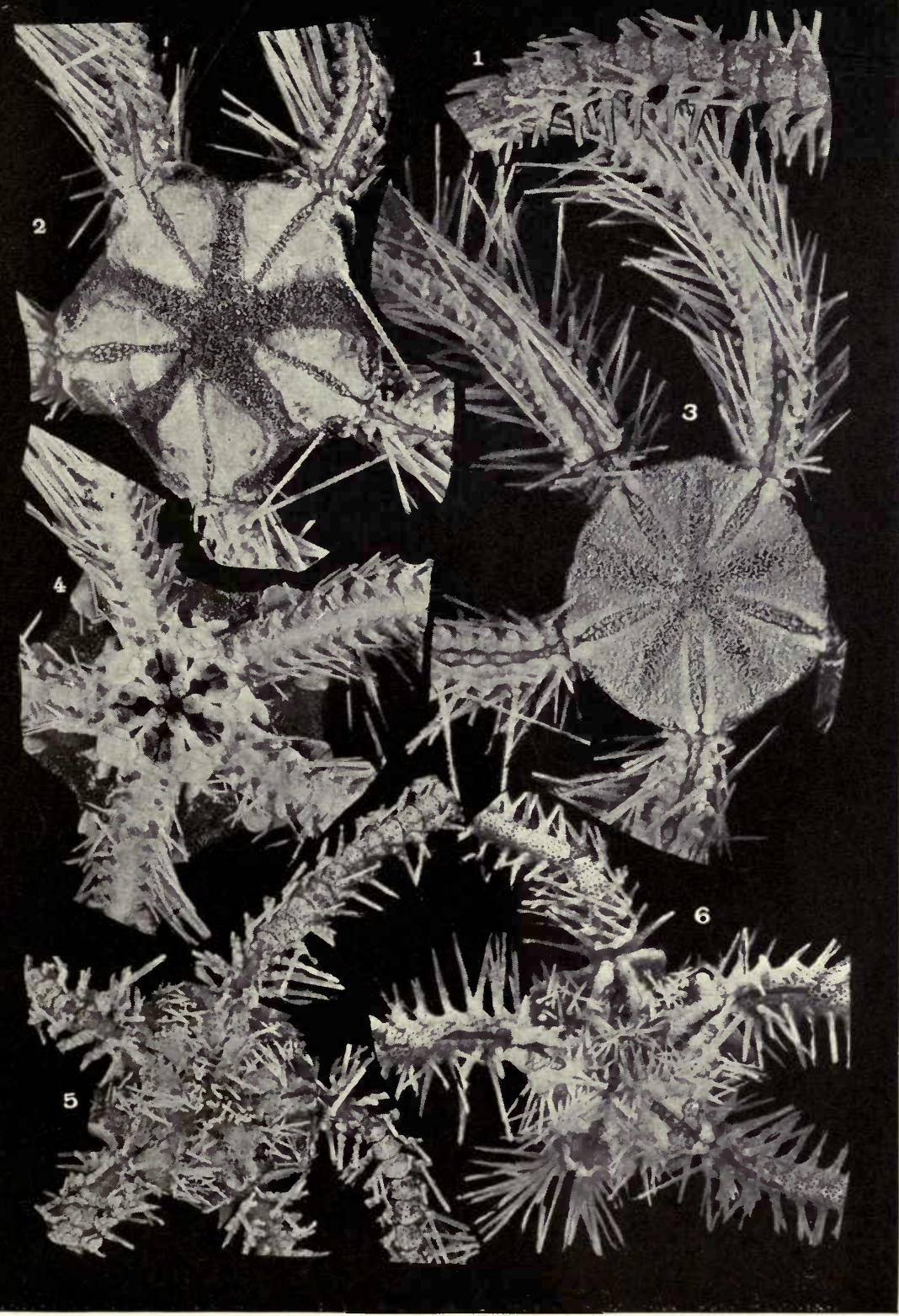

Ophiurans of the Philippine Seas and adjacent Waters.

For explanation of PLATE SEe Page 460. 


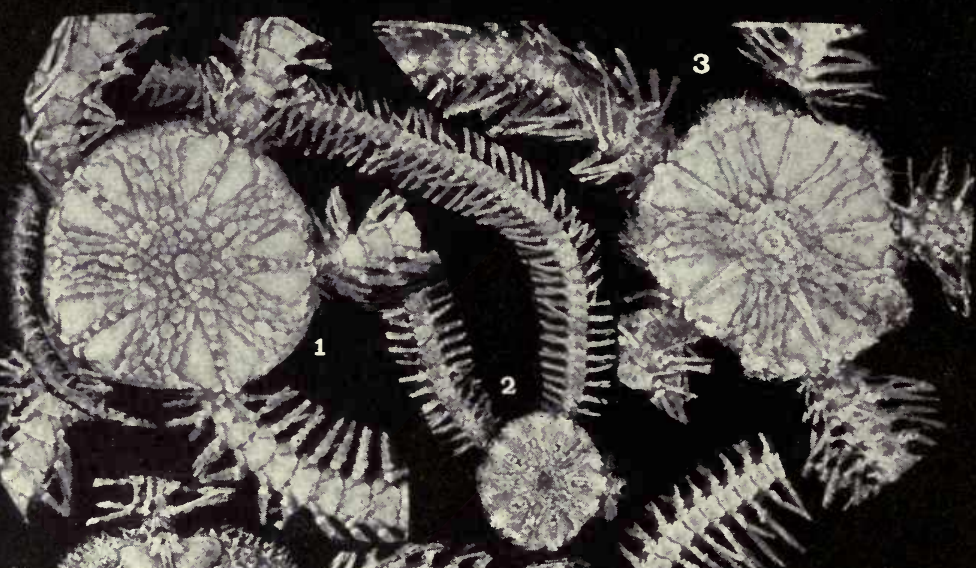

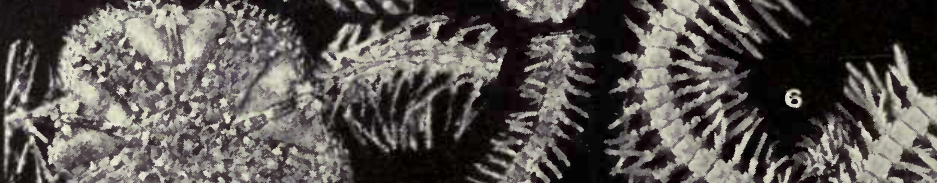

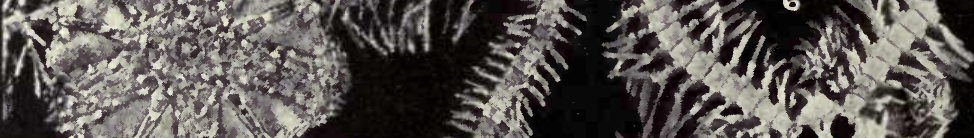
$47 x y$.

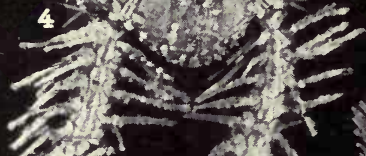

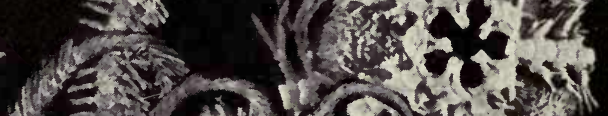

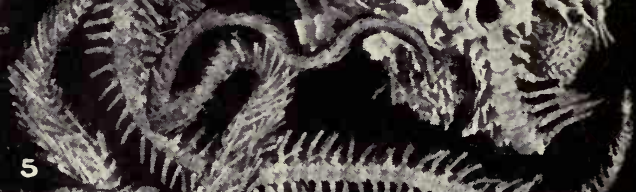

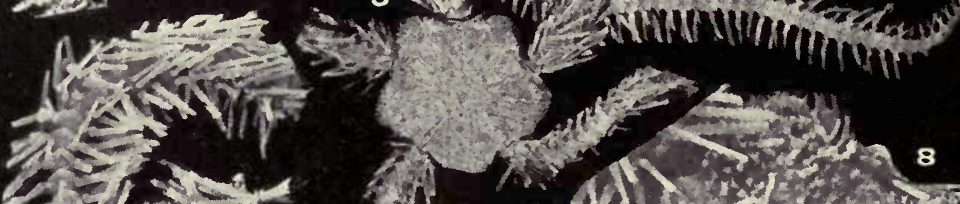

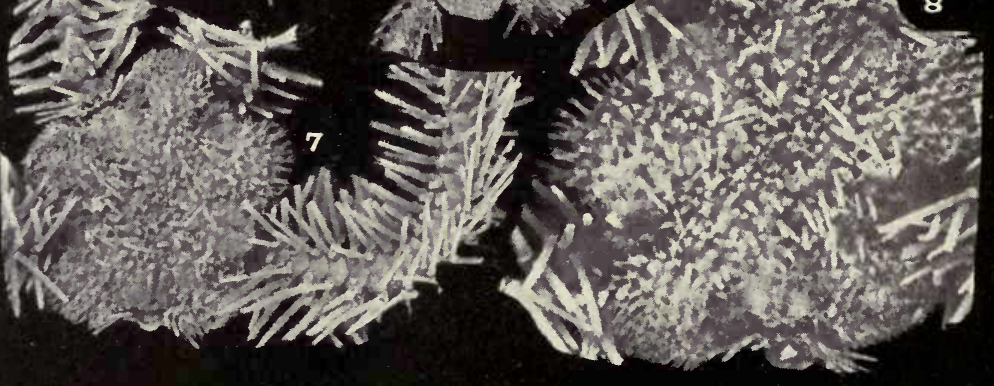

Ophiurans of the Philippine Seas and adjacent Waters. 


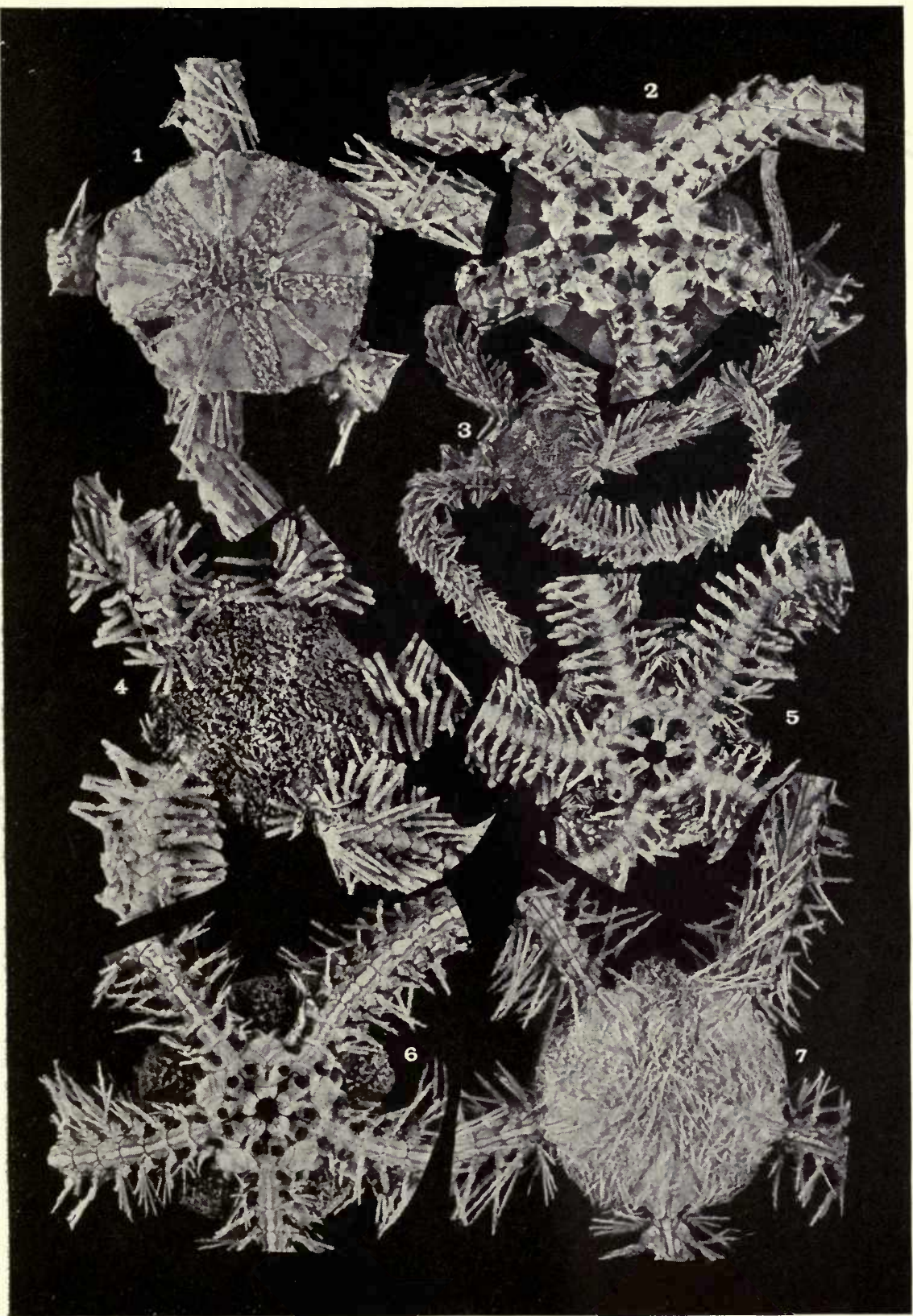

Ophiurans of the Philippine Seas and Adjacent Waters.

For explanation of plate see page 461 . 


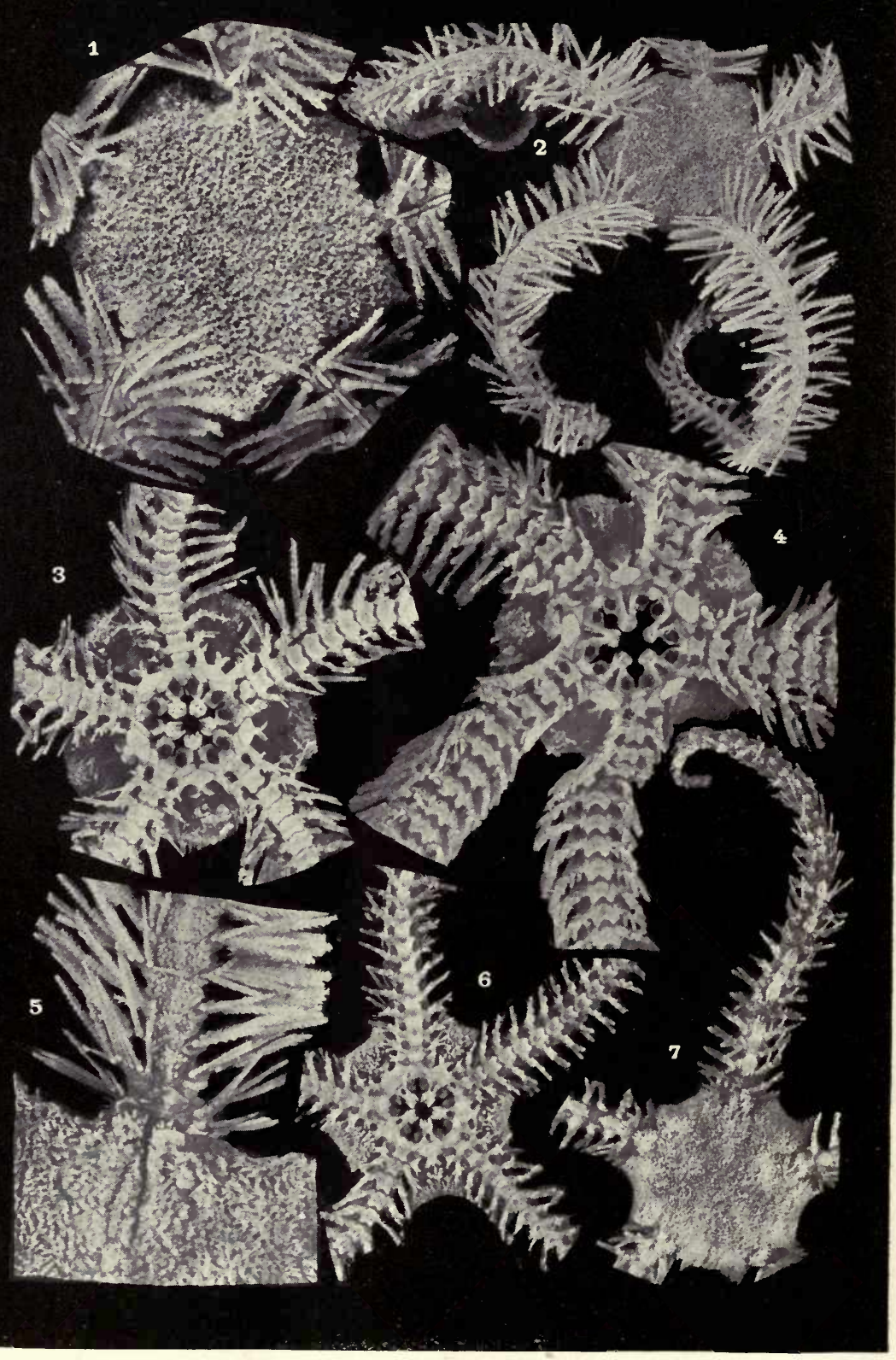

Ophiurans of the Philippine Seas and Adjacent Waters.

Fos EXPLANATION OF PLATE SEE PAgE 46I 


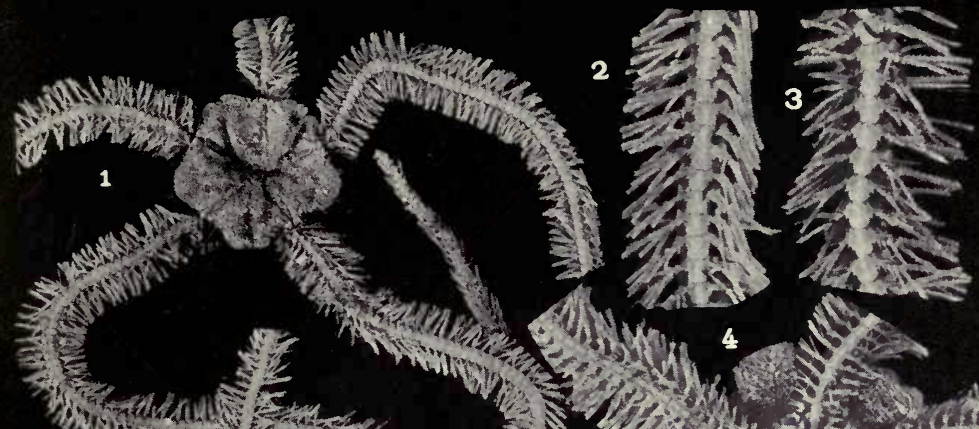

137n

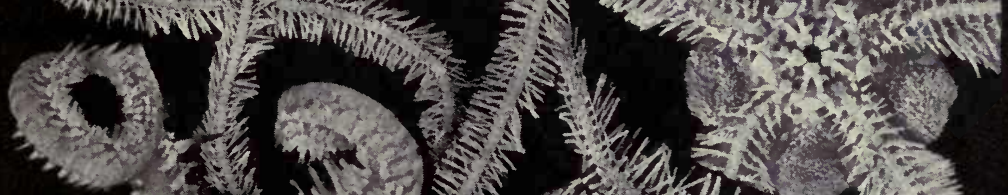

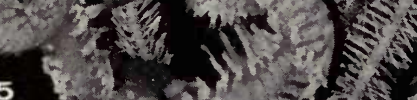
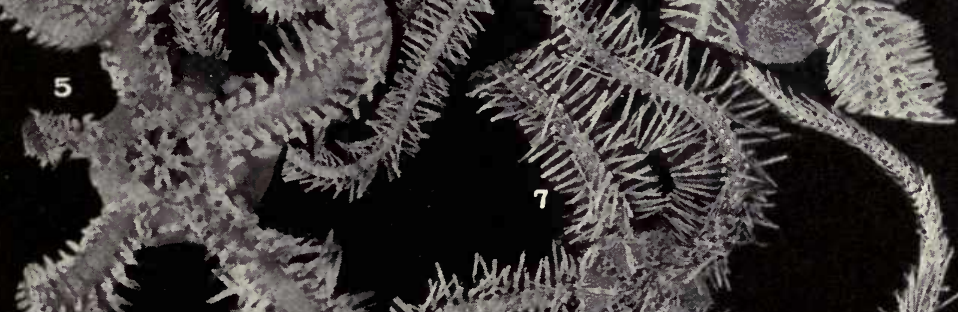

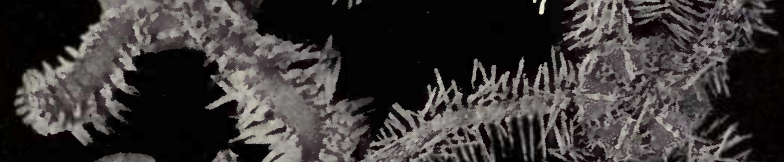

$7=10$

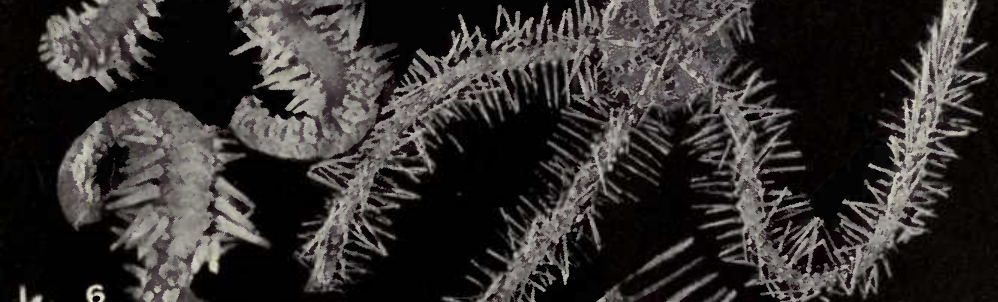

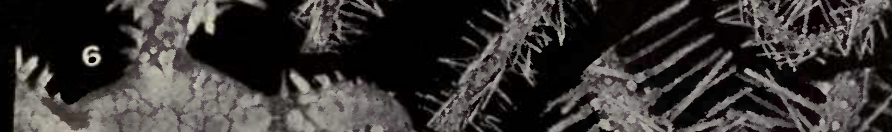

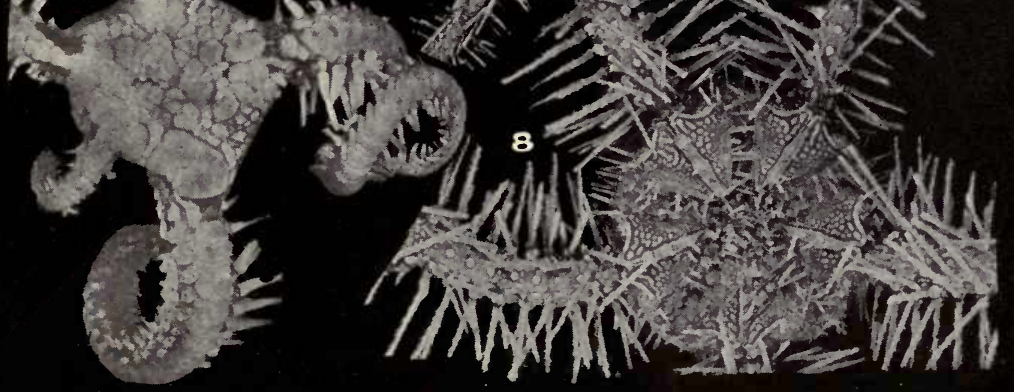

Ophiurans of the Philippine Seas and Adjacent Waters.

For explanation of plate see pags 461. 


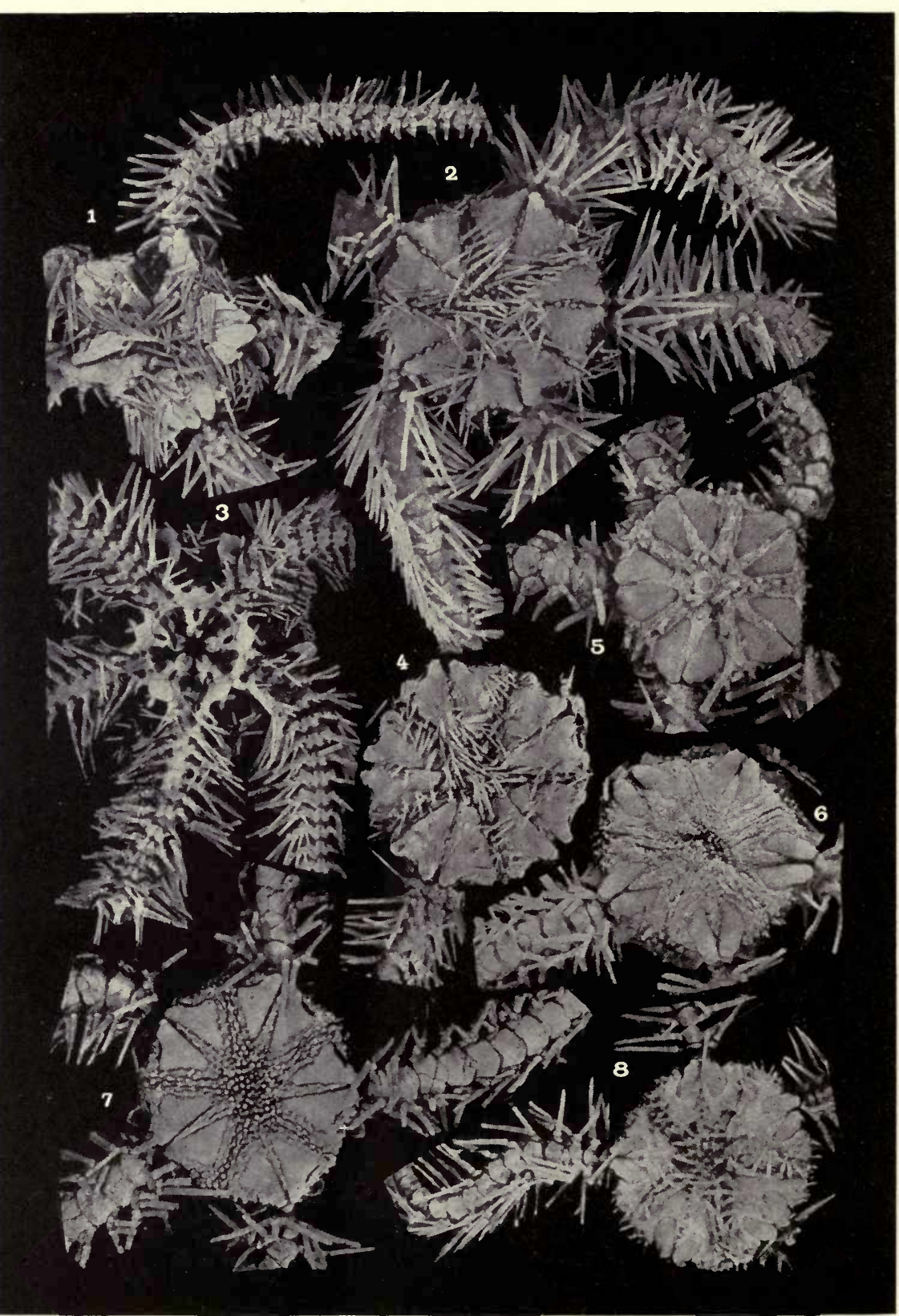

Ophiurans of the Philippine Seas and Adjacent Waters.

For explanation of plate see page 461 ! 


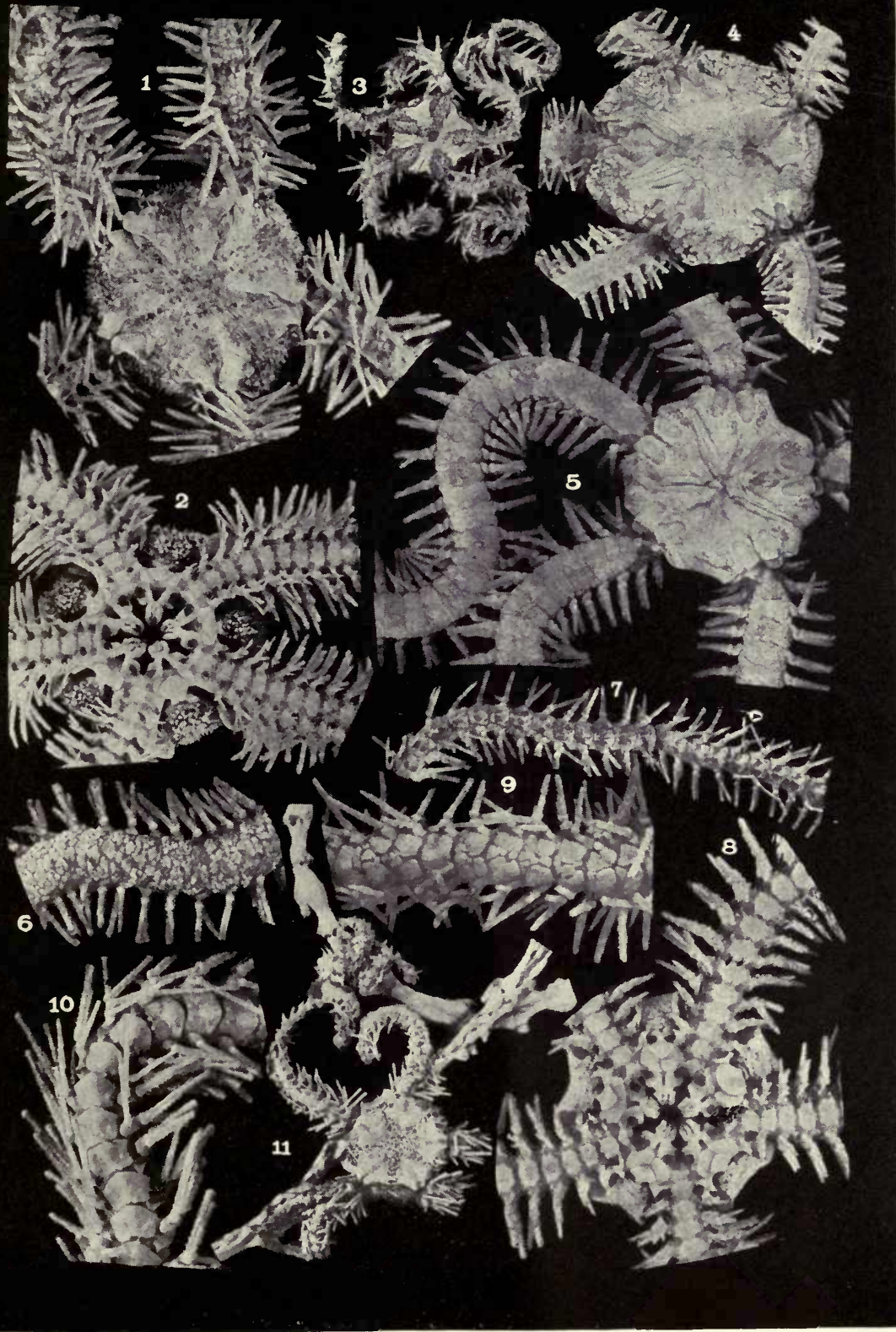

Ophivrans of the Philippine Seas and Adjacent Waters.

For explanation of plate see page 462 


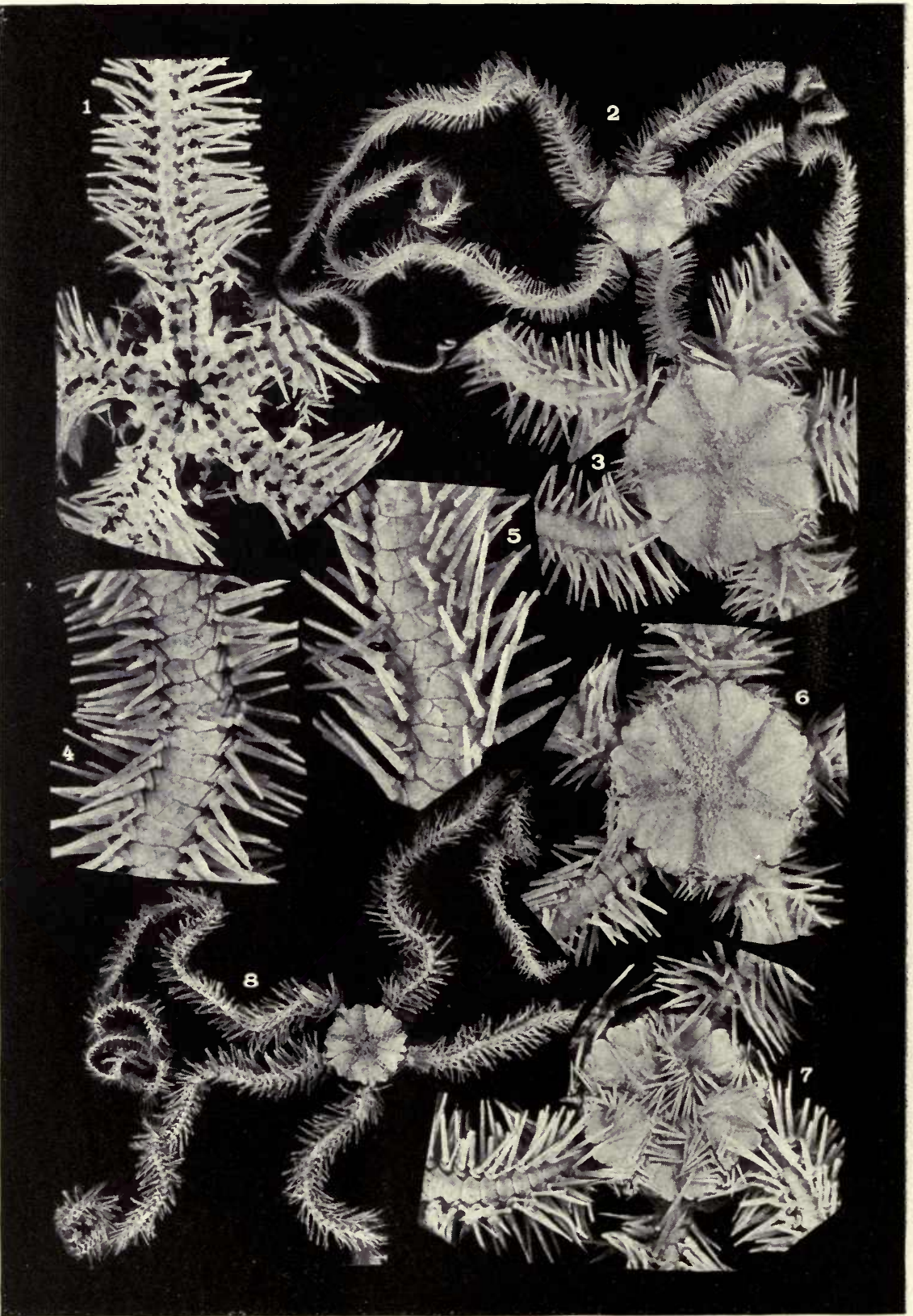

Ophiurans of the Philippine Seas and Adjacent Waters. 

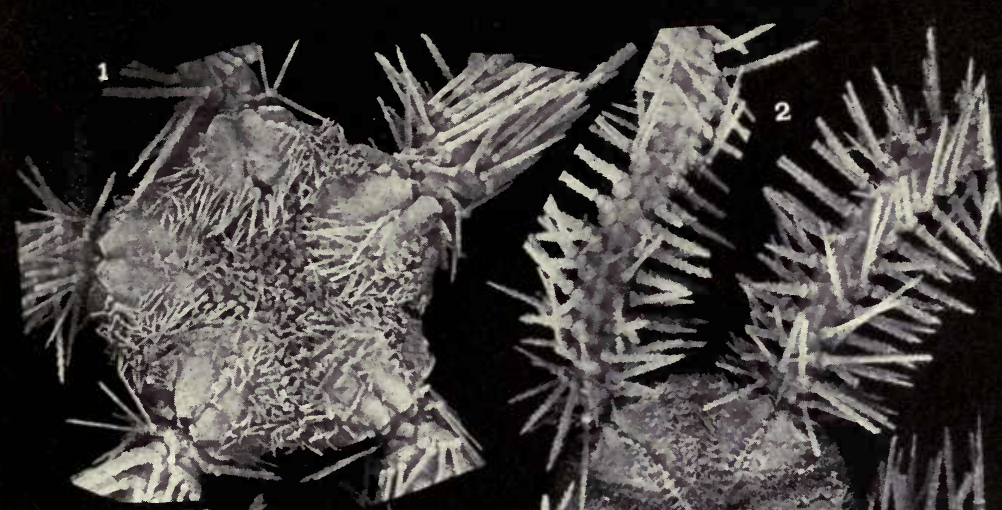

2.

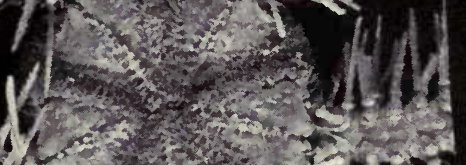

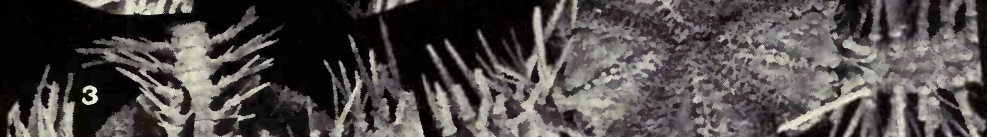

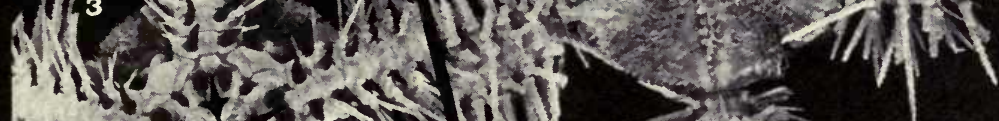
wets

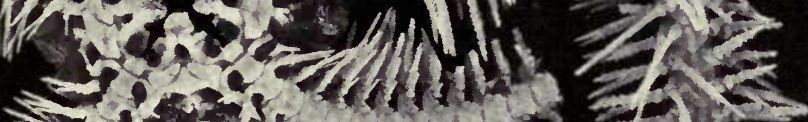
Fin.

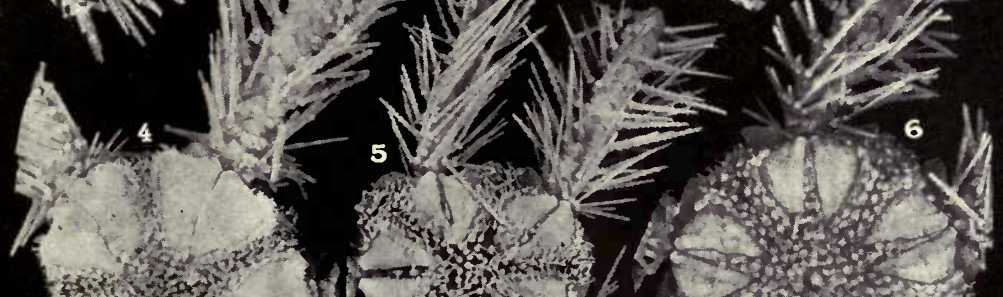

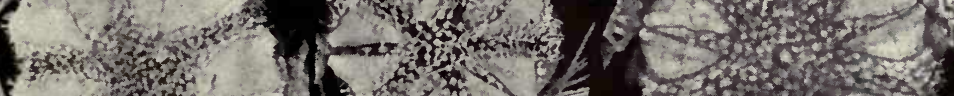

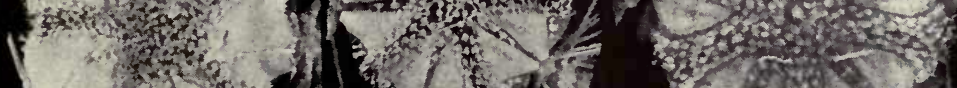

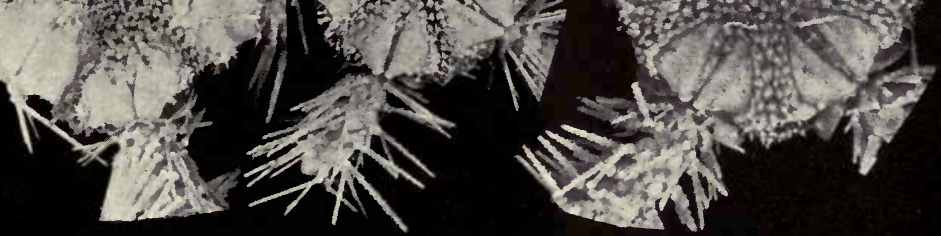

Ophiurans of the Philippine Seas and Adjacent Waters.

For explanation of plate see page 462. 


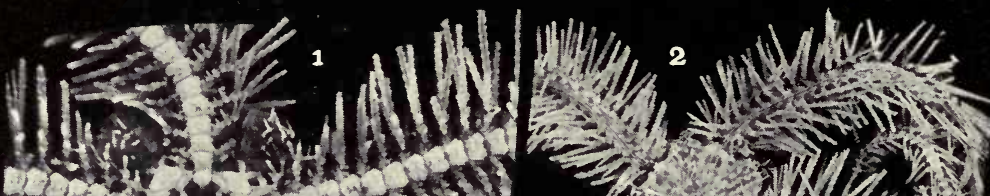

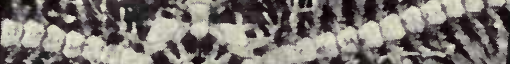

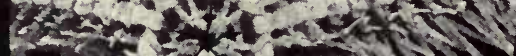

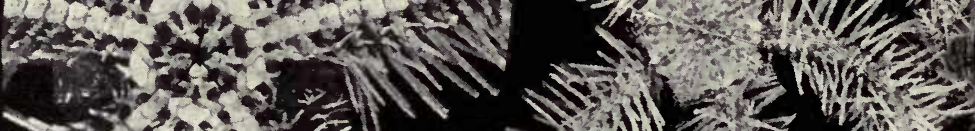

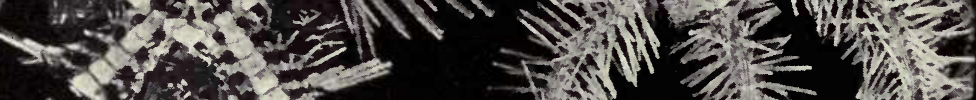

wion

aln w in

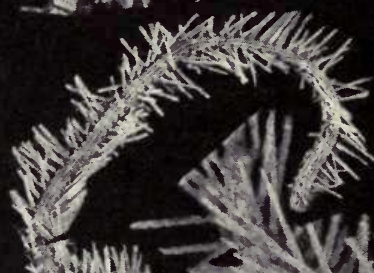

If

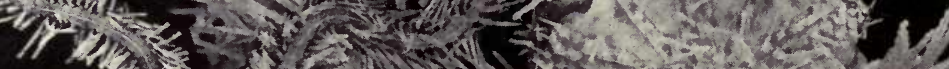

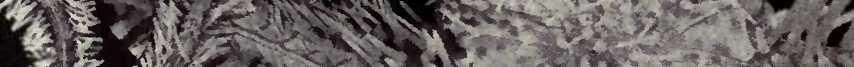

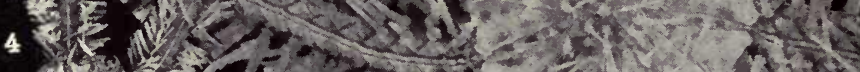

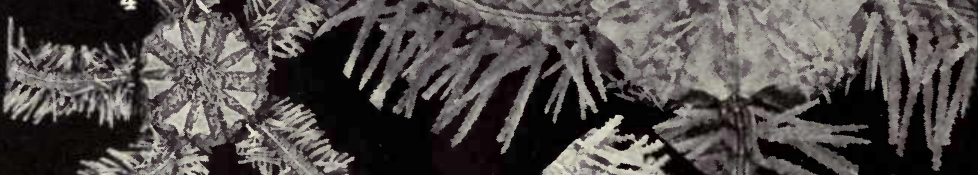

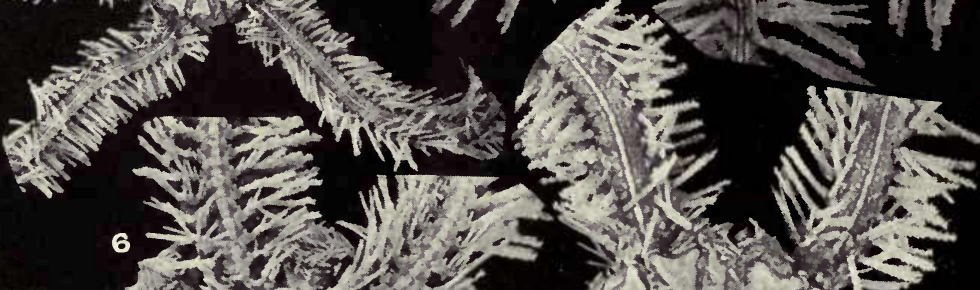

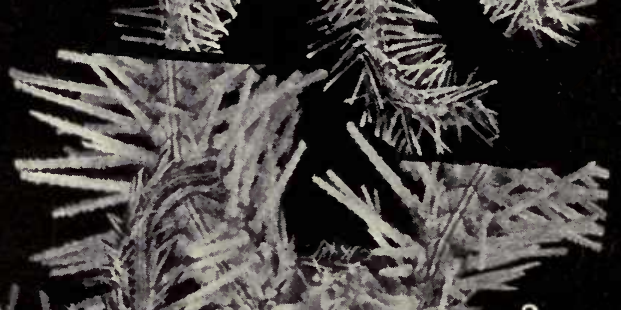




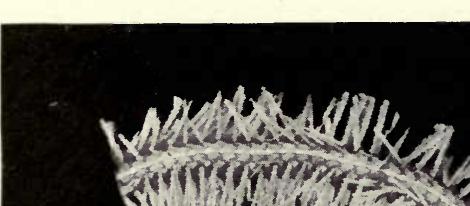

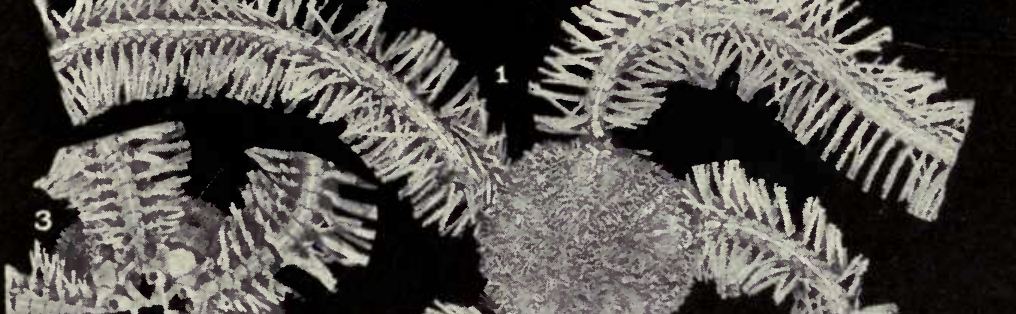
Botion

in $-3,15$

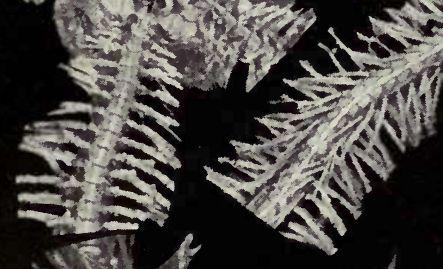

$+\infty)^{2}$ 1 $1 \times 17^{2}$ ins

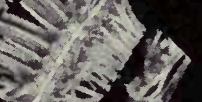
in $\rightarrow+16$

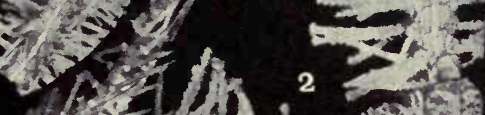
4.0. (1) $22^{2}=$

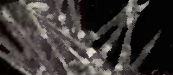
as $\left.\ln ^{4}\right)^{2}$

$4 .(5215020$

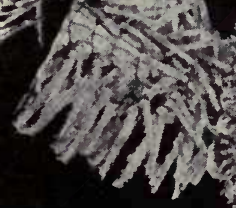

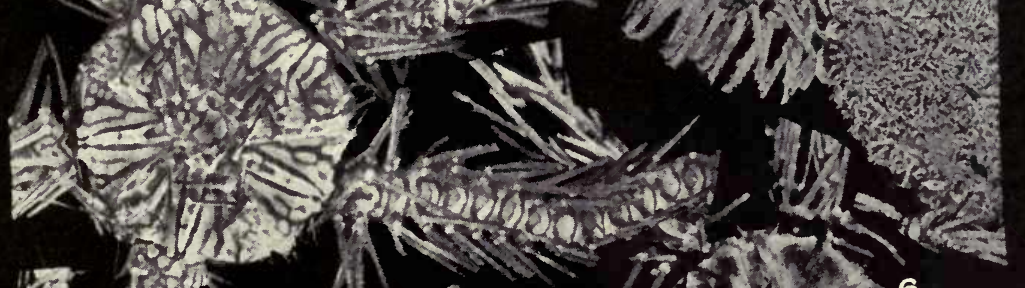
(5)

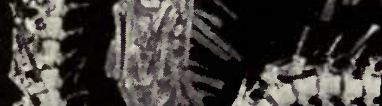

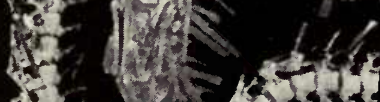

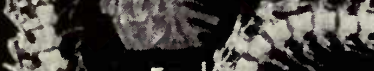
if 5 inte1.

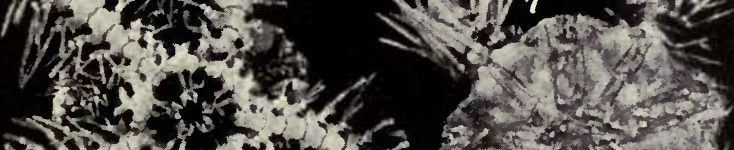

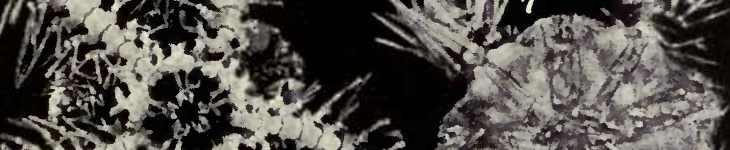

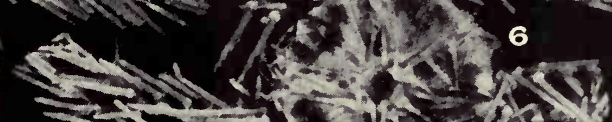

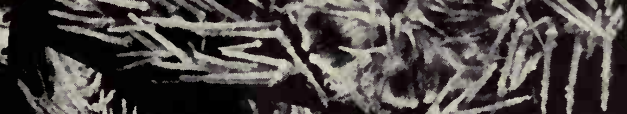

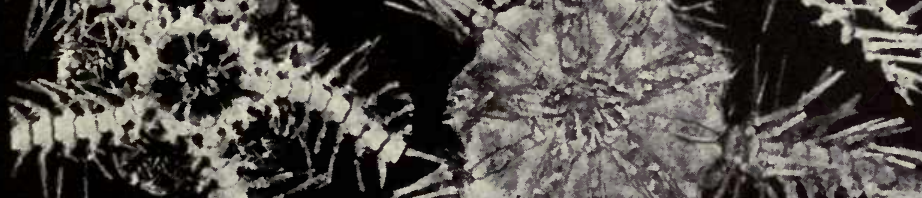

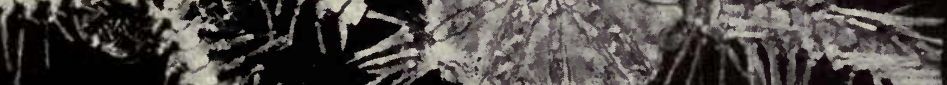
a

Ophiurans of the Philippine Seas and adjacent Waters. for explanation of plate see pages 462 ano 463' 


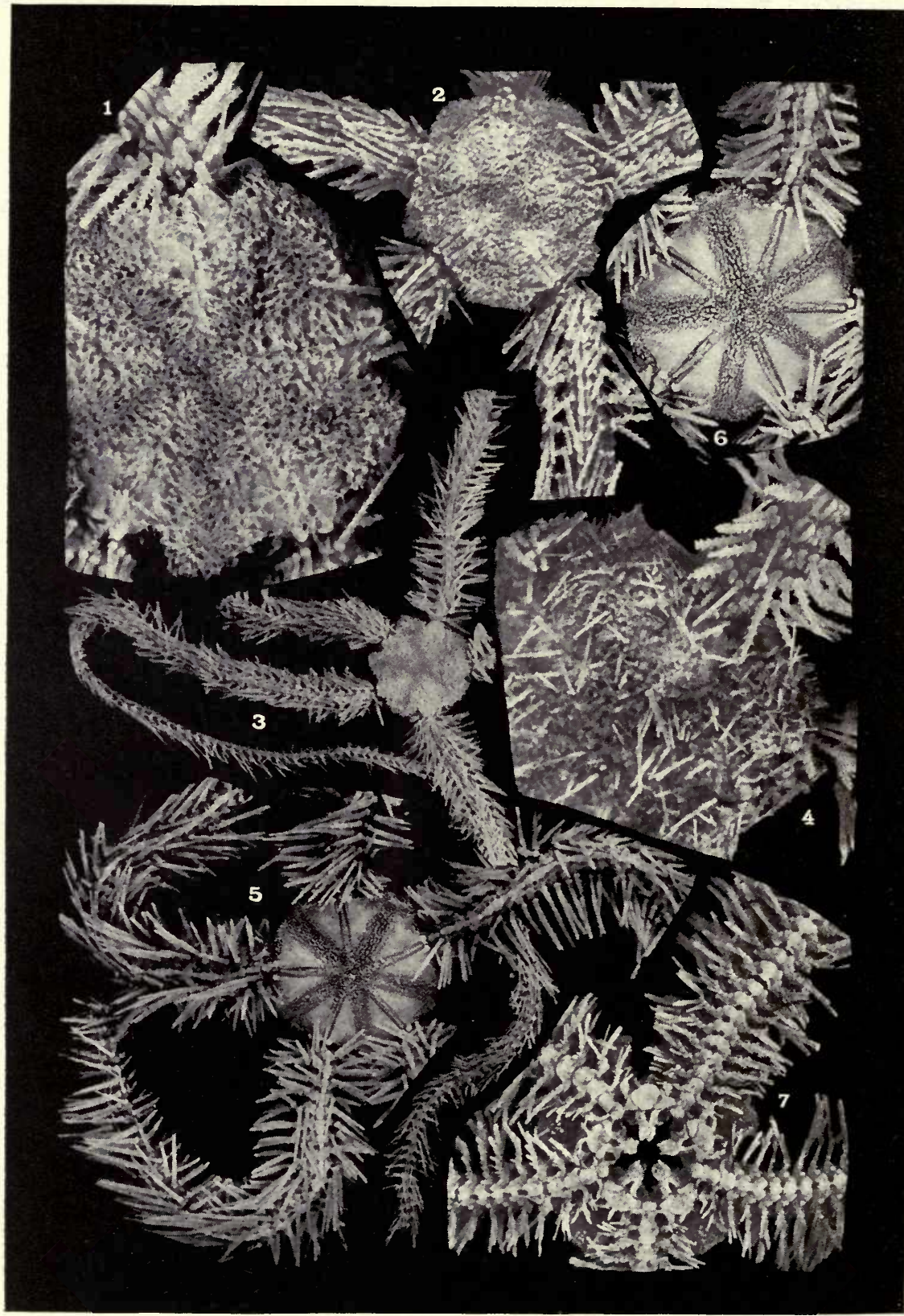

Ophiurans of the Philippine Seas and adjacent Waters.

FoR EXPLANATION OF PLATE SEE PAGE 463. 


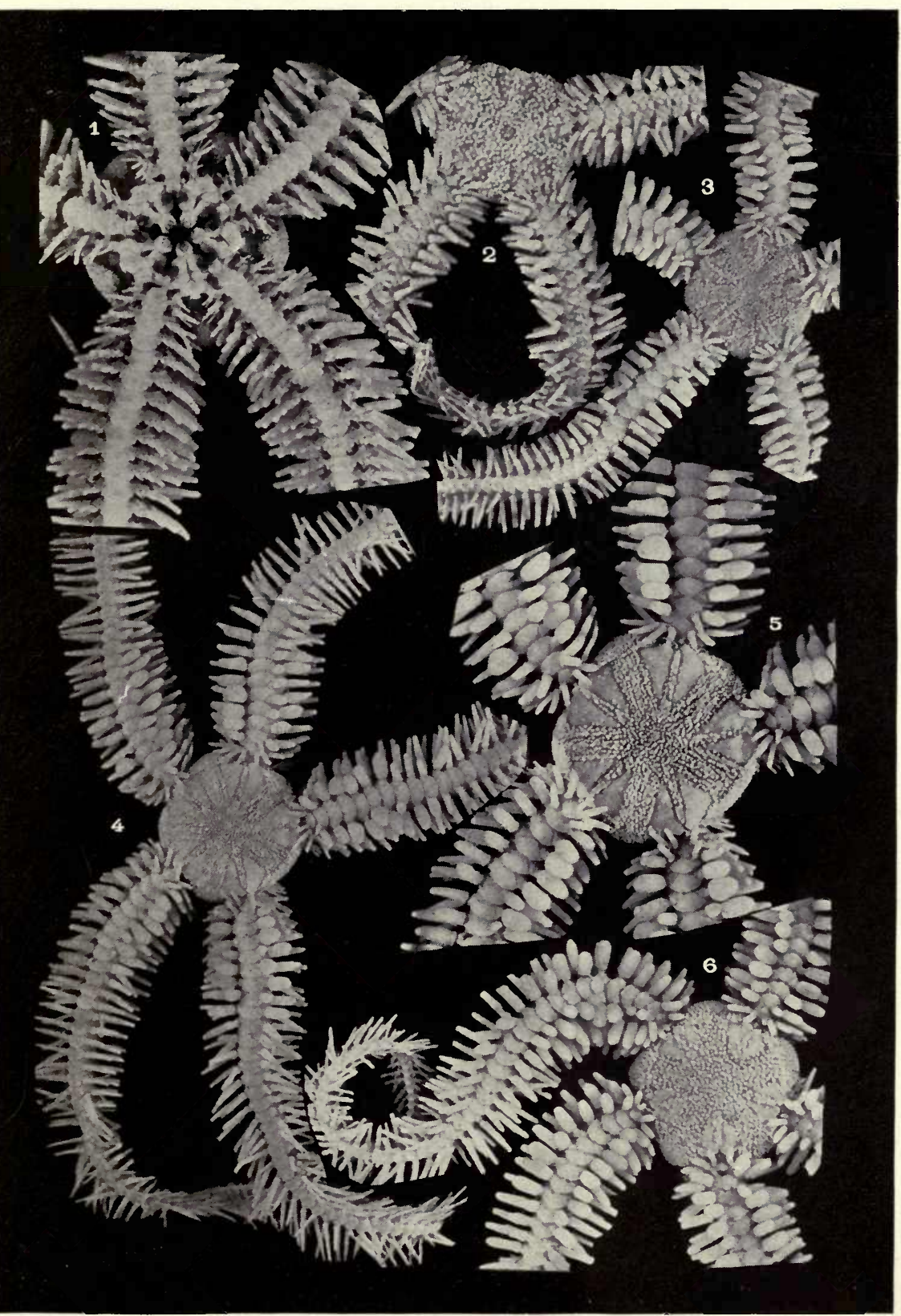

Ophiurans of the Philippine Seas and Adjacent Waters. For EXPLANATION OF PLATE SEe PAgE 463. 


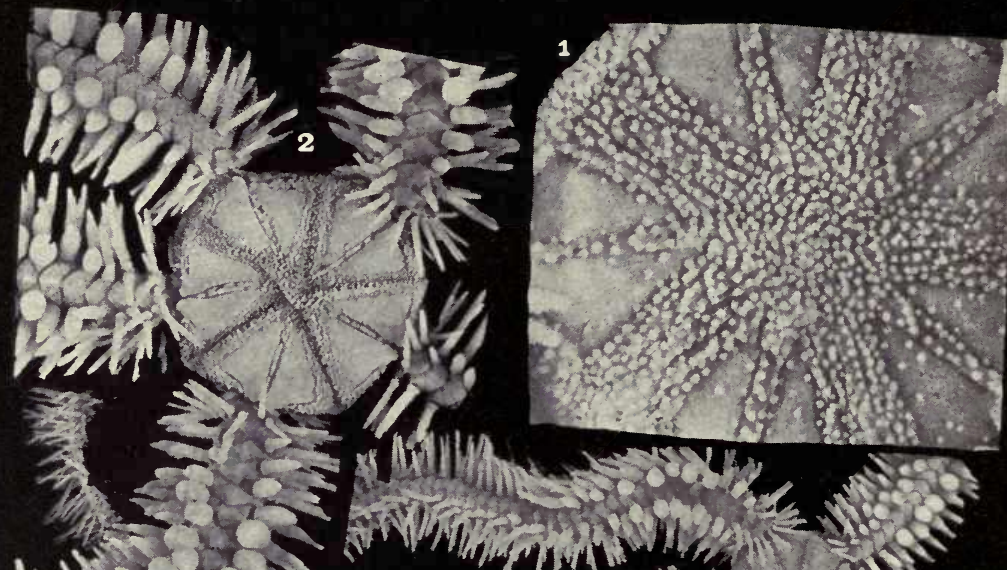

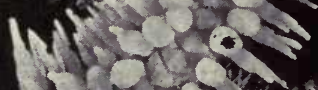

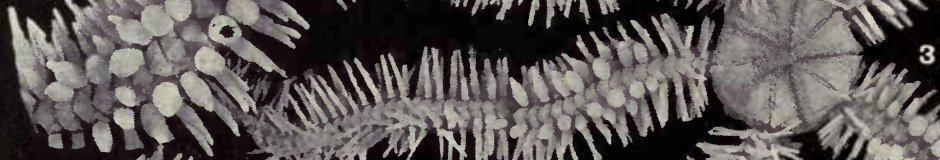

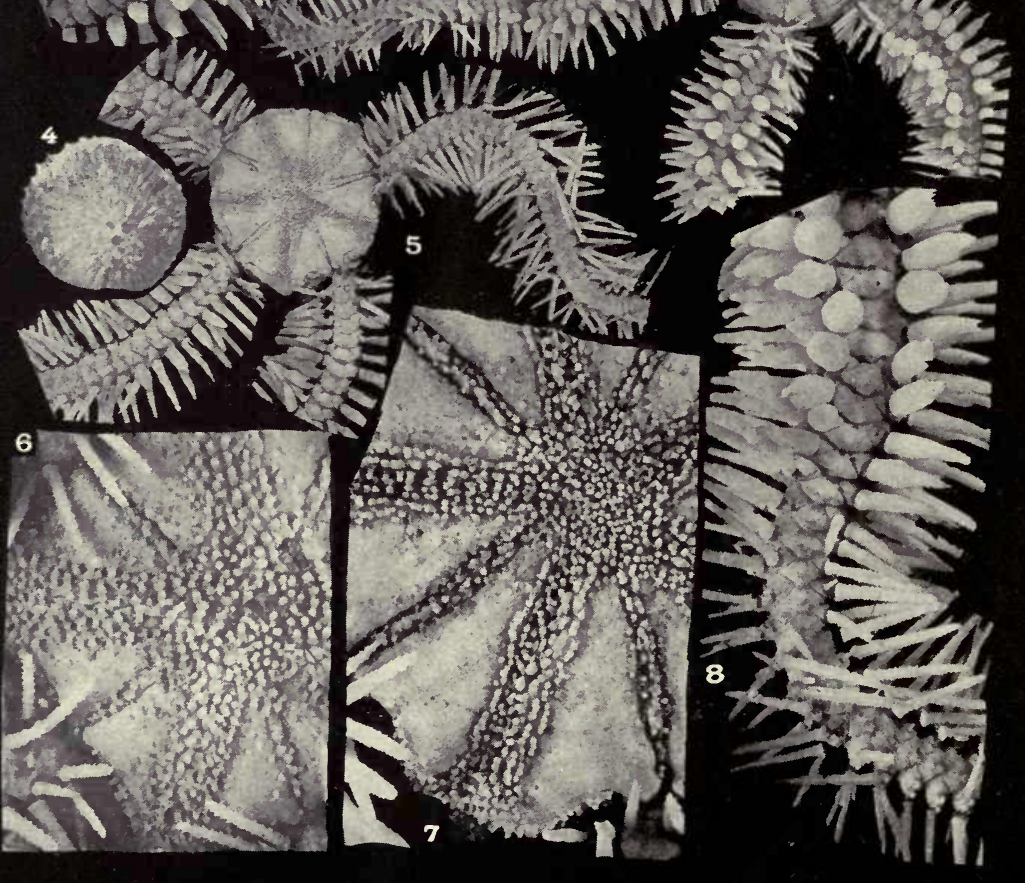

Ophiurans of the Philippine Seas and Adjacent Waters

For EXPLANATION OF PLATE SEE PAgE 463 


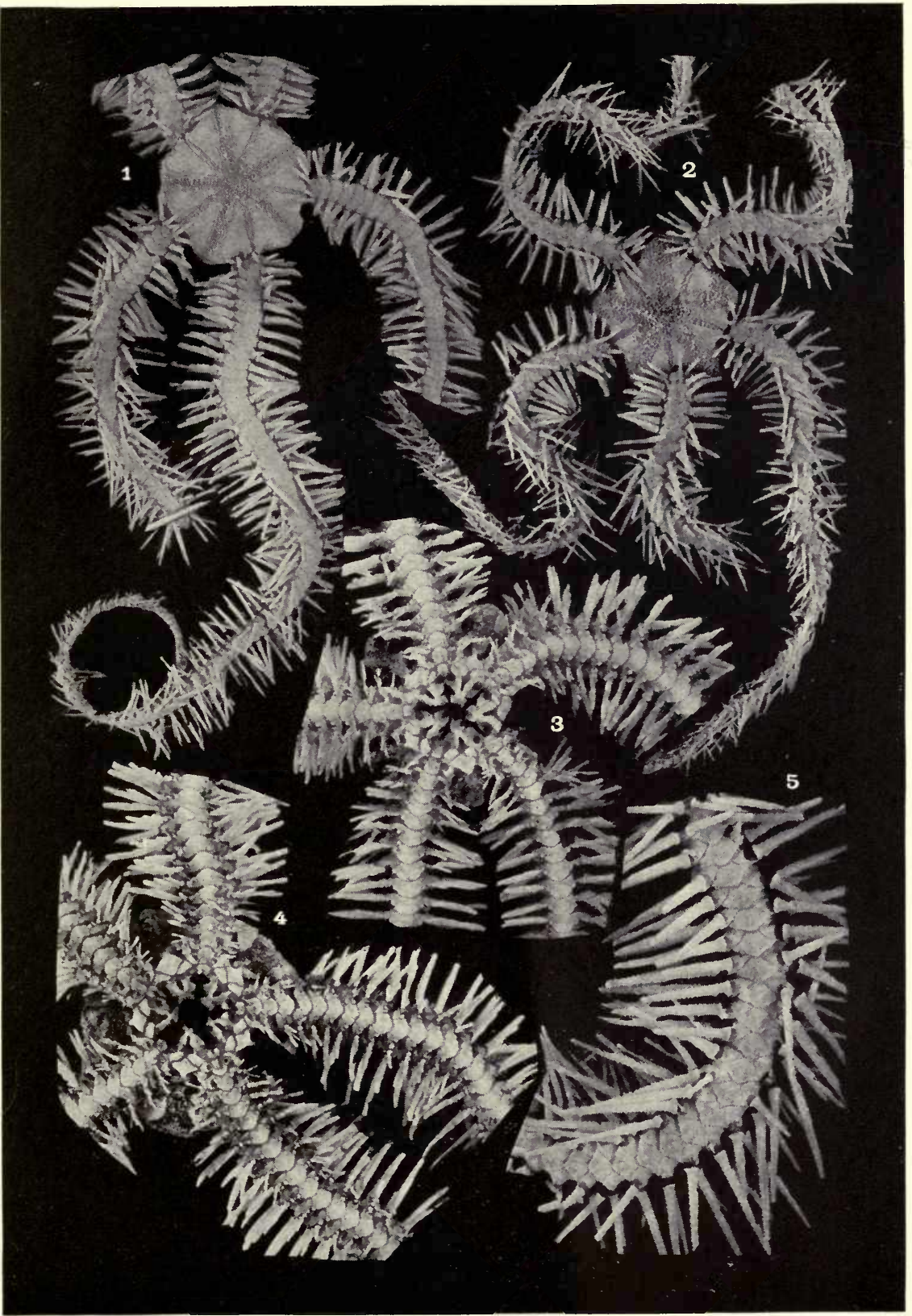

Ophiurans of the Philippine Seas and Adjacent Waters.

For explanation of plate see page 463. 


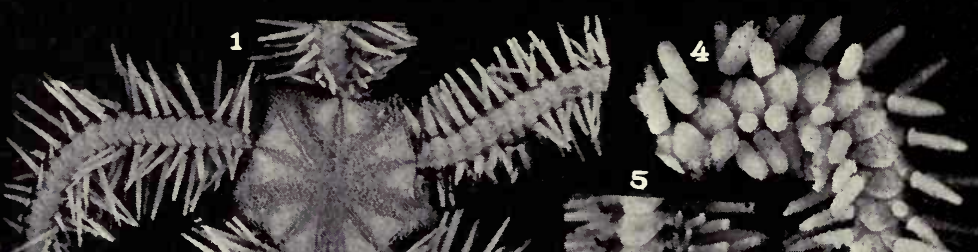

and

$1 \times=$

Tru

Wis.

S.:

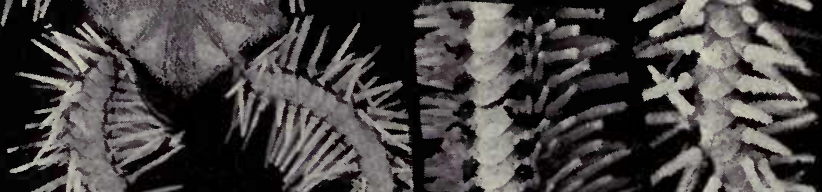

2

2.) $\rightleftharpoons$

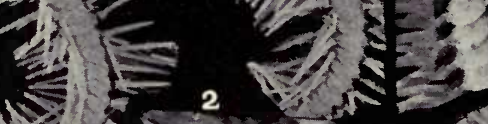

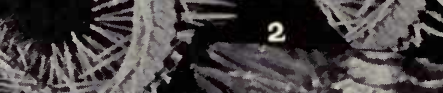

3
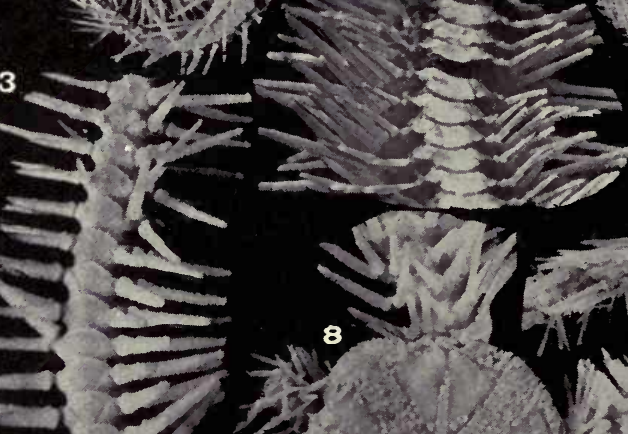

- ildith

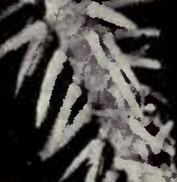
ivit

bis?

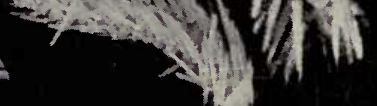

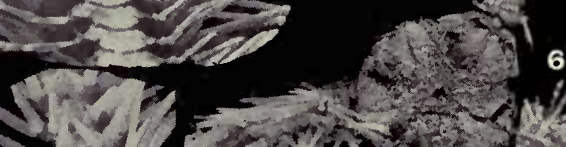

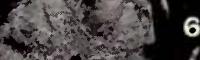

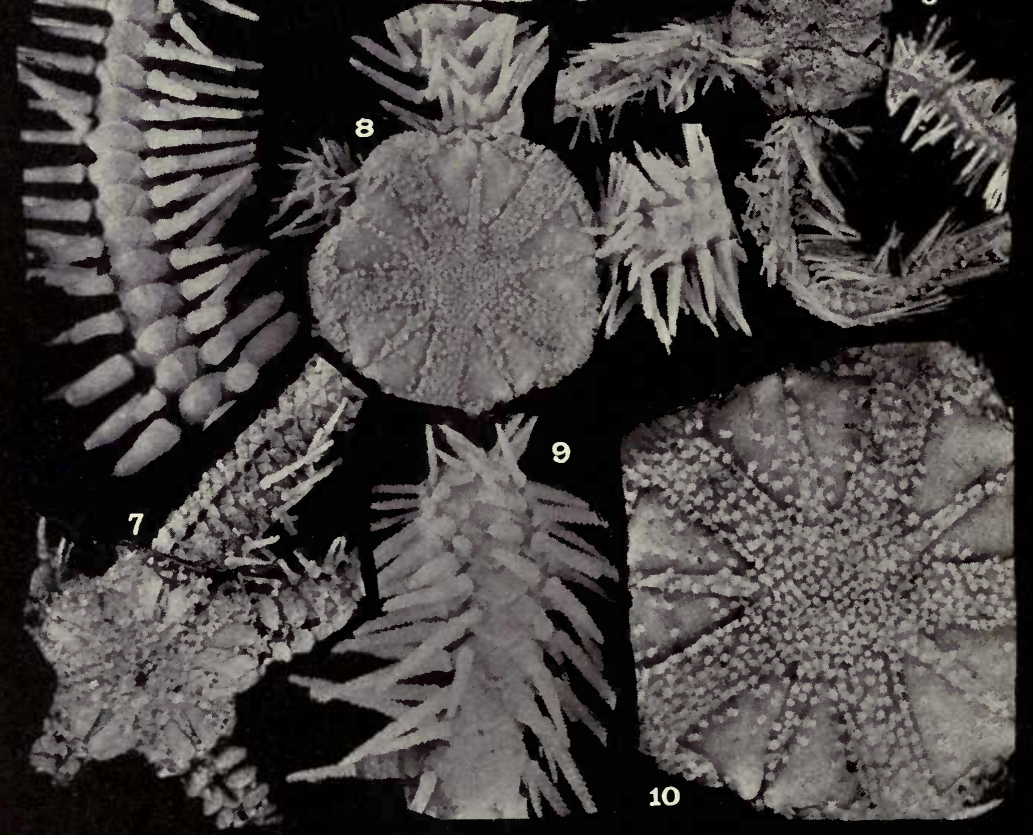

Ophiurans of the Philippine seas and adjacent Waters. 


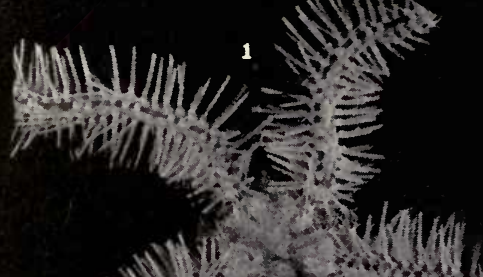

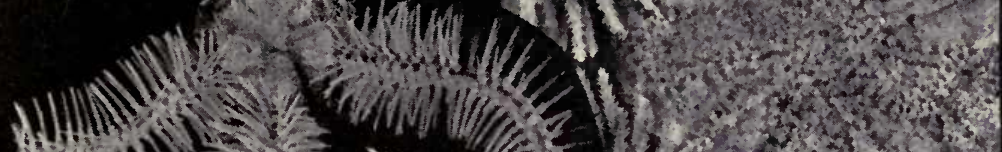

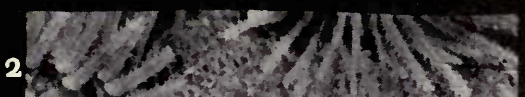

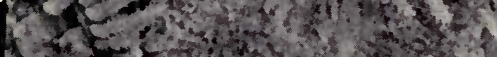

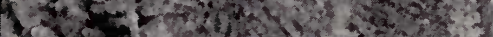

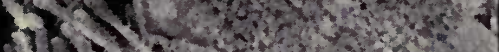

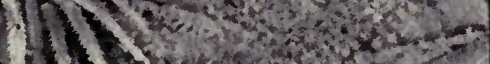

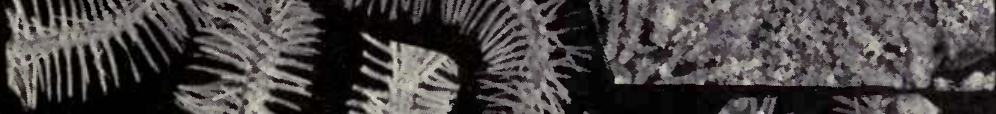

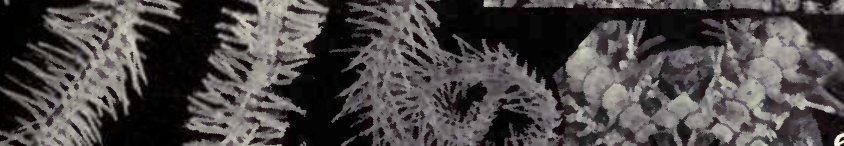

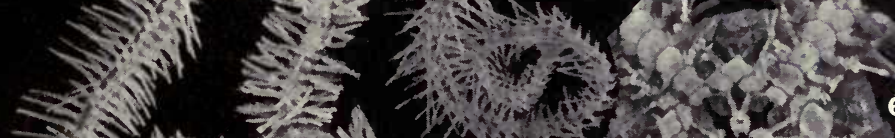

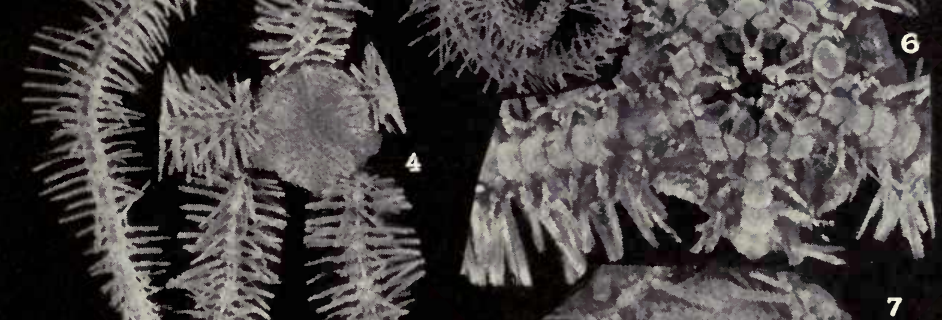

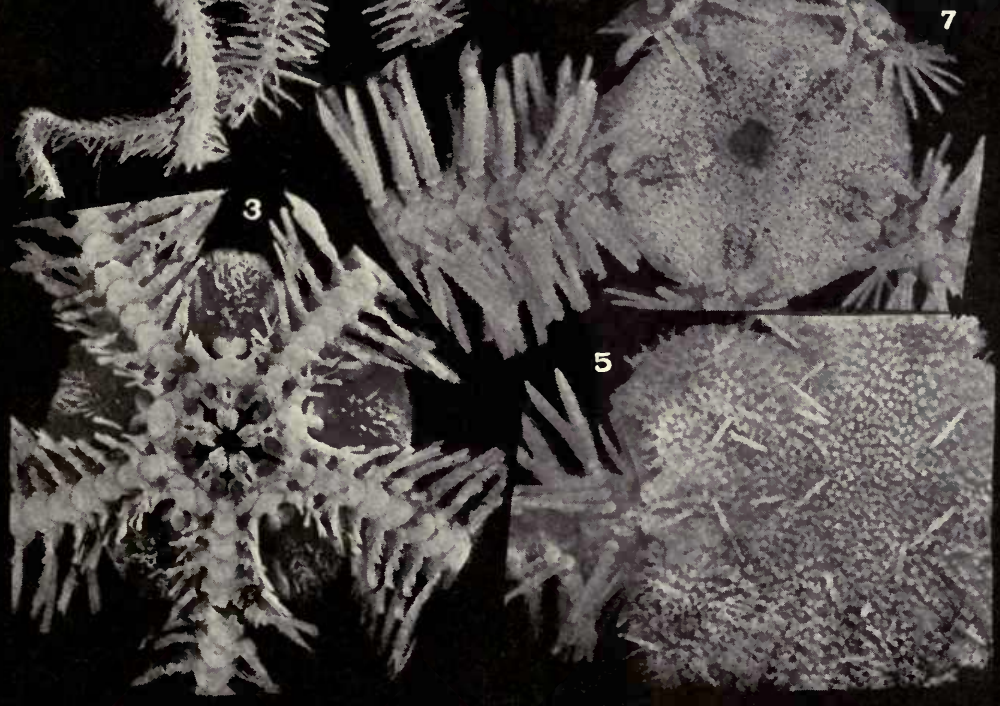

Ophiurans of the Philippine Seas and Adjacent Waters.

For explanation of plate see page 464. 

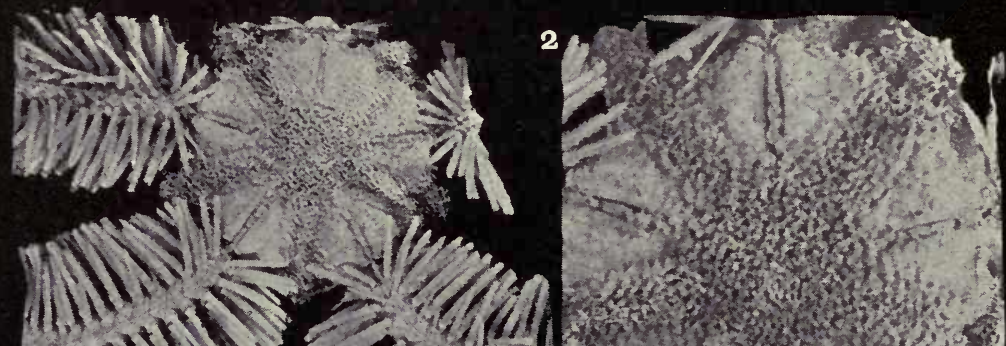

minuming

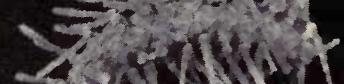

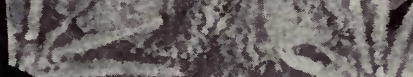

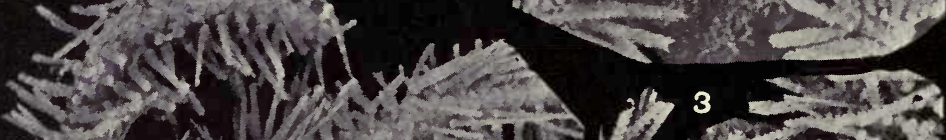

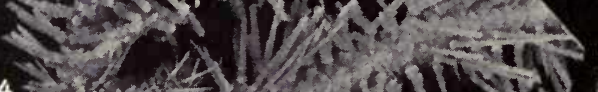

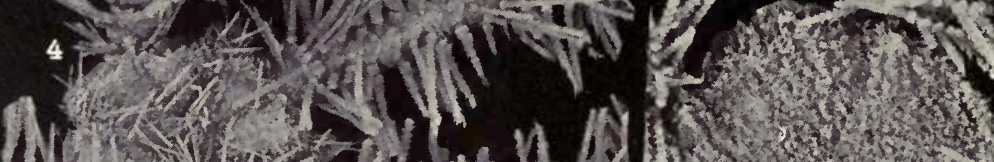
H. W.

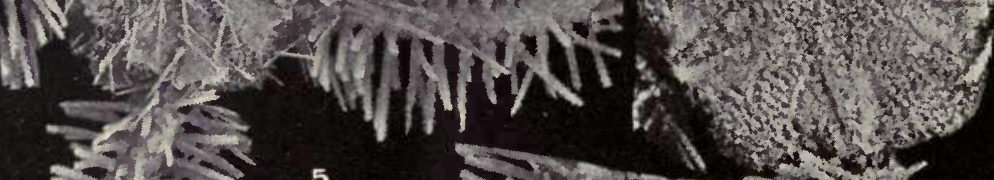

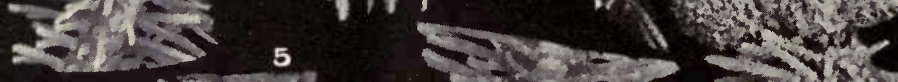

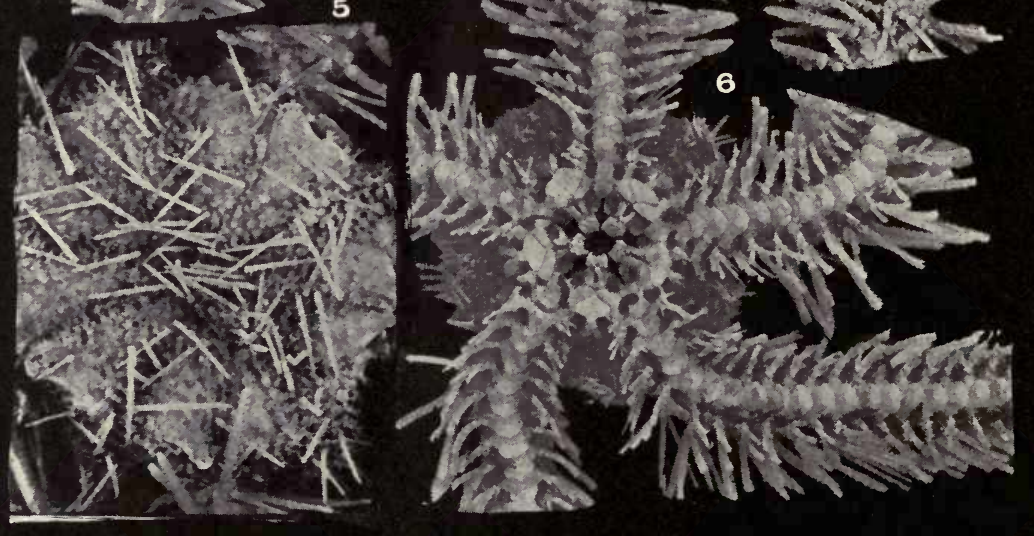

Ophiurans of the Philippine Seas and adjacent Waters.

For explanation of plate see page 464 


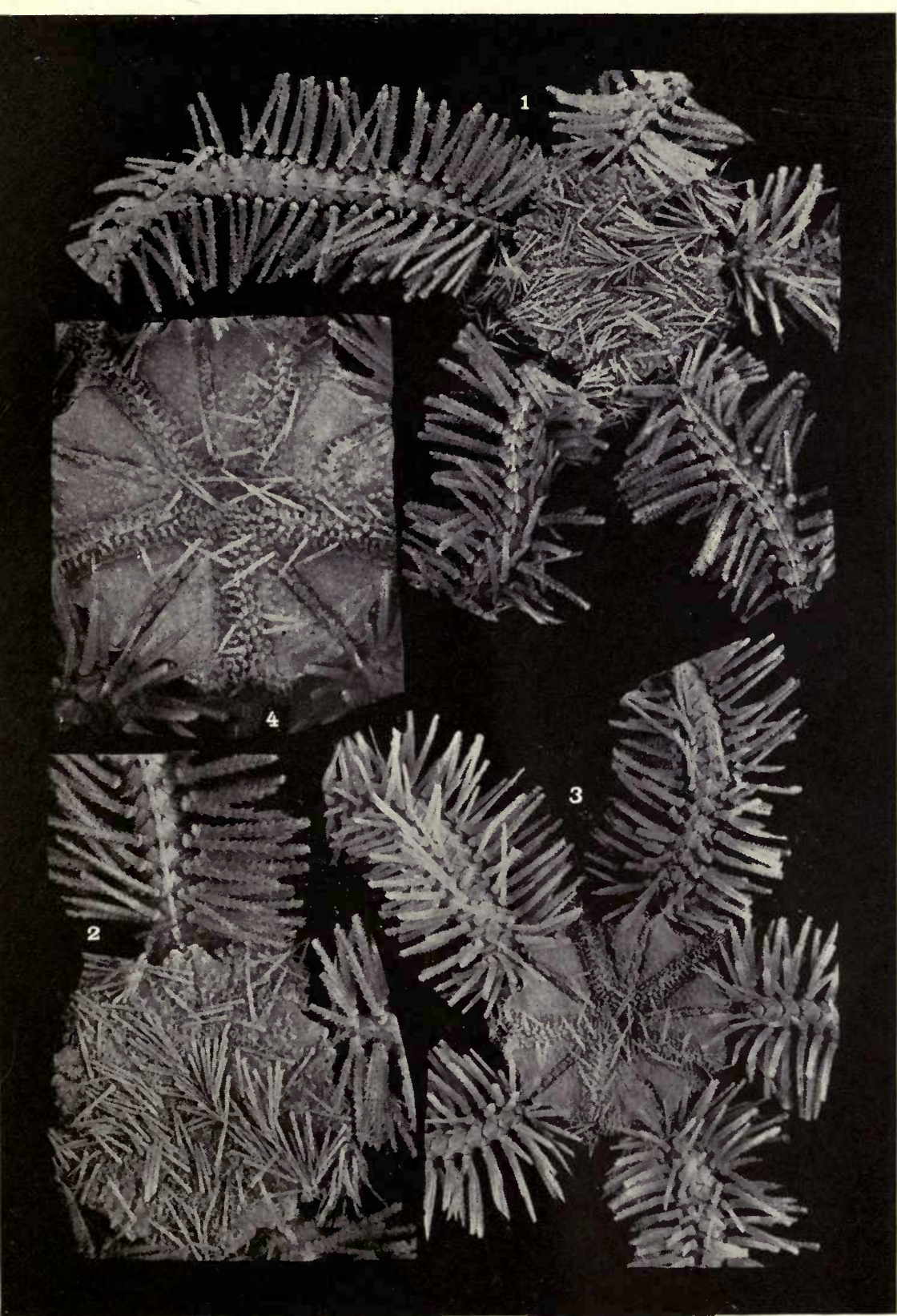

Ophiurans of the Philippine Seas and Adjacent Waters.

For EXPLANAT:ON OF PLATE SEE PAgE 464. 


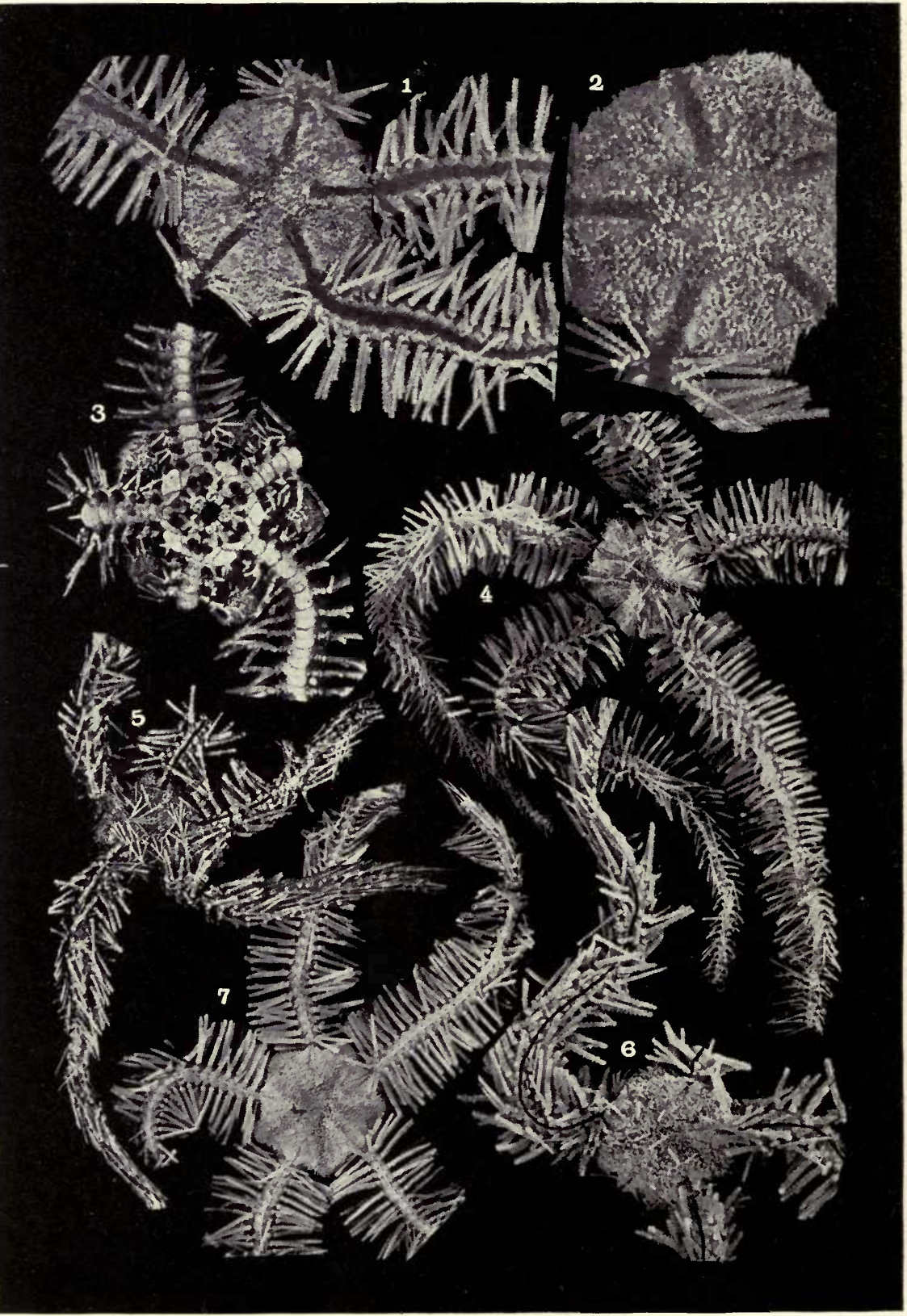

Ophiurans of the Philippine Seas and Adjacent Waters.

For EXPLANATION of PLATE SEe PAge 464. 


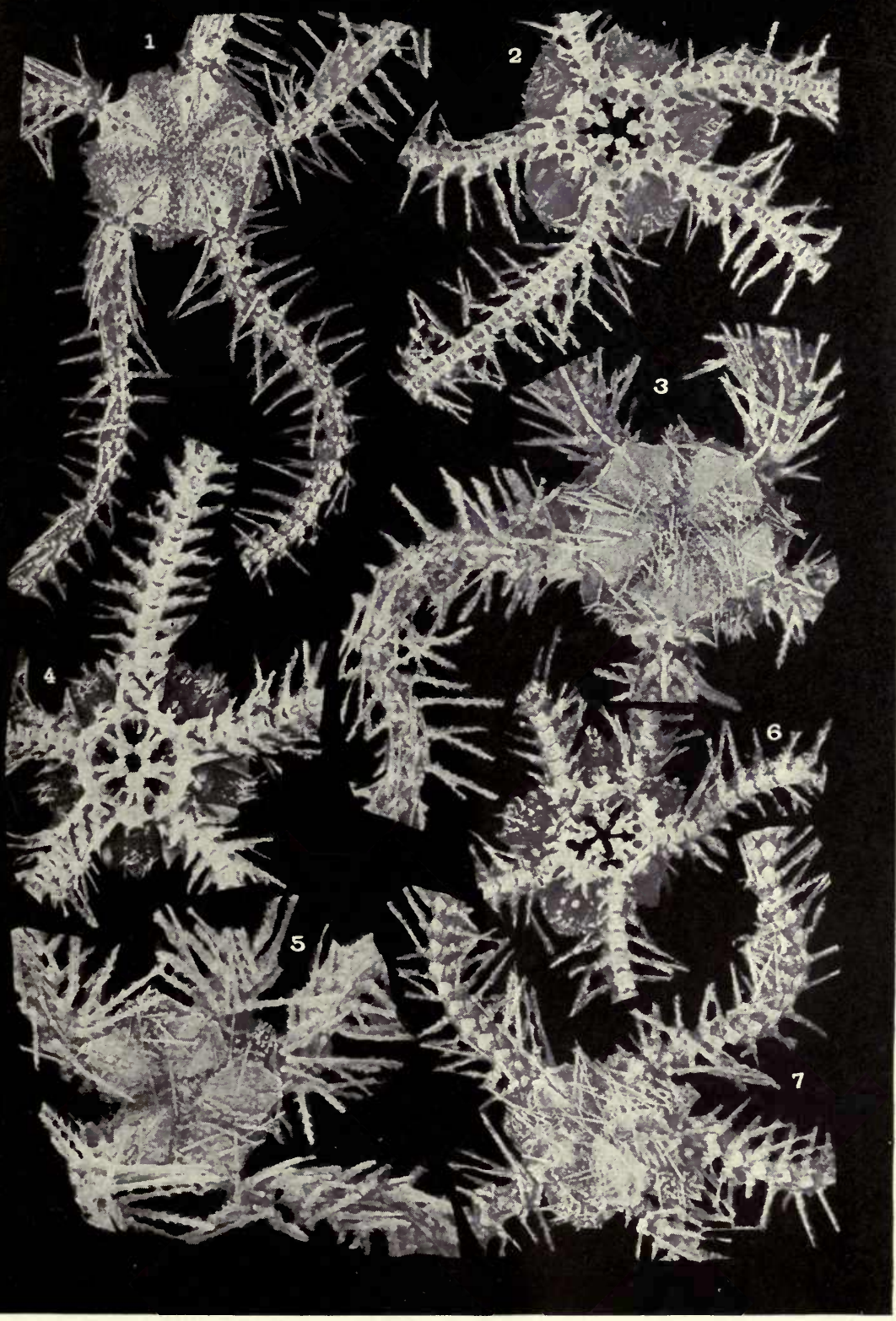

Ophiurans of the Philippine Seas and adjacent Waters.

For explanation of PLATE SEe Page 464. 


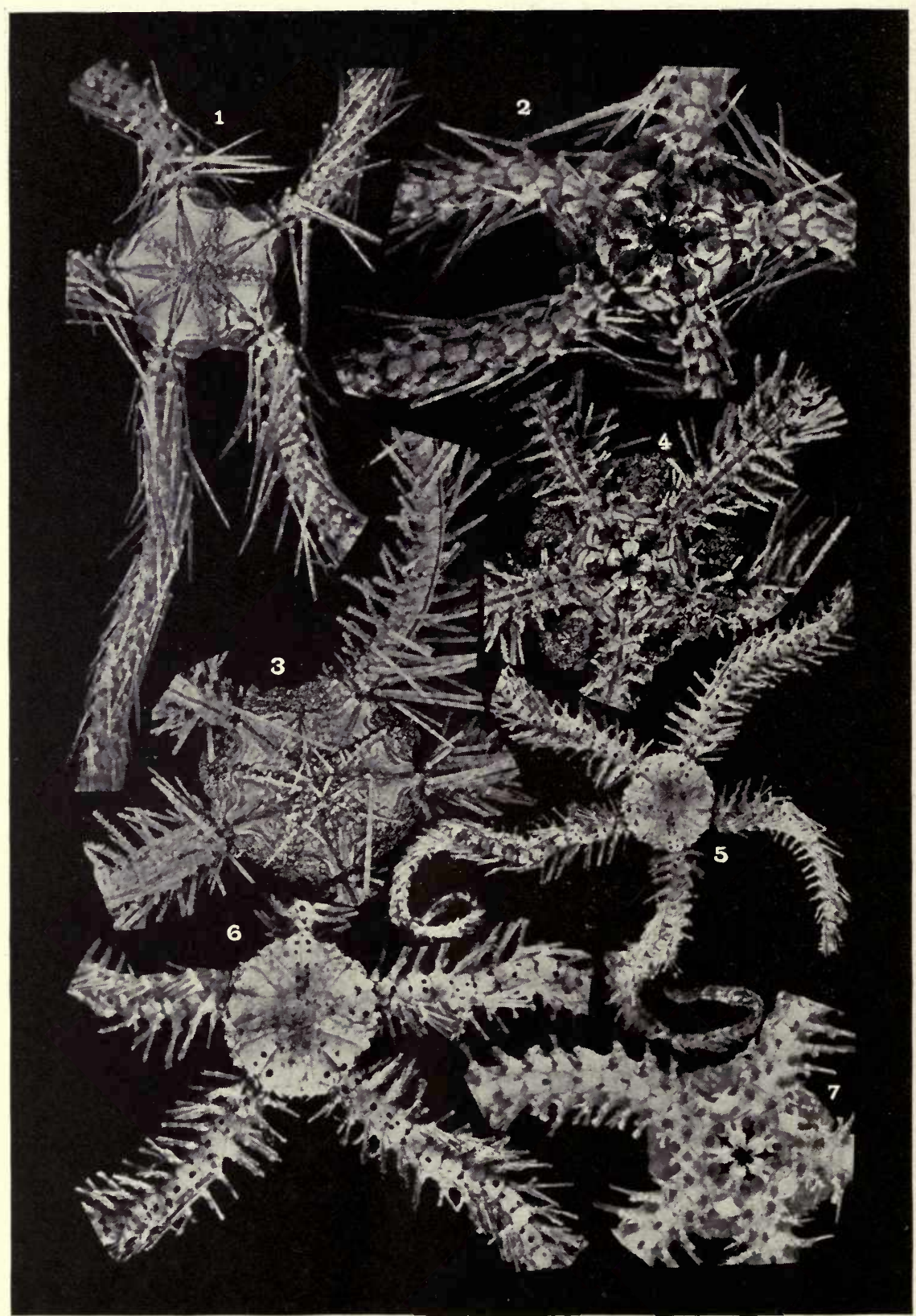

Ophiurans of the Philippine Seas and adjacent Waters. 


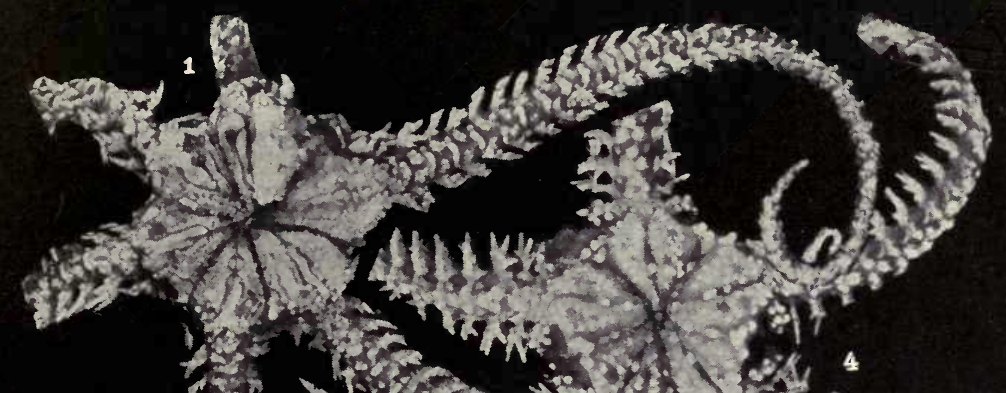

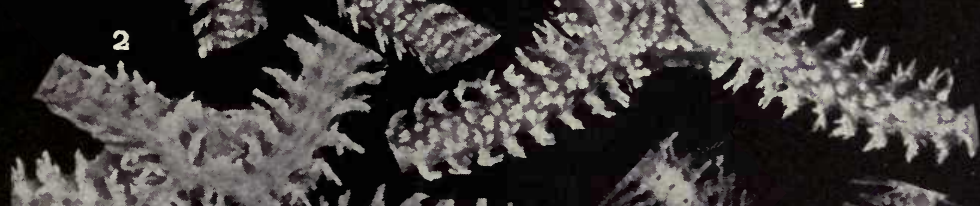

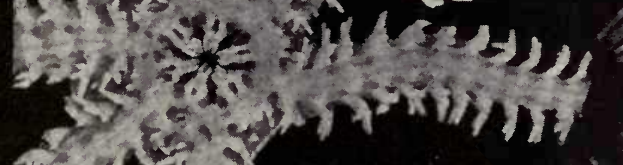

\section{(c)} Nit?

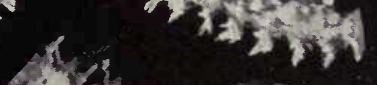

$20, \frac{10}{6}$

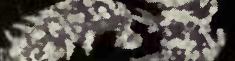
I.

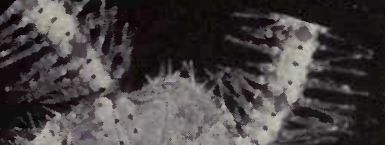

E. $x$ int

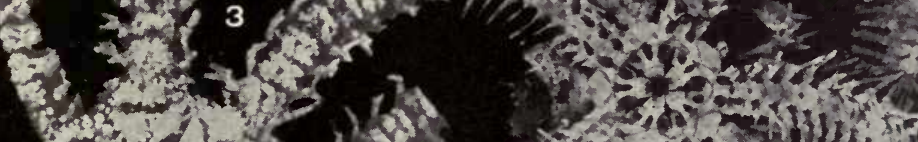

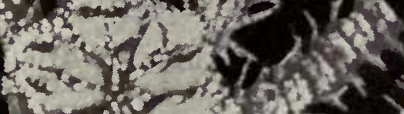

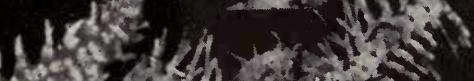

5 in $>$ int ios 5

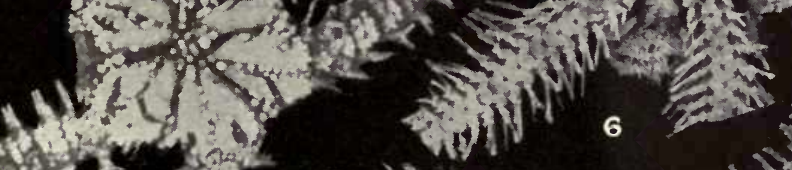

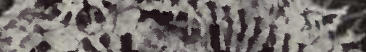

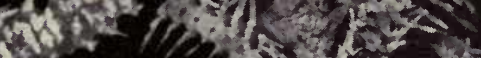

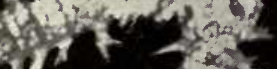

$$
\text { 礁 }
$$




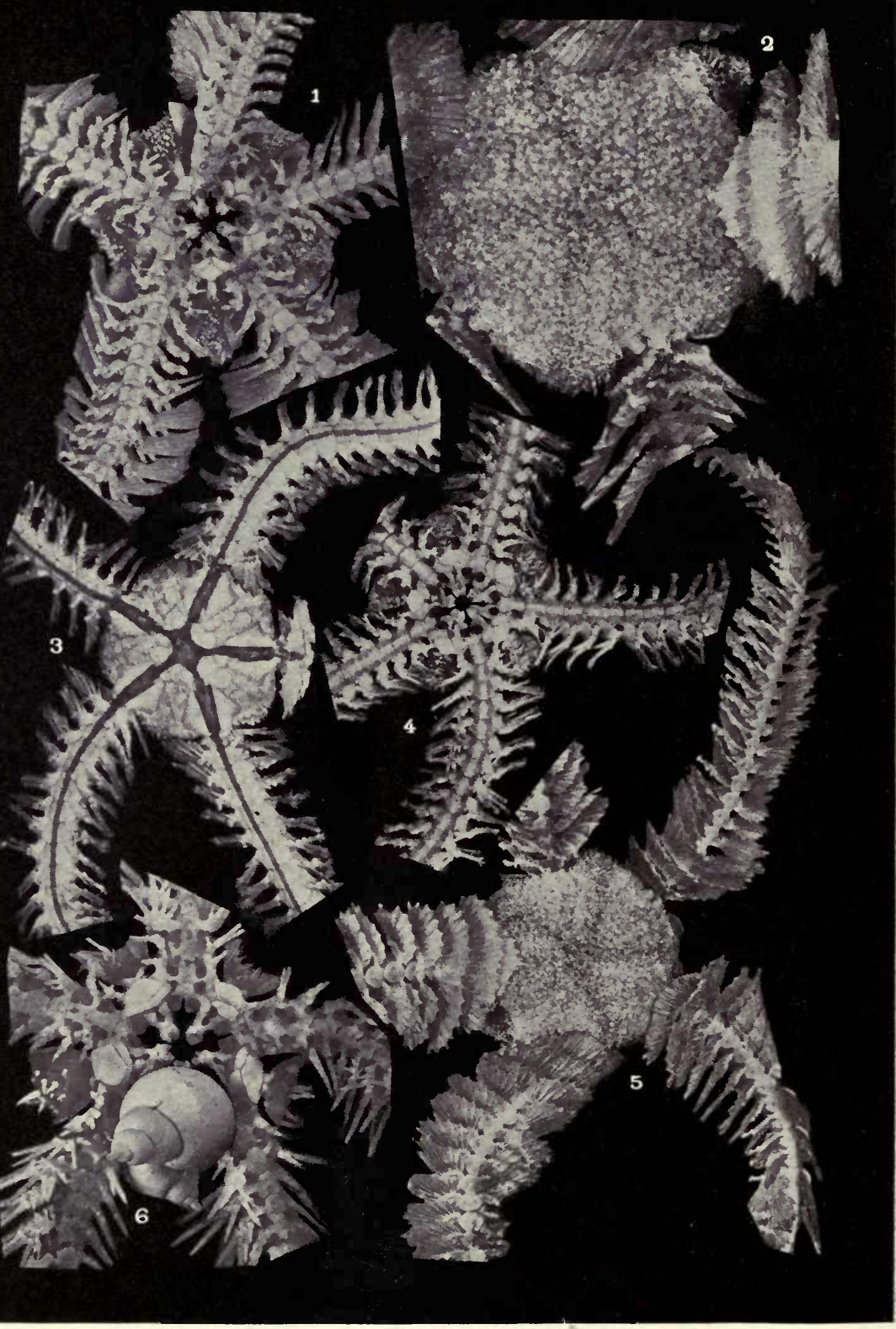

Ophiurans of the Philippine Seas and Adjacent Waters. 


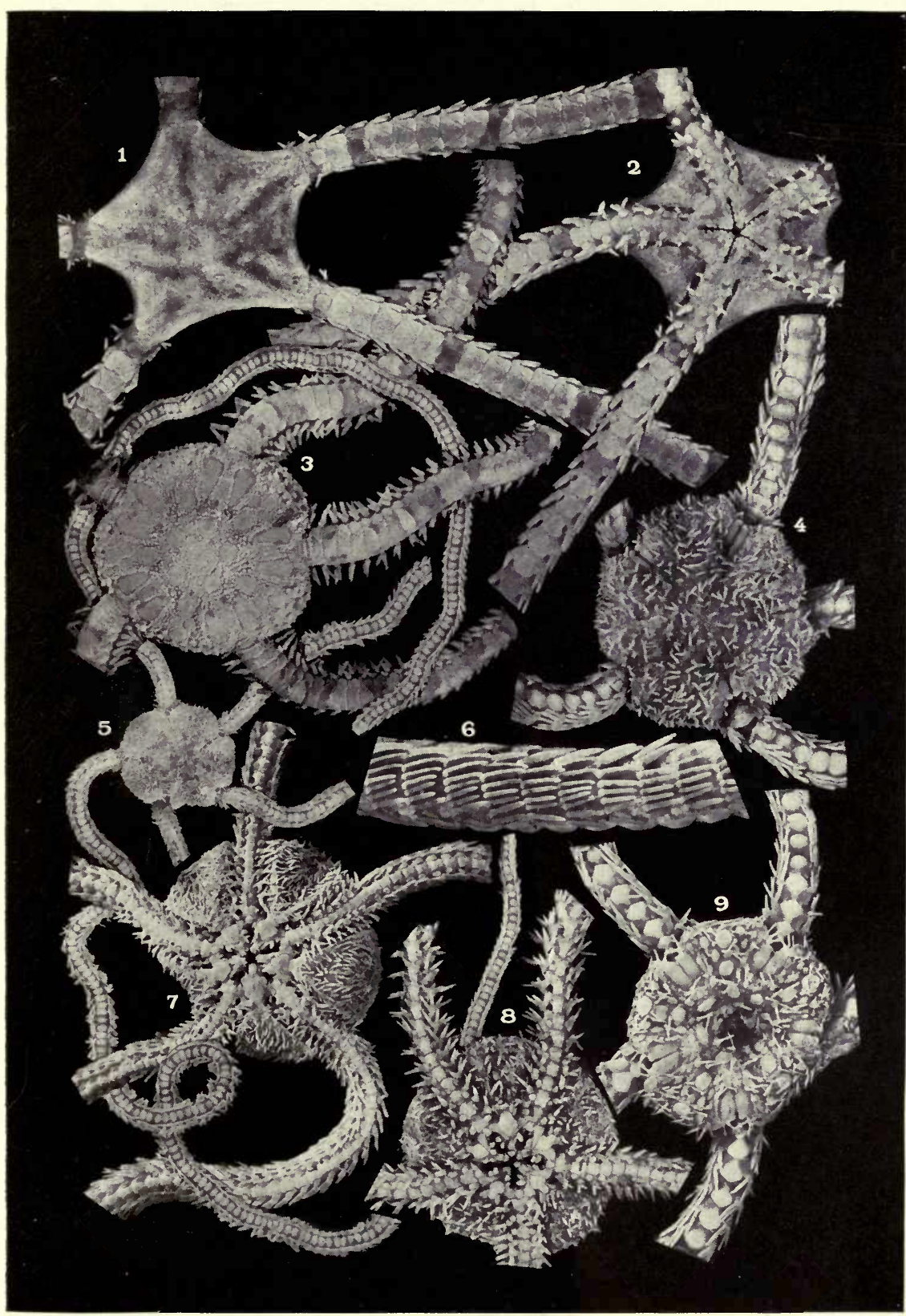

Ophiurans of the Philippine Seas and adjacent Waters.

For EXPLANATION OF PLATE SEE PAGE 465 


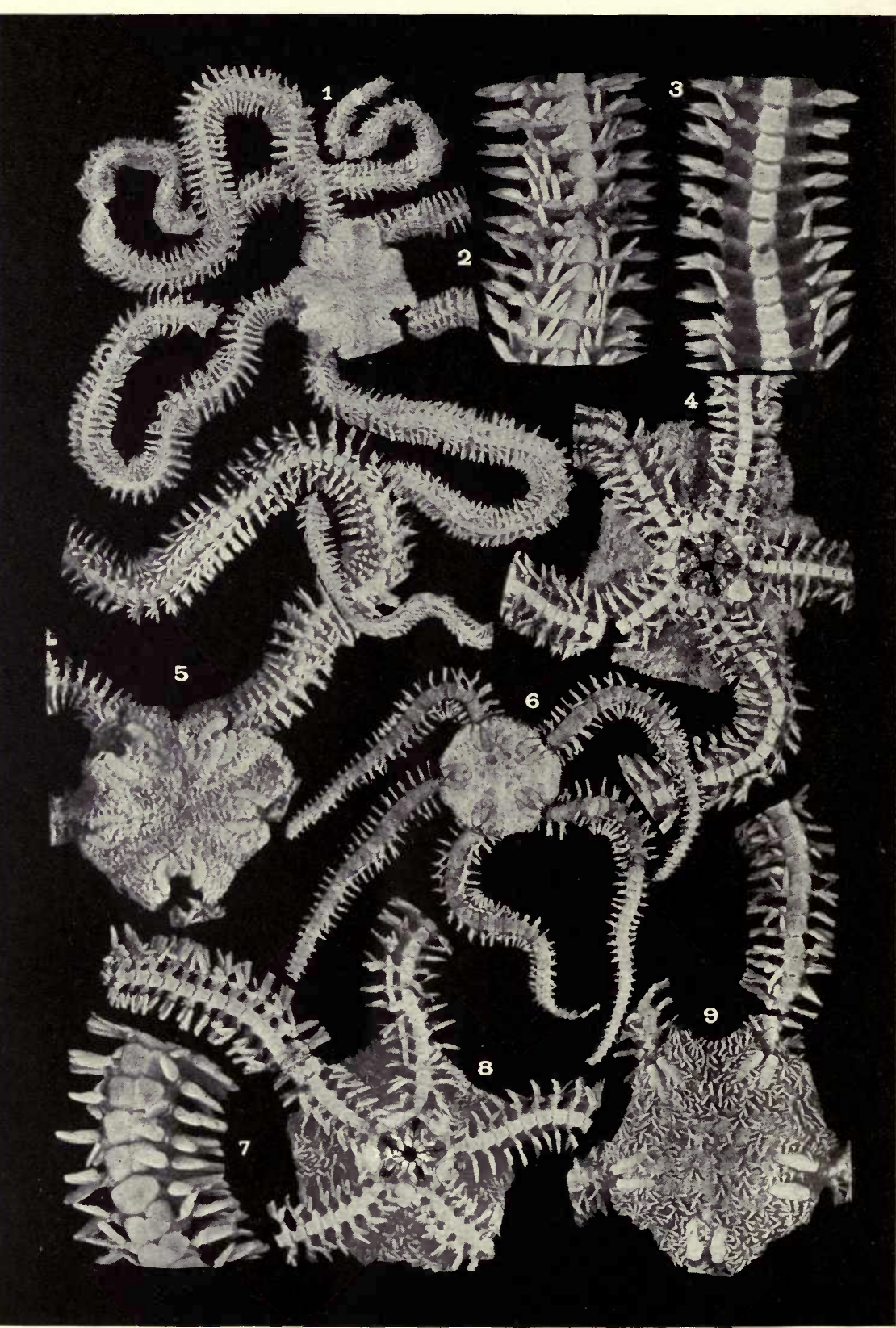

Ophiurans of the Philippine Seas and adjacent Waters. 


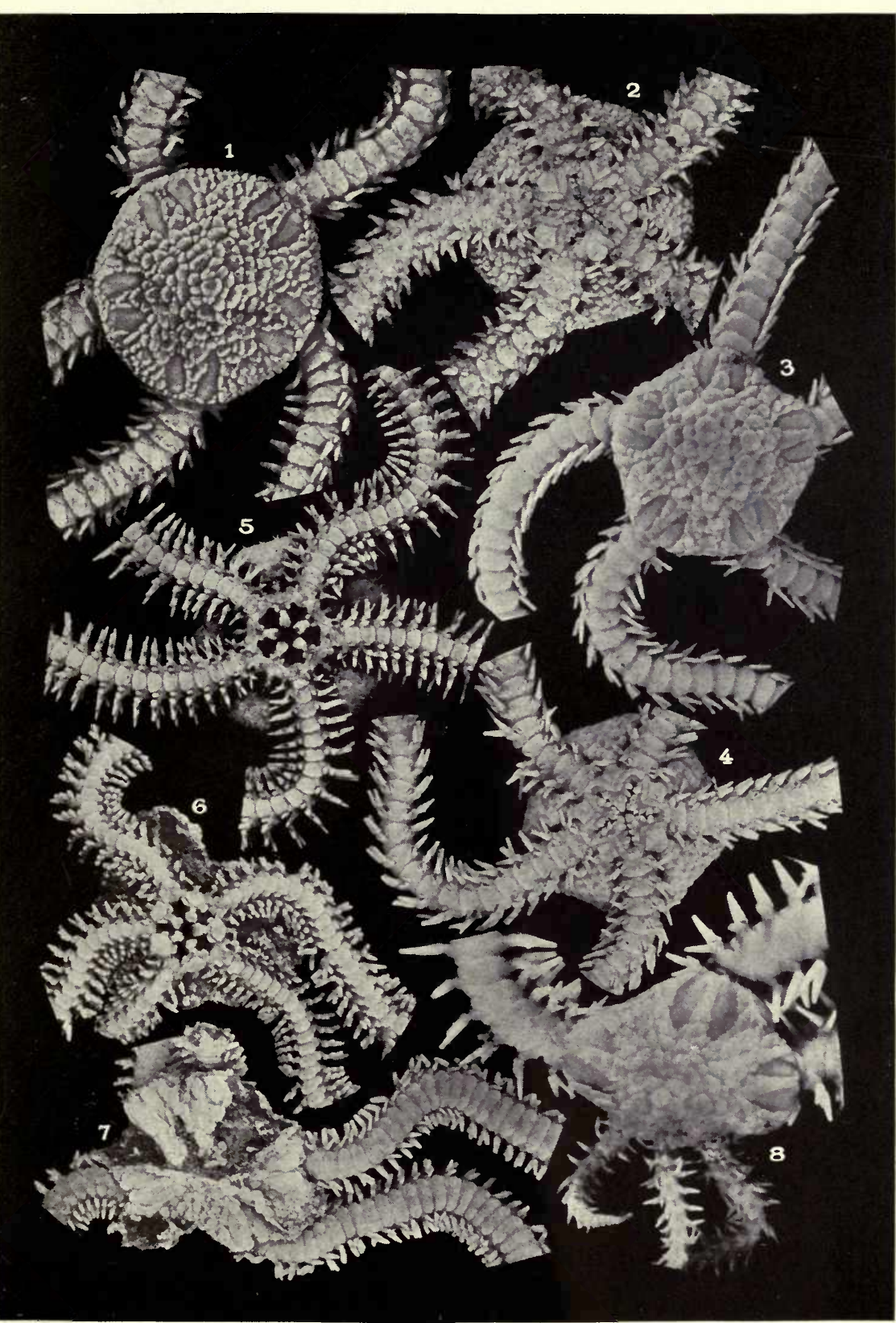

Ophiurans of the Philippine Seas and Adjacent Waters.

For EXPLANATION OF PLATE SEe PAges 486 AND 466 , 


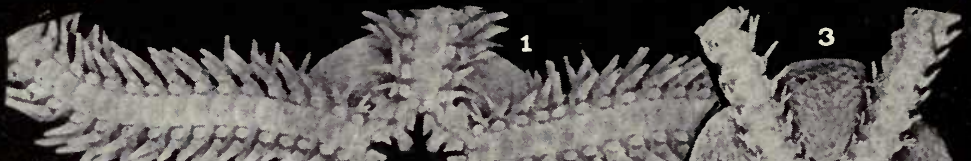

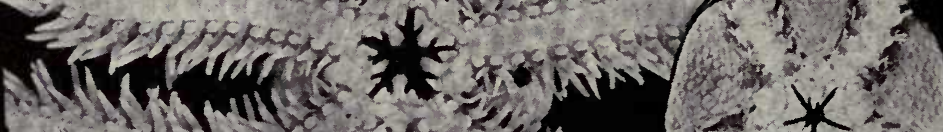

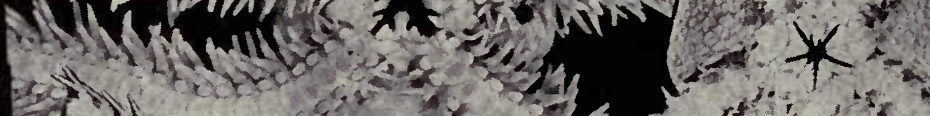

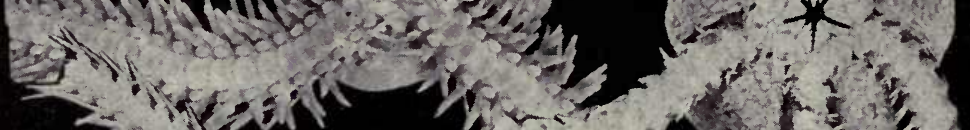

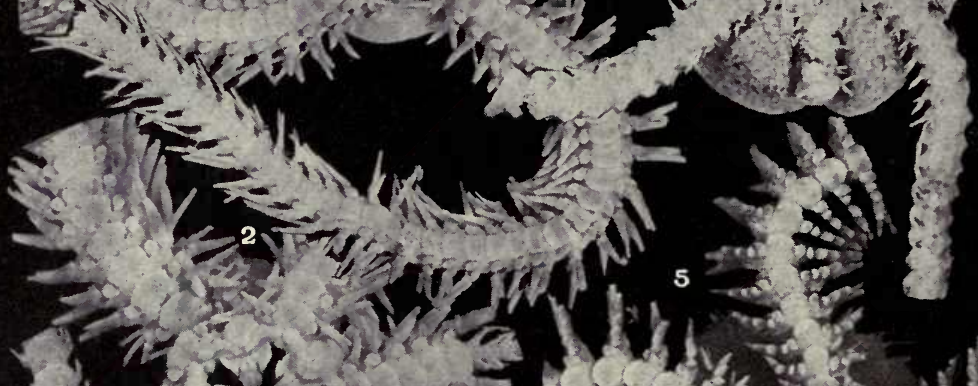

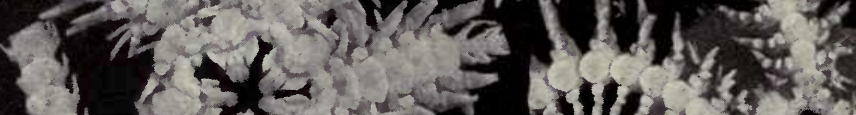

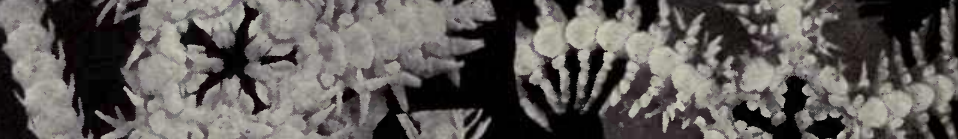
1 2 te $4-21,5$

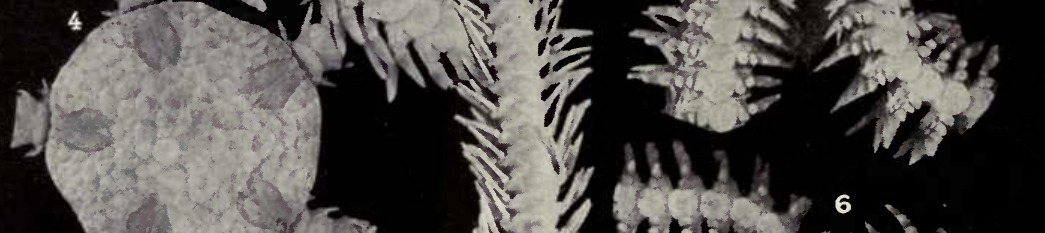

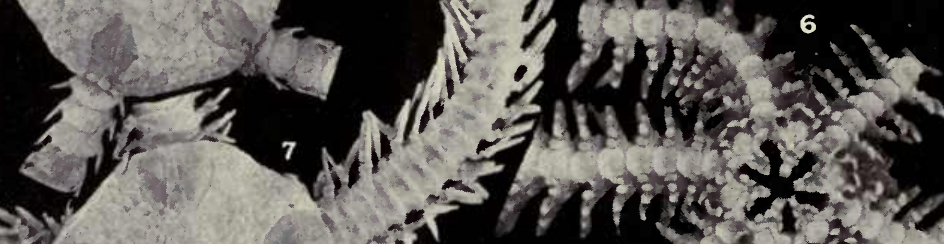

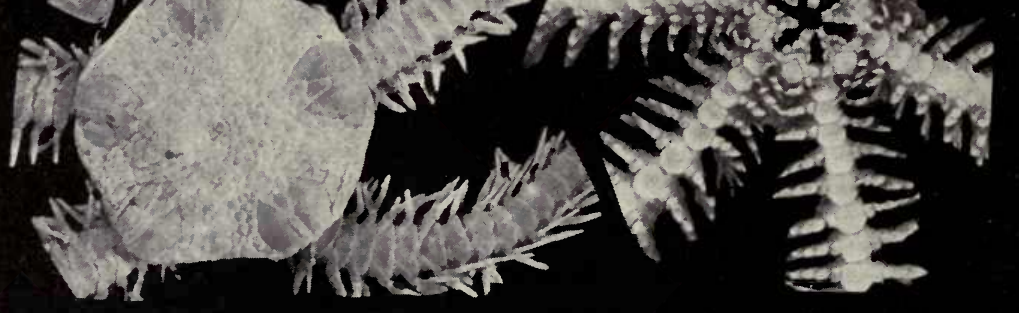
Ophiurans of the Philippine Seas and adjacent Waters For explanation of plate see page 466. 


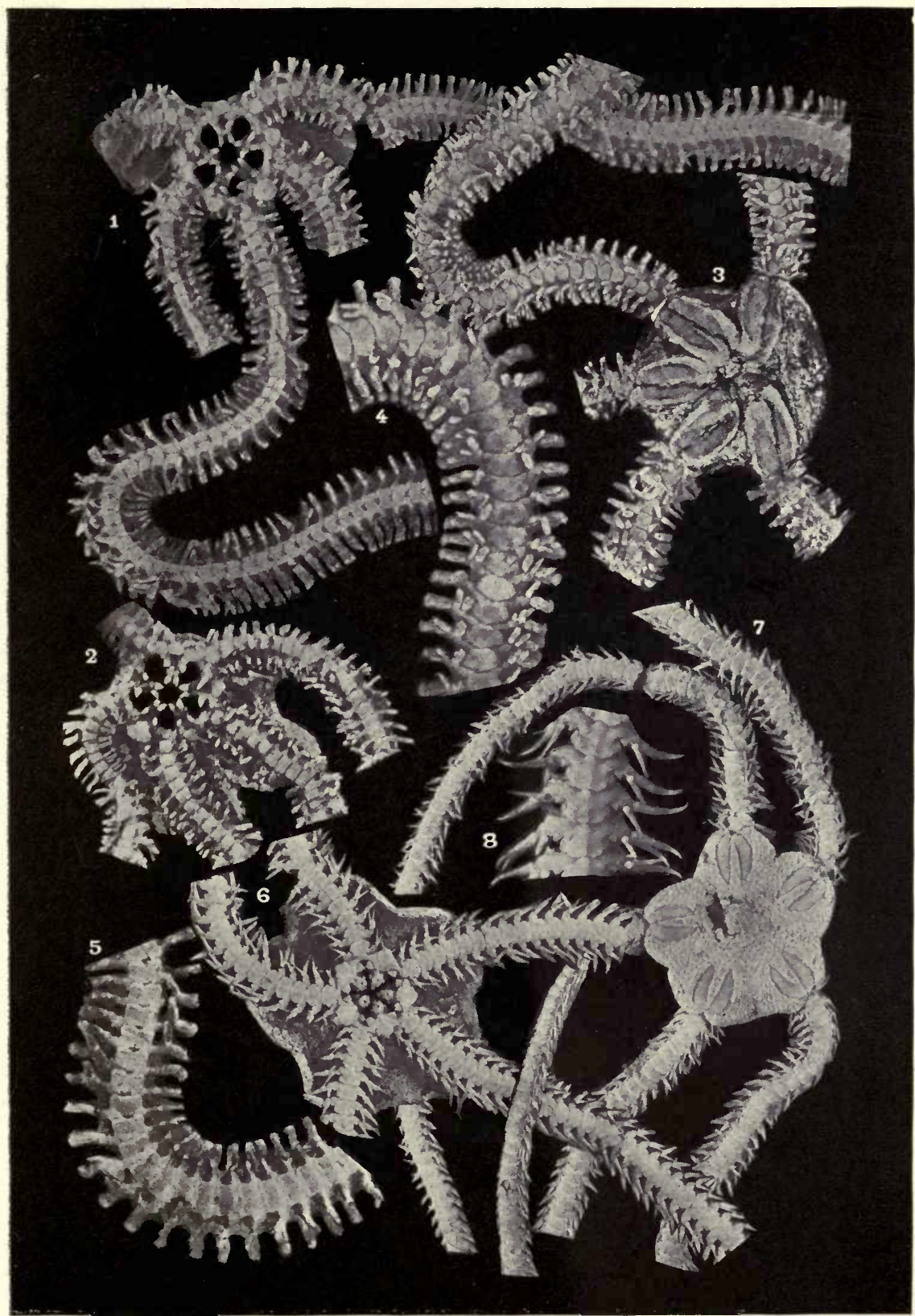

Ophiurans of the Philippine Seas and Adjacent Waters.

For EXPLANATION OF PLATE SEE PAgE 466 


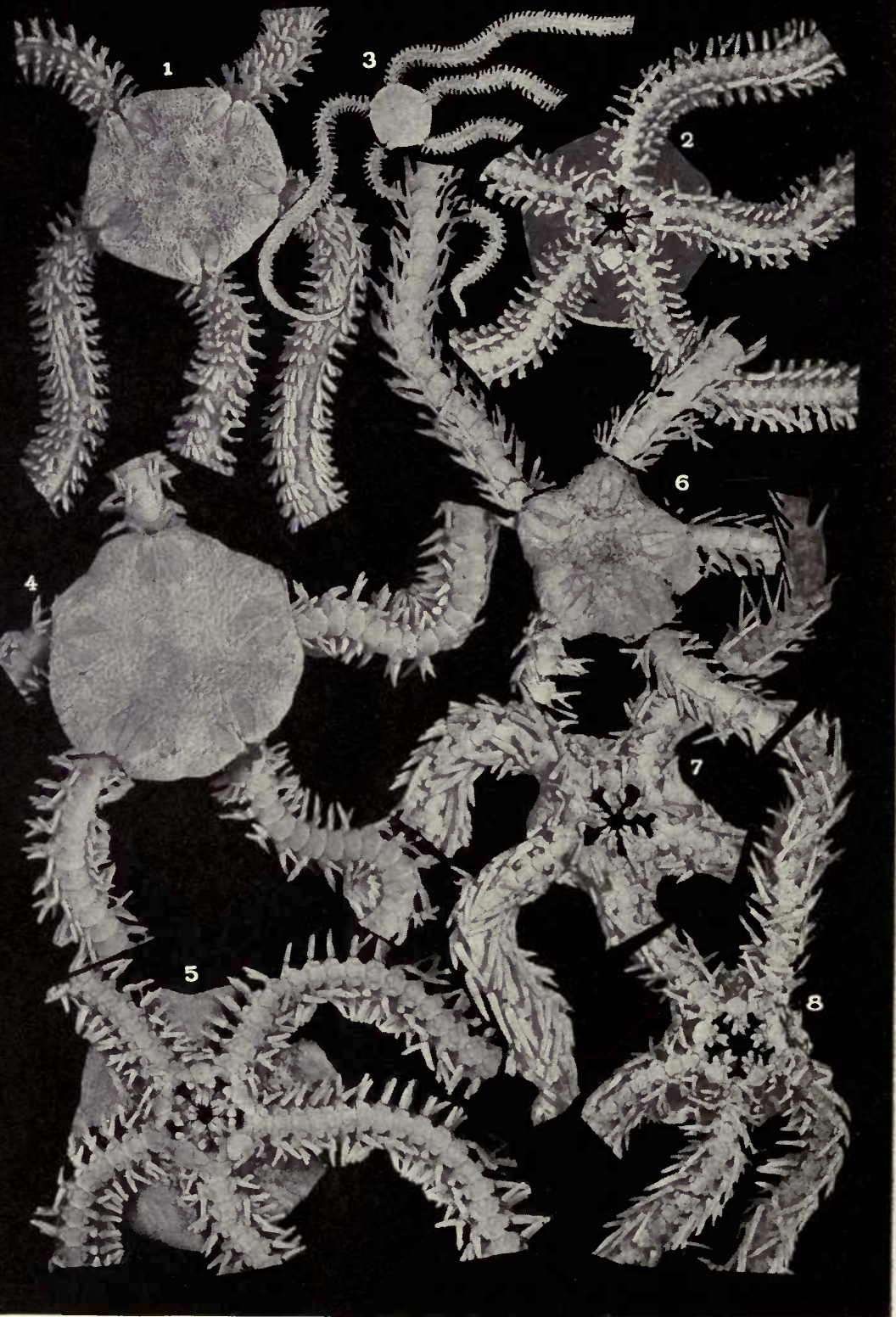

Ophiurans of the Philippine Seas and adjacent Waters.

For explanation of PLATE SEe PAge 468 . 


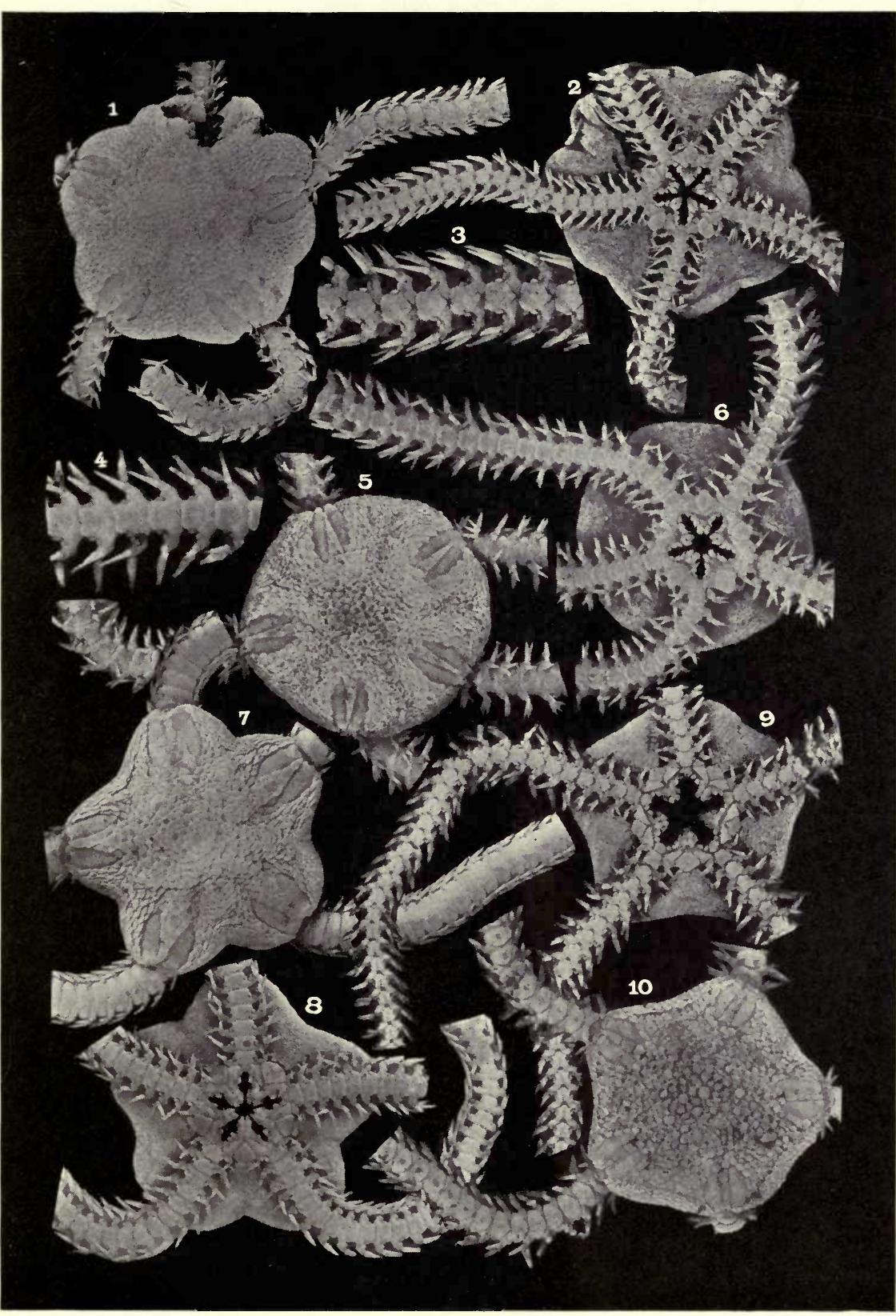

Ophiurans of the Philippine Seas and Adjacent Waters.

for explanation of plate see page 466. 


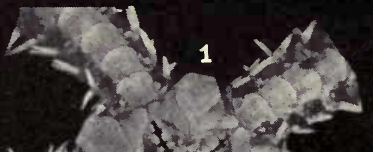

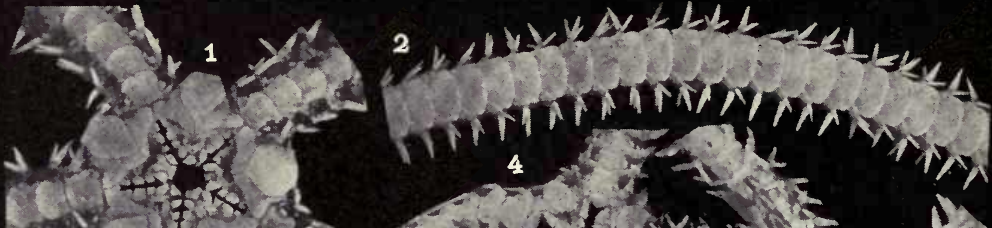

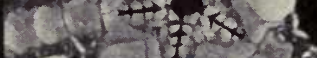

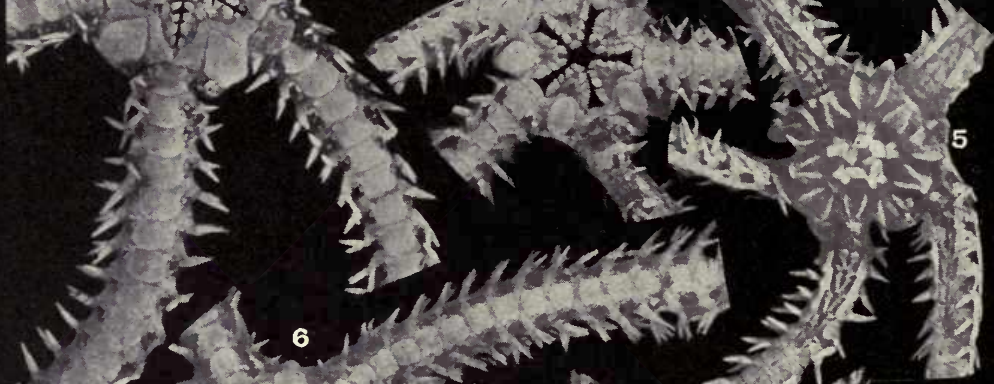

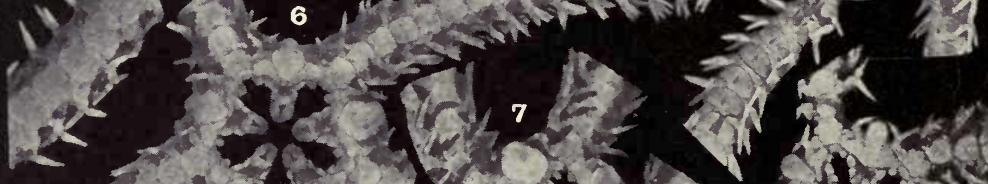

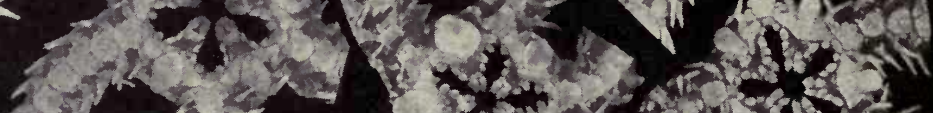

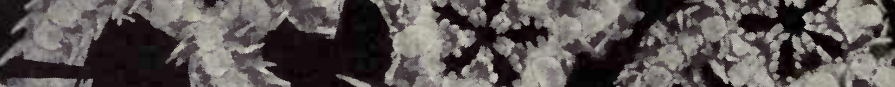

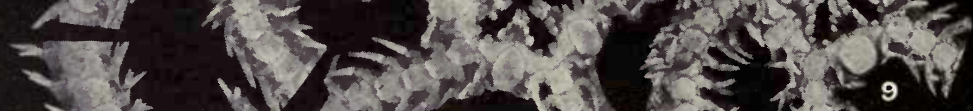

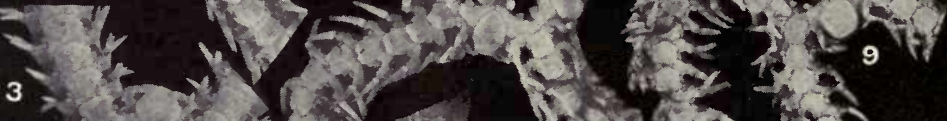

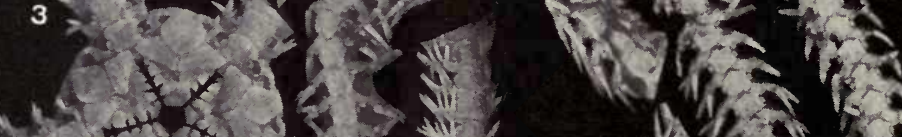

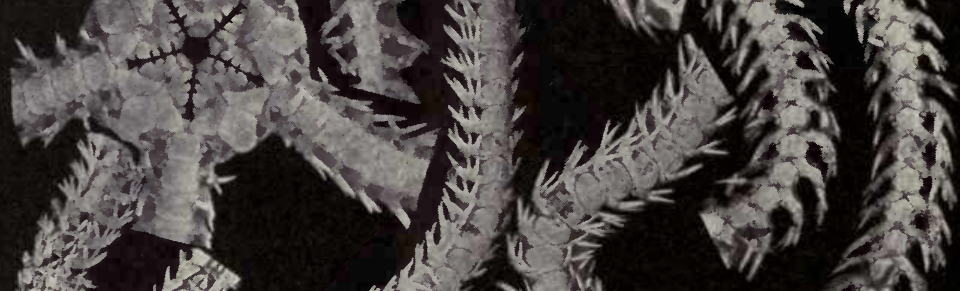

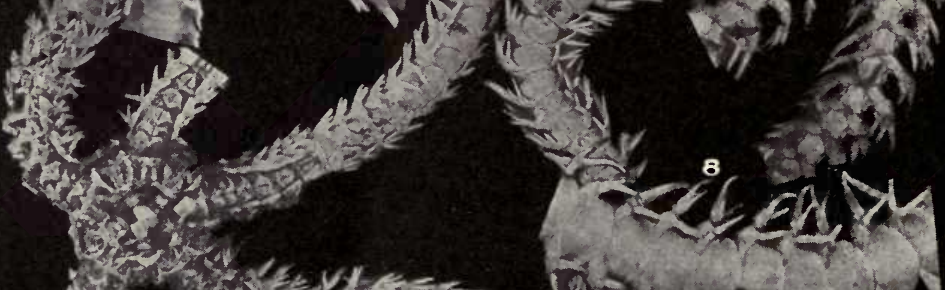

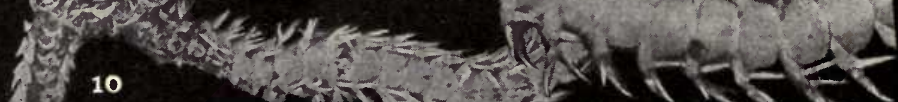

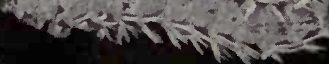

Ophiurans of the Philippine Seas and Adjacent Waters.

For EXPLANATION OF PLATE SEE PAgE 467 


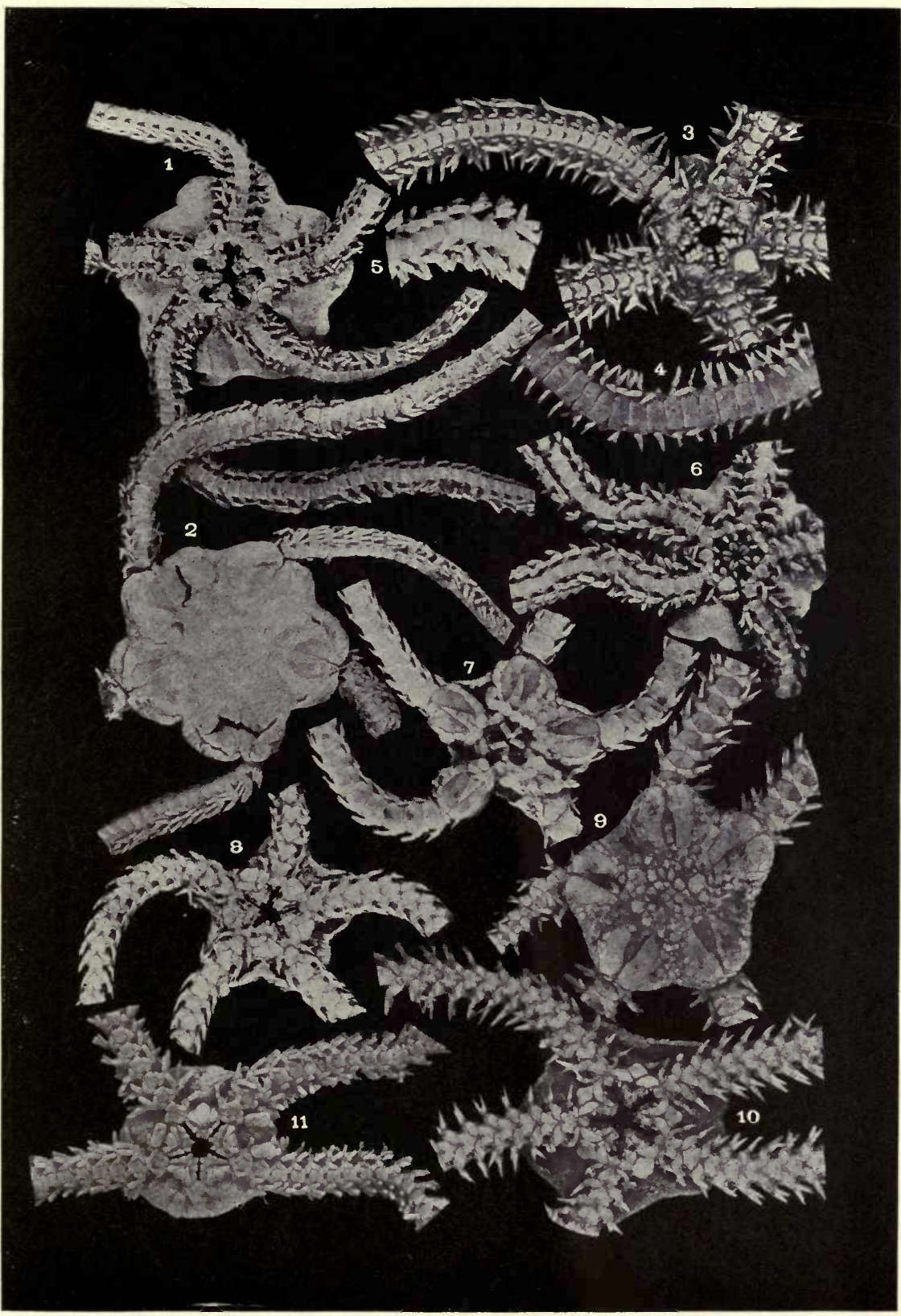

Ophiurans of the Philippine Seas and Adjacent Waters.

For EXPLANATION OF PLATE SEe PAge 467 


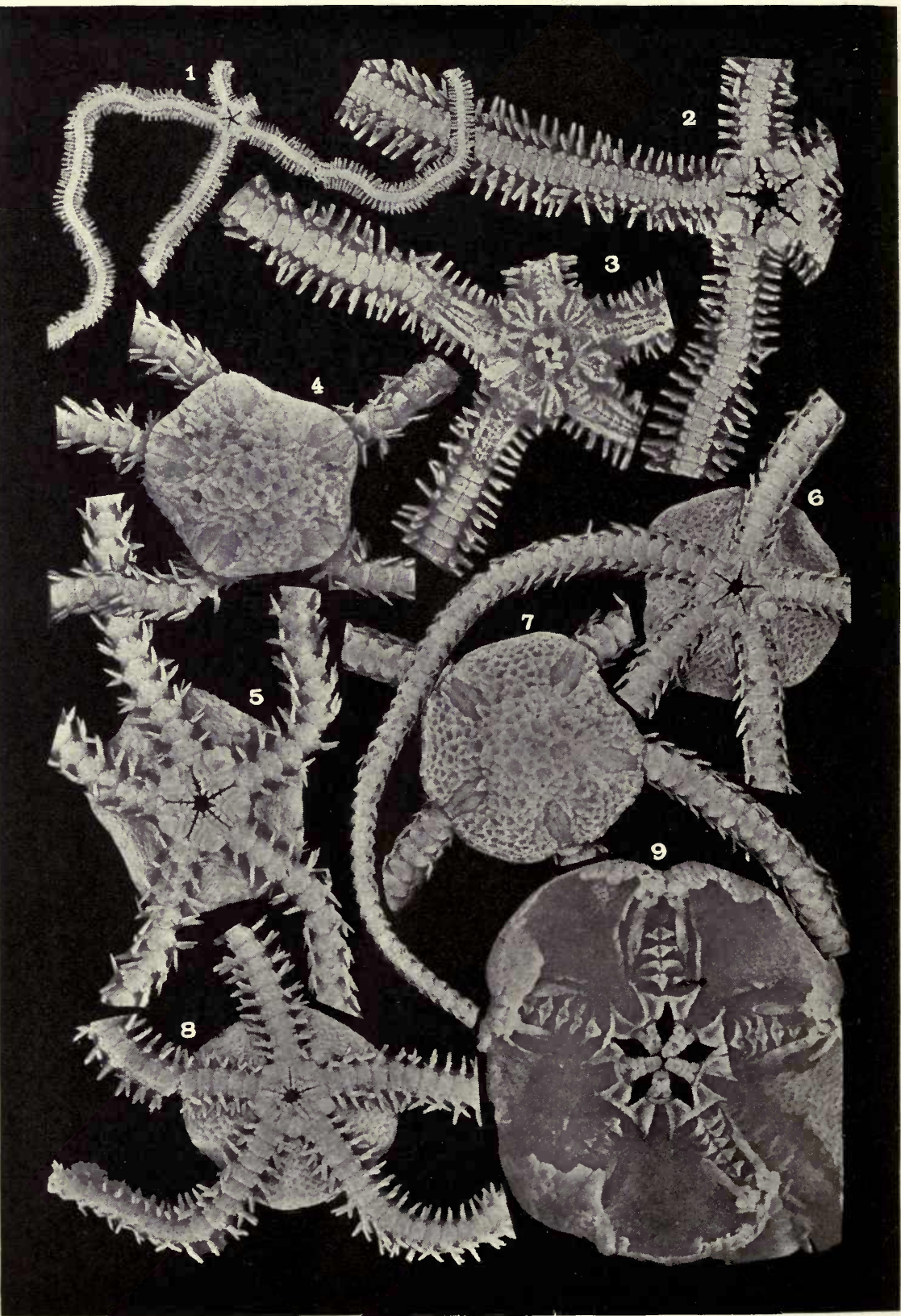

Ophiurans of the Philippine Seas and Adjacent Waters.

For EXPLANATION OF PLATE SEe PAgE 467. 


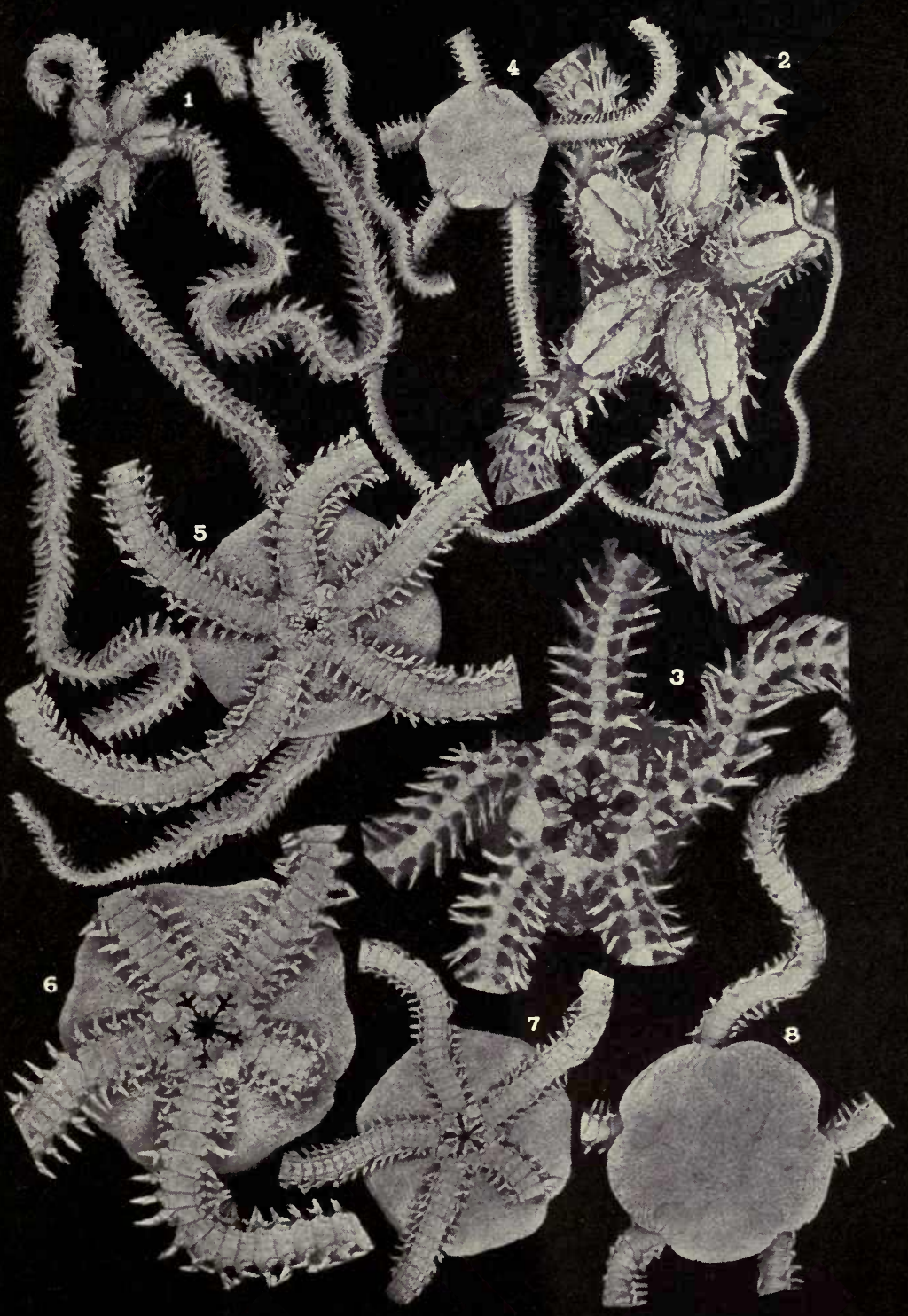

Ophiurans of the Philippine Seas and adjacent Waters.

For explanation of plate see page 467. 


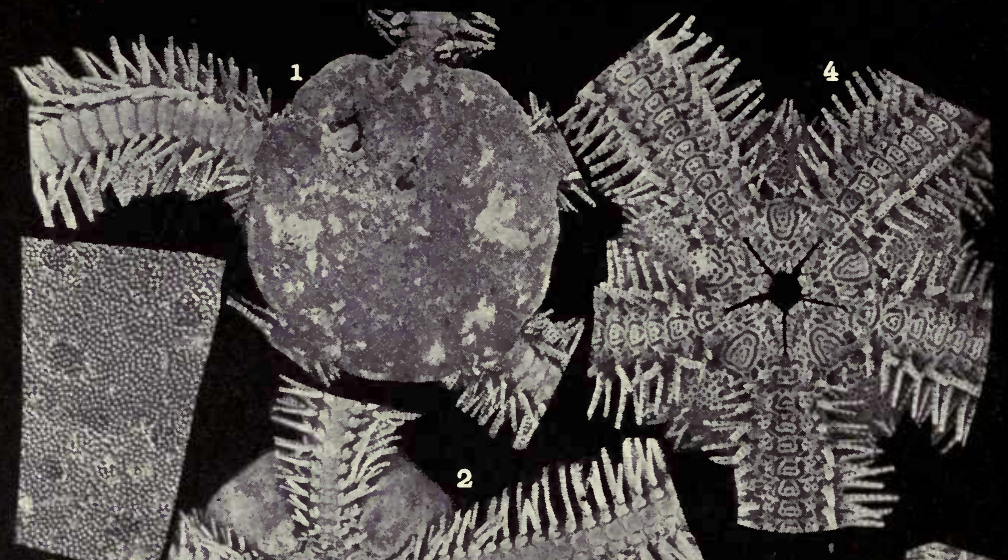

3 2. (3)

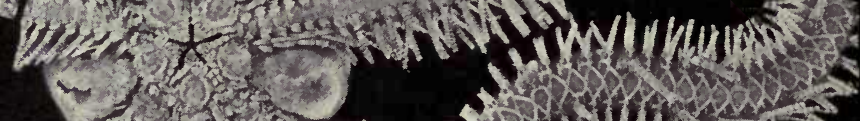

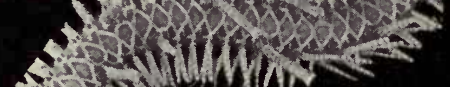

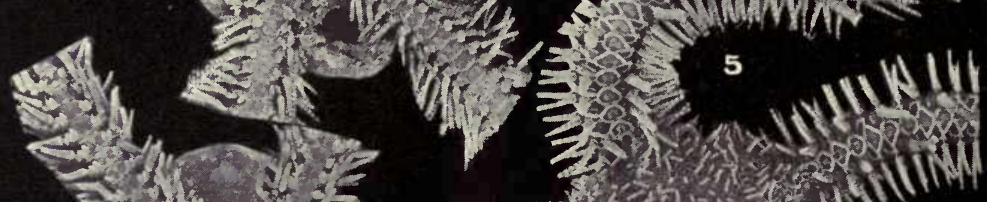

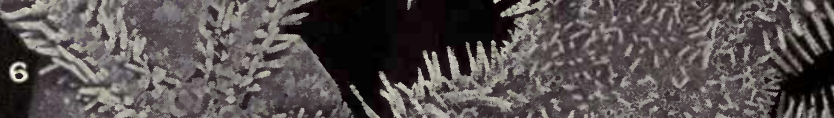

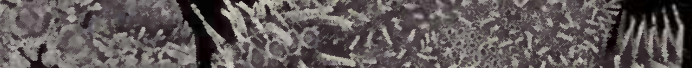

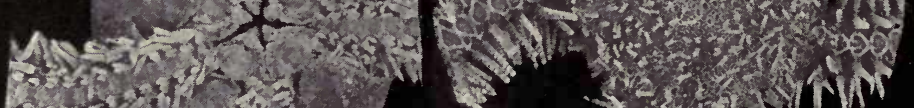

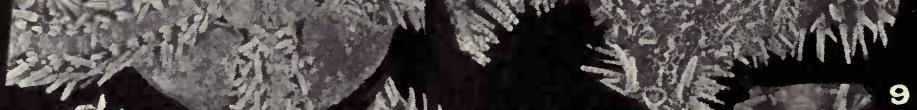

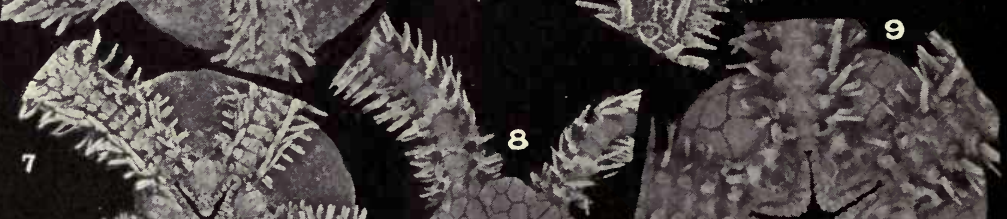
where -1 .

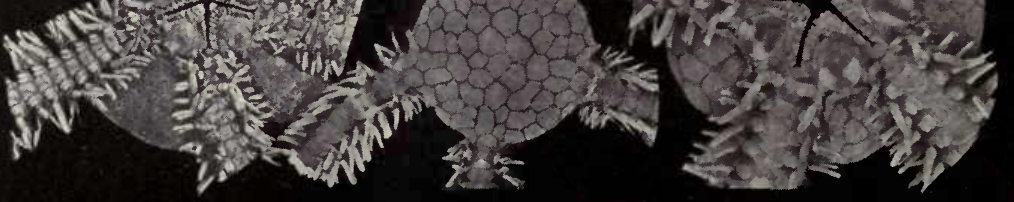

Ophiurans of the Philippine Seas and adjacent Waters.

For EXPLANATION OF PLATE SEe PAges 467 AND 468. 


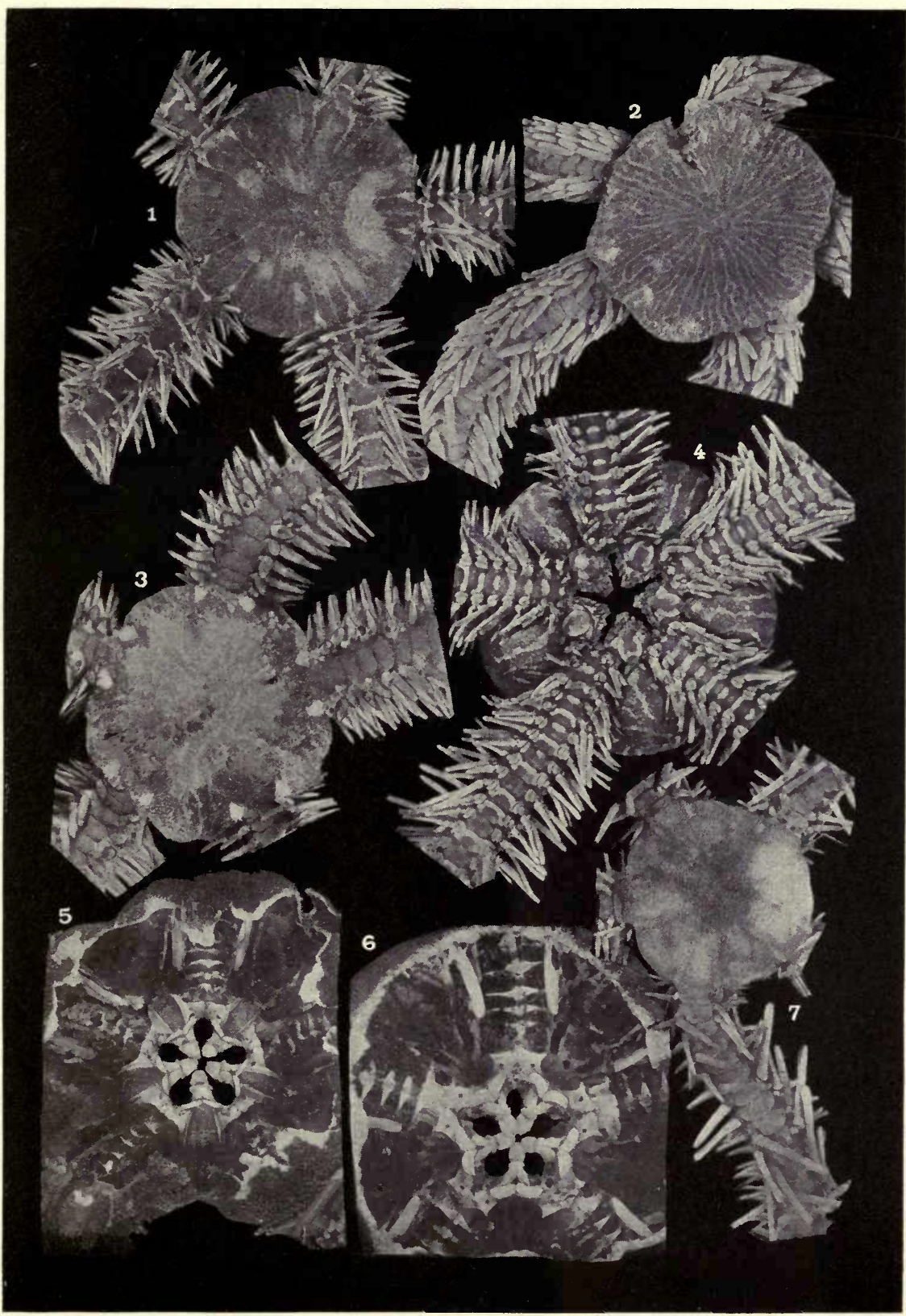

Ophiurans of the Philippine Seas and adjacent Waters.

For EXPLANATION OF PLATE SEE PAGE 468. 


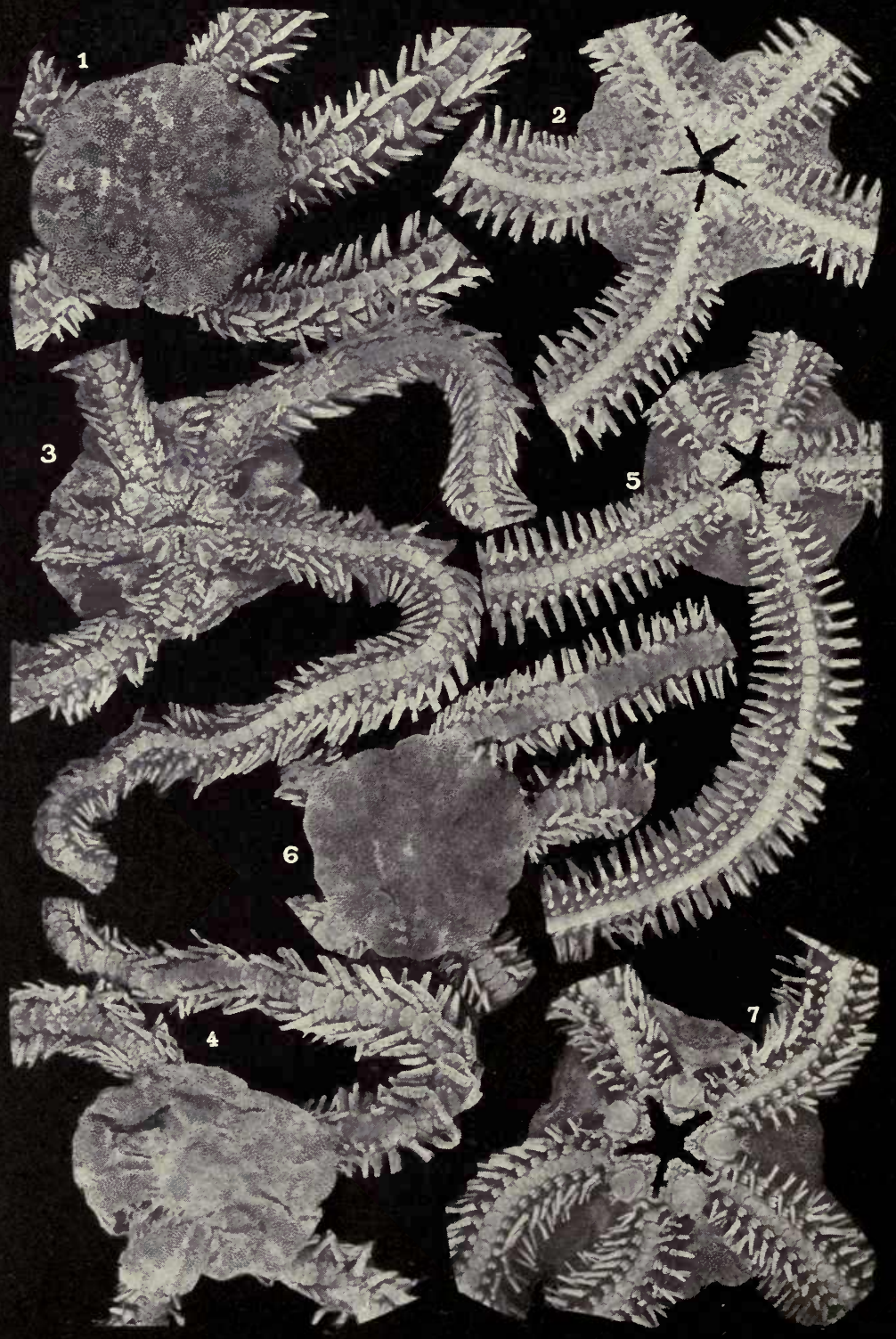

Ophiurans of the Philippine Seas and Adjacent Waters.

For explanation of plate see page 468. 


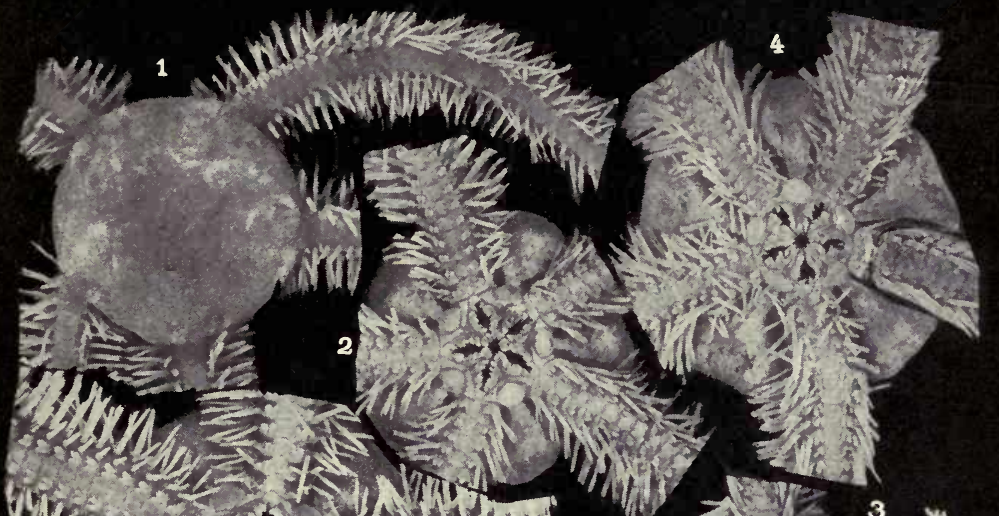

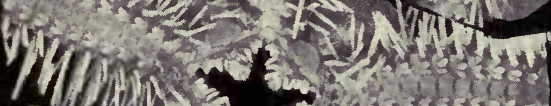
5 (I) III

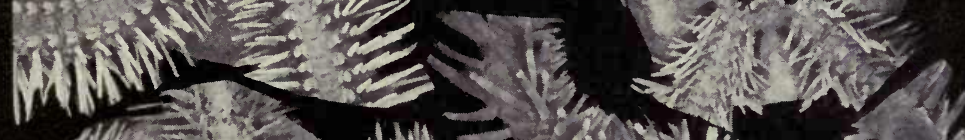

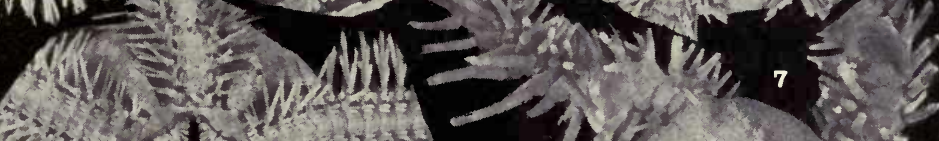

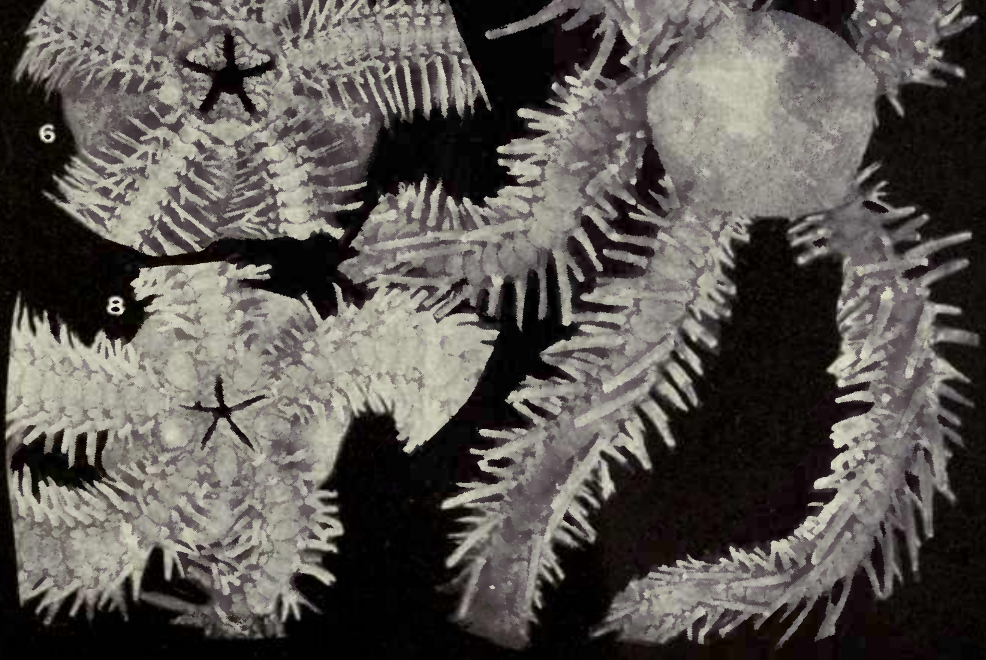

Ophiurans of the Philippine Seas and Adjacent Waters.

For explanation of plate see page 468. 


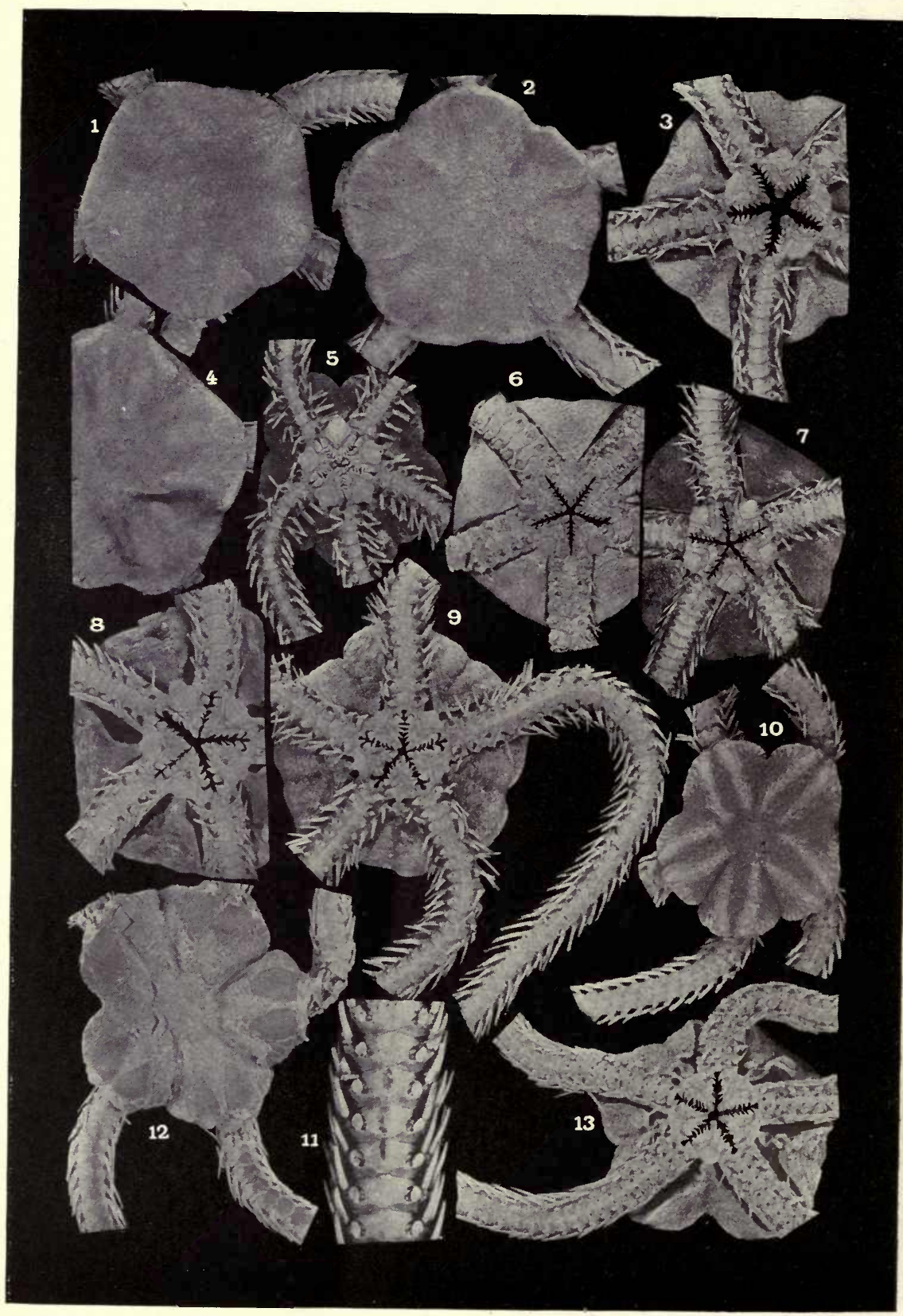

Ophiurans of the Philippine Seas and adjacent Waters.

For EXPLANATION OF PLATE SEe PAge 468. 


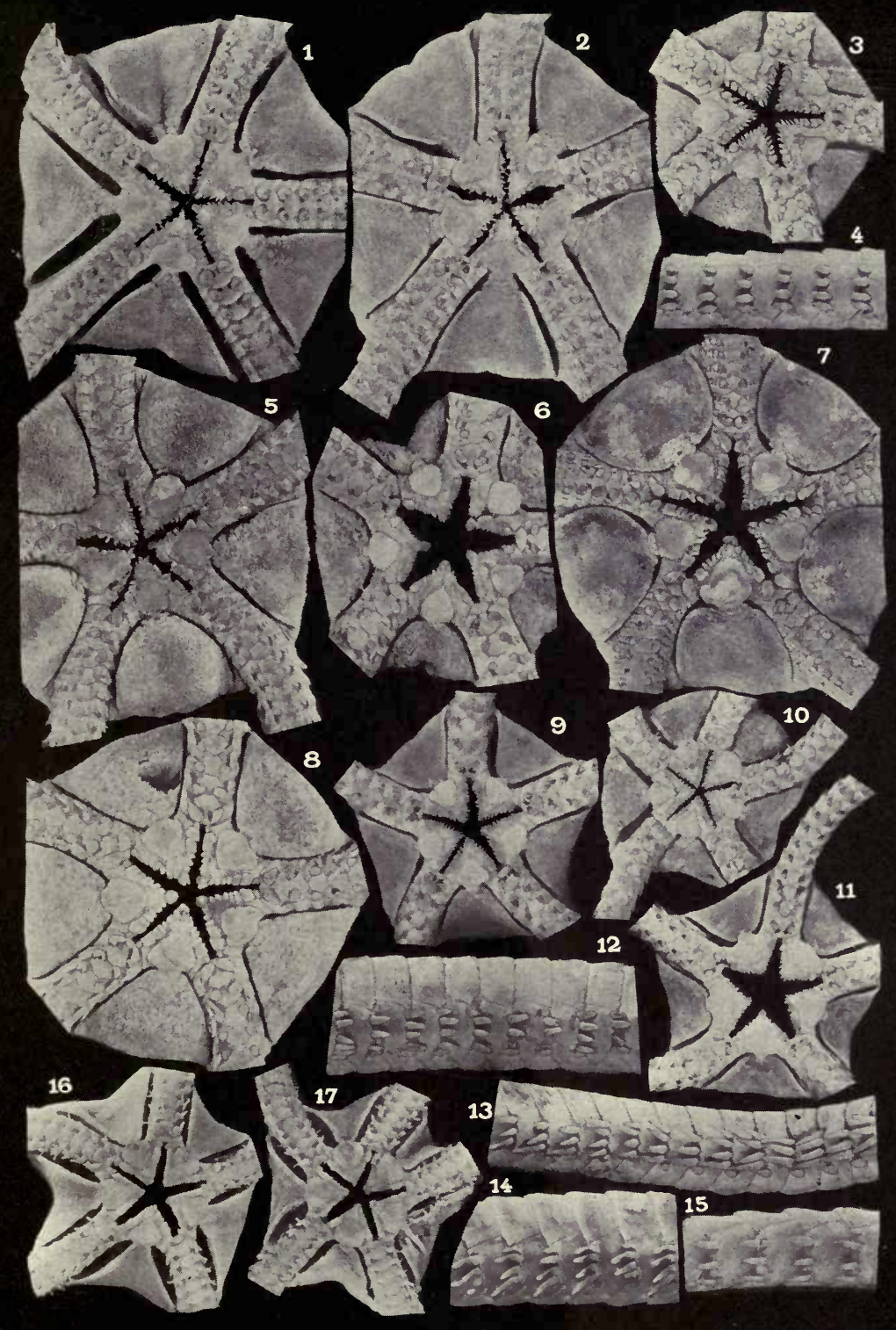

Ophiurans of the Philippine Seas and adjacent Waters. 


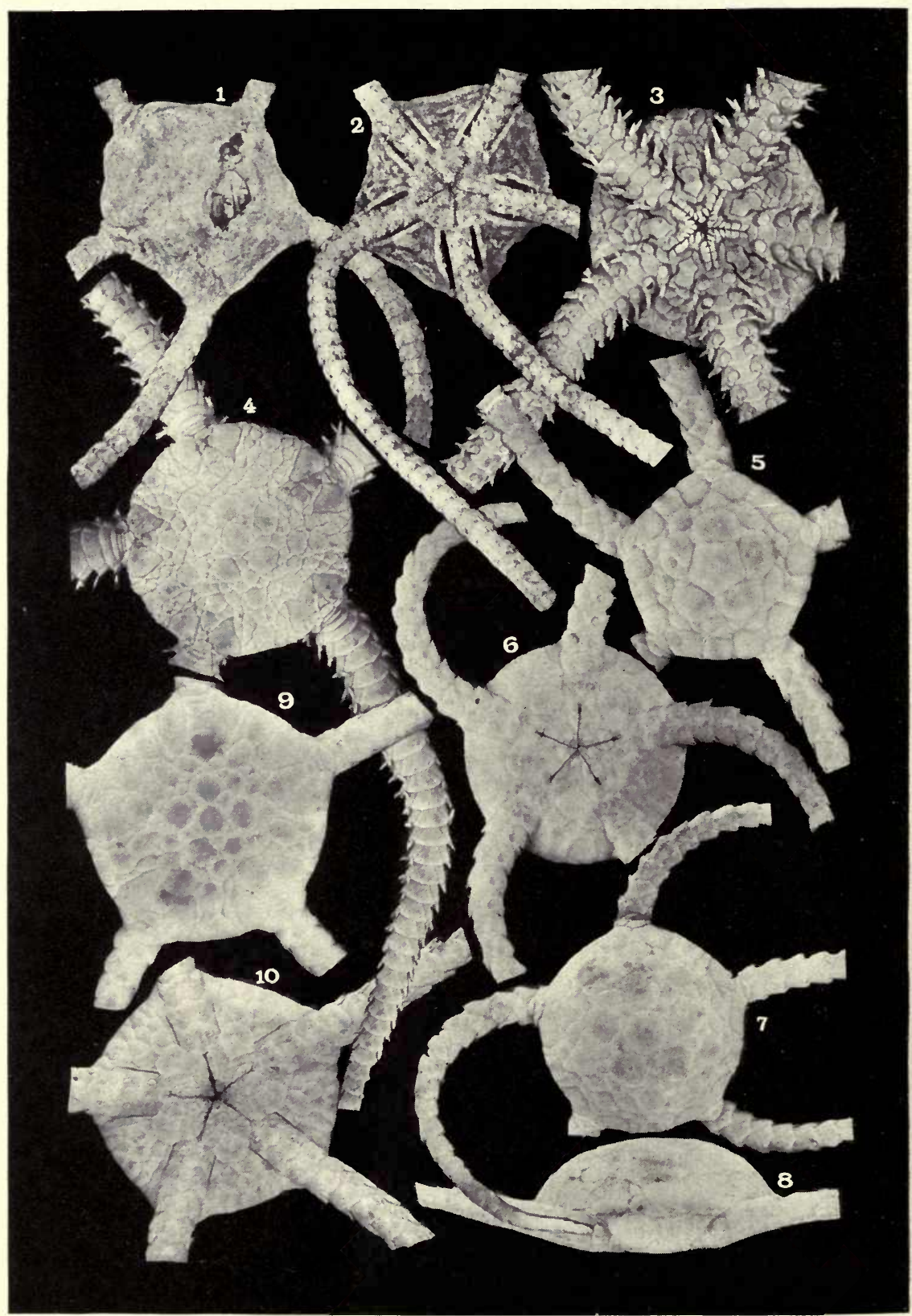

Ophiurans of the Philippine Seas and Adjacent Waters.

For explanation of PLATE SEe Page 469. 


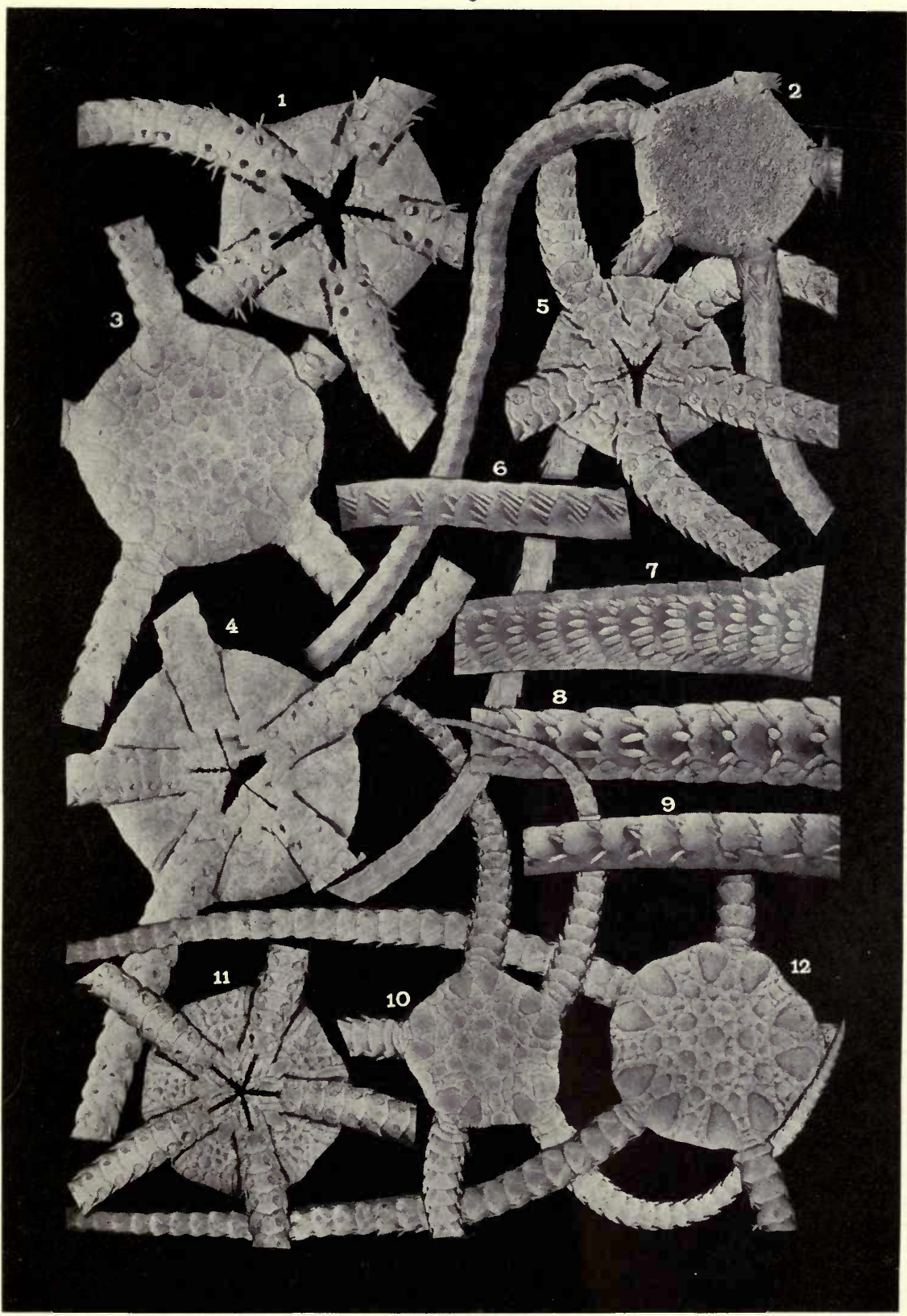

Ophiurans of the Philippine Seas and Adjacent Waters.

For explanation of PLATE SEe Page $469^{\circ}$ 


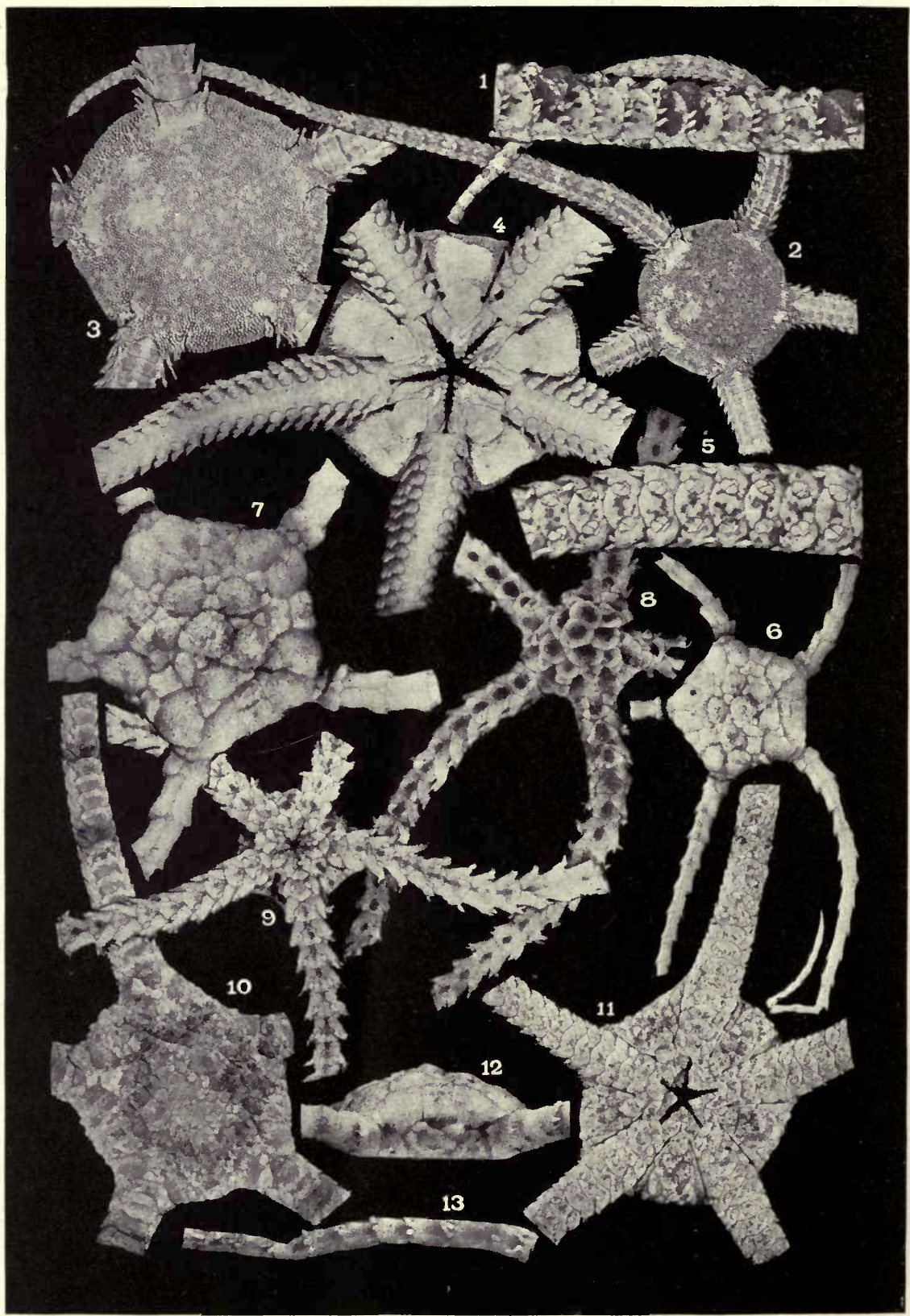

Ophiurans of the Philippine Seas and Adjacent Waters.

For EXPLANATION OF PLATE SEe PAges 469 AND 470. 


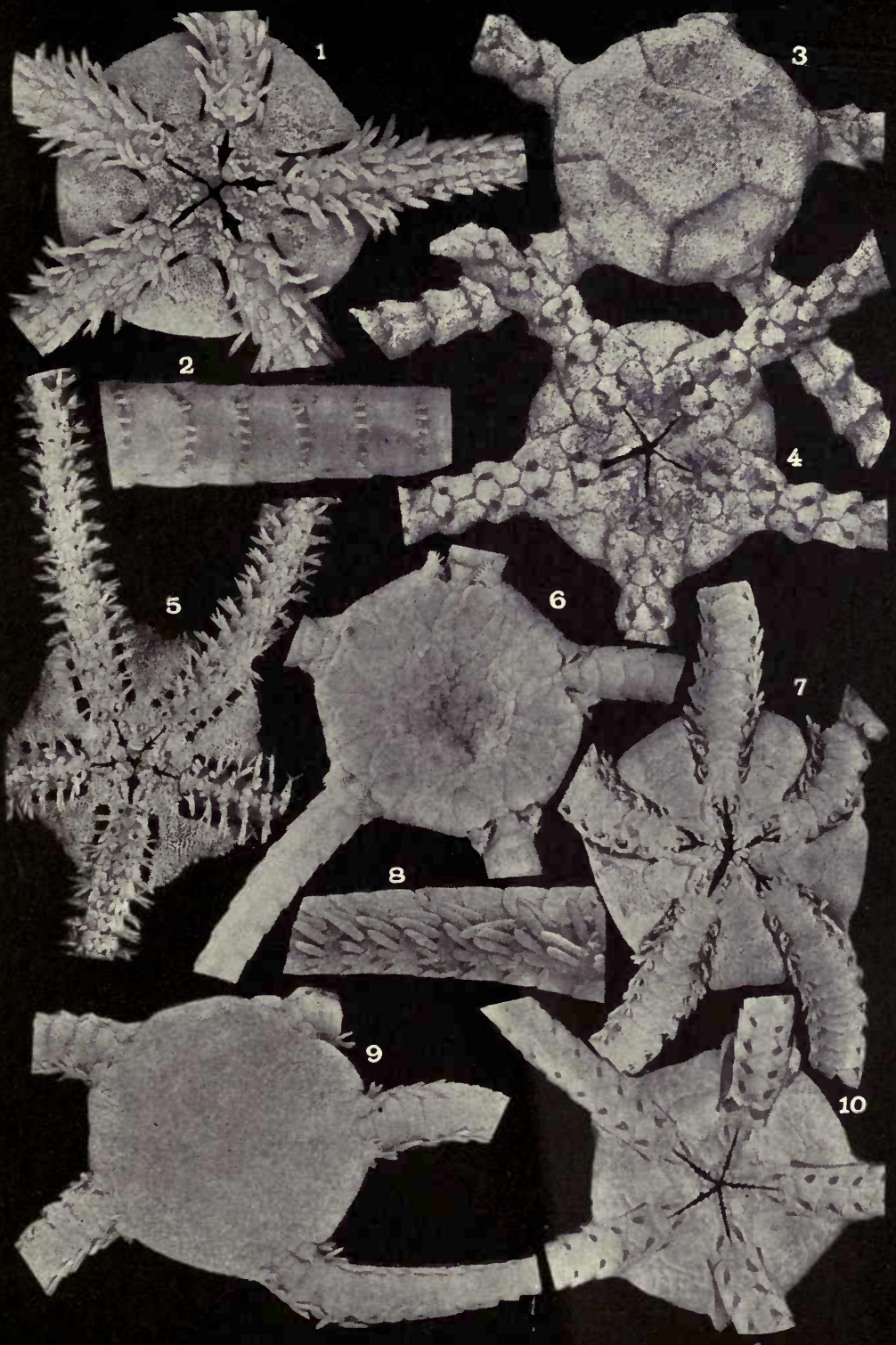

Ophiurans of the Philippine Seas and Adjacent Waters.

For explanation of PLATE SEe PAge 470. 


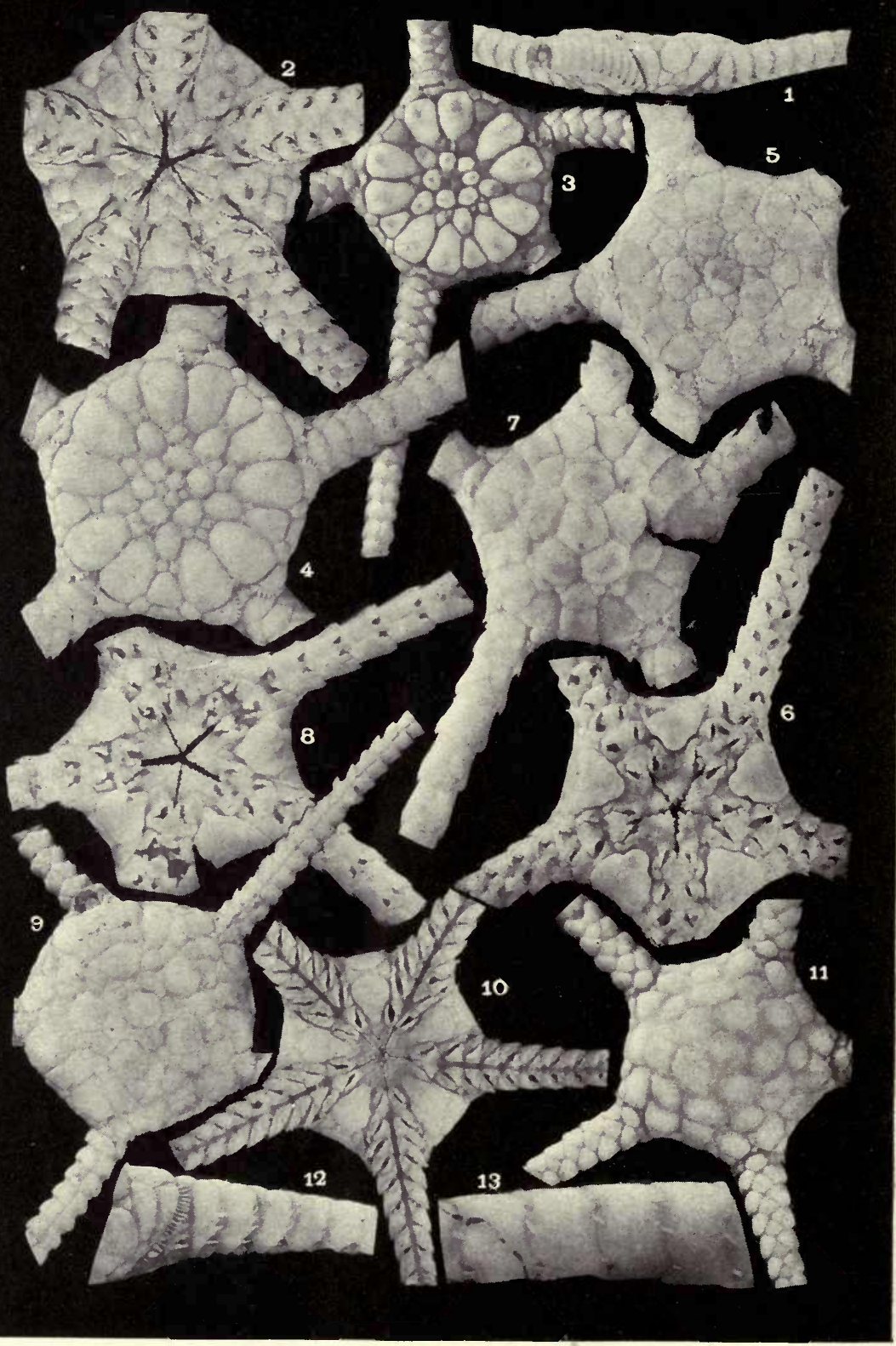

Ophiurans of the Philippine Seas and adjacent Waters.

For explanation of PLATE see page 470. 


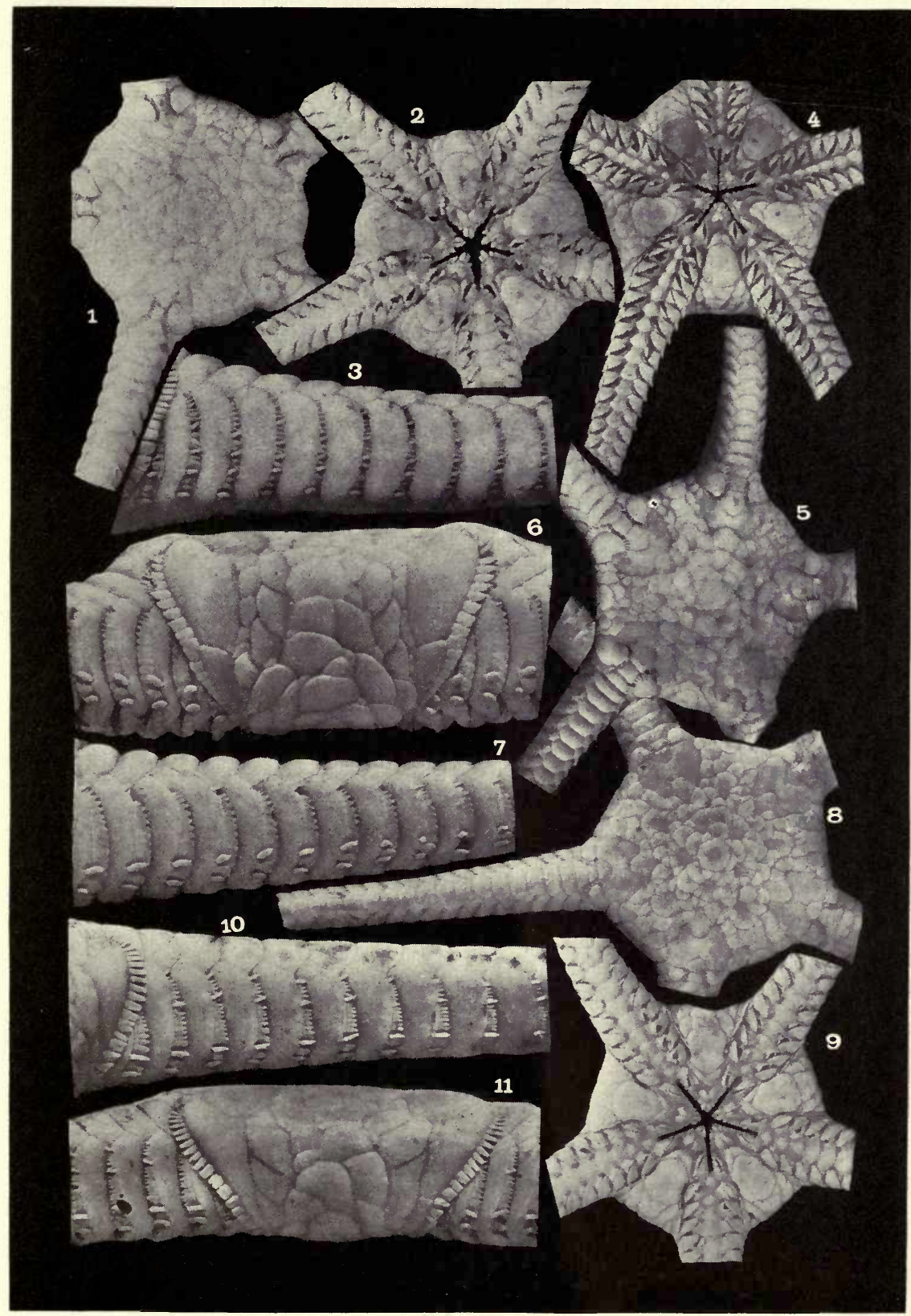

Ophiurans of the Philippine Seas and Adjacent Waters.

For explanation of PLATE see Page 470. 


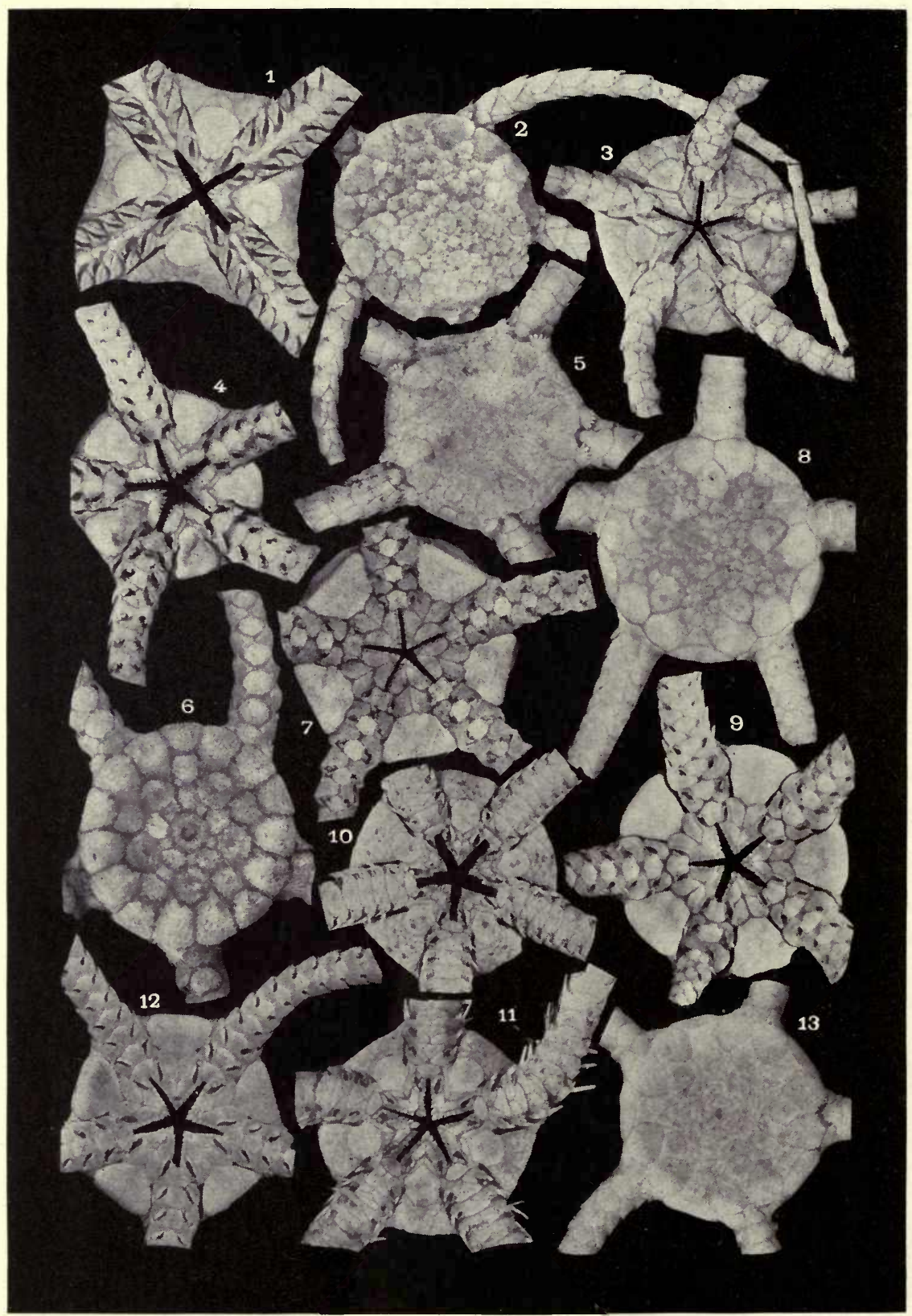

Ophiurans of the Philippine Seas and Adjacent Waters. 


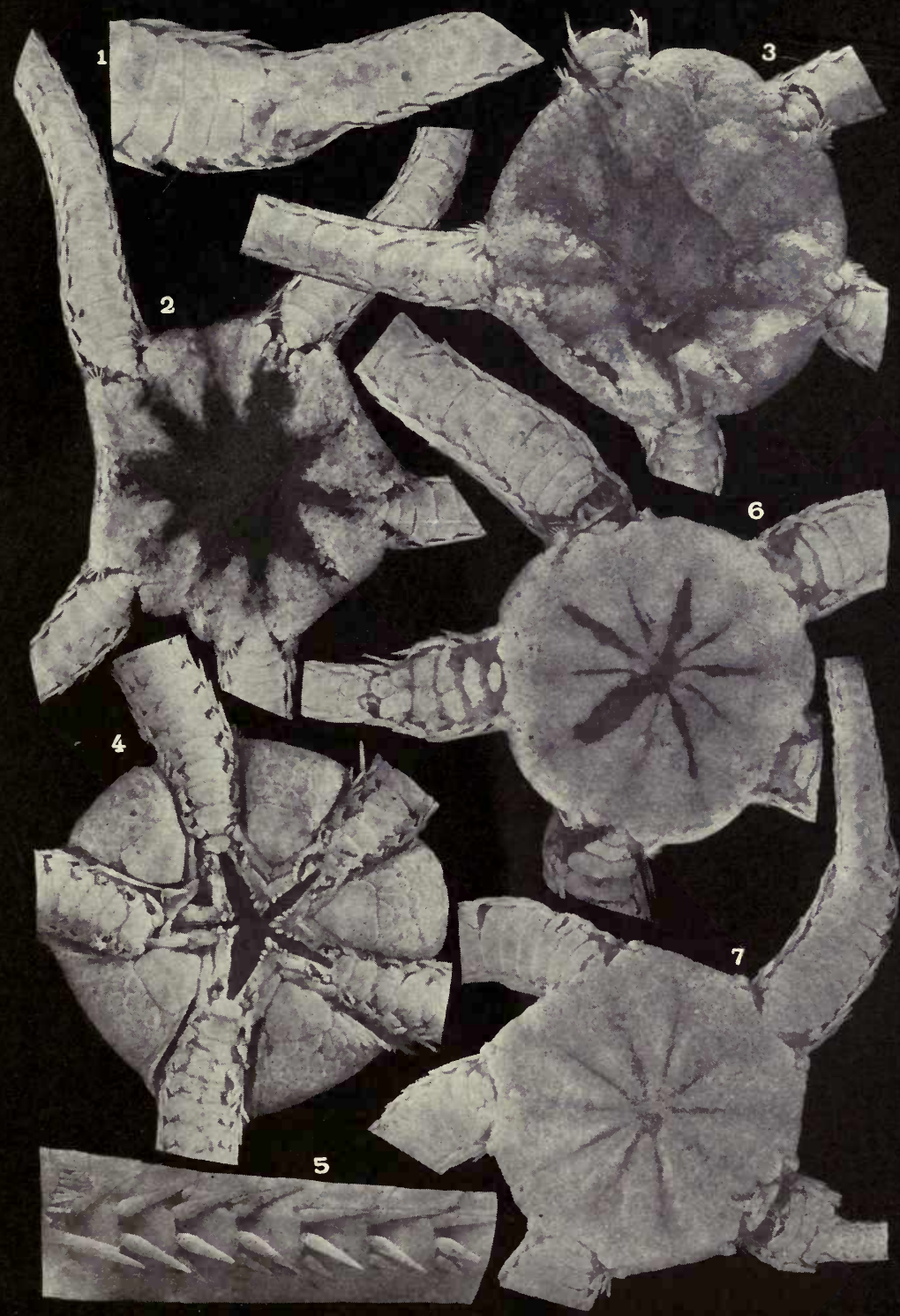

Ophiurans of the Philippine Seas and adjacent Waters.

For EXPLANATION OF PLATE SEE PAgE 471. 


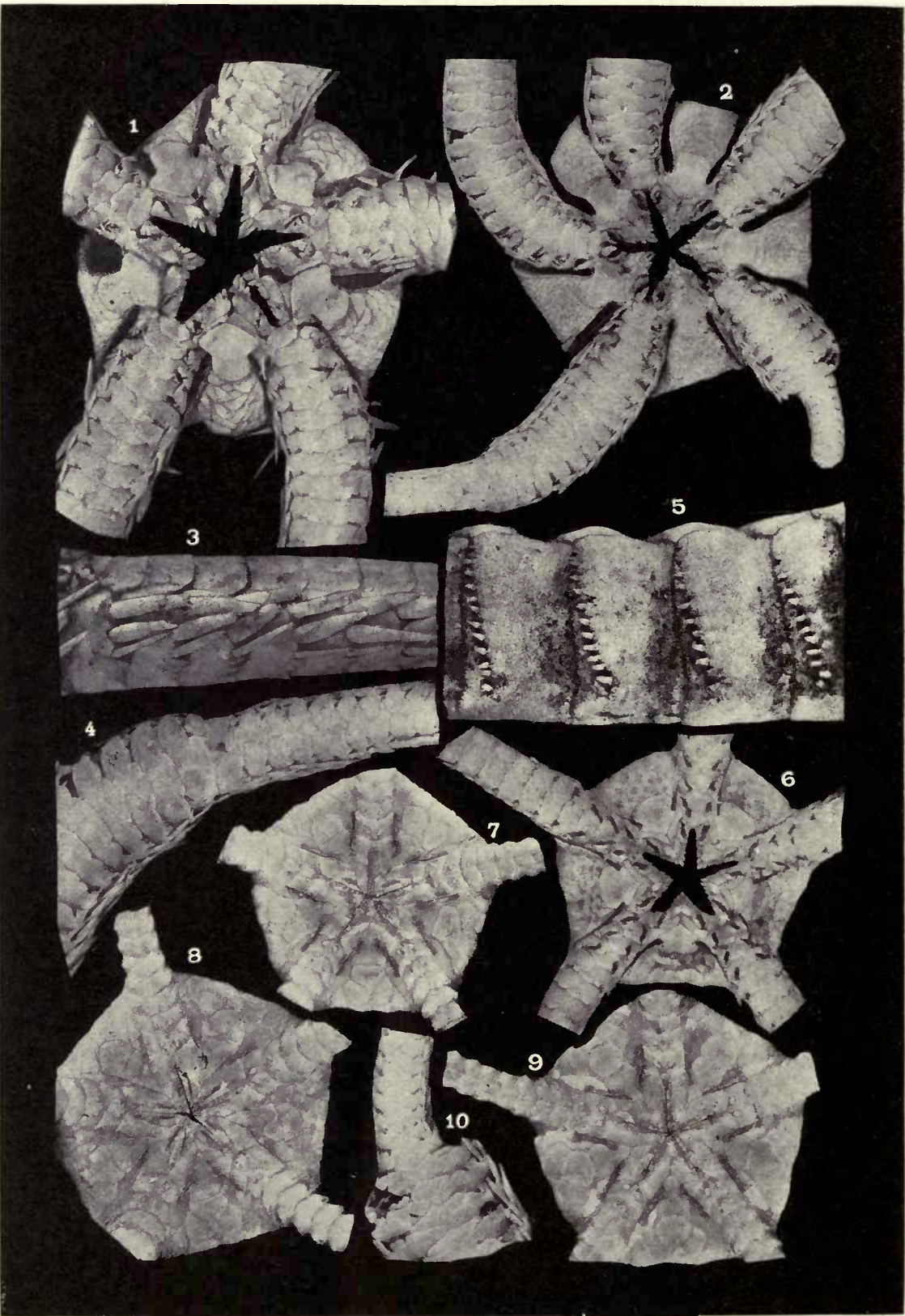

Ophiurans of the Philippine Seas and adjacent Waters.

For EXPLANation of PLATE see Page 471. 


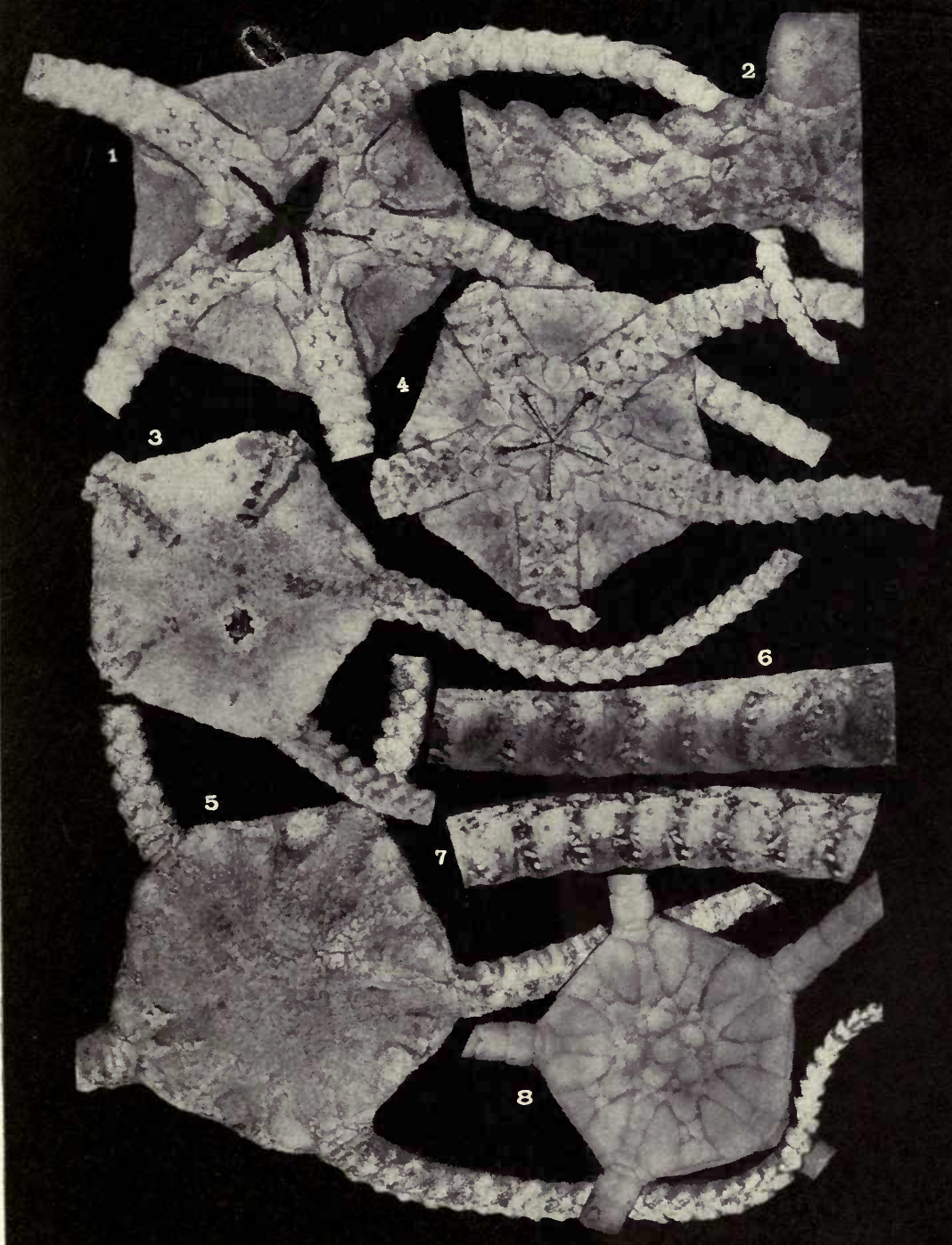

Ophiurans of the Philippine Seas and Adjacent Waters.

For explanation of plate see page 471. 


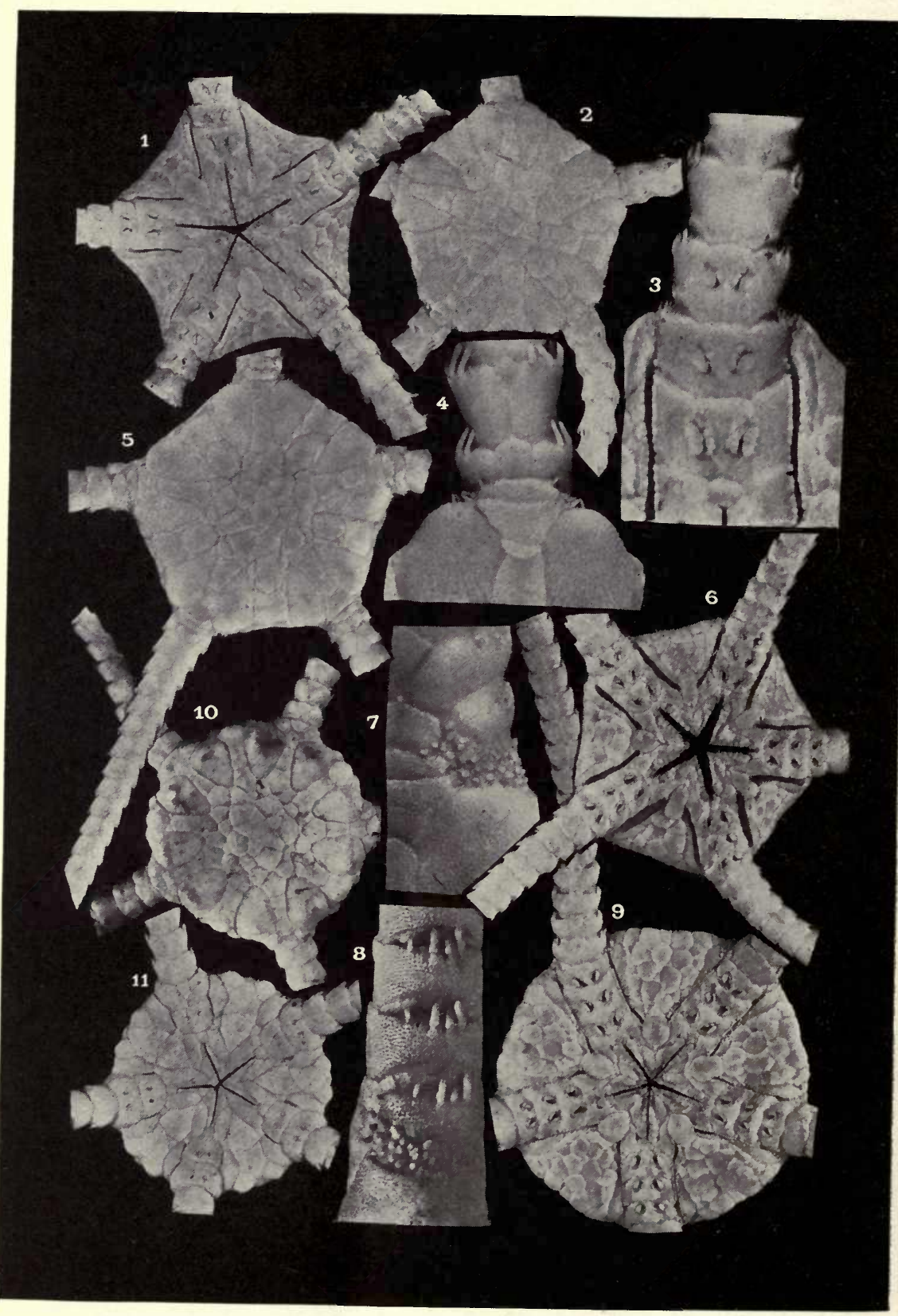

Ophiurans of the Philippine seas and Adjacent Waters. 


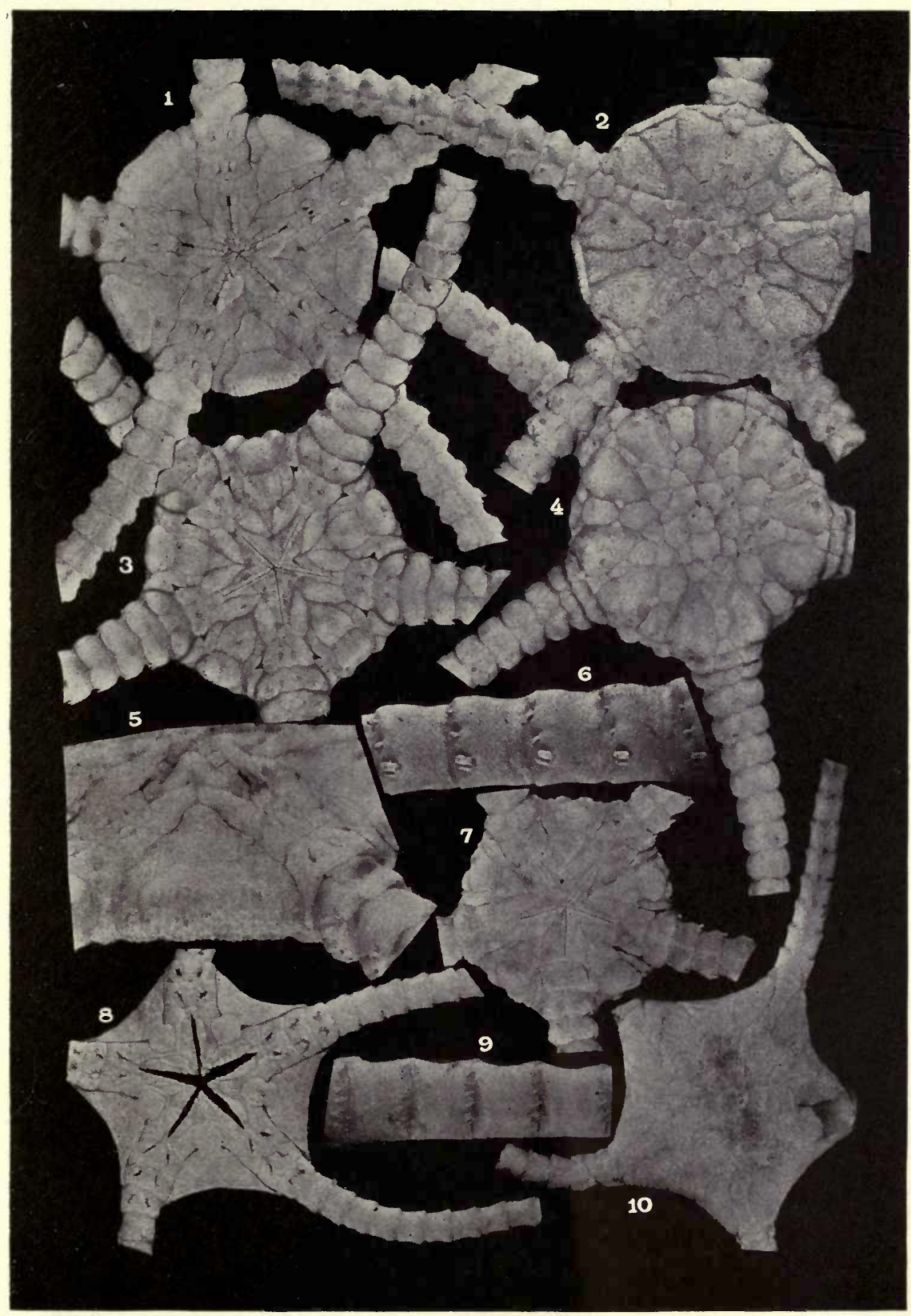

Ophiurans of the Philippine Seas and Adjacent Waters.

For explanation of plate see page 472. 


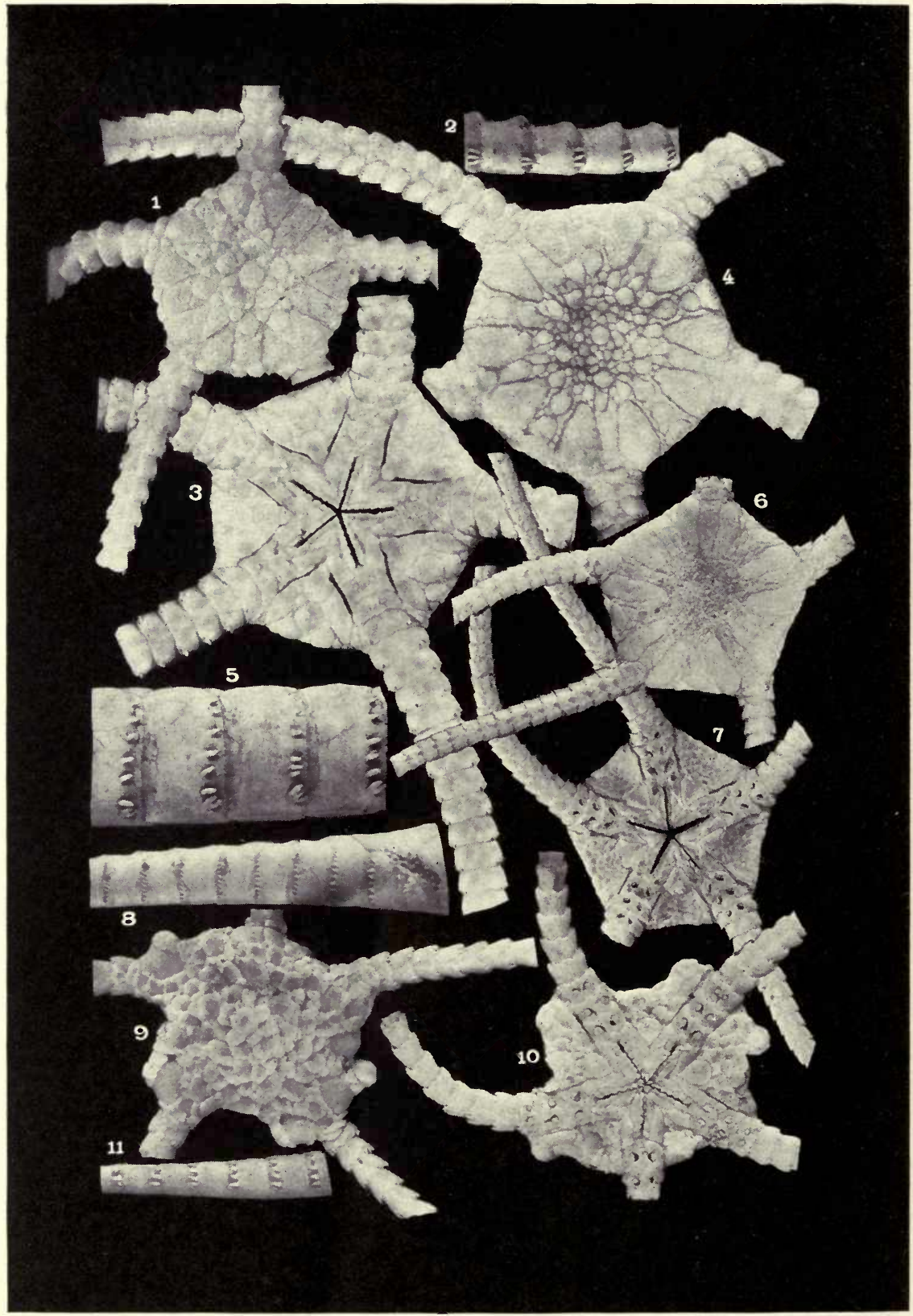

Ophiurans of the Philippine Seas and adjacent Waters. For explanation of plate see page 472.1 


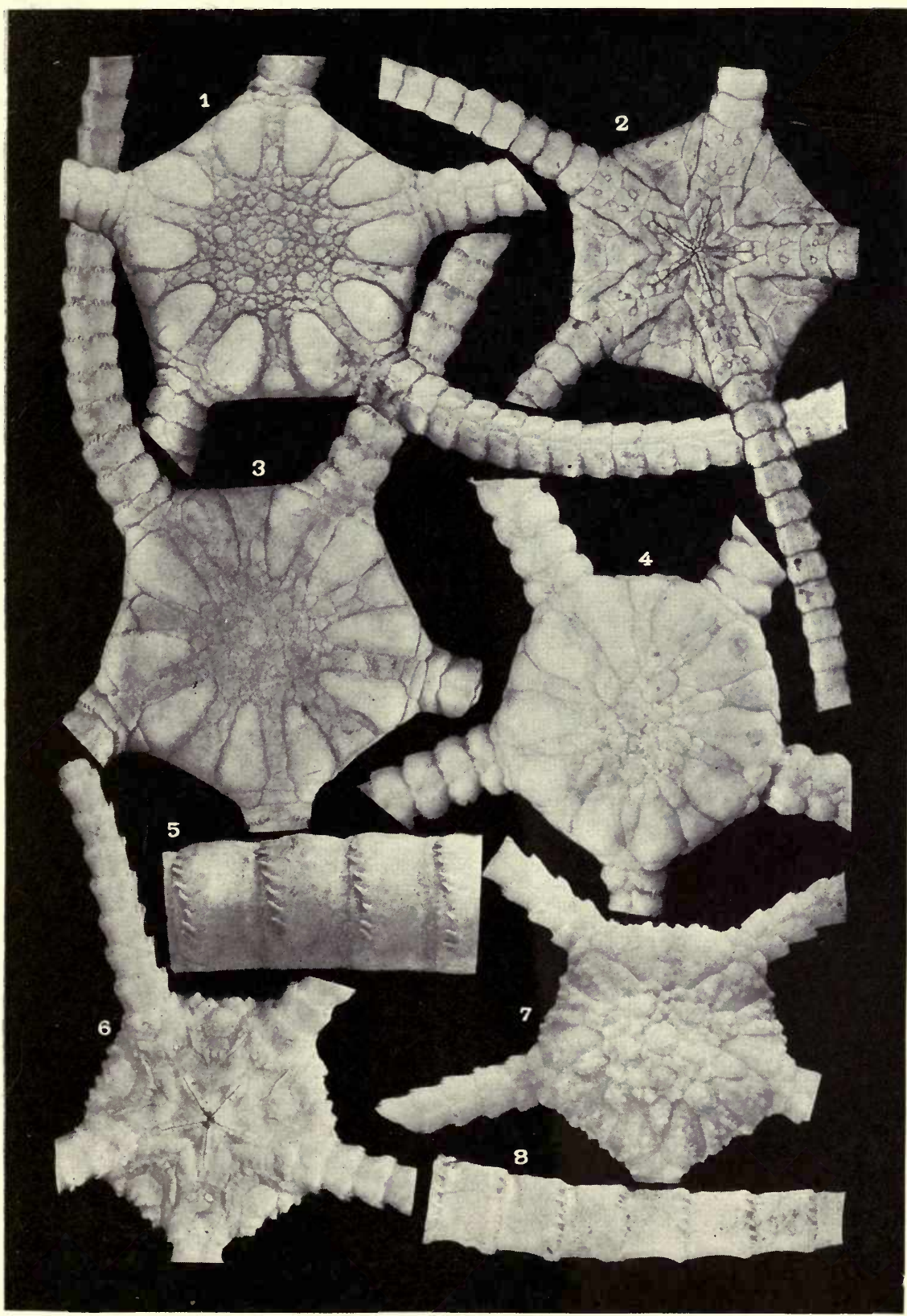

Ophiurans of the Philippine Seas and Adjacent Waters.

for explanation of PLATE see page 472. 


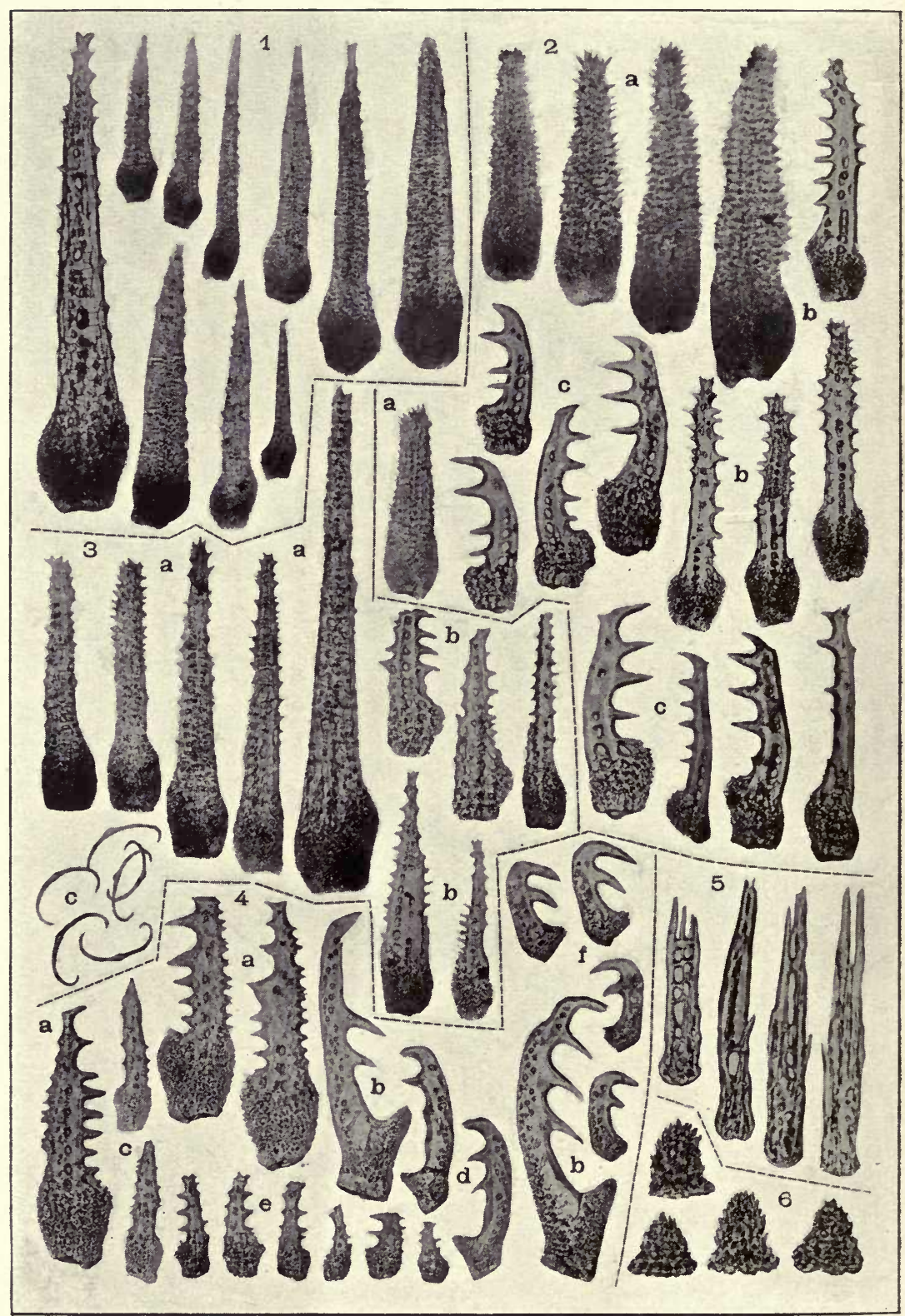

Ophiurans of the Philippine Seas and adjacent Waters.

For EXPLANATION OF PLATE SEE PAGES 472 AND 473. 


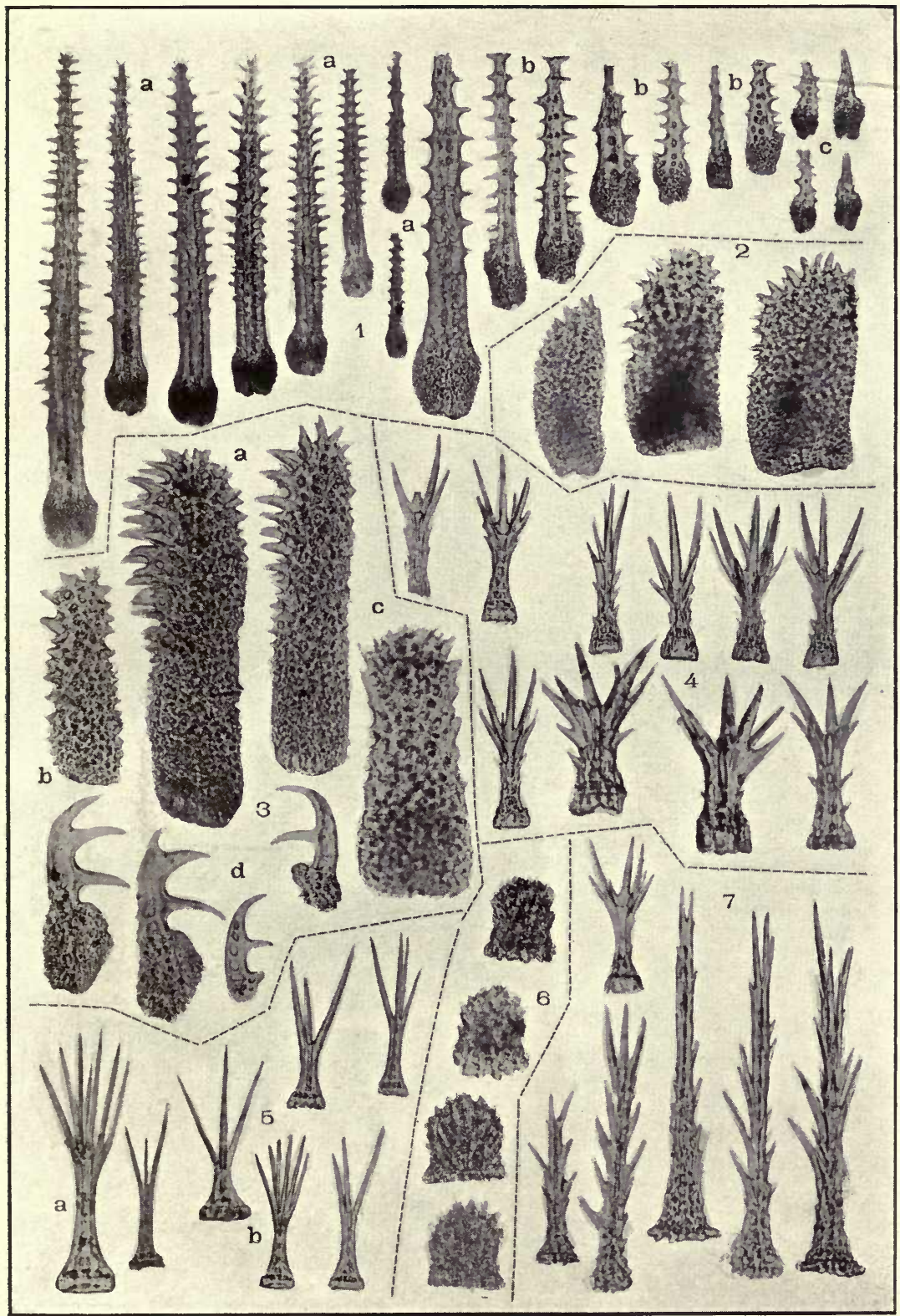

Ophiurans of the Philippine Seas and Adjacent Waters.

For EXPLANATION OF PLATE SEE PAOE 473 


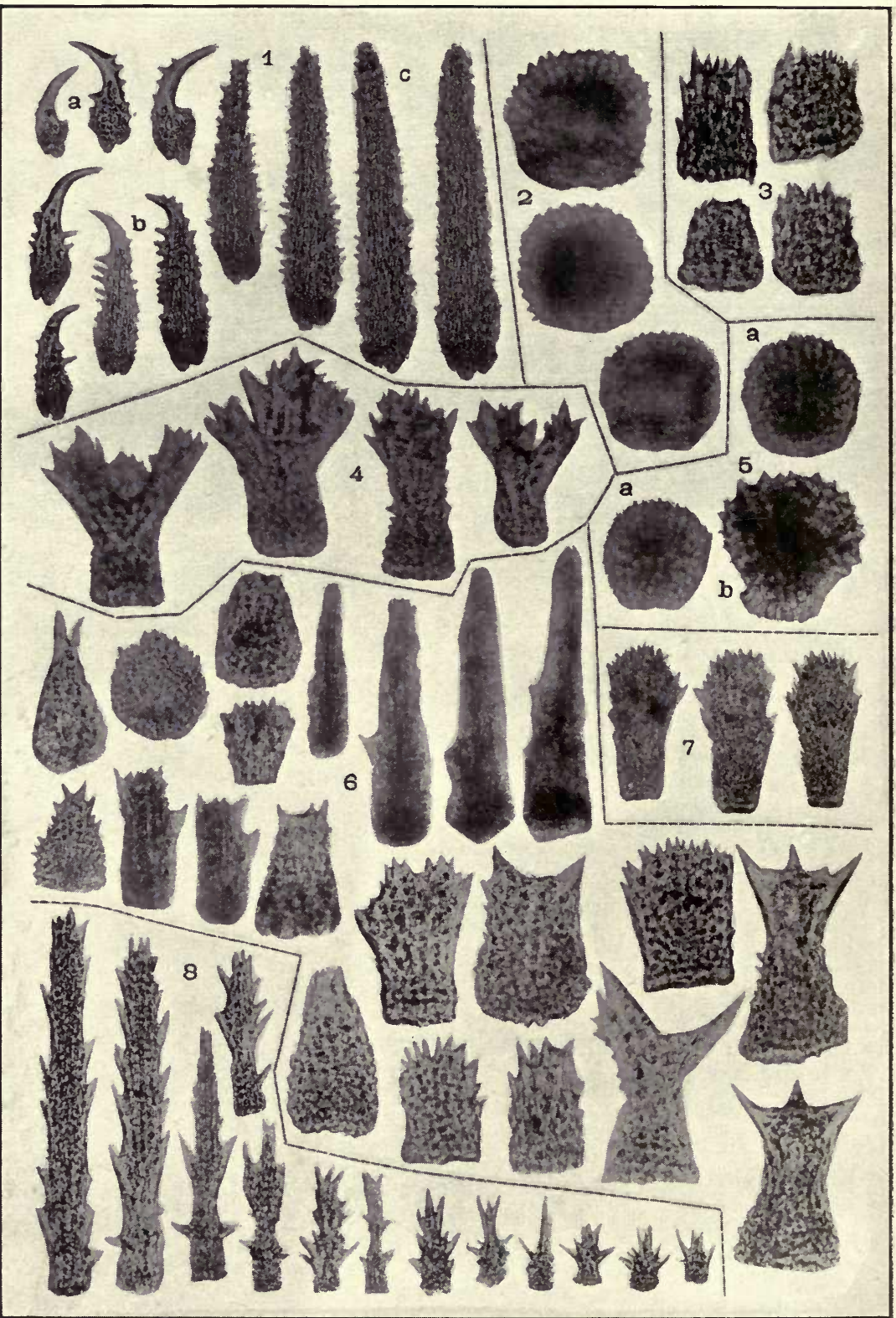

Ophiurans of the Philippine Seas and Adjacent Waters.

FOR EXPLANATION OF PLATE SEE PAgE 473. 


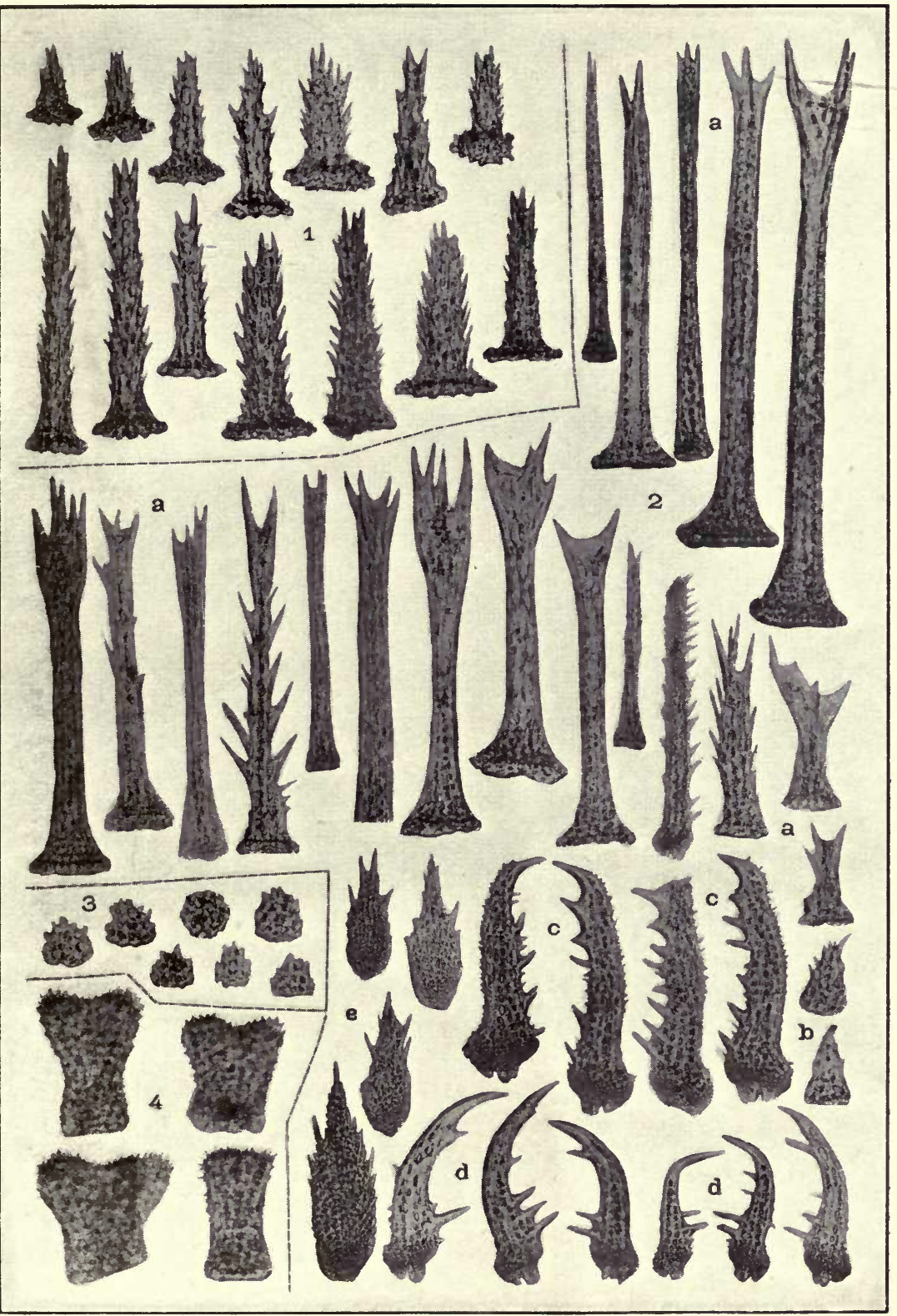

Ophiurans of the Philippine Seas and Adjacent Waters. 


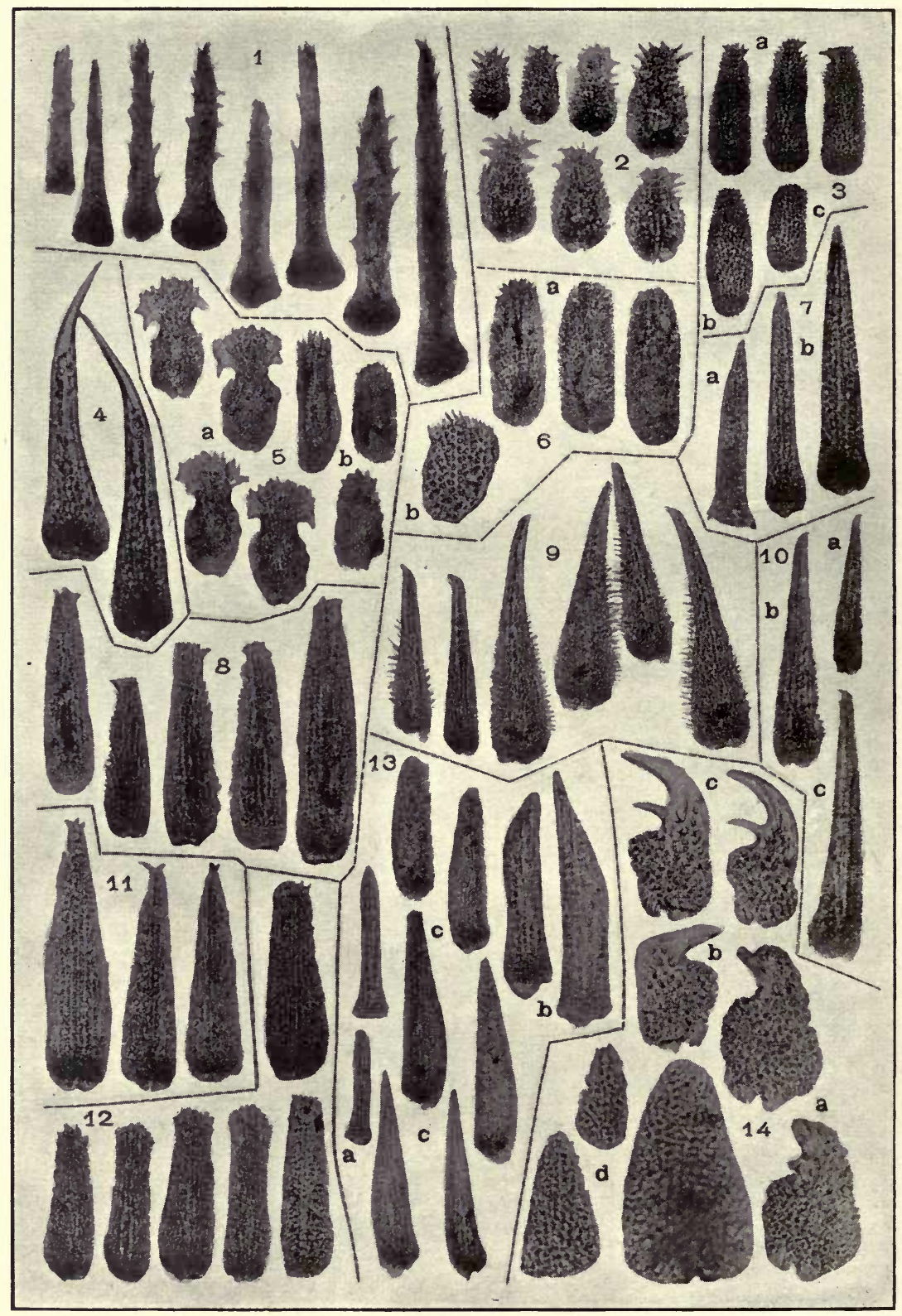

Ophiurans of the Philippine Seas and adjacent Waters.

For EXPLANATION OF PLATE SEe PAge 474. 


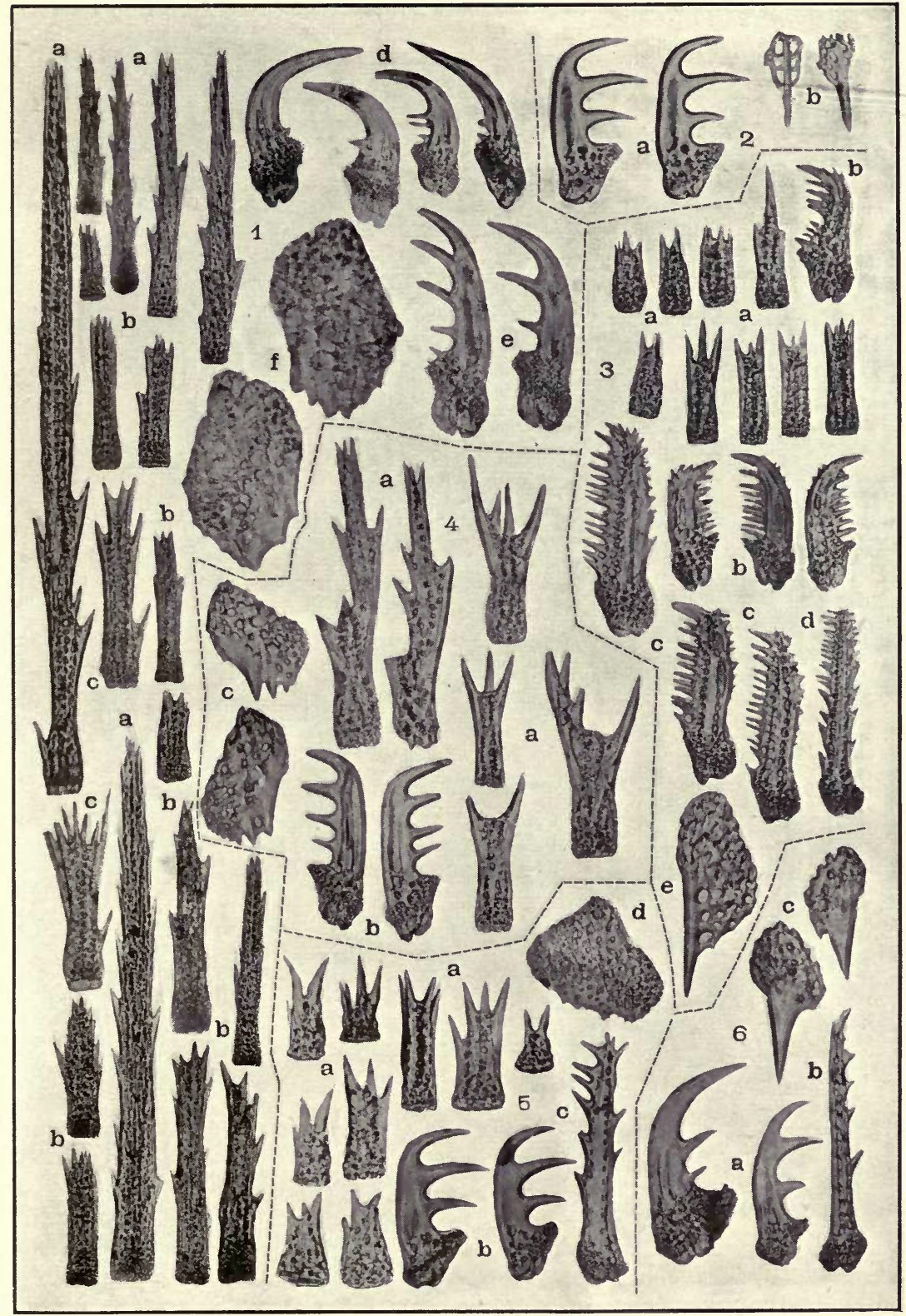

Ophiurans of the Philippine Seas and adjacent Waters.

For EXPLANATION OF PLATE SEE PAGE 475. 


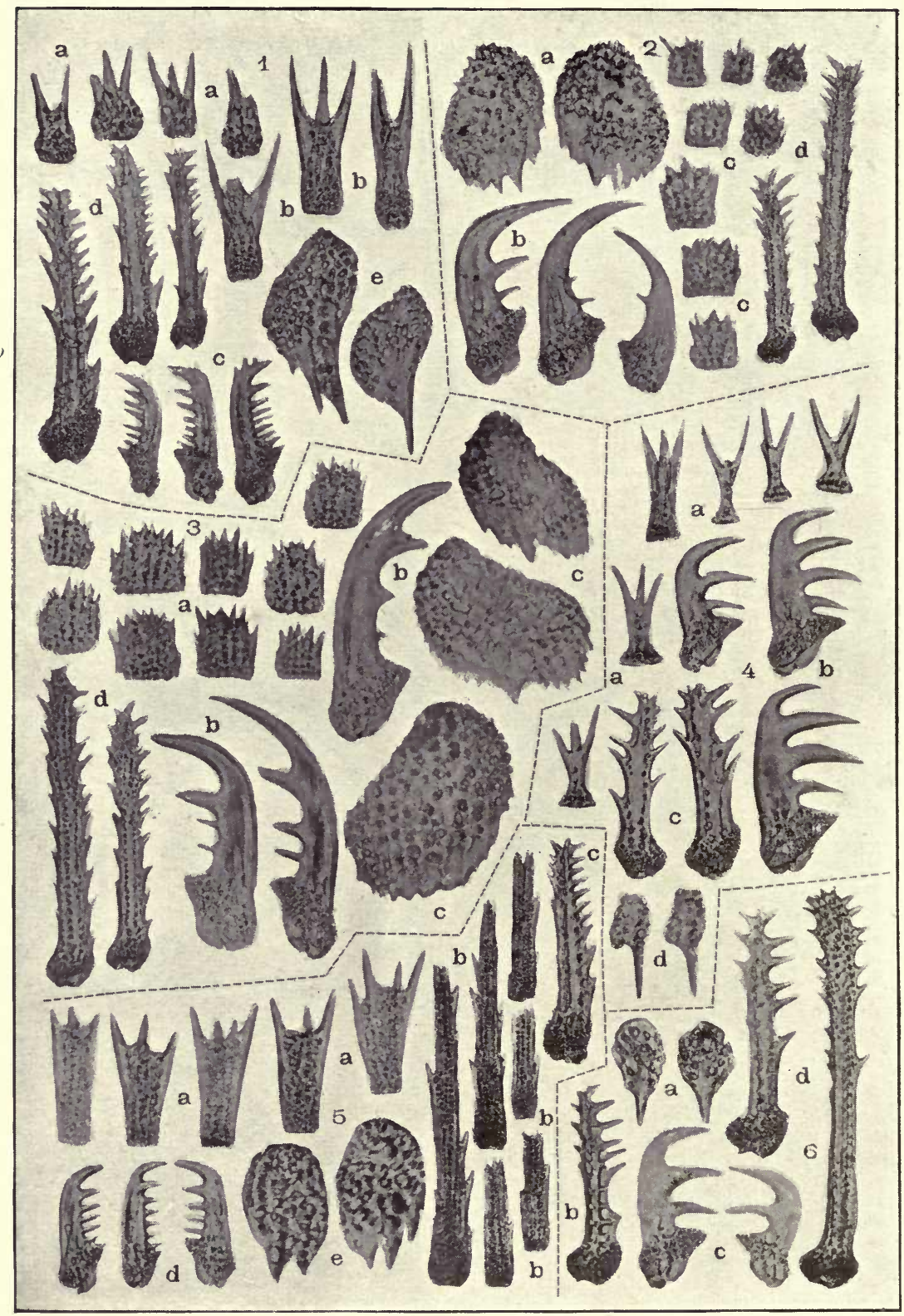

Ophiurans of the Philippine Seas and adjacent Waters.

For EXPLANATION OF PLATE SEe PAges 475 AND 476. 


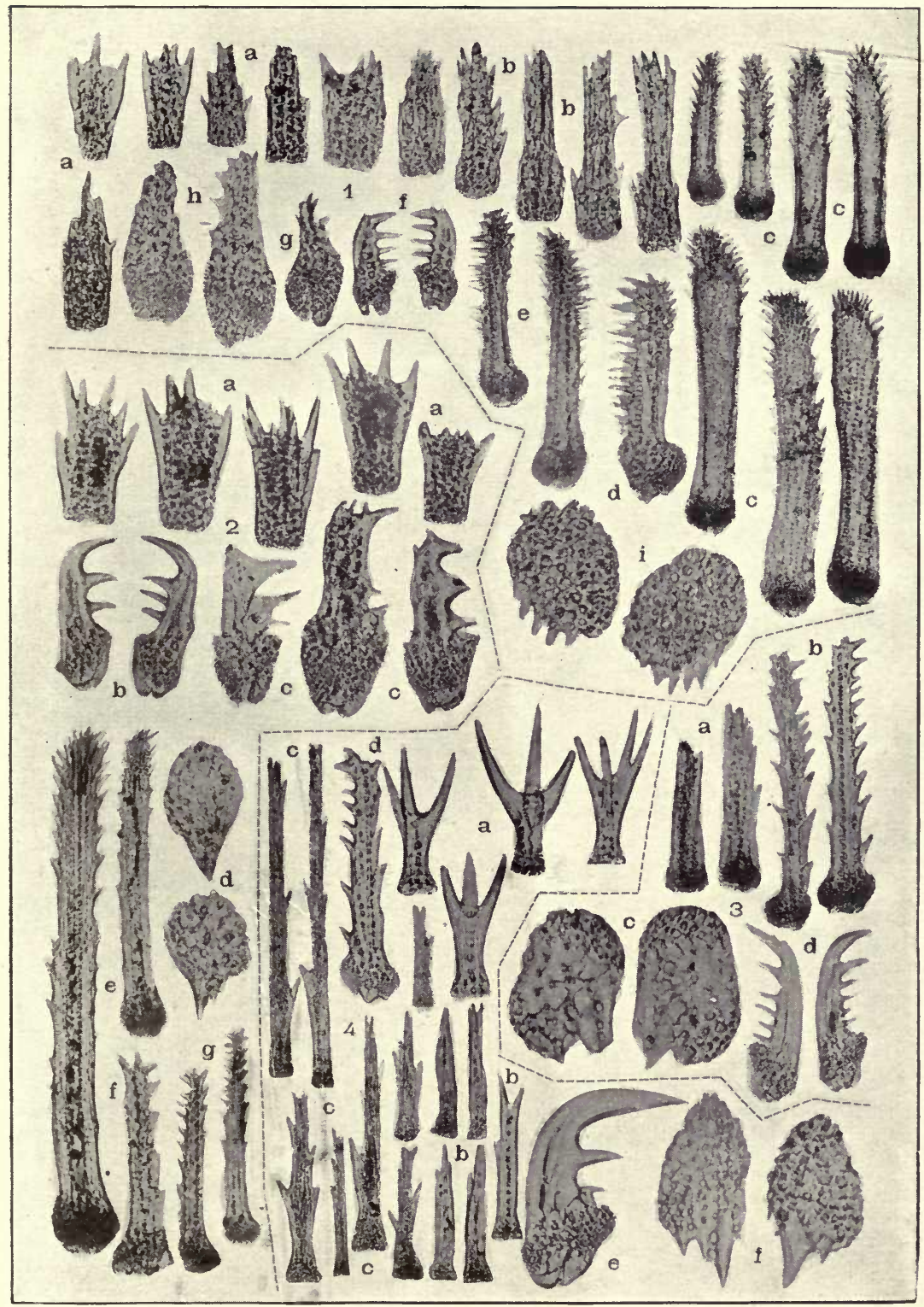

Ophiurans of the Philippine Seas and Adjacent Waters.

For explanation of plate see page 476. 


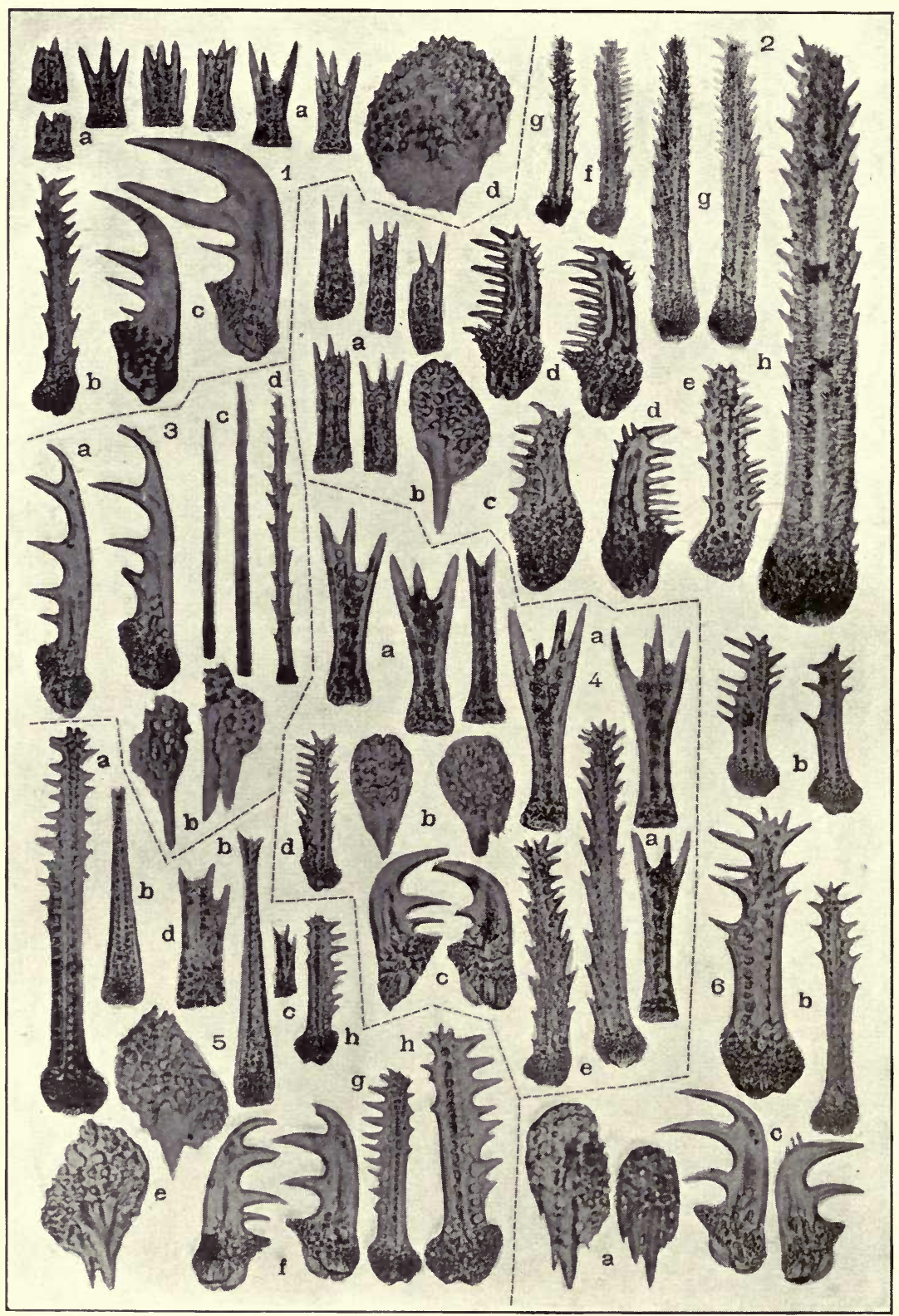

Ophiurans of the Philippine Seas and Adjacent Waters.

For explanation of plate see pages 476 and 477. 


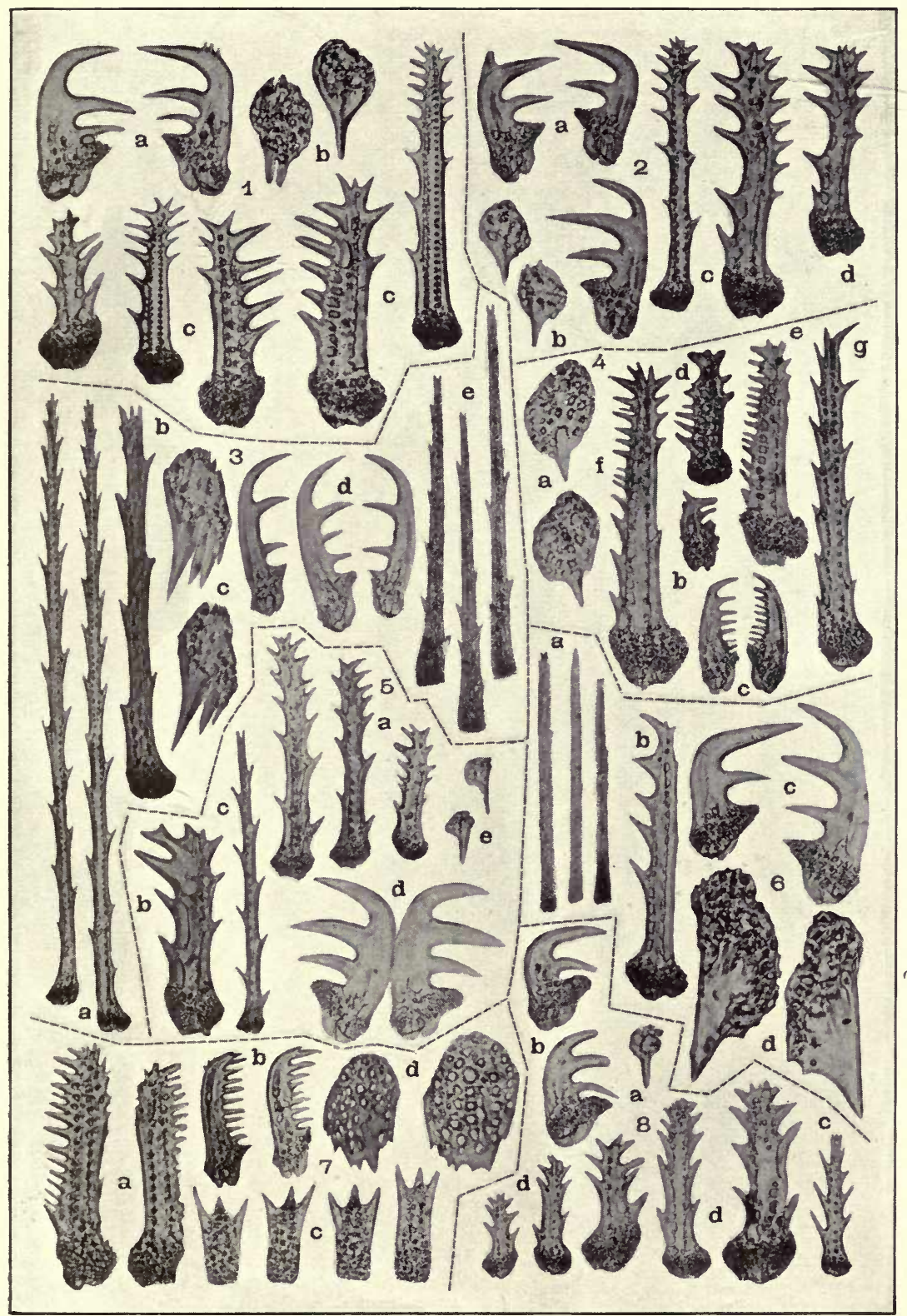

Ophiurans of the Philippine Seas and adjacent Waters. 


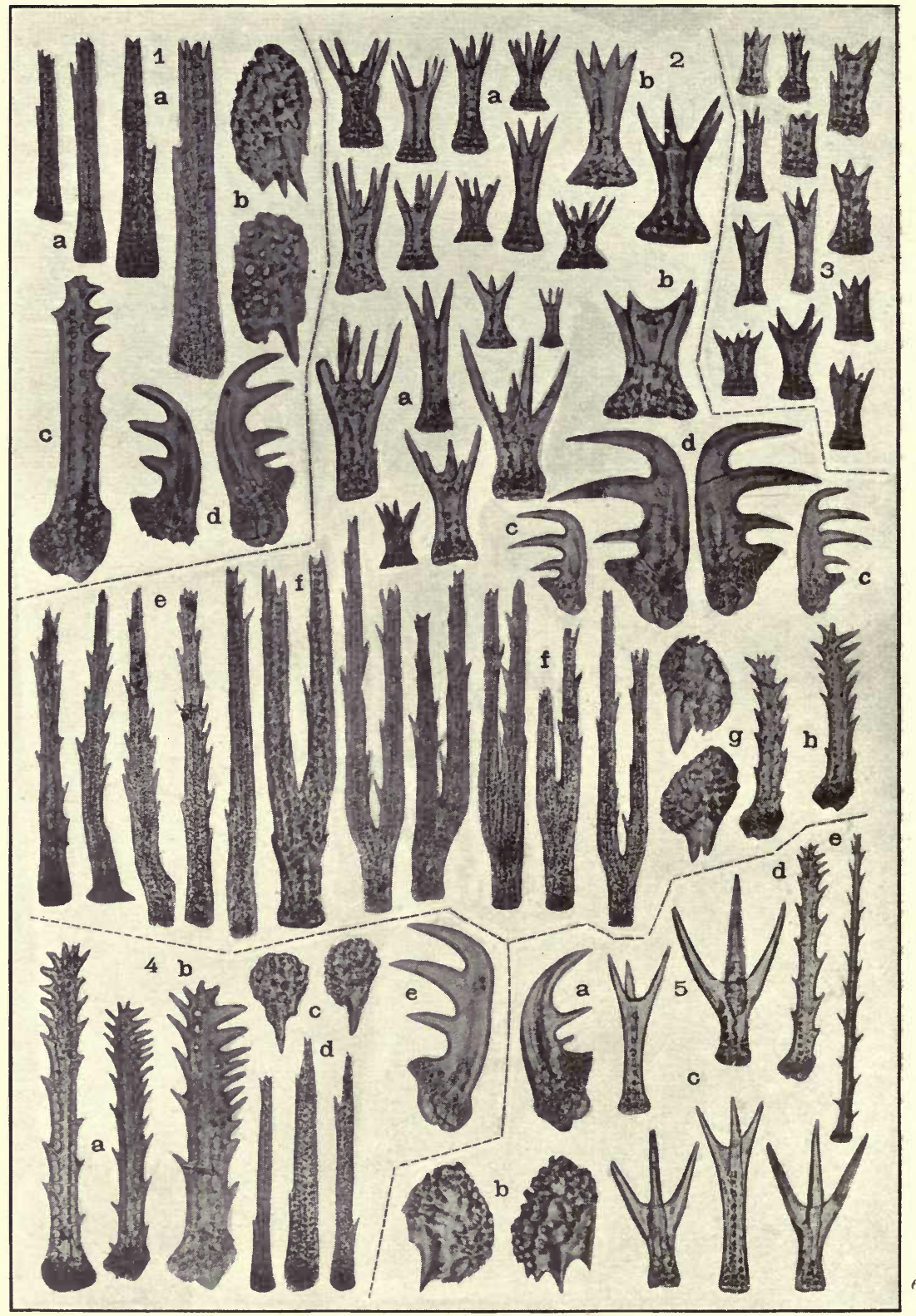

Ophiurans of the Philippine Seas and Adjacent Waters. 


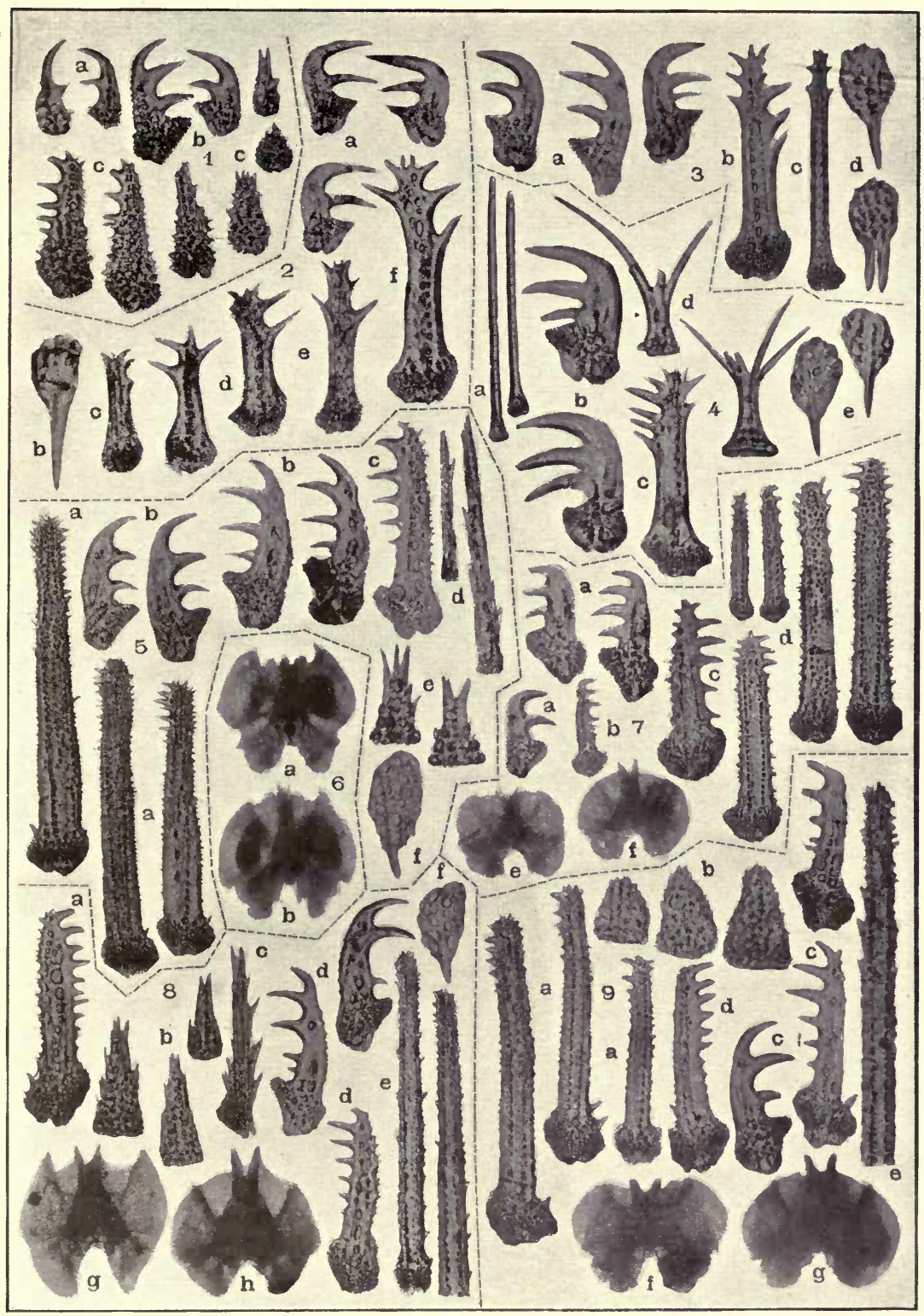

Ophiurans of the Philippine Seas and Adjacent Waters.

FOR EXPLANATION OF PLATE SEE PAGES 479 AND 480. 



\section{N D E X.}

aculeatus, Ophiocentrus

adsper'sus, Ophiernus

aequalis, Ophioglypha

Ophiopeza

Ophiura

Pectinura

aethiops, Opliocoma

affinis, Ophiactis

Ophiothamnus

l'age.

4,196

7,440

373

337

6,373

$6,33 i$

311

4,186

102

agitata, Amphiura

alboviridis, Ophiocentrus _ _ 199

alexandri, Ophiocoma _._._._._. 311

altum, Ophiomusium _______ 7,389

ambigua, Amphiura________ 4, 152

americana, Ophiomitrella _._._._. 122

Amphiactis duplicata _._._-____ 4, 204 partita

Amphilepis protecta

4, 202 remititens

$4,202,452$

Amphilimna multispina _....__ 4, 183, 452

Amphiocnida aspera

199

Amphiodia crassa

4,167

debita $4,168,452$ partita__________ $\quad 204$

Amphiophiura canaliculata _._- 6, 357, 452 fastigiata improba________ 6,362 insolita _._._-_-__- 6,362 paupera radiata _________ 6,363 sculptilis________ 6,364 sordida ________ 6,364 spatulifera ____ $6.365,452$ stellata_________ 6,369

Amphioplus conductus _._____ 4, 172. 452 impressa

impressus

4,174

legatus

$4,169,452$

lucidus

$4,176,452$

luctator.

178,452

relictus

4,179

rhadinobrachius

4,183

Amphipholis impressa

174

kochii

4,163

loripes

, 164, 452 misera

4,165

Amplinira agitata

4, 151

ambigua

4, 152

conimutata

$4,152,452$

crassa

167

dejecta

$4,154,452$

demissa

$4,156,452$

ailomedea

4,158

duplicata

204

4, 159

misela

164

partita

204

relicta

179

uncinata

4,160

vadicola

$+, 161$ anchilabra, Ophiacantha

Page.

annectens, Ophiernus _._._._._- 440

unulosa, Ophiolepis _. 434

Ophiomastix _._._-_-_ 6,329

antarctica, Ophlolimna_________ 15

aristulata, Ophiothrix _______ 4, 205

armata, Ophiothrix

armatum, Ophiomusium__._._._- 7, 389

asper, Ophiocentrus___________ 4, 199

aspera, Amphiocnida_________ 199

aspidota, Ophiothrix_________ 4, 209

assimilis, Ophiotoma__._._._. 3,91

aster, Cryptopelta

Asteronyx loveni _._._._._._._. 2,34

Astroceras pergamena__._._-___ 2,33

Astrocharis virgo____________ 2,32

Astrothamnus deficiens _._____ 2, 35, 452

Bathypectinura conspicua elata__._. 342

gotoi _._-___-_._ 342

heros _.--_-

modesta_.._..... 342

tessellata__._..._. $\quad 342$

bellax, Ophiothrix _-__-__-_-_-_ 4, 211

bengalensis, Ophiomyxa _._._._._ 2,17

benigna, Ophiacantha

bispinosa, Ophiozona_________ 422

Ophiozonella_____._-_- 7,422

bollonsi, Ophiocoma_________ 311

brachiatus, Ophiocentrus_____-_ 199

brevipes, Ophiocoma__-_____- 6, 311, 319

brevispina, Cryptopelta_______

Ophiocoma________ 311

cacaotica, Ophiomaza _.______ 5. 299

canaliculata, Amphiophiura_____-_ 6,357

Ophiocoma_____ $\mathbf{3 1 1}$

capillaris, Ophiothrix _-__-____ 4, 214

casta, Ophiozona_______._. 423

Ophiozonella___.___-__-_-_ 7,423

cataleimmoida, Ophiacantha___-_-_ 122

Ophiopthalmus_-_-_- 124

chelys, Ophiacantha__-__-_-_-_- 130

Ophiomitra___________ 131

Ophioplinthaca _.________ 3, 131

cincta, Ophioconis__________- 15, 351

cinctus, Ophiurodon

clemens, Ophioglypla ______-__-_ 374

Ophiura

codonomorpha, Ophiomitra__-_-_- 122

codonomorphus, Ophiophthalmus_-_ 124

coerulescens, Gymnophiura_______ 375

commutata, Amphiura

composita, Ophiacantha_______- 3,46

conductus, Amphioplus

continis, Ophiophrixus_______- 2,30

confusa, Ophiacantha_______-__ 3,47

congesta, Ophiacantha________- 85

Ophialcoea _._. 3,85

conjungens, Ophiopeza.-_-_-_-_ 338

conspicua, Bathypectinura

Pectinura 
Page.

contrarius, Ophiodoris

5,310

coronata, Ophiothrix

crassa, Ampliodia

Amphiura

5,217

4,167

167

crassipes, Neoplax

crassispina, Ophiothrix

Cryptopelta aster

2,22

5, 218

15

brevispina

granulifera tecta

cumulata, Ophiothrix

cupida, Ophiurodon

$6,350,452$

dallasii, Ophiacantha

5,220

danae, Ophiothela

49

debita, Amphiodia

5,297

4,168

deceptor, Ophiothrix

5,225

declinaus, Ophloceramis________. 7,421

deficiens, Astrothamnus_______ 2,35

definita, Ophiactis___________ 4, 187

dejecta, Amphiura____________ 4, 154

delata, Ophiomyces_._________ 3,41

demissa, Amphiura__-_________ 4, 156

diastata, Ophiolimna _._._._. 15

dilatatus, Ophiocentrus_____-_-_ 199

diomedeae, Amphiura__._._._.__ 4, 158

diploa, Ophiacantha____._. 50

discrepans, Ophiomedea_._._. 3,95

dives, Ophiomitra__________- 3,107

divisa, Homalophiura _._._._._._ 387

Ophioglypha_... 387

döderleini, Ophiocoma _._._._._ 311

dubia, Ophionereis _

duplex, Ophiacantha_..._._._._. 3,50

duplicata, Amphiactis_._-_._-_-_ 4, 204

Ophiactis _._._._._._- 204

elata, Bathypectinura_________ 342

Pectinura__._._._._._. 342

elegans, Ophiarthrum_... 6, 331

Ophiogymna__._._._._._ 5, 281

Ophiomusium _..._._-____ 7, 391

Ophioteron _._._._._._. 5, 301

Ophiothrix________ 5, 227, 281

erinaceus, Ophiocoma _...... 6, 611,322

eurypoma, Ophiacantha _._._-_.-- 122

eurypomus, Ophiophthalmus _._._- 124

excavatus, Ophiurothamnus _____ 3,105

exlgua, Ophiothrix____-__-___- 5, 228

exilis, Ophiomitrella_____._._. 3,110

eximia, Ophiacantha

Ophlotreta

expedita, Ophiothrix.

70

3,70

229

facetum, Ophiomusium

7,394

facundum, Ophiomusium

7,398

fastigatus, Ophiochiton

5,305

fastigiata, Amphiophiura

6,359

fimbriatum, Ophiomusium

7,403

flaccida, Ophiomastix

6,330

flagellata, Ophioglypha__.___-_ 6, 375

$$
\text { Ophiura }
$$

375

fluctuans, Ophiura.

6,377

forbesi, Ophioconis

foveolata, Ophiothrix

5,238

fugiens, Ophiocanops

2. 26

fulgens, Ophiogymna

funesta, Ophlogymna

fusca, Ophiomaza

5,299

galatheae, Ophiothrix globata, Ophioplinthaca__.__-_-_---

gorgonia, Ophiarachnella

Page.

Pectinura

gotoi, Bathypectiuura

grandisquama, Amphiura________ 4, 159

Ophiudoron _....... 15

granifera, Ophiomitra______ 122

graniferus, Ophiophthalmus__._._ 124

granulatus, Ophiolipus________- 7,421

granulifera, Cryptopelta

graphica, Ophiacantha

gratiosa, Ophiacantha_____._. 71

Ophiotreta _._._._. 3,71

gratum, Ophiopteron__._. 5, 302

Grmnopelta indica _._. 15

Gymnophiura coerulescens

habrotata, Ophiomitra _._.___- 102

hastata, Ophioplinthaca__._._._. 4, 137

hastatum, Ophiocten________ 7, 388

heros, Bathypectinura _._._._. 342

Pectinura_____._. 342

hirsuta, Ophiothrix___. 5, 234

Homalophiura divisa__________- 387

inflata

inornata _...___ 6, 387

nana $\quad 386$

honorata, Ophiarachnella______ 6, 340

hybrida, Ophiothrix _._________ 5, 239

hylacantha, Ophiacantha__._._. 122

hylacanthus, Ophiophthalmus__... 124

imbricatus, Ophioplocus________ 7, 435

impotens, Ophiomusium _._._. 7, 406

impressa, Amphipholis___...._. 174

Amphioplus___._._._._- 174

impressu's, Amphioplus _.

improba, Amphiophiura___.__ 6, 362

Ophioglypha _._. 362

inaequalis, Ophiocentrus__._._. 199

indica, Gymnopelta

inermis, Ophiocampis_._._._._._. 281

infernalis, Ophiarachnella

Pectinura _.......... 341

infirma, Ophiothrix __________. 5, 241

inflata, Homalophiura

Ophioglypha__________ $\quad 386$

Ophiura _. 386

inornata, Homalophiura

Ophioglypha__._._._._. 387

Ophiura__._. 387

insolita, Amphiophiura _._.__ 6, 362

intorta, Ophiobyrsella _______ 2,27

inutilis, Ophiacantha

Ophiocirce__________- 7,436

irregularis, Ophiolepis____._._._ 7, 434

Ophiomyxa _... 2, 17

irrorata, Ophioglypha________ 380

Ophiura _._.

kinbergi, Ophioglypha _._._. 381

Ophiura __________ 6, 381

kochii, Amphipholis _._._. 4, 163

koreana, Ophiothrix_________ 5, 242

lambda, Ophiacantha_._._._. 64

languida, Ophiomitrella

legata, Ophiacantha_______. 3,53

legatus, Amphioplus

lepida, Ophiothrix

lepidus, Ophiothrix_._. 246 
Page.

leucorhabdota, Ophiacantha _._._.- 122

leucosticta, Ophiacantha_........- 85

leucostictum, Ophientrema__._._ 3,85

ligatum, Ophiomusium________ 7,408

lineolata, Ophiocoma__._._. 6, 324, 311

longidens, Ophiacantha

longipeda, Ophiothrix________- 5, 235

loripes, Amphipholis__________- 4, 164

loveni, Asteronyx _-___-__-_ 2, 34

lubrica, Ophiocoma__________- 311

luctator, Amphioplus _.___._. 4, 178

lugator, Amphioplus__________- 179

lunare, Ophiomusium

lütkeni, Ophiomastix _.______ 6, 330

lymani, Ophiomusium _..._-_._ 7, 411

maculosa, Ophiactis_________ 190

malignus, Ophiodoris__________ 5, 311

marenzelleri, Ophiothrix _______ 5, 248

marginata, Ophioripa_________-_ 3,11s

marmorata, Ophiocnemis________ 5, 296

Ophiocoma__._. 311

martensi, Ophiothrix____-_ 5,250

matura, Ophiacantha_______-_ 76 Ophiotreta

media, Ophiozona depressa, var___- 424

Ophiozonella__________- 7, 424 depressa, var..-- 424

melanosticta, Ophiothrix______-_ 5, 251

micrantha, Ophiura__._._._._. 6, 6, 383

microphilax, Ophiomitra_______. 122

miliaria, Ophiuroconis________ 15

minima, Ophioleda__-_-_-_-_-- 102

mirabilis, Ophiopholis_.________-_ 4195

Ophiolepis___-_-_-_-_-_ 195

misera, Amphipholis _-___-___- 4, 164

Amphiura__-_._-_-__-_ 164

mitescens, Ophiura____- 6, 383

mitis, Ophioplinthaca ___.._._._. 140

mixta, Ophiomastix______._. 6, 330

modesta, Bathypectinura _._.__ 342

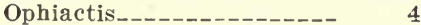

Pectinura _........ 342

molesta, Ophiozona _-_-___-__- 425

Ophiozonella _..._._._._._ 7,425

monolepis, Ophiuroconis__.-_- 15

morio, Ophiomusium_____-__-_ 7, 413

multispina, Amphilimna__________ 4, 183

mutata, Ophiomitrella___._____- 122

nana, Homalophiura_-______-_ 386

Ophioglypha_________-_ 386

Ophiura _._._._._._._- 386

neglecta, Ophiodera

Ophiomyxa

Neoplax crassipes _._._. 2, 22. 452

nereidina, Ophiothrix _._._._._. 5, 252

nitens, Ophiarachnella

Pectinura__-____-_-__-_- 341

noclosa, Ophlogyptis_______- 3,40

normani, Ophiacantha______-_-_ 122

Ophiophthalmus _.--_---- 124

nugator, Ophioripa __________ 3,119

obscura, Ophiozonoida______-_-_- 7, 431

obstricta, Ophioceramis _._._._-_._ 38

Ophiomoeris _. 3,38

obstrictus, Ophiurases._. 38
Page.

124

124

Ophiacantha anchilabra_._._._- 63

benigna_______ $3,45,452$

cataleimmoida _...-_- 122

chelys_..._._. 130

composita _._._._. 3,46

confusa _._._._._._. 3,47

congesta_.________ 85

dallasii _..._._._._. 3,49

diploa_-_-__-_-_-_-_ 50

duplex _._-

eurypoma___._. 122

eximia _._._-_._-_-_ 70

graphica_____.___ 51, 452

gratiosa__._._._... 71

hylacantha _-_-_-_-_ 122

inutilis_._._._._. 71

lambda_-_-_-_-_-_-_- 64

legata _-_______ 3, 53, 452

leucorhabdota_._._-_- 122

leucosticta__.______- 85

longidens__________ 3,55

matura

normani_______-__-_ 122

oedidisca _._._._-_._. 124

(Ophiotreta) valenci-

ennesi__._._._-__-_ 84

pa.cata_-__-_-_-_ 3, 57, 452

pentagona_________ 3,59

perfida__-___-___-_ 64

placida_._._-_._-_- 130

relicta

severa__.______- $3,61,452$

valenciennesi_.._._._._ $\quad 84$

vorax__._______ 3,63

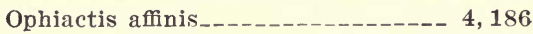
definita _._._._.___ $4,187,452$

duplicata._. 204

maculosa _._._._._._. 190

modesta_._._._. 4

profundi

pteropoma

savignyi_______________ 4, 193

Ophialcoea cougesta _________ 3,85

Ophiarachna quinquespinosa__- 6, 331, 452

Ophiarachnella gorgonia_________ 6, 339

honorata _._._._. 6,340

infernalis _._._._._. 6,341

nitens

Ophiarthrum elegans_________- 6, 331

Ophientrema leucostictum _....... 3,85

Ophiernus adspersus _._. 7,440

annectens_._-_._-_-_- 440

Ophiobyrsella intorta

Ophiocamax polyploca

rugosa____-_-_-_-_-_- 4,147

Ophiocampis inermis..._._. 281

Ophiocanops fugiens__-_._._- 2, 26, 452

Ophiocentrus aculeatus______-_-_ 4, 196

alboviridis____-__-_- 199

asper --_--_--_-_-_-- 4, 199

brachiatus____-_-_-_ 109

dilatatus _..._-_._- 199

inaequalis _._._._._. 199 


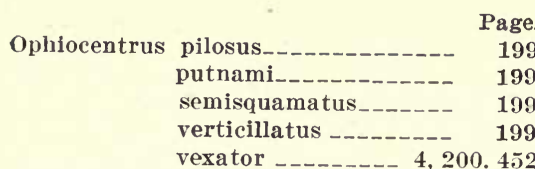

Ophioceramis declinans__.__-__-_ 7, 421

obstricta _._._._. 38

tenera

Ophiochiton fastigatus__._._._. 5,305

Ophiocirce inutilis___________- 7, 436

Ophiocnemis marmorata

Ophiocnida aspera______._____- 199

Ophiocoma aethiops______ 311

alexandri__._._._._._- 311

bollonsi _._._._._-____. 311

brevipes

brevispina_._._._-_._- 311

canaliculata _._._._._. 311

doderleini _._._._._. 311

erinaceus_._._._._._. 311,322

lineolata _..._._._ $6,311,324$

lubrica__._._._._. 311

marmorata _._._._._. 311

parva_._._. 311

pica _-_-__- 324

pumila _._._._. 312

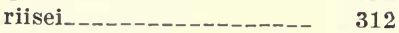

sannio _..._.-_-_- 324

schönleini _._._._-___ 312

scolopendrina $-6,312,322,325$

valenciae_..__._._._._ 312

variegata_._. 312

wendtii _..._-_._. $6,312,328$

Ophioconis cincta___________ 351

forbesi_... 15

permixta _. 352

Opliocopa singularis _-_____- 3, 98, 45ㄴ

Ophiocten hastatum _._._._._. 7,388 pacificum__._._._. $38 \mathrm{~s}$

Ophiodera neglecta_. 2,20

Ophiodictys uncinatus

Ophiodoris contrarius _._..______ 5, 310

malignus _._._._.___. 5, 311

Ophiogema punctata

Ophioglypha aequalis _._._._._. 373

clemens _-_.

divisa_._._._._._._._._ 387

flagellata

improba_... 362

inflata

inornata

irrorata______-_-_ 380

kinbergi__.________- 381

nana

paupera_-___-____-_ 363

radiata _._._._._. 363

sculptilis_____-_____ 364

sinensis______ 381

sladeni____ 369

sordida _..-

stellata

Ophiogymna elegans

fulgens__.._-_-_-__- 5,288

funesta _._._._. $5,292,452$

pulchella _._._-_-_-_-_ 5, 295

Ophiogyptis nodosa

Ophioleda minima_______._... 102

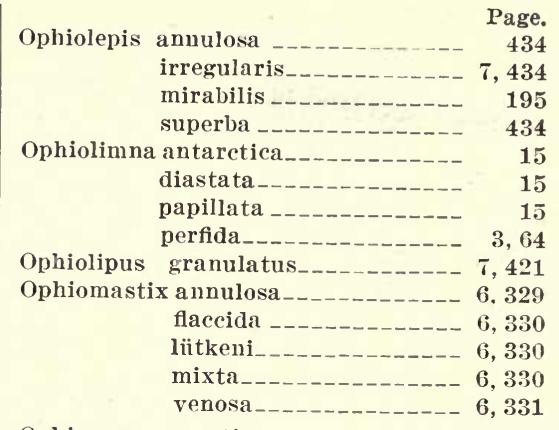

Ophiomaza cacaotica_________ 5, 299

fusca

Ophiomedea discrepans_____._. $3,95,452$

Ophiomelina placida__________- 3,130

Ophiomidas reductum_________ 7,434

reductus _.

Ophiomitra chelys

codonomorpla _..._._. 122

dives_________ $3,107,452$

granifera_.._._..._._. 122

habrotata _._. 102

microphilax _..._._. 122

Ophiomitrella americana

exilıs ________ $3,110,452$

languida _._. 122

mutata _._._-_._-_- 122

placida__.___._._. 122, 130

sagitta_______ $3,111,452$

subjecta _______ $3,114,452$

Ophiomoeris obstricta_________ 3,38

spinosa _-_._-_-_-_-_ 3,40

tenera

Ophiomusium altum _._-_-____- 389 armatum _____ $7,389,452$

elegans ________ 7,391

facetum__..___ $7,394,452$

facundum _._. $7,398,452$

fimbriatum _._._ $7,403,452$

impotens _._____ $7,406,452$

ligatum _._._._. $7,408,452$

lunare _._-______- 7,410

lymani _._._._._. 7,411

morio______ $7,413,452$

properum _..._-_-_ 7,416

relictum _-

sanctum _._._._._._ 417

scalare_._-_____-_ 7,417

simplex _._._._. 7,417

spinulosum _... 7, 718,452

Ophiomyces delata _._._._._. 3,41

Ophiomyxa bengalensis_________ 2,17

irregularis _._._._._ 2, 17

neglecta_._. 20

Ophionephthys phalerata

Ophionereis dubia _._._._._._. 5, 310 semoni _-

Ophiopallas paradoxa _._.

valens_________ $7,437,452$

Ophiopeza aequalis

conjungens _._-_-_-_-_- 338

yoldii_____________ 338

Ophiopezella spinosa 
Page.

Ophiopholis mirabilis

4,195

Ophiophrixus confinis._...... 2, 30, 452

Ophiophthalmus cataleimmoida_...- 124 codonomorphus _-_- 124 eurypomus _...... 124 graniferus _...... $\quad 124$ hylancanthus__._. 124 normani _._._._._. 124 placidus _._._._- 130 relictus_.___._._. 3,124 suspectus____- $3,127,452$

Ophioplinthaca chelys_______._-_ 3, 131 gloøata _._._. $4,132,453$ hastata _...__ $4,137,453$ mitis__._._._._. 140 pulchra _..-_._.-. 4, 140 rudis____________- 4,142

Ophioplocus imbricatus _..._... 7, 435 Ophiopsammus yoldii _._._._._._._ 338

Ophiopteron elegans _._._._. 5, 301 gratum__._._. $5,302,453$ puncto-coeruleum _-_-_ 5,305

Ophiopyrgus planulatus______ $6,355,453$

Oplioripa marginata _..___._. $3,118,453$ nugator.______ $3,119,453$

Ophiosemnotes oedidisca_________ 124

Ophiothamnus affinis___.___._. 102 remotus____._._._. 102 stultus_________- 104 venustus___-__ $3,100,102$ vicarius__._._._._. 102

Ophiothela danae___._._._._. 5,297 vincula _._._._._._. 5, 298

Ophiothrix aristulata armata _............. 4, 208 aspidota _... bellax _._._._._. 4, 211, 453 capillaris._._._._._._. 214 coronata _..._._._._._. 5, 217 crassispina _._._._._. 5,218 cumulata _....... $5,220,453$ deceptor_..._._._. $5,225,453$ elegans_.___._._. $5,227,281$ exigua _..._.......... 228 expedita__._._._____- 5, 229 var. rhabdota $--\quad 230$ îoveolata_._. galatheae___________ 5,233

hirsuta__._._._._._. 5, 234 hybrida _._._._.__ 5, 239

infirma_._._._._._. 5, 241

korcaua _._._.______ 5, 242

lepida_____________ 5, 246

lepidus____________ 246

longipeda___._.______ 5,235

marenzelleri _..._._._. 5,248

martensi _._._._._.__ 5,250

melanosticta __________ 5,251

nereidina____________ 5, 252

pavida__._._._._ 5,2526453

plana__._._._._._._._. 5, 255

propinqua _._._._____ 5,256

prostrata

proteus _._._._._._._._. 5, 260

purperea _._-_-_-_-_-_- 5, 261

pusilla _._._._._._... 5, 262
Ophiothrix Page.

230

signata _._._._._. $5,263,453$

spinosissima _......._. 5,266

stelligera________-_-_- 5, 267

striolata _._._-_____- 5,277

trilineata__. 5,279

vitrea_-_-_--_-_-_-_-_- 279

Ophiotoma assimilis__________ 3,91

Ophiotrema tertium _..._..._. $3,88,453$

Ophiotreta eximia_........... 3, 70

gratiosa

matura

spatulifera _________ $3,81,453$

valenciennesi__._______ 3,84

Ophiotriton semoni

Ophiozona bispinosa____________- 422

casta___._._._._._._-_-_ 423

depressa, var. media__-_ 424

molesta

Ophiozonella bispinosa_._._._-__-_ 7, 422

casta____________ 7,423

depressa, var. media_- 424

media _._._._._._._-_ 7,424

molesta_-__-_-_-_-_-- 7,425

subtilis_.____-__ $\mathbf{7}, 428,453$

Ophiozonoida obscura_______- 7, 431, 458

Ophiura aequalis _..._._._._._._ 6,373

clemens__________- 6,374

flagellata _-__-___-_-_-_ 6, 375

fluctuans _._._... $6,377,453$

inflata_._._._._. 386

inornata _._. $38 \pi$

irrorata_..___. 6,380

kinbergi _._._-_______-_ 6, 381

micrantha

mitescens _._._._._._ $6,383,453$

nana

sarsii______-__-___- 6, 386

stiphra _-_-__-_-_-_-_-_ 369

Ophiurases obstrictus_______- 38

Ophiuroconis miliaria _._._._-_._ 15

monolepis_._._._._. 1.5

pulverulenta _.....-- 15

Ophiurodon cincta

cinctus _._.

cupida

grandisquama

permixta___-_-_-_-_-_ 15

permixtus_______-__- 6,352

Ophiurothamnus excavatus $\ldots \ldots+3,105,45.3$ stultus _.______ 3,104

racata, Opliacantha _..._. 3,57

pacificum, Ophiocten _..._._._._. 388

papillata, Ophiolimna _._._._. 15

paradoxa, Ophiopallas_________ $7,4: 36$

partita, Amphiactis._._.

Amphiodia _..._._._._. 204

Amphiura _._._._._._. 204

parva, Ophiocoma _.____ \$11

paupera, Amphiophiura

Ophioglypha _._- 363

pavida, Ophiothrix _..._______ $5, \mathbf{2 5 2}$

I'ectinura aequalis _._._.

conspicua _._._-___-__- 342

elata _-_______._. 342

gorgonia _._._._._._. 339 
Page.

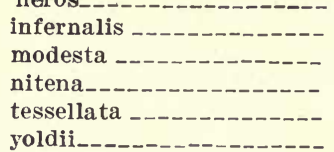

pentagona, Ophiacantha

perfida, Ophiacantha.

pergamena, Astroceras

permixta, Ophioconis

Ophiurodon

permixtus, Ophiurodon

phalerata, Ophionephthys_._._._._._

pica, Ophiocoma

pilosus, Ophiocentrus

placida, Ophiacantha__________-

Ophiomelina _..........

Ophiomitrella

122,130

placidus, Ophiophthalmus___-___-_-_

plana, Ophiothrix.

planulatus, Ophiopyrgus

polyploca, Ophiocamax.

profundi, Ophiactis

properum, Ophiomusium

propinqua, Ophiothrix

prostrata, Ophiothrix

protecta, Amphilepis

proteus, Amphilepis

pteropoma, Ophiactis

pulchella

pulchra, Ophioplinthaca

pulverulenta, Ophiuroconis

pumila, Ophiocoma

punctata, Ophiogema_

puncto-coeruleum, Ophiopteron -...

purpurea, Ophiothrix _._.

pusilla, Ophiothrix

putnami, Ophiocentrus _._-_-_-_-_-

quinquespinosa, Ophiarachna_______

radiata, Amphiophiura

Ophioglypha _._._._-_._-

reductum. Ophiomidas _-

reductus, Ophiomidas _..-_-

relicta, Amphiura

Ophiacantha

255

6,355

147

4,192

7,416

5,256

257

4, 202

5,260

192

5,295

4,140

15

312

3,67

Ј, 305

5,261

5,262

199

6,331

6,363

363

7,434

434

179

122,124

relictum, Ophiomusium

7,416

relictus, Amphioplus

4, 179

Ophiophthalmus

3,124

remittens, Amphilepis_.

remotus, Ophiothamnus _......

rhabdota, Ophiothrix

expedita var.-

rhadinobrachius, Amphioplus

riisei, Ophiocoma

rudis, Ophioplinthaca

sagitta, Ophiomitrella.

sanctum, Ophiomusium

sannio, Ophiocoma___________

sarsii, Ophiura

4,202

102

230

230

4, 183

312

4, 142

4,147

3,111

417

324

6,386

savignyi, Ophiactis___.________ 4, 193

scalare, Ophiomusium_______ 7,417

schönleini, Ophiocoma _________ 312

scolopendrina, Ophiocoma $-6,312,322,325$
Page.

6,364

364

199

5, 310

310

3,61

5. 263

7,417

381

3,98

369

6,369

6,364

364

6,365

3,81

3,40

6,338

5,266

spinulosum, Ophiomusium
Stegophiura sladeni_-_-
sterilis

spinulosum, Ophiomusium
Stegophiura sladeni_-_-
sterilis

sterilis _______ $6,370,453$

stellata, Amphiophiura _______ 6, 369

Ophioglypha__._. 369

Ophiothrix _._._-_._. 5, 267

sterilis, Stegophiura__________ 6, 370

stiphra, Ophiura

striolata, Ophiothrix__________- 5,277

stultus, Ophiothamnus ________- 104

Ophiurothamnus __-__-__-_ 3,104

subjecta, Ophiomitrella_________ 3, 114

subtilis, Ophiozonella

superba, Ophiolepis__________ 434

suspectus, Ophiophthalmus_______ 3,127

tecta, Cryptopelta_______ 6, 350

tenera, Ophioceramis________- 40

Ophiomoeris _._-_-_-_-_-_ $\quad 3,40$

tertium, Ophiotrema _._._._. 3,88

tessellata, Bathypectinura._. 342

Pectinura_______-__- 342

trilineata, Ophiothrix_______- 5,279

uncinata, Amphiura _-_-__-_____ 4, 160

uncinatus, Ophiodictys____.___._ 3,42

vadicola, Amphiura___________ 4, 161

valenciae, Ophiocoma _._._-_._-_ 312

valenciennesi, Ophiacantha _..._._- 84

(Oph i o -

treta) _ 84

Ophiotreta_._._. 3,84

valens, Ophiopallas___________ 7, 437

variegata, Ophiocoma

venosa, Ophiomastix

venustus, Ophiothamnus _._._. $3,100,102$

verticillatus, Ophiocentrus_______.. 199

vexator, Ophiocentrus _... 4, 200

vicarius, Ophiothamnus_________ 102

vincula, Ophiothela__________ 5, 298

virgo, Astrocharis____._. 2,32

vitrea, Ophiothrix____-_._- 279

vorax, Ophiacantha

wendtii, Ophiocoma____-__-_ 6, 312, 328

yoldii, Ophiopeza_______-_._- 338

Ophiopsammus_._. 338

Pectinura _____ 6, 338 






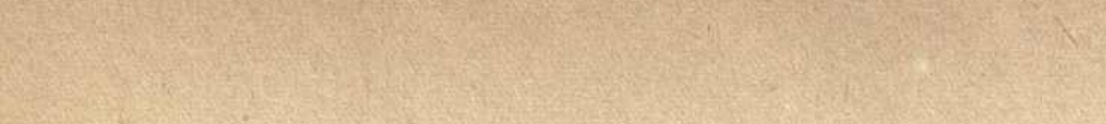

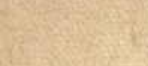






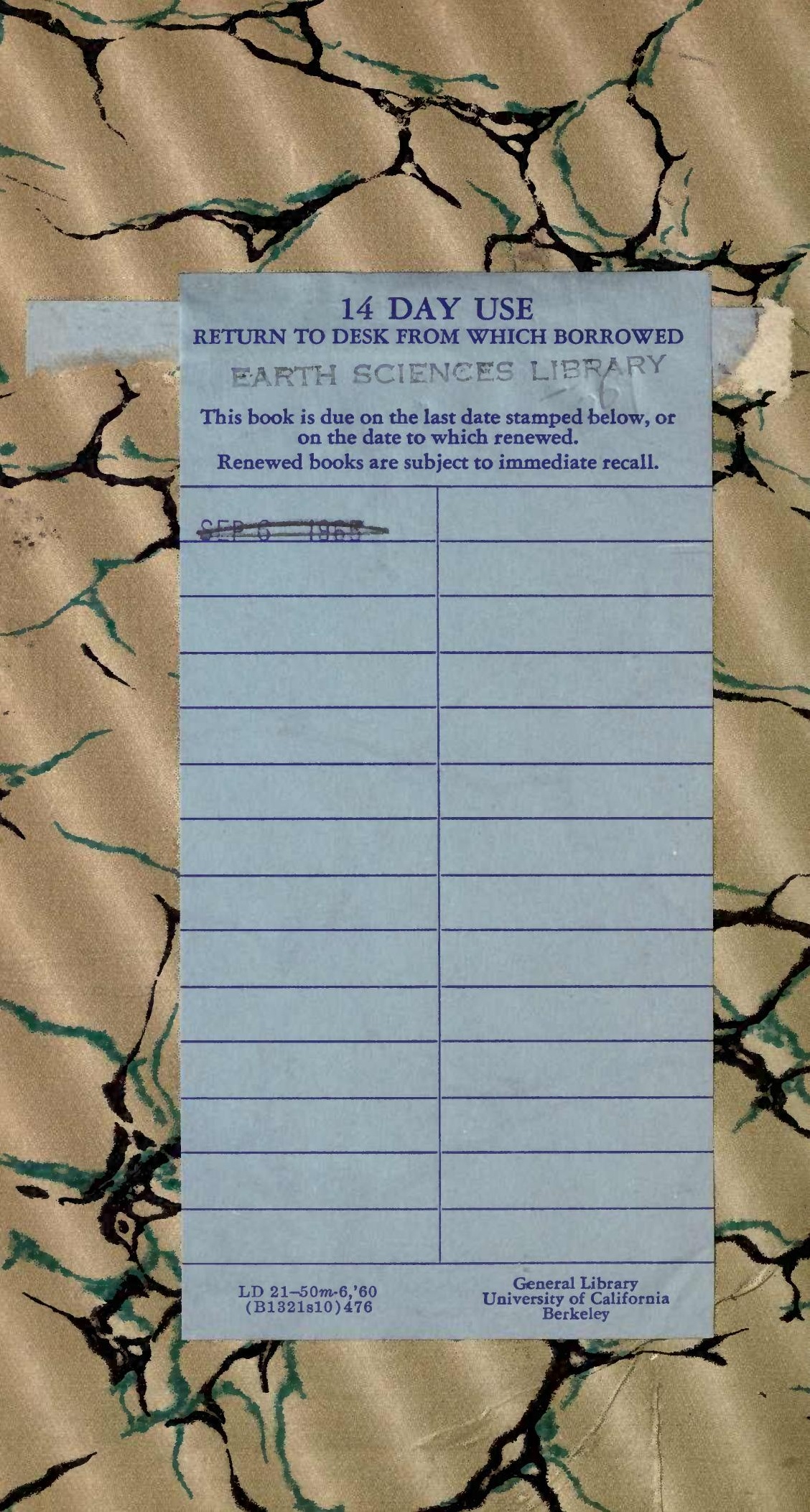


